Georg-August-Universität Göttingen - Philosophische Fakultät

\title{
DIE ERSTE STADT AN DER ÄUßERSTEN GRENZE
}

Die historische Entwicklung der Stadt Tengchong im Prozeß der Entstehung und Konsolidierung des Grenzgebietes im

Westen der chinesischen Provinz Yunnan

Dissertation von

Diana Kott

Hannover 2003 



\section{INHALTSVERZEICHEIS}

\section{KAPITEL I \\ EINLEITUNG}

1. Die Stadt Tengchong ..................................................................................... 1

1. 1. Die geographische Lage der Stadt Tengchong.............................................................. 1

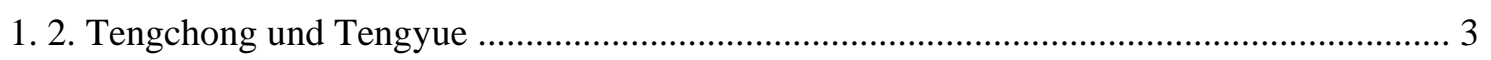

1. 3. Die Stadt Tengchong und ihr Umfeld ......................................................................... 5

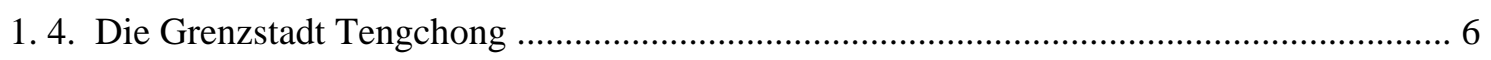

2. Die Provinz Yunnan als Gegenstand westlicher Forschung ................................. 9

2. 1. Die Beschäftigung mit Yunnan in den westlichen Ländern vor 1949 .................................. 9

2. 2. Tengyue in westlichen Reise- und Expeditionsberichte (1868 bis 1945) ......................... 10

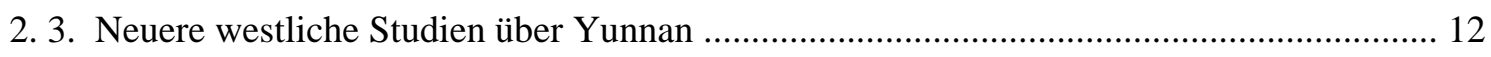

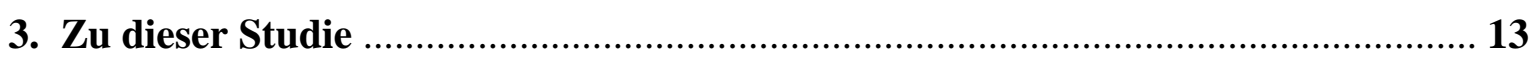

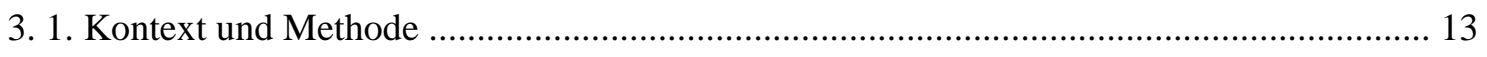

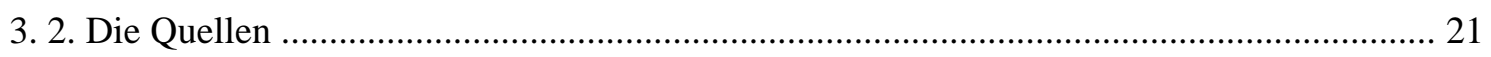

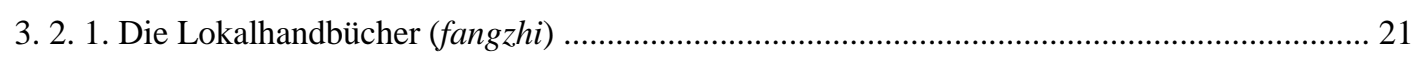

3. 2. 2. Die Lokalhandbücher von Tengchong / Tengyue .............................................................. 23

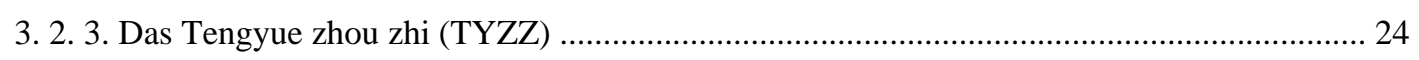

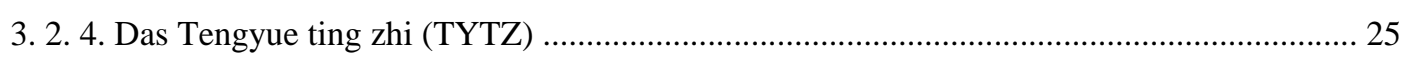

3. 2. 5. Andere Lokalhandbücher aus der Region ……………………………………………....... 27

3. 2. 6. Andere chinesische Quellen ................................................................................................. 29

3. 2. 7. Das Reisetagebuch des Xu Xiake ................................................................................... 30

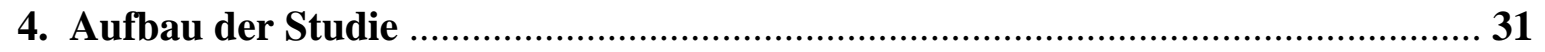

\section{KAPITEL II}

DIE ENTSTEHUNG EINES GRENZGEBIETES:

DIE REGION DES STROMSCHLUCHTENFÄCHERS VON DER HAN- BIS ZUR YUAN-ZEIT (206 v. Chr. - 1368 n. Chr.)

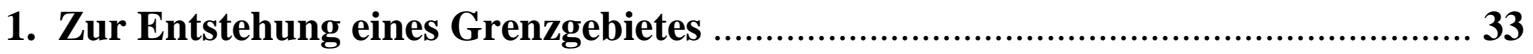

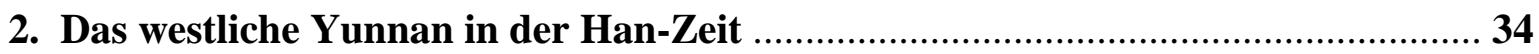


3. Das chinesische Engagement in Yunnan während der Sui- und der Tang-Zeit ... 38

4. Die Region des Stromschluchtenfächers als Teil der Königreiche von Nanzhao und Dali 39

5. Der Name Tengchong und die Benennung der Region in chinesischen Quellen

5. 1. Tengchong im Werk von Jia Dan und im Manshu von Fan Chuo ..................................... 42

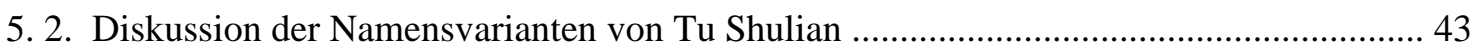

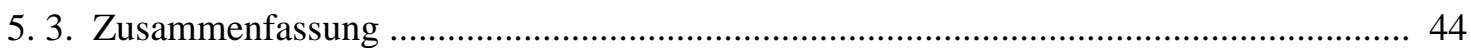

6. Die Einbindung des westlichen Yunnan in die Verwaltungsstrukturen des

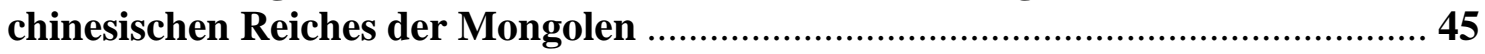

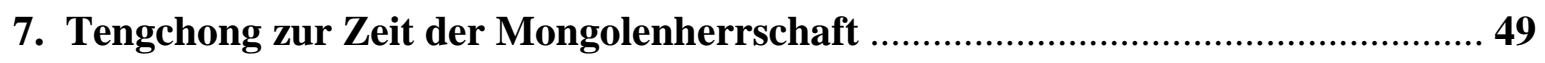

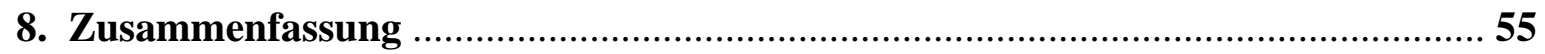

\section{KAPITEL III}

DIE KONSOLIDIERUNG DES GRENZGEBIETES:

DIE ENTWICKLUNG TENCHONGS IN DER MING-ZEIT (1368-1644)

A. Die Entwicklung Tengchongs bis zur Mitte des 16. Jahrhunderts

1. Das westliche Yunnan zu Beginn der Ming-Zeit.

1. 1. Die Entwicklung der chinesischenVerwaltungseinheiten in der Region des Stromschluchtenfächers bis zur Mitte des 15. Jahrhunderts

1. 2. Die Eingliederung der Gebiete im Südwesten Jinchis in das

Verwaltungssystem des Ming-Reiches

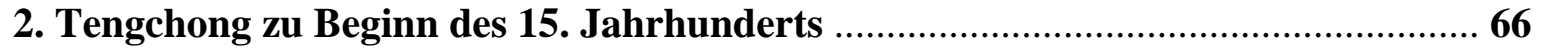

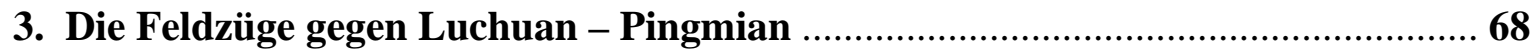

4. Die lokale Militärkommandantur Tengchong …...................................................68

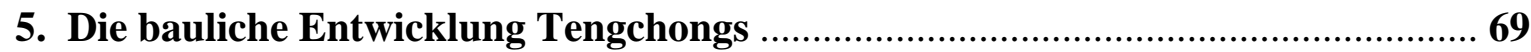

5. 1. Bauwerke aus der Zeit vor der Errichtung der Stadtmauer ............................................... 69

5. 2. ,Die erste ummauerte Stadt an der äußersten Grenze‘ .................................................... 71

5. 3. Weitere in der Ming-Zeit errichtete Bauwerke .................................................................. 76

6. Die Entwicklung der Verwaltungseinheit Tengchong bis zur Mitte des 16. Jahrhunderts

7. Die Politik der Ming gegenüber den Kleinstaaten im Südwesten von Tengchong 
B. Die Unterpräfektur Tengyue und die Konsolidierung des Grenzgebietes

1. Die Gründung der Unterpräfektur Tengyue Mitte des 16. Jahrhunderts ............ 89

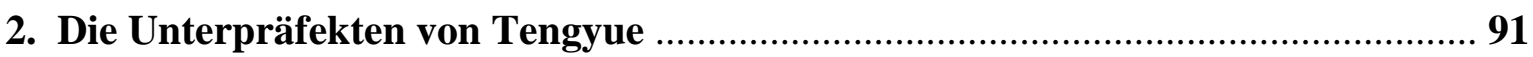

3. Die Bevölkerungsentwicklung in Yunnan und ihre Dokumentation in den

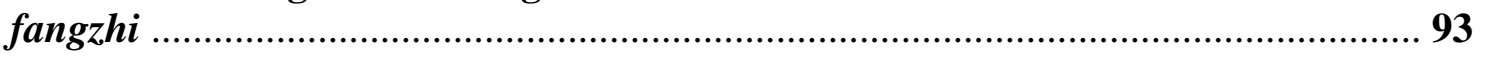

3. 1. Die Bevölkerung von Tengchong / Tengyue in der Ming-Zeit ....................................... 95

3. 2. Die Bevölkerung der Unterpräfektur Tengyue Mitte des 16. Jahrhunderts ...................... 98

4. Chinesische Verwaltungseinheiten an der äußersten Grenze:

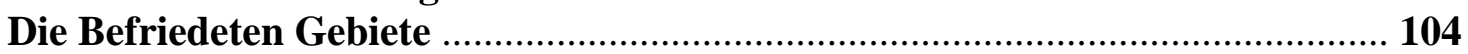

4. 1. Das tusi-System und die Befriedeten Gebiete im Südwesten von Tengyue ..................... 104

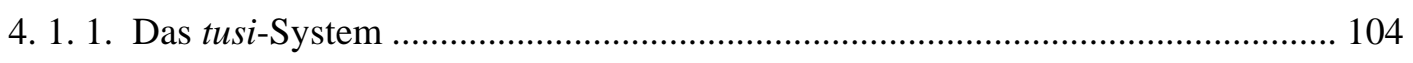

4. 1. 2. Die Befriedeten Gebiete im Südwesten der Unterpräfektur Tengyue ................ 106

4. 2. Der Konflikt zwischen Mengmi und Mubang ............................................................ 116

4. 3. Die historische Entwicklung Birmas vom 13. bis zum 16. Jahrhundert ......................... 119

4. 4. Die Herrscher von Toungoo in den fangzhi von Tengyue ............................................. 121

4. 5. Der Kleinstaat Mengyang an der Wende zum 17. Jahrhundert ....................................... 123

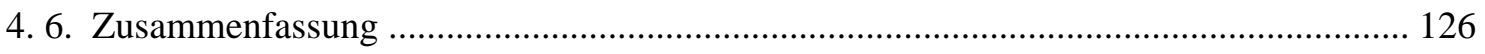

5. Die Expansion der Birmanen in die Region des Stromschluchtenfächers und die Reaktion der Ming auf die Invasion aus dem Südwesten ............................ 128

6. Gouverneur Chen Yongbins Maßnahmen zur Befriedeung der Gebiete im

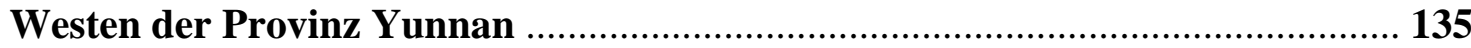

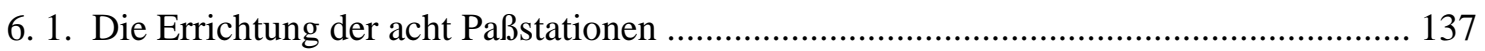

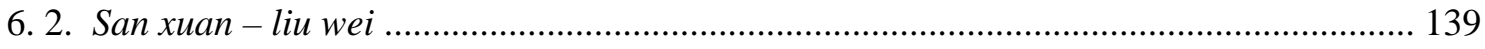

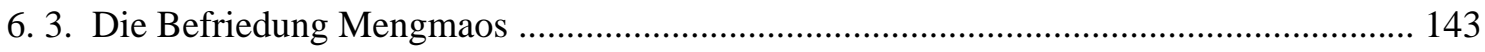

6. 4. Manmo und die Entwicklung der tusi-Gebiete nach der Errichtung

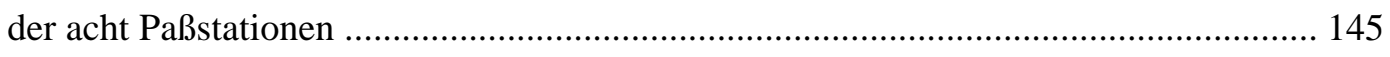

7. Der Konflikt um die Förderung von Edelsteinen im Gebiet von Mengmi ........... 152

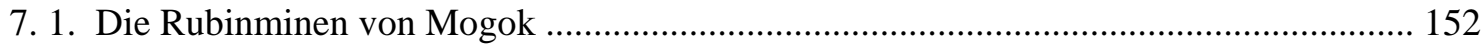

7. 2. Der chinesische Edelsteinhandel und seine Auswirkungen auf die Region ..................... 154

7. 3. Gouverneur Chen Yongbin und seine Kritik am chinesischen Engagement bei der Förderung von Edelsteinen in Mengmi ............................................................. 160

8. Die Beschreibung der acht Paßstationen im Reisetagebuch des Xu Xiake .......... 166

9. Die Stadt Tengyue zur Zeit der Ära Wanli ........................................................... 169

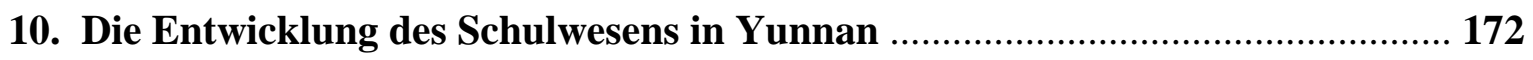

10. 1. Die Entwicklung des Schulwesens in Yongchang ..................................................... 174

10. 2. Das Schulwesen in Tengchong/Tengyue in der Ming-Zeit ....................................... 177 
11. Das Ende der Herrschaft der Ming in Yunnan 182

11. 1. Die Schlacht am Mopanshan und die Flucht des Yongli-Kaisers nach Birma 189

11. 2. Der Vorstoß der Qing-Truppen und das Ende der Ming im Südwesten 192

KAPITEL IV

DIE KONTINUITÄT DES GRENZGEBIETES:

DIE ENTWICKLUNG DER UNTERPRÄFEKTUR TENGYUE IN DER QING-ZEIT (1644-1911)

\section{A. Krieg und Frieden: Die Verwaltungseinheit Tengyue vom 17. bis zum Beginn} des 19. Jahrhunderts

1. Die Präfektur Yongchang und die tusi-Gebiete zu Beginn der Qing-Zeit 195

1. 1. Die Herrschaft Wu Sanguis in Yunnan 200

1. 2. Maßnahmen zum Wiederaufbau Yunnans nach der Rebellion 203

2. Die Verwaltungseinheit Yongchang bis zur Mitte des 18. Jahrhunderts ............. 205

3. Der chinesisch-birmanische Krieg, 1766-1769 210

3. 1. Birma im 18. Jahrhundert: Die Herrschaft der Konbaung-Dynastie 210

3. 2. Der Verlauf der chinesisch-birmanischen Kriege, der Friedensschluß und die Darstellung der Ereignisse im TYTZ

3. 3. Die Darstellung der chinesisch-birmanischen Beziehungen in der Nachkriegszeit in den fangzhi

4. Nachkriegszeit: Die Unterpräfektur Tengyue im 18. Jahrhundert

4. 1. Unterpräfekt Wu Kai

4. 2. Die Veränderungen in der Zivil- und Militärverwaltung von Yongchang und Tengyue zur Zeit der Ära Qianlong

5. Die Entwicklung der chinesischen Bevölkerung im Südwesten des Kaiserreiches in der Qing-Zeit 238

5. 1. Die Registrierung der Bevölkerung Yunnans in den Qing-zeitlichen Quellen 240

5. 2. Die chinesische Bevölkerung der Unterpräfektur Tengyue in der Qing-Zeit 240

5. 3. Die Registrierung der einheimischen Bevölkerung in den tusi-Gebieten und die Versorgungslage in der Unterpräfektur Tengyue

5. 4. Die ,verschiedenen Volksgruppen“ (zhongren) im Gebiet des Regionalen Militärbezirks Tengyue

6. Das Schulwesen in Tengyue in der Qing-Zeit 255

6. 1. Der Konfuziustempel (Xianshi miao/ Xuegong) ................................................................ 255

6. 2. Die Laifengshan Akademie 259

6. 3. Gemeinde- und Freischulen 261 
6. 3. 1. Zur Entwicklung der Gemeinde- und Freischulen seit der Ming-Zeit .............................. 261

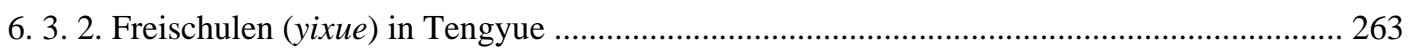

6. 4. Erfolge des Bildungswesens von Tengyue - jinshi, juren und gongsheng .................... 265

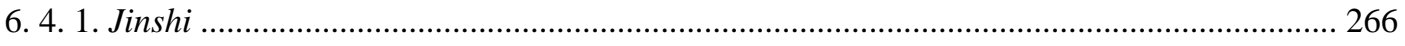

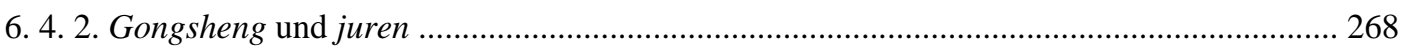

6. 5. Die Schuldirektoren von Tengyue und Yongchang .................................................. 272

6. 6. Wuju - Die Absolventen der Militär-Prüfungen .................................................. 274

6. 7. Der Stand des Bildungswesens in Yongchang ....................................................... 275

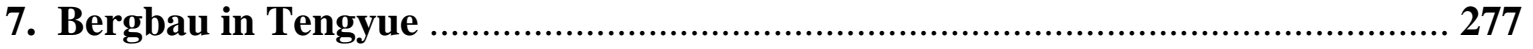

7. 1. Die Entwicklung der Bergbauindustrie in Yunnan und die Geldpolitik der Qing ......... 277

7. 2. Der Abbau von Bodenschätzen in Tengyue und Yongchang ..................................... 281

7. 2. 1. Die Minenbetriebe ..................................................................................................... 284

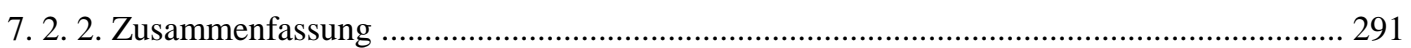

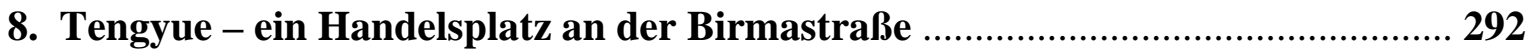

8. 1. Natürliche Ressourcen und örtliche Produkte ...................................................... 292

8. 2. Handelswaren im Im- und Export ............................................................... 296

8. 3. Handel und Politik ........................................................................................ 298

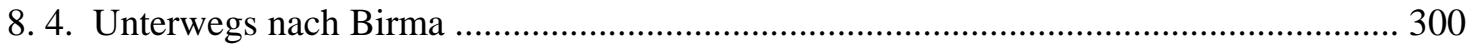

9. Die Brücken in der Präfektur Yongchang …........................................................ 302

B. Rebellion und Restauration: Die Verwaltungseinheit Tengyue im 19. Jahrhundert

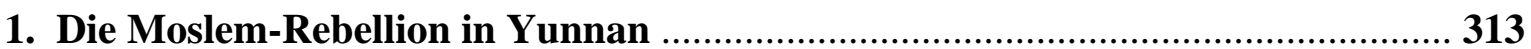

1. 1. Überblick über die historische Entwicklung der moslemischen Bevölkerungsgruppe

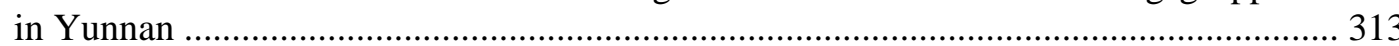

1. 2. Die Moslem-Rebellion in Yunnan ....................................................................... 318

1. 2. 1. Die Vorboten der Rebellion: Die Unruhen in Yongchang in den Jahren 1843 bis 1848

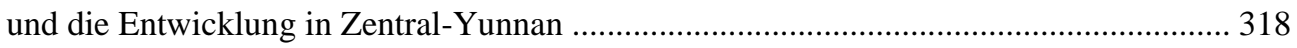

1. 2. 2. Die Gründung des Sultanats von Dali ........................................................................ 325

1. 3. Tengyue in der Zeit der Moslem-Rebellion ........................................................ 331

1. 3. 1. Die Hui und die Moslem-Rebellion in den Lokalhandbüchern von Tengyue .................... 331

1. 3. 2. Die Moslem-Rebellion in Tengyue ................................................................................... 333

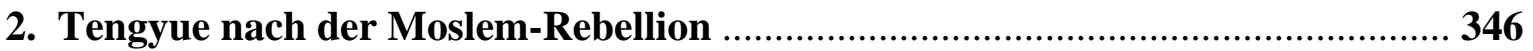

2. 1. Exkurs: Britische Handelsinteressen in Yunnan im 19. Jahrhundert ............................ 346

2. 2. Ein Zwischenfall im Grenzgebiet: Die ,Margary-Affäre‘ .......................................... 349

2. 3. Die Militärrevolte und der Kampf um Tengyue im Jahr 1876 ................................. 350

2. 4. Die Bevölkerungsentwicklung in Tengyue Ende des 19. Jahrhunderts ....................... 353 
3. Die Restauration der Verwaltungseinheit Tengyue ............................................ 355

3. 1. Der Status quo ante: Die Verwaltungseinheit Tengyue vor der Moslem-Rebellion ......... 356

3. 2. Die Restauration des Verwaltungsapparates der Unterpräfektur Tengyue ....................... 360

3. 3. Der Wiederaufbau der Stadt Tengyue unter der Leitug von Unterpräfekt

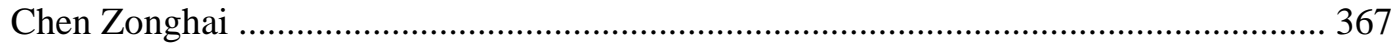

3. 3. 1. Prioritäten: Die Stadtmauer und der Amtssitz des Unterpräfekten ...................................... 369

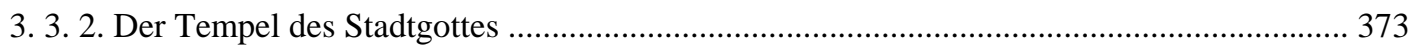

3. 3. 3. Weitere Bauprojekte unter der Leitung von Chen Zonghai .................................................. 374

3. 4. Das Schulwesen in Tengyue in der zweiten Hälfte des 19. Jahrhunderts ........................ 382

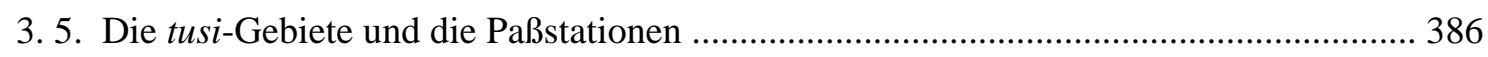

3. 6. Maßnahmen zum Grenzschutz und das militärische Engagement Chinas im

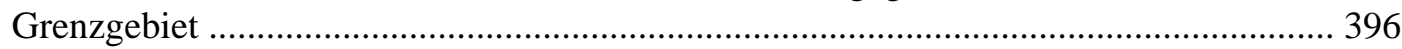

4. Die obersten Verwaltungsbeamten von Tengyue ................................................ 404

4. 1. Die Unterpräfekten (zhizhou/tongzhi) von Tengyue in der Qing-Zeit .............................. 404

4. 1. 1. Die Amtszeit der Unterpräfekten ………......................................................................... 407

4. 1. 2. Die akademischen Titel der Verwaltungsbeamten ............................................................... 408

4. 2. Die Militärkommandeure von Tengyue in der Qing-Zeit .................................................. 410

4. 3. Die Unterpräfekten als Herausgeber der Lokalhandbücher .............................................. 413

\section{KAPITEL V}

CHINA UND DIE VÖLKER DER REGION - DAS PROBLEM DER SPRACHLICHEN UND SCHRIFTLICHEN VERSTÄNDIGUNG

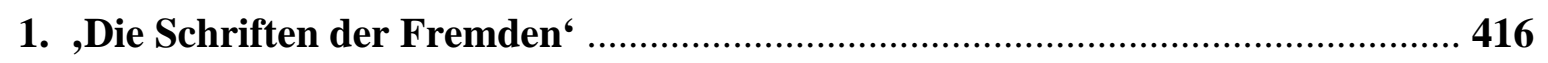

2. Die Sprachen und Schriften der Birmanen, Shan und Yi ................................ 421

2. 1. Die Sprachen der Birmanen und der Shan ......................................................................... 421

2. 2. Die Schriften der Birmanen und der Shan ....................................................................... 422

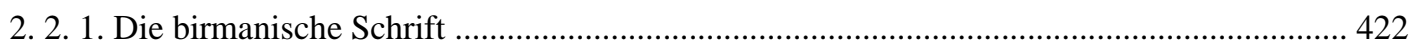

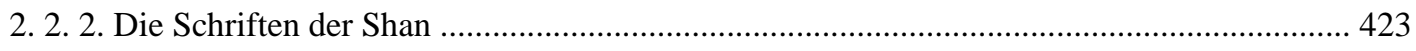

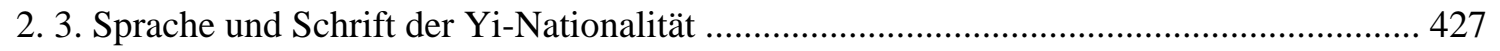

2. 4. Die Entwicklung der Yi-Schrift (cuan wen) nach chinesischen Quellen ........................ 429

2. 5. Die Beschreibung der ,Schriften der Fremden` im TYTZ ............................................ 431

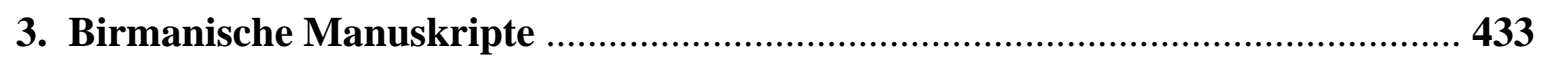

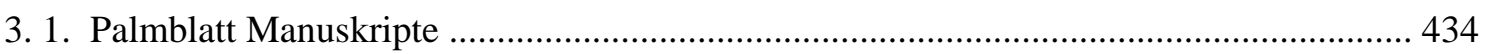

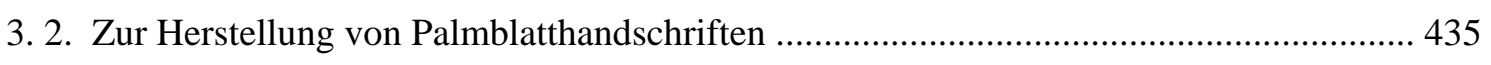

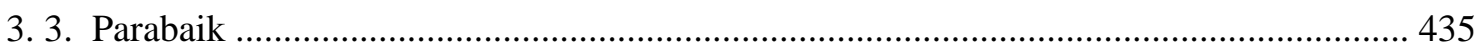

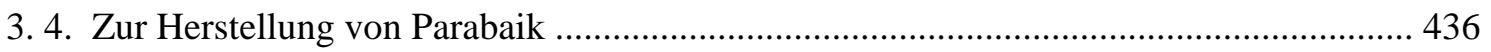


3. 5. Die Beschreibung birmanischer Manuskripte von Wu Kai 437

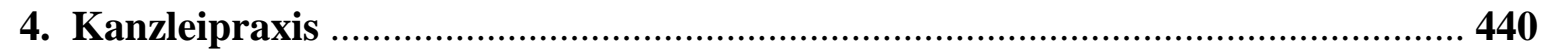

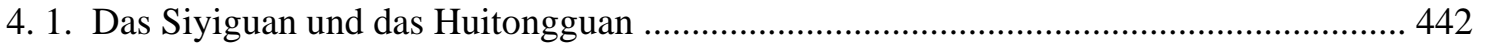

4. 2. Die Wörterbücher der Übersetzungsbüros - Huayi yiyu .................................................. 445

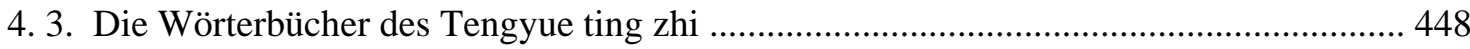

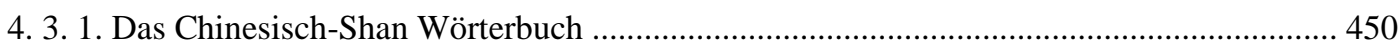

4. 3. 2. Das Chinesisch-birmanische Wörterbuch …………………………………………....... 451

5. Kanzleipraxis in Yunnan - Probleme in Tengyue .............................................. 459

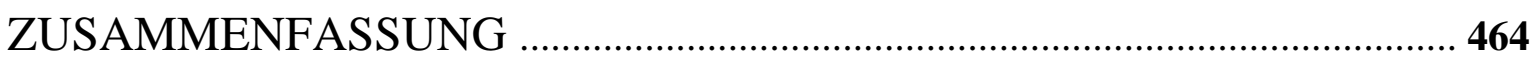

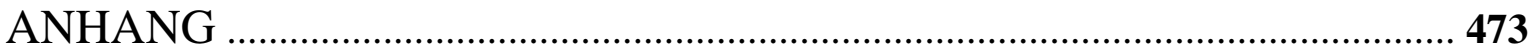

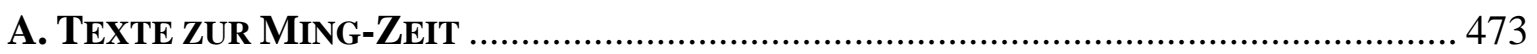

1. Die Reise des Gesandten Guo Xu zum Jinshajiang im Jahr 1501 ............................................ 473

2. Die Beschreibung des Befriedeten Gebietes Mengmi .............................................................. 475

3. Das Befriedete Gebiete Manmo an der Wende zum 17. Jahrhundert ....................................... 479

4. Die Balladen von den Edelsteinminen von Yang Shen und Zhang Han ................................... 481

5. Die Throneingabe des Gouverneurs Chen Yongbin bezüglich der

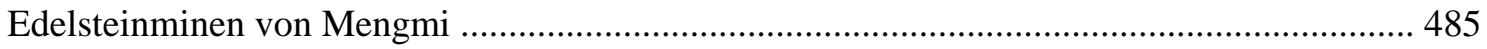

6. Die Kurzbiographien der Brüderpaare Liu und Wang im YCFZ ........................................... 490

B. TEXTE ZUR QING-ZEIT ........................................................................................ 493

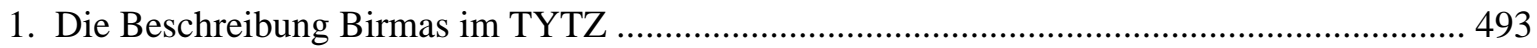

2. Das Kapitel über den ,Grenzschutz‘ im TYTZ ……................................................................ 498

3. Die Proklamation der Hui von Tengyue ............................................................................ 503

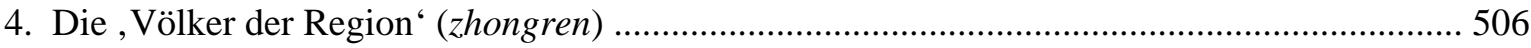

LITERATURVERZEICHNIS .......................................................................... 516

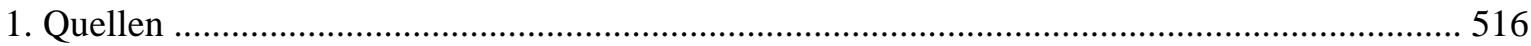

2. Literatur in asiatischen Sprachen .................................................................................... 516

2. 1. Literatur in chinesischer Sprache .................................................................................. 516

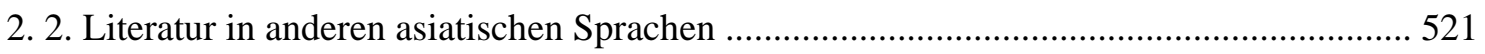

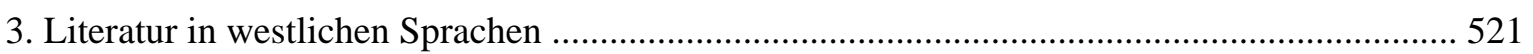

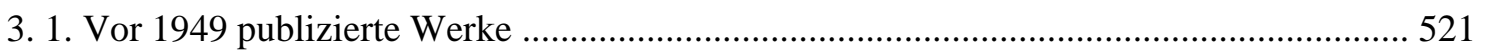

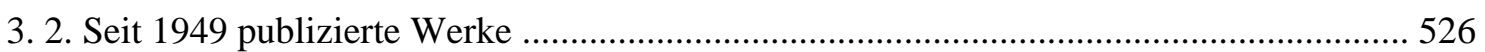




\section{Verzeichnis der Karten und Abbildungen}

Karte 1: Die Region des Stromschluchtenfächers im Westen der Provinz Yunnan (VR China) ...... 2

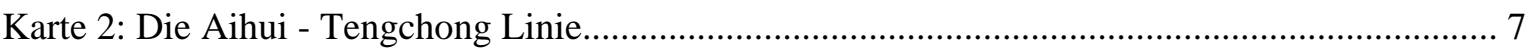

Karte 3: China zur Zeit der Westlichen Han-Dynastie (206 v.Chr.- 9 n.Chr.) ................................ 35

Karte 4: Das Königreich Nanzhao - Städte und Hauptverkehrsstraßen ......................................... 40

Karte 5: Die Region des Stromschluchtenfächers im 13. Jahrhundert:

Die Verwaltungseinheiten Dali und Jinchi ..................................................................... 48

Karte 6: ,Die erste ummauerte Stadt an der äußersten Grenze‘ ........................................................ 74

Karte 7: Verwaltungsgebäude und Tempel in der ,ersten ummauerten Stadt ${ }^{\star}$................................... 79

Karte 8: Die acht Paßstationen in der Unterpräfektur Tengyue zur Zeit der Ära Wanli ............... 138

Karte 9: Die Verbreitung des Staatlichen Bildungswesens in Yunnan in der Ming-Zeit .............. 176

Karte 10: Die Feldzüge der Qing-Armeen im chinesisch-birmanischen Krieg .............................. 216

Karte 11: Die Unterpräfektur Tengyue zur Zeit der Ära Qianlong (1736-1796) ............................ 232

Karte 12: Die Unterpräfektur Longling am Ende des 19. Jahrhunderts ......................................... 234

Karte 13: Verwaltungseinheiten der Provinz Yunnan zur Zeit der Moslem-Rebellion ................. 327

Karte 14: Die Präfektur Yongchang in der zweiten Hälfte des 19. Jahrhunderts ......................... 357

Karte 15: Die Stadt Tengchong zu Beginn des 20. Jahrhunderts ............................................... 372

Karte 16-1: Die Grenze im Westen der Präfektur Yongchang Ende des 19. Jahrhunderts:

Die Karte der Region des Stromschluchtenfächers im TYTZ ..................................... 392

Karte 16-2: Die Grenze im Westen der Präfektur Yongchang: Paßstationen und tusi-Gebiete .... 393

Karte 17-1: Die Unterpräfekturstadt Tengyue in der zweiten Hälfte des 19. Jahrhunderts ........... 398

Karte 17-2: Die tusi-Gebiete im Südwesten von Tengyue in der zweiten Hälfte des

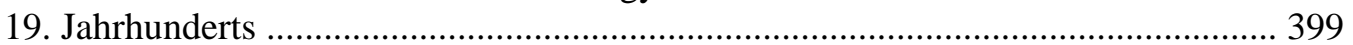

Karte 18: Der Bezirk Baoshan und der autonome Bezirk Dehong der Dai und Jingpo ................. 471

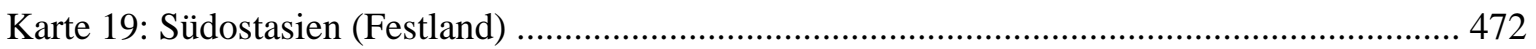

Abb. 1: Verkehrswege in der Region des Stromschluchtenfächers - Brücken und Straßen .......... 303

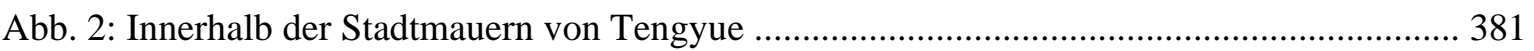

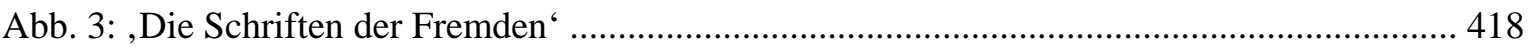

Abb. 4: Beispiele der verschiedenen Shan-Schriften - die Basiskonsonanten ............................... 423

Abb. 5: Tabelle der vier in der VR China gebräuchlichen Alphabete der Dai ............................... 425

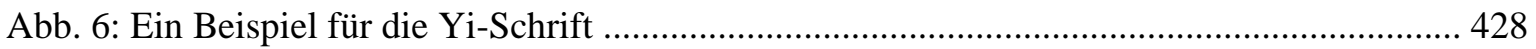

Abb. 7: Die Wörterbücher des Tengyue ting zhi

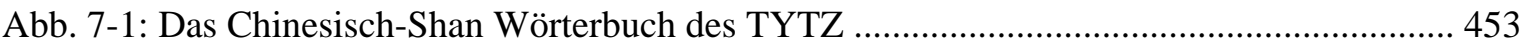

Abb. 7-2: Das Chinesisch-birmanische Wörterbuch des TYTZ …….............................................. 456 


\section{KAPITEL I}

\section{EINLEITUNG}

\section{Die Stadt Tengchong}

Die Stadt Tengchong liegt im äußersten Westen der chinesischen Provinz Yunnan nahe der Grenze zu Birma (Myanmar). Tengchong war seit dem 13. Jahrhundert der am weitesten nach Südwesten vorgeschobene Außenposten des Kaiserreiches. „Kein Ort auf der Welt ist so fern wie Yunnan, kein Ort in Yunnan ist so fern wie Teng, es ist der am weitesten entfernte Ort in China“, so beschreibt ein chinesischer Minister zu Beginn des sechzehnten Jahrhunderts die Lage der Stadt. ${ }^{1}$ Weit entfernt von den politischen und wirtschaftlichen Zentren der Kernregion war Tengchong ein Handelsplatz, Militärstützpunkt und Verwaltungszentrum in der Peripherie des chinesischen Reiches (siehe Karte 1). Verantwortlich für Sicherheit und Stabilität in einem vielschichtigen Grenzgebiet war sie die ,erste ummauerte Stadt an der äußersten Grenze‘.2 Im achtzehnten Jahrhundert noch Ausgangspunkt für chinesische Vorstöße nach Birma, sollte Tengchong ein Jahrhundert später für das britische Kolonialreich Eingangstor zum Südwesten Chinas werden; noch Anfang des zwanzigsten Jahrhunderts wurde die Stadt zum Vertragshafen (treaty port) erklärt. Das prosperierende Gewerbe der Jadebearbeitung machte Tengchong in den 1930er Jahren als ,Stadt der Jade‘ bekannt. Zur Zeit der Republik China erhielt Tengchong den Status einer Kreisstadt, den sie auch nach der Gründung der Volksrepublik beibehielt. Heute gehört die Kreisstadt Tengchong zu den historischen Kulturstädten der Provinz Yunnan. Sie ist für den internationalen Handel geöffnet und erhielt im Jahr 1991 den Status eines ,offenen Außenhandelsplatzes auf Provinzebene‘ ${ }^{3}$

\section{1. Die geographische Lage der Stadt Tengchong}

Die Landschaft im Westen der Provinz Yunnan wird von Gebirgen, weiten Hochplateaus und tiefen Flußtälern geprägt. Die Gebirgszüge des Yunlingshan, Nushan und des Gaoligongshan ziehen sich parallel mit den großen Strömen des Mekong (chin. Lancangjiang)

\footnotetext{
${ }^{1}$,Tian xia mou yuan yu Dian, Dian mou yuan yu Teng, qi qu Zhongguo xia jue yi‘; so Zhang Zhichun in einem Bericht aus dem Jahr 1511 (TYTZ, S. 285; TYZZ, S. 72). Zhang stammte selbst aus der Gegend um Tengchong. Während der Ära Zhengde (1506-22) der Ming-Dynastie war er Vize-Minister des Amtes für die kaiserlichen Opferzeremonien (taichang si) und als solcher gleichzeitig Direktor des Institutes für Übersetzungen (siyiguan). Später wurde er zum VizeMinister des Finanzministeriums (hubu) in Nanjing ernannt (YCFZ, S. 227).

${ }^{2}$,Jibian di yi cheng': In den Lokalhandbüchern verwendete Bezeichnung für die Stadt Tengchong nach dem Bau der Stadtmauer (1445-48) (TYZZ, S. 50, 83; TYTZ, S. 67).

3 ,Shengji kaifang kouan' (BTG, S. 4).
} 
Karte 1 : Die Region des Stromschluchtenfächers im Westen der Provinz Yunnan (VR China)

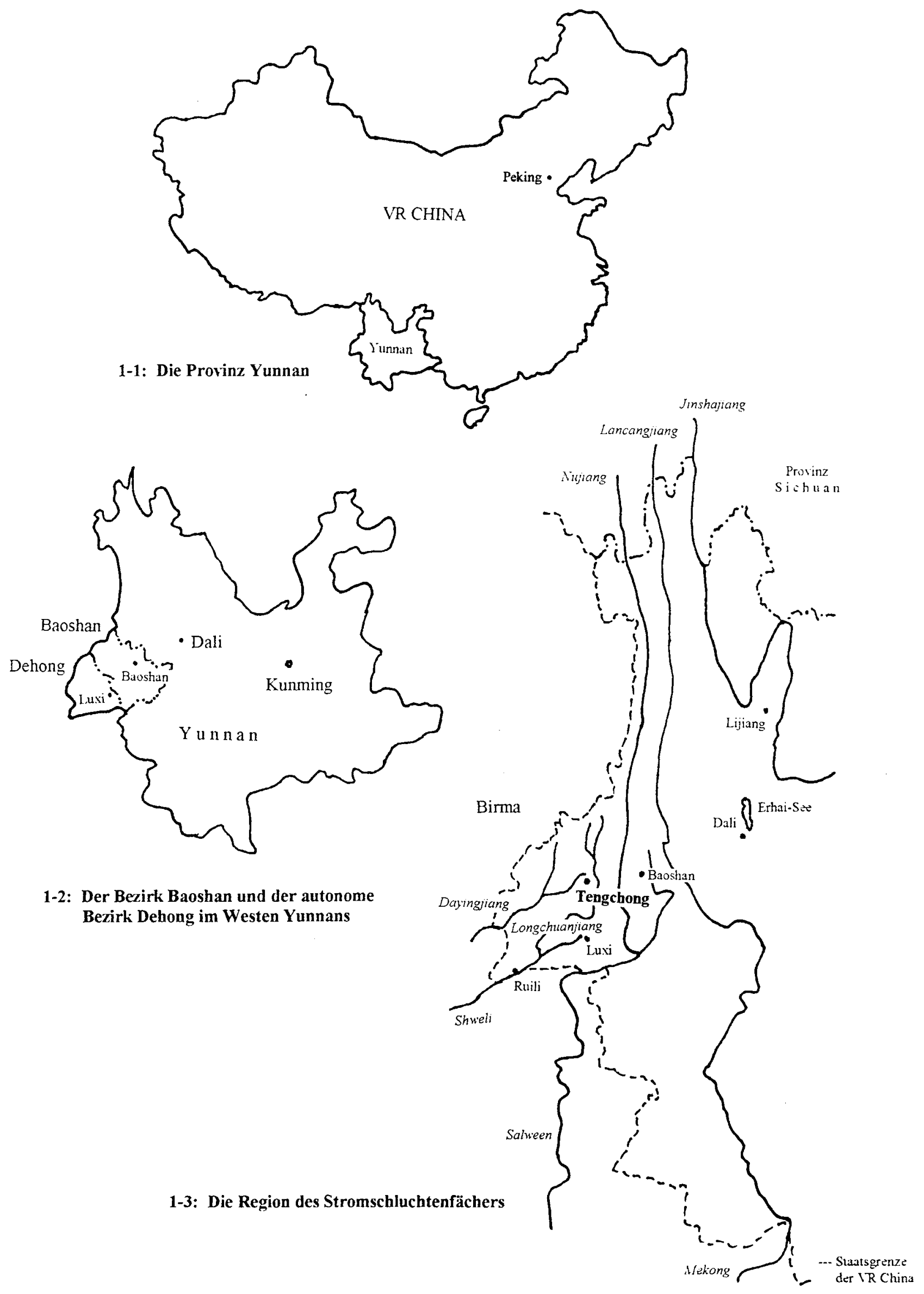


und Salween (chin. Nujiang, auch Lujiang) verlaufend von den östlichen Ausläufern des Himalaya nach Süden, um sich dann zum Gebiet des sogenannten Stromschluchtenfächers zu verbreitern. Der westlichste der drei Gebirgszüge, der bis über 3500m ansteigende Gaoligongshan, bildet die Wasserscheide zwischen dem Einzugsgebiet des Salween im Osten und dem des Irawadi im Westen. ${ }^{4}$ Die Stadt Tengchong (25 Grad nördlicher Breite und 98.5 Grad östlicher Länge) liegt in 1620m Höhe am westlichen Rand des GaoligongGebirges, auf einer fruchtbaren Hochebene am östlichen Ufer des Flusses Dayingjiang. Die Umgebung der Stadt wird durch eine Kette von neunundsiebzig erloschenen Vulkanen aus dem Neozoikum bestimmt, darunter der $2614 \mathrm{~m}$ hoch aufragende Dayingshan. ${ }^{5}$ Der vulkanische Charakter der Landschaft kommt auch in den über achtzig heißen Quellen zum Ausdruck. Bis in die Gegenwart hat es in der Region immer wieder Erdbeben gegeben, so ereignete sich am 8. Juni 2001 in Shidian südöstlich von Tengchong ein Beben der Stärke 5,3 auf der Richterskala. ${ }^{6}$

Das Klima Tengchongs wird durch den Südwest-Monsun bestimmt. Das GaoligongGebirge bildet hier eine Wetterscheide. Während die Stadt Tengchong auf der Luvseite des Gebirges noch durchschnittlich einhundertsechzig Regentage pro Jahr mit einem Jahresniederschlag von ca. 1500mm hat, gibt es in der auf der Windschattenseite des Gaoligongshan in 1690 m Höhe gelegenen Stadt Baoshan nur noch etwa einhundert Regentage pro Jahr mit einem durchschnittlichen Niederschlag von $960 \mathrm{~mm}^{7}$ Ansonsten sind die klimatischen Bedingungen der Region abhängig von der jeweiligen Höhe über dem Meeresspiegel. In den Flußniederungen herrscht ein tropisches bis subtropisches Klima, welches die Ausbreitung der Malaria begünstigt. In den Bergen in über 2000m Höhe ist das Klima feucht und nebelig, die Temperatur kann dort auch unter den Gefrierpunkt fallen.

\section{2. Tengchong und Tengyue}

Das moderne Tengchong war im Laufe seiner Geschichte zeitweise unter dem Namen Tengchong, zeitweise auch als Tengyue bekannt. Tengchong ist die ältere Bezeichnung, die in den Regionalhandbüchern seit etwa dem 10. Jahrhundert als belegt gilt und die die

\footnotetext{
${ }^{4}$ Im Jahr 2000 wurde das Gaoligong-Gebirge in die Liste des World Biosphere Reserve Network der UNESCO aufgenommen.

${ }^{5}$ Der Vulkan-Park von Tengchong ist eine von drei Stätten mit säulenartigen Magmaablagerungen in China. Die beiden andern befinden sich in Nanning in der Provinz Jiangsu und am Berg Emei in der Provinz Sichuan.

${ }^{6}$ Bereits einige Wochen zuvor, am 13. April 2001, hatte sich ebendort ein Erdbeben ereignet.

${ }^{7}$ Kolb, Yunnan, S.17. Cressey, S. 374, 1934: 1479 mm.
} 
Stadt bis heute insgesamt über 600 Jahre lang geführt hat. Der Name Tengyue wurde erstmals im 13. Jahrhundert verwendet und zweieinhalb Jahrhunderte später im Jahr 1523 erneut eingeführt. Er blieb der Stadt fast vierhundert Jahre lang bis zum Ende der Kaiserzeit erhalten. Seit der Gründung der Republik China im Jahr 1912 führt die Stadt wieder den Namen Tengchong, der seit der Schriftreform im Jahr 1956 mit vereinfachten Schriftzeichen geschrieben wird.

Tabelle 1: Tengchong und Tengyue - die verschiedenen Namen der Stadt

\begin{tabular}{|c|c|c|c|}
\hline NAME & & ZEIT & JAHRE \\
\hline \multirow[t]{5}{*}{ Tengchong } & 騰 (藤) 充 & 8. und 9. Jh & \\
\hline & & 10. Jh -1274 & ca. 250 \\
\hline & 瑪 嘢 & $1277-1523$ & 246 \\
\hline & & $1912-1956$ & 44 \\
\hline & 腾 冲 & $1956-2003<$ & $\sqrt{2}$ \\
\hline \multirow[t]{2}{*}{ Tengyue } & 藤越 & $1274-1277$ & 3 \\
\hline & 騰越 & $1523-1912$ & $\begin{array}{l}389 \\
\text { (gesamt: } 392 \text { Jahre) }\end{array}$ \\
\hline
\end{tabular}

Der erste Teil des Namens, teng (,galoppieren, dahineilen; springen; frei machen`), wurde unverändert mit dem gleichen Schriftzeichen geschrieben, abgesehen von der im 13. Jahrhundert kurzzeitig verwendeten Schreibvariante teng mit der Bedeutung ,Flechtrohr`. Flechtrohr und Flechtrohrprodukte aus dem westlichen Yunnan waren seit der Tang-Zeit (618-907) in Zentral-China bekannt. ${ }^{8}$ In der Region des Stromschluchtenfächers selbst dienten Seile aus Flechtrohr (teng) seit alters her auch zum Bau von Brücken, um die zahlreichen Flüsse zu überwinden (yue). ${ }^{9}$

Das Schriftzeichen yue (,überschreiten, überwinden; hinausgehen über`) wurde als zweiter Bestandteil des Namens erstmals im 13. Jahrhundert und erneut vom 16. bis zum Beginn

\footnotetext{
${ }^{8}$ Die Verfasser des TYTZ bemerken hierzu: Aus diesem „dünnen Rohr kann man Seile fertigen, dicke Rohre dienen als Stöcke; auch können hunderterlei Gefäße daraus hergestellt werden; die [abweichende] Schreibweise von Tengyue in alten Chroniken leitet sich von [diesem Wort] her“ (TYTZ, S. 60).

Siehe auch Bai Juyis (772-846) Gedicht Hong teng zhang (,Ein Stab aus rotem Rohr`) (Yunnan keai de difang, S. 282). Noch Ende des 19. Jahrhunderts waren Korbwaren aus Tengyue eine bekannte Handelsware.

${ }^{9}$ Luce, Manshu, S. 70; Hsiang Da, Kap. 7, S. 196-197; TYTZ, S. 61
} 
des 20. Jahrhunderts an Stelle von chong (,überfluten; vorwärtsstürmen; Knotenpunkt, Durchgangsstraße‘) verwendet.

Tengchong kann als ,über die Ebene dahineilen‘, ,die Durchgangsstraße frei machen‘, ,auf der Straße dahineilen` oder als ,freiräumen und vorwärtsstürmen` übersetzt werden. In diesem Namen kommt die strategische Lage der Stadt an einer wichtigen Verkehrsroute zum Ausdruck. In Ortsnamen ist chong auch gebräuchlich als Bezeichnung für eine kleine Ebene mit einem Fluß; so spiegelt der Name Tengchong zudem die geographische Lage der Stadt am Fluß Daying auf einem Hochplateu im Gaoligong-Gebirge wieder.

Tengyue kann mit ,Hindernisse überwinden` oder ,überspringen` übersetzt werden. Beide Namen sind Programm, sie drücken dynamische Bewegung aus, weisen auf die vielbenutzten Verkehrswege hin, zeigen aber auch, daß hier ein gewisser Status quo erreicht worden ist, über den man jedoch hinausgehen und weiter in die Regionen jenseits des Hochplateaus gelangen kann. Die Namen der Stadt machen seit alters her also nicht nur den Anspruch deutlich, das Gebiet beherrschen zu wollen, sondern zeigen ebenso das Bestreben, den Machtbereich der chinesischen Zentralregierung über die Stadt hinaus weiter vergrößern zu wollen. ${ }^{10}$

\section{3. Die Stadt Tengchong und ihr Umfeld}

Die schwer zugängliche Region des Stromschluchtenfächers war auch in früheren Jahrhunderten keineswegs völlig isoliert, sondern wurde von verschiedenen Verkehrswegen durchzogen, die sie mit den großen Reichen in ihrer weiteren Umgebung in Kontakt brachten: Seit etwa dem zweiten vorchristlichen Jahrhundert sind Handelsverbindungen zwischen China und Indien bekannt, die von Sichuan über Yunnan und Birma weiter nach Westen führten. ${ }^{11}$ Die wichtigste dieser Handelsrouten führte in Yunnan, ebenso wie die gegenwärtige Hauptverkehrsader der Provinz, von Kunming über Dali nach Baoshan. Dort teilte sich die alte Handelsroute in eine südliche und eine westliche Teilstrecke. Die südliche führte über Longling und Wanding nach Birma. Entlang dieser Strecke verlief auch die sogenannte ,Burma Road‘, die in den Jahren von 1938 bis 1942 die wichtigste Nachschubroute der national-chinesischen Regierung im Krieg gegen Japan war. Die westliche Route führte von Baoshan über das Gaoligong-Gebirge auf die Hochebene von Tengchong

\footnotetext{
${ }^{10}$ Auch in der Zeit der Reform- und Öffnungspolitik Ende des 20. Jahrhunderts wird der Name der Stadt gerne wieder als Programm verstanden und ihre Zukunft mit dem optimistischen und dynamischen Bild eines Vogels gezeichnet, der sich ,mit den Flügeln schlagend emporschwingt und in die höchsten Sphären vordringt‘ (zhenchi tengfei, zhichong jiuxiao); so z. B. in der Jingji ribao vom 24. Mai 1998 (di ba ban).

${ }^{11}$ Coedes, S. 61
} 
und weiter nach Südwesten, wo sie sich in drei Strecken teilte, die schließlich in Bhamo im modernen Birma wieder zusammentrafen, von wo aus sie den Irawadi, die Hauptverkehrsader Birmas, erreichten.

Das Gebiet des Stromschluchtenfächers ist ebenso wie die gesamte Provinz Yunnan ein dreidimensionales Mosaik von Siedlungsgebieten verschiedener Völker. Eine Region, die bis heute von den Kulturen dieser Völker, wie den Dai (birm. Shan), Jingpo (birman. Kachin), Lisu, Bai, Achang und anderen, geprägt ist und in die Han-Chinesen in größerer Zahl erst seit der Ming-Zeit einwanderten. Seitdem wurde die Integration Yunnans in das chinesische Reich vorangetrieben. Mit der Errichtung von befestigten Städten wurde das politische und gesellschaftliche System der Kernregion im fernen Südwesten etabliert und auch die Bemühungen verstärkt, die Völker der Region fester an die Kernregion zu binden und in die regulären Verwaltungsstrukturen einzugliedern.

Ihre geographische Lage stellt die Entwicklung der Stadt Tengchong in einen engen Zusammenhang zur Gestaltung der politischen Beziehungen des chinesischen Reiches zu seinen Nachbarn, zu Birma sowie zu den Herrschaftsgebieten der Shan und Kachin in der Grenzregion. Diese bestanden in Handelsverbindungen, Tributgesandtschaften und auch in kriegerischen Auseinandersetzungen, die Tengchong in Friedenszeiten zu einem florierenden Handelszentrum, in Kriegszeiten zu einem Truppenlager machten und entsprechend auch das Verhältnis der zivilen und militärischen Verwaltungsorgane zueinander beeinflußten. In diesem Spannungsfeld einer Grenzregion mußte Tengchong unterschiedlichen Anforderungen gerecht werden. Neben den regulären Verwaltungstätigkeiten galt es nicht nur die militärische Grenzsicherung zu gewährleisten, sondern auch Handel, Märkte und Tributleistungen sowie die verschiedenen Völker und regionalen Machthaber zu kontrollieren, Bestrebungen zur Assimilierung des Umlandes zu fördern, besonders jedoch die Stabilität in diesem vielschichtigen Grenzgebiet zu wahren.

\section{4. Die Grenzstadt Tengchong}

Die besondere Grenzlage Tengchongs läßt sich mittels der Aihui-Tengchong Linie deutlich machen (siehe Karte 2, S. 7). Diese Linie verbindet Tengchong mit dem Kreis Aihui im Norden der Provinz Heilongjiang. Sie teilt China in eine westliche und eine östliche Hälfte und wird von chinesischen Geographen verwendet, um die extremen Unterschiede zwischen diesen beiden Teilen des riesigen Landes zu veranschaulichen. 


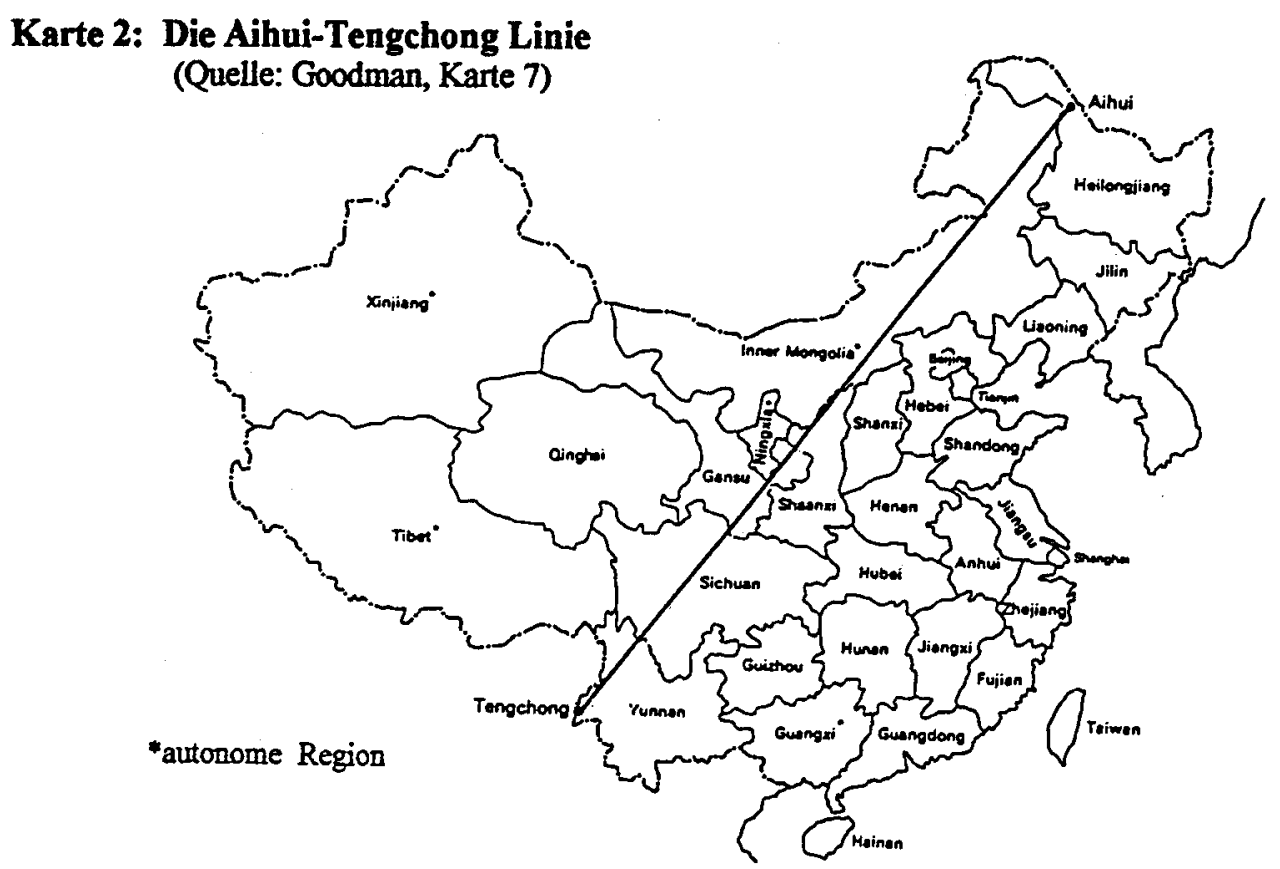

Westlich der Linie befinden sich über sechzig Prozent der Landfläche der Volksrepublik China, die jedoch nur von etwa sechs Prozent der Gesamtbevölkerung bewohnt werden. ${ }^{12}$ Die Bevölkerung des westlichen Teils des Landes setzt sich, im Gegensatz zum östlichen Teil, der mehrheitlich von Han-Chinesen bewohnt wird, überwiegend aus verschiedenen anderen Volksgruppen zusammen. Diese Unterschiede spiegeln sich auch in der Verwaltungsorganisation Chinas wieder: Westlich der Linie befinden sich wenige großflächige Verwaltungseinheiten, darunter vier der fünf autonomen Regionen, im Osten hingegen liegen die kleineren Provinzen sowie die regierungsunmittelbaren Städte. Ebenso wie die autonomen Regionen der westlichen Landeshälfte liegen auch Heilongjiang und Yunnan an der Staatsgrenze der Volksrepublik China. Beide zählen hier jedoch fast vollständig zur östlichen Landeshälfte und haben den Status von Provinzen; sie sind die zweit- bzw. drittgrößten der Provinzen mit mehrheitlich Han-chinesischer Bevölkerung.

Als Endpunkt der Aihui-Tengchong Linie ist Tengchong in mehrfacher Hinsicht Grenzgebiet. Zum einen nach außen, aufgrund der geographischen Nähe zur Staatsgrenze, zum anderen innerhalb Chinas, als Schnittpunkt, an dem die beiden von dieser Linie gebildeten Hälften des Landes mit ihren unterschiedlichen Bevölkerungsstrukturen zusammentreffen. Schließlich ist Tengchong der südwestlichste reguläre Verwaltungsbezirk Chinas und befindet sich somit an der Grenze bestimmter administrativer und politischer Strukturen.

${ }^{12}$ Kirkby 1985, S. 260 
Mit ihrem südlichen Endpunkt markiert die Aihui-Tengchong Linie den gegenwärtigen Stand des Entwicklungsprozesses, den Yunnan in seiner Geschichte durchlaufen hat und der die Provinz zu einem festen Bestandteil des chinesischen Reiches werden ließ, der heute sehr viel enger an die Kernregion angebunden ist als die Grenzgebiete im Norden und Nordwesten der Volksrepublik.

Doch der Prozeß der Ausgestaltung und Konsolidierung dieses Grenzgebietes im Südwesten ist noch keineswegs abgeschlossen. Die Reform- und Öffnungspolitik der VR China sowie die politische und wirtschaftliche Zusammenarbeit mit den Ländern Südostasiens haben der Provinz Yunnan seit Ende der 80er Jahre des 20. Jahrhunderts neue Impulse gegeben. Bereits 1988 haben China und Birma ein bilaterales Grenzhandelsabkommen unterzeichnet. Außerdem ist die Volksrepublik gemeinsam mit Birma, Thailand, Laos, Kambodscha und Vietnam Teil der Wachstumsregion ,Greater Mekong Subregion“ (GMS), einer von der Asian Development Bank unterstützten Entwicklungszusammenarbeit der Länder Südostasiens und Chinas. Die politischen Weichenstellungen erleichtern die Ansiedlung von Handelsunternehmen, der zügige Ausbau der Infrastruktur in Yunnan (gefördert auch durch das GMS-Programm) ermöglicht eine Vervielfachung des grenzüberschreitenden Güter- und Personenverkehrs; die günstigen Rahmenbedingungen ziehen zahlreiche Zuwander aus Zentral-Yunnan und dem chinesischen Kernland an. Eng mit der Bevölkerungsentwicklung und dem wirtschaftlichen Aufschwung verbunden, sind im Grenzgebiet bereits neue Verwaltungseinheiten entstanden, die ebenfalls die Dynamik widerspiegeln, mit der sich die Region gegenwärtig verändert. ${ }^{13}$ Mit der Wiedereröffnung der Birma-Straße und dem Ausbau der Grenzorte Wanding und Ruili hat China eine neue Phase der Entwicklung seiner südwestlichen Grenzregion in Gang gesetzt, in deren Mittelpunkt jedoch die Erschließung der Ressourcen der Mekong-Region steht.

Neben dem Ausbau der Wasserstraße ist China insbesondere an der Nutzung des Flusses als Stromlieferanten interessiert. ${ }^{14}$ Der Bau von Wasserkraftwerken im Mekong ist Teil der großangelegten staatlichen ,Projekte zum Transport von Energie aus dem Westen nach

\footnotetext{
${ }^{13}$ Die prosperierenden Grenzstädte Ruili und Wanding wurden zu Kreisstädten aufgewertet und die Ortschaft Jiegao am gleichnamigen Grenzübergang zu Birma über den Fluß Ruili (Shweli) im April 2000 zu einer Sonderzone des Grenzhandels (bianmao tequ) erklärt.

${ }^{14}$ Zur Gewinnung von Energie aus Wasserkraft hat die VR China für die sogenannte ,Yunnan cascade‘ zunächst sieben, insgesamt sogar bis zu vierzehn Kraftwerke im Mekong geplant. Realisiert worden sind bereits der Staudamm Manwan (im Jahr 1993 in Betrieb genommen) cirka einhundert Kilometer südlich von Dali, der Strom für die Provinzhauptstadt Kunming produziert sowie ein erster Bauabschnitt des südlich gelegenen Dachaoshan-Dammes, der ebenfalls schon Strom liefert. Anfang des Jahres 2002 wurde mit dem Bau des nördlich von Manwan gelegenen deutlich größeren Xiaowan-Dammes begonnen, der 2012 fertiggestellt sein soll. Für einen zusammenfassenden Überblick über die wirtschaftliche Nutzung des Mekong und deren Konsequenzen für die Anrainerstaaten siehe Mathias Haase, ,Die MekongRegion - Potenziale und Risiken aus chinesischer Perspektive`, in: CHINA aktuell, Oktober 2002, S. 1156-1170.
} 
Osten ' (xi qi dong shu gongcheng; das Mekong-Projekt wird mit dem Slogan xi dian dong song ,Energie von West nach Ost' bezeichnet). Der bereits gewonnene Strom deckt heute nicht allein den Bedarf der Provinz Yunnan, sondern wird auch nach Guangdong geliefert. In Zukunft soll damit die lokale Verarbeitung der in Yunnan reichlich vorhandenen Rohstoffe weiter gefördert und Strom zudem in die Nachbarländer vor allem nach Thailand exportiert werden. ${ }^{15}$ Insgesamt verstärken diese Entwicklungprojekte die Anbindung des Grenzgebietes im äußersten Westen des Landes an die Kernregion und besonders an die dynamischen Wirtschaftszentren an Chinas Ostküste.

\section{Die Provinz Yunnan als Gegenstand westlicher Forschung}

\section{1. Die Beschäftigung mit Yunnan in den westlichen Ländern vor 1949}

In den Blickpunkt des Interesses der westlichen Nationen ist die Provinz Yunnan erstmals in der zweiten Hälfte des 19. Jahrhunderts gerückt. Nachdem die Briten im Jahr 1852 Niederbirma erobert hatten, begannen sie die Möglichkeiten zu erforschen, die jahrhundertealten Handelsrouten, die Birma via Yunnan mit China verbanden, für sich zu nutzen, um so, sozusagen durch die Hintertür, Zugang zu den in China erhofften Märkten zu bekommen. Neben den politischen spielten daher vor allem wirtschaftliche Gründe eine entscheidende Rolle bei der Annektion Oberbirmas im Jahr 1886. Hinzu kam die Rivalität auf beiden Gebieten mit Frankreich, das sich seit der Errichtung seines Protektorats über Vietnam (1883) ebenfalls bemühte, seinen Einfluß im Südwesten Chinas zu verstärken.

Das neuerwachte Interesse am Südwesten führte immer mehr Reisende aus westlichen Nationen nach Yunnan. Entdeckungsreisende, Naturforscher aus England und Frankreich, aber auch aus Amerika, Deutschland oder Österreich bereisten die Provinz. Auch die Missionare insbesondere der protestantischen britischen China Inland Mission, die seit 1877 in Yunnan aktiv war, und der katholischen französischen Société des Missions Étrangers de Paris, die von Sichuan aus (wo sie bereits seit 1756 präsent war) ihre Aktivitäten nach Yunnan ausgedehnt hatte, berichteten über ihre Arbeit, womit sie auch um finanzielle Mittel für deren Fortsetzung warben. So wie Père Paul Vial, der sowohl populäre als auch wissenschaftliche Werke über das Volk der Sani und seine Missionarstätigkeit bei diesem verfaßte.

\footnotetext{
${ }^{15}$ Haase, S. 1163
} 
Expeditionen wurden ausgerichtet, die sowohl von Regierungen als auch von den Handelskammern und wissenschaftlichen Instituten unterstützt wurden. Als Beispiele seien die britischen Expeditionen unter Colonel Sladen und Colonel Browne in den Jahren 1868 und 1875, die französische Mission von Vicomte d’Ollone 1906-09 sowie die österreichische des Freiherrn von Handel-Mazzetti 1914-1919 genannt.

Die rege Reisetätigkeit spiegelt sich in der zahlreicher werdenden Literatur über Yunnan wieder. Eine von Liu Hsiu-yeh zusammengestellte Auswahlbibliographie der bis zum Jahr 1938 erschienenen westlichen Literatur zum Thema Yunnan umfaßt mehr als eintausend Titel. ${ }^{16}$ Expeditions- und Reiseberichte sowie allgemeine Beschreibungen der Provinz erschienen ebenso wie Publikationen zu Botanik, Geologie, Geschichte, Handel, Verkehrswesen und besonders zur Völkerkunde Yunnans. Mit ,La province chinoise du Yunnan“ von Émile Rocher wurde in den Jahren 1879/1880 eine erste umfassende Einführung in die Geschichte der Provinz Yunnan publiziert.

Waren zu Beginn des 19. Jahrhunderts zunächst nur vereinzelte Schriften erschienen, so nahm die Anzahl der Werke ab 1863 insgesamt gesehen deutlich zu. Besonders viele Titel sind in der Zeit von 1895 bis zum 1. Weltkrieg erschienen. Aber auch in den zwanziger und dreißiger Jahren war Yunnan noch Thema diverser Publikationen westlicher Autoren. Das Interesse des Westens an der Provinz Yunnan fand sein vorläufiges Ende mit dem zweiten Weltkrieg und Beschreibungen der Birma-Straße. Danach hatte Yunnan seine Position als Interessengebiet von Politik und Wirtschaft der westlichen Nationen sowie auch als Thema wissenschaftlicher Forschung verloren; sowohl bei der Darstellung zeitgenössischer als auch historischer Entwicklungen trat die Grenzregion im fernen Südwesten Chinas hinter andere Provinzen des Landes zurück.

\section{2. Tengyue in westlichen Reise- und Expeditionsberichten (1868 bis 1945)}

Um die Jahrhundertwende nutzten zahlreiche Reisende aus westlichen Ländern die Möglichkeit, in Birma auf dem Irawadi bis nach Bhamo zu reisen und von dort auf den alten Verbindungswegen über Tengyue (seit 1912 offiziell wieder Tengchong genannt) weiter ins Landesinnere zu gelangen oder von dort kommend China auf diesem Wege zu verlassen. Die folgende kurze Zusammenstellung von Reise- und Expeditionsberichten erfaßt nur

\footnotetext{
${ }^{16}$ Liu Hsiu-yeh: ,A selected bibliography of Yunnan and of the tribes of southwestern China', in: Quarterly Bulletin of Chinese Bibliography, Kunming 1940-1941.
} 
einen kleinen Teil dieser Publikationen, es werden lediglich Werke von Autoren vorgestellt, die selbst in Tengyue/Tengchong gewesen sind und aus eigener Anschauung berichtet haben.

Als der Handel mit Yunnan wegen des Moslem-Aufstandes (1855-1873) in der Provinz stark zurückgegangen war, sollte 1868 eine britische Expedition unter der Leitung von Major E. B. Sladen die Situation im Grenzgebiet erforschen und eine Wiederaufnahme der Handelsverbindungen errreichen. Der Expedition gelang es, bis nach Tengyue zu reisen, das zu dieser Zeit von den Aufständischen besetzt war. Der von Major Sladen verfaßte Bericht über die Expedition erschien 1869 in Rangun. ${ }^{17}$ An dieser und einer zweiten Expedition im Jahr 1875 nahm auch Dr. John Anderson teil, der in seinem 1876 erschienenen Buch ,Mandalay to Momien` die Reiseroute, die Stadt Tengyue (birman. Momien) und die Auswirkungen der Rebellion auf das Leben im Grenzgebiet ausführlich beschrieben hat. ${ }^{18}$

An der zweiten Expedition hatte auch Augustus Margary als Dolmetscher teilgenommen. Er hielt sich im Januar 1875 einen Monat vor seiner Ermordung im Grenzgebiet einige Tage in Tengyue auf. Sein Reisebericht erschien 1876 posthum unter dem Titel ,The journey of Augustus R. Margary“.

Im Juni 1882 erreichte die Expedition von Archibald Colquhoun Tengyue, die sich mit der Untersuchung einer möglichen Route für eine Eisenbahnverbindung von Birma nach Yunnan befaßte. In seinem Reisebericht ,Across Chryse‘ liefert Colquhoun eine kurze wenig informative Beschreibung der Stadt Tengyue.

Eine etwas umfangreichere Darstellung der Stadt Tengyue gibt Henry Randolph Davies, der sich auf seinen Reisen in den Jahren 1895, 1898 und 1899 mehrmals in Tengyue aufhielt, in seinem Buch ,Yün-nan, the link between India and the Yangtzi`, das 1909 in Cambridge erschien. Das Grenzgebiet zwischen Britisch-Birma und China hat Davies in seinem Expeditionsbericht ,Report on the expedition ... to find the Hu-chi, Tien-ma and Han-lung gates‘ von 1894 beschrieben.

Als weitere Reise- bzw. Expeditionsberichte, in denen die Stadt Tengyue beschrieben wird, sind noch zu erwähnen: Edward Colbourne Baber, ,Report on ... Grosvenor's mission

\footnotetext{
17 ,Expedition from Burma via the Irrawaddy and Bhamo to South-western China' (in: Journal of the Royal Geographic Society, vol. 41, 1871, pp. 251-281) und ,Official narrative of and papers connected with the expedition to explore the trade routes to China via Burma' (Rangoon 1869), eine deutsche Übersetzung erschien 1871 in Berlin.

${ }^{18}$ Siehe auch T. T. Cooper: ,Reise zur Auffindung eines Überlandweges von China nach Indien' (Originaltitel: ,Travels of a pioneer of commerce in pigtail and petticoats‘, London 1871), deutsche Übersetzung und Anhang von H. L. von Klenze, Jena 1877.
} 
between Tali-fu and Momein .... (1878); Heinrich Hackmann, ,Vom Omi bis Bhamo، (1905); Fritz Weiss, ,Von Bhamo nach Tengyüe‘ (1909); Beatrix Metford, ,On the BurmaChina frontier: From Bhamo to Tengyue (1933) und Neville Bradley, ,The Old Burma Road' (1945).

\section{3. Neuere westliche Studien über Yunnan}

Erst seit den achtziger Jahren des 20. Jahrhunderts sind im Westen wieder vermehrt Studien publiziert worden, die sich unter verschiedenen Fragestellungen mit der Provinz Yunnan beschäftigen. Diese Publikationen lassen sich grob in zwei große Gruppen einteilen. Erstere umfaßt Werke, die ausgehend von Yunnan als Verwaltungseinheit des chinesischen Reiches Entwicklungen in der Provinz in ihrer Gesamtheit darstellen. ${ }^{19}$ Eine Studie hingegen, die die Eingliederung dieses von mehrheitlich nicht Han-chinesischen Völkern bewohnten Gebietes in das chinesiche Reich und die damit für die Region verbundenen Veränderungen beschreibt, so wie sie Claudine Lombard-Salmon in ,Un exemple d'acculturation chinoise‘ (1972) für die Provinz Guizhou vorgelegt hat, gibt es für Yunnan bisher nicht.

Der bestimmende Faktor für die Entwicklung Yunnans zu einer Provinz des chinesischen Reiches ist die Zuwanderung der Han-chinesischen Bevölkerung, die James Lee in seiner Studie ,Food supply and population growth in Southwest China, 1250-1850، (1982) insbesondere in ihrer regional unterschiedlichen Ausprägung vorstellt und so die Grundlage für eine differenzierte Betrachtung der einzelnen Verwaltungseinheiten im Vergleich zur Gesamtentwicklung ermöglicht.

Die Stadt Tengchong und die Region des Stromschluchtenfächers sind in den Arbeiten zur Provinz Yunnan nur am Rande Thema innerhalb der Gesamtdarstellung. Lediglich Ann Maxwell Hill weist in ihrer Studie ,Merchants and migrants, ethnicity and trade among Yunnanese Chinese in Southeast Asia“ (1998) ausdrücklich auf die besondere Position Tengchongs im Geflecht der politischen und der Handelsbeziehungen zwischen den verschiedenen Völkern, die in den Grenzgebieten im Westen Yunnans leben bzw. Handel treiben, hin.

\footnotetext{
${ }^{19}$ Zum Beispiel Sylvie Pasquet in ihrer Untersuchung des Postwesens in der Qing-Zeit (,L'évolution du système postal: la province du Yunnan à l'époque Qing [1644-1911]', Paris 1986) oder D. S. Sutton mit seiner Studie über die Provinzarmee während der Republikzeit (,Provincial militarism and the Chinese Republic: The Yunnan Army, 1905-1925‘, Ann Arbor 1980).
} 
Die zweite Gruppe der Publikationen zu Yunnan sind die völkerkundlichen Studien, die zum einen allgemeine Darstellungen umfassen, die einen Überblick über die verschiedenen in der Provinz ansässigen Völker vermitteln und über Geschichte und Sprachen ebenso informieren wie über Brauchtum oder Volkserzählungen. Zum anderen sind es Studien, die sich mit einzelnen Volksgruppen beschäftigen. Hierbei stehen Forschungsarbeiten über die Naxi, die Yi und die Dai in Xishuangbanna im Vordergrund des wissenschaftlichen Interesses, während andere Völker bisher nur wenig beachtet worden sind. ${ }^{20}$

Insgesamt beschäftigen sich die neueren westlichen Studien vorwiegend mit den dichter besiedelten zentralen Regionen um die Provinzhauptstadt Kunming und die Stadt Dali am Erhai-See, während die entlegeneren Gebiete weniger untersucht werden, sowohl in Bezug auf ihre allgemeine Entwicklung als auch in Fragen der chinesischen Zuwanderung und deren Auswirkung auf die verschiedenen Regionen. Hier wiederholt sich innerhalb der Provinz, was für China insgesamt beobachtet werden kann: Der intensiven Beschäftigung mit dem Zentrum steht eine relative Vernachlässigung der Randgebiete gegenüber.

Die neuere westliche wissenschaftliche Literatur über Yunnan ist für ein Randgebiet des chinesischen Reiches umfangreich und vielfältig. Sicherlich zwingt die Vielschichtigkeit der Provinz zu einer Konzentration auf bestimmte Themenkreise und einzelne Gruppen der Bevölkerung, wobei andere zunächst unbeachtet bleiben. Auffällig ist jedoch, daß bestimmte Regionen wie zum Beispiel der äußerste Westen kaum untersucht werden und bestimmte Genre, wie die für die Kernregion sehr zahlreich vorhandenen Lokal- bzw. Regionalstudien, bisher nicht vorliegen.

\section{Thema dieser Studie}

\section{1. Kontext und Methode}

Thema dieser Studie ist die historische Entwicklung der Stadt Tengchong, die im Kontext der Entstehung des Grenzgebietes im äußersten Westen der Provinz Yunnan dargestellt wird und den Prozeß der Konsolidierung der chinesischen Verwaltungseinheiten in der Region des Stromschluchtenfächers beschreibt.

\footnotetext{
${ }^{20}$ Für eine Bibliographie völkerkundlicher Studien siehe Alain Y. Dessaint: ,Minorities of southwest China. An introduction to the Yi (Lolo) and related peoples and an annotated bibliography', New Haven 1980.
} 
Die vorliegende Arbeit schließt sich an die in den letzten Jahrzehnten in der westlichen Sinologie zahlreich erschienenen Lokalstudien an, die sich unter den verschiedensten Aspekten mit der historischen Entwicklung einzelner Orte oder Regionen Chinas beschäftigen. So unterschiedlich die in den neueren Lokalstudien untersuchten Gebiete sind, so ist ihnen doch gemeinsam, daß sie sich hauptsächlich im Osten der Volksrepublik China befinden, konzentriert auf einen Raum, der Peking, die Küstenprovinzen und das Gebiet des mittleren Yangzi umfaßt. ${ }^{21}$ Auch hier spiegeln sich die mittels der Aihui-Tengchong Linie dargestellten Unterschiede zwischen dem östlichen und dem westlichen China wieder, denn Lokal- oder Regionalstudien, die sich mit den westlichen, den Inlands- und den Grenzprovinzen beschäftigen, gibt es bisher nur wenige. ${ }^{22}$

Ebenso konzentrieren sich auch im Genre der Grenzstudien die Arbeiten auf ein Gebiet, hier die Nord- und Nordwestgrenzen Chinas, während der Südwesten kaum untersucht ist. $^{23}$ Schon Owen Lattimore hat in seiner grundlegenden Studie ,Inner Asian frontiers of China‘ (1940) die Grenzen im Norden Chinas in den Mittelpunkt seiner Untersuchung gestellt. Im Norden hatte die chinesische Expansion den Rand eines Gebietes erreicht, in dem alternative an die besondere Steppenlandschaft angepaßte Gesellschaften existierten, auf deren Territorien sich die chinesische Form der Landwirtschaft, die von ihr geprägte Lebensweise des Kernlandes sowie dessen politische Strukturen nicht ausdehnen ließen und deren militärische Stärke zu Konflikten führte, die durchaus eine existenzielle Bedrohung für das chinesische Reich darstellten. ${ }^{24}$ Nach Süden hingegen erwies sich der Raum für die chinesische Expansion als mehr oder weniger unbegrenzt. Militärische Konflikte blieben lokal begrenzt, die einheimische Bevölkerung wurde zumeist assimiliert oder aus den landwirtschaftlich nutzbaren Gebieten verdrängt und die charakteristische „Strukturform, die ,zellulare‘ Einheit, der ummauerten Stadt mit den sie umgebenden ländlichen Gebieten“, konnte in den neu erschlossenen Gebieten dauerhaft etabliert werden. ${ }^{25}$ Bei

\footnotetext{
${ }^{21}$ Die historische Entwicklung einzelner Städte bzw. Region stellen z.B. David Buck in ,Urban change in China: Politics and development in Tsinan, Shantung, 1890-1949، (1978), Hilary Beattie in ,Land and lineage in China: A study of T'ung-ch'eng county, Anhwei' (1979) oder Harriet T. Zurndorfer in ihrer Studie, Change and continuity in chinese local history“ (1989) über die Präfektur Huizhou dar. Weiterhin ist besonders William T. Rowes umfassende Studie ,Hankow: Commerce and society in a chinese city“ (1984) zu nennen.

${ }^{22}$ Clausen/Thogersens Lokalstudie über Harbin, ,The making of a chinese city (1995), und James A. Millwards Studie ,Beyond the pass. Economy, ethnicity, and empire in Qing Central Asia, 1759-1864‘ (1998), gehören zu den wenigen Arbeiten, die sich mit Gebieten in der Peripherie Chinas beschäftigen.

${ }^{23}$ So überwiegt beispielsweise in dem von Dabringhaus und Ptak herausgegebenen Sammelband ,China and her neighbours، (1997), der Beiträge eines Symposiums enthält, die die Wahrnehmung von Grenzen, Grenzgebieten und deren Bevölkerung durch die Chinesen sowie die daraus resultierende Politk untersuchen, die Beschäftigung mit den nördlichen Grenzen ergänzt lediglich um zwei Studien, die sich maritimen Grenzgebieten (Spratley Inseln und Taiwan) widmen.

${ }^{24}$ Lattimore, S. 241, 409, 472

${ }^{25}$ Lattimore, S. 423
} 
ihrem Vorstoß nach Süden, so stellte Owen Lattimore fest, „mußten die Chinesen lediglich Probleme der Größenordnung bewältigen - den Transport, die Reichweite der Verwaltung, die Anpassung des imperialen Überbaus an den provinziellen regionalen Unterbau“ ${ }^{26}$

Entsprechend waren zunächst nicht Grenzen und die Entstehung von Grenzgebieten Themen sinologischer Forschung, sondern der Prozeß der Han-chinesischen Expansion nach Süden in seiner Gesamtheit, wie ihn Herold J. Wiens (,Han Chinese expansion in South China‘, 2. Aufl., Yale 1967, New Haven 1967; Titel der ersten Auflage: ,China's march to the tropics'; Hamdon, Conn. 1954) und Charles Patrick Fitzgerald (,The southern expansion of the Chinese people‘, New York 1972) dargestellt haben. Beide Autoren schildern den Verlauf dieser Expansion, die Besiedelung, die Erschließung landwirtschaftlicher Flächen, die Ausdehnung administrativer Strukturen des Kaiserreiches, bis sie im Norden der südostasiatischen Halbinsel die Region des Stromschluchtenfächers erreichte.

Ende des 20. Jahrhunderts sind in den USA zwei Dissertationen erschienen, die sich mit der historischen Entwicklung dieses Grenzgebietes beschäftigen. Sun Laichen untersucht in seiner Studie ,Ming-Southeast Asian overland interactions, 1368-1644‘ (University of Michigan 2000) Chinas Einfluß auf die Entwicklung der Kleinstaaten im Westen Yunnans (im Gebiet des modernen Shan-Staates von Birma, in Xishuangbanna und Nordvietnam). Vom nördlichen Mohnyin bis zum südlichen Dai Viet haben zwei Faktoren den Aufstieg dieser Kleinstaaten vom späten 14. Jahrhundert bis in die zweite Hälfte des 16. Jahrhunderts bestimmt: Die Übernahme der fortschrittlichen Militärtechnologie der Ming und der Aufschwung des Handels insbesondere mit den in China begehrten Edelsteinen. Sun Laichen stellt die beherrschende Stellung heraus, die die einheimischen Herrscher im Norden der südostasiatischen Halbinsel regional inne hatten, die in diesem Zeitraum mehr als nur Pufferzone zwischen China und Birma waren, sondern eine eigene dynamische Entwicklung aufwiesen. Diese und die eigenen Handelsinteressen bestimmten die chinesische Politik gegenüber den Kleinstaaten, führten zur Entstehung eines differenzierten Grenzgebietes an der Peripherie des Ming-Reiches und beeinflußten die Ausgestaltung der chinesischen Verwaltungseinheiten im äußersten Westen Yunnans.

\footnotetext{
${ }^{26}$ Lattimore S. 8, 470
} 
C. P. Giersch stellt in seiner Dissertation ,Qing China's reluctant subjects: Indigenous communities and empire along the Yunnan frontier ${ }^{6}$ (Yale University, 1998 ${ }^{27}$ ) nicht die Mechanismen staatlicher Politik, sondern die Interaktion zwischen den verschiedenen Bevölkerungsgruppen im Grenzgebiet in den Mittelpunkt seiner Untersuchung. Sein Konzept des Grenzgebietes als middle ground überträgt einen Forschungsansatz der modernen amerikanischen Geschichtswissenschaft auf das Yunnan der Qing-Zeit. Kernpunkt dieses Ansatzes ist, daß bei der Entstehung eines Grenzgebietes Gruppen aufeinander treffen, die jeweils ebenso Initiatoren wie auch Objekte von Veränderungen sind, so daß einseitige Konzepte von Eroberung und Assimilierung oder Widerstand nicht genügen, um die vielfältigen Interaktionen in einem Grenzgebiet zu beschreiben, zu denen auch Innovation und Anpassung alter Traditionen und Institutionen zählen. Das Konzept des middle ground umfaßt sowohl den geographischen Ort, den Prozeß der Vermischung sowie die Veränderungen, die die Beziehungen zwischen der Grenzbevölkerung durchlaufen. ${ }^{28}$

Die Bedeutung des Konzeptes liegt für Giersch insbesondere darin, daß es die Diversität der chinesichen Kultur und die unterschiedlichen Interessen der verschiedenen Gruppen von chinesischen und mandschurischen Beamten, von Kaufleuten, Arbeitern im Bergbau oder Bauern berücksichtigt sowie den Beitrag der einheimischen Bevölkerung hervorhebt. Gerade letztere war keineswegs eine passive Gruppe, die lediglich darauf gewartet habe, vom Charisma der chinesischen Kultur absorbiert zu werden, sondern sei an der Gestaltung des Grenzgebietes aktiv beteiligt gewesen. Charakteristisch für den middle ground ist die vielschichtige Grenzstadt (mixed frontier town), in der ein gemeinsamer städtischer Raum unter Beteiligung aller Bevölkerungsgruppen entstanden ist. ${ }^{29}$

Das Konzept des middle ground hebt die Bedeutung der politischen Strukturen und der kulturellen Traditionen der einheimischen Bevölkerung im interaktiven Prozeß der Gestaltung des Grenzgebietes hervor. Deutlich wird zudem die Vielschichtigkeit der Kategorien Einheimische, Zuwanderer und Qing-Beamte, die sich jeweils aus verschiedenen Interessengruppen zusammensetzten, die ihre Position im Grenzgebiet sehr flexibel behaupteten. Zwar weist auch Giersch darauf hin, daß das Entstehen eines Raumes, in dem sich die Traditionen Chinas und Südostasiens miteinander zu neuen Strukturen verbanden, nicht im Interesse der Qing-Regierung lag und eine Anpassung an örtliche Gegebenheiten lediglich

\footnotetext{
${ }^{27}$ Eine gekürzte Fassung der Dissertation ist unter dem Titel ,A motley throng: social change on Southwest China's early modern frontier, 1700-1880، im Journal of Asian Studies (60, no.1, Feb. 2001, S. 67-94) erschienen.

${ }^{28}$ Giersch, A motley throng, S. 72

${ }^{29}$ Ebd., S. 71, 77-80
} 
mit Blick auf die Sicherung der Vorherrschaft über ein bestimmtes Gebiet erfolgte. ${ }^{30}$ Insgesamt wird beim Konzept des middle ground aber das Ungleichgewicht zu wenig berücksichtigt, in dem die verschiedenen Gruppen miteinander agieren und das in dem ideologischen Anspruch Chinas, die Randvölker zu ,zivilisieren‘, zum Ausdruck kommt. Sowie nicht zuletzt auch in der militärischen Stärke der Qing (und früherer chinesischer Dynastien), die es ermöglichte, diesen Anspruch auch zu realisieren und nachdem die Oberhoheit über ein Gebiet gesichert war, den Rahmen abzustecken, in dem sich ein middle ground erst entwickeln konnte.

Dieses Ungleichgewicht ist jedoch ein entscheidender Faktor im Prozeß der Ausgestaltung eines Grenzgebietes des chinesischen Reiches. Die verschiedenen Völker, die in den Randgebieten Chinas leben, sind seit Jahrhunderten einer Reihe von Versuchen unterworfen worden, „sie zu verändern und sie denen, die sie verändern wollen, anzugleichen oder im Sprachgebrauch der Veränderer: Sie zu ,zivilisieren““.31 Die Art und Weise, in der chinesische Regierungen in Vergangenheit und Gegenwart das politische und gesellschaftliche System sowie die kulturellen Traditionen der Kernregion auf die Grenzgebiete auszudehnen strebten, faßt Stevan Harrell mit dem Begriff der civilization projects zusammen. ${ }^{32}$

Unter einem solchen ,Zivilisierungsprojekt“ versteht Harrell eine „bestimmte Form der Interaktion zwischen Völkern, bei der eine Gruppe, das zivilisierende Zentrum, mit anderen Gruppen (den Randvölkern) im Rahmen eines bestimmten Ungleichgewichtes interagiert. Die ideologische Basis für das Ungleichgewicht bildet der Anspruch des Zentrums, einen höheren Grad an Zivilisation zu haben. Hinzu kommt das Bestreben, die Randvölker auf das Niveau der Zivilisation des Zentrums anzuheben oder wenigstens näher an dieses heranführen zu wollen“; dabei geht es nicht mehr nur um militärische Eroberung und Festigung der Herrschaft, sondern „um den Glauben, daß diese Herrschaft ein Prozeß ist, der den Beherrschten hilft, gerade die höheren kulturellen, religiösen und moralischen Qualitäten, die das Zentrum selbst ausmachen, zu erreichen oder sich ihnen zumindest anzunähern“. 33

\footnotetext{
${ }^{30}$ Giersch, S. 83

${ }^{31}$ Harrell, S. 3

32 Stevan Harrell: ,Civilizing projects and the reaction to them', in: S. Harrell (Hrsg.), ,Cultural encounters on China's ethnic frontiers' (Washington 1995), S. 3-36. Dieses Konzept umfaßt für Harrell sowohl ,konfuzianisch‘ als auch ,sozialistisch‘ geprägte Projekte, wie auch die Bemühungen der christlichen Missionare zur Verbreitung ihrer Religion in China um die Wende zum 20. Jahrhundert.

${ }^{33}$ Harrell, S. 4
} 
Als Form der Interaktion zwischen Völkern haben ,Zivilisierungsprojekte‘ folglich immer zwei Gruppen von Beteiligten, das Zentrum und die Randvölker, die immer beide von dem Projekt beeinflußt werden. Denn um ein solches Projekt durchzuführen, benötigt das Zentrum zunächst eine Definition seiner selbst, die deutlich macht, worin die eigene Zivilisation besteht, die weitergeben werden soll und worin der Mangel bei den anderen besteht, den es zu beheben gilt. Aus dieser Gegenüberstellung entwickelt sich zumeist ein schärferes Bewußtsein des Zentrums für die eigene Identität. ${ }^{34}$

Die ,Zivilisierung‘ der Randvölker Chinas ist Teil eines Projektes der Zivilisierung der chinesischen Bevölkerung insgesamt. Dabei sollte der gebildete Gelehrte, der junzi, durch sein den konfuzianischen Wertvorstellungen entsprechendes Verhalten ein Vorbild für die chinesische Bevölkerung sein, dem diese nacheifern sollte; ebenso sollte dann auch die Zivilisation des Zentrums generell das Vorbild für die Randvölker sein. ${ }^{35}$

Folglich kann der Forschungsansatz der ,Zivilisierungprojekte‘ im Grenzgebiet nicht allein auf die Interaktionen zwischen den beiden Gruppen Zentrum und Randvölker beschränkt werden, sondern muß auch die Gruppe der Han-chinesischen Bevölkerung im Grenzgebiet mit einbeziehen, die ebenfalls Träger der Zivilisation des Zentrums ist, deren Interessen sich jedoch häufig von denen der staatlichen Institutionen, den Initiatoren und Trägern des Projektes unterscheiden. Die chinesischen Regierungen waren sich dieser Problematik bewußt und versuchten dem Auseinanderdriften der Interessengruppen entgegenzusteuern, indem sie beispielsweise den Zuzug ins Grenzgebiet bzw. die Abwanderung in Gebiete unter einheimischer Herrschaft, den Erwerb von Land oder die Bergbauaktivitäten der chinesischen Zuwanderer reglementierten oder ganz zu unterbinden versuchten, um so das Entstehen autonomer Strukturen jenseits der staatliche Kontrolle zu verhindern. Die chinesischen Zuwanderer waren also sowohl Akteure als auch Adressaten des, Zivilisierungsprojektes‘ im Grenzgebiet. Dort wurde zudem mit dem Bau von Stadtmauern, Amtsgebäuden und Tempeln, der Gründung von Städten ganz allgemein, auch ein architektonischer Rahmen vorgegeben, in dem sich die Han-chinesische Bevölkerung im Grenzgebiet einrichten konnte, ohne in der Interaktion mit den einheimischen Kulturen selbst alternative Modelle zu entwickeln. Die Schaffung eines middle ground, in dem Interaktion zu Innovation führte, lag nicht im staatlichen Interesse, das der Einbindung des Grenzgebietes

\footnotetext{
${ }^{34}$ Harrell, S. 7

${ }^{35}$ Harrell, S. 17
} 
in die politischen Strukturen des Kernlandes galt sowie der Definition von Territorien, auf die sich diese Strukturen nicht mehr ausdehnen ließen. Die chinesische Expansion nach Südwesten führte so zur Entstehung eines vielschichtigen Grenzgebietes im Norden der südostasiatischen Halbinsel: Weit entfernt gelegene Gebiete wurden dem chinesischen Reich von der Zentralregierung im Rahmen des Tributsystems assoziiert, in der Region des Stromschluchtenfächers schlossen sich Verwaltungseinheiten mit Sonderstatus an Einheiten der regulären Zivil- und Militärverwaltung des Kernlandes an.

Der Prozeß der Entstehung und Ausgestaltung einer solchen regulären Verwaltungseinheit in der Peripherie des chinesischen Reiches ist Thema der vorliegenden Studie.

Im Mittelpunkt der Untersuchung steht die Stadt Tengchong, denn gerade die Gründung von ummauerten Städten ist ein charakteristisches Merkmal der Entwicklung der Grenzgebiete Chinas. Die von Chinesen in den Randgebieten errichteten Städte orientierten sich an den chinesischen Traditionen des Städtebaus. Mit ihrer Ausrichtung nach den Himmelsrichtungen, den geraden Durchgangsstraßen und der Bauweise der zentralen Verwaltungsgebäude, der Schulen, Tempel und Wohnhäuser reproduzierten die bewußt angelegten Grenzstädte die Traditionen der Kernregion und waren, wie Piper Rae Gaubatz in einer Studie zur Entwicklung der politischen Zentren in den Randgebieten Chinas dargestellt hat, weit häufiger ,typisch chinesische Städte‘, als die organisch gewachsenen Städte im Kernland. ${ }^{36}$ Die Stadt im Grenzgebiet wird somit zum „Symbol sowohl für kulturelle Werte als auch für Machtverhältnisse; Vorstellungen, Werte und Machtverhältnisse formen die Struktur einer Stadt und werden ihrerseits von dieser bestätigt““. ${ }^{37}$

\footnotetext{
${ }^{36}$ Gaubatz, S. 313. Piper Rae Gaubatz hat in der Studie ,Beyond the Great Wall: Urban form and transformation on the chinese frontiers' (1996) die Entwicklung, die Formen und Funktionen chinesischer Städte in den Randgebieten des Reiches untersucht. Gegenstand der Studie sind die Großstädte Hohot, Lanzhou, Ürumqi, Xining und Kunming, allesamt Hauptstädte von Provinzen oder autonomen Regionen. Sie waren (und sind) politische Zentren, denen die Verwaltung großflächiger Gebiete unterstand und die sich einerseits in der Peripherie Zentralchinas befanden, andererseits aber auch selbst Kernregionen der sie umgebenden Randgebiete waren.

Zwei charakteristische Merkmale für die Entwicklung der Grenzgebiete Chinas stellt Gaubatz in den Mittelpunkt der Studie. Zum einen die Kontinuität: „Regionen, die heute als Grenzgebiete charakterisiert werden können, sind nie vollständig in das nationale System integriert worden und in kultureller und wirtschaftlicher Hinsicht noch fast genauso ,Grenzgebiete‘, wie sie es bereits während der Han-Dynastie waren“ (Gaubatz, S. 20).

Das zweite Merkmal der Grenzgebiete ist das Vorherrschen urbaner Ansiedlungen der Chinesen in den Grenzgebieten. Dieser ,urbane Charakter` der Grenzregionen zeigt sich für Gaubatz insbesondere darin, daß noch bis ins 20. Jahrhundert hinein die Präsenz des chinesischen Militärs, der Zivilbeamten und der Han-chinesichen Zuwanderer in den meisten Gebieten auf Festungen und ummauerte Städte beschränkt war und ihre ländlichen Ansiedlungen selten weit über das Hinterland der Stadt hinausgingen (ebd. S. 310). Die Abgrenzung der Stadt von ihrem Umfeld wird durch die Stadtmauer besonders deutlich gemacht. Ebenso wie die Große Mauer im Norden Chinas symbolisieren auch die Mauern der Grenzstädte ethnische Grenzen und spiegeln das politische und sozio-ökonomische System des Reiches in Kleinformat wieder (ebd., S. 309). Anders als die Große Mauer waren jedoch die Stadtmauern, trotz der Entstehung multikultureller Ansiedlungen, oft dauerhafte Trennungslinien zwischen der Stadt in der die Han-Chinesen die Mehrheit der Bevölkerung stellten und dem Hinterland, in dem andere Volksgruppen dominierten (ebd., S. 312). Die Grenzstadt mit ihrer Stadtmauer symbolisiert so gerade auch das Bewußtsein der kulturellen Unterschiede und in diesem wiederum liegt für Gaubatz auch die Dauerhaftigkeit der Grenzen als solche begründet (ebd., S. 311).

${ }^{37}$ Gaubatz, S. 312
} 
Anhand der historischen Entwicklung der Stadt Tengchong wird im Folgenden dargestellt, welche Vorstellungen von Seiten Chinas mit der Gründung der,ersten Stadt an der äußersten Grenze“ und der sie umgebenden Verwaltungseinheit realisiert worden sind und welche anderen Faktoren die Ausgestaltung des Grenzgebietes in ihrer Peripherie mitbestimmt haben. Ansatzpunkt ist das ,Projekt zur Zivilisierung : Das Bestreben der Zentralregierung, politische, gesellschaftliche und kulturelle Strukturen des Kernlandes in der Region des Stromschluchtenfächers zu etablieren. Ziel dieser Studie ist es, herauszuarbeiten, welche dieser Strukturen den Rahmen für die Entwicklung Tengchong bildeten und wie sie jeweils an die Situation im Grenzgebiet angepaßt wurden. Eckpunkte dieses Rahmens sind die militärische Vorherrschaft, der Ausbau der zivilen Verwaltungsstrukturen, die von Regierungsbeamten organisierten Baumaßnahmen sowie die Beziehungen zu den Gebieten unter einheimischer Herrschaft, deren historische Entwicklung im Folgenden nachgezeichnet wird. Ergänzt werden sie um die Darstellung des chinesischen Schulwesens in Tengchong. Gerade die Gründung von chinesischen Schulen in den Grenzgebieten Chinas, die insbesondere den Han-chinesischen Schülern, aber auch Angehörigen einheimischer Volksgruppen konfuzianische Wertvorstellungen vermitteln sollten, zeigt den Zusammenhang der beiden Ausprägungen der ,Zivilisierungsprojekte‘, die die ,Zivilisierung‘ der Randgebiete mit dem allgemeinen ,Zivilisierungsprojekt‘, das sich an alle Bevölkerungsgruppen wandte, verbanden. So wurde gerade auch die Etablierung des Schulwesens von den Trägern des ,Projektes‘ im Grenzgebiet selbst als Gradmesser einer gelungenen Anbindung an das Kernland interpretiert.

Die Träger der ,Zivilisierungsprojekte“ vor Ort waren in erster Linie Verwaltungsbeamte, die von der Zentralregierung eingesetzt wurden und für die Umsetzung der Maßnahmen zur Gestaltung der Verwaltungseinheit und des Grenzgebietes verantwortlich waren. Ihnen oblag die Verwaltungsarbeit, die Rechtsprechung, die Registrierung der Bevölkerung, die Erhebung der Steuern und die Organisation von Bauprojekten. Tätigkeiten, die allesamt in den unter ihrer Leitung verfaßten Lokalhandbüchern (fangzhi) dokumentiert werden.

Die Lokalhandbücher von Tengchong (siehe unten 3. 2. 1.) sind denn auch die wichtigsten Quellen für diese Studie, da ihre Verfasser die historische Entwicklung aus lokaler Sicht darstellen, sie aber gleichwohl auch Ausdruck des ,Zivilisierungsprojektes‘ sind, da die geschilderten Ereignisse aus der Perspektive des ,zivilisierenden Zentrums` interpretiert werden. 


\section{2. Die Quellen}

\section{2. 1. Die Lokalhandbücher (fangzhi)}

Die chinesischen Lokalhandbücher (difangzhi oder kurz fangzhi) sind Sammelwerke, in denen die verschiedensten Informationen über eine bestimmte Verwaltungseinheit (einen Kreis, eine Präfektur oder eine Provinz), einem einheitlichen Aufbauschema folgend in chronologischer, tabellarischer und literarischer Form zusammengestellt sind. ${ }^{38}$

Die Lokalhandbücher informieren über Geographie und Geschichte, über Steuern und örtliche Produkte, sie listen die Schulen und Tempel auf, die am Ort tätigen Beamten ebenso wie die erfolgreichen Kandidaten der Staatsprüfungen und die tugendhaften Frauen.Außerdem enthalten sie eine Auswahl der literarischen Erzeugnisse aus der Region. Die fangzhi wurden mit dem Anspruch verfaßt, praktische Handbücher zu schaffen, welche die mit der Lokalverwaltung betrauten ortsfremden Beamten durch konkrete Informationen und Hintergrundwissen mit der Situation vor Ort vertraut machen sollten. Ein Anspruch, der in den charakteristischen tabellarischen Aufzählungen, die sowohl einen summarischen Überblick über die Verwaltungseinheit ermöglichen als auch das Herauslesen einzelner Fakten erleichtern, deutlich zum Ausdruck kommt. ${ }^{39}$

Mit ihrer Konzentration auf eine bestimmte Verwaltungseinheit unterscheiden sich die fangzhi von den zongzhi genannten Handbüchern, die einen Überblick über das gesamte chinesische Reich geben, wobei die fangzhi gewissermaßen deren Grundlage bildeten: So wurden die fangzhi eines Kreises (xianzhi) oder einer Unterpräfektur (zhouzhi) für die Erstellung des Handbuches der ihnen übergeordneten Präfektur (fuzhi) zusammengefaßt, während die fangzhi der verschiedenen Präfekturen ihrerseits für die Zusammenstellung

\footnotetext{
${ }^{38}$ Fangzhi: Wiethoff übersetzt den Begriff als ,Regionalbeschreibung (Wiethoff, S.149). Im englischen Sprachraum werden sie als ,local gazetteers‘ bezeichnet, im französischen als ,monographies locales‘. Die hier gewählte Übersetzung als ,Lokalhandbücher‘ soll den Charakter der fangzhi als systematisch aufgebaute praktische Nachschlagewerke betonen. ${ }^{39}$ Grundlegende chinesische Studien zu den fangzhi sind: Li Taifen, ,Fangzhi xue , Shanghai 1935 und Fu Chenlun, ,Zhongguo fangzhi xue tonglun', Shanghai 1935. Einen umfangreichen Katalog von über siebentausend fangzhi in chinesischen Bibliotheken hat Zhu Shijia (,Zhongguo difangzhi zonglu‘, zengdingben, Shanghai 1958) zusammengestellt. Westliche Studien zu den Lokalhandbüchern:

$\mathrm{Zu}$ den Inhalten und dem Stellenwert der fangzhi siehe Bodo Wiethoff, ,Bemerkungen zur Bedeutung der Regionalbeschreibungen (fang-chih)‘ (1968).

Timothy Brook (,Geographical sources of Ming-Qing history‘, 1988) gibt einen Überblick über die historische Entwicklung und die Bedeutung der fangzhi. Für einen kurzen Abriß der historischen Entwicklung der fangzhi siehe Harriet T. Zurndorfer: ,China bibliography. A research guide to reference works about China past and present" (1995). Der Katalog der Sammlungen von Lokalhandbüchern von Donald Leslie und Jeremy Davidson (,Catalogues of Chinese local gazetteers', 1967) enthält in der Einleitung eine Darstellung der historischen Entwicklung der fangzhi sowie ein Glossar der Fachterminologie und verweist auf relevante chinesische Studien.

Eine umfangreiche Liste der Lokalhandbücher aus Chinas südwestlichen Provinzen findet sich bei Jae-Hyon Byon,,Local gazetteers of Southwest China. A handbook' (1979). Nach Verwaltungseinheiten geordnet führt Byon die fangzhi chronologisch auf; mit Hinweisen auf die Sammlungen von Lokalhandbüchern, in denen sie enthalten sind.

Für eine kritische Beurteilung der fangzhi und Vorschläge zur Reform dieser lokalen Geschichtsschreibung im China des 18. Jahrhunderts siehe David Shepard Nivison, ,The life and thought of Chang Hsüeh-ch'eng (1738-1801)‘ (1966). (Zu Zhang Xuecheng siehe auch Li Taifen, ,Fangzhi xue‘, Kapitel 3.)
} 
von Provinzhandbüchern (tongzhi) herangezogen wurden, die wiederum Material für die Reichshandbücher lieferten. ${ }^{40}$

Die Lokalhandbücher können in China auf eine lange Tradition systematischer landeskundlicher Darstellungen zurückblicken. ${ }^{41}$ Das für die fangzhi charakteristische Aufbauschema und die Einteilung des Inhalts in bestimmte Rubriken sind ebenso wie der Gattungsname zhi während der Song-Zeit (960-1279) entstanden. Seit der Ming-Zeit (13681644) wurden dann in fast allen Verwaltungseinheiten des chinesischen Reiches Lokalhandbücher verfaßt, deren Produktion seit dem 16. Jahrhundert stark zunahm.

Ein erneuter deutlicher Anstieg der Zahl der neu zusammengestellten fangzhi in der QingZeit (1644-1912) war auch durch den Erlaß kaiserlicher Edikte mitbestimmt. So ergingen in den Jahren 1672 und 1729 Edikte, in denen die Verwaltungsbeamten der einzelnen Provinzen aufgefordert wurden, Handbücher ihrer Provinz zu erstellen, wozu diese auf Material aus den untergeordneten Amtsbezirken angewiesen waren. ${ }^{42}$ Mit der zunehmenden Publikation von Lokalhandbüchern ging auch eine stärkere Vereinheitlichung ihrer Inhalte einher: Die Methode der Kompilation, die Form und der Stil der Texte wurden durch staatliche Vorgaben geregelt, die ebenfalls Thema kaiserlicher Edikte waren. ${ }^{43}$

Für die Umsetzung dieser Vorschriften waren die jeweiligen Herausgeber verantwortlich. Dies waren zumeist die örtlichen Verwaltungsbeamten selbst, zusammen mit Angehörigen der lokalen Gentry, denen die fangzhi Ausdruck des Lokalstolzes und Medium der Selbstdarstellung waren, welche die örtlichen Besonderheiten herausstellen, gleichzeitig aber auch ihren Heimatort als Bestandteil der literaturorientierten chinesischen Kulturnation ausweisen sollten. ${ }^{44}$ Die fangzhi spiegeln dabei auch das Bestreben ihrer Verfasser wider, Traditionen zu erhalten und zu bestätigen. Dies zeigte sich beispielsweise in den Dekaden

\footnotetext{
${ }^{40}$ Zurndorfer, S. 187. Ebenfalls zur Gattung der fangzhi gehören die chuanzhi, Spezialhandbücher („topographical and institutional gazetteers“ [T. Brook]), die einzelne Tempel, Klöster, Akademien oder auch einen Berg oder Flußlauf zum Thema haben (Zurndorfer, S. 191; siehe auch T. Brook, ,Geographical sources of Ming-Qing history“).

${ }^{41}$ Die Tradition solcher landeskundlicher Darstellungen läßt sich bis auf das Huayang guozhi (ein Bericht über das südwestliche China aus dem 4. Jahrhundert) oder sogar das Zhouli (4./3. Jh. v. Chr.) zurückführen; eine Tradition, die auch in der Zeit der chinesischen Republik und in den Anfangsjahren der Volksrepublik fortgesetzt und in den achtziger Jahren des 20. Jahrhunderts wieder aufgenommen worden ist (s.a. Brook, S. 53).

${ }^{42}$ Howland, S. 165

${ }^{43}$ Zurndorfer, S. 189. Das Bestreben die Inhalte dieser vielfältigen regional geprägten Werke stärker zu kontrollieren führte dazu, daß auch Lokalhandbücher der von Kaisers Qianlong veranlaßten literarischen Inquisition unterworfen wurden. So erging am 25. 12. 1779 ein Edikt des Kaisers, in dem die örtlichen Beamten angewiesen wurden, aus den in ihren Verwaltungsbezirken kompilierten fangzhi nunmehr verbotene Inhalte zu entfernen (siehe Goodrich, Literary Inquisition, S. 186).

${ }^{44}$ Zurndorfer faßt die mit der Erstellung von Lokalhandbüchern verbundenen Ziele folgendermaßen zusammen: Sie sollten „(1) die Regierung unterstützen (zizhi) und (2) den Lokalpatriotismus [aixiang] anregen“ (Zurndorfer, S. 190).
} 
nach der Taiping-Rebellion (1850-1864), als gerade in von den Kämpfen besonders betroffenen Gebieten von Jiangnan zahlreiche Lokalhandbücher neu herausgegeben wurden, mit denen die Verfasser, wie Timothy Brook es ausdrückt, „ihre soziale Welt, die während der Taiping-Rebellion verwüstet worden war, wieder zu rekonstruieren suchten“. 45

Unter Leitung des ranghöchsten Verwaltungsbeamten vor Ort entstanden, waren die fangzhi zu politischer Korrektheit verpflichtet. Ihre Verfasser, meist einheimische Gelehrte und Prüfungskandidaten, neigten daher dazu, die Verwaltungspraxis mit Blick auf die Vorgaben der Zentralregierung und beeinflußt durch die historischen Werke an denen sie geschult waren, zu idealisieren, um ein möglichst positives Bild ihrer Heimat zu vermitteln. ${ }^{46}$ Die Autoren beschreiben was sie sehen, wie sie es sehen und wie der Leser es sehen soll. Ebenso zeichnen sie auf, was sie lediglich vom Hörensagen kennen und übernehmen Texte aus anderen Werken, manchmal unreflektiert, manchmal versehen mit Erklärungen oder kritischen Anmerkungen. So zeigen die fangzhi, wie sich Geschichte und Gegenwart der Verwaltungseinheit aus einer bestimmten Perspektive darstellen. ${ }^{47}$ Nichtsdestoweniger sind sie Dank ihres Detailreichtums und des breiten Spektrums der angesprochenen Themen die wichtigsten Quellen für die Regionalgeschichte Chinas.

\section{2. 2. Die Lokalhandbücher von Tengchong / Tengyue}

In Tengchong entstanden die ersten fangzhi in der Ming-Zeit. Die Etablierung Tengchongs als regionaler Verwaltungssitz brachte seit dem 15. Jahrhundert eine ausführlichere Dokumentation der Angelegenheiten der Stadt und ihrer Umgebung mit sich. Die Erfordernisse der Verwaltung und das Bestreben der Chinesen ihre Umwelt schriftlich zu erfassen, kulminierten auch dort in der Zusammenstellung von Lokalhandbüchern (fangzhi), in denen eine Fülle an Informationen über die Verwaltungseinheit Tengchong zusammengefaßt wurde. Das früheste Lokalhandbuch Tengchongs, das Tengchong si zhi gao, ist im Jahr 1512 von dem Gelehrten Yi Yizhi, einem Absolventen der Provinzprüfungen (juren) aus Tengchong, zusammengestellt worden. ${ }^{48}$

\footnotetext{
${ }^{45}$ Brook, S. 53

${ }^{46}$ Zurndorfer, S. 190, 191

${ }^{47}$ Entsprechend bezeichnet Wiethoff die fangzhi als „Schlüssel zum Wissens- und Bewußtseinsraum eines Lokalbeamten zu einer bestimmten Zeit an einem bestimmten Ort“ (Wiethoff, S. 166). Wobei die fangzhi als Gemeinschaftsprojekt der Beamten und der lokalen literarisch gebildeten Gentry weniger eine einzelne Meinung, als vielmehr den örtlichen Konsens über die Präsentation der Verwaltungseinheit vermitteln.

${ }^{48}$ TYTZ, S. 213; YCFZ, S. 281; Deng, S.241: Teng si zhi gao. Siehe auch Fang Guoyu, S. 442. (Zu Yi Yizhi siehe auch Kap. III, 10. 2., S. 179-180.)
} 
Mehr als ein halbes Jahrhundert später, im ersten Jahr der Ära Longqing (1567) begann Unterpräfekt Shen Zuxue (1567 bis 1573 in Tengyue tätig) mit der Zusammenstellung eines Handbuches; sein Entwurf wurde später von dem juren Wu Zongyao aus Tengyue weiter bearbeitet und als Tengyue zhou zhi in zwei Kapiteln herausgegeben. ${ }^{49}$

Ein weiteres fangzhi, bestehend aus drei Kapiteln, wurde unter der Leitung von Unterpräfekt Li Zhiren (ab 1614 in Tengyue) von Zhang Bangjiao, einem Angehörigen der örtlichen Gentry (shenshi), im Jahr 1614 verfaßt. ${ }^{50}$ Von diesen frühen Handbüchern soll lediglich das Tengyue zhou zhi von Wu Zongyao erhalten geblieben sein.

Die Existenz eines Lokalhandbuches der Stadt bezeugt auch der Reisende und Literat Xu Xiake, der während seines Aufenthaltes dort im Jahr 1639 Gelegenheit hatte, ein fangzhi einzusehen, dessen Titel er kurz als Zhou zhi bzw. Teng zhi angibt. ${ }^{51}$

Im 18. Jahrhundert sind zwei weitere fangzhi der Verwaltungseinheit Tengyue zusammengestellt worden, deren Inhalte in die beiden im 19. Jahrhundert publizierten Lokalhandbücher, das Tengyue zhou zhi und das Tengyue ting zhi, aufgenommen worden sind.

\section{2. 3. Das Tengyue zhou zhi (TYZZ)}

Das Tengyue zhou zhi, ein fangzhi in 13 Kapiteln, ist zuerst im Jahr 1838 erschienen und in einer revidierten Fassung erneut im Jahr 1897 herausgegeben worden, mit Vorworten aus dem selben Jahr von Cun Kaitai aus Tengyue und Huang Bingkun. ${ }^{52}$ Diese hatten eine ältere Chronik von Tu Shulian neu zusammengestellt. Tu Shulian gilt als eigentlicher Herausgeber des TYZZ. Er war von 1787 bis 1791 als Unterpräfekt in Tengyue tätig; sein Vorwort zum Lokalhandbuch ist auf das Jahr 1790 datiert. Bei der Zusammenstellung seines Werkes hatte sich Tu auf die Aufzeichnungen aus der Ming-Zeit, besonders aber auf das Werk eines seiner Amtsvorgänger gestützt: Wu Kai (1770 bis 1779 in Tengyue tätig), dessen Vorwort zu einem Bezirkshandbuch von Tengyue aus dem Jahr 1779 Tu Shulian in sein Handbuch mit aufgenommen hat. ${ }^{53}$

\footnotetext{
${ }^{49}$ TYTZ S. 108, 141 (Shen Zuxue); TYTZ, S. 209, 199 (Wu Zongyao); BSDQWHGK, S.181

${ }^{50}$ TYZZ, S. 6; TYTZ, S. 142

${ }^{51}$ Liu Chunming, S. 82, 99; Ding Wenjiang, Xu Xiake youji, juan 17, Dian youriji 10, S. 1,9

${ }^{52}$ Cun Kaitai hatte den akademischen Titel eines jinshi im Jahr 1897 (Guangxu 23) erworben und war zum Sekretär im Justizministerium (xingbu zhushi) ernannt worden (TYZZ, S. 3). Cun ist auch der Herausgeber einer anderen Beschreibung Tengyues, dem in der Ära Guangxu (1875-1909) verfaßten Tengyue xiangtu zhi in 8 Kapiteln.

${ }^{53}$ Siehe Fang Guoyu, S. 712.
} 


\section{2. 4. Das Tengyue ting zhi (TYTZ)}

Das umfangreichste Lokalhandbuch der Verwaltungseinheit ist das von Unterpräfekt Chen Zonghai und dem juren Zhao Duanli herausgegebene Tengyue ting zhi. ${ }^{54}$ Das Handbuch war bereits im Jahr 1879 (Guangxu 5) fertiggestellt worden. Da sich jedoch beim Abschluß der Arbeiten, noch ehe das Manuskript in Druck gegangen war, herausstellte, daß es nicht dem vom Provinzhandbuch (tongzhi) vorgegebenen Muster (guishi) entsprach, mußte es noch einmal überarbeitet werden.

Als Herausgabedatum des TYTZ wird generell das Jahr Guangxu 13 (1887-1888) angegeben. ${ }^{55}$ Das von Unterpräfekt Chen Zonghai verfaßte Vorwort stammt aus dem 12. Monat dieses Jahres (1888). Das TYTZ enthält darüberhinaus jedoch auch verschiedene Texte, die sich auf Ereignisse in den ersten Monaten des Jahres 1888 (Guangxu 14) beziehen. ${ }^{56}$ Außerdem wird im Vorwort ausdrücklich darauf hingewiesen, daß die Überarbeitung des Manuskriptes zwölf Jahre in Anspruch genommen hatte. ${ }^{57}$ Demnach wäre das TYTZ tatsächlich erst im Jahr 1891 fertiggestellt worden.

Das Projekt der Herausgabe des Lokalhandbuches stand unter der Leitung (zongxiu) des Unterpräfekten Chen Zonghai, unterstützt (xiexiu) wurde dieser von vier Beamten, unter anderem von dem obersten Militärführer in Tengyue, Regionalkommandeur (zongbingguan) Ding Huai, sowie einem Vize-Direktor des Justizministeriums (xingbu yuanwailang), weiterhin beaufsichtigten (jianxiu) zehn Beamte, darunter der Direktor der Schule der Unterpräfektur (xuezheng), die Arbeiten (vier Personen aus dieser Gruppe waren Anwärter, houbu, auf einen Beamtenposten, wie zum Beispiel den des Assistierenden Präfekten, tongpan).

Für die eigentliche Arbeit der Kompilation war der juren Zhao Duanli verantwortlich (zongli zuanxiu), der seinerseits von achtzehn Mitarbeitern, Akademikern und Studenten (juren, suisheng, linsheng u.ä.), unterstützt wurde (chengxiu, fenxiu). Zudem waren an dem Projekt noch vier Korrektoren (jiaodui), ein Kopist (tenglu) und ein Kartograph (huitu) beteiligt sowie dreiundneunzig namentliche genannte Personen, die mit dem Sammeln des

\footnotetext{
${ }^{54}$ Chen Zonghai war von 1878 bis 1883 und erneut ab 1885 als Unterpräfekt in Tengyue tätig.

${ }^{55}$ So z.B. in der Faksimileausgabe in der Serie Chung-kuo fang-chih ts'ung-shu, Taipei 1967.

${ }^{56}$ Die Chronologie der militärischen Ereignisse im TYTZ erstreckt sich bis auf das Jahr 1888 (S. 196-197); der Wiederaufbau des Tempels des Stadtgottes (S. 310) und des Tempels für die Generäle Liu und Deng (S. 161) erfolgte ebenfalls zu Beginn dieses Jahres.

${ }^{57}$ TYTZ, S. 7
} 
Materials (caifang) beschäftigt waren. Hinzu kamen noch vier weitere Herausgeber (zuanli), die mit der Überarbeitung des ursprünglichen Manuskripts von 1879 befaßt waren und am Schluß der Namensliste genannt werden. Insgesamt waren damit 137 Personen an der Herausgabe dieses Lokalhandbuchs beteiligt. ${ }^{58}$

Für ihr Lokalhandbuch haben die Verfasser des TYTZ die meisten Texte des älteren TYZZ übernommen und ihrem Layout angepaßt. Das TYTZ ist übersichtlicher gegliedert, eine tabellarische Anordnung und großzügigere Absätze zwischen den einzelnen Einträgen erleichtern das Nachschlagen und heben den Handbuchcharakter des Werkes hervor.

Das TYTZ umfaßt insgesamt zwanzig Kapitel, die durch fünf Karten, vier Landkarten und eine Karte der Sternbilder (xingye zhi tu) ergänzt werden. Die Rubriken des Tengyue ting zhi sind:

$\begin{array}{ll}\text { Himmelskunde (tianwen zhi) } & \text { Kapitel } 1 \\ \text { Landeskunde (diyu zhi) } & \text { Kapitel } 2 \text { und } 3 \\ \text { Entstehungsgeschichte (jianzhi zhi) } & \text { Kapitel } 4 \\ \text { Steuerwesen (zhengfu zhi) } & \text { Kapitel } 5 \text { und } 6 \\ \text { Auflistung der Beamten (zhiguan zhi) } & \text { Kapitel } 7 \text { und } 8 \\ \text { Tempel und Opferstätten (cisi zhi) } & \text { Kapitel } 9 \\ \text { Schulwesen (xuexiao zhi) } & \text { Kapitel } 10 \\ \text { Militärwesen (wubei zhi) } & \text { Kapitel } 11 \\ \text { Persönlichkeiten (renwu zhi) } & \text { Kapitel } 12 \text { bis } 14 \\ \text { Völker in der Region (zhuyi zhi) } & \text { Kapitel } 15 \\ \text { Literatur (yiwen zhi) } & \text { Kapitel } 16 \text { bis } 19 \\ \text { Miszellen (za ji zhi) } & \text { Kapitel } 20\end{array}$

Die Unterpräfektur Tengyue befand sich an der äußersten Grenze des chinesischen Reiches, an sie schlossen sich Gebiete an, die unter lokaler Sonderverwaltung standen und solche, die lediglich nominell in die chinesische Verwaltungshierarchie eingegliedert waren, wie zum Beispiel Birma. Informationen über diese Gebiete und die verschiedenen dort ansässigen einheimischen Volksgruppen sind ebenfalls in das TYTZ aufgenommen worden. So schließt das Kapitel 8 (Auflistung der Beamten II) mit einem Abschnitt zur

\footnotetext{
${ }^{58}$ TYTZ, S. 5-7
} 
historischen Entwicklung der einzelnen Sonderverwaltungseinheiten, den sogenannten Befriedeten Gebieten (xuanfu si, anfu si usw.). ${ }^{59}$ Den verschiedenen Völkern der Region ist ein eigenes Kapitel gewidmet (Kapitel 15), das sich aus drei Abschnitten zusammensetzt. Im ersten Abschnitt, ,Grenzgebiete‘ (bianyi) werden die historische Entwicklung der höherrangigen Befriedeten Gebiete (xuanwei si), zu denen unter anderem auch Birma gezählt wurde, und ihre Beziehungen zu China dargestellt. Der Abschnitt schließt mit einer Landkarte Birmas (Miandian yudi quantu). ${ }^{60}$ Der zweite Abschnitt enthält eine Aufzählung der Völker der Region (zhongren); Achang, Puren, Mianren (,Birmanen`) und andere, insgesamt zweiundzwanzig Völker werden dort anhand ihrer Kleidung und Lebensumstände mit wenigen Sätzen charakterisiert. ${ }^{61}$ Der dritte und letzte Abschnitt dieses Kapitels ist den lokalen Sprachen (fangyan) gewidmet. Er besteht aus zwei Wörterbüchern: Eines für Chinesisch und Shan, das andere für Chinesisch und Birmanisch. Beide enthalten sowohl eine Wiedergabe der fremden (Shan bzw. birmanischen) Aussprache, deren Lautgehalt mittels chinesischer Zeichen dargestellt wird als auch die Vokabeln in der jeweiligen Originalschrift. $^{62}$

Faksimiles der Originalausgaben des Tengyue zhou zhi (in der revidierten Ausgabe von 1897) und des Tengyue ting zhi (in der ,Originalausgabe von 1888`) sind in der in Taiwan herausgegebenen Reihe Chung-kuo fang-chih ts'ung-shu erschienen. Diese umfangreiche Sammlung von Nachdrucken von Lokalhandbüchern wurde in drei Serien aufgelegt. ${ }^{63}$ Das Tengyue zhou zhi ist als Nummer 41, das Tengyue ting zhi als Nummer 42 der Serie von 1967 in Taipei erschienen.

Diese Nachdrucke wurden für die vorliegende Studie verwendet. Die Lokalhandbücher werden im Folgenden abgekürzt als TYZZ und TYTZ zitiert; alle genannten Seitenzahlen der fangzhi sind die der Faksimile-Ausgaben.

\section{2. 5. Andere Lokalhandbücher aus der Region}

Von den fangzhi der Tengchong übergeordneten Verwaltungsebenen ist vor allem das Handbuch der Präfektur Yongchang, das Yongchang fu zhi (YCFZ) zu nennen, das 1885

\footnotetext{
${ }^{59}$ TYTZ, S. 151-156

${ }^{60}$ TYTZ, S. 239-246

61 TYTZ, S. 247-248

${ }^{62}$ TYTZ, S. 249-254

${ }^{63}$ Siehe auch Zurndorfer, S. 198.
} 
vom Präfekten Liu Yuke herausgegeben worden ist. Das Handbuch beinhaltet in sechsundsechzig Kapiteln Informationen über die gesamte Präfektur Yongchang mit den beiden Unterpräfekturen Longling und Tengyue sowie den Kreisen Baoshan und Yongping. Das YCFZ setzt ältere Handbücher aus der Ming- und Qing-Zeit fort, die als separate Werke nicht erhalten geblieben sind. ${ }^{64}$

Ebenso wie die fangzhi der Unterpräfektur Tengyue enthält auch das YCFZ verschiedene Kapitel, die sich mit den Sonderverwaltungseinheiten im Grenzgebiet und den Völkern der Region befassen: In Kapitel 37 (tusi) wird die Entwicklung der Befriedeten Gebiete (xuanfu si, anfu si u.a.) beschrieben. In Kapitel 56 (waiyi) die der höherrangigen Befriedeten Gebiete (xuanwei si).

Kapitel 57 (zhongren) enthält kurze Beschreibungen der Charakteristika der einzelnen Völker und Kapitel 58 (fangyan) ein Wörterbuch. In diesem werden in verschiedenen Abschnitten jeweils die birmanische (Mianren) Übersetzung einer thematisch geordneten Gruppe von Stichworten (wie z. B. Himmelskunde, tianwen lei) und anschließend die Übersetzung in Shan (Baiyi) angegeben. Ein Teil der Stichworte ist auch in Originalschrift aufgezeichnet. $^{65}$

Das Yongchang fu zhi ist ebenfalls als Faksimile der Originalausgabe von 1885 in der taiwanesischen Reihe Chung-kuo fang-chih ts'ung-shu nachgedruckt worden. Es erschien als Nummer 28 der Serie von 1967 in Taipei. Das Lokalhandbuch wird in dieser Studie als YCFZ zitiert, die genannten Seitenzahlen sind die der Faksimile-Ausgabe.

Neben den oben genannten gibt es noch ein weiteres Lokalhandbuch von Tengchong, das 1941 von Li Genyuan (1879-1965) aus Tengchong und Liu Chuxiang zusammengestellt worden ist: Das zweiunddreißig Kapitel umfassende Tengchong xian zhi gao. ${ }^{66}$ Es folgt in seinem Aufbau dem Schema der älteren fangzhi, enthält diverse Karten und informiert über

\footnotetext{
${ }^{64}$ Vorläufer des YCFZ von 1885 waren in der Ming-Zeit, das Yongchang fu zhi, in 4 juan, hrsg. von Yu Jia im Jahr Jiajing 33 (1554); in der Qing-Zeit das Yongchang fu zhi, in 26 juan, hrsg. von Liu Bin im Jahr Kangxi 41 (1702); das Yongchang fu zhi, in 26 juan, hrsg. von Xuan Shitao im Jahr Qianlong 50 (1785) sowie das Yongchang fu zhi, ebenfalls in 26 juan, hrsg. von Chen Tingyu im Jahr Daoguang 6 (1826) (siehe YCFZ, S. 16; Fang Guoyu, S. 442).

${ }^{65}$ YCFZ, S. 334-336

${ }^{66}$ Li Genyuan (1879-1965) stammte aus Tengchong. Im Jahr 1912 wurde er Vorsitzender der neugegründeten Guomindang-Partei in Yunnan, in den Jahren 1918 bis 1921 war Li Kommandant der Yunnan-Armee, ab 1921 gehörte er als Minister für Landwirtschaft der Regierung an, 1923 zog sich Li aus dem Amt zurück. 1954 und 1958 war er für die politische Konsultativkonferenz der VR China nominiert (siehe Boorman/Howard, vol. II, S. 305-307).
} 
Verwaltung und Bevölkerung des Grenzgebietes ebenso wie auch über den Im- und Exporthandel der Region zu Beginn des 20. Jahrhunderts.

Die Entwicklung der Region bis in die Republikzeit dokumentiert das Baoshan xian zhi, mit dessen Kompilation 1885 begonnen wurde. Eine nicht im Druck erschienene Fassung aus dem Jahr 1946 ist 1963 von Wang Jiefan und Wang Miansheng überarbeitet und zu sechsunddreißig Kapiteln zusammengefaßt worden. Neben der Beschreibung der historischen Ereignisse enthält das Handbuch eine umfangreiche Schilderung der Völker der Region, der einheimischen Sitten und der Religionen (Buddhismus, Islam, Christentum). Fortgesetzt wird diese Darstellung mit dem Baoshan xian zhi xubian in fünf Kapiteln, in welchem besonders Industrie und Handel der Region sowie in einem Nachtrag die Entwicklung in den Jahren von 1945 bis 1949 beschrieben werden. ${ }^{67}$

\section{2. 6. Andere chinesische Quellen}

Die umfangreichste Sammlung der Werke von Literaten aus der Präfaktur Yongchang sowie des historischen Materials über die Grenzregion wurde 1941 ebenfalls von Li Genyuan (1879-1965) herausgegeben. Sein Yongchang fu wenzheng umfaßt vier Abschnitte: Gedichte (shi), Literatur (wen), Aufzeichnungen (jizai) und Biographien (liechuan) mit insgesamt 136 Kapiteln. Den Schwerpunkt der Sammlung bilden Quellen aus der Ming-, Qing- und der Republikzeit, die Li Genyuan im Original wiedergibt.

Die Situation Tengchongs zur Zeit des Aufstandes der Moslems in Yunnan im 19. Jahrhundert findet sich in dem von dem Wirtschaftshistoriker Bai Shouyi 1953 herausgegebenen Sammelwerk Huimin qiyi dokumentiert. Der Herausgeber stellt darin zahlreiche zeitgenössische Quellen einheimischer Autoren zusammen, unter anderem auch den chronologischen Bericht der Ereignisse in der Stadt Tengyue, den von Cao Kun verfaßten Tengyue Du luan jishi (,Tatsachenbericht über den Aufstand Du [Wenxius] in Tengyue $).^{68}$

\footnotetext{
${ }^{67}$ Ausgaben der drei letzgenannten fangzhi befinden sich als Kopien handschriftlicher Manuskripte in der Bibliothek von Baoshan (Baoshan diqu tushuguan).

${ }^{68}$ Bai Shouyi, Huimin qiyi (,Der Moslem-Aufstand`), 4 Bde., Shanghai 1953 (Zhongguo jindaishi ziliao congkan, di si zhong).
} 


\section{2. 7. Das Reisetagebuch des Xu Xiake}

Der Forschungsreisende, Geograph und Literat Xu Xiake (1586-1641) hielt sich im Sommer des Jahres 1639 etwa zwei Monate lang im Gebiet um Tengchong auf. Die Beob-achtungen und geographischen Untersuchungen, die er auf seinen Wanderungen in der Umgebung Tengchongs gemacht hatte, notierte er ebenso wie genaue Informationen über Reiseroute und Entfernungen in seinem Reisetagebuch.

Neben der älteren von Ting Wen-chiang kommentierten Textausgabe von Xus Tagebuch von 1928 (Xu Xiake youji er ce. The travels of Hsü Hsia-ko with a volume if maps) sind in den letzten beiden Jahrzehnten in der VR China und in Taiwan verschiedene neue Ausgaben publiziert worden. Im Jahr 1980 erschien das Xu Xiake youji in zwei Bänden, herausgegeben von Chu Shaotang und Wu Yingshou (Shanghai 1980), das eine „ausladend narrative Erzählweise (ergänzt nach einem Neutextfund von Ji Mengliang) beinhaltet“, während die Ausgabe von Yang Jialuo (Hrsg.), Xu Xiake youji (Taipei 1992, eine Neuauflage von 1964), „die klassische Textversion wiedergibt“ ${ }^{69}$

Im Jahr 1985 erschien eine weitere kommentierte Ausgabe, herausgegeben von Zhu Huirong, das Xu Xiake youji jiaozhu. Anhand dieser Textausgabe hat Liu Chunming die Kapitel, in denen Xu Xiake über die Region Tengchong berichtet, in seinem Xu Xiake Tengyue youji (1993) zusammengestellt und seinerseits mit Anmerkungen versehen.

Ebenfalls von Zhu Huirong (und anderen) herausgegeben erschien im Jahr 1997 eine neue umfassendere Edition der Reiseaufzeichnungen des Xu Xiake in vier Bänden, das Xu Xiake youji quanyi (Guizhou 1997).

Eine vollständige Übersetzung der Reisetagebücher Xu Xiakes in eine westliche Sprache gibt es bisher nicht. Teilübersetzungen liegen von Li Chi oder Jacques Dars vor, die hauptsächlich literarisch anspruchsvollere, vom Autor selbst nachträglich für die Publikation bearbeitete Texte der früheren Reisen zu berühmten Bergen oder Sehenswürdigkeiten enthalten; die Aufzeichnungen Xus aus Yunnan sind hingegen noch nicht übersetzt worden. ${ }^{70}$

\footnotetext{
${ }^{69}$ Riemenschnitter, S. 193

${ }^{70}$ Siehe Li Chi, ,The travel diaries of Hsü Hasi-k’o‘ (1974); Jacques Dars, ,Xu Xiake (Hsü Hsia-k’e), Randonnées aux sites sublimes‘ (1993). Zur Bedeutung von Xus Werk, seiner Motivation und autobiographischen Repräsentation unter besonderer Berücksichtigung der Südwestreise, siehe A. Riemenschnitter, ,China zwischen Himmel und Erde` (1998), Kapitel IV, S. 183-227.
} 


\section{Aufbau der Studie}

Diese Studie ist in zwei Themenkreise gegliedert. Im Hauptteil, den Kapiteln II bis IV, wird die Entwicklungsgeschichte Tengchongs und des Grenzgebietes chronologisch dargestellt. Der zweite Teil der Studie (Kapitel V) befaßt sich anhand eines Fallbeispiels mit einem Aspekt der Beziehungen zwischen China und seinen Nachbarn im äußersten Westen Yunnans, dem Problem der sprachlichen und schriftlichen Verständigung.

Am Anfang (Kapitel II) steht ein Überblick über die frühen Kontakte Chinas mit dem fernen Südwesten, beginnend mit der Han-Zeit (206 v.Chr. - 220 n.Chr.), als erstmals Strukturen eines chinesischen Reiches in die Region des Stromschluchtenfächers ausgedehnt worden sind. Die Darstellung zeichnet dann die Entwicklung weiter über die Zeit der einheimischen Königreiche bis zum 13. Jahrhundert nach, als unter der Herrschaft der Mongolen die Provinz Yunnan gegründet wurde und in ihrem äußerstem Westen, in der Umgebung von Tengchong, ein Grenzgebiet des chinesischen Reiches zu entstehen begann.

Im Mittelpunkt der Studie stehen die Stadt und die Verwaltungseinheit Tengchong / Tengyue in der Ming- (1368-1644) und der Qing-Zeit (1644-1912).

Anhand der Analyse ihrer Entwicklung in der Ming-Zeit, deren zentrale Ereignisse der Bau der Stadtmauer (Mitte 15. Jahrhundert), die Gründung einer zivilen Verwaltungseinheit (Anfang des 16. Jahrhunderts) und die Ordnung des chinesischen Einflußbereichs jenseits der Hochebene von Tengchong (Ende des 16. Jahrhunderts) waren, wird zunächst herausgearbeitet, wie die Anbindung der Region des Stromschluchtenfächers an das chinesische Kernland und die damit verbundene Abgrenzung von weiter entfernten Gebieten verlaufen ist und welche Faktoren diesen Prozeß bestimmt haben (Kapitel III).

Die in der Ming-Zeit etablierten Strukturen bildeten die Grundlage, auf der sich die Verwaltungseinheit Tengyue unter der Herrschaft der nachfolgenden Qing-Dynastie (16441912) weiterentwickelte (Kapitel IV). In dieser Zeit beeinflußten die militärischen Auseinandersetzungen im Gebiet der Provinz Yunnan (Dynastiwechsel, Rebellion Wu Sanguis, Krieg mit Birma und die Moslem-Rebellion) immer auch die Region des Stromschluchtenfächers. Das zivile Leben und die Administration der Stadt Tengyue und der Verwaltungseinheiten im Grenzgebiet mußten danach jeweils reorganisiert und im Spannungsfeld zwischen dem Bestreben nach Kontinuität und notwendiger Veränderung in einzelnen Bereichen modifiziert werden. 
Zur Beschreibung der historischen Entwicklung Tengchongs werden jeweils Texte aus den Lokalhandbüchern (TYTZ, TYZZ, YCFZ) herangezogen. Dabei handelt es sich zum Teil um zeitgenössische Berichte, die von den Verfassern aus älteren fangzhi übernommen wurden, wie auch um ihre eigene Sicht auf die Geschehnisse in der Verwaltungseinheit aus der Perspektive des späten 19. Jahrhunderts.

Die Lokalhandbücher geben auch den zeitlichen Rahmen für diese Studie vor; mit der Zusammenstellung des TYTZ im Jahr 1888 endet die chronologische Darstellung der Geschichte Tengchongs.

Im zweiten Teil der Studie (Kapitel V) steht ein Bericht aus den fangzhi im Mittelpunkt, in dem die Schwierigkeiten der chinesischen Verwaltungsbeamten im Umgang mit Schriftstücken aus Birma und den Staaten der Shan im 18. Jahrhundert, erörtert werden. Auf die Analyse dieses Textes folgt die Darstellung der chinesischen Kanzleipraxis im Umgang mit fremdsprachlichen Dokumenten. Diese Untersuchung schließt sich thematisch an meine Magisterarbeit (,Der Gebrauch der birmanischen Schrift in China nach den Aufzeichnungen des Tien-nan tsa-chih [1810]‘, Göttingen 1994) an.

Die Verwendung von Schrift ist ein Aspekt, der auch im Zusammenhang mit den ,Zivilisierungsprojekten` zu sehen ist, sind doch Kenntnisse der chinesischen Schrift (wen) aus chinesischer Sicht das charakteristische Merkmal für ,Zivilisierung‘ (wenhua, wenming) schlechthin. Der Umgang mit Schriften, den fremden und der eigenen, an der Peripherie des chinesischen Reiches ist daher auch ein wichtiger Hinweis auf zeitgenössische Vorstellungen von Grenzen und den Gebieten diesseits und jenseits davon.

Insgesamt will diese Studie einen Beitrag zum besseren Verständnis des Prozesses leisten, in dem die Strukturen der chinesischen Kernregion in Yunnan etabliert worden sind, die ein Randgebiet zu einem festen Bestandteil des chinesischen Reiches gemacht und es gleichzeitig von Gebieten weiter im Westen abgegrenzt haben sowie auf die besondere Bedeutung hinweisen, die der ,ersten Stadt an der äußersten Grenze` in dieser Entwicklung zukam. 


\section{KAPITEL II}

DIE ENTSTEHUNG EINES GRENZGEBIETES:

DIE REGION DES STROMSCHLUCHTENFÄCHERS VON DER HAN- BIS ZUR YUAN-ZEIT (206 v. Chr. - 1368 n. Chr.)

\section{Zur Entstehung eines Grenzgebietes}

Eine Grenze, die zwei oder mehr durch bestimmte Eigenschaften definierte Einheiten voneinander trennt, ist oft keine absolute Trennungslinie, sondern vielmehr eine Zone, in der sich die verschiedenen Elemente der einzelnen Einheiten, die hier aufeinandertreffen, vermischen. Das Grenzgebiet zwischen China und Birma, das sich in einem breiten halbmondförmigen Bogen vom modernen Bezirk Baoshan im Norden über die Shan-Staaten Birmas bis nach Xishuangbanna im Süden Yunnans erstreckt, ist eine solche Zone, in der verschiedene Völker zusammentreffen: Tibeto-birmanische und Mon-Khmer Völker, TaiVölker und Chinesen aus den diversen Provinzen des Reiches sind über Jahrhunderte in diese Region eingewandert, haben sich dauerhaft angesiedelt oder sind weiter gezogen bzw. von nachrückenden Gruppen wieder verdrängt worden.

$\mathrm{Zu}$ einer Grenzzone wird ein Gebiet jedoch erst, wenn sich bestimmte Einheiten als solche definieren und abgrenzen oder wenn bereits bestehende Einheiten sich ausdehnen und auf andere treffen. Die Entstehung eines Grenzgebietes ist daher immer ein zeitliches Phänomen: Seine Existenz beginnt mit dem Zusammentreffen verschiedener Einheiten zu einem bestimmten Zeitpunkt. Nach Lamar und Thompson wird ein Grenzgebiet „in dem Moment ,eröffnet‘, in dem die ersten Repräsentanten der vordringenden Gruppe ankommen und ,geschlossen`, wenn diese ihre politische Vorherrschaft über das Gebiet etabliert haben“. ${ }^{71}$ Bei einem linearen Verlauf der Entwicklung, ist der Status als Grenzgebiet nur ein Zwischenstadium auf dem Weg zur Integration in die Kernregion. Wenn es der expandierenden Einheit nicht gelingt, ihre Vorherrschaft endgültig zu sichern, kann eine zyklische Entwicklung einsetzen, bei der das Gebiet, abhängig von der Stärke oder Schwäche der Kernregion, mal mehr mal weniger eng mit dieser verbunden wird und so auf Dauer als Grenzgebiet bestehen bleibt.

\footnotetext{
${ }^{71}$ Lamar/Thompson, 1981, zitiert nach Gaubatz, S. 20
} 


\section{Das westliche Yunnan in der Han-Zeit}

$\mathrm{Zu}$ welchem Zeitpunkt sich die ersten Han-chinesischen Einwanderer in der Region des Stromschluchtenfächers niedergelassen haben, wird sich wohl nicht mehr feststellen lassen. Chinesen, die im Rahmen von Militärexpeditionen in den Südwesten gekommen sind oder als Siedler, die Verbindung zu den Verwaltungsstrukturen des chinesischen Reiches hielten, werden in historischen Quellen als seit der Han-Zeit (206 v. Chr. - 220 n. Chr.) in der Region ansässig dokumentiert.

In der Han-Zeit war das Gebiet des Stromschluchtenfächers den Chinesen als Dianyue oder Dianyueguo bekannt. Der Name Dianyue (,Hinausgehen über Dian`) soll eingeführt worden sein, nachdem die südlichen Handelswege über Sichuan und Yunnan nach Indien am Kaiserhof bekannt geworden waren. ${ }^{72}$

Kaiser Han Wudi (140-86 v. Chr.) hatte von seinem Gesandten Zhang Qian erfahren, daß es im Süden seines Reiches Verkehrswege gibt, über die man die Länder im Westen erreichen kann, ohne die Gebiete der kriegerischen Nomadenvölker im Norden Chinas durchqueren zu müssen. Daraufhin sandte er zunächst Botschafter zur Erkundung in den Südwesten. Wenig später folgten Militärexpeditionen nach Zentral-Yunnan. Im Jahr 109 v. Chr. eroberten chinesische Truppen das Reich von Dian, dessen Zentrum sich im Gebiet des modernen Kunming befand. Der König von Dian unterwarf sich und erhielt vom Kaiser ein goldenes Siegel zum Zeichen der Eingliederung seines Herrschaftsgebietes in das chinesische Reich. Dian wurde Teil des Regierungsbezirks (jun) Yizhou, einer Verwaltungseinheit im Südwesten des chinesischen Reiches (siehe Karte 3, S. 35). ${ }^{73}$

Der Regierungsbezirk Yizhou verwaltete vierzehn Kreise (xian). Der westlichste dieser Kreise war Buwei, im Gebiet des modernen Baoshan. ${ }^{74}$

Den Namen Buwei verdankte der Kreis chinesischen Siedlern: Die Nachfahren des Lü Buwei, eines Beamten des Kaisers Qin Shi Huangdi (221-206 v. Chr.), waren zur Regierungszeit Kaiser Han Wudis in den Westen Yunnans umgesiedelt und hatten ihre neue Heimat nach ihrem Ahnen benannt. ${ }^{75}$ In Buwei war zur Zeit des Kaisers Chengdi

\footnotetext{
${ }^{72}$ TYZZ, S. 12; eine andere Bezeichnung, die in Han-zeitlichen Quellen für dieses Gebietes verwendet wurde, war ,Land, in dem man auf Elephanten reitet‘ (Chengxiangguo) (siehe auch Shiji, Dawan liechuan).

${ }^{73}$ Lutz, S. 21, 92

${ }^{74}$ Im YCFZ heißt es, daß der Kreis Buwei bereits im Jahr 122 v. Chr. gegründet worden ist (YCFZ, S. 49).

${ }^{75}$ Zhang Zengqi, S. 252. Der Kreis Buwei befand sich im Gebiet des modernen Dorfes Jinji, ,dem Dorf der goldenen Hühner', 15 km nordöstlich von Baoshan. (Der Legende nach waren dort vor Zeiten zwei Phönixe erschienen, die in goldenem Licht erstrahlten. Da den Menschen diese Vögel unbekannt waren, nannten sie sie schlicht ,goldene Hühner`, so entstand der Name des Dorfes [Yang Zhongshi, S. 21].)
} 
(32-6 v.Chr.) zudem ein chinesischer Verwaltungsbeamter (Buwei ling) tätig: Chen Li aus Shu (dem modernen Sichuan). ${ }^{76}$

Das Gebiet um die heutige Stadt Tengchong befand sich damals westlich des Kreises Buwei, in Dianyueguo, einem ,Land jenseits von Dian‘ ${ }^{77}$

\section{Karte 3 : China zur Zeit der Westlichen Han-Dynastie (206 v.Chr.- 9 n.Chr.) und die Seidenstraßen nach Westasien}

(Quelle: A. Lutz [Hrsg.] Dian. Ein versunkenes Königreich in China, Abb. 4, S. 20)

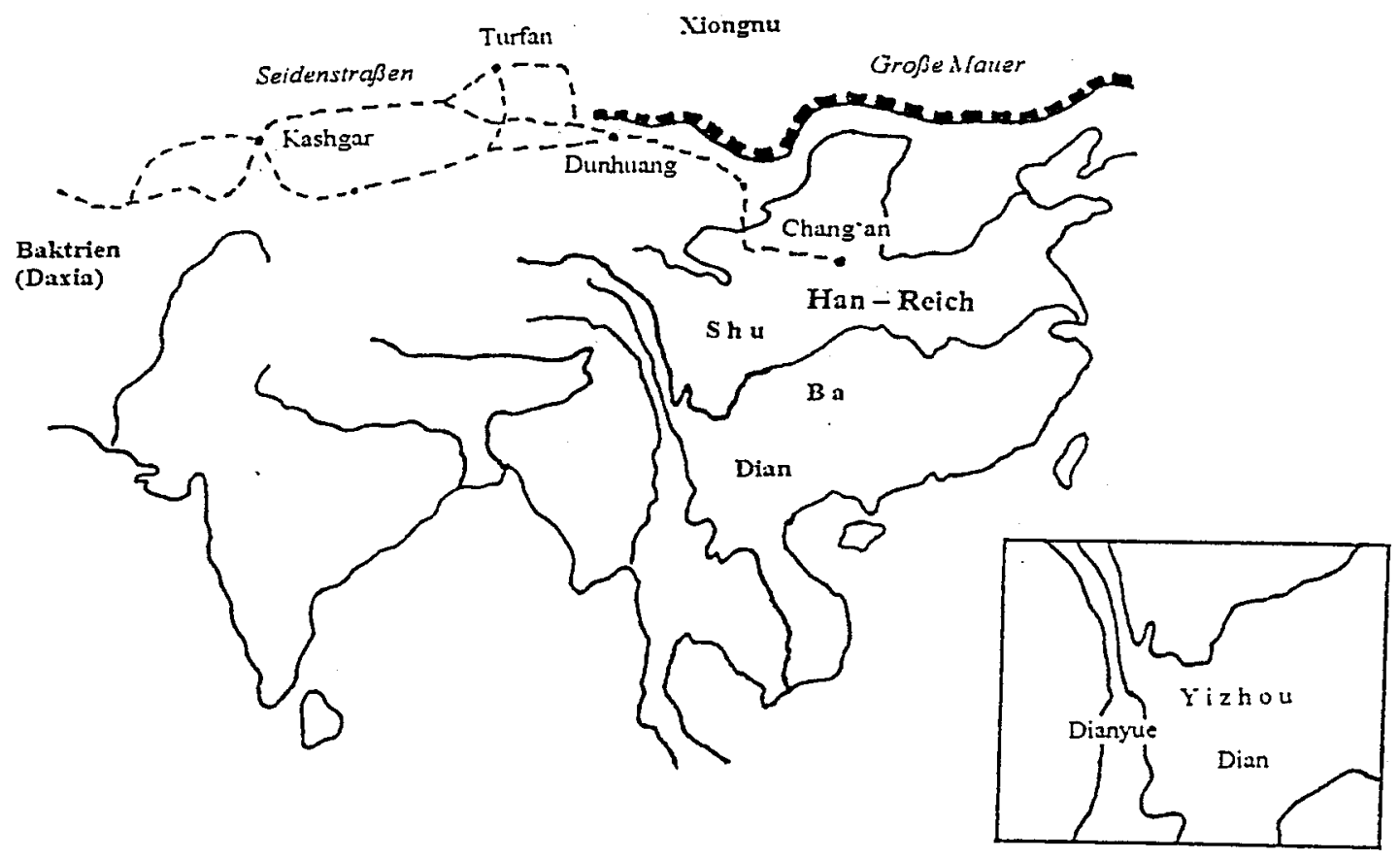

Während der Östlichen Han-Dynastie (25 n.Chr. bis 220 n.Chr.) führte der Gouverneur von Yizhou im Westen einen Feldzug gegen das Volk der Ailao, in dessen Verlauf er im Jahr 58 n.Chr. den Regierungsbezirk Lancang mit den beiden Kreisen Ailao und Bonan gründete. ${ }^{78}$ Nachdem sich die Ailao unterworfen hatten, wurden die Verwaltungseinheiten im Westen Yunnans unter Einbeziehung des neugewonnenen Territoriums reorganisiert. Die sechs westlichen Kreise des Regierungsbezirks Yizhou sowie Ailao und Bonan wurden im Jahr 69 n.Chr. dem neugegründeten Regierungsbezirk Yongchang („ewiges Gedeihen“; im Gebiet des modernen Baoshan) unterstellt, der von einem Gouverneur

\footnotetext{
${ }^{76}$ YCFZ, S. 149

${ }^{77}$ TYTZ, S. 65. An anderer Stelle im Lokalhandbuch wird darauf hingewiesen, daß auch Dianyueguo bereits zu dieser Zeit der Kommandantur Yizhou unterstellt war (shu Yizhou jun) (TYTZ, S. 63, s. a. You Zhong, S. 49).

${ }^{78}$ YCFZ, S. 49
} 
(taishou) verwaltet wurde. ${ }^{79}$ Ailao wurde später noch einmal in zwei Kreise unterteilt und ebendort im ehemaligen Dianyue, so die Verfasser der fangzhi, „befinden sich nun das Teng[yue des 19. Jahrhunderts] sowie die verschiedenen Befriedeten Gebiete“ ${ }^{80}$

Nach dem Sturz der Han-Dynastie im Jahr 220 entstanden in ihrem Herrschaftsgebiet drei Reiche: Das Wei-Reich im Norden, das Wu-Reich im Yangzi-Tal und das südliche Reich Shu-Han (221-263) in Sichuan.

Shu-Han war von Liu Bei (161-223), einem Nachfahren der kaiserlichen Familie der Han, gegründet worden und verdankt seinen Aufschwung vor allem seinem Kanzler Zhuge Liang (181-234). ${ }^{81}$ Zhuge wurde im Jahr 223 zum Fürsten von Wu (Wu hou) ernannt und mit der Verwaltung Yizhous betraut. Im Jahr 225 unternahm Zhuge Liang einen Feldzug nach Südwesten „bis zum Dian-See und befriedete die vier Regierungsbezirke Yizhou, Yongchang, Zangke und Yuexi““. ${ }^{82}$ Anschließend teilte er die Verwaltungsbezirke in diesem Gebiet neu ein, so daß sieben Regierungsbezirke (jun) entstanden, für die je ein Gouverneur (taishou) ernannt wurde.

Einige dieser Beamten waren aus dem Kerngebiet von Shu-Han im modernen Sichuan gekommen, um ihr Amt im Südwesten anzutreten, andere stammten aus einflußreichen Familien der Region, wie Lü Kai aus Buwei/Yongchang, der als Gouverneur dem neugegründeten Regierungsbezirk Yunnan vorstand, einer Verwaltungseinheit, die sich von Yongchang bis in das Gebiet um den Erhai-See erstreckte. ${ }^{83}$

Im YCFZ werden insgesamt achtzehn Beamte genannt, die das Amt eines Gouverneurs von Yongchang bzw. Yunnan während der Han-Zeit und der Shu-Han-Zeit innehatten. Darunter waren sowohl Männer aus Yongchang, als auch Beamte aus anderen Teilen des Han-Reiches, aus Ba und Shu, aber auch aus Bezirken im Gebiet der modernen Provinzen Henan und Hebei. ${ }^{84}$

\footnotetext{
${ }^{79}$ TYTZ, S. 65; YCFZ, S. 50; You Zhong, S. 50

${ }^{80}$ TYTZ, S. 65, 63. (Zu den Befriedeten Gebieten [tusi] siehe unten Kap. III B. 4., S. 104ff.)

${ }^{81}$ Yang Jianyu, S. 209-212; ZGRMDCD, S. 170 (Liu Bei); 512 (Zhuge Liang)

${ }^{82}$ YCFZ, S. 165. Yuexi bezeichnete ein Gebiet, daß sich von der modernen Stadt Xichang, im Süden der Provinz Sichuan, bis nach Lijiang im nördlichen Yunnan erstreckte; Zangke umfaßte das Gebiet um Kaili und Huangping in Guizhou.

${ }^{83}$ You Zhong, S. 91; Li Xiejun, S. 24; YCFZ, S. 171. Während der Han-Zeit waren Lü Kai und sein Sohn Lü Xiang als Gouverneure (taishou) in Yunnan tätig; ein Sohn Lü Xiangs übte dieses Amt zur Zeit der Jin-Dynastie (265 - 420) aus (YCFZ, S. 171). Dieser war auch der letzte bekannte amtierende Gouverneur dieses Regierungsbezirks. Im YCFZ wird nach ihm lediglich noch ein untergeordneter Beamter (congshi) namentlich erwähnt. Verwaltungsbeamte des chinesischen Reiches sind dort erst wieder für die Yuan-Zeit verzeichnet (YCFZ, S. 171). Zu den einflußreichen Familien chinesischer Herkunft im Südwesten siehe auch You Zhong, Kap. 3. 2. (S. 81ff).

${ }^{84}$ YCFZ, S. 171
} 
Schon der Zerfall des Han-Reiches hatte neue Siedler aus dem chinesischen Kernland in den Südwesten gebracht. Auch die Truppen, die Zhuge Liang nach Yunnan führte, siedelten sich nach dem Ende des Feldzuges in der Region an.

Zhuge Liang und seinem Feldzug nach Südwesten kommt nach Ansicht der Herausgeber der fangzhi von Yongchang und Tengyue eine große Bedeutung für die Entwicklung der Region zu. Ihm wird die ,Befriedung‘ der einheimischen Bevölkerung, die Etablierung von Verwaltungsstrukturen, aber auch die Förderung von Landwirtschaft und Handel im Südwesten zugeschrieben. So beginnt die Darstellung der Geschichte der Präfektur Yongchang im YCFZ mit der Feststellung, daß

„die Anfänge Yongchangs in der Zeit des Kaisers Han Wudi liegen, ihre Entwicklung aber vom Fürsten von Wu [Zhuge Liang] entscheidend gefördert wurde“. 85

Für die Herausgeber der fangzhi ist Zhuge Liang daher eine wichtige Symbolfigur, die die Kontinuität der Anbindung des Südwestens und seines äußersten Grenzgebietes an das chinesische Kernland repräsentiert. Die Verfasser des TYTZ legen entsprechend Wert darauf, nachzuweisen, daß Zhuge persönlich bis in den äußersten Westen Yunnans gekommen ist:

„Im 3. Jahr der Ära Jianxing (225 n. Chr.) kam [Zhuge Liang] auf seinem Feldzug nach Süden bis nach Teng. Davon zeugen noch Steine der Militärgarnison, ... . Außerdem gibt es die Stadt (cheng) auf dem WasserscheidenGebirgskamm (Fenshuiling). Es wird erzählt, daß der Kanzler dort Truppen stationiert hatte und als er einmal dort übernachtete, ließ er die Stadt bauen. Das ist die sogenannte Zhuge-Liang-Stadt, die in Quellen aus der Tang-Zeit erwähnt wird. ... In Jiulongjiang bewahrt man bis heute ein bronzenes Geschütz (tong pao) und ein Schwert von Zhuge auf. Seitdem hatte man [hier] Kenntnis von Feuerwaffen (huoqi). Während der Ära Zhengtong (1436-1450) der Ming-Dynastie wurde eine Gedenkhalle (ci) für ihn errichtet“. ${ }^{86}$

\footnotetext{
${ }^{85}$ Yongchang zhao zi Han Wu er fa meng yu Wu hou (fa meng heißt wörtlich übersetzt ,erleuchten‘, ,aufklären‘, auch im Sinne von ,Elementarunterricht erteilen') (YCFZ, S. 49). Siehe auch TYTZ, S. 139.

${ }^{86}$ TYTZ, S. 139. Steine von der ehemaligen Militärgarnison befanden sich im 19. Jahrhundert in der Gedenkhalle für den Fürsten von Wu in Tengchong (TYZZ, S. 57). Mit pao wurden ursprünglich Wurfmaschinen oder deren Geschosse bezeichnet; seit der Ming-Zeit wurde der Begriff für Kanonen verwendet. Feuerwaffen (Gewehre u.ä.) wurden zuerst von den Mongolen in Yunnan eingesetzt und waren erst in der Ming-Zeit auch im Grenzgebiet verbreitet (siehe Sun, MingSoutheast Asian overland interactions, Kap. 3). Möglicherweise meinen die Verfasser hier lediglich ein solches Geschoß, daß vielleicht auch aus späterer Zeit stammte und lediglich Zhuge zugeschrieben wurde, um seine Anwesenheit in der Region zu bestätigen. Beweise dafür, daß Zhuge Liang tatsächlich selbst in Yongchang gewesen ist, gibt es gegenwärtig nicht.
} 
Mit dem Bau einer Gedenkhalle für Zhuge Liang stellten die chinesischen Beamten in der Ming-Zeit eine Verbindung zwischen der Einbeziehung des fernen Südwestens in das Verwaltungssystem des Han-Reiches und der Gründung der Stadt Tengchong Mitte des 15. Jahrhunderts her. Sie machten deutlich, daß die Stadt und die sie umgebende Verwaltungseinheit in ihrer Entwicklung an eine alte Tradition aus der Han- bzw. der Shu-Han-Zeit anknüpfen konnten und überbrückten so die Zeit, in der der Südwesten von unabhängigen Reichen einheimischer Völker beherrscht worden war, bis die Region im 13. Jahrhundert zur Provinz Yunnan des chinesischen Reiches der Mongolen wurde.

\section{Das chinesische Engagement in Yunnan während der Sui- und der Tang-Zeit}

Die Herausgeber der fangzhi betonen zwar, daß der Regierungsbezirk Yongchang der HanDynastie seinen Status als Verwaltungseinheit des chinesischen Reiches bis in die Zeit der Sui-Dynastie (581-618) beibehalten hat, der einzige tatsächliche Hinweis auf Beziehungen zwischen einem chinesischen Reich und der Region des Stromschluchtenfächers stammt jedoch aus der Zeit der Jin-Dynastie (265-420), als noch ein Mitglied der Familie Lü als Gouverneur von Yongchang amtierte. ${ }^{87}$

Auch nachdem das chinesische Reich nach der Zeit der Teilung in die Nördlichen und Südlichen Dynastien (420-589) unter der Sui-Dynastie (581-618) wieder geeint worden war, befand sich die Region um Yongchang jenseits des Einflußbereiches des neuen Herrscherhauses, das aber mit zwei Militärexpeditionen in das nordöstliche Yunnan immerhin sein Bestreben deutlich machte, seine Kontrolle auch über die Gebiete im Südwesten des Reiches weiter auszubauen. ${ }^{88}$

Unter der nachfolgenden Tang-Dynastie (618-907) wurden zunächst diplomatische Missionen in den Südwesten entsandt und im Jahr 621 die Garnison und Grenz-Präfektur Yaozhou (das moderne Yaoan im Bezirk Chuxiong) gegründet. Mit der Präsenz in Yaozhou konnte China ein gewisses Maß an direkter Kontrolle über das strategisch wichtige Gebiet am Erhai-See ausüben, in dem die Verkehrswege aus Indien und Tibet zusammentreffen. Yaozhou war der wichtigste Außenposten des Tang-Reiches im Südwesten, der im Jahr 664 sogar zum Sitz eines Generalgouverneurs ( $d u d u f u$ ) aufgewertet wurde. ${ }^{89}$ Ausgehend von Yaozhou führten die Truppen der Tang in Zentral-Yunnan Feldzüge gegen

\footnotetext{
${ }^{87}$ TYTZ, S. 63, 65; YCFZ, S. 52, 171

${ }^{88}$ Backus, S. 3

${ }^{89}$ Backus, S. 195. Im Jahr 680 zogen sich die Tang aus Yaozhou zurück, einige Jahre später wurden jedoch erneut Soldaten in der Garnison stationiert, die im Jahr 750 von Truppen Nanzhaos zerstört wurde (ebd., S. 195-196).
} 
die einheimischen Völker, wie die Cuan oder die Kunming, deren Herrschaftsgebiete der chinesischen Verwaltung als jimi-Bezirke zugeordnet wurden. Denn „allein Yaozhou war dem Kernland unterstellt worden (shu neidi), ansonsten gab es lediglich jimi-Bezirke“. ${ }^{90}$ Jimi bedeutet wörtlich übersetzt „mit einem Zaumzeug zügeln“, „bändigen“. Die so benannten Bezirke waren Einheiten der lokalen Verwaltung, die in Gebieten eingerichtet wurden, die von nicht Han-chinesischen Volksgruppen bewohnt waren, die sich China unterworfen hatten. Sie wurden weiterhin von ihrem einheimischen Oberhaupt regiert, das Tributmissionen an den Kaiserhof sandte und dessen Herrschaftsgebiet mit dem jimi-Status formal in die chinesische Verwaltungshierarchie eingebunden war.

Nach dem Feldzug einer Armee der Tang im Jahr 670 gegen die Kunming-Völker im Gebiet von Yongchang galt auch die Region des Stromschluchtenfächers in China als befriedet und wurde dort fortan als jimi-Bezirk (jimi zhou) Yuetan bezeichnet. ${ }^{91}$

\section{Die Region des Stromschluchtenfächers als Teil der Königreiche von Nanzhao und}

\section{Dali}

In der ersten Hälfte des 8. Jahrhunderts entstand in der Gegend um das moderne Menghua (südlich des Erhai-Sees) das Königreich von Nanzhao. Nachdem Piluoge (728-748) von Mengshe (heute Weishan) zunächst die sechs Fürstentümer des Meng-Clans unter seiner Herrschaft vereint hatte, gelang es ihm und seinen Nachfolgern, ihren Machtbereich auf das Gebiet der modernen chinesischen Provinz Yunnan, das südliche Sichuan und das westliche Guizhou auszudehnen. Das Königreich von Nanzhao war ein Vielvölkerstaat, der von Angehörigen zweier Volksgruppen beherrscht wurde. Der regierende Meng-Clan gehörte der ethnischen Gruppe der Wuman an, den Vorfahren des Volkes der Yi, die zu den Völkern der tibeto-birmanischen Sprachenfamilie zählen. Ebenso wie die Baiman, Vorfahren des Bai-Volkes, die in Nanzhao wichtige Beamtenposten innehatten und erheblichen Einfluß auf die Verwaltung des Reiches ausübten. ${ }^{92}$

Nanzhao unterhielt diplomatische Beziehungen zum Reich der Tang und schickte Tributgesandtschaften an den chinesischen Kaiserhof. Im Jahr 738 erhielt Piluoge vom chinesischen Kaiser den Titel eines ,Königs von Yunnan“ (Yunnan wang) verliehen. ${ }^{93}$ Sein

\footnotetext{
${ }^{90}$ TYZZ, S. 20. Insgesamt soll es in der Region zweiundneunzig solcher ,Bezirke der verschiedenen Barbaren` (zhu man zhou) gegeben haben, welchem allerdings das Gebiet um das moderne Tengchong zugeordnet war, war den Herausgebern des TYZZ im 19. Jahrhundert nicht mehr bekannt (ebd.).

${ }^{91}$ TYTZ, S. 12, 65; an anderer Stelle wird die Verwaltungseinheit nach dem früheren Regierungsbezirk (jun) Yongchang auch als jimi jun bezeichnet (TYTZ, S. 63).

${ }^{92}$ Korn-Riedlinger, S. 3, 55, 134; Backus, S. 47, 50

${ }^{93}$ Yang Jianyu, S. 564; Backus, S. 195
} 
Nachfolger Kolofeng (748-779) verbündete Nanzhao mit Tibet gegen das Tang-Reich, festigte seine Herrschaft über Yunnan und expandierte auch nach Westen. Im Jahr 762 rückten die Truppen Kolofengs bis über den Irawadi vor, um sich die Kontrolle über die nördlichen Handels- und Verkehrswege nach Indien zu sichern, die das Gebiet des Stromschluchtenfächers über Yongchang, Tengchong und das nördliche Birma mit Assam verbanden.

\section{Karte 4 : Das Königreich von Nanzhao - Städte und Hauptverkehrsstraßen}

(Quelle: A. Lutz, Der Tempel der drei Pagoden von Dali, S. 18, Abb. 4)

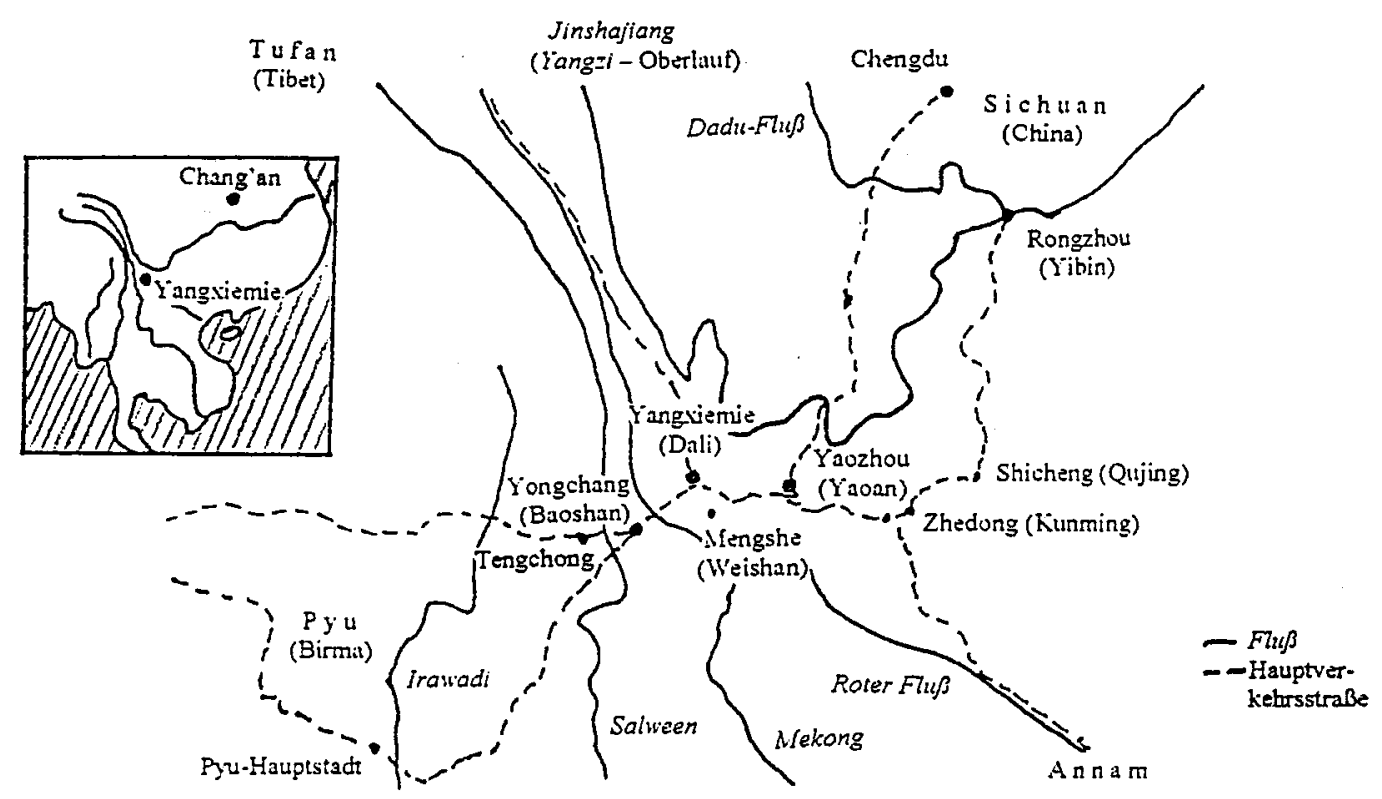

Unter der Herrschaft von König Yimouxun (reg. 779-808) erlebte Nanzhao eine Phase der Konsolidierung. Die politische Organisation des Reiches wurde gefestigt, die Beziehungen zu China wieder aufgenommen; die im Zentrum des Nanzhao-Reiches etablierten Verwaltungsstrukturen wurden auch auf neu eroberte Gebiete, wie das im Jahr 796 unterworfene Yuetan, ausgedehnt.

Yuetan, so erläutern die Verfasser der fangzhi von Yongchang und Tengyue, bezeichnet das Gebiet „im Westen von Yongchang, in dem die drei Barbaren[völker] (san man) Bo, Piao und Echang leben ..., es ist das moderne Tengyue“. Dort gründete Yimouxun nun die Verwaltungseinheit Präfektur Ruanhua (Ruanhua fu). ${ }^{94}$ 
Auch unter den Nachfolgern Yimouxuns expandierte das Königreich von Nanzhao weiter nach Westen und dehnte seinen Machtbereich mit der Zerstörung einer Hauptstadt des Reiches der Pyu im Jahr 832 auch auf Oberbirma aus. ${ }^{95}$ Die Hochebene von Tengchong war damit Teil eines Reiches geworden, das zwar in alle vier Himmelsrichtungen expandierte, dessen Zentrum sich aber dauerhaft von Mengshe nach Osten verlagert hatte: Seit dem Jahr 780 war das weiter nordöstlich am Erhai-See gelegene Yangxiemie Hauptstadt Nanzhaos geworden; im Jahr 809 wurde Shanchan (vorher Zhedong, heute Kunming) zur östlichen Hauptstadt des Reiches ernannt. Nach Osten wandte sich Nanzhao auch beim Aufbau und der Verwaltung des Reiches, wo es sich am Vorbild seines Nachbarn, dem China der Tang-Dynastie, orientierte.

Ende des 9. Jahrhunderts begann der Niedergang des Reiches von Nanzhao. Kriege hatten die Ressourcen des Landes erschöpft; die schwache Zentralregierung konnte das Reich nicht länger zusammenhalten, während die Volksgruppe der Baiman von der Region am Erhai-See ausgehend weiter an Einfluß gewann. Nach dem Tod König Shunhuazhens im Jahr 902 zerfiel das Reich.

Unter den kurzlebigen Nachfolgereichen Nanzhaos und dem im 10. Jahrhundert von den Baiman gegründeten Königreich Dali (937-1253) blieb das Gebiet am Erhai-See das politische Zentrum der Region. ${ }^{96}$ Im Stromschluchtenfächer westlich des Gaoligong-Gebirges gründeten die Herrscher von Dali die Präfektur (fu) Tengchong. ${ }^{97}$ Diese wurde von einem Präfekten verwaltet, dessen Amt über Generationen in einer einflußreichen Familie von Tengchong weiter vererbt wurde. ${ }^{98}$ Die Präfektur Tengchong umfaßte ein Gebiet, das sich vom Fluß Longchuan nach Westen bis zum Oberlauf des Irawadi erstreckte und bildete dort die westlichste Verwaltungseinheit des Königreiches von Dali und die Grenze seines Hoheitsgebietes. $^{99}$

\footnotetext{
${ }^{95}$ In älteren Studien wird Halin als eroberte Hauptstadt der Pyu genannt (so z.B. Luce, Pagan, S. 3). Neueren Ausgrabungen zufolge könnte es sich dabei auch um Maingmaw (südlich von Kyaukse gelegen) handeln, einen weiteren zentralen Ort des Pyu-Reiches (siehe Frasch, S. 39-41).

${ }^{96}$ Eine ausführliche Darstellung der Entwicklung der einheimischen Königreiche im Südwesten gibt Karin Korn-Riedlinger in ihrer Dissertation ,Dian, Nanzhao, Dali - Staatsgründungen auf dem Gebiet der heutigen Provinz Yunnan (VR China)‘, Bonn 1988.

${ }^{97}$ In den Darstellungen der Entwicklungsgeschichte von Tengchong in den fangzhi wird das Gebiet für die Zeit des 10. Jahrhunderts erstmalig mit dem Namen Tengchong bezeichnet (TYTZ, S. 63, 65; TYZZ, S. 20).

${ }^{98}$ TYZZ, S. 14

99 You Zhong, S. 222.

Im modernen Oberbirma, im Gebiet von Kyaukse war zu dieser Zeit das birmanische Königreich von Pagan entstanden, das Mitte des 11. Jahrhunderts unter König Anawrahta (reg. ca. 1044-1077) expandierte. Im Süden wurde das Reich der Mon erobert und in birmanischen Quellen ist auch ein Feldzug nach Norden überliefert, wo Anawrahta am Irawadi entlang bis zum modernen Bhamo 43 Festungen zum Schutz seines Reiches errichten ließ (siehe Frasch, S. 77-78).
} 


\section{Der Name Tengchong und die Benennung der Region in chinesischen Quellen}

Während der Name Tengchong in den fangzhi von Tengyue und Yongchang erst seit der Zeit des Reiches von Dali (seit dem 10. Jahrhundert) dokumentiert ist, wird er in zwei chinesischen Quellen aus der Tang-Zeit bereits für das 8. und 9. Jahrhundert belegt, allerdings in einer anderen Schreibweise (siehe Tab.1, S. 4).

\section{1. Tengchong im Werk von Jia Dan und im Manshu von Fan Chuo}

Eine von Jia Dan (730-805) zusammengestellte Beschreibung der Reisewege von China in verschiedene Regionen Asiens aus der Epoche Zhenyuan (785-805) ist im Xin Tang shu (dili zhi) überliefert worden. ${ }^{100}$ Darunter befindet sich auch eine Beschreibung der Verkehrswege, die über Yunnan nach Indien führen.

Die beiden von Jia Dan beschriebenen Routen nach Indien führten von Yangxiemie, der Hauptstadt von Nanzhao am Erhai-See, weiter nach Yongchang und Zhuge-Liang-Stadt (Zhuge Liang cheng) im Gaoligong-Gebirge. Dort trennten sie sich in eine südliche und eine westliche Route. Letztere führte von Zhuge-Liang-Stadt nach Westen und erreichte nach einhundert Kilometern die Stadt Tengchong (Tengchong cheng). ${ }^{101}$

Paul Pelliot kommt in seiner Untersuchung des Textes von Jia Dan, dem ,Deux itinéraires de Chine en Inde، (1904), aufgrund eines Vergleichs mit den Angaben des Manshu zu dem Schluß, daß das Tengchong des Jia Dan sich etwa an der Stelle der modernen Stadt Tengchong befunden hat. ${ }^{102}$

Das Manshu (auch Nanyi zhi oder Yunnan zhi) von Fan Chuo ist ein geographisches Werk über Yunnan aus dem 9. Jahrhundert, in dem die Topographie des Gebietes von Nanzhao, die Sitten, örtlichen Produkte usw. systematisch darstellt werden. Das Manshu ist als eigenständiges Werk verlorengegangen, wurde aber im 18. Jahrhundert aus den im Yongle dadian enthaltenen Fragmenten erneut zusammengestellt. ${ }^{103}$

Eine Stadt Tengchong wird im Manshu im Kapitel über die Berge und Ströme sowie im Kapitel über die lokalen Produkte erwähnt. ${ }^{104}$ Die Schreibweise des Namens Tengchong

\footnotetext{
100 ,Die neue Geschichte der Tang-Dynastie“ (Xin Tang shu) wurde von Ouyang Xiu in Jahren 1045-1061 zusammengestellt (CY 744.4).

101 „Zi Yangxiemie cheng xi zhi Yongchang gu jun san bai li. You xi du Nujiang, zhi Zhuge-Liang-cheng er bai li. .... Yi lu zi Zhuge-Liang-cheng xi qu Tengchong cheng er bai li“ (Xin Tang shu, juan 43 xia, S. 1152; s. a. TYTZ, S. 56).

${ }^{102}$ Pelliot, S.361, 167-168

${ }^{103}$ ZGRMDCD, S. 654; Luce: Man shu; Pelliot, S. 122. Die Literatursammlung Yongle dadian wurde im Jahr 1407 herausgegeben.

${ }^{104}$ Xiang Da, S. 42, 199, 201; Luce: Man shu, S. 18, 70, 71
} 
weicht von der später in den fangzhi gebräuchlichen ab, es wird hier anstelle des Zeichens chong (,überfluten; vorwärtsstürmen; Knotenpunkt, Durchgangsstraße‘) das gleichlautende chong (,füllen;vollständig; fungieren als') verwendet, ebenso wie bei Jia Dan. Die Schreibweise des Schriftzeichens teng variiert innerhalb des Manshu, so wird im 2. Kapitel das in den fangzhi gebräuchliche teng (,dahineilen'), im 7. Kapitel hingegen teng (,Flechtrohr‘) verwendet. $^{105}$

\title{
5. 2. Diskussion der Namensvarianten von Tu Shulian
}

Die Frage der Entstehung und Bedeutung der verschiedenen Bezeichnungen der Stadt und ihrer Umgebung wird auch von Unterpräfekt Tu Shulian (1788-1791 in Tengyue tätig), in der Geschichte Tengyues, die er Ende des 18. Jahrhunderts für sein Lokalhandbuch zusammengestellt hat, erörtert:

\begin{abstract}
„... Der Name Yuetan erscheint im Tang shu und im Yuan shi. Im Kapitel über die Geographie des Yuan shi heißt es: Die Sonder-Präfektur Tengchong (Tengchong $\mathrm{fu}$ ) befindet sich im Westen von Yongchang; das ist das Gebiet von Yuetan. In der Tang-Zeit ist dort ein jimi-Bezirk eingerichtet worden. Yimouxun, ein Abkömmling des Meng-Clans in der neunten Generation, hatte Yuetan eingenommen, alle Barbaren vertrieben und dann deren Gebiete zur Präfektur Ruanhua gemacht. Später lebten dort die Baiman-Barbaren (Baiman yi) und änderten [den Namen] in Präfektur Tengchong. Der Name Tengchong stammt also von den Baiman (Tengchong zhi ming qi zi Baiman yi) “. ${ }^{106}$
\end{abstract}

Während Jia Dan den Namen Yuetan nicht erwähnt, bezeichnet Fan Chuo im Manshu das Gebiet westlich des Gaoligongshan, in dem sich die Stadt Tengchong befindet, als Yuetan. ${ }^{107}$ Die Quellen stimmen darin überein, daß sie den Namen Tengchong bereits für die Zeit des Reiches von Nanzhao belegen. Auch Tu Shulian berücksichtigt den Text von Jia Dan und präzisiert seine Aussage zur Entstehung des Namens Tengchong:

\footnotetext{
${ }^{105}$ Xiang Da, S. 42; Luce S. 18 und Xiang Da, S. 199, 201; Luce, S.70, 71.

106 TYZZ, S. 14. Die ,Geschichte der Tang-Dynastie‘ (Tang shu, auch Jiu Tang shu genannt) wurde im Jahr 945 von Liu Xu herausgegeben (CY 1411.2). Die ,Geschichte der Yuan-Dynastie“ (Yuan shi) wurde im Jahr 1370 publiziert.

${ }^{107}$ Xiang Da, S. 41. Luce: Man shu, S. 18, s.a. die Karte am Ende des Buches. Abweichend Ma Changshou, der in seiner Karte, die die ethnische Zusammensetzung der Bevölkerung von Nanzhao darstellt, und Yuetan als Name eines Ortes nördlich von Tengchong verzeichnet (siehe Korn-Riedlinger, S. 282).

Tu Shulian diskutiert auch die Entstehung und Bedeutung des Namens Yuetan, wobei er zu dem Schluß kommt, daß der Namensteil tan eine Verwaltungseinheit bezeichnet und mit zhou (,Präfektur`) gleichzusetzen ist: „So kam es zu dem Namen Yuetan, dieser entspricht Yuezhou.“ Den Unterschied zwischen Yuetan und Tengchong macht er abschließend noch einmal deutlich: „Das Gebiet (di) von Yuetan kann man daher keineswegs mit der Stadt (cheng) Tengchong gleichsetzen“ (TYZZ, S. 14).
} 
„Jia Dan aber, der in der Tang-Zeit die Reisewege nach Indien untersuchte, stellte fest, daß ,eine Route von Zhuge-Liang-Stadt 200 li nach Westen bis nach Tengchong führt‘. Also gab es diese Stadt Tengchong doch schon früher, [d.h. vor dem 10. Jahrhundert]. Daher stammt ihr Name; nur verwendete man [später das Schriftzeichen] chong [,vorwärtsstürmen'; ,Durchgangsstraße‘] an Stelle des [früher gebräuchlichen] chong [,füllen; vollständig ‘]“ 108

\section{3. Zusammenfassung}

Berücksichtigt man die Tang-zeitlichen Quellen so kann man davon ausgehen, daß eine Ansiedlung, deren Name im Chinesischen mit Tengchong wiedergegeben wurde, bereits im 8. Jahrhundert existiert hat. Bei Jia Dan wird Tengchong ebenso wie zum Beispiel Yangxiemie oder Zhuge-Liang-Stadt als cheng (,Stadt') bezeichnet. Fan Chuo nennt lediglich den Namen Tengchong. Keiner der beiden Autoren macht weitere Angaben zum Aussehen oder zur Größe Tengchongs. In Verbindung mit ihrer geographischen Lage an einem wichtigen Verkehrsweg deutet die Bezeichnung als Stadt bei Jia Dan darauf hin, daß es sich bei dem Tang-zeitlichen Tengchong um eine Ansiedlung von zumindest regionaler Bedeutung handelte, die sich von den Dörfern der Umgebung unterschied und wahrscheinlich von einer Umfriedung begrenzt gewesen ist (cheng: ,Stadtmauer').

Die fehlende Erwähnung des Namens Tengchong für diese frühe Zeit in historischen chinesischen Quellen, wie den fangzhi der Stadt, ist ein Indiz dafür, daß es sich dabei um einen einheimischen Namen handelte, welcher zwar in spezielleren Werken erwähnt wird, der generell aber zugunsten der chinesischen Bezeichnung für das Gebiet westlich des Gaoligongshan - jimi-Bezirk Yuetan - zurückstand. Auch läßt sich vermuten, daß der Name, nachdem Yimouxun (reg. 779-805) von Nanzhao dieses Gebiet erobert und, wie es in den fangzhi heißt, die einheimische Bevölkerung vertrieben hatte, nicht mehr gebräuchlich war. ${ }^{109}$ Möglich auch, daß die Siedlung Tengchong unter ihrem Namen weiterbestand, aber im offiziellen Sprachgebrauch und in den Dokumenten Nanzhaos hinter der neuen Bezeichnung der größeren Verwaltungseinheit, die im Chinesischen als Präfektur Ruanhua wiedergegeben wurde, zurück trat. Allerdings erwähnen weder Jia Dan, dessen Text zur Regierungszeit von König Yimouxun erschien, noch Fan Chuo ein halbes Jahrhundert später eine Präfektur Ruanhua.

\footnotetext{
${ }^{108}$ TYZZ, S. 14

${ }^{109}$ TYTZ, S. 63
} 
Unterpräfekt Tu Shulian führt in seiner Darstellung der Entwicklung des Namens der Stadt aus, daß die Volksgruppe der Baiman nach der Gründung des Reiches von Dali im 10. Jahrhundert den Namen Tengchong für das Gebiet der Präfektur Ruanhua eingeführt und damit eine alte Bezeichnung wieder aufgenommen hat, die nun allerdings nicht mehr nur eine bestimmte Ansiedlung sondern auch die sie umgebende Verwaltungseinheit, die Präfektur Tengchong, benannte.

Parallel dazu hat sich auch die Schreibweise des Namens in den chinesischen Quellen verändert, indem die zweite Silbe des Namens nun mit einem anderen Schriftzeichen geschrieben wurde, das die besondere geographische Lage Tengchongs an einer wichtigen Verkehrsroute (chong, ,Knotenpunkt‘, ,Ebene mit Fluß`) deutlicher betonte.

Tu Shulian teilt jedoch nicht mit, ob diese Schreibweise im Königreich von Dali selbst oder von zeitgenössischen chinesischen Autoren in ihren Berichten über Dali geprägt worden ist. In jedem Fall wird diese neuere Schreibweise des Namens Tengchong in chinesischen Quellen seitdem einheitlich verwendet.

Die anfänglich wechselnde Schreibweise des Namens in den chinesischen Quellen läßt vermuten, daß es sich bei Tengchong um eine ältere einheimische Bezeichnung für die Stadt gehandelt hat, deren Lautgehalt von den chinesischen Autoren im Verlauf der Zeit mit verschiedenen Schriftzeichen wiedergegeben worden ist. Die Namensvariante Tengyue wird in den Tang-zeitlichen Quellen und für die Zeit des Königreiches von Dali nicht erwähnt, sie erscheint in chinesischen Quellen erst im 13. Jahrhundert zur Zeit der Mongolenherrschaft. ${ }^{110}$

\section{Die Einbindung des westlichen Yunnan in die Verwaltungsstrukturen des chine- sischen Reiches der Mongolen}

Mitte des 13. Jahrhunderts begannen die Mongolen unter Führung Kublais einen Feldzug in das Gebiet der modernen Provinz Yunnan, um das chinesische Reich der Südlichen Song-Dynastie auch von Südwesten her anzugreifen. Das in seiner Endphase in regionale Machtzentren zersplitterte Reich von Dali konnte den Mongolen keinen gemeinsamen Widerstand entgegensetzen, die schließlich mit der Eroberung der Region um den Erhai-

\footnotetext{
${ }^{110}$ Von den ebenfalls in dem Gebiet ansässigen Shan (chin. Dai) wurde die Stadt im 19. Jahrhundert ,Möng Myen` genannt; nach Davies war dies auch ihr ursprünglicher Name, da dieses Gebiet zunächst von Shan bewohnt gewesen sei (Davies, S. 45; Anderson, S. 190; Captain Hannay schreibt im Jahr 1836 ,Moung-yen or Tengyechow‘).

Im Birmanischen wurde der Name der Stadt zu ,Momien`. Diese Bezeichnung wurde im 19. Jahrhundert von den Briten als ,Momien` oder ,Momein‘ übernommen und zum Teil anstelle von ,Tengyue‘ verwendet. In den chinesischen Lokalhandbüchern aus dem 19. Jahrhundert wird dieser Name für die Stadt jedoch nicht erwähnt.
} 
See im Jahr 1253 die Herrschaft der Könige von Dali beendeten. Kublai zog sich bereits 1254 wieder aus Yunnan zurück und überließ es dem General Wulianghatai, den Südwesten zu konsolidieren.

Einige Volksgruppen Yunnans schlossen sich den Eroberern an, während andere Völker wie die Bai und die Yi ihren Widerstandskampf noch über ein Jahrzehnt lang fortsetzten. Im Jahr 1264 konnten diese schließlich von den Mongolen unterworfen werden, die nun ihre Vormachtstellung in Zentral-Yunnan (die Gebiete östlich des Lancangjiang und nördlich des Honghe) weiter festigen konnten. Um ihre Herrschaft über diese Gebiete dauerhaft behaupten zu können, begannen sie in Zentral-Yunnan ein militärisches Kontrollsystem aufzubauen, in das auch die einheimischen Völker Yunnans mit eingegliedert wurden.

Dieses militärische Kontrollsystem basierte, so der Historiker You Zhong in seiner Geschichte der Völker Yunnans, auf den militärischen Organisationsformen nach denen die Mongolen zur Zeit ihres Aufstiegs im Norden intern ihre Clans und Stämme organisiert hatten. Nachdem die Mongolen den Südwesten erobert hatten, „,verbanden sie diese Strukturen mit denen der einheimischen Bai und Yi, indem sie die Lehensfürsten und die Aristokraten der großen Stämme zu Brigade-Kommandanten (wanhu), die Adligen der kleineren Stämme und die Clan-Oberhäupter zu Anführern von Bataillonen und Kompanien (qianhu, baihu) ernannten““ ${ }^{111}$ In den Jahren von 1253 bis 1273 wurden insgesamt neunzehn solcher Brigaden (wanhu) in Yunnan gegründet. Die einheimischen Herrscher kontrollierten wie zuvor ihre angestammten Hoheitsgebiete, zumindest formal waren sie jedoch mongolischen Oberbefehlshabern ( $d u$ yuanshuai) unterstellt, die mit einem Truppenkontingent an strategisch wichtigen Orten Yunnans in Garnisonen stationiert wurden. ${ }^{112}$

Mit der Konsolidierung ihrer Position in Zentral-Yunnan haben die Mongolen ihren Einflußbereich weiter nach Westen ausgedehnt und die in der Region des Stromschluchtenfächers ansässigen Völker der Jinchi und Baiyi in ihr Kontrollsystem eingegliedert und deren Siedlungsgebieten den Status von sogenannten Befriedeten Gebieten (xuanwei si) zugewiesen. ${ }^{113}$ Bereits im Jahr 1261 sind in der Region

„Befriedete Gebiete wie Jinchi mit Brigade-, Bataillons- und anderen Stützpunkten (wanhu fu, qianhu suo deng) gegründet worden. ... [In einem anderen

\footnotetext{
${ }^{111}$ You Zhong, S. 269.

112 You Zhong, S. 269-270

${ }^{113}$ Der Name Jinchi, der ,goldene Zähne‘ bedeutet, nimmt Bezug auf die Sitte der einheimischen Bevölkerung, ihre Vorderzähne mit Gold zu überkronen. Entsprechend wurden sie von den Chinesen als ,Barbaren mit goldenen Zähnen` (jinchi man) bezeichnet. Baiyi (,hundert Barbaren`) ist die Bezeichnung für die in der Region ansässigen Tai-Völker.
} 
Handbuch heißt es], daß dort damals auch mongolische Soldaten (Menggu bing) stationiert worden sind. Außerdem wurden zehntausend Männer der Volksgruppen der Cuan und Bo, ebenso wie Männer aus neu eroberten Gebieten als Soldaten angeworben“. 114

Mit ihrer Militärpräsenz, dem Aufbau des Kontrollsystems und der Einbindung der einheimischen Hoheitsgebiete war es den Mongolen gelungen, das zuletzt in lokale Machtzentren zersplitterte Gebiet des vormaligen Königreichs von Dali unter ihrer Herrschaft zur Provinz Yunnan wieder zu vereinigen.

An der Spitze der Verwaltung Yunnans stand ein Mitglied des Kaiserhauses:

„Im 8. Monat des 4. Jahres der Ära Zhiyuan (1267) wurde Hugechi, der Sohn des Kaisers, zum Prinzen von Yunnan (Yunnan wang) ernannt““. ${ }^{115}$

Hugechi hatte den Oberbefehl über alle Verwaltungseinheiten der Provinz Yunnan, die in fünf Gebieten (diqu) zusammengefaßt wurden, denen wiederum die neunzehn Brigaden (wanhu) und andere Einheiten zugeordnet wurden. Diese fünf Gebiete waren:

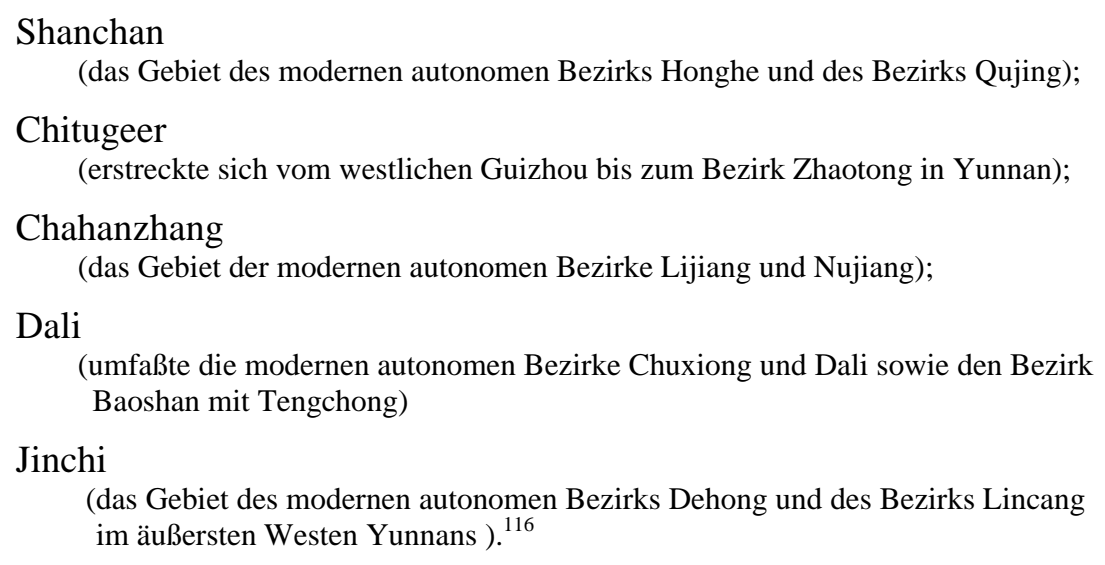

Bezeichnend für die weitere Entwicklung des westlichen Yunnan ist die Unterteilung der Region des Stromschluchtenfächers in zwei Gebiete (diqu): Dali, das sich von ZentralYunnan bis auf die Hochebene von Tengchong erstreckte, und Jinchi, dessen Territorium sich westlich bzw. südwestlich davon befand (siehe Karte 5, S. 48).

\footnotetext{
114 TYTZ, S. 175-176

${ }^{115}$ Dian-Yun linian chuan, juan 5; zitiert nach You Zhong, S. 269 und S. 284. Der Prinz von Yunnan wurde auch mit dem Titel eines Prinzen von Liang (Liang wang) bezeichnet. Mit dem Namen Liang wird eine alte chinesische Bezeichnung für den Südwesten wieder aufgenommen. Im Kapitel Yugong, des Shangshu wird die chinesische Welt in neun Bezirke (zhou) eingeteilt, deren südwestlichster Liangzhou ist. Die Herausgeber der fangzhi von Tengchong beginnen die Entwicklungsgeschichte der Stadt entsprechend mit dem Hinweis, daß das Gebiet von Tengchong während der Xia- und Shang-Dynastien Teil von Liangzhou gewesen sei (TYTZ, S. 63, 65).

${ }^{116}$ You Zhong, S. 274
} 


\section{Karte 5: Die Region des Stromschluchtenfächers im 13. Jahrhundert: Die Verwaltungseinheiten Dali und Jinchi}

(Quelle: Tan Qixiang, Yunnan xingsheng zhongbu, S. 25-26)

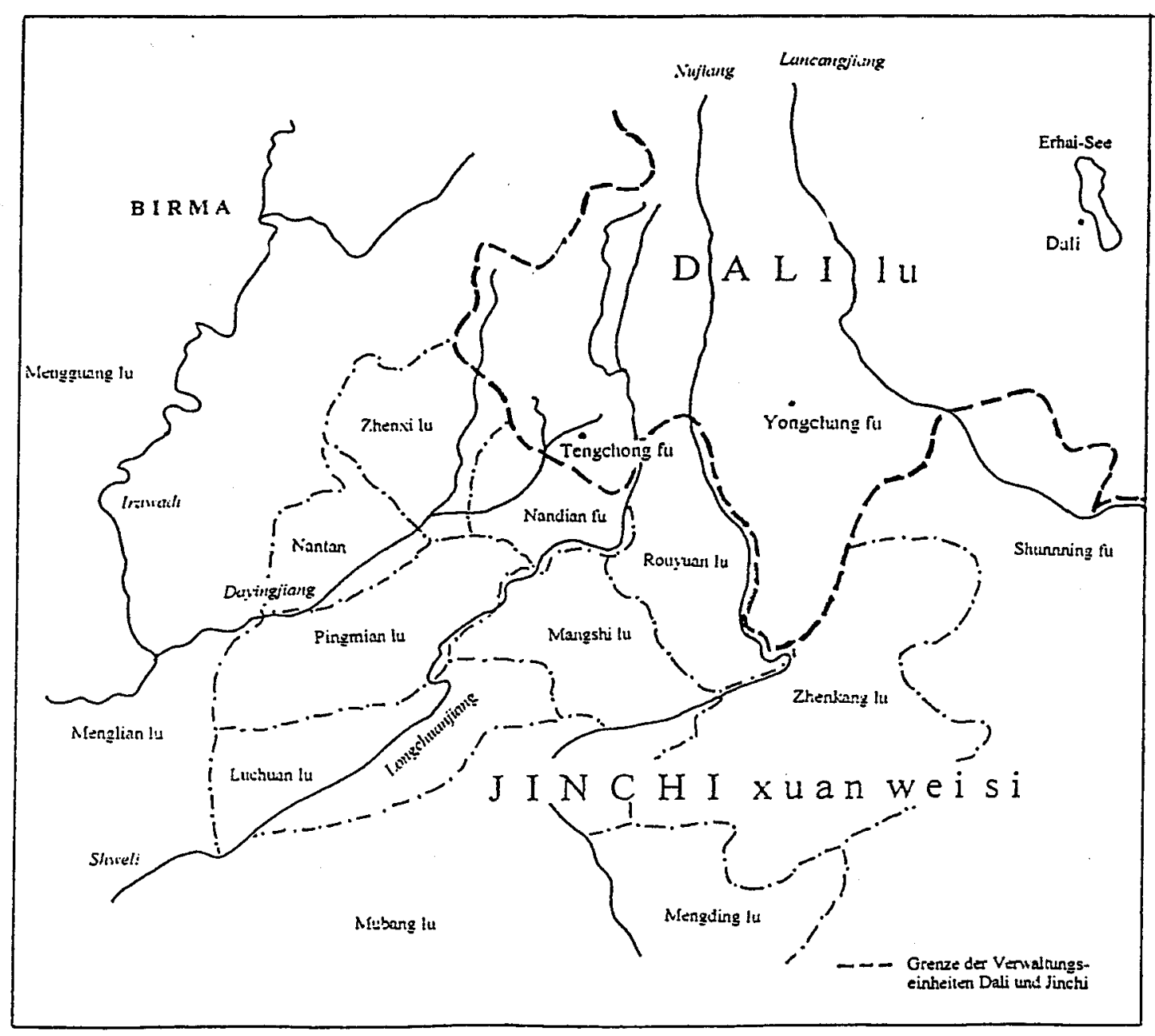

Als die Mongolen im Zuge der Konsolidierung ihres chinesischen Reiches zentrale Verwaltungsstrukturen auf den Südwesten ausdehnten und im Jahr 1271 die militärischen Kontrollorgane, die Brigaden usw., in reguläre Verwaltungseinheiten umwandelten, trat der unterschiedliche Charakter der beiden Verwaltungsgebiete deutlicher hervor. Dali wurde Regierungsbezirk (lu) und ein fester Bestandteil der zentralen Administration, der von regulären Staatsbeamten verwaltet wurde. Das Befriedete Gebiet (xuanweisi) Jinchi hingegen setzte sich aus Herrschaftsgebieten einheimischer Völker zusammen, in denen die Angehörigen der lokalen Oberschicht mit einem Sonderstatus als einheimische Beamte (tuguan) in das Verwaltungsystem des chinesischen Reiches der Mongolen mit einbezogen wurden. 
Auf die Reform der Verwaltungseinheiten im Jahr 1271 mit der Gründung von siebenunddreißig Regierungsbezirken $(l u)$ mit untergeordneten regulären Einheiten der Regionalverwaltung (fu, zhou, xian) folgte drei Jahre später die Reorganisation der obersten Provinzverwaltung. Parallel zum Sekretariat (zhongshu sheng) in der Hauptstadt Peking wurde im Jahr 1274 in Yunnan ein Provinzsekretariat (Yunnan xing zhongshu sheng) eingerichtet. Dessen Zuständigkeit sich auf sämtliche Armee- und Verwaltungsangelegenheiten in den Regierungsbezirken (lu) erstreckte; das Amt seinerseits war dem Sekretariat in der Hauptstadt verantwortlich. An die Spitze der Provinzverwaltung trat ein Gouverneur (pingzhang zhengshi).

Der erste Inhaber dieses Amtes war Sayyid Ajall Shams ad-Din (? - 1307; chin. Saidianchi Shansiding; von 1274 bis 1279 in Yunnan tätig), ein Moslem, dessen Vorfahren aus Buchara stammten. Gouverneur Sayyid Ajall organisierte die Gründung von Präfekturen und Kreisen sowie den Aufbau der Verwaltung und des Steuerwesen in der Provinz, er schuf ein System von Poststationen, propagierte fortschrittliche Ackerbaumethoden, ließ Bewässerungsprojekte durchführen, Konfuzius-Tempel und chinesische Schulen errichten. Mit seiner solchermaßen ,konfuzianisch` geprägten Politik legte er in seiner dreijährigen Amtszeit den Grundstein für eine Entwicklung, die langfristig zur Integration Yunnans in das chinesische Reich führen sollte. ${ }^{117}$

\section{Tengchong zur Zeit der Mongolenherrschaft}

Bis zur Mitte des 13. Jahrhunderts war die Präfektur Tengchong der südwestlichste Verwaltungsbezirk des Königreichs Dali und wurde über Generationen vom Oberhaupt einer dort ansässigen einflußreichen Familie beherrscht. Nach der Chronologie der fangzhi soll sich der Präfekt von Tengchong namens Gao Jiu bereits im Jahr 1253 den Mongolen unterworfen haben und von diesen in seiner ererbten Position als Präfekt bestätigt worden sein:

„Im 3. Jahr (1253) der Regierung Xianzongs [Möngke Khan] unterwarf sich Gao Jiu, lokaler Befehlshaber (tuqiu) von Tengyue. Da Angehörige der Familie Gao (Gao shi) dieses Amt in Teng seit Generationen inne hatten, wurden seine Nachfahren wie gehabt zum Präfekten (zhifu) von Tengchong befohlen, bis hin zu Gao Tai und Gao Hui““. 118

\footnotetext{
${ }^{117}$ You Zhong, S. 276; ZGRMDCD, S. 643; Wang Jianping, S. 71-72

118 TYZZ, S. 14. TYTZ, S. 63, 106: Gao Tai war zur Zeit Kaiser Shundis (1333-68) als Präfekt tätig; Gao Hui wird nach Gao Tai in der selben Position genannt (TYTZ, S. 106). Als Tu Shulian diesen Text Ende des 18. Jahrhunderts verfaßt hat, wurde die Verwaltungseinheit Tengyue genannt, entsprechend verwendet er hier diesen Namen und weist im Nachsatz ausdrücklich darauf hin, daß das Gebiet im 13. Jahrhundert als Präfektur Tengchong bezeichnet wurde.
} 
Während sich Präfekt Gao nach Angaben der fangzhi schon 1253 der neuen Militärmacht in der Region angeschlossen haben soll, hat sich sein Lehnsherr Duan Xingzhi, der letzte König von Dali, erst im Jahr 1255 den Mongolen unterworfen. Nach seinem Tod begab sich sein jüngerer Bruder Duan Xinjuri

„im Jahr 1261 an den mongolischen Hof, wo er ein Tigersymbol (hufu) überreicht bekam; diese Auszeichnung wurde auch in Tengyue und anderen Städten bekanntgegeben“. ${ }^{119}$

Zurück in Yunnan beteiligte sich Duan Xinjuri an den Kämpfen zur Befriedung der einheimischen Völker und wurde für seine Verdienste im Jahr 1274 von Gouverneur Sayyid Ajall zum Kommandeur (zongguan) von Dali ernannt. In dieser Position war Duan für die Verwaltung des gesamten Regierungsbezirkes Dali verantwortlich, außerdem hatte er den Oberbefehl über alle Militärstützpunkte (wanhu fu usw.) in diesem Gebiet. ${ }^{120}$

Dazu gehörte auch Tengchong, das zunächst den Status eines Bataillonsstützpunktes (qianhu suo) erhalten hatte, einem von dreizehn, die in der ,Oberen Brigade Dali‘ (Dali shang wanhu) zusammengefaßt waren. ${ }^{121}$ Im Rahmen der Konsolidierung der Provinzverwaltung, die mit der Umwandlung der Brigaden, Bataillone usw. in reguläre Verwaltungseinheiten (lu, fu, zhou, xian) einherging, entstand in Tengchong im Jahr 1274 eine Präfektur Tengyue (Tengyue zhou).

In diesem Zusammenhang wird in den chinesischen Quellen erstmalig die Bezeichnung Tengyue verwendet und zwar, wie Unterpräfekt Tu Shulian in seiner Ende des 18. Jahrhunderts für das TYZZ verfaßten Geschichte Tengyues erläutert, mit einer neuen Schreibung der ersten Silbe des Namens:

„Im 11. Jahr der Ära Zhiyuan (1274) wurde [das Gebiet] zur Präfektur Tengyue (Tengyue zhou) gemacht und außerdem ein Kreis (xian) Tengyue

\footnotetext{
${ }^{119}$ TYTZ, S. 184. Zur Verwendung des Namens Tengyue siehe oben.

${ }^{120}$ You Zhong, S. 266. Yuan shi, Xinjuri chuan; s. You Zhong, S. 269. Duan Xinjuri sollte Dali insgesamt 23 Jahre lang verwalten. Seine Nachfahren hatten während der gesamten Yuan-Zeit das vererbbare Amt eines Kommandeurs des Regierungsbezirks (zongguan) von Dali inne (You Zhong, S. 266 - 267; ZGRMDCD, S. 452).

Im Yuan shi (Xinjuri chuan) wird in diesem Zusammenhang auch Tengyue als Teil des Verwaltungsgebietes von Dali erwähnt und ausdrücklich als Stadt (cheng) bezeichnet.

${ }^{121}$ You Zhong, S. 270. In Dali waren bereits im Zuge der Errichtung militärischer Kontrollorgane zwei Brigaden (wanhu) gegründet worden: Zur ,Oberen Brigade Dali‘ (Dali shang wanhu) gehörten dreizehn Bataillone (qianhu), darunter ein Bataillon im Gebiet des modernen Tengchong (Tengchong qianhu) und zwei Bataillone im Gebiet des modernen Baoshan (Yongchang er qianhu); die ,Untere Brigade Dali‘ (Dali xia wanhu) umfaßte vier Bataillone (qianhu), die in der Region um den Erhai-See und in Yaoan stationiert waren.

Im YCFZ wird die Einrichtung der Bataillonsstützpunkte (qianhu suo) erst auf das Jahr 7 der Ära Zhiyuan (1270) datiert (YCFZ, S. 50).
} 
gegründet. Dabei wurde [die Silbe] teng (,dahineilen') nun als teng (,Flechtrohr') geschrieben.

Im 14. Jahr (1277) wurde eine Sonder-Präfektur Tengchong (Tengchong fu) gegründet, außerdem wurden die Präfektur Shunjiang (Shunjiang zhou) sowie die drei Kreise Tengyue, Yuedian und Guyong geschaffen“. ${ }^{122}$

Abweichend von diesen Ausführungen Tu Shulians wird im einhundert Jahre später zusammengestellten TYTZ die Gründung der Präfektur Shunjiang und der beiden Kreise Yuedian und Guyong bereits auf das Jahr 1274 datiert. Außerdem wird dort ausdrücklich darauf hingewiesen, daß die Sonder-Präfektur Tengchong im Jahr 1277 ,zusätzlich ge-

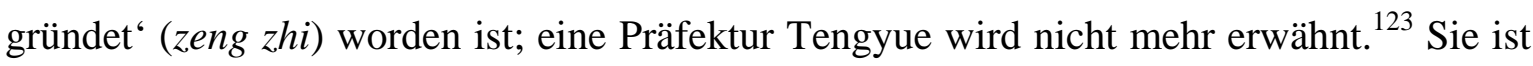
in der Sonder-Präfektur aufgegangen; spätestens im Jahr 1288, als und darin sind sich die Verfasser der beiden Lokalhandbücher einig, die genannten Präfekturen und Kreise wieder abgeschafft wurden und lediglich die Sonder-Präfektur Tengchong wie zuvor weiterbestand. $^{124}$

Bei ihrer Gründung im Jahr 1274 war die Sonder-Präfektur Tengchong dem Regierungsbezirk $(l u)$ Dali unterstellt worden. ${ }^{125}$ Damit hatte sich die Position Tengchongs in der Hierarchie der Verwaltungseinheiten in der Region zunächst nicht verändert. Zur Zeit des Königreichs von Dali hatte die Präfektur Tengchong, verwaltet von einem Präfekten aus der Familie Gao, den Königen aus der Dynastie der Duan unterstanden. Mit der Ernennung Duan Xinjuris zum Kommandeur des Regierungsbezirks Dali im Jahr 1274, dessen Posten ebenso wie der des Präfekten von Tengchong an die Nachfahren vererbt werden konnte, blieben diese lokalen Herrschaftsverhältnisse auch unter den neuen Machthabern zunächst bestehen.

\footnotetext{
122 TYZZ, S. 14. Der Name des 1277 gegründeten Kreises Tengyue wird von Tu Shulian bereits wieder mit dem Schriftzeichen teng (,dahineilen') geschrieben. Die Schreibweise des Schriftzeichens yong im Namen Guyong unterscheidet sich in den beiden fangzhi von Tengyue. Tu Shulian verwendet das Schriftzeichen yong (,tapfer`) (TYZZ, S. 14); ebenso auch bei Tan Qixian, auf seiner Karte Yunnans in der Yuan-Zeit. Im TYTZ (S. 63, 65, 66) wird das gleichlautende yong (,lang andauernd') verwendet, das auch heute zur Schreibung des Ortsnamens gebräuchlich ist. Zur Bedeutung des Status einer Sonder-Präfektur siehe unten S. 52.

${ }^{123}$ TYTZ, S. 63- 64, 65. In der Tabelle zur Entwicklungsgeschichte Tengyues im TYZZ heißt es, allerdings ohne Jahresangaben, daß die Sonder-Präfektur ( $f u$ ) Tengchong einen Kreis Tengyue verwaltete und die Präfektur (zhou) Tengyue einen Kreis Tengyue, die beiden letzteren mit dem Schriftzeichen teng in der Bedeutung ,Flechtrohr` geschrieben (TYZZ, S. 21). Im YCFZ (S. 52) wird die weitere Entwicklung der Verwaltungseinheit Tengyue nach dem Jahr 1274 folgendermaßen zusammengefaßt: „Im 14. Jahr der Ära Zhiyuan (1277) wurde die Präfektur (zhou) Tengyue in einen Kreis (xian) Tengyue umgewandelt (gai), danach wurde sie in eine Sonder-Präfektur ( $f u$ ) umgewandelt und dann in ein Amt des Befriedeten Gebietes (zhaotaoshi si)“.

${ }^{124}$ TYZZ, S. 14; TYTZ, S. 64, 65

${ }^{125}$ Der Regierungsbezirk Dali $(l u)$ umfaßte neben der Tengchong noch eine weitere Sonder-Präfektur ( $f u$ ), sowie ein Amt (si), einen Kreis (xian) und fünf Präfekturen (zhou) (TYTZ, S. 66).
} 
Administrative Veränderungen wie die Gründung von Kreisen innerhalb der Präfektur und die Umwandlung in eine Sonder-Präfektur weisen aber bereits auf eine zunehmende Einflußnahme der zentralen Provinzregierung auf die Verwaltung des Gebietes hin. Sie förderten die engere Anbindung Tengchongs an die Strukturen Zentral-Yunnans, im Unterschied zu den Gebieten unter einheimischer Verwaltung im weiter südwestlich gelegenen Verwaltungsgebiet Jinchi.

Bereits zur Zeit des Königreichs Dali grenzte die Präfektur Tengchong im Osten an die gleichrangige Präfektur Yongchang (Yongchang $f u$ ). Nachdem die mongolischen Truppen in die Region des Stromschluchtenfächers vorgedrungen waren, hatten sie dort zunächst zwei Bataillone (qianhu) gegründet, die ebenfalls der ,Oberen Brigade‘ (shang wanhu) von Dali unterstellt worden sind. Im Jahr 1274 wurden diese in eine Präfektur Yongchang (Yongchang zhou) umgewandelt und deren Verwaltungssitz (im modernen Baoshan) mit einer Stadtmauer umgeben. Im Jahr 1278 wurde Yongchang zu einer Sonder-Präfektur ( $f u$ ) ernannt und ebenso wie die ein Jahr zuvor gegründete Sonder-Präfektur Tengchong dem Regierungsbezirk Dali unterstellt. ${ }^{126}$

Eine Sonder-Präfektur (fu) unterschied sich von den regulären Präfekturen (zhou) durch ihre strategisch wichtige Lage, sei es in der Umgebung der Hauptstadt oder in einer Grenzregion. Die Umwandlung der Präfektur Tengyue in eine Sonder-Präfektur Tengchong stand in direktem Zusammenhang mit der Situation im Grenzgebiet zu Birma in der Zeit um das Jahr 1277. ${ }^{127}$ Das Vordringen einer birmanischen Armee in das Gebiet der Präfektur Tengyue hatte die Mongolen 1277 zur Entsendung von Truppen veranlaßt, um ihre Vorherrschaft über die Region zu behaupten. Unter der Führung Duan Xinjuris und anderer Generäle konnten ihre Soldaten die Birmanen zunächst zurückdrängen. Anschliessend führten sie im Gebiet von Tengchong einen Feldzug gegen die Völker der Puman, Achang und Jinchi, die sich bisher nicht unterworfen hatten. ${ }^{128}$ Im selben Jahr rückte eine birmanische Armee erneut bis nach Tengchong vor, die aber wiederum von den Truppen Duan Xinjuris zurückgedrängt werden konnte. ${ }^{129}$

\footnotetext{
${ }^{126}$ YCFZ, S. 50. Während der Yuan-Zeit waren verschiedene Oberbefehlshaber (du yuanshuai), darunter ein Mongole und zwei Angehörige des einheimischen Volkes der Bo, ein Vize-Präfekt eines Befriedeten Gebietes (xuanweisi tongzhi), die Kommandeure (zongguan) von Dali Duan Shi (Duan Xinjuri) und sein Sohn Duan Zhong, sowie Präfekten (tongzhi) aus den Provinzen Henan, Sichuan oder Shaanxi mit der Verwaltung von Yongchang befaßt (alle ohne Jahresangaben; siehe YCFZ, S. 171).

${ }^{127}$ YCFZ, S. 50, 54. Zu den Kämpfen mit Birma siehe auch Maung Htin Aung, S. 67-75.

${ }^{128}$ TYTZ, S. 189; YCFZ, S. 130. In anderen Quellen werden die Angriffe der birmanischen Truppen bereits auf das Jahr Zhiyuan 13 (1276) datiert (TYTZ, S. 184; siehe auch ZGRMDCD, S. 452).

${ }^{129}$ TYTZ, S. 189; YCFZ, S. 130
} 
In den folgenden Jahren gingen die Kämpfe um die Vorherrschaft in der Region des Stromschluchtenfächers zwischen birmanischen und mongolischen Truppen weiter. Im Winter 1283/84 eroberte eine Armee aus Yunnan die birmanischen Stützpunkte in Nasaungkhyam, Kaungzin und Tagaung am Irawadi, im Mai wurden sie von den Birmanen wieder zurückgedrängt. Als die Mongolen im Winter 1287/88 einem weiteren Vorstoß nach Süden unternahmen, floh König Narathihapate aus seiner Hauptstadt Pagan. Damit galt Birma den Mongolen als befriedet. Wegen des für sie ungewohnten heißen Klimas zogen sich die mongolischen Truppen jedoch wenig später wieder aus Birma zurück, ohne dort Garnisonsstützpunkte gegründet zu haben. ${ }^{130}$

Nach dem Rückzug aus Birma begannen die Mongolen ihren direkten Einflußbereich in der Region des Stromschluchtenfächers von den Herrschaftsgebieten der einheimischen Völker abzugrenzen. Im Gebiet von Jinchi wurden Truppen in Garnisonen stationiert. ${ }^{131}$ Militäreinsätze, der Abschluß von Bündnisverträgen und die Stärkung der Verwaltung dienten dazu, ihre Position im Gebiet der Sonder-Präfektur Tengchong zu konsolidieren.

Zur Befriedung des Gebietes westlich des Gaoligongshan schlossen die Mongolen ein Bündnis mit dem Volk der Daboyi. ${ }^{132}$ Dieser Friedensschluß wurde während der Ära Zhizheng (1341-1368) mit dem Bau eines buddhistischen Tempels in Tengchong, dem Ximeng si (,Tempel des westlichen Bündnisses`), bekräftigt und trug zur Sicherung der Sonder-Präfektur Tengchong als westlichster Verwaltungseinheit Chinas bei. ${ }^{133}$

In Tengchong hatten die Mongolen bereits während der Invasion nach Birma im 13. Jahrhundert eine neue Behörde gegründet:

Das ,Amt Tengchong für die Feldzüge zur Befriedung Birmas‘ (Tengchong zheng Mian zhaotaoshi si), dem ein Direktor vorstand. ${ }^{134}$

\footnotetext{
130 TYTZ, S. 189, 184; YCFZ, S. 130-131

${ }^{131}$ Nach dem Feldzug gegen Birma und erneut zu Beginn des 14. Jahrhunderts waren es hauptsächlich Truppenteile mit moslemischen Soldaten, die in Militärstützpunkten in Jinchi stationiert wurden (siehe unten Kap. IV. B. 1., S. 313ff).

${ }^{132}$ Daboyi war die chinesische Bezeichnung für eine westlich von Longchuan ansässige Volksgruppe (siehe TYTZ, S. 247-248).

${ }^{133}$ TYTZ, S. 160, 295

134 TYTZ, S. 64, 106; TYZZ, S. 14. Jahresangaben zur Gründung des Amtes oder der Amtszeit des als Direktor (zhaotaoshi) tätigen Qiu Fuqing werden in den fangzhi nicht gemacht, auch der Aufgabenbereich des Amtes wird nicht erläutert. Es handelte sich hierbei vermutlich um eine Art Koordinationsstelle, die die Verbindung zwischen den Truppen in Birma und der Provinzverwaltung in Zentral-Yunnan aufrechterhielt (siehe auch Hucker 304).
} 
Die Eingliederung Tengchongs in die zentralen Verwaltungsstrukturen des chinesischen Reiches der Mongolen wurde nun durch die Entsendung von Beamten, die als Präfekten tätig waren, weiter gefestigt. In der Liste der Beamten des TYTZ werden neben den Präfekten aus der Familie Gao noch zwei weitere Amtsträger genannt: Meng Guang, der ebenso wie Gao Tai, während der Regierungszeit Shundis, des letzten Kaisers der YuanDynastie (1333-1368), als Präfekt von Tengchong tätig war und Yang Liyi aus Kunming. ${ }^{135}$ In seiner Kurzbiographie im TYTZ erscheint Yang Liyi als ein vorbildlicher von konfuzianischen Idealen geprägter Staatsdiener, der für seine ausdauernde Arbeit als verdienstvoller Beamter (xunli) ausgezeichnet und zudem als pietätvoller Sohn geehrt wurde. ${ }^{136}$ Diese Darstellung hebt die Tatsache hervor, daß ein Beamter der regulären Zivilverwaltung in Tengchong tätig war und die Präfektur nun nicht mehr nur von einheimischen Amtsträgern in einer vererbbaren Machtposition verwaltet wurde. Diese Veränderung wird besonders in der Liste der Beamten des YCFZ deutlich, wo lediglich Meng Guang und Yang Liyi aufgelistet sind, während die Präfekten aus der Familie Gao gar nicht mehr genannt worden sind. ${ }^{137}$

Tengchong hat seinen offiziellen Status als Präfektur bzw. Sonder-Präfektur im Regierungsbezirk Dali im Verlauf der Yuan-Zeit zwar beibehalten, innerhalb der Verwaltungseinheit haben jedoch entscheidende Veränderungen stattgefunden, mit denen sich Tengchong von einem Gebiet unter der Oberhoheit einheimischer Machthaber zu einer von Zivilbeamten verwalteten regulären Einheit des chinesischen Reiches zu entwickeln begann.

Eine Beschreibung der Siedlung Tengchong bzw. Tengyue in der Yuan-Zeit gibt es in den chinesischen Quellen ebenso wenig wie Informationen über deren Bevölkerung. Nach den Baiman zur Zeit des Reiches von Dali wird nunmehr lediglich allgemein auf die in diesem Gebiet ansässigen Völker der Puman, Achang, Jinchi und Daboyi hingewiesen. Siedler aus der chinesischen Kernregion, wie sie in Yongchang schon aus der Han-Zeit bekannt sind, sind in den Quellen aus Tengchong noch nicht dokumentiert. So scheinen die Ende des 13. Jahrhunderts entsandten Beamten und Soldaten die ersten Repräsentanten eines chinesischen Reiches in Tengchong gewesen zu sein.

\footnotetext{
135 TYTZ, S. 106. Der Heimatort Meng Guangs ist nicht vermerkt. Jahresangaben zur Amtszeit Yang Liyis werden im TYTZ nicht gemacht. In der Auflistung der Beamten der Yuan-Zeit ist er nach Gao Tai, Meng Guang und Gao Hui der letzte der dort Genannten (ebd.).

${ }^{136}$ TYTZ, S. 144

${ }^{137}$ YCFZ, S. 181
} 


\section{Zusammenfassung}

Die militärische Expansion unter Kaiser Han Wudi hatte dem chinesischen Reich im Südwesten neue Gebiete erschlossen, die teilweise direkt, teilweise nur nominell der chinesischen Verwaltung unterstellt worden waren. Deren Hoheitsgebiet wurde im 1. Jahrhundert n. Chr. nach Westen hin erweitert, wo mit der Gründung des Regierungsbezirks Yongchang im Gebiet des modernen Baoshan erstmalig ein Grenzgebiet ,eröffnet‘ wurde, in dem sich ein chinesisches Reich von den Gebieten weiter im Westen abzugrenzen begann. In Yongchang hatten sich bereits Zuwanderer aus dem chinesischen Kernland angesiedelt, von denen einige regional Einfluß gewannen und zu Verwaltungsbeamten des Han-Reiches ernannt wurden, wie die Familie Lü in Buwei/Yongchang, deren Angehörige als erste Repräsentanten eines chinesischen Reiches in der Region des Stromschluchtenfächers gelten können. Auch Beamte aus anderen Landesteilen wurden bis in das 3. Jahrhundert dorthin entsandt, die über die Verkehrsverbindungen zum Gebiet um den Erhai-See den Kontakt zwischen Yongchang und dem chinesischen Kernland aufrechterhielten. Im Westen jenseits des Gaoligong-Gebirges war die Hochebene von Tengchong hingegen allenfalls nominell Teil des Regierungsbezirkes geworden. Chinesische Siedler aus dieser Zeit sind in Tengchong nicht bekannt; Beamte wurden nicht ernannt. Die Einteilung der Gebiete im Westen von Yongchang in zwei Kreise spiegelt so eher Chinas neu gewonnene Kenntnisse über deren Geographie und Bevölkerung wieder, als daß damit eine tatsächliche Anbindung an das Kernland hergestellt worden wäre.

Mit dem Zerfall des Han-Reiches und schließlich dem Niedergang des Reiches von ShuHan riß die Verbindung zwischen dem fernen Südwesten und den Verwaltungseinheiten der chinesischen Kernregion wieder ab.

Während der Tang-Zeit im 7. Jahrhundert sind die Gebiete im Stromschluchtenfächer dem chinesischen Reich zwar als jimi-Bezirke noch einmal formal assoziiert worden, eine direkte Einflußnahme Chinas auf die von einheimischen Völkern beherrschte Region war damit jedoch nicht verbunden.

Mit der Entstehung des Königreiches von Nanzhao im 8. Jahrhundert setzte ein Prozeß der Zentralisierung ein, in dessen Verlauf das Gebiet der modernen Provinz Yunnan erstmals unter einer einheimischen Herrscherdynastie geeint wurde. Von ihrem Zentrum am ErhaiSee aus hatten die Könige von Nanzhao ihr Reich auf den Stromschluchtenfächer 
ausgedehnt und über die Stadt Tengchong (die erstmalig in zeitgenössischen chinesischen Quellen erwähnt wird) hinaus weiter bis nach Oberbirma expandiert.

Unter dem im 10. Jahrhundert gegründeten Königreich von Dali wurde der Prozeß der Anbindung Tengchongs an das politische Zentrum des Reiches am Erhai-See mit der Gründung einer neuen Verwaltungseinheit fortgesetzt: Die Präfektur Tengchong erstreckte sich vom Gaoligong-Gebirge bis zum Oberlauf des Irawadi und bildete dort die westliche Grenze des Reiches von Dali.

Nachdem die Mongolen im 13. Jahrhundert das Königreich von Dali erobert hatten, gliederten sie dessen Territorium als Provinz Yunnan in die zentrale Verwaltung ihres chinesischen Reiches ein. Die neuen Herrscher profitierten von den unter der Herrschaft von Nanzhao und Dali geschaffenen administrativen Strukturen. So übernahmen sie auch die Verwaltungseinheit Präfektur Tengchong, die nach Beendigung des Feldzuges gegen Birma neu ausgestaltet wurde. Tengchong blieb als Teil des Regierungsbezirkes Dali mit dem Gebiet um den Erhai-See verbunden und hatte sich bis zum 14. Jahrhundert zu einer regulären Einheit der Zivilverwaltung entwickelt. Auf der Hochebene von Tengchong hatte das chinesische Reich seitdem seine politische Vorherrschaft dauerhaft etablieren können. Im Südwesten der Hochebene hingegen war ein Grenzgebiet ,eröffnet‘ worden, in dem die Siedlungsgebiete der einheimische Völker zwar der chinesischen Zentralverwaltung nominell angegliedert wurden, sie ansonsten aber unter der Herrschaft ihrer einheimischen Oberhäupter weiterbestanden. In diesem Grenzgebiet sollten sich einheimische Völker, China und Birma über Jahrhunderte die Vorherrschaft streitig machen und ihre Einflußsphären immer wieder neu voneinander abgrenzen. 


\section{KAPITEL III}

\section{DIE KONSOLIDIERUNG DES GRENZGEBIETES:}

DIE ENTWICKLUNG TENGCHONGS IN DER MING-ZEIT (1368-1644)

\section{A. Die Entwicklung Tengchongs bis zur Mitte des 16. Jahrhunderts}

\section{Das westliche Yunnan zu Beginn der Ming-Zeit}

Mitte des 14. Jahrhunderts wurden die Mongolen von den Truppen der neu gegründeten chinesischen Ming-Dynastie aus Zentralchina verdrängt. Lediglich die Provinz Yunnan blieb ihnen noch als letztes Rückzugsgebiet im Territorium ihres ehemaligen chinesischen Reiches. Dort residierte weiterhin ein mongolischer Regent, Basalawarmi, der Prinz von Liang.

Für Zhu Yuanzhang, den ersten Kaiser der neuen Ming-Dynastie (Regierungsdevise Hongwu, 1368-1399) war es daher notwendig, die Situation im fernen Südwesten besonders zu berücksichtigen, wollte er seine Herrschaft über ganz China dauerhaft festigen. Solange in Yunnan noch feste Strukturen des Yuan-Reiches weiterbestanden, mußte er damit rechnen, daß sich dort Widerstand gegen die Ming formieren und im Zusammenschluß mit den im Norden des Reiches ansässigen Mongolen eine ernsthafte Bedrohung für seine neue Dynastie darstellen könnte.

Vorrangig mit der Sicherung der Nordgrenzen befaßt, versuchte der Hongwu-Kaiser den Prinzen von Liang zunächst auf diplomatischem Wege zum Anschluß an das Ming-Reich zu bewegen. ${ }^{138}$ Das Scheitern der insgesamt fünf diplomatischen Missionen in den Jahren 1370 bis 1375 führte schließlich dazu, daß er 1382 die Invasion Yunnans befahl. Eine entscheidende Schlacht wurde in Qujing (160 km östlich von Kunming) geschlagen, die mit der Niederlage der mongolischen Truppen und dem Selbstmord Basalawarmis endete.

Die Ming-Armee rückte unter Führung der Generäle Mu Ying und Lan Yu weiter nach Westen vor und eroberte Kunming und Dali. ${ }^{139}$ Entlang der Hauptverkehrsroute von Zentral-Yunnan und auf den Spuren der von den Mongolen etablierten Strukturen drangen die Ming-Truppen bei der Eroberung der Provinz geradewegs bis in die Region des Stromschluchtenfächers vor, wo ihr Vorstoß, so wie letztlich schon der ihrer mongolischen

\footnotetext{
${ }^{138}$ You Zhong, S. 336-340

${ }^{139}$ Mu Ying (1345-1392) war ein Adoptivsohn des ersten Ming-Kaisers Zhu Yuanzhang. Nach der Eroberung Yunnans 1382 wurde er zum obersten Militärkommandeur der Provinz ernannt und erhielt das Privileg, dieses Amt an seine Nachkommen zu vererben. Die Familie Mu konnte ihre im Ming-Reich einzigartige Vormachtstellung in dieser Provinz bis über das Ende der Dynastie hinaus weiter behaupten (siehe DMB, S. 1079-83).
} 
Vorgänger, zum Stehen kam. Dort wurde auf der Hochebene von Yongchang, dem modernen Baoshan, die Garnison Jinchi (Jinchi wei) gegründet und ein Kontingent Soldaten in dem neuen Militärstützpunkt stationiert. ${ }^{140}$

Nach Angaben des TYTZ wurde auch Tengchong im Westen des Gaoligong-Gebirges bereits im Jahr 1382 (Hongwu 15) von Truppen der Ming ,befriedet“ und das Gebiet sogleich direkt der Kontrolle der Provinzbehörde (buzheng si) unterstellt. ${ }^{141}$

Die Provinzbehörde war eine der sogenannten drei Behörden (san si), den obersten Verwaltungsorganen einer Provinz. Seit 1376 hatten die Ming in der Nachfolge der Provinzsekretariate (xing zhongshu sheng) der Yuan-Dynastie in den Provinzen Chinas jeweils drei Behörden gegründet: Die Provinzbehörde (chengxuan buzhengshi si), die Regionale Militärkommission (du zhihuishi si) und das Provinzkontrollamt (tixing ancha shi si). In Yunnan sind die Provinzbehörde und die regionale Militärkommission im Jahr 1382 geschaffen worden, das Provinzkontrollamt hingegen erst im Jahr 1398. ${ }^{142}$

Ebenso wie die Verfasser des TYTZ in ihrem Bericht über den Beginn der Mongolenherrschaft hervorgehoben haben, daß sich der Präfekt von Tengchong sogleich der neuen Militärmacht in der Region angeschlossen hatte, legten sie auch bei der Darstellung der Anfänge der Herrschaft der Ming über die Region Wert darauf, zu betonen, daß die Hochebene von Tengchong mit zu den ersten Gebieten gehörte, die schon im Jahr 1382 den neuen Provinzverwaltungsbehörden unterstellt wurden und betonen so die Zugehörigkeit der Region zum chinesischen Reich und die Anbindung an die Verwaltungsstrukturen des Kernlandes.

Offiziell als ,befriedet‘ galt die Provinz Yunnan den Ming seit dem Jahr 1384, aber auch nach diesem Zeitpunkt wurden noch verschiedene Feldzüge geführt, um die Oberhoheit über weitere Siedlungsgebiete einheimischer Völker zu erlangen, wie zum Beispiel die großangelegte Militäraktion in das Gebiet von Dongchuan nordöstlich von Kunming im Jahr 1386. Weitere Vorstöße der Ming-Truppen nach Südwesten in Gebiete jenseits von Jinchi wurden nicht geführt.

\footnotetext{
${ }^{140}$ YCFZ, S. 50; You Zhong, S. 340

${ }^{141}$ TYTZ, S. 189, 64

${ }^{142}$ Hucker, 4912; You Zhong, S. 347
} 


\section{1. Die Entwicklung der chinesischen Verwaltungseinheiten in der Region des} Stromschluchtenfächers bis zur Mitte des 15. Jahrhunderts

Nach der Befriedung der Provinz Yunnan begann die Ming-Regierung im Zuge der Gründung der drei Behörden auch andere Strukturen der Zentralverwaltung auf den fernen Südwesten auszudehnen. Um diese den örtlichen Gegebenheiten anzupassen, wurden im Gebiet der Provinz zwei Zonen unterschieden, in denen verschiedenartige Verwaltungseinheiten geschaffen wurden. Die innere Zone nördlich einer Linie, die von Yongchang im Westen bis nach Yuanjiang südwestlich von Kunming verlief, wurde hauptsächlich in Präfekturen, Unterpräfekturen und Kreise unterteilt, in denen auch einheimische Beamte (tuguan) als lokale Präfekten, Unterpräfekten (tu zhifu, tu zhizhou) usw. amtierten. ${ }^{143}$ In Zentral-Yunnan waren zu Beginn der Ming-Zeit zunächst zwanzig solcher Präfekturen geschaffen worden. ${ }^{144}$

In den abgelegeneren Gebieten südlich der Linie Yongchang - Yuanjiang wurden hingegen sogenannte Befriedete Gebiete (xuanweisi, xuanfusi, usw) gegründet, in denen die Oberhäupter der einheimischen Bevölkerung als tusi mit der Verleihung von Amtstiteln der chinesischen Verwaltungshierarchie angegliedert und sozusagen von den Ming in ihrer angestammten Position bestätigt wurden.

In der Region des Stromschluchtenfächers war als erste Einheit der Zivilverwaltung des neuen Ming-Reiches im Jahr 1382 die Präfektur (fu) Yongchang, die bereits unter der vorangegangenen Yuan-Dynastie bestanden hatte, neu gegründet worden. Für deren Verwaltung wurden ein Präfekt (zhifu) sowie ein assistierender Präfekt (tongpan) und ein Richter (tuiguan) ernannt. ${ }^{145}$

Im selben Jahr war bereits die Garnison (wei) Jinchi geschaffen worden. Jinchi, der Name der ,Barbaren mit goldenen Zähnen‘, war schon während der Yuan-Zeit als Bezeichnung für eine Verwaltungseinheit in der Region verwendet worden, nämlich für die Gebiete unter einheimischer Herrschaft im Süden von Yongchang, jenseits des Regierungsbezirks Dali. Er wurde nun zur Benennung des neuen weiter nördlich im Gebiet der Präfektur

\footnotetext{
${ }^{143}$ Im Gebiet um Yuanjiang am gleichnamigen Fluß, dem Oberlaufes des Honghe (Roter-Fluß) gründeten die Ming 1382 eine Präfektur, deren Hoheitsgebiet sich im Südwesten von Kunming im Dreieck der modernen Bezirke Yuxi, Simao und dem autonomen Bezirk Honghe der Yi- und Hani-Nationalitäten befand.

${ }^{144}$ An diese angrenzend wurden drei weitere Präfekturen im Gebiet der modernen Provinz Sichuan gegründet. Unter diesen insgesamt dreiundzwanzig Präfekturen gab es sechs, in denen reguläre Beamte (liuguan) als Präfekten tätig waren. In drei Präfekturen amtierten ein regulärer Beamter als Präfekt und ein einheimischer Beamter (tuguan) als Vize-Präfekt. In vierzehn Präfekturen waren ausschließlich einheimische Beamte (tuguan) als Präfekten tätig (Ming shi, dili zhi, zitiert nach Yunnan keai de difang, S. 608).

${ }^{145}$ YCFZ, S. 50
} 
Yongchang gelegenen Garnisonsstüzpunktes wieder aufgenommen. ${ }^{146}$ Die Garnison Jinchi war Teil der zentralen Militärverwaltung der Provinz, die von der Regionalen Militärkommission (du zhihuishi si/ dusi), einer der drei Behörden (san si), kontrolliert wurde. Der Garnison unterstanden zwei Bataillone (qianhu), Yongchang qianhu und Jinchi qianhu, deren Truppen beide im Gebiet des modernen Baoshan stationiert waren.

Die Regionalen Militärkommissionen (RMK) waren entsprechend ihrer geographischen Lage einer der fünf Zentralen Militärkommissionen ( wu jun dudu fu) in der Hauptstadt Nanjing unterstellt. Yunnan wurde von der Rechten Zentralen Militärkommission verwaltet, die für den Westen, den Südwesten und den Süden des Ming-Reiches zuständig war. ${ }^{147}$ Die RMK kontrollierten sämtliche Militäreinheiten in ihren Provinzen, die mit dem Sammelbegriff weisuo bezeichnet wurden.

Mit wei bzw. wei zhihuishi si wurden die wichtigeren Garnisonsstützpunkte oberhalb der Präfektursebene bezeichnet, mit suo bzw. qianhu suo die nächst kleineren, die Bataillonsstützpunkte in den Präfekturen. ${ }^{148}$ Sie alle waren an strategisch wichtigen Orten errichtete befestigte Militärposten, in denen die regulären Soldaten (zhengjun / qijun) mit ihren Familien dauerhaft stationiert waren. Die Anzahl der Soldaten in einer Garnison (wei) sollte fünftausendsechshundert Mann betragen, die in fünf Bataillone (qianhu) mit je eintausendeinhundertundzwanzig Mann eingeteilt waren, von denen jedes wiederum aus je zehn Kompanien (baihu) mit je einhundertundzwölf Soldaten bestand, die ihrerseits in kleinere Truppenverbände aufgeteilt wurden (siehe Tab. 2, S. 61). ${ }^{149}$ Allen Truppeneinheiten stand jeweils ein Kommandant (zhihuishi, qianhu, baihu) vor.

\footnotetext{
${ }^{146}$ Liew Foon Ming, Treatises, Bd. 2, S. 92, 222. Jinchi: Diese ,goldenen Zähne‘, die zum Teil noch mit Rubinen oder Jadestücken verziert werden, kann man auch heute noch in den Shan-Staaten des modernen Birma sehen, zum Beispiel bei Angehörigen der Völker der Palaung, Taungyo oder Riang (siehe Diran, S. 72, 80, 90).

${ }^{147}$ Liew Foon Ming, Treatises, Bd. 1, S. 45. Die Linke Zentrale Militärkommission (ZMK) war für den Nordosten des Ming-Reiches zuständig, für die Provinzen Zhejiang, Liaodong und Shandong. Die Mittlere ZMK verwaltete die Region um die Hauptstadt Nanjing, die Provinz Henan; die Zuständigkeit der Vorderen ZMK erstreckte sich auf den Südosten des Ming-Reiches, auf Huguang, Fujian, Jiangxi und Guangdong. Die Hintere ZMK war für das Gebiet um Peking, für Shanxi, Shaanxi und die nördlichen Grenzgebiete zuständig (ebd.).

${ }^{148}$ Liew Foon Ming, Treatises, Bd. 1, S. 10-11. Im Jahr 1393 (Hongwu 26) unterstanden der RMK von Yunnan insgesamt fünfzehn Garnisonen (wei) und ein Bataillonsstützpunkt (qianhu suo) (ebd., S. 368).

(Yunnan keai de difang [S. 610]: Nachdem die Ming im Jahr 1381 mit einer 300.000 Mann starken Armee in Yunnan eingerückt waren, hatten sie dort zunächst zwanzig Garnisonen (wei sowie drei $y u$ ) und achtzehn Bataillonsstützpunkte (suo) mit insgesamt 133 Bataillonen (qianhu suo) gegründet. Das würde eine Truppenstärke von 112.000 Soldaten in den zwanzig Garnisonen und 148.000 Soldaten in den Bataillonen bedeuten; zusammen 260.000 Mann [Die Quelle dieser Textstelle wird nicht genannt, vermutlich handelt es sich um ein Zitat aus dem Ming shi].)

${ }^{149}$ Liew Foon Ming, Treatises, Bd. 1, S. 69-70, 231-233
} 
Tabelle 2: Reguläre Truppenstärke in den Militärstützpunkten ${ }^{150}$

$\begin{array}{lr}1 \text { Garnison (wei) } & 5600 \text { Soldaten } \\ 1 \text { Bataillon (qianhu) } & 1120 \text { Soldaten } \\ 1 \text { Kompanie (baihu) } & 112 \text { Soldaten } \\ 1 \text { Staffel (zhengqi) } & 56 \text { Soldaten } \\ 1 \text { Abteilung (xiaoqi) } & 11-12 \text { Soldaten }\end{array}$

Die tatsächliche Truppenstärke war jedoch häufig geringer, da Soldaten bei Fronteinsätzen getötet wurden oder aufgrund der schwierigen Lebensbedingungen desertierten. ${ }^{151}$ Denn die Truppen waren schlecht bezahlt. Die Soldaten mußten zusätzlich zu ihren militärischen Aufgaben noch Bauarbeiten leisten, nicht nur beim Aufbau ihrer Stützpunkte, sondern z.B. auch bei der Errichtung von Stadtmauern. In jedem Stützpunkt waren die Soldaten in zwei Einheiten organisiert, von denen die eine für die Verteidigung, die andere für die Feldarbeit zu ihrer aller Versorgung zuständig war. In der Theorie betrug das Verhältnis der beiden Teile dreißig zu siebzig Prozent. Gerade in abgelegenen Gebieten sah die Praxis dieses tuntian genannten Systems häufig so aus, daß die Soldaten dort fast ausschließlich mit der Produktion von Nahrungsmitteln beschäftigt waren, um überhaupt ihren Lebensunterhalt bestreiten zu können. Machten schlechte Bodenverhältnisse, Mißernten und eine hohe Abgabenlast bzw. umfangreiche Frondienste dies unmöglich, so blieb den Soldaten oft keine andere Wahl, als ihren Posten zu verlassen. Besonders in den von Tai-Völkern beherrschten Gebieten im Südwesten der neugegründeten Verwaltungseinheiten der Ming in Yunnan wurden desertierte chinesische Soldaten wohlwollend aufgenommen, da sie überlegene militärische Kenntnisse, wie zum Beispiel zur Herstellung von Feuerwaffen, mitbrachten.

Neben den Garnisonen, den Bataillons- und den ihnen untergeordneten Stützpunkten gab es in den Provinzen noch drei weitere Einheiten der regionalen Militärverwaltung:

a) Die lokalen Militärkommandanturen (junmin zhihuishi si und junmin qianhu suo);

b) die Unabhängigen Bataillonsstützpunkte (shouyu qianhu suo) und die Unabhängigen Kompaniestützpunkte (shouyu baihu suo);

c) die tusi-Gebiete.

\footnotetext{
${ }^{150}$ Liew Foon Ming, Treatises, Bd. 1, S. 70; siehe auch S. 231-232. Eine andere Bezeichnung für die Staffeln (zengqi) lautet zongqi.

${ }^{151}$ Zur Anzahl der Soldaten bzw. der Militärkolonisten in Tengchong/ Tengyue siehe unten die Darstellung der Entwicklung der Bevölkerung in Tengchong (B. 3. 1., S. 95ff).
} 
a) Die lokalen Militärkommandanturen (junmin zhihuishi si und junmin qianhu suo):

Die mit dem Präfix junmin benannten Einheiten wurden in Grenzregionen, aber auch in Gebieten im Inland gegründet, die hauptsächlich von nicht Han-chinesischen Volksgruppen besiedelt waren. Junmin-Einheiten wurden dort gegründet, wo es nicht möglich war, Präfekturen oder Unterpräfekturen der regulären Zivilverwaltung (fu, zhou) aufrecht zu erhalten oder diese, zum Beispiel nach Aufständen der einheimischen Bevölkerung, wieder abgeschafft wurden. Diese Gebiete wurden dann einem Militärkommandanten unterstellt, dessen Autorität sich sowohl auf die Militär- (jun) als auch auf die Zivilbevölkerung (min) erstreckte. $^{152}$

Im Jahr 1390 wurde in der Region des Stromschluchtenfächers die acht Jahre zuvor gegründete Präfektur Yongchang wieder abgeschafft und zusammen mit der Garnison Jinchi in die lokale Militärkommandantur Jinchi (Jinchi junmin zhihuishi si) umgewandelt, die fünf Bataillonsstützpunkte (qianhu suo) kontrollierte. ${ }^{153}$ Im Jahr darauf wurde der Bataillonsstützpunkt Yongping im Osten Yongchangs, der 1386 gegründet worden war, zu einer Garnison (wei) aufgewertet, der wie bisher zwei Bataillone (qianhu) zugeordnet waren.

Ein solches Bataillon wurde jedoch nicht nur für die regulären Soldaten der Ming-Armee gegründet, auch Einheiten der einheimischen Bevölkerung konnten in Bataillone eingeteilt werden:

„Im 32. Jahr der Ära Hongwu (1399) wurde für diejenigen der [einheimischen] $\mathrm{Pu}$ und Bo aus den befestigten Bergdörfern, die nicht in den Bevölkerungsregistern erfasst waren, das Bataillon Yongchang gegründet (zhaoji shanzhai Pu Bo zhu wu hujizhe she Yongchang qianhu)“. ${ }^{154}$

b) Die Unabhängigen Bataillonsstützpunkte (shouyu qianhu suo) und die Unabhängigen Kompaniestützpunkte (shouyu baihu suo):

Charakteristisch für diese unabhängigen Einheiten war, daß sie von der regulären Militärhierarchie ausgenommen waren. Sie unterstanden im allgemeinen keiner Garnison sondern direkt der RMK und wurden mit eigenen geographischen Namen bezeichnet. Zum Teil waren sie jedoch nicht gänzlich unabhängig, sondern einer nahegelegenen Garnison zu-

\footnotetext{
${ }^{152}$ Liew Foon Ming, Treatises, Bd. 1, S. 72-73

${ }^{153}$ YCFZ, S. 51

${ }^{154}$ YCFZ, S. 51
} 
bzw. untergeordnet (li), wobei sie jedoch ihren eigenen Namen beibehielten. ${ }^{155}$ Ein solcher Unabhängiger Bataillonsstützpunkt (shouyu qianhu suo) wurde im Jahr 1403 in Tengchong gegründet, dieser blieb der lokalen Militärkommandantur Jinchi zugeordnet (shu Jinchi junmin si). ${ }^{156}$ Im selben Jahr wurde auch das Unabhängige Bataillon der Präfektur Yongchang (Yongchang fu shouyu qianhu) gegründet und ebenfalls der lokalen Militärkommandantur Jinchi unterstellt. ${ }^{157}$

c) Die tusi-Gebiete:

Die Herrschaftsgebiete der verschiedenen einheimischen Völker im Süden und in den Grenzgebieten des chinesischen Reiches wurden von den Ming ihrer Zentralverwaltung und der Militärorganisation im Rahmen des tusi-Systems assoziiert. ${ }^{158}$ Im Südwesten der Provinz Yunnan erstreckten sich diese Gebiete bis in das moderne Birma, Laos und Thailand. Die lokalen Oberhäupter fungierten für die Ming quasi als deren Statthalter vor Ort, regierten ihre Herrschaftsgebiete jedoch weiterhin autonom. Sie waren zum Teil zu Steuerleistungen verpflichtet, sandten in der Regel alle drei Jahre Tribut an den Kaiserhof. Die Herrscher kommandierten ihre eigenen Truppen. Diese sollten den Ming gegebenenfalls als sogenannte einheimische Soldaten (tubing / tujun) zur Verfügung stehen und von ihnen für Feldzüge mobilisiert werden können. ${ }^{159}$

In der Hauptstadt Nanjing waren für die Verwaltung dieser Gebiete das Büro für die Verleihung offizieller Titel des Personalministeriums (libu yanfeng qinglisi) oder das Büro für die Ernennung des Militärpersonals des Kriegsministeriums (bingbu wuxuan qinglisi) zuständig. Entsprechend waren diese tusi-Gebiete entweder Teil der Militärverwaltung und somit nahegelegenen Garnisonen, Bataillonsstützpunkten bzw. direkt der RMK unterstellt oder sie waren der Zivilverwaltung zugeordnet und den Präfekturen bzw. direkt der Provinzbehörde untergeordnet. ${ }^{160}$

\footnotetext{
${ }^{155}$ Liew Foon Ming, Treatises, Bd. 1, S. 71

${ }^{156}$ TYTZ, S. 64; Liew Foon Ming, Treatises, Bd. 2, S. 94, 99. Die Gründung des Unabhängigen Bataillons Tengchong wird in den verschiedenen fangzhi unterschiedlich datiert. TYTZ, S. 65: Hongwu 32 (1399). TYZZ, S. 14: „Im 33. Jahr der Ära Hongwu (1400) wurde das Tengchong shouyu qianhusuo gegründet und dem Jinchi si unterstellt, man sagt auch, daß das shouyusuo im 9. Jahr der Ära Yongle [Yongle jiu nian, möglicherweise ein Schreibfehler für Yongle yuan nian (1403)] eingerichtet worden sei“. Nach den Angaben des YCFZ (S. 51) ist das Unabhängige Bataillon Tengchong ebenfalls im 33. Jahr der Ära Hongwu (1400) gegründet worden.

${ }^{157}$ Liew Foon Ming, Treatises, Bd. 2, S. 223

${ }^{158} \mathrm{Zu}$ den tusi-Gebieten in der Region des Stromschluchtenfächers siehe unten B. 4., S. 106ff.

${ }^{159}$ Liew Foon Ming, Treatises, Bd. 1, S. 47

${ }^{160}$ Liew Foon Ming, Treatises, Bd. 1, S. 66
} 


\section{2. Die Eingliederung der Gebiete im Südwesten Jinchis in das Verwaltungssystem des Ming-Reiches}

Der Vorstoß der Ming-Truppen nach Yunnan hatte viele der einheimischen Machthaber veranlaßt, sich zunächst der neuen mit überlegenen Feuerwaffen ausgerüsteten Militärmacht in der Region zu unterwerfen:

„Im 16. Jahr (1383) erkannten Luchuan, Miandian und andere tusi die Vorherrschaft [der Ming] an“. ${ }^{161}$

Auch Si Lunfa, Oberhaupt der Mao-Shan im Südwesten der neuen chinesischen Garnison Jinchi, unterwarf sich nach einer verlorenen Schlacht den Ming-Truppen. ${ }^{162}$ Indem Si Lunfa daraufhin die Vorherrschaft der Ming anerkannte, konnte er die fremden Truppen aus seinem Herrschaftsbereich heraushalten und die eigene Machtposition behaupten.

Da die Ming in dieser Zeit vorrangig mit der Sicherung ihrer Herrschaft in ZentralYunnan, in den Gebieten um die beiden großen Seen Dianchi und Erhai, beschäftigt waren, konnte Si seine Position im Grenzgebiet ungestört weiter ausbauen, zumal er so aus der Sicht der Ming für eine ruhige Grenze im Südwesten von Jinchi sorgte. Vom chinesischen Kaiserhof wurde er denn auch zum Oberhaupt des Befriedeten Gebietes (xuanwei shi) von Pingmian ernannt und, nachdem er 1384 Tribut an den Hof gesandt hatte, zum Oberhaupt des Befriedeten Gebietes (junmin xuanwei shi) von Luchuan und Pingmian befördert. ${ }^{163}$ Sein Herrschaftsgebiet erstreckte sich über das moderne Grenzgebiet zwischen Yunnan und Birma, vom oberen Irawadi bis zum oberen Salween. Si Lunfas Vorherrschaft über die Region wurde 1397 vorläufig beendet, als er von seinem vormaligen Untergebenen Dao Ganmeng vertrieben wurde, der anschließend mit seinen Truppen bis nach Tengchong vordringen und den dortigen Stützpunkt der Ming erobern konnte. ${ }^{164}$ Daraufhin erhielt Si Lunfa von den Ming Unterstützung zur Rückgewinnung seines Herrschaftsgebietes: Auf

\footnotetext{
${ }^{161}$ TYTZ, S. 64

${ }^{162}$ Mao-Shan, auch Maw-Shan genannt: „Von dem Namen der Shan für den Fluß Shweli, ,Nam Mao“ (nam = Wasser) haben seine Anwohner die Bezeichnung ,Mao Shan“ erhalten“ (Sherman, S. 42). Maw-Shan ist die birmanische Bezeichnung für diese Tai-Völker. Die zeitgenössische chinesische Bezeichnung für das Siedlungsgebiet der Mao-Shan am Fluß Shweli im Gebiet des modernen Ruili lautete Luchuan.

${ }^{163}$ Pingmian (,Befriedung Birmas`) befand sich im Gebiet des modernen Kreises Longchuan. Die chinesische Bezeichnung des Gebietes war ebenso wie Luchuan bereits während der Yuan-Dynastie eingeführt worden. Der Name Pingmian war entstanden, als die mongolischen Truppen dieses Gebiet auf ihrem Feldzug nach Birma durchquerten (YCFZ, S. 51).

${ }^{164}$ Nach Angaben von Liew (The Luchuan-Pingmian campaigns, S.166) war der Auslöser für die Rebellion Dao Ganmengs die Tatsache, daß Si Lunfa dem buddhistischen Mönch, der ihn bekehrt hatte, eine höhere Stellung gab, als den anderen Anführern. Im Ming shilu (Band 1, S. 162) wird die hohe Stellung, die Si Lunfa geflohenen chinesischen Soldaten gegeben hatte, da diese die Mao-Shan mit der Herstellung von Feuerwaffen vertraut gemacht hatten, als Grund für Daos Unzufriedenheit genannt.
} 
kaiserlichen Befehl unternahm der Oberkommandierende der Truppen von Yunnan, Mu Chun, 1397 einen Feldzug gegen Dao Ganmeng; daraufhin konnte Si im folgenden Jahr wieder in sein Reich zurückkehren. ${ }^{165}$

Mit ein Grund für den Einsatz der Ming-Truppen zur Unterstützung Si Lunfas war das Bestreben, den Stützpunktes Tengchong zurückzugewinnen. Entsprechend verstärkten die Ming nach ihrem siegreichen Feldzug ihre Position in der Region mit der Gründung des Unabhängigen Bataillons (shouyu qianhu) Tengchong. Um das Jahr 1400 kontrollierte die lokale Militärkommandantur Jinchi damit insgesamt vierzehn Bataillone (qianhu), die in Yongchang, Tengchong und Yongping untergebracht waren. ${ }^{166}$ Bei einer Soll-Stärke von 1.120 Mann pro Bataillon wären somit 15.680 Soldaten der regulären Armee im Gebiet der Militärkommandantur Jinchi stationiert gewesen. ${ }^{167}$

Ihre starke Militärpräsenz im Südwesten Yunnans ermöglichte den Ming auch eine Neuorganisation der tusi-Gebiete in der Region. So mußte der Si-Clan in den folgenden Jahren eine Verkleinerung seines Herrschaftsgebietes hinnehmen, das auf die beiden Regierungsbezirke (lu) Luchuan und Pingmian reduziert wurde, und zwar in dem Umfang, den diese zur Zeit der vorhergehenden Yuan-Dynastie gehabt hatten (siehe Karte 5, S. 48).

Außerdem wurden die Herrschaftsgebiete der einheimischen Machthaber in der Region von den Ming neu geordnet und ihre Oberhäupter erhielten neue Amtstitel verliehen. Es entstanden die drei Präfekturen (fu) Mengyang (im Norden des modernen Birma), Mubang (Hsenwi, in den nördlichen Shan-Staaten Birmas) und Mengding (im Gebiet des heutigen Gengma), die der Provinz unterstellt wurden, sowie die vier Befriedeten Gebiete (zhangguan si) Lujiang (westlich des modernen Baoshan, auf dem Lujiang Hochplateu), Ganya (heute Yingjiang), Dahou (heute Yunxian) und Wandian (im Süden des modernen Kreises Changning), die der Garnison (wei) Jinchi unterstanden. ${ }^{168}$

\footnotetext{
${ }^{165}$ Liew, The Luchuan-Pingmian campaigns, S. 166. Mu Chun (1363-1398) war der älteste Sohn von General Mu Ying. Er hatte 1392 das Amt und den Adelstitel seines Vaters übernommen. Mu Chun starb während des Feldzuges gegen Dao Ganmeng. Sein Bruder Mu Sheng (1368-1439) übernahm den Titel und sein Amt in Yunnan (siehe DMB, S. 1081).

${ }^{166}$ YCFZ, S. 51

${ }^{167}$ Die Zahl von 15.000 in der Region des Stromschluchtenfächers stationierten Ming-Soldaten wird in den Quellen erneut für die Zeit Mitte des 15. Jahrhunderts genannt (siehe unten 5. 2., S. 72).

${ }^{168}$ Siehe auch Karte 18, S. 471. ,Meng‘ ist die chinesische Wiedergabe des Shan-Wortes muin, der Bezeichnung für eine politische Einheit, ein ,Herrschaftsgebiet‘ oder ein ,Land‘, das von einem Oberhaupt regiert wird. In westlichen Publikationen wird muin in phonetischer Transkription meist als möng (Scott/Hardiman), muang (Anderson) oder mong (Mangrai) wiedergegeben (s. a. Hill, S. 65). Die Shan im Grenzgebiet zwischen China und Birma bezeichnen ihre Staaten als muin, u.a. Muin Mit (chin. Mengmi) oder Muin Mav (chin. Mengmao), entsprechend werden auch andere Staaten benannt, so z. B. China und Birma als Muin Ke und Muin Man (siehe Cushing, Handbook, 1888, S. 125; Dictionary, 1914, S. 510-512). Im Ming shi (juan 350, liechuan, S.9) wird noch auf eine andere zeitgenössische Bezeichnung für den Kleinstaat Mubang, nämlich Mengbang, hingewiesen (s. a. YCFZ, S. 329). Mubang und Mengyang wurden im 2. Jahr der Ära Yongle (1404) als höherrangige Befriedete Gebiete (xuanwei si) eingestuft (You Zhong, S. 345). „Im Februar 1403, (Yongle 1) ... wurden fünf neue Befriedete Gebiete (zhangguan si), nämlich Zheledian, Dahou, Ganya, Wandian und Lujiang gegründet und direkt der Regionalen Militärkommission Yunnan unterstellt“ (Liew, S. 167).
} 
Mit der Unterteilung der Region in mehrere kleinere autonome Herrschaftsgebiete sollte eine Machtbalance geschaffen und die Oberhoheit der Ming über diese Gebiete gestärkt werden. Diese Politik brachte aber auch eine weitere Zersplitterung der Region mit sich und führte zu neuen Machtkämpfen der einheimischen Herrscher untereinander, die aus der Sicht der Ming häufig ein erneutes Eingreifen zur Sicherung ihrer Position im Südwesten des Reiches erforderten.

\section{Tengchong zu Beginn des 15. Jahrhunderts}

Im Jahr 1430 (Xuande 5) wurde der Unabhängige Bataillonsstützpunkt (shouyu qianhu suo) Tengchong auf Betreiben des Vize-Kommandanten (fu qianhu) des örtlichen Bataillons, Zhang Ming, in eine Unterpräfektur (zhou bzw. tuzhou) umgewandelt. Zhang Ming hatte in einer Throneingabe auf die besondere Lage an der äußersten Grenze sowie auf die Gefahr der von den Mao-Shan in Luchuan ausgehenden Vorstöße in die Region hingewiesen. Seinem Gesuch wurde stattgegeben, er selbst wurde daraufhin zum Unterpräfekten (zhizhou) ernannt. ${ }^{169}$ Die Unterpräfektur war zunächst noch der Lokalen Militärkommandantur (junmin zhihuishi si) Jinchi zugeordnet, wurde dann aber direkt der Provinzbehörde (buzheng si) unterstellt.

Bereits im Jahr darauf wurde wieder ein Unabhängiges Bataillon geschaffen und der Regionalen Militärkommission von Yunnan (Yunnan du zhihuishi si/dusi) unterstellt. ${ }^{170} \mathrm{Im}$ Jahr 1438 (Zhengtong 3) wurde Tengchong dann erneut der lokalen Militärkommandantur Jinchi untergeordnet. ${ }^{171}$

Die häufigen Statuswechsel Tengchongs zu Beginn des 15. Jahrhunderts spiegeln das Engagement der Ming im äußersten Westen Yunnans wider. ${ }^{172}$ Sie machen das Bestreben der neuen Herrscher deutlich, in der Region geordnete Verwaltungsstrukturen zu etablieren, wobei die noch unsichere Lage im Grenzgebiet Flexibilität und Anpassung an die örtlichen Gegebenheiten erforderte und folglich verschiedene Organisationsmodelle erprobt wurden.

\footnotetext{
${ }^{169}$ TYZZ, S. 14, 77

170 TYTZ, S. 64; Liew Foon Ming, Treatises, Bd. 2, S. 77

${ }^{171}$ TYTZ, S. 64

${ }^{172}$ Im YCFZ werden die Statuswechsel Tengchongs folgendermaßen zusammengefaßt: „Im 5. Jahr der Ära Xuande wurde die Unterpräfektur (zhou) Tengchong eingerichtet, die in einen Kreis (xian) umgewandelt und dann zur Präfektur (fu) aufgewertet wurde, [anschließend] wurde die Präfektur wieder heruntergestuft und ein Amt (si, d.h. junmin zhihuishi si) gegründet“ (YCFZ, S. 52).
} 


\section{Tabelle 3: Die Entwicklung der Verwaltungseinheiten in der Region des Strom-} schluchtenfächers in der ersten Hälfte des 15. Jahrhunderts

1382 Gründung der Provinzbehörde und der Regionalen Militärkommission in Yunnan.

Gründung der Garnison Jinchi in der Präfektur Yongchang.

Tengchong der Provinzbehörde unterstellt.

1383 Gründung der beiden Bataillone Yongchang und Jinchi in der Garnison Jinchi.

1386 Gründung von fünf Bataillonen in der Garnison Yongchang und zwei Bataillonen in Yongping.

1390 Die Präfektur Yongchang wird abgeschafft.

Die Garnison Jinchi wird in die lokale Militärkommandantur umgewandelt, in der fünf Bataillone der Ming-Truppen stationiert sind.

1391 Gründung der Garnison Yongping, dieser unterstehen zwei Bataillone.

1399 Gründung des Bataillons Yongchang der Pu und Bo.

1403 Gründung des Unabhängigen Bataillons Tengchong, das der lokalen Militärkommandantur Yongchang unterstellt wird.

Gründung eines Unabhängigen Bataillons der Präfektur Yongchang, das der lokalen Militärkommandantur Yongchang unterstellt wird.

1430 Die lokale Unterpräfektur Tengchong wird gegründet und zunächst der Kommandantur Jinchi, dann der Provinzbehörde unterstellt.

1431 Das Unabhängige Bataillon Tengchong wird direkt der Regionalen Militärkommission Yunnan unterstellt.

1438 Das Unabhängige Bataillon Tengchong wird wieder der Kommandantur Jinchi unterstellt.

1445 Das Unabhängige Bataillon wird zur lokalen Militärkommandantur Tengchong aufgewertet, es kontrolliert fünf Bataillone und untersteht direkt der Regionalen Militärkommission Yunnan. 


\section{Die Feldzüge gegen Luchuan - Pingmian}

Im Westen hatte im Jahr 1413 Si Renfa ${ }^{173}$, ein Sohn von Si Lunfa, die Macht in LuchuanPingmian übernommen und damit begonnen, sein Territorium zu vergrößern. Seine Truppen rückten via Nandian und Tengchong bis über den Salween vor und bedrohten im Jahr 1436 Yongchang. Der chinesische Kaiser lehnte einen Feldzug gegen Si zunächst ab, da er den finanziellen Aufwand für nicht gerechtfertigt hielt. ${ }^{174}$

Nachdem der Bataillonsstützpunkt Tengchong 1438 und 1439 mehrfach von Si Renfas Truppen überrannt und geplündert worden war, änderte er jedoch seine Meinung. In einem ersten Feldzug im Jahr 1439 gelang es den Ming-Truppen, Si Renfa wieder nach Südwesten zurückzudrängen. Um jedoch die chinesische Vormachtstellung auch im Grenzgebiet zu behaupten, waren noch drei weitere Feldzüge notwendig, die sich über einen Zeitraum von zehn Jahren hinziehen sollten. Erst im Jahr 1449 wurden die Kampfhandlungen mit dem Abschluß eines Friedensvertrages beendet. ${ }^{175}$

\section{Die lokale Militärkommandantur Tengchong}

Während der Feldzüge zur Unterwerfung Luchuans in den Jahren 1441 bis 1449 diente Tengchong den Truppen der Ming aufgrund der strategisch günstigen Lage am westlichen Ausläufer des schwer zu passierenden Gaoligong-Gebirges als Sammelplatz und bot ihnen als Ausgangsbasis für weitere Vorstöße die Möglichkeit, auf verschiedenen Routen nach Südwesten vorzudringen. Entsprechend der Bedeutung, die der Bataillonsstützpunkt Tengchong zur Zeit der Feldzüge erlangte, wurde er im 3. Monat des 10. Jahres der Ära Zhengtong (1445) zur lokalen Militärkommandantur Tengchong (Tengchong junmin zhihui shisi) aufgewertet. Diese kontrollierte fünf Bataillone (qianhu) und war direkt der Regionalen Militärkommission (RMK, dusi) von Yunnan unterstellt. ${ }^{176}$

Nach den Feldzügen gegen Luchuan richtete die RMK in Zentral-Yunnan im Gebiet von Chuxiong und Jingdong zahlreiche neue Brigadestützpunkte ein. Die dort stationierten Soldaten sollten für Schutz vor Rebellen sorgen und wurden zudem zur Erschließung von Militärkolonien herangezogen, die nun in großem Umfang in der Region gegründet wurden, um zukünftige Einsätze von Truppen weiter im Südwesten vorzubereiten und um

\footnotetext{
${ }^{173}$ Birm.: Thonganbwa (Schreibweise in westlichen Quellen des 19. Jahrhunderts auch : Chau-Ngan-Pha)

${ }^{174}$ Yingzong, Regierungsdevise Zhengtong, 1436-50. Siehe auch Cambridge History of China, Ming-Zeit, S. 315; DMB, S. 1209.

${ }^{175}$ Eine ausführliche Darstellung der Feldzüge der Ming gegen Si Renfa gibt Liew Foon Ming in der Studie ,The Luchuan-Pingmian campaigns (1436-1449) in the light of official chinese historiography“ (1996).

${ }^{176}$ Anders als das Unabhängige Bataillon Tengchong, daß während der Ära Hongwu und der Ära Yongle bestanden hatte und noch der lokalen Militärkommandantur Jinchi untergeordnet war.
} 
die Versorgung der Soldaten zu gewährleisten. Auch im Bataillonsstützpunkt Tengchong wurden Militärkolonien (tuntian) gegründet, in denen

„drei Zehntel der Soldaten aus den fünf Bataillonen für militärische Aufgaben eingeteilt waren, während sieben Zehntel Ackerbau betrieben. Jeder [von ihnen] erhielt $30 \mathrm{mu}$ Land zugewiesen (ren shou tian san shi mu)““. ${ }^{177}$

Die Soldaten erhielten Saatgetreide (zhonggu), das ihnen aus dem Speicher der Militärkolonie (tuncang) zugeteilt wurde, sowie eine monatliche Ration Getreide zu ihrer Versorgung, mit der die Zeit überbrückt werden sollte, bis die neu erschlossenen Felder ausreichende Erträge einbringen würden.

Die Gründung der Militärkommandantur und die Organisation der Militärkolonien stärkte die Position der Ming auf der Hochebene im Westen des Gaoligong-Gebirges und zog umfangreiche Baumaßnahmen zur Befestigung ihres Stützpunktes Tengchong nach sich.

\section{Die bauliche Entwicklung Tengchongs}

\section{1. Bauwerke aus der Zeit vor der Errichtung der Stadtmauer}

Bei den ältesten in den fangzhi verzeichneten Bauwerken handelt es sich um Tempel im Gebiet der Hochebene von Tengchong, deren Gründung auf die Zeit des Königreichs von Nanzhao (7. bis 10. Jahrhundert) zurückgehen soll. Drei dieser Tempel waren buddhistische Tempel:

\footnotetext{
177 TYZZ, S. 63. Die Flächenmaßeinheit $m u$ bezeichnete je nach Zeit und Ort unterschiedlich große Flächen. Dreißig $m u$ waren eine durchschnittliche Fläche, die tuntian-Soldaten in der Ming-Zeit zugeteilt bekamen (Liew, Tuntian farming, S. 148).

Liew geht für die Ming-Zeit von einer Standardgröße von etwa $400 \mathrm{~m}^{2}$ („two tennis courts“) für ein mu aus (ebd., S. 101). Mit $30 \mathrm{mu}$ hätte demnach jeder Soldat in Tengchong $12 \mathrm{~km}^{2}$ Land zugeteilt bekommen. Eine solche Fläche zu bearbeiten wäre für den Einzelnen unmöglich. Die tatsächliche Größe der Maßeinheit mu in Yunnan war sicherlich deutlich geringer.

Im Jahr 1388 waren in Yunnan insgesamt 65.303 Soldaten der regulären Streitkräfte (guanbing) stationiert. Diese bewirtschafteten schätzungsweise $435.636 \mathrm{mu}$ Ackerland in den Militärkolonien [bei 70\% Ackerbau treibenden Soldaten entspräche das ca. 9,5 mu pro Soldat], deren Ertrag von ca. 336.000 dan Getreide dem Jahresbedarf von 100.000 Soldaten entsprach. Bis zum Jahr 1392 war die Fläche der Militärkolonien auf über eine Millionen mu angewachsen, im Jahr 1510 wurden 1,27 Millionen $m u$ von den Soldatenhaushalten der Militärkolonien bewirtschaftet (Yunnan keai de difang, S. 611). Um das Jahr 1600 seien, so James Lee, noch weitere 2 Millionen mu erschlossen worden; im Jahr 1605 habe die bewirtschaftete Fläche bereits 10 Millionen $m u$ betragen (Lee, S. 714, 715).
} 
- Der Jinlun Tempel befand sich cirka drei Kilometer westlich der Stadt, er wurde auch Dafosi (,Tempel des großen Buddha‘) genannt und galt in den älteren fangzhi als der vortrefflichste unter den Tempeln Tengchongs. ${ }^{178}$

- Der Baofeng Tempel befindet sich auf dem etwa fünf Kilometer westlich der Stadt gelegenen Berg Baofeng. ${ }^{179}$ Seine Gründung wird einem indischen Mönch namens Majiatuo zugeschrieben. Majiatuo (in den fangzhi auch Mojiatuo oder Majietuo genannt) ist eine chinesische Bezeichnung für Indien bzw. für das Reich von Maghada. Der Name kann sicherlich auch als Hinweis auf die Her-kunft des Mönches verstanden werden. Der Baofeng Tempel könnte damit in der Tradition der Verbreitung des Buddhismus in Yunnan durch Mönche aus Indien stehen, die im Königreich von Nanzhao zu hohem Ansehen gelangt waren und besonders eine Schule des esoterischen Buddhismus (chin. Mizong, ,Geheimschule‘) verbreitet hatten. ${ }^{180}$

- Der Huzhu Tempel (auch Gan’e Tempel genannt) cirka sieben Kilometer nordwestlich der Stadt gelegen. ${ }^{181}$

Zwei weitere in den fangzhi nicht näher bezeichnete Tempel aus dieser Zeit sind der Zhongxiao Tempel etwa fünfzehn Kilometer südlich der modernen Stadt Tengchong gelegen,dessen Gründung dem Mönch Zhaochun aus dem Meng-Clan der Könige von Nanzhao zugeschrieben wird sowie der Laifeng(shan)shen ci im Süden der Stadt.

Zur Zeit des Königreichs von Dali (10. bis 13. Jh) war die Präfektur Tengchong gegründet worden. Wie oben erwähnt, bestand diese zunächst unter der folgenden Yuan-Dynastie weiter; auch der Präfekt Gao Jiu konnte sein Amt weiterhin ausüben. Diese Angaben lassen vermuten, daß in Tengyue zu jener Zeit auch entsprechende Gebäude, wie z.B. eine Residenz des Präfekten und seiner Angehörigen, vorhanden waren. Informationen zu der Existenz und Gestalt der frühen Siedlung bzw. zu weiteren Bauwerken gibt es in den fangzhi jedoch nicht.

\footnotetext{
${ }^{178}$ TYZZ, S. 58; TYTZ, S. 78. Zur Zeit der Herausgabe des TYTZ Ende des 19. Jahrhunderts existierte der Tempel nicht mehr.

${ }^{179}$ Nach Fletcher galt der populäre Baofeng Tempel um 1920 als ,der beste Tempel` in der Region (Fletcher, S. 135); er existiert heute noch.

${ }^{180}$ Siehe auch Lutz, S. 22-23.

181 TYTZ, S. 78. Dieser Tempel existiert heute noch.
} 
Sie überliefern erst wieder die Gründung zweier buddhistischer Tempel aus der Zeit der Ära Zhizheng (1341-1368) am Ende der Yuan-Zeit:

- Der Ximeng Tempel war anläßlich eines Bündnisses der Mongolen mit dem Volk der Daboyi gegründet worden. Beim Bau der Stadtmauer Mitte des 15. Jahrhunderts wurde der Tempel von dieser umschlossen, so daß er sich seitdem im Nordwestviertel der Stadt befand. ${ }^{182}$ Unter der Leitung des Vize-Ministers Hou Jin (siehe unten 5. 2.) wurde der Tempel zu dieser Zeit renoviert und von ihm in Wanshousi (,Tempel des langen Lebens') umbenannt. ${ }^{183}$

- In der zweiten Hälfte des 14. Jahrhunderts war auch der sieben Kilometer nördlich der Stadt gelege Puji Tempel errichtet worden. ${ }^{184}$

Die Gründung der Tempel verweist auf die Verbreitung des Buddhismus unter der einheimischen Bevölkerung in der Region des Stromschluchtenfächers, dessen religiöse Traditionen seit der Zeit des Reiches von Nanzhao auch im Gebiet von Tengchong kontinuierlich weiter gepflegt wurden.

\section{2. ,Die erste ummauerte Stadt an der äußersten Grenze‘}

Zu Beginn des 15. Jahrhunderts wurde Tengchong Stützpunkt eines Unabhängigen Bataillons (shouyu qianhu suo) der Truppen der Ming, der im Jahr 1411 von einem Erdwall (tucheng) umgeben gewesen ist. ${ }^{185}$ Trotz dieser Befestigung konnte Tengchong im Jahr 1439 den Angriffen Si Renfas von Luchuan nicht standhalten. Tengchong wurde geplündert, seine Einwohner niedergemetzelt. ${ }^{186}$ Wenige Monate später konnte die Ming-Armee Tengchong zurückgewinnen. Noch während der Feldzüge gegen Luchuan wurde der Stützpunkt durch den Bau einer Stadtmauer befestigt.

„Teng ist ein entlegener Ort. Verkehrswege verbinden ihn mit den verschiedenen Barbaren. Eine Stadtmauer zu bauen und einen Graben auszuheben ist daher zum Schutz der Grenze eine wichtige Aufgabe. Während der Han- und Tang-Zeit war [die Gegend] so entlegen und fern, daß es unsinnig gewesen

\footnotetext{
${ }^{182}$ TYTZ, S. 160. Daboyi ist die chinesische Bezeichnung für eine westlich von Longchuan ansässige Volksgruppe (siehe TYTZ, S. 247-248).

${ }^{183}$ TYTZ, S. 160

${ }^{184}$ TYZZ, S. 58. Auch Puguang si oder Puxiang yuan genannt. Als der Tempel später zerstört wurde, baute ihn die Bevölkerung aus der Umgebung (liren) wieder auf (ebd.). Keine Jahresangaben in den fangzhi.

${ }^{185}$ TYTZ, S. 191; YCFZ, S. 55. Dieser soll sich an derselben Stelle (gu zhi) befunden haben, an der später die Stadtmauer errichtet wurde (TYZZ, S. 50; TYTZ, S. 67). Bemerkung zu des Resten der tucheng, siehe auch TYZZ, S. 43.

${ }^{186}$ TYTZ, S. 190
} 
wäre [eine Mauer zu errichten]. Auch in der Yuan-Zeit wurde noch kein Bau veranlaßt. Erst in der Ära Zhengtong der Ming (1436-1450) wurde damit begonnen. Die Zinnen, die gebaut wurden, verbanden sich mit den Wolken; in den großen Graben tauchte der Mond ein. Deshalb nennt man sie die erste [Stadtmauer] an der äußersten Grenze. Es verging eine lange Zeit, ohne daß die Mauer einstürzte oder repariert werden mußte.“ 187

Mit dem Bau der Stadtmauer in den Jahren 1445 bis 1448 wurde nicht nur ein Truppenstützpunkt umfriedet, sondern auch die Entwicklung Tengchongs zu einem regionalen Verwaltungszentrum des Ming-Reiches eingeleitet. Von nun an wurde die Bautätigkeit in der Stadt, die Errichtung von Verwaltungsgebäuden und Schulen sowie von Tempeln (innerhalb wie außerhalb der Stadtmauern), aber auch der Bau von Straßen und Brücken, dokumentiert und später in den Lokalhandbüchern überliefert.

Der Bau der Stadtmauer von Tengchong wurde im Winter des Jahres 1445, zur Zeit des dritten Feldzuges der Truppen der Ming gegen Luchuan, begonnen. Das Projekt stand unter der Leitung der Vize-Minister des Kriegsministeriums (bingbu shilang) Yang Ning und Hou Jin, die fünfzehntausend Offiziere und Soldaten, unter Führung des Kommandanten (zhihui shi) Li Sheng zur Arbeit an der Stadtmauer heranzogen.

Zunächst hatte Vize-Minister Yang Ning im 10. Monat genau an der Stelle des zerstörten Erdwalles (tucheng) einen neuen errichten lassen. ${ }^{188}$ Im folgenden Jahr wurde mit dem Bau einer Steinmauer begonnen, die im Frühjahr des Jahres 1448 fertiggestellt wurde. ${ }^{189}$ In der Mitte des so gewonnen Areals wurde ein Glockenturm errichtet. Im 1. Jahr der Ära Jingtai (1450) wurde eine knapp zwei Meter hohe Glocke gegossen, deren Inschrift von den Feldzügen gegen Luchuan berichtet. ${ }^{190}$

\footnotetext{
${ }^{187}$ Aus der Einleitung der Herausgeber zum Kapitel ,Stadtmauer und Graben` (in Kap. 4 des TYTZ, S. 67). Die in diesem Zusammenhang in den fangzhi häufig verwendete Phrase der ,ersten ummauerten Stadt an der Grenze` (jibian di yi cheng) findet sich in diesem Zitat abweichend in der Variante ,der erste Sieg an der Grenze'. Es handelt sich hier wohl um einen - bezeichnenden - Schreibfehler: Anstelle des Schriftzeichens cheng (,Stadt[mauer]') wurde sheng (,Sieg') gesetzt. Der Name der Stadt wird von den Verfassern der fangzhi in ihren Texten häufig als ,Teng‘ abgekürzt. ${ }^{188}$ TYTZ, S. 191; YCFZ, S. 55. ,An derselben Stelle‘ (gu zhi): TYTZ, S. 67; TYZZ, S. 50, siehe auch S. 43.

${ }^{189}$ Daraufhin wurde Tengchong in den fangzhi als ,die erste ummauerte Stadt an der äußersten Grenze bezeichnet (,jibian di yi cheng'). TYZZ, S. 50-51; TYTZ, S. 67, 284

${ }^{190} \mathrm{Im}$ Jahr 1512 stürzte der Glockenturm bei einem Erdbeben ein und wurde anschließend vor dem Tempel der Literatur (Wenmiao) wieder aufgebaut. Seine große Glocke wurde jeweils morgens und abends geläutet. Von der Glocke hieß es in einem älteren fangzhi, daß immer wenn sie herunterfiele ein Unglück bevorstehen würde: Dreimal sei sie heruntergefallen und jedesmal sei es so gekommen (TYTZ, S. 71). Diese nach Hou Jin benannte Glocke (Hou Jin zhong) befindet sich heute im Kulturhaus von Tengchong.
} 
In seiner Gedenkinschrift zur Errichtung der Mauer erklärt der für den Bau verantwortliche Vize-Minister Hou Jin, daß die Soldaten zunächst begonnen hätten, eine Mauer aus Ziegeln zu bauen, es aber aufgrund der Kriegssituation nicht möglich gewesen wäre, eine solche zu vollenden. Deswegen habe Li Sheng ihnen beigebracht, die Mauer aus Steinen zu errichten. Die Steine seien vom drei Kilometer entfernten Berg Xishan geholt worden; sie seien „fest und schön und konnten mit nur geringem Kraftaufwand herausgemeißelt werden“. 191

Die Stadtmauer war etwa viereinhalb Kilometer lang und umschloß eine fast genau quadratische Fläche von einem Quadratkilometer. Die Mauer war acht Meter hoch, sechs Meter breit und mit Zinnen versehen. Abweichend von der in China generell üblichen Ausrichtung der Mauerseiten parallel zu den Himmelsrichtungen war sie so angelegt, daß ihre Ecken in die vier Himmelsrichtungen zeigten. Entsprechend öffnete sich das Nordtor nach Nordwesten, das Osttor nach Nordosten usw. (siehe Karte 6, S. 74).

Jeder der vier Torbauten hatte eine Länge von etwa vierzig Metern, eine Höhe von neun und eine Tiefe von dreiundzwanzig Metern. ${ }^{192}$ Die Tordurchgänge waren fünf Meter breit und etwa fünfeinhalb Meter hoch; die hölzernen Torflügel waren mit Eisen beschlagen. Auf den Torbauten befanden sich dreizehn Meter hohe und einundzwanzig Meter breite mehrstöckige Gebäude (lou). ${ }^{193}$

Im Sommer des 3. Jahres der Ära Longqing (1569) wurde zur Befestigung der Stadt zusätzlich eine halbmondförmige Schutzmauer (yuecheng) vor das Südtor gebaut. Diese war fünf Meter hoch, vier Meter breit, insgesamt etwa einhundert Meter lang und hatte an der West- und Ostseite je ein Tor von knapp vier Meter Höhe. ${ }^{194}$ Der Bau war von Zou Guangzuo, dem Kommandeur des Militärbezirks (bingbei dao) Jin-Teng, initiiert worden, um für einen besseren Schutz der Bevölkerung zu sorgen. Auf eine zusätzliche Befestigung der anderen Stadttore wurde jedoch in der Annahme verzichtet, daß der Stadt aufgrund ihrer geographischen Lage ein Angriff nur aus südwestlicher Richtung, von den Völkern im Grenzgebiet oder von Truppen aus Birma, drohen könnte. Aber auch finanzielle Erwägungen spielten bei dieser Entscheidung eine wichtige Rolle: Der Ausbau aller Tore wäre viel zu teuer gewesen.

\footnotetext{
191 TYTZ, S. 284; TYZZ, S. 51. Die Inschrift ist nicht datiert.

192 TYZZ, S. 51. Hou Jin weist in seiner Gedenkinschrift zum Bau der Mauer darauf hin, daß die Stadt aufgrund dieser Torbauten den Namensteil yue erhalten haben (yu cheng cheng yue) (TYTZ, S. 284).

193 TYZZ, S. 51; TYTZ, S. 285 (ebenda: Jedes Torgebäude wurde von achtunddreißig Pfeilern getragen).

${ }^{194}$ TYZZ, S. 52; TYTZ, S. 68, 314; YCFZ, S. 55
} 





Zur Zeit des Mauerbaus ist auch ein Stadtgraben angelegt worden, der einhundert Jahre später, im 29. Jahr der Ära Jiajing (1550), auf Veranlassung des Kommandeurs des Militärbezirkes Guo Chunchen vertieft wurde, so daß er an jeder der vier Seiten der Stadt eine Tiefe von drei Metern bei einer Breite von sieben Metern erreichte. ${ }^{195}$ Um Wasser aus der Stadt in den Graben ablaufen lassen zu können, war in die Nordmauer ein Abfluß eingebaut worden, was jedoch dazu führte, daß Wasser in die Stadt zurückfloß, wenn der Graben bei starken Regenfällen, die in Tengchong besonders im Herbst regelmäßig für Hochwasser sorgten, anschwoll. Dabei wurden die Hauptstraßen überschwemmt und häufig auch Teile der Stadtmauer unterspült. Um dies zu vermeiden, ließ Zhang Yongsheng, ein Bewohner der Stadt (zhoumin), nachträglich ein Schleusentor einbauen. ${ }^{196}$

Die ummauerte Fläche der Stadt Tengchong wurde von Anfang an von zwei Straßen, die das Nord- mit dem Südtor bzw. das Ost- und das Westtor direkt miteinander verbanden, in vier gleichgroße Viertel unterteilt. Auf der von ihnen gebildeten Straßenkreuzung in der Mitte der Stadt befand sich ein zweistöckiges Gebäude mit Tordurchgängen, der Wenxinglou-Pavillon. ${ }^{197}$

Der Bau der Stadtmauer, der zur Sicherung des Stützpunktes Tengchong dienen sollte, war auf Initiative der Befehlshaber des Luchuan-Feldzuges unter der Leitung zweier VizeMinister des Kriegsministeriums (bingbu shilang) durchgeführt worden. Die spätere Anlage von Graben und Schutzmauer war von Beamten der regulären Provinzverwaltung, den Kommandeuren des Militärbezirks (bingbei dao), die dem Provinzkontrollamt (tixing anchashi si) unterstellt waren, veranlaßt worden. Für die Instandhaltung der Mauer war dann der amtierende Unterpräfekt (zhizhou) der Stadt zuständig, der auch die Ausführung aller anfallenden Renovierungsarbeiten an Amtsgebäuden und Tempeln zu organisieren hatte. Die besondere Lage der Stadt machte des öfteren umfangreiche Arbeiten notwendig. Wenn in späteren Jahren Truppen für einen Feldzug gegen die tusi oder gegen Birma in Tengchong zusammengezogen wurden, dann waren anschließend immer Instandsetzungsund Renovierungsarbeiten an den vom Militär genutzten Gebäuden erforderlich. Die politischen Ereignisse und vor allem Militäreinsätze in der Region beeinflußten so immer auch die bauliche Entwicklung der Stadt.

\footnotetext{
195 TYZZ, S. ; TYTZ, S. 67-68; YCFZ, S. 55. Im 17. und 18. Jahrhundert wurden noch Reparaturarbeiten am Graben ausgeführt, später geriet er jedoch in Verfall und trocknete aus. Siehe auch Zhu Huirong, S. 85.

${ }^{196}$ TYTZ, S. 68; TYZZ, S. 52

${ }^{197}$ Wenxing oder Wenchang ist der Name eines Sternbildes im Großen Bären; ,Stern der Literatur' ist auch eine Bezeichnung für berühmte Gelehrte und Literaten (CY 735.3, siehe auch CH 1732.1). Zum Bau des Wenxinglou gibt es in den fangzhi keine Jahresangaben.
} 
Da sich Tengchong in einem Erdbebengebiet befindet, wurden die Stadtmauer und die anderen Bauwerke im Laufe der Zeit häufig durch Erdstöße beschädigt. So wurden bei einem starken Beben im Jahr 1577 viele Amtsgebäude und Tempel beschädigt, außerdem sind etwa siebzig Prozent aller Privathäuser eingestürzt. ${ }^{198}$

Bedingt durch die geographische Lage der Stadt, die im Norden und Osten vom Fluß Yinmashui und den westlichen Ausläufern des Gaoligong-Gebirges umschlossen und im Westen vom Fluß Daying begrenzt wird, sich aber im Südwesten zur Hochebene hin öffnet, siedelten sich außerhalb der Stadtmauer zahlreiche Familien gerade an dieser Seite an. Vor dem Südtor entstand eine prosperierende Vorstadt, die sich zu einem Markt- und Handelszentrum an der Straße nach Birma entwickelte.

Der Kommandeur des Militärbezirks Jin-Teng Zou Guangzuo berichtete im Jahr 1568, daß bereits an die tausend Familien außerhalb der Mauern von Tengyue wohnen würden. ${ }^{199}$ In einer Throneingabe schlug Zou daher vor, die Stadtmauer zu erweitern und um die Vorstadt herumzuführen. Dieses Vorhaben wurde jedoch nicht ausgeführt, da die damit verbundenen Kosten zu hoch gewesen wären. ${ }^{200}$

Seitdem hat die Stadt Tengchong ihre ursprüngliche Form mit dem quadratischen Grundriß, wie sie ihr im 15. Jahrhundert mit dem Bau der Stadtmauer vorgegeben worden ist, beibehalten. Auch nach der Zerstörung der Stadtmauer im Jahr 1944 blieb die ursprüngliche Straßenführung weiter bestehen und läßt sich heute noch im Stadtbild von Tengchong erkennen.

\section{3. Weitere in der Ming-Zeit errichtete Bauwerke}

In den fangzhi wird nur für einige der Gebäude der Stadt Tengchong das Datum ihrer Erbauung genannt. Die Verfasser stellen in ihrer Darstellung der Baugeschichte eher die Renovierungsarbeiten in den Vordergrund, die von den Unterpräfekten organisiert wurden. Sie verweisen damit auf die Dauerhaftigkeit der Einbindung der Stadt in die politische und soziale Ordnung des Kernlandes und auf das kontinuierliche Engagement der Verwaltungsbeamten, zur Erhaltung und Entwicklung der Stadt beizutragen.

\footnotetext{
${ }^{198}$ Im Jahr 1577 brachte ein Erdbeben der Stärke 6 1/2 auf der Stärke der Richterskala die Mauer auf mehreren Dutzend Metern zum Einsturz (TYTZ, S. 28-30; YCFZ, S. 30-34).

${ }^{199}$ Throneinggabe Zou Guangzuos aus dem Jahr 1568 (TYTZ, S. 314); siehe auch TYTZ, S. 49-50, 68; TYZZ, S. 61-62.

${ }^{200}$ Ebenda, TYTZ, S. 314.
} 
Das wichtigste Verwaltungsgebäude Tengchongs war der Amtssitz des Unterpräfekten. Von hier aus wurden die Stadt und das Grenzgebiet verwaltet, wurden Steuern eingezogen und Gerichtsverhandlungen abgehalten. Das Gebäude befand sich im Nordwesten der Stadt, in der Nähe des Nordtores. Während der Ära Zhengtong (1436-50) war es Sitz des Regionalkommandanten (canjiang zhenshou) von Tengchong.

Im ersten Jahr der Ära Jiajing (1522) wurde die Militärkommandantur in eine zivile Unterpräfektur umgewandelt (siehe B. 1., S. 89ff) und das Gebäude im Jahr 1525 zum Amtssitz des Unterpräfekten (zhouzhi) umgebaut. Erste umfangreiche Renovierungsarbeiten ließ Unterpräfekt Shen Zuxue (1567 bis 1573 in Tengyue) ausführen. Unter seiner Leitung wurde der Gebäudekomplex insgesamt deutlich erweitert. ${ }^{201}$

Shen Zuxue war einer der Unterpräfekten, die sich für die Renovierung verschiedener Bauwerke in der Stadt besonders engagierten. ${ }^{202}$ Zu seinen Bauprojekten gehörten öffentliche Kornspeicher ebenso wie eine Akademie (shuyuan). ${ }^{203}$ An der Straßenkreuzung in der Mitte der Stadt ließ Shen einen Ehrenbogen (si pai fang) errichten. An diesem waren vier Gedenktafeln angebracht, auf denen die Namen der Absolventen der Staatsprüfungen (jinshi, juren), die Namen der Studenten der staatlichen Hochschule Guozijian, die ihren Titel käuflich erworben hatten (gongsheng), die Namen pietätvoller Söhne und tugendhafter Frauen und schließlich die Namen verdienstvoller Beamter aufgelistet wurden. ${ }^{204}$

Das zweite wichtige Verwaltungsgebäude innerhalb der Stadtmauern war das des obersten Militärbeamten in der Region: Der Kommandeur des Militärbezirks (bingbei dao) Jin-Teng hatte seinen Amtssitz im Südwesten der Stadt. ${ }^{205}$

Das staatliche Schulwesen nahm in Tengchong ebenfalls in der Ming-Zeit seinen Anfang. Im Jahr 1485 wurde der Bau des Schultempels (wenmiao/xuegong) im Südosten der Stadt vollendet und einige Jahre darauf wurde während der Ära Hongzhi (1488-1506) die Xiufeng Akademie (shuyuan) gebaut, mit dem ,Pavillon des Frühlingswindes‘ (chunfeng ting), der als Amtssitz des Schuldirektors (xuezheng) diente. ${ }^{206}$

\footnotetext{
${ }^{201}$ TYTZ, S. 69, 286-287

202 Shen Zuxue stammte aus der Provinz Zhejiang und hatte den akademischen Titel eines juren erworben. Während seiner Amtszeit in Tengyue kontrollierte er sorfältig das Einziehen der Bodensteuern und verfaßte ein Lokalhandbuch; für seine Verdienste in der Verwaltung der Unterpräfektur wurde er in die Liste der ,berühmten Beamten` (mingchen) des TYTZ aufgenommen (TYTZ, S. 108, 141).

${ }^{203}$ TYTZ, S. 141

${ }^{204}$ TYTZ, S. 71

205 TYTZ, S. 70. Ebenso wie die Unterpräfektursverwaltung wurde auch das Amt des Militärbeamten von der Ming-Zeit bis in das 20. Jahrhundert kontinuierlich als solches genutzt.

${ }^{206}$ TYTZ, S. 78. Zum Schulwesen siehe unten B. 10., S. 172ff.
} 
Karte 7: Verwaltungsgebäude und Tempel in der ,ersten ummauerten Stadt`

(TYTZ, S. 32, Karte der Unterpräfektur Tengyue Ende des 19. Jahrhunderts [Ausschnitt])

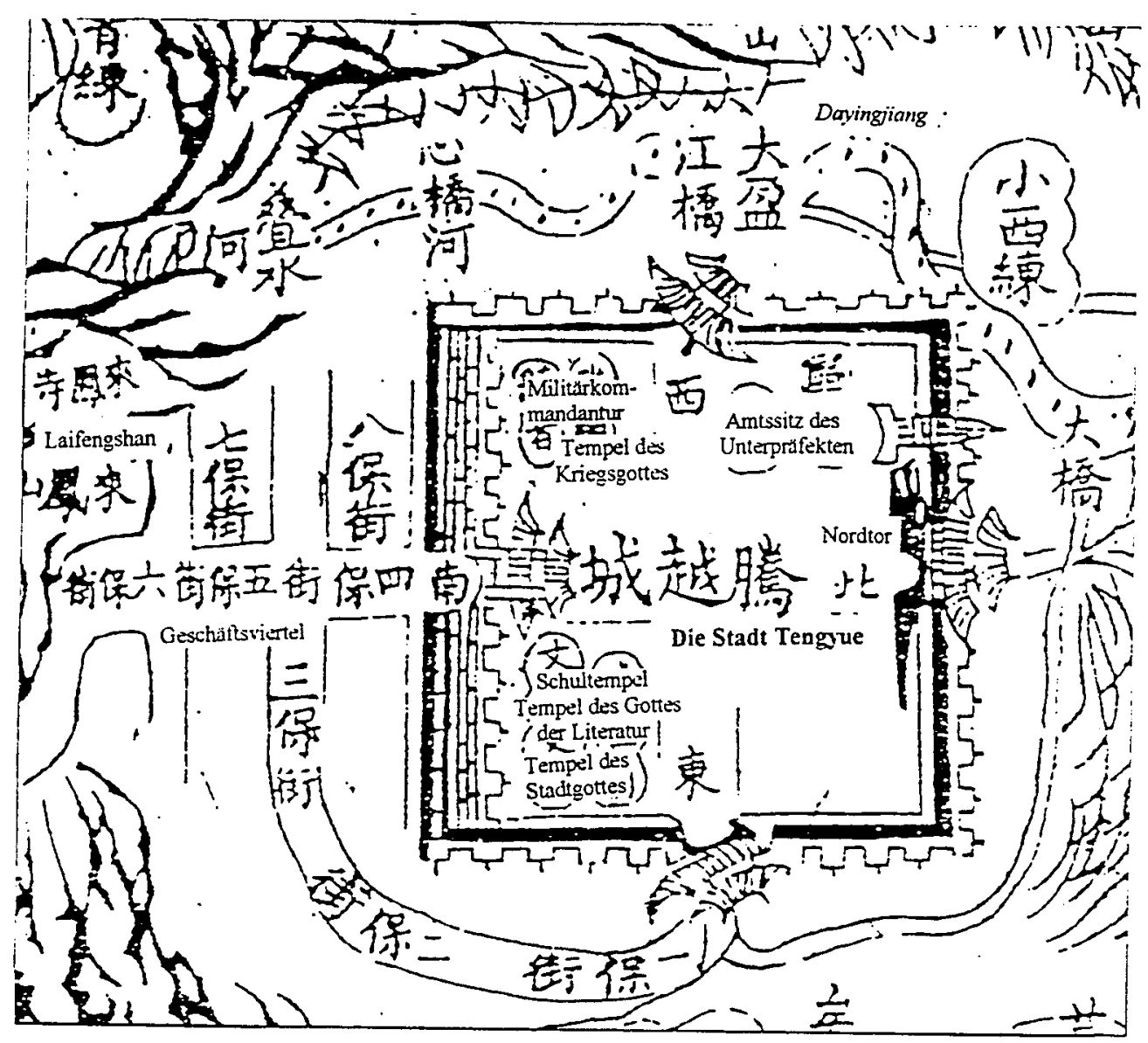

Eine erste religiöse Opferstätte, die in Tengchong gebaut wurde, war der Altar des Erdgottes und des Gottes des Getreides (Sheji tan), der während der Ära Zhengtong (1436-1450) etwa einen Kilometer westlich der Stadt errichtet wurde. Ursprünglich nur ein Erdhügel, an dem die Beamten eine Tafel aufstellten und die Zeremonien des Frühlings- und Herbstopfers durchführten, wurde die Anlage später um verschiedene Gebäude erweitert. ${ }^{207}$

Neben den Verwaltungsgebäuden und nationalen Opferstätten, wie dem Sheji tan, gehörte die Gedenkhalle für den Fürsten von Wu (Wu hou ci) aus dem Jahr 1515 zu den ältesten Bauwerken Tengchongs, die nach anderen Angaben sogar schon während der Ära Zhengtong (1436-1450) erbaut worden sein soll. ${ }^{208}$ Mit der Errichtung der Gedenkhalle wird an Zhuge Liang, den Fürsten von Wu, und seinen Feldzug nach Yunnan im Jahr 225 n.Chr. erinnert. Die Ming-zeitlichen Erbauer Tengchongs spannten einen Bogen von der Han-Zeit bis in ihre Gegenwart, die sie so mit der Tradition dieser frühen chinesischen Expansion nach Südwesten verbanden.

${ }^{207}$ TYTZ, S. 157; TYZZ, S. 57; YCFZ, S. 117

${ }^{208}$ TYTZ, S. 139 
Tabelle 4: Ming-zeitliche Tempel in Tengchong/Tengyue nach Angaben der fangzhi ${ }^{209}$

\section{Bauwerk}

Altar des Erd- und Getreide-

Gottes (Sheji tan)

Gedenkhalle für den Fürsten

von $\mathrm{Wu}$ (Wuhou ci)

Tempel für die Generäle Liu und Deng

(Liu Deng er jiangjun miao)

Tempel des Erdgottes

(Zhao Teng tuzhu miao)

Tempel des Kriegsgottes

(Guandi miao)

Li tan

\section{Buddhistische Tempel ${ }^{210}$}

Pilu si

Huayan si

Wanfu si

Qingping si
Baujahr

Ära Zhengtong

(1436-50)

1515 (Zhengde 10)

$$
--
$$

$-$

$--$

Ming-Zeit

1612 (Wanli 40)

Ming-Zeit

Ära Wanli (1573-1620)
Jahr der ersten erwähnten

Renovierung

während der Amtszeit von

Unterpräfekt Yu (1587-99)

während der Amtszeit von

Unterpräfekt Zheng (1601-04)

Ära Tianqi (1621-1628)

Ära Tianshun (1457-1465)

Außerdem wird in den fangzhi der Bau zahlreicher Pavillons (ting) an landschaftlich schönen Aussichtspunkten in der Umgebung der Stadt erwähnt, die in der Ming-Zeit beliebte Ausflugsziele waren. ${ }^{211}$

\section{Die Entwicklung der Verwaltungseinheit Tengchong bis zur Mitte des 16. Jahr- hunderts}

Während der Feldzüge gegen Luchuan hatte sich Tengchong Mitte des 15. Jahrhunderts zunächst als Militärstützpunkt im Grenzgebiet etablieren können. Nach dem Friedensschluß mit Luchuan und der Errichtung der Stadtmauer blieb die Region weiterhin unter militärischer Verwaltung. Es vergingen noch fast einhundert Jahre, bis der Bataillonsstützpunkt Tengchong schließlich auch in die Strukturen der regulären Zivilverwaltung des chinesischen Reiches integriert wurde. Eine Einheit der zivilen Verwaltung, eine Unterpräfektur (zhou), war zwar in Tengchong schon einmal im Jahr 1430 gegründet worden, diese

\footnotetext{
${ }^{209}$ TYTZ, S. 69-72, 157-162

${ }^{210}$ Der Forschungsreisende Xu Xiake hat während seines Aufenthaltes in Tengyue im Jahr 1639 verschiedene buddhistische Tempel in der Stadt und ihrer Umgebung besucht. In seinem Reisetagebuch erwähnt er folgende Tempel: Ximeng si, Baofeng si, Guanyin si / Yuquan si sowie den Yunfengshan si auf dem Gipfel des Yunfengshan im Norden der Stadt (TYTZ, S. 160-162. Zu Xu Xiake siehe auch unten B. 8., S. 166ff).

${ }^{211}$ TYTZ, S. 77-78
} 
hatte jedoch der Regionalen Militärkommission Yunnan (Yunnan du zhihui shi si/ dusi) unterstanden und war von den Garnisonskommandanten (zhihui shi) verwaltet worden. ${ }^{212}$ Im Jahr 12 der Ära Chenghua (1476) wurden die Gebiete von Yongchang und Tengchong zu dem Militärbezirk (bingbei dao) Jin-Teng zusammengefaßt. ${ }^{213}$ Dieser unterstand dem Provinzkontrollamt (tixing anchashisi). Damit war Tengchong in das Verwaltungsnetz aller drei obersten Verwaltungsbehörden der Provinz (san si) eingebunden.

Auch nach dem Friedensschluß mit Luchuan blieb die Sicherung des Stützpunktes Tengchong die wichtigste Aufgabe der lokalen Amtsträger. Zur Verstärkung der Militärorganisation wurden deshalb seit der Ära Zhengtong (1436-50) zwei Verteidigungskommandeure (zhenshou) für Tengchong ernannt. Aufgabe eines Verteidigungskommandeurs war es, die militärische Kontrolle über eine Provinz oder eine besonders gefährdete Grenzregionen zu organisieren. $^{214}$ Dort führte er gegebenenfalls Feldzüge durch, die die verschiedenen Volksgruppen und regionalen Machthaber ,befrieden` und sicherstellen sollten, daß sie die Oberhoheit des Ming-Kaisers anerkannten. Für Tengchong waren je ein Regionalkommandant (canjiang zhenshou) und ein Palasteunuch (taijian zhenshou) in dieser Position tätig. $^{215}$

Bereits seit der Ära Yongle (1403-1424) waren Eunuchen häufig mit militärischen Aufgaben betraut worden, die sie selbständig oder in Zusammenarbeit mit den lokalen Beamten ausführten. Vielfach wurden sie als Verteidigungskommandeure in Garnisonsstützpunkte entlang der Grenzen des Reiches entsandt, insbesondere in die strategisch wichtigen Gebiete im Norden Pekings sowie der Provinzen Shanxi und Shaanxi, aber auch in den Westen Yunnans. ${ }^{216}$ Die doppelte Besetzung dieser Ämter war ein fester Bestandteil des politischen Systems der Ming-Zeit; die gegenseitige Kontrolle der verschiedenen Beamten sollte die Durchsetzung der Regierungspolitik gewährleisten und die Entstehung lokaler

\footnotetext{
${ }^{212}$ TYTZ, S. 144. In der Liste der Unterpräfekten (zhihzhou) im TYTZ wird als erster Beamter in dieser Position Zhang Ming genannt, der während der Ära Xuande (1426-1436) dort tätig war. Als seine Nachfolger im Amt werden der Kommandant (zhihui shi) Li Sheng (z.Z. der Ära Zhengtong, 1436-1450) und Chen Jian genannt, der während der Ära Chenghua (1465-1488) amtierte und den Titel eines Kommandanten und Vize-Präfekten (zhihui tongzhi) führte (TYTZ, S. 108, 144).

${ }^{213}$ TYTZ, S. 176. Die Einrichtung des Militärbezirks Jin-Teng erfolgte aufgrund einer Petition des Gouverneurs (xunfu) Wang Shu im Jahr 1476 (YCFZ, S. 51). Nach anderen Angaben (s. TYTZ, S. 64; TYZZ, S. 15) wurde der Militärbezirk (bingbei dao) erst im 2. Jahr der Ära Hongzhi (1489) eingerichtet. Die Liste der Zivilbeamten im TYTZ beginnt mit der Aufzählung der Kommandeure der Militärbezirke. Der erste der Genannten, He Yuanzhong, amtierte während der Ära Hongzhi (1488-1506).

${ }^{214}$ Hucker 390 und S. 80.

${ }^{215}$ TYZZ, S. 77; TYTZ, S. 176 (wuyin wei canjiang dudu; ... taijian wei zhenshou jianjun). Für die Präfektur Yongchang war im Jahr Jingtai 1 (1450) ein Verteidigungskommandeur (zhenshou) eingesetzt worden. In dieser Position waren dort abwechselnd ein Eunuch (neichen) und ein Angehöriger des Militärs (wuchen) tätig (YCFZ, S. 134).

${ }^{216}$ Tsai, S. 62-63
} 
Machtzentren verhindern. In den Verwaltungseinheiten führte die Überschneidung der Befugnisse jedoch häufig zu Konflikten zwischen den mit besonderem kaiserlichen Auftrag entsandten Eunuchen und den Amtsträgern der regulären Zivil- oder Militärbürokratie.

Während der Ära Chenghua (1465-1488) amtierten Angehörige der Familie Mu, Nachfahren des Mu Ying, einige Jahre lang als Regionalkommandanten (canjiang). Sie schalteten sich in die Kämpfe einheimischer Machthaber ein und führten Feldzüge durch, um Aufstände niederzuschlagen. Ihre Verdienste werden in den fangzhi in der Rubrik ,berühmte Beamte‘ (mingchen) gewürdigt:

„Mu Zan war der jüngere Bruder des Mu Lin, Herzog von Qianguo; ein vortrefflicher Reiter und Bogenschütze. Im 3. Jahr der Ära Chenghua (1467) wurde er als Stellvertretender Regionalkommandeur (fu zongbing) nach Tengchong versetzt. Er ließ den Schutzwall der Stadt (cheng lei) instandsetzten und die Menge des Getreides [in den Speichern] erhöhen. Er [umgab sich mit] gebildeten und fähigen Leuten und gründete Schulen. Er verbot Korruption und entließ korrupte Beamte. Er befriedete die rebellierenden Barbaren (yi) von Luchuan. Nach dem Tod Zans folgte ihm sein ältester Sohn Mu Cheng auf diesem Posten nach.

Mu Cheng, Beiname Zeshan, ältester Sohn von Mu Zan. Mit sieben Jahren (sui) beherrschte er den ,Klassiker der Kindespietät‘ (Xiaojing) und die ,Gespräche des Konfuzius‘ (Lunyu). Gut geschult in der Kriegskunst war er auch ein talentierter Rezitator und vortrefflicher Kalligraph der Grasschrift. Als die Barbaren (man) von Mangshi an der Grenze für Unruhe sorgten, führte er die Soldaten an, die [Mangshi] befriedeten. Als er im Alter von sechsundzwanzig Jahren starb, übernahm der zweite Sohn Mu Zans, Mu Xiang, seinen Posten. Mu Xiang, Beiname Zeming, war der zweite Sohn des Mu Zan. Zu der Zeit als er in Tengchong stationiert war, überfiel Si Ye von Mengmi Mubang. Xiang begab sich persönlich dorthin, um den Frieden wiederherzustellen. Er ordnete an, daß Si Ye das Land, welches er an sich gerissen hatte, wieder zurückgeben sollte. Im 21. Jahr der Ära Chenghua (1485) schlossen sich die Häuptlinge des Volkes der Pu, A Lin und Mang Qiu, zu einem Aufstand zusammen. Xiang organisierte die Strafexpedition, bei der beide festgenommen wurden. Im Jahr 22 (1486) schlug er eine Rebellion in Ganya mit Waffengewalt nieder. Als 
daraufhin seine Amtsführung kritisiert wurde, legte er sein Amt nieder und kehrte in die Provinzhauptstadt zurück, wo er Selbstmord beging““. 217

Mu Zan und seine beiden Söhne werden hier in den für diese Art von biographischen Notizen typischen Klischees beschrieben, die sie geradezu als Verkörperungen der verschiedenen Typen von idealen Militärbeamten erscheinen lassen. Mu Zan ein fähiger Soldat, der wohltätig für die Sicherheit der Stadt sorgte, die Lebensumstände der Bevölkerung verbesserte und gegen Korruption vorging. Mu Sheng, in der klassischen Tradition erzogen, künstlerisch begabt und ein erfolgreicher Truppenführer. Mu Xiang schließlich, der die Vormachtstellung der Ming im Grenzgebiet sicherte und nach einem Fehlverhalten die Konsequenzen zog, indem er sein Amt niederlegte und seine Fehler durch Selbstmord sühnte. Genauer wird diese Angelegenheit in den fangzhi nicht dargestellt.

Anders bei seinen Nachfolgern im Amt, Lu He und Mu Song, die in deutlichen Worten kritisiert werden:

„Lu He war von niedriger Abstammung. Gestützt auf den Einfluß seines Pflegesohnes, des Palasteunuchen Qian Ning, war es ihm gelungen, dem MuClan das Amt des Regionalkommandanten zu entreißen. Wegen seiner zahlreichen gesetzwidrigen Handlungen, so hatte er vier Männer getötet und deren Ehefrauen geraubt, wurde er von dem Zensor (xun'an) Tang Long angezeigt. Qian Ning richtete um seinetwillen eine Petition an den Kaiser, aber Lu He mußte dennoch sterben, wie das Gesetz es vorschrieb, nachdem er sich schuldig bekannt hatte“. ${ }^{218}$

„Danach übernahm $\mathrm{Mu}$ Song, der Sohn einer Nebenfrau des Herzogs von Qianguo, den Posten des Verteidigungskommandeurs. Song war äußerst korrupt und grausam. Er wurde von dem Zensor Chen Cha, der auch den Palasteunuchen Liu Yu beschuldigt hatte, angezeigt und daraufhin aus dem Amt entfernt. “219

\footnotetext{
${ }^{217}$ TYTZ, S. 139-40; TYZZ, S. 87. Für eine Beschreibung des Volkes der Pu, ,die in Bergschluchten südlich von Yongchang leben' siehe TYTZ, S. 247.

${ }^{218}$ TYTZ, S. 128; TYZZ, S. 87

${ }^{219}$ TYTZ, S. 128; TYZZ, S. 87. Jahresangaben zur Amtstätigkeit von Lu He und Mu Song werden in den fangzhi nicht gemacht. Die Eunuchen Qian Ning und Liu Yu waren während der ersten beiden Dekaden des 16. Jahrhunderts in Tengchong tätig (Lu He um 1501) (siehe auch Sun Laichen, Ming-Southeast, S. 140). In den Auflistungen der Beamten in den fangzhi wird Lu He direkt nach Mu Xiang genannt. Nach ihm ist Mu Song der letzte genannte Regionalkommandant (canjiang), das Amt selbst wurde zu Beginn der Ära Jiajing (1522-1567) abgeschafft (s. u. S. 89, Fußnote 234) (ebd.).
} 
Die hier geschilderten Ereignisse zeigen zunächst, daß die Zensoren ihrer Aufgabe, die Amtsführung der Beamten zu kontrollieren, auch in Bezug auf die Gebiete an der äußersten Südwestgrenze des Reiches nachkamen. ${ }^{220}$ Gleichzeitig beinhaltet die Kritik der Zensoren an den beiden Beamten von Tengchong (und deren Dokumentation in den fangzhi) auch Kritik an den Eunuchen im Allgemeinen und an deren großen Einfluß am Kaiserhof und in Yunnan (siehe unten). Die beiden Eunuchen werden hier mit Personen zweifelhafter Herkunft und deren gesetzwidrigem Verhalten in Verbindung gebracht, was ihr eigenes Fehlverhalten noch unterstreichen soll.

Ebenso sollen sich auch schon ihre Amtsvorgänger, die als Verteidigungskommandeure in Tengchong stationierten Palasteunuchen (taijian zhenshou), nicht durch militärische oder administrative Leistungen ausgezeichnet haben, sondern hauptsächlich durch ihr Streben nach Selbstbereicherung:

„Während der Ära Chenghua (1465-1488) amtierte der Palasteunuch Wang Ju als Verteidigungskommandant (neiguan jiangjun). Er ließ eine Schule (si xue) bauen. ${ }^{221}$ In Mengmi gab es Rubinminen. Ju hatte ein unstillbares Verlangen [nach Juwelen]. Später wurde eine Throneingabe über seine Verbrechen (zui) eingereicht und eine Untersuchung angestrengt.

Zur Zeit der Ära Hongzhi (1488-1506) waren Ji Qing und Sun Xu in diesem Amt tätig. Ji war ein übler junger Bursche, der mit Wang Ju aus der Hauptstadt gekommen war und die Bevölkerung ( $\min$ ) ausplünderte, ohne je genug zu bekommen. Er liebte die Edelsteine und wenn er gute [Steine] erhalten hatte, bewahrte er sie in seiner Sammlung auf. Seine zahlreichen Gefolgsleute waren ganz versessen darauf und als Ji Qing krank wurde, bestachen sie den Arzt, der ihn mit dem [giftigen] Goldstein-Medikament (jinshi ji/yao) tötete. Nachdem Ji gestorben war, suchten sie allesamt mit Edelsteinen beladen das Weite. Seinen Leichnam ließen sie liegen und er mußte von amtlicher Seite begraben werden“. 222

Mit ihrer Gier nach Reichtümern, hier insbesondere nach den in der Region geförderten Edelsteinen, und der sie umgebenden üblen Clique von Gefolgsleuten entsprechen die in

\footnotetext{
${ }^{220}$ Das Zensorat (du chayuan), das Kontrollorgan zur Überwachung des gesamten Verwaltungsapparatesdes chinesischen Reiches, war bereits im Jahr 1382 in Nanjing gegründet worden. Ob die genannten Zensoren tatsächlich persönlich auf einer ihrer Inspektionsreisen bis nach Tengchong gekommen sind, wird in den fangzhi nicht ausgeführt.

${ }^{221}$ Si хиe, das ist die staatliche Schule (хие) in der Lokalen Militärkommandantur (junmin zhihui shis $\underline{\text { si) }}$ Tengchong.

${ }^{222}$ TYTZ, S. 128; TYZZ, S. 87
} 
Tengchong tätigen Palasteunuchen, so wie sie in den fangzhi dargestellt werden, einer weiteren in biographischen Notizen häufig anzutreffenden Klischeefigur, der des raffgierigen und korrupten Eunuchen. In dieser Figur spiegeln sich aber auch die Spannungen zwischen den verschiedenen Amtsträgern in der Region wider. Indem die Zivilbeamten und Angehörigen der lokalen Gentry als Verfasser der Biographien die negativen Aspekte der Tätigkeit der Eunuchen in den Vordergrund stellen, üben sie auch generell Kritik an der Politik der Entsendung der Eunuchen und deren Eingreifen in die örtliche Verwaltung.

Für Tengchong wird einzig die Gründung einer staatlichen Schule als positive Errungenschaft ihrer Amtstätigkeit als Verteidigungskommandeure erwähnt. Unerwähnt bleibt hingegen, daß Palasteunuchen, die in die Provinz Yunnan geschickt wurden, häufig ausdrücklich damit beauftragt waren, Juwelen und Edelmetalle für den kaiserlichen Hof zu akquirieren. Während der Ära Chenghua (1465-1488) waren das zumeist Agenten der Favoritin des Kaisers, der Dame Wan Guifei, die in ganz Yunnan die Förderung von Edelsteinen sowie den Abbau von Kupfer-, Silber- und Goldvorkommen überwachten. ${ }^{223}$ Der Mißbrauch ihrer Macht und die persönliche Bereicherung der einzelnen Eunuchen bei der Ausbeutung der Bodenschätze führten mancherorts zu Unruhe unter der Bevölkerung, so daß sich der Kaiser schließlich veranlaßt sah, ihren Einfluß in der Provinz zu beschränken: Im Jahr 1477 beauftragte er den Gouverneur von Yunnan, Wang Shu (1416-1508), die illegalen Aktivitäten der Eunuchen und dabei insbesondere die des Qian Neng (1468 bis 1480 in Yunnan) zu unterbinden. ${ }^{224}$

Vor diesem Hintergrund mag die negative Darstellung der Palasteunuchen in Tengchong durchaus eher der Realität entsprechen, als nur die Wiederholung eines bekannten Klischees zu sein. Die formelhafte Darstellung der einzelnen Personen in den Kurzbiographien der fangzhi macht ihre kritische Beurteilung schwierig, dennoch vermitteln sie zumindest einen Einblick in die Lage im Gebiet des Stromschluchtenfächers von der Mitte des 15. bis zur Mitte des 16. Jahrhunderts. Sie machen Art und Umfang des Einflusses deutlich, den die Ming durch Militärkommandanten und zivile Beamte auf das Gebiet der Verwaltungseinheit Tengchong ausübten. Zudem weisen sie auf die ökonomischen Interessen hin, die nicht nur lokale Kaufleute und Beamte, sondern vor allem die Mitglieder des Kaiserhofes an dieser weit von den politischen und wirtschaftlichen Zentren des

\footnotetext{
${ }^{223}$ DMB, S. 301

${ }^{224}$ Wang Shu gelang es zwar, den direkten Erwerb von Edelsteinen aus Annam durch Qian Neng zu beenden, der Eunuch blieb jedoch weiter in Yunnan tätig, während Wang auf einen anderen Posten versetzt wurde (DMB, S. 1417; ZGRMDCD, S. 37).
} 
Reiches entfernt gelegenen Region hatten. Interessen, die die Anbindung der Hochebene von Tengchong an das chinesische Kernland förderten und die auch über Tengchong hinausgingen und sich auf die Herrschaftsgebiete der Kleinstaaten weiter im Südwesten erstreckten, insbesondere auf die Rubinminen von Mengmi am Unterlauf des Flusses Shweli im Nordosten des modernen Birma.

\section{Die Politik der Ming gegenüber den Kleinstaaten im Südwesten von Tengchong}

Die Kleinstaaten der Shan und anderer einheimischer Volksgruppen im Süden und Westen der Lokalen Militärkommandantur (junmin zhihui shisi) Tengchong wurden von den Ming als Befriedete Gebiete (xuanfu si) in das Verwaltungssystem des Reiches eingegliedert, so zum Beispiel Nandian (1443/44), Ganya (1444) oder Luchuan (1446). ${ }^{225}$ Sie unterstanden nominell der Oberhoheit der Ming und leisteten Tributzahlungen. Diese Gebiete fielen in den Zuständigkeitsbereich der Verteidigungskommandeure von Tengchong, deren Aufgabe es war, für loyales Verhalten gegenüber dem Ming-Reich zu sorgen und Unruhen dort durch den Einsatz von Truppen zu unterdrückten.

Die jenseits des Jinshajiang [zeitgenössische chinesische Bezeichnung für den Oberlauf des Irawadi] und südlich des Shweli gelegenen Staaten wie Mengyang und Mubang hingegen erhielten den Status von höherrangigen Befriedeten Gebieten (xuanwei si). Wegen der großen Entfernung und des schwer zu passierenden Geländes zwischen ihnen und dem Garnisonsstützpunkt Tengchong waren militärische Interventionen durch Truppen der Ming zu kostspielig und wenig erfolgversprechend. Kam es zu Konflikten dieser Staaten untereinander, so entsandte die Provinzregierung gegebenenfalls Beamte, die als Vermittler die Parteien zur Annahme der Position der chinesischen Regierung in der Streifrage bewegen, vor allem jedoch den Anspruch der Ming auf die Oberhoheit über die Region deutlich machen sollten.

Am Beispiel der Mission des chinesischen Gesandten Guo Xu, der zu Beginn des 16. Jahrhunderts im Konflikt zwischen Mengmi, Mubang und Mengyang vermitteln sollte, werden die verschiedenen Arten der Einflußnahme von Seiten der Ming auf die Kleinstaaten jenseits des Jinshajiang deutlich.

\footnotetext{
${ }^{225} \mathrm{Zu}$ den tusi-Gebieten siehe unten B. 4. 1. 2., S. $106 \mathrm{ff}$.
} 
Si Ye, der Herrscher von Mengmi, hatte damals einen Teil des Territoriums von Mubang erobert und dieses Gebiet,

„obwohl er mehrfach [aus China] den Befehl dazu erhalten hatte, nicht zurückgegeben. Daraufhin wurde angeordnet, daß Si Lu, Oberhaupt (xuanfu) des benachbarten Mengyang, Truppen entsende, um Mengmi einzuschüchtern. Si Ye gab nun die eroberten Gebiete zurück; da aber im Kampf sehr viele Soldaten aus Mengyang getötet worden waren, schickte Si Lu erneut Truppen über den Jinshajiang, um sich zu rächen und seinerseits jenes Gebiet zu erobern“. ${ }^{226}$

Zunächst sind also lediglich Befehle, vermutlich schriftliche, von Boten übermittelt worden. Da diese unbeachtet blieben, forderte die chinesische Regierung den Nachbarstaat Mengyang zur Intervention auf. Für die Ming gehörte es zu den Verpflichtungen des Herrschers eines tusi-Gebietes, Truppen zur Unterstützung Chinas bereitzustellen. Mit der Delegation der Aufgabe, den Konflikt um Mubang zu lösen, folgten die Ming der in solchen Fällen häufig angewandte Maxime, ,Barbaren einzusetzen, um andere Barbaren zu bekämpfen‘ (yong yi gong yi). Diese Maßnahme führte jedoch dazu, daß noch ein weiterer Kleinstaat in den Konflikt hineingezogen wurde. Anstatt also den Status quo wieder herzustellen, veränderte sich das Machtgefüge in der Region erneut und machte ein weiteres Engagement von Seiten der Ming notwendig.

Im 14. Jahr der Ära Hongzhi (1501) schickte der Gouverneur (xunfu) [von Yunnan], Chen Jincheng, den Vize-Direktor der Provinzbehörde (canzheng) Guo Xu und den VizeMinister (fushi) Cao Yu nach Mengyang:

„Er ordnete an, daß sie innerhalb von zehn Tagen in Jinchi eintreffen sollten. Der Regionalkommandant [von Tengchong], Lu He, hatte Truppen zusammengezogen ... und einen Beamten entsandt, der zur Poststation eilen und [Guo Xu] davon unterrichten sollte. Der Beamte richtete die Botschaft jedoch nicht aus. He fürchtete sich, [da er keine Antwort bekam,] und kehrte mit seinen Truppen nach Ganya zurück. Dort traf er mit Xu zusammen, schilderte ihm die Lage und warnte ihn davor weiter vorzurücken. Aber darauf konnte sich Xu nicht [einlassen]. Cao Yu blieb aus Krankheitsgründen zurück. Also ritt Xu allein weiter, nur mit einem Gefolge von einigen Dutzend Leuten“. ${ }^{227}$

\footnotetext{
${ }^{226}$ TYTZ, S. 140; TYZZ, S. 99

${ }^{227}$ TYTZ, S. 140
} 
Deutlich wird hier die schlechte Zusammenarbeit der einzelnen in der Region tätigen Beamten. Zunächst mißlingt die Kommunikation zwischen dem Regionalkommandanten Lu He und dem Gesandten der Provinzregierung. Als beide schließlich zusammentreffen, versucht $\mathrm{Lu} \mathrm{He}$, anstatt die Gesandtschaft des Guo $\mathrm{Xu}$ zu unterstützen, diesen von der Durchführung seiner Mission abzuhalten.

Der Ort ihres Treffens war das Befriedete Gebiet (xuanfu si) Ganya cirka einhundert Kilometer südwestlich von Tengchong. Dies zeigt wiederum, daß die Gebiete westlich Tengchongs noch zum Einsatzbereich des Regionalkommandanten gehörten, in dem auch Truppen der Ming zum Einsatz kamen.

Mit Guo Xu erscheint in den Kurzbiographien der fangzhi eine weitere Klischeefigur, neben dem ,mustergültigen Soldaten“ und dem ,korrupten Eunuchen‘ ist er der ,mutige Gesandte‘ par excellence, dessen vorbildliches Verhalten die einheimischen ,Barbaren`zur Anerkennung der Oberhoheit Chinas veranlaßte.

Auf seiner Reise scheute Guo keine Mühen, das unwegsame Territorium zu durchqueren. Als „das Gelände steil und gefährlich wurde, konnten [Guo und sein Gefolge] nicht weiterreiten und mußten sich zu Fuß ihren Weg durch das Gestrüpp bahnen. [Die steilen Berge] konnten sie nur mit Hilfe von Seilen erklimmen““. ${ }^{228}$ Schließlich reiste er in einer von einem Elefanten getragenen Sänfte weiter. „Auf schwer begehbaren schlammigen Wegen durch giftigen Dunst ... kam er schließlich in Menglai an; von dort waren es nur noch zwei Marschetappen bis zum Jinshajiang, [dem Oberlauf des Irawadi]“. ${ }^{229}$ Als er von „Soldaten [aus Mengyang], die mehrere zehntausend Elefanten und Pferde in der Nacht über den Fluß geführt hatten und die lange Lanzen und starke Bogen in den Händen trugen“, umzingelt wurde, hielt er sein kleines Gefolge zusammen und ließ sich auch durch Geschenke nicht von seinem Auftrag abbringen. Beeindruckt von seiner Integrität und Tapferkeit, „kam Si Lu [von Mengyang] selbst zu Guo Xu. Dieser würdigte zunächst die Verdienste des Anderen, dann beseitigte er einige Ungerechtigkeiten, danach aber tadelte er ihn für seine Rebellion. Alle Häuptlinge hörten dies, daraufhin warfen sie sich nieder und riefen ,lang lebe der Kaiser‘ (wan sui)“; schließlich wurden auch die eroberten Gebiete zurückgegeben. ${ }^{230}$

\footnotetext{
${ }^{228}$ TYTZ, S. 140; TYZZ, S. 100

${ }^{229}$ TYTZ, S. 140. Eine Marschetappe der Armee (she) umfaßte dreißig li [ungefähr fünfzehn Kilometer] (CY 1411.4).

${ }^{230}$ Ebenda.
} 
Die Bemühungen Chinas, zur Beilegung der Konflikte zwischen den Kleinstaaten im Südwesten Yunnans beizutragen, sollten vor allem dazu dienen, ein stabiles Gleichgewicht (unter chinesischer Oberhoheit) zu wahren. Am Beispiel der Gesandtschaftsreise des Guo Xu zeigt sich das zu diesem Zweck eingesetzte vielfältige Repertoire der Ming-Regierung im Umgang mit den Völkern an der Peripherie ihres Reiches. Die verschiedenen Maßnahmen, die dabei getroffen wurden, verdeutlichen auch, daß zu Beginn des 16. Jahrhunderts in der Region des Stromschluchtenfächers westlich des Gaoligongshan ein Grenzgebiet mit unterschiedlichen Zonen entstanden ist. An die Hochebene von Tengchong, auf der sich die ummauerte Militärkommandantur fest etabliert hatte, schlossen sich im Südwesten tusiGebiete an, in denen die Ming-Truppen selbst agierten, wie z.B. in Ganya. Weiter im Westen, bis nach Menglai, erhielt Guo Xu noch Unterstützung (in Form einer Elefantensänfte). Den Irawadi überquerte er jedoch nicht; auf die Gebiete jenseits des Flusses konnte China zu dieser Zeit keinen Einfluß mehr ausüben. Obgleich die Oberhoheit Chinas über diese Gebiete also eine nominelle blieb, hat Guo Xu doch gerade diesen Hoheitsanspruch deutlich gemacht und so aus chinesischer Sicht seine Mission erfolgreich beendet. Denn es war ja schließlich der tusi von Mengyang, der den Fluß überquert hatte, um mit Guo Xu zusammenzutreffen. Darauf weisen die Verfasser der fangzhi in diesem Zusammenhang ausdrücklich hin und interpretieren die Ereignisse in ihrem Sinne.

Aus der Sicht der Kleinstaaten im Südwesten Chinas stellte sich die Situation ganz anders dar. Die Expansion der Ming Ende des 14. Jahrhundert hatte, wie Sun Laichen in seiner Dissertation herausgearbeitet hat, zur Verbreitung von chinesischen Schußwaffen in den Herrschaftsgebieten der Shan im Südwesten und zu einer Intensivierung des profitablen Handels mit China geführt. ${ }^{231}$ Ihre zunehmende militärische und ökonomische Stärke hatte es diesen Staaten von Mengyang im Nordwesten bis nach Sipsongpanna und Dai Viet im Süden Chinas ermöglicht, sich über ein Jahrhundert lang als eigenständige Herrschaftsgebiete zu behaupten und die Bemühungen der Ming um Einflußnahme auf die Region höchstens zum eigenen Nutzen gelten zu lassen. Die Kleinstaaten expandierten ihrerseits und traten auch den Hoheitsansprüchen der Ming entgegen, wie Si Lu von Mengyang deutlich gemacht hat, indem er mit seinen Truppen den Irawadi überquerte, um Guo Xu zu begegnen. So lassen sich die dargestellten Ereignisse aus der Sicht von Mengyang auch dahingehend interpretieren, daß Si Lu hier seinen Hoheitsanspruch gegenüber China behauptet hat.

\footnotetext{
${ }^{231}$ Sun Laichen: Ming-Southeast Asian overland interactions, 1368-1644, University of Michigan, 2000
} 


\section{B. Die Unterpräfektur Tengyue und die Konsolidierung des Grenzgebietes}

\section{Die Gründung der Unterpräfektur Tengyue Mitte des 16. Jahrhunderts}

Die Entwicklung Tengchongs von einem Militärstützpunkt zu einer regulären Einheit der Zivilverwaltung des Ming-Reiches begann in den zwanziger Jahren des 16. Jahrhunderts. Die Grundlage dafür schuf He Mengchun, der in den Jahren von 1519 bis 1521 als Gouverneur von Yunnan tätig war und sich in einer Throneingabe für die Abschaffung der Posten der Verteidigungskommandeure (zhenshou) in Yongchang einsetzte. Seinem Vorschlag wurde stattgegeben und im ersten Jahr der Ära Jiajing (1522) wurde folglich die Militärkommandantur (zhihuishi si) Jinchi in die Präfektur (junmin fu) Yongchang umgewandelt. ${ }^{232}$ Die Präfektur wurde dem Verwaltungsbezirk (dao) Jin-Cang der Provinzbehörde von Yunnan unterstellt (siehe Schaubild, S. 90). ${ }^{233}$ Außerdem wurden der Kreis (xian) Baoshan und die Garnison (wei) Yongchang gegründet, in der acht Bataillone zusammengefaßt wurden. Weiterhin wurde Yongping, nordöstlich der Präfektursstadt Yongchang gelegen, zum Stützpunkt eines Unabhängigen Bataillons (shouyu qianhu suo) gemacht. $^{234}$

Im Zuge der Reorganisation der Präfektur Yongchang wurden im Jahr 1522 auch die Posten der beiden Verteidigungskommandeure (zhenshou) von Tengchong abgeschafft und eine Unterpräfektur (zhou) gegründet. ${ }^{235}$ Die Unterpräfektur erhielt den Namen Tengyue und wurde der Präfektur Yongchang unterstellt. Mit der Verwaltung wurde zunächst der Kommandant der Militärkommission (zhihui tongzhi) beauftragt. ${ }^{236}$ Ein erster Zivilbeamter trat im Jahr 1526 das Amt des Unterpräfekten (zhizhou) an. ${ }^{237}$

Das in Tengyue stationierte Truppenkontingent behielt zunächst den Status einer Militärkommandantur (junmin zhihui shi si). Im Jahr 1532 wurde es dann in eine Garnison umgewandelt, welche die Bezeichnung Garnison Tengchong (Tengchong wei) erhielt. Ihr Name wurde also im Unterschied zu der zivilen Verwaltungseinheit nicht in Tengyue abgeändert.

\footnotetext{
232 YCFZ, S. 51; zu He Mengchun siehe auch DMB, S. 1531-32.

233 Der Verwaltungsbezirk Jin-Cang erstreckte sich auf Jinchi und die im Osten daran angrenzenden Gebiete am Lancangjiang (Mekong). Die entsprechende Verwaltungseinheit des Provinzkontrollamtes, der Militärbezirk (bingbei dao) Jin-Teng, war bereits im Jahr 1476 (Chenghua 12) gegründet worden und bestand weiterhin.

${ }^{234}$ YCFZ, S. 51

${ }^{235}$ TYTZ, S. 65. An anderer Stelle heißt es, daß „der Posten des Verteidigungskommandeurs (zhenshou canjiang) im 9. Jahr der Ära Jiajing (1530) abgeschafft wurde“ (TYTZ, S. 176/128). Auch im YCFZ wird ein anderes Datum genannt: „Im 2. Jahr der Ära Jiajing (1523) wurde die Unterpräfektur Tengchong gegründet und der junmin-Präfektur Yongchang (Yongchang junmin fu) unterstellt“" (YCFZ, S. 52).

${ }^{236}$ TYTZ, S. 144

${ }^{237}$ Ebenda.
} 


\section{Die Verwaltungseinheit Präfektur Yongchang Mitte des 16. Jahrhunderts}

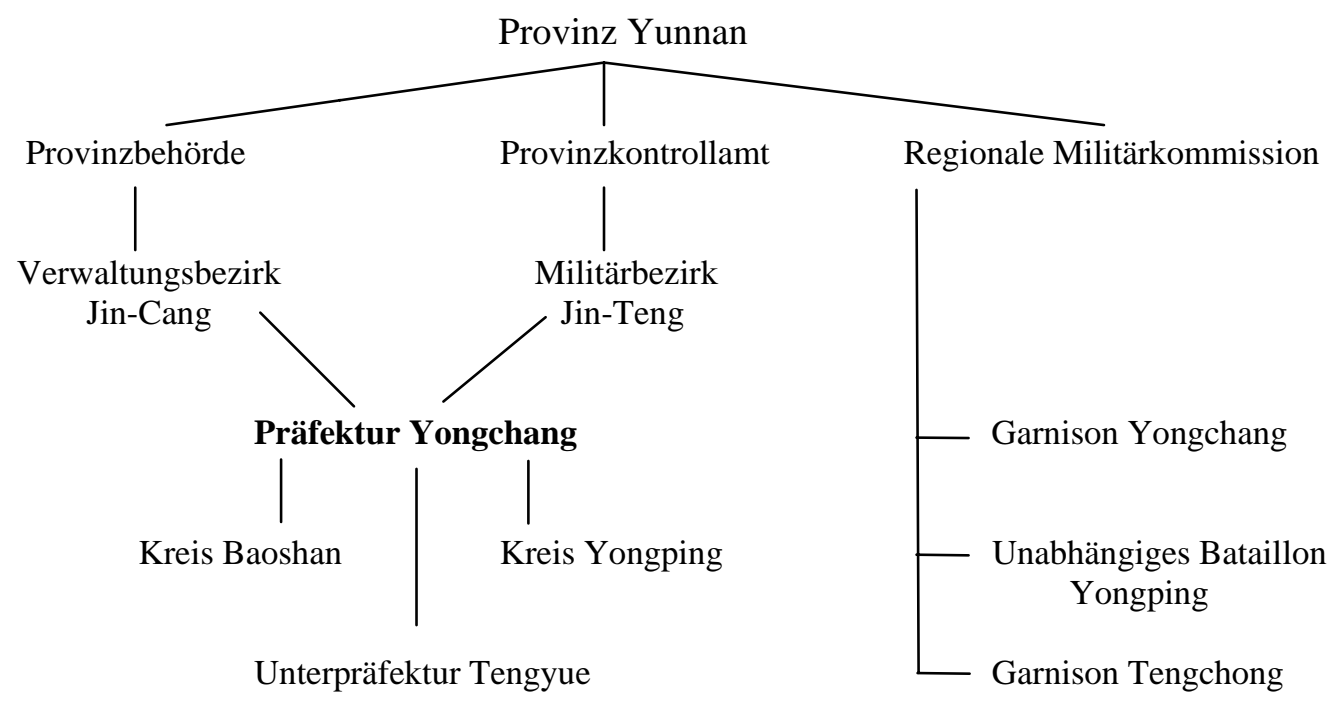

Die Unterpräfektur Tengyue bildete die westliche Grenze der Präfektur Yongchang, die außerdem die Kreise Baoshan und Yongping sowie die Verwaltungseinheiten der Gebiete der einheimischen Bevölkerung (Chashan si, Wadian anfu si, Fengqi si, Lujiang anfu si und Shidian si) umfaßte. ${ }^{238}$ Im Westen der Stadt Tengyue folgten dann die Verwaltungseinheiten Nandian xuanfu si, Ganya xuanfu si und Luchuan xuanfu si sowie Zhanda fu xuanfu si und Mangshi si. Im Jahr 1534 wurde für diese Gebiete ein für die Angelegenheiten der einheimischen Bevölkerung im Grenzgebiet zuständiger ,Unterpräfekt zur Besänftigung der Barbaren` (fu yi tongzhi) der Präfektur Yongchang ernannt und in Tengyue stationiert. Dieses Amt bestand bis zur Zeit der Ära Tianqi (1621-1628). ${ }^{239}$

Zou Guangzuo, Kommandeur des Militärbezirks (bingbei dao) Jin-Teng während der Ära Longqing (1567-1573), hat die Entwicklung vom Militärstützpunkt Tengchong zur Unterpräfektur Tengyue noch einmal kurz und bündig zusammengefaßt:

„Früher habe ich gehört, daß die Kriegsschäden [in Tengchong] nach der Rebellion Luchuans sehr groß waren. Auf Befehl des Himmelssohnes hatte der Kriegsminister Wang Ji [Luchuan] unterworfen und gemeldet, daß die Vize-

\footnotetext{
${ }^{238}$ Der Kreis Yongping war bereits zur Zeit der Mongolenherrschaft gegründet und der Präfektur Yongchang unterstellt worden (YCFZ, S. 52).

${ }^{239}$ TYTZ, S. 107-108, 143; YCFZ, S. 51. Insgesamt werden in den Listen der Beamten in den fangzhi zehn fu yi tongzhi namentlich genannt, jedoch ohne Jahresangaben zu ihrer Amtszeit.
} 
Kriegsminister Yang Ning und Hou Jin das Territorium, wie befohlen, besetzt hatten. Danach haben sie mit dem Bau einer Stadtmauer [in Tengchong] begonnen, um diese entlegene Gegend von einem festen strategisch günstig gelegenen Ort aus zu schützen. Die Verwaltung sorgte für Frieden“. ${ }^{240}$

Die Verwaltung der neuen Unterpräfektur stand unter der Kontrolle der drei Provinzbehörden, die bereits seit dem 15. Jahrhundert Beamte auf die Hochebene von Tengchong entsandt hatten und zwar jeweils

einen Kommandeur des Militärbezirks (bingbei; Rang 4a/5a; seit 1489), einen Direktor des Verwaltungsbezirks (shouxun; Rang 4a/5a; seit der Ära Yongle, 1403-1425)

und einen Garnisonskommandanten der Militärkommission (zheng zhihui shi;

Rang 3a; seit 1443). ${ }^{241}$

Verantwortlich für die eigentliche Verwaltungsarbeit war der Unterpräfekt (zhizhou) von Tengyue. Ihm waren ein Assistent (panguan), ein Schuldirektor (jiaoshou), ein VizeSchuldirektor (xundao) und ein Polizeidirektor (limu) unterstellt sowie ein Polizeichef (xunjian), der am Übergang über den Fluß Longchuan stationiert wurde. ${ }^{242}$

\section{Die Unterpräfekten von Tengyue}

Der oberste Beamte der neugegründeten Verwaltungseinheit Tengyue war der Unterpräfekt (zhizhou) mit dem Rang 5b in der Beamtenhierarchie. Als erster Zivilbeamter trat im Jahr 1526 (Jiajing 5) Zhou Quan aus der Provinz Jiangxi das Amt des Unterpräfekten an. ${ }^{243}$ Insgesamt waren während der Ming-Zeit dreißig Unterpräfekten in Tengyue tätig. Die Länge ihrer Amtsperioden variierte erheblich, von einem bis zu zwölf Jahren. Diese beiden Extreme waren jedoch Ausnahmen, die meisten der Unterpräfekten waren zwischen zwei und sechs Jahren in Tengyue.

\footnotetext{
${ }^{240}$ TYTZ, S. 107, 314 (,Nachruf auf den [nicht realisierten] Plan zum Bau einer äußeren Stadtmauer“ [yi zhu wai cheng jiwen]).

${ }^{241}$ In Tengchong/Tengyue waren zwischen dem Jahr Hongzhi 2 (1482) und der Zeit der Ära Wanli (1573-1620) insgesamt vierundzwanzig Kommandeure des Militärbezirks (bingbei) stationiert. Sie alle waren jinshi, Träger des höchsten akademischen Titels der Absolventen der Staatsprüfungen in der Hauptstadt (siehe TYTZ, S. 106-107).

Unter den sechzehn Verwaltungsdirektoren (shouxun) befanden sich dreizehn jinshi (ein gongsheng [Student der Staatsuniversität Guozijian], zwei ohne Angabe), die von der Zeit der Ära Yongle (1403-1425) bis zur Ära Wanli nach Teng entsandt worden waren (siehe TYTZ, S. 107).

In der Liste der Beamten des TYTZ werden lediglich vier Kommandanten der Militärkommission (zheng zhihui shi) genannt, die in der Zeit zwischen dem Jahr Zhengtong 8 (1443) und dem Jahr Jiajing 15 (1536) in Teng Dienst taten (TYTZ, S. 119). Ihnen waren verschiedene niederrangige Militärbeamte und Truppenführer unterstellt, die im TYTZ bis zur Zeit der Ära Wanli aufgelistet sind (siehe TYTZ, S. 119ff).

${ }^{242}$ Siehe TYTZ, S. 108-118.

${ }^{243}$ TYTZ, S. 144
} 
Die Mehrzahl von ihnen stammte aus den Provinzen südlich des Yangzi; acht Unterpräfekten kamen allein aus Yunnans Nachbarprovinz Guizhou, weitere fünf aus Sichuan. ${ }^{244}$

Sechzehn der Unterpräfekten hatten den akademischen Titel eines Graduierten der Provinzprüfungen (juren); sieben davon kamen aus Guizhou, drei aus Sichuan. Fünf Beamte führten den Titel eines Absolventen der staatliche Hochschule (jiansheng). Keiner der Unterpräfekten besaß den höchsten akademischen Titel eines Absolventen der Prüfungen in der Hauptstadt, den des jinshi. ${ }^{245}$

Anders in der übergordneten Verwaltungseinheit, der Präfektur Yongchang. Dort hatte bereits im Jahr 1523 der erste Präfekt (zhifu) sein Amt angetreten: Yan Shitai, ein jinshi aus Zhejiang. Von den sechsundzwanzig Präfekten der Ming-Zeit hatten fünf den Titel eines jinshi und acht den eines juren erworben. ${ }^{246}$ Die meisten Präfekten kamen aus den Provinzen Zhejiang (5), Sichuan (4) und Guizhou (3). Zwei der Präfekten von Yongchang mit einem jinshi-Titel stammten aus den nördlichen Provinzen Liaoning und Shandong. ${ }^{247}$

Vierzehn der Unterpräfekten von Tengyue sind als ,verdiente Beamte’(mingchen [4] und xunli [10]) ausgezeichnet worden. Die fangzhi enthalten kurze biographische Notizen, teilweise mit Angaben zu ihrer Herkunft und Karriere. ${ }^{248}$

Bei fünf der genannten Beamten wird vermerkt, daß ihre Versetzung nach Tengyue eine Beförderung bedeutete. Vordem waren sie als Kreismagistrat (zhixian), Assistierender Präfekt (tongpan) oder Richter in einer Präfektur (tuiguan) in den Provinzen Zhili, Hubei, Henan, Guizhou und Yunnan tätig gewesen. Vier der ,verdienten Beamten’ sind nach ihrer Tätigkeit als Unterpräfekten zu Präfekten befördert worden, zwei traten Posten in Yunnan an (in Lijiang und Dali), einer wurde nach Hebei, ein anderer nach Guangdong versetzt. Ein weiterer wurde zum Kommandeur eines Militärbezirks ernannt.

Die Beispiele zeigen, daß das Amt des Unterpräfekten in der Regel nicht der erste Posten im Laufe einer Beamtenkarriere war, so daß die Männer, die nach Tengyue entsandt

\footnotetext{
${ }^{244}$ Heimatprovinzen der dreißig Unterpräfekten von Tengyue in der Ming-Zeit: Anhui (1), Fujian (1), Guangdong (1), Guizhou (8), Hunan (1), Jiangxi (1), Sichuan (5), Yunnan (1), Zhejiang (2), keine Angabe (9) (TYTZ, S. 108-109).

${ }^{245}$ TYTZ, S. 108-110. Ein Unterpräfekt führte den Titel eines bagong, ein weiterer hatte den käuflichen Titel eines ligong erworben (ebd.). Keine Angaben in den fangzhi zu den akademischen Titeln der anderen sieben Unterpräfekten.

${ }^{246}$ Über den akademischen Status der anderen Präfekten gibt es im YCFZ keine Informationen. Die fehlenden Angaben erklären sicherlich auch die vergleichsweise geringe Anzahl der juren unter den Präfekten.

${ }^{247}$ YCFZ, S. 171-172, 150. Je ein Präfekt stammte aus den Provinzen Fujian und Hubei, zu den anderen werden keine Angaben gemacht.

Sechs der Präfekten von Yongchang sind während der Ming-Zeit als ,verdiente Beamte‘ (mingchen) bezeichnet worden. Angaben zu ihrer Karriere werden im YCFZ jedoch nicht gemacht. Lediglich bei zwei Präfekten wird eine Beförderung vermerkt, eine zum Salz-Kontrolleur (yanyunshi) in Fujian und eine zum Kommandeur eines Militärbezirks; ohne Ortsangabe) (YCFZ, S. 150).

${ }^{248}$ Siehe TYTZ, S. 144-145.
} 
wurden, bereits praktische Kenntnisse in der Lokalverwaltung erworben hatten. So war z.B. Liu Xuan zunächst Richter (tuiguan) in der Provinzhauptstadt Yunnan fu, ehe er nach Tengyue versetzt wurde, wo er sieben Jahre lang (1541-1548) als Unterpräfekt tätig war, woraufhin er befördert wurde und das Amt des Präfekten von Lijiang (nördlich von Yongchang und Dali gelegen) antrat. ${ }^{249}$ Während sich Liu Xuans Beamtenkarriere hauptsächlich in Yunnan, der Nachbarprovinz seiner Heimat Guizhou, abgespielt hat, sind die anderen Unterpräfekten, soweit genannt, zuvor in verschiedenen Provinzen des Reiches tätig gewesen und brachten ihre Erfahrungen aus der Verwaltungspraxis des Kernlandes in die Grenzregion mit.

Die Entsendung von Beamten in Verwaltungseinheiten fernab ihrer Heimat war gängige Praxis im Ming-Reich. In Tengyue spiegeln die verschiedenen Herkunftsorte der Unterpräfekten auch die Zusammensetzung der Bevölkerung wider, die ebenfalls aus den verschiedenen Provinzen Chinas in den Südwesten einwanderte.

\section{Die Bevölkerungsentwicklung in Yunnan und ihre Dokumentation in den fangzhi}

Die Eingliederung Yunnans in das chinesische Reich im 13. Jahrhundert hat einen Prozeß in Gang gesetzt, der die Bevölkerungsstruktur der Region stark veränderte. Aus strategischen Erwägungen hat die Zentralregierung Chinas seitdem die Besiedelung des fernen Südwestens gefördert, um ihn dauerhaft zu befrieden und enger an die Kernregion anzubinden. In der Ming-Zeit wurde diese Politik fortgesetzt. Zunächst waren es chinesische Truppen, die in Militärkolonien stationiert wurden und teils Militärdienst leisteten, teils Ackerbau betrieben (tuntian). Ihnen folgten Beamte der Zivilverwaltung und zahlreiche Siedler aus Zentralchina, insbesondere aus den Provinzen am Yangzi. ${ }^{250}$

In seiner Untersuchung der Bevölkerungsentwicklung im Südwesten Chinas kommt James Lee zu dem Ergebnis, daß die Bevölkerung dort (in Yunnan, Guizhou, dem südlichen Sichuan) in der Zeit von 1250 bis 1850 insgesamt um beinahe das Siebenfache zugenommen hat. ${ }^{251}$ Er unterteilt diesen Zeitraum in zwei Perioden, die Zeit von 1250 bis 1600, in der die Zahl der Bevölkerung von drei auf fünf Millionen und die Zeit von 1700 bis 1850, in der sie weiter auf zwanzig Millionen gestiegen ist. ${ }^{252}$ Im Ergebnis stellt Lee eine Zunahme

\footnotetext{
${ }^{249}$ TYTZ, S. 145

${ }^{250}$ Im einer zusammenfassenden Darstellung der historischen Entwicklung Yunnans, dem Band ,Yunnan keai de difang‘, wird darauf hingesiesen, daß im Jahr 1389 ca. 2,5 Millionen Menschen aus Jiangnan und Jiangxi nach Yunnan umgesiedelt worden sind, im folgenden Jahr erneut 800.000 aus Jiangnan und später noch weitere 300.000 Menschen aus der Region Nanjing (ebd., S. 612).

${ }^{251}$ James Lee, Food supply and population growth in Southwest China, 1250-1850

${ }^{252}$ Lee, S. 712
} 
der Bevölkerung besonders im 15. und 16. Jahrhundert fest und zwar sowohl in den dichter besiedelten Gebieten wie Dali und Anning am Dian-See, als auch in Grenzgebieten wie Tengchong oder Shiping (Präfektur Lin’an). ${ }^{253}$

Nachdem der Militärstützpunkt Tengchong Mitte des 15. Jahrhunderts befestigt worden war, wurde auch dort damit begonnen, die Entwicklung der örtlichen chinesischen Bevölkerung schriftlich festzuhalten. Die fangzhi von Tengyue und Yongchang enthalten Statistiken, in denen die Bevölkerungszahlen aus verschiedenen Jahrgängen zum einen nach der Anzahl der Haushalte $(h u)$, zum anderen nach der der Einzelpersonen (kou/dingkou) aufgeführt sind. Diese Listen basieren auf den Angaben der örtlichen Bevölkerungsregister; sie sind jeweils chronologisch in drei Abschnitte gegliedert: Zunächst die Zeit der Militärkommandantur Tengchong (Tengchong si), dann folgt die Zeit der Unterpräfektur Tengyue während der Ming-Dynastie und schließlich die Daten aus der Qing-Zeit. ${ }^{254}$

Die ersten Zahlen stammen aus dem Jahr 1464, die letzten Daten aus der Ming-Zeit aus dem Jahr 1567. Diese Daten lassen viele Fragen offen. Worauf beziehen sich die angegebenen Zahlen? Geben sie lediglich die Anzahl der Bevölkerung innerhalb der Stadtmauern wieder oder beinhalten sie auch die Bewohner der Vorstadt vor dem Südtor, der Dörfer in näherer oder weiterer Umgebung der Stadt? Und welche Personen wurden überhaupt gezählt? In den fangzhi gibt es lediglich zu den Daten aus dem 16. Jahrhundert eine Aufschlüsselung nach Personengruppen, der zu entnehmen ist, daß generell Militär- und Zivilhaushalte, Männer und Frauen gezählt worden sind.

James Lee weist darauf hin, daß in den zeitgenössischen Statistiken aus der Ming- und der anschließenden Qing-Zeit in der Regel nur ein Teil der Gesamtbevölkerung erfaßt worden ist. Sie geben zumeist nicht die tatsächliche Zahl der chinesischen Bevölkerung wieder, sondern die Anzahl der zu Steuerleistungen im Rahmen des lijia-Systems Verpflichteten; Unterregistrierung, um der Pflicht zum Frondienst zu entgehen, war entsprechend weit verbreitet. ${ }^{255}$ Häufig wurden neu zugewanderte Personen, die noch nicht in dieses System eingegliedert waren, nicht mitgezählt. ${ }^{256}$ Eine andere Gruppe, die von den Statistiken nicht erfaßt wurde, waren Han-Chinesen, die in die Gebiete der tusi umgesiedelt waren. Die

\footnotetext{
${ }^{253}$ Lee, S. $715-716$

${ }^{254}$ Zur Bevölkerungsentwicklung in der Qing-Zeit siehe unten Kap. IV. A. 5., S. $238 f f$.

${ }^{255}$ Lee, S. 714

${ }^{256}$ TYTZ, S. 49-50
} 
größte nicht registrierte Gruppe im Südwesten Chinas waren die verschiedenen einheimischen Völker innerhalb und außerhalb der chinesischen Verwaltungseinheiten. ${ }^{257}$

Die Statistiken in den Lokalhandbüchern erfassen somit lediglich einen Teil der chinesischen Bewohner des Grenzgebietes. Hinzu kommt, daß den dort aufgeführten Bevölkerungszahlen der einzelnen Jahrgänge jeweils unterschiedliche, im Einzelnen nicht näher erläuterte Erhebungskriterien zu Grunde liegen, so daß diese sich nur bedingt miteinander vergleichen lassen. Die Verfasser der fangzhi waren sich dieser Problematik bewußt, sie weisen selbst sehr nachdrücklich auf die Unvollständigkeit und Fehlerhaftigkeit der Bevölkerungsregister hin. ${ }^{258}$ Ihre kritischen Anmerkungen tragen zum Verständnis der Statistiken bei und so können die Daten aus den fangzhi immerhin eine ungefähre Vorstellung von der Größe und Zusammensetzung der Bevölkerung von Teng vermitteln.

\section{1. Die Bevölkerung von Tengchong / Tengyue in der Ming-Zeit}

Im Jahr 1445 wurde in Tengchong eine Militärkommandantur (junmin zhihui shisi) gegründet, die fünf Bataillone kontrollierte. Zu dieser Zeit war die Region Kriegsgebiet, in das immer neue Truppeneinheiten entsandt wurden. Tengchong war ihr zentraler Stützpunkt, wo nun weit mehr Soldaten stationiert waren, als die regulär 5600 Mann der fünf Bataillone. Allein für den Bau der Stadtmauer in den Jahren 1445 bis 1448 sollen 15.000 Soldaten zur Verfügung gestanden haben. ${ }^{259}$

Folglich beziehen sich die ersten Angaben zur Bevölkerung von Tengchong in den fangzhi auf die dort stationierten Soldaten. In den Statistiken wird in diesem Zusammenhang lediglich die Zahl der Soldaten der regulären Truppen (Han jun) genannt und darauf hingewiesen, daß es in deren Rängen bereits seit der Ära Zhengtong (1436-1450) Lücken gegeben habe und daß sich die Anzahl der 5600 Soldaten der fünf Bataillone dann im Laufe der Zeit sogar um die Hälfte reduziert habe. ${ }^{260}$ Gründe für diesen deutlichen Rückgang der Truppenstärke in der Ming-Zeit sehen die Verfasser der fangzhi nicht allein im Berufsrisiko der Soldaten, sondern auch in den klimatischen Bedingungen in der Region und in den unzulänglichen politischen Maßnahmen, die keine wirkliche Lösung der Probleme vor Ort anzubieten hatten:

\footnotetext{
${ }^{257}$ Lee, S. 715

${ }^{258}$ Siehe TYZZ, S. 62; TYTZ, S. 49.

${ }^{259}$ TYTZ, S. 67; TYZZ, S. 50

${ }^{260}$ TYZZ, S. 62; TYTZ, S. 49
} 
„Obwohl es in den Rängen der regulären Truppen Lücken gab, waren sie ursprünglich doch recht zahlreich. Warum sind bis heute so viele Soldaten entflohen?

Teng ist eine Garnison an der Grenze, wo das Land karg ist. Die siebzig Prozent [der Soldaten], die Ackerbau betrieben, haben sich zerstreut, da es aufgrund von Mißernten schwierig für sie war, die Steuern zu bezahlen. [Es kommt hinzu, daß sich] das Land nahe dem Gebiet befindet, in dem die Malaria verbreitet ist (zhang xiang).

Die [restlichen] dreißig Prozent, die exerzierten, wurden bei der Grenzverteidigung getötet. Als [ihre Anzahl] überprüft wurde, wurden die Lücken [in ihren Reihen] festgestellt, so daß die Ränge durch die ackerbautreibenden Soldaten (tunzhongzhe) ergänzt werden mußten. Deshalb nahm [auch die Zahl der] Soldaten, [die noch ihre Felder bestellen konnten], immer weiter ab und obwohl die Steuern mehrere Jahre lang gesenkt wurden, konnten [die Ackerbau betreibenden Soldaten] die festgesetzte Quote für den [abzuliefernden] Reis nicht erfüllen“. ${ }^{261}$

Mit der lapidaren Bemerkung, daß die zur Grenzverteidigung eingesetzten Soldaten getötet worden sind, wird hier darauf hingewiesen, wie verlustreich die jahrelangen Kriege gegen Luchuan und die Sicherung des Stützpunktes Tengchong für das Ming-Reich tatsächlich gewesen sind.

Um die Verluste auszugleichen und den Stützpunkt Tengchong zu sichern, wurden die Soldaten, die eigentlich Ackerbau betreiben sollten, rekrutiert; diese fehlten dann bei der Feldarbeit. Zudem machten die Verbreitung der Malaria, Mißernten und hohe Steuern den Militärkolonisten von Tengchong zu schaffen. Zwar hatte die Regierung die Schwierigkeiten vor Ort erkannt und entsprechend die Steuern gesenkt, mit dieser Maßnahme allein konnte jedoch nicht verhindert werden, daß weiterhin Soldaten desertierten.

Gleichwohl nahm die Zahl der registrierten Bevölkerung von Tengchong zu dieser Zeit langsam zu. Die Statistiken zur Bevölkerungsentwicklung in den fangzhi beginnen mit den Angaben zu zwei Jahrgängen aus der Zeit nach Beendigung der Kriege gegen Luchuan. In den acht Jahren von 1464 bis 1472 hatte die Bevölkerung um etwa sechzig Haushalte und

${ }^{261}$ TYZZ, S. 62; TYTZ, S. 49 
einhundertzwanzig Personen zugenommen. In Tengchong waren demnach knapp vierhundert Haushalte sowie etwa zweieinhalbtausend Personen ansässig. Ob es sich bei den Haushalten lediglich um Militärhaushalte gehandelt hat oder auch um zivile, geht aus den Statistiken nicht hervor. Die im Verhältnis zu den Haushalten große Zahl der Einzelpersonen verweist auf Soldaten oder andere alleinstehende Zuwanderer. ${ }^{262}$

Tabelle 5: Die Bevölkerungsentwicklung von Tengchong/Tengyue nach den Angaben der fangzhi ${ }^{263}$

Jahr Haushalte $(h u) \quad$ Personen (kou/dingkou)

Militärkommandantur Tengchong

$\begin{array}{rcc}\mathbf{1 4 6 4} & 317 & 2540 \\ \mathbf{1 4 7 2} & 379 & 2661 \\ \mathbf{1 5 0 2} & 2560^{264} & 7020 \\ \mathbf{1 5 1 2} & 1658 & 9742 \\ \text { Unterpräfektur Tengyue } & & \\ \mathbf{1 5 3 2} & 1836 & 11.326^{265} \\ \mathbf{1 5 5 2} & 1909 & 11.120 \\ \mathbf{1 5 6 7} & 1909 & 11.120\end{array}$

Betrachtet man die Bevölkerungszahlen für die Militärkommandantur Tengchong, so fällt zunächst die starke Zunahme der Bevölkerung in den dreißig Jahren von 1472 bis 1502 auf. Dabei ist die Zahl der registrierten Haushalte um fast das Siebenfaches gestiegen, während sich die Zahl der Personen lediglich knapp verdreifacht hat. Auffällig ist auch, daß die Anzahl der für das Jahr 1512 verzeichneten Haushalte (1658 hu) deutlich geringer ist, als die für das Jahr 1502 genannte (2560 hu), während die Anzahl der Einzelpersonen im selben Zeitraum stark zugenommen hat (von 7020 kou auf 9742 kou). Zur Erklärung

\footnotetext{
${ }^{262}$ Verteilte man die angegebenen Personen auf die Haushalte, so ergäbe sich eine Anzahl von durchschnittlich acht Personen pro Haushalt. Diese Zahl wäre für die Haushalte von Soldaten oder Siedlern in diesem neuen Grenzgebiet zu hoch, sie zeigt, daß sich zunächst hauptsächlich Einzelpersonen neu in Tengchong angesiedelt haben.

Die Zahl der Einzelpersonen entspräche auch in etwa der Hälfte der Soll-Stärke der fünf Bataillone. Auf diese Größe soll sich, wie oben erwähnt, die Truppe verkleinert haben. In den fangzhi gibt es jedoch keine Angaben dazu, ob hier lediglich Soldaten oder auch Zivilpersonen registriert worden sind.

${ }^{263}$ TYTZ, S. 49-50; TYZZ, S. 61-63; YCFZ, S. 99

${ }^{264}$ Im TYZZ (S. 61) wird die Gesamtzahl der Haushalte abweichend mit 2568 angegeben.

265 TYZZ, S. 61-63: Die Summe der angegebenen Einzelposten beträgt 11.326; als Gesamtsumme ist im fangzhi jedoch 10.326 angegeben.
} 
dieses Sachverhaltes zitieren die Verfasser der fangzhi ein altes Handbuch aus dem 16. Jahrhundert, in dem erläutert wurde, daß es

„zu jener Zeit außer den Militärhaushalten viele Zugezogene (kehu) gegeben habe, deren Nachkommen zahlreicher wurden. ... Ursprünglich waren sie nicht zur Leistung von Arbeitsdiensten verpflichtet, dennoch gab es einige, deren Geburt im Anhang des Registers aufgeführt wurde. Einige haben auch für viel Geld eine Haushaltsregistrierung erkauft, dabei ihr Vermögen und infolge dessen wiederum ihre Registrierung verloren. Die Personen selbst existierten natürlich weiterhin.

Vor der Ära Zhengde (1506-1522) haben die beiden Verteidigungskommandeure (zhenshou) auch Haushalte von Zugezogenen in das Bevölkerungsregister eingetragen, danach ist dies jedoch nicht fortgesetzt worden“ ${ }^{266}$

Die Angaben für das Jahr 1502 beruhen demnach auf neuen Erhebungskriterien, die der größer gewordenen Bevölkerung von Tengchong Rechnung trugen und anders als zuvor auch die inzwischen neu zugezogenen Siedler registrierten. So vermitteln die für das Jahr 1502 aufgeführten Zahlen vermutlich ein durchaus realistisches Bild von der Größe der chinesischen Bevölkerung der Militärkommandantur Tengchong.

Später wurde die Zählung der Zuwanderer nicht mehr konsequent fortgesetzt, gleichzeitig gab es Haushalte, die ihre Registrierung verloren, auch die schwierigen Lebensbedingungen haben sicher dazu beigetragen, daß sich Haushalte auflösten, deren Angehörige jedoch weiterhin in den Listen der Einzelpersonen verzeichnet blieben.

\section{2. Die Bevölkerung der Unterpräfektur Tengyue Mitte des 16. Jahrhunderts}

Mit der Gründung der Unterpräfektur Tengyue im Jahr 1522 wurde die Bevölkerung neu geordnet und die Haushalte von acht Nachbarschaften (li; ein li umfaßte regulär 110 Familien) in Tengyue registriert, die recht programmatische Namen führten:

Jingbian (,die Grenze befrieden'),

Zhanhua (,Veränderungen ausbreiten'),

Yongan (,dauerhafter Friede'),

Taiping (,großer Friede‘),

${ }^{266}$ TYTZ, S. 49; TYZZ, S. 61. Zitiert wurde ebendort aus dem fangzhi des Unterpräfekten Shen Zuxue, der von 1567 bis 1573 in Tengyue tätig war. 


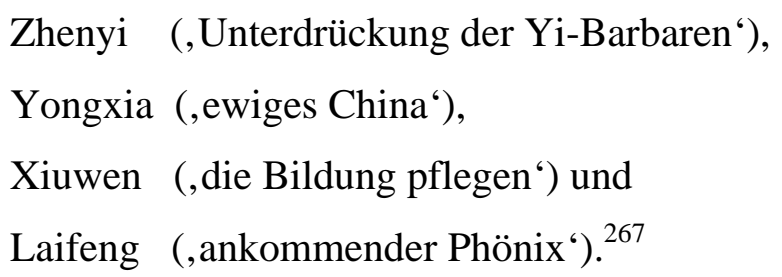

Die knapp neunhundert Familien der Nachbarschaften waren ursprünglich Militärhaushalte. Nach der Gründung der Unterpräfektur wurde die Bevölkerung insgesamt nach neuen Kriterien erfaßt, wobei ehemalige Militärangehörige nun teilweise auch als Zivilisten registriert wurden. Diese neue Datenerhebung brachte jedoch erhebliche Probleme für die betroffenen Personen mit sich, die in den fangzhi ausführlich geschildert werden:

\begin{abstract}
„Als die Verwaltung der Unterpräfektur [im Jahr 1522] neu organisiert wurde, wurden diejenigen klassifiziert (bie), die bisher nicht in das Register für die Zivilbevölkerung (minji) aufgenommen worden waren. Dann wurden die regulären Truppen (guanqi) eingeteilt und der Garnison Tengchong als Soldaten zugewiesen. Die Restlichen (yu) wurden der Unterpräfektur unterstellt und als Zivilbevölkerung registriert. Aber auch im Register der Soldaten waren sie weiterhin eingetragen. [Gleichzeitig] blieb die [ursprüngliche] Truppenstärke erhalten. Unterpräfektur und Garnison ließen [die Soldaten] doppelt Dienst tun. Wie sollten sie da nicht an einen anderen Ort entfliehen?

Die Verbrecher (zui), die verbannt und zum Militärdienst verurteilt wurden, kamen hierher. Aber wenn sie ihre Strafe verbüßt hatten, gingen sie wieder [zurück in ihre Heimat]. In der ursprünglichen [Bevölkerungs]zahl waren sie ohnehin nicht mit eingerechnet worden. ${ }^{268} \ldots . .$.

Wenn die regulären Truppen geflohen waren, sollten die Reserve-Soldaten (yuding ${ }^{269}$ ) [die Lücken] in den fünf Bataillonen füllen. Doch wenn schon die Haushalte der regulären Truppen nicht mehr da waren, wieso sollten dann die Reserve-Soldaten allein noch geblieben sein?
\end{abstract}

\footnotetext{
${ }^{267}$ YCFZ, S. 52; CY 1711.4 (Stichwort lijia).

Der Begriff xiuwen entstammt einem Zitat aus dem Shangshu (Wucheng), dessen Wortlaut yan wu xiu wen (,die militärischen Aktivitäten einstellen und die Bildung pflegen') die Entwicklung Tengchongs vom Garnisonsstützpunkt hin zu einer Einheit regulären Zivilverwaltung widerspiegelt (siehe Zhongguo chenghuawen cidian, S. 1498). Der ,Berg des ankommenden Phönix‘ (Laifeng shan) befindet sich im Süden der Stadt.

${ }^{268}$ Nicht nur Straftäter wurden während der Ming-Zeit nach Yunnan verbannt, die Provinz diente auch als Exilort für in Ungnade gefallene Beamte.

269 Jeder Militärhaushalt mußte den Vorschriften entsprechend jeweils einen regulären Soldaten stellen. Dieser konnte, wenn er eingezogen wurde, einen weiteren erwachsenen Mann mitbringen, der als zusätzlicher Soldat (yuding) diente und so in seiner Heimat keine Bodensteuern zahlen und keinen Frondienst leisten mußte (Liew, Treatises, Bd.1, S. 255).
} 
Die [Bevölkerung der] acht Nachbarschaften (lijia min) [von Tengyue] bestand ursprünglich auch aus Militärangehörigen (weiguan shejun) der Garnison. Außerdem gab es jene, die Felder und Hütten besaßen. Einige von diesen hatten die Felder verkauft, das Getreide geschnitten und waren Soldaten geworden. So enthielten die Listen derjenigen, die Frondienst leisten mußten, viele falsche Eintragungen.

Die Einheimischen (tumin) sind die in den ehemaligen Bataillonen (suo) von Tengchong registrierten einheimischen Soldaten (tujun). Das Militärregister war noch so wie früher, aber die Leute wurden damals zwangsweise auch als Zivilisten ( $\mathrm{min}$ ) registriert, da sie Einheimische waren.

Die lijia-Bevölkerung mußte Frondienst sowie weitere Abgaben und Dienste leisten. Ach, der Frondienst war wahrlich zuviel [für sie] geworden! Ja, wären nur Fron und Steuern reduziert worden, wären die Menschen dann nicht schon glücklich gewesen? Das ist es eben, was sich die Bevölkerung von ihrem Unterpräfekten erhofft“ ${ }^{270}$

Das Hauptanliegen bei der Neuregistrierung der Bevölkerung der Unterpräfektur war also die Erhaltung der Truppenstärke der fünf Bataillone der Garnison Tengchong. Gleichzeitig wollten die verantwortlichen Beamten aber auch dafür sorgen, daß in der neuen Einheit der Zivilverwaltung auch Zivilbevölkerung ansässig war. So wurden zunächst bisher nicht registrierte Einwohner in die Listen aufgenommen und Reserve-Soldaten als Zivilpersonen registriert. Letztere wurden jedoch auch weiterhin im Militärregister geführt; eine Abgleichung der beiden Register scheint nicht vorgenommen worden zu sein. Zumal diese Reserve-Soldaten nach wie vor bei Bedarf in die regulären Truppeneinheiten nachrücken mußten, wofür ohnehin kaum genug Personen zur Verfügung gestanden haben, da viele bereits desertiert waren.

Folglich verzeichnen die Statistiken zur Bevölkerungsentwicklung Mitte des 16. Jahrhunderts bei einer Zunahme der registrierten Haushalte insgesamt auch eine steigende Zahl von Zivilhaushalten, während die Anzahl der Militärhaushalte abgenommen hat (siehe Tab. 6, S. 101).

\footnotetext{
${ }^{270}$ TYZZ, S. 62; TYTZ, S. 49. Die Verfasser der fangzhi weisen hier nachdrücklich auf das Versagen der örtlichen Beamten hin, deren Aufgabe es gewesen wäre, für eine korrekte Registrierung zu sorgen. Sie schließen ihre Darstellung mit einem deulichen Appell an die Unterpräfekten, derartige Mißstände zu beheben. Hier zeigt sich, daß die fehlerhafte Registrierung der Bevölkerung auch in späteren Jahren ein Problem für die Verwaltung der Unterpräfektur darstellte. Schließlich waren die Unterpräfekten auch mit dem Einziehen der Steuern befaßt und mußten Diskrepanzen zwischen der festgelegten Quote und dem tatsächlichen Steueraufkommen ausgleichen.
} 
Tabelle 6: Die Bevölkerung der Unterpräfektur Tengyue nach Haushalten ${ }^{271}$

\begin{tabular}{lcrr}
\multicolumn{1}{c}{ Jahr } & $\underline{\mathbf{1 5 3 2}}$ & $\underline{\mathbf{1 5 5 2}}$ & $\underline{\mathbf{1 5 6 7}}$ \\
Militärhaushalte (junmin) & 1380 & 1171 & 1103 \\
Zivilhaushalte (minhu) & $171^{272}$ & 439 & 806 \\
Haushalte der Poststationen (mazhanhu) & 272 & 272 & - \\
Mönchshaushalte (senghu) & 13 & 27 & - \\
& & & 1909
\end{tabular}

Die Registrierung der Haushalte war mehr als nur eine Formalie, sie bildete die Grundlage für die Bemessung der Abgaben, die die Familie leisten mußte. Falsche oder doppelte Einträge in die Register führten dazu, daß die Belastungen der Menschen in Tengyue erhöht wurden, indem ihnen zusätzlicher Militär- und Frondienst sowie höhere Steuern abverlangt wurden, die sich in der neuen Verwaltungseinheit allein mit Ackerbau anfangs kaum erwirtschaften ließen.

Generell war die Landwirtschaft im Südwesten im 14. Jahrhundert weniger entwickelt als in Zentralchina und die Nutzflächen aufgrund der geographischen Bedingungen insgesamt kleiner, verstreut gelegen und schwieriger zu bearbeiten. Daher zogen die Regionen, die leichter zu kultivieren waren, wie z. B. Dali am Erhai-See oder die Hochebenen von Yongchang und Tengchong, chinesische Zuwanderer an und bildeten dichter besiedelte ,Inseln“ in ansonsten noch ursprünglicher Landschaft. Die Migration in den Südwesten wurde vom Staat gefördert und Siedler sowie Militärkolonisten auch mit der Zuteilung von Saatgut, Vieh und Werkzeug unterstützt. Erst durch die Verbesserung der landwirtschaftlichen Anbaumethoden im Verlauf der Ming-Zeit konnte jedoch die Nutzfläche in der Provinz Yunnan vergrößert werden. ${ }^{273}$ Dies bot den Neuansiedlern die Möglichkeit, sich eine Lebensgrundlage zu schaffen und legte den Grundstein für den weiteren Zuwachs der chinesischen Bevölkerung in der Provinz. Die Aufzeichnungen aus Tengyue machen deutlich, unter welch schwierigen Bedingungen (klimatischen und bürokratischen) die Erschließung dieses Neulandes trotz der vergleichsweise günstigen Lage der Stadt vor sich gegangen ist.

\footnotetext{
${ }^{271}$ TYTZ, S. 49-50; TYZZ, S. 61-63. Eine Aufschlüsselung der Bevölkerung nach Haushalten gibt es in den fangzhi nur für die drei genannten Jahrgänge des 16. Jahrhunderts.

${ }^{272}$ TYZZ, S. 61: min 171. Abweichend davon nennt das TYTZ (S. 49) 170 minhu. Als Summe der Haushalte ergäbe sich dann lediglich 1835. Die Gesamtzahl aller Haushalte $(h u)$ wird aber ebendort auch mit 1836 angegeben.

${ }^{273}$ Lee, S. 717, 720
} 
Sie zeigen aber auch, daß die chinesische Bevölkerung der Unterpräfektur trotz dieser Schwierigkeiten bis zur Mitte des 16. Jahrhunderts insgesamt weiter zugenommen hat.

Während die Gesamtzahl der Haushalte gestiegen ist, hat die Zahl der registrierten Einzelpersonen nach den Angaben der fangzhi im selben Zeitraum leicht abgenommen. Allerdings hat nur die Anzahl der männliche Bevölkerung von Tengyue abgenommen, während die Zahl der Frauen gestiegen ist. Insgesamt lebten nach wie vor mehr Männer als Frauen in Tengyue.

Tabelle 7: Die Anzahl der Männer und Frauen in der Unterpräfektur Tengyue ${ }^{274}$

$\begin{array}{lccc}\text { Jahr } & \underline{\mathbf{1 5 3 2}} & \underline{\mathbf{1 5 5 2}} & \underline{\mathbf{1 5 6 7}} \\ \text { Männer } & 7141 & 6819^{275} & 6819 \\ \text { Frauen } & 4185 & 4301 & 4301 \\ \text { Gesamt } & 11.326^{276} & 11.120 & 11.120\end{array}$

Waren zu Beginn der Ming-Zeit zunächst chinesische Soldaten auf der Hochebene von Tengchong stationiert worden, so machten der Bau der Stadtmauer, der Aufschwung des Edelsteinhandels, die Verbesserung der landwirtschaftlichen Produktionsmethoden und schließlich die Etablierung ziviler Verwaltungsstrukturen das Gebiet ein Jahrhundert später auch für Zuwanderer, die mit ihren Frauen und Familien umsiedelten, interessant. In der Ming-Zeit galt zudem ein Gesetz, welches Migranten vorschrieb, zu heiraten, bevor sie in den Südwesten des Reiches umsiedeln konnten. Auch konnten weibliche Straftäter an Siedler verheiratet und damit sozusagen ins Exil geschickt werden. ${ }^{277}$ Jedenfalls stieg auch in Tengyue die Anzahl der Frauen und infolge die der Familien. Informationen dazu gibt lediglich eine Statistik im TYZZ, wo für das Jahr 1567 die Personengruppen der Männer und Frauen noch in Erwachsene und Minderjährige aufgeschlüsselt sind (s. Tab. 8, S. 103).

\footnotetext{
${ }^{274}$ TYZZ, S. 61. Die identischen Zahlen der Jahre 1552 und 1567 sind vermutlich eine von der anderen abgeschrieben worden. Das kann Hinweis auf die Nachlässigkeit der Autoren sein, aber auch ein Indiz dafür, daß die Bevölkerungsregister in diesem Zeitraum nicht kontinuierlich aktualisiert worden sind.

${ }^{275}$ Im TYZZ wird die Anzahl mit 1819 angegeben, wahrscheinlich handelt es sich dabei um einen Schreibfehler für 6819; siehe die Gesamtsumme ebendort sowie die Angaben zum Jahr 1567.

${ }^{276}$ Die Aufschlüsselung der Personen nach Männern und Frauen findet sich nur im TYZZ (S. 61), als Gesamtsumme der Bevölkerung für das Jahr 1532 ist dort 10.326 angegeben, die Summe der aufgeführten Einzelposten beträgt jedoch 11.326.

${ }^{277}$ Lee, S. 714 (siehe auch Ming huidian, 155,1a).
} 
Tabelle 8: Die Anzahl der Erwachsenen und Kinder in der Unterpräfektur Tengyue im Jahr $1567^{278}$

$\begin{array}{lllr}\text { Männer: } & 6819 & \text { Frauen: } & 4301 \\ \text { Volljährige (chengding } & & \\ \text { Minderjährige (bu chengding) } & 5720 & \text { Erwachsene (dakou) } & 3620 \\ \text { Ming } & \text { Kinder (xiaokou) } & 681\end{array}$

Die im Vergleich zu den Jungen geringe Anzahl der Mädchen läßt sich sicherlich auch darauf zurückführen, daß Töchter generell seltener registriert wurden als Söhne.

Nimmt man die Zahl der erwachsenen Frauen als Richtwert, so ergibt sich aus diesen Daten eine Anzahl von über dreitausend Familien. Eine Zahl, die deutlich höher ist als die der genannten 1909 registrierten Haushalte.

Haushalte bestanden in Yunnan jedoch nicht nur aus einer Kernfamilie. So war es bis ins 19. Jahrhundert üblich, daß arme Familien, nicht in einem eigenen Haushalt sondern bei Verwandten mit registriert wurden, ebenso konnten Zuwanderer auch bei ihrem Arbeitgeber oder Vermieter mit registriert werden. ${ }^{280}$ Entsprechend war die Zahl der Familien generell höher als die der registrierten Haushalte.

Die wachsende Bevölkerung von Tengyue lebte nicht nur innerhalb der Stadtmauern. Zou Guangzuo, der während der Ära Longqing (1567-1573) als Kommandeur des Militärbezirks Jin-Teng tätig war, berichtet im Jahr 1568 in einer Throneingabe, daß bereits tausend Familien (qian jia) außerhalb der Mauern von Tengyue wohnen würden. ${ }^{281}$ Bezogen auf die Angaben der Statistiken in den fangzhi hätte demnach mindestens ein Drittel der Bevölkerung Tengyues außerhalb der Stadtmauern gelebt, die meisten vor dem Südtor, wo Mitte des 16. Jahrhunderts eine prosperierende Vorstadt entstanden war, in der sich auch viele Händler und Kaufleute angesiedelt hatten.

\footnotetext{
${ }^{278}$ TYZZ, S. 61

${ }^{279}$ In der Ming-Zeit galten junge Leute ab sechzehn sui (also mit fünfzehn Jahren nach westlicher Zählung) als Erwachsene (ding) (CY 10. 2, Stichwort: dinglao).

${ }^{280}$ Lee, S. 725

${ }^{281}$ TYTZ, S. 314
} 


\section{Chinesische Verwaltungseinheiten an der äußersten Grenze: Die Befriedeten}

\section{Gebiete}

\section{1. Das tusi-System und die Befriedeten Gebiete im Südwesten von Tengyue}

\section{1. 1. Das tusi-System}

Unter der Bezeichnung ,tusi-System‘ lassen sich die verschiedenen Maßnahmen zusammenfassen, mit denen die Chinesen die Völker in den Randgebieten ihres Reiches sowie auch in weiter entfernten Ländern ihrer Oberhoheit unterstellt haben. ${ }^{282}$ Deren Herrschaftsgebiete wurden dann als sogenannte ,Befriedete Gebiete‘ in die Verwaltungsstrukturen des chinesischen Reiches eingebunden. Sie trugen verschiedene Bezeichnungen, wie xuanwei si, xuanfu si, anfu si oder zhangguan si und wurden allgemein auch mit dem Begriff tusi (,lokales Amt', ,einheimische Behörde‘) bezeichnet. ${ }^{283}$

Diese Regelung der Beziehungen zu anderen Völkern hatte in China eine lange Tradition, die auch die mongolischen Herrscher der Yuan-Dynastie fortgesetzt haben. Unter der Herrschaft der Ming-Dynastie wurde die Ausdehnung dieser Verwaltungsstrukturen des Kernlandes weiter systematisiert und die Beziehungen zwischen China und seinen Randvölkern wurden stärker institutionalisiert. Im Südwesten des Reiches führte diese Entwicklung zu einer engeren Anbindung Zentral-Yunnans an das chinesische Kernland, während sich das Grenzgebiet in der Region des Stromschluchtenfächers weiter differenziert entwickelte.

In Yunnan gab es während der Ming-Zeit insgesamt dreihundertzweiunddreißig tusiGebiete, darunter befanden sich elf xuanwei si, fünf xuanfu si, zwei fu xuanfu si, sieben anfu si und siebenunddreißig zhangguan si. ${ }^{284}$

Die Oberhäupter dieser Verwaltungseinheiten wurden entsprechend als xuanwei shi oder kurz als xuanwei, als xuanfu shi oder xuanfu usw. bezeichnet. Auch der generische Name tusi wurde mit der Bedeutung ,einheimischer Beamter` oder ,lokaler Beamter` von den

\footnotetext{
${ }^{282}$ Zum tusi-System in der Ming-Zeit siehe Ming shi (tusi chuan); siehe auch You Zhong, S. 348-352 und Gong Yin, S. 49-58.

${ }^{283}$ Hucker übersetzt die verschiedenen Bezeichnungen dieser Verwaltungseinheiten als ,Pacification Office‘, ,Pacification Commission` und ,Chief’s Office‘ (Hucker, 2682, 2661, 17, 304, 149).

Neben den genannten Bezeichnungen für die Befriedeten Gebiete gab es noch eine Variante derselben, ihre Verbindung mit dem Präfix fu- (,Vize-`, ,sekundär'). So hatte das Befriedete Gebiet von Zhanda (siehe unten 4. 1. 2.) im Jahr 1449 zunächst den Status eines xuanfu si inne gehabt, während der Ära Wanli (1573-1620) erhielt es dann den Status eines fu xuanfu si, eines Sekundären Befriedeten Gebietes (TYTZ, S. 154; TYZZ; S. 145).

${ }^{284}$ Gong Yin, S. 54. In der Ming-Zeit wurden im chinesischen Reich insgesamt 621 tusi-Titel verliehen, darunter 398 tuguan und 223 tusi (Herman, S. 51). Somit befand sich mehr als die Hälfte aller tusi-Gebiete des gesamten Reiches in Yunnan. [Anm.: In der Qing-Zeit wurden 708 tusi-Titel verliehen, darunter 112 tuguan und 596 tusi (ebd.)]
} 
Chinesen als Bezeichnung für diese Herrscher verwendet. Mit der Verleihung der Amtstitel erhielten sie ein Siegel (yinxin) und eine Ernennungsurkunde (haozhe), die ihre Autorität über das Gebiet im Namen des chinesischen Kaisers bestätigte. Mit diesen Titeln wurden sie zwar nominell Beamte der chinesischen Regionalverwaltung; ihre Herrschaftsgebiete regierten sie jedoch weiterhin autonom. Sie konnten ihre Beamtentitel vererben; die Erbfolge, auch die weiblicher Familienmitglieder, wurde dann in der Regel vom chinesischen Kaiser bestätigt.

Mit der Verleihung von unterschiedlichen Titeln kam auch eine gewisse Rangabstufung zum Ausdruck. ${ }^{285}$ In der neunstufigen Beamtenhierarchie erhielten die tusi Ränge zwischen $3 b$ und $7 \mathrm{~b}$ zugewiesen, mit denen jedoch, anders als bei den regulären Verwaltungsbeamten, kein offizielles Gehalt verbunden war.

\section{Tabelle 9: Die Rangstufen der Befriedeten Gebiete im Westen} der Provinz Yunnan in der Ming-Zeit ${ }^{286}$

$\begin{array}{lc}\text { xuanwei si } & 3 \mathrm{~b} \\ \text { xuanfu si } & - \\ \text { anfu si } & 5 \mathrm{~b} \\ \text { zhangguan si } & 6 \mathrm{a}\end{array}$

Entsprechend der allgemeinen Organisation der chinesischen Verwaltung wurden die einheimischen Machthaber zudem entweder zu lokalen Zivilbeamten (tuguan) oder zu lokalen Militärbeamten (tusi) ernannt, die dem entsprechend entweder dem Personalministerium (libu) oder dem Kriegsministerium (bingbu) unterstellt wurden.

\footnotetext{
${ }^{285}$ Die Verwaltungsbeamten Chinas wurden in die Ränge eins (höchster Rang) bis neun (niedrigster) eingeteilt; in jeder Rangstufe gab es zwei Gruppen, deren eine Vorrang vor der anderen genoß und die in der westlichen Literatur entsprechend mit den Buchstaben a und b gekennzeichnet werden.

${ }^{286}$ Hucker, 2682, 2661, 17, 149. Die Rangstufe des xuanfusi nennt Hucker nicht (Hucker 2661).

Am Beispiel von Zhanda und dem des Befriedeten Gebietes von Nandian, dessen Oberhaupt Dao Leying während der Ära Wanli (1573-1620) von einem xuanfu shi zum xuanwei shi befördert worden ist (TYZZ, S. 138), wird deutlich, daß das xuanfu si unterhalb des xuanwei si, aber über dem zhangguan si einzuordnen ist. Hucker (304) nennt noch eine weitere in der Yuan- und Ming-Zeit gebräuchliche Bezeichnung für ein Befriedetes Gebiet unter der Verwaltung eines einheimischen Herrschers in Südwest-China, das zhaotao si (Rang 5b). Im Gebiet des Stromschluchtenfächers westlich von Tengyue war jedoch keine derartige Verwaltungseinheit gegründet worden.

Die Aufwertung eines Befriedeten Gebietes erfolgte in der Region des Stromschluchtenfächers zumeist während bzw. nach Militäraktionen der Ming. Hatte das Oberhaupt einer solchen Verwaltungseinheit seine Loyalität gegenüber dem Ming-Reich bewiesen, indem es dessen Feldzüge in der Region unterstützte, wurde es mit der Ernennung zu einem ranghöheren Befriedeten Gebiet belohnt. Die meisten Veränderungen im Status der Befriedeten Gebiete im Südwesten Tengyues erfolgten zur Zeit der Feldzüge gegen Luchuan (Mitte des 15. Jahrhunderts) und der Kämpfe mit Birma in den achtziger Jahren des 16. Jahrhunderts. Zu den Veränderungen in einzelnen tusi-Gebieten südwestlich von Tengyue siehe unten 4. 1. 2.
} 
Die Herrschaftsgebiete der einheimischen Zivilbeamten befanden sich in der Regel innerhalb von Provinzgrenzen, während sich die der einheimischen Militärbeamten an politischen Grenzen des Reiches befanden. Die tusi genossen größere Autonomie als die tuguan, die auch darin zum Ausdruck kam, daß sie größere Truppenverbände unterhielten, welche sie auf Aufforderung der chinesischen Regierung gegebenenfalls zur Verteidigung der Grenzen Chinas bereitzustellen hatten. Die Hauptaufgabe der einheimischen Herrscher sah man in China darin, daß sie den Frieden und Stabilität in ihren Hoheitsgebieten und somit an der Peripherie des Kaiserreiches aufrecht zu erhalten hatten. ${ }^{287}$

\section{1. 2. Die Befriedeten Gebiete im Südwesten der Unterpräfektur Tengyue}

Von der Unterpräfekturstadt Tengyue nach Südwesten bis hin zum Oberlauf des Irawadi erstreckten sich zunächst drei Gebiete, die von den Ming zu Verwaltungseinheiten unter lokaler Sonderverwaltung (tusi) erklärt wurden: Die Befriedeten Gebiete (xuanfu si) Nandian und Ganya sowie das sekundäre Befriedete Gebiet (fu xuanfusi) Zhanda. Südlich dieser drei tusi befand sich Longchuan xuanfu si (das frühere Luchuan), mit dem sekundären Befriedeten Gebiet (fu xuanfusi) Zhefang. Zu Beginn der Ära Wanli (1573-1620) entstand im Gebiet von Longchuan noch eine sechste einheimische Verwaltungseinheit, das Mengmao anfu si (siehe Karten 6, S. 74, und 8, S. 138).

\footnotetext{
${ }^{287}$ Herman, S. 50 .

Hucker weist darauf hin, daß die Begriffe tuguan und tusi seit dem 16. Jahrhundert zur Bezeichnung unterschiedlicher Verwaltungseinheiten verwendet wurden (Hucker 7352, 7355). Die Befriedeten Gebiete waren generell dem Kriegsministerium (bingbu) untergeordnet und wurden von ihren jeweiligen Häuptlingen (tuguan) autonom regiert (Hucker 7352, 7355). Als tusi wurden nun vor allem solche Gebiete bezeichnet, in denen zwar die Mehrheit der Bevölkerung einheimischen Volksgruppen angehörte, die aber von der regulären Zivilverwaltung assimiliert und lediglich mit dem Präfix tu- (,Erde‘, ,lokal`) gekennzeichnet wurden. Die Bezeichnung dieser Verwaltungseinheiten mit dem Präfix tu- war seit der Yuan-Zeit üblich (Hucker 7342). Mit der Verwaltung dieser Einheiten waren neben einheimischen Hauptleuten auch Beamte der regulären Verwaltung befaßt, die allesamt dem Personalministerium (libu) unterstanden.

Tengchong hatte im Jahr 1430 ebenfalls zeitweise den Status einer Lokalen Unterpräfektur (tuzhou) gehabt. Damals war ein Bataillons-Vizekommandant auf der Hochebene stationiert, der entsprechend zum Unterpräfekten ernannt und der Provinzbehörde zugeordnet wurde. Bereits im Jahr darauf wurde Tengchong jedoch wieder den Militärbehörden unterstellt.

Gong Yin hingegen erklärt, daß die Benennung der Befriedeten Gebiete, die der Militärverwaltung unterstanden, als tusi und die der Lokalen Präfekturen (tufu), Lokalen Unterpräfekturen (tuzhou) usw., welche der Zivilverwaltung unterstanden, als tuguan lediglich in der Yuan-Zeit üblich war, während diese Verwaltungseinheiten in der Ming-Zeit sämtlich als tusi bezeichnet wurden. (Gong Yin, S. 53).

In den fangzhi von Tengyue aus dem 19. Jahrhundert werden die Gebiete der einheimischen Machthaber im Südwesten von Tengyue, wie Nandian oder Ganya, als tusi bezeichnet, während kleinere Gebiete unter einheimischer Verwaltung, die sich zum Teil auch innerhalb der tusi-Gebiete befanden, unter der Rubrik tubian (einer in der Qing-Zeit gebräuchlichen Bezeichnung für „einheimische niederrangige Militärbeamte“, [CY 560.1]) aufgelistet worden sind (siehe TYTZ, S. 151-156).

In chinesischen Quellen werden zudem die Begriffe toumu, tumu oder tushe zur Bezeichnung von einheimischen Hauptleuten verwendet. Bei diesen Personen handelt es sich zumeist um Familienangehörige oder andere von den tusi eingesetzte Personen, die für die Verwaltung einer oder mehrerer Siedlungen im Herrschaftsgebiet des tusi verantwortlich waren (Herman, S. 50).
} 
Durch die tusi-Gebiete führten entlang der Flußtäler die Hauptverkehrswege, die Yunnan mit Birma verbanden und die aufgrund der geographischen Bedingungen in der Region von großer strategischer Bedeutung waren, da sie nicht umgangen werden konnten. Für den Handel und für Truppenbewegungen in Richtung Birma waren die Chinesen daher immer auf den Zugang zu diesen Routen angewiesen. Umgekehrt konnten auch Truppen aus Birma nur auf diesen Verbindungswegen in den Westen Yunnans vordringen.

Um die Sicherheit der Unterpräfektur Tengyue zu gewährleisten, war es für China daher notwendig, sich der Loyalität der einheimischen Bewohner der Befriedeten Gebiete zu versichern. Vorraussetzung dafür waren zunächst einmal Kenntnisse über die geographische Lage und die lokalen Machthaber jener Gebiete. Mit der Darstellung der historischen Entwicklung der Befriedeten Gebiete wollten die Herausgeber der fangzhi den Beamten aus dem chinesischen Kernland, die in Tengyue tätig waren und die ja auch für die Kontrolle der lokalen Sonderverwaltungseinheiten zuständig waren, entsprechende Informationen vermitteln.

Im Folgenden wird die historische Entwicklung der Befriedeten Gebiete im Südwesten der Unterpräfektur Tengyue bis zum Ende des 16. Jahrhunderts anhand der Darstellungen in den fangzhi von Tengyue und Yongchang kurz zusammengefaßt:

\section{a) Nandian ${ }^{288}$}

Das Befriedete Gebiet von Nandian befand sich im Südwesten der Unterpräfekturstadt. Sein Zentrum, die Stadt Nandian, liegt etwa vierzig Kilometer von Tengyue entfernt im Tal des Dayingjiang. Im Süden von Nandian teilte sich der Hauptverkehrsweg von Tengyue in drei Routen, deren wichtigste durch das Gebiet von Ganya und Zhanda am Fluß Daying entlang führte und in Bhamo am Irawadi wieder mit den anderen zusammentraf.

Zu Beginn der Ära Hongwu der Ming-Dynastie (1368-1399) war Dao Gongmeng, der eigentlich mit Familiennamen Gong hieß und aus Shangyuan (Präfektur Yingtian/Nanjing) in Jiangnan stammte, mit den Truppen des Südfeldzuges nach Nandian gekommen. Nachdem Gong bei der Befriedung der Region Verdienste erworben hatte, war er zum

\footnotetext{
${ }^{288}$ TYTZ, S. 151; TYZZ S. 138-139; YCFZ S.198. Nandian befand sich im Gebiet des modernen Kreises Lianghe (siehe auch Karte 18, S. 471).
} 
Kommandanten des Bataillons (qianhu) von Tengchong ernannt worden. ${ }^{289}$ Anschließend wurde Gong in Nandian stationiert und änderte seinen Familiennamen in Dao. ${ }^{290}$

Im 15. Jahr der Ära Hongwu (1382) wurde die Präfektur (fu) Nandian gegründet. Im 11. Jahr der Ära Yongle (1413) wurde sie in eine Unterpräfektur (zhou) umgewandelt und der Provinzbehörde (buzhengsi) von Yunnan unterstellt. Dao Gonghan, der jüngere Bruder und Nachfolger des Dao Gongmeng, sandte damals Tribut an den chinesischen Hof und erhielt daraufhin den Titel eines Lokalen Unterpräfekten (tu zhizhou) verliehen.

Da der tusi Dao Leying die Ming bei ihren Feldzügen gegen Si Renfa von Luchuan unterstütze, wurde er im 8. Jahr der Ära Zhengtong (1443) für seine Verdienste zum Oberhaupt des Befriedeten Gebietes (xuanfu) von Nandian befördert.

Nach der Niederwerfung Yue Fengs von Longchuan erhielt Dao Lelin im 11. Jahr der Ära Wanli (1583) den höherrangigen Titel eines xuanwei shi verliehen.

\section{b) Ganya 291}

Das Befriedete Gebiet von Ganya befand sich im Westen von Nandian, etwa einhundert Kilometer südwestlich von Tengyue im Tal des Dayingjiang.

\footnotetext{
${ }^{289}$ In der Liste der Militärbeamten von Tengchong ist ein Gong Meng nicht aufgeführt (TYTZ, S. 125).

${ }^{290}$ Für die Änderung des Familiennamens gibt es in den fangzhi unterschiedliche Erklärungen. Im TYTZ heißt es nicht nur im Fall von Nandian, daß neu in tusi-Gebiete zugewanderte Chinesen sich entweder selbst umbenannt haben oder daß ihnen diese Namen von chinesischer Seite für zumeist militärische Verdienste verliehen worden sind.

Die Verfasser des TYZZ deuten Namensänderungen von Chinesen generell als Bestreben, sich den Einheimischen anzupassen. Der Familienname Dao für Gong Meng soll denn auch nicht verliehen worden, sondern folgendermaßen entstanden sein:

„Die tusi [von Nandian] gehörten ursprünglich der Familie Gong an, einer berühmten alten Familie aus Shangyuan. Von den Barbaren (yi) wurden sie Dao genannt. Diese Bezeichnung soll angeblich von einem ihnen verliehenen Familiennamen herstammen. Doch das ist eher unwahrscheinlich.

Früher gab es dort drei Barbarenhäuptlinge, die sich China unterworfen hatten. Längst waren sie nach und nach mit den chinesischen Sitten vertraut geworden und hatten darum gebeten, daß ihnen Familiennamen gewährt werden. Der [chinesische] Oberbefehlshaber [Dao Gongmeng] sagte daraufhin verächtlich: ,Ihr fürchtet bloß von [unseren] Schwertern in Stücke gehauen zu werden' ( ru bei pa dao duo). Aus diesen Worten wurden dann die Familiennamen gemacht. Und da die nun Dao genannte Familie am größten war, wurde aus dieser ein tusi ernannt. Auf zehn [Personen] der Familie Dao, kamen sechs bis sieben zugewanderte Han-Chinesen, die alle ihren Namen in Dao änderten. Auch der Name Gong wurde mit folgender Absicht in Dao geändert: Durch den Namen Dao konnte sich das männliche Oberhaupt einer Generation [der Familie Gong] den verschiedenen Barbaren anpassen. [Zuwanderer wie] Zhong Yongsi, Wu Zhuangqiao und Wang Dian richteten sich ebenfalls sämtlich nach dieser Gewohnheit, so daß, nachdem das Amt [des tusi] einige Male weitergegeben worden war, einige nicht mehr Chinesen ähnelten; wie seltsam das ist“" (TYZZ, S. 139).

In diesem Text wird die Verschmelzung von chinesischen Zuwanderern mit der einheimischen Bevölkerung hervorgehoben: Letztere sollen zwar ,mit chinesischen Sitten vertraut gewesen sein', im weiteren Verlauf der Entwicklung wird jedoch deutlich, daß es die chinesischen Zuwanderer waren, die sich den einheimischen Namen und Sitten angepaßt haben und so wiederum vor Ort selbst auch an Einfluß gewinnen konnten.

${ }^{291}$ TYTZ, S. 154; TYZZ S. 144-145; YCFZ S. 197; Ming shi (juan 350, S. 6). Ganya befand sich im Gebiet des modernen Kreises Yingjiang (siehe auch Karte 18, S. 471).
} 
Bereits zur Zeit der Herrschaft Kublai Khans, zu Beginn der Ära Zhongtong (1260-1264), hatte sich der Herrscher von Ganya den Mongolen unterworfen. Im 12. Jahr der Ära Zhiyuan (1275) erhielt sein Hoheitsgebiet den Status der Kommandantur (junmin zongguan fu) des Regierungsbezirks Zhenxi (Zhenxi lu; siehe Karte 5, S. 48).

Im 15. Jahr der Ära Hongwu (1382) der Ming-Dynastie wurde der Regierungsbezirk in die Präfektur ( $f u$ ) Zhenxi umgewandelt und im ersten Jahr der Ära Yongle (1403) wurde dann das Befriedete Gebiet (zhangguan si) Ganya gegründet. Dessen Oberhaupt war Xi Zhongguo, der bei dem Feldzug zur Unterwerfung Yunnans Verdienste erworben hatte und nun seinen Namen in Nang Huan abänderte. Xi Zhongguo, der ursprünglich aus Yingtian in Jiangnan stammte, gilt nach Darstellung der fangzhi als Stammvater der Herrscherdynastie von Ganya. „Zum Ausdruck seiner Ehrerbietung sandte er Elefanten und Pferde als Tribut an den Kaiserhof und erhielt Geldscheine geschenkt“ (feng biao gong xiang ma ci chao bi). ${ }^{292}$ Einige Jahre darauf wurde in Ganya die Poststation Guci eingerichtet, woraufhin der tusi erneut Tributgeschenke an den Kaiser übersandte. Anschließend wurde Nang Huans Sohn Si Nang der Familienname Dao gewährt; fortan nannte er sich Dao Nanglian. ${ }^{293}$

Im 6. Jahr der Ära Xuande (1430) wurde Ganya der Regionalen Militärkommission (dusi) von Yunnan unterstellt, im 3. Jahr der Ära Zhengtong (1438), im Vorfeld des Truppeneinsatzes gegen Luchuan, dann der Militärkommandantur (junmin zhihuishisi) Jinchi. Im 9. Jahr (1444) wurde der tusi von Ganya aufgrund seiner Verdienste im Feldzug gegen Luchuan zum xuanfu shi ernannt.

In den Jahren 1490 bis 1491 kam es zu Streitigkeiten innerhalb der Familie Dao um die Herrschaft. Ein Onkel des minderjährigen tusi hatte die Macht (und das chinesische Amtssiegel) an sich gerissen, was zu militärischen Auseinandersetzungen in Ganya führte. „Im Jahr 4 der Ära Hongzhi (1491) verfaßten der Beamte der Provinzverwaltung (fu shi) Lin Jun und der Regionalkommandant (canjiang) Mu Xiang eine Bekanntmachung, woraufhin die Truppen [in Ganya] entlassen und das Siegel [an den tusi] zurückgegeben wurde“ ${ }^{294}$

\footnotetext{
292 TYTZ, S. 154; TYZZ, S. 144. Im Ming shi (juan 350, S. 6) heißt es, das Nang Huan außerdem ein Nashorn sowie Gold- und Silbergerät überreichen ließ.

Die Wirtschaft des Ming-Reiches am Ende des 14. Jahrhunderts litt noch unter den Zerstörungen des Kampfes gegen die Mongolen und dem Bürgerkrieg; die meisten Transaktionen wurden in Naturalien getätigt. Die neuen Herrscher veranlaßten jedoch verschiedene Maßnahmen, um das Papiergeld durchzusetzen: 1394 wurde Kupfergeld mit Papiergeld aufgekauft, 1403 die Verwendung von Silber und Gold als Zahlungsmittel verboten und die Beamtenschaft in Papiergeld bezahlt. Dessen Emission wurde jedoch im Jahr 1450 eingestellt und in der Folgezeit nur selten wieder aufgenommen, die Noten waren aber bis um das Jahr 1573 in Umlauf. Erst 1643 wurden wieder Banknoten ausgegeben (Gernet, S.352).

293 Gründe für die Namensänderungen werden in den fangzhi nicht genannt. Vermutlich sollten sie, ebenso wie in Nandian, die Eingliederung der Personen in die einheimische Gesellschaft zum Ausdruck bringen.

${ }^{294}$ Der Kommandeur des Militärbezirks (bingbei dao, daotai) und der Direktor des Verwaltungsbezirks (shouxun, daotai) wurden auch mit dem Titel fushi (,Amtsleiter‘; Hucker 1941, 1943: ,Surveillance Commissioner`) bezeichnet.
} 
Zu Beginn der Ära Wanli (1573-1620) kam es nach dem Tod des tusi Paju zwischen Ganya und Mubang zu Kämpfen um die Nachfolge, die Dank der Unterstützung aus Birma mit einem Sieg Mubangs endeten. Dessen Herrscher Han Ba übergab dann das Amt des xuanfu an seine Schwester, die Witwe des tusi von Ganya.

Im 10. Jahr (1582) wurde Ganya von Yue Feng von Longchuan zerstört, dabei ging auch das Amtssiegel des tusi von Ganya verloren und das Gebiet hatte für die nächsten dreißig Jahre aus chinesischer Sicht kein offizielles Oberhaupt mehr. Erst im 39. Jahr (1611) erhielt Dao Dingbian, nachdem er sich an der Niederschlagung von Aufständen im Grenzgebiet beteiligt hatte, von der Ming-Regierung wieder das vererbbare Amt eines xuanfu shi, außerdem wurde ihm für seine Verdienste die Amtsrobe eines Beamten des dritten Ranges (san pin fu) übersandt.

\section{c) Zhanda ${ }^{295}$}

Das Territorium des Befriedeten Gebietes von Zhanda befand sich im Südwesten von Ganya. Der Berg Yaweishan bildete die Grenze zwischen den beiden Gebieten. Der Wohnsitz der tusi von Zhanda lag am Fuß dieses Berges, ganz im Westen der Verwaltungseinheit Unterpräfektur Tengyue.

Die Herrscher von Zhanda gehören derselben Familie an, wie die tusi von Ganya.

Nachdem Dao Paibian von Ganya für seine Verdienste im Kampf gegen Luchuan mit dem Amt eines xuanfu shi belohnt worden war, sandte er im 14. Jahr der Ära Zhengtong (1449) Tribut an den Kaiserhof. Daraufhin wurde ihm der Name Dao Sizhong gewährt und sein Sohn Si Xiao zum Oberhaupt eines sekundären Befriedeten Gebietes (fu zhangguan) mit Amtssitz in Zhanda ernannt. ${ }^{296}$

Im 10. Jahr der Ära Wanli (1582) wurde sein Wohnsitz von Yue Feng von Longchuan und Truppen aus Birma zerstört, die „mit einigen hunderttausend Soldaten, die auf Elefanten ritten, auf verschiedenen Wegen in das Landesinnere [Chinas] eindrangen“ ${ }^{297}$ 1584 besiegten die Ming-Truppen Yue Feng.

Das Amt des tusi von Zhanda wurde in der Familie Dao über die Jahre weiter vererbt bis an Si Tao, der am Ende der Ming-Dynastie Mitte des 17. Jahrhunderts per kaiserlichem

\footnotetext{
295 TYTZ, S. 154-155; TYZZ S. 145-146; YCFZ S. 198. Zhanda befand sich im Gebiet des modernen Kreises Yingjiang, am Berg Lianhua (siehe auch Karte 18, S. 471).

${ }^{296}$ Gründe für die Namensänderung werden in den fangzhi nicht genannt.

${ }^{297}$ TYTZ, S. 154; TYZZ, S. 145
} 
Erlaß zum Oberhaupt eines höherrangigen sekundären Befriedeten Gebietes ( $f u$ xuanfu) befördert wurde und ein entsprechendes Amtssiegel erhielt.

\section{d) Longchuan ${ }^{298}$}

Longchuan (das frühere Luchuan-Pingmian) befand sich südwestlich der drei zuvor genannten Befriedeten Gebiete am Longchuanjiang, einem Oberlauf des Shweli (Ruilijiang). Durch das Gebiet von Longchuan führte die südliche Handelsroute, die Tengyue mit den Rubinminen von Mengmi verband.

Als die Mongolen Mitte des 13. Jahrhunderts das Gebiet des Königreiches von Dali eroberten, hatte der Häuptling von Luchuan, Duo Xiangua, sich ihnen im Jahr 1260 unterworfen. Später wurde er von der Familie Si als Herrscher von Luchuan abgelöst (yu Si shi tui wei Luchuan taomeng). ${ }^{299}$ Im 12. Jahr der Ära Zhiyuan (1275) erhielt das Gebiet den Status eines Regierungsbezirks Luchuan (Luchuan $l u$ ); im Jahr darauf wurde Pingmian lu gegründet und Luchuan unterstellt.

Zu Beginn der Ära Zhizheng (1341-68) begann Si Kefa von Pingmian sein Territorium auf Kosten seiner Nachbarn zu vergrößern. ${ }^{300}$ Den Verfassern der fangzhi war nicht bekannt, in welchem Verhältnis Si Kefa zu Duo Xiangua stand, sie vermuten, daß er dessen Untergebener war. ${ }^{301}$ Zwei Strafexpeditionen der Yuan-Truppen gegen Luchuan blieben erfolglos, da die Soldaten das feuchtheiße Klima (yi zhang qi) nicht vertragen konnten und sich zurückziehen mußten. Si Kefa hingegen gelang es, einige der benachbarten Regierungsbezirke zu annektieren. Anschließend schickte er seinen Sohn Mansan mit einer Entschuldigung an den Kaiserhof und wurde daraufhin von den Mongolen, die zu dieser Zeit mit

\footnotetext{
298 TYTZ, S. 151-153; TYZZ S. 139-143; YCFZ S. 197. Siehe auch Liew Foon Ming, The Luchuan-Pingmian campaigns. Longchuan befand sich im Gebiet der modernen Kreise Longchuan und Ruili (siehe auch Karte 18, S. 471). 299 TYZZ, S. 142; TYTZ, S. 153. Der Herrscher von Luchuan wird hier als taomeng bezeichnet, mit dem Hinweis, daß dies die Bezeichnung für ein Oberhaupt (toumu) in der Sprache der einheimischen [Shan] sei.

300 Si Kefa: Die Namen der Shan-Herrscher von Luchuan-Pingmian werden in den chinesischen Quellen in Kombination mit den Schriftzeichen si und fa wiedergegeben (so auch Si Lunfa, Si Renfa u.a.). E. H. Parker erläutert, daß si dem ShanWort sao (auch saw) entspricht, was Herrscher bedeutet, also ein Titel ist und kein Familienname (Scott/Hardiman, S. 346). Liew Foon Ming weist darauf hin, daß der Namensbestandteil $f a$ auf das Shan-Wort bwa (auch pha) zurückgeht, welches König bedeutet (Ming, The Luchuan-Pingmian campaigns, S. 164; ebenso DMB, S. 1208). Die Shan-Herrscher bezeichnen sich mit dem Titel sawbwa. Die chinesische Version ihrer Namen ist also eine Kombination aus Herrschertitel und Eigennamen.

301 TYZZ, S. 139. Die Beziehungen zwischen den Familien Duo und Si während der Yuan- und der Ming-Zeit werden in den verschiedenen Texten der fangzhi nicht weiter erläutert. Den Darstellungen läßt sich lediglich entnehmen, daß die Duo bereits während der Yuan-Zeit von den Si verdrängt worden sind, an anderer Stelle wird aber darauf hingewiesen, daß Männer aus der Familie Duo von 1260 bis Mitte des 15. Jahrhunderts als Oberhaupt (taomeng) von Luchuan fungierten (TYTZ, S. 153).
} 
Unruhen in Zentralchina zu kämpfen hatten und sich nicht weiter im Grenzgebiet im Südwesten engagieren wollten, als Herrscher von Luchuan-Pingmian anerkannt.

Als die Ming- Truppen im Jahr 1382 in die Region des Stromschluchtenfächers einrückten, erklärte der tusi Si Lunfa von Pingmian, ein Sohn von Mansan, den Ming seine Loyalität. Im 17. Jahr der Ära Hongwu (1384) erhielt sein Hoheitsgebiet den Status des Befriedeten Gebietes (xuanweishi si) von Pingmian. Nachdem Si Lunfa Tributgeschenke an den Kaiser übersandt hatte, wurde sein Hoheitsgebiet Pingmian zu einem Befriedeten Gebiet mit Zuständigkeiten für militärische und zivile Verwaltung (Pingmian junmin xuanweishi si) aufgewertet. Kurz darauf wurde es in Luchuan-Pingmian junmin xuanweishi si umbenannt und somit die beiden Regierungsbezirke der Yuan-Zeit zusammengeführt. ${ }^{302}$

Im Jahr 1385 drangen Si Lunfas Truppen bis nach Tengchong und in die Präfektur Jingdong (südlich des Erhai-Sees) vor. Die Ming konnten ihm zunächst keinen Einhalt gebieten. Im Jahr 1388 führte Lunfa einen weiteren Feldzug und rückte mit „dreihunderttausend Mann und über einhundert Kriegselefanten“ in der Region des Stromschluchtenfächers nach Osten vor. ${ }^{303}$ Der Oberbefehlshaber der Ming-Truppen in Yunnan, Mu Ying, mobilisierte daraufhin über dreißigtausend Soldaten, die Dank ihrer besseren Ausrüstung mit Schußwaffen Si Lunfa besiegen konnten. Anschließend erkannten die Ming im ehemaligen Herrschaftsgebiet von Luchuan einige neue tusi an, darunter Mengyang und Mubang, um die Vormachtstellung Luchuans in der Region zu beenden. ${ }^{304}$

Als Si Lunfa jedoch im Jahr 1397 von seinem Untergebenen Dao Ganmeng abgesetzt wurde, erhielt er Unterstützung von den Ming und konnte bereits im folgenden Jahr in sein Herrschaftsgebiet zurückkehren.

Im Jahr 1413 (Yongle 11) übernahm Si Renfa, ein Sohn Si Lunfas, die Macht in LuchuanPingmian und begann sein Hoheitsgebiet zu erweitern. In den folgenden Jahrzehnten kam es immer wieder zu Kämpfen um die Vorherrschaft zwischen den verschiedenen Kleinstaaten im Südwesten von Tengchong.

\footnotetext{
${ }^{302}$ Zu den Ereignissen am Beginn der Ming-Zeit heißt es im YCFZ, daß der tusi Waimen von Luchuan den Ming seine Loyalität erklärte. Daraufhin erhielt sein Hoheitsgebiet im 17. Jahr der Ära Hongwu (1384) den Status eines Befriedeten Gebietes (xuanweishi si) von Luchuan-Pingmian. Die Familie Si wird in diesem Zusammenhang nicht erwähnt (YCFZ, S. 197).

${ }^{303}$ TYZZ, S. 140

304 Mengyang (Shan: Möng Yang, birman.: Mohnyin) und Mubang (Shan: Hsenwi, birman.: Thein-ni) waren zwei Herrschaftsgebiete der Shan im Nordosten des modernen Birma.
} 
So wird im YCFZ berichtet, daß ein Krieg mit dem benachbarten Mubang zur Zeit der Ära Xuande (1426-1436) mit der Niederlage Luchuans endete, das daraufhin von Angehörigen der Familie Dao von Mengyang verwaltet wurde. Bis zum Jahr 1437 (Zhengtong 2), als Si Ren von Luchuan einen Eroberungsfeldzug in der Region begann. Er vertrieb Dao Binyu aus Luchuan, drang über Mengding und Wandian bis nach Tengchong vor; im Westen eroberte er auch Mengyang. Dao Binyu war nach Longchuan geflohen, wo er kurz darauf starb. $^{305}$

Die Vorstöße Si Renfas in die Region des Stromschluchtenfächers veranlaßten die Ming schließlich im Jahr 1439 einen Feldzug gegen Luchuan zu führen, für den an die fünfzigtausend Soldaten mobilisiert wurden. Si Renfa konnte die Truppen der Ming zurückschlagen und seinerseits nach Osten bis Jingdong und Mengding vordringen. ${ }^{306}$ Die Ming entschlossen sich zu einem weiteren Feldzug; die Kämpfe sollten schließlich ein Jahrzehnt andauern und erst im Jahr 1449 mit einem Friedensvertrag beendet werden.

Nach dem Tod von Si Renfa im Jahr 1446 hatten sich die Kämpfe weiter nach Westen verlagert. Luchuan war von den Ming in Longchuan xuanfu si umbenannt und der einheimische Häuptling (yi mu) Gong Xiang als Oberhaupt des Befriedeten Gebietes bestätigt worden. Während der Herrschaft von Gong Xiang waren in Longchuan ein Unterpräfekt namens Dao Waimeng und zwei weitere Beamte ernannt worden.Als es später zu Kämpfen mit den Söhnen Si Renfas, Si Ji und Si Bu kam, floh Gong und ließ sich schließlich in Qujing im Osten Yunnans nieder. Der Unterpräfekt Dao Waimeng wurde zum xuanfu shi ernannt. Nach seinem Tod übernahm Duo Waimen, ein Nachfahre des Duo Xiangua (Oberhaupt von Luchuan um 1260), die Herrschaft, die seine Nachfahren bis in das 16. Jahrhundert ausübten. ${ }^{307}$

Im 5. Jahr der Ära Wanli (1577) wurde der tusi Duo Shining von seinem Sekretär (mu), einem chinesischen Kaufmann aus Jiangxi namens Yue Feng, der mit einer Schwester des tusi verheiratet war, getötet. Zuvor hatte der König von Birma

„versucht, Duo Shining von Longchuan zur Rebellion [gegen die Ming] zu verleiten. Shining hatte sich jedoch nicht [an diesem Plan] beteiligen wollen. Daraufhin tötete sein Sekretär, Yue Feng, den Shining. Dessen Frau, eine

\footnotetext{
${ }^{305}$ Demnach hätten sich Angehörige der Familie Duo weiterhin als Oberhaupt von Luchuan behaupten können, möglicherweise als Statthalter der Familie Si von Luchuan-Pingmian.

${ }^{306}$ Liew Foon Ming, The Luchuan-Pingmian campaigns, S. 175

${ }^{307}$ TYZZ, S. 142; YCFZ, S. 197
} 
geborene Han, floh mit dem Siegel [des Befriedeten Gebietes] und mit ihren beiden Söhnen, Duo Zhong und Duo Xiao, nach Yongchang. Damals konnte man ihr dort nicht helfen und veranlaßte sie zurückzukehren. Yue Feng tötete sie, raubte das Siegel; so nahm er Longchuan in Besitz“. ${ }^{308}$

Um seine Herrschaft über Longchuan zu festigen, verbündete sich Yue Feng mit den Birmanen. Nach jahrelangen Kämpfen in der Region nahmen die Ming-Truppen Yue Feng im Jahr 1584 gefangen. Anschließend wurde Duo Sishun (ein Enkel von Duo Shining) zum tusi von Longchuan ernannt und das Amt in seiner Familie weitervererbt. ${ }^{309}$

\section{e) Zhefang und Mengmao ${ }^{310}$}

Zhefang (im Osten von Longchuan) hatte zu Beginn der Ära Zhengtong (1436-1450) den Status eines sekundären Befriedeten Gebietes (fu xuanfu si) des Ming-Reiches erhalten, nachdem sein Oberhaupt Duo Huaimen Verdienste im Kampf gegen den Si-Clan von Luchuan-Pingmian erworben hatte. Duo Huaimen war ebenso wie Duo Waimen von Longchuan ein Nachfahre des Duo Xiangua, der während der Yuan-Zeit Luchuan beherrscht hatte.

Das Befriedete Gebiet (anfu si) von Mengmao befand sich im äußersten Südwesten der Unterpräfektur Tengyue, südlich von Zhefang am Fluß Shweli. Es war ursprünglich Teil des Territoriums von Longchuan und erhielt erst in der zweiten Hälfte des 16. Jahrhunderts den Status einer Verwaltungseinheit des chinesischen Reiches.

Ebenso wie Zhefang war auch Mengmao ein Ort von strategischer Bedeutung für das Ming-Reich. Beide lagen an der südlichen Hauptverkehrsroute, die die Unterpräfektur Tengyue direkt mit den Kleinstaaten Mengmi und Mubang sowie mit Birma verband.

Nachdem Yue Feng zu Beginn der Ära Wanli (1573-1620) den tusi von Longchuan, Duo Shining, getötet hatte, wurden im Gebiet von Longchuan zwei einheimische Herrscher von den Ming anerkannt: Duo Gong wurde zum Vize-Oberhaupt (fushi) des Befriedeten

\footnotetext{
${ }^{308}$ YCFZ, S. 134

${ }^{309}$ TYZZ, S. 147

${ }^{310}$ TYTZ, S. 155; TYZZ, S. 147-148; YCFZ, S. 197 (Zhefang). TYTZ S. 153-154; TYZZ S. 143-144; YCFZ S. 197-198 (Mengmao). Zhefang befand sich an der südlichen Verkehrsroute nach Birma, im Gebiet des modernen Zhefang zwischen Luxi und Wanding; Mengmao befand sich weiter südwestlich im Gebiet um die moderne Stadt Ruili direkt an der Grenze zu Birma (siehe auch Karte 18, S. 471).
} 
Gebietes von Longchuan ernannt und residierte in Zhefang; der Vize-Magistrat (tongzhi)

Duo An hatte seinen Amtssitz weiter im Süden, in Mengmao. 311

Duo An versuchte, mit Unterstützung der Birmanen seinen Einflußbereich zu vergrößern. Daraufhin zogen Ende des Jahres 1598 (Wanli 26) Duo Sishun von Longchuan und andere mit ihm verbündete tusi gegen Duo An zu Felde und brachten ihm ein Niederlage bei. Duo An überfiel Zhefang, mußte sich jedoch auch dort geschlagen geben und flüchtete nach Mubang.

Die Entwicklung der tusi-Gebiete im Südwesten der Unterpräfektur Tengyue in den letzten Jahrzehnten des 16. Jahrhunderts war von den Kämpfen zwischen den tusi, Birma und den Ming-Truppen bestimmt, die weiter unten dargestellt werden (siehe unten 7., S. 152).

Nach einem Vorstoß in den Südwesten errichteten die Ming-Truppen eine Festung im Gebiet von Mengmao, die sie Pinglucheng (,Stadt der Befriedung von Lu') nannten; außerdem wurden dort Soldaten stationiert und Militärkolonien gegründet (s.u. 6.3.,S.143-45). ${ }^{312}$

Einige Jahre danach übernahm Duo Anmin das Amt des tusi und verbündete sich mit den Birmanen. Später wurde er gefangengenommen und hingerichtet. Die Ming ernannten daraufhin seinen Bruder Duo Anjing zum Oberhaupt des Befriedeten Gebietes von Mengmao. Da dieser noch ein Kind war, wurde zunächst Duo Sitan (Sohn des xuanfu Duo Gong aus Zhefang) beauftragt, die Amtsgeschäfte zu führen.

Später wurde Si Zhong (Nachfahre des Si Hua von Manmo) vom Gouverneur der Provinz Yunnan zum Oberhaupt (anfu shi) von Mengmao ernannt und änderte seinen Familiennamen in Kan. Das Amt wurde nach Zhongs Tod in seiner Familie weitervererbt.

\section{f) Andere Befriedete Gebiete in der Region}

Neben den sechs zuvor genannten Befriedeten Gebieten im Südwesten der Unterpräfektur Tengyue hatten auch verschiedene Kleinstaaten jenseits des Irawadi und südlich des Shweli (im Nordosten des modernen Birma) den Status lokaler Sonderverwaltungseinheiten des chinesischen Reiches erhalten. So waren z.B. Mengyang und Mubang bereits kurz nach der Eroberung des westlichen Yunnan durch die Ming im Jahr 1382 zu Präfekturen (fu) erklärt

\footnotetext{
311 TYTZ, S. 153. Duo Gong wird im YCFZ (S. 197) als Duo Cha geschrieben; ebenso auch im Dian zhi, worauf die Verfasser des TYZZ ausdrücklich hinweisen (TYZZ, S. 147; ebenso TYTZ, S. 155).

${ }^{312}$ Pinglucheng: ,Lu‘ steht für Luchuan, den früheren chinesischen Namen von Longchuan.
} 
und einige Jahre später dann zu höherrangigen Befriedeten Gebieten (xuanwei si) ernannt worden; Mengyang im Jahr 1384, Mubang im Jahr 1404.

Auch das birmanische Königreich von Ava hatte im 27. Jahr der Ära Hongwu (1394) den nominellen Status einer solchen Verwaltungseinheit erhalten und war zum Befriedeten Gebiet von Mianzhong (Mianzhong xuanwei shi si) erklärt worden. ${ }^{313}$

Die Kleinstaaten in der Region des Stromschluchtenfächers, wie Luchuan/Longchuan, Mengyang und Mubang, wurden von Angehörigen der Tai-Volksgruppe der Shan (chin. Baiyi, heute: Dai) beherrscht. ${ }^{314}$ Deren Oberhäupter waren miteinander verwandt oder verschwägert. So waren die tusi von Mengyang Angehörige des Si-Clans von Luchuan, die sich nach ihrer Niederlage in den Kämpfen mit Ming-Truppen Mitte des 15. Jahrhunderts nach Mengyang zurückgezogen hatten. Ein anderes Beispiel ist der xuanfu Paju, der zu Beginn der Ära Wanli (1573-1620) Ganya beherrschte und mit der jüngeren Schwester des xuanwei Han Ba von Mubang verheiratet war. Deshalb waren, kam es in Zusammenhang mit Streitigkeiten um die Nachfolge eines Herrschers oder aufgrund von Expansionsbestrebungen einzelner Staaten zu militärischen Konflikten, auch immer die verwandten tusi in die Auseinandersetzungen involviert.

\section{2. Der Konflikt zwischen Mengmi und Mubang}

Der letzte Kleinstaat, der in der Region des Stromschluchtenfächers während der MingZeit von der chinesischen Regierung den Status eines Befriedeten Gebietes erhielt, war Mengmi am Unterlauf des Shweli gelegen, im Nordosten des Shan-Staates des modernen Birma. $^{315}$

Mengmi war ursprünglich ein Teil des Staates von Mubang (Shan: Hsenwi). Während der Ära Jingtai (1450-57) führte nach dem Tod des Herrschers von Mubang seine Tochter Nang Han Nong, die mit dem Häuptling von Mengmi verheiratet war, eine Revolte gegen seinen Enkel und Nachfolger Han Kongfa an. ${ }^{316}$ In den folgenden Jahren gelang es ihr, jenen zu vertreiben und die Macht über einen Großteil des Territoriums von Mubang zu

\footnotetext{
${ }^{313}$ Ming shi (juan 315, liechuan, S. 2)

${ }^{314}$ Scott/Hardiman, S. 181, 345; Mangrai, S. 26; Hendershot, S. 1, 77, 91

315 TYTZ, S. 241. Shan: Möng Mit, birman.: Momeit.

${ }^{316}$ Der erste Bestandteil der chinesischen Schreibung des Namens Nang Han Nong gibt den von den Shan vor Frauennamen verwendeten Präfix nang wieder, mit dem hochrangige Frauen oder Prinzessinnen bezeichnet wurden (Cushing, Dictionary, S. 348). Der Name Nang Han Nong läßt sich als ,Prinzessin Nong aus der Famile Han` übersetzen.
} 
erobern. Ihr Sohn Si Bing ernannte sich selbst zum ,Oberhaupt eines Befriedeten Gebietes` (xuanwei) und sandte Tribut an China.

In den Konflikt zwischen Mengmi und Mubang wollte die chinesische Regierung nicht direkt eingreifen und so wurde als Antwort auf eine Petition des tusi von Mubang lediglich ein kaiserliches Dekret erlassen, das die Parteien besänftigen sollte.

Nang Han Nong, die Herrscherin von Mengmi, verstand es, ihre Position durch Bestechung der Palasteunuchen in Tengchong und anderer Beamter zu festigen. Mengmi verfügte zu diesem Zweck über eine begehrte Ware: Edelsteine, insbesondere Rubine, die in den Minen von Mogok abgebaut wurden. Die Juwelen wurden am Kaiserhof und von der chinesischen Oberschicht hochgeschätzt und seit dem 15. Jahrhundert von den nach Tengchong entsandten Eunuchen in großen Mengen aufgekauft. Die örtlichen Beamten wollten dieses lukrative Geschäft nicht gefährden und so fand das Anliegen Mubangs bei ihnen kein Gehör. Da Nang Han Nong zudem Edelsteine als Tribut an den chinesischen Hof schickte, sah man auch dort keinen Grund, Maßnahmen zu ergreifen, die über die Entsendung eines Vize-Zensors hinausgingen, der im Jahr 1482 einen Vermittlungsversuch unternahm.

In den fangzhi von Tengyue werden die historische Entwicklung Mengmis und der Verlauf der Mission des Vize-Zensors ausführlich dargestellt. Folgendes hatte sich ereignet:

Im 18. Jahr (1482) hatten der Vize-Zensor (fudu yushi) Chen Zong und der Beamte (xu-ban) des Amtes für den Empfang ausländischer Gesandtschaften (honglu si) Su Quan den Auftrag erhalten, sich nach Mengmi zu begeben. Die Herrscherin von Mengmi, Nang Han Nong,

„verließ sich auf die Unterstützung, die sie im Innern ihres Landes hatte, sie blieb hochmütig dort sitzen und kam nicht heraus, um Zong zu empfangen. Überdies verlangte sie, daß Zong den Berg Nanyashan überquere, um sie zu treffen. Bei den Verhandlungen gelang es Zong nicht, sich ihrer Gefolgschaft zu versichern. Nang Han Nong selbst sagte: ,Mein Mengmi ist im Verhältnis zu Mubang so wie ein kleiner Elefant zu dem großen Elefanten, der ihn geboren hat. Jetzt ist der Körper des kleinen Elefanten doppelt so groß geworden wie der des großen Elefanten. Wie könnte er da wieder in den Bauch des großen Elefanten zurückkehren?‘ 
Chen Zong konnte sie nicht umstimmen. Su Quan nahm daraufhin heimlich Bestechungsgeld von ihr an und täuschte Zong bei der Abfassung der Throneingabe“. ${ }^{317}$

Die Darstellung der Ereignisse in den fangzhi macht deutlich, welch große Bedeutung wirtschaftliche Faktoren insbesondere die Förderung von und der Handel mit Juwelen für den Aufschwung Mengmis gehabt haben. Mit der Kontrolle über die Edelsteinminen begann Nang Han Nongs Aufstieg zur Macht, ihr Reichtum ermöglichte ihr die Expansion auf Kosten von Mubang, ihre begehrte Handelsware sicherte ihr das Wohlwollen der Ming und die Anerkennung ihres Herrschaftsgebietes als eigenständiges Befriedetes Gebiet: Im 20. Jahr der Ära Chenghua (1484) erhielt ihr Sohn Si Bing vom Kaiser den chinesischen Titel eines anfu shi verliehen. ${ }^{318}$

Han Kongfa, der ehemalige tusi, hatte sich, nachdem er aus Mengmi vertrieben worden war, mit dem Häuptling von Mengyang verbündet, um die von Mengmi in Mubang besetzten Gebiete zurückzuerobern, so daß auch der Kleinstaat Mengyang in den Konflikt hineingezogen wurde. Sie konnten Mengmi jedoch nicht erobern und auch Petitionen sowohl der Nachfahren des tusi von Mubang als auch von Regierungsbeamten aus Yunnan, die um die Entsendung von Truppen ersuchten, um den ehemaligen Status quo im Gebiet von Mubang wiederherzustellen, blieben erfolglos.

In Mengmi konnten Si Bing und seine Nachfolger ihre Position weiter festigen und waren schließlich Ende des 16. Jahrhunderts in wechselnden Allianzen in den Kämpfen zwischen China, Birma und den Kleinstaaten im Grenzgebiet engagiert. Mit der Expansion Birmas veränderten sich die Machtverhältnisse in der Region (siehe unten Abschnitt 5 und 6). Um sich in dieser Zeit die Loyalität Mengmis zu erhalten, wollten die Ming im Jahr 16 der Ära Wanli (1588) den tusi Si Zhong zum xuanfu befördern. Doch noch ehe es dazu kam, hatte sich dieser den Birmanen angeschlossen und so wurde der Titel auf seine Mutter Han Hong übertragen. Einen Angriff birmanischer Truppen im selben Jahr konnte Han Hong nicht abwehren und mußte fliehen. Das gesamte Gebiet von Mengmi unterstand von da an der Oberhoheit Birmas. ${ }^{319}$

\footnotetext{
317 TYTZ, S. 241; TYZZ, S. 151. Eine vollständige Übersetzung des Textes zur Geschichte Mengmis findet sich im Anhang.

${ }^{318}$ Im YCFZ (S. 51) heißt es abweichend, daß der Titel bereits im Jahr Chenghua 19 (1483) verliehen worden ist. Der Titel anfu shi, den die Ming-Regierung dem tusi von Mengmi verliehen hat, ist ein niederrangigerer Titel für das Oberhaupt eines Befriedeten Gebiete unter einheimischer Herrschaft, als der zuvor von Si Bing selbst gewählte Titel eines xuanwei shi.

${ }^{319}$ TYTZ, S. 241; TYZZ, S. 152
} 


\section{3. Die historische Entwicklung Birmas vom 13. bis zum 16. Jahrhundert}

In den letzten beiden Dekaden des 16. Jahrhunderts verstärkten die Birmanen ihren Einfluß auf die Region des Stromschluchtenfächers und drangen auf ihren Feldzügen nach Osten über den Irawadi und den Shweli vor. Das starke Engagement Birmas in der Region ist ein Faktor, der die Ausdifferenzierung des Grenzgebietes im Südwesten Chinas entscheidend beeinflußt hat. Die chinesische Politik der Konsolidierung der Grenze Chinas im Westen Yunnans wird daher erst verständlich, wenn man auch die historische Entwicklung Birmas und seine seit dem 16. Jahrhundert betriebene Expansionspolitik berücksichtigt, die das Machtgefüge in der Grenzregion dauerhaft verändern sollte.

Die Feldzüge, die die Mongolen in den Jahren 1284 bis 1300 gegen Birma unternommen hatten, führten zu einer Zersplitterung des Reiches der birmanischen Dynastie von Pagan. In den folgenden sechs Jahrzehnten teilten sich drei Brüder, frühere Minister Pagans, von Sagaing, Myinsaing und Pinya aus die Herrschaft über die Region. ${ }^{320}$ Im Jahr 1364 gründete einer ihrer Nachfahren, Thadominbya, die Stadt Ava am Zusammenfluß des Myitgne mit dem Irawadi und vereinigte Oberbirma unter seiner Herrschaft. In den folgenden fünfzig Jahren gelang es den Herrschern von Ava, ihren Einfluß auch auf die Kleinstaaten im Grenzgebiet zu Yunnan geltend zu machen. ${ }^{321}$ Im Jahr 1527 verlor das Reich von Ava seine Vormachtstellung in Oberbirma wieder; es wurde von den Shan aus Mohnyin (chin. Mengyang) erobert, die ihre Herrschaft über die Region bis 1555 aufrecht erhalten konnten. ${ }^{322}$

Während Birma im 14. und 15. Jahrhundert von der Auseinandersetzung zwischen den Königreichen von Ava in Ober- und Pegu in Niederbirma geprägt wurde, hatten die Herrscher eines kleinen Reiches mit Zentrum in der Stadt Toungoo am Fluß Sittang in Niederbirma versucht, ihre Selbständigkeit zu wahren. ${ }^{323}$ Mit der Krönung Tabinshwehtis zum König von Toungoo im Jahr 1531 begann der Aufstieg dieses Reiches. Im Jahr 1538 besiegte Tabinshwehti zunächst Pegu; mit der Eroberung von Prome und Martaban konnte er seine Herrschaft über Niederbirma festigen und sie auch auf Oberbirma ausdehnen, wo

\footnotetext{
${ }^{320}$ Siehe Michael Aung-Htwin: ,The myth of „the Shan brothers“ ... ‘ür den Nachweis, daß die drei Brüder keine Shan, das Königreich von Ava kein Shan-Königreich gewesen ist.

${ }^{321}$ Aung-Htwin, S. 892

322 Aung-Htwin, S. 898

${ }^{323}$ Birman.Tonnu, gesprochen Taunggu, in der westlichen Literatur meist als Toungoo transkribiert. (So z.B. Esche Wörterbuch, S. 207).
} 
er im selben Jahr in Pagan zum König eines neu geeinten birmanischen Reiches gekrönt wurde. $^{324}$

Nach Tabinshwehtis Tod 1551 schlug sein Nachfolger Bayinnaung einen Aufstand der Mon von Pegu nieder und konnte so die Einheit des Reiches wahren. Er machte Pegu zu seiner Hauptstadt, die sich zu einem prosperierenden Handelszentrum entwickelte, das mit China Waren austauschte und dessen Produkte von den Portugiesen bis nach Europa befördert wurden. ${ }^{325}$ Der Kontakt mit den Portugiesen brachte die Birmanen auch in den Besitz moderner Feuerwaffen, deren technische Überlegenheit entscheidend zu ihren militärischen Erfolgen über ihre Nachbarländer beitrug.

Eroberungsfeldzüge führten die Truppen Bayinnaungs in den folgenden Jahren auch in die Staaten der Shan im Norden und Osten Birmas sowie nach Siam. Im Jahr 1555 beendete Bayinnaung endgültig die Herrschaft der Shan aus Mohnyin (chin. Mengyang) über Oberbirma. ${ }^{326}$ Die militärische Stärke Birmas veranlaßte viele der Herrscher der Kleinstaaten in der Region des Stromschluchtenfächers, sich König Bayinnaung zu unterwerfen. ${ }^{327}$ Um die Oberhoheit über diese Gebiete zu festigen, ließ er an strategischen Punkten Garnisonen einrichten und Beamte an den Residenzen der einheimischen Herrscher, der Sawbwas, stationieren. Außerdem führte Bayinnaung eine Reihe von politischen Maßnahmen durch, die auf eine Angleichung an das birmanische Königreich, an seine Kultur und Religion abzielten. Die Staaten der Shan im Nordosten Birmas erhielten den Status von Verwaltungseinheiten des birmanischen Königreiches. Innerhalb ihrer Hoheitsgebiete blieb die Herrschaft der Sawbwas jedoch unangetastet. Ihre Position war vererbbar, die birmanischen Könige behielten sich allerdings das Recht vor, sie bei Fehlverhalten aus ihrem Amt zu entfernen und durch ein anderes Mitglied der Herrscherfamilie zu ersetzen. Um sich die Loyalität der Shan zu sichern, führte Bayinnaung die Tradition der birmanischen Könige wieder ein, eine Shan-Prinzessin zu heiraten und als Königin am birmanischen Hof zu etablieren. Außerdem verlangte er, daß die Sawbwas je einen ihrer Söhne zu ihm schickten, dieser sollte nicht nur als Geisel das Wohlverhalten seines Vaters garantieren, sondern auch in die birmanische Kultur hineinwachsen und diese an seine Heimat weitergeben, um

\footnotetext{
${ }^{324}$ Hendershot, S. 95; Tate, S. 397; Cady, S. 190

${ }^{325}$ Maung Htin Aung, S. 122

${ }^{326}$ Aung-Htwin, S. 898

${ }^{327}$ Unter anderem unterwarfen sich in den Jahren 1556-59 die Shan-Staaten Hsipaw, Mogaung und Chiang Mai, 1562 folgten, Mongmau [chin. Mengmao], Sanda [chin. Zhanda], Hosa [chin. Husa], Lasa und später Mongmit [chin. Mengmi] und Kengtung (Mangrai, S. 43, 51).
} 
die Assimilierung der Herrschaftsgebiete der Sawbwas an das birmanische Königreich voranzutreiben. Weitere Maßnahmen zu diesem Zweck waren die Einführung des birmanischen Gewohnheitsrechts sowie der Maße und Gewichte, besonders jedoch die Unterstützung des Theravada-Buddhismus. Dieser hatte sich seit dem 13. Jahrhundert in den Staaten der Shan erst wenig verbreitet. Um den vorherrschenden animistischen Volksglauben zurückzudrängen, verbot König Bayinnaung Menschen- und Tieropfer; er veranlaßte zudem den Bau von Tempeln und Klöstern, spendete buddhistische Schriften und ermunterte Mönche aus Zentral-Birma in den Nordosten zu ziehen. ${ }^{328}$

Die Intensität, mit der die Birmanen die Shan-Staaten im Nordosten ihres Reiches kontrollierten, schwankte unter der Herrschaft von Bayinnaungs Nachfolgern. Gänzlich befreien konnten sich die westlich des Irawadi und südlich des Shweli gelegenen Shan-Staaten wie Mengyang oder Mengmi von der Oberhoheit der birmanischen Könige jedoch nicht mehr. $^{329}$

\section{4. Die Herrscher von Toungoo in den fangzhi von Tengyue}

Die häufigen Veränderungen der Machtverhältnisse in Oberbirma und im Grenzgebiet, die Dynastien- und Herrscherwechsel machten es den chinesischen Autoren schwer, die einzelnen Könige zu identifizieren. So hatten die Verfasser der fangzhi zwar erkannt, daß ein neues Machtzentrum in Toungoo entstanden war, von dem zur Zeit der Ära Wanli die birmanischen Eroberungen im Grenzgebiet ausgingen, ihnen war jedoch nicht bewußt, das auch ein neues Herrscherhaus an die Macht gekommen war, das Birma bis zur Mitte des 18. Jahrhundert regieren sollte. In den fangzhi erscheinen die Herrscher der birmanischen Dynastie von Toungoo denn auch als Nachfahren der Dynastie von Ava:

„Früher gab es [den König] Mang Jisui [von Ava]. Zur Zeit der Ära Jiajing (1522-1567) war jener von [den Shan] aus Mengyang getötet worden. Sein Sohn Ruiti flüchtete nach Toungoo, der Heimat seiner Mutter. Von dort aus annektierte er die benachbarten Gebiete ...“. ${ }^{330}$

In den Lokalhandbüchern wird folgende Chronologie der Herrscher Birmas im 16. Jahrhundert aufgestellt:

\footnotetext{
${ }^{328}$ Maung Htin Aung, S. 117

${ }^{329}$ Hendershot, S. 1; Tate, S. 397

${ }^{330}$ YCFZ, S. 134; Ming shi (juan 315, liechuan, S. 3). In den fangzhi von Tengyue (TYTZ, TYZZ) wird anders als im YCFZ der Name Toungoo (chin. Tongwu) nicht einmal genannt.
} 


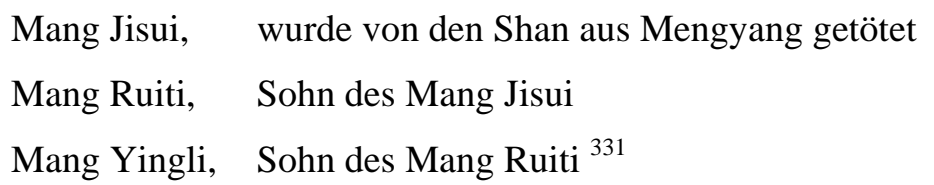

Bei dem Mang Jisui genannten König handelt es sich sicherlich um den letzten Herrscher der Dynastie von Ava, König Shwenankyawshin, der 1502 den Thron bestieg und im Jahr 1527 von Mao-Shan aus Mohnyin (chin. Mengyang) abgesetzt wurde. In den folgenden drei Jahrzehnten herrschten die Shan über Oberbirma, während weiter im Süden das birmanische Königreich von Toungoo expandierte und im Jahr 1555 auch Ava und Oberbirma unter der Herrschaft von König Bayinnaung vereint wurden. Die Chronologie der Herrscher über Birma in diesem Zeitraum ist folgende ${ }^{332}$ :

Shwenankyawshin von Ava (reg. 1502-1527)

Shan-Herrschaft über Oberbirma, 1527-1555

\section{Dynastie von Toungoo}

Minkyinyo, König von Toungoo

(reg. ca. 1486-1531)

Tabinshwehti, Sohn des Minkyinyo,

(reg. 1531-1555)

Bayinnaung, General und Schwager Tabinshwehtis, (reg. 1555-1581)

Nandabayin, Sohn Bayinnaungs,

(reg. 1581-1599)

Prinz von Nyaungyan, Sohn Bayinnaungs,

(reg. 1599-1605)

Anaukpetlun, Sohn des Prinzen von Nyaungyan,

(reg. 1605-1628)

Bei dem in den fangzhi in der Beschreibung der Kämpfe im Grenzgebiet zur Zeit der Ära Wanli (1573-1620) genannten Herrscher Mang Ruiti handelt es sich um König Bayinnaung (Tabinshwehti war bereits im Jahr 1555 verstorben), dem sein Sohn Mang Yingli, das ist König Nandabayin, auf den Thron folgte. ${ }^{333}$ Erwähnt wird auch dessen jüngerer Bruder Mang Yinglong, damit ist wahrscheinlich der Nachfolger Nandabayins, der Prinz von Nyaungyan gemeint.

\footnotetext{
${ }^{331}$ YCFZ, S. 134-135; TYTZ, S. 191-192, 240, 243. Der Name des Königs Mang Yingli wird im YCFZ (S. 135) in den Jahren Wanli 19 (1591) und 21 (1593) mit einem anderen Schriftzeichen li geschrieben als in den Einträgen zu den vorangegangenen Jahren, in den fangzhi von Tengyue variiert die Schreibweise nicht. Außerdem wird Mang Yinglong, ein jüngerer Bruder des Mang Yingli erwähnt, der im Jahr 10 der Ära Wanli (1582) mit seinen Truppen bis nach Yaoguan in der Präfektur Yongchang vorrückte (TYTZ, S. 191; s. a. You Zhong, S. 440).

${ }^{332}$ Maung Htin-Aung, S. 104, 106, 337, 339; Mian Han cidian, S. 1250-1251

${ }^{333}$ Anders als in der birmanischen Geschichtsschreibung wird im YCFZ (S. 134) das Jahr Wanli 10 (1582) als das Jahr genannt, in dem Mang Ruiti gestorben ist und sein Sohn Yingli die Nachfolge angetreten hat.
} 


\section{5. Der Kleinstaat Mengyang an der Wende zum 17. Jahrhundert}

Mengyang befand sich aus chinesischer Sicht jenseits des Jinshajiang (d. h. dem Oberlauf des Irawadi], „im Norden grenzt es an Tibet, im Westen hat es Verbindung zu Indien“, im Süden grenzt es an Manmo und Mubang bzw. Mengmi und an Birma. Das Herrschaftsgebiet Mengyangs umfaßte beinahe den gesamten Norden des modernen Birma. ${ }^{334}$

Die folgende Darstellung faßt den Bericht über die historische Entwicklung von Mengyang in den fangzhi von Tengyue zusammen. ${ }^{335}$

Dieser beginnt mit der Feststellung, daß das Gebiet bereits in der Yuan-Zeit zu einer Präfektur (zongguan fu) des chinesischen Reiches erklärt worden war.

Zu Beginn der Ming-Dynastie soll Mengyang nach den fangzhi bereits im 17. Jahr der Ära Hongwu der Ming (1384) den Status eines höherrangigen Befriedeten Gebietes (junmin xuanwei si) erhalten haben. Tatsächlich war Mengyang zu dieser Zeit noch Teil des Herrschaftsgebietes der Mao-Shan von Luchuan und wurde erst einige Jahre später eigenständig, als in der Zeit der Ära Xuande (1426-1436) die Herrscherfamilie der Si von Luchuan zeitweise ihre Macht verloren und ihr vormaliges Herrschaftsgebiet stattdessen unter die Oberhoheit von Mengyang kam. ${ }^{336} 1437$ gelang es dann Si Renfa, die Macht an sich zu reißen und den herrschenden Dao-Clan zu vertreiben. Der tusi Dao Binyu floh nach Yongchang. Auch nachdem ihre Vormachtstellung in Luchuan nach den Kämpfen mit den Ming Mitte des 15. Jahrhundert geschwächt war (nach der Auslieferung des tusi Si Jifa war das Gebiet im Jahr 1454 zeitweilig Birma unterstellt worden) konnten die Si ihre Position in Mengyang behaupten. ${ }^{337}$

\footnotetext{
334 TYTZ, S. 240; TYZZ, S. 150; siehe auch You Zhong, S. 431-32. Ein anderer in der Ming-Zeit für Mengyang gebräuchlicher Name war Yixi (,in Richtung Westen') (s.a. TYTZ, S. 240; TYZZ, S. 150). Im Ming shi (juan 350, liechuan, S. 13) heißt es abweichend Yishui; in der Yuan-Zeit war das Gebiet in China als Regierungsbezirk (lu) Yunyuan bekannt.

Die birmanische Bezeichnung für Mengyang, Mohnyin, ist nach Scott/Hardiman (S.345) eine Wiedergabe des ShanNamens Möng Yang, möng bedeute Land und yang sei der Name eines Vogels (,paddy-bird‘). Nach einheimischer Tradition sollen die Einwohner von chinesischer Abstammung sein, die bei ihrer Ankunft in dem Gebiet einen Elefanten haben grasen lassen, auf dessen Rücken sich ein Vogel niedergelassen habe, was als gutes Omen galt und dem Land den Namen gegeben haben soll.

${ }_{335}$ TYTZ, S. 239-240; TYZZ, S. 148-150. Englische Übersetzung von Parker in Scott/Hardiman, S. 346-349. Siehe auch You Zhong, S. 439.

${ }^{336}$ Parker erklärt in seiner Übersetzung der Geschichte von Mohnyin an dieser Stelle, daß das chinesische Wort Si dem Shan-Wort Sao, welches Häuptling bedeutet, entspricht, also ein Titel sei und kein Familienname (siehe Scott/Hardiman, S. 346).

${ }^{337}$ TYTZ, S. 239; TYZZ, S. 148. Anläßlich der Thronbesteigung des Hongzhi-Kaisers im Jahr 1488 erhielt Mengyang ebenso wie die anderen tusi in der Region wieder die goldene Tafel und die Insignien eines Befriedeten Gebietes verliehen (siehe You Zhong, S. 433).
} 
Im Konflikt zwischen Mubang und Mengmi hatte der tusi von Mengyang, Si Lu, zunächst auf die Aufforderung des Vize-Direktors der Provinzbehörde (canzheng) von Yunnan, Mao Ke, einige tausend Soldaten gegen Mengmi ins Feld geschickt, die jedoch schlecht ausgerüstet waren und von Mengmi geschlagen wurden. Daraufhin war Si Lu selbst mit neuen Truppen vorgerückt und hatte den wichtigen Handelsplatz Manmo sowie siebzehn andere Orte, die sich zwischen Mengyang und Mengmi befanden, erobern können. Diese Offensive war von den Beamten der chinesischen Regionalverwaltung mit Mißtrauen beobachtet worden; der Gouverneur von Yunnan, Jin Xianmin, reichte eine Petition ein, in der er um die Entsendung eines großen Truppenkontingents gegen Si Lu ersuchte. Der Kaiser gab dieser Bitte jedoch nicht statt. Im Jahr 1505 schickte Mengyang eine Gesandtschaft an den chinesischen Hof und zog sich aus einigen der eroberten Orte wieder zurück.

Zu Beginn der Ära Jiajing (1522-1567) kämpfte Si Lun, der Sohn Si Lus, gemeinsam mit Mengmi und Mubang gegen Ava, tötete den birmanischen Herrscher und seine Familie und setzte seinen Sohn Thohanbwa als neuen König von Ava ein.

Daraufhin wurde Yan Shitai, der Präfekt von Yongchang, im Jahr 1527 von der Provinzregierung beauftragt, die Lage vor Ort zu erkunden. Si Lun aber

„ließ seine Truppen nachts unter großem Lärm ausschwärmen, die Poststation anzünden und den Bataillonskommandanten Cao Yi töten; Shitai fürchtete sich sehr, deshalb übertrug er dem Häuptling (tushe) Mang Buxin die Verantwortung für die Verteidigung und zog sich zurück“. ${ }^{338}$

Später ließ der birmanische König seinen Truppenführer Zhuo Ji Mengyang angreifen. Im Jahr Jiajing 29 (1550) wurde Zhuo Ji vom Schwager des tusi von Mengyang getötet, der anschließend jedoch selbst von den Birmanen gefangengenommen wurde.

Daraufhin entsandte der Kommandeur des Militärbezirks Jin-Teng, Xu Tianqi, den Kommandanten Hou Du mit dem Befehl, die verschiedenen einheimischen Völker für einen Feldzug zu rekrutieren. ${ }^{339}$

Der Häuptling (toumu) Si Ge aus Yixi [d. h. Mengyang] entschied die Frage, ob er dem Befehl gehorchen sollte oder nicht, folgendermaßen:

\footnotetext{
${ }^{338}$ TYTZ, S. 240

${ }^{339}$ TYTZ, S. 107, 141; YCFZ, S. 169
} 
„Er fertigte zwei Holztafeln an. Auf die eine schrieb er die Regierungsdevise des chinesischen Kaisers, auf die andere den Namen von Häuptling Mang [Ruiti, das ist König Bayinnaung]. Dann versammelte er seine Leute um die Tafeln. Alle verneigten sich vor ihnen und erwarteten einen Orakelspruch. Just in diesem Moment kippte die Tafel für Häuptling Mang um. Die Tafel für den chinesischen Kaiser hingegen ragte weiterhin aufrecht empor. Erst daraufhin entschloß sich [Si Ge] dem Befehl zu gehorchen“. ${ }^{340}$

Als König Bayinnaungs Armee Si Ge angriff, ersuchte dieser Kommandeur Xu Tianqi von Jin-Teng um Unterstützung, der daraufhin den Kommandeur Luo Rufang mit einem Truppenkontingent aus Han-chinesischen und einheimischen Soldatan nach Tengyue entsandte. ${ }^{341}$ Daraufhin schickte Si Ge mehr als zehntausend Mann nach Ava und stellte den birmanischen Truppen bei Jiasa am Irawadi eine Falle. Er schnitt ihnen den Rückweg ab und ließ am Fluß einen steinernen Damm öffnen, so daß ihre Schiffe von der Strömung fortgespült würden. Außerdem ersuchte er die chinesischen Truppen, sie von hinten, von der Grenze Longchuans aus, anzugreifen. Si Ges Falle schnappte zu: Über einen Monat lang hielt er die birmanischen Truppen umzingelt. Diese litten Hunger,

„sie schlachteten zuerst ihre Elefanten und Pferde, dann schälten sie die Rinde von den Bäumen und schließlich aßen sie Gräser und Wurzeln. Unter den Soldaten brach eine Seuche aus und die Toten stapelten sich zuhauf“، ${ }^{342}$

Auf ein Friedensangebot von König Bayinnaung wollte Si Ge nicht eingehen. Da aber die chinesischen Truppen von Gouverneur Wang Ning den Befehl erhalten hatten, in Tengyue zu bleiben und so die von Si Ge erwartete Verstärkung ausblieb, mußte er die Belagerung schließlich aufgeben, als Yue Feng aus Longchuan den Birmanen zur Flucht verhalf. Si Ge verfolgte sie und vernichtete den größten Teil der Truppen; selbst Bayinnaung soll nur knapp entkommen sein.

Um die Region zu befrieden, wurde ein Gesandter des chinesischen Hofes im Jahr 1578 nach Mengyang geschickt, der Si Ge aufforderte,

\footnotetext{
${ }^{340}$ TYTZ, S. 240

${ }^{341}$ TYTZ, S. 107, 141; siehe auch DMB, 975-978.

${ }^{342}$ TYTZ, S. 240
} 
„die kriegsgefangenen birmanischen Soldaten und Elefanten freizulassen; außerdem wurden Birma Gold und Seide als Geschenke mit freundlichen Worten zur Besänftigung übersandt. Aus Birma kam kein Dank dafür““ ${ }^{343}$

Im Gegenteil: Im folgenden Jahr griff König Bayinnaung erneut an, Si Ge wurde gefangengenommen und getötet.

Daraufhin übernahmen die Birmanen die Vorherrschaft über die Gebiete westlich des Irawadi. Viele Häuptlinge und ihre Soldaten flohen nach Yongchang und siedelten sich dort an. Im Jahr 1584 kehrte ein Nachfolger des tusi namens Si Yi nach Mengyang zurück. Sein Nachfolger Si Wei besiegte die Birmanen bei Midu. 1589 sandte dann Si Yuan Tribut an den chinesichen Hof und wurde zum Oberhaupt des Befriedeten Gebietes (xuanwei shi) Mengyang ernannt. Im Jahr darauf eroberten die Birmanen ihr verlorenes Terrain zurück und setzten einen eigenen Statthalter ein, nachdem Si Yuan und sein Sohn Si Hong geflohen waren. Si Hong schloß sich mit Si Zheng von Manmo zu einer Allianz zusammen. Im Jahr 1602 unterlag Si Zheng den Birmanen, zwei Jahre später wurde auch Si Hong besiegt. Die Birmanen setzten Si Hua als Oberhaupt von Mengyang ein, nach dessen Tod übernahm seine Frau, eine geborene Pa, das Amt.

Soweit die Darstellung der Ereignisse in den fangzhi von Tengyue.

\section{6. Zusammenfassung}

In die Kämpfe zwischen den einzelnen tusi im Süden der Region des Stromschluchtenfächers hatten sich die Ming zunächst nicht eingeschaltet. Nachdem jedoch zu Beginn der Ära Jiajing (1522-1567) Si Lun von Mengyang den Herrscher von Ava getötet hatte, war ein Beamter aus Yongchang entsandt worden, um die Lage zu erkunden: Er wurde von Si Lun geradezu in die Flucht geschlagen. Als sich der Konflikt zwischen Mengyang und Birma weiter verschärfte, versuchte die chinesische Regierung, die tusi in der Region zum Kampf gegen das expandierende Birma zu bewegen (yong yi gong yi).

Die in den fangzhi von Tengyue beschriebene Entscheidung des Si Ge, ein Orakel darüber bestimmen zu lassen, wem seine Loyalität in Zukunft gelten sollte, veranschaulicht die starke und unabhängige Stellung Mengyangs in der Region. Mengyang hatte Dank seiner Lage an der Handelsroute nach Westen sowie seiner Jade- und Bernsteinvorkommen seit

\footnotetext{
${ }^{343}$ TYTZ, S. 240
} 
Mitte des 15. Jahrhundert ebenso wie Mengmi vom Handel mit China profitieren können. Der nominelle Status eines Befriedeten Gebietes bedeutete einen Prestigegewinn und ermöglichte profitable Beziehungen zum chinesischen Reich. Aufgrund seiner wirtschaftlichen und militärischen Stärke konnte Mengyang auf Kosten seiner Nachbarn expandieren und die Dynastie von Ava stürzen. Mitte des 16. Jahrhunderts begann sich die Lage jedoch entscheidend zu verändern. Die nach Norden vordringenden birmanischen Truppen stellten eine existenzielle Bedrohung dar, der sich Menyang stellen mußte. Der Entscheidungsprozeß wird im Bericht in den fangzhi durch das Aufstellen der beiden Tafeln symbolisiert, die die beiden Möglichkeiten aufzeigen, sich entweder Birma zu unterwerfen oder Widerstand zu leisten. Und dabei auf Unterstützung durch die Ming zu hoffen, die ihrerseits einheimische Truppen für einen Feldzug mobilisieren wollten. Hier kommt die chinesische Vorstellung zum Ausdruck, daß es Aufgabe der tusi sei, ihre Truppen zur Sicherung der zum Kernland hin angrenzenden regulären chinesischen Verwaltungseinheiten zur Verfügung zu stellen. Mit dem Verweis auf das Orakel bringt der chinesische Autor des Textes im TYTZ auch zum Ausdruck, daß eine Oberhoheit des chinesischen Kaisers über die Region ohnehin bestand und sich nun durch übernatürliche Kräfte manifestierte. Unberücksichtigt bleibt im Text dabei, wie im weiteren Verlauf der Ereignisse deutlich wird, das handfeste Interesse Si Ges an militärischer Unterstützung durch die Chinesen, die er in seine Expansionspläne miteinbezogen hatte.

Indem die Ming ein zusätzliches Truppenkontingent in Tengyue, ihrem westlichsten Stützpunkt, stationierten, sah es auch zunächst so aus, als ob sie in den Kampf eingreifen würden. Tatsächlich erhielten die Truppen jedoch keinen Einsatzbefehl. Der chinesischen Regierung war vor allem daran gelegen, eine Ausweitung der Kämpfe zu verhindern und den Status quo aufrechtzuerhalten. Dies zeigt auch der erfolglos gebliebene Versuch, im Jahr 1578 zwischen den Parteien zu vermitteln, indem die Ming Mengyang zur Freilassung der Gefangenen drängten und Geschenke an Birma sandten. Deutlich wird eine insgesamt zurückhaltende, teilweise auch unentschlossene Politik der chinesischen Regierung, die sowohl die Machtentfaltung Mengyangs als auch Birmas mit Argwohn betrachtete, sich jedoch nicht direkt in die Kämpfe einschaltete. Ehe chinesische Truppen in den achtziger Jahren des 16. Jahrhunderts tatsächlich im Grenzgebiet eingesetzt wurden, mußten die Kämpfe erst näher an die Befriedeten Gebiete (xuanfu si) im Südwesten von Tengyue heranrücken und die Unterpräfekturstadt selbst bedrohen. 
Die Darstellungen in den fangzhi von Tengyue zeigen, wie sich Mengmi und Mengyang seit Mitte des 15. Jahrhunderts zu eigenständigen prosperierenden und expandierenden Staaten entwickelt hatten. Diese Entwicklung war Teil eines Prozesses, der charakteristisch für das gesamte Gebiet im Norden des modernen Südostasien war.

Wie Sun Laichen in seiner Dissertation ,Ming-Southeast Asian overland interactions“ gezeigt hat, brachte der Vorstoß der Ming nach Südwesten Ende des 14. Jahrhunderts die fortschrittliche chinesische Militärtechnologie, insbesondere Feuerwaffen, in die Region. Im 15. Jahrhundert entwickelte sich aufgrund der großen Nachfrage nach Edelsteinen ein lebhafter Handel mit China. ${ }^{344}$ Die ökonomische und militärische Stärke, aber auch Faktoren wie eine Intensivierung der Landwirtschaft und Bevölkerungswachstum trugen zum Aufschwung von Kleinstaaten wie Mengyang (Mohnyin), Mengmi (Mongmit), Lanna, Xishuangbanna oder auch Dai Viet im Süden Yunnans bei, die ihre Eigenständigkeit etwa ein Jahrhundert lang behaupten konnten, ehe die Feldzüge der Birmanen in der zweiten Hälfte des 16. Jahrhunderts das Machtgefüge im Norden des modernen Südostasien dauerhaft veränderten.

\section{Die Expansion der Birmanen in die Region des Stromschluchtenfächers und die Reaktion der Ming auf die Invasion aus dem Südwesten}

In der zweiten Hälfte des 16. Jahrhunders begann sich die politische Situation in der Region des Stromschluchtenfächers zu verändern. Das neue birmanische Königreich der Dynastie von Toungoo war ein ernstzunehmender Konkurrent um die Vorherrschaft in der Region, der sich nicht wie die Ming mit Loyalitätserklärungen und der nominellen Eingliederung in das eigene Reich zufriedengab, sondern Eroberungsfeldzüge führte, um die zumeist von Shan beherrschten Kleinstaaten im Gebiet des Stromschluchtenfächers unter seine direkte Kontrolle zu bringen. Neben den militärischen Vorstößen warben die Birmanen auch um Verbündete unter den tusi. So fanden unzufriedene Angehörige der einheimischen Herrscherfamilien besonders bei Streitigkeiten um die Nachfolge verstorbener Herrscher häufig Unterstützung bei den birmanischen Königen.

Die Feldzüge der Birmanen beschränkten sich nicht nur auf die Kleinstaaten südwestlich der Unterpräfektur Tengyue, ihre Truppen waren auch weiter im Südosten Yunnans bis in das Gebiet von Xishuangbanna vorgedrungen und hatten bereits im Jahr 1558 das Königreich von Chengmai (im Nordosten des modernen Thailand) erobert. ${ }^{345}$ Im Jahr 1562

\footnotetext{
${ }^{344}$ Sun Laichen: ,Ming-Southeast Asian overland interactions, 1368-1644‘, Ph. D. diss., University of Michigan, 2000.

${ }^{345}$ Maung Htin Aung, S. 116
} 
konnte König Bayinnaung Siam annektieren, das er 1565 erneut erobern und dessen Hauptstadt Ayutthaya er im Jahr 1568 zeitweise besetzt halten konnte. ${ }^{346}$

Eine entscheidende Rolle in den Kämpfen um die Vorherrschaft im Südwesten der Unterpräfektur Tengyue spielte der an dem gleichnamigen Flußlauf gelegene Kleinstaat Longchuan. Aufgrund seiner geographischen Lage kam ihm eine Schlüsselposition in der Region zu. Ihn durchquerte der südliche der Hauptverkehrswege, die China mit den Befriedeten Gebieten am Shweli verbanden und der den Chinesen den Zugang zu den Rubinminen von Mengmi ermöglichte. Die Birmanen hatten Mengmi schon einmal im Jahr 1554 erobern können, aber erst nach einigen Jahrzehnten militärischer Auseinandersetzungen gelang es ihnen im Jahr 1588 dieses Gebiet ganz ihrem Königreich zu unterstellen. ${ }^{347}$

Unterstützung für Vorstöße nach Norden in Richtung Yongchang erhielten die Birmanen zu Beginn der Ära Wanli auch vor Ort. Nachdem der xuanfu shi von Longchuan, Duo Shining, im Jahr 1577 von seinem Schwager, einem chinesischen Kaufmann aus Jiangxi namens Yue Feng, getötet worden war, hatte sich jener mit den Birmanen verbündet, um seine Herrschaft über Longchuan zu festigen. Während die Truppen Bayinnaungs in den folgenden Jahren ihre Angriffe auf Mengyang konzentrierten, das sie schließlich 1579 erobern konnten, kämpften verbündete Truppen aus Mubang und Longchuan im Süden gegen Mengmi und rückten im Norden bis nach Ganya vor.

Im Jahr 1581 trat in Birma König Nandabayin (chin. Mang Yingli) die Nachfolge seines Vaters Bayinnaung an. Im darauffolgenden Jahr eroberte Yue Feng Ganya im Gebiet der Unterpräfektur Tengyue. ${ }^{348}$ Außerdem intrigierte er gegen seinen früheren Verbündeten Han Ba von Mubang und veranlaßte Nandabayin dessen Herrschaftsgebiet unter direkte Kontrolle Birmas zu stellen; einer der Söhne Han Bas unterwarf sich den Birmanen, ein anderer, mit chinesischem Namen Han Jinzhong, flüchtete nach Osten über den Salween. Von der Armee Mang Yinglongs, dem jüngeren Bruder des birmanischen Königs, wurde er bis zum Gebirgspaß Yaoguan im Süden von Shidian, einer lokalen Sonderverwaltungseinheit der Präfektur Yongchang, verfolgt. ${ }^{349}$ Im Jahr 1583 brandschatzten die birmanischen Truppen Shidian und griffen die weiter westlich gelegene Präfektur Shunning an. Ihr

\footnotetext{
${ }^{346}$ Maung Htin Aung, S. 121

${ }^{347}$ You Zhong, S. 437

${ }^{348}$ YCFZ, S. 134

${ }^{349}$ TYTZ, S. 191; You Zhong, S. 440
} 
Verbündeter Nangwu, der Sohn des Yue Feng von Longchuan, zerstörte die auf dem Hochplateau von Longling gelegene Festung (zhai) Menglin und ließ die dort stationierten chinesischen Soldaten töten. Außerdem eroberten seine Soldaten das Befriedete Gebiet Zhanda, dessen Oberhaupt Dao Siding China zuvor vergeblich um Unterstützung gebeten hatte:

„Seine Stadt (cheng) wurde zerstört, seine Frau, seine Söhne, seine ganze Sippe und seine Untertanen wurden allesamt ausgelöscht“. 350

Auch im Nandian xuanfu si machte sich der Einfluß Birmas bemerkbar. Über dessen Ausmaß waren sich die Verfasser der fangzhi allerdings nicht einig. So heißt es einerseits, daß Nandian erobert worden sei, andererseits, daß sein Oberhaupt mit Birma verbündet gewesen sei. $^{351}$

Die Feldzüge der Birmanen in der Region des Stromschluchtenfächers verliefen durch Eroberung (wie in Ganya und Zhanda) oder auch mit Unterstützung von Verbündeten (wie in Longchuan) äußerst erfolgreich. König Nandabayin von Birma

„hatte mehrere zehntausend auf Elefanten reitende Soldaten in Marsch gesetzt, die auf verschiedenen Wegen ins Landesinnere eindrangen“ und bis an den Salween vorrückten. ${ }^{352}$

Die Truppen aus Birma zogen sowohl über die westliche Verkehrsroute im Tal des Dayingjiang sowie auch über die südliche Route in die tusi-Gebiete im Südwesten der Unterpräfektur Tengyue. Schon

„ließ [Birmas Verbündeter] Nangwu [von Longchuan] auch Tengyue, Yongchang, Dali, Jingdong, Menghua und Zhenyuan auskundschaften“. ${ }^{353}$

Die chinesische Regierung hatte sich bis dahin auf politische Maßnahmen beschränkt, um ihre Oberhoheit in der Region des Stromschluchtenfächers zu sichern und lediglich einige Beamte zum Krisenmanagement in die Befriedeten Gebiete entsandt, die sich der Loyalität

\footnotetext{
${ }^{350}$ TYZZ, S. 93, 191; TYTZ, S. 142; YCFZ, S. 134; You Zhong, S. 440

${ }^{351}$ TYZZ, S. 138. In der ,Kurzbiographie des Liu Ting ‘ weisen die Verfasser der fangzhi von Tengyue darauf hin, daß es in alten Chroniken fälschlicherweise heißen würde, daß Nandian im 1. Monat des Jahres Wanli 11 (1583) angegriffen worden sei. Es müsse dies jedoch entsprechend dem Kapitel über die tusi des Ming shi geändert werden und richtig heißen, daß Shidian angegriffen worden sei; zumal Dao Letai von Nandian mit Mang Yingli verbündet gewesen sei (TYTZ, S. 142; TYZZ, S. 111; s. a. YCFZ, S. 134).

352 TYZZ, S. 93. An anderer Stelle ist sogar von „mehreren hunderttausend Soldaten“ die Rede (TYTZ, S. 381).

${ }^{353}$ TYZZ, S. 93
} 
der einzelnen tusi versichern sollten. Den Bitten einiger Oberhäupter der Befriedeten Gebiete um Unterstützung gegen die Invasoren aus Birma waren die Ming nicht nachgekommen; die in der Region stationierten chinesischen Truppen hatten nicht in die Kämpfe eingegriffen.

Doch nun waren nicht mehr allein die Gebiete der tusi im Südwesten der Unterpräfektur mit ihrer fast ausschließlich einheimischen Bevölkerung von einer Invasion bedroht, sondern auch Präfekturen mit Han-chinesischer Bevölkerung in ummauerten Verwaltungsstädten und Garnisonsstützpunkten.

Die Haltung der chinesischen Regierung änderte sich, als sich diese Bedrohung realisierte und die Soldaten Nangwus 1583 die Festung Menglin zerstörten. Im Kampf um die Festung wurden der chinesische Garnisonskommandant Wu Jixun, der Bataillonskommandant Qi Jinyuan sowie sechs Soldaten getötet. ${ }^{354}$ Daraufhin baten der Gouverneur Liu Shizeng und der Zensor Dong Yuhui den Kaiser in einer Throneingabe um die Entsendung von Soldaten. $^{355}$ Dem Ersuchen wurde stattgegeben. Der General (jiangjun) Liu Ting ${ }^{356}$ wurde nach Tengyue und der Regionalkommandant (canjiang) Deng Zilong ${ }^{357}$ nach Yongchang entsandt, um mit jeweils fünftausend Mann den Invasoren entgegen zu ziehen. ${ }^{358}$

„Am 26. Tag des 11. Monats [des Jahres Wanli 11 (1583/84)] rückten Liu und Deng auf verschiedenen Wegen [von ihren Stützpunkten aus] vor. Yue Feng, [der tusi von Longchuan], und [der birmanische König] Mang Yingli waren im Westen zusammengetroffen. Sie hatten Truppen aus Miandian [Birma], Meng-yang, Mengmi und Manmo in Mengmao im Osten versammelt und Truppen aus Cheli, Babai, Menglang und Mubang in Mengyan, um den Gebirgspaß Yaoguan angreifen. ${ }^{359}$ Da die Soldaten sämtlicher zehn tusi, zusammen einige hunderttausend Mann, auf einmal nach Yaoguan vordrangen, konnten sie nicht alle über [den Paß] ausschwärmen. Deng Zilong hatte die

\footnotetext{
354 TYTZ, S.191; TYZZ, S. 93; YCFZ, S. 134

${ }^{355}$ Siehe TYZZ, S. 92-93; YCFZ, S. 169

${ }^{356}$ Liu Ting (1552-1619) „stammte aus Nanchang. Sein Vater Liu Xian war Militärkommandant (dudu). Ting war mutig. Wegen des Ruhmes seines Vaters ... erhielt er den Posten eines Garnisonskommandanten (zhihuishi). Seine militärischen Verdienste waren sehr groß“ (TYTZ, S. 142; TYZZ, S. 111-114; zur Biographie des Liu Ting siehe DMB, S, 964-68).

${ }^{357}$ TYTZ, S. 143, 381; TYZZ, S. 114-115. In den fangzhi wird erläutert, daß der Posten des Regionalkommandanten im 3. Jahr der Ära Wanli (1583) wieder eingeführt wurde und Liu Ting sowie Deng Zilong in dieses Amt eingesetzt wurden (TYTZ, S. 128); „später wurde aufgrund des von Yue Feng verursachten Aufruhrs wieder ein Regionalkommandant (canjiang) ernannt. Diesen Posten hatten mehrere berühmte Generäle (jiang) inne“ (TYZZ, S. 87).

Deng Zilong stammte aus Fengcheng in der Provinz Jiangxi (TYTZ, S. 143, siehe auch S. 354); zu Deng Zilong siehe DMB, S, 170; 965)

${ }^{358}$ TYTZ, S. 142; YCFZ, S. 134

${ }^{359}$ Der strategische Gebirgspaß „Yaoguan befindet sich 40 li [ca. 20 km] östlich von Shidian, 260 li [ca. 130 km] von Yongchang entfernt“" (TYZZ, S. 111).
} 
Befestigungsanlagen ausbauen lassen und wartete ruhig ab. $\mathrm{Zu}$ jener Zeit waren die Banditen äußerst stark. Ting und Zilong erkundeten [erst die Lage] und griffen dann plötzlich an. Sie brachten [den Invasoren] eine gründliche Niederlage bei und töteten Han Qian von Mubang und [Jing] Zongzhen [von Wandian]. Da Zongzhen getötet worden war, hatten die Banditen (zei) ihren [ortskundigen] Führer verloren. Sie ergriffen die Flucht und wurden vollständig aufgerieben. $^{360}$ Ting erinnerte da-ran, daß die Banditen von Yue Feng aufgestachelt worden waren und daß jener noch nicht gefaßt worden sei. Also zerstreuten sich [die chinesischen Truppen] und schlossen sich dann so wieder zusammen, daß Yue Feng zwischen ihnen einkesselt wurde.“361

Yue Feng und sein Sohn Nangwu wurden gefangengenommen; die chinesischen Truppen hatten die Kontrolle über die Befriedeten Gebiete wieder gewonnen und konnten sogar bis nach Ava vordringen, dessen Stadthalter kapitulierte, woraufhin sich die chinesischen Soldaten wieder zurückzogen. ${ }^{362}$

General Liu Ting hatte ursprünglich nicht die Absicht gehabt, Yue Feng gefangen zu nehmen und an den chinesischen Hof auszuliefern. Sein Plan war es, die Loyalität der anderen tusi, die sich an der Invasion beteiligt hatten, zurückzugewinnen, indem er sich Yue gegenüber gnädig zeigte und ihn nicht töten ließ, so wie er es als Rebell im chinesischen Herrschaftsgebiet eigentlich zu erwarten gehabt hätte. ${ }^{363}$ Tatsächlich veranlaßte Lius Verhalten einige tusi, wie z.B. Si Hua von Mengha, Si Wei von Mengyang und Han Feng von Mubang, sich den chinesischen Truppen zu unterwerfen und die in ihren Gebieten stationierten Birmanen zu töten. ${ }^{364}$ Die chinesische Regierung drängte Liu jedoch dazu, Yue Feng und seinen Sohn Nangwu gefangen zu nehmen und sie in die Hauptstadt zu

\footnotetext{
${ }^{360}$ Im TYTZ wird auf eine Überlieferung hingewiesen, der zufolge der Sieg errungen wurde, weil Deng „Zilong bei der Vertreibung der Elefanten[-Kavallerie]einem [der Tiere] einen Fußtritt gegeben hat, woraufhin der Elefant gestorben ist. Die Barbaren (man) waren darüber sehr erschrocken. Deshalb konnten sie vernichtend geschlagen werden und die auch Schlachtordnung ihrer Elefanten konnte durchbrochen werden“ (TYTZ, S. 381, siehe auch TYTZ, S. 354; 362).

${ }^{361}$ TYTZ, S. 142; TYZZ, S. 111-112

${ }^{362}$ TYTZ, S. 142; YCFZ, S. 134; You Zhong, S. 440.

Um die weite Strecke bis in die Hauptstadt Birmas, nach Ava zurückzulegen, benötigten die chinesischen Truppen über einen Monat. „Die früher von den Truppen der Yuan (Yuan ren) zerstörte birmanische Stadt Jiangtoucheng ist eine Wegstrecke von fünfzehn Tagen von Tengyue entfernt. Zehn Tage weiter im Süden befindet sich Taigongcheng. Nach [weiteren] acht Tagen [in Richtung] Süden folgt Malaicheng, nach [weiteren] fünf Tagen [in Richtung] Süden dann Anzhengguocheng und noch [einmal] fünf Tage [weiter] südlich liegt Pagan, die Stadt des birmanischen Königs, das heißt die Stadt Ava. Das sind dreiundvierzig Tage gerechnet von der Unterpräfektur (zhou) [Tengyue] aus. ... Bis [Liu Ting] in Pagan anlangte, hatte er [einen Teil] seiner Truppen verloren und kehrte um, als Birma befriedet war“ (TYZZ, S. 113; TYTZ, S. 142).

${ }^{363}$ YCFZ, S. 134

${ }^{364}$ YCFZ, S. 134; You Zhong, S. 441
} 
überstellen, wo beide schließlich hingerichtet wurden. ${ }^{365}$ Liu Tings Plan, Gnade vor Recht ergehen zu lassen, um Loyalität zu gewinnen, war damit gescheitert. Aus Furcht, ein ähnliches Schicksal wie Yue Feng zu erleiden, schlossen sich einige tusi König Nandabayin von Birma an, so zum Beispiel der Herrscher von Mengmi, Si Zhong. Andere wie Si Wei, dessen Herrschaftsgebiet Mengyang ein Hauptziel der birmanischen Angriffe war, erklärten sich weiterhin den Ming gegenüber loyal.

Die chinesischen Truppen in der Region waren in die beiden Bataillone (ying) Yaoan und Tengchong aufgeteilt worden, ersteres wurde von Deng Zilong (jiang Yao bing) befehligt, das zweite von Liu Ting (jiang Teng jun). Für ihre militärischen Erfolge wurden beide Truppenführer befördert und zu stellvertretenden Regionalkommandeuren (fu zongbing) ernannt. ${ }^{366}$ Zwischen den beiden Armeen herrschte jedoch Uneinigkeit und es kam zu Kämpfen der Soldaten untereinander. Als dies der Regierung bekannt wurde, wurde Liu Ting, dem man zudem den Vorwurf machte, seine Truppen nicht an einer Plünderung der Stadt Tengyue gehindert zu haben, abgesetzt. ${ }^{367}$ Sein Stellvertreter Liu Tianfeng trat an seine Stelle. Die beiden Bataillone Yaoan und Tengchong wurden anschließend zusammengelegt und Deng Zilong zum Regionalkommandeur (zongbing) befördert. ${ }^{368}$

Der Sieg der chinesischen Truppen bei Yaoguan und ihr Vorstoß nach Ava hatten die militärischen Auseinandersetzungen in der Region nicht beenden können. Die Ming hatten die drei Befriedeten Gebiete Nandian, Ganya und Longchuan wieder ihrer Oberhoheit unterstellt, im Süden und Westen dieser drei tusi-Gebiete gingen die Kämpfe zwischen Birma, Mengmi, Mengyang und Manmo jedoch noch ein Jahrzehnt lang weiter.

„Im 13. Jahr (1585) ließ [der birmanische König] Mang Yingli erneut Yixi [Mengyang] angreifen; die beiden Städte (cheng) Midu und Susong wurden erobert. Daraufhin bat Si Wei, der Häuptling [von Mengyang, die chinesische Regierung] um Hilfe. ${ }^{369}$ Der damalige Unterpräfekt zur Besänftigung der Barbaren (fu yi tongzhi) in Tengyue, Song Ru, hielt es für zu schwierig [Si Wei] zu helfen; Li Cai, der Kommandeur des Militärbezirks von Jin-Teng, wünschte [jedoch], Verdienste um die Festlegung der Grenze zu erwerben (xi li bian

\footnotetext{
365 TYZZ, S. 113; YCFZ, S. 134; You Zhong, S. 441

${ }^{366}$ TYZZ, S. 113; TYTZ, S. 143

${ }^{367}$ DMB, S. 965

${ }^{368}$ TYZZ, S. 113; TYTZ, S. 143

369 TYTZ, S. 140. Im YCFZ heißt es abweichend: „Im 15. Jahr der Ära Wanli (1587) ...“ (YCFZ, S. 135).
} 
gong). ${ }^{370}$ Er befahl dem Regionalkommandanten Liu Tianfeng sich dorthin zu begeben und [Mengyang] zu unterstützen. Tianfeng scheute davor zurück, sich in Marsch zu setzen und befahl seinerseits den Kommandanten (bazhong) Du Shi und Li Chao sich mit ihren Soldaten nach Mi[du] zu begeben. Sie übergaben Fahnen und militärische Ausrüstung aus der Garnison an Yixi. Die einheimischen Soldaten (yi bing) verteilten sich, so daß die Birmanen meinten, daß eine große Armee [aus China] gekommen wäre. Sie gerieten deshalb in Panik und wurden vernichtend geschlagen. Bei dem Zusammenstoß [der Truppen] schlug Si Wei über eintausend [Feinden] die Köpfe ab. Tianfeng verkündete [dem Hof] den Sieg [als den seinigen]. Der Gouverneur [von Yunnan] Liu Shizeng und Regionalkommandeur (zongbing) Mu Changzuo unterstützten aufgrund dieser Mitteilung Cais Beförderung zum Assitierenden Zensor (you qian du yushi) und zum Gouverneur von Yunyang [in Huguang]. ${ }^{371}$

Fünf Jahre später beschuldigte der Zensor Su Zan den Li Cai, seine Verdienste nur vorgetäuscht zu haben. Auf kaiserlichen Befehl wurde Li verhaftet, ebenso wie der Präfekt von Yongchang, Chen Yanzhi, der Unterpräfekt Song Ru und der Unterpräfekt von Tengyue, Chen Kehou [1580-1587 in Tengyue tätig]; sie wurden auf kaiserlichen Befehl hin eingekerkert. ${ }^{372}$ In den folgenden fünf Jahren wurden für Li Cai über fünfzig Throneingaben eingereicht, die aber sämtlich nicht zu einer Reduzierung seiner Strafe führten. Si Wei [von Mengyang] entsandte einen Boten, der ein Schreiben (biao) und lokale Produkte als Tributgeschenke überreichen sollte. Ein Beamter nahm das Schreiben heraus und veränderte es. Dann übersandte er es an den Hof. Dort wußte man nichts [von Si Weis Absicht, Li Cai zu unterstützen, da das Schreiben verfälscht worden war] und im 21. Jahr (1593) wurde Cai an die Grenze in die Garnison Dianhai verbannt. ... Nach langer Zeit wurde ihm seine Strafe erlassen. Dann kehrte er in seine Heimat zurück und starb dort.““373

Bereits im Jahr 1591 hatte Deng Zilong seine Truppen in Luobosizhuang (in Mangdong im Südwesten des modernen Kreises Lianghe) im Gebiet von Nandian stationiert. Um die fortgesetzten Angriffe der Birmanen besser abwehren zu können, ließ er die Soldaten zum

\footnotetext{
370 TYTZ, S. 108, 141. Li Cai (ca. 1520 - ca. 1606); für biographische Angaben siehe DMB, S. 1562.

${ }^{371}$ TYZZ, S. 92-93; YCFZ, S. 169. Siehe auch DMB, S. 1562.

372 Auch Liu Tianfeng wurde von dem Zensor Su Zan angezeigt und verhaftet, nach einer Untersuchung aber wieder freigelassen“ (TYTZ, S. 128, 187).

${ }^{373}$ TYTZ, S. 140; YCFZ, S. 135. Siehe auch You Zhong, S. 441.
} 
Denglianshan (westlich des modernen Kreises Longchuan) und weiter bis Kongha vorrücken, wo es ihm im folgenden Jahr gelang, die birmanischen Truppen zurückzuschlagen. ${ }^{374}$ Diese zogen sich auf eine Sandbank im Fluß zurück, wohin ihnen die Truppen der Ming, die keine Boote besaßen, nicht folgen konnten.

Im Jahr darauf (1593) eroberten die Birmanen Manmo, wo sie eine Festung errichteten, die ihnen als Ausgangspunkt für einen erneuten Vorstoß diente, welcher sie auf verschiedenen Routen (über Zhefang und Mangshi, über Lasa und Mansang sowie über Shanmulong) nach Longchuan führte, dessen tusi in das benachbarte Mengmao floh. ${ }^{375}$

In der letzten Dekade des 16. Jahrhunderts konzentrierten sich die Kämpfe zwischen den Truppen der birmanischen Toungoo- und der chinesischen Ming-Dynastie auf ein Gebiet, das sich von Manmo bis nach Longchuan erstreckte. In dieser endlosen Reihe von Angriffen und Gegenangriffen gelang es keiner der beiden großen Kriegsparteien einen entscheidenden Sieg zu erringen und sich die Vorherrschaft über die verschiedenen Kleinstaaten in der Region dauerhaft zu sichern.

\section{Gouverneur Chen Yongbins Maßnahmen zur Befriedung der Gebiete im Westen}

\section{der Provinz Yunnan}

Im Jahr 1593 (Wanli 21) wurde ein neuer Gouverneur (xunfu) für die Provinz Yunnan ernannt: Chen Yongbin (ca. 1547-1617). Er blieb fünfzehn Jahre lang bis 1608 in diesem Amt tätig. ${ }^{376}$ Von Beginn an engagierte er sich besonders für die Befriedung der Region des Stromschluchtenfächers und reiste noch im Jahr seines Amtsantritts selbst in die Präfektur Yongchang. Anders als seine Vorgänger beschränkte sich Gouverneur Chen nicht darauf, nur Truppen zu entsenden, um einzelne Vorstöße der Birmanen aufzuhalten. Ziel seiner Bemühungen war es, die Kampfhandlungen in den Gebieten der tusi auf Dauer zu beenden. Dazu bediente er sich sowohl militärischer als auch politischer Mittel.

Chen Yongbin war über die ebenfalls seit einigen Jahrzehnten andauernden Kämpfe zwischen Birma und Siam informiert und wollte die Rivalität der beiden Nachbarstaaten für seine Pläne nutzen.

Siam, das in den Jahren 1562 bis 1568 mehrfach von birmanischen Truppen unter König Bayinnaung besetzt worden war, hatte im Jahr 1587 seine Unabhängigkeit wiedererlangt

\footnotetext{
${ }^{374}$ You Zhong, S. 442. Deng Zilong wurde im Jahr 1592 wegen Fehlverhaltens kritisiert und seines Amtes enthoben, im Jahr 1598 jedoch wieder rehabilitiert (DMB, S. 170).

${ }^{375}$ You Zhong, S. 442

${ }^{376}$ Chen Yongbin stammte aus Jinjiang in der Provinz Fujian. Im Jahr 1567 hatte er den akademischen Titel eines juren erworben, im Jahr 1571 den jinshi-Titel. Chen war in verschiedenen Verwaltungsämtern zunächst in Suzhou, dann in den Provinzen Shanxi, Sichuan, Zhejiang und Huguang tätig, ehe er 1593 nach Yunnan versetzt wurde (zur Biographie Chen Yongbins siehe DMB, S. 192-194 und TYTZ, S. 141).
} 
und in der Folgezeit fünf Invasionen des birmanischen Königs Nandabayin zurückschlagen können. ${ }^{377}$ In den neunziger Jahren des 16. Jahrhunderts mußte Nandabayin auch im eigenen Land deutliche Machtverluste hinnehmen. Einer Rebellion der Mon und ihrer siamesischen Verbündeten in Niederbirma im Jahr 1593 folgten Aufstände der Gouverneure von Prome, Toungoo, Chengmai und Ava, die die Position des Königs weiter schwächten. ${ }^{378}$ In dieser Phase der Zersplitterung der Zentralmacht konzentrierten sich die Kräfte der Birmanen auf den Kampf um die Vorherrschaft im Landesinnern, der Vorrang vor Expansionsfeldzügen an der Peripherie hatte.

Chen Yongbin sandte noch im Jahr 1593 Boten zum König von Siam, die für ein gemeinsames Vorgehen beider Staaten gegen Birma werben sollten. ${ }^{379}$ Diese diplomatische Initiative Chens hatte Erfolg und im Jahr 1594 (Wanli 22) begann ein zeitgleicher Angriff chinesischer und siamesischer Truppen, die den Birmanen an zwei Fronten deutliche Niederlagen beibrachten.

Südwestlich der Unterpräfektur Tengyue hatten die Truppen Birmas und ihrer Verbündeten unter den tusi (z.B. Duo An von Mengmao) von ihrem Stützpunkt Manmo aus im Jahr 1593 einen Vorstoß nach Longchuan unternommen.Die chinesischen Truppen zogen ihnen von vier Punkten aus entgegen: Regionalkommandant (canjiang) Wang Yilin führte den Angriff auf Denglianshan (westlich des modernen Kreises Longchuan),General (zhong jun) Lu Chenjue rückte von Leiyin (Mangyun im Südwesten des modernen Yingjiang) aus vor, die Militärkommandanten (duzhihui) Qian Zhongxian und Zhang Xiansheng von Manyin (das moderne Jingkan im Westen des Kreises Longchuan) aus, Kommandant (shoubei) Zhang Xianyun führte seine Soldaten von Daxian (Dengxiu im Süden des Kreises Ruili) aus gegen den Feind. ${ }^{380}$ Den Truppen der Ming gelang es zunächst, die Birmanen nach Manmo zurückzudrängen, dort gerieten sie jedoch in einen Hinterhalt und mußten sich ihrerseits zurückziehen. Einen erneuten Angriff der Birmanen auf Longchuan konnten die chinesischen Truppen jedoch abwehren und die Vorstöße der Birmanen auf die sechs tusi im Gebiet der Unterpräfektur Tengyue zunächst beenden. ${ }^{381}$

\footnotetext{
377 Siehe Maung Htin Aung, S. 131

${ }^{378}$ Maung Htin Aung, S. 132-134. Im Jahr 1599 wurde Nandabayin von seinem Cousin, dem Gouverneur von Toungoo, und dessen Verbündeten, dem König von Arakan, gefangengenommen. Aus den folgenden Machtkämpfen ging der Gouverneur von Ava, Nandabayins jüngerer Bruder, der Prinz von Nyaungyan, siegreich hervor.

${ }^{379}$ TYTZ, S. 141, 191; YCFZ, S. 135; DMB, S. 193

${ }^{380}$ You Zhong, S. 442

${ }^{381}$ You Zhong, S. 442
} 


\section{1. Die Errichtung der acht Paßstationen}

Um die mit dem Sieg über Birma gewonnene Position zu festigen und die Serie der birmanischen Angriffe dauerhaft zu beenden, veranlaßte Gouverneur Chen Yongbin im Jahr 1594 (Wanli 22) den Bau von acht Paßstationen und zwei Festungen (ba guan er bao). ${ }^{382}$ Diese sollten südwestlich der Unterpräfektur Tengyue auf Berggipfeln errichtet werden, um die strategisch wichtigen Gebirgspässen zu kontrollieren und die tusi-Gebiete zwischen Tengyue und dem Fluß Irawadi im Osten und dem Shweli im Süden vor Angriffen aus Birma schützen (siehe Karte 8, S. 138). Mit dem Bau der Paßstationen beauftragte er Qi Wenchang, den Vize-Präfekten (tongzhi) Yongchangs, und Wu Xianzhong, den Regionalkommandanten (canjiang) von Jin-Teng. ${ }^{383}$

Von Norden nach Süden wurden auf den folgenden acht Bergpässen Stationen errichtet:

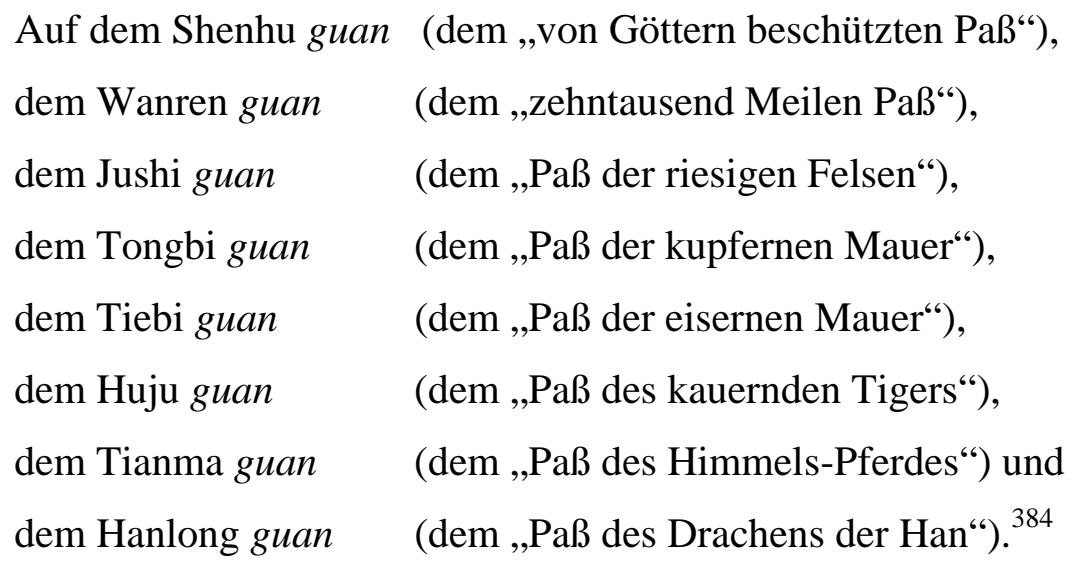

$\overline{382}$ TYTZ, S. 192; YCFZ, S. 135; DMB, S. 193

${ }^{383}$ YCFZ, S. 135, 169; TYTZ, S. 107, 128, 141, 192; TYZZ, S. 11; siehe auch You Zhong, S. 443, S. 484-485.

Qi Wenchang war für seine Verdienste während des Feldzuges zur Befriedung des Südwestens zuvor zum Kommandeur des Militärbezirks (bingbei) Jin-Teng ernannt worden (YCFZ, S. 169; TYTZ, 107). Qi war u.a. im Jahr 1588 auf Befehl des Gouverneur Xiao Yan nach Manmo gereist, um sich der Loyalität des tusi Si Hua zu versichern. Qi begab sich, wie es die Autoren der fangzhi in der Tradition der Klischeefigur des ,mutigen Gesandten ‘ besonders betonen, ,allein in die Festung der Banditen und tat ihnen die Bedeutung der Tugendhaftigkeit kund. Die Barbaren (yi) respektierten seine ehrlichen Worte, sie verneigten sich zum Kotau (qi shou; YCFZ: pu fu [,Sie krochen vor ihm auf dem Boden. ']) und gehorchten den Befehlen“ (TYTZ, S. 141; TYZZ, S. 110; YCFZ, S. 169).

${ }^{384}$ Zur Lage der acht Paßstationen siehe auch TYTZ, S. 179. Liu Chunming (S. 21) beschreibt die heutige Lage der Paßstationen folgendermaßen:

\footnotetext{
„Shenhu guan: [Das ist das moderne] Kongjiawan, nordöstlich von Sudianshao im modernen Kreis Yingjiang.

Wanren guan: Menglong im Nordwesten des modernen Kreises Yingjiang.

Jushi guan : Xima im westlichen Teil des modernen Kreises Yingjiang.

Tongbi guan: Jiadushan im westlichen Teil des modernen Kreises Yingjiang.

Tiebi guan: Unterhalb von Walanling, westlich des modernen Kreises Longchuan, diesseits des Flusses Xipa.

Huju guan: Bei Luban, westlich des modernen Kreises Longchuan.

Tianma guan: Befindet sich im Gebiet des Dreiecks von Mengmao, südwestlich des modernen Kreises Ruili.

Hanlong guan: Am Nordufer des Oberlaufes des Flusses Nanpo, südwestlich des modernen Kreises Ruili.“
} 
Karte 8: Die acht Paßstationen in der Unterpräfektur Tengyue zur Zeit der Ära Wanli (1573-1620)

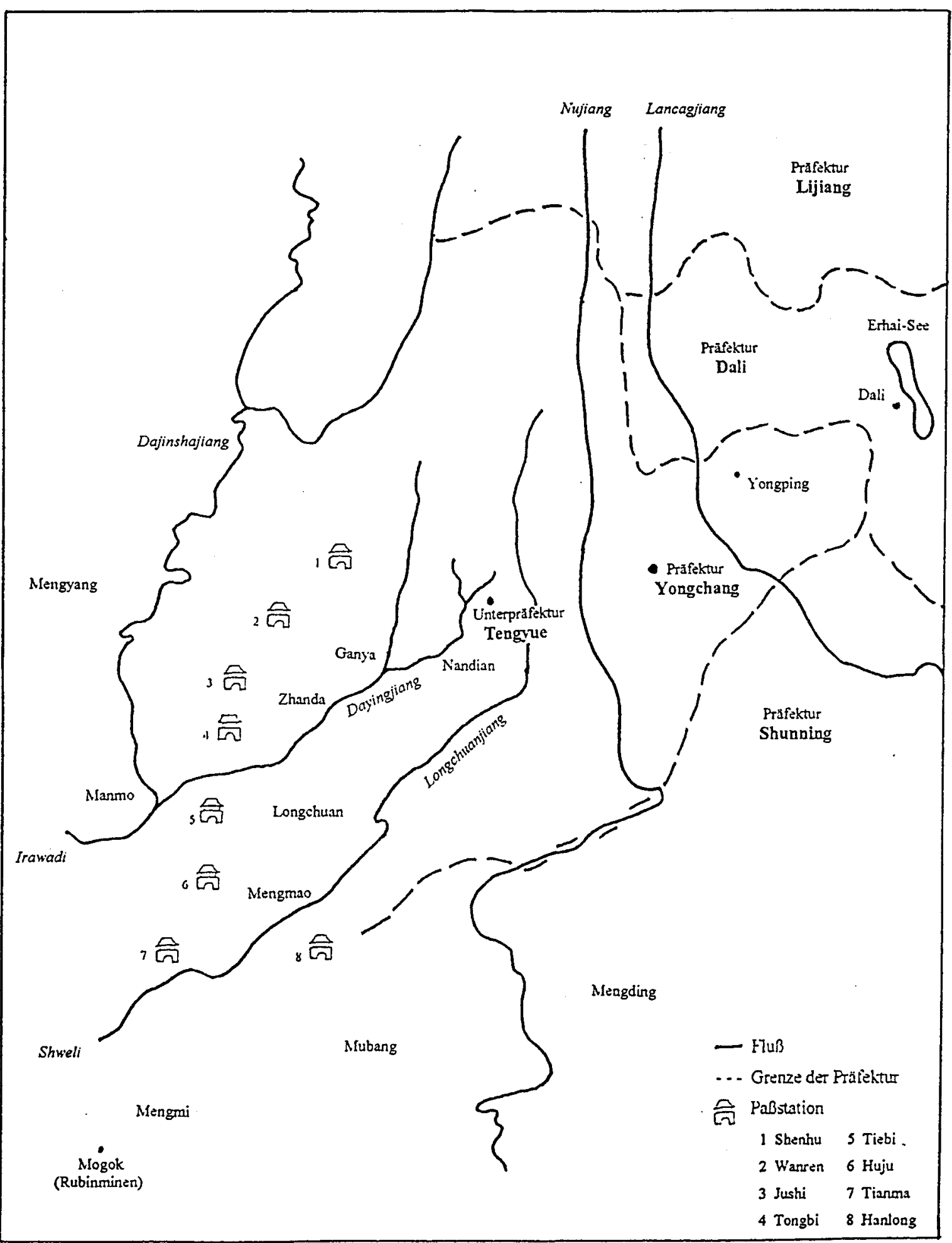


Die Paßstationen wurden in zwei Gruppen aufgeteilt, die vier nördlichen unterstanden dem Kommandanten (shoubei) der Festung Manha, die vier südlichen dem Kommandanten der Festung Longba. ${ }^{385}$ Diesen beiden unterstanden die einhundertvierundachtzig Regierungssoldaten (guanbing), die auf den acht Pässen stationiert wurden. ${ }^{386}$

In dem von Bergketten und Flußtälern geprägten Gelände im Südwesten von Tengyue sollten die Soldaten in den Paßstationen auf den strategisch wichtigen Gebirgspässen den Zugang zu den Hauptverkehrswegen überwachen, die in diesem schwer zu passierenden Gelände einzig die Möglichkeit boten, größere Truppenverbände vorrücken zu lassen. So kontrollierten sie z. B. von der Paßstation Shenhu aus die westliche Route von Tengyue nach Mengyang und von der Paßstation Tiebi aus die Route nach Manmo und Ava. ${ }^{387}$ Die Soldaten in der Paßstation Tianma bewachten die südliche Route nach Mengmi; von der Paßstation Hanlong aus wurde die südöstliche Route nach Mubang überwacht. ${ }^{388}$

\section{2. San xuan - liu wei}

Mit der Errichtung der Paßstationen und der Überwachung der Verbindungsstraßen sollten weitere Invasionen der Birmanen verhindert werden. Diese Maßnahmen bedeuteten zwar keine Abriegelung der Verbindungswege von und nach Westen, welche weiterhin für den Handelsverkehr mit Birma und den Kleinstaaten an Shweli und Irawadi offen blieben. Aber die von den acht Paßstationen gebildete, von Nord nach Süd verlaufende Linie bedeutete doch eine gewisse Unterteilung der Region des Stromschluchtenfächers. Es entstanden zwei Zonen, die jeweils eine bestimmte Gruppe von tusi-Gebieten umfaßten.

Die innere Zone erstreckte sich auf das Gebiet zwischen der Stadt Tengyue und den acht Paßstationen. In dieser Zone lagen die als die drei Befriedeten Gebiete (san xuan) bezeichneten tusi. In der äußeren Zone, die sich über das Gebiet jenseits der Paßstationen bis nach Birma erstreckte, befanden sich die sogenannten sechs höherrangigen Befriedeten Gebiete (liu wei).

\footnotetext{
385 TYTZ, S. 129

386 TYTZ, S. 176

${ }^{387}$ Die Paßstation Shenhu „befindet sich 180 li [ca. 90 km] südwestlich der Stadt [Tengyue], hinter Zhanxi auf dem Berg Mengjia; sie kontrolliert die Straßen nach Chashan, Guyong, Weimian, Yixi und anderen [Orten]“. Die Paßstation Tiebi „liegt 480 li [ca.240 km] südlich der Stadt auf dem Berg Denglian und kontrolliert den Wasserweg (shuilu) nach Manmo“ (TYTZ, S. 179).

${ }^{388}$ TYTZ, S. 179. Siehe auch Xu Xiake Tengyue youji (Liu Chunming, S. 17).
} 
San xuan und liu wei waren in der Ming-Zeit gebräuchliche zusammenfassende Bezeichnungen für die tusi-Gebiete im Südwesten der Unterpräfektur Tengyue, wie sie auch im Schriftverkehr der Regionalverwaltung oder in Throneingaben verwendet wurden. ${ }^{389}$ San xuan ist die Abkürzung für san xuanfu si und bezieht sich auf die drei Befriedeten Gebiete Nandian, Ganya und Longchuan. Diese drei Einheiten der lokalen Sonderverwaltung waren während der Ära Zhengtong (1436-1450) eingerichtet worden. Das Nandian xuanfu si im Jahr 1443, Ganya xuanfu si im Jahr 1444 und Longchuan xuanfu si 1446. Bis zum Ende des 16. Jahrhunderts waren in dem Gebiet der inneren Zone östlich der Linie der Paßstationen noch zwei weitere tusi entstanden: Das bereits im Jahr 1449 von den Ming anerkannte Zhanda xuanfu si, das ursprünglich Teil von Ganya war, sowie Mengmao, das sich während der Ära Wanli (1573-1620) von Longchuan abgespalten und den Status eines Befriedeten Gebietes (anfu si) erhalten hatte. Diese beiden tusi zählten ebenfalls zur Gruppe der san xuan.

Der Begriff liu wei steht für liu xuanwei si und bezeichnet die tusi-Gebiete westlich der Linie der acht Paßstationen. Gouverneur Chen Yongbin erklärt in seiner ,Erläuterung zur Bestimmung der sechs höherrangigen Befriedeten Gebiete، (Hai ding liu wei hou shuo), einer Bestandsaufnahme der Situation im Grenzgebiet nach 1594, welche tusi zu dieser Gruppe zählen. Er schreibt:

„Die sechs Befriedeten Gebiete (liu wei) bilden die äußerste Grenze des Südwestens des Reiches (guojia xi 'nan zhi jiji). In der Tat reihen sich jenseits (wai) von Teng[yue] und Yong[chang] die Vasallenstaaten (fan) auf einer Breite von acht- bis neuntausend li [über viertausend Kilometer] aneinander. Aus dem Altertum gibt es keine Berichte über sie. Seit der Han-, Tang-, Song-Zeit und auch danach war es nicht möglich, sie gänzlich in Besitz zu nehmen (xian bu neng you zhi).

Was aber die Autorität und die Tugend (wei de) unserer Dynastie betrifft, so gibt es keinen Ort, auf den sie sich nicht erstrecken. Und so wurden [die Kleinstaaten] zu den sechs Befriedeten Gebieten (liu xuanwei) erklärt. Diese sind Mubang, Miandian, Babai, Cheli, Laowo, Mengyang sowie das niederrangige Befriedete Gebiet (xuanfu) Mengmi; sie alle bilden die offizielle Grenze (xian

\footnotetext{
${ }^{389}$ So z.B. in einer Throneingebe des Gouverneurs von Yunnan, Chen Jin, um 1503 (siehe You Zhong, S. 435), ebenso bei Chen Yongbin (siehe TYTZ, S. 329; TYZZ, S. 47-49, 93-94).
} 
wei zhi zheng jiangjie). ${ }^{390}$ Seit zweihundert Jahren sind Würdenträger der Ming dorthin gekommen, haben die Häuptlinge ihre Herrschaftsgebiete (wei) befriedet (an) und hat die einheimische Bevölkerung (yimin) ihr Leben geordnet“. ${ }^{391}$

Insgesamt waren es also, da noch das niederrangigere Befriedete Gebiet von Mengmi mit hinzu kam, sieben Gebiete, die der Provinz Yunnan im Südwesten als Einheiten der lokalen Sonderveraltung angegliedert waren. Die Errichtung der acht Paßstationen bedeutete für diese Gebiete, ebenso wie für die drei xuanfu si, keine Neuordnung der administrativen Einheiten in der Region, da alle Gebiete, mit Ausnahme Mengmis, bereits zu Beginn der Ming-Zeit, bzw. schon kurz nach der Eroberung der Region durch die Truppen Kaiser Hongwus, einen Status als Befriedete Gebiete zugewiesen bekommen hatten.

Mengyang hatte im Jahr 1384 den Status eines xuanwei si erhalten, der im Jahr 1589 erneut verliehen wurde; Mubang war seit 1404 xuanwei si, Laowo seit 1405, Babai seit 1391, Miandian seit 1403 und Cheli seit 1384; Mengmi, ursprünglich Teil von Mubang, hatte den Status eines anfu si seit dem Jahr 1484 inne. ${ }^{392}$

Gouverneur Chen macht in seiner Bestandsaufnahme deutlich, daß die Paßstationen keine Grenze bildeten. Seiner Ansicht nach sollten sie lediglich die Verkehrswege und den Zugang zur Präfektur Yongchang kontrollieren, nicht jedoch das Hoheitsgebiet der Ming begrenzen, deren ,Autorität und Tugend‘ sich auch auf die Gebiete jenseits der Paßstationen erstreckten. Erst „die sechs Befriedeten Gebiete (liu wei) bildeten die äußerste Grenze des Südwestens des Reiches“ (guojia xi`nan zhi jiji), die „offizielle Grenze“ (zheng jiangjie), die also auch Birma mit umfaßte. ${ }^{393}$

\footnotetext{
${ }^{390}$ Zu Miandian: Bereits im Jahr 1394 (Hongwu 27) war Birma von den Ming zum Mianzhong xuanwei si erklärt worden, im Jahr 1403 (Yongle 1) wurde es dann zum Miandian xuanwei si (siehe TYTZ, S. 243).

Die Beschreibung Birmas in Kapitel 15 des TYTZ (S. 241-245) beinhaltet eine ausführliche Darstellung der historischen Entwicklung des Landes, die sich auf die entsprechenden Kapitel des Han shu, Tang shu und vor allem auf das Kapitel tusi chuan des Ming shi stützen. Da die Angaben zu Birma auch in den Beschreibungen der anderen tusi enthalten sind, werden sie im folgenden nicht noch einmal einzeln dargestellt.

Bei der Darstellung der Entwicklung der Kleinstaaten im Grenzgebiet werden in dieser Studie lediglich diejenigen der sechs Befriedeten Gebiete (liu wei) berücksichtigt, die an die Verwaltungseinheit Tengyue angrenzen und im TYTZ, im Kapitel über die Völker der Region (Kapitel 15) beschrieben werden, also Mengyang, Mengmi und Mubang sowie ein weiteres Befriedetes Gebiet, das Gouverneur Chen Yongbin in seiner Aufzählung nicht nennt: Das Manmo xuanfu si (zu Manmo siehe unten 6. 4., S. 145ff).

${ }^{391}$ TYTZ, S. 329 und TYZZ, S. 93-94; beide ohne Jahresangabe.

${ }^{392}$ TYTZ, S. 240-245; YCFZ, S. 329-330; 51; siehe auch Ming shi (juan 315). Im YCFZ werden ebendort diese Verwaltungseinheiten dem vollständigen Titel des junmin xuanwei shi si (,Befriedetes Gebiet, mit Zuständigkeit für die Militärund Zivilverwaltung') bezeichnet.

Cheli (bezeichnete das Gebiet um Jinghong im modernen autonomen Bezirk Xishuangbanna) ist in die Auflistungen der tusi-Gebiete, bzw. der Fremdvölker (wai yi) im TYTZ, TYZZ und YCFZ nicht mit aufgenommen worden (zu Cheli siehe Ming shi, juan 315, S. 16). Während im Präfekturshandbuch YCFZ auch die beiden Gebiete Laowo und Babai (YCFZ, S. 329: „Der einheimische Name lautet Jingmai“ [das ist Chiang Mai im Norden Thailands]) im Kapitel 56 einzeln beschrieben werden, sind diese beiden nicht mit in die fangzhi der Unterpräfektur Tengyue aufgenommen worden.

393 TYTZ, S. 329
} 
Um so verwerflicher erschienen Chen Yongbin die Eroberungsfeldzüge des birmanischen Herrschers, die er kurz skizziert, um anschließend die Lage im Südwesten folgendermaßen zusammenzufassen:

„Seit dem 9. Jahr der Ära Wanli (1581) hat die Bevölkerung von Yunnan (Dian min) Rüstungen angelegt und Lanzen aufgepflanzt ... [weil die] Banditen [aus Birma] ... Manmo angegriffen und die drei xuan in Unruhe versetzt hatten. Jahrelang hat es nicht einen Tag gegeben, der frei war [von Kämpfen]“. ${ }^{394}$

Um diese zu beenden sei ein energisches Durchgreifen notwendig, deshalb müsse man „bei diesen Banditen eifrig die Höhle auskehren und den Hof umpflügen“. ${ }^{395}$ Da jedoch „in diesem unfruchtbaren Gelände kein Militär eingesetzt werden könne, gelte für diese entlegene Gegend das Prinzip, keine weiten Feldzüge durchzuführen (bu mao fei yong wu zhi di, jue yu wu yuan tao zhi li). [Hinsichtlich dessen müsse] man gewissenhaft sein; wenn man aufrichtig von der Autorität des Reiches spricht, kann man darauf vertrauen, jene [dennoch] zu besänftigen. Dann werden die Menschen erfreut und die wilden Tiere verärgert sein. Es ist schwierig etwas zu unterhalten, aber leicht etwas zu ruinieren. Wenn man sie am Morgen besänftigt, dann werden die Abtrünnigen am Abend Schwäche zeigen. Man muß ihre Kraft prüfen und das Steigen oder Fallen ihrer Macht berechnen. Man muß das Ferne durch das Ferne angreifen lassen und Barbaren einsetzen, um andere Barbaren zu bekämpfen (wei yuan gong yuan, gong you bi yi yi gong yi)“ ${ }^{396}$

Gouverneur Chen beschreibt hier nicht nur allgemeine Grundsätze der Politik der Ming, sondern macht auch seine eigenen Verdienste um die Befriedung der Region deutlich. Während die Strategie, sich die Rivalitäten der sechs Befriedeten Gebiete untereinander und mit Birma zu Nutze zu machen, häufig auf eine passive Politik des Laisser-faire hinauslief, hatte Chen sie mit seiner Initiative zum gemeisamen Vorgehen Chinas und Siams, auf die er in diesem Zusammenhang auch noch ausdrücklich hinweist, erfolgreich in die Praxis umsetzen können. Dieselbe Strategie verfolgte er erneut wenige Jahre später im Konflikt zwischen Mengmao und Mubang.

\footnotetext{
${ }^{394}$ TYTZ, S. 329; TYZZ, S. 93

${ }^{395}$ Ebenda.

${ }^{396}$ Ebenda.
} 


\section{3. Die Befriedung Mengmaos}

Der Sieg der chinesischen Truppen über Birma und die Errichtung der acht Paßstationen hatten zunächst nicht zu einem Ende der Kampfhandlungen in der Region geführt. Nicht nur in den Kleinstaaten im Westen der Paßstationen wurde weiterhin gekämpft, auch in der von ihnen gebildeten inneren Zone im Südwesten der Unterpräfektur Tengyue flammten die Kämpfe immer wieder auf.

Ein Brennpunkt der militärischen Auseinandersetzungen zwischen den Ming-Truppen, Birma und seinen Verbündeten war in den letzten Jahren des 16. Jahrhunderts wieder einmal das Gebiet der beiden tusi von Longchuan und Mengmao. Während die Herrscher von Longchuan mit den Ming verbündet waren, hatte sich Duo An von Mengmao den Birmanen angeschlossen. Besorgt über diese Verbindung mobilisierte der tusi des benachbarten Longchuan, Duo Sishun, im Jahr 1596 Truppen gegen Mengmao, woraufhin Duo An zurückschlug und nun seinerseits Zhefang, die Residenz des Herrschers von Longchuan zerstören ließ. ${ }^{397}$ Anschließend wandte er sich nach Süden und eroberte den Berg Nangyi, der sich im Gebiet von Mubang befand.

Qi Wenchang, Vize-Präfekt von Yongchang, der bereits die Errichtung der acht Paßstationen geleitet hatte, entwickelte im Auftrag Chen Yongbins einen Plan, mit dem es Han Qin, dem Oberhaupt von Mubang, gelang, Duo An und seine Söhne zu ergreifen und sie enthaupten zu lassen. ${ }^{398}$

Die chinesische Seite hat in diesem Konflikt einmal mehr mit diplomatischen Mitteln agiert, so wurde Mubang zwar ein Schlachtplan übermittelt, selbst setzten die Ming jedoch keine Truppen ein. Auch eine Beteiligung der in den beiden Grenzstationen Tianma und Hanlong im Süden von Mengmao stationierten Soldaten an der Umsetzung dieses Planes ist aus den Darstellungen in den fangzhi nicht ersichtlich. Die Kämpfe dieser tusi untereinander wurden zu diesem Zeitpunkt nicht als Bedrohung für die Unterpräfektur Tengyue angesehen. Die Provinzregierung beschränkte sich deshalb auf logistische Unterstützung und förderte das Eigeninteresse Mubangs an der Rückeroberung seines verlorenen Territoriums, um die einheimischen Herrscher ihren Konflikt untereinander austragen zu lassen. Nach dem Tod Duo Ans nutzte Gouverneur Chen Yongbin das entstandene Machtvakuum, um die Kontrolle über das Gebiet von Mengmao zu verstärken: Zur Befriedung Mengmaos

\footnotetext{
397 TYTZ, S. 192; YCFZ, S. 135. An anderer Stelle heißt es, daß Duo Sishun im Jahr 26 der Ära Wanli (1598) Duo An angreifen ließ, woraufhin jener im 12. Monat des 26. Jahres (1599) zurückschlug (TYZZ, S. 144; TYTZ, S. 155).

${ }^{398}$ TYZZ, S. 144; TYTZ, S. 192; YCFZ, S. 135
} 
wurde im Jahr 1596 Pinglucheng, die ,Stadt der Befriedung von Lu‘, errichtet, ein Militärbezirk (bingbei dao) und zweiundzwanzig Militärkolonien (tuntian) gegründet, in denen einhundert Soldaten (dian bing yi bai ming) stationiert wurden. ${ }^{399}$ Mit der Gründung von Militärkolonien war eine wichtige Voraussetzung für eine längerfristige Befriedung des Gebietes von Mengmao geschaffen worden, konnten diese abgelegenen Außenposten doch überhaupt nur durch Selbstversorgung unterhalten werden.

Denn, so schreibt Feng Su rund ein Jahrhundert später in seinem Sammelwerk über die Provinz Yunnan, dem Dian kao,

„zu jener Zeit war das Grenzgebiet in Aufruhr, die Kosten für den Sold [der Soldaten] waren gewaltig, für die Beförderung von einem dan Reis betrugen die Transportkosten bis zu zehn Gold[stücke]; das lohnte sich nicht. ${ }^{400}$ Die Regierungsbezirke (jun yi) konnten [die Versorgung allein] nicht aufrecht erhalten, deshalb war Chen Yongbin fest entschlossen, Militärkolonien einzurichten. Die Barbaren der drei Befriedeten Gebiete (san xuan) leisteten Fron und zahlten Bodensteuer, überzählige Felder aber waren nicht zahlreich, außer in Mengmao, dem ehemaligen Luchuan, dort waren die Felder ertragreich und seit dem Tod Duo Ans war das Gebiet ohne Oberhaupt, deshalb sollten die Garnisonssoldaten (yingbing) dort Militärkolonien gründen; diejenigen, die keine Garnisonssoldaten (fei yingbing) waren, aber dennoch Kolonisten zu sein wünschten (yuan tunzhe) ... [erhielten ebenfalls drei Jahre lang einen Steuernachlaß]“. 401

Die Maßnahmen zur Kontrolle über das Gebiet von Mengmao ließen dessen Status als lokale Sonder-Verwaltungseinheit unverändert. Das Amt des Oberhauptes von Mengmao übernahm Si Zhong, der vormalige xuanfu shi von Manmo, der aus seinem Herrschaftsgebiet vertrieben worden war. Er änderte seinen Namen in Kan Zhong und erhielt später für seine Verdienste beim Kampf gegen Duo Anmin von Longchuan im Jahr 1610 den vererbbaren Titel eines anfu shi verliehen. ${ }^{402}$

\footnotetext{
399 TYTZ, S. 89; 141. Diese Anzahl der Soldaten wird im Kapitel ,Garnisonswesen` des TYTZ genannt, dort ist allerdings lediglich von zwanzig Militärkolonien (tuntian ershi dian) die Rede. (TYTZ, S. 176). Die Kolonien wurden mit dem Begriff dian („Außenbezirk“, „Domäne“) bezeichnet; jede wurde von einem Kolonie-Vorsteher (dian tou) verwaltet (TYTZ, S. 176, 89).

${ }^{400}$ Das Dian kao von Feng Su wurde während der Ära Kangxi (1662-1723) gedruckt; das Vorwort stammt aus dem Jahr 1665. Das chinesisches Hohlmaß dan entspricht ungefähr 100 Liter.

${ }^{401}$ Zitiert nach You Zhong, S. 443-444

${ }^{402}$ TYZZ, S. 144
} 


\section{4. Manmo und die Entwicklung der tusi-Gebiete nach der Errichtung der acht Paßstationen}

Das Befriedete Gebiet (xuanfu si) von Manmo befand sich im Westen der Paßstation Tiebi. Im Norden grenzte es an Mengyang, im Südwesten an Birma und im Süden an Mengmi. Sein Zentrum war der am Dayingjiang gelegene Ort Manmo. ${ }^{403}$

Der Fluß Dayingjiang entspringt im Gebirge im Norden der Stadt Tengyue und fließt in südwestlicher Richtung durch die Befriedeten Gebiete Nandian, Ganya und Zhanda, dann nördlich der Paßstation Tiebi nach Manmo und weiter nach Westen bis er im Norden der modernen Stadt Bhamo in den Irawadi mündet. Die Strecke entlang des Dayingjiang ist die kürzeste Verbindung von Tengyue nach Birma. Sie ist Teil der Jahrhunderte alten Handelsroute, die Yunnan mit Indien verbindet und führt zunächst von Tengyue nach Nandian, von wo aus drei Hauptrouten entlang der Hochplateaus am Dayingjiang und seiner Zuflüsse nach Südwesten führen, die in Manmo wieder zusammentreffen und die Stadt zu einer Drehscheibe des Handels werden ließen. Entlang dieser Strecke reisten auch die Tributgesandtschaften aus Birma nach China, ebenso war sie auch eine günstige Route für eine Invasion von Birma in die drei Befriedeten Gebiete und die Unterpräfektur Tengyue.

Die chinesische Regierung war sich der strategischen Lage Manmos sehr wohl bewußt und war bestrebt, sich der Loyalität Manmos zu versichern. So war der Herrscher von Manmo, Si Shun, nachdem er sich in den achtziger Jahre des 16. Jahrhunderts General Liu Ting gegenüber loyal erklärt hatte, vom chinesischen Hof als xuanfu shi bestätigt worden. ${ }^{404}$

Loyalitätsbekundungen gegenüber ihren mächtigen Nachbarn China und Birma waren für die einheimischen Herrscher von Manmo ein Mittel, sich gegen deren Vormachtsansprüche zu behaupten und ihre eigene Machtposition in diesem strategisch wichtigen Gebiet zu wahren. In der Kurzbiographie der Han Song von Manmo, die von den Verfassern der fangzhi in ihre ,Liste der tugendhaften Frauen‘ (lie nü - zhen lie) aufgenommen worden ist, wird dieses Bemühen deutlich:

„Während der Ära Wanli (1573-1620) ging Si Shun, [der Herrscher von Manmo], wie schon sein Vater nach Birma. [Seine Mutter] Han Song, ihr zweiter

\footnotetext{
${ }^{403}$ Die chinesische Bezeichnung Manmo gibt den Shan Namen Manmaw (auch Wanmaw) wieder, der ,Töpfer-Dorf ‘ bedeutet (Scott/Hardiman, S. 56). Im 19. Jahrhundert wurde Manmo in der westlichen Literatur auch als das alte Bhamo bezeichnet: Die alte Stadt Bhamo der Shan lag „am Fluß Taping [chin. heute Dayingjiang], zwei Tage entfernt vom Irawadi, am Fuße der Kachin Hügel“ (Scott/Hardiman, S. 71). Die moderne Stadt Bhamo liegt östlich des alten Bhamo (Manmo), direkt am Ufer des Irawadi.

${ }^{404}$ TYTZ, S. 240
} 
Sohn Si Hua und der Enkel Si Shang [aber] verteidigten Manmo. Später verließ Shun Birma und kehrte zurück. Als die Birmanen Zhefang angriffen, ging Shun wieder nach Birma. Die Birmanen schickten Shun zurück und sandten einen Boten, um seine Mutter Han Song aufzusuchen. Die Mutter tötete den Boten, tat dessen Kopf in einen Kasten und gab diesen Si Hua und Si Shang, die heimlich flohen. Han Song lobte Si Shangs Treue und Redlichkeit. Der hatte sich in Ganya niedergelassen und erhielt jährlich Reis von Han Song sowie Silber und Seidenstoffe als Unterstützung. Han Song [lebte] einsam. Eine Barbarenfrau (yi fu), die von ihrem Mann und ihrem Sohn wiederholt Ungerechtigkeiten hatte erleiden müssen. Dennoch unterstützte sie die Waisen und bewahrte ihre Unabhängigkeit. Sie war selbständig und furchtlos. Mehrmals ließ sie Boten [aus Birma] enthaupten und widersetzte sich damit dem Sohn. Man kann sagen, sie wußte, was Recht und was Unrecht war“. 405

Hier kommen die Konflikte innerhalb der Herrscherfamilie zum Ausdruck, deren Angehörige teils in Birma, teils in China Beistand suchten. In beiden Nachbarländern war man daran interessiert, sich ihrer Loyalität zu versichern. Han Song erwies sich als die Siegerin im familiären Machtkampf und machte ihren Sohn Si Hua zum Herrscher von Manmo. Sie hatte auf die Unterstützung durch die Ming gesetzt, die ihr loyales Verhalten auch anerkannten. Als Si Hua im Jahr 1591 von Truppen aus Birma angegriffen wurde, zögerte die chinesische Regierung dann auch nicht, Soldaten nach Manmo zu entsenden:

„Der Vize-General (pijiang) Wan Guochun eilte [daraufhin] bei Nacht dorthin. Er ließ viele Fackeln anzünden, um so [eine größere als die tatsächliche Anzahl von] Soldaten vorzutäuschen. Die Birmanen fürchteten sich und zogen sich zurück. Sie erlitten eine große Niederlage. Dies war der größte Kampferfolg [chinesischer Truppen] im Südwesten seit Beginn der Ära Wanli“. ${ }^{406}$

Aufgrund der strategischen Lage von Manmo konnte sein Herrscher auch in den folgenden Jahren mit militärischer Unterstützung von seiten der Ming rechnen, die verhindern wollten, daß sich die Birmanen an dem wichtigsten Verkehrsknotenpunkt der Region dauerhaft festsetzten. Im Zuge der Errichtung der acht Paßstationen war im Jahr 1594 auf dem Berg Denglian die Station Tiebi errichtet worden, die den Zugang von Manmo zum

\footnotetext{
405 TYTZ, S. 235; YCFZ, S. 323

${ }^{406}$ TYTZ, S. 240; TYZZ, S. 150
} 
Gebiet der drei xuanfu si kontrollieren sollte. Als Manmo im Jahr 1596 wiederum von Truppen aus Birma angegriffen wurde, wurde der Bitte Si Huas um Unterstützung mit der Entsendung des Regionalkommandanten Wu Xuanzhong entsprochen, dessen Truppen die Birmanen besiegten.

Zwar hat Gouverneur Chen Yongbin in seiner, Erläuterung zur Bestimmung der sechs Befriedeten Gebiete، Manmo nicht in die Auflistung dieser tusi-Gebiete mit aufgenommen, die in seinem Auftrag errichtete Paßstation Tiebi ebenso wie die Entsendung von Truppen zeigen jedoch, daß Manmo in seiner Politik zur Befriedung der Region dennoch eine wichtige Rolle spielte. In einer Throneingabe aus dem Jahr 1603 betont Chen dann auch ausdrücklich die Schlüsselposition, die Manmo aufgrund seiner strategischen Lage zukommt. Er schreibt:

„Was ist Manmo denn für ein Ort? Es ist der Zaun der drei Befriedeten Gebiete (san xuan zhi fanli ye). Die drei Befriedeten Gebiete sind wie eine Mauer (yuan yong) für Tengyue und Yongchang. Tengyue und Yongchang sind die Türen (menhu) zu ganz Yunnan. Wenn Manmo verloren geht, wird es auch die drei Befriedeten Gebiete bald nicht mehr geben. Wenn die drei Befriedeten Gebiete verloren gehen, wird es auch Tengyue und Yongchang bald nicht mehr geben“. 407

Mit der bildhaften Darstellung des Hauses Yunnan, mit seinen Türen Tengyue und Yongchang, umgeben von der Schutzmauer der tusi-Gebiete, das gesamte Grundstück schließlich abgeschirmt von der Umgebung durch den ,Zaun` Manmo hebt Chen die Bedeutung der verschiedenen Verwaltungseinheiten in der Peripherie im Südwesten des chinesischen Reiches hervor. Die Einheiten der regulären Zivilverwaltung am Rande der Provinz halten die Verbindung zu den Herrschaftsgebieten der einheimischen Bevölkerung aufrecht, die in Einheiten der lokalen Sonderverwaltung eingeteilt sind. Diese bilden entsprechend ihrer geographischen Lage verschiedene Gruppen, wobei die jeweils näher gelegenen, wie die drei xuanfu si östlich der Linie der acht Paßstationen, zum Schutz vor Angriffen aus den weiter entfernten Gebieten dienten, die weniger leicht zu kontrollieren waren. Dazwischen befand sich Manmo, daß Chen mit der Bezeichnung ,unser Manmo‘ (wo Manmo) noch einmal ausdrücklich der Oberhoheit der chinesischen Regierung unterstellt. ${ }^{408}$

\footnotetext{
407 ,Throneingabe bezüglich der Einstellung der Förderung in den Edelsteinminen` (Ba cai baojing shu) (TYZZ, S. 4749; Yunnan tongzhi, juan 29, yiwen 3).

${ }^{408}$ TYZZ, S. 48
} 
Die entfernteren tusi-Gebiete, die sechs xuanwei si (zu denen die Ming auch Birma zählten), hat Chen Yongbin in seiner ,Erläuterung zur Bestimmung der sechs Befriedeten Gebiete‘ allgemein als die äußerste Grenze des Südwestens des Reiches (guojia xi ‘nan zhi jiji) bezeichnet. In seiner Throneingabe aus dem Jahr 1603 geht er auf den Status dieser Gebiete nicht näher ein. Doch erscheinen sie durch die Betonung der zentralen Rolle, die Manmo für die Sicherheit der Präfektur Yongchang bzw. der gesamten Provinz Yunnan zugewiesen wird, deutlich von den Gebieten östlich der Paßstationen abgegrenzt.

Aus dem Vorangehenden ergibt sich die Frage, ob diese Gebiete nach wie vor die offizielle Grenze (zheng jiangjie) des Ming-Reiches bildeten oder ob sich das Verhältnis der Kleinstaaten zueinander und zu ihren beiden großen Nachbarn am Anfang des 17. Jahrhunderts verändert und zu einer anderen Abgrenzung des chinesischen Einflußbereiches geführt hatte. Zur Beantwortung dieser Frage wird im Folgenden zunächst die Entwicklung in den vier tusi-Gebieten Mengmi, Mubang, Mengyang und Manmo und ihr Verhältnis zu ihren Nachbarn China und Birma an der Wende zum 17. Jahrhundert zusammengefaßt. Danach wird anhand seiner Throneingabe dargestellt, wie Gouverneur Chen diese Entwicklung beurteilt hat (siehe unten 7. 3., S. 160ff).

Nach der Errichtung der acht Paßstationen hatte die chinesische Provinzregierung mit der Gründung Pingluchengs und der Militärkolonien in Mengmao ihre Kontrolle über die Region verstärkt und mit der Bestimmung der sechs Befriedeten Gebiete eine offizielle Grenze festgelegt. Die tusi-Gebiete galten nun insgesamt als befriedet. Die Chronisten des YCFZ stellen dazu fest:

„Im 26. Jahr der Ära Wanli (1598) haben sich sämtliche Barbaren von Birma losgesagt und leisten nun [China] Tribut (... zhu man ju jue Mian ru gong)“. 409

Etwas anders formuliert heißt es im TYTZ:

„Zu dieser Zeit besaß [China] großes Ansehen im Grenzgebiet, so daß sich sämtliche Barbaren von Birma lossagten und Tribut [an China] sandten (shi bian wei shao zhen, zhu yi jie jue Mian ru gong) ${ }^{*}{ }^{410}$

\footnotetext{
${ }^{409}$ YCFZ, S. 135

410 TYTZ, S. 240. Eine von Gouverneur Chen Yongbin und dem Zensor Liu Huizou zu Beginn des Jahres 1600 veranlaßte Strafexpedition zur Niederschlagung eines Aufstandes in Midu (im Gebiet von Mengyang), die von zusätzlich nach Yongchang entsandten Truppen unter dem hochrangigen Oberbefehlshaber Mu Rui durchgeführt wurde, zeigt, daß die Ming sich nicht allein, wie im Fall der Befriedung Mengmaos, auf logistische Unterstützung der tusi beschränkten, sondern auch weiterhin Truppen in der Region im äußersten Südwesten Yunnans einsetzten (YCFZ, S. 135). Im 11. Kapitel des TYTZ (Militärische Angelegenheiten), wird dieser Feldzug zur Unterstützung des tusi von Mengyang nicht erwähnt (TYTZ, S. 192).
} 
Um welche tusi-Gebiete es sich dabei im einzelnen handelte, wird dort nicht ausgeführt. Ausdrücklich erwähnt wird, daß Si Hong, der Herrscher von Mengyang, China im Jahr 1598 seine Loyalität erklärt hat. Dies veranlaßte die Birmanen im folgenden Jahr zu einem Angriff auf Mengyang. Die chinesische Regierung rief daraufhin die verschiedenen tusi dazu auf, die Angreifer abzuwehren.

„So wurden die Birmanen vernichtend geschlagen. Si Zheng, der Sohn des Si Hua [von Manmo], und Si Hong [von Mengyang] rückten gemeinsam bis zum Fluß Jinshajiang [dem Oberlauf des Irawadi] vor und kämpften [dort] gegen die Birmanen. Im 29. Jahr (1601) nutzte Si Zheng [die Gelegenheit] und überfiel Longchuan während der Trauerfeier für Duo Sishun, den [verstorbenen] tusi von Longchuan. Dann kehrte er nach Manmo zurück. Im 30. Jahr (1602) überfielen Yong Han von Ava und Han Gai von Mubang Si Zheng, sie enthaupteten ihn und zogen sich wieder zurück. Si Hong hatte seine Elefantenkavallerie in Eilmärschen [nach Manmo] geführt, um ihn zu retten, doch er war nicht mehr rechtzeitig gekommen.“411

Anders als die miteinander verbündeten tusi von Mengyang und Manmo, denen es zunächst noch gelang, die Angriffe der Birmanen abzuwehren, standen die beiden Nachbarstaaten Mengmi und Mubang nach den Aufzeichnungen der fangzhi bereits seit 1590 unter birmanischer Oberhoheit. ${ }^{412}$ Ihren Anspruch auf die Vorherrschaft über diese Gebiete machten die Birmanen deutlich, indem sie neue Oberhäupter bestimmten. Diese waren entweder Angehörige der besiegten Herrscher, die sich Birma gegenüber loyal erklärten, wie zum Beispiel in Mengmi. Dessen Territorium unter birmanische Oberhoheit gekommen war, als die Herrscherfamilie nach einem Angriff birmanischer Truppen fliehen mußte und sich Si Ren (ein Neffe der vorherigen Herrscherin) den Birmanen unterwarf, die ihm daraufhin das Gebiet von Mengmi unterstellten. ${ }^{413}$ Oder die Birmanen bestimmten ihrerseits einen Statthalter, wie in Mubang, wo die Angehörigen der Herrscherfamilie der Han bei der Eroberung ihres Territoriums durch die Birmanen getötet worden waren. Die Birmanen unterstellten Mubang nun ebenfalls Si Ren von Mengmi. ${ }^{414}$ Damit war Mengmi,

\footnotetext{
${ }^{411}$ TYTZ, S. 240; TYZZ, S. 150-151

${ }^{412}$ Hier weicht die Darstellung in den fangzhi von der Auffassung Chen Yongbins ab. Während im Kapitel 15 (Völker der Region) des TYTZ im Abschnitt über die Grenzen die Aufzeichnungen über Mengmi und Mubang mit dem Jahr 1590 enden, in dem diese Gebiete als für China verlorengegangen (wang) bezeichnet werden, macht Chen Yongbin in seiner ,Erläuterung‘ deutlich, daß diese Gebiete gerade nicht von China abgegrenzt worden sind.

${ }^{413}$ TYTZ, S. 241

${ }^{414}$ TYTZ, S. 241
} 
das sich im 15. Jahrhundert von Mubang abgespalten hatte, zeitweise wieder mit diesem vereinigt, diesmal allerdings unter der Vorherrschaft des Herrschers von Mengmi.

Im Jahr 1604 kam es erneut zu Kämpfen in Mengmi. Als diese sich auch auf Mengyang auszuweiten begannen, schalteten sich die Ming in den Konflikt ein. Die Birmanen hatten zunächst versucht,

„[zu ihrer Unterstützung] Truppen des Si Hong [von Mengyang] zu rekrutieren. [Der chinesische] Regionalkommandant Wang Tingguang hielt Hong davon ab, [Truppen zu entsenden]. Dieser ließ den Gesandten der Birmanen enthaupten und [den Kopf] als Geschenk überbringen ${ }^{415}$. Erzürnt darüber griffen die Birmanen Hong an; Hong kam auf der Flucht [vor ihnen] um. Der Oberkommandierende (dusi) der Ming-Truppen, Wang Wannian, war nicht mehr rechtzeitig gekommen, um ihm helfen zu können“. 416

Nach dem Tod Si Hongs im Jahr 1604

„bestimmten die Birmanen einen der ihren ( $q$ i $m u$ ), den Si Hua, [der den Angriff auf Si Hong angeführt hatte], Mengyang in Besitz zu nehmen. Nach dessen Tod übernahm seine Frau, eine geborene Pa, die Herrschaft. Danach lösten andere [von Birma als Oberhaupt eingesetzte Personen] (ta mu) einander [auf diesem Posten ab]“. ${ }^{417}$

Damit hatte der König von Birma auch Mengyang dauerhaft seiner Oberhoheit unterstellt. Obwohl die Ming zunächst noch eine gewisse Kontrolle über Manmo ausüben konnten, so beauftragte Chen Yongbin im Jahr 1605 „den Regionalkommandeur Chen Yin damit, einen Birmanen (Mian mu) namens Han Fu, [der Manmo kontrollierte], gefangen zu nehmen“, stellen die Verfasser der Lokalhandbücher von Tengyue fest, daß schließlich auch „Manmo bald ganz von den Birmanen eingenommen wurde (Manmo hou zhong xian yu Mian)“. ${ }^{418}$

\footnotetext{
${ }^{415}$ E. H. Parker vermutet, daß der Kopf dem chinesischen Kaiser als Geschenk überbracht wurde (Scott/Hardiman, S.61).

${ }^{416}$ TYTZ, S. 240; TYZZ, S. 151

${ }^{417}$ TYTZ, S. 240; TYZZ, S. 149

${ }^{418}$ TYTZ, S. 240; TYZZ, S. 151
} 
Tabelle 10: Chronologie der Kämpfe in den tusi-Gebieten westlich der acht Paßstationen in der zweiten Hälfte der Ära Wanli nach den Angaben der fangzhi von Tengyue

1590 Birmanische Truppen erobern Mengyang, Mengmi und Mubang.

1591 Birmanische Truppen umzingeln Manmo, werden von chinesischen Truppen unter Vize-General Wan Guochun geschlagen.

1592/93 Erneute Angriffe der Birmanen auf Manmo; 1593 muß der tusi Si Hua fliehen. Si Hong, Nachfahre des tusi von Mengyang, erobert zusammen mit Si Zheng von Manmo Mengyang von den Birmanen zurück.

1594 Gouverneur Chen Yongbin veranlaßt den Bau von acht Paßstationen und zwei Festungen.

1596 Gouverneur Chen veranlaßt die Gründung von Pinglucheng und den Militärkolonien im Gebiet von Mengmao.

1598 Si Hong von Mengyang wendet sich von Birma ab und erklärt China seine Loyalität.

1599 Birmanischer Angriff auf Mengyang. China ruft die verschiedenen tusi auf, gegen Birma zu kämpfen; Si Zheng von Manmo und Si Hong kämpfen am Oberlauf des Irawadi gegen die Birmanen.

1600 Um den von Gouverneur Chen und Zensor Liu Huizou veranlaßten Feldzug gegen Midu zu unterstützen, führt Oberbefehlshaber Mu Rui Truppen nach Yongchang.

1601 Si Zheng überfällt Longchuan und zieht sich anschließend wieder nach Manmo zurück.

1602 Truppen aus Ava und Mubang greifen Manmo an, Si Hong von Mengyang kommt zu spät, um den tusi Si Zheng vor dem Tod zu retten.

1603 Throneingabe von Gouverneur Chen bezüglich der Beendigung des chinesischen Engagements in den Rubinminen von Mengmi.

1604 Birmanische Truppen greifen Mengmi an. Nachdem es ihnen nicht gelingt, Unterstützung von Si Hong zu erhalten, greifen sie Mengyang an. Si Hong wird getötet und die Birmanen setzen einen eigenen Statthalter für Mengyang ein.

Gouverenur Chen läßt den von Birma eingesetzten Statthalter von Manmo gefangennehmen. 


\section{Der Konflikt um die Förderung von Edelsteinen im Gebiet von Mengmi}

Trotz der verschiedenen Maßnahmen, die Gouverneur Chen Yongbin ergriffen hatte, war es aus seiner Sicht nicht gelungen, die Grenzregion im Südwesten zu befrieden. Die fortgesetzten Angriffe der Birmanen auf Manmo und ein Feldzug des Oberhauptes von Manmo in das Gebiet von Longchuan bedeuteten nach wie vor eine Gefahr für die Sicherheit der Präfektur Yongchang. In seiner Throneingabe aus dem Jahr 1603 analysiert Chen Yongbin die Ursachen für die unruhige Lage in der Region. ${ }^{419}$ Zunächst einmal war da Birma, das

„seit alters her ein Ärgernis für China gewesen ist. [Die Birmanen] sind so habgierig wie Schweine und Schlangen und wagen es, sich uns zu widersetzen. Im kleinen fressen sie wie Seidenraupen Stück um Stück von den Gebieten der verschiedenen Völker in sich hinein, im großen dringen sie bis über die Grenze vor. ...... Früher hatte ich mit Rauchzeichen eine eilige Warnung geschickt, bezüglich des Problems, daß die drei Befriedeten Gebiete (san xuan) verloren gehen könnten. Im 2. Monat desselben Jahres nun hat sich Yonghan, der Häuptling der Birma-Bande (Mian chou) von Ava, mit Mubang und anderen Barbaren (yi) verbündet und ist mit mehr als einhunderttausend Mann direkt nach Manmo vorgedrungen, er hat die drei Befriedeten Gebiete mit Füßen getreten und ist sogar vor Tengyue aufgetaucht““. ${ }^{420}$

Es waren aber nicht allein die Angriffe der Birmanen, in denen Chen eine Gefahr für die Stabilität der Region sah. Ein weiteres Problem war die Förderung von Edelsteinen im Gebiet von Mengmi. Diese Juwelen waren am chinesischen Kaiserhof und in der chinesischen Oberschicht begehrte Luxusgüter; zu deren Erwerb seit über einhundert Jahren eigens Beamte, zumeist Eunuchen, in den Südwesten Yunnans entsandt wurden. Diese waren mit Sondervollmachten ausgestattet, was häufig zu Konflikten mit den lokalen Verwaltungsbeamten führte. Auch der Handel vor Ort, die Höhe der Steuern der Bevölkerung und die Tributbeziehungen zu den Kleinstaaten der Region wurden von dem kaiserlichen Interesse am Erwerb von Edelsteinen aus Mengmi beeinflußt.

\section{1. Die Rubinminen von Mogok}

Die berühmten Rubinminen von Birma befinden sich in Mogok, einem von Bergen umgebenen weiten Talkessel auf etwa 1200m Höhe im Nordwesten des Shan Staates des

\footnotetext{
${ }^{419}$ Ba cai baojing shu (TYZZ, S. 47-49; s. a. Yunnan tongzhi, juan 29, yiwen 3).

${ }^{420}$ TYZZ, 47-48
} 
modernen Birma, im Gebiet von Möng Mit, dem Mengmi xuanfu si des Ming-Reiches. In der ganzen Region um den Ort Mogok gibt es reiche Vorkommen, insbesondere von Rubinen, aber auch Saphire, Chrysoberylle, Spinelle und andere Edelsteine werden dort bis heute gefördert.

Vermutlich schon seit dem 6. Jahrhundert ist im Gebiet von Mogok nach Edelsteinen geschürft worden. Chinesische Quellen weisen darauf hin, daß die Förderung von Edelsteinen dort in der Zeit der Yuan-Dynastie (13. bis 14. Jahrhundert) betrieben worden ist. ${ }^{421}$

Zur Gewinnung der Edelsteine werden verschiedene, dem jeweiligen Gelände angepaßte Techniken angewandt, um die obere Erdschicht abzutragen und die etwa drei bis acht Meter tiefer gelegene edelsteinhaltige Geröllschicht freizulegen und aus dieser die Juwelen herauszuwaschen.

Eine Methode ist es einen Schacht, ähnlich einem Brunnen zu graben, aus dem das edelsteinhaltige Geröll dann mit Körben wie aus einem Ziehbrunnen herausgeholt und anschließend in Wasser durchgesiebt wird, um die Edelsteine herauszulösen. Hinweise darauf, daß diese Methode bereits in der Ming-Zeit angewandt wurde, gibt die im 16. Jahrhundert gebräuchliche Bezeichnung der Minen in zeitgenössischen chinesischen Quellen als ,Schatzbrunnen‘ (baojing).

Eine weitere Technik ist die Anlage von Gräben, in die Wasser geleitet wird, welches das Geröll herausschwemmt, das dann aufgefangen und ausgsiebt wird. Außerdem kann das Gestein in Tunnelanlagen, die in die Berghänge gegraben werden, abgebaut werden oder es wird Wasser zu einem Teich gestaut, der dann ausgebaggert wird. Die Minenarbeiter tauchen zu seinem Grund und bringen Körbe voll Geröll an die Oberfläche, aus dem die Edelsteine herausgelesen werden. ${ }^{422}$ Auch diese Methode ist in der Ming-Zeit bereits angewandt worden zu sein, so schreibt Gu Yanwu (1613-1682) in seiner geographischen Abhandlung Tianxia junguo libing shu, in der er Quellen aus der Ming-Zeit auswertet und mit eigenen Forschungsergebnissen vergleicht, daß die Juwelen

„aus Mengmi stammen, aus den sogenannten Edelsteinminen. Ebenso wie bei den Perlenteichen von Lianzhou [in der Provinz Guangdong] heißt es auch hier, daß man [die Juwelen] teils tauchend gewinnen kann, teils indem man sie mit Haken aus dem Wasser angelt“. ${ }^{423}$

\footnotetext{
${ }^{421}$ TYZZ, S. 49; TYTZ, S. 360

${ }^{422}$ Siehe Scott/Hardiman, S. 19-22.

${ }^{423}$ Tianxia junguo libing shu (juan 107), zitiert nach You Zhong, S. 420. Zum Tianxia junguo libing shu siehe CY 378.3; Gernet, S. 423.
} 


\section{2. Der chinesische Edelsteinhandel und seine Auswirkungen auf die Region}

Seit dem 15. Jahrhundert florierte der Handel mit Edelsteinen zwischen Mengmi, Mengyang (wo Bernstein und Jade gefördert wurden) und dem chinesischen Reich. Die Juwelen erfreuten sich am Kaiserhof und in vermögenden Haushalten großer Beliebtheit. Rubine, Bernsteine, Jade und andere kostbare Steine wurden von den Kleinstaaten im Südwesten Yunnans auch als Tributgeschenke nach China gesandt.

„Ursprünglich hat es für Edelsteine keine festgesetzte Steuer gegeben“, so erläutert Gu Yanwu, „wenn [dem Kaiserhof Juwelen] überreicht wurden, dann sind diese geprüft und [ihrem Wert] entsprechend mit Silber aus der Schatzkammer bezahlt worden“. ${ }^{424}$ Um den steigenden Bedarf an Edelsteinen zu decken, ließen die Ming-Kaiser die Edelsteine bald direkt im Südwesten aufkaufen. Mit dieser Aufgabe wurden seit Mitte des 15. Jahrhunderts Eunuchen betraut, die aus der Hauptstadt nach Yunnan und auch direkt in die Präfektur Yongchang entsandt wurden, um Edelsteine an den Förderstätten oder von lokalen Händlern auf den Märkten von Tengchong, Yongchang oder Yunnan fu einzukaufen. Zur Finanzierung des Handels stellten die Provinzbehörde sowie die Regionalverwaltungen von Yongchang und Tengchong seit der Ära Chenghua (1465-88) Silber zur Verfügung.

In der ganzen Provinz Yunnan wurde zu dieser Zeit zudem der Abbau von Bodenschätzen gefördert und neue Eisen-, Kupfer-, Silber- und Goldminen in Betrieb genommen. Zumeist wurden die Bergwerke als private Unternehmen geführt, deren Steuerabgaben eine wichtige Einnahmequelle für den Kaiserhof bedeuteten. Daneben waren aber auch Eunuchen selbst mit der Leitung von Bergwerksbetrieben befaßt. ${ }^{425}$

Der Umfang des Edelsteinhandels wird an einem Beispiel aus der Jiajing-Zeit deutlich, das zeigt, wie häufig Juwelen vom Kaiserhof verlangt und in welchen Mengen sie in die chinesische Hauptstadt geliefert wurden:

Im Jahr 1563 hatte die Provinz Yunnan zweimal Juwelen als Tribut an den Hof gesandt. Beim ersten Mal waren Edelsteine mit einem Gesamtgewicht von über 360 liang, beim zweiten Mal waren dann 7769 grüne, gelbe und rote Edelsteine übergeben worden. Im Jahr 1564 wurde wiederum zweimal Tribut übersandt: Zum einen Steine mit einem Gewicht von insgesamt 700 liang, zum anderen über 650 Edelsteine. ${ }^{426}$

\footnotetext{
${ }^{424}$ Gu Yanwu (1613-1682): Tianxia junguo libing shu (juan 107), zitiert nach You Zhong, S. 420.

${ }^{425}$ Eberstein, S. 12, 24, 63

${ }^{426}$ You Zhong, S. 421; s. a. Yunnan linian chuan (juan 8). Die historische Maßeinheit liang entsprach etwa $31 \mathrm{Gramm.}$ Demnach wären im Jahr 1563 ca. 11,2 kg Edelsteine, im Jahr 1564 sogar knapp 22,0 kg Edelsteine sowie die genannten Stückzahlen an den Hof übersandt worden.
} 
Trotz der großen Anzahl und Vielfalt der Edelsteine bemängelte der Jiajing Kaiser, daß noch zu wenig Edelsteine geliefert würden und befahl, daß alle Steine mit einem Durchmesser von mehr als einem cun (ca.3,3cm) angekauft und ihm überreicht werden sollten. ${ }^{427}$ Auch die Nachfolger des Jiajing Kaisers fanden Gefallen an den Juwelen aus dem Südwesten. So verlangte der Longqing Kaiser im Jahr 1572 von seinen Agenten, zwanzigtausend Edelsteine in Yunnan zu erwerben. ${ }^{428}$

Diese Zahlen machen deutlich, welche Mengen an Edelsteinen in den Minen von Mogok Jahr für Jahr gefördert worden sind. Dabei war China nicht der einzige Abnehmer, auch die Könige Birmas erwarben große Mengen an Edelsteinen. Mengmi und Mengyang, das Jade und Bernstein lieferte, verdankten diesem profitablen Handel ihren Aufstieg zu eigenständigen Staaten, die auf Kosten ihrer Nachbarn expandierten und etwa einhundert Jahre lang ihre Vormachtstellung in der Region behaupten konnten.

In Tengchong liefen die verschiedenen Handelsrouten aus dem Südwesten zusammen und machten die ,erste Stadt an der äußersten Grenze‘ zu einem wichtigen Umschlagplatz des Edelsteinhandels. Tengchong begann sich zu einem Zentrum der Jadeverarbeitung zu entwickeln, auch Handel und Handwerk boten willkommene Verdienstmöglichkeiten, zumal der Boden auf der Hochebene von Tengchong zwar fruchtbar war, die landwirtschaftliche Nutzfläche insgesamt jedoch nicht ausreichte, um die zunehmende Bevölkerung zu ernähren. Denn gerade auch die Aussicht auf Beschäftigung im Handel, Karawanenverkehr oder dem Handwerk zog weitere Zuwanderer an. Nach den Statistiken der fangzhi hat sich allein die Bevölkerung Tengchongs von der Mitte des 15. bis zur Mitte des 16. Jahrhunderts etwa vervierfacht und ist von 2661 Personen (dingkou) im Jahr 1472 auf 11.120 Personen im Jahr 1567 gestiegen. ${ }^{429}$ Dabei erfassen diese Statistiken nur einen Teil der Bevölkerung der Unterpräfektur; die Menschen, die in die tusi-Gebiete und zu den Edelsteinvorkommen weitergezogen sind, werden in ihnen nicht berücksichtigt.

Verschiedene zeitgenössische Quellen beschreiben die Anziehungskraft, die der Reichtum der Minen trotz der großen Entfernung und des unwirtlichen Klimas auf viele Chinesen ausgeübt und sie veranlaßt hat, nach Mengmi zu gehen.

\footnotetext{
${ }^{427}$ You Zhong, S. 421; siehe auch Yunnan linian chuan (juan 8).

${ }^{428}$ Tsai, S. 184

${ }^{429}$ TYTZ, S. 49-50; TYZZ, S. 61-63
} 
Yang Shen (1488-1559), Autor geographischer und historischer Werke über Yunnan, kannte den Edelsteinhandel und seine Auswirkungen auf das Leben in der Präfektur Yongchang aus eigener Anschauung. ${ }^{430}$

In seiner ,Ballade von den Edelsteinminen“ (Baojing yao) schildert er den Reichtum der Vorkommen als Auslöser eines wahren ,Goldrausches’ in der Region:

„Farbige Steine und glänzende Perlen - seit alters her werden sie hoch geschätzt und sind ein Spielzeug der Schönen und Reichen. Wer weiß schon, daß wegen zwei edlen Steinen, die wie Wolken den Haarknoten zieren, die Tributleistungen der Barbaren neu festgelegt worden sind?

Die Edelsteinminen sind bekannt geworden. [Obwohl] die Wege dorthin weit sind und [trotz] der Schlangen und des feuchten Klimas sind [viele Männer] dorthin ans Ende der Welt geeilt. Schnell hat sich die Kunde verbreitet und Tausende folgten [ihr] in großer Hast.

Öffnet man die Landkarte, so sind es zehntausend li [bis zu den Minen] und [doch] eilten sie um die Wette [dorthin]. Siehst du nicht die Straße, die südlich der Stadt Yongchang zu den Edelsteinen führt? Vor dem Sieben-li-Pavillion befindet sich die Poststation Wanshui. In ihrem Herzen wissen die [Reisenden], daß sie sich hier in den Tod verabschieden und daß nur wenige von ihnen lebend zurückkehren werden. Unter Tränen beklagen ihre [zurückbleibenden] Ehefrauen und Eltern gegenseitig [ihr Schicksal].

Der Weg ist so lang; das laute Schluchzen jener bald weit entfernt und nicht mehr zu hören. Sie sehen nur den goldenen Dunst, der von der gelben Erde aufsteigt. In Lujiang und Bawan herrscht ein feuchtheißes Klima. Ebenen mit gelbem Gras folgen auf Hügel mit wilden Tigern. ... Eingestürzte Sandbänke und Treibsand, dort wo der Fluß einst seine Richtung geändert hat. ...

Die Köpfe umwickelt, die Zähne lackiert - das ist Manmo ... Für jemanden, der hier an der stummen Malaria (ya zhang) erkrankt, gibt es keine rettende Medizin. ....

Dunkelrote Edelsteine sind tausende von Goldstücken wert. Echte und unechte fallen ins Auge, sie sind nicht zu unterscheiden.

\footnotetext{
${ }^{430}$ Yang Shen, Mitglied der Hanlin-Akademie, war für seine kritische Haltung in der Kontroverse um die Verleihung kaiserlicher Titel an den verstorbenen Vater des Jiajing Kaisers im Jahr 1524 nach Yongchang verbannt worden. Im Exil verfaßte Yang zahlreiche Publikationen über Geographie und Geschichte der Provinz Yunnan (siehe auch DMB, S. 15311535). Die Herausgeber des TYZZ bemerken dazu: „[Yang] Shen war nach Jinchi verbannt worden. Er hat die Verhältnisse dort mit eigenen Augen gesehen und selbst unter ihnen gelitten“ (TYZZ, S. 47).
} 
Einen Edelstein zu erlangen und heimzukehren, das ist wie eine Wiedergeburt. [Doch aus Angst, das Juwel zu verlieren] fürchtet man jeden Schatten und ängstigt sich noch im Traum. ... Hätte man doch nur die Fähigkeit der Unsterblichen, Entfernungen zusammenschrumpfen zu lassen, dann könnte man die Edelsteinminen gleich [nach Peking] in die Chang’an Straße verlegen“. ${ }^{31}$

Yang Shen stellt die Schwierigkeiten, mit denen sich die ,Schatzsucher konfrontiert sahen, sehr plastisch dar: Die Trennung von der Familie, das unwegsame Gelände, die Furcht inmitten der fremdartigen einheimischen Bevölkerung einer tödlichen Krankheit zu erliegen und selbst mit dem Fund oder Erwerb eines Edelsteins waren die Gefahren noch nicht vorüber. Deutlich werden aber auch der Mut und der Unternehmungsgeist der Menschen, die diesen Gefahren trotzten, um am profitablen Edelsteinhandel teilzuhaben.

Yang Shen bemerkt, daß ,die Tributleistungen der Barbaren neu festgelegt worden sind‘, genauere Angaben macht er nicht. Nach dem Textzusammenhang zu urteilen, sollten Edelsteine vermutlich generell oder in größerer Zahl als Tribut an den Kaiserhof gesandt werden. Ein weiterer zeitgenössischer Autor, Zhang Han, weist ebenso wie der oben zitierte Gu Yanwu darauf hin, daß die Edelsteine ursprünglich nicht von den Einheimischen als Tributgaben gefordert worden waren. Bereits Ende des 15. Jahrhunderts hatte Nang Han Nong, die Herrscherin von Mengmi, allerdings aus eigener Initiative Juwelen als Tributgeschenke übersandt, um sich das Wohlwollen der Ming zu sichern. Anscheinend hat der steigende Bedarf an Edelsteinen Anfang des 16. Jahrhunderts den Kaiserhof dazu veranlaßt, auch das tusi-System zu nutzen, um über die Tributgesandtschaften der Randvölker mehr Edelsteine zu erhalten.

Die meisten Edelsteine wurden jedoch auch weiterhin von den staatlichen Aufkäufern vor Ort erworben.

Zhang Han, ein juren aus der Präfektur Yongchang, beschreibt in seiner ,Ballade von den Edelsteinminen“ (Baojing yao) die Probleme, die die Aufkäufer der Juwelen in der südwestlichen Grenzregion verursachten. ${ }^{432}$ Zhang weist auf das Elend der Bevölkerung in der Präfektur Yongchang hin, die zusätzliche Steuern zahlen mußte und unter der Ausbeutung durch diese Beamten zu leiden hatte:

\footnotetext{
${ }^{431}$ TYZZ, S. 47; TYTZ, S. 360. Die vollständige Übersetzung der Ballade findet sich im Anhang.

${ }^{432}$ Als Autor der Ballade wird Zhang Han im TYTZ (S. 360) als juren aus Baoshan bezeichnet. Diesen akademischen Titel hatte Zhang im Jahr 1522 erworben, im Jahr 1532 erlangte er zudem den Titel eines jinshi (YCFZ, S. 206, 202).
} 
„Schon während der Ära Chenghua (1465-1488) galten Edelsteine als wertvoll. Private Haushalte kauften sie heimlich und auch Beamtenhaushalte kauften sie. In der Hauptstadt gab man Silber aus den Schatzkammern dafür aus und hatte nicht von den südlichen Barbaren verlangt, diese Kostbarkeiten als Tribut zu übergeben. ....

Seit dem Jahr dingke der Ära Jiajing (1527) kommen Beamte als Aufkäufer in die Garnison Yongchang. Die kaiserlichen Beamten zahlen den festgesetzten Regierungspreis. Sie mischen sich in die lokalen Angelegenheiten ein und dem Volk geht es sehr schlecht. Dem Volk geht es sehr schlecht; wozu soll man sich darum kümmern? Auf der Poststraße und in den staatlichen Rasthäusern gibt es viele Tiger und Panther. Sobald die kaiserlichen Aufkäufer ihre Fahnen entrollen, beginnt selbst das Gebirge zu erzittern. [Gezwungen die eigenen] Söhne und Töchter zu verkaufen, weint das Volk bitterlich. Bis heute ist dies schon vierzehn Mal vorgekommen. Lautlos fließen die Tränen [der Menschen], denen das Herz aus dem Leib gerissen wird“‘. ${ }^{433}$

Die wiederholten kaiserlichen Forderungen nach der Übersendung einer beträchtlichen Anzahl von Juwelen (Zhang Han nennt vierzehn solcher Missionen zum Erwerb von Edelsteinen), die in relativ kurzen Zeiträumen geliefert werden mußten, machen aber auch die hohen Anforderungen deutlich, die an die Eunuchen, die mit dem Ankauf beauftragt waren, gestellt wurden. ${ }^{434}$ Sie sind mit eine Ursache für die in den zeitgenössischen Quellen angeprangerte Ausbeutung der Region durch die Eunuchen. Als Sonderbeauftragte des Kaisers konnten sie vor Ort ihre Autorität geltend machen, wobei Konflikte mit den lokalen Beamten nicht ausblieben. Die Beamten sahen sich in ihrer Amtsführung beeinträchtigt, zudem standen sie den Bergbau- und anderen kommerziellen Aktvitäten gerade der Eunuchen generell kritisch gegenüber. Doch Machtmißbrauch, die Ausbeutung der Bevölkerung und persönliche Bereicherung durch die Eunuchen wurden häufig auch zu Recht beklagt; Throneingaben von Zensoren, die diese Mißstände anprangerten, blieben jedoch angesichts der finanziellen Interessen und der Vorliebe des Kaiserhofes für Juwelen erfolglos. $^{435}$

\footnotetext{
${ }^{433}$ TYZZ, S. 47; TYTZ, 360. Die vollständige Übersetzung der Ballade findet sich im Anhang.

${ }^{434}$ Zhang Hans Ballade ist nicht datiert. Der Hinweis in den fangzhi auf seinen akademischen Titel (juren), deutet darauf hin, daß er den Text verfaßt hat, bevor er im Jahr 1532 die Prüfung zum jinshi ablegte. Demnach hätten die vierzehn Missionen zum Kauf von Edelsteinen in einem Zeitraum von nur fünf Jahren, zwischen 1527 und 1532, stattgefunden.

${ }^{435}$ Tsai, S. 180-182; TYZZ, S. 49
} 
Yang Shen und Zhang Han prangern in ihren Balladen die Gier nach immer mehr Edelsteinen und die Mißstände des staatlichen organisierten Handels an. Yang verweist gar auf die Gefilde der Unsterblichen: Dort „am Kunlun Gebirge würden sie die [Edel]steine den Elstern geben und am Ort der glückverheißenden Wolken das Gold den Schildkröten hinwerfen“; so kritisiert er die Juwelen als eitlen Tand und deutet an, daß ein Kaiser eigentlich über diesen Dingen stehen sollte. ${ }^{436}$ Beide Autoren waren Gelehrte, die mit einer klassischen Bildung hohe akademische Titel erworben hatten. Sie sahen weniger auf die wirtschaftlichen Vorteile, die dieser Handel für die Region bedeutete und der erheblich zur Etablierung Tengyues als reguläre Verwaltungseinheit des chinesischen Reiches beigetragen hat. Vielmehr hoben sie die negativen Begleitumstände des Edelsteinhandels hervor, hauptsächlich das Auftreten der Eunuchen, die mit großem Gefolge reisend und mit besonderen Machtbefugnissen versehen, ihre Autorität in der Region geltend machten. Beide Balladen sind vom sozialen Gewissen der Autoren geprägt, die das Leid der einfachen Bevölkerung in den Mittelpunkt ihrer Werke stellen. Auch die Verfasser der fangzhi von Tengyue im 19. Jahrhundert schlossen sich dieser kritischen Sichtweise auf den Edelsteinhandel an und kommentieren die Balladen mit der Feststellung, daß

„die Juwelen für viele Generationen in Yunnan wie ein Gift waren. Hat man Yang Shens Ballade über die Edelsteinminen gelesen, dann muß man Mitleid [mit den Menschen damals] haben“. So sollten „diese beiden Gedichte als Warnung vor den Edelsteinen, diesen Dingen aus der Ferne, dienen.“ 437

Ausdrücklich kritisiert wird an dieser Stelle auch die Einmischung der Eunuchen in die Grenzpolitik, in der die Verfasser ebenso wie der damalige Gouverneur von Yunnan, Chen Yongbin, eine Gefahr für die Sicherheit der Unterpräfektur sahen:

„Dann hatten sich die Eunuchen verschworen, die Grenzangelegenheiten ernstlich zu stören; sie [und die regulären Beamten] behinderten sich gegenseitig [bei der Verwaltung der Region]. Der Häuptling von Birma nutzte diese Gelegenheit, um sich zu erheben. Während der Ära Wanli (1573-1620) griff er mit vielen [Soldaten] Manmo direkt an, wobei er Instruktionen des für den Ankauf von Edelsteinen zuständigen Beamten folgte, der ihm befohlen hatte, Si Zheng von Manmo zu töten, um so den Weg freizumachen. Entrüstet darüber verfaßte Gouverneur Chen Yongbin eine Throneingabe“. 438

\footnotetext{
${ }^{436}$ TYZZ, S. 47; TYTZ, S. 360

${ }^{437}$ TYTZ, S. 360; TYZZ, S. 47

${ }^{438}$ TYZZ, S. 47
} 


\section{3. Gouverneur Chen Yongbin und seine Kritik am chinesischen Engagement bei der Förderung von Edelsteinen in Mengmi}

Als sich Ende des 16. Jahrhunderts die finanzielle Lage des Staates verschlechtert hatte, veranlaßte der Wanli-Kaiser den Abbau von Bodenschätzen zu intensivieren und entsandte im Jahr 1596 wiederum Eunuchen aus der Hauptstadt in verschiedene Provinzen, um weitere Bergbauaktivitäten durchzuführen, Bodenschätze zu fördern und Steuern einzuziehen. ${ }^{439}$ Nach Yunnan wurde im Jahr 1599 der Eunuch Yang Rong entsandt, der auch die Leitung des Erwerbs von Edelsteinen für den Kaiserhof übernahm. Verschiedene Autoren haben die historischen Quellen dahingehend interpretiert, daß der Eunuch Yang Rong persönlich nach Mengmi gereist ist, um die Ausbeutung von Edelsteinminen zu leiten und dort mit seinem Verhalten gegenüber den Einheimischen eine Rebellion provoziert hat, in deren Verlauf er getötet wurde. ${ }^{440}$ Sun Laichen hingegen weist darauf hin, daß Yang lediglich seine Gefolgsleute zu den Minen geschickt hat, um Edelsteine zu erwerben. Er selbst residierte in der Provinzhauptstadt, wo die Ausbeutung der Bevölkerung zu einer Rebellion führte, bei der Yang Rong getötet wurde. ${ }^{441}$ In jedem Fall weckte das Engagement der Eunuchen im Minendistrikt bei den lokalen Beamten in Yunnan die Befürchtung, daß sich die ohnehin konfliktreiche Situation in der Region des Stromschluchtenfächers weiter verschärfen könnte. Denn zu dieser Zeit haben sich die Machtverhältnisse im Südwesten der Unterpräfektur Tengyue dahingehend verändert, daß die Staaten der Shan in der Region ihre Eigenständigkeit verloren. Im Jahr 1588 eroberten Truppen aus Birma Mengmi, wo König Nandabayin ein Mitglied der einheimischen Herrscherfamilie, das ihm seine Loyalität erklärt hatte, zum neuen Oberhaupt des Gebietes ernannte.

Die Förderung von Edelsteinen in Mogok wollten die Birmanen jedoch in eigener Regie ausüben und der birmanische König unterstellte sie einige Jahre später seiner Herrschaft: Ein königliches Edikt zur Übernahme der Minen wurde im Jahr 1597 erlassen. ${ }^{442}$ Im Jahr 1607 erhielt Mengmi vom birmanischen König im Austausch für den Minenbezirk das Gebiet von Tagaung zugeteilt; seitdem wurden die Minen direkt von der Hauptstadt Birmas aus verwaltet. ${ }^{443}$

\footnotetext{
439 Tsai, S. 179, Eberstein, S. 64, 86

${ }^{440}$ Siehe DMB, S. 193-194

${ }^{441}$ Sun Laichen, Ming-Southeast Asian overland interactions, S. 144-145, 147

${ }^{442}$ Scott/Hardiman, II, 3, S. 26; Enriquez, S. 58

${ }^{443} \mathrm{Scott} /$ Hardiman, II, 3, S. 4, 26. Rubine waren in Birma ein Monopol des Königs. Steine ab einer bestimmten Größe mußten an den Herrscher abgeliefert werden; Diebstähle wurden streng bestraft. Die Herausgeber der fangzhi bemerken dazu, daß „der Häuptling von Birma Gebäude um die Edelsteinminen herum errichten und streng bewachen ließ, .... im Innern des Gebäudes wurde dann mit der Grabung begonnen und wenn dabei ein schöner Stein gefunden wurde, so
} 
Mit der Errichtung der acht Paßstationen hatte China die Unterpräfektur Tengyue und die ihr zugeordneten tusi von den Gebieten jenseits dieser Linie, auf die China keine Kontrolle mehr ausüben konnte, abgegrenzt. Aufgrund des Engagements von Yang Rong und seinen Gefolgsleuten in Mengmi bestand nun die Gefahr, daß eine Situation entstehen könnte, in der China erneut in Kämpfe mit den Birmanen verwickelt würde, was wiederum die Sicherheit der chinesischen Verwaltungseinheiten gefährden würde.

Der Verzicht auf eine direkte Einflußnahme auf die Gebiete jenseits der Paßstationen und die Stärkung Manmos in seiner Funktion als ,Schutzzaun`, waren die beiden Eckpfeiler der Politik von Gouverneur Chen zur Sicherung des Südwestens der Provinz Yunnan. Diese Politik sah Chen Yongbin durch die Aktivitäten Yang Rongs gefährdet. Er richtete deshalb eine Eingabe an den Kaiser, mit der er die Einstellung des chinesischen Engagements beim Abbau der Edelsteinvorkommen zu erreichen suchte.

In der ,Throneingabe bezüglich der Einstellung der Förderung in den Edelsteinminen` (Ba cai baojing shu) aus dem Jahr 1603 macht Chen die Auswirkungen deutlich, die das chinesische Engagement im Edelsteinhandel in dieser Zeit auf die Entwicklung im Grenzgebiet hatte. ${ }^{444}$ Zunächst schildert er den Zusammenhang, der zwischen dem Abbau der Rubinvorkommen in Mengmi durch die Eunuchen und der Besetzung Manmos durch die Birmanen bestand. So hätten die Birmanen und ihre Verbündeten Manmo im Jahr 1602 auf Anweisung von Yang Rong hin angegriffen. Chen schreibt:

„[Der Anführer der Birmanen] erklärte dazu, daß der Gesandte Chinas, der mit dem Minenbetrieb befaßt war (kai cai Han shi), ihm befohlen hätte, Si Zheng, [den Herrscher von Manmo], zu töten, um den Weg nach Manmo freizumachen. So hätte er ein Übel (hai) für den kaiserlichen Hof beseitigt.

$\mathrm{Zu}$ einer anderen Zeit waren die Generäle und subalternen Beamten dem Befehl dieses Ministers gefolgt, der verkündet hatte, daß der Häuptling für das Verbrechen seines Eindringens bestraft werden muß. ... Ohne ihn hat der Herrscher von Ava nun keine Gründe mehr [hierzusein]. Gemäß dem schriftlichen Befehl dieses Ministers, sollten sie ihre Rüstungen zusammenrollen und nach Ava zurückkehren. Weshalb blieben also noch Soldaten zurück, um

erfuhren es die Leute draußen nicht und [der Stein] wurde sodann dem Häuptling von Birma überreicht“ (TYZZ, S. 49; TYTZ, S. 360).

${ }^{444}$ TYZZ, S. 47-49; siehe auch Yunnan tongzhi (juan 29, yiwen 3). Die komplette Übersetzung der Throneingabe befindet sich im Anhang. 
Manmo zu verteidigen? Die verschlagenen Birmanen hatten nur vorgetäuscht, die Edelsteinminen zu übergeben (jia Mian zhi jia xian jing) und sich gedacht, sie könnten die Grenze öffnen, indem sie Si Zheng verfolgten, wobei ihnen beim Gedanken an Manmo schon das Wasser im Munde zusammenlief. Ihr heimtückischer Plan ist uns jedoch vollständig zugetragen worden“. ${ }^{445}$

Zwar hatte auch Chen Yongbin selbst eine Bestrafung Si Zhengs für sein Vordringen nach Longchuan im Jahr zuvor verlangt und deren Ausführung durch die Birmanen entsprach durchaus seiner Politik, ,Barbaren einzusetzen, um andere Barbaren zu bekämpfen‘ (yi yi gong yi). Da die Anordnung nun aber von Yang Rong gekommen war, hatten sich die Birmanen die einander überschneidenden Befugnisse des Gouverneurs und des Eunuchen zu nutze gemacht, um sich in Manmo festzusetzen. Angeblich im Austausch für die Überlassung von Minen, befand sich dieses Gebiet doch seit einigen Jahren unter birmanischer Oberhoheit. Für Chen Yongbin war die Frage der Sicherung des Grenzgebietes daher auch eine Frage der Bedeutung seines Amtes. Er macht in seiner Throneingabe unmißverständlich klar, daß für die Verwaltung der Provinz ebenso wie für den Grenzschutz in erster Linie der Provinzgouverneur zuständig ist und andere Beamte sich nicht in dessen Politik einzumischen haben. Er schreibt:

„Das ganze Unglück Yunnans begann mit der Öffnung der Edelsteinminen. Wenn man die Edelsteinminen betreiben will, dann kann man Manmo nicht zurückgewinnen. Wenn man Manmo zurückgewinnen will, dann kann man die Arbeit in den Minen nicht beginnen. Beides zusammen geht in dieser Situation nicht. Wenn man die Edelsteinminen begehrt, dann muß man den Zaun entfernen. Wenn man den Zaun behalten will, dann muß man den Aufkäufern mitteilen, aufzuhören. Es geht nur eines, nicht alles zusammen. ......

Gegenwärtig hat Eure Majestät einen Provinzgouverneur eingesetzt, der die militärischen Angelegenheiten zu ordnen hat. Außerdem hat Eure Majestät einen Steuer-Aufseher ( $d u$ shui) eingesetzt, der Förderung und Ankauf zu überwachen hat. Derjenige, der die militärischen Angelegenheiten verwaltet, soll bezüglich der Grenzangelegenheiten Warnungen mitteilen sowie eindringende Banditen bezwingen. Derjenige, der Förderung und Ankauf zu überwachen hat, soll sich um die Fragen bezüglich der Juwelen kümmern. Warnungen braucht jener nicht zu übermitteln, Banditen braucht jener nicht zu bezwingen.

\footnotetext{
445 TYZZ, S. 48; siehe auch Yunnan tongzhi (juan 29, yiwen 3).
} 
Dieser Zustand wird [nun aber] beeinträchtigt. Wenn eine Störung nicht aufhört, dann kommt es zu einer Stauung, wenn eine Stauung nicht beendet wird, dann werden die Vorbereitungen vernachlässigt. Wenn die Vorbereitungen vernachlässigt werden, dann kann die Kavallerie der Birmanen über Manmo unaufhaltsam bis zu den drei Befriedeten Gebieten (san xuan) vorrücken. Wenn sie in dieses menschenleere Gebiet kommt, muß die Region von Tengyue und Yongchang fürchten, nicht mehr zu Euer Majestät zu gehören. Eure Majestät haben in vielen Jahren Milde gegenüber den Gebieten [im Südwesten] gezeigt. Noch ist das Land der Vorfahren geeint, wenn aber die Minen in Betrieb genommen werden, dann wird das Land in Gefahr sein. Dieser Minister weiß, daß das nicht der Wille eurer Majestät sein kann.

Weshalb sind die Edelsteinminen [eigentlich] Kostbarkeiten? Sind sie nicht nur ein Stückchen Land? Ist ein Edelstein so wichtig? Ist das Land so wichtig? Wegen eines nutzlosen Stückchens Land kann ein zehntausend li großes Grenzgebiet (fengjiang) zerstört werden. Der Handel [mit Edelsteinen] genießt unverdientes Ansehen, ist doch der Preis, den man bekommt, in Wirklichkeit Unheil für das Grenzgebiet. Dieser Minister weiß, daß Eure Majestät dies nicht wollen.

Dieser Minister hat von Eurer Majestät große Gunst erwiesen bekommen. Im Grenzgebiet sind Sicherheit und Gefahr alles [entscheidend]. Wenn er nur untätig dasitzen und zusehen, aber nicht sprechen würde, würde dieser Minister dem Grenzgebiet Schaden zufügen und sich Eurer Majestät gegenüber undankbar zeigen. Ich hoffe, daß unser Kaiser schnell seine Entscheidung bekanntgibt und die Tätigkeiten des Förderns und Handelns an den Edelsteinminen schnell einzustellen befiehlt. Den bisher [dort tätigen] hohen Generälen und mächtigen Beamten möge er befehlen, schnell an ihren Heimatort zurückzukehren und nicht erneut Streit [über diese Fragen] zu beginnen. Die Generäle und subalternen Beamten im Grenzgebiet sollen sich einig mit der Untersuchung militärischer Operationen beschäftigen. So gibt es die Idee, die Rückeroberung von Manmo zu planen. Wenn die Birmanen abziehen, werden sie nicht verfolgt. Wenn sie vordringen, müssen sie abgewehrt werden. Dann kann man in allen Grenzangelegenheiten ohne Sorgen sein, denn der Süden wird unterworfen und ungeteilt bleiben“. ${ }^{446}$

${ }^{446}$ TYZZ, S. 48; siehe auch Yunnan tongzhi (juan 29, yiwen 3). 
Während Chen durch den Verlust der Kontrolle über das strategisch gelegene Manmo die Sicherheit des gesamten Südwestens der Provinz gefährdet sah und verglichen damit, der Förderung von Edelsteinen nur wenig Bedeutung beimaß, unterstützte der Kaiser weiterhin das Minenprojekt. Die Throneingabe von Gouverneur Chen blieb ohne Erfolg. ${ }^{447}$

Ein Aufstand der Bevölkerung, der nach Meinung von Gouverneur Chen durch die Unterdrückung und Ausbeutung der Menschen durch die chinesischen Eunuchen ausgelöst worden ist, bot Chen Yongbin die Gelegenheit, seine Forderung nach der Einstellung des chinesischen Engagements in den Minen auf recht drastische Weise zu realisieren, indem er den Aufstand erst niederschlagen ließ, nachdem Yang Rong und seine Gefolgsleute getötet worden waren. Der Wanli-Kaiser verzichtete, vor vollendete Tatsachen gestellt, auf eine Wiederaufnahme der Praxis des staatlichen Ankaufs von Edelsteinen im Grenzgebiet. ${ }^{448}$

Die Birmanen hatten inzwischen Mengyang, Mubang, Mengmi und Manmo ihrer Oberhoheit unterstellt. Die Kleinstaaten als solche blieben jedoch auch weiterhin bestehen, ihre Herrscher wurden vom birmanischen König eingesetzt bzw. bestätigt.

Die Befürchtung von Gouverneur Chen, daß durch den Verlust der chinesischen Kontrolle über Manmo auch die Unterpräfektur Tengyue, ja die gesamte Präfektur Yongchang, von den Birmanen erobert werden würden, hatte sich nicht realisiert. Die Truppen Birmas waren zwar bis an den ,Zaun` Manmo vorgedrungen, die ,Mauer` der drei Befriedeten Gebiete sorgte jedoch weiterhin für den Schutz des ,Hauses‘ Yunnan. Zu weiteren Vorstößen der Birmanen und ihrer Verbündeten in Richtung auf die Unterpräfektur Tengyue kam es in dieser Zeit nicht mehr.

Chen Yongbin hat in seiner Erläuterung zu den sechs Befriedeten Gebieten (Hai ding liu wei hou shuo) noch sämtliche tusi-Gebiete im Südwesten einschließlich Birmas als Grenze des Reiches (guojia xi‘nan zhi jiji) bezeichnet.Auf eine Verschiebung des tatsächlichen chinesischen Einflußbereiches weist er auch später höchstens indirekt hin: Mit seiner Betonung der Funktion Manmos als ,Schutzzaun` für die Präfektur Yongchang und seiner Forderung nach der Aufgabe des chinesischen Engagements in Mengmi.

\footnotetext{
${ }^{447}$ Ebenso erfolglos blieb auch eine Eingabe des Zensors Song Xingzu, der sich in derselben Angelegenheit an den Kaiser gewandt und darum ersucht hatte, Yang Rong zu entlassen (TYZZ, S. 49).

${ }^{448}$ DMB, S. 194. Chen Yongbin hatte durch sein Verhalten gegenüber Yang Rong die Gunst des Kaisers verloren. Im Jahr 1608 wurde er für angebliche Fehler bei der Niederschlagung einer Rebellion in der Präfektur Wuding (im Norden Kunmings) angeklagt. Er verbrachte schließlich neun Jahre im Gefängnis und starb kurz nach seiner Freilassung (ebd.).
} 
Hatte Chen zunächst noch betont, daß mit der Errichtung der acht Paßstationen keine Grenze geschaffen werden sollte, so bildeten diese am Ende der Ära Wanli doch eine Trennungslinie, die den direkten Einflußbereich der chinesischen Regierung deutlich von den Gebieten weiter im Westen abgrenzte, über die die Chinesen nun keine Kontrolle mehr ausübten. Sie ist das Ergebnis eines Prozesses der Ausdifferenzierung des Grenzgebietes im Südwesten Yunnans in der Ming-Zeit, der nach der anfänglichen Eroberung der Region des Stromschluchtenfächers während der Ära Hongwu mit der Unterscheidung von Gebieten, in denen chinesisches Militär zum Einsatz kam und denen, auf die die Regierung lediglich mit diplomatischen Mitteln Einfluß zu nehmen suchte, begonnen hatte. Durch die Zuweisung eines unterschiedlichen Status in der Verwaltungshierarchie wurde die Entstehung zweier Zonen im Grenzgebiet deutlicher herausgestellt und dieser Entwicklung mit der Errichtung der acht Paßstationen auch ein sichtbares Zeichen gesetzt. ${ }^{449}$

Tabelle 11: Die chinesische Politik gegenüber den tusi-Gebieten nach der Errichtung der acht Paßstationen

\section{Gebiete westlich der Paßstationen (liu wei)}

- Diplomatische Initiativen

- einzelne zeitlich befristete militärische Vorstöße als Reaktion auf Angriffe von Birma

\author{
Gebiete östlich der \\ Paßstationen (san xuan) \\ - Militärische Interventionen \\ - Häufigere Feldzüge zur Nieder- \\ schlagung von ,Rebellionen“ \\ - Unterhalt von Paßstationen und \\ Militärkolonien
}

\footnotetext{
449 Diese Einteilung der tusi-Gebiete in zwei Gruppen und die damit verbundene Abgrenzung von Einflußsphären spiegelt sich auch im Lokalhandbuch von Tengyue wieder. Im TYTZ wird zunächst im Kapitel 8 (Auflistung der Beamten II) auch die Entwicklung der lokalen Sonderverwaltungseinheiten (tusi), der Gebiete im Osten der Paßstationen, beschrieben; die im Westen gelegenen Gebiete hingegen werden erst im Kapitel 15 (Völker der Region) unter der Überschrift ,Grenzen` (bianyi) erörtert. Die Verfasser des TYTZ im 19. Jahrhundert beenden ihre Darstellung der historischen Entwicklung der einzelnen Gebiete jenseits der acht Paßstationen in der vorletzten Dekade der Ära Wanli jeweils mit der Bemerkung, daß das Gebiet für China verloren gegangen war bzw. von Birma erobert worden ist (wang / xian yü Mian) (siehe TYTZ, Kapitel 15, Grenzen [bianyi], S. 239-245). Über die Entwicklung dieser Gebiete in der Zeit der nachfolgenden Qing-Dynastie wird in den fangzhi nicht berichtet, im Gegensatz zu der Darstellung der lokalen Sonderverwaltungseinheiten (tusi) im Osten der acht Paßstationen, die sich auch auf die Zeit der Qing-Dynastie erstreckte (siehe TYTZ, Kapitel 8, Lokale Sonderverwaltungseinheiten [tusi], S. 151-156). Im TYZZ werden beide Gruppen von tusi-Gebieten zusammen im Kapitel 10, ,Grenzschutz‘ (bianfang) erörtert (siehe TYZZ, S. 138-154)
} 
Die Birmanen haben mit ihren Eroberungen den Einflußbereich der Ming auf die innere Zone im Osten der Paßstationen begrenzt, in der diese ihre Oberhoheit auch weiterhin energisch behaupteten.

So entsandte Zhou Jiamu (1546-1629), seit 1608 Nachfolger Chen Yongbins im Amt des Gouverneurs von Yunnan, im Winter 1610/1611 Truppen zur Niederschlagung eines Aufstandes von Duo Anmin, tusi von Longchuan, und ernannte anschließend den jüngeren Bruder des Duo Anmin zum neuen Oberhaupt (xuanfu) von Longchuan. ${ }^{450}$

\section{Die Beschreibung der acht Paßstationen im Reisetagebuch des Xu Xiake}

Der Forschungsreisende Xu Hongzu (1586-1641), besser bekannt unter seinem literarischen Namen Xiake, wurde im Dorf Nanyangqi, in der Nähe von Jiangyin, Provinz Jiangsu, geboren. Als Sohn einer angesehenen und wohlhabenden Familie erhielt er die typische literarische Ausbildung, die ihn auf die staatlichen Beamtenprüfungen vorbereiten sollte. Sein Interesse wandte sich jedoch bald von dem vorgeschriebenen Schulpensum ab, hin zur Geschichte und besonders zur Geographie, mit der er sich sein ganzes Leben lang beschäftigen sollte. Finanziell unabhängig erschien es $\mathrm{Xu}$ wenig erstrebenswert, die Beamtenlaufbahn einzuschlagen, statt dessen widmete er sich auf insgesamt siebzehn Reisen der Erkundung seines Landes. ${ }^{451}$

Xu Xiake hat seine Reisen sorgfältig geplant, indem er Literatur und Karten studierte und sich unterwegs vor Ort aus den Lokalhandbüchern weitere Informationen besorgte.

Er war ein sehr disziplinierter Reisender, der bei Tagesanbruch aufbrach und meist zu Fuß bis zum Abend unterwegs war. Auf seinen Reisen führte Xu sorgfältig Tagebuch, er notierte allabendlich seine Beobachtungen, geographischen Untersuchungen sowie genaue Informationen über Reiseroute und Entfernungen. Allein seine Aufzeichnungen aus Yunnan umfassen 1234 Tage mit durchschnittlich 650 Worten pro Tag.

Mit seiner Reise in den Südwesten Chinas erfüllte sich Xu im Alter von fünfzig Jahren den lange gehegten Wunsch, „, in den Südwesten zu reisen; ich habe aber zwei Jahre vertrödelt,

\footnotetext{
${ }^{450}$ Siehe auch TYTZ, S. 368 und DMB, S. 264.

${ }^{451} \mathrm{Xu}$ Xiake kann als der erste Forschungsreisende Chinas gelten, der aus wissenschaftlichem Interesse Reisen unternahm und nicht nur zum Zeitvertreib oder, wie andere berühmte Reisende vor ihm, in politischer (wie z.B. Zhang Qian, 139-126 v.Chr. und Zheng He, 1405-1433) oder religiöser Mission (wie z.B. Faxian, 399-412, und Xuanzang, 629-645) unterwegs war.

Wichtige Entdeckungen, die Xu Xiake zum Beispiel auf seiner Reise in den Südwesten Chinas machte, waren die Erforschung des Flusses Panjiang in Guizhou, sowie die Feststellung, daß der Jinshajiang der Oberlauf des Yangzi ist und daß es sich bei Lancangjiang (Mekong) und Lujiang (Salween) um zwei verschiedene Flüsse handelt.
} 
nun werde ich immer älter und kann nicht mehr länger warten, so beginne ich meine weite Reise am 17. Oktober [1636]“. 452

Anschließend war er vier Jahre lang im Gebiet der modernen Provinzen Hunan, Guangxi und vor allem in Guizhou und Yunnan unterwegs. Xu Xiake brach zu seiner Reise in den Südwesten in Begleitung zweier Diener und des Mönches Jingwen auf, der den Tempel am Jizushan in der Nähe von Dali besuchen wollte. Ein Diener verließ Xu schon zu Beginn der Reise, Jingwen starb im Herbst 1637, nachdem er bei einem Überfall verwundet worden war. Im September 1639 verließ ihn schließlich auch sein letzter Diener. Xu hatte zwar seine Reise mit reichlich Geldmitteln versehen angetreten, war jedoch unterwegs mehrmals ausgeraubt worden, so war er, als er Yunnan erreichte, völlig mittellos und mußte sogar einige Kleidungsstücke verkaufen. ${ }^{453}$

Seine Reise führte Xu bis in die Region des Stromschluchtenfächers und in das Grenzgebiet zu Birma. Im Jahr 1639 (Chongzhen 12) hielt sich Xu über vier Monate lang in Yongchang auf. Auf seinen Wanderungen durch die Präfektur machte er auch wiederholt in der Stadt Tengyue Station. In seinem Reisetagebuch beschreibt er das Grenzgebiet im Südwesten der Unterpräfektur Tengyue, die Lage der acht Paßstationen und die von ihnen kontrollierten Verkehrswege. Dabei weist er ausdrücklich daraufhin, daß die acht Paßstationen eine Grenze zwischen China und den Gebieten der einheimischen Völker bilden:
„Eine Tages[reise von der Unterpräfekturstadt] nach Süden erreicht man Nandian, dann [geht es weiter] nach Longchuan und Birma. Anderthalb Tage nach Westen erreicht man Guyong gegenüber dem Berg Chashan. ${ }^{454}$ Andert- halb Tage nach Osten erreicht man den Wasserscheiden-Paß (Fenshui guan); dahinter befindet sich Yongchang.
Die acht Paßstationen (ba guan) bilden eine schräge Linie von Nordwest nach Südost. Die vier westlichen Paßstationen unterstehen dem Kommandanten von Manha und heißen von Nord nach Südost: Shenhu, Wanren, Jushi und Tong- bi.Die vier östlichen unterstehen dem Kommandanten von Longba und heißen, von Südwest nach Südost: Tiebi, Huju, Tianma und Hanlong.

\footnotetext{
${ }^{452}$ Li Chi, S. 19, 224

${ }^{453}$ Li Chi, S. 224. Nach einer langwierigen Rückreise erreichte Xu Xiake schließlich Ende 1640 seine Heimat, wo er im folgenden Jahr erschöpft von seiner strapaziösen Reise starb.

${ }^{454}$ Liu Chunming, S. 21: „Das ist das moderne [mit einem anderen Zeichen für gu geschriebene] Guyong. Bereits in der Yuan-Zeit war der Kreis Guyong eingerichtet worden, später kam es zur Präfektur Tengchong (Tengchong fu), in der Ming-Zeit wurde die Paßstation Guyong (Guyong guan) eingerichtet. Heute ist es das Dorf Guyong (Guyong xiang)“; nördlich der Stadt Tengchong gelegen.

Chashan: Im Gebiet der Jingpo-Nationalität von Jingshan nördlich von Guyong.
} 
Jenseits der acht Paßstationen führt die westliche Straße von der Paßstation Shenhu nach Yixi [Mengyang], von wo Bernstein und runde durchbohrte Jadescheiben (biyu) ausgeführt werden. Von der Paßstation Tianma führt die südliche Straße nach Mengmi, wo es Edelsteinminen gibt. Von der Paßstation Hanlong führt die südöstliche Straße nach Mubang, welches Bangyang-Stoffe ausführt. Von der Paßstationen Tiebi führt ein direkter Weg auch auf einer südlichen Straße über Manmo nach Ava in Birma.

Früher waren Manmo und Mengmi sämtlich chinesische Gebiete. Seit im 22. Jahr der Ära Wanli (1594) Qi Wenchang, der Kommandeur des Militärbezirks Jin-Teng, die acht Paßstationen errichteten ließ, gehörten alle einheimischen Völker (yi), die jenseits der Pässe leben, zu Ava.

Geht man von der Unterpräfekturstadt nach Süden, so kommt man nach Nandian, wo sich der Weg teilt: Der westliche [Abzweig] in Richtung Ganya führt zu den Gebirgspässen von Manha, der südliche [Abzweig] in Richtung Longchuan führt zu den Gebirgspässen von Longba.

Geht man von der Bezirksstadt nach Westen, so kommt man nach Mianqing, wo sich der Weg teilt: Der westliche [Abzweig] führt über die Paßstationen Shenhu hinaus nach Yixi, der nordöstliche überquert das Gebirge und führt nach Guyong.

Es ist nun in etwa so, daß die drei Befriedeten Gebiete zu der Zone innerhalb der Pässe gehören (san xuan you shu guan nei), während sich die Sechs Befriedeten Gebiete sämtlich jenseits der Grenze befinden (liu wei suo shu, ju zhi guan wai). So ist die Grenze zwischen China und den einheimischen Völkern eingeteilt worden. Das ist die Aussicht, wenn man von der Stadt [Tengyue] ringsum in die Ferne blickt“. 455

Auch Xu Xiake spricht hier nicht von einer Grenze des Reiches, sondern von einer Grenze der Kulturen bzw. der chinesischen Zivilisation: „So ist die Grenze zwischen China und den einheimischen Völkern eingeteilt worden (sui fen hua yi zhi jie)“.

An anderer Stelle in seinem Reisetagebuch schreibt Xu:

„Tengyue befindet sich in der Nähe der verschiedenen einheimischen Völker, tatsächlich schirmt es den Westen Yunnans ab (Tengyue mier zhu yi, shi Dian

\footnotetext{
${ }^{455}$ Zitiert nach Liu Chunming, Xu Xiake Tengyue youji, S. 17.
} 
xi fan ping). Die allgemeine Lage an der Grenze Yunnans (Dian jing) ist, daß es im Norden an Tibet (Tufan) grenzt, im Süden gehören sämtliche Völker zu Birma, die Regierungsbezirke (junyi), die eingerichtet worden waren, befinden sich zwischen diesen Gebieten, die nur durch die Autorität des Herrschers (shengjiao) im Zaum gehalten werden (jimi)....

Unlängst habe ich jedoch gehört, daß nur noch Nandian, Ganya und Longchuan [von China] beherrscht werden (ting yue shu zhi wei Nandian, ...)“. ${ }^{456}$

An dieser Stelle hebt Xu Xiake die Existenz einer Grenze südwestlich der Unterpräfektur Tengyue ausdrücklich hervor und macht deutlich, daß es sich hierbei auch um eine politische Grenze handelt: „Im Süden gehören sämtliche Völker zu Birma“ (jie yi Mian). $\mathrm{Xu}$ hat sich auf seinen Wanderungen selbst von der Lage im Grenzgebiet überzeugt. In seinen Aufzeichnungen erwähnt er auch häufig Gespräche mit Einwohnern von Tengyue, zum Beispiel mit dem Regionalkommandanten Wu, in dessen Haus Xu Xiake eine Karte mit einer Darstellung der Region (ba guan, san xuan, liu wei tu) gezeigt bekommen hat, die er sich „Punkt für Punkt kopierte“. ${ }^{457}$ Seine Beschreibung spiegelt so sicherlich Vorstellungen wieder, die sich die Menschen in Tengyue zu dieser Zeit von der Existenz der Grenze gemacht haben.

\section{Die Stadt Tengyue zur Zeit der Ära Wanli}

Die Geschichte des Grenzgebietes in der späten Ming-Zeit und besonders der Ära Wanli (1573-1620) ist geprägt von den Kämpfen zwischen den verschiedenen Kleinstaaten sowie Birma und China, die auch die Sicherheit der Unterpräfektur Tengyue bedrohten. Diese werden in den fangzhi ausführlich dokumentiert, das zivile Leben in der Stadt Tengyue zu dieser Zeit findet daneben kaum Berücksichtigung. Doch verweist die Darstellung der militärischen Aktivitäten zumindest indirekt auf deren Auswirkungen auf die Bevölkerung. Soldaten, die in der Region operierten, mußten dort stationiert und verpflegt werden. Die Hauptlast dieser Versorgung hatte ohne Zweifel die gesamte Präfektur Yongchang zu tragen. Andererseits stellte die Regierung Finanzmittel für die Feldzüge zur Verfügung, die in der Region des Stromschluchtenfächers zum Ankauf von Lebensmitteln usw. verwendet wurden, so daß die Anwesenheit der Truppen sich teilweise durchaus als profitabel erwies.

\footnotetext{
${ }^{456}$ Jin Teng zhu yi shuo lüe, Zhu Huirong, S. 1130; Ding Wenjiang, Xu Xiake youji (Dian you riji) Kapitel 11

${ }^{457}$ Liu Chunming, S. 103
} 
Auch zusätzliche Bauprojekte, die in Zusammenhang mit der Anwesenheit des Militärs standen, wurden durchgeführt. So ließ Unterpräfekt Yu Maoxue (1587-1599 in Tengyue tätig) für den Regionalkommandanten Deng Zilong nahe der Stadt die Residenz Wanhuaguan errichten, zu der auch eine Gartenanlage gehörte, in der sich „Pavillons,Teiche, Obstgärten, Stein[formationen] befanden; es gab dort Bambus[haine], Bäume, Blumen, Vögel und Fische“. ${ }^{458}$ Der gesamte Komplex wurde im Jahr 1592 fertiggestellt. ${ }^{459}$

Die Entsendung von Palasteunuchen zum Erwerb von Edelsteinen bedeutete eine Belastung für die Bevölkerung. Die Eunuchen, die in die Provinzen reisten, wurden von einem großem Gefolge begleitet, das mehrere hundert Personen umfassen konnte. ${ }^{460}$ Wie die Einheimischen die Anwesenheit der kaiserlichen Abgesandten empfanden, hat Zhang Han in seiner Ballade aus der Zeit der Ära Jiajing zum Ausdruck gebracht, indem er sie mit gefährlichen Raubtieren verglich:

„Auf der Poststraße und in den staatlichen Rasthäusern gibt es viele Tiger und Panther. Sobald die kaiserlichen Aufkäufer ihre Fahnen entrollen, beginnt selbst das Gebirge zu erzittern“. ${ }^{461}$

Dabei war man in Tengyue aufgrund der geographischen Nähe zu den Herkunftsorten der edlen Steine noch am ehesten in der Lage auf Vorräte zurückzugreifen, um die geforderten Quoten zu erfüllen.

„Im 23. Jahr (1595) befahl Kaiser Shenzong, daß die Provinz Yunnan über 200 jin [ca. 100 kg] Bernstein zu liefern habe. Die Beamten in Yunnan verteilten diese Menge auf die Präfekturen, Unterpräfekturen und Kreise des westlichen Yunnan. Doch nur im Depot von Tengchong gab es etwas mehr als 20 jin. [Dort] konnte [man das Soll] gerade noch mühsam erfüllen, die restlichen Unterpräfekturen und Kreise konnten dem Befehl nicht nachkommen. Die lokalen Beamten preßten daraufhin die Bevölkerung aus, dies führte dazu, daß Bernstein zu dieser Zeit sehr teuer war. Die einfachen Leute mußten deswegen oft ihre Familien zugrunde richteten und trotzdem konnte die Quote nicht erfüllt werden“. ${ }^{462}$

\footnotetext{
${ }^{458}$ Wanhuaguan ji (,Notiz zum Wanhuaguan`) von Qi Wenchang, Präfekt von Yongchang (TYTZ, S. 287).

459 TYTZ, S. 287. Siehe auch TYTZ, S. 77: Dort wird das Datum der Fertigstellung des Wanhuaguan mit Wanli 21 (1593) angegeben. Zur Zeit der Herausgabe des TYTZ Ende des 19. Jahrhunderts existierte die Anlage nicht mehr (ebd.). ${ }^{460}$ Tsai, S. 183

461 Zhang Han in seiner Ballade Baojing yao (TYZZ, S. 47; TYTZ, 360).

${ }^{462}$ You Zhong, S. 421; siehe auch Zhuge Yuansheng, Dian shi (juan 13).
} 
Die Kämpfe um die Vorherrschaft im Grenzgebiet konzentrierten sich auf die Region jenseits der Paßstationen, gelegentlich griffen die Unruhen auch auf das Gebiet von Longchuan in der Unterpräfektur über, die Stadt Tengyue selbst war jedoch nur indirekt davon betroffen. Eine sehr viel unmittelbarere Gefahr bedeutete für die Bevölkerung die Lage der Stadt in einem Erdbebengebiet. Allein während der Ära Wanli (1573-1620) ereigneten sich in Tengyue elf Erdbeben, mit Stärken bis zu $6 \frac{1}{1 / 2}$ auf Richterskala, die Teile der Stadtmauern zum Einsturz brachten, Häuser und Tempel zerstörten, Erdrutsche auslösten, Überflutungen verursachten und zahlreiche Menschen das Leben kosteten. ${ }^{463}$ Zudem sorgten Monsunregenfälle im Herbst häufig für Hochwasser und Überschwemmungen, die die Ernten vernichteten. Die Folge dieser Naturkatastrophen waren Mißernten und Hungersnöte im Gebiet der Unterpräfektur.

Tabelle 12: Naturkatastrophen in Tengyue zur Zeit der Ära Wanli (1573-1620) ${ }^{464}$

$\begin{array}{clll}\text { Wanli } 4(1576) & \text { Erdbeben } & \text { Wanli } 19(1591) & \text { Erdbeben } \\ \text { Wanli } 5(1577) & \text { Erdbeben } & \text { Wanli } 20(1592) & \text { Mißernte } \\ \text { Wanli } 9(1581) & \text { Erdbeben } & \text { Wanli } 27(1599) & \text { Überschwemmungen, Erdbeben } \\ \text { Wanli } 12(1584) & \text { Mißernte } & \text { Wanli } 28(1600) & \text { Überschwemmungen } \\ \text { Wanli } 13(1585) & \text { Erdbeben } & \text { Wanli } 31(1603) & \text { Mißernte, Überschwemmungen } \\ \text { Wanli } 14(1586) & \text { Erdbeben } & \text { Wanli } 36(1608) & \text { Erdbeben } \\ \text { Wanli 15(1587) } & \text { Mißernte, Erdbeben } & \text { Wanli } 45(1617) & \text { Erdbeben } \\ \text { Wanli 16(1588) } & \text { Erdbeben } & & \end{array}$

Naturphänomene wurden von den Chinesen als glückversprechende oder besorgniserregende Vorzeichen aufgefaßt, die in Beziehung zu den politischen Entwicklungen in der Region gesetzt wurden und so noch zusätzlich an Bedeutung gewannen. Die Herausgeber der fangzhi haben diese Naturereignisse entsprechend in einem eigenen Abschnitt unter dem Titel ,Omina‘ (xiangyi) aufgezeichnet, wo sie gegebenenfalls die Geschehnisse vermerken, die von ihnen angekündigt worden sein sollten. ${ }^{465}$

So wird zum Beispiel der Eintrag zum Erdbeben von 1577 und dem Erscheinen eines Kometen (huixing) im selben Jahr, „der den Himmel im Südwesten erhellte“ (xi’nan guang mang zhu tian) mit der Anmerkung versehen, daß die „birmanischen Banditen [aus dem Südwesten] danach das Grenzgebiet überfallen haben“ (hou Mian kou fan bian). ${ }^{466} 1577$

463 TYTZ, S. 28-29; Gu Gongxu, S. 788

464 TYTZ, S. 28-29; YCFZ, 32-33

465 TYTZ, S. 28-30; YCFZ, S. 30-34

${ }^{466}$ TYTZ, S. 28. Im YCFZ (S. 32) heißt es in diesem Zusammenhang sogar ausdrücklich, daß die Birmanen Tengyue überfallen hätten (fan Tengyue). 
war das Jahr, in dem der chinesische Kaufmann Yue Feng die Herrschaft über Longchuan übernommen und sich mit den Birmanen verbündet hatte; der gemeinsame Vorstoß ihrer Truppen hatte eine ernste Bedrohung auch für die Stadt Tengyue dargestellt.

Die sorgfältige Auflistung und Interpretation der Naturkatastrophen unterstreicht die unruhige Lage im Grenzgebiet während der Ära Wanli und spiegelt die Ängste der Bevölkerung in einer von kriegerischen Auseinandersetzungen bestimmten Zeit wider.

\section{Die Entwicklung des Schulwesens in Yunnan}

Als Beispiel für das zivile Leben in dieser von Kriegen und Naturkatastrophen geprägten Epoche wird im Folgenden die Entwicklung des Schulwesens in Tengchong/Tengyue vorgestellt. Dies wird in den fangzhi von Tengyue jeweils in einem eigenen Kapitel ausführlich beschrieben und beginnt mit einem Hinweis auf die historische Entwicklung des Schulwesens im Gebiet der Provinz Yunnan. ${ }^{467}$

In dem von Unterpräfekt Tu Shulian (1787-1791 in Tengyue tätig) verfaßten und im TYZZ abgedruckten historischen Abriß heißt es, daß das staatliche chinesische Bildungswesen in Yunnan bereits während der Han-Zeit, im 2. Jahrhundert v. Chr. seinen Anfang genommen hatte:

„Es hat sich im fernen Südwesten allmählich zu entwickeln begonnen, nachdem [der Dichter] Sima Xiangru dorthin gekommen war und viele Gelehrte seinem Beispiel gefolgt waren, so daß auch der entlegene Süden allmählich Kenntnis von der Existenz des Schulwesen erhalten hatte (nan huang jian zhi уои хие)“. 468

Und auch einige Jahrhunderte später, so Tu Shulian, waren im Hoheitsgebiet der Königreiche von Nanzhao und Dali immerhin die Nachkommen der Herrscher chinesischkonfuzianisch unterrichtet worden, so wie zum Beispiel Yimouxun (754-808) von Zheng

\footnotetext{
${ }^{467}$ Im 10. Kapitel des TYTZ wird das Schulwesen der Stadt Tengyue in den vier Abschnitten Tempelschule (miaoxue), Studentenkontingent (хиеe), Akademien (shuyuan) sowie Freischulen (уіхие) beschrieben (TYTZ, S. 163-174). Das von Tu Shulian verfaßte Kapitel über das Bildungswesen im TYZZ (Kapitel 6) enthält die Abschnitte Schultempel (xuegong), Gemeindeschulen (shexue), Freischulen (yixue), Akademien (shuyuan) und Lehrfächer (kegong) (TYZZ, S. 72-76). Siehe auch YCFZ, Kapitel 23-24, S. 106-115; Kapitel 39-40, S. 202-221.

${ }^{468}$ TYZZ, S. 72. Im TYTZ (S. 163) heißt es: „Der entlegene Süden erhielt allmählich Kenntnis von den Schulprüfungen im Fach Kanonische Bücher“ (nanhuang jian zhi you xuejiu).

Sima Xiangru (179-117 v.Chr.) stammte aus Shu (der modernen Provinz Sichuan); er war ein berühmter Dichter, dessen Stil die Gattung der cifu (lyrische Essays) entscheidend prägte. Während seiner Tätigkeit als Minister wurde er von Kaiser Wudi (140-86 v.Chr.) als Gesandter in den Südwesten geschickt (siehe ZGRMDCD, S. 121).
} 
Hui, einem in Nanzhao in Kriegsgefangenschaft gerateten chinesischen Beamten. ${ }^{469}$ Obwohl die Region zu jener Zeit von unzivilisierten Menschen erobert gewesen sei (xian yu hua wai), habe es doch bereits chinesische kulturelle Einflüsse (you huafeng) gegeben, die zumindest die Elite haben prägen können. ${ }^{470}$ Die Formulierungen des Textes von Unterpräfekt Tu lassen deutlich sein Bemühen erkennen, den fernen Südwesten des chinesischen Reiches auch in dieser frühen Zeit nicht als ein völlig kulturloses Gebiet (d. h. ohne Hanchinesische Kultur) erscheinen zu lassen. ${ }^{471}$

Die Entwicklung eines staatlichen Schulwesens nach dem Vorbild des chinesischen Kernlandes begann in Yunnan zur Zeit der Mongolenherrschaft. Bereits während der Amtszeit des Gouverneurs Sayyid Ajall in den Jahren 1274 bis 1279 wurden Konfuziustempel errichtet. Aufgabe dieser Schulen sollte es sein, konfuzianisches Gedankengut zu vermitteln, um die einheimischen Sitten zu verändern, sie an die Han-chinesischen anzugleichen und so dazu beizutragen, die Herrschaft der Zentralregierung über die verschiedenen Völker Yunnans zu festigen. ${ }^{472}$

In den Tempelschulen waren Gelehrte aus Sichuan als Lehrer tätig (yi Shu shi chong jiao guan); hauptsächlich in den Gebieten der Bai- und Yi-Nationalitäten in Zentral-Yunnan, aber auch generell in allen Verwaltungseinheiten (lu, fu, zhou, xian), in denen Schulen gegründet worden waren und auch in der Sonder-Präfektur Yongchang im äußersten Westen der Provinz. ${ }^{473}$ In der Sonder-Präfektur (fu) Tengchong hingegen war zu dieser Zeit, wie Tu Shulian bedauernd feststellt, „,noch kein [Schultempel] errichtet worden““ ${ }^{474}$

\section{1. Die Entwicklung des Schulwesens in Yongchang}

Dauerhaften Anschluß an das chinesische Schulwesen fand die Region des Stromschluchtenfächers erst im Verlauf der Ming-Zeit. Auf der Hochebene von Yongchang wurde schon

\footnotetext{
${ }^{469}$ TYZZ, S. 72. Zheng Hui stammte aus Xiangzhou (dem modernen Anyang in der Provinz Henan). Er war während der Ära Tianbao (742-756) der Tang-Dynastie als Kreismagistrat (xianling) von Xilu in Xizhou tätig. Im ersten Jahr der Ära Zhide (756) geriet er in Kriegsgefangenschaft von Nanzhao. Da er ein gelehrter Konfuzianer war, erlangte er die Hochachtung König Kolofengs und erhielt von diesem den Namen Manli (die chinesischen Zeichen des Namens bedeuten übersetzt „zum Nutzen der Barbaren“). Er wurde beauftragt, die Nachkommen des Königshauses zu unterrichten, auch der Enkel Kolofengs, Yimouxun studierte bei ihm. Nachdem Yimouxun den Thron bestiegen hatte, ernannte er Zheng zum Kanzler (qingpingguan). Während seiner Amtstätigkeit förderte Zheng das Bündnis zwischen den Tang und Nanzhao (ZGRMDCD, S. 410).

${ }_{470}$ TYZZ, S. 72

${ }^{471}$ Auch die Herausgeber des YCFZ legen Wert darauf zu erwähnen, daß es in der Region des Stromschluchtenfächers bereits zur Zeit von Nanzhao chinesischen Unterricht gegeben hat, dieser sei allerdings nur sehr rudimentär ausgefallen (you jiao Zhongguo zhi xиe xi pilou), da es unter den Einheimischen niemanden gegeben habe, der die klassischen Schriften hätte erläutern können (YCFZ, S. 278).

${ }^{472}$ You Zhong, S. 294

${ }^{473}$ Ebenda. YCFZ, S. 106 (miaoxue - xianshi miao).

${ }^{474}$ TYZZ, S. 72
} 
kurze Zeit nach der Eroberung Yunnans durch die Truppen der Ming im Jahr 1382 (Hongwu 15) wieder ein Schultempel (xianshimiao) gegründet. Die Schule, die während der Yuan-Zeit im 13. Jahrhundert errichtet worden war, existierte zu diesem Zeitpunkt nicht mehr und auch der neue Schultempel wurde während der militärischen Auseinandersetzungen in der Region in den folgenden Jahren wieder zerstört. Nichtsdestoweniger wurde im Jahr 1394 der Hanlin-Akademiker Yu Zixi nach Yongchang geschickt, um „die Kinder der Militär- und Zivilbevölkerung zu unterrichten“ (wu zhi jun min); eine Tätigkeit, die Yu bis zum Jahr 1419 ausübte. ${ }^{475}$

Die Gründung des Schultempels stand in enger Beziehung zu den militärischen Vorstößen in das Grenzgebietes. Sobald die Ming-Truppen auf die Hochebene von Yongchang vorgerückt waren, wurde dort ein Schultempel errichtet und so in den neugegründeten Verwaltungseinheiten neben dem Anspruch auf militärische Vorherrschaft auch ein Grundstein für die Entwicklung des zivilen Lebens nach dem Vorbild des chinesischen Kernlandes gelegt und damit wiederum der Anspruch auf eine dauerhafte Vorherrschaft untermauert. Ebenso mobilisierten die Ming Mitte des 15. Jahrhunderts, als die Expansion des tusi von Luchuan auch Yongchang bedrohte, nicht nur Truppen, sondern führten Baumaßnahmen durch, die nicht allein der Befestigung ihres Stützpunktes dienten, sondern auch die auf Dauer angelegte Anbindung der Region an die Strukturen des Kernlandes zum Ausdruck brachten: So gründeten der Vize-Minister Yang Ning und der Oberkommandierende der Truppen Mu Bin im Verlauf der Feldzüge gegen Luchuan im Jahr 1444 in Yongchang wieder eine Schule, die entsprechend der nunmehr als lokale Militärkommandantur Jinchi bezeichneten Verwaltungseinheit als Kommandanturschule Jinchi (Jinchi sixue) bezeichnet wurde. ${ }^{476}$

Der militärischen Expansion der Ming folgend, verbreitete sich auch das Schulwesen in der Provinz Yunnan von Osten nach Westen. Dies wird besonders deutlich im Vergleich der Anzahl der Graduierten der Staatsprüfungen in der Hauptstadt (jinshi), die als Inhaber des höchsten akademischen Grades, als Zeichen für ein erfolgreich etabliertes Schulwesen in ihren jeweiligen Heimatpräfekturen gelten können.

\footnotetext{
${ }^{475}$ YCFZ, S. 106

${ }^{476}$ YCFZ, S. 106. Diese wurde nach der Einführung der Präfektur Yongchang im Jahr 1524 (Jiajing 3) in Präfekturschule (fuxue) umbenannt (ebd.).
} 


\title{
Tabelle 13: Die Anzahl der jinshi in ausgewählten Präfekturen
}

\author{
der Provinz Yunnan in der Ming-Zeit ${ }^{477}$
}

$\begin{array}{lc}\text { Präfektur (fu) } & \text { Gesamtzahl der jinshi } \\ \text { Yunnan } & 63 \\ \text { Qujing } & 11 \\ \text { Lin'an } & 53 \\ \text { Guangxi } & 1 \\ \text { Chuxiong } & 4 \\ \text { Yaoan } & 2 \\ \text { Chengjiang } & 3 \\ \text { Dali } & 45 \\ \text { Heqing } & 17 \\ \text { Yongchang } & 21(26)^{478} \\ \text { Menghua } & 7 \\ \text { Gesamt } & \mathbf{2 2 7}\end{array}$

Die meisten jinshi kamen aus den Präfekturen in Zentral-Yunnan. Die deutlich größte Gruppe (insgesamt 134 jinshi) stammte aus der Region um die Provinzhauptstadt: Aus Yunnan fu (63 jinshi) und den angrenzenden Präfekturen Qujing, Chuxiong, Chengjiang sowie Lin’an (zusammen 71 jinshi). Die Zahlen unterstreichen die Abhängigkeit der Bildungseinrichtungen von ihrem Umfeld. So ist es kein Wunder, daß die meisten jinshi aus den Verwaltungs- und Wirtschaftszentren der Provinz kamen: Neben der Provinzhauptstadt auch aus Lin’an und aus der Region um Dali (aus der weitere 71 jinshi stammten). ${ }^{479}$ Die Entwicklung des Schulwesens in Yunnan in der Ming-Zeit entsprach der geographischen Ausbreitung der Strukturen des Kernlandes und hat sich ebenso wie die administrativen und wirtschaftlichen Zentren entlang der Hauptverkehrswege der Provinz entwickelt: Entlang der westlichen Handelsroute von der Provinzhauptstadt nach Dali und Yongchang sowie der südlichen Route über Lin’an nach Annam (Vietnam) (siehe Karte 9, S. 176). ${ }^{480}$

\footnotetext{
${ }^{477}$ Nach den Angaben des Ming-Qing jinshi timinglu suoyin; zitiert nach Lan Yong, Xinan lishi wenhua dili, S. 111112, biao 4-11 (Ming dai Yunnan jinshi fenbubiao).

${ }^{478}$ Im YCFZ werden abweichend insgesamt sechsundzwanzig jinshi der Präfektur Yongchang in der Ming-Zeit aufgelistet (YCFZ, S. 202-203).

${ }^{479}$ Die Region Dali umfaßt hier die Präfekturen Dali (45 jinshi), Yaoan (2), Heqing (17) und Menghua (7).

${ }^{480}$ Eine Ausnahme bildet die Präfektur Chuxiong, zwischen Yunnan und Dali zentral gelegen und etwa ebenso groß wie diese Präfekturen. Aus ihr sind jedoch lediglich vier jinshi hervorgegangen. Zwar entwickelten sich in der Präfektur eine florierende Bergbauindustrie sowie die Salzgewinnung, als adminstrative Einheit stand sie jedoch in ihrer Bedeutung deutlich hinter den beiden benachbarten Verwaltungszentren Yunnan fu und Dali zurück.
} 
Die Präfektur Yongchang steht nach Yunnan, Lin'an und Dali an vierter Stelle, was die Anzahl der aus ihr hervorgegangenen jinshi betrifft. Mit einundzwanzig bzw. sechsundzwanzig erfolgreichen Prüfungsabsolventen hebt sie sich deutlich ab von den anderen sieben genannten Präfekturen, die nur einen bis elf Graduierte aufzuweisen haben. Zwar umfassen diese zum Teil erheblich kleinere Gebiete, die jedoch zentraler gelegen sind.

Zahlenmäßig liegt Yongchang die Präfektur Heqing (nördlich von Dali) am nächsten. Auch diese ist deutlich kleiner als Yongchang, liegt aber ebenfalls an einem wichtigen Verkehrsweg, der Handelsstraße nach Tibet.

Karte 9: Die Verbreitung des staatlichen Bildungswesens in Yunnan in der Ming-Zeit (Karte nach Lan Yong, Xinan lishi wenhua dili, Karte 4-4, Ming dai Yunnan jiaoyu fazhan shuiping tu)

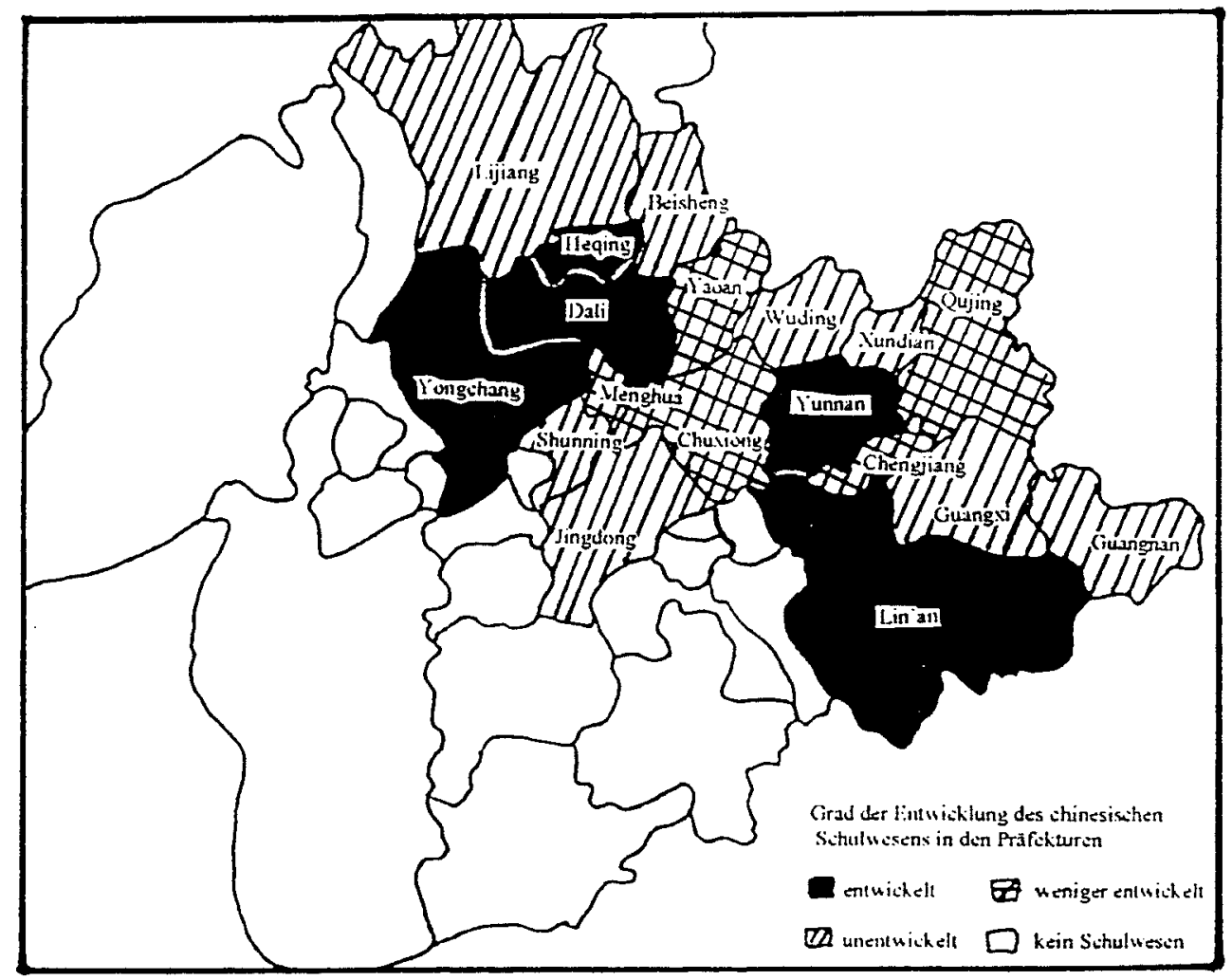

Die Verbreitung des Schulwesens in Yunnan unterstreicht, in welchen Teilen der Provinz die Strukturen des chinesischen Kernlandes erfolgreich etabliert worden sind. In Abgrenzung zu Verwaltungseinheiten, die eine weitere Gruppe von Präfekturen, Unterpräfekturen und tusi-Gebieten an der Peripherie Yunnans bilden, in denen ein chinesisch-konfuzianisches Schulwesen gar nicht etabliert worden ist bzw. nur wenig entwickelt war. Deutlich wird die besondere Position der Präfektur Yongchang und parallel dazu die der Präfektur 
Lin'an, die von Zentralchina aus betrachtet jenseits der beiden wichtigsten Verwaltungszentren der Provinz (Dali und Yunnan fu) liegen, an den Hauptverkehrswegen, die in Gebiete von Zentralstaaten jenseits des direkten Einflußbereiches der Ming (Birma und Annam) führen. Beide Präfekturen weisen ein entwickeltes Schulwesen auf, daß die Anbindung dieser Randgebiete an das Kernland hervorhebt.

\section{2. Das Schulwesen in Tengchong/Tengyue in der Ming-Zeit}

Tengchong erhielt seine erste staatliche Schule fünfundzwanzig Jahre nachdem dort eine Militärkommandantur gegründet und mit einer Mauer befestigt worden war. Da die Bevölkerung danach durch Zuwanderer aus Jiangnan weiter zunahm, ersuchte Garnisonskommandant (zhihui tongzhi) Chen Jianqing im 1471 (Chenghua 7) um die Genehmigung zur Gründung einer Schule. Im selben Jahr wurde mit dem Bau des Schultempels (xianshimiao) begonnen, der im Jahr 1485 vollendet wurde; die Tengchong sixue begann Schüler aufzunehmen. ${ }^{481}$ Als zu Beginn der Ära Jiajing (1522-1567) die Unterpräfektur Tengyue eingerichtet wurde, wurde die Schule im selben Jahr entsprechend in eine Unterpräfekturschule (zhouxue) umbenannt. ${ }^{482}$

Neben der Schule im Konfuziustempel wurde innerhalb der Stadtmauern von Tengyue auch eine Akademie (shuyuan) errichtet: Zhao Jiong, der Kommandeur des Militärbezirks Jin-Teng, veranlaßte während der Ära Hongzhi (1488-1506) die Gründung der XiufengAkademie. $^{483}$

Für die Angleichung des Unterrichts an das Niveau der staatlichen Schulen des Kernlandes sorgten, wie Tu Shulian mit Genugtuung vermerkt,

„Beamte, die aus Zentralchina (zhongtu) nach Yunnan berufen wurden. Unter den Lehrern und Konfuzianern (shi ru), die hierherkamen, waren auch viele Gelehrte aus Chu und Shu, die seit jeher als vortrefflich, begabt und belesen galten“. ${ }^{484}$

\footnotetext{
${ }^{481}$ TYTZ, S. 163, 144; TYZZ, S. 72

${ }^{482}$ Abweichend davon heißt es im YCFZ (S. 109), daß die Schule erst im Jahr Jiajing 3 (1524) umbenannt worden ist.

483 TYTZ, S. 166; YCFZ, S. 174-175. Während der Ming-Zeit gab es in Tengyue noch eine zweite Akademie, die Chunqiu shuyuan, zu der die fangzhi jedoch keine weiteren Angaben enthalten.

${ }^{484}$ TYZZ, S. 72. Chu und Shu sind andere Bezeichnungen für die Gebiete der modernen Provinzen Hubei (das Huguang der Ming-Zeit) und Sichuan.
} 
Im Jahr 1486 (Chenghua 22) war zunächst ein Vize-Direktor (xundao) mit der Leitung des Schulbetriebes betraut worden. Ein erster Direktor (jiaoshou) für die Schule im Konfuziustempel wurde in Tengchong im Jahr 1516 ernannt. Im Jahr 1529 wurde dessen Amtsbezeichnung in xuezheng abgeändert. In der Ming-Zeit hatten insgesamt fünfundzwanzig Beamte diesen Posten inne, darunter waren zweiundzwanzig Absolventen der Staatsuniversität (gongsheng) und ein Graduierter der Provinzprüfungen (juren). ${ }^{485}$

Die ersten Direktoren stammten aus der Provinz Guizhou; im Jahr 1563 wurde zum ersten Mal ein Beamter aus Yunnan in dieses Amt eingesetzt. Von den fünfzehn während der Ära Wanli (1573-1620) in Tengyue tätigen Direktoren stammten neun aus der Provinz Yunnan. ${ }^{486}$ Aus den von Tu Shulian genannten Regionen ,Chu und Shu' waren während der gesamten Ming-Zeit tatsächlich nur einer bzw. drei der Beamten gekommen, die meisten Direktoren stammten hingegen aus Yunnan selbst sowie aus dessen Nachbarprovinz Guizhou. Im Jahr 1574 kam erstmals ein Direktor aus dem nördlichen China, aus Beizhili (im Gebiet der modernen Provinz Hebei), nach Tengyue.

Tabelle 14: Heimatregionen der Direktoren (xuezheng) von Tengchong/Tengyue in der Ming-Zeit im Vergleich mit der Präfektur Yongchang ${ }^{487}$

$\begin{array}{lrll}\text { Tengchong/Tengyue } & \text { Yongchang } \\ \text { Yunnan } & 11 & \text { Yunnan } & 6 \\ \text { Guizhou } & 6 & \text { Guizhou } & 3 \\ \text { Sichuan } & 3 & \text { Huguang } & 2 \\ \text { Beizhili } & 1 & \text { Sichuan } & 1 \\ \text { Huguang } & 1 & \text { Shaanxi } & 1 \\ & & \text { Zhejiang } & 1 \\ & & \text { Jiangxi } & 1 \\ \text { Keine Angabe } & 3 & \text { Keine Angabe } & 5 \\ \text { Gesamt } & \mathbf{2 5} & \text { Gesamt } & \mathbf{2 0}\end{array}$

Im Vergleich mit der Präfektur Yongchang fällt auf, daß zwar auch dort die meisten Direktoren aus Yunnan kamen, ihre Anzahl aber nur etwas mehr als ein Drittel der Gesamtzahl ausmachte, während in Tengyue beinahe die Hälfte aller Schulleiter aus dieser Provinz selbst stammte. Auch in Yongchang folgten an zweiter Stelle nach Yunnan die

\footnotetext{
485 TYTZ, S. 113. Zum akademischen Status der zwei verbleibenden Direktoren werden keine Angaben gemacht.

${ }^{486}$ Zwei weitere stammten aus Guizhou, zwei aus Sichuan, je einer aus Beizhili und Huguang (TYTZ, S. 113). Der juren Yang Zhouyan, der während der Ära Wanli als Direktor in Tengyue tätig war stammte aus Yunnan, aus Dengchuan (Präfektur Dali) (ebd.).

${ }^{487}$ TYTZ, S. 113, YCFZ, S. 174-175 (im YCFZ sind die Direktoren unter der Rubrik jiaoshou ohne Angaben zu ihrem akademischen Status und dem Jahr ihres Amtsantrittes aufgeführt).
} 
Beamten aus der Nachbarprovinz Guizhou, deren Anzahl sich jedoch nicht mehr ganz so stark von denen aus anderen Provinzen abhob, wie dies in Tengyue der Fall war, wo die Heimatprovinzen Yunnan und Guizhou deutlich dominieren, während bei den Direktoren in Yongchang die Anzahl der einzelnen Heimatprovinzen, deren literarische Traditionen sie in den Südwesten mitbrachten, insgesamt größer war.

Die offizielle Anerkennung und Unterstützung des Bildungswesens in Yongchang und Tengyue zeigt sich in der Zulassung von Studenten zu den staatlichen Prüfungen und in der Vergabe von staatlichen Stipendien.

Kandidaten aus der Präfektur Yongchang waren durch einen kaiserlichen Erlaß aus dem Jahr 1450 (Jingtai 1), sechs Jahre nach der Gründung der staatlichen Schule, zu den Provinzprüfungen (xiangshi) in Yunnan zugelassen worden. Gleich im Jahr der Zulassung erlangten die ersten beiden Kandidaten aus Yongchang den juren-Titel.Der erste Absolvent der höchsten Staatsprüfungen aus Yongchang, Wen Shu, stammte aus der Umgebung der Präfekturstadt, aus dem Kreis Baoshan, und erhielt den jinshi-Titel im Jahr 1466. ${ }^{488}$

Erste staatliche Studienstipendien (linshan) wurden während der Ära Tianshun (14571465) nach Yongchang vergeben. ${ }^{489}$

In Tengchong gab es seit 1485, dem Jahr, in dem der Schultempel fertiggestellt wurde, Regierungsstipendiaten.

Im Jahr 1489 (Hongzhi 2) erhielten zum ersten Mal zwei Kandidaten aus Tengchong nach bestandener Provinzprüfung den Titel des juren.

Daß bereits an der Wende zum 16. Jahrhundert traditionelle Bildungsinhalte des Kernlandes vermittelt wurden, zeigt auch das Beispiel des Gelehrten Yi Yizhi. Der Mann aus Tengchong hatte im Jahr 1507 die staatlichen Beamtenprüfungen auf Provinzebene mit der Erwerb des juren-Titels abgeschlosssen. Anschließend war er zunächst als Schuldirektor tätig, ehe er zum Kreismagistraten von Changshou (Provinz Sichuan) befördert wurde. Da er mit seinen Vorgesetzten in Regierungsfragen nicht übereinstimmte, gab er sein Amt auf

\footnotetext{
${ }^{488}$ YCFZ, S. 202. Der letzte der jinshi aus Yongchang in der Ming-Zeit, Gong Ding aus Baoshan, erwarb seinen Titel im Jahr 1643 (Chongzhen 26) (YCFZ, S. 203).

Die jinshi aus der Präfektur Yongchang in der Ming-Zeit / nach Jahrgängen (YCFZ, S. 202-203):

Ära Chenghua (1465-1488)

Ära Hongzhi (1488-1506)

Ära Zhengde (1506-1522)

Ära Jiajing (1522-1567)

${ }^{489}$ YCFZ, S. 134

$\begin{array}{lr}\text { Ära Wanli (1573-1620) } & 7 \\ \text { Ära Taichang (1620-1621) } & - \\ \text { Ära Tianqi (1621-1628) } & 2 \\ \text { Ära Chongzhen (1628-1644) } & 4 \\ \text { Gesamt } & \mathbf{2 6}\end{array}$
}


und kehrte in seine Heimat zurück, wo er sich am Longchuanjiang ansiedelte. Er verstand es, „,alte und neue Angelegenheiten vortrefflich zu erläutern“ und „wurde von der Bevölkerung deshalb sehr geschätzt“; Yi Yizhi verfaßte 1512 das erste Lokalhandbuch von Tengchong und verschiedene andere Bücher, darunter einen Kommentar zu den ,Vier Büchern` (Sishu yinyi), eine Ausgabe der Standardwerke der Frühlings- und Herbst-Periode (Chunqiu jingzhuan) sowie kritische Ausgaben alter und neuer Gedichte. ${ }^{490}$

Mehr als achtzig Jahre nachdem erstmals Männer aus Tengchong bei Provinzprüfungen erfolgreich waren, schloß Chen Yidian, der 1570 den Titel eines juren erworben hatte, im Jahr 1571 als erster Kandidat aus Tengyue die Prüfungen in der Hauptstadt mit Erhalt des jinshi-Titels ab. ${ }^{491}$

Erst am Ende der Ming-Zeit erlangten noch zwei weitere Prüfungskandidaten aus Tengyue diesen höchsten akademischen Titel: Die Brüder Hu Lian und Hu Xuan, jinshi in den Jahren 1628 (juren 1621) bzw. 1634 (juren 1630). ${ }^{492}$

Hingewiesen sei auch auf die beruflichen Tätigkeiten, die die drei jinshi aus Tengyue nach ihrem erfolgreichen Abschluß ausübten: Chen Yidian und Hu Lian traten beide Posten in der Hauptstadt als Vize-Direktoren eines Büros in einem der Sechs Ministerien (yuanwai lang) mit dem Rang 5b an, während Hu Xuan ebendort als Vize-Direktor im Amt für die Verwaltung des kaiserlichen Marstalls (taipusi lang) tätig war. ${ }^{493}$

Auffällig ist der große zeitliche Abstand von beinahe sechzig Jahren, der zwischen dem Erwerb des jinshi-Titels durch Chen Yidian im Jahr 1571 und denen der Brüder Hu in den Jahren 1628 und 1634 lag. Im selben Zeitraum von 1571 bis 1628 absolvierten hingegen insgesamt elf Kandidaten aus anderen Gebieten der Präfektur Yongchang die jinshiPrüfungen in der Hauptstadt. ${ }^{494}$

Studenten aus Tengyue hatten in dieser Zeit weiterhin an den Prüfungen auf Provinzebene teilgenommen (s.Tab.15, S.181). Zur Zeit der Ära Wanli (1573-1620) haben immerhin acht Kandidaten die Prüfungen mit dem Erwerb des juren-Titels erfolgreich abgeschlossen. ${ }^{495}$

\footnotetext{
490 TYTZ, S. 213; YCFZ, S. 281

491 TYTZ, S. 198, 199. [Während der Ära Jiajing waren insgesamt sieben Kandidaten aus Tengyue juren geworden (ebd.). Zu dieser Zeit wird die Gesamtzahl der erwachsenen Männer in Tengyue mit 5720 Personen angegeben (TYZZ, S. 61, Angaben für das Jahr 1567).]

${ }^{492}$ TYTZ, S. 198

493 TYTZ, S. 198

${ }^{494}$ YCFZ, S. 202-203

${ }^{495}$ TYTZ, S. 199-200. Die Kandidaten hatte ihre Titel in den Jahr 1576, 1582, 1585 (2), 1588, 1594 und 1597 (2) erlangt.
} 
Insgesamt haben in der Ming-Zeit siebenundzwanzig Männer aus Tengyue den Titel eines juren erlangt.

Tabelle 15: Die Anzahl der juren aus der Präfektur Yongchang in der Ming-Zeit ${ }^{496}$

Zeit

Ära Jingtai (1450-1457)

Ära Tianshun (1457-1465)

Ära Chenghua (1465-1488)

Ära Hongzhi (1488-1506)

Ära Zhengde (1506-1522)

Ära Jiajing (1522-1567)

Ära Longqing (1567-1573)

Ära Wanli (1573-1620)

Ära Tianqi (1621-1628)

Ära Chongzhen (1628-1644 )

Gesamt
Präfektur Yongchang

insgesamt davon aus Tengyue

$\begin{array}{rr}4 & - \\ 1 & - \\ 16 & - \\ 22 & 5 \\ 25 & 2 \\ 78 & 7 \\ 12 & 1 \\ 75 & 8 \\ 16 & 2 \\ 24 & 2 \\ 273 & 27\end{array}$

Die Teilnahme von Studenten aus Tengyue an den staatlichen Prüfungen ist sicherlich ein Zeichen für die erfolgreiche Vermittlung des konfuzianischen Bildungskanons in der ,ersten Stadt an der äußersten Grenze' in der Ming-Zeit. Betrachtet man jedoch die Gesamtzahl von 273 juren aus Yongchang, wird eine große Diskrepanz zwischen den beiden Verwaltungseinheiten der Präfektur deutlich. Die Mehrheit der erfolgreichen Prüfungskandidaten stammte aus der Präfekturstadt und dem Kreis Baoshan, inklusive sechs juren aus dem nördlichen Kreis Yongping. Lediglich zehn Prozent der juren kamen aus Tengyue. Die Anzahl der Absolventen der Provinzprüfungen aus Tengyue ist damit deutlich niedriger, als die Bevölkerungszahlen vermuten lassen: Ende des 16. Jahrhunderts lebte etwa ein Viertel der Bevölkerung der Präfektur Yongchang im Gebiet der Unterpräfektur Tengyue. ${ }^{497}$ Die niedrigen Zahlen sind sicherlich auch auf die persönlichen Interessen und Fähigkeiten der jungen Männer in Tengyue zurückzuführen. Deutlich wird jedoch, daß das staatliche Schulwesen in Tengyue zwar etabliert, aber noch weit weniger entwickelt war

\footnotetext{
${ }^{496}$ YCFZ, S. 205-210. Abweichend von der Auflistung des TYTZ werden im YCFZ nur vier juren aus Tengyue zur Zeit der Ära Hongzhi genannt (YCFZ, S. 206).

${ }^{497}$ Im Jahr 1567 zählte die Bevölkerung von Tengyue 11.120 Personen (TYZZ, S. 61); in Yongchang wurden im Jahr 157543.661 Personen registriert (Lee, S. 718, Tab. 2).
} 
als das der Präfekturstadt. Die relativ geringe Anzahl an Prüfungskandidaten aus Tengyue, die eine Beamtenlaufbahn anstrebten, spiegelt sicherlich auch die Zusammensetzung der Bevölkerung von Tengyue wieder, einer Stadt, die zu allererst ein Handels- und Militärstützpunkt war.

Doch als Heimat von immerhin drei Absolventen der höchsten Staatsprüfungen kann die Unterpräfektur Tengyue insgesamt betrachtet seit dem 16. Jahrhundert als äußerster Vorposten eines entwickelten staatlichen Schulwesens im Südwesten des chinesischen Reiches gelten. Die folgende Tabelle veranschaulicht diesen kleinen Anteil, den die Unterpräfektur an der Gesamtzahl der jinshi in China gehabt hat und hebt so noch einmal ihre besondere Lage hervor: Als ,erste Stadt an der äußersten Grenze‘ gelegen, ist Tengyue gleichwohl auch in die Strukturen des Bildungswesens des Kernlandes eingebunden.

Tabelle 16: Die Anzahl der jinshi in der Ming-Zeit ${ }^{498}$

$\begin{array}{lr}\text { Unterpräfektur Tengyue: } & 3 \\ \text { Präfektur Yongchang: } & 26 \\ \text { Provinz Yunnan: } & 228 \\ \text { China insgesamt: } & 22.980\end{array}$

\section{Das Ende der Herrschaft der Ming in Yunnan}

Der Prozeß der Konsolidierung der Region des Stromschluchtenfächers zeigt beispielhaft die Flexibilität und die Möglichkeiten auf, die der Ming-Staat nutzte, um die Provinz Yunnan mit ihren verschiedenen Volksgruppen dem Kerngebiet des chinesischen Reiches anzugliedern. Den lokalen Bevölkerungsstrukturen und der steigenden Zahl von Zuwanderern aus Zentralchina entsprechend, hatte die Zentralverwaltung entweder Herrschaftsgebiete einheimischer Machthaber (tusi) oder Einheiten der regulären Zivilverwaltung gegründet; den Anspruch der Ming auf Oberhoheit sicherten zudem die in Garnisonsen stationierten chinesischen Soldaten.

Oberbefehlshaber der Truppen war jeweils an Mitglied der Familie Mu, deren starke Stellung als Feudalherren Yunnans eine einmalige Besonderheit in der Verwaltung einer Provinz des Ming-Reiches war. Der Ahnherr der Familie, Mu Ying, ein Adoptivsohn des ersten Kaisers der Ming, hatte nach der Eroberung Yunnans durch die Ming-Truppen den

\footnotetext{
${ }^{498}$ He Bingkun, Mingdai jinshi yu dongnan renwen, zitiert nach Lan Yong, Xinan lishi wenhua dili, S. 112 und YCFZ, S. 202-203. Andere Quellen nennen Zahlen von insgesamt 241 bzw. 263 jinshi in der Provinz Yunnan in der Ming-Zeit (siehe Lan Yong, ebd., S. 111).
} 
militärischen Oberbefehl über die Provinz und das Recht erhalten, diese Position zu vererben. Mu Yings Nachfahren hatten, seit 1408 als Herzöge von Qianguo, die Vormachtstellung der Familie als militärische Befehlshaber und als Besitzer großer Ländereien in Yunnan weiter gefestigt.

In den ersten Dekaden des 17. Jahrhunderts begannen die zentralen Verwaltungsstrukturen in Yunnan zu verfallen. Während die einheimischen Herrscher ihre Positionen stärken konnten, war die Familie der Mu nicht länger in der Lage, ihre Autorität in der Provinz geltend zu machen. Der 13. Herzog, Mu Tianbo (amtierte seit 1628), hatte die Verwaltung seiner Ländereien vernachlässigt; das Mißmanagement sorgte für Unruhe unter Mu Tianbos untergebenen Militäroffizieren und einigen der lokalen Machthaber, deren Unzufriedenheit sich in Aufständen gegen die Herrschaft der Familie Mu bzw. der Ming-Dynastie äußerte. ${ }^{499}$

Der Südwesten Chinas war bereits in den 20er Jahren des 17. Jahrhunderts Schauplatz militärischer Auseinandersetzungen zwischen Ming-Truppen und einheimischen Bevölkerungsgruppen. Unter der Führung der beiden tusi She Chongming und An Bangyan (,SheAn-Rebellion‘ [1621-1629]) kämpften die Yi im Dreieck des südlichen Sichuan, des westlichen Guizhou und im nördlichen Yunnan um die Vorherrschaft. Die Aufständischen eroberten Chongqing, sie belagerten Chengdu und Guiyang.

Auch die Präfektur Yongchang im Westen Yunnans war zur Zeit der Ära Chongzhen (1628-1644) von Rebellen bedroht:

„Wang Pan, ein Mann aus diesem Regierungsbezirk (junren), verbündete sich mit den einheimischen Beamten (tuguan) von Caojian, das sich weiter oben am Fluß [Lujiang] befindet, sowie mit den Lisu und den Yeren, um zu rebellieren. Zunächst verbrannten sie die Brücke an der Orchideenfurt (Lanjin qiao). Als sie die nördliche Stadtmauer (bei cheng) von Yongchang angriffen, führte Richter (tuiguan) Chen Xunye die Soldaten der Garnison (wei) [dorthin], um jene abzuwehren. Die Banditen konnten den Angriff nicht weiterführen und flohen“. 500

\footnotetext{
499 Struve, S. 145

${ }^{500}$ YCFZ, S. 135. Caojian befindet sich im Norden von Yongchang, in der Unterpräfektur Yunlong (Präfektur Dali); der Lujiang fließt von Caojian südwärts in das Gebiet von Yongchang (YCFZ, S. 26). An der Orchideenfurt (Lanjin) überspannt die Jihong-Brücke den Lancangjiang (Mekong); über diese Brücke, etwa 40 km nördlich von Yongchang, führt die Verbindungsstraße ins Landesinnere (YCFZ, S. 69).
} 
An dieser Darstellung der Ereignisse fällt besonders auf, daß weder die lokalen Militärnoch die obersten Zivilbeamten (wie der Präfekt) erwähnt werden, sondern lediglich der Richter (tuiguan, der vierthöchste Beamte in der Präfektur). ${ }^{501}$ Er ist es, der die erfolgreiche Verteidigung der Stadt organisiert und selbst die Soldaten anführt. Dies kann wohl als Hinweis darauf gewertet werden, daß die Strukturen der Regionalverwaltung in dieser Zeit des Umbruchs bereits zerfielen.

Während der fast ein Jahrzehnt andauernden She-An-Rebellion und anderer miltärischer Auseinandersetzungen wurden weite Teile der südwestlichen Provinzen Chinas verwüstet; für Yunnan brachten sie zudem häufige Unterbrechungen der Verkehrverbindungen von der Provinz ins Landesinnere mit sich. ${ }^{502}$ Infolgedessen riß die Kommunikation mit der Zentralregierung immer wieder ab und die Verwaltungsbeamten in Yunnan blieben bei der Bewältigung der Situation zunehmend auf sich selbst gestellt.

Die Verbindung zum Norden wurde endgültig unterbrochen, als die Mandschu, die bereits die nordöstlichen Provinzen Chinas erobert hatten, nach dem Selbstmord des ChongzhenKaisers im Jahr 1644, Peking besetzten und die Herrschaft der Ming-Dynastie in der Hauptstadt beendeten. Die Mandschu-Truppen der neugegründeten Qing-Dynastie rückten weiter nach Zentralchina und in den Süden vor; 1647 erreichten sie Kanton.

Im Südwesten war Sichuan zum Zentrum eines Aufstandes gegen die Ming geworden. Um das Übergreifen von Unruhen auf Yunnan zu verhindern, schickte Mu Tianbo im Jahr 1644 Soldaten in das nordöstliche Yunnan, um dort den Vormarsch der Truppen des Rebellenführers Zhang Xianzhong, der bereits Chengdu erobert und sich dort zum König seines ,großen westlichen Reiches‘ (daxiguo wang) ernannt hatte, aufzuhalten. Der Einfluß der Rebellen hatte sich dennoch in der Provinz bereits bemerkbar gemacht. So berichtet das TYTZ, daß ein General Zhang Xianzhongs,

„der herumziehende Bandit (liu kou) Sun Kewang den Pseudo-Regionalkommandanten (wei zhongbing) Yang Wu entsandt hatte, um im Gebiet von Teng Unruhe zu verbreiten (zi rao Teng jing)“. ${ }^{503}$

\footnotetext{
${ }^{501}$ In der Liste der Beamten der Präfektur Yongchang wird Chen Xunye in der Rubrik der Richter allerdings nicht erwähnt (siehe YCFZ, S. 174).

${ }^{502}$ You Zhong, S. 444-445

${ }^{503}$ TYTZ, S. 192
} 
Der Vormarsch der Soldaten Mu Tianbos führte zu weiteren Kämpfen um die Vorherrschaft mit den tusi in den betroffenen Verwaltungseinheiten, die sich auch auf andere Gebiete der Provinz ausdehnten. Dabei gelang es Sha Dingzhou, dem Sohn des Herrschers des Annan zhangguansi (im modernen Kreis Mengzi), im Dezember 1645 mit seinen Truppen die Provinzhauptstadt Yunnan fu zu erobern. Mu Tianbo floh nach Westen; zunächst nach Chuxiong, dann weiter bis nach Yongchang. ${ }^{504}$

Nachdem Zhang Xianzhong im Jahr 1647 von Qing-Truppen in Sichuan getötet worden war, reorganisierten seine Generäle Sun Kewang, Li Dingguo und andere ihre verbliebenen Streitkräfte in Guizhou. Dort erreichte Sun Kewang die Bitte des tusi von Shiping (Präfektur Lin'an) nach Yunnan vorzurücken und die Herrschaft Sha Dingzhous zu beenden. ${ }^{505}$ Unter dem Vorwand die Herrschaft der Familie Mu und der Ming-Dynastie wieder herstellen zu wollen, kam Sun dieser Bitte nach, die ihm die Möglichkeit bot, sich eine neue Machtbasis im Südwesten zu schaffen. Seine Truppen eroberten Yunnan fu und im Jahr 1648 konnte Li Dingguo Sha Dingzhou endgültig besiegen. ${ }^{506}$

Sun Kewang wurde von Mu Tianbo und anderen Beamten in Yunnan zunächst als ,herumziehender Bandit‘ (liu kou) abgelehnt, bald arrangierten sie sich jedoch mit ihm, in der Hoffnung, so die Ordnung in der Provinz wieder herstellen zu können. ${ }^{507}$

Mu Tianbo selbst war nicht in der Lage gewesen, seine Kontrolle über die Militärorganisation in der Provinz zu nutzen, um die Vormachtstellung des Mu-Clans aufrechtzuerhalten. In den Machtkämpfen der folgenden Jahre spielte er keine aktive Rolle mehr.

Sun Kewang hatte unterdessen begonnen, in Yunnan fu eine Regierung nach dem Vorbild der Ming-Regierung in Peking aufzubauen und entsprechend sechs Ministerien (liu si) gegründet, Beamte ernannt sowie Steuern von den Verwaltungseinheiten erhoben. ${ }^{508}$ Unter den von Sun ernannten Beamten waren auch zwei Männer aus Yongchang, Gong Ding und Gong Yi. ${ }^{509}$ Die amtierenden Verwaltungsbeamten in Yongchang waren nicht bereit, sich Sun zu unterwerfen. Im YCFZ werden die Ereignisse des Jahres 1647 folgendermaßen geschildert:

\footnotetext{
${ }^{504}$ You Zhong, S. 447

${ }^{505}$ You Zhong, S. 449

${ }^{506}$ Struve, S. 146; You Zhong, S. 450

${ }^{507}$ You Zhong, S. 450. Auch in den fangzhi von Yongchang und Tengyue aus dem 19. Jahrhundert werden Sun Kewang und seine Truppen als ,herumziehende Banditen` (liu kou) bezeichnet.

${ }^{508}$ Struve, S. 146

${ }^{509}$ You Zhong, S. 451
} 
„Als der herumziehende Bandit Sun Kewang im Jahr dinghai nach Yunnan kam, ging der Herzog von Qian, Mu Tianbo, nach Yongchang. Als Kewang nach Dali kam, rief er Tianbo zu sich und verlangte zudem das Siegel der Präfektur Yongchang . Der Assistierende Präfekt (tongpan) [von Yongchang,] Liu Tingbiao und der Richter (tuiguan) Wang Yunkai haben sich erhängt. Daraufhin wurde Yunkais jüngerer Bruder, der juren Yunhong festgenommen und sollte gezwungen werden, das Amt zu übernehmen. Yunhong fügte sich dem aber nicht, sondern ertränkte sich selbst im Lujiang [Salween]. [Sun Kewangs General] Liu Wenxiu ließ Tianbo ergreifen und zurückbringen. Tianbo trug nach wie vor das alte Siegel am Gürtel“. 510

Die Truppen Sun Kewangs waren vorerst nur bis nach Dali vorgerückt, mit dem schriftlichen Befehl zur Übergabe des Siegels von Yongchang machten sie jedoch auch ihren Anspruch auf die Vorherrschaft über die Gebiete weiter im Westen deutlich. Diese bedrohliche Lage führte zur Auflösung der zivilen Verwaltung Yongchangs. Als Assistierender Präfekt und Richter standen Liu Tingbiao und Wang Yunkai an dritter bzw. vierter Stelle in der Hierarchie der Beamten der Präfektur Yongchang. Sie hatten auf Befehl Mu Tianbos das Amtssiegel an sich genommen. Das läßt vermuten, daß ihre Vorgesetzten, der Präfekt und der Unterpräfekt, nicht mehr zugegen waren. Liu und Wang aber erwiesen sich als vorbildliche loyale Beamte, die, nachdem sie ihre Familienangehörigen zur Sicherheit nach Tengyue geschickt hatten, eher Selbstmord begingen, als sich den ,Banditen“ zu unterwerfen. ${ }^{511}$ Damit hatte die Präfektur ihre obersten zivilen Verwaltungsbeamten verloren. ${ }^{512}$

Wie schon bei der zuvor geschilderten Verteidigung der Stadt Yongchang werden in diesem Zusammenhang die Militärbeamten ebenfalls nicht erwähnt, auch über Kämpfe der im Militärbezirk Jin-Teng stationierten Soldaten gegen die Truppen Sun Kewangs gibt es in den fangzhi keinerlei Informationen. Möglicherweise konzentrieren die ,zivilen“ Verfasser ihre Berichte auf die Angelegenheiten der Zivilbeamten. Insgesamt vermitteln die Darstellungen jedenfalls den Eindruck, daß das chinesische Militär im Westen der Provinz den neuen Machthabern keinen Widerstand entgegenzusetzen hatte. Der Grund

\footnotetext{
${ }^{510}$ YCFZ, S. 135-136

${ }^{511}$ Die Übersetzung der Kurzbiographien von Liu und Wang mit der Schilderung der angesprochenen Ereignisse (YCFZ, Kapitel 33, zhonglie, S. 153) findet sich im Anhang.

${ }^{512}$ In der Auflistung der Beamten der Präfektur Yongchang im YCFZ werden zwar noch zwei weitere Assistierende Präfekten (tongpan) aufgeführt, allerdings ohne Jahresangaben. Aus der Liste geht jedoch nicht hervor, von wem diese beiden zu einer Zeit, in der die reguläre Verwaltungsorganisation der Ming in Yunnan nicht länger bestand, als Amtsnachfolger Liu Tingbiaos in ihre Ämter eingesetzt worden sind (YCFZ, S. 174).
} 
dafür lag vermutlich ebenso wie bei der Zivilverwaltung in der Auflösung der hierarchischen Befehlsstrukturen der zentralen Militärverwaltung, die auch von keiner Initiative lokaler Kommandanten ersetzt wurde.

Mit der Schwächung ihres Verwaltungsapparates hatte die Präfektur auch ihre Autorität im Grenzgebiet eingebüßt. Die unsicheren Machtverhältnisse in der Region boten den tusi die Gelegenheit, ihre eigenen Positionen auszubauen; häufig erwiesen sich jedoch die Truppen Sun Kewangs als die militärisch überlegenen:

„So gab es im Jahr jichou (1649) in Yongchang einen Zauberer-Mönch (yaoseng), der sich ,General, der das Reich beschützt‘ (huguo jiangjun) nannte und ein gefälschtes Siegel (wei yin) herstellte. Er versammelte die tusi von fünfzehn Befriedeten Gebieten (xuan) und achtundzwanzig befestigten Dörfern (zhai), um zu rebellieren und gemeinsam die Präfekturstadt anzugreifen. Daraufhin kamen die herumziehenden Banditen [des Sun Kewang] nach Yongchang, brachten jenen eine Niederlage bei und enthaupteten den Zauberer-Mönch““. ${ }^{513}$

Für die Organisation seiner Machtbasis in Yunnan, die Finanzierung der Kämpfe gegen die aus dem Norden vorrückende Qing-Armee und den Unterhalt seiner Soldaten, deren Anzahl sich in den letzten drei Jahren vervierfacht hatte und die nun etwa zweihunderttausend Mann betrug, benötigte Sun Kewang große finanzielle Mittel, die er in Form von Steuern von der Bevölkerung einzog. ${ }^{514}$ Blieben die geforderten Leistungen aus, dann, so zeigt ein Beispiel aus Tengyue, setzte Sun seine Ansprüche unter Einsatz seiner Soldaten mit Gewalt durch:

Im Jahr 1651 „entsandte Kewang den Pseudo-Oberbefehlshaber (wei dudu) Wang Fuchen [nach Südwesten], weil Ganya und Longchuan die Frist für die Zahlung der Steuern hatten verstreichen lassen. Deshalb ließ [Wang] den tusi von Ganya, Dao Zhenguo und [seinen Vater] Dao Dingbian, der vom Amt des tusi zurückgetreten war, ebenso töten wie Duo Anjing, den tusi von Longchuan“. 515

\footnotetext{
${ }^{513}$ YCFZ, S. 136

${ }^{514}$ You Zhong, S. 451

515 TYTZ, S. 192 (siehe auch TYTZ, S. 153; TYZZ, S. 143).
} 
Um seinen Herrschaftsanspruch zu stärken, hatte Sun Kewang Kontakt zum Hof des letzten Kaisers der Südlichen Ming-Dynastie, Yongli (Zhu Youlang, Prinz von Gui [Gui wang]), aufgenommen und im Gegenzug für seine Unterstützung, um eine Ernennung zum Prinzen von Qin (Qin wang) nachgesucht, die ihm jedoch nicht gewährt wurde.

Im Jahr 1650 führte Sun seine Truppen zunächst nach Guizhou; in den folgenden fünf Jahren gelang es ihm, die Qing-Armeen fast vollständig aus den südwestlichen Provinzen zu verdrängen. ${ }^{516} 1651$ sandte Sun Kewang seine Soldaten zum Yongli-Kaiser nach Nanning in der Provinz Guangxi und stellte ihn unter seinen Schutz.

Der Vorstoß der Armee der Qing nach Guangxi zwang Yongli zur Flucht aus Nanning, die ihn schließlich nach Anlong im Südwesten von Guizhou führte, wo Yongli und sein Hofstaat die nächsten vier Jahre unter der Kontrolle von Sun Kewang zubringen sollten. ${ }^{517}$

Auch in Yunnan konnte Sun Kewang seine Vorherrschaft, die er im Westen bis auf die tusi-Gebiete jenseits von Tengyue hatte ausdehnen können, weiterhin behaupten. Allerdings nicht unangefochten, da die einheimischen Machthaber in der Region den Kampf gegen Suns Truppen fortführten. Diese reagierten mit aller Härte, um ihre Vormachtstellung zu sichern:

„Im Jahr renchen [1652] versammelte der ehemalige Soldat Li Zhongwu die verbliebenen [tusi] aus den verschiedenen Befriedeten Gebieten (xuan) und den befestigten Dörfern (zhai) und griff die Präfekturstadt [Yongchang] erneut an. Die herumziehenden Banditen [des Sun Kewang] besiegten sie jedoch und nahmen eine große Anzahl der tusi gefangen. Einigen [der Gefangenen] wurde die Haut abgezogen, einige wurden geköpft, andere mit dem Stock zu Tode geprügelt. Außerdem wurde der Befehl gegeben, allen Einheimischen (turen) von Shidian die Hände abzuhacken. Eine große Zahl [von Menschen] ist gestorben“. 518

Diese drastische Schilderung der Ereignisse des Jahres 1652 im YCFZ hebt die Kriegsgreuel unter denen die Bevölkerung in der Präfektur Yongchang zu leiden hatte, sehr eindringlich hervor. Und die Kämpfe in der Region des Stromschluchtenfächers sollten noch ein Jahrzehnt lang weitergehen, ausgefochten zwischen zwei weiteren Kriegsparteien, die

\footnotetext{
516 Struve 147

517 Struve 152

${ }^{518}$ YCFZ, S. 136
} 
in diesem Jahr nach Yunnan einrückten und die Machtverhältnisse in der Provinz erneut veränderten.

Weiter im Osten hatte Li Dingguo bis 1652 mit seinen Truppen weite Teile von Guangxi und Huguang erobern können. ${ }^{519}$ Seine Erfolge führten zu Konflikten mit Sun Kewang, der seinen Anspruch auf die Vorherrschaft durch Li gefährdet sah; deshalb versuchte er, Li zu entmachten. In den folgenden Jahren kam es zwischen Li Dingguo und dem Yongli-Kaiser zu einer Annäherung und 1656 gelang es Li Dingguo, Yongli und seinen Hofstaat von Anlong nach Yunnan fu zu führen und die Stadt unter seine Kontrolle zu bringen. ${ }^{520}$ Im Jahr darauf besiegten Lis Truppen Sun Kewang, der sich bis nach Huguang zurückzog, wo er sich schließlich den Qing ergab. ${ }^{521}$

Der großangelegte Vorstoß der Qing-Truppen zur Eroberung des Südwestens begann im Jahr 1658. Aus Sichuan, Huguang und Guangxi wurden die Armeen der drei Generäle Wu Sangui, Loto und Jobtei in Guizhou unter dem Oberbefehl des Generalgouverneurs der südlichen Provinzen, Hong Chengchou, zusammengezogen. Von Guizhou aus rückten die Armeen auf drei verschiedenen Routen nach Yunnan vor, die in Qujing wieder zusammenführten. Trotz einiger anfänglicher Siege über die Qing-Armeen konnte Li Dingguo deren Vormarsch nicht aufhalten und mußte sich nach Westen zurückziehen. Anfang des Jahres 1659 eroberten die Qing die Provinzhauptstadt Yunnan fu.

Yongli und sein Hofstaat, der zu dieser Zeit noch etwa viertausend Personen umfaßte, waren unter der Führung Herzog Mu Tianbos bereits nach Yongchang geflohen, in der Hoffnung, daß es den Streitkräften Li Dingguos gelänge, ihre Verfolger in dem schwer zugänglichen Gelände im Westen der Provinz aufzuhalten. ${ }^{522}$

Unter Führung von Wu Sangui und Jobtei rückten die Truppen der Qing jedoch weiter nach Dali und Yongchang vor, das sie nur wenige Tage nachdem Yongli und sein Gefolge die Stadt in Richtung Tengyue verlassen hatten, erreichten.

\section{1. Die Schlacht am Mopanshan und die Flucht des Yongli-Kaisers nach Birma}

Die letzte große Schlacht zwischen den Truppen Li Dingguos und der Qing Armee fand am Berg Mopan (auch Mopanshishan) statt. Die Qing hatten am 10. März 1659 bereits Yongchang eingenommen; der Yongli Kaiser und sein Gefolge waren nach Tengyue

\footnotetext{
${ }^{519}$ Hummel, S. 490

${ }^{520}$ Struve, S. 153-154

${ }^{521}$ Struve, S. 154; Hummel, S. 679

${ }^{522}$ Struve, S. 169
} 
geflohen, als Li Dingguo noch einmal seine Truppen sammelte. ${ }^{523}$ Er stationierte sie im Westen des Salween am Mopanshan, dessen „Bergpfade gefährlich sind und wo dichte Bambuswälder jeweils nur einem Reiter Platz bieten“. ${ }^{524}$ An diesem strategisch günstig gelegen Ort an der Verbindungsstraße zwischen Yongchang und Tengyue sollte die nachrückende Qing Armee im Gebirge in einen Hinterhalt gelockt werden.

Li Dingguos Plan wurde jedoch von einigen Überläufern an die Qing verraten. ${ }^{525}$ Diese setzten Musketen und Kanonen ein, um die Soldaten Lis aus ihren Verstecken zu treiben. Nachdem die Schlacht verloren war, gelang es Li Dingguo mit einem Rest seiner Leute zu entkommen. Sein General Bai Wenxuan führte seine verbliebenen Truppen über Mubang in das nordöstliche Birma, Li zog von Tengyue aus nach Südosten in Richtung Menggen. ${ }^{526}$ In den folgenden Jahren hielt er sich im Gebiet von Mengding und Menglian auf, wo er gemeinsam mit den einheimischen Shan weiter gegen die Qing kämpfte. ${ }^{527}$ Li versuchte auch mehrfach weiter nach Birma vorzudringen, um wieder mit dem Yongli-Kaiser zusammenzutreffen, wurde jedoch von birmanischen Truppen zurückgeschlagen. ${ }^{528}$

Als der Yongli-Kaiser Anfang März Tengyue erreicht hatte, befand er sich in einer verzweifelten Lage. ${ }^{529}$ Sein Gefolge war im Verlauf der Flucht nach Westen auf etwa eintausendfünfhundert Personen zusammengeschrumpft. Es standen ihnen kaum noch finanzielle Mittel zur Verfügung, alle Wertgegenstände, Juwelen und auch Kleidungsstücke waren längst verkauft oder gestohlen worden, da die Gruppe unterwegs mehrfach überfallen worden war. In Tengyue waren die Flüchtlinge in einem kleinen Lager untergebracht, wo sie „nicht einmal mehr weißen Reis zu essen hatten und sich von Pferdefleisch ernähren mußten“. 530

Nachdem die Schlacht am Mopanshan verloren war, blieb dem Yongli-Kaiser nur noch die Flucht nach Birma. Der tusi von Nandian gab dem Kaiser und seinem Gefolge am Fluß Daying entlang Geleitschutz und schließlich gelangten sie über den Tongbi-Pass nach Manmo. Der tusi von Manmo, Si Mian, „der für die Birmanen den Fluß Nangmu

\footnotetext{
523 Struve, S. 170

${ }^{524}$ TYTZ, S. 44

${ }^{525}$ You Zhong, S. 456

${ }^{526}$ Xie Guozhen, S. 188

${ }^{527}$ You Zhong, S. 456

${ }^{528}$ TYTZ, S. 149; YCFZ, S. 154

${ }^{529}$ Nach Struve (S. 170) erreichte Yongli Tengyue am 10. März; nach Hummel (S. 194 Chu Yu-lang) hielt sich der letzte Ming-Kaiser vom 8. bis 13. März 1659 in Tengyue auf. Im TYZZ (S. 18) wird als Datum lediglich ,der zweite Monat“ angegeben.

${ }^{530}$ Struve, S. 170
} 
bewachte“, meldete ihre Ankunft dem birmanischen König und war erst dann bereit, sie mit Lebensmitteln zu versorgen, als sie sämtliche Waffen abgegeben hatten. ${ }^{531}$

Dann führte er sie ans Ufer des Irawadi, wo die Flüchtlinge von den Birmanen in zwei Gruppen aufgeteilt wurden. Während sich die größere Gruppe der Gefolgsleute zu Fuß auf den Weg nach Süden machten, fuhr Yongli zusammen mit etwa sechshundert Personen in Booten den Irawadi hinunter bis nach Htigyaing. Dort wurden sie von den Birmanen zunächst festgehalten und aufgefordert, sich auszuweisen, was ihnen mit Hilfe des Siegels von Herzog Mu Tianbo gelang, das den Birmanen von älteren Dokumenten her bekannt war $^{532}$ :

„Die Birmanen ... zeigten ein Schreiben mit dem Siegel des Kaisers Shenzong [Regierungsdevise Wanli] vor und verlangten, daß entsprechende goldene Siegel zu sehen, denn sie hatten Zweifel, ob [die Ankömmlinge] nicht eine falsche [Identität angeben] würden. Tianbo überreichte daraufhin sein eigenes Siegel, welches mit dem auf früher übersandten Dokumenten übereinstimmte. Die Birmamen glaubten [den Flüchtlingen] jetzt und brachten sie nach Zhekeng in Birma, wo sie in Strohhütten wohnen mußten“. ${ }^{533}$

$\mathrm{Zu}$ dieser Zeit lieferten sich die Birmanen Gefechte mit Bai Wenxuan, der mit seinen Truppen dem Yongli-Kaiser gefolgt war. Die Birmanen sahen sich von den Truppen aus China, die nach Birma vordrangen, bedroht und fürchteten ihren Einfluß auf die Gebiete im Nordosten ihres Reiches (die Kleinstaaten der Shan) zu verlieren, wenn es den Chinesen gelänge, sich dort eine Machtbasis aufzubauen. So ließen sie die große Gruppe der Flüchtlinge, die sich auf dem Weg nach Ava befand, unterwegs töten. Nun blieben nur noch Yongli und sein Gefolge, die im Juni auf Geheiß des birmanischen Königs mit Booten nach Sagaing gefahren und dort in einem einfachen Lager untergebracht wurden. ${ }^{534}$

Seit dem Frühjahr des Jahres 1660 führten Li Dingguo und Bai Wenxuan ihre Truppen wiederholt in Richtung Ava. Aufgrund der ständigen Kämpfe verschlechterte sich das Verhältnis der Birmanen zu den chinesischen Flüchtlingen. Yongli und sein Gefolge wurden kaum noch mit Lebensmitteln versorgt und so sahen sie sich gezwungen, auch noch

\footnotetext{
${ }^{531}$ TYTZ, S. 149, 244; Struve, S. 170, You Zhong, S. 456

532 Struve, S. 171

${ }^{533}$ TYTZ, S. 149; TYZZ, S. 106

${ }^{534}$ Struve, S. 171
} 
ihre allerletzten Wertgegenstände inklusive des kaiserlichen Siegels zu verkaufen, um sich am Leben zu erhalten. ${ }^{535}$

Im Juni 1661 veränderte sich die Lage in Birma entscheidend. Weil es König Pindale nicht gelungen war, das Problem der chinesischen Flüchtlinge zu lösen und zudem eine Rebellion der Mon im Süden die Stabilität des Reiches gefährdete, wurde er vom Ministerrat abgesetzt. ${ }^{536}$ Sein Nachfolger König Pye (reg. 1661-1673) beschloß, die Chinesen endgültig loszuwerden. ${ }^{537}$ Unter einem Vorwand befahl er die chinesischen Beamten aus dem Gefolge Yonglis an seinen Hof:

„Zu dieser Zeit hatte der Häuptling der Birmanen seinen Bruder getötet und machte sich selbst zum Herrscher und nannte sich Mang Mengbai [i.e. König Pye].

Außerdem beabsichtigte er sämtliche Minister, zivile und Militärs, zu töten. Er ließ sie zu sich kommen und sagte, daß die Barbaren (man) Wert darauf legen, einander Treue zu schwören, daher bitte er darum, mit den Fürsten des kaiserlichen Hofes das Wasser zum Schwur [eines Bündnisses] zu trinken (yin zhou shui). Unterdessen hatte er sie von Soldaten umzingeln lassen und nun ließ er sie, alle zweiundvierzig Personen, umbringen. Ehe Tianbo starb, hat er eigenhändig noch zahlreiche Männer des birmanischen Häuptlings töten können“. ${ }^{538}$

Zur gleichen Zeit drangen birmanische Soldaten in das Lager der Flüchtlinge ein und töteten alle Männer, nur Yongli und seine engsten Familienanghörigen sowie die Frauen und Kinder blieben am Leben. ${ }^{539}$

\section{2. Der Vorstoß der Qing-Truppen und das Ende der Ming im Südwesten}

Der Oberbefehlshaber der Qing-Armee, Hong Chengchou hatte sich inzwischen in der Provinzhauptstadt Yunnan fu etabliert und begann mit der Konsolidierung Yunnans. Schon im Jahr 1659 hatte der Shunzhi-Kaiser einen Betrag von dreihunderttausend liang Silber für Yunnan bewilligt, der zur Hälfte für Heeresbedarf und zur Hälfte als Katastrophenhilfe für die Bevölkerung eingesetzt wurde und so zur Befriedung der zentralen Region der Pro-

\footnotetext{
${ }^{535}$ Struve, S. 172-173

${ }^{536}$ Maung Htin Aung, S. 149-150

${ }^{537}$ Struve, S. 173-4; s. a. Struve, Cataclysm, S. 250-252

538 TYTZ, S. 149; TYZZ, S. 106. Im TYTZ wird ausdrücklich darauf hingewiesen, daß König Pye handelte, nachdem er ,einen Befehl von Wu Sangui erhalten hatte, diesem den Prinzen [von Gui] zu übergeben“ (TYTZ, ebd.).

${ }_{539}$ Struve, S. 173-4; s. a. Struve, Cataclysm, S. 250-252.
} 
vinz beitragen sollte. Noch im Jahr 1659 richtete Hong Chengchou eine Proklamation an Birma, in der er die Auslieferung Yonglis forderte. Nachdem Hong von seinem Posten zurückgetreten war, wurde Wu Sangui zum Oberbefehlshaber über Yunnan ernannt. Wu hatte zu dieser Zeit im Südwesten gegen Truppen Li Dingguos und dessen einheimische Verbündete gekämpft. Im Mai 1660 reichte er eine Petition ein, in der er darlegte, daß nur ein Feldzug nach Birma und die Gefangennahme Yonglis für Frieden im Grenzgebiet sorgen würden. Aufgrund der hohen Kosten, die ein solcher Feldzug mit sich bringen würde, wurde die Durchführung der Militärexpedition am Kaiserhof lange diskutiert; erst im September 1660 erhielt der Mandschu-General Aixing'a den Befehl, gemeinsam mit Wu Sangui nach Birma vorzurücken. ${ }^{540}$ Im März 1661 setzten sie ihre Truppen in Richtung Mubang in Bewegung, um so einen Keil zwischen Li Dingguo im Osten und Bai Wenxuan, der sich weiter nach Nordwesten zurückgezogen hatte, zu treiben.

Die Chronisten des TYTZ und des YCFZ führen hier noch einen anderen Grund für den Vormarsch der Qing-Armee nach Birma an. Deren Absicht war es nicht allein, den YongliKaiser gefangen zu nehmen, sondern vielmehr noch, den birmanischen König im Kampf gegen die Truppen Li Dingguos zu unterstützen:

„Im ersten Monat des Jahres Shunzhi 18 (1661) griff Li Dingguo Birma an. Der Häuptling der Birmanen (Mian qiu) bat um Unterstützung (qingjiu) und Wu Sangui ließ fünftausend Soldaten aus Yongchang und Tengyue ihnen weit entgegenrücken (yao ying). ${ }^{541}$

Im 11. Monat befehligten die Generäle, die den Westen befriedet hatten (dingxi jiangjun)`, Herzog Aixing’a und Wu Sangui, eine große Armee aus Mandschuund Han-chinesischen Soldaten, die nach Birma einrückte. Sie verfolgten Bai Wenxuan bis nach Chashan“. ${ }^{542}$

Die reale Besorgnis der Birmanen über das Eindringen chinesischer Truppen in den Norden ihres Reiches bildet den Hintergrund für diese Darstellung. Die Bitte des Königs, sein Reich zu beschützen, rechtfertigt den Vormarsch der Armee; eine solche Rechtfertigung erschien den Verfassern der fangzhi anscheinend notwendig, sei es um die Qing-Armee positiv von den anderen Truppeneinheiten und ,herumziehenden Banditen` abzuheben, die

\footnotetext{
${ }^{540}$ Struve, S. 174-175

${ }^{541}$ Im YCFZ (S. 136) wird darauf hingewiesen, daß Wu Sangui „,berittene Soldaten der Grenztruppen (fangbian bingma) angeführt hatte“.

${ }^{542}$ TYTZ, S. 192; YCFZ, S. 136
} 
in den letzten Jahren in der Region des Stromschluchtenfächers agierten und von Yunnan aus nach Birma eingedrungen waren.

Bai Wenxuan mußte sich schließlich ergeben und die Qing-Armee rückte weiter nach Ava vor. Am 20. Januar 1662 kamen die Truppen in der Nähe der birmanischen Hauptstadt an und drohten damit, Ava anzugreifen, sollte Yongli nicht ausgeliefert werden. ${ }^{543}$

Die Birmanen hatten unterdessen Yongli und sein kleines Gefolge auf Booten untergebracht und sie von Sagaing aus über den Irawadi nach Ava geleitet. Hier wurden sie schließlich General Aixing’a übergeben und kurz darauf traten die Qing-Truppen mit ihren Gefangenen den Rückweg nach Yunnan an. Drei Monate später trafen sie in der Provinzhauptstadt Yunnan fu ein und dort wurden im Mai 1662 Yongli und sein Sohn, der Kronprinz, hingerichtet. ${ }^{544}$

Li Dingguo hielt sich zu dieser Zeit noch im Grenzgebiet zu Birma auf, seine verbliebenen Truppen hatten sich inzwischen aufgelöst, er selbst war erkrankt und starb einige Monate nach dem Yongli-Kaiser:

„Als Li Dingguo erfuhr, daß der Prinz von Gui ergriffen und nach Yunnan zurückgebracht worden war, schlug er sich an die Brust und stampfte mit den Füßen. Er weinte laut und warf sich an die hundert Mal auf den Boden. Drei Tage lang aß er nichts und nach weiteren sieben Tagen starb er; er wurde in Jingxian begraben. Sein Sohn Sixing unterwarf sich später Wu Sangui und erhielt den Titel eines Grafen von Taian verliehen“. 545

Soldaten der chinesischen Truppen von Bai Wenxuan und Li Dingguo ließen sich danach im modernen Grenzgebiet zwischen Yunnan, Birma und Thailand nieder, wo sie Neuland erschlossen und Bergbau, insbesondere den Abbau von Silbervorkommen betrieben. ${ }^{546}$ Die einheimische Bevölkerung, insbesondere die Dai- (Shan), Yi- und Miao-Nationalitäten führten ihren Kampf gegen die Qing vielerorts weiter, in Zentral-Yunnan, im Gebiet von Kunming, Dali, in Xi'e und Shiping (Präfektur Lin'an), in Yuxi oder Mengzi und auch in den südlichen und östlichen Randgebieten Yunnans sowie in Guizhou. ${ }^{547}$

\footnotetext{
543 Struve, S. 176

${ }^{544}$ Struve, S. $177-178$

545 TYTZ, S. 149; YCFZ, S. 154, s.a. S. 352

${ }^{546}$ Xie Guozhen, S. 190

${ }^{547}$ Xie Guozhen, S. 190; You Zhong, S. 457-458, 460
} 
KAPITEL IV

DIE KONTINUITÄT DES GRENZGEBIETES:

DIE ENTWICKLUNG DER UNTERPRÄFEKTUR TENGYUE IN DER QING-ZEIT

(1644-1911)

\section{A. Krieg und Frieden: Die Verwaltungseinheit Tengyue vom 17. bis zum 19. Jahr- hundert}

\section{Die Präfektur Yongchang und die tusi-Gebiete zu Beginn der Qing-Zeit}

Im Westen der Provinz Yunnan waren die Qing-Truppen nach der Schlacht am Mopanshan zunächst nur bis auf die Hochebene von Tengyue und nach Nandian vorgerückt:

„Im 16. Jahr der Ära Shunzhi, jihai, (1659) war die große Armee nach Yunnan eingezogen. Deshalb [geleiteten] der Herzog der früheren Ming[-Dynastie] Mu Tianbo und Li Dingguo ihren Herrn, den Prinzen von Gui ehrerbietig bis nach Tengyue.

Li Dingguo versammelte seine Soldaten am Berg Mopan, sie hielten diesen strategisch wichtigen Ort und widersetzten sich unseren Truppen (wo shi) bis zum Tod; Zhao Buda [i.e. Jobtei] und Wu Sangui mußten alle Kräfte einsetzen, um ihnen eine Niederlage beizubringen. *Li Dingguo ging nach Menggen.* Der Prinz von Gui begab sich nach Birma. ${ }^{\circ}$ Daraufhin wurde Tengyue eingenommen (ke). Die tusiGebiete Nandian, Ganya und Longchuan unterwarfen sich (guifu) eines nach dem anderen ${ }^{\circ}$. 548

Diese Darstellung eines reibungslosen Verlaufs der Etablierung der Oberhoheit der Qing über die Gebiete der einheimischen Machthaber im Westen von Tengyue mag durchaus der Realität entsprochen haben und nicht allein dem Wunsch der Kompilatoren der fangzhi, den Beginn der Herrschaft ihrer Dynastie im Südwesten als ganz natürlich darzustellen. Die Unterwerfung unter die Qing war angesichts der Tatsache, daß deren starke Armee, die bereits Zentral-Yunnan erobert hatte, nun auch bis zu ihren Herrschaftsgebieten vorgedrungen war, vor allem eine pragmatische Entscheidung für die einheimischen Machthaber in der Region des Stromschluchtenfächers. Hinzu kam, daß die Qing-Armee die Truppen Sun

\footnotetext{
${ }^{548}$ TYTZ, S. 192; YCFZ, S. 136. Die Texte mit der Darstellung der Ereignisse weichen in den beiden zitierten fangzhi voneinander ab: Der mit * markierte Satz steht nur im YCFZ. Im YCFZ wird Zhao Butai als chinesischer Name für Jobtei verwendet (S. 136). Die mit ${ }^{\circ}$ markierten Sätze stehen nur im Text des TYTZ (S. 192).
} 
Kewangs besiegt hatte, die zuvor die Kleinstaaten bedroht und einige der einheimischen Oberhäupter getötet hatten. Die Strategie der tusi, sich den veränderten Machtverhältnissen in der Region anzupassen, erwies sich als erfolgreich, um auch unter der neuen Herrscherdynastie Chinas die eigene Machtposition aufrecht zu erhalten:

„Im Jahr Shunzhi 17 (1660) reichte Wu Sangui eine Throneingabe ein. Daraufhin wurden Dao Chengxiang von Nandian, Duo Shaoning von Longchuan, Dao Jianxun von Ganya und Dao Sitao von Zhanda wie zuvor die Siegel der Befriedeten Gebiete (xuanfu yin) übergeben und das Erbrecht an ihren Amtstiteln bestätigt“ . ${ }^{549}$

Aus der Sicht der Verfasser der Lokalhandbücher von Tengyue stellt sich die Situation in den tusi-Gebieten am Übergang von der Ming- zur Qing-Zeit folgendermaßen dar:

\section{NANDIAN}

Dao Chengxiang, der Herrscher von Nandian, hat das Verdienst, sich unterworfen zu haben (toucheng gong), schon am längsten. Im ersten Jahr der Ära Kangxi (1662) wurden ihm wiederum ein Siegel und eine Ernennungsurkunde (yinxin haozhi) verliehen. ${ }^{550}$

\section{LONGCHUAN}

Während der Wirren am Ende der Ming-Zeit war Duo Anjing, der Herrscher von Longchuan, von Wang Fucheng, einem Untergebenen des herumziehenden Banditen Sun Kewang, getötet worden. Seinem Sohn Duo Shaoning kam das Verdienst zu, sich unterworfen zu haben. Zu Beginn der Ära Kangxi erhielt er wie zuvor den Titel eines Oberhauptes des Befriedeten Gebietes und das Privileg,das Amt an seine Nachkommen zu vererben. ${ }^{551}$

\section{GANYA}

Als Dao Dingbian, der Herrscher von Ganya alt geworden war, setzte er seinen Sohn Zhenguo in sein Amt ein. Der herumziehende Bandit Sun Kewang hatte Yunnan eingenommen und schickte seinen Pseudo-Oberbefehlshaber Wang Fuchen nach Ganya. Weil die Entsendung von lokalen Produkten als Tribut zu langsam ging, wurden anschließend noch mehr Soldaten dorthin abkommandiert. Zu dieser Zeit wollte der Herrscher des Befriedeten Gebietes von Zhanda, Dao Sitao, die Unruhen nutzen, um die Position des Oberhauptes von Ganya an sich zu reißen. Nachdem er im Geheimen die schriftliche

\footnotetext{
${ }^{549}$ TYTZ, S. 192; YCFZ, S. 136. Im TYTZ (S. 192) wird der Name des tusi von Longchuan abweichend als Duo Shaolin geschrieben. Im YCFZ und ebenso auch im Kapitel über die tusi im TYTZ (S. 153) wird der Name einheitlich als Duo Shaoning angegeben.

${ }^{550}$ TYZZ, S. 138. TYTZ, S. 151; YCFZ, S. 198

${ }^{551}$ TYTZ, S. 153; TYZZ, S. 143; YCFZ, S. 197
} 
Zustimmung von Sun erhalten hatte (mi feng mingwen), ließ er Dao Dingbian, seinen Sohn Zhenguo und weitere drei Personen in die Provinzhauptstadt bringen, wo sie alle getötet wurden. Im Jahr Shunzhi 16 (1659) unterwarf sich der Sohn von Dao Zhenguo, Dao Jianxun. Er erhielt das Privileg, sein Amt zu vererben. Im 18. Jahr (1661) kümmerte er sich um die Versorgung der Truppen, die nach Birma zogen, deswegen wurde er als verdiente Persönlichkeit ausgezeichnet. ${ }^{552}$

\section{ZHANDA}

Nachdem Dao Sitao als Herrscher eingesetzt worden war, hatte Zhanda erstmals per kaiserlichem Dekret das Amtssiegel eines sekundären Befriedeten Gebietes (fu xuanfu si) erhalten. Zwar war die Ermordung von Dao Dingbian und Dao Zhenguo von Ganya durch Sun Kewang auf Veranlassung von Dao Sitao geschehen, doch anschließend im Jahr Shunzhi 16 (1659) kam Sitao das Verdienst zu, sich der neuen Dynastie unterworfen zu haben und so er erhielt den Titel eines Oberhauptes des sekundären Befriedeten Gebietes von Zhanda sowie das Privileg, sein Amt zu vererben. ${ }^{553}$

Mit der Verleihung von Amtstiteln an die tusi setzten die Qing die Politik der Ming-Dynastie gegenüber den einheimischen Machthabern im Grenzgebiet westlich von Tengyue fort. ${ }^{554}$ Diese erhielten dieselben Titel, die sie bereits unter der vorangegangenen Dynastie erhalten hatten. Entsprechend wurde auch der Status des Befriedeten Gebietes von Ganya bestätigt, das zuvor von der Eroberung durch Zhanda bedroht gewesen war. Die Konflikte der tusi untereinander interessierten die Qing nicht, entscheidend war allein, daß die lokalen Anführer sich loyal erklärt hatten. Folglich wurde auch der tusi von Zhanda in seinem Amt bestätigt. Die Einbindung der neu an die Macht gekommenen einheimischen Herrscher (deren Vorgänger von den Truppen Sun Kewangs getötet worden waren) in die Verwaltungsorganisation Chinas mag diesen als zusätzliche Legitimierung gedient haben. Für die Qing war sie ein Mittel, sich der Loyalität der tusi zu versichern, durch deren Gebiete der geplante Feldzug nach Birma zur Verfolgung des Yongli-Kaisers führen sollte und um zu verhindern, daß die noch verbliebenen Truppen der Ming-Loyalisten unter Bai Wenxuan und Li Dingguo mit Unterstützung der einheimischen Bevölkerung im Grenzgebiet Fuß fassen konnten.

\footnotetext{
552 TYTZ, S. 154; TYZZ, S. 145; siehe auch YCFZ, S. 197

${ }^{553}$ TYTZ, S. 154; TYZZ, S. 145-146; s.a. YCFZ, S. 198.

${ }^{554}$ Im ersten Jahr der Ära Kangxi (1662) wurde der amtliche Status weiterer tusi im Süden und Südwesten von Tengyue bestätigt: „Wu Sangui reichte eine Throneingabe ein, in der er darum nachsuchte, Mengmao, Zhefang, Mangshi und anderen tusi das Privileg zu verleihen, ihre Amtstitel vererben zu dürfen“ (YCFZ, S. 136).
} 
Zur Absicherung ihrer Position im Westen Yunnans gründeten die Qing ihren westlichsten Truppenstützpunkt, wie schon die Ming, auf dem Hochplateau von Tengyue:

\begin{abstract}
„Im selben Jahr [1660] wurde Yongchang zum Regionalen Militärbezirk (zhen) erklärt, Zhang Guozhu zum [Regionalkommandeur (zongbing) ernannt] und in Tengyue wurde die Zusatz-Brigade (xie ying) Shunyun aufgestellt““ 555

„Für Tengyue wurde ein Vize-Regionalkommandeur (fujiang) ernannt und dem [entsprechend neu benannten] Regionalen Militärbezirk Yong-Shun unterstellt. “556
\end{abstract}

Die Stationierung von Truppen im Gebiet von Yongchang und Tengyue erfolgte im Zuge des Aufbaus einer Militärorganisation für Yunnan, mit dem bereits im Jahr 1659 begonnen worden ist. ${ }^{557}$ Zunächst sind zu den vier größeren Militärstützpunkten Wuding, Qujing, Chuxiong und Erhai jeweils dreitausend Soldaten abkommandiert worden. Der neu gegründete Stützpunkt Yong-Shun im Westen der Provinz gehörte, zusammen mit Lin-Yuan, Qu-Xun und Guang-Luo, zu der Gruppe der vier kleineren Militärstützpunkte. Für den Regionalen Militärbezirk (zhen) Yong-Shun wurde ein Regionalkommandeur ernannt, dem 2400 Soldaten unterstanden. Der Vize-Regionalkommandeur der Zusatz-Brigade (xie fujiang) von Tengyue befehligte 1000 Soldaten; die Brigade (ying) Shunyun umfaßte weitere 600 Soldaten. ${ }^{558}$ Somit waren 4000 Mann der regulären Armee zur Sicherung der eroberten Gebiete in der Präfektur Yongchang stationiert.

Insgesamt sind in Yunnan nach den Angaben des TYZZ in diesem Jahr 47.000 Soldaten in den neuen Militär- und Brigadestützpunkten der Qing stationiert gewesen. ${ }^{559}$

\footnotetext{
555 YCFZ, S. 136. Zhang Guozhu stammte aus Liaodong, er war zunächst Regionalkommandeur des Militärbezirks Yong-Shun, später wurde er zum Militärkommandanten (tidu) von Yunnan befördert (YCFZ, S. 189).

${ }^{556}$ TYTZ, S. 192. Li Shiyao, der erste Vize-Kommandeur in Tengyue, stammte aus Liaodong (ebd., S.129; TYZZ, S. 88).

${ }^{557}$ Bereits im Jahr 1659 war der noch aus der Ming-Zeit stammende Posten des Garnisonskommandanten (zhihui) von Tengchong abgeschafft und stattdessen ein Kommandant sowie zwei Kompanie-Kommandanten (qianzongguan) eingesetzt worden: „Der Kommandant (shoubei) führte die Garnison (wei) Tengchong, die Kompanie-Kommandanten unterstützten ihn dabei“ (YCFZ, S. 51; TYTZ, S. 64).

${ }^{558}$ TYZZ, S. 135

559 TYZZ, S. 135. „Im Jahr 16 der Ära Shunzhi (1659) nahm die große Armee Yunnan ein. Zu dieser Zeit sicherte Wu Sangui Yunnan und war zum Prinzen ersten Ranges (Qin wang) ernannt worden. Mit den beiden Oberkommandierenden der Banner (dutong), den Vize-Bannerkommandanten (fu dutong) und Kommandanten der Bannerkompanien (zuoling), befehligte er [zusammen] zweiundvierzig Militärführer und 8400 Soldaten. Außerdem wurden Zhongyong und Yiyong mit je fünf Brigaden (ying) und zehn Regionalkommandeuren (zongbing) gegründet. Jeder Regionalkommandeur befehligte 1200 Soldaten, insgesamt also 12.000 Mann, die dem Feudalherren [Wu Sangui] unterstanden (li fan xia). Zur Verstärkung der angreifenden Truppen gab es den Linken, den Rechten, den Vorderen und den Hinteren, also vier Regionale Militärstützpunkte (zhen). Der Regionalkommandeur des [Linken Militärstützpunktes] wurde in Wuding stationiert, der des Rechten in Qujing, der des Vorderen in Chuxiong und der des Hinteren in Erhai. Zu jedem der Regionalen Militärbezirke gehörten 3000 Soldaten, insgesamt 12.000 Mann, die dem Feudalherren unterstanden (li fan xia). Außerdem wurden noch die vier Regionalen Militärbezirke (zhen) Lin-Yuan, Qu-Xun, Guang-Luo und Yong-Shun gegründet. Die Regionalkommandeure dieser Regionalen Militärbezirke befehligten jeder 2400 Soldaten, zusammen 9600 Mann. Dazu wurden noch in Yuanjiang und Tengyue die Vize-Regionalkommandeure der Zusatz-Brigaden (xie fujiang) eingesetzt. Jeder der [Vize-Kommandeure] der Zusatz-Brigaden befehligte 1000 Mann, zusammen also 2000. Außerdem wurden fünf Brigaden (ying) aufgestellt: Beisheng, Xunzhan, Xinxi, Shunyun und Fenghua; jede Brigade mit 600 Soldaten“ (TYZZ, Kapitel 10, Militärwesen). Insgesamt wären demnach 47.000 Soldaten unter zweiundsechzig Kommandeurern verschiedener Ränge in Yunnan stationiert worden.
} 
Die Militärorganisation im Westen der Provinz wurde anschließend weiter ausgebaut. Im Jahr Shunzhi 17 (1660) wurden im Gebiet der Unterpräfektur Tengyue die militärischen Kommandostrukturen neu festgelegt und zudem die Truppeneinheiten reorganisiert. Dem Vize-Regionalkommandeur (fujiang) der Brigade und dem Vize-Regionalkommandeur der Zusatz-Brigade (xie fujiang),wurden nun folgende Militärführer und Soldaten unterstellt:

$\begin{array}{ll}1 & \text { Kommandant (shoubei), } \\ 2 & \text { Kompanie-Kommandanten (qianzhong), } \\ 4 & \text { Gruppenführer (bazong), } \\ 100 & \text { Kavalleristen (mazhanbing), } \\ 400 & \text { Infanteristen (buzhanbing), } \\ 500 & \text { Wachsoldaten (shoubing). }{ }^{560}\end{array}$

Insgesamt waren demnach eintausend Soldaten und acht Truppenführer der regulären Streitkräfte (guanbing) in Tengyue stationiert, die nach wie vor dem Regionalen Militärbezirk (zhen) Yong-Shun unterstellt waren.

Die Soldaten wurden in Militärkolonien organisiert (tuntian), mit den Erträgen ihrer Feldarbeit trugen sie nicht nur Versorgung ihres Stützpunktes, sondern auch zur Finanzierung der Militärkampagnen in Yunnan im Allgemeinen und der Stärkung der Machtposition Wu Sanguis im Besonderen bei:

„Im Jahr Shunzhi 17 (1660) standen die Felder der Militärkolonien unter der Sonderverwaltung von $\mathrm{Wu}$ Sangui und die Steuern waren, verglichen mit den [Feldern unter] ziviler [Verwaltung], zehnmal so hoch“. 561

Mit den Einnahmen aus den Militärkolonien und anderen Steuern aus der Provinz Yunnan allein konnte die Finanzierung der Militärkampagnen bei weitem nicht bestritten werden. Am Ende der Ära Shunzhi betrugen die Ausgaben für Wu Sanguis Armee, die in Yunnan etwa 65.000 Soldaten umfaßte, neun Millionen liang, was zwei Fünftel der gesamten Staatseinnahmen ausmachte. ${ }^{562}$ Im Jahr 1667 benötigten Yunnan und Guizhou mit vier Millionen liang, zehnmal soviel Geld wie die Steuereinnahmen der beiden Provinzen

\footnotetext{
560 TYTZ, S. 176

561 TYZZ, S. 63. Für die Organisation der Militärkolonien waren die örtlichen Kommandanten zuständig; verwaltet wurden sie von der Regionalen Militärkommission von Yunnan (Yunnan tuntian dusi) (TYTZ, S. 192).

${ }^{562}$ Kessler, S. 76, 78; Tsao, S. 66-67
} 
zusammen erbrachten. ${ }^{563}$ Bestritten wurden diese Mehrkosten mit Steuermitteln aus reichen Provinzen wie Jiangsu, Huguang und Hunan.

Die Hälfte der jährlichen Steuereinnahmen des Staates wurde zu dieser Zeit für die Finanzierung der drei Feudalherren Shang Kexi (in Guangdong), Geng Jimao (in Fujian) und Wu Sangui (in Yunnan), die den Süden des Reiches für die Qing sichern sollten, aufgewendet.

\section{1. Die Herrschaft Wu Sanguis in Yunnan}

Seit seiner Ernennung zum Oberbefehlshaber von Yunnan und Guizhou im Jahr 1663 hatte Wu Sangui seine Machtposition in der Region stetig ausgebaut. ${ }^{564}$ Er hatte die Besitzungen der Familie Mu übernommen, zog Steuern ein und errichtete Monopole auf Salz, auf Goldund Kupferminen sowie auf den Handel mit seltenen Produkten wie zum Beispiel Ginseng oder Rhabarber. ${ }^{565}$

Wu beherrschte das Verwaltungs-, Militär- und Finanzwesen; seine starke Stellung ermöglichte es ihm, die in der Region tätigen Zivilbeamten und Militärkommandeure selbst zu bestimmen; dem Personalministerium in Peking blieb nur noch deren Ernennung zu bestätigen. ${ }^{566}$ Darüber hinaus konnte er sich auch in den Nachbarprovinzen von Yunnan und Guizhou ein Netzwerk loyaler Gefolgsleute schaffen.

Letztlich blieb Wu Sanguis Stellung in Yunnan jedoch ein Posten auf Zeit, von dem ihn der Kaiser jederzeit abberufen konnte. Zumal nach der Verfolgung der Ming-Loyalisten und der Hinrichtung des letzten Kaisers der Südlichen Ming kein Grund mehr für die Aufrechterhaltung der kostspieligen Sonderstellung Wus und für eine so starke Truppenpräsenz in Yunnan bestand. Wu Sangui rechtfertigte den Verbleib seiner Soldaten in der Provinz und die damit verbundenen hohen Ausgaben mit der Notwendigkeit, die verschiedenen einheimischen Bevölkerungsgruppen zu befrieden. Um seinen Standpunkt zu untermauern, führte er mehrere Feldzüge hauptsächlich im nordöstlichen Yunnan und im westlichen Guizhou durch. ${ }^{567}$

\footnotetext{
${ }^{563}$ Kessler, S. 78; Tsao, S. 67. Gernet spricht sogar von einer Summe von 30 Millionen liang Silber, die Wu im Jahr 1667 zum Unterhalt seiner Truppen erhalten habe (Gernet, S. 399).

${ }^{564}$ Der Militärkommandant Wu Sangui (1612-1678) stammte aus Liaodong. Am Shanhaiguan, dem strategischen Paß an der Großen Mauer stationiert, schloß sich Wu im Jahr 1644 den Mandschu-Truppen an, mit denen er Peking eroberte. In den folgenden Jahrzehnten führte er Feldzüge zur Eroberung Zentralchinas und kam 1659 nach Yunnan, um die Herrschaft der Südlichen Ming endgültig zu beenden. Für seinen Erfolg wurde er zum Prinzen ersten Ranges (Qin wang) ernannt und mit weitreichenden Machtbefugnissen ausgestattet (siehe Hummel, S. 877-880).

${ }^{565}$ Hummel, S. 879, Gernet, S. 399; Tsao, S. 68

${ }^{566}$ Kessler, S. 77-78; You Zhong, S. 460-461. Die Ernennung der Beamten durch Wu Sangui wurde in Anlehnung an seinen Titel ,Prinz, der den Westen befriedet hat‘ (ping xi wang) als xi xuan (,ausgewählt durch den Prinzen, der den Westen befriedet hat') bezeichnet (ebd.).

${ }^{567}$ Tsao, S. 62
} 
Besorgt über die Machtkonzentration in den Händen Wu Sanguis und der anderen Feudalherren im Süden des Reiches beschloß der Kangxi Kaiser im Jahr 1673 deren Sonderstellung abzuschaffen. Daraufhin rebellierte Wu Sangui und verkündete die Gründung seiner Zhou-Dynastie. ${ }^{568}$ Er wurde unterstützt von Geng Jingzhong, dem Gouverneur von Fujian und Sun Yanling, Militärkommandant von Guangxi. Auch Wang Fuchen, Gouverneur von Shanxi und Gansu sowie Shang Zhixin von Guangdong schlossen sich der Rebellion an und es schien zunächst tatsächlich möglich, daß sie ganz China von den Mandschu zurückerobern könnten. Im Jahr 1676 unterwarfen sich jedoch Wang und Geng den Qing, im folgenden Jahr ergab sich auch Shang und die Truppen Wus erlitten mehrere schwere Niederlagen. Wu ernannte sich im Jahr 1678 zwar noch zum Kaiser seiner Zhou-Dynastie, er starb jedoch im selben Jahr. Sein Enkel Wu Shifan trat die Nachfolge an; er wurde aber von den Qing-Truppen bis nach Yunnan zurückgedrängt und beging schließlich im Jahr 1681 in Kunming Selbstmord. Damit war die ,Rebellion der drei Feudalherren` (san fan zhi luan) im Süden (Wu, Geng und Shang) beendet. ${ }^{569}$

Trotz Wu Sanguis Bemühungen, die Verwaltungsposten in seinem Herrschaftsbereich mit Gefolgsleuten zu besetzen, schlossen sich nicht alle Beamten seiner Rebellion an. Der Gouverneur von Yunnan sowie der Generalgouverneur von Yunnan und Guizhou verhielten sich loyal gegenüber den Qing; ersterer wurde daraufhin von Wu getötet, der andere beging Selbstmord. ${ }^{570}$

Auch im Westen Yunnans hat es, wie im Lokalhandbuch der Präfektur Yongchang berichtet wird, Widerstand gegen die Rebellion Wu Sanguis gegeben:

„Im 12. Jahr der Ära Kangxi (1673) rebellierte Wu Sangui. Tian Jinxue, der Regionalkommandeur (zongbingguan) von Yong-Shun mobilisierte [im Jahr 1678] seine Truppen, um Wu zu bekämpfen, aber er konnte ihn nicht besiegen und starb“. ${ }^{571}$

\footnotetext{
${ }^{568}$ Zum Verlauf der Rebellion der drei Feudalherren siehe Kessler, S. 74-90 und Tsao, S. 70ff.

${ }^{569}$ Kessler, S. 85ff; Gernet, S. 399; You Zhong, 459-464

${ }^{570}$ Kessler, S. 82; Tsao, S. 76

${ }^{571}$ YCFZ, S. 136, 189; TYTZ, S. 176. Etwas anders formuliert heißt es dazu an anderer Stelle im TYTZ (S. 129): „Tian Jinxue stammte aus Shaanxi. Er hatte im 2. Jahr der Ära Kangxi (1663) sein Amt als Vize-Regionalkommandeur (fujiang) von Yong-Shun angetreten. Im 18. Jahr (1678) gelang es ihm nicht, die Banditen, die Yongchang angriffen, zu besiegen (tao Yongchang zei bu ke) und er wurde getötet“.

In der Liste der Militärbeamten von Tengyue wird Tian Jinxue als fujiang geführt (s. TYTZ, S. 129). In den Jahren nach 1663 wurde Tian zum Regionalkommandeur befördert. Entsprechend wird er auch in der Liste der Militärbeamten der Präfektur Yongchang in der Rubrik zongbing aufgeführt, allerdings ohne Jahresangaben (YCFZ, S. 189). Insgesamt war Tian Jinxue fünfzehn Jahre lang als Kommandeur in der Region des Stromschluchtenfächers tätig. (Auch Tians Amtsvorgänger Li Shiyao hatte nacheinander diese beiden Ämter in der Region inne gehabt.)
} 
Der für Tengyue verantwortliche Militärkommandeur hatte sich den Rebellen entgegengestellt, war jedoch mit dem Versuch gescheitert, die Präfektur zu verteidigen. Das Verhalten der leitenden zivilen Beamten von Yongchang, der Präfekten und Unterpräfekten während der Rebellion bleibt hingegen, wie schon das ihrer Vorgänger zur Zeit des Dynastiewechsels, in den fangzhi unerwähnt. Da in den Listen der fangzhi genauere Angaben und insbesondere die Jahreszahlen aus diesem Zeitraum fehlen, läßt sich dort nicht feststellen, welche der Beamten in der Präfektur Yongchang tatsächlich von Wu Sangui ernannt worden sind. ${ }^{572}$

Von den ersten vier Präfekten Yongchangs in der Qing-Zeit trat der zweite, Wang Jiaxiang aus Shaanxi, sein Amt im Jahr 1663 (Kangxi 2) an. Die Daten seines Amtsnachfolgers werden nicht genannt. Der vierte Präfekt, Zhang Chengci, ein Angehöriger des blauen Banners (zhenglanqi) aus Liaodong, ist im Jahr der Niederschlagung der Rebellion (1681, Kangxi 20) ernannt worden. ${ }^{573}$

Berücksichtigt man die Politik der Regierung, zum Wiederaufbau der Verwaltung keine Beamten einzustellen, die bereits unter den Rebellen Ämter innegehabt hatten, so weisen Zhang Chengcis Herkunft und das Jahr seines Amtsantritts ebenso wie die von ihm durchgeführten Maßnahmen zur Reorganisation der Verwaltungseinheit darauf hin, daß hier ein neuer Mann einen von Wu Sangui eingesetzten bzw. ihm gegenüber loyalen Beamten ersetzt hat. ${ }^{574}$

In der Lobrede auf Zhang Chengci in der Liste der ,berühmten Beamten“ (mingchen) des YCFZ sind die Verdienste dieses „gütigen“ und „unbestechlichen“ Beamten verzeichnet, der auch „über militärische Fähigkeiten verfügte“; er „reduzierte die Steuerlast der Bevölkerung, erleichterte den Frondienst, gründete Schulen und schätzte [den Umgang mit] Gelehrten; er ordnete die öffentlichen Getreidespeicher und [unterstützte die Armen, auch indem er dafür sorgte, daß] Leichname eingesargt und beerdigt wurden““.575

\footnotetext{
${ }^{572}$ Bei den Unterpräfekten (zhizhou) von Tengyue wird zunächst nur für den ersten Amtsträger, Duan Rongjian aus Jiangnan, das Datum seines Amtsantritts im Jahr 1660 (Shunzhi 17) verzeichnet. Erst bei dem siebenten Unterpräfekten, Zhuang Jin aus Jiangsu, wird wieder das Jahr des Amtsantritts, nämlich 1684 (Kangxi 23), angegeben (TYTZ, S. 109). Zhuang Jin ist in die Liste der ,aufrechten Beamten“ (xunli) des TYTZ aufgenommen worden: „Zhuang Jin, ein jinshi aus dem Kreis Wujin in der Provinz Jiangsu. Amtsantritt im Jahr Kangxi 23. Er hatte es den Dörfern von Siyizhuang erlassen, weitere 720 dan Reis [als Steuern abzuliefern]. Die Bevölkerung ( $\mathrm{min}$ ) hatte keine Lasten zu tragen (wu zhonglei). Zhuang versah sein Amt hervorragend (shanzheng zhuoran)“(TYTZ, S. 145, 51).

${ }^{573}$ YCFZ, S. 151, 172. Wie lange Zhang als Präfekt in Yongchang tätig war, geht aus den Angaben nicht hervor.

574 Tsao, S. 169

${ }^{575}$ YCFZ, S. 151
} 
Diese Aktivitäten Zhangs machen vor allem deutlich, daß in all diesen Bereichen Handlungsbedarf bestand, um nach unruhigen Zeiten die Ordnung in der Präfektur wieder herzustellen. Mit Erfolg, wie im YCFZ abschließend ausdrücklich hervorgehoben wird:

„Die Zivilverwaltung und das Militär (wen wu) [arbeiteten] einträchtig [zusammen], die Soldaten und die Bevölkerung waren glücklich, wie die Enten im Schilf (bing min you fu zao zhi le)“. ${ }^{576}$

\section{2. Maßnahmen zum Wiederaufbau Yunnans nach der Rebellion}

Für ganz Yunnan begann nach der Niederschlagung der Rebellion Wu Sanguis eine Phase der Konsolidierung. Die Regierung veranlaßte verschiedene Maßnahmen zur Umstrukturierung und zur Vereinfachung der Militärorganisation sowie der lokalen Zivilverwaltung: Die Zeit der mit besonderen Privilegien ausgestatteten Feudalherren war vorüber, Yunnan wurde in die reguläre Zivilverwaltung eingegliedert und die Kontrolle Pekings über die Provinz insgesamt verstärkt. ${ }^{577}$ Dazu trugen auch die verbesserten Verkehrsverbindungen bei, die noch während der Rebellion ausgebaut worden waren, um die Übermittlung von Informationen und die Versorgung der Qing-Truppen zu gewährleisten. Die Entwicklung im Südwesten war Teil des Prozesses der Gestaltung des militärischen, politischen und wirtschaftlichen Systems des chinesischen Reiches der Mandschu, das bis zum Ende der Qing-Dynastie in seinen Grundzügen bestehen bleiben sollte.

Insbesondere die Landwirtschaft mußte reorganisiert werden, um die Versorgung der Bevölkerung und Steuereinnahmen für den Staat zu garantieren.Die jahrzehntelangen Kämpfe und die hohen Belastungen die daraus für die Bauern und Militärkolonisten entstanden waren, hatten dazu geführt, daß viele ihr Land verließen und die Äcker brachlagen. Das galt in Yunnan besonders für die ehemaligen Lehensgüter der Familie Mu, die nach dem Dynastiewechsel von Wu Sangui übernommen worden waren.

So hatte es beispielsweise im Gebiet der Präfektur Yongchang, die Felder der Zivilbevölkerung (mintian) und der Lehensgüter der Familie Mu (zhuangtian) zusammengenommen, ursprünglich mehr als 2328 qing [ca.15.528 ha] Ackerland gegeben. ${ }^{578}$ Mitte der Ära

\footnotetext{
${ }^{576}$ YCFZ, S. 151

${ }^{577}$ You Zhong, S. 503; Tsao, S. 145, 179

578 YCFZ der Ära Kangxi, zitiert nach You Zhong, S. 502. Die historische Flächenmaßeinheit qing entspricht generell etwa 6,67 Hektar.
} 
Kangxi wurden nur noch etwa 1500 qing [ca. 10.000 ha] tatsächlich landwirtschaftlich genutzt, das restliche Ackerland lag brach, wobei der Anteil an unbebautem Land in den ehemaligen Lehensgütern am höchsten war.

Noch deutlicher hatte der Umfang der tatsächlich bewirtschafteten Felder der Militärhaushalte und der Militärkolonien abgenommen. Während der Ming-Zeit umfaßte das Ackerland, daß der Garnison zugewiesen war (weisuo juntian), insgesamt über 1143 qing [ca. 7624 ha]. Doch bis zur Mitte der Ära Kangxi wurde davon nur noch ein Drittel, etwa 364 qing [ca. 2428 ha], kultiviert; zwei Drittel des Ackerlandes lagen brach. Die Felder der Militärkolonien (tundi) hatten zunächst eine Größe von 140 qing [ca. 934 ha] gehabt, von denen zu der Zeit lediglich etwa 16 qing [ca. 107 ha] Ackerland übriggeblieben war, daß tatsächlich bewirtschaftet wurde. ${ }^{579}$ Zusammengenommen hatten die Felder des Militärs also ursprünglich etwa 1283 qing [8558 ha] umfaßt, von denen Mitte der Ära Kangxi nur noch 380 qing [2535 ha] bewirtschaftet wurden.

\section{Tabelle 17: Bewirtschaftetes Ackerland in der Präfektur Yongchang in qing}

$\begin{array}{lcc}\text { Ackerland } & \begin{array}{r}\text { Ming-Zeit } \\ (1368-1644)\end{array} & \begin{array}{c}\text { Ära Kangxi } \\ (1662-1723)\end{array} \\ \begin{array}{l}\text { mintian / } \\ \text { zhuangtian } \\ \text { juntian } \\ \text { tundi }\end{array} & 2328 & 1500 \\ \text { Gesamt } & 1143 & 364 \\ & 140 & 16 \\ & \mathbf{3 6 1 1} & \mathbf{1 8 8 0}\end{array}$

In der Ming-Zeit sind, die Felder der Zivilbevölkerung (mintian), des Militärs (juntian, tundi) und der ehemaligen Lehensgüter (zhuangtian) zusammengerechnet, demnach in der Präfektur Yongchang etwa 3611 qing [24.086 ha] Ackerland kultiviert worden, dessen Umfang sich nunmehr auf 1880 qing [12.540 ha] reduziert und damit nahezu halbiert hatte.

Um die Bauern zur Kultivierung des Brachlandes zu veranlassen, waren Veränderungen im System der Verwaltung des Ackerlandes notwendig, die in den folgenden Jahrzehnten umgesetzt werden sollten. Im Jahr 1685 hatte Cai Yurong, Generalgouverneur von Yunnan und Guizhou eine Throneingabe eingereicht, in der er die Abschaffung der Lehensgüter

$\overline{579}$ YCFZ der Ära Kangxi, Kapitel 9 (tunfei) zitiert nach You Zhong, S. 504. 
empfahl. Dem entsprechend wurde das Land nun den jeweiligen Präfekturen, Unterpräfekturen und Kreisen zugeteilt, so daß diese direkt die Steuern einziehen konnten und die Kontrolle der Zivilverwaltung über diese Gebiete insgesamt gestärkt wurde. Bis zum Ende des 17. Jahrhunderts wurden schließlich auch die noch verbliebenen Felder der Militärhaushalte der ehemaligen Garnisonen der Ming zivilen Verwaltungseinheiten zugeordnet und in Felder der Zivilbevölkerung umgewandelt; zudem wurden die steuerlichen Belastungen für alle Haushalte vereinheitlicht. ${ }^{580}$

Zur Förderung der Landwirtschaft in Yunnan wurden außerdem weitere staatliche Maßnahmen durchgeführt; insbesondere wurden Projekte zur Verbesserung der Bewässerung umgesetzt. Während der Ära Yongzheng (1723-1736) veranlaßte Ortai (1680-1745), der von 1726 bis 1731 als Generalgouverneur der drei südwestlichen Provinzen Yunnan, Guizhou und Guangxi tätig war, zahlreiche Wasserbauprojekte; unter anderem wurden auch zwei Flüsse nahe der Präfekturstadt Yongchang ausgebaggert. ${ }^{581}$

\section{Die Verwaltungseinheit Yongchang bis zur Mitte des 18. Jahrhunderts}

Zu Beginn der Qing-Zeit war das Militär in Yunnan zunächst in zwanzig Garnisonen (wei) und einundzwanzig Bataillonsstützpunkte (suo) eingeteilt worden; deren westlichste waren entsprechend der Einteilung der vorangegangenen Ming-Zeit die Garnisonen Tengchong und Yongchang sowie das Bataillon Yongping. Nach der Gründung der Regionalen Militärbezirke und der Reorganisation der Truppeneinheiten wurde die Anzahl dieser Bataillonsstützpunkte noch während der Ära Kangxi (1662-1723) in ganz Yunnan allmählich reduziert. Bereits im Jahr 1663 wurden drei Bataillonsstützpunkte abgeschafft, bis zum Jahr 1668 folgten zehn Garnisonen und weitere elf Bataillonsstützpunkte, darunter auch Yongping: Der unabhängige Bataillonsstützpunkt (shouyu suo) Yongping und mit ihm der Posten des Kompanie-Kommandanten (qianzong) waren bereits im Jahr 1666 abgeschafft und das Gebiet in den Kreis Yongping (Yongping xian) zurückgeführt worden. ${ }^{582}$ Auch die Brigade Shunyun (ying) auf der Hochebene von Tengyue im äußersten Westen der Provinz war im Jahr 1665 abgeschafft worden. Im Jahr 1682 wurde die Brigade allerdings wieder neu aufgestellt und wie zuvor dem Regionalen Militärbezirk (zhen) YongShun unterstellt. ${ }^{583}$

\footnotetext{
${ }^{580}$ You Zhong, S. 503-505

${ }^{581}$ You Zhong, S. 508

${ }^{582}$ Niu Pinghan, S. 393; YCFZ, S. 51. Im 8. Jahr (1669) wurden erneut zwei Garnisonen (wei) aufgelöst.

${ }^{583}$ YCFZ, S. 51
} 
Nach der Niederschlagung der ,Rebellion der drei Feudalherren“ wurde die Anzahl der chinesischen Soldaten der Grünen Brigaden (lüying) im Südwesten insgesamt reduziert; in Yunnan waren im Jahr 1685 nurmehr 42.000 Soldaten der Grünen Brigaden stationiert. ${ }^{584}$ Im Jahr 1687 wurden die zu diesem Zeitpunkt noch in Yunnan verbliebenen sieben Bataillonsstützpunkte und acht Garnisonen abgeschafft, darunter auch die beiden Garnisonen Tengchong und Yongchang. ${ }^{585}$ Die Gebiete, die noch unter der Verwaltung der Garnisonen gestanden hatten, wurden in die reguläre Verwaltung der Unterpräfektur (zhou) Tengyue bzw. des Kreises (xian) Baoshan eingegliedert, was unter anderem bedeutete, wie im Handbuch der Präfektur ausdrücklich hervorgehoben wird, daß diese nun die Steuern einzogen. ${ }^{586}$

Nachdem die militärische Verwaltungseinheit Garnison Tengchong im Jahr 1687 (Kangxi 26) abgeschafft worden war, blieben in Tengyue weiterhin die 1660 gegründete ZusatzBrigade (xie ying) sowie die 1682 reorganisierte Brigade (ying) stationiert, die direkt dem Regionalen Militärbezirk Yong-Shun unterstanden. ${ }^{587}$ Die Zusatz-Brigade war auch für den Unterhalt von Militärposten zur Sicherung des Grenzgebietes zuständig. Kleine Truppenkontingente wurden zu diesem Zweck vom Gaoligong-Gebirge zwischen Yongchang und Tengyue bis nach Mengmao im Süden an strategisch wichtigen Orten stationiert:

„Zu Beginn der Qing-Zeit waren über neunhundert Soldaten der ZusatzBrigade zum Grenzschutz abkommandiert worden. An sechs strategischen Pässen, am Wasserscheiden-Gebirgskamm (Fenshuiling) und in Zhanxi [nordwestlich der Stadt Tengyue] wurden jeweils zehn Mann der Grenzschutztruppen stationiert. An den acht Paßstationen wurden Militärposten (xun) aufgestellt, mit jeweils zwanzig Soldaten, die später wieder abgezogen wurden. Im Militärposten Mengmao wurden sechzig Soldaten stationiert. In Zhanda wurde ebenfalls ein Militärposten mit sechzig Soldaten besetzt. In allen Militärposten zusammen waren dreihundert Soldaten stationiert.

Die Einheimischen (turen) erzählen, daß sich die Soldaten (guanbing) damals gefreut hätten, wenn sie zu den Militärposten aufbrachen. Zu Beginn des Winters zogen sie zu den Militärposten hinaus, spät im Frühling kehrten sie

\footnotetext{
${ }^{584}$ Kessler, S. 109

${ }^{585}$ Niu Pinghan, S. 393; YCFZ, S. 52; TYTZ, S. 64; TYZZ, S. 63. Bereits im Jahr Kangxi 6 (1667) waren die Posten der Kompanie-Kommandanten in den Garnisonen Yongchang und Tengchong abgeschafft worden (YCFZ, S. 51).

${ }^{586}$ YCFZ, S. 51

${ }^{587}$ Für die Zusatz-Brigade war inzwischen ein Assistierender Kommandant der Brigade (xie shoubei) ernannt worden, dessen Posten im Jahr 1733 in den eines Assistierenden Brigade-Vize-Kommandanten (dusi qianshu) umgewandelt wurde (TYTZ, S. 64).
} 
wieder zu ihrer Brigade zurück. Über einhundert Jahre lang gab es keinen [Soldaten], der bei seiner Rückkehr kein Bündel [mit allerlei Handelswaren] zu transportieren gehabt hätte“ ${ }^{588}$

Ein Teil der Truppen aus dem Regionalen Militärbezirk Yong-Shun wurde also direkt im Grenzgebiet stationiert, in neugegründeten Stützpunkten, die sich innerhalb der tusiGebiete von Nandian, Longchuan oder Mengmao befanden und abhängig vom örtlichen Klima saisonal oder ganzjährig besetzt wurden. Die Militärstützpunkte kontrollierten die Gebiete im Süden und Westen der Unterpräfekturstadt bis hin zu den acht Paßstationen, die seit Ende des 16. Jahrhunderts das Hoheitsgebiet der Unterpräfektur Tengyue begrenzten. Während die Truppen der Qing in der Provinz Yunnan insgesamt reduziert und die militärischen Verwaltungseinheiten mehrfach reorganisiert worden sind, hat die neue Regierung von ihren Verwaltungszentren in der Region des Stromschluchtenfächers, von Yongchang und Tengyue aus, die Kontrolle über die Befriedeten Gebiete im Südwesten und damit auch über die Handelsrouten verstärkt, ohne dabei über den unter der vorangegangenen Ming-Dynastie geschaffenen geographischen Rahmen hinaus zu gehen.

Neben den militärischen Strukturen in Yunnan sind auch die Ämter, die die regionalen Verwaltungseinheiten für die Provinzregierung überwachten, seit der Ära Kangxi neu organisiert worden. Im Jahr 1666 (Kangxi 5) wurde im Westen Yunnans die bisherige Verwaltungsregion Jin-Cang des Provinzkontrollamtes (fenxun Jincang dao) abgeschafft und statt dessen eigens eine Verwaltungsregion der Provinzbehörde (fenshou Yongchang dao) mit Sitz in Dali eingerichtet. ${ }^{599}$ Im Jahr 1670 wurde dann die Verwaltungsregion Yongchang (shoubei dao) ebenfalls mit Sitz in der Präfektur Dali gegründet.

Diese wiederum wurde im Jahr 1730 (Yongzheng 8) in die Verwaltungsregion Yixi (Yixi dao, ,Verwaltungsregion West') umbenannt, Verwaltungssitz blieb wie zuvor Dali. Das Verwaltungsgebiet der Region Yixi umfaßte den gesamten Westen der Provinz Yunnan; ihr unterstanden die zehn Präfekturen Dali, Heqing, Lijiang, Yongbei, Yongchang, Shunning, Chuxiong, Yaoan, Jingdong und Menghua. ${ }^{590}$

\footnotetext{
588 TYTZ, S. 177

${ }^{589}$ YCFZ, S. 51

${ }^{590}$ Niu Pinghan, S. 394. Im Jahr 1770 wurden die drei Präfekturen Yongbei, Menghua und Jingdong in Unabhängigen Unterpräfekturen (zhili ting) umgewandelt, die weiterhin der Militärregion (dao) unterstellt blieben. Außerdem wurde Heqing junmin fu herabgestuft zu einer Unterpräfektur (zhou) und der Präfektur Lijiang zugeordnet; Yaoan junmin fu wurde abgeschafft und das Gebiet der Präfektur Chuxiong unterstellt (ebd.).
} 
Parallel dazu wurde ebenfalls im Jahr 1730 die Verwaltungsregion des Provinzkontrollamtes Yidong (fenxun Yidong dao, ,Verwaltungsregion Ost'), mit Sitz in der Präfektur Qujing gegründet, deren Hoheitsgebiet sich über dreizehn Präfekturen erstreckte: Yunnan, Wuding, Puer, Qujing, Zhaotong, Chengjiang, Guangnan, Dongchuan, Kaihua, Guangxi, Lin’an, Yuanjiang und Zhenyuan. ${ }^{591}$

Zur Sicherung des äußersten Südwestens ihres chinesischen Reiches in der Zeit nach dem Dynastiewechsel und der Niederschlagung der Rebellion Wu Sanguis hatte für die Mandschu jeweils der Aufbau einer effektiven Militärorganisation in der Region des Stromschluchtenfächers Vorrang vor einer Neuordnung der Zivilverwaltung. Diese wurde auf der Grundlage der Verwaltungseinheiten fortgeführt, wie sie unter der vorangegangenen Ming-Dynastie Anfang des 16. Jahrhundert organisiert worden sind: Die Präfektur Yongchang (Yongchang junmin fu) verwaltete die Unterpräfektur Tengyue und die beiden Kreise (xian) Baoshan und Yongping sowie verschiedene Einheiten der lokalen Sonderverwaltung (Befriedete Gebiete, tusi).

Nachdem die tusi im äußersten Westen der neuen Dynastie ihre Loyalität erklärt hatten, sind ihre Herrschaftsgebiete wie unter der vorangegangenen Ming-Dynastie der Verwaltung der Präfektur Yongchang zugeordnet worden. ${ }^{592}$ Einige der Befriedeten Gebiete wurden direkt von der Präfektur Yongchang verwaltet, so Mangshi anfu si, Gengma xuanfu si, Menglian zhangguan si und die einheimische Präfektur (tufu) Mengding. Die zweite Gruppe von tusi-Gebieten wurde von der Unterpräfektur Tengyue aus verwaltet: Nandian xuanfu si, Ganya xuanfu si, Zhanda fu xuanfu si, Longchuan xuanfu si, Zhefang fu xuanfu si und Mengmao anfu si. ${ }^{593}$

\footnotetext{
${ }^{591}$ Niu Pinghan, S. 394.

Im Jahr 1766 wurden die vier Präfekturen Puer, Zhenyuan, Yuanjiang und Lin’an abgeteilt und der neu geschaffenen Verwaltungsregion Yi‘nan des Provinzkontrollamtes (fenxun Yi‘nan dao, ,Verwaltungsregion Süd`) zugeordnet, die ihren Sitz in der Präfektur Puer hatte. Im selben Jahr wurden die beiden Präfekturen Yunnan und Wuding von Yidong abgeteilt und in einer eigenen Getreide-Steueregion (Yunwu liangchudao; Hucker 3663: Grain Tax Circuit) der Provinz zusammengefaßt; im Jahr 1770 wurde Wuding zur Unabhängigen Unterpräfektur (zhiliting) gemacht (Niu Pinghan, S. 393). Diese Einteilung der Verwaltungregionen des Privinzkontrollamtes blieb bis Ende des 19. Jahrhunderts unverändert bestehen.

[Im Jahr 1887 (Guangxu 13) wurde die Verwaltungsgebiete von Yidong und Yi’nan verkleinert und die drei Präfekturen Lin'an, Kaihua und Guangnan zur Verwaltungsregion Lin’an-Kaiguang mit Zuständigkeit für die Zollangelegenheiten (jianguan guanwu dao) zusammengefaßt, die ihren Sitz in Mengzi in der Präfektur Lin'an hatte (ebd, S. 394).

1902 (Guangxu 28) wurde der Verwaltungssitz der Region Yixi in die Unterpräfektur Tengyue verlegt; von dort wurden die fünf Präfekturen Dali, Chuxiong, Shunning, Lijiang und Yongchang sowie drei Unabhängige Unterpräfekturen (Jingdong, Menghua,Yongbei) verwaltet (Niu Pinghan, S. 394).]

${ }^{592}$ Diese Kontinuität in der Zuordnung und Verwaltung der tusi-Gebiete über die Zeit des Dynastiewechsels hinaus wird in den historischen chinesischen Quellen ausdrücklich betont. So z. B. auch im Chongxiu yitongzhi (juan 498) aus der Ära Jiaqing (1796-1821) oder dem Xu Yunnan tongzhi gao (juan 99) aus der Ära Guangxu (1875-1909) (siehe You Zhong, S. 482-489).

${ }^{593}$ Niu Pinghan, S. 385. Im Jahr Shunzhi 16 (1659) waren zudem die beiden Unabhängigen Unterpräfekturen (zhilizhou bzw. zhili tuzhou) Zhenkang und Wandian gegründet und der Präfektur Yongchang unterstellt worden (ebd. S. 385, 401). Menglian zhangguan si wurde im Jahr Kangxi 48 (1709) zum Menglian xuanfu si aufgewertet (ebd. S. 385).
} 
Das Verwaltungsgebiet der Unterpräfektur Tengyue und der Präfektur Yongchang in der frühen Qing-Zeit entsprach in seinem Umfang insgesamt dem der vorangegangenen MingDynastie. Seine westliche Grenze bildeten die acht Paßstationen (ba guan) und die strategisch wichtigen Pässe (ai). Die Gebiete weiter im Westen wie Mengmi, Mengyang oder Mubang, die durch die Errichtung der Paßstationen im Jahr 1594 abgegrenzt worden waren, werden in den Quellen im Zusammenhang mit dem Dynastiewechsel und der Etablierung der Qing-Verwaltung im Westen Yunnans nicht erwähnt: Sie befanden sich seit Ende des 16. Jahrhunderts jenseits der Strukturen der regulären chinesischen Zivilverwaltung und den ihr zugeordneten tusi-Gebieten. Diese Einteilung blieb in den folgenden einhundert Jahren nahezu unverändert bestehen. ${ }^{594}$

Ganz anders hingegen war die Situation der Kleinstaaten der Shan im südlicheren Grenzgebiet der Provinz Yunnan. Diese waren zur Zeit der Ära Yongzheng (1722-1736) Ziel der militärischen Expansion des Qing-Reiches, dessen Truppen Garnisonen in Weiyuan, Puer (ab 1729 Präfektur) und Simao gründeten. In den eroberten Gebieten ließ Generalgouverneur Ortai (1726 bis 1731 in Yunnan) die einheimischen Machthaber durch chinesische Beamte ersetzen (gaitu guiliu), um diese Gebiete direkt in die Strukturen des chinesichen Kernlandes einzugliedern. Der Widerstand der einheimischen Bevölkerung und das tropische Klima verhinderten dann zwar ein weiteres Vordringen nach Sipsongpanna (chin. Xishuangbanna); mit der Gründung von Garnisonen und zivilen Verwaltungseinheiten hatten die Qing aber ein neues Grenzgebiet im Südwesten Yunnans eröffnet und einen Prozeß der Anbindung dieses Gebietes an das chinesische Kernland sowie der Abgrenzung nach Süden und Westen in Gang gesetzt. ${ }^{595}$

In der ersten Hälfte des 18. Jahrhunderts wird die unterschiedliche Entwicklung des nördlichen und des südlichen Teils des Grenzgebietes im Westen der Provinz Yunnan deutlich.

\footnotetext{
${ }^{594}$ Einzige Veränderung im Verwaltungsgebiet von Yongchang innerhalb der nächsten einhundert Jahre war die Abschaffung der beiden niederrangigen Befriedeten Gebiete (zhangguan si) Husa und Lasa im 2. Jahr der Ära Yongzheng (1724) (Niu Pinghan, S. 385). Husa und Lasa, beide im Gebiet des modernen Longchuan gelegen, waren während der Ära Zhengtong der Ming-Dynastie (1436-1450) zu Befriedeten Gebieten ernannt worden. Im Gebiet von Luchuan-Pingmian (Longchuan) gelegen, wurden diese kleinen tusi-Gebiete jedoch im Verlauf der Ming-Zeit im Zusammenhang mit der Einteilung des Grenzgebietes (san xuan liu wei) in den Quellen nicht mehr eigens als Verwaltungseinheiten erwähnt (TYTZ, S. 146). Während der Ära Qianlong (1736-1796) wurden beide wieder als tusi-Gebiete bestätigt (siehe unten 4. 2., S. 231).

595 Die chinesische Expansion nach Südwesten, die unterschiedliche Entwicklung des nördlichen und des südlichen Grenzgebietes im Westen der Provinz Yunnan sowie die Interaktion der verschiedenen Bevölkerungsgruppen im ,middle ground‘ Sipsongpanna (Xishuangbanna) stellt C. P. Giersch in seiner Dissertation ,Qing China's reluctant subjects: indigenous communities and empire along the Yunnan frontier" (Yale University 1998) dar.

Siehe auch Kent Clark Smith, ,Ch'ing policy and the development of Southwestern China: Aspects of Ortai's GovernorGeneralship, 1726-31‘, Ph. D. diss. Yale University 1970.
} 
Charakteristisch für die nördliche Präfektur Yongchang ist die Kontinuität ihrer geographischen Grenzen, die die neue Herrscherdynastie Chinas im 17. Jahrhundert von ihren Vorgängern übernommen und weiterhin beibehalten hatte. Politische und militärische Maßnahmen der Qing zur Konsolidierung der Grenzregion blieben auf das Gebiet östlich der acht Paßstationen beschränkt. Innerhalb dieses Rahmens wurden die Militärstützpunkte reorganisiert, um die Sicherheit des Grenzgebietes zu gewährleisten. Eine weitere Expansion nach Westen erfolgte jedoch nicht, auch die Herrschaftsgebiete der einheimischen Machthaber blieben als tusi-Gebiete unverändert bestehen.

Bei dem chinesischen Vordringen nach Südwesten hingegen spielten neben der militärischen Expansion und dem Bestreben, das Grenzgebiet neu zu ordnen, auch wirtschaftliche Gründe eine Rolle. Im Süden, im Gebiet von Weiyuan und Zhenyuan wurde Salz gewonnen, Pu'er ist bis heute ein bekanntes Teeanbaugebiet. Mit der Eroberung dieser Gebiete begann die chinesische Regierung Steuern auf diese Produkte einzuziehen und übernahm die Kontrolle über den profitablen Teehandel. Diese Einnahmen bildeten die finanzielle Basis für eine dauerhafte chinesische Präsenz in der Region. ${ }^{596}$

Westlich der Präfektur Yongchang boten sich für die chinesische Regierung hingegen keine derartigen finanziellen Anreize für eine Expansion. Die wichtigste Einnahmequelle der Präfektur waren Zollgebühren und Steuern auf Handelswaren, die von und nach Birma transportiert wurden. Diese ließen sich bequem in Yongchang oder Tengyue einziehen, da die Handelskarawanen, die zwischen Zentral-Yunnan und Birma unterwegs waren, eine der beiden auf den Hochplateaus gelegenen Städte in jedem Fall passieren mußten, wo zudem ein angenehmes Klima herrschte, im Gegensatz zum Grenzgebiet, in dem Tropenkrankheiten wie die Malaria verbreitet waren.

\section{Der chinesisch-birmanische Krieg, 1766-1769}

\section{1. Birma im 18. Jahrhundert: Die Herrschaft der Konbaung-Dynastie}

Mitte des 18. Jahrhunderts war Birma ein Land im Bürgerkrieg. Fraktionskämpfe innerhalb des Königshauses hatten das Reich geschwächt, Unruhen in den Provinzen, Revolten der Shan im Norden und Invasoren aus dem ostindischen Manipur trugen zum Zerfall des Staates bei. ${ }^{597}$ Im Jahr 1752 hatten dann die Mon aus Niederbirma Ava erobert und die regierende Toungoo-Dynastie gestürzt. Aus den Machtkämpfen dieser Zeit ging schließlich

\footnotetext{
${ }^{596}$ Giersch, Qing China, S. 68-71, 77-79, 87-88

${ }^{597}$ Lieberman, S. 153
} 
der Herrscher von Moksobo (Shwebo) im Norden von Ava siegreich hervor und stellte als König Alaungpaya die Einheit des birmanischen Reiches unter seiner neu gegründeten Konbaung-Dynastie wieder her. Als Alaungpaya 1760 während eines Feldzuges gegen Siam starb, hinterließ er ein geeintes Reich, das sich auf ein starkes Militär stützen konnte und weiter expandierte. Alaungpayas zweiter Sohn Hsinbyushin (reg. 1763-1776) setzte den Feldzug gegen Siam im Jahr 1764 fort: Seine Armeen zogen über Chiengmai und Vientiane nach Ayuthia, das sie 1767 eroberten.

Zur Konsolidierung des Nordens des birmanischen Reiches hatte schon Alaungpaya Truppen entsandt, um die Staaten der Shan im Grenzgebiet zu China unter seine Kontrolle zu bringen. Diese hatten seit Ende des 16. Jahrhunderts unter birmanischer Oberhoheit gestanden. Gegen Ende der Toungoo-Zeit hatte Birma seinen Einfluß auf die Kleinstaaten jedoch wieder verloren, während das Qing-Reich seine Position im Grenzgebiet stärken konnte und verschiedene Herrschaftsgebiete in der Region, wie Gengma xuanfu si und Mengding tufu, seiner Verwaltungshoheit unterstellt hatte. ${ }^{598}$

Nun drangen die Truppen König Hsinbyushins in die Region vor, um die Tributbeziehungen zu Birma wieder herzustellen. Einige der Herrscher, deren Territorien von den Birmanen erobert wurden, wie zum Beispiel der sawbwa von Bhamo, flohen nach China, wo sie die chinesische Provinzverwaltung um Hilfe im Kampf gegen die Birmanen ersuchten. 599

Aus der Sicht der Qing gehörte es zu den Aufgaben der tusi, die Sicherheit in ihren Herrschaftsbereichen zu gewährleisten und zu verhindern, daß Angreifer in ihre Gebiete und weiter ins Landesinnere Chinas vordringen konnten. Als die birmanischen Truppen im Jahr 1758 Hsenwi (Mubang) eroberten, forderten die Qing die angrenzenden tusi entsprechend auf, den Kontakt zu Hsenwi abzubrechen und ihre Grenzen zu schließen. Ein militärisches Eingreifen wurde von Seiten Chinas nicht für erforderlich gehalten, da sich Hsenwi, wie in den fangzhi von Tengyue dargestellt wird, jenseits der Territorien unter chinesischer Oberhoheit befand. ${ }^{600}$

Für die einheimischen Herrscher dieser Gebiete existierte jedoch keine solch eindeutige Abgrenzung. Ihre Familien waren untereinander verwandt und entsprechend in die Konflikte diesseits und jenseits der acht Paßstationen involviert.

\footnotetext{
598 Jung, S. 78

${ }^{599}$ U Aung Sein Han, S. 130-131; Jung, S. 79

600 Siehe TYTZ, S. 241, TYZZ, S. 153
} 
Nach der Eroberung von Hsenwi flüchtete Gong Liyan (birman. Gunna aim), der Leiter eines Bergbaubetriebes in Hsenwi, der gegen die Birmanen gekämpft hatte, in das angrenzende Gebiet von Menglian. Dort kam es zu Konflikten mit dem einheimischen Herrscher, die mit der Ermordung der Familie des tusi durch Gongs Gefolge endeten. Gong wurde später vom tusi von Gengma an die Qing ausgeliefert und in Yongchang hingerichtet; seiner Frau Nang Zhan (birman. Nam khyam) gelang die Flucht nach Birma. ${ }^{601}$

König Hsinbyushins Truppen drangen daraufhin von Hsenwi aus weiter bis nach Gengma und Mengding (in der Präfektur Yongchang) vor. Damit hatten die Kämpfe auch Gebiete unter der Oberhoheit der Qing erreicht, die folglich ein erstes chinesisches Truppenkontingent mobilisierten. ${ }^{602}$

Die Aktivitäten Birmas zur Kontrolle der Shan-Staaten sowie der Vormarsch birmanischer Truppen in das Grenzgebiet zu China (nach Sipsongpanna und im Rahmen des Feldzuges gegen Siam) veränderten das Gleichgewicht in der Grenzregion und brachten China und Birma in direkten Konflikt miteinander. Zum Schutz der Gebiete unter chinesischer Verwaltungshoheit und zur Wahrung der Vormachtstellung Chinas im Grenzgebiet erschien den Qing daher eine Militäraktion geboten. Diese sollte zunächst nur der ,Bestrafung‘ der birmanischen Invasoren und der Wiederherstellung der Ordnung im Grenzgebiet dienen.

In birmanischen Quellen werden auch wirtschaftliche Interessen als Auslöser des Krieges genannt: Konflikte zwischen chinesischen Händlern und birmanischen Beamten haben dazu geführt, daß sich die Händler nach ihrer Rückkehr in die Heimat bei der Provinzverwaltung über eine ungerechte Behandlung von Seiten Birmas beschwert und China somit weitere Gründe für ein militärisches Eingreifen geboten haben. ${ }^{603}$

Erst im Verlauf der Kämpfe wurde auch die Eroberung Avas von China als Kriegsziel formuliert. Dies schien berechtigt, da man in China Alaungpaya zunächst als einen Eroberer betrachtete, der die Herrschaft von der rechtmäßigen, das heißt der China Tribut leistenden Toungoo-Dynastie an sich gerissen hatte. Im TYTZ heißt es in der Darstellung der historischen Entwicklung Birmas denn auch:

„Die Nachfolge war von Alaungpaya, dem Häuptling von Moksobo usurpiert worden (si wei Mushu qiu Wengjiya suo cuan)“. ${ }^{604}$

\footnotetext{
${ }^{601}$ U Aung Sein Han, S. 132-133; Jung, S. 79

${ }^{602}$ Maung Htin Aung, S. 176; Jung, S. 80; Giersch, Qing China, S. 240

${ }^{603}$ U Aung Sein Han, S. 129-130; Maung Htin Aung, S. 176; Jung, S. 79

${ }^{604}$ TYTZ, S. 244
} 
Die Bedeutung des Dynastiewechsels für die Entstehung eines neu geeinten birmanischen Reiches war in China zunächst nicht erkannt und die militärische Stärke der neuen Herrscher im fernen Südwesten unterschätzt worden. ${ }^{605}$

\section{2. Der Verlauf des chinesisch-birmanischen Krieges, der Friedensschluß und die Darstellung der Ereignisse im TYTZ}

Mit den Kämpfen im Gebiet von Hsenwi begannen die militärischen Auseinandersetzungen, die sich zu einem Krieg zwischen China und Birma entwickeln sollten.

Der Qianlong-Kaiser hatte Yang Yingju zum Generalgouverneur ernannt und mit dem militärischen Oberbefehl betraut. Yang mobilisierte die chinesischen Truppen und konnte weiter südöstlich bei Cheli (Sipsongpanna) einen Sieg über die Birmanen erringen; die anschließenden Kämpfe um das benachbarte Menglian verlor China jedoch.

Zu dieser Zeit gab der Kaiser darüber hinaus sein Einverständnis zu einem Plan der Beamten in Yunnan, das Gebiet von Hsenwi (Mubang) mit Zustimmung des einheimischen Herrschers zu besetzen und die Birmanen daraus zu vertreiben. Dieses Vorhaben gelang zunächst. Chinesische Truppen waren nach Bhamo und Hsenwi vorgerückt. Eine Armee unter Führung des Generals Zhao Hongbang hatte Bhamo erobert und war bis nach Kaungton (chin. Laoguantun) gezogen, der strategischen wichtigen Festung der Birmanen am Irawadi. ${ }^{606}$ Dort wurde sie jedoch von Birmanen besiegt und mußte sich bis in das Gebiet von Ganya und Zhanda zurückziehen. Auch die chinesischen Truppen in Hsenwi wurden zurückgeschlagen. ${ }^{607}$ Die Birmanen rückten bis an die südlichen der acht Paßstationen vor; die tusi-Gebiete in der Region wurden während der Kämpfe verwüstet. ${ }^{608}$ Anfang 1767 drangen birmanische Truppen in das Gebiet von Mengmao ein. Eine chinesischen Armee unter Führung von General Ha Guoxing konnte sie zunächst wieder zurückdrängen und ihrerseits Mengmao besetzen; die Kämpfe in diesem Gebiet gingen jedoch weiter. ${ }^{609}$

General Ha Guoxing kam nach der Darstellung des TYTZ eine bedeutende Rolle im chinesisch-birmanischen Krieg zu. ${ }^{610}$ Er stammte aus einer Soldatenfamilie aus Zhili und hatte bereits verschiedene Posten als Militärkommandant in Yunnan innegehabt, ehe er als

\footnotetext{
${ }^{605}$ Das spärliche Wissen über die aktuelle Lage in Birma, wie es unter anderem in den Beschreibungen der fangzhi aus Tengyue deutlich wird, zeigt, darauf weist auch Richard L. K. Jung hin, daß das chinesische Reich tatsächlich kein Interesse an einer Expansion weiter nach Südwesten bzw. der Eroberung Birmas hatte (Jung, S. 80).

${ }^{606}$ Maung Htin Aung, S. 177; Jung, S. 85

${ }^{607}$ U Aung Sein Han, S. 135-136

${ }^{608}$ Jung, S. 85

${ }^{609}$ TYTZ, S. 188

${ }^{610}$ Siehe TYTZ, S. 188
} 
Truppenführer in den äußersten Südwesten entsandt wurde. Obwohl General Ha während der Kämpfe um Mengmao verwundet worden war (,eine Kugel hatte seine Wange durchbohrt und ihm die Vorderzähne ausgeschlagen“) und einen Genesungsurlaub angetreten hatte, nahm er bereits wenige Monate später wieder am Feldzug unter Generalgouverneur Mingrui teil. Auch in dem folgenden Feldzug unter dem Oberkommando von Fuheng übernahm er, inzwischen zum Militärkommandanten (tidu) der Provinz Guizhou befördert, ein Kommando und war schließlich auch an den Friedensverhandlungen mit den Birmanen beteiligt. $^{611}$

Die Kurzbiographie des Ha Guoxing im TYTZ enthält eine zusammenhängende und relativ ausführliche Darstellung der Kampfhandlungen aus chinesischer Sicht, anders als das Kapitel über Birma oder die Chronologie militärischer Ereignisse in den Lokalhandbüchern, die nur äußerst knapp auf einzelne chinesische Erfolge im Verlauf des Krieges eingehen. $^{612}$

Seit Beginn der Kämpfe in der Grenzregion hatte Gouverneur Yang Yingju Peking nur über Erfolge der chinesischen Truppen informiert. Da die Kampfhandlungen dennoch immer weitergingen, vermutete der Kaiser, daß die Berichte Yangs nicht der Wahrheit entsprachen. Im Februar 1767 berichtete Yang Yingju erneut von Siegen und schlug die Annahme eines angeblich von den Birmanen gemachten Angebotes der Kapitulation vor. Dabei wies er insbesondere auf die Schwierigkeiten hin, die ein weiterer Feldzug aufgrund der militärischen Stärke Birmas, des ungewohnten Klimas und der Gefahr der Malaria bedeuten würde sowie auf den hohen Kosten- und Zeitaufwand. Dies bestätigte den Kaiser in seinen Zweifeln an den Siegesmeldungen aus Yunnan und er entsandte seinen Ratgeber Fuheng in die Provinz, der dann wahrheitsgemäß über die Niederlagen der chinesischen Truppen berichtete. ${ }^{613}$

Daraufhin ernannte der Kaiser den Militärkommandeur Mingrui, einen Neffen Fuhengs, im Jahr 1767 zum Generalgouverneur von Yunnan und neuen Oberkommandeur. ${ }^{614}$

Chinesische Soldaten aus Guizhou, Sichuan und Yunnan, insgesamt zwanzigtausend Mann, sowie dreitausend Mandschu-Soldaten wurden mobilisiert; die Kämpfe im Grenzge-

\footnotetext{
${ }^{611}$ TYTZ, S. 188

${ }^{612}$ Siehe TYTZ Kapitel 11, ,Militärische Verdienste‘ (S. 188), Kapitel 15, ,Birma‘ (S. 243-245) und die Chronologie militärischer Ereignisse ebenfalls in Kapitel 11 (S.192). Kaiserliche Denkschriften und Throneingaben zu Ereignissen während des Krieges sind dem TYTZ in einem Anfangskapitel (juan zhi shou, lie shengyu zhi) vorangestellt (S. 17-24).

${ }^{613}$ Jung, S. 85-86

${ }^{614}$ Herzog Mingrui stammte aus dem Fuca-Clan, seine Tante war die erste Ehefrau des Qianlong-Kaisers. In den 1750er Jahren war Mingrui an der Eroberung und Kolonisierung der Region Ili im Nordwesten des Qing-Reiches beteiligt und wurde für seine Verdienste zum Militärgouverneur von Ili befördert, diesen Posten hatte er bis zum Jahr 1766 inne. Im folgenden Jahr wurde er zum Generalgouverneur von Yunnan ernannt (Hummel, S. 578).
} 
biet weiteten sich nunmehr endgültig zu einem Krieg aus. ${ }^{615}$ Oberkommandeur Mingrui plante mit seinen Truppen über Wanding nach Hsenwi und Lashio vorzurücken und Ava zu erobern; ein zweites chinesisches Heer sollte ihnen über Bhamo und Mengmi folgen. ${ }^{616}$ Mingrui gelang es bis nach Singaung südlich von Maymyo vorzurücken. Als die Birmanen jedoch seine Versorgungslinien unterbrachen, mußte er sich bis in die Nähe von Wanding zurückziehen. Die birmanischen Truppen rückten über Hsenwi weiter vor und umzingelten Mingrui und die Nachhut seiner Armee in Mongyu in der Nähe von Wanding, wo der Oberkommandeur im März 1768 Selbstmord beging. ${ }^{617}$

Im TYTZ heißt es dazu, daß Mingrui in der Schlacht umgekommen ist (zhen wang), als „er persönlich die Nachhut geführt hatte, dabei von den [birmanischen] Banditen verwundet wurde und dann bei Wanding gestorben ist.

Der Häuptling von Birma überreichte ein Schreiben auf einem Palmblatt ( $p u$ ye shu), in dem er darum bat, daß die [chinesischen] Truppen abgezogen würden. [Dieser Bitte] wurde jedoch vom Kaiser nicht stattgegeben“. 618

Eine Bitte um Frieden von den doch siegreichen Birmanen erscheint unwahrscheinlich und entspricht wohl eher dem Wunsch des Autors dieses Textes als den Tatsachen. Deutlich wird hier das Bemühen des Verfassers, die schmähliche Niederlage zu beschönigen und eine positive Darstellung der Ereignisse in den fangzhi festzuhalten.

Zum Nachfolger Mingruis als Oberkommandeur der Truppen wurde sein Onkel Fuheng ernannt, der im Mai 1769 nach Tengyue kam, um zusammen mit den Generälen Agui und Aligun einen weiteren Feldzug gegen Ava zu führen, für den über vierzigtausend Soldaten mobilisiert wurden. ${ }^{619}$

\footnotetext{
${ }^{615}$ Hummel, S. 578; Jung, S. 87

${ }^{616}$ U Aung Sein Han, S. 137. Nach U Aung Sein Han soll Mingrui auch den Auftrag gehabt haben, den birmanischen König gefangen zu nehmen (ebd.).

${ }^{617}$ U Aung Sein Han, S. 139; Jung, S. 87-88

${ }^{618}$ TYTZ, S. 188; 244

${ }^{619}$ Fuheng aus dem Fuca-Clan war der jüngere Bruder der ersten Ehefrau des Qianlong Kaisers. Er hatte bei der Niederschlagung der Rebellion in der Region Jinchuan im westlichen Sichuan Verdienste erworben und war auch an der Eroberung der Ili-Region beteiligt. Im Jahr 1767 wurde er auf eigenen Wunsch zum Oberkommandeur der Feldzüge gegen Birma ernannt (Hummel, S. 252-253).

Agui, ein Angehöriger des Zhangjia-Clans, war Mitte des 18. Jahrhunderts an verschiedenen Militärkampagnen in der Region Ili und an der Kolonisierung des Gebietes beteiligt, zuletzt als Assistent des Militärgouverneurs Mingrui, dessen Amt er 1767 übernahm, ehe er 1768 ebenfalls nach Yunnan entsandt wurde, wo er kurzzeitig das Amt des Generalgouverneurs innehatte, bis er 1769 ein Kommando im Birma-Feldzug erhielt (Hummel, S. 6-8).
} 
Karte 10: Die Feldzüge der Qing-Armeen im chinesisch-birmanischen Krieg

(Karte nach Richard L. K. Jung, The Sino-Burmese War, Karten 2 und 3)

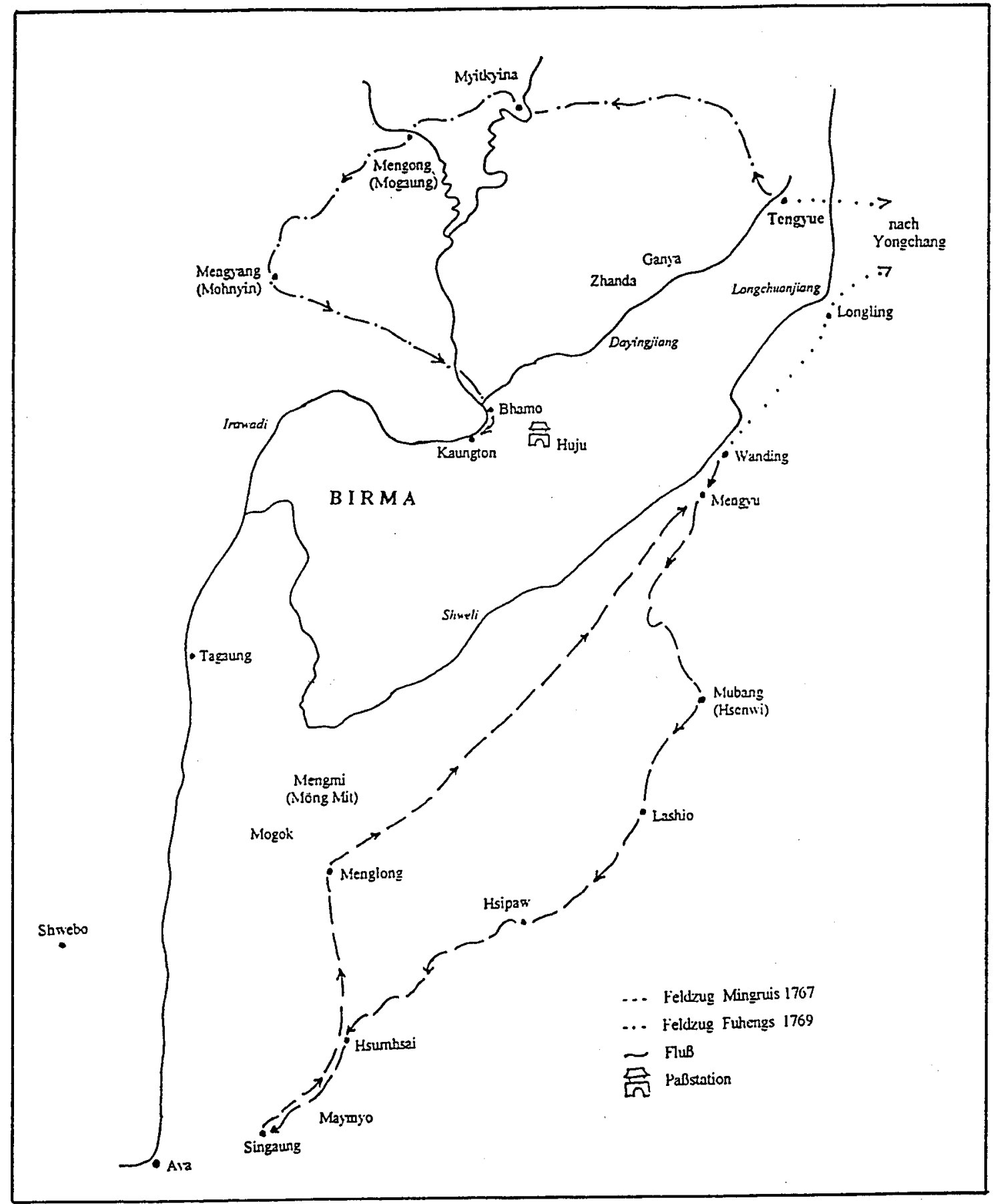


Fuheng wählte eine nördlichere Marschroute als sein Vorgänger und rückte am 20. Tag des 7. Monats von Tengyue nach Westen vor und überquerte den Irawadi südlich von Myitkyina. ${ }^{620}$ Die Kleinstaaten in der Region, Menggong (Mogaung), Mengyang (Mohnyin) sowie Nanfeng, Menglie und Mengba, unterwarfen sich der chinesischen Armee. ${ }^{621}$

Nach diesen Erfolgen wandte Fuheng sich wieder nach Osten und eroberte Anfang des 9. Monats zusammen mit General Agui Bhamo. ${ }^{622}$ In den Wäldern am Wenggushan fanden sie ausreichend Material für den Bau von Booten und auf der angrenzenden Hochebene von Yeniu auch einen zum Bootsbau geeigneten Ort, „an dem es angenehm kühl war, die Luft nicht mit Miasmen (wu zhang qi) belastet war und man gut zahlreiche Soldaten und Handwerker stationieren konnte“, die von den Einheimischen bei ihrer Arbeit unterstützt wurden. ${ }^{623}$ Gemeinsam rückten ihre Armeen dann bis Kaungton vor. Die Birmanen hielten jedoch wie zuvor diese strategische Festung, die sie „zu Wasser und zu Lande entschlossen verteidigten“. ${ }^{624}$ Die chinesischen Truppen, denen auch Marinesoldaten aus der Küstenprovinz Fujian angehörten, griffen Kaungton vom Fluß her an, ihre Boote wurden jedoch von einer birmanischen Flotte versenkt. ${ }^{625}$

Die chinesischen Truppen hatten während der Feldzüge ohnehin schon große Verluste erlitten, denn im Kriegsgebiet „herrschte ein übles Klima; zwar ließen die Miasmen im Winter nach, aber im Frühling war es ganz unmöglich, dort weiter vorzurücken““. ${ }^{626}$ Zwei Drittel der Soldaten waren bereits umgekommen,

„lediglich die zehntausend Soldaten, die General Agui von Longling zur Unterstützung über den Huju-Paß neu herbeigeführt hatte, konnten noch militärische Stärke zeigen. Sie rückten auf dem Landweg nach [Kaungton] vor. Dabei errichteten sie eine Plattform, auf der sie Kanonen abfeuern konnten (zhu tai fa huopao) und griffen an. Die Birmanen fürchteten sich sehr“. 627

\footnotetext{
${ }^{620}$ TYTZ, S. 19 (Throneingabe Fuhengs aus dem Jahr 1769)

${ }^{621}$ TYTZ, S. 188

${ }^{622}$ TYTZ, S. 19

${ }^{623}$ TYTZ, S. 18 (Throneingabe Fuhengs aus dem Jahr 1769)

${ }^{624}$ TYTZ, S. 188

${ }^{625}$ Maung Htin Aung, S. 180-181; Jung, S. 89; TYTZ, S. 19. Fuheng berichtete in seiner Throneingabe hingegen von einem Sieg seiner Armee: Die chinesischen Truppen hätten ihre Gewehre und Geschütze am östlichen Ufer des Irawadi in Stellung gebracht. Als sich ihnen ein großes Schiff der Birmanen genähert habe, das von einem in Rot gekleideten Kommandanten gesteuert wurde, seien die Han-chinesischen Marinesoldaten dem Feind entgegen gezogen, hätten mit ihren Geschützen das Schiff zerstört und die Birmanen in die Flucht geschlagen (siehe TYTZ, S. 19).

${ }^{626}$ TYTZ, S. 20 (Throneingabe Fuhengs aus dem Jahr 1769).

${ }^{627}$ TYTZ, S. 188
} 
Gleichwohl verteidigten die Birmanen ihre Stellung. Die chinesischen Truppen hingegen mußten nicht nur militärische Rückschläge hinnehmen, sondern auch weiterhin das für sie ungewohnte tropische Klima ertragen. Angesichts dieser Erfahrungen kamen die Herausgeber des TYTZ zu folgendem Schluß:

„In Birma herrscht ein übles Klima. Schon immer waren Regierungssoldaten, die man dort hingeschickt hatte, jedesmal erkrankt und viele sind sogar gestorben. Das ist wahrlich kein Land, in dem man Militär einsetzen kann“ ${ }^{628}$

Aufgrund der großen Verluste durch Tropenkrankheiten (zhangli) - General Aligun und der für den Bootsbau verantwortliche Kommandant waren gestorben und auch der Oberkommandeur Fuheng selbst war an Malaria erkrankt - beschloß der Qianlong Kaiser den Rückzug seiner Soldaten. ${ }^{629}$

Doch ehe dieser tatsächlich angeordnet wurde, hatten im Kriegsgebiet bereits Friedensverhandlungen der Kommandeure der beiden Armeen begonnen.

Im TYTZ wird die Rolle General Ha Guoxings, der bereits einige Erfahrung im Umgang mit fremden Völkern gemacht hatte, bei den Friedensverhandlungen mit dem Befehlshaber von Kaungton besonders hervorgehoben:

„Hatte er mit den Fremdvölkern an der Grenze (bian yi) zu tun, so wendete Ha die Taktik an, es zuerst mit Verhandlungen zu versuchen und erst falls diese fehlschlugen, Soldaten einzusetzen (xian li hou bing). Deshalb diskutierte (yi hua) er genauso auch mit den Fremden von jenseits der Grenze (wai yi). ...

Zu dieser Zeit ließ Xieyiwan, der birmanische Häuptling ( $m u$ ) von Kaungton, seinen Anführer ( $m u$ ) Deluwen ein Schreiben überreichen (di wen), in dem er inständig darum bat, die [chinesischen] Soldaten abzuziehen. Am Tag darauf kam Deluwen heraus, um Guoxing zu treffen. Xing ging auch in die Festung (zha) hinein, um jene zu treffen und machte Xieyiwan und den anderen mit strengen [Worten] drei Punkte klar: Erstens sei es ihnen nicht erlaubt, erneut Übergriffe über die Grenze zu wagen ( $b u$ xu qinrao bianjie), zweitens seien unsere Leute, die von ihnen festgehalten würden, sämtlich freizulassen und drittens hätten sie alle zehn Jahre eine Tributmission zu entsenden“‘ ${ }^{630}$

\footnotetext{
${ }^{628}$ TYTZ, S. 21

${ }^{629}$ Jung, S. 89; TYTZ, S. 22

${ }^{630}$ TYTZ, S. 188
} 
Nachdem diese Vorverhandlungen erfolgreich abgeschlossen worden waren, wurde in Kaungton am 13. Dezember 1769 ein Friedensvertrag geschlossen, ohne daß die Oberkommandierenden beider Seiten zuvor die Zustimmung ihrer Herrscher eingeholt hatten. ${ }^{631}$

Die chinesischen Truppen zogen sich daraufhin über den Huju-Paß nach Yunnan zurück. Oberkommandeur Fuheng stellte dem Kaiser gegenüber Chinas Niederlage als Sieg dar; schließlich war die Oberhoheit über einige Gebiete unter einheimischen Machthabern gesichert worden:

„Der tusi von Menggong, Hunjue, hat sich im neunten Monat des Jahres 34 (1769) ergeben ... und Elfenbein sowie Ochsen [als Tribut] überreicht ..., im zehnten Monat übersandte er weitere vier Elefanten. Das Amtsiegel eines Befriedeten Gebietes (xuanfusi) wurde geprägt und ihm übergeben. Danach haben [die chinesischen Truppen] auch Mengyang erobert“ ${ }^{632}$

Somit war eines der ursprünglichen Kriegsziele erreicht und der Frieden im Grenzgebiet wieder hergestellt worden. Außerdem bestätigte Fuheng dem Kaiser Birmas Status als Tributstaat. Die Verpflichtung Birmas zur Übersendung von Tribut wird auch in der Darstellung des TYTZ besonders hervorgehoben. Auf eine Erwähnung der Niederlagen der chinesischen Armeen wird in der äußerst knappen Zusammenfassung der Ereignisse hingegen verzichtet:

„Im 12. Monat des Jahres 34 (1769/1770) hatten [die chinesischen Truppen] Kaungton umzingelt; Meng Bo [das ist der birmanische König Hsinbyushin] überreichte ausländische Brokate, Baumwoll- und andere Stoffe sowie verschiedene Geschenke und ersuchte eindringlich (kenqiu) darum, die Kämpfe einzustellen; er versprach, alle zehn Jahre Tribut zu übersenden. Der Kaiser gestattete dies. ...

Im 35. Jahr (1770) wurden die chinesischen Truppen abgezogen“ ${ }^{633}$

Der Qianlong-Kaiser akzeptierte zwar nachträglich den Friedensvertrag. Er machte jedoch die Wiederaufnahme des bilateralen Handels von der Übersendung des Tributs aus Birma abhängig. $^{634}$

\footnotetext{
${ }^{631}$ U Aung Sein Han, S. 144-146.

${ }^{632}$ TYTZ, S. 244

${ }^{633}$ TYTZ, S. 244

${ }^{634}$ Siehe Jung, S. 90-92.
} 
Der birmanische König Hsinbyushin hingegen lehnte den Friedensvertrag ab. ${ }^{635}$ Da seine siegreichen Truppen die chinesischen Armeen dreimal zurückgeschlagen hatten, kam für ihn eine auch nur nominelle Anerkennung des Tributstatus nicht in Frage.

In China traf also kein Tribut aus Birma ein, folglich verhängte der Kaiser ein Handelsembargo. Der Generalgouverneur von Yunnan und Guizhou, Zhangbao, schickte BrigadeVizekommandant Su Erxiang nach Birma, um den Tribut einzufordern. Der birmanische König ließ Su gefangennehmen. ${ }^{636}$ General Agui schlug daraufhin eine neue Militärkampagne vor, um die chinesischen Forderungen durchzusetzen. Der Qianlong-Kaiser lehnte dies jedoch ab, da er sich von Birma nicht zu einem neuen teuren Krieg provozieren lassen wollte, zumal die chinesischen Truppen in den Jahren 1771 bis 1776 für die Kämpfe in Jinchuan (Sichuan) benötigt wurden. ${ }^{637}$ Su Erxiang wurde erst 1777 von den Birmanen freigelassen:

\begin{abstract}
„Nach sieben Jahren entsandte der birmanische Häuptling den Deluwen [von Kaungton], seine Gefolgsleute Meng Wei, Meng Ling, Meng Mei und andere, die lokale Produkte überreichten und Su Erxiang [nach Yunnan] zurückbegleiteten“. 638
\end{abstract}

Birma war aus dem Krieg mit China siegreich hervorgegangen und hatte seine Autorität über die Kleinstaaten der Region und seine Vormachtstellung im Grenzgebiet festigen können. Der Versuch Yang Yingjus den chinesischen Einflußbereich durch die Eroberung von Mubang (Hsenwi) weiter nach Südwesten auszudehnen, war hingegen fehlgeschlagen. Im Westen Yunnans bildeten nach wie vor die acht Paßstationen die Grenze zwischen den Gebieten unter chinesischer Oberhoheit und denen jenseits davon.

\title{
3. 3. Die Darstellung der chinesisch-birmanischen Beziehungen in der Nachkriegszeit am Ende des 18. Jahrhunderts in den fangzhi
}

Erst Bodawpaya, seit 1782 König von Birma, nahm wieder offiziell Beziehungen zu China auf und schickte 1788 eine Gesandtschaft nach China, die von den örtlichen Beamten in

\footnotetext{
${ }^{635}$ Maung Htin Aung, S. 182

${ }^{636}$ Jung, S. 92-93. Siehe auch TYTZ, S. 21-22, 137.

${ }^{637}$ Jung, S. 93. General Agui hatte die Friedensverhandlungen mit den Birmanen geführt. Als der erwartete Tribut aus Birma nicht in Peking eintraf, wurde er vom Kaiser verantwortlich gemacht und degradiert. Dank seiner militärischen Erfolge bei der Niederschlagung der Rebellion im Gebiet von Jinchuan im Jahr 1776 wurde er jedoch rehabilitiert und befördert. Im Jahr 1776 wurde er noch einmal für kurze Zeit nach Yunnan entsandt (Hummel, S. 7-8).

638 TYTZ, S. 137
} 
Gengma und Yunnan fu als Tributgesandschaft deklariert und dann von der Präfektur Shunning aus zur kaiserlichen Audienz in die Sommerhauptstadt Jehol geleitet wurde. ${ }^{639}$ Es waren vor allem pragmatische Gründe, die König Bodawpaya veranlaßten, die Beziehungen zu China wieder aufzunehmen. Im Jahr 1785 hatte er einen neuen Krieg gegen Siam begonnen und war daran interessiert, sowohl Ruhe an der Grenze zu China zu haben als auch eine Allianz zwischen China und Siam, wie sie im 16. Jahrhundert von Generalgouverneur Chen Yongbin geschlossen worden war, zu verhindern. ${ }^{640}$

Der Qianlong-Kaiser hob nach dem Empfang der Gesandtschaft das Handelsembargo auf, erkannte Bodawpaya im Jahr 1790 als König von Birma an und übersandte ihm eine Ernennungsurkunde und ein Siegel. ${ }^{641}$

Die chinesische Gesandtschaft, die diese kaiserlichen Gaben überbringen sollte, reiste von Tengyue aus nach Birma und wurde von Unterpräfekt Tu Shulian (von 1788 bis 1791 im Amt) begleitet. Der Verlauf der Gesandtschaftsreise wird in den fangzhi von Tengyue im Kapitel über Birma ausführlich beschrieben:

\section{Bericht über die Reise der chinesischen Gesandtschaft nach Birma:}

„Im Jahr 55 (1790) wurde Meng Yun ${ }^{642}$ [vom chinesischen Kaiser mit dem Titel] des Königs von Ava-Birma belehnt und erhielt ein kaiserliches Edikt, einen Kamelknopf (tuoniu) und ein vergoldetes Siegel aus Silber. *Der Kaiser ließ ein Gedicht (shi yi zhang), eine kaiserliche Denkschrift (chiyu yi dao) sowie eine Schmuckbörse mit von Hand aufgefädelten Perlen (zhenzhu shou chuan hebao) und andere Dinge übersenden. ${ }^{643 *}$ Der Beamte der Steuerbehörde, Yonghui, und Bai Fu, Regionalkommandant der Brigade Guangnan, erhielten den Befehl, sich nach Birma zu begeben und den Edikt über den Lehensstatus zu verkünden (xuan feng). ${ }^{644}$ Unterpräfekt Tu Shulian begleitete sie. Am 15. Tag des 6. Monats überquerten sie den Tiebi-Paß....

\footnotetext{
${ }^{639}$ Koenig, S. 18. Nachdem König Bodawpaya von der Umbenennung seiner Gesandtschaft in eine Tributmission erfahren hatte, unterbrach er die diplomatischen Beziehungen zwischen den beiden Reichen in den Jahren 1796 bis 1823, der bilaterale Handel wurde davon jedoch nicht beeinträchtigt (ebd.). Bis zur Eroberung durch die Briten 1886 sandte Birma dann weiterhin Tribut nach China.

640 Jung, S. 94-95

${ }^{641}$ Jung, S. 94

${ }^{642}$ Das ist König Bodawpaya (reg. 1782-1819).

${ }^{643}$ Im TYZZ werden noch andere Geschenke aufgezählt als im Text des TYTZ. Der entsprechende Satz aus dem TYZZ ist hier eingefügt und mit * gekennzeichnet; ebenso weiter unten in der Übersetzung.

644 Die Verwaltungseinheit Getreide-Steuerregion (liangchudao) Yunwu war 1766 gegründet worden. Liangdao (TYTZ, S. 245; Hucker 3683: Tax Ciruit) bzw. liangchudao (,Getreide-Steuerregion‘; TYZZ, S. 162; Hucker 3663: Grain Tax Circuit).
} 
Meng Yun schickte einen Minister und außerdem seinen Sohn nach Kaungton, um sie willkommen zu heißen. Auf dem weiteren Weg, schenkten diese [den Chinesen] Fische, Salz und Reis. Sie verhielten sich äußerst ehrerbietig. Yonghui und die Anderen wußten es zu würdigen, daß sie [diese Dinge] geschenkt bekamen, die ihnen [unterwegs] sonst gefehlt hätten.

Am 19. Tag kamen sie in Xinjie (Bhamo) an, wo Meng Gan ihnen Schiffe überließ. Sie hissten die Segel und fuhren den Fluß [Irawadi] hinab. Meng Yun selbst kam ihnen bis zur Stadt Jiuniu, die vier Stationen (zhan) von Ava entfernt liegt, entgegen, um sie zu empfangen.

Am 10. Tag des 7. Monats trafen Yonghui und die Anderen in Ava ein und verkündeten [den Edikt] zur Belehnung [mit dem Königstitel]. Meng Yun kniete nieder, so wie es Sitte ist, um [den Edikt] zu empfangen. Er führte die zeremoniellen (li) drei Verbeugungen und die neun Kotau aus, ehe er die Belehnung, *die kaiserliche Denkschrift, das Gedicht, die Schmuckbörse mit den von Hand aufgefädelten Perlen und die anderen Dinge* kniend entgegennahm und sie respektvoll verwahrte.

Yonghui und die Anderen kehrten am 13. Tag zu den Schiffen zurück. Meng Yun kam aus der Stadt heraus, um sie persönlich zu verabschieden. Außerdem entsandte er einen seiner Anführer, der ein Schreiben auf Goldblatt, zwei gezähmte Elefanten sowie verschiedene andere Tributgaben überreichen und im Gefolge von Yonghui in die [chinesische] Hauptstadt reisen sollte. Er wollte sich damit für das [kaiserliche] Wohlwollen bedanken, [versprach,] den Status eines Vasallen über Generationen zu erhalten, und alle zehn Jahre einmal Tribut zu senden. .......

Am 21. Tag des 8. Monats passierten sie den Tiebi-Paß, am 27. Tag erreichten sie Tengyue. Yonghui und Bai Fu begleiteten die birmanischen Gesandten zu einer geeigneten Wohnung. Die drei [Gesandten] Kongsuming, Jueying und Dajue (mit Begleitern und Dienern insgesamt neun Personen), die die Tributgeschenke und das Schreiben überreichen sollten, reisten dann in die Hauptstadt [Peking] weiter. Unterpräfekt Tu Shulian versorgte sie mit Proviant für unterwegs und begleitete sie bis in die Provinzhauptstadt.“645

${ }^{645}$ TYTZ, S. 245; TYZZ, S. 162-163 
Der Bericht über die Gesandtschaftsreise in den Lokalhandbüchern von Tengyue hebt besonders das respektvolle, geradezu unterwürfige Verhalten des birmanischen Königs hervor, das ganz dem traditionellen chinesischen Zeremoniell für derartige Anlässe entsprochen haben soll, bis hin zum neunfachen Kotau vor den Geschenken des Kaisers. Das pragmatische Interesse König Bodawpayas an der Wiederaufnahme der Beziehungen, der der chinesischen Delegation sicherlich einen protokollarischen Empfang zukommen ließ, bleibt selbstverständlich unerwähnt. Zwei Jahrzehnte nach dem Ende des chinesischbirmanischen Krieges war mit dem Austausch der Gesandtschaften das Einvernehmen zur Zufriedenheit beider Nachbarn wiederhergestellt.

Zum Abschluß ihrer Darstellung der Ereignisse fassen die Herausgeber des TYTZ den Stand der Beziehungen zwischen China und Birma gegen Ende des 19. Jahrhunderts aus chinesischer Sicht noch einmal zusammen:

„Vom Jahr Qianlong 53 (1788) bis zum gegenwärtigen Jahr Guangxu 11 (1885) hat [Birma] Tribut geschickt und kann als ein sehr gehorsamer Vasallenstaat bezeichnet werden (cheng fan ji wei gongshun)“. ${ }^{646}$

\section{Nachkriegszeit: Die Unterpräfektur Tengyue im 18. Jahrhundert}

Der Krieg zwischen China und Birma hatte in den sechziger Jahren des 18. Jahrhunderts zunächst mit militärischen Auseinandersetzungen südlich von Yongchang und Tengyue, im Gebiet von Mubang, Gengma und Menglian begonnen. In den folgenden Jahren spielten sich die Kampfhandlungen zumeist in diesem Gebiet und in Kaungton (chin. Laoguantun) am Irawadi ab.

Im Jahr 1766 (Qianlong 31) hatten sich die Truppen Zhao Hongbangs vor den nachrückenden Birmanen, den Flußtälern des Dayingjiang nach Norden folgend, bis nach Ganya und Zhanda zurückziehen müssen. Dieser Vorstoß der birmanischen Truppen bis in die tusiGebiete südwestlich der Unterpräfekturstadt weckte große Besorgnis in der Region. Es stand zu befürchten, daß sie noch weiter nach Osten vordringen und auch Tengyue erobern könnten. Daher ließen der Militärkommandant und der Präfekt von Yongchang vorsichtshalber eine Brücke über den Salween zerstören, um zu verhindern, daß die Birmanen den Fluß überqueren und Yongchang angreifen könnten. ${ }^{647}$

\footnotetext{
${ }^{646}$ TYTZ, S. 245. In dem genannten Jahr 1885 endeten die Tributbezieuhngen zwischen Birma und China. Anschließend wird im TYTZ berichtet, daß die Engländer im Jahr 1886 Birma erobert haben; Tributbeziehungen werden danach nicht mehr erwähnt (ebd.).

${ }^{647}$ TYTZ, S. 57 (Tianji qiao, siehe unten Abschnitt 9, S. 310-311).
} 
Der tusi von Nandian hegte ähnliche Befürchtungen und zog sich in ein Dorf am Berg Yongan zurück, das etwa zehn Kilometer von seinem Amtssitz entfernt lag, dessen Verteidigung er einem seiner Untergebenen überließ. ${ }^{648}$

Tengyue selbst war nicht direkt vom Kampfgeschehen betroffen. Die Stadt und ihre Umgebung waren jedoch Aufmarsch- und Rückzugsgebiet der chinesischen Truppen und so bestimmte der Krieg jahrelang das Leben auf der Hochebene von Tengyue.

Die Zentralregierung finanzierte die Feldzüge nach Birma; da sich die Truppen vor Ort mit Proviant eindeckten, konnten Händler und Produzenten in der Region durchaus von der Situation profitieren. Im Jahr 1769 jedoch, als Fuheng seinen Feldzug nach Oberbirma von Tengyue aus begonnen hatte, verschlechterte sich die Versorgungssituation der Bevölkerung erheblich, als eine Mißernte zu einer Hungersnot führte. ${ }^{649}$

Nach Kriegsende mußte die Militärverwaltung der Unterpräfektur reorganisiert und den veränderten Machtverhältnissen im Grenzgebiet angepaßt werden. In der Stadt galt es vor allem die vom Militär genutzten Gebäude zu renovieren, so daß sie wieder ihrer ursprünglichen Bestimmung gemäß genutzt werden konnten. Verantwortlich für die Organisation dieser Arbeiten war der amtierende Unterpräfekt von Tengyue.

\section{1. Unterpräfekt Wu Kai}

Nach dem Ende des chinesisch-birmanischen Krieges trat ein neuer Unterpräfekt sein Amt in Tengyue an: Wu Kai, der aus dem Kreis Jiangyin in der Provinz Jiangsu stammte. Er hatte die Staatsprüfungen in der Hauptstadt erfolgreich absolviert und den akademischen Titel eines jinshi erworben. Im Jahr 1763 war Wu nach Yunnan gekommen und zunächst als Kreismagistrat (xianling) tätig gewesen. ${ }^{650}$

Im Jahr 1769 hatte er am Feldzug von Generalgouverneur Fuheng nach Birma teilgenommen. Anhand seiner persönlichen Erfahrungen und unter Hinzuziehung historischer Quellen verfasste Wu Kai eine Abhandlung über den chinesisch-birmanischen Krieg, Zheng Mian jilüe (,Eine kurze Darstellung der Feldzüge nach Birma`), in der er neben

\footnotetext{
648 TYTZ, S. 293

${ }^{649}$ TYTZ, S. 29

${ }^{650}$ TYTZ, S. 109, 146, 259; TYZZ, S. 80, 116-118; YCFZ, S. 162. Wu Kai soll nach diesen Angaben außerdem in Yongping und in der Präfektur Yongchang tätig gewesen sein. In den Listen der in der Präfektur Yongchang tätigen Beamten des YCFZ wird Wu Kai jedoch nur als Unterpräfekt von Tengyue genannt.
} 
einer detailreichen Schilderung des Kampfgeschehens der Jahre 1765 bis 1769 auch die beiden Gesandtschaften aus Birma in den Jahren 1787 und 1789 beschreibt, welche die offizielle Wiederaufnahme der Beziehungen zwischen den beiden Ländern einleiteten. ${ }^{651}$

Als Wu Kai im Jahr 1770 das Amt des Unterpräfekten von Tengyue antrat, hatte er also bereits Erfahrungen in der Lokalverwaltung der Provinz Yunnan gesammelt und war aus eigener Anschauung mit der aktuellen Situation im Grenzgebiet vertraut. Wu war neun Jahre lang in Tengyue tätig. In den fangzhi wird er als tüchtiger und umsichtiger (ganlian jingxi) Verwaltungsbeamter beschrieben, der im Jahr 1779 von seinem Amt entbunden wurde, um die Trauerzeit für seine Eltern einhalten zu können. ${ }^{652}$

In die Amtszeit des Unterpräfekten Wu Kai fielen etliche größere Renovierungsprojekte (siehe Tab. 18, S. 226), denn als Oberkommandeur Fuheng am 20. Tag des 7. Monats des Jahres Qianlong 34 (1769) von der Stadt Tengyue aus den letzten der chinesischen Feldzüge nach Birma begann, diente ihm Tengyue als Truppenstützpunkt und verschiedene Amtsgebäude und Tempel in der Stadt und ihrer Umgebung wurden vom Militär genutzt und waren anschließend reparaturbedürftig.

In den fangzhi des 19. Jahrhunderts sind die jeweiligen Hinweise auf die von Wu Kai veranlaßten Renovierungsarbeiten an den diversen Tempeln, Amts- und anderen Gebäuden in den Auflistungen der Bauwerke von Tengyue sowie die Gedenkinschriften Wu Kais die einzigen und auch nur indirekten Hinweise darauf, wie stark die jahrelange Truppenpräsenz während des chinesisch-birmanischen Krieges das öffentliche Leben in Tengyue bestimmt hat.

\footnotetext{
${ }^{651}$ Siehe Sun Laichen, Chinese historical sources on Burma, S. 36. Das Zheng Mian jilüe ist in der Edition von Wang Chang (1725-1802) erhalten. Diese wurde von Li Genyuan in sein 1941 herausgegebenes Kompendium historischer Materialien zur Präfektur Yongchang, Yongchang fu wenzheng, aufgenommen (siehe YCFWZ, Aufzeichnungen [jizai], juan 17, Qing 6). 
Tabelle 18: Unter der Leitung von Unterpräfekt Wu Kai renovierte Bauwerke ${ }^{653}$

$\begin{array}{ll}\text { Jahr } & \text { Bauwerk } \\ 1770 & \text { Amt der Unterpräfektur (Ting shu) } \\ & \text { Schultempel (Xuegong) } \\ & \text { Tempel des Kriegsgottes (Shenyong Guandi miao) } \\ & \text { Tempel des Erdgottes (Zhao Teng Tuzhu miao) } \\ 1771 & \text { Altar der Landwirtschaft (Xiannong tan) } \\ 1773 & \text { Ximeng Tempel } \\ 1776 & \text { Amt der Unterpräfektur (Ting shu) } \\ & \text { Eisenkettenbrücke über den Longjiang } \\ & \\ 1777 & \text { Getreides } \\ & \text { (Sheji tan) } \\ & \text { Altar der Gottheiten der Naturerscheinungen } \\ & \text { (Feng yun lei yu shan chuan tan) } \\ & \\ 1776 & \text { Tempel des Stadtgottes (Chenghuang miao) } \\ & \text { Gedenkhalle für den Fürsten von Wu (Wu hou ci) } \\ & \text { Laifengshan Akademie } \\ \text { Ohne Jahresangabe } & \\ & \\ & \end{array}$

Eines der ersten Projekte Wu Kais war der Wiederaufbau des Verwaltungssitzes der Lokalregierung. Erste Arbeiten ließ Wu dort bereits im Jahr seines Amtsantrittes ausführen, die im folgenden Jahr fortgesetzt wurden und von 1776 bis 1777 wurden dann noch einmal sechs Monate dauernde Erweiterungs- und Renovierungsarbeiten durchgeführt. ${ }^{654}$ Neben den umfangreichen Baumaßnahmen an seinem Amtssitz ließ Wu Kai gleich zu Beginn seiner Amtszeit den Schultempel renovieren, der während der Kriege als Büro für Heeresbedarf zweckentfremdet worden war.Wu Kais Bemühen, Tengyue wieder Anschluß an das staatliche Bildungswesen gewinnen zu lassen, zeigt sich auch in seinem Engagement bei der Restaurierung der Laifengshan Akademie und der Gründung von Freischulen (siehe unten 6.3.1., S. 261ff). 
Mit eines seiner ersten Bauprojekte war die Wiederherstellung des Tempels des Kriegsgottes Guandi, der auch als Gott der Gerechtigkeit und des Reichtums sowie als Beschützer der Händler verehrt wurde. In der Gedenkinschrift, die Wu Kai zu diesem Renovierungsprojekt verfaßt hat, hebt er die große Bedeutung hervor, die er diesem Tempel zumißt, denn dieser Gott repräsentiere, wie sein Beiname Shenyong besagt, militärische Macht und Würde, und so gebe es von der Hauptstadt bis in die entlegensten Gebiete an der Grenze keine Stadt ohne einen Tempel des Kriegsgottes, dem auch in Tengyue von allen Bevölkerungsgruppen (Wu nennt ausdrücklich verheiratete Frauen, Kinder und Militärangehörige (furen, xiaozi, wufu; in dieser Reihenfolge) höchster Respekt gezollt werde. ${ }^{655}$

Außerdem leitete Wu auch die Renovierung der regulären und der volkstümlichen Opferstätten (diansi und susi). ${ }^{656}$ Notwendig waren vor allem Arbeiten am Altar des Erdgottes und des Gottes des Getreides (Sheji tan), wo die Beamten die jährlichen Frühlings- und Herbstopfer vollzogen. Etwa einen Kilometer westlich der Stadt gelegen, fand Wu Kai die Stätte „unkultiviert; es gab keine Stelle zum Niederknien, es war schmutzig und respektlos“; außerdem waren dort die Altäre der Gottheiten der Naturerscheinungen (Feng yun lei yu shan chuan tan) untergebracht, die jedoch ganz willkürlich zusammengestellt waren, so daß die Gefahr bestand, die Gottheiten zu verwechseln und mit den Zeremonien gar ein Unwetter heraufzubeschwören. ${ }^{657}$ Folglich ließ Wu Kai im Jahr 1777 die ganze Anlage erweitern und vier Altäre aufstellen, denen er die einzelnen Gottheiten sorgfältig zuordnete. Die Altäre wurden mit einem Erdwall umgeben und es wurden weitere Nebengebäude errichtet. Die Arbeiten dauerten insgesamt zwei Monate. ${ }^{658}$

Renoviert wurden unter Wu Kais Leitung darüberhinaus die Tempel zweier Gottheiten, denen der Schutz der Bevölkerung und der Stadt oblag: Der Tempel des Stadtgottes (Chenghuang miao) und der Tempel des Erdgottes (Zhao Teng Tuzhu miao). Letzterer war während der Kriege als Geschütz-,Fabrik‘ genutzt worden. Wu Kai ließ den Tempel wieder instandsetzen und dort einen Gedenkstein für die Erbauer der Stadtmauer, die Beamten der Ming-Dynastie (Hou Jin, Yang Ning und Li Sheng) neu aufstellen. ${ }^{659}$ An ein historisches Ereignis erinnert auch der Ximeng Tempel (,Tempel des westlichen Bündnisses‘), der während der Yuan-Dynastie als Symbol des Bündnisses zwischen den

\footnotetext{
${ }^{655}$ TYZZ, S. 202; TYTZ, S. 293 (Gedenkinschrift Wu Kais zum Wiederaufbau des Tempels des Kriegsgottes).

${ }^{656}$ TYTZ, S. 157-158, 159

${ }^{657}$ TYTZ, S. 294 (Gedenkinschrift Wu Kais zum Wiederaufbau der Altäre).

${ }^{658}$ TYZZ, S. 203; TYTZ, S. 294-295

${ }^{659}$ TYZZ, S. 58
} 
Yuan und der einheimischen Bevölkerung errichtet worden war. Der innerhalb der Stadtmauern gelegene Ximeng Tempel ist der einzige buddhistische Tempel, dessen Instandsetzung Wu Kai persönlich organisierte. ${ }^{660}$

Ein weiteres Renovierungsprojekt, die Gedenkhalle für den Fürsten von Wu (Wu hou ci), verweist ebenfalls auf ein wichtiges historisches Ereignis: Auf Zhuge Liang und das Vordringen der Chinesen in das Gebiet der Präfektur Yongchang im 3. Jahrhundert zur Zeit der Shu-Han-Dynastie. ${ }^{661}$

Die Gebäude, die unter Leitung von Wu Kai renoviert wurden, befanden sich hauptsächlich in der Stadt selbst oder ihrer näheren Umgebung. Zudem organisierte Wu auch einige Renovierungsprojekte an anderen Orten im Gebiet der Unterpräfektur. So veranlaßte er den Wiederaufbau des Getreidespeichers der Gemeinde (lian) Longjiang, etwa dreißig Kilometer nordöstlich von Tengyue, „in dem früher über 100.000 Liter Getreide gelagert worden sind, die in den Kriegsjahren aber gänzlich aufgebraucht wurden““662 Wu ernannte dort zunächst einen neuen Gemeindevorsteher (shezhang), den er zusammen mit Angehörigen der örtlichen Oberschicht (shimin) mit dem Neubau des Speichers und dem Ankauf von Getreide beauftragte. Außerdem ließ Wu die etwa dreißig Kilometer östlich von Tengyue gelegene Brücke über den Fluß Longjiang, eine während der Ming-Zeit gebaute Eisenkettenbrücke, renovieren, um die Verkehrsverbindung nach Yongchang und ins Landesinnere zu verbessern. ${ }^{663}$

Weiterhin war Wu Kai an der Leitung von Baumaßnahmen in Nandian beteiligt, die in Zusammenhang mit der Stationierung von chinesischen Truppen in dem tusi-Gebiet standen (siehe unten S. 237-238). Auch in Tengyue wurden während der Amtszeit von Wu Kai verschiedene Gebäude für die Militärverwaltung gebaut bzw. ältere Amtsgebäude renoviert (siehe Tab. 19, S. 229). Verantwortlich für die Durchführung dieser Arbeiten war der oberste Militärbeamte in Tengyue, der Vize-Regionalkommandeur (fujiang). ${ }^{664}$

\footnotetext{
${ }^{660}$ TYTZ, S. 160

661 TYTZ, S. 158

662 TYTZ, S. 294 (Gedenkinschrift Wu Kais zum Wiederaufbau des Getreidespeichers von Longjiang).

663 TYZZ, S. 204-205 (Gedenkinschrift Wu Kais von 1776 zur Renovierung der Longjiang-Brücke).

${ }^{664}$ Das Amt des fujiang von Tengyue wurde im Verlauf der neunjährigen Amtszeit Wu Kais fünfmal neu besetzt (TYTZ, S. 130).
} 
Tabelle 19: Während der Amtszeit von Wu Kai renovierte bzw. neu errichtete Gebäude für die Militärverwaltung ${ }^{665}$

\author{
Renovierung von Amtsgebäuden für die Militärverwaltung \\ 1770 \\ Amt des Brigade-Vizekommandanten (Dusi shu) \\ 1774 \\ Amt des Brigade-Kommandanten (Youji shu)
}

Neubau von Amtsgebäuden für die Militärverwaltung

1775

Zwei Amtsgebäude für die Kommandanten

(Shoubei shu)

Zwei Amtsgebäude für die Kompanieführer

(Qianzong shu)

Drei Ämter für die Korporäle (Bazong shu)

Arsenal (Junqi ju)

1776

Amt des Regionalkommandeurs (Zongbing guan)

Wu Kai hat sich während seiner gesamten Amtszeit stark für die Renovierung der in Kriegszeiten beschädigten Gebäude von Tengyue engagiert. Besonders am Herzen lag ihm,

„die Altäre und Tempel für die wichtigsten Opferriten einen nach dem anderen wieder neu zu errichten und zwar sorgfältig den alten Riten entsprechend und nach der Überprüfung der [einschlägigen historischen] Texte“ ${ }^{666}$

Dokumentiert hat Wu Kai seine Bemühungen in einem Lokalhandbuch, dem Tengyue zhouzhi, das er während seiner neunjährigen Amtszeit in Tengyue zusammenstellte; das Vorwort verfaßte er im Jahr 1779. ${ }^{667}$ Das Handbuch wurde von seinem Amtsnachfolger Tu Shulian (von 1788 bis 1791 in Tengyue tätig) erweitert und bildete so die Grundlage für die im 19. Jahrhundert überarbeiteten und neu herausgegebenen fangzhi von Tengyue, das Tengyue zhou zhi (1839 bzw. 1897) und das Tengyue ting zhi (1888). Beide Lokalhandbücher enthalten zahlreiche Originaltexte von Wu Kai, insbesondere die Gedenkinschriften, welche die von ihm veranlaßten Renovierungsmaßnahmen schildern.

Wichtig war es Wu Kai in seinen Gedenkinschriften zu den verschiedenen Bauprojekten immer wieder zu betonen, daß es sich bei diesen religiösen Stätten um solche handelte, die im ganzen Land, „von der Hauptstadt bis in die entlegensten Grenzgebiete“, in allen

\footnotetext{
665 TYTZ; S. 70

${ }^{666}$ Wu Kai in seiner Gedenkinschrift zur Renovierung des Altars des Erdgottes und des Gottes des Getreides (Sheji tan), um 1777 (TYZZ, S. 203; TYTZ, 294-295).

${ }^{667}$ Siehe TYTZ, S. 280-281; TYZZ, S. 116-118
} 
Städten zu finden sind. ${ }^{668}$ Er hob damit die erfolgreiche Einbindung Tengyues in das chinesische Reich hervor und zwar nicht nur in dessen ziviles und militärisches Verwaltungssystem, sondern auch in die gesellschaftlichen und kulturellen Strukturen des Kernlandes. Dessen Traditionen wurden auch an der äußersten Grenze gepflegt und von Wu Kai unter anderem mit der Herausgabe eines Lokalhandbuches gleichzeitig dokumentiert und in ihrer Gültigkeit bestätigt.

\section{2. Die Veränderungen in der Zivil- und Militärverwaltung von Yongchang und} Tengyue zur Zeit der Ära Qianlong

Im Verlauf der Ära Qianlong (1736-1796) veranlaßte die Qing-Regierung verschiedene Maßnahmen zur Stärkung der Zivilverwaltung im westlichen Grenzgebiet der Provinz Yunnan. Im Jahr 1764 (Qianlong 29) wurden die drei Befriedeten Gebiete Gengma xuanfu si, Mengmeng xuanfu si und Menglian zhangguan si von der Präfektur Yongchang abgetrennt und der Präfektur Shunning unterstellt. ${ }^{669}$ Von dort aus konnten die drei neu zugeordneten tusi-Gebiete besser kontrolliert werden, als zuvor von der weiter entfernt gelegenen Präfekturstadt Yongchang. Das in der Ming-Zeit noch relativ kleine Verwaltungsgebiet der Präfektur Shunning ist damit nach Südwesten hin deutlich erweitert und die Position Shunnings als weitere Einheit der regulären Zivilverwaltung im Grenzgebiet neben der Präfektur Yongchang gestärkt worden. ${ }^{670}$

Die erfolgreiche Eingliederung der Präfektur Yongchang in die regulären Verwaltungsstrukturen des chinesischen Reiches wurde im Jahr 1765 (Qianlong 30) bestätigt, indem die Regierung aus der offiziellen Bezeichnung der Präfektur die Schriftzeichen ,jun min` streichen ließ. An die Stelle der bisherigen ,Präfektur mit besonderer Zuständigkeit für militärische und zivile Angelegenheiten“ Yongchang junmin fu trat nun die reguläre ,Präfektur‘ Yongchang $f u{ }^{671}$ Diese Änderung erfolgte gleichzeitig mit der Umbenennung der beiden junmin fu Wuding (nördlich von Yunnan fu) und Qujing (im Osten Yunnans) in reguläre Präfekturen und betont somit die Gleichstellung Yongchangs mit den Gebieten in

\footnotetext{
668 TYZZ, S. 202 (Gedenkinschrift Wu Kais zur Renovierung des Tempels des Kriegsgottes [Guandi miao]).

${ }^{669}$ YCFZ, S. 199. Die beiden Befriedeten Gebiete Gengma xuanfu si und Menglian zhangguan si waren zu Beginn der Qing-Zeit im Jahr 1660 (Shunzhi 17) der Präfektur Yongchang zugeordnet worden.

${ }^{670}$ Im Jahr 1770 wurde in der Präfektur noch der Kreis Shunning gegründet. Nach weiteren Reformen Ende des 19. Jahrhunderts umfaßte die Präfektur Shunning schließlich die Verwaltungseinheiten Unterpräfektur (ting) Mianning (bis 1747: Mengmian zhangguan si) und Unterpräfektur (zhou) Yunzhou sowie den Kreis (xian) Shunning und das Befriedete Gebiet (xuanfu si) Gengma (Niu Pinghan, S. 386).

${ }^{671}$ Deren Verwaltungshoheit unterstanden nach Angaben des YCFZ (S. 51) zu diesem Zeitpunkt eine Unterpräfektur (ting), eine Unterpräfektur (zhou), zwei Kreise (xian), eine einheimische Präfektur (tufu) und zwei einheimische Unterpräfekturen (tuzhou). Dabei handelte es sich um Tengyue zhou, Baoshan xian und Yongping xian, Mengding tufu, Zhenkang tuzhou und Wanding tuzhou. Mit der Unterpräfektur (ting) ist hier das erst 1770 gegründete Longling gemeint (s.u.).
} 
Zentral-Yunnan, ebenso wie auch die Abgrenzung von Gebieten unter einheimischer Sonderverwaltung.

Nach dem Ende des chinesisch-birmanischen Krieges hatte zwar die Sicherung des Grenzgebietes Priorität. Die Regierung reorganisierte folglich zunächst die Militäreinheiten in der Region, aber auch die Zivilverwaltung wurde weiter entwickelt. Bereits im 34. Jahr der Ära Qianlong (1769) war auf den Vorschlag des militärischen Oberbefehlshabers Fuheng zur Unterstützung seines Feldzuges ein Kommandant (shoubei) für die Brigade Nandian ernannt worden und dort mit zusätzlichen Soldaten stationiert worden. ${ }^{672}$ Zunächst waren es zweihundert Mann, dann kamen weitere dreihundert hinzu, so daß das Truppenkontingent in Nandian im folgenden Jahr schließlich insgesamt eintausendfünfhundert Mann umfaßte. Die Soldaten begannen in Nandian mit der Erschließung von Brachland und errichteten Unterkünfte. ${ }^{673}$

Nicht nur die militärischen Strukturen des Reiches wurden auf Nandian ausgedehnt. Ebenfalls im Jahr 1769 wurde zudem ein Beamter der Zivilverwaltung in dem tusi-Gebiet stationiert: Ein Assitierender Unterpräfekt (zhoupan), für den dort ein Amtsgebäude errichtet wurde. ${ }^{674}$ Im Gebiet der Präfektur Yongchang entstanden nach Kriegsende neue Einheiten der einheimischen Sonderverwaltung und der regulären Zivilverwaltung, die ebenfalls zu einer besseren Kontrolle des Grenzgebietes beitragen sollten.

Im Jahr 1770 (Qianlong 35) erhielten die beiden zhangguan si Husa und Lasa wieder den Status von Befriedeten Gebieten, die beide der Verwaltung von Tengyue zugeordnet wurden. ${ }^{675}$ Der Unterpräfektur Tengyue unterstanden damit sieben tusi-Gebiete: Nandian, Ganya, Zhanda, Husa, Lasa, Longchuan und Mengmao (siehe Karte 11, S. 232).

\footnotetext{
672 TYTZ, S. 64, 176. Nach Angaben Wu Kais wurden der Kommandant und die Truppen erst im Jahr Qianlong 35 (1770) in Nandian stationiert (s. TYTZ, S. 293).

673 TYTZ, S. 293

${ }^{674}$ TYTZ, S. 70, S. 296. Im Jahr 1774 (Qianlong 39) wurde das Amt des Assistierenden Unterpräfekten (zhoupan) von Nandian erneut bestätigt (TYTZ, S. 64).

${ }^{675}$ TYTZ, S. 64. Die beiden zhangguan si Husa und Lasa waren Mitte des 15. Jahrhunderts von den Ming als Befriedete Gebiete anerkannt worden; in der Qing-Zeit war dieser Status im Jahr 1724 abgeschafft worden.
} 


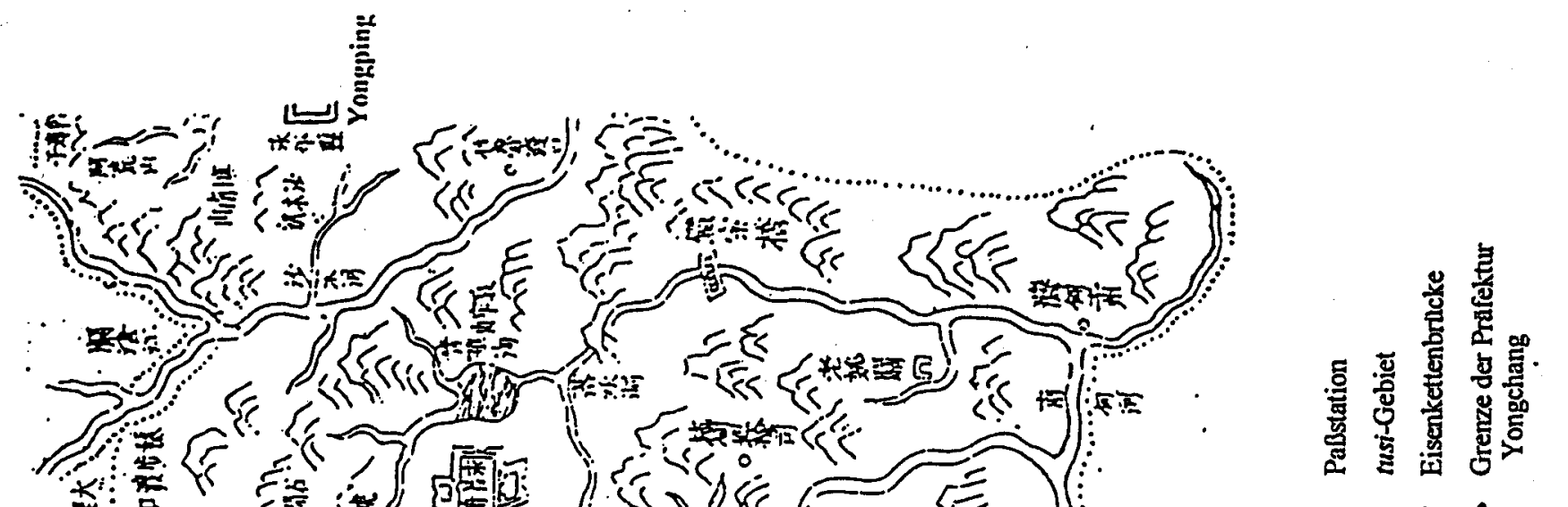

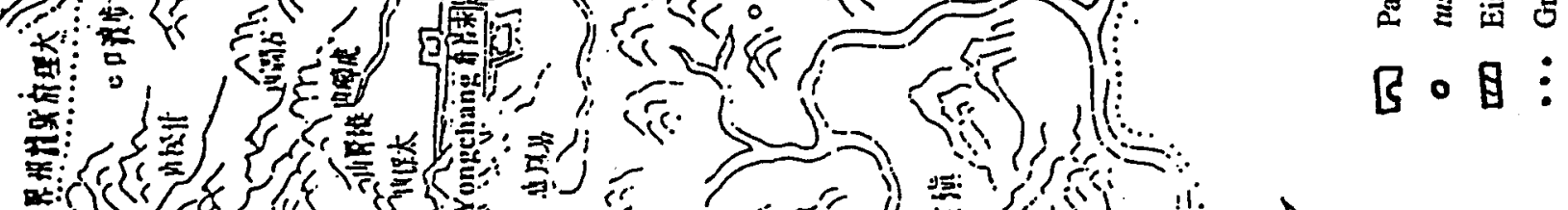

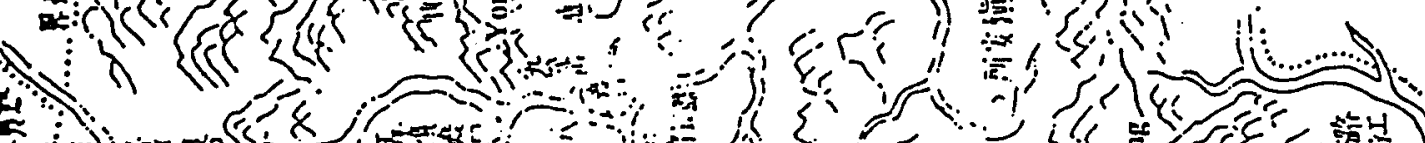

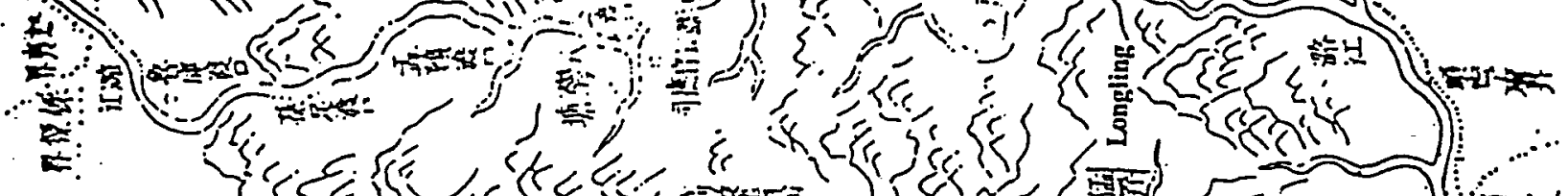

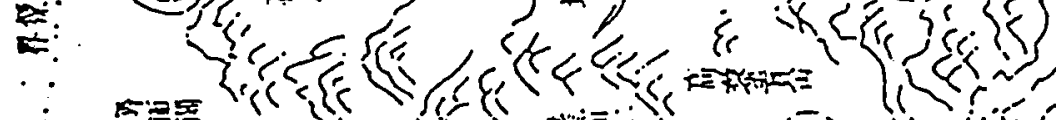

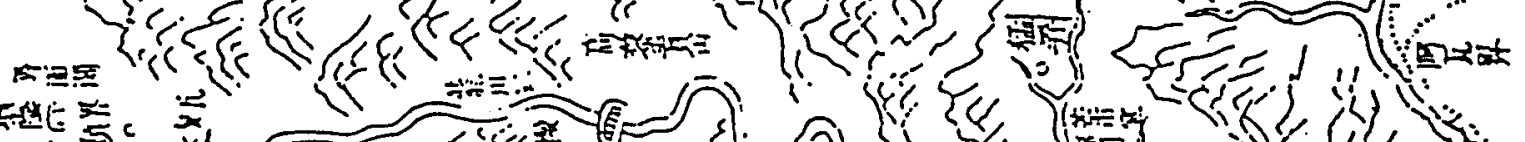

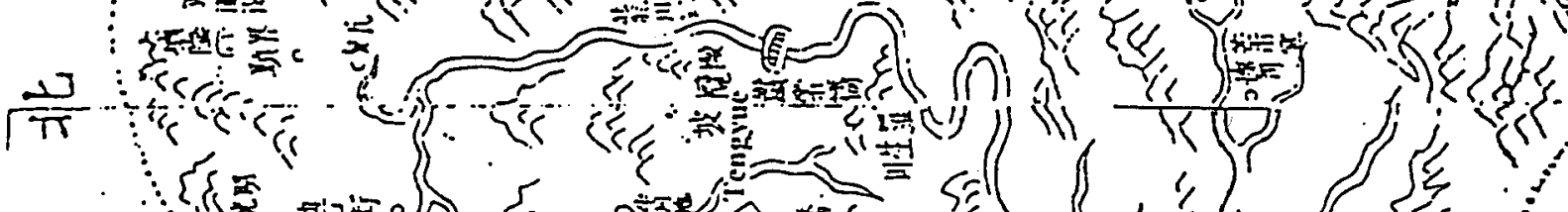

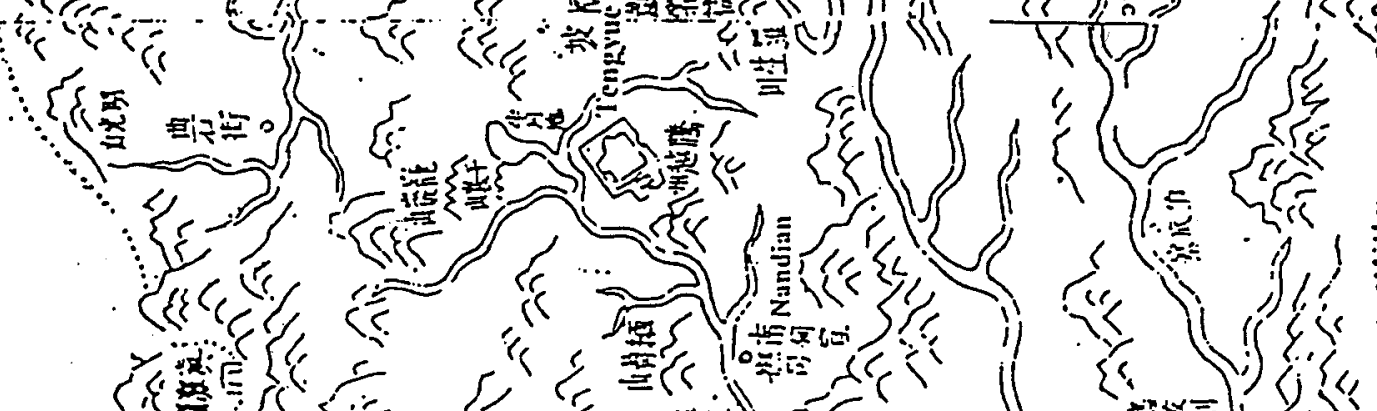

$\frac{\Phi}{5}$

:

这

:

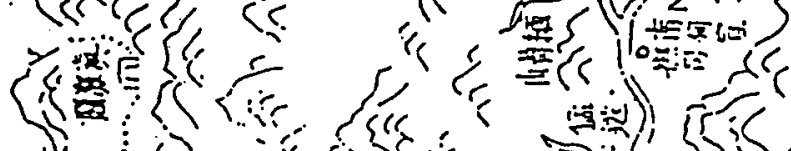

- (
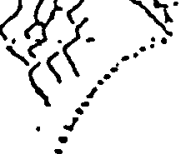

D

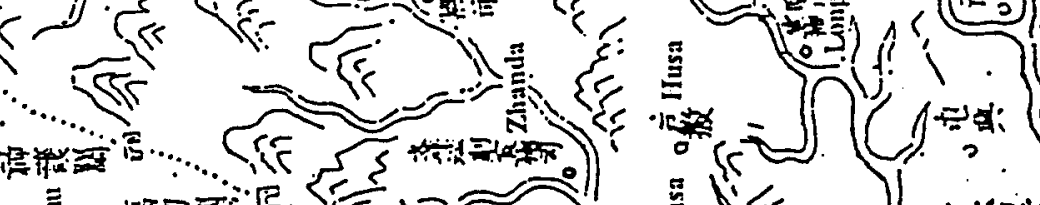

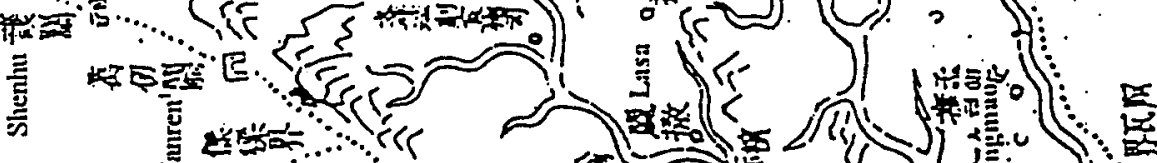

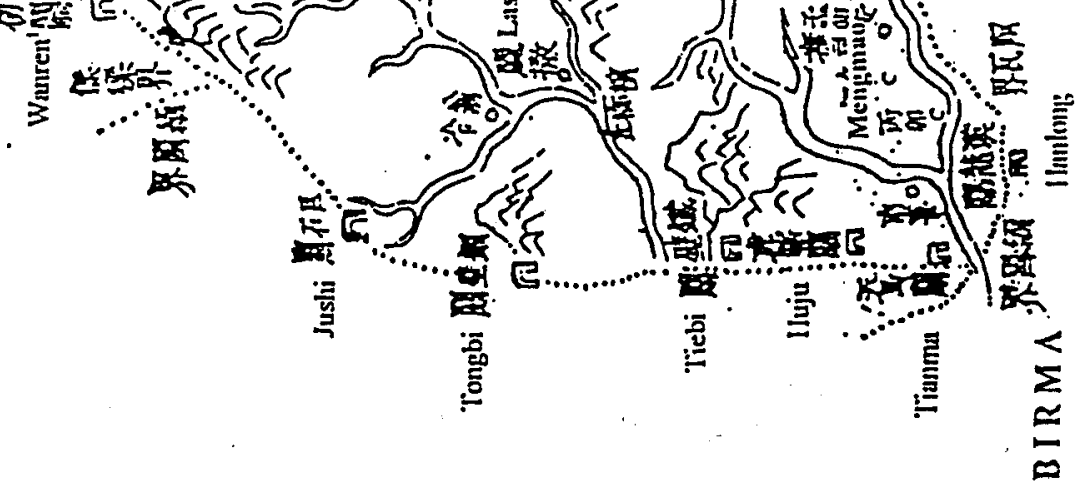


Ebenfalls im Jahr 1770 wurde in der Präfektur Yongchang eine zweite Unterpräfektur gegründet: Im Gebiet von Menglong südlich der Präfekturstadt im Kreis Baoshan entstand die Unterpräfektur (ting) Longling (siehe Karte 12, S. 234). Eine Stadtmauer zur Umfriedung des neuen Verwaltungszentrums wurde jedoch nicht gebaut.

Für die neue Verwaltungseinheit Longling wurden im selben Jahr ein Unterpräfekt (tongzhi) und ein Polizeichef (xunjian) ernannt, die von Longling aus auch die drei tusi-Gebiete Lujiang, Mangshi und Zhefang verwalteten. ${ }^{676}$

Weiterhin wurde in Longling ein Brigadestützpunkt (ying) neu gegründet, in dem sechshundert Soldaten stationiert wurden. Deren Anzahl wurde im Jahr 1776 auf eintausendfünfhundert aufgestockt und die Brigade in eine Zusatz-Brigade (xie ying) umbenannt. ${ }^{677}$

Ein großer Teil der Truppen, die gegen Birma gekämpft hatten, war direkt nach dem Ende der Kampfhandlungen wieder aus der Region abgezogen worden; es blieben jedoch weiterhin Soldaten aus Yunnan und Guizhou zum Schutz der vier Bezirke (lu) Longchuan, Zhanda, Mangshi und Mianning zurück. Im Jahr 1776 wurden außerdem dreitausenddreihundert Soldaten in Longchuan, eintausend Soldaten in Zhanda, eintausend Soldaten in Mangshi und vierhundert Soldaten in Mianning stationiert. ${ }^{678}$

Insgesamt befanden sich somit 7200 Mann zum Schutz der Grenzen der Verwaltungseinheit an strategischen Punkten in Tengyue und in den Befriedeten Gebieten.

Das ungewohnte feuchtheiße Klima im südwestlichen Grenzgebiet der Unterpräfektur Tengyue hatte den Soldaten aus dem chinesischen Kernland seit jeher zu schaffen gemacht. Nicht nur während der Feldzüge gegen Birma waren die chinesischen Truppen durch Tropenkrankheiten stark dezimiert worden, auch die regulär in Tengyue stationierten Soldaten liefen Gefahr, zu erkranken. So war zum Beispiel der Vize-Regionalkommandeur von Tengyue, Wuerjiang’a, (ein Mandschu, der das Amt im Jahr 1769 angetreten hatte) ebenso wie sein Amtsvorgänger Wu Shisheng (aus der Provinz Anhui) an Malaria erkrankt und gestorben (shou zhang $\mathrm{zu}$ ). ${ }^{679}$

\footnotetext{
${ }^{676}$ YCFZ, S. 52

${ }^{677}$ YCFZ, S. 128

${ }^{678}$ TYTZ, S. 177

${ }^{679}$ TYTZ, S. 130. Weitere Jahresangaben zur Amtstätigkeit der beiden Beamten werden im TYTZ nicht gemacht.
} 

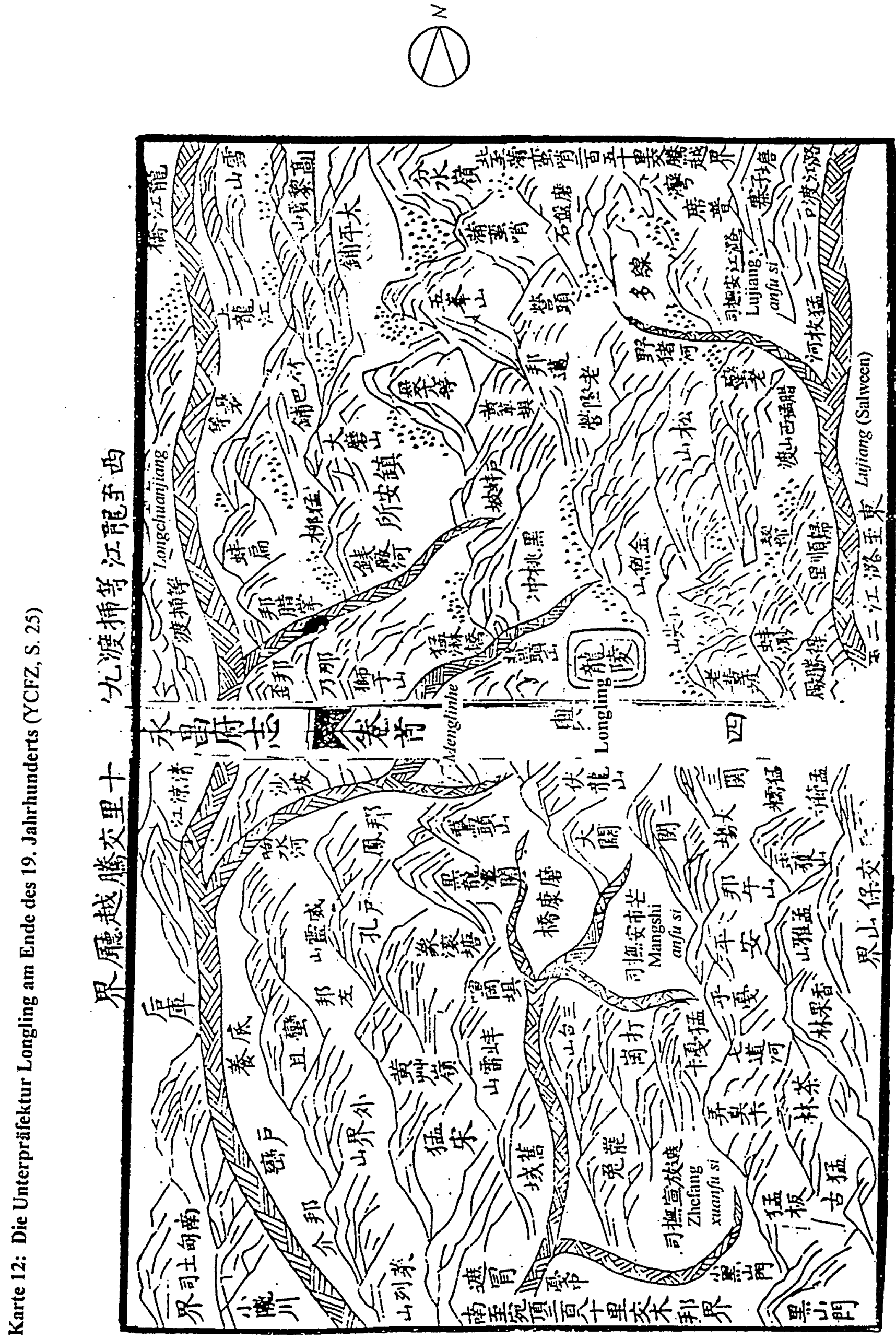
Für die Militärverwaltung war das unwirtliche Klima im Jahr 1771 Grund, die Truppenpräsenz in diesen Gebieten zu reduzieren und die Soldaten, die an den Paßstationen stationiert waren, wieder abzukommandieren. Die Truppen kehrten zum Nangsongguan bei Nandian zurück. Erst im Winter, als die Gefahr, zu erkranken geringer war, rückten erneut Soldaten nach Süden aus, um das Gebiet von Longchuan zu sichern; eintausend Mann wurden dort in Longbaotai stationiert. ${ }^{680}$

Bis zum Jahr 1773 wurde auch die Anzahl der Soldaten, die zum Schutz von Longchuan, Zhanda, Mangshi und Mianning eingesetzt waren, weiter verringert. Es waren jedoch noch immer annähernd 4500 Mann in der Region stationiert. ${ }^{681}$

Im Jahr 1775 wurde einer Throneingabe des Generalgouverneurs Tuside stattgegeben und die 1660 gegründete Zusatz-Brigade (xie ying) Tengyue zu einem Regionalen Militärbezirk (Tengyue zhen) aufgewertet. ${ }^{62}$

Der Regionale Militärbezirk Tengyue umfaßte das gesamte Verwaltungsgebiet der Unterpräfektur Tengyue und

„kontrollierte die sechzehn tusi: Nandian, Ganya, Longchuan, Zhanda, Mengmao, Husa, Lasa, Zhefang, Mangshi, Lujiang, Gengma, Menggen, Mengding, Zhenkang, Wandian und Menglian. ....

Dieser Regionale Militärbezirk im Südwesten [Chinas] ist wirklich enorm groß“. 683

Zur Sicherung der chinesischen Vorherrschaft über dieses weiträumige Grenzgebiet wurden im Regionalen Militärbezirk Tengyue zu dieser Zeit folgende Truppenkommandanten mit ihren Einheiten stationiert:

$$
\begin{array}{ll}
1 & \text { Regionalkommandeur (zongbing), } \\
1 & \text { Kommandant der mittleren Brigade (zhong ying youji), } \\
1 & \text { Vize-Kommandant der linken Brigade (zuo ying dusi), } \\
1 & \text { Vize-Kommandant der rechtenBrigade (you ying dusi), } \\
3 & \text { Assistierende Kommandanten (shoubei), } \\
& \text { je einer für die mittlere, die linke und die rechte Brigade, }
\end{array}
$$

\footnotetext{
${ }^{680}$ TYTZ, S. 177

681 TYTZ, S. 177

${ }^{682}$ TYTZ, S. 176. An anderer Stelle im TYTZ (Kapitel 4, Entstehungsgeschichte) heißt es, daß der Regionale Militärbezirk bereits im Jahr Qianlong 39 (1774) gegründet worden ist (TYTZ, S. 64) .

${ }^{683}$ TYTZ, S. 176; siehe auch TYZZ, S. 136-137.
} 
6 Kompanieführer (qianzong),

12 Korporäle (bazong),

18 Zusätzliche Kompanieführer (waiwei qianbazong) sowie

15 Zusätzliche Truppenführer (ewai waiwei). ${ }^{684}$

Die Zahl der Soldaten wurde zudem durch die Entsendung weiterer Truppeneinheiten vergrößert:

„Zusätzlich wurden 1500 Soldaten in Tengyue selbst stationiert. Insgesamt befanden sich [dort] dreitausend Soldaten. Dazu gehörten zusammen mit dem Vize-Kommandanten der linken Brigade, ... [sowie dreizehn niederrangigeren Truppenführern], auch die eintausend Soldaten, die in Nandian stationiert wurden. Entsprechend den sechs Regionalen Militärbezirken (zhen) und den sechs Zusatz-Brigaden (xie) der Provinz Yunnan hatte der gesamte Regionale Militärbezirk Tengyue also den Oberbefehl über zwei Zusatz-Brigaden (xie ying) und eine Brigade (ying) mit insgesamt 7500 Soldaten“. 685

Mit der Gründung des Regionalen Militärbezirks war Tengyue im Westen der Präfektur Yongchang endgültig zum Zentrum der Militärverwaltung der Region des Stromschluchtenfächers geworden. Um den damit verbundenen Aufgaben gerecht zu werden, wurde die Anzahl der in der Region stationierten Soldaten deutlich erhöht. Verglichen mit den zu Beginn der Qing-Zeit Mitte des 17. Jahrhundert zur Grenzverteidigung eingesetzten viertausend Solaten, ist sie im Zuge der Gründung des Militärbezirks fast verdoppelt worden. Allein die Zahl der ursprünglich eintausend Mann, die direkt in Tengyue stationiert worden war, hatte sich dabei verdreifacht.

Auch die Organisation der Truppeneinheiten wurde entsprechend weiter ausgebaut. Zusätzlich zu der Ende des 17. Jahrhundert gegründeten Zusatz-Brigade und der Brigade kam eine weitere Zusatz-Brigade hinzu. Der oberste Militärbeamte wurde zu einem Regionalkommandeur (zongbing, Rang 2a) aufgewertet, der in der Beamtenhierarchie etwas höher eingestuft war, als der zuvor in Tengyue amtierende Vize-Regionalkommandeur (fujiang, Rang 2b). Entsprechend den nunmehr drei Brigaden wurde auch die Zahl der untergeordneten Kommandanten erhöht. Außerdem wurden zahlreiche zusätzliche Truppenführer für

\footnotetext{
${ }^{684}$ TYTZ, S. 176; siehe auch S, 119.

${ }^{685}$ TYTZ, S. 176
} 
die einzelnen kleinen Truppeneinheiten, die zur Sicherung des Grenzgebietes in Militärstützpunkten in den Befriedeten Gebieten verteilt waren, ernannt.

Das größte Truppenkontingent in einem tusi-Gebiet entfiel auf Nandian. Dort wurden nun eintausend Soldaten und deren Kommandanten stationiert und entsprechend waren umfangreiche Baumaßnahmen notwendig, um Unterkünfte für die Soldaten und die Verwaltungsgebäude zu schaffen. Im Jahr 1775 wurden in Nandian zur Unterbringung der Truppen

„sechshundertundzweiundsechzig Militärbarracken gebaut, außerdem wurden elf Amtsgebäude für zivile und Militärbeamte, ein Depot für militärische Ausrüstung und Zäune an den Straßen errichtet; nach mehr als fünf Monaten waren die Arbeiten abgeschlossen“. ${ }^{686}$

Bei der Planung der Baumaßnahmen hatten der Präfekt von Yongchang und Unterpräfekt Wu Kai von Tengyue zunächst erwogen, das damals nicht bewohnte Anwesen des tusi von Nandian zu kaufen, um dort den Amtssitz des Brigade-Vizekommandanten einzurichten. Wu Kai berichtet, daß die Witwe des tusi das Angebot mit den Worten abgelehnt habe, sie „würde es nicht wagen, Geld für den Besitz ihres Mannes anzunehmen und könne es zudem nicht übers Herz bringen, sich davon zu trennen“; daraufhin habe sie über hundert ihrer Leute herbeigeführt, die die drei Hauptgebäude des Anwesens zerstörten. ${ }^{687}$ Danach übernahmen die Chinesen die übrigen Gebäude; Unterpräfekt Wu Kai ließ die Anlage mit einer Mauer umgeben. 688

Nandian blieb zwar weiterhin ein Befriedetes Gebiet unter einheimischer Sonderverwaltung, mit der verstärkten Truppenpräsenz hat die Qing-Regierung ihre Kontrolle im Süden der Hochebene von Tengyue, dort wo sich die Hauptverkehrsverbindung nach Birma in drei Routen teilt, deutlich verstärkt.

In den Jahren 1778 bis 1779 wurden die Stützpunkte der Grenzschutztruppen reduziert und die Militärposten im Gebiet von Tengyue abgeschafft. Nach wie vor blieben jedoch Soldaten in der Region stationiert: In Ganya verblieben einhundert, in Shanmulong (im

\footnotetext{
${ }^{686}$ TYTZ, S. 293 (Aufzeichnungen Wu Kais über die Parkanlage von Nandian).

687 TYTZ, S. 293. Die Witwe und ihr Sohn, der neue tusi, residierten im zehn Kilometer entfernten Yongan, wohin sich der verstorbene tusi zu Beginn des chinesisch-birmanischen Krieges im Jahr 1766 zurückgezogen hatte (TYZZ, S. 139).

${ }^{688}$ Nachdem die Chinesen das Anwesen übernommen hatten, nannte Wu Kai es ,Nandian-Park‘ (Nandian yuan), aufgrund seiner Naturschönheiten, von denen Wu besonders den alten Baumbestand, die weißen Reiher am See und den Aussichtsturm erwähnt (TYTZ, S. 293).
} 
Gebiet von Nandian) zweihundertfünfzig Soldaten, die auf die Kontrollstationen (guanqia) in diesen Gebieten verteilt wurden. ${ }^{689}$ Beide Stützpunkte befanden sich südwestlich der Stadt Tengyue an strategischen Orten an den Verkehrsrouten, etwa auf halber Strecke zu den acht Paßstationen und bildeten eine vorgeschobene Verteidigungslinie vor Nandian und Tengyue.

Um die Sicherung des Grenzgebietes insgesamt und den Schutz der chinesischen Bevölkerung der Unterpräfektur zu gewährleisten, ordnete die Regierung im Jahr 1779 weiterhin an, daß der Generalgouverneur (zongdu) die Grenze einmal pro Jahr inspizieren solle (xun bian), der Provinz-Militärkommandant (tidu) und der Regonalkommandeur (zongbing) jeweils zweimal im Jahr. ${ }^{690}$

\section{Die Entwicklung der chinesischen Bevölkerung im Südwesten des Kaiserreiches in der Qing-Zeit}

Nach dem halben Jahrhundert ständiger Kämpfe mit dem Dynastiewechsel und der Niederschlagung der ,Rebellion der drei Feudalherren` begann sich die Bevölkerung im Südwesten des chinesischen Reiches insgesamt nur langsam wieder zu erholen. Um das Jahr 1700 erreichte sie mit cirka fünf Millionen Menschen erneut den Stand des 16. Jahrhunderts. In den folgenden einhundertfünfzig Jahren nahm die Bevölkerung dann jedoch um ein Vierfaches zu und der Südwesten (Yunnan, Guizhou und das südwestliche Sichuan) verzeichnete eine der höchsten Wachstumsraten des chinesischen Reiches. ${ }^{691}$ Von etwa fünf Millionen um das Jahr 1700 stieg die Bevölkerung bis 1775 auf elf Millionen Menschen, um sich bis zum Jahr 1850 noch einmal auf etwa zwanzig Millionen zu verdoppeln. ${ }^{692}$ In Yunnan allein hat sich die registrierte Bevölkerung in der Zeit von 1741 bis 1850 versiebenfacht. ${ }^{693}$

Diese Zunahme der chinesischen Bevölkerung beruhte nicht allein auf natürlichem Wachstum bedingt durch die Ausweitung und Intensivierung der landwirtschaftlichen Produktion, die das Angebot an Nahrungsmitteln vergrößerte, sondern auch auf der Zunahme

\footnotetext{
${ }^{689}$ TYTZ, S. 177, 180

${ }^{690}$ TYTZ, S. 177. Hinweise darauf, daß solche Inspektionsreisen in das Grennzgebiet zu Birma tatsächlich stattgefunden haben, gibt es in den fangzhi von Tengyue und Yongchang nicht.

${ }^{691}$ Lee, S. 720

${ }^{692}$ Lee, S. 720. Die Wachstumsrate der Bevölkerung in Yunnan entsprach im Jahr 1775 mit 7 pro mille dem nationalen Durchschnitt, 1785 war sie auf 10 pro mille angestiegen und 1795 lag sie mit 20 pro mille deutlich höher als in anderen Provinzen.Von 1775 bis 1825 stieg die registrierte Bevölkerung in Yunnan durchschnittlich um 14,6 pro mille und damit um doppelt so viel wie in China insgesamt (7,3 pro mille). Erst um 1845 sank der Durchschnitt der jährlichen Wachstumsrate der Bevölkerung von Yunnan unter den Gesamtchinas (Lee, S. 731).

${ }^{693}$ Lee, S. 722-723, Tabelle 4
} 
kommerzieller und industrieller Unternehmungen, wie dem Fernhandel und der Förderung von Bodenschätzen, die eine große Zahl von Immigranten anzogen. ${ }^{694}$

Um 1750 waren bereits zehn Prozent der Bevölkerung im Südwesten Zuwanderer aus anderen Provinzen. ${ }^{695}$ Mit den Immigranten standen Arbeitskräfte zur Verfügung, die einen wirtschaftlichen Aufschwung ermöglichten, welcher wiederum den Bedarf an Arbeitskräften steigen ließ und die Region für neue Zuwanderer attraktiv machte. Aufgrund der neuen Möglichkeiten der ökonomischen Entwicklung im Südwesten zogen die urbanen Zentren immer mehr Immigranten an, so daß insbesondere der Anteil der städtischen Bevölkerung stieg und um 1830 zehn Prozent der Gesamtbevölkerung im Südwesten Chinas ausmachte (um 1700 waren es nur fünf Prozent gewesen).

Die chinesische Bevölkerung von Yunnan nahm während der Qing-Zeit in allen Regionen zu, zunächst jedoch besonders im Osten und in den zentralen Regionen der Provinz. Die Wachstumsraten in den westlichen Gebieten waren insgesamt zwar niedriger, doch auch in der Peripherie nahm die Bevölkerung deutlich zu, auch durch die Abwanderung aus den zentralen Regionen Yunnans in die Randgebiete der Provinz. ${ }^{696}$ Dort bot sich die Möglichkeit, Neuland zu erschließen und entsprechend nahm gerade in der Peripherie die landwirtschaftlich genutzte Fläche weiter zu, so auch in der Präfektur Yongchang, deren Hochplateaus sich gut zum Anbau von Reis eigneten.

Der schneller wachsenden Bevölkerung in den zentralen Regionen der Provinz stand hingegen immer weniger Land zur Verfügung, das seit 1700 zunehmend für den Anbau von cash crops wie Tabak und Baumwolle genutzt wurde, so daß diese Regionen zur Versorgung auf Getreidelieferungen aus den Randgebieten angewiesen waren und dieser Bedarf wiederum die Intensivierung des Anbaus ebendort anregte. Außerdem wurden Getreidemärkte eingerichtet und Karawanen für den Transport organisiert, die den Handel innerhalb der Provinz stimulierten und weitere Anreize für Zuwanderer boten, sich in den Randgebieten niederzulassen. ${ }^{697}$

\footnotetext{
${ }^{694}$ Lee, S. 712. Die enge Verbindung zwischen der Entwicklung der Bevölkerung und der des Bergbaus zeigt sich auch daran, daß zu Beginn des 19. Jahrhunderts, als viele Minen ausgebeutet waren und geschlossen wurden, auch die Immigration sogleich deutlich nachließ (Lee, S. 742-743).

${ }^{695}$ Lee, S. 742

${ }^{696}$ Lee, S. 732, 738

${ }^{697}$ Lee, S. $740-741$
} 


\section{1. Die Registrierung der Bevölkerung Yunnans in den Qing-zeitlichen Quellen}

Die starke Zunahme der Bevölkerung im Südwesten Chinas spiegelt sich in zeitgenössischen Aufzeichnungen wieder. Doch neben dem tatsächlichen Zuwachs der Bevölkerung sind auch die Bemühungen der Regierung um eine Verbesserung der Registrierung mit ein Grund für die im Vergleich zu früher deutlich gestiegenen Bevölkerungszahlen in den historischen Quellen: Es sollten in den Verwaltungseinheiten nun nicht mehr nur die steuerpflichtigen Männer gezählt werden, sondern die gesamte Bevölkerung, so wie sie im baojia-System erfaßt war. Seit dem Jahr 1748 wurden auch die Frauen mitgezählt; im Lokalhandbuch von Yongchang wird ausdrücklich darauf hingewiesen, daß sämtliche Männer und Frauen, Erwachsene und Kinder (nan fu da xiao gong) gezählt wurden. ${ }^{698}$

Seit 1756 waren die regulären Verwaltungseinheiten aufgefordert, die nicht Han-chinesische Bevölkerung ebenfalls in die Statistiken einzubeziehen und ab 1775 sollten auch die neuen Zuwanderer mit berücksichtigt werden. Nach wie vor unberücksichtigt blieb die einheimische Bevölkerung in den tusi-Gebieten, ebenso wie die dort lebenden HanChinesen. ${ }^{699}$ Die in einigen Regionen Yunnans durchgeführte Überführung von Gebieten unter der Verwaltung einheimischer Herrscher in Einheiten der regulären Zivilverwaltung (gaitu guiliu) führte dazu, daß die Einwohner dieser Gebiete ebenfalls in die Bevölkerungsregister aufgenommen wurden. ${ }^{700}$

Diesen Vorgaben entsprechend beginnt die Zusammenstellung der Bevölkerungsdaten in den Verwaltungseinheiten häufig im Jahr der Einführung des baojia-Systems vor Ort, so auch in der Unterpräfektur Tengyue, wo die ersten Angaben in den fangzhi zur Anzahl der Bevölkerung in der Qing-Zeit aus dem Jahr 1760 datieren, dem Jahr, in dem dort die Einteilung der Haushalte nach dem baojia-System erfolgte. ${ }^{701}$

\section{2. Die chinesische Bevölkerung der Unterpräfektur Tengyue in der Qing-Zeit}

Die Verfasser der fangzhi von Tengyue waren sich natürlich der Tatsache bewußt, daß die Registrierung der vielschichtigen Bevölkerung der Unterpräfektur nach wie vor nur unzureichend erfolgte und daß es aufgrund der wechselnden Kriterien, die jeweils zu Grunde gelegt wurden, schwierig war, einen Überblick über die tatsächliche Entwicklung der Bevölkerung zu gewinnen. So sind zwar

\footnotetext{
${ }^{698}$ Lee, S. 721; YCFZ, S. 98-99

${ }^{699}$ Lee, S. 721, 724-725

${ }^{700}$ Lee, S. 728

${ }^{701}$ Lee, S. 724; TYTZ, S. 50; TYZZ, S. 62
} 
„alle Haushalte gemäß dem baojia-[System] registriert worden. In den Aufzeichnungen sind Zuwanderer und Mönchshaushalte anfangs aber nicht mit eingetragen worden. Auch gibt es in den Gebieten aller sieben tusi HanChinesen, die dorthin übergesiedelt sind. Es läßt sich daher nicht so allgemein aufzeichnen, wie groß die gesamte Bevölkerung von Teng tatsächlich ist““ ${ }^{702}$

Die nach den Angaben der Bevölkerungsregister zusammengestellten Zahlenreihen in den fangzhi können daher nur eine ungefähre Vorstellung von der Größe der Bevölkerung der Unterpräfektur in der Qing-Zeit vermitteln; immerhin zeigen sie den allgemeinden Trend der Entwicklung.

Tabelle 20: Die Bevölkerungsentwicklung in Tengyue in der Qing-Zeit nach Angaben der fangzhi ${ }^{703}$

$\begin{array}{lcc}\text { JAHR } & \text { HAUSHALTE } & \text { PERSONEN } \\ 1760 & 12.087 & 177.173^{\mathrm{a}} \\ 1775 & 13.515 & 197.001 \\ 1776 & 13.886 & 197.001 \\ 1777 & 14.329^{\mathrm{b}} & 198.032 \\ 1779 & 14.891^{\mathrm{bc}} & 200.870 \\ 1797 & 20.136^{\mathrm{d}} & 200.813 \\ 1823 & 48.512^{\mathrm{a}} & 373.870 \\ 1874^{\mathrm{e}} & 10.958 & 56.325 \\ 1878^{\mathrm{e}} & 11.170 & 58.821 \\ 1879^{\mathrm{f}} & 10.936^{\mathrm{d}} & 55.407 \\ 1883^{\mathrm{e}} & 11.482^{\mathrm{d}} & 62.463^{\mathrm{g}}\end{array}$

a TYTZ, S. 50: Erwachsene und Kinder (da xiao dingkou); TYZZ, S. 62: Männer und Frauen, Erwachsene und Kinder (nan fu da xiao dingkou).

b TYTZ, S. 50; TYZZ, S. 62: Einheimische (tuzhumin) und Militärkolonisten (tunmin) zusammen.

c TYTZ, S. 50. TYZZ, S. 62: Genannt werden Gesamtzahlen von 14.889 Haushalten mit 199.583 Personen. Die Summe der aufgeführten Einzelposten beträgt hingegen 14.891 Haushalte mit 200.870 Personen.

Einheimische (tuzhumin)

YCFZ, S. 99

TYTZ, S. 50

Die Summe der angegebenen Einzelposten beträgt 62.463; als Gesamtsumme ist jedoch 62.462 angegeben.

\footnotetext{
${ }^{702}$ TYTZ, S. 50; TYZZ, S. 62-63

${ }^{703}$ TYTZ, S. 50; TYZZ, S. 62; YCFZ, S. 99
} 
Seit die Bevölkerung von Tengyue im Jahr 1760 für die Einteilung nach dem baojiaSystem erfaßt worden ist, sind die Register auch in den folgenden Jahren fortgeschrieben worden. In den fangzhi sind jedoch für die Jahrgänge von 1760 bis 1775 im Einzelnen keine Zahlen aufgelistet, dort ist lediglich zusammenfassend eine generelle Zunahme der Anzahl der Einwohner vermerkt. Dem TYTZ zufolge ist in den nach 1760 ,angelegten Bevölkerungsregistern ein jährlicher Zuwachs von einigen zehn Haushalten (zeng shu shi hu) verzeichnet worden““. ${ }^{704}$ Im TYZZ heißt es dazu hingegen, daß

„in den [seit 1760] jährlich abgefaßten Berichten die Anzahl der Haushalte [genauso groß] gewesen ist wie früher, die Anzahl der Personen jedoch zugenommen hatte (dingkou zisheng) und zwar jährlich um einige zehn (zeng shu shi ming), was bis zum Jahr 39 (1774) im allgemeinen gleich geblieben ist““ ${ }^{705}$

Einmal wird also eine Zunahme der Haushalte, einmal die der Einzelpersonen betont. Insgesamt hat die Bevölkerung in den fünfzehn Jahren von 1760 bis 1775 nach den Angaben der fangzhi jedenfalls sowohl um 1428 Haushalte, als auch um 19.828 Personen zugenommen. Verteilt man diese auf die Jahre, so ergibt sich ein durchschnittlicher Zuwachs von 95 Haushalten bzw. 1322 Personen pro Jahr; deutlich mehr als nur ,einige zehn`.

In diesem Zeitraum war die Region des Stromschluchtenfächers einige Jahre lang Aufmarschgebiet für die Qing-Truppen während des chinesisch-birmanischen Krieges (1766 1769). Die Kampfhandlungen fanden hauptsächlich im Südwesten der Unterpräfektur Tengyue, in Birma und den Kleinstaaten unter birmanischer Oberhoheit im Grenzgebiet statt. Vorstöße der birmanischen Armee weiteten die militärischen Auseinandersetzungen zeitweise bis in die tusi-Gebiete südwestlich der Unterpräfekturstadt aus.

Für die Bevölkerung in den umkämpften Gebieten hatten die Kriege schwerwiegende Konsequenzen. Felder wurden verwüstet, ganze Dörfer zerstört und ihre Bewohner getötet oder verschleppt. Die Folge waren Hungersnöte. Zeitgenössische Quellen berichten, daß die Bevölkerung vielerorts drastisch abgenommen hatte, nicht nur in den südlicheren Gebieten wie Mubang oder Menglian, auch die tusi im Südwesten von Tengyue waren davon betroffen. Longchuan hat in dieser Zeit etwa die Hälfte seiner Bevölkerung verloren, Zhanda sechzig Prozent und Mengmao sogar mehr als neunzig Prozent. ${ }^{706}$

\footnotetext{
704 TYTZ, S. 50

${ }^{705}$ TYZZ, S. 62

${ }^{706}$ Giersch, Qing China, S. 248, Tab. 5.1.
} 
Die Hochebene von Tengyue blieb hingegen von Kämpfen verschont. Die generelle Zunahme der chinesischen Bevölkerung über die Kriegsjahre hinaus verweist auf die feste Einbindung der regulären Verwaltungseinheit Tengyue in die Strukturen des Kernlandes und betont deren Kontinuität ebenso wie die der Hoheitsgebiete einheimischer Herrscher als Grenzgebiet im Südwesten der Unterpräfektur, in dem die Einflußsphären der verschiedenen Machthaber in der Region wieder einmal voneinander abgegrenzt wurden.

Die chinesische Bevölkerung der Unterpräfektur Tengyue hat auch in den folgenden Jahren weiter zugenommen; in den fangzhi wird diese Entwicklung nun differenzierter dargestellt (siehe Tab. 21). So sind für die Ermittlung der Bevölkerungszahlen der beiden Jahrgänge 1777 (Qianlong 42) und 1779 (Qianlong 44) in Tengyue

„die Haushalte der einheimischen Zivilbevölkerung (tuzhumin) und die der Militärkolonisten (tunmin) entsprechend [der Vorgabe] des kaiserlichen Erlasses [zur Bevölkerungsregistrierung] getrennt aufgezeichnet worden““ ${ }^{707}$

\section{Tabelle 21: Bevölkerungsgruppen in Tengyue in den Jahren 1777 und 1779}

Jahr Einheimische (tuzhumin)

$\begin{array}{lcc} & \text { Haushalte } & \text { Personen }^{\mathrm{a}} \\ \mathbf{1 7 7 7} & 11.394 & 158.675 \\ \mathbf{1 7 7 9} & 11.742 & 159.570\end{array}$

1779
Militärkolonisten (tunmin)

\section{Gesamt}

$\begin{array}{cccl}\text { Haushalte } & \text { Personen }^{\mathrm{a}} & \text { Haushalte } & \text { Personen }^{\mathrm{a}} \\ 2935 & 39.357 & 14.329 & 198.032 \\ 3149 & 41.300 & 14.891 & 200.870^{709}\end{array}$

a Männer und Frauen, Erwachsene und Kinder

In diesen zwei Jahren hat die einheimische Bevölkerung demnach um 348 Haushalte bzw. 895 Personen zugenommen, während die Gruppe der Militärkolonisten um 214 Haushalte bzw. 1943 Personen größer geworden ist. Auffällig ist, daß bei der einheimischen Bevölkerung eine relativ große Zahl an Haushalten hinzugekommen ist (348). Die Zahl der neuen tunmin-Haushalte ist kleiner (214), die Anzahl der Einzelpersonen dieser Gruppe (1943) jedoch mehr als doppelt so groß wie die der neu hinzugekommenen tuzhumin (895).

\footnotetext{
${ }^{707}$ TYTZ, S. 50. Im TYZZ (S. 62) heißt es etwas anders formuliert: „... entsprechend der Anordnung wurden die baojiaHaushalte getrennt notiert“. Die Zahlen werden dort jedoch ebenfalls unter den Rubriken tuzhumin und tunmin notiert. ${ }^{708}$ TYTZ, S. 50; TYZZ, S. 62

${ }^{709}$ TYZZ, S. 62: Genannt werden Gesamtzahlen von 14.889 Haushalten und 199.583 Personen. Die Summe der aufgeführten Einzelposten beträgt hingegen 14.891 Haushalte sowie 200.870 Personen.
} 
Insgesamt hat die Bevölkerung in diesem Zeitraum pro Jahr durchschnittlich um 281 Haushalte bzw. 1419 Personen zugenommen. Verglichen mit den Durchschnittswerten für die Jahre von 1760 bis 1775 fällt besonders der hohe Zuwachs an registrierten Haushalten auf: Von 1777 bis 1779 sind an Haushalten pro Jahr etwa dreimal so viele hinzugekommen, wie in dem früheren Zeitraum. Auch die Zahl der registrierten Einzelpersonen hat, wenn auch weniger stark als die der Haushalte, nun jährlich um einiges mehr zugenommen. Ein Zuwachs, der hautsächlich auf die gestiegene Zahl von neu registrierten Militärkolonisten (tunmin) zurückzuführen ist.

Die Bevölkerungszahlen spiegeln die besondere Stellung Tengyues als ,erste ummauerte Stadt an der äußersten Grenze` wieder. In der fest etablierten zivilen Verwaltungseinheit nimmt die Bevölkerung zu und es werden vermehrt, zivile‘ Zuwanderer mit ihren Familien angezogen: Die Zahl der registrierten Haushalte der tuzhumin nimmt zu. Gleichzeitig ist Tengyue ein Außenposten an der Peripherie des chinesischen Reiches, wo nach den Kriegen mit Birma zusätzlich Soldaten stationiert worden sind. Deren Stützpunkte sind zu ihrer Versorgung auf Militärkolonien angewiesen, die in dieser abgelegenen Bergregion von Soldaten und alleinstehenden Kolonisten besiedelt sind: Die Anzahl der Einzelpersonen in der Gruppe der tunmin ist deutlich gestiegen.

Auch zum Ende des 18. Jahrhunderts hin, in der Zeit von 1779 bis 1797, hat die Zahl der Haushalte in Tengyue weiter zugenommen, während die Zahl der registrierten Personen minimal um einige Dutzend abgenommen hat. Auffällig ist dabei der deutliche Anstieg der Bevölkerung in den folgenden Jahren bis 1823. Die Zahl der Haushalte hat sich in diesen sechsundzwanzig Jahren mehr als verdoppelt und auch die Zahl der Einzelpersonen ist um knapp das Doppelte gestiegen. Mit 48.512 Haushalten bzw. 373.870 Personen ist die registrierte Bevölkerung von Tengyue im Jahr 1823 am größten gewesen (siehe auch Tab. 20, S. 241).

Die folgende Tabelle (Tab. 22) zeigt die Entwicklung der Bevölkerung der Unterpräfektur Tengyue im Vergleich mit den entsprechenden Zahlen für die Provinz Yunnan insgesamt; berücksichtigt wurden dabei lediglich die registrierten Einzelpersonen. 
Tabelle 22: Bevölkerung in Yunnan und Tengyue / Registrierte Einzelpersonen ${ }^{710}$

$\begin{array}{lll}\text { Jahr } & \text { Yunnan } & \text { Tengyue } \\ & & \\ \mathbf{1 7 6 0} & 2.069 .171 & 177.173 \\ \mathbf{1 7 7 5} & 3.083 .499 & 197.001 \\ \mathbf{1 7 7 6} & 3.102 .948 & 197.001 \\ \mathbf{1 7 7 7} & 3.125 .069 & 198.032 \\ \mathbf{1 7 7 9} & 3.174 .261 & 200.870 \\ \mathbf{1 7 9 7} & 4.174 .586 & 200.813 \\ \mathbf{1 8 2 3} & 6.255 .753 & 373.870\end{array}$

Vergleicht man die Daten aus der Unterpräfektur Tengyue mit den Angaben zur Bevölkerungsentwicklung von ganz Yunnan, wie sie James Lee zusammengestellt hat, so zeigt sich, daß die Bevölkerung von Tengyue in der Zeit von 1760 bis 1823 durchschnittlich ein Sechzehntel der Bevölkerung der Provinz Yunnan ausmachte. ${ }^{711}$

Während sich die Zahl der registrierten Einwohner Yunnans in diesem Zeitraum etwa verdreifacht hat, hat sich die von Bevölkerung Tengyue, die zwar ebenfalls kontinuierlich zugenommen hat, lediglich verdoppelt.

Allerdings, darauf sei abschließend noch hingewiesen, stammen die Angaben zu den Jahren 1797 und 1823 nicht aus den fangzhi der Unterpräfektur selbst, so daß sie sich nur bedingt mit den anderen Zahlen vergleichen lassen. Daten aus Tengyue standen den Herausgebern der fangzhi für diesen Zeitraum nicht zur Verfügung, denn

„während der Ära Jiaqing (1796-1821) und der Ära Daoguang (1821-1851) sind die Haushaltsregister nicht überprüft worden. Weil die aufständischen Moslime im 10. Jahr der Ära Xianfeng (1860) die Stadt erobert und die Register zerstört hatten, gab es keine Möglichkeit [mehr, die Zahlen noch nachträglich] zu überprüfen. Nur im Provinzhandbuch (Tongzhi) findet man die Angaben ... [zu den Jahren Jiaqing 2 (1797) und Daoguang 3 (1823)]“. ${ }^{712}$

\footnotetext{
${ }^{710}$ Angaben zu Yunnan: Lee, S. 715, Tabelle 1; Angaben zu Tengyue: TYTZ, S. 50; TYZZ, S. 62; YCFZ, S. 99.

${ }^{711}$ Lee, S. 722-723, Tabelle 4

712 TYTZ, S. 50
} 


\section{3. Die Registrierung der einheimischen Bevölkerung in den tusi-Gebieten und die} Versorgungslage in der Unterpräfektur Tengyue

War schon die Ermittlung der Bevölkerungszahlen für die Stadt und ihre Umgebung problematisch, so erwies sich die Registrierung der einheimischen Bevölkerung in den tusiGebieten als unmöglich,

„obwohl alle tusi schon Dokumente (wen) erhalten hatten [und aufgefordert worden waren] ebenso wie im Kernland (neidi) die Bevölkerung nach Haushalten und Personen ( $h u$ kou) zu registrieren, haben sie alle dennoch vieles nicht wahrheitsgemäß aufgezeichnet“ ${ }^{713}$

Ein Überblick über die verschiedenen Volksgruppen, die in den tusi-Gebieten siedelten, ließ sich ohnehin nur schwer gewinnen, denn

„die Menschen der Fremdvölker (yimin) sind von unterschiedlichen Arten. Sie wechseln ihren Aufenthaltsort und halten sich nicht ständig in einem Gebiet auf. Ihre Gewohnheit ist es, kaum daß sie [an einem Ort] angekommen sind, ein befestigtes Dorf (zhai) zu errichten und in der Wildnis (huangdi) neben dem Dorf den Boden zu bestellen. ...

Es gibt hinterhältige Fremdvölker (jian yi), die in den verschiedenen tusiGebieten umherziehen. Ganze Dörfer, mehrere hundert Menschen machen sich auf den Weg, wie es bei ihnen Sitte ist (xi yi wei su). Dann existieren nur mehr die Namen der [verlassenen] Dörfer ...“.714

Ihre ehemaligen Bewohner hingegen waren längst weitergezogen und hatten sich andernorts niedergelassen. Nicht nur die Menschen ließen sich so kaum langfristig registrieren, auch Lage und Umfang der Anbauflächen veränderten sich ständig. Zudem sind

„ihre Felder ohnehin nicht [entsprechend den Maßeinheiten] qing und mu eingeteilt, so daß man sie überprüfen könnte. Deshalb kann man sie auch nicht nach dem Vorbild des Kernlandes (neidi) erfassen. ....

Die Felder in den verschiedenen tusi-Gebieten bringen hohe Erträge“، ${ }^{715}$

\footnotetext{
${ }^{713}$ TYTZ, S. 50; TYZZ, S. 63. Die Verfasser des TYZZ (S. 63) stellen die Registrierung der einheimischen Bevölkerung als eine Maßnahme zur Kontrolle des Grenzgebietes in Kriegszeiten vor: Sie erläutern, wie „nach Beginn des Militäreinsatzes [gegen Birma im Jahr 1766] die Paßstationen äußerst streng abgesperrt worden sind. Den tusi war dann mehrfach befohlen worden, [Bevölkerungsregister] anzulegen, doch sie alle haben vieles nicht wahrheitsgemäß aufgezeichnet“.

${ }^{714}$ TYTZ, S. 50; TYZZ, S. 63

${ }^{715}$ TYTZ, S. 50
} 
„Die Erträge der Felder der Unterpräfektur hingegen waren nicht ausreichend. Für die Versorgung der Bevölkerung war man daher auf Unterstützung aus den verschiedenen tusi-Gebieten angewiesen. Immer nachdem sie die Ernte eingebracht hatten, gingen Männer und Frauen nach Ganya, Nandian oder Luoxiaosi zhuang, um von dort Nahrungsmittel zu holen. So ist es früher gewesen. Wir haben dies zur Information für die Nachkommenden aufgeschrieben.“ “716

Zwar sind die örtlichen Bedingungen dieselben geblieben: „In Teng gibt es viele Berge und wenig Wasser, der Boden ist ganz unterschiedlich, hier fruchtbar, da karg“. ${ }^{717}$ Doch hat sich bis zum Ende des 19. Jahrhunderts ansonsten einiges verändert. Im Vergleich mit der Ming-Zeit sprechen die Herausgeber der fangzhi im Kapitel über die lokalen Produkte von einer, allerdings nur pauschal erwähnten Verbesserung der Versorgungssituation. Zusammenfassend heißt es ebenda:

„Untersucht man die Aufzeichnungen, die unter der früheren Ming-Dynastie gemacht wurden, so heißt es da: Die Befriedeten Gebiete (san xuan liu wei) diesseits und jenseits des Dajinjiang [Oberlauf des Irawadi] hatten alle den kaiserlichen Befehl erhalten. Darüber hinaus gab es noch Jiajiu, Manmo, Mengong und Mengyang. Die dazugehörigen [Gebiete] waren äußerst ausgedehnt und ihre Produkte äußerst zahlreich. Auch war [Tengyue] ein Sammelpunkt (sou) für [den Handel mit] Edelsteinen. Am Ende der Ming-Zeit war ein dem Militär angehörender (wufu) billiger Eunuch (yanshu) als Verteidigungskommandeur (zhenshou) tätig, dessen ausbeuterische Herrschaft (ke suo) ihn bei der Bevölkerung täglich verhaßter werden ließ (ri shen yuan pan) und zu einer Rebellion führte. Danach gehörten die Gebiete jenseits der acht Paßstationen nicht mehr zu uns (fei wu suo). Das Territorium war schmaler geworden und die Erzeugnisse weniger. Das war so in etwa die allgemeine Lage.

Tugend und Autorität unserer prächtigen Dynastie haben sich nun weit verbreitet. Außergewöhnliche Dinge (yiwu) kommen wieder als Tribut aus weit entfernten Gebieten. Auf reichlich vorhandenem fruchtbarem Boden wird fortwährend [verschiedenes] angebaut. Das übertrifft die vorangegangene Dynastie bei weitem“. ${ }^{718}$

\footnotetext{
716 TYZZ, S. 63

717 TYTZ, S. 60

${ }^{718}$ TYTZ, S. 60
} 
Das Territorium, auf das Tengyue für seine Versorgung zurückgreifen konnte, war zwar seit der Ming-Zeit kleiner geworden, dafür war das Ackerland in der Unterpräfektur selbst inzwischen besser erschlossen worden und so stand ausreichend Anbaufläche zur Verfügung. An Getreidesorten wurden in der Unterpräfektur neben Reis noch Hirse, Weizen und Buchweizen angebaut, auch Sesam und Hülsenfrüchte werden in den fangzhi genannt. ${ }^{719}$ Mit der Intensivierung des Anbaus landwirtschftlicher Produkte folgte Tengyue dem zeitgenössischen Entwicklungstrend in Yunnan und produzierte zeitweise einen Überschuß. Mit dessen Verkauf konnte die Unterpräfektur vom steigenden Bedarf an Getreide in den zentralen Regionen der Provinz profitieren. So wurden beispielsweise um 1850 in Tengyue Karawanen zusammengestellt, die Getreide in die Region Kunming transportierten. ${ }^{720}$

Ein Indiz für die verbesserte Versorgungslage der Bevölkerung von Tengyue sind auch die relativ seltenen Mißernten. In den ersten zweihundert Jahren der Qing-Dynastie hat es lediglich sechsmal Mißernten gegeben, deren Folgen (Hungersnöte und die Verteuerung des Grundnahrungsmittels Reis) so gravierend waren, daß sie von den Verfassern der fangzhi im Kapitel über die Omina vermerkt worden sind.

Tabelle 23: Mißernten und ihre Folgen für die Unterpräfektur Tengyue in der Qing-Zeit ${ }^{721}$
Jahr Ereignis
1661 Mehr als sechstausend Menschen starben während der Hungersnot.
1769 Es herrschte Hungersnot; ein dou Reis kostete 1 liang 7 qian Silber. ${ }^{722}$
1787 Es herrschte Hungersnot.
1817 Es gab viele Tote während der Hungersnot.
1839 Nach der Überschwemmung der Felder war Reis mehrere Jahre lang teuer. Schnee vernichtete die Ernte im Gebiet von Puwo; unzählige Menschen verhungerten. ${ }^{723}$

Zu Zeiten wurde versucht, die Folgen dieser Naturkatastrophen durch staatliche Hilfen für die Bevölkerung zu mildern. So zum Beispiel

\footnotetext{
${ }^{719}$ Kulturpflanzen wie Mais oder Süßkartoffeln, die bereits seit dem 16. Jahrhundert in Yunnan angebaut wurden und die, wie James Lee in seiner Studie zur Bevölkerungsentwicklung feststellt, zunächst in den Gebirgsregionen an den Grenzen der Provinz, dann aber im 19. Jahrhundert in großem Umfang genutzt wurden, werden in der Liste der örtlichen Produkte Tengyues nicht erwähnt (Lee, S. 738, 740-741).

${ }^{720}$ Lee, S. $740-741$

${ }^{721}$ TYTZ, S. 29-30

722 Ein dou entspricht etwa 10 Litern.

${ }^{723}$ Die Gemeinde (lian) Puwo befindet sich im Südosten von Tengyue.
} 
„im Jahr 1782, als bei starken Überschwemmungen in den Gebieten der tusi von Nandian und Ganya Häuser eingestürzt und Felder überflutet worden waren und [den Betroffenen], nachdem eine Petition eingereicht worden war, Unterstützung gezahlt wurde“.724

Die Hilfeleistung für Katastrophenopfer in Nandian und Ganya hebt die enge Anbindung dieser tusi-Gebiete an die Unterpräfektur Tengyue hervor. Sie sind Teile der Verwaltungseinheit und haben als solche Pflichten gegenüber dem chinesischen Reich (Loyalität, Zahlung von Steuern), erhalten aber auch Unterstützung. Da die Bevölkerung von Tengyue zu ihrer Versorgung auch Nahrungsmittel aus diesen Gebieten bezog, hatte die chinesische Verwaltung zudem sehr pragmatische Gründe, Hilfe zum Wiederaufbau zu leisten, die wiederum der Unterpräfektur zugute kam und dabei auch die Verbindung zwischen tusiGebieten und Zivilverwaltung stärkte.

\section{4. Die ,verschiedenen Volksgruppen` (zhongren) im Gebiet des Regionalen Militär- bezirks Tengyue}

„Der Regionale Militärbezirk Tengyue (Tengyue zhen) kontrolliert sechzehn tusi. ... Das gesamte Gebiet erstreckt sich im Osten über Jinniutun bis zur Grenze der [Unterpräfektur] Menghua bei Yangbi. Im Süden erstreckt sich das Gebiet bis zu den auswärtigen Barbaren (wai yi) an der Grenze von Manmo, im Westen bis an die Grenze zu den Yeren (,den wilden Menschen') und im Norden bis an die Grenze zu den Lisu in Lijiang.“725

Diese Beschreibung der Region um Tengyue unterstreicht erneut die in der Ming-Zeit eingeführte Trennung zwischen den tusi-Gebieten, die der Verwaltung von Tengyue und Yongchang unterstanden und den im Süden jenseits der acht Paßstationen gelegenen Gebieten der , auswärtigen Barbaren` (wai yi).

Zur Gruppe der ,auswärtigen Barbaren` (wai yi) zählen in den fangzhi die von einheimischen Herrschern regierten Kleinstaaten im Grenzgebiet zu Birma, die während der MingZeit den Titel eines Befriedeten Gebietes (xuanweishi si, xuanfu si, zhangguan si) oder

\footnotetext{
${ }^{724}$ TYTZ, S. 29. Zum Getreideanbau in Nandian, Ganya oder den anderen tusi-Gebieten im allgemeinen (Nutzflächen, Erträge, etc.) werden in den fangzhi keine Angaben gemacht.

${ }^{725}$ TYTZ, S. 176; siehe auch TYZZ, S. 136-137.
} 
auch den einer einheimischen Präfektur ( $f u$ ) erhalten hatten. Im YCFZ werden unter dieser Rubrik folgende Verwaltungseinheiten beschrieben:

Mubang junmin xuanweishi si,

Laowo junmin xuanweishi si,

Miandian junmin xuanweishi si,

Mengmi xuanfu si,

Lima zhangguan si,

Niuwu zhangguan si. $^{726}$
Babai dadian junmin xuanweishi si, Mengyang junmin xuanweishi si, Menggen $f u$, Chashan zhangguan si, Manmo xuanfu si,

Diese Befriedeten Gebiete der wai yi waren durch das Vorhandensein bestimmter politischer Strukturen in Form einer einheimischen Herrscherdynastie und des von ihr kontrollierten Hoheitsgebietes charakterisiert. Die Herrscherfamilien gehörten zumeist der Volksgruppe der Shan (chin. Dai) oder auch den Kachin (chin. Jingpo) an. Die Bevölkerung in den einzelnen Befriedeten Gebieten umfaßte daneben jedoch auch verschiedene andere einheimische Volksgruppen.

Neben den tusi und den wai yi wird hier noch eine dritte Gruppe der einheimischen Bevölkerung im Südwesten benannt, zu der die Yeren und die Lisu zählen: Die ,verschiedenen Volksgruppen“ (zhongren) der Region, die sowohl dies- als auch jenseits der Paßstationen beheimatet waren. ${ }^{727}$ In den Kapiteln über die zhongren in den fangzhi geht es anders als bei den tusi und wai yi nicht um Verwaltungseinheiten sondern, wie der Name schon besagt, um die Völker der Region, die „innerhalb und außerhalb des Regierungsbezirkes ansässig sind“, deren Sitten und Gebräuche, Bekleidung, Wohnstätten und Eßgewohnheiten kurz beschrieben werden. ${ }^{728}$ Politischen Einheiten werden diese Gruppen nicht zugeordnet.

\footnotetext{
${ }^{726}$ YCFZ, S. 329-331. Im TYTZ werden im Kapitel 15 unter der Rubrik ,Grenzgebiet` lediglich Mengyang, Manmo, Mengmi, Mubang und Miandian aufgezählt (S. 239-245).

${ }^{727}$ Die Herausgeber der fangzhi folgen bei der Beschreibungen dieser Gebiete und ihrer einheimischen Bevölkerung generell diesem Schema und gliedern sie entsprechen in drei Kapitel bzw. Abschnitte:

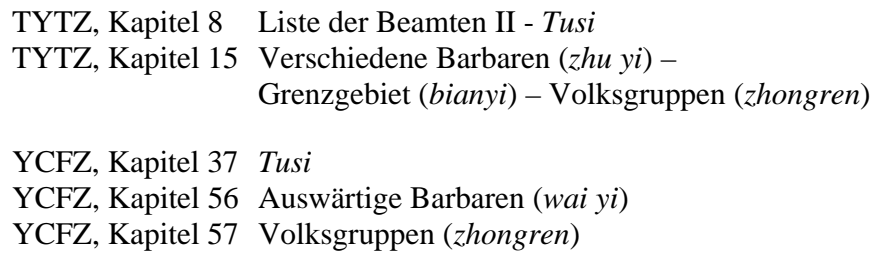

Im TYZZ sind die Gebiete diesseits und jenseits der acht Paßstationen zwar in einem Kapitel unter der Überschrift ,Tusi` zusammengefaßt worden (Kapitel 10, Grenzschutz [bianfang] - tusi), in einer kurzen Einleitung wird jedoch ausdrücklich darauf hingewiesen, daß einige der Gebiete jenseits der Paßstationen lediglich aufgrund ihrer Nähe zu Tengyue und ihrer Bedeutung in Kriegszeiten an dieser Stelle ebenfalls beschrieben werden (TYZZ, S. 148). 
Ihre Siedlungsgebiete waren häufig nicht homogen, sie lebten „verstreut in den Schluchten der Gebirge“ oder „auf hohen Bergen““. ${ }^{729}$

Im YCFZ werden in der Rubrik zhongren siebzehn verschiedene Volksgruppen genannt:

\begin{tabular}{|c|c|c|c|}
\hline Puren, & Jiexiezi, & Echang, & Miao Luoluo, \\
\hline Bai Guoluo, & Yeren, & Boyi, & Baiyi, \\
\hline Bengjing, & Lisu, & Kelie, & Jiala, \\
\hline Piaoren, & Mangren, & Qiawa, & Xiaoboyi, \\
\hline
\end{tabular}

Die Liste im TYTZ ist noch um einiges länger, dort werden zweiundzwanzig verschiedene Volksgruppen beschrieben:

$\begin{array}{llll}\text { Xiaoboyi, } & \text { Daboyi, } & \text { Puren, } & \text { Achang, } \\ \text { Piaoren, } & \text { Hala, } & \text { Jiexie, } & \text { Zhexie, } \\ \text { Diyanggui, } & \text { Hashe, } & \text { Yeren, } & \text { Cuanman, } \\ \text { Miao Luoluo, } & \text { Boyi, } & \text { Lisu, } & \text { Lalu, } \\ \text { Jiala, } & \text { Mianren, } & \text { Jiexiezi, } & \text { Qiawa, } \\ \text { Yeman, } & \text { Mubang. }{ }^{731} & & \end{array}$

Es sind jedoch nicht alle im YCFZ genannten Volksgruppen auch in der längeren Liste des TYTZ mit enthalten. Die Bai Guoluo, Baiyi, Bengjing, Kelie und die Mangren werden im TYTZ nicht genannt.Nimmt man die Aufzeichnungen beider Lokalhandbücher zusammen, so waren insgesamt sogar siebenundzwanzig verschiedene Volksgruppen in der Präfektur Yongchang beheimatet. ${ }^{732}$

Darunter gibt es Völker, die den Chinesen in manchem recht ähnlich waren bzw. Aspekte der chinesischen Kultur aufgenommen haben. Sie wurden als ,gekochte Barbaren‘ (shu yi) bezeichnet (im Gegensatz zu den ,rohen Barbaren`) und mit einer gewissen Sympathie beschrieben, wobei besonders Kenntnisse der chinesischen Sprache positiv vermerkt wurden, wie zum Beispiel bei den Xiaoboyi:

\footnotetext{
${ }^{729}$ TYTZ, S. 247

${ }^{730}$ YCFZ, S. 332-333

${ }^{731}$ TYTZ, S. 247-248

${ }^{732}$ Eine Übersetzung der Beschreibungen der verschiedenen Volksgruppen in den fangzhi von Tengyue und Yongchang findet sich im Anhang.
} 
„Sie sind ,gekochte Barbaren“, die sämtlich im Südwesten in der Umgebung von Tengyue leben. Männer und Frauen tragen nur wenig Kleidung und Schmuck. Sie sind beinahe chinesisch (jin zhonghua) und können auch die chinesische Sprache sprechen (neng hanyu). Sie wohnen in befestigten Dörfern (cun zhai). Ihr Charakter ist folgsam und besonnen (xing shun jin). Sie pflügen, um sich zu ernähren und weben ihre Kleidung (geng shi zhi yi). Sie haben jedoch keine Etikette, [die das Verhalten von] Erwachsenen und Kindern [regelt] (wu chang you li)“. ${ }^{733}$

Andere Volksgruppen hingegen wiesen kaum Gemeinsamkeiten mit den Chinesen auf, wie die Lisu, die „verstreut in Yaoan [Präfektur Chuxiong], in Dali und Yongchang leben“ und „ihren Aufenthaltsort ganz unregelmäßig wechseln“; sie sind geschickte Jäger mit der Armbrust, aber sie „pflanzen auch Buchweizen und Hirse an“ und immerhin haben sie „eine Barbaren-Sprache, aber keine Barbaren-Schriftzeichen“ (you yi yu wu yi zi). ${ }^{734}$

Gänzlich fremd erschienen den Verfassern der fangzhi die Jiexiezi, zu deren Beschreibung sie deshalb auf Begriffe aus dem Tierreich zurückgriffen:

Diese Volksgruppe ist aus Mengyang im Westen nach Tengyue gekommen. [Die Jiexiezi] haben runde Augen und Münder wie Krähen (huan yan wuhui). Sie tragen große Ringe aus Elfenbein in den Ohren. Sie haben keine Kleidung. Unter dem Bauch bedecken sie sich mit einem Streifen Stoff. Reis und Fleisch essen sie ungekocht. Sie sind tapfer und gesund (yong jian). Gewehr und Messer (qiang dao) in Händen haltend verstehen sie zu kämpfen, dabei stoßen sie ein Geschrei aus, das wie Hundegebell [klingt]“. ${ }^{735}$

Auch die Yeren, die im Norden von Tengyue, jenseits des Chashan lebten, unterschieden sich in ihrem Aussehen und in ihrem Lebensstil völlig von den Han-Chinesen; ihre Beschreibung fällt entsprechend wenig schmeichelhaft aus:

„Sie haben rote Haare und gelbe Augäpfel. Ihre Kleidung ist aus Baumrinde. Auf dem Kopf tragen sie einen Kranz aus Knochen, an den Fasananfedern

\footnotetext{
733 TYTZ, S. 247

734 TYTZ, S. 247-248; YCFZ, S. 333. (In der Volksrepublik China wurde im Jahr 1957 eine alphabetische Schrift für die Sprache der Lisu geschaffen [siehe Ma Yin, S. 269].)

${ }^{735}$ TYTZ, S. 248; YCFZ, S. 332
} 
angebunden sind und in den rotes Flechtrohr (hongteng) hineingesteckt wird“ ${ }^{736}$ „Meist [wohnen sie] in Grashütten (caopeng) und sie lieben es umzuziehen (hao qianyi). ... Sie tragen gekrümmte Messer (gou dao) und große Klingen (da ren). Sie jagen und fangen Vögel und wilde Tiere, sie essen Schlangen und Ratten. Ihr Wesen ist rücksichtslos und böse.““737 „Sie lieben es zu töten.

Während der vorangegangenen Ming-Dynastie gab es die beiden Befriedeten Gebiete (zhangguan si) Lima und Chashan, die [die Yeren] unter Kontrolle hielten. Am Ende der Ming-Zeit sind die [Oberhäupter] der beiden Befriedeten Gebiete jedoch von den Yeren vertrieben worden und ins Landesinnere (neidi) geflohen. Heute haben die Söhne und Enkel dieser tusi den Familiennamen Zao, sie leben in Guyong und Wusuo [nördlich der Stadt Tengyue].“738

„Einige [Yeren leben] über tausend li von Teng entfernt, andere dreihundert li von Teng entfernt. Der Ort, von dem aus die Grenze vor ihnen geschützt wird (qi fang jiexian zhi chu) heißt Diantanguan. Zum Schutz gibt es dort einen Militärposten (xun), der von Soldaten bewacht wird.“739

Während die Kapitel über die Befriedeten Gebiete der tusi der Unterpräfektur und der ,auswärtigen Barbaren' (wai yi) in den fangzhi die historische Entwicklung, die Chronologie der Beziehungen zum chinesischen Reich und die Genealogie der Herrscher enthalten, steht bei den Beschreibungen der ,verschiedenen Volksgruppen` (zhongren) das Exotische im Mittelpunkt: Die fremdartige Kleidung (die Frauen der Hala „wickeln sich rotes oder schwarzes Flechtrohr einige Dutzend Mal um die Taille“), die sonderbaren Sitten (bei den Miao Lolo ist es üblich, daß „Männer und Frauen .... ihre Ehepartner selbst aussuchen“) oder die Fähigkeit Zauberei auszuüben (die Diyanggui können die inneren Organe eines Menschen „in Holz oder Stein verwandeln; [das Opfer] ist nicht mehr zu retten und muß sterben“). ${ }^{740}$

\footnotetext{
${ }^{736}$ TYTZ, S. 247

${ }^{737}$ YCFZ, S. 332

738 TYTZ, S. 247. Chashan befand sich nördlich der Unterpräfektur Tengyue, Lima lag westlich von Chashan. Ursprünglich hatten beide zum Territorium von Mengyang gehört. Während der Ära Yongle der Ming-Zeit, in den Jahren 1407 und 1408, wurden sie von China als eigenständige tusi-Gebiete anerkannt (YCFZ, S. 330-331). Heute gehören diese Gebiete zu Birma.

739 TYTZ, S. 247; YCFZ, S. 332

${ }^{740}$ TYTZ, S. 247 (jeweils unter dem Stichwort der genannten Volksgruppe).
} 
Angaben über die Siedlungsgebiete der Volksgruppen sind hingegen eher vage. So heißt es beispielsweise von den Jiala, daß sie verstreut ,überall innerhalb und außerhalb von Yongchang und Tengyue leben“ “. ${ }^{71}$ Hinweise auf die Größe der Bevölkerung der einzelnen Volksgruppen fehlen ganz.

Sorgten einheimische Volksgruppen für Unruhe im Grenzgebiet, so wurde,wie das Beispiel der Yeren zeigt, eher das Territorium der Unterpräfektur neu abgegrenzt, als das China dort direkt eingriff: Nachdem die von der chinesischen Regierung anerkannten tusi aus Chashan und Lima vertrieben worden waren, wurde kein Versuch unternommen, die neuen Machthaber in der Region ebenfalls in das tusi-System einzubinden. Stattdessen bildete nunmehr lediglich das nächstgelegene kleine Befriedete Gebiet Diantanguan tumu einen Puffer zwischen den Yeren und den Han-chinesischen Siedlern in der Unterpräfektur, das allerdings zusätzlich mit einem Militärposten verstärkt wurde. ${ }^{742}$

Deutlich wird, daß sich diese verschiedenen einheimischen Volksgruppen in der Region des Stromschluchtenfächers außerhalb der Strukturen des chinesischen Kernlandes befanden. Bis zum Ende des 19. Jahrhunderts sind sie von der chinesischen Regionalverwaltung nicht erfaßt worden und von Seiten der örtlichen Beamten sind auch keine Anstrengungen unternommen worden, überhaupt auf eine Eingliederung dieser Bevölkerungsgruppen in die politischen Strukturen der Verwaltungseinheit hinzuwirken.

\footnotetext{
${ }^{741}$ TYTZ, S. 248

742 Das Befriedete Gebiet Diantanguan (auch Diantan'ai) war zu Beginn der Ming-Zeit gegründet worden, als der Feldzug die Truppen des Hongwu-Kaisers in die Region des Stromschluchtenfächers geführt hatte. Dort wurde Chai Xiangxian, ein Soldat aus Huguang, zur Grenzverteidigung in Diantan stationiert und das Amt unter seinen Nachkommen weitervererbt (YCFZ, S. 198).
} 


\section{Das Schulwesen in Tengyue in der Qing-Zeit}

Der Prozeß der Angleichung des Schulwesens in der Unterpräfektur Tengyue an das Bildungssystem des chinesischen Kernlandes, der in der Ming-Zeit in Gang gesetzt worden war, hatte zwar erste Erfolge gezeigt, erwies sich jedoch insgesamt als langwierig, wie in dem fortgesetzten Bemühen um die Errichtung neuer Schulen im Grenzgebiet unter der Qing-Dynastie deutlich wird:

„Erst unter der gegenwärtigen Dynastie erging der Befehl, in allen äußeren Präfekturen und Kreisen Tempelschulen (miaoxue) zu errichten, damit sich diese Grenzregion in Kultur und Bildung allmählich dem Kernland (zhong tu) angleichen könne“ ${ }^{743}$

Wie dieser Prozeß in der Qing-Zeit verlaufen ist, spiegelt sich sowohl in der baulichen Entwicklung der Bildungsstätten in Tengyue, des Konfuziustempels, der Akademie Laifengshan sowie auch in der Gründung von Gemeinde- und Freischulen wieder. Die Erfolge des Bildungswesen in der Region des Stromschluchtenfächers zeigen sich in den Zahlen der Prüfungskandidaten und Akademiker der Präfektur Yongchang und im Vergleich mit der Provinz Yunnan insgesamt.

\section{1. Der Konfuziustempel (Xianshi miao/ Xuegong)}

Der Konfuziustempel war seit der Ming-Zeit das älteste und wichtigste Schulgebäude in Tengyue. Im Jahr 1471 als Schule des Amtes Tengchong (Tengchong si xue) gegründet, wurde die Anlage erst 1485 fertig gestellt und nahm den Betrieb auf. Als im Jahr 1522 das Amt in eine Unterpräfektur umgewandelt wurde, wurde die Schule entsprechend zur Unterpräfekturschule (zhouxue). ${ }^{744}$

Zunächst hatte sich der Schultempel an der Stelle des späteren Schießpulverlagers (huoyaoju) der Garnison der Brigade des Regionalen Militärbezirks befunden. Im Jahr 1694 wurde die Schule dann in das bisherige Amtsgebäude des Garnisonskommandanten (zhihui shu) verlegt. Im Jahr 1705 wurde der Schultempel auf Initiative des Unterpräfekten Tang Hanbi und des Schuldirektors (xuezheng) Duan Quanzhang auf einem Grundstück direkt südlich der Verwaltung der Unterpräfektur (ting zhi) neu errichtet. Dort befand sich ein

\footnotetext{
${ }^{743}$ TYTZ, S. 163

${ }^{744}$ TYZZ, S. 72; TYTZ, S. 163 und YCFZ, S. 109 (dort wird Jiajing 3 [1524] als Jahr, in dem die Umbenennung erfolgte genannt).
} 
See, den die beiden Beamten in Panchi (,Teich der Staatshochschule') umbenannten; anschließend wurden verschiedene neue Gebäude errichtet und die gesamte Anlage mit einer roten Mauer umgeben. ${ }^{745}$

Im Laufe der Jahre wurde der Schultempel immer wieder restauriert und verschönert, so zum Beispiel im Jahr 1725, als

„der Unterpräfekt Kong Yuzhen, ein Nachkomme des Weisen, Porträts der vier würdigen Persönlichkeiten und der zehn Schüler des Konfuzius (si pei shi zhe) aus Qufu anbringen ließ. Auch hatte er [aus dem Wald] am Mausoleum des Konfuzius einen Pistazienbaum (jiemu) mitgebracht, den er vor der Halle einpflanzte“. ${ }^{746}$

Im Jahr 1743 (Qianlong 8) ließ der Unterpräfekt Tang Shiliang zudem am Panchi „eine steinerne Bogenbrücke von wirklich großem Ausmaß“ (guimo shen zhuang) errichten. ${ }^{747}$

Während des Krieges mit Birma in den Jahren 1766-1770 „prägten militärische Angelegenheiten Tengyue“ und der Schultempel wurde zum Büro für Heeresbedarf (junxuju) umfunktioniert. ${ }^{748}$ Anschließend war die Anlage reparaturbedürftig und wurde unter der Leitung von Unterpräfekt Wu Kai wieder instand gesetzt:

„Nachdem die Jahre 32, 33 und 34 (1767-1769) vergangen waren, waren die Gebäude verlassen und eingestürzt. Im 35. Jahr (1770) ersuchte Unterpräfekt Wu Kai das Provinzschatzamt um Geld und erhielt eine Summe von über 1000 liang in Gold. Dazu kam noch das vom ehemaligen Unterpräfekten Jiang Yuesi gespendete (juanshu) Silber. Der Vize-Schuldirektor Chen Wencan wurde mit der Erneuerung der Mauer um den Teich betraut. An beiden Seiten wurden Gittertore aufgestellt und bis zur Beendigung der Bauarbeiten war das Hindurchgehen verboten“. ${ }^{749}$

\footnotetext{
745 „Rechts wurde der Tempel für den Gott der Literatur errichtet, in der Mitte war das Lingxing-Tor, dahinter in der zweiten Reihe befand sich das Yimen, weiter erhöht die Halle Dachengdian, zwei überdachte Säulengänge reihen sich an ein Durchgangstor. ... Rechts befindet sich das Amtsgebäude des Schuldirektors (xuezheng xie), links die Mingluntang, dahinter das Amtsgebäude des Vize-Direktors (xundao). Alle [Gebäude] haben Tore und Mauern und [die ganze Anlage] ist ringsum von einer roten Mauer (hong qiang) umgeben. ... Jenseits des Panchi gibt es zwei Dämme, links den Tengjiao (,sich aufbäumender Wasserdrache'), rechts den Qifeng (,aufsteigender Phönix‘)““ (TYTZ, S. 163).

${ }^{746}$ TYTZ, S. 163. Kong Yuzhen war von 1725 bis 1734 als Unterpräfekt in Tengyue tätig (TYTZ, S. 109, 145).

Die vier würdigen Persönlichkeiten, denen auch im Konfuziustempel geopfert wurde (si pei), waren Yan Yuan, Zeng Can, Meng Ke und Zi Si (CY 304. 2). [Zu den zehn Schülern des Konfuzius (shi zhe) siehe auch CY 216.2.]

${ }^{747}$ Ebenda.

${ }^{748}$ TYTZ, S. 163. S. TYTZ, S. 299

${ }^{749}$ TYTZ, S. 297 (von Tu Shulian); S. 299 (von Wu Kai).
} 
Schon fünfzehn Jahre später waren erneut umfangreiche Bauarbeiten notwendig, da alle Gebäude des Schultempels bei dem großen Erdbeben im Jahr 1785 (Qianlong 50) eingestürzt sind. Den Wiederaufbau organisierte Unterpräfektur Tu Shulian im Jahr 1788 und ließ dabei die Anlage insgesamt erweitern. ${ }^{750}$

Im Jahr 1845 (Daoguang 25) initiierte Unterpräfekt Li Hengqian eine Spendensammlung (changjuan zhongxiu), um Reparaturarbeiten an der Tempelanlage zu ermöglichen. Da die Arbeiten während seiner Amtszeit nicht beendet werden konnten, wies sein Nachfolger im Amt, Peng Songyu, im Jahr 1847 den Schuldirektor Xu Wenzao und den Vize-Direktor Fan Anguo sowie Jie Binwang und andere Angehörige der örtlichen Gentry (shenshi) an, sie zu vollenden. ${ }^{751}$

Nachdem die Stadt Tengyue im Jahr 1861 von Moslem-Rebellen erobert worden war, zerstörten diese im folgenden Jahr den Konfuziustempel (bingxian fenhui). Erst nach der Niederschlagung des Aufstandes im Jahr 1873 wurde die Anlage wieder aufgebaut. ${ }^{752}$ Unterpräfekt Wu Qiliang organisierte im Jahr 1874 (Tongzhi 13) den Bau der DachengHalle. Diese wurde noch mit der restlichen Summe des Geldes (yu kuan changjian), das die Regierung für die Niederschlagung der Rebellion zur Verfügung gestellt hatte, finanziert. ${ }^{753}$ Die Halle wurde jedoch während seiner Amtszeit nicht mehr fertiggestellt und die Arbeiten dann unter seinem Amtsnachfolger Chen Zonghai im Jahr 1879 (Guangxu 5) fortgesetzt. Unterpräfekt Chen Zonghai beschaffte (choujuan) über 5000 liang in Gold und spendete selbst (juanlian) 600 liang in Gold für die Renovierung der DachengHalle und

„ließ den Qishenggong verlegen, die östlichen und westlichen Galerien sowie das Dacheng-Tor, die Mingluntang, den Xiangxian- und Minghuanci, das Lingxing-Tor und zwei Ehrenbögen neu aufbauen. Außerhalb des Tores ließ er

\footnotetext{
${ }^{750}$ Tu Shulian war von 1787 bis 1791 in Tengyue tätig. Er ließ „die Dachengdian, den Qishenggong und das LingxingTor restaurieren, er ließ den Xiangxianci und den Minghuanci umgestalten, im Osten und Westen zwei Ehrenbögen hinzufügen, die Umfassungsmauer des Sees Dache [das ist der Panchi], zwei überdachte Säulengänge, das Dacheng-Tor und die Mingluntang ... wiedererrichten“ (TYTZ, S. 164). Zum Wiederaufbau des Schultempels verfaßte Tu 1788 eine Gedenkinschrift (siehe TYTZ, S. 297-298).

${ }^{751}$ TYTZ, S. 164

752 YCFZ, S. 109. Die Entwicklung des Schulwesens in Tengyue im 19. Jahrhundert unter besonderer Berücksichtigung der Zeit der Moslem-Rebellion und der anschließenden Phase des Wiederaufbaus wird weiter unten in einem eigenen Kapitel (B. 3. 4., S. 382ff) dargestellt.

753 TYTZ, S. 164
} 
eine steinerne Balustrade sowie zwei Ehrenbögen im Osten und Westen hinzufügen und beide Seiten des Panchi von einer Mauer umgeben“. ${ }^{754}$

Am Beispiel der Baumaßnahmen am Konfuziustempel wird die zentrale Position deutlich, die den Unterpräfekten bei der Durchführung derartiger Bauprojekte zukam. Sie planten nicht nur den Wiederaufbau der einzelnen Gebäude, sondern waren vor allem für die Finanzierung einer solchen Unternehmung verantwortlich;sie beantragten staatliche Mittel, förderten die Bauprojekte mit eigenen Geldspenden und veranlaßten die örtliche Oberschicht, sich an der Finanzierung und der Organisation der Bauarbeiten zu beteiligen.

Tabelle 24: Unterpräfekten von Tengyue, die sich besonders für die Renovierung des Schultempels engagiert haben ${ }^{755}$

\begin{tabular}{lll}
\multicolumn{2}{c}{ Jahr der Renovierung } & Name \\
1668 & (Kangxi 7) & Wang Lü \\
1687 & (Kangxi 26) & Yang Duanxian \\
1770 & (Qianlong 35) & Wu Kai \\
1788 & (Qianlong 53) & Tu Shulian \\
1845 & (Daoguang 25) & Li Hengqian \\
1847 & (Daoguang 27) & Peng Songyu \\
1874 & (Tongzhi 13) & Wu Qiliang \\
1879 & (Guangxu 5) & Chen Zonghai
\end{tabular}

Die Baugeschichte des Schultempels ist exemplarisch für die gesamte bauliche Entwicklung der Stadt Tengyue, die in der Qing-Zeit von den zwei großen Einschnitten, zum einen die Kriege mit Birma im 18. Jahrhundert und zum anderen die Besetzung durch die aufständischen Moslime im 19. Jahrhundert, geprägt wurde. Im 18. Jahrhundert war Tengyue Aufmarschgebiet und Truppenstützpunkt für die Qing-Armeen, die die Gebäude als Unterkünfte, Lager usw. nutzten und sie nach ihrem Abzug stark beschädigt zurückließen. Im 19. Jahrhundert hingegen wurden zahlreiche öffentliche Gebäude, Schulen und Tempel, als Symbole der staatlichen Ordnung, die die Aufständischen bekämpften, vorsätzlich zerstört. Und auch bei den Kämpfen zur Rückeroberung der Stadt durch die Qing-Truppen wurden weitere Bauwerke beschädigt. Hinzu kamen mehrere schwere Erdbeben insbesondere in der zweiten Hälfte des 18. Jahrhunderts, die zahlreiche Gebäude und auch Teile der Stadt-

\footnotetext{
754 TYTZ, S. 163-64; TYZZ, S. 72-74

${ }^{755}$ TYTZ, S. 163-164; YCFZ, S. 109
} 
mauer zum Einsturz brachten und immer wieder aufwendige Instandsetzungsarbeiten erforderlich machten.

\section{2. Die Laifengshan Akademie}

Die ,Akademie des herbeikommenden Phönix‘ (Laifengshan shuyuan) ist nach dem Berg Laifeng im Süden von Tengyue benannt worden, an dessen nördlichem Abhang sie sich ursprünglich befunden hatte. Die Anlage dort war jedoch schon seit einiger Zeit zerstört gewesen, als Unterpräfekt Tang Shiliang die Akademie im Jahr 1749 neben dem Unterpräfektursamt neu errichten ließ. Der Akademie wurden Ländereien zugeteilt, deren Erträge zur Deckung von Studienkosten und Lehrervergütung verwendet wurden. Unter anderem sind der Akademie vom Unterpräfekten auch Steuergelder von Feldern, die sich in den tusi-Gebieten Ganya und Zhanda befanden, zugeteilt worden. ${ }^{756}$

Im Jahr 1766, zu Beginn des Krieges mit Birma, wurde die Akademie Laifengshan vorübergehend als Militärbüro (xingtai) genutzt, so daß der Unterricht nicht mehr fortgesetzt werden konnte. Nach Kriegsende ließ Unterpräfekt Wu Kai sie wieder instand setzen und die Anlage erweitern. Seinen ürsprünglichen Plan, die Akademie außerhalb der Stadt im Norden des Laifengshan ganz neu zu errichten, konnte er jedoch nicht realisieren.

Im Jahr 1789 ließ Unterpräfekt Tu Shulian die Akademie innerhalb der Stadt, rechts neben dem Konfuziustempel (xuegong) neu errichten. Zur Akademie gehörten

„drei Haupthallen (shangfang/zhufang), sechs Seitengebäude, ... [zwölf weitere Gebäude] im Osten und im Westen ... sowie eine Küche. In der Mitte hatten alle [Gebäude] mehrflügelige Türen. Außerhalb befand sich das Haupttor; alles war von einer Mauer umgeben. Die Arbeiten waren im 10. Monat begonnen worden und im ersten Monat des folgenden Jahres wurden sie beendet. Die Aufsicht darüber führten die Angehörigen der örtlichen Gentry: Long Zitai, Zhou Chenglin, Huang Jinbang und Jie Xinyuan“. ${ }^{757}$

Während der Ära Tongzhi (1862-1875) ist die Laifengshan Akademie von den MoslemRebellen zerstört worden. Nach der Niederschlagung der Rebellion 1873, wurde die Lehr-

\footnotetext{
${ }^{756}$ TYTZ, S. 168

757 TYTZ, S. 166; TYZZ, S. 75 (Qianlong 54 [1789]; YCFZ, S. 112 (Qianlong 56 [1791].
} 
stätte für einige Jahre vorübergehend im Wohnsitz der Familie Liu am Westtor untergebracht.

Da ihr alter Platz verödet und zu klein war, spendete (juanlian) Unterpräfekt Chen Zonghai über 1570 liang in Gold für ihren Wiederaufbau auf einem Stück Brachland innerhalb des Südtores (nanmen nei huang chan yi duan), an der Hauptstraße der Südstadt (nancheng zhengjie). Verschiedene Gebäude wurden errichtet und mit einer cirka 600m langen Mauer umgeben. Zur Finanzierung der Laifengshan-Akademie

„ließ Unterpräfekt Chen Zonghai der Akademie in den Jahren Guangxu 6 (1880), 12 (1886) und 14 (1888) Felder zuweisen. Hinzu kam noch der Pachtzins für das Gelände, [mit insgesamt 20 Gebäuden an der Hauptstraße der südwestlichen Vorstadt,] in der Wubao-Straße, deren Wiederaufbau Unterpräfekt Chen Zonghai im 5. Jahr der Ära Guangxu (1879) veranlaßt hatte (changjuan)“. 758

Die Arbeiten an der Laifengshan Akademie sind im Herbst des 7. Jahres der Ära Guangxu (1881) begonnen und im Winter des 8. Jahres abgeschlossen worden. ${ }^{759}$

Im Jahr 1887 wurde die finanzielle Basis der Akademie von Chen Zonghai geordnet und die Mittel für die Akademie neu festgelegt. Im Jahr darauf teilte er ihr erneut Ländereien zu und veranlaßte, die Einkünfte, die die Akademie aus den verschiedenen Quellen zu erhalten hatte, in dem neuen Lokalhandbuch im Einzelnen aufzulisten. ${ }^{760}$

Unterpräfekt Chen Zonghai bemühte sich jedoch nicht nur um den materiellen Wiederaufbau der Lehrstätte, sondern spendete der Akademie auch einen Teil seines Zusatzgehalts (juanlian) für die Anschaffung von Büchern, deren Titel sämtlich im Lokalhandbuch TYTZ aufgelistet worden sind. Diese Bücher wurden besonders gekennzeichnet und sorgfältig gepflegt:

„Die Bücher wurden zwischen zwei Deckel eingebunden und so in Bücherschränken im ,Haus der Büchersammlung‘(Cangshulou) aufbewahrt. Jeden Sommer mußte der Direktor (xuezhang) sie überprüfen, nachzählen und zum Trocknen an die Luft bringen, um zu vermeiden, daß sie verfaulen oder von

\footnotetext{
${ }^{758}$ Siehe auch YCFZ, S. 113

${ }^{759}$ TYTZ, S. 166, 298; TYZZ, S. 74-75; YCFZ, S. 112-113

${ }^{760}$ TYTZ, S. 167-169
} 
Würmern zerfressen würden. Sie durften nicht nach außerhalb der Akademie verlagert werden, ... insgesamt waren es vierzig Bücher in 1511 Bänden““. ${ }^{761}$

Außerdem wurden in der Akademie die Druckplatten von zehn Büchern aufbewahrt, die zu dieser Zeit neu gedruckt worden sind. ${ }^{762}$ Bei diesen Büchern handelt es sich um konfuzianische Klassiker, Geschichtsbücher und philosophische Werke sowie Gedichtsammlungen, die von Schülern in ganz China im Verlauf ihrer traditionellen Ausbildung studiert wurden. Mit der Auflistung der Buchtitel heben die Verfasser des Lokalhandbuchs hervor, daß in der fernen Grenzstadt Tengyue die gleichen Lehrinhalte vermittelt werden, wie im Landesinnern und betonen, daß die Ausbildung, zumindest in der Akademie Laifengshan, durchaus das Niveau der Kernregion erreicht hat und die Angleichung an das Bildungswesen in diesem Bereich gelungen ist.

\section{3. Gemeinde- und Freischulen}

\section{3. 1. Zur Entwicklung der Gemeinde- und Freischulen seit der Ming-Zeit}

Die Gründung von Gemeindeschulen (shexue) geht auf ein Edikt des Kaisers Hongwu der Ming-Dynastie von 1375 zurück, indem verfügt wurde, daß besonders in ländlichen Gebieten Gemeindeschulen zu gründen seien. Mit der Gründung der Schulen wurden die jeweiligen obersten lokalen Verwaltungsbeamten beauftragt, die für die Finanzierung und Instandhaltung der Gemeindeschulen Sorge zu tragen hatten. ${ }^{763}$

Aufgabe der Schulen war es, Kindern bis zum Alter von etwa vierzehn Jahren traditionelle konfuzianische Werte zu vermitteln, um so Stabilität und Ordnung nach der Zeit der Mongolenherrschaft und des Dynastiewechsels wiederherzustellen. ${ }^{764}$ Da dieses Schulsystem jedoch keine dauerhafte staatliche Unterstützung erhielt, hing sein Erfolg allein von der Förderung durch die örtlichen Beamten ab. Bis zum Ende der Ming-Zeit hatte sich diese Verantwortung dann von den Staatsbeamten hin zu den führenden Mitgliedern der örtlichen Gemeinden verschoben. ${ }^{765}$ Auch die Zielsetzung der Schulen begann sich zu

\footnotetext{
${ }^{761}$ TYTZ, S. 166-167

762 Die Titel der Werke lauten: 1. Shengyu guangxun (,Heilige Edikte‘ des Kangxi-Kaisers von 1662, ergänzt 1670 sowie vom Yongzheng-Kaiser [1723-36]), 2. Qingxiang miyue, 3. Tengyue zhi, 4. Sishi dushu le (,Lesevergnügen in den vier Jahreszeiten', mit Anhang: Jiuchenggong und andere Musterschriften), 5. Dizi gui (,Vorschriften für Schüler`), 6. Tongmeng jiyao (mit Anhang: Xiaoer yu), 7. Zixue juyu (Mustertexte für die Beamtenprüfungen; Hrsg. von Long Qirui, 1814-1858, Bester der Hanlin Prüfungen während der Ära Daoguang, Rektor der staatlichen Schule und Direktor des Provinzschatzamtes in Jiangxi (CY 423.4; ZGRM DCD, S. 89), 8. Shihuan jinzhen (mit Anhang: Sansheng quan shi wen, xun chang yu), 9. Kechang tiaoli (,Richtlinie für den Prüfungssaal`) und 10. Yingyan liangfang (TYTZ, S. 167). (Siehe auch unten B. 3. 4., S. 385.)

${ }^{763}$ Angela Leung, S. 383

${ }^{764}$ Ebenda, S. 382

${ }^{765}$ Ebenda, S. 383
} 
ändern. Waren sie zunächst nur für die Ausbildung generell von begabten Kindern gedacht, so bereiteten die shexue doch in der Regel nur Kinder aus wohlhabenden Familien auf die Staatsprüfungen vor. Später sollten sie sich jedoch wieder mehr um die ärmeren Kinder der Gemeinde kümmern und diesen Elementarunterrichtet erteilen. ${ }^{766}$

Diese Vorstellungen führten zur Entstehung von Freischulen (yixue), die kostenfreien Unterricht erteilten und die eher als die shexue wirkliche von den Gemeinden bzw. der lokalen Elite betriebene Schulen waren, bei denen der Aspekt der Wohltätigkeit für die Allgemeinheit im Vordergrund stand. ${ }^{767}$

In der Ming-Zeit existierten in Tengyue drei Gemeindeschulen (shexue), die jedoch unter der folgenden Dynastie nicht weitergeführt wurden. ${ }^{768}$

Auch unter der Qing-Dynastie war zunächst die Gründung von Gemeindeschulen (shexue) propagiert worden. Nachdem der Kangxi-Kaiser allerdings im Jahr 1702 die erste kostenfreie Wohltätigkeits- oder Freischule (yixue) in Peking gegründet hatte, wurden anschliessend im ganzen Reich zunehmend diese Art von Schulen eröffnet.

Im Jahr 1713 erging ein kaiserliches Edikt, in dem ausdrücklich festgelegt wurde, daß die yixue Unterricht für Kinder armer Familien anbieten sollten. ${ }^{769}$ Auch im TYTZ wird diese Aufgabe ausdrücklich erwähnt und zudem der Standort der Freischulen in ländlichen Regionen hervorgehoben (jian yixue yi jiao ge xiang zhi zi di). ${ }^{770}$

In der Provinz Yunnan wurde die Gründung von Freischulen (yixue) in der ersten Hälfte des 18. Jahrhunderts durch die Tätigkeit Chen Hongmous gefördert, der von 1733 bis 1738 Direktor der Provinzbehörde (buzhengshi si) war und es sich zur Aufgabe gemacht hatte, besonders in Gebieten mit nicht Han-chinesischer Bevölkerung chinesische Grundschulen zu etablieren. ${ }^{771}$ Deren Aufgabe war es, Kenntnisse der chinesischen Schrift in der gesamten Bevölkerung der Provinz zu fördern und ihr eine standardisierte traditionelle Grundausbildung zukommen zu lassen, um so die Einheit des Reiches zu festigen. ${ }^{772}$ Die Gründung der Schulen ging vor Ort von den örtlichen Verwaltungsbeamten aus, unterhal-

\footnotetext{
${ }^{766}$ Angela Leung, S. 384

${ }^{767}$ Ebenda, S. 384

${ }^{768}$ TYZZ, S. 74: Tu Shulian berichtet, daß sie während seiner Amtszeit (1787-91) schon nicht mehr existiert haben.

${ }^{769}$ Angela Leung, S. 384.

770 TYTZ, S. 170

${ }^{771}$ Rowe, Education, S. 417

${ }^{772}$ Ebenda, S. 428-29
} 
ten wurden sie jedoch von den Gemeinden selbst, wofür Chen verschiedene Finanzierungsmöglichkeiten empfahl und die Beamten mit der Verwaltung der Gelder beauftragte. ${ }^{773}$ Während der Amtszeit Chens sollen an die siebenhundert Schulen in Yunnan gegründet bzw. alte renoviert worden sein. ${ }^{774}$ Die Initiative zur Gründung der Freischulen von Chen Hongmou trug damit erheblich zur Förderung des Bildungswesens in Chinas südwestlichster Provinz bei.

\section{3. 2. Freischulen (yixue) in Tengyue}

In den fangzhi der Unterpräfektur Tengyue werden insgesamt vierundvierzig Freischulen aufgelistet. Die älteste erwähnte Freischule, die Nanmen yixue, ist bereits im Jahr 1699 gegründet worden:

„Sie befand sich früher im Bereich des Südtores, an der Stelle der ehemaligen Frühling und Herbst Akademie (Chunqiu shuyuan). Man sagt auch, daß es die Stelle des alten Tempels des Stadtgottes des Regierungsbezirks gewesen sei. Im 38. Jahr der Ära Kangxi (1699) spendete (juan) Unterpräfekt Tang Hanbi für den Bau [der Schule]. Im Jahr 12 der Ära Yongzheng (1734) ließ ihn Unterpräfekt Kong Yuzhen restaurieren. Nachdem im Jahr 1774 der Hörsaal (jiangtang) eingestürzt war, ließ Unterpräfekt Wu Kai Mittel für einen Neubau außerhalb des Südtores anweisen (bokuan). ${ }^{775}$

Später erteilten die Angehörigen der Gentry der Region (yishen) Lu Zitai, Lu Jiayan, Yin Kaiwen, Zhou Shaosheng, Jin Ze, Zhang Bida, Li Zhanze u.a. dort nacheinander den Unterricht (jiao du). Der Schule waren einige Felder zugewiesen worden und die Vergütung des Lehrers betrug jährlich 33 dan 5 dou 8 sheng [ca. 3358l] Getreide (jingdou gu)“. ${ }^{776}$

Chen Hongmou wird in den fangzhi von Tengyue nicht ausdrücklich erwähnt. Während seiner Amtszeit in Yunnan (1733-1738) sind in den ländlichen Gebieten in der Umgebung Tengyues von den jeweiligen Unterpräfekten sieben Freischulen gegründet worden. Eine Initiative, die sicher in Zusammenhang mit der allgemeinen Förderung des Bildungswesens in Yunnan zu dieser Zeit zu sehen ist.

\footnotetext{
${ }^{773}$ Ebenda, S. 428, 432-33

${ }^{774}$ Nach Angaben des Xin zuan Yunnan tongzhi gab es in Yunnan während der Qing-Zeit insgesamt 674 Freischulen (siehe Lan Yong, Xinan lishi wenhua dili, S. 126).

775 YCFZ, S. 113

${ }^{776}$ TYTZ, S. 170, 147; TYZZ, S. 74. Ein dan entsprach 100 Liter.
} 
Während der Ära Qianlong (1736-1796) sind insgesamt elf Schulen gegründet worden, zu Beginn des 19. Jahrhunderts wurden dann von Unterpräfekt Yilibu und seinem Amtsnachfolger Hu Qiying noch einmal sieben Schulen neu errichtet.

Die Namen der Freischulen verweisen auf ihre Standorte in den ländlichen Gemeinden (lian), in denen die Ansiedlungen mit überwiegend Han-chinesischer Bevölkerung in der Umgebung der Stadt Tengyue zusammengefaßt wurden.

\section{Tabelle 25: Von den Unterpräfekten von Tengyue gegründete Freischulen (yixue) ${ }^{777}$}

\begin{tabular}{|c|c|c|}
\hline $\begin{array}{l}\text { Name des } \\
\text { Unterpräfekten }\end{array}$ & Jahr & Name der Schule \\
\hline Kong Yuzhen & 1734 & $\begin{array}{l}\text { Donglian yixue (1), Qiluo yixue, } \\
\text { Heshun yixue, Jiewei und Jietou yixue }\end{array}$ \\
\hline \multirow[t]{2}{*}{ Wu Zuozhe } & 1737 & Chengbao yixue \\
\hline & 1738 & Minglang yixue \\
\hline \multirow[t]{2}{*}{ Zhu Jinchang } & 1745 & $\begin{array}{l}\text { Donglian yixue (2), Puwo yixue, } \\
\text { Dazhonglian yixue }\end{array}$ \\
\hline & ---- & Longjiang yixue \\
\hline Tang Shiliang & 1768 & Daxi yixue \\
\hline \multirow[t]{2}{*}{ Wu Kai } & 1776 & Liandonggan yixue \\
\hline & 1779 & Beilian yixue \\
\hline Tu Shulian & 1790 & Mianqing yixue \\
\hline Zhou Mingyan & 1796 & Wadian yixue \\
\hline Xu Hengchao & 1808 & Xiaoxi yixue \\
\hline \multirow[t]{3}{*}{ Yilibu } & 1820 & Qingkou yixue \\
\hline & 1821 & Qingshui yixue, Guyong yixue \\
\hline & ---- & Hexi yixue, Zhanxi yixue \\
\hline Hu Qiying & 1822 & Siyizhuang yixue, Luoshisi yixue \\
\hline
\end{tabular}

Seit Beginn der Qing-Dynastie hatte sich die Regierung bemüht, auch die tusi im Südwesten des Reiches an das staatliche Bildungswesen heranzuführen. In der Zeit der Ära Kangxi wurden verschiedene Edikte erlassen, in denen die Erbfolge der tusi geregelt wurde und in denen die tusi aufgefordert wurden, ihre Söhne in die chinesischen Schulen zu schicken. Ein Erlaß aus dem Jahr 1682 legte dann fest, daß nicht mehr nur die Söhne der tusi die Schulen besuchen sollten, sondern auch die Söhne ihrer Gefolgsleute. ${ }^{778}$ Seit dem Jahr 1703 war es Schülern aus den tusi-Gebieten gestattet, an den staatlichen Beamten-

\footnotetext{
${ }^{777}$ TYTZ, S. 170-174. Die Gründungsdaten der übrigen Freischulen werden im TYTZ nicht genannt.

${ }^{778}$ Herman, S. 59
} 
prüfungen teilzunehmen. ${ }^{779}$ Im Jahr 1705 bestimmte ein Edikt, daß nur der Sohn eines tusi die Nachfolge antreten konnte, der eine chinesische Schule besucht und dort bestimmte Grundkenntnisse erworben hatte, die die örtlichen Beamten zu überprüfen hatten. ${ }^{780}$

John Herman stellt in seiner Untersuchung der Maßnahmen zur Reform des tusi-Systems zu Beginn der Qing-Zeit fest, daß die einheimischen Eliten generell durchaus Interesse daran hatten, ihre Söhne in die Schulen zu schicken, was zum Neubau von Freischulen, auch in einigen tusi-Gebieten, führte. ${ }^{781}$

Im Kapitel über das Schulwesen in Tengyue im TYTZ wird nur die Gründung von zwei Freischulen in einem tusi-Gebiet erwähnt: Die beiden neuen Freischulen in Nandian. ${ }^{782}$ Das Befriedete Gebiet von Nandian ist das der Stadt Tengyue am nächsten gelegene tusiGebiet. Im Jahr 1775 wurden ein größeres Truppenkontingent chinesischer Soldaten stationiert sowie auch zivile Beamte dorthin entsandt, so daß dieses Gebiet stärker unter der Kontrolle der chinesischen Verwaltung stand als die weiter entfernt gelegenen tusi.

Hinweise auf Schulen in den anderen tusi-Gebieten der Unterpräfektur bzw. auf die Teilnahme von Schülern aus den tusi-Gebieten am Unterricht in den staatlichen Schulen von Tengyue gibt es in den fangzhi nicht. Hier sind die staatlichen Vorschriften, die die Regelung der Erbfolge der tusi vom Besuch einer chinesischen Schule abhängig machen sollten, unbeachtet geblieben.

\section{4. Erfolge des Bildungswesens von Tengyue - jinshi, juren und gongsheng}

Während die Freischulen in Tengyue und in den ländlichen Gebieten in der Umgebung der Stadt vor allem die Aufgabe hatten, für eine Grundausbildung zu sorgen und die traditionellen konfuzianischen Wertvorstellungen zu vermitteln, sollten der Unterricht im Schultempel und in den Akademien die Schüler auf die Teilnahme an den staatlichen Prüfungen vorbereiten und ihnen den Eintritt in die Beamtenlaufbahn ermöglichen. Die Anzahl der erfolgreichen Kandidaten der Prüfungen in der Hauptstadt und in der Provinz (jinshi, juren) sowie der nominellen Studenten der staatlichen Hochschule Guozijian (gongsheng) macht das Niveau des Bildungswesens in der Verwaltungseinheit deutlich und

\footnotetext{
779 Herman, S. 65

${ }^{780}$ Herman, S. 67

${ }^{781}$ Herman, S. 66

${ }^{782}$ TYTZ, S. 173. Die Gründungsdaten der Schulen werden in den fangzhi nicht genannt, es wird lediglich auf die Renovierung der beiden neuen Freischulen Nandian hingewiesen, für die Unterpräfekt Chen Zonghai im 13. Jahr der Ära Guangxu (1887) die finanziellen Mittel zur Verfügung stellte (juanlian xiujian) (ebd.).
} 
zeigt in wie weit die Angleichung an das Schulsystem des Kernlandes über den Bau von Schulgebäuden hinaus auch bei den Unterrichtsinhalten gelungen ist.

\section{4. 1. Jinshi}

In der Qing-Zeit haben lediglich zwei Männer aus Tengyue die Staatsprüfungen in der Hauptstadt bestanden und den akademischen Titel eines jinshi erworben, beide erst relativ spät, zur Zeit der Ära Jiaqing (1796-1821). Xu Erchao hatte im Jahr 1798 (Jiaqing 3) zunächst die Prüfungen zum Erwerb des Titels eines juren bestanden (enci juren). Drei Jahre später, im Jahr 1801 (Jiaqing 6), hatte er den Titel eines jinshi erlangt und ist in die HanlinAkademie berufen worden (enci Hanlin).

Jiang Lu hatte im Jahr 1801 den Titel eines juren erhalten, jedoch erst sechzehn Jahre später, im Jahr 1817 (Jiaqing 22), die Prüfung zum jinshi erfolgreich absolviert. Jiang Lu war danach als Kreismagistrat (zhixian) in der Provinz Shanxi tätig und wird in den historischen Quellen als gerechter und unbestechlicher Beamter (qingtian) lobend erwähnt. ${ }^{783}$

In der Ming-Zeit hatten noch drei Männer aus Tengyue den jinshi-Titel erlangt. Auch in der Präfektur Yongchang insgesamt haben in der Qing-Zeit weniger Kandidaten den Titel eines jinshi erworben als zuvor. Unterdessen hat jedoch die Anzahl der jinshi in der Provinz Yunnan insgesamt in der Qing-Zeit deutlich zugenommen und auch der Anteil der jinshi aus Yunnan an der Gesamtzahl der jinshi aus ganz China ist größer geworden. ${ }^{784}$

Tabelle 26: Anzahl der jinshi in der Ming- und Qing-Zeit ${ }^{785}$

$\begin{array}{lrr} & \text { Ming-Zeit } & \text { Qing-Zeit } \\ \text { Unterpräfektur Tengyue: } & 3 & 2 \\ \text { Präfektur Yongchang: } & 26 & 17 \\ \text { Provinz Yunnan: } & 241 & 658 \\ \text { China insgesamt: } & 22.980 & 26.747\end{array}$

Trotz ihrer Entwicklungsfortschritte gehörte die Provinz Yunnan auch in der Qing-Zeit weiterhin zu den Gebieten mit einem weniger entwickelten Bildungswesen. Im Vergleich

\footnotetext{
${ }^{783}$ TYTZ, S. 198-199, 212

${ }^{784}$ Ein Trend, der auch in der Gründung von neun Häusern der Landsmannschaften in Peking, in denen die Prüfungskandidaten aus der Provinz Yunnan in der Hauptstadt Unterkunft fanden (keju huiguan), zum Ausdruck kam (Lan Yong, Xinan lishi wenhua dili, S. 128).

${ }^{785}$ Lan Yong, S. 111, 126. Siehe auch YCFZ, S. 202-204. He Bingkun, Mingdai ji, nennt eine Zahl von 263 bzw. 228 jinshi in der Provinz Yunnan in der Ming-Zeit und 662 jinshi in der Qing-Zeit (siehe Lan Yong, ebd.).
} 
mit den anderen Provinzen des Reiches lag Yunnan in Bezug auf die Anzahl der jinshi an viertletzter Stelle. ${ }^{786}$

\section{Tabelle 27: Die Anzahl der jinshi aus den Verwaltungseinheiten der Provinz Yunnan in der Qing-Zeit ${ }^{787}$}

$\begin{array}{lrlr}\text { Verwaltungseinheit } & \begin{array}{c}\text { Gesamtzahl } \\ \text { der jinshi }\end{array} & \text { Verwaltungseinheit } & \begin{array}{r}\text { Gesamtzahl } \\ \text { der jinshi }\end{array} \\ \text { Yunnan fu } & 218 & \text { Puer fu } & 1 \\ \text { Dali fu } & 101 & \text { Yongbei ting } & 5 \\ \text { Wuding fu } & 2 & \text { Menghua ting } & 15 \\ \text { Lijiang fu } & 23 & \text { Jingdong ting } & 2 \\ \text { Chuxiong fu } & 36 & \text { Zhenyuan ting } & 1 \\ \text { Yongchang fu } & \mathbf{1 7} & & \\ \text { Shunning } f u & 1 & \text { Zhenxiong zhou } & 2 \\ \text { Qujing fu } & 21 & \text { Guangxi zhou } & 10 \\ \text { Dongchuan fu } & 7 & \text { Guangnan zhou } & 3 \\ \text { Zhaotong } f u & 9 & \text { Yuanjiang zhou } & 3 \\ \text { Chengjiang fu } & 37 & & \mathbf{6 5 8} \\ \text { Lin'an fu } & 138 & \text { Gesamt } & \\ \text { Kaihua } f u & 6 & & \end{array}$

Wie unter der vorangegangenen Dynastie stammten die meisten jinshi der Provinz auch unter der Qing-Dynastie aus den Präfekturen in Zentral-Yunnan (siehe Tab. 27). Die bei weitem größte Gruppe bildeten, ebenso wie in der Ming-Zeit, die jinshi aus der Region um die Provinzhauptstadt (218, darunter 155 aus dem Kreis Kunming) sowie den Präfekturen Lin’an (138) und Dali (101).

Mit weitem Abstand folgt dann eine zweite Gruppe von Präfekturen und Unterpräfekturen mit fünfzehn bis knapp vierzig jinshi. Dazu gehören die Präfekturen Chengjiang (37), Chuxiong (36), Lijiang (23), Qujing (21), Yongchang (17) und die Unterpräfektur Menghua (15). Die verbleibenden dreizehn Verwaltungseinheiten haben lediglich ein bis zehn jinshi hervorgebracht. $^{788}$

\footnotetext{
${ }^{786}$ Lan Yong, Xinan lishi wenhua dili, S. 128

${ }^{787}$ Nach Angaben des Ming-Qing jinshi timinglu suoyin. Zitiert nach Lan Yong, Xinan lishi wenhua dili, S. 127; Biao 4-21, Qingdai Yunnan jinshi fenbubiao.

Wuding war seit 1765 (Qianlong 30) Präfektur (fu) und wurde im Jahr 1770 (Qianlong 35) in eine unabhängige Unterpräfektur (zhilizhou) umgewandelt (Niu Pinghan, S. 395).

${ }_{788}$ Lan Yong, Xinan lishi wenhua dili, S. 128. Lan Yong teilt die Verwaltungseinheiten Yunnans nach dem Stand der Entwicklung ihres Schulwesens entsprechend in drei Gruppen ein:
} 
Während die Präfektur Yongchang in der Ming-Zeit nach Anzahl der jinshi noch an vierter Stelle der Verwaltungseinheiten der Provinz gestanden hatte, nahm sie in der Qing-Zeit nur noch den achten Platz in der Liste ein, mit einem sehr viel größeren Abstand zu den Präfekturen an der Spitze der Liste als zuvor. Entgegen der allgemeinen Entwicklung in Yunnan hat sich das Bildungswesen der Präfektur Yongchang, so wie es in der Anzahl der jinshi zum Ausdruck kommt, verschlechtert.

Deutlich wird dieses Gefälle auch, wenn man die Zahl der jinshi in Relation zur Gesamtbevölkerung der einzelnen Verwaltungseinheiten setzt. In der Präfektur Yunnan kommt ein jinshi auf 4311 Einwohner. In Lin'an ist es einer von 2989 und in Dali einer von 5544 Einwohnern, in Yongchang ist es nur einer von 27.058 Einwohnern. Auffällig ist hier die relativ hohe Anzahl der jinshi pro Einwohner in der Präfektur Lin’an, während die zentral gelegenen Präfektur Chuxiong nur einen jinshi auf 10.555 Einwohner aufweist; in der Präfektur Shunning südöstlich von Yongchang kam lediglich ein jinshi auf 110.000 Einwohner. ${ }^{789}$

\section{4. 2. Gongsheng und juren}

Der weit aus größte Teil der Absolventen der Schulen der Unterpräfektur hatte den Status der zu den zivilen Provinzprüfungen zugelassenen Kandidaten und Studenten der Staatsuniversität Guozijian (shengyuan, gongsheng, bagong, yougong) inne. Insgesamt sind in der Qing-Zeit 183 Kandidaten (yougong) aus Tengyue zu den Provinzprüfungen zugelassen worden (siehe Tab. 28, S. 269).

Für diese stand der Unterpräfektur Tengyue eine reguläre Quote (ding'e) von jeweils dreissig Regierungsstipendien (linshansheng) zur Verfügung. ${ }^{790}$

Die Kandidaten hatten bereits die Möglichkeit, eine Anstellung als niederrangige Beamte zu finden. Im TYTZ wird allerdings nur bei wenigen eine spätere berufliche Tätigkeit vermerkt. Die Angaben verweisen dann zumeist auf eine Anstellung als Lehrer (xundao, VizeSchuldirektor, bis Rang 7a) an einer staatlichen Schule in Kreisen oder Unterpräfekturen.

\footnotetext{
1) Die entwickelten Gebiete (fada $q u$ ) Yunnan $f u$, Lin'an fu, Dali fu, Chengjiang fu und Chuxiong fu;

2) die durchschnittlich entwickelten Gebiete (yiban fada qu) Qujing fu, Yongchang fu, Menghua ting, Guangxi zhou, Zhaotong ting, Dongchuan fu und Kaihua fu und

3) die rückständigen Gebiete (luohou qu) Guangnan zhou, Yuanjiang zhou, Zhenxiong zhou, Jingdong ting, Wuding fu, Shunning fu, Zhenyuan ting und Puer fu (ebd.).

${ }^{789}$ Lan Yong, Xinan lishi wenhua dili, S. 128

${ }^{790}$ TYTZ, S. 165. In der Präfektur Yongchang gab es 40 Stipendiaten, im Kreis Baoshan 30 (inklusive der Unterpräfektur Longling mit zwei Stipendiaten seit 1883) und im Kreis Yongping 20. Zusammen mit den 30 aus Tengyue waren es 110 linshansheng im Gebiet der Präfektur Yongchang (YCFZ, S. 110).
} 
Tabelle 28: Die yougong der Unterpräfektur Tengyue ${ }^{791}$

Ära

Kangxi (1662-1723)

Yongzheng (1723-1736)

Qianlong (1736-1796)

Jiaqing (1796-1821)

Daoguang (1821-1851)

Xianfeng (1851-1862)

Tongzhi (1862-1875)

Guangxu (1875-1909)

Gesamt
Anzahl der yougong

31

8

53

17

43

12

3

16

183

Alle drei Jahre fanden die ,Jahresprüfungen“ (suishi) in der Präfekturstadt statt, an denen alle Kandidaten teilnehmen mußten, um ihren akademischen Status beibehalten zu können. Für die Teilnahme und den erfolgreichen Abschluß der Prüfungen sind vom Staat Quoten festgelegt worden. Im 19. Jahrhundert konnten an den zivilen Prüfungen zwanzig Kandidaten (wentong) aus Tengyue teilnehmen und an den militärischen fünfzehn (wutong). Zu den ebenfalls im Abstand von drei Jahren abgehaltenen zivilen Provinzprüfungen (keshi) waren zwanzig Kandidaten aus Tengyue zugelassen; sechsundsiebzig aus der Präfektur Yongchang insgesamt. $^{792}$

Nach dem Studium in Privatunterricht oder an einer Akademie und den bestandenen Zulassungsprüfungen haben dann im Verlauf der Qing-Zeit in einem Zeitraum von einhundertsechzig Jahren dreiunddreißig Kandidaten aus Tengyue die alle drei Jahre stattfindenden Prüfungen auf Provinzebene mit dem Erwerb des akademischen Titels eines juren abgeschlossen. Das sind sechs mehr als in der Ming-Zeit, als siebenundzwanzig Männer aus der Unterpräfektur die Provinzprüfungen bestanden hatten.

Der erste juren der Qing-Zeit hatte die Prüfung im Jahr 1723 (Yongzheng 1) bestanden. Elf der juren hatten den Titel während der Ära Daoguang und jeweils sieben während der Ära Qianlong und der Ära Guangxu erlangt; die beiden letzten in den fangzhi genannten juren im Jahr 1882 (siehe Tab.29, S. 270). ${ }^{793}$

\footnotetext{
${ }^{791}$ TYTZ, S. 205-207

792 TYTZ, S. 165. Jeweils zwanzig Prüfungskandidaten (wentong) kamen aus Yongchang, Baoshan und Tengyue, vier aus Longling und zwölf aus Yongping (YCFZ, S. 110).

${ }^{793}$ TYTZ, S. 200-201
} 
Drei weitere Kandidaten hatten zwar die Prüfungen nicht bestanden, ihre Leistungen reichten aber aus, um in die ,Liste der würdig Gescheiterten“ (fubang) aufgenommen zu werden und zwar in den Jahren 1696 (Kangxi 35), 1822 (Daoguang 2) und 1843 (Daoguang 23). ${ }^{794}$

\section{Tabelle 29: Die Anzahl der juren aus der Präfektur Yongchang in der Qing-Zeit nach Angaben des YCFZ (in Klammern abweichende Angaben des TYTZ) ${ }^{795}$}

\begin{tabular}{|c|c|c|}
\hline \multirow[t]{2}{*}{ Zeit } & \multicolumn{2}{|c|}{ Präfektur Yongchang } \\
\hline & insgesamt & davon aus Tengyue \\
\hline Ära Shunzhi (1644-1662) & 1 & - \\
\hline Ära Kangxi (1662-1723) & 18 & - \\
\hline Ära Yongzheng (1723-1736) & 3 & 2 \\
\hline Ära Qianlong (1736-1796) & 28 & 7 \\
\hline Ära Jiaqing (1796-1821) & 13 & 4 \\
\hline Ära Daoguang (1821-1851) & 24 & $4(11)$ \\
\hline Ära Xianfeng (1851-1862) & 6 & $--\quad(2)$ \\
\hline Ära Tongzhi (1862-1875) & 6 & -- \\
\hline Ära Guangxu (1875-1909) & 19 & $6 \quad(7)$ \\
\hline Gesamt & 118 & $23(33)$ \\
\hline
\end{tabular}

Im TYTZ sind die späteren beruflichen Tätigkeiten lediglich von einem Dutzend der dreiunddreißig juren verzeichnet worden. Sechs von ihnen hatten nach dem erfolgreichen Bestehen der Prüfung das Amt eines Kreismagistraten (zhixian, Rang 7a) angetreten. Ein juren der Prüfung des Jahres 1849 (Daoguang 29) war zunächst als Unterpräfekt (tongzhi, Rang 5a) tätig und trat dann während der Ära Guangxu im Jahr 1879 einen Posten als Kreismagistrat an. Auch ein juren der Ära Xianfeng amtierte nach bestandener Prüfung auf Provinzebene als Unterpräfekt (zhizhou, Rang 5b). ${ }^{796}$ Zwei der juren der Ära Qianlong und einer der Ära Daoguang waren als Direktoren an staatlichen Schulen (xuezheng, jiaoyu, Rang 8a) tätig. Ein juren der Ära Jiaqing hatte zunächst ebenfalls den Posten eines Schuldirektors inne und trat anschließend ein Amt als Kreismagistrat an. Insgesamt sind also acht der juren aus Tengyue als Kreismagistraten tätig gewesen. Dieses Amt hatte auch einer der ,würdig gescheiterten Kandidaten` (fubang) während der Ära Kangxi ausgeübt. ${ }^{797}$

\footnotetext{
${ }^{794}$ TYTZ, S. 201. Im YCFZ werden für die gesamte Präfektur Yongchang sechzehn fubang aufgelistet, darunter lediglich einer aus Tengyue (YCFZ, S. 213-214).

${ }^{795}$ YCFZ, S. 210-213; TYTZ, S. 200-201

796 TYTZ, S. 200-201

${ }^{797}$ TYTZ, S. 200-201
} 
Ebenso wie die Anzahl der jinshi ist auch die der juren der Präfektur Yongchang in der Qing-Zeit deutlich geringer als in der vorangegangenen Ming-Zeit. In einem Zeitraum von etwa zweihundert Jahren haben wärend der Ming-Dynastie zweihundertunddreiundsiebzig Kandidaten die Provinzprüfungen bestanden. ${ }^{798}$ In der Qing-Zeit, in den etwa zweihundertundzwanzig Jahren von 1661 (Shunzhi 18), als ein Kandidat aus Yongchang zum ersten Mal den juren-Titel erhalten hatte, bis zum Jahr 1885, als das YCFZ herausgegeben wurde, haben lediglich einhundertundachtzehn Männer den Titel eines juren erworben. Das sind nicht einmal halb so viele wie zur Ming-Zeit.

Dieser Trend spiegelt sich auch in der Entwicklung der Akademien wieder.Die Akademien (shuyuan) waren die eigentlichen Lehrstätten in der Verwaltungseinheit, in denen die Schüler auf die staatlichen Prüfungen vorbereitet wurden. Von der Regierung unterstützt, unterstanden diese dem obersten Verwaltungsbeamten, von dessen Engagement und dem der örtlichen Oberschicht ihre Existenz als akademisches Zentrum auf Dauer ebenso abhing wie ihr Erfolg, der sich letztlich auch in der Zahl der erfolgreichen Prüfungskandidaten zeigte.

Während die Zahl der Akademien in Yunnan insgesamt von fünfundsechzig in der MingZeit auf einhundertdreiundneunzig in der Qing-Zeit gestiegen ist, hat in Yongchang die Zahl der Akademien in der Präfektursstadt und in der Unterpräfektur Tengyue abgenommen. ${ }^{799}$ Die beiden Akademien, die in Tengyue in der Ming-Zeit bestanden hatten, wurden unter der Qing-Dynastie nicht weitergeführt. Es gab dort nur noch eine Akademie, die Laifengshan shuyuan, diese allerdings wurde von den jeweiligen Unterpräfekten seit Mitte des 18. Jahrhunderts kontinuierlich unterstützt.

In der Präfekturstadt Yongchang hatten die beiden Akademien aus der Ming-Zeit sowie eine weitere aus der Zeit der Ära Kangxi der Qing-Dynastie, die noch im Jahr 1780 (Qianlong 45) renoviert worden war, den Schulbetrieb wieder eingestellt, so daß dort seit dem 18. Jahrhundert nurmehr eine Akademie existierte, die im Jahr 1785 gebaute Yongbao shuyuan. $^{800}$

\footnotetext{
${ }^{798}$ Siehe Kap. III B 10. 2, S. 181-182, Tab. 15.

${ }^{799}$ Lan Yong, Xinan lishi, S. 113, 128

${ }^{800}$ YCFZ, S. 111
} 
Weiterhin befanden sich im Gebiet der Präfektur Yongchang noch zwei Akademien in der Kreisstadt Yongping und eine in der Unterpräfektur Longling; insgesamt gab es im Gebiet der Präfektur Yongchang an der Wende zum 19. Jahrhundert fünf Akademien. ${ }^{801}$

Sicherlich ist die Schließung von Akademien, die Vorbereitung auf die Prüfungen anboten und somit gerade auch in abgelegenen Verwaltungseinheiten eine wichtige Ergänzung zum privaten Unterricht darstellten, mit ein Grund für den Rückgang der Anzahl der erfolgreichen Kandidaten aus Yongchang. Andererseits gab es in der Unterpräfektur Tengyue ebenfalls weniger Akademien als während der Ming-Zeit. Dennoch hatte die Unterpräfektur ihr Bildungsniveau, zumindest in Bezug auf die Anzahl der erfolgreichen Prüfungskandidaten, beibehalten und was die juren betrifft, sogar steigern können.

Damit hat sich auch das Verhältnis der Anzahl der juren aus den Verwaltungseinheiten Yongchangs (Kreis Baoshan, Kreis Yongping, Unterpräfektur Longling) und der Unterpräfektur Tengyue verändert. Waren es während der Ming-Zeit nur zehn Prozent, so kam während der Qing-Zeit immerhin ein knappes Drittel aller juren der Präfektur aus dem Gebiet der Unterpräfektur Tengyue.

\section{5. Die Schuldirektoren von Tengyue und Yongchang}

Verantwortlich für den Schulbetrieb in der Unterpräfektur Tengyue waren in der QingZeit, ebenso wie während der vorangegangenen Ming-Zeit, ein Schuldirektor (xuezheng) und ein Vize-Direktor (xundao), die in der Hierarchie der Beamten der Verwaltungseinheit dem Unterpräfekten unterstellt waren.

Während der Qing-Zeit stammten deutlich mehr Direktoren der staatlichen Schulen von Tengyue und Yongchang aus Yunnan selbst als noch während der Ming-Zeit, was auf einen Aufschwung des Bildungswesens in der Provinz verweist, wo nun genügend qualifiziertes Personal für diese Tätigkeit zur Verfügung stand (s. Tab. 30, S. 273). Die wenigen Direktoren aus anderen Provinzen kamen entweder aus Hebei oder Guangdong; der erste Direktor der Schule der Präfektur Yongchang zu Beginn der Qing-Zeit stammte aus Nord-

\footnotetext{
${ }^{801}$ YCFZ, S. 114, 112. Die Bonan-Akademie in Yongping war im Jahr 1705 (Kangxi 44) gegründet worden; Mittel für den Bau der Huaping-Akademie spendete der Kreismagistrat Cao im Jahr 1832 (Daoguang 12) (YCFZ, S. 114). Im Jahr 1844 (Daoguang 24) erwarb erstmals in der Qing-Zeit ein Kandidat aus Yongping den Titel eines juren (YCFZ, S. 212). Das Beispiel Yongping zeigt, daß nicht allein die Anzahl der Akademien der entscheidende Faktor bei der Ausbildung der Prüfungskandidaten ist. So hat Tengyue mit nur einer Akademie deutlich mehr juren hervorgebracht.

Das Gründungsjahr der Longshan-Akademie in Longling (seit 1770 Unterpräfektur) wird in den fangzhi nicht genannt; vermerkt ist nur, daß die Akademie im Jahr 1803 (Jiaqing 8) in ein neues Gebäude umgezogen ist. Sie ist während des Moslem-Aufstandes im Jahr 1861 (Xianfeng 11) zerstört und im Jahr 1877 (Guangxu 3) wieder aufgebaut worden. Zur Zeit der Herausgabe des YCFZ (1885) war die Akademie bereits in eine Freischule umgewandelt worden (YCFZ, S. 112). Jeweils ein Kandidat aus Longling war in den Jahren 1835 (Daoguang 15) und 1882 (Guangxu 8) bei den jurenPrüfungen erfolgreich.
} 
china, aus der Provinz Liaodong. Aus den Nachbarprovinzen Guizhou und Sichuan sind anders als noch während Ming-Zeit keine Direktoren mehr nach Tengyue und Yongchang gekommen.

Tabelle 30: Heimatprovinzen der Direktoren (xuezheng) von Tengyue in der Qing-Zeit im Vergleich mit der Präfektur Yongchang ${ }^{802}$

\begin{tabular}{lrlr} 
Tengyue & \multicolumn{3}{c}{ Yongchang } \\
Yunnan & 26 & Yunnan & 20 \\
Guangdong & 2 & Liaodong & 1 \\
Hebei & 1 & Hebei & 2 \\
Keine Angabe & 4 & Keine Angabe & 1 \\
Gesamt & $\mathbf{3 3}$ & Gesamt & $\mathbf{2 4}$
\end{tabular}

Die Schuldirektoren aus Yunnan, die in Tengyue und Yongchang tätig waren, kamen aus den Präfekturen mit der größten Zahl von Absolventen der Staatsprüfungen (siehe Tab.31). Die meisten Direktoren stammten aus Lin’an, der Präfektur mit dem größten Anteil an erfolgreichen Prüfungskandidaten an der Gesamtbevölkerung. Auch aus den zentralen Präfekturen Yunnan und Chuxiong waren mehrere Männer als Direktoren nach Tengyue gekommen, zwei weitere stammten aus der nördlichen Präfektur Lijiang

Tabelle 31: Herkunft der Schuldirektoren aus Yunnan

(nach Präfekturen und Unterpräfekturen) ${ }^{803}$

\begin{tabular}{lrlr} 
Tengyue & \multicolumn{3}{c}{ Yongchang } \\
Yunnan & 5 & Yunnan & 4 \\
Lin’an & 9 & Lin’an & 10 \\
Dali & 1 & Dali & 2 \\
Chengjiang & 1 & & \\
Chuxiong & 4 & Chuxiong & 2 \\
Lijiang & 2 & & 1 \\
Qujing & 1 & Qujing & 1 \\
Menghua & 2 & Menghua & \\
Dongchuan & 1 & & $\mathbf{2 0}$ \\
Gesamt & $\mathbf{2 6}$ & Gesamt
\end{tabular}


Die Direktoren hatten verschiedene akademische Titel erworben. In Yongchang waren auch Schuldirektoren mit dem Titel eines jinshi angestellt; insgesamt sechs, von denen fünf aus Yunnan stammten und einer aus der Provinz Hebei.

\section{Tabelle 32: Akademische Titel der Direktoren (xuezheng / jiaoshou) von Tengyue und Yongchang ${ }^{804}$}

$\begin{array}{lcc}\text { Titel } & \text { Tengyue } & \text { Yongchang } \\ \text { jinshi } & - & 6 \\ \text { juren } & 17 & 11 \\ \text { Andere } & 7 & 2 \\ \text { Keine Angabe } & 9 & 5 \\ \text { Gesamt } & \mathbf{3 3} & \mathbf{2 4}\end{array}$

Inhaber des höchsten akademischen Titels (jinshi) waren in Tengyue nicht als Direktoren tätig. Die siebzehn Direktoren in Tengyue, die den Titel eines juren führten, stammten alle aus der Provinz Yunnan selbst, in Yongchang waren zehn juren aus Yunnan und ein juren aus Hebei in dieser Position tätig.

\section{6. Wuju - Die Absolventen der Militär-Prüfungen}

Kandidaten aus der Unterpräfektur Tengyue haben in der Qing-Zeit nicht nur an den zivilen Prüfungen teilgenommen, sondern auch an den militärischen. Die militärischen Prüfungen haben im Verlauf der Qing-Zeit insgesamt siebenundzwanzig Kandidaten aus Tengyue bestanden und den Titel eines Absolventen der Militärprüfungen auf Provinzebene (wuju) erhalten; in der Präfektur Yongchang insgesamt waren es beinahe doppelt so viele (siehe Tab. 33, S. 275). ${ }^{805}$

Zum ersten Mal hatte in der Qing-Zeit ein Kandidat aus der Präfektur Yongchang im Jahr 1666 (Kangxi 5) den Titel eines wuju erworben; einem ersten Prüfling aus Tengyue gelang dies im Jahr 1711(Kangxi 50).

\footnotetext{
${ }^{804}$ TYTZ, S. 113-114; YCFZ, S. 175

${ }^{805}$ Für die vorangegangene Ming-Zeit werden im TYTZ lediglich aus dem 16. Jahrhundert drei erfolgreiche Kandidaten der Militär-Prüfungen (wuju) namentlich genannt (TYTZ, S. 202). In der Präfektur Yongchang (Kreis Baoshan) gab es in der Ming-Zeit acht wuju (YCFZ, S. 223). Sowohl in der Ming-Zeit (im Jahr 1532) als auch in der Qing-Zeit (im Jahr 1754) hatte je ein Kandidat aus Baoshan die obersten Militär-Prüfungen mit dem Erwerb des Titels eines wu jinshi abgeschlossen (YCFZ, S. 223).
} 
Tabelle 33: Die Anzahl der wuju aus der Präfektur Yongchang in der Qing-Zeit nach Angaben des YCFZ (in Klammern abweichende Angaben des TYTZ) ${ }^{806}$

Zeit

Ära Kangxi (1662-1723)

Ära Yongzheng (1723-1736)

Ära Qianlong (1736-1796)

Ära Jiaqing (1796-1821)

Ära Daoguang (1821-1851)

Ära Xianfeng (1851-1862)

Ära Tongzhi (1862-1875)

Ära Guangxu (1875-1909)

Gesamt

\author{
Präfektur Yongchang \\ insgesamt davon aus Tengyue
}

$\begin{array}{rcc}14 & 2 & \\ 2 & 1 & \\ 17 & 11 & (13) \\ 8 & 4 & (7) \\ 3 & 3 & (4) \\ -- & -- & \\ 1 & -- & \\ 4 & -- & \end{array}$

49

Besonders viele Kandidaten aus Tengyue haben die militärischen Prüfungen während der Ära Qianlong, einige Jahre nach dem Ende des chinesisch-birmanischen Krieges (17661769), abgeschlossen. Nach dem Friedensschluß mit Birma war die Präsenz der QingTruppen im Grenzgebiet im Südwesten von Tengyue zunächst verstärkt worden, später wurden die Militäreinheiten reorganisiert und Tengyue im Jahr 1775 zu einem Regionalen Militärbezirk aufgewertet, der für die Sicherung des gesamten Grenzgebietes der Präfektur verantwortlich war. Die große Bedeutung, die der Militärverwaltung der Unterpräfektur damit zukam, hat anscheinend zahlreiche Männer aus Tengyue veranlaßt, eine Militärlaufbahn einzuschlagen. So kamen von den vierzehn Prüfungsabsolventen der Jahre 1777 bis 1798 elf aus der Unterpräfektur Tengyue und lediglich drei aus dem Kreis Baoshan; in den Jahren 1786 bis 1798 waren sogar ausschließlich Kandidaten aus Tengyue erfolgreich. ${ }^{807}$

\section{7. Der Stand des Bildungswesens in Yongchang}

Betrachtet man die Situation des Bildungswesens (ausgehend von der Anzahl der erfolgreichen Prüfungsabsolventen) in der Provinz Yunnan während der Qing-Zeit insgesamt, so haben fast alle Präfekturen im Vergleich mit der vorangegangenen Ming-Zeit einen

\footnotetext{
${ }^{806}$ YCFZ, S. 223-225; TYTZ, S. 202-203; siehe auch CY 904.1. Die wuju der Präfektur Yongchang in der Qing-Zeit stammten, sofern nicht aus Tengyue, aus dem Kreis Baoshan; lediglich ein Absolvent der Militäprüfungen (im Jahr 1708) kam aus dem nördlichen Kreis Yongping (YCFZ, S. 224).

${ }^{807}$ Die Liste der wuju im YCFZ endet mit dem Jahr 1882; Kandidaten aus Tengyue sind zuletzt im Jahr 1822 bei den Militär-Prüfungen erfolgreich gewesen. Erst nach der Niederschlagung der Moslem-Rebellion hat im Jahr 1873 wieder ein Kandidat aus der Präfektur Yongchang den Titel eines wuju erhalten; der Mann stammte ebenso wie die weiteren bis 1882 genannten vier wuju aus dem Kreis Baoshan (YCFZ, S. 225).
} 
Entwicklungsfortschritt zu verzeichnen. Auffällig ist jedoch, daß der Abstand zwischen den führenden Präfekturen (Yunnan, Lin’an, Dali) und den nächstfolgenden (Chuxiong, Qujing, Yongchang) sehr viel größer ist als noch während der Ming-Zeit.

\section{Tabelle 34: Vergleich der Anzahl der jinshi aus sechs Präfekturen in der Ming- und der Qing-Zeit}

\begin{tabular}{lclc}
\multicolumn{2}{c}{ Ming-Zeit } & \multicolumn{2}{c}{ Qing-Zeit } \\
$\begin{array}{l}\text { Präfektur } \\
(f u)\end{array}$ & $\begin{array}{c}\text { Gesamtzahl } \\
\text { der jinshi }\end{array}$ & $\begin{array}{c}\text { Präfektur } \\
(\text { fu })\end{array}$ & $\begin{array}{c}\text { Gesamtzahl } \\
\text { der jinshi }\end{array}$ \\
Yunnan & 63 & Yunnan & 218 \\
Lin’an & 53 & Lin'an & 138 \\
Dali & 45 & Dali & 101 \\
Yongchang & 26 & Yongchang & 17 \\
Qujing & 11 & Qujing & 21 \\
Chuxiong & 4 & Chuxiong & 36
\end{tabular}

Mit einer deutlich geringeren Anzahl von erfolgreichen Prüfungskandidaten in der QingZeit ist die Präfektur Yongchang eine Ausnahme von dem generellen Trend einer positiven Entwicklung des Bildungswesens in Yunnan. Neben dem Rückgang der Anzahl der jinshi von 26 auf 17 erfolgreiche Absolventen, ist besonders auffällig, daß die Anzahl der erfolgreichen juren von 273 auf 118 um mehr als die Hälfte zurückgegangen ist. Zählte Yongchang in der Ming-Zeit zu den Gebieten mit einem entwickelten Bildungswesen, so kann die Präfektur in der Qing-Zeit im Vergleich der Präfekturen Yunnans nunmehr als Gebiet mit einem weniger entwickelten Bildungswesen gelten.

Während sich das Niveau in Yongchang zwar verschlechtert hat, hat es sich in einem Randgebiet der Präfektur, nämlich der Unterpräfektur Tengyue, insgesamt leicht verbessert. Die Anzahl der jinshi ist zwar auch hier etwas zurückgegangen, gleichzeitig hat die Zahl der juren jedoch deutlich zugenommen. ${ }^{808}$ Für die Unterpräfektur Tengyue läßt sich anhand der Zahlen der Prüfungskandidaten zusammenfassend feststellen, daß die Angleichung an das Bildungswesen des Kernlandes im Verlauf der Qing-Zeit auch bei den Unterrichtsinhalten durchaus gelungen ist.

\footnotetext{
${ }^{808}$ Lan Yong verzeichnet in seiner Karte (Lan Yong, Xinan lishi wenhua dili, Karte 4 - 7) eine ähnliche Entwicklung wie in Yongchang für die Präfektur Lin'an, die er ebenfalls zu einem Gebiet mit weniger entwickeltem Bildungssystem zurückstuft. Ebenso wie für Yongchang stellt Lan jedoch auch für ein Randgebiet im Südosten von Lin'an (für die seit 1666 selbständige Präfektur Kaihua) fest, daß das Gebiet das Niveau eines entwickelten Bildungssystems aufrechterhalten hat. Ausgehend von der Anzahl der jinshi aus Lin'an, die in der Qing-Zeit ebenso wie in den Präfekturen Yunnan und Dali deutlich höher ist als noch während der Ming-Zeit, sowie der relativ hohen Anzahl der jinshi pro Einwohner in Lin'an (Lan Yong, S. 128), scheint die Rückstufung der Präfektur zu einem Gebiet mit weniger entwickeltem Bildungssystem insgesamt nicht berechtigt.
} 


\section{Bergbau in Tengyue}

Die Provinz Yunnan ist reich an Bodenschätzen, deren Abbau im Verlauf der Qing-Zeit teils in privater, teils in staatlicher Initiative insgesamt intensiviert wurde, denn die Gewinnung von Silber und Kupfer für die Münzherstellung lag im besonderen Interesse des Qing-Staates. Da die Bergbaubetriebe besteuert wurden, sind die Erzvorkommen in der Unterpräfektur Tengyue von den Verfassern der Lokalhandbücher im Kapitel über das Steuerwesen ausführlich aufgelistet worden. ${ }^{809}$

Im Folgenden wird zunächst die Entwicklung der Bergbauindustrie in der Qing-Zeit in Zusammenhang mit der Geldpolitik der Regierung zusammengefaßt und anschließend in diesem Zusammenhang der Abbau von Bodenschätzen in Tengyue bzw. im Gebiet der Präfektur Yongchang dargestellt.

\section{1. Die Entwicklung der Bergbauindustrie in Yunnan und die Geldpolitik der Qing}

Der Aufschwung der Bergbauindustrie in Yunnan stand in engem Zusammenhang mit der Finanzpolitik des Qing-Reiches. Silber und Kupfer waren die gebräuchlichen Zahlungsmittel: Steuerzahlungen, die von den lokalen Verwaltungseinheiten an die Zentralregierung weitergeleitet wurden, erfolgten in Silber. Die Zahlungsmittel, die von der Bevölkerung in großen Mengen für die alltäglichen Geschäfte benötigt wurden, waren hingegen die Kupfermünzen. Die Erschließung von Erzvorkommen zur Gewinnung der Metalle lag daher im besonderen Interesse des Staates; vor allem die Förderung von Kupfererz. Folglich beschränkte sich die Geldpolitik der Zentralregierung in der frühen Qing-Zeit auf Regelungen bezüglich der Herstellung und Zirkulation des Kupfergeldes. ${ }^{810}$ Aufgabe der Verwaltung war es, für die Beschaffung der notwendigen Metalle zu sorgen, die Münzanstalten zu betreiben, und die Herstellung von Kupfermünzen entsprechend den vorgegebenen Quoten zu gewährleisten. ${ }^{811}$

In den Provinzen Yunnan und Guizhou konnte auf Betreiben von Generalgouverneur Cai Yurong (von 1682 bis 1686 im Amt) in der Zeit von 1682 bis 1705 Kupfererz in privater Initiative gefördert, verarbeitet und vermarktet werden. ${ }^{812}$ Die Minen in Yunnan wurden zumeist von kleineren Unternehmern betrieben, die der Kontrolle der örtlichen

\footnotetext{
${ }^{809}$ TYTZ, Kapitel 5, Steuerwesen - Steuersätze (kecheng), S. 94-95; TYZZ, Kapitel 5, Steuerwesen, S. 68-71; im YCFZ hingegen werden die Erzvorkommen im Rahmen der ,örtlichen Produkte‘ aufgelistet (Kapitel 22, S. 105).

${ }^{810}$ Vogel, S. 377

${ }^{811}$ Vogel, S. 378

${ }^{812}$ Vogel, S. 392-393
} 
Verwaltungsbeamten unterstanden, welche für die Beschaffung des Kupfers, die Einziehung der Steuern, den Transport des Metalls nach Peking und andere Verwaltungsaufgaben im Zusammenhang mit den Minen zuständig waren. ${ }^{813}$ Der Unterhalt großer Minenbetriebe sowie die hohen Transportkosten gerade in den entlegeneren Regionen der Provinz Yunnan überstiegen jedoch die finanziellen Möglichkeiten einzelner Unternehmer und wurden in der Regel von den Provinzbehörden organisiert. ${ }^{814}$ Dies mündete in die Einführung des staatlichen Monopols auf den Ankauf von Kupfer, die auf Initiative von Beihenuo, Generalgouverneur von Yunnan und Guizhou, im Jahr seines Amtsantritts 1705 erfolgte. ${ }^{815}$

Die Förderung und Gewinnung von Silber lag zunächst ebenfalls in den Händen von privaten Unternehmern. Das änderte sich erst, als um das Jahr 1810 das Ausmaß deutlich wurde, in welchem Silber für den Import von Opium benötigt wurde und sich die Regierung um Regelungen bemühte, die Verwendung von Silber als Zahlungsmittel für die Auslandsgeschäfte einzuschränken. ${ }^{816}$

In der frühen Qing-Zeit war es der Regierung gelungen, den Münzanstalten regelmäßig eine ausreichende Menge an Metallen zur Verfügung zu stellen, so daß die Münzproduktion mit der sich entwickelnden Wirtschaft Schritt halten konnte. ${ }^{817}$ Verschiedene Maßnahmen führten zur Stabilisierung des Währungssystems, größere Reformen blieben jedoch aus. So konnten zwar die Kupferkrisen des 16. und 17. Jahrhunderts überwunden werden, nicht aber die um 1835 einsetzende Abwertung des Kupfergeldes. ${ }^{818}$

Die Knappheit des Metalls hatte bereits um das Jahr 1673 zu einer ersten Kupferkrise geführt, die die Regierung seit 1683 mit dem Import von Kupfer aus Japan hatte überwinden können. Die steigende Nachfrage nach Kupfer und der Rückgang der Importe aus Japan führten um 1715 zu einer zweiten Kupferkrise. Um dem erneuten Mangel an Kupfer zu begegnen, wurde der Bergbau im eigenen Land intensiviert und insbesondere die reichen Bodenschätze der Provinz Yunnan verstärkt gefördert.

Bisher waren die Erzvorkommen dort vielerorts „bald abgebaut, bald waren sie erschöpft“, entsprechend war es für die Beamten in Yunnan „schwierig, [überhaupt] festzustellen, was

\footnotetext{
${ }^{813}$ Vogel, S. 387-388

${ }^{814}$ Ebd., S. 393

${ }^{815}$ Ebd., S. 392, ZGRMDCD, S. 67

816 Ebd., S. 377-378

${ }^{817}$ Ebd., S. 380

${ }^{818}$ Ebd., S. 380-381
} 
[an Bodenschätzen tatsächlich] vorhanden war“. ${ }^{819}$ Auch aufgrund der fehlenden Infrastruktur waren die Bodenschätze zuvor nur in geringem Umfang abgebaut worden, zumal sich die Vorkommen häufig in tusi-Gebieten in den abgelegenen Grenzregionen der Provinz befanden.

Bereits im Zuge der Niederschlagung der Rebellion Wu Sanguis am Ende des 17. Jahrhunderts sind die Verkehrsverbindungen zwischen dem Kernland und dem fernen Südwesten verbessert worden. Anfang des 18. Jahrhunderts wurde der Ausbau der Transportwege in der Provinz und ihr Anschluß an das Verkehrsnetz des chinesischen Reiches weiter vorangetrieben und damit die umfangreichere Ausbeutung der Bodenschätze Yunnans ermöglicht und der Grundstein für die weitere Entwicklung von Handel und Industrie in der Provinz gelegt. Zahlreiche Minen wurden neu in Betrieb genommen und es entwickelte sich eine florierende Bergbauindustrie.

Seit 1738 konnten die Münzanstalten in der Hauptstadt und in den Provinzen folglich auf ausreichende Kupferlieferungen aus Yunnan zurückgreifen. ${ }^{820}$ In der Zeit von 1737 bis 1810 erreichte die Kupferförderung in Yunnan mit etwa 6000 Tonnen im Jahr ihren Höhepunkt. $^{821}$

In diesen Zeitraum fällt auch die Eröffnung von acht der zehn Kupferminen in der Präfektur Yongchang, eine weitere Mine wurde im Jahr 1811 in Betrieb genommen. Der Aufschwung der Bergbauindustrie im äußersten Westen Yunnans beschränkte sich nicht auf die Erschließung der Kupfervorkommen, auch zahlreiche neue Bergbaubetriebe zur Förderung von Gold, Silber und Eisen wurden in dieser Zeit eröffnet. ${ }^{822}$

Der Staat hatte das Monopol für den Aufkauf des Kupfers, er bestimmte die Quoten für die Produktion und die Steuern. Der Preis wurde festgelegt und den Minenarbeitern ein entsprechender Lohn im Voraus ausgezahlt. Die vereinbarte Liefermenge war dann den zuständigen Beamten zu übergeben. Da die festen Preise niedriger waren als die Produktionskosten, machten die Minen Verluste. Die lokalen Regierungen waren gezwungen, Maßnahmen zur Entschuldung der Minen durchzuführen, um die weitere Versorgung der Münzanstalten sicher zu stellen. Diese Verwaltungsmaßnahmen waren nur bedingt

\footnotetext{
${ }^{819}$ YCFZ, S. 104

${ }^{820}$ Vogel, S. 381-382

${ }^{821}$ Vogel, S. 382. In den Jahren um 1862 wurde versucht, den Kupferbergbau in Yunnan wieder zu beleben, zu dieser Zeit konnten jedoch lediglich 300 bis 600 Tonnen des Metalls pro Jahr gefördert werden (ebd.).

${ }^{822}$ YCFZ, S. 105
} 
erfolgreich, häufig mußten Kredite gewährt oder den Minenarbeiter Reis, Öl usw. zusätzlich zur Verfügung gestellt werden, manchmal wurden die Schulden per Edikt ganz erlassen; schließlich wurde auch das staatliche Monopol gelockert. ${ }^{823}$

Trotz dieser Schwierigkeiten florierte die Bergbauindustrie in Yunnan und zog immer mehr Immigranten aus anderen Provinzen an. Das Beispiel der Tangdan Mine bei Dongchuan im Nordosten Yunnans macht deutlich, welchen Umfang ein solcher Minenbetieb erreichen konnte: Im Jahr 1764 waren allein dort zweihundert- bis dreihunderttausend Arbeiter beschäftigt. ${ }^{824}$ Die Bergbaubetriebe im äußersten Westen der Provinz waren deutlich kleiner: Die Silbermine Maolong, eine der größten Förderstätten im Grenzgebiet zu Birma, beschäftigte zu ihrer Blütezeit Mitte des 18. Jahrhundert immerhin bis zu dreißigtausend Arbeiter.

Der Verfall des Finanzsystems des Qing-Reiches zu Anfang des 19. Jahrhunderts führte dazu, daß der Bedarf der Münzanstalten an Kupfer deutlich sank. Maßnahmen zur Anpassung der Produktion in Yunnan wurden jedoch nicht durchgeführt. Während die hohe Fördermenge in der Provinz zunächst zur Stabilisierung des Währungssystems beitrugen, führte das Überangebot an Kupfer während der Ära Daoguang (1821-1851) zu einem Wertverfall der Kupferwährung. ${ }^{825}$

Zudem stiegen die Kosten im Bergbau; über die Jahre wurde der Abbau in vielen Minen technisch immer schwieriger. Außerdem verteuerte die fortschreitende Abholzung der Wälder die Holzkohle für den Schmelzprozeß. Da der Staat die Preise für den Aufkauf des Kupfers niedrig hielt, verschlechterte sich die finanzielle Situation der Minenbetriebe weiterhin. $^{826}$

Während des Ersten Opiumkrieges (1839-1842) und der Taiping Rebellion (1850-1864) wurden Gelder, die eigentlich für den Kupferbergbau und das Transportwesen in Yunnan vorgesehen waren, von der Zentralregierung zur Deckung der Kosten für das Militär verwendet. Infolgedessen verschlechterte sich die wirtschaftliche Lage der Minenarbeiter weiter und die Verwaltung sah sich zeitweise gezwungen, die neugegossenen Münzen direkt an die Arbeiter auszugeben. Die angespannte Situation in den Minen führte zu gewalttätigen Auseinandersetzungen zwischen Han-chinesischen und moslemischen (Hui) Minenarbeitern, die in den Moslem-Aufstand der Jahre 1855 bis 1873 mündeten. ${ }^{827}$

\footnotetext{
${ }^{823}$ Vogel, S. 383

${ }^{824}$ Ebd., S. 384

${ }^{825}$ Ebd., S. 390; 385

${ }^{826}$ Ebd., S. 390

${ }^{827}$ Ebd., S. 391
} 


\section{2. Der Abbau von Bodenschätzen in Tengyue und Yongchang}

Vorkommen von Gold, Silber, Kupfer und anderen Bodenschätzen im Gebiet der Präfektur Yongchang werden schon in historischen Quellen wie der Geschichte der späteren HanDynastie (Hou Han shu, ca. 430 n.Chr.) erwähnt. Der Abbau der Erzvorkommen in der Region und die Gewinnung der Metalle ist auch aus der Zeit der Herrschaft des Königreiches von Nanzhao (649-902) bekannt. Unter der Herrschaft der Yuan-Dynastie (12711368) wurde der Abbau der Bodenschätze intensiviert und brachte dem Staat hohe Steueeinnahmen ein. Während der Ming-Dynastie (1368-1644) ging die Gewinnung von Gold deutlich zurück, während die Produktion von Silber und Kupfer weiter zunahm. ${ }^{828}$

Am Ende des 17. Jahrhunderts hatten chinesische Immigranten, zumeist Anhänger des letzten Kaisers der Südlichen Ming aus dem Umfeld seines Generals Li Dingguo, in der Grenzregion zwischen China und Birma mit der Erschließung von Silbervorkommen begonnen. Unter anderem gründeten sie die Silbermine Polong (nahe dem heutigen Lashio in Birma), in der zu ihrer Blütezeit bis zu vierzigtausend Arbeiter beschäftigt waren. ${ }^{829}$

Die Bodenschätze im Gebiet der Präfektur Yongchang wurden hingegen erst seit Beginn des 18. Jahrhunderts verstärkt genutzt. Zu dieser Zeit wurde ein knappes Dutzend Minen neu in Betrieb genommen; auch in der Unterpräfektur Tengyue wurden neue Minen eröffnet, in denen Eisen- und Kupfererze sowie goldhaltiges Gestein abgebaut wurden. ${ }^{830}$ In der Präfektur Yongchang wurde zudem Silbererz gefördert und ein Zinnobervorkommen erschlossen. ${ }^{831}$ Nach den Angaben der fangzhi ist in der ersten Dekade des 18. Jahrhunderts bereits mit dem Abbau je eines Kupfer-, Gold- und Zinnobervorkommens begonnen worden. In den folgenden etwa einhundert Jahren erlebte die Bergbauindustrie in Yongchang ihren größten Aufschwung.In dieser Zeit wurden in der Präfektur insgesamt zwanzig Erzvorkommen ausgebeutet. Das am häufigsten abgebaute Erzvorkommen war im 18. und 19. Jahrhundert auch im äußersten Westen Yunnans das Kupfer. Unter den zusammen siebenundzwanzig in den fangzhi von Tengyue und Yongchang aufgelisteten Förderstätten

\footnotetext{
${ }^{828}$ Siehe Sun Laichen, S. 97-105

${ }^{829}$ You Zhong, S. 513

${ }^{830}$ Die Verfasser der Lokalhandbücher von Tengyue beschränken sich in ihrer Darstellung des Bergbauwesens in der Unterpräfektur auf die Entwicklung zur Zeit der Qing-Dynastie. Für die Verwaltungsbeamten von Tengyue bestand das vorrangige Interesse an den Minen im Einziehen der Steuern. Folglich finden sich die Auflistungen der Bergbaubetriebe im Kapitel über die Steuereinkünfte der Unterpräfektur; Angaben zur Größe der einzelnen Minen, der Anzahl der dort beschäftigten Arbeiter usw. werden in den fangzhi hingegen nicht gemacht.

${ }^{831}$ YCFZ, S. 105. Außerdem weist das YCFZ daraufhin, daß früher am Xishan im Kreis Baoshan Achat abgebaut worden ist (ebd.). Unter der Rubrik ,Metalle‘ nennt das YCFZ Gold, Silber, Kupfer, Eisen, Blei und Quecksilber als lokale Erzeugnisse (S. 104).
} 
von Bodenschätzen befinden sich zehn Kupfervorkommen, während für Gold fünf, für Silber und Eisen jeweils vier Fundstätten verzeichnet sind.

Tabelle 35: Die Erschließung von Bodenschätzen im Gebiet der Präfektur Yongchang im 18. und 19. Jahrhundert / Anzahl der Minen ${ }^{832}$

\begin{tabular}{l|ccccc} 
& Gold & Silber & Kupfer & Eisen & Andere \\
\hline Yongchang $f u$ & - & 3 & - & - & - \\
Tengyue ting & 4 & - & 2 & 3 & $(2)$ \\
Baoshan xian & 1 & - & 5 & 1 & 1 \\
Yongping xian & - & 1 & 3 & - & 1 \\
Gesamt (27) & 5 & 4 & 10 & 4 & 4
\end{tabular}

In den fangzhi von Tengyue werden darüberhinaus noch zwei Förderstätten genannt, in denen während der Ming-Zeit Erze abgebaut worden sind:

„Die Mingguang Mine und die Qiandong Mine sind während der vorangegangenen Ming-Zeit in Betrieb gewesen. Während ihrer Blütezeit gab es in [den beiden Minen] einundfünfzig Schmelzöfen. Sie wurden Yin-Yang Minen genannt, [weil] das Schmelzen [des in ihnen geförderten Erzes] zusammen durchgeführt wurde. Es waren eine Steuerquote auf die Minenöfen (kuanglu ke) und eine Handelssteuer (shangshui) festgesetzt worden (ezheng). Die Steuer betrug 1780 liang 7 qian 6 fen [ca. 66,44 kg] in Silber. Nachdem die Qiandong Mine eingestürzt war, gab es nur noch die Mingguang Mine. Später wurde das Erz dort allmählich weniger. Bei der regulären Steuer gab es täglich Einbußen (zheng ke ri kui), deshalb ist die Mine geschlossen worden“. ${ }^{833}$

Auch in der Qing-Zeit wurden die Erträge der Minen nach einer festgesetzten Quote besteuert. Dazu kamen noch Waage- und andere Abgaben, wie die oben genannten Minenofen- und Handelssteuern. In Schaltjahren wurde eine weitere zusätzliche Steuer erhoben. Die Verfasser der fangzhi haben jedoch lediglich für elf der insgesamt siebenundzwanzig aufgelisteten Minen in der Präfektur Yongchang eine Steuerquote vermerkt und zwar für

\footnotetext{
${ }^{832}$ YCFZ, S. 105. Die Minen Mingguang und Qiandong sind in der Tabelle in Klammern gesetzt, da in den fangzhi nicht ausdrücklich erwähnt wird, welche Vorkommen dort abgebaut worden sind. Wahrscheinlich handelte es sich bei beiden um Kupferminen (siehe Fußnote 832). Auch das Datum der Schließung wird im TYTZ nicht verzeichnet.

${ }^{833}$ TYTZ, S. 94. Iim Kapitel ,Berge und Ströme‘ des TYTZ wird darauf hingewiesen, daß sich am Berg Mingguang, etwa einhundert Kilometer nördlich von Tengyue, zwei Kupferminen befinden (ebd., S. 36).
} 
die Eisen- und Silberminen, die Zinnobermine sowie für zwei der Goldminen. Für die übrigen drei Goldminen war keine Quote festgelegt worden, der Ertrag dieser Minen mußte vollständig abgeliefert werden (jin shou jin jie). ${ }^{834}$ Bei den Kupferminen wurde lediglich für eine einzige Förderstätte, die Husuan-Mine im Kreis Baoshan, eine Steuerquote verzeichnet. $^{835}$

Dabei sprechen die Verfasser lediglich allgemein von den im Jahr eingezogenen Steuern (jie nian na zheng ke), eine direkte Bezugsgröße wird nicht angegeben. Da es sich bei den genannten Steuerquoten um eher kleine Beträge handelt, beziehen diese sich wohl auf die Steuer, die pro jin (1 jin entsprach 597g) des gewonnenen Metalles zu zahlen war bzw. auf die Steuer, die auf eine bestimmte Anzahl von jin erhoben wurde (siehe die Angaben zur Zinnobermine Xili, 7.2.1.).

Tabelle 36: Betriebsdauer der Minen in Yongchang bis zum Jahr 1885 / Minen mit einer Betriebsdauer von mehr als zehn Jahren ${ }^{836}$

$\begin{array}{lllr}\text { Name } & \text { Vorkommen } & \text { Betriebsdauer } & \text { Jahre } \\ \text { Xili } & \text { Zinnober } & 1705-1885 & 180 \\ \text { Axing } & \text { Eisen } & 1728-1857 & 129 \\ \text { Sandaogou } & \text { Silber } & 1777-1885 & 108 \\ \text { Munai } & \text { Silber } & 1728-1810 & 82 \\ \text { Kuangqing } & \text { Kupfer } & 1705-1784 & 79 \\ \text { Hetaoping } & \text { Kupfer } & 1811-1885 & 74 \\ \text { Luohanshan } & \text { Kupfer } & 1825-1885 & 60 \\ \text { Huangcaoba } & \text { Gold } & 1801-1857 & 56 \\ \text { Lujiang } & \text { Gold } & 1707-1750 & 43 \\ \text { Ankushan } & \text { Kupfer } & 1743-1770 & 27 \\ \text { Qingyang } & \text { Kupfer } & 1748-1773 & 25 \\ \text { Bangfa } & \text { Silber } & 1800-1815 & 15\end{array}$

${ }^{834}$ YCFZ, S. 105

${ }^{835}$ YCFZ, S. 105

${ }^{836}$ YCFZ, S. 105; TYTZ, S. 94. Jahresangaben zur Betriebszeit werden in den fangzhi nur für zweiundzwanzig der insgesamt siebenundzwanzig aufgelisteten Minen genannt. Die Silbermine Munai ist zwar in der Liste verzeichnet, seit 1764 gehörte dieses Gebiet jedoch nicht mehr zu Yongchang, sondern zur Präfektur Shunning. 
Die Betriebsdauer der einzelnen Minen im Gebiet der Präfektur Yongchang war sehr unterschiedlich. So wurden in einigen Minen sechzig bis achtzig ja sogar bis zu einhundertachtzig Jahre lang Bodenschätze abgebaut, während andere Minen schon nach wenigen Jahren wieder geschlossen worden sind. Hauptgründe für die Schließung der Minen waren meist die Erschöpfung der Vorkommen (tong lao shan kong) oder Unrentabilität; aber auch der Einsturz einer Förderstätte konnte zur endgültigen Einstellung der Arbeiten führen, ebenso wie fehlende Technologie zum Abbau schwer zugänglicher Erzvorkommen. ${ }^{837}$

Acht der Minen in Yongchang hatten eine Betriebsdauer von mehr als fünfzig Jahren, drei davon sogar von mehr als einhundert Jahren. In vier weiteren Minen wurden immerhin noch zwanzig bis vierzig Jahre lang kontinuierlich Bodenschätze gefördert. Sechs der Förderstätten in der Präfektur sind bereits nach ein bis drei Jahren wieder geschlossen worden, wobei eine dieser Minen sechzig Jahre später erneut in Betrieb genommen worden ist.

\section{2. 1. Die Minenbetriebe}

\section{a) Die Zinnobermine}

Seit dem Jahr 1705 wurde in Xili im Kreis Yongping Zinnober gefördert. Dieses glänzende Mineral (Quecksilbersulfid) ist die wichtigste Komponente bei der Herstellung von Quecksilber. Lösungen von Metallen in Quecksilber bzw. Legierungen von Metallen und Quecksilber (Amalgame) wurden zur Gewinnung von Gold und Silber aus den Erzen benutzt. Auch in der daoistischen Alchemie findet das Quecksilber Verwendung.

Für die Xili Zinnobermine ist eine Steuerquote festgelegt worden: Für jedes sechste jin [ca. 500g] mußte ein jin als Steuer abgeführt werden. Die so erzielten Einnahmen waren mit über 175 liang (6,5 kg) verglichen mit denen der anderen Minenbetrieben recht hoch. In Schaltjahren erhöhte sich die Summe sogar noch um mehr als 13 liang (ca. 485g; insgesamt also etwa $7 \mathrm{~kg}$ ). Die Mine war mit mindestens einhundertachtzig Jahren Betriebsdauer die am längsten kontinuierlich genutzte Förderstätte in der Präfektur. ${ }^{838}$

\footnotetext{
${ }^{837}$ YCFZ, S. 105: Siehe Silbermine Maolong und Kupfermine Hetaoping. Siehe auch die Minen Mingguang und Qiandong (TYTZ , S. 94).

${ }^{838}$ YCFZ, S. 105
} 


\section{b) Die Kupferminen}

Der erste der im 18. Jahrhundert in der Präfektur Yongchang neu gegründeten Minenbetriebe war der der Kupfermine Kuangqing im Kreis Yongping. Die Mine wurde 1705 (Kangxi 44), im Jahr der Einführung des staatlichen Monopols für den Ankauf von Kupfer, eröffnet. Entsprechend wurde dieses Ereignis von Generalgouverneur Beihenuo, dem Initiator des Kupfermonopols, eigens in einem Schreiben gewürdigt.

Mit einer Betriebszeit von neunundsiebzig Jahren war Kuangqing das am längsten ausgebeutete Kupfervorkommen in der Präfektur Yongchang; erst im Jahr 1784 (Qianlong 47) wurde die Förderung in der Mine endgültig eingestellt. ${ }^{839}$

In der Unterpräfektur Tengyue sind im 18. Jahrhundert lediglich zwei Kupferminen betrieben worden. Die Lijiashan Mine wurde 1735 geöffnet und bereits drei Jahre später wieder geschlossen; in Ankushan wurde immerhin siebenundzwanzig Jahre lang (von 1743 bis 1770) Kupfer gewonnen.

Weitere Kupfervorkommen wurden in den Kreisen Yongping und Baoshan abgebaut. In der Qingyang Kupfermine (Kreis Yongping) wurde fünfundzwanzig Jahre lang Kupfer gefördert (von 1748 bis 1773). Manche Minen erwiesen sich hingegen rasch als unproduktiv und wurden bereits kurze Zeit nach ihrer Öffnung wieder geschlossen, wie zum Beispiel die Daxiang Kupfermine (Kreis Yongping), die 1774 eröffnet und noch im selben Jahr wieder geschlossen wurde. In einigen Minen wurde Jahre nach ihrer Schließung erneut mit der Förderung begonnen. So wurde in der Luohanshan Kupfermine im Kreis Baoshan, die schon ein Jahr nach ihrer Eröffnung 1758 wieder stillgelegt worden war, im Jahr 1825 erneut mit dem Abbau von Kupfererz begonnen. Auch neue Kupfervorkommen wurden weiterhin erschlossen: Im Jahr 1811 wurde die Hetaoping Mine eröffnet, 1883 die Shuanghe Mine (beide im Kreis Baoshan). Beide waren zur Zeit der Herausgabe des YCFZ im Jahr 1885 noch in Betrieb. ${ }^{840}$

Mit einer Anzahl von insgesamt zehn Förderstätten waren die meisten Minenbetriebe im Gebiet von Yongchang mit dem Abbau von Kupfererz befaßt. Allerdings galt für die grössere Anzahl der Betriebe, was die Verfasser des YCFZ für die Erzvorkommen in Yunnan insgesamt festgestellt haben, nämlich daß sie „bald abgebaut wurden, bald [wieder] 
erschöpft waren“. ${ }^{841}$ Ende des 19. Jahrhunderts waren lediglich noch zwei der Kupferminen über mehrere Dekaden in Betrieb.

Wie groß die geförderte Erzmenge in den einzelnen Betrieben war, geht aus den Angaben der fangzhi nicht hervor. Einzig für die Husuan Kupfermine im Kreis Baoshan, die bis zum Jahr 1801 in Betrieb war, ist im YCFZ überhaupt eine Steuerquote verzeichnet, die immerhin „17.800 jin [cirka 10.600 kg] in Kupfer“ betrug und damit die mit Abstand ergiebigste Förderstätte der Präfektur gewesen ist. ${ }^{842}$

Ansonsten spricht die insgesamt eher kürzere Betriebsdauer der einzelnen Minen (die Hälfte aller Kupferminen war weniger als zehn Jahre in Betrieb) dafür, daß die Erzvorkommen in der Präfektur wenig ergiebig waren und zum größten Teil bereits Ende des 18. Jahrhunderts ausgebeutet waren, so daß der Minenbetrieb eingestellt werden mußte.

\section{c) Die Silberminen}

Der Silberbergbau war in der Grenzregion von chinesischen Zuwanderern bereits seit dem 17. Jahrhundert in größerem Umfang betrieben worden. Direkt im Gebiet der Präfektur Yongchang wurde mit dem Abbau von Silbererz allerdings erst Anfang des 18. Jahrhun-derts zur Zeit der Ära Yongzheng (1723-1736) begonnen. Insgesamt wurden in der Prä-fektur Yongchang vier größere Silbervorkommen abgebaut.

Zwei der in den fangzhi genannten Silbervorkommen befanden sich in den Wa Hills (chin. Washan, auch Avashan), der Heimat des Volkes der Wa (chin. auch Kawa oder Qiawa). ${ }^{843}$ Diese Erzvorkommen standen in der Qing-Zeit unter der Oberhoheit einheimischer Machthaber, die einen Teil der Fördermenge als Steuer an den chinesischen Staat ablieferten. So erhob der tusi Dao Paiding des Befriedeten Gebietes (zhangguan si) von Menglian, in dessen Hoheitsgebiet sich die Munai Silbermine befand, zunächst eine Steuer von 600 liang (ca. 22, 4 kg) in Silber; später reichte Generalgouverneur Ortai (von 1726 bis 1731 im Amt) eine Throneingabe ein, nach der diese Steuer um die Hälfte reduziert wurde. ${ }^{844}$ Betrieben wurden die Minen von chinesischen Arbeitern.

\footnotetext{
${ }^{841}$ YCFZ, S. 104

${ }^{842}$ YCFZ, S. 105

${ }^{843}$ Durch die Wa Hills verläuft die heutige Grenze zwischen China und Birma. Die Regionen um die beiden Silberminen gehören heute zum Staatsgebiet der VR China: Die Maolong Silbermine befand sich im Gebiet des modernen autonomen Kreises Cangyuan, die Munai Mine lag weiter südlich im heutigen autonomen Kreis Ximeng.

Eine weitere Silbermine in der Präfektur war Sandaogou im Kreis Yongping, diese war mit einhundertundacht Jahren Betriebsdauer die am ländsten genutzte Förderstätte für Silbererz in der Präfektur: Im Jahr 1777 war dort mit der Förderung begonnen worden; erst im Jahr 1829 (Daoguang 9) wurde eine Steuerquote festgelgt: Diese betrug „, 4 liang 8 qian 7 fen 9 li in Silber“; das entspricht 182 g (siehe Vogel, ,Weights and measures`). Zur Zeit der Herausgabe des YCFZ im Jahr 1885 wurde in der Mine nach wie vor Silber gefördert. Die vierte Silbermine, Bangfa, wurde im Jahr 1800 eröffnet; sie war fünfzehn Jahre lang in Betrieb, ehe sie 1815 wieder geschlossen wurde (YCFZ, S. 105).

${ }^{844}$ Die Munai Mine war die älteste Silbermine im Gebiet der Präfektur Yongchang. Sie ist im Jahr 1728 in Betrieb genommen worden, nach zweiundachtzig Jahren wurde die Förderung im Jahr 1810 eingestellt.
} 
Nachdem das Befriedete Gebiet von Menglian zunächst von der Präfektur Yongchang verwaltet worden war, wurde es im Jahr 1764 ebenso wie die Befriedeten Gebiete (xuanfu si) Gengma (wo ebenfalls Silber gefördert wurde) und Mengmeng der Präfektur Shunning zugeordnet, deren Verwaltungsbeamte seitdem auch für das Einziehen der Steuern verantwortlich waren. ${ }^{845}$

Auch das Silbervorkommen von Maolong befand sich seitdem im Gebiet der erweiterten Präfektur Shunning. Die Verfasser des fangzhi machen jedoch deutlich, daß es ursprünglich ebenfalls zum Verwaltungsgebiet von Yongchang gehört hatte:

„Die Silbermine von Maolong befand sich im Gebiet der Qiawa, welches der Präfektur Yongchang unterstellt war. Mit dem Abbau von Silber wurde dort im Jahr Qianlong 42 (1777) begonnen. Von jedem liang Silber, der gefördert wurde, wurden 9 fen als Steuern eingezogen. Die Hälfte davon wurden den [einheimischen] Qiawa übergeben. Im Jahr Jiaqing 5 (1800) war das Vorkommen erschöpft und die Mine wurde geschlossen““. ${ }^{846}$

Das YCFZ nennt zwar das Jahr 1777 als den Beginn der Silberförderung in Maolong. Die Minen dort sind jedoch schon sehr viel früher in Betrieb gewesen.

Bereits 1746 bauten auch chinesische Arbeiter unter der Führung von Wu Shangxian Silbererz in Maolong ab, wofür sie dem Oberhaupt der Wa eine Gebühr entrichteten. Wu Shangxian wurde von der Qing-Regierung zum Steuerinspektor (kezhang) ernannt, der für die Zahlung der Steuern sowie für die Verwaltung des Minenbetriebes und den Unterhalt einer Miliz zum Grenzschutz verantwortlich war. Seine einflußreiche Stellung ermöglichte es Wu, seine Machtposition in diesem Gebiet zu etablieren. Mitte des 18. Jahrhunderts sollen unter Wu Shangxians Kontrolle in der Maolong Mine zwanzig- bis dreißigtausend chinesische Arbeiter beschäftigt gewesen sein. ${ }^{847}$

Der Zusammenschluß einer so großen Zahl von Han-chinesischen Immigranten im Grenzgebiet wurde von der Qing-Regierung mit Argwohn betrachtet, da diese autonom waren und nicht direkt der Kontrolle einer chinesischen Verwaltungseinheit unterstanden.

\footnotetext{
${ }^{845}$ YCFZ, S. 199; siehe auch Niu Pinghan, S. 386

${ }^{846}$ YCFZ, S. 105. Die Steuer betrug hier $9 \%$ je liang Silber, das macht ca. 3,3g bei einem Gewicht von etwa 37g für ein liang (siehe Vogel, ,Weights and measures').

${ }^{847}$ You Zhong, S. 513
} 
Als sich die Arbeiter der Polong Mine im Gebiet von Hsenwi (chin. Mubang) unter ihrem Anführer Gong Liya 1752 zur Zeit des Dynastiewechsels in Birma an der Eroberung Avas beteiligten, sah sich die Qing-Regierung in ihrer Vorstellung von den Minenarbeitern als Unruhestifter bestätigt und beschloß deren Anführer, die beiden ,Tiger des Grenzgebietes‘ (bianfang liang $h u$ ), Gong Liya und Wu Shangxian, auszuschalten. ${ }^{848}$

Daraufhin wurde Wu Shangxian, der eine Tributmission aus Birma nach Peking begleitet hatte, im Jahr 1753 bei seiner Rückkehr nach Kunming verhaftet und starb im Gefängnis. Gong Liya wurde 1762 verhaftet und in Kunming hingerichtet. ${ }^{849}$ Während einige chinesische Quellen berichten, daß die Minen daraufhin geschlossen und die Arbeiter vertrieben wurden, wird im YCFZ darauf hingewiesen, daß im Grenzgebiet auch weiterhin Silbererz gefördert und die Maolong Mine nur wenige Jahre nach diesen Ereignissen wieder offiziell in Betrieb genommen und erst im Jahr 1800 geschlossen wurde.

\section{d) Die Goldminen}

Gold wurde in Tengyue seit der Zeit des Königreichs von Nanzhao (649-902) gewonnen. Fan Chuo beschreibt in seinem Man shu, die Art und Weise, wie das Gold am Jinbaoshan (dem ,Goldschatz-Berg‘ nördlich das damaligen Tengchong) ausgewaschen wurde:

„Zwischen Frühling und Winter heben [die Goldsucher] zunächst Gräben an den Bergen aus, die über ein zhang [ca. 3m] tief und mehrere zehn Schritte breit sind. Wenn in den Sommermonaten das Wasser herunterläuft, lagert sich nach und nach Schlamm in den Gräben ab. Dort, wo sich die Erde angesammelt hat, entdecken sie zwischen Sand und Steinen das Gold und sammeln es auf. Sie können Blättchen oder Nuggets finden. Große können einen oder sogar zwei catties [ca. 600g] wiegen, kleine einen bis drei liang [ca. 37-117g]. Deren Preis ist um ein vielfaches höher als der von Goldstaub.

Die Gesetze der Barbaren sind sehr streng, so müssen siebzig bis achtzig Prozent [der Erträge] an die Regierung abgeliefert werden. Den Rest können [die Goldsucher] für ihren eigenen Gebrauch mit nach Hause nehmen. Wenn jemand die Abgabe an den Staat nicht zahlt, dann muß ein Bericht darüber eingereicht werden, in dem derjenige anzeigt wird“. 850

\footnotetext{
${ }^{848}$ You Zhong, S. 514; Maung Htin Aung, S. 161

${ }^{849}$ You Zhong, S. 514

${ }^{850}$ Man shu, zitiert nach Luce, S. 70-71.
} 
Während der Yuan-Zeit wurden in der Region des Stromschluchtenfächers neue Minen erschlossen und große Mengen an Gold als Steuern an die Zentralegierung abgeführt. ${ }^{851}$ Während der Ming-Zeit ging die Förderung des Edelmetalls in ganz Yunnan zurück und auch in Yongchang erwies sich der Goldgehalt der Gesteinsvorkommen in späteren Zeiten häufig als zu gering, als daß sich der Abbau in größerem Umfang überhaupt gelohnt hätte. Da nur noch geringe Mengen gefördert wurden, wurde das Gold aus der Präfektur Yongchang entsprechend teurer. So heißt es beispielsweise im YCFZ, daß es zwar

„im Fluß oberhalb von Yongping Gold gebe, es aber sehr schwierig sei, dies auszusondern, so daß die Arbeit eines ganzen Tages einem Mann nicht mehr als paar Gramm einbringen, der Preis dann jedoch den anderer Orte übersteigen würde“. ${ }^{852}$

Erst im Jahr 1707 wurde wieder ein Goldvorkommen in größerem Maßstab erschlossen. Der Förderbetrieb in der Lujiang Goldmine im Kreis Baoshan war so erfolgreich, daß eine Steuerquote festgelegt werden konnte. Es wurden „24 liang 5 qian 6 fen in Gold“(ca. 916g) eingezogen, ausdrücklich vermerkt wird, daß diese Quote in den Schaltjahren nicht wie sonst üblich erhöht worden ist. Die Mine war dreiundvierzig Jahre lang in Betrieb, bis sie im Jahr 1750 wieder geschlossen wurde. ${ }^{853}$

In der Unterpräfektur Tengyue wurde der Abbau von goldhaltigem Gestein in einem regulären Minenbetrieb erst zu Beginn des 19. Jahrhunderts aufgenommen: Im Jahr 1801 wurde in vier Goldminen mit der Förderung des Edelmetalls begonnen. Zwei der Minen, die Lengshuiqing und die Jinlongqing Mine wurden jedoch bereits 1803 wieder geschlossen, die Kuidian Mine bald darauf im Jahr 1809. Der Versuch, die Goldvorkommen in der Unterpräfektur in größerem Umfang zu erschließen, war gescheitert.

Lediglich in der Huangcaoba Mine wurde noch bis zum Jahr 1857 Gold gefördert. Mit sechsundfünfzig Jahren war sie die Goldmine mit der längsten Betriebsdauer in der Unterpräfektur. Sie war auch die einzige der vier Minen, für deren Erträge überhaupt eine Steuerquote festgesetzt wurde. Für die anderen Goldminen war lediglich allgemein festgelegt worden, daß die Erträge sämtlich abzuliefern seien (jin shou jin jie). Mit knapp 10 qian (ca. 37g) im Jahr 1829 lag die Quote für die Huangcaobao Mine deutlich unter der

\footnotetext{
${ }^{851}$ Siehe Sun Laichen, S. 97-99

852 YCFZ, S. 105

853 YCFZ, S. 105
} 
Steuerquote von über 24 liang (etwa 900g), die noch ein Jahrhundert zuvor in der Lujiang Mine erwirtschaftet worden war. ${ }^{854}$

Am Ende des 19. Jahrhunderts wurde die Gewinnung von Gold in der Unterpräfektur Tengyue gänzlich eingestellt.

\section{e) Die Eisenminen}

Eisenerz wurde in der Unterpräfektur Tengyue seit 1728 in der Axing Mine gefördert. Die dafür festgesetzte Steuer betrug 4 liang (149g) Silber. Im Jahr 1829 konnte sogar ein Überschuß im Wert von weiteren 50 liang (1,8 kg) Silber erwirtschaftet werden. Während der Ära Daoguang wurden in Axing auch Lagerstätten von silber- und kupferhaltigen Erzvorkommen ausgebeutet. Mitte des 19. Jahrhunderts waren in Tengyue noch zwei weitere Eisenminen in Betrieb:

„Heutzutage sind der Unterpräfektur nur noch drei Eisenminen unterstellt: Die Axing, die Shala und die Shuiqing Eisenmine. Von jeder Mine werden im Jahr vier liang Silber als reguläre Steuer (zheng ke) eingezogen. [Alle erwirtschaften zudem] einen Gewinn (ying) von über fünfzig liang Silber. Insgesamt werden pro Jahr zwölf liang [ca. 448g] Silber eingezogen. Im Schaltjahr wird zusätzlich [eine Steuer von] einem liang Silber [ca. 37,3g] erhoben. Insgesamt wird jährlich ein Gewinn von mehr als einhundertfünfzig liang [ca. 5,6 kg] in Silber eingenommen“. 855

Während die Minen Axing und Shuiqing im Jahr 1857 geschlossen wurden, war die Shalaqing Mine zur Zeit der Herausgabe des Lokalhandbuches im Jahr 1888 noch in Betrieb und auch sie erzielte weiterhin einen Überschuß von 50 liang in Silber. ${ }^{856}$

Auch das Eisenerzvorkommen in Dongshan im Kreis Baoshan wurde ebenso wie das Vorkommen von Shalaqing in der Unterpräfektur Tengyue zur Zeit des Erscheinens des Lokalhandbuches YCFZ (1885) weiter abgebaut und war mit einer festen Steuer von „15 liang in Silber“ (560g) belegt. ${ }^{857}$

\footnotetext{
${ }^{854}$ YCFZ, S. 105; TYTZ, S. 94

${ }^{855}$ TYZZ, S. 69

${ }^{856}$ TYTZ, S. 94

${ }^{857}$ YCFZ, S. 105
} 


\section{2. 2. Zusammenfassung}

Die sieben Jahrzehnte von 1737 bis 1810, in denen die Bergbauindustrie in Yunnan und insbesondere die Kupferförderung ihren größten Aufschwung erlebte, waren auch in der Präfektur Yongchang die Zeit, in der die meisten Neuerschließungen von Erzvorkommen erfolgten. In siebzehn der siebenundzwanzig in den fangzhi genannten Vorkommen wurde in diesem Zeitraum mit der Förderung begonnen.

Noch in der ersten Dekade des 19. Jahrhunderts wurden in der Präfektur Yongchang gleich mehrere Minenbetriebe gegründet: Ein Silber- und ein Kupfervorkommen wurden neu erschlossen und mit der Eröffnung von gleich vier Goldminen im Jahr 1801 wurde versucht, an die alte Tradition der Goldgewinnung in Tengyue anzuknüpfen. Vier dieser Betriebe erwiesen sich jedoch als unrentabel und wurden schon nach wenigen Jahren wieder geschlossen; nur eine der neuen Goldminen sowie die Kupfermine blieben über mehrere Jahrzehnte in Betrieb. Die 1811 eröffnete Kupfermine Hetaoping war für über achtzig Jahre die letzte Neugründung eines Minenbetriebes in Präfektur Yongchang, erst während der Ära Guangxu (1875-1909) wurde noch einmal eine neue Förderstätte erschlossen: Die 1883 in Betrieb genommene Kupfermine Shuanghe.

Die Entwicklung der Bergbaubetriebe in der Präfektur Yongchang zeigt, daß dort seit Beginn des 18. Jahrhunderts erhebliche Anstrengungen unternommen wurden, die verschiedenen Erzvorkommen abzubauen. Die Vorkommen im Gebiet der Präfektur waren zwar vielfältig, so wurden Gold, Silber, Kupfer, Eisen und Zinnober gewonnen, allerdings weisen lediglich acht der Förderstätten eine Betriebsdauer von über fünfzig Jahren auf, mehr als die Hälfte aller Minen war weniger als zwanzig Jahre in Betrieb. Die insgesamt eher kurze Betriebsdauer der Mehrzahl der Minen und die wenigen Angaben zu den regulären Steuerquoten weisen darauf hin, daß es sich bei den meisten Erzvorkommen um verhältnismäßig kleine Lagerstätten gehandelt hat, die bald ausgebeutet waren.

Bis zum Jahr 1821 waren bereits vierzehn der im YCFZ genannten siebenundzwanzig Förderstätten geschlossen; bis zur Mitte des 19. Jahrhunderts nahm die Zahl der Bergbaubetriebe weiter ab. Zur Zeit der Herausgabe des Lokalhandbuches YCFZ im Jahr 1885 waren in der Präfektur nurmehr sechs Förderstätten in Betrieb: Zwei Eisen-, drei Kupferund die Zinnobermine, von denen immerhin vier Betriebe eine festgelegte Steuer zahlten. Insgesamt hatte die Bergbauindustrie nur einen geringen Anteil am gesamten Steueraufkommen der Präfektur, das sich hauptsächlich aus den Boden- und Handelsteuern zusammensetzte. 


\section{Tengyue - ein Handelsplatz an der Birmastraße}

\section{1. Natürliche Ressourcen und örtliche Produkte}

Für die Verfasser der fangzhi von Tengyue und Yongchang ist der Handel in Tengyue nur da Thema ihrer Darstellungen, wo er erhebliche Auswirkungen auf die chinesische Politik im Grenzgebiet gehabt hat. Entsprechend konzentrieren sie sich auf die Beschreibung des staatlich organisierten Edelsteinhandels in der Ming-Zeit und seine Konsequenzen. Der private Handel hingegen, der neben der Landwirtschaft die wichtige Einkommensquelle der Bevölkerung von Tengyue war und dessen Möglichkeiten über die Jahrhunderte immer wieder Zuwanderer anzogen, wird in den Lokalhandbüchern nur am Rande erwähnt. Die fangzhi enthalten jedoch Kapitel über die natürlichen Ressourcen und örtlichen Produkte (tu chan), in denen auch Handelswaren berücksichtigt werden. ${ }^{858}$ Die Pflanzen- und Tierwelt im Allgemeinen, landwirtschaftliche Erzeugnisse und Nutztiere, „allesamt gewöhnliche Produkte, wie sie in den verschiedenen Regierungsbezirken [Chinas] gleich sind“, werden dennoch ausführlich aufgezählt und auch lokale Spezialitäten wie Arzneipflanzen, Erzeugnisse der einheimischen Volksgruppen und Importwaren werden genannt. ${ }^{859}$

Bereits in der ,Geschichte der späten Han-Dynastie‘ (Hou Han shu) aus dem 5. Jahrhundert werden die lokalen Produkte des Regierungsbezirks Yongchang aufgezählt: Kupfer, Eisen, Blei, Zinn, Gold, Silber, Bernstein, Bergkristall, Perlen, Wollwaren, Baumwollstoffe, Elfenbein, Rhinozeroshorn, Pfauen, Eisvögel und Affen gelangten aus der Region des Stromschluchtenfächers nach Zentralchina. ${ }^{860}$ Besonders für ihre exotische Tierwelt war die Region in chinesischen historischen Quellen bekannt:

„Im Westen von Yuetan gab es viel Gras, dort wurden gute Pferde gezüchtet. Diese sind seit Generationen unter dem Namen Yuetan-Pferde bekannt. Bei ihrer Geburt glichen sie Lämmern, als Einjährige wurden sie mit einem aus Gras geflochtenen [Halfter] angebunden; sie erhielten Reiswasser zu trinken. Mit sieben Jahren konnten sie eingespannt werden und an einem Tag mehrere hundert li weit galoppieren““. ${ }^{861}$ Auch Nashörner lebten im Südwesten und in Yongchang gab es „sogenannte ,Haken-Schlangen“, die mehrere zehn zhang

\footnotetext{
${ }_{858}$ TYTZ, S. 60-62; TYZZ, S. 45-49; YCFZ, S. 102-105

${ }^{859}$ TYZZ, S. 46

${ }^{860}$ Li Xiejun, S. $20-21$

${ }^{861}$ TYZZ, S. 46. Diese Beschreibung der Yuetan-Pferde findet sich bereits im Man shu (s. Hsiang Da, S. 200-202).
} 
lang werden konnten, sich mit dem Schwanz am Ufer festhakten und [aus dieser Position] Tiere und Menschen fraßen.

In den verschiedenen [überlieferten] Lokalhandbüchern wird dies schon nicht mehr vermerkt und auch heutzutage [im 19. Jahrhundert] gibt es diese Dinge nicht mehr. Blüte und Verfall örtlicher Besonderheiten in der Gegenwart unterscheiden sich von denen der Vergangenheit“. ${ }^{862}$

Diese Beschreibung betont, wie sich die lokalen Zustände im Laufe der Zeit verändert haben und daß es Produkte, die z.B. noch in Tang-zeitlichen Quellen als typisch für die Region galten, in späteren Jahrhunderten nicht mehr gab. Dies gilt vor allem für die besondere Tierwelt Yunnans. Bis in die Neuzeit hinein war die Provinz ein Rückzugsgebiet für wilde Tiere, die einst in ganz Südchina weit verbreitet waren. Doch die zunehmende Besiedelung und die damit verbundene Erschließung von Ackerland führten dazu, daß Tiger, Nashörner, Pythonschlangen, Menschenaffen und Elefanten auch dort in unzugängliche Randgebiete verdrängt oder ganz ausgerottet wurden. ${ }^{863}$ Beigetragen hat dazu auch der große Wert der Tiere, wie er gerade auch in ihrer Auflistung in den fangzhi als „örtliche Produkte“ zum Ausdruck kommt. Tigerfelle, Elfenbein, Arzneimittel aus Nashorn oder Tigerknochen usw. waren nicht nur wertvolle Handelswaren, sondern wurden auch als Tributgeschenke an den chinesischen Hof übergeben.

Manchmal auch in Form des lebendigen Tieres: So hatte schon das Königreich Nanzhao im Jahr 854 ein Nashorn als Tribut an den chinesischen Kaiser gesandt. ${ }^{864}$ Später waren es

\footnotetext{
${ }^{862}$ TYZZ, S. 46. 1 zhang enspricht ca. 3,33 Meter.

${ }^{863}$ Während der Ming-Zeit war die Gefahr, die Tiger nicht nur auf dem Lande sondern auch für die Stadtbewohner bedeuteten noch Thema für die Verfasser der fangzhi. In den Kapiteln über die Omina (xiangyi) wird auf die Existenz besonders vieler Tiger in bestimmten Jahren hingewiesen und das Vordringen eines solchen Raubtieres bis nach Tengyue ausdrücklich vermerkt: Zhengde 3 (1508), ,viele Tiger‘; Jiajing 3 (1524), ,im Sommer gab es viele Tiger‘; Wanli 7 (1579), ,ein Schakal (chai) und ein Tiger drangen in die Vorstadt ein“; Wanli 31(1603), ,ein Tiger drang in die Vorstadt ein und verletzte Menschen' (TYTZ, S. 28-30). Dem Tiger wurden auch übernatürliche Qualitäten zugeschrieben, indem sein Erscheinen als Vorzeichen gedeutet wurde oder auch in der chinesischen Vorstellung, daß die Angehörigen einiger Volksgruppen im Südwesten die Fähigkeit besäßen, sich in einen Tiger zu verwandeln. Ein kurzer Bericht über eine solche Verwandlung wurde auch in das Schlußkapitel des TYTZ aufgenommen (siehe TYTZ, S. 387; YCFZ, S. 347). Aus der Qing-Zeit sind keine ähnlichen Ereignisse mehr in den fangzhi überliefert; die Tiger werden nur noch in der Liste der heimischen Tierwelt erwähnt (TYTZ, S. 61).

${ }^{864}$ Nashörner waren in prähistorischer Zeit in ganz China verbreitet; im Südwesten des Reiches waren sie einst weit zahlreicher als Elefanten. Im 4. Jahrhundert hat Chang Qu im Huayang guo zhi Nashörner als Produkte Yongchangs genannt (Xiang Da, S. 202). Auch im Reich von Nanzhao gab es im 8. und 9. Jahrhundert Nashörner; die Einheimischen (man) „produzierten Rhinozerosleder und [fertigten daraus] Schilde und Rüstungen, auch für ihre Pferde“ (Hsiang Da, S. 202; Luce, Man shu, S. 72).

Seit der Ming-Zeit nahm die Anzahl der Tiere im Südwesten rasch ab. In Guizhou existierten spätestens seit der Ära Daoguang (1821-51), in Sichuan seit der Ära Tongzhi (1826-75) keine Nashörner mehr. Lediglich in Yunnan gab es zu Beginn des 20. Jahrhunderts noch einige Tiere (Lan Yong, S. 118). In den fangzhi von Tengyue wird das Horn des Rhinozeros ebenso wie Elfenbein nur mehr als exotisches Importprodukt erwähnt.
} 
hauptsächlich Elefanten, die von Birma als Tributgeschenk an den chinesischen Hof geschickt wurden. ${ }^{865}$

Bis zum Ende des 19. Jahrhunderts hat sich die Situation erheblich verändert und in Bezug auf die exotischen Nutztiere stellen die Verfasser der fangzhi fest, daß

„es zum Beispiel seit Jahren keine gezähmten Elefanten der Yeren mehr gibt. In alten Chroniken von Tengyue heißt es noch, daß hier vorzügliche Pferde gezüchtet werden, heutzutage sind sie wirklich nicht schön“. ${ }^{866}$

Neben den Produkten aus der örtlichen Landwirtschaft, Viehzucht und dem Handwerk wurden auf den Märkten von Tengyue auch Spezialitäten der einheimischen Völker der Unterpräfektur gehandelt. Dazu zählten unter anderem

„Tuche aus Menglian und Dadong; das Tuch der Baiyi [Shan] aus den Gebie-
ten dieser tusi ist Serge, den es in fünf Farben gibt. In der Unterpräfektur
werden Seide und Seidenraupen wenig genutzt. Es gibt keine Handwerker, die
sie weben können. Bei den tusi gibt es jedoch die Brokate aus Ganya. Die
Baiyi-Frauen haben diese handwerklichen Fertigkeiten, sie können die Formen
von Blumen, Gräsern, Vögeln und Tieren in Brokat und Satin weben. Diese
sind äußerst fein und genau [gearbeitet]. Papier kommt aus Xiaoxilian, dort
gibt es ,doppeltes Kopienpapier (shuangchaozhi), das verhältnismäßig fest

\footnotetext{
${ }^{865}$ Zitiert nach Lan Yong, S. 113. So wurden z.B. im 18. Jahrhundert in den Jahren 1788 und 1790 (Qianlong 53 und 55) Elefanten an den Kaiserhof übersandt (TYTZ, S. 244-45, 277; TYZZ, S. 161, 162).

${ }^{866}$ YCFZ, S. 104-105; TYZZ, S. 46-47; siehe auch Luce, Man shu, S. 71.

In der Han-Zeit war die Region im Westen der modernen Provinz Yunnan insgesamt als „Land, in dem man auf Elefanten reitet“ (Chengxiangguo) bekannt (Shiji, Dawan liechuan; Lan Yong, S. 121). In der Tang-Zeit waren Elefanten im südwestlichen Yunnan noch sehr zahlreich. Im Man shu heißt es: „In Kainan und Yi'nan gibt es sehr viele [Elefanten]. Wenn es den Leuten gelungen ist, einen zu fangen, bilden sie ihn aus, um ihn bei der Feldarbeit einzusetzen“ (Hsiang Da, S. 204, sowie juan 4; Luce, Man shu, S. 73). Aus der Haut der Elefanten werden Rüstungen und Schilde hergestellt“". Elefanten bzw. Elfenbein wurden von verschiedenen Volksgruppen der Region als Tribut an den chinesichen Hof gesandt. Auch im Yuan shi wird berichtet, daß aus Jinchi (Yongchang) Elefanten als Tribut übersandt worden sind (Lan Yong, S. 123).

In der Ming-Zeit lebten in Sichuan und Guizhou bereits keine Elefanten mehr, in Yunnan waren sie in die Randgebiete der Provinz wie Jingdong, Dehong oder Xishuangbanna zurückgedrängt worden. Dort wurden sie weiterhin als Nutztiere gehalten und insbesondere als Kriegselefanten eingesetzt. So setzten die tusi von Luchuan-Pingmian bei ihrem Kampf um die Vorherrschaft über Südwesten Yunnans in den Jahren 1388-1442 auch Elephanten gegen die Ming-Truppen ein. Von General Deng Zilong, der Ende des 16. Jahrhunderts in der Region des Stromschluchtenfächers gegen die Birmanen kämpfte, sind in den fangzhi mehrere Anekdoten überliefert, die schildern, wie er die Elefantenkavallerie der Birmanen besiegte. Zum Beispiel, indem er ,an einem strategischen Ort Wein vergraben ließ, denn wenn die Elefanten Wein riechen, so laufen sie nicht mehr weiter und so konnten seine Soldaten sie mit scharfen Speeren verletzen und in die Flucht schlagen` (TYTZ, S. 387). Bei militärischen Auseinandersetzungen in der Region standen die Truppen Chinas bis in die Qing-Zeit den Kriegselefanten der birmanischen Armeen gegenüber. Selten setzten auch chinesische Heerführer Elefanten ein, so z.B. Li Dingguo im Kampf gegen die Truppen der Mandschu am Ende der Ming-Zeit.
} 
ist. ${ }^{867}$ Wachs gibt es in drei Sorten: Gelbes, weißes und kastanienbraunes, ... es wird von den Yeren verkauft. Der Tuan-Tee ist von schwarzer Farbe, er reicht jedoch bei weitem nicht an den Puer-[Tee aus Xishuangbanna] heran. [TuanTee] kommt aus dem Gebiet von Xiaochashan (dem „kleinen Tee-Berg“, jenseits des Diantanguan [im Norden von Tengyue]. Es gibt zwei Sorten von Honig, gelben und weißen. Tabakblätter werden in sämtlichen Gebieten der Barbaren angepflanzt. Es wird auch Wein hergestellt. [Für die Gärung wird bei Branntwein (shaojiu), gelbem Reiswein (huangjiu) und bei Schnaps (baijiu) jeweils Klebreis verwendet. ${ }^{868}$ ] Es gibt Rapsöl, Sesamöl, Tungöl, Schilfblütenöl und Su-Öl. ${ }^{869}$.... Muntjak-Leder kommt von jenseits der Pässe, Lack kommt aus Jietou, Laka-Holz [zur Gewinnung von Weihrauch] gibt es überall in Beilian, Qushi, Wadian und Jietou. Auch Regenschirme kommen aus Jietou“ ${ }^{870}$

Im Anhang an diese Liste lokaler Besonderheiten nennen die Verfasser des TYZZ noch Produkte der ,äußeren Barbaren“ (wai yi): „Die Produkte Bhamos sind weiße Jade, Nephrit und dunkle Jade, Menggong produziert Bernstein, Mengmi Edelsteine“; abschließend vergessen sie nicht darauf hinzuweisen, daß diese Gebiete der wai yi ,seinerzeit zum Kernland (nei di) gehört haben“ und somit durchaus zu den lokalen Produkten gezählt werden können. ${ }^{871}$

Die Verfasser des YCFZ hingegen legen Wert auf die Unterscheidung der Erzeugnisse Yongchangs und der Handelswaren aus anderen Gebieten, um Fehler zu vermeiden, wie sie in historischen Quellen zu finden seien, in denen diese Dinge über die großen Entfernungen oft verfälscht dargestellt würden, so daß das Gebiet der Präfektur Yongchang darin selbst als Herkunftort von Produkten genannt würde, die eigentlich aus Birma importiert worden seien; so hieße es in historischen Abhandlungen oft, daß

„[bestimmte Güter] in Yongchang produziert würden. Die Aufzeichnungen wurden überliefert, aber die Unterschiede waren nicht bekannt. Das lag sicher daran, daß [diese Dinge] über Yongchang importiert worden sind und dann nicht weiter überprüft worden ist, woher sie tatsächlich gekommen sind“ ${ }^{872}$

\footnotetext{
${ }^{867}$ Papier wird auch heute noch in Tengchong produziert. Seit 1974 stellt die örtliche Fabrik hochwertiges Xuan-Papier in der Qualität der landesweit bekannten Papiersorte xuanzhi aus dem Kreis Xuanzhou in Anhui her sowie Reispapier und Papiere aus den traditionellen Materialien Baumrinde und Hanf.

${ }^{868}$ YCFZ, S. 104

${ }^{869}$ Su-Öl wird aus den Samen der Perilla ocymoides gewonnen und als Lampenöl verwendet.

${ }^{870}$ TYZZ, S. 46-47. Beilian liegt im Nordwesten der Stadt Tengyue. Qushi, Wadian und Jietou sind benachbarte Gemeinden (lian) im Norden von Tengyue.

${ }^{871}$ TYZZ, S. 47

${ }^{872}$ YCFZ, S. 104-105; TYTZ, S. 60-62
} 


\section{2. Handelswaren im Im- und Export}

Die günstige Lage der Stadt machte Tengyue zu einem wichtigen Handels-, Rast- und Stapelplatz der Kaufleute an der Hauptverkehrsroute, die Zentral-Yunnan mit Birma verbindet und die in Dali die Handelsrouten aus dem südlichen Xishuangbanna und die Strecke nach Tibet kreuzt. Von Dali zogen Händler und Karawanen nach Westen über Yongchang und das Gaoligong-Gebirge auf die Hochebene von Tengyue und dann weiter nach Birma. Dort erreichten sie Bhamo, einen zentralen Ort des Fernhandels, von dem aus chinesische Waren auf dem Irawadi weitertransportiert wurden und die Händler birmanische Produkte für den Import aufnahmen.

Die bekannteste und in China hochgeschätzte Importware waren die Edelsteine. Seit der Yuan- besonders aber in der Ming-Zeit blühte der Handel mit Rubinen, Smaragden, Bernstein und Jade aus Birma und den Kleinstaaten im Grenzgebiet. Auch im 18. und 19. Jahrhundert wurden aus Birma hauptsächlich Luxusgüter nach China exportiert:

„Die verschiedensten Dinge kommen von auswärts. Manche kommen aus über tausend li, manche sogar aus mehreren tausend li Entfernung. Die Kaufleute packen Proviant ein und reisen mehrere zehn Tage lang bis sie ihr Ziel erreichen. Das Einkaufen ist sehr schwierig. Die Waren sind sehr wertvoll, wie zum Beispiel Edelsteine, Bernstein oder dunkle Jade. Und je kostbarer sie sind, desto ferner sind sie“. 873

Außer den genannten wurden noch weitere Waren wie Achat, Koralle, Serpentin und Elfenbein, Vogelfedern, Häute und Felle (von Leoparden, Füchsen, Fischottern und Hirschen), Hirschhorn und andere in der Medizin verwendete Substanzen sowie Betelnüsse, eßbare Vogelnester und Lack aus Birma eingeführt. ${ }^{874}$

Bis zur Mitte des 18. Jahrhunderts war Rohseide aus Sichuan zur wichtigsten chinesischen Handelsware geworden, die via Yunnan nach Birma gebracht und über den Irawadi weiter transportiert wurde, um bis nach Europa verschifft zu werden. Dieser Export nahm so stark zu, daß sich der birmanische König Bodawpaya (reg. 1782-1819) veranlaßt sah, im Jahr 1812 die Ausfuhr chinesischer Seide auf europäischen Schiffen zu verbieten, um eine

\footnotetext{
${ }^{873}$ YCFZ, S. $104-105$

${ }^{874}$ TYTZ, S. 60-62; TYZZ, S. 46-47; YCFZ, S. 104-105. Serpentin ist ein meist grünes Mineral von geringer Härte, das als Schmuckstein verwendet wird; gefördert wird es in Mogaung.
} 
ausreichende Belieferung der Seidenindustrie in seiner Hauptstadt Amarapura zu gewährleisten.

Aus China wurden neben Seide (rohe und verarbeitete) auch andere Textilien wie Samt, Satin oder Filz ausgeführt. Im 18. Jahrhundert wurden zudem Nadeln, Garn, Seile und Gongs exportiert. Weiterhin wurden Metalle wie Eisen, Kupfer, Silber oder Gold (auch in Form von Blattgold oder Gold- und Silberfäden) und Metallwaren, besonders eiserne Töpfe und Pfannen, nach Birma ausgeführt. Für einige geschmiedete Metalle galt um 1826 nach chinesischem Recht ein Ausfuhrverbot, das durch Schmuggel umgangen wurde.

\section{Tabelle 37: Exportwaren aus Birma und China im 18. und 19. Jahrhundert}

(Auswahl der Handelswaren, nach Angaben der fangzhi und zeitgenössischer westlicher Quellen) ${ }^{875}$

Exporte aus Birma

Baumwolle
Bernstein
Betelnüsse
Edelsteine
Elfenbein
Fische
Hirschhorn
Jade
Lack
Schwalbennester
Serpentin
Vogelfedern

\section{Exporte aus China}

$\begin{array}{lll}\text { Alaun } & \text { Messingwaren } & \text { Schuhe } \\ \text { Blei } & \text { Metallwaren } & \text { Silber } \\ \text { Eisen } & \text { Nadeln } & \text { Spiritus } \\ \text { Fächer } & \text { Orpiment } & \text { Tabak } \\ \text { Filz } & \text { Papier } & \text { Tee } \\ \text { Früchte /einge- } & \text { Pistazien } & \text { Teppiche } \\ \text { machte Früchte } & \text { Porzellan } & \text { Walnüsse } \\ \text { Garn } & \text { Quecksilber } & \text { Zinn } \\ \text { Gold / Blattgold } & \text { Rohseide / } & \text { Zinnober } \\ \text { Gongs } & \text { verarbeitete Seide } & \\ \text { Honig } & \text { Salz } & \\ \text { Kupfer } & \text { Satin } & \end{array}$

Generell exportierten die chinesischen Händler Fertigprodukte und importierten Rohstoffe aus Birma. Der größte Anteil an den Exportartikeln aus Birma entfiel auf zwei Handelsgüter:

„Heutzutage handeln die Kaufleute in Tengyue erstens mit Juwelen und zweitens mit Baumwolle. Die Juwelen kommen als unbearbeitete Edelsteine, die Baumwolle wird in Bündeln befördert. Die Transport[karawanen] mit ihren Maultieren und Packpferden füllen die Wege und verstopfen die Verbindungsstraßen. Heute hört der Lärm des Schleifens in den Jadewerkstätten der Provinzhauptstadt Tag und Nacht nicht mehr auf, so viel [Jade] ist aus Tengyue gekommen. Die Baumwolle geht dann hinab nach Guizhou“. ${ }^{876}$

\footnotetext{
${ }^{875}$ TYTZ, S. 60-62; siehe auch Forbes, S. 22 sowie bei Sangermano, Crawfurd, Anderson.

${ }^{876}$ TYZZ, S. 46-47
} 
Im 19. Jahrhundert war Baumwolle zum wichtigsten Handelsgut geworden. ${ }^{877} 1885$ überstieg der Anteil von Baumwollgarnen und -stoffen an den registrierten Importen mit 36\% zum ersten Mal selbst den Anteil des aus Britisch-Indien eingeführten Opiums. ${ }^{878}$ Der Handel lag ganz in den Händen der Chinesen, die im Dezember und Januar im modernen Bhamo ankamen und ihre mit der Baumwolle beladenen Karawanen von dort über das alte Bhamo (oder Manmo) zu Wasser und zu Land in drei Tagen nach Mowan, von dort in weiteren acht bis neun Tagen nach Tengyue und weiter ins Landesinnere transportierten. ${ }^{879}$

Zentrum des Handels in Tengyue war die südwestliche Vorstadt. Zu beiden Seiten der Hauptstraße erstreckten sich, wie John Anderson 1868 beobachtet hat, vom Südtor aus etwa achthundert Meter weit eingeschossige Geschäfte, an Markttagen war die Straße zudem mit zwei Reihen von Ständen dicht besetzt, an denen Chinesen und Angehörige einheimischer Volksgruppen Handel trieben. Trotz des Niedergangs des Handels während der Moslem-Rebellion fand Anderson dort ein reichliches Angebot an Obst, Gemüse und Gewürzen, auch Betelnüsse und Mohnkapseln wurden verkauft sowie Stoffe, Schmuck und Nutztiere. ${ }^{880}$ Weitere Geschäfte und die Werkstätten der Schneider, Kupferschmiede und Jadehandwerker befanden sich in den Seitenstraßen der Vorstadt. ${ }^{881}$ Die Edelsteine wurden in der Babaojie gehandelt, der Straße direkt vor der südlichen Stadtmauer, die deshalb auch ,Straße der hundert Edelsteine“ (Baibaojie) genannt wurde. ${ }^{882}$

\section{3. Handel und Politik}

Die enge Verbindung zwischen dem Fernhandel insbesondere mit Edelsteinen, den Beziehungen Chinas zu den Herrschaftsgebieten in der Region des Stromschluchtenfächers und der Entwicklung der Verwaltungseinheit Tengyue hat in der Ming-Zeit die Entstehung des Grenzgebietes entscheidend beeinflußt. Politische Ereignisse und die militärischen Auseinandersetzungen in der Region wirkten sich auch später immer auf den Handel aus.

So werden z.B. in birmanischen Quellen wirtschaftliche Interessen mit als Auslöser des Krieges zwischen China und Birma Mitte des 18. Jahrhunderts genannt. Demnach hätten

\footnotetext{
${ }^{877}$ Im Jahr 1863 reisten die Briten C. E. Watson und Francis Fedden von Toungoo via Yamethein nach Oo-Noung am Ufer des Salween. Wichtigstes Erzeugnis dieses Distriktes war Baumwolle, die fast ausschließlich nach Yunnan exportiert wurde (siehe Woodman, S. 183).

${ }^{878}$ Osterhammel, S. 182. Im YCFZ wird auch Opium (hafurong) als örtliches Produkt genannt (YCFZ, S. 104). Opium aus Yunnan wurde hauptsächlich in andere chinesische Provinzen exportiert.

${ }^{879}$ Captain Hannay, um 1836.

${ }^{880}$ Anderson, S. 199, 200, 205

${ }^{881}$ Ebd., S. 205

${ }^{882}$ TYTZ, S. 61
} 
Beschwerden chinesischer Händler über eine ungerechte Behandlung durch birmanische Beamte der chinesischen Regierung zusätzliche Gründe für ihre Militäraktion geboten. Nachdem der Krieg mit einem Friedensschluß im Jahr 1770 beendet worden war, verhängte der chinesische Kaiser ein Verbot des Handels mit Birma, welches für Tengyue und Yongchang erhebliche wirtschaftliche Verluste bedeutete. Die Hauptverkehrsrouten in der Region wurden nun von Soldaten kontrolliert, die immer wieder Händler festnahmen, die trotz des Embargos unterwegs waren. Die Einbußen im Handel brachten aber nicht nur für die Kaufleute, sondern auch für den Staat finanzielle Verluste mit sich. Die Steuerleistungen der Präfektur Yongchang betrugen in den Jahren nach dem Friedensschluß nur etwa ein Sechstel der früheren Steuereinnahmen, da die Im- und Exportsteuern, die die Händler auf ihre Waren entrichten mußten, weggefallen waren. ${ }^{883}$

In der zweiten Hälfte des 19. Jahrhunderts setzte der Niedergang des florierenden Fernhandels ein: Im Jahr 1854 wurde Baumwolle in Birma zum königlichen Monopol erklärt und in Yunnan brachte der Moslem-Aufstand von 1855 bis 1873 den internationalen Handelsverkehr zeitweise ganz zum Erliegen. ${ }^{884}$

Mitte des 19. Jahrhunderts schalteten sich auch die Briten in den Yunnan-Handel ein. Seit sie im Jahr 1862 einen Vertrag mit dem birmanischen König ausgehandelt hatten, der es ihnen erlaubte, bis nach Bhamo zu reisen und dort mit den chinesischen Kaufleuten Handel zu treiben, war der Ausbau ihres Handels mit China über Yunnan eines der Hauptinteressen Großbritanniens in der Region. ${ }^{885}$ Die Unterbrechung des Fernhandels während der Moslem-Rebellion veranlaßte die Briten, von Birma aus eine Expedition nach Yunnan zu entsenden, um die Ursache für das Ausbleiben der Karawanen zu ermitteln und die Möglichkeit einer Wiederaufnahme der Warentransporte zu untersuchen. Mit der Niederschlagung der Rebellion durch chinesische Regierungstruppen im Jahr 1873 wurde auch der Handel unverzüglich wieder aufgenommen und erlebte eine neue Blütezeit.

Noch im selben Jahr setzte die britische ,Irrawaddy Flotilla Company“ aufgrund des steigenden Warenaufkommens mehr Dampfschiffe ein, die zunächst einmal monatlich, dann alle vierzehn Tage von Bhamo nach Rangun verkehrten. ${ }^{886}$

\footnotetext{
${ }^{883}$ Giersch, Qing China, S. 260-262

${ }^{884}$ Baumwollstoffe blieben noch bis etwa 1930 die wichtigste Importware Chinas aus Birma (Osterhammel, S. 182).

${ }^{885}$ Siehe unten Abschnitt B. 2. 1., S. 346-349.

${ }^{886}$ Woodman, S. 196
} 


\section{4. Unterwegs nach Birma}

Von Tengyue aus machten sich Karawanen auf den Weg nach Birma, die oftmals aus mehreren hundert Packtieren und deren Begleitmannschaft bestanden. ${ }^{887}$ Die Verkehrswege, die sie passierten, waren enge, teilweise mit Kopfsteinen gepflasterte Pfade, die über die Jahrhunderte ausgetreten und abgeschliffen waren und die in Stufen und Serpentinen die Höhenunterschiede in der Region des Stromschluchtenfächers überwanden (siehe Abb.1, S. 303).

In der Regenzeit von Juni bis September waren die Wege für Packtiere oft unpassierbar; diese wurden dann durch Träger ersetzt. Insgesamt war das Transportvolumen während der Regenzeit jedoch deutlich geringer, als in den anderen Monaten des Jahres.

Auch außerhalb der Regenzeit herrscht in den Flußtälern der Region des Stromschluchtenfächers ein feuchtheißes Klima, das bei den chinesischen Reisenden besonders gefürchtet war, da sie der Ansicht waren, das dort Miasmen Tropenkrankheiten auslösen würden. Im Südosten von Tengyue am Salween

„ist das Klima beständig heiß und dunstig, Miasmen breiten sich aus (zhang pen). Die verschiedenen Völker dort leben alle auf den Bergen, keiner wagt es auf dem flachen Land zu wohnen. Die Reisenden fürchten sich und erkranken jedesmal. ... Aus der Erde [steigen] giftige Ausdünstungen [auf]“. ${ }^{888}$

Und besonders an der Handelsroute nach Bhamo, in den tusi-Gebieten von „Nandian, Ganya, Zhanda und Mengmao sind Tropenkrankheiten (zhangli) weit verbreitet, nur in Husa und Lasa ist das Klima angenehm. ... Ansonsten gibt es keinen Ort ohne Bergnebel, Dunst oder Miasmen. ... Die giftige Atmosphäre (zhang $d u$ ) verursacht häufig Malaria (nüeji); die ärgste wird ,stumme Malaria‘ (yazhang) genannt. Unter zehn Erkrankten sind nicht einmal zwei oder drei, die wieder gesund werden“. 889

\footnotetext{
${ }^{887}$ Cressey (1934) berichtet, daß die Karawanen zu Beginn des 20. Jahrhunderts meist sehr groß waren; sie konnten 2000 Ponies, 300 bis 400 Ochsen, deren Treiber und eine Wachmannschaft umfassen (Cressey, S. 378).

${ }^{888}$ TYTZ, S. 313. Gedenkinschrift von Chen Zonghai zum Wiederaufbau der Brücke über den Lujiang (Salween). Mit dem Bau der Brücke sollte die Gefahr für die Reisenden, in der Flußniederung mit Krankheitserregern in Kontakt zu kommen, beseitigt werden (ebd.).

${ }^{889}$ TYTZ, S. 27; TYZZ, S. 44. „Außer in den drei Wintermonaten und am Frühlingsanfang wagen es diejenigen, die mit den Barbaren in [Geschäfts]verbindung stehen nicht, [weiter nach Südwesten]“ zu reisen, heißt es in der Einleitung zu einem Gedicht des Shi Wu (Ming-Zeit), das den Widerstreit zwischen Handelsinteressen und der Furcht vor den Tropenkrankheiten prägnant zum Ausdruck bringt: „In Birma fallen schon die Blüten und bedecken die Berge der Wilden; dunkle Edelsteine [selbst in Mengen bis zu] eintausend liang [Gewicht] werden sofort bezahlt; am Tag vor dem Totenfest [Anfang April] fließt der Regen, man muß sich vor den Miasmen in Acht nehmen; die Han-Chinesen wagen es nun nicht mehr, Yaoguan zu überqueren“. Der strategische Paß Yaoguan befindet sich südlich von Shidian im Süden Yongchangs. Verschiedene Arten der Malaria waren in der Region noch im Jahr 1903 weit verbreitet, sowohl im Grenzgebiet zwischen Birma und China, als auch in Tengyue selbst (siehe Tengyue Trage Report, 1903, S. 916).
} 
Doch nicht nur bei der Überwindung der Gebirgszüge und Flußtäler drohten den Reisenden Gefahren, auch vor Überfällen galt es die Karawanen zu schützen. Die chinesischen Militärstützpunkte in der Unterpräfektur Tengyue boten den Reisenden nur bedingt Sicherheit. ${ }^{890}$ Die bewaffnete Wachmannschaft allein, von der sich die Händler in der Regel begleiten ließen, bedeutete keinen ausreichenden Schutz. Da es in der Region keine alternativen Verkehrswege gab, auf die die Karawanen ausweichen konnten, blieb den Kaufleuten nichts anderes übrig, als an die einheimischen Völker, deren Gebiete sie durchqueren mußten, ein Schutzgeld zu zahlen.

Auch die Shan-tusi im Südwesten der Unterpräfektur Tengyue nahmen aktiv am Handel teil und waren daher an einem ungehinderten Warenverkehr ebenso interessiert wie die Chinesen. Der Durchzug von Karawanen durch ihre Gebiete und das im Süden anschliessende Territorium der Kachin (chin. heute: Jingpo) wurde häufig mit Unterstützung der chinesischen Beamten im Rahmen des tusi-Systems ausgehandelt: Gegen eine Gebühr, meist in Form von Geld, Salz oder Reis konnten die Händler passieren. ${ }^{891}$ Doch auch diese vorab geregelten Abgaben boten nur bedingt Schutz, wenn sich Gruppen der einheimischen Bevölkerung über die Abmachungen hinwegsetzten oder chinesische Banditen die Karawanen überfielen.

Wie geschickt einige Volksgruppen die Handelskarawanen als Einnahmequelle für sich zu nutzen wußten, zeigt das Beispiel der Qiawa (Wa). Aus chinesischer Sicht stellten sie ein Ärgernis dar und entsprechend negativ fällt die Beschreibung der Qiawa und ihrer Praktiken in den fangzhi aus:

„Die Qiawa sind unter den Fremdvölkern die starrsinnigsten. ... Ihr Äußeres ist häßlich und ihr Charakter schlecht (mao chou xing e). ... Sie haben scharfe Messer und Spieße, mit denen sie sich insgeheim an den Hauptverkehrswegen in einen Hinterhalt legen, um die reisenden Händler auszuplündern. Diese müssen sich zu mehreren zusammentun und zudem [einheimische] Beschützer (baohuzhe) engagieren, dann erst können sie es wagen, diese Orte zu passieren. Heutzutage hört diese Sitte allerdings langsam auf. Generell sind es die Kaufleute, die von Tengyue nach Mubang gehen, um Hölzer und Brokate zu kaufen, die deren Territorium durchqueren müssen. Man sagt: ,Von den Qia profitieren die Wa‘ (wei Qia li Wa). Denn es gibt zwei Arten von ihnen, ,rohe‘ und

\footnotetext{
${ }^{890}$ Ende des 19. Jahrhunderts zahlten die Kaufleute eine Steuer für die Soldaten in den chinesischen Militärstützpunkten, die für die Sicherheit entlang der Strecke nach Bhamo sorgen sollten (siehe Hill, S. 48).

${ }^{891}$ Hill, S. 61; siehe auch S. 53-57.
} 
,gekochte“ (sheng shu): Die ,Rohen“ plündern [die Kaufleute] aus und die

,Gekochten` beschützen [sie auf] den Straßen [vor Plünderern]. ${ }^{892}$

Auch die Briten sahen sich bei der Ausweitung ihrer Handelsaktivitäten in Bhamo mit diesem Problem konfrontiert. Im Jahr 1863 berichtete der Reisende Dr. Williams, daß die Straße bis zur chinesischen Grenze von den dort ansässigen Kachin blockiert sei, so daß nun große Mengen verschiedener Waren, hauptsächlich Baumwolle in Bhamo gelagert werden müßten und dort auf den Weitertransport nach Yunnan warteten. ${ }^{893}$

Nach der Eroberung Oberbirmas 1885 gingen die Briten energisch gegen das Banditentum in der Region vor und trugen damit auch zum neuerlichen Aufschwung des Fernhandels von Yunnan über Bhamo bei. ${ }^{894}$

\section{Die Brücken in der Präfektur Yongchang}

Die Verkehrsrouten in der Region des Stromschluchtenfächers überwinden abwechslend bis über dreitausend Meter hoch ansteigende Gebirgszüge, die im Winter von Schnee bedeckt sein können, und überqueren Flüsse, die tiefe Schluchten aus den Bergen herausgespült haben, an deren Grund zuweilen ein feuchtheißes Klima herrscht. Soldaten und Verwaltungsbeamte, Händler und Zuwanderer aus dem Landesinneren mußten breite Ströme wie den Lancangjiang (Mekong) und den Nujiang (Salween), den Longchuanjiang sowie zahlreiche andere Flußläufe überqueren, um bis nach Tengyue zu gelangen, das

„sich inmitten von zehntausend Bergen befindet; wo nach jedem Regen tosende Bäche aus den Gebirgen herabstürzen. Boote können die beiden Flüsse Long und Lu dann nicht mehr überqueren. Seit jeher sind die Flußübergänge als gefährlich bekannt (cheng xian du)“. ${ }^{895}$

\footnotetext{
${ }^{892}$ TYTZ, S. 248; YCFZ, S. 333

${ }^{893}$ Woodman, S. 177

${ }^{894}$ Forbes, S. 41

895 TYTZ, S. 57. Lujiang ist eine anderer Name für den Fluß Nujiang (Salween).

Nicht nur das Übersetzen über den Nujiang war ein riskantes Unterfangen, schon das für Chinesen aus dem Kernland ungewohnte Klima in den Flußtälern barg Gefahren: „Weil es [am Fluß] häufig dunstig war, erkrankten [viele] der Reisenden“ und vom Shamuhe „hieß es früher, daß es im Wasser unter der [Fengming-Brücke] viele Miasmen gegeben habe, so daß Menschen und Tiere, die davon tranken, krank geworden seien; heutzutage [am Ende des 19. Jahrhunderts] ist das aber nicht mehr so“ (YCFZ, S. 69, Huiren qiao und ebd., S. 70, Fengming qiao).
} 
Abbildung 1:

Verkehrswege in der Region des

Stromschluchtenfächers -

Brücken und Straßen

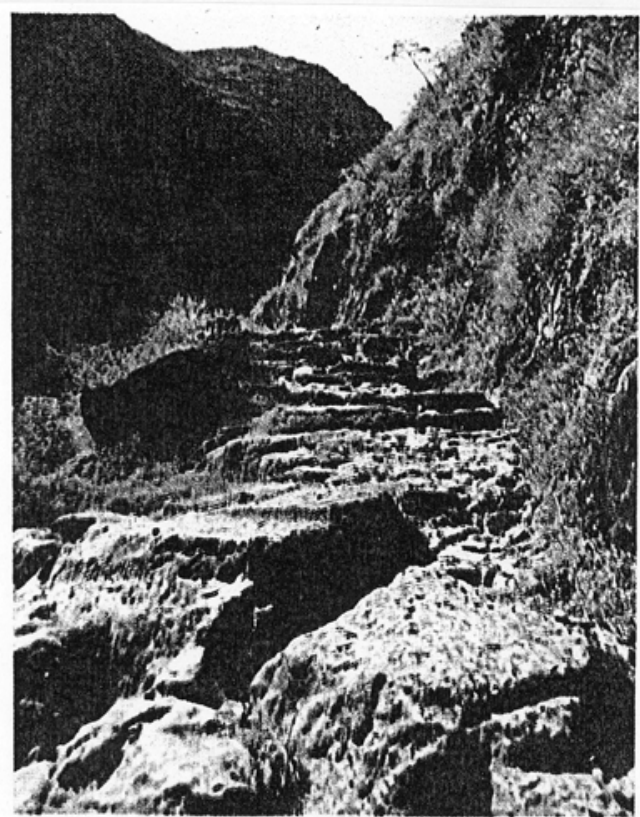

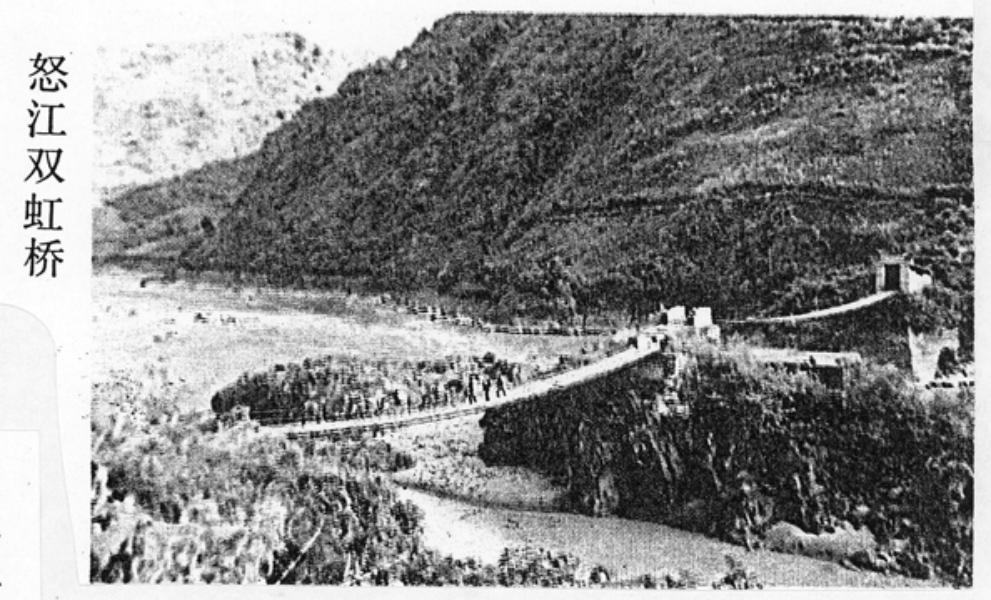

Oben: Die ,Brücke der zwei Regenbogen ' (Shuanghong qiao) über den Salween, Ende des 20. Jahrhunderts, aus: Liu/Ni, Nanfang silu

Links: Die Seidenstraße des Südens - alte Poststraße bei Yongchang, Ende des 20. Jahrhunderts, aus: Liu/Ni, Nanfang silu

Unten: Kettenbrücke über den Mekong zwischen Yongchang und Dali, Ende des 19. Jahrhunderts, aus: G. E. Mitton, Scott of the Shan Hills, ggü. Seite 280

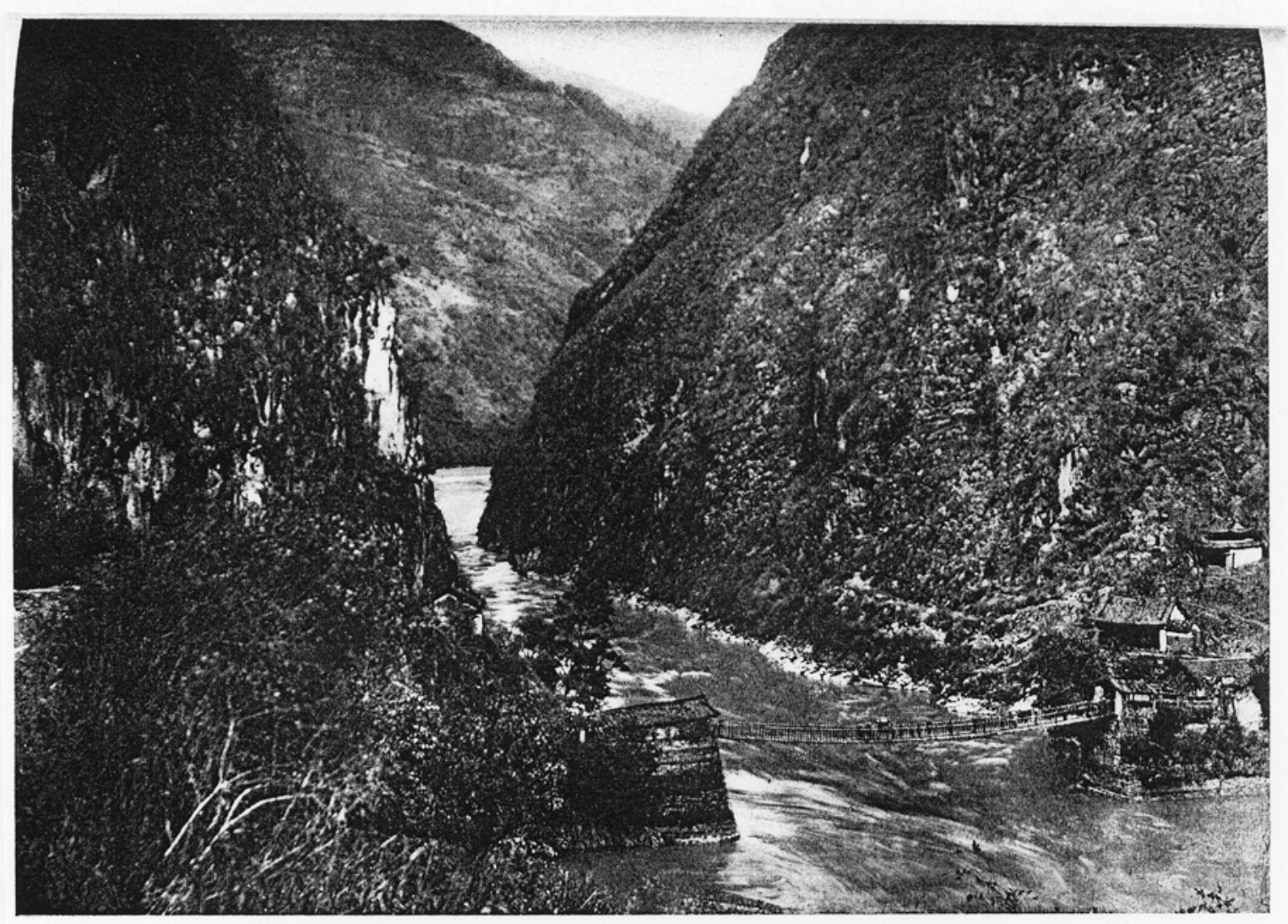

Chain Bridge over the Mekhong between Yung Chang and Tali

The bridge swavs with mule traffic so that the animals have to be taken over a few at a time. Elephants cannot cross. The caravan track makes a hairpin bend to avoid the precipitous descent 
Die Überquerung der schnell dahinfließenden Gebirgsströme war riskant und bei Hochwasser oft ganz unmöglich; sie war aber (in einer anderen Übersetzung des hier verwendeten Begriffes xian $d u$ ) gerade wegen der großen strategischen Bedeutung möglichst ganzjährig zu sichern. Denn erst die Brücken ermöglichten es der Zentralregierung, die Verkehrswege so zu nutzen, daß eine Kontrolle über die Ansiedlungen in der Region des Stromschluchtenfächers ausgeübt und deren Entwicklung dauerhaft bestimmt werden konnte. Seit dem 14. Jahrhundert sind zahlreiche neue Brücken errichtet worden, um bessere Verkehrsverbindungen zu den neu geschaffenen militärischen und zivilen Verwaltungseinheiten im Westen Yunnans herzustellen. Die Etablierung einer jeden neuen Herrscherdynastie Chinas in Yunnan war folglich immer mit dem Bau von Brücken verbunden: Allein während der Ära Hongwu (1368-1399) zu Beginn der Ming-Zeit sind fünf, während der Ära Kangxi (1662-1723) am Anfang der Qing-Dynastie sind vier neue Brücken in der Präfektur Yongchang gebaut worden.

Die große Bedeutung, die dem Bau und der Instandhaltung von Brücken zukam, spiegelt sich in den Lokalhandbüchern der Region wieder: Die Verfasser der fangzhi widmen den Brücken innerhalb ihres Verwaltungsgebietes jeweils ein Kapitel, in dem sie die Baugeschichte der Brücken im Gebiet der Präfektur Yongchang darstellen. ${ }^{896}$ Im YCFZ werden insgesamt siebenundneunzig Brücken in der Verwaltungsregion gezählt (siehe Tabelle 38). Im TYTZ werden allein vierundsechzig Brücken aufgeführt, die während der Qing-Zeit im Gebiet der Unterpräfektur Tengyue existierten, darunter neun Eisenkettenbrücken (tiesuo qiao), fünfundzwanzig aus Stein gebaute Brücken (shi qiao) sowie dreißig Brücken aus Holz (mu qiao).

\section{Tabelle 38: Anzahl der Brücken in den Verwaltungseinheiten der Präfektur} Yongchang am Ende des 19. Jahrhunderts nach Angaben des YCFZ (in Klammern die Anzahl der Brücken in Tengyue nach Angaben des TYTZ) ${ }^{897}$

$\begin{array}{ll}\text { Präfektur Yongchang, Kreis Baoshan } & 33 \\ \text { Unterpräfektur Tengyue } & 40 \\ \text { Unterpräfektur Longling } & 14 \\ \text { Kreis Yongping } & 10\end{array}$

Gesamt

\footnotetext{
${ }^{896}$ TYTZ, Kapitel 3 (S. 57-59); TYZZ, Kapitel 2 (S. 27-28); YCFZ, Kapitel 13 (S. 69-71).

${ }^{897}$ YCFZ, S. 69-71; TYTZ, S. 57-59. Bei drei der in der Präfektur Yongchang, Kreis Baoshan, genannten dreiunddreißig Brücken wird ausdrücklich darauf hingewiesen, daß sie zur Zeit der Herausgabe des Lokalhandbuches im Jahr 1885 nicht mehr existiert haben (YCFZ, S. 69).
} 
Außerdem wird im TYTZ auf drei Brücken aus Flechtrohr (teng qiao) hingewiesen, die während der Ming-Zeit den Longchuanjiang überspannt hatten, die jedoch unter der nachfolgenden Dynastie nicht mehr existierten. ${ }^{898}$

Flechtrohr (teng) ist sicherlich das älteste der Materialien, die in Yunnan zum Bau von Brücken benutzt wurden. Sein reiches Vorkommen und seine vielfältige Verwendung im Gebiet von Tengyue hatten der Verwaltungseinheit im 13. Jahrhundert auch für einige Jahre ihren Namen gegeben: Mit „[Seilen aus] Flechtrohr (teng) [konnte man die Flüsse] überqueren“ (уue) und über diese natürlichen Grenzen hinausgehen; dazu „bindet man [die Seile] aus Flechtrohr an jedem Ufer an einen Baum. Dann können die Leute sich daran festhalten und sich hinüberziehen““. ${ }^{899}$

Bei der reißenden Strömung in den engen, tief eingeschnittenen Flußtälern vieler Wasserläufe im westlichen Yunnan sind solche Seilbrücken mancherorts bis heute die einzige Möglichkeit zum anderen Ufer hinüber zu gelangen.

Der Neubau von Brücken durch die Chinesen erfolgte häufig im Rahmen von Feldzügen in den Westen Yunnans. So war bereits Anfang des 3. Jahrhunderts von den Truppen des Herzogs von Wu, Zhuge Liang (181-234), an der Orchideenfurt (lanjin) nördlich von Yongchang eine Brücke über den Lancangjiang (Mekong) gebaut worden:

\begin{abstract}
„Schon in alter Zeit haben Boote an dieser Stelle den Fluß überquert. Später verwendete man als Brücke Seile aus Bambusbast (mie sheng), an denen man sich hinüberziehen mußte. Während des Feldzuges des Herzogs von Wu wurde eine Holzbrücke errichtet, damit der Feldherr den Fluß überqueren konnte. ... Später wurde die neue Brücke entfernt und der Fluß wieder mit Booten überquert“. 900
\end{abstract}

\footnotetext{
${ }^{898}$ TYTZ, S. 57-59. Im TYZZ werden fünf Eisenkettenbrücken, einundzwanzig Brücken aus Stein und zehn Brücken aus Holz aufgezählt (TYZZ, S. 27-28). Im YCFZ wird auf zwei weitere Brücken aus Flechtrohr hingewiesen, die sich um 1885 in Wadian und in Qushi, im Gebiet der Unterpräfektur Tengyue befunden haben (YCFZ, S. 70).

${ }^{899}$ YCFZ, S. 70

900 YCFZ, S. 69. In der ,Geschichte der Han-Dynastie‘ (Hanshu) wird darauf hingewiesen, daß sich am Lancangjiang (Mekong) ,Bonan Lanjin“ („die Orchideenfurt von Bonan“) befand (YCFZ, S. 41). Bonan ist die Han-zeitliche Bezeichnung für das Gebiet von Yongping im Norden von Yongchang.

Eine Brücke über den Mekong im Norden von Yongchang erwähnt auch Fan Chuo im 9. Jahrhundert in seinem Werk Manshu, ebenfalls mit einem Hinweis auf den Feldzug Zhuge Liangs. Fan Chuo beschreibt die Brücke zu seiner Zeit als aus Seilen von Bambusbast gefertigt, die mit Matten und Holzbrettern belegt und mit einem Schutzdach aus Bambus bedeckt worden sind (siehe Luce, Manshu, S. 20).

Auch während der Ming-Zeit wurden Brücken im Verlauf von Feldzügen errichtet: Deng Zilong im Jahr 1583 als Regionalkommandant in die Präfektur Yongchang entsandt worden, um eine Invasion birmanischer Truppen zurückzuschlagen. Nach einer Schlacht in der Nähe seines Stützpunktes Yaoguan ließ er an der Stelle, an er den birmanischen Häuptling besiegt hatte, die ,Brücke des blutigen Kampfes‘ (Xuezhan qiao) bauen, um einen zügigen Vormarsch seiner Truppen weiter nach Westen zu ermöglichen (YCFZ, S. 70).
} 
Bereits kurze Zeit nach der Eroberung Yunnans durch die Truppen der Ming im Jahr 1382 sind in der Präfektur Yongchang mehrere Brücken errichtet worden, um zunächst die Verkehrswege auszubauen, die die Provinzhauptstadt Yunnan fu mit der Region des Stromschluchtenfächers verbanden, wo im selben Jahr die Präfektur Yongchang und die Garnison Jinchi gegründet worden sind. Der Bau von zunächst drei Brücken im Norden von Yongchang ist von dem Kommandanten (zhuihui) der örtlichen Garnison organisiert worden. $^{901}$

Im Jahr 1390 (Hongwu 23) ist die Präfektur Yongchang abgeschafft und das Gebiet in eine lokale Militärkommandantur (junmin zhihuishi si) umgewandelt worden. Zu Beginn der Ära Yongle (1403-1425) wurde die lokale Militärkommandantur dann durch die Gründung zweier unabhängiger Bataillone (shouyu qianhu suo) in Yongchang und Tengchong verstärkt und infolge dessen unter der Leitung des örtlichen Garnisonskommandanten (zhihui) eine weitere Brücke gebaut, um die Verbindung zwischen den beiden Stützpunkten zu verbessern. $^{902}$

Die Straßenverbindung von Yongchang nach Westen ist ebenfalls mit der Errichtung einer Brücke weiter ausgebaut worden: Die ,Brücke des Friedens aller [Menschen] ' Zhongan qiao)

„überspannt den Unterlauf des Shaheshui 7 li [etwa 3,5 km] südlich der Stadt, an der Hauptstraße, die Yongchang und Tengyue miteinander verbindet. Sie wurde während der Ära Hongwu (1368-1399) der Ming-Dynastie von dem Garnisonskommandanten Hu erbaut. Während der Ära Zhengde (1506-1522) ließen der Regionalkommandant Mu Song und während der Ära Jiajing (152267) der Vize-Minister Guo nacheinander Renovierungsarbeiten durchführen. Die Brücke war aus Stein gemauert und 1 zhang 2 chi [ca. $4 \mathrm{~m}]$ breit, über 5 zhang [ca. 17m] hoch und 6 zhang [ca. 20m] lang; das war außergewöhnlich (you qi)“.903

Während der Ära Hongwu ist auch an der Orchideenfurt (lanjin), an der Hauptverkehrsroute von der Provinzhauptstadt in den Westen, erneut mit dem Bau einer Brücke über den

\footnotetext{
${ }^{901}$ Die Ji'an-, Dongjin- und Beijin-Brücke wurden unter der Leitung von Kommandant Li Guan errichtet (YCFZ, S. 69).

${ }^{902}$ YCFZ, S. 70, Shenji qiao

${ }^{903}$ YCFZ, S. 69. Auch während der Qing-Dynastie wurde die Brücke renoviert: Unter Leitung von Regionalkommandeur Bian wurden die Arbeiten im Jahr Kangxi 29 (1690) durchgeführt (ebd.).
} 
Lancangjiang (Mekong) begonnen worden. ${ }^{904}$ Die ,Brücke des Regenbogens am aufklarenden Himmel` (Jihong qiao) überspannte den Fluß etwa vierzig Kilometer nördlich der Präfekturstadt Yongchang.

„Im 28. Jahr der Ära Hongwu (1395) ließ Hua Yue, Militärrichter der Garnison (zhenfu), zwei Pfosten aus Eisen gießen, die auf die Felsen gestellt wurden; auch der Bootsverkehr wurde weiter aufrechterhalten. Später wurde eine Holzbrücke gebaut, die jedoch wieder abgebrannt ist.

Während der Ära Chenghua (1465-88) sammelte der Mönch Liaoran [Geld] für den Bau einer sehr hohen Brücke mit Pfeilern aus Holz; daran wurden Eisenketten waagerecht von einem Ufer zum anderen gespannt. Darunter gab es nichts, was sie abstützte, darüber nichts woran sie angelehnt war, sie war eine in der Luft schwebende Brücke. ... An beiden Ufern sind Gebäude errichtet worden. Vize-Minister Wu ließ [die folgende Inschrift] in den Felsen eingravieren: ,Die erste Brücke des Südwestens‘ (xi ‘nan di yi qiao). Am Nordufer ist ein Verwaltungsgebäude gebaut und dreißig Soldaten sind dort stationiert worden .... .

[Verschiedentlich wurden Reparaturarbeiten an der Brücke durchgeführt, meist unter der Leitung von Militärbeamten, u.a.von Regionalkommandant Mu Song. Am Ende der Ming-Zeit ist die Brücke abgebrannt. Zu Beginn der Qing-Zeit erfolgte ein Neubau aus Spendengeldern.] ....

Später ist die Brücke wieder abgebrannt. Im Jahr Kangxi 12 (1673) wurde sie von Regionalkommandeur Zhang wieder aufgebaut. Dann ist sie niedergebrannt und im Jahr Kangxi 20 (1681) vom Kreismagistraten Jiang erneut aufgebaut worden. Im Jahr Kangxi 27 (1688) wurde die Brücke von Regionalkommandeur Lun und erneut im Jahr Kangxi 38 (1699) von den örtlichen Militär- und Zivilbeamten (zongbing, zhifu, zhixian) repariert. Im 7. Monat des Jahres Qianlong 15 (1750) riß das Wasser die Brücke weg; Präfekt und Kreismagistrat ließen sie wieder errichten. Im Jahr Daoguang 26 (1846) wurde sie von Moslem-Rebellen niedergebrannt, [die am Ufer stationierten Soldaten wurden bei dem Kampf um die Brücke getötet]; die Eisenketten versanken im Fluß. Präfekt Li Hengqian ließ die Brücke anschließend wieder aufbauen.“ 905

\footnotetext{
${ }^{904}$ Während der Yuan-Dynastie war im Rahmen des Feldzuges von Yexianbuhua nach Westen (um 1295) an dieser strategischen Furt ein hölzerne Brücke errichtet und Jihong qiao genannt worden (Guo Xinquan, S. 296; ZGRMDCD, S. 12). ${ }^{905}$ YCFZ, S. 69. Vor seiner Ernennung zum Präfekten von Yongchang war Li Hengqian in den Jahren Daoguang 24 bis 26 (1844-46) als Unterpräfekt in Tengyue tätig gewesen (TYTZ, S. 110; s. a. YCFZ, S. 172). Für eine Beschreibung des Kampfes um die Brücke im Jahr 1846 siehe auch Kapitel IV B. 1. 2. 2., S. 328, Fußnote 969.

Die Jihong-Brücke war die größte Eisenkettenbrücke im Südwesten Chinas, die seit 1983 zu den besonders schützenswerten Kulturdenkmälern der Provinz zählte. Im Oktober 1986 wurde die Brücke nach starken Regenfällen vom Hochwasser wegspült. Lediglich die Brückenpfeiler, Gebäudeteile und die Inschriften in den Felsen sind heute noch erhalten (Liu Bingchao/ Ni Kaisheng, S. 38-39; Guo Xinquan, S. 296-297).
} 
Nachdem mit der Fertigstellung der Eisenkettenbrücke über den Lancangjiang während der Ära Chenghua (1465-1488) eine bessere Verbindung von Zentral-Yunnan nach Yongchang geschaffen worden war, galt es, die Verkehrsroute nach Westen weiter auszubauen. Zu diesem Zweck wurde wenige Jahre später eine stabilere Brücke über den Fluß Longchuan (Longchuanjiang qiao) errichtet:

„Früher hatte man [dort] Flechtrohr (teng) zu einer Brücke geflochten, die dann mit kleinen Brettern ausgelegt worden war. Während der Ära Hongzhi (14881506) ließ der Vize-Kommandeur des Militärbezirks (bingbei fushi) Zhao Jiongjian eine Brücke am Oberlauf des Flusses bauen. Diese existiert jedoch nicht mehr“.906

Als im Jahr 1522 (Jiajing 1) die beiden Militärkommandanturen in die Präfektur Yongchang und die Unterpräfektur Tengchong umgewandelt wurden, wurde erneut mit dem Bau einer festen Brücke über den Longchuanjiang begonnen und nach dem Vorbild der JihongBrücke eine Eisenkettenbrücke errichtet, die den Fluß etwa fünfunddreißig Kilometer östlich von Tengyue bei der Poststation Longchuan überspannte:

„Während der Ära Jiajing (1522-67) ließ Pan Run, der Vize-Kommandeur des Militärbezirks, sie dann in Nachahmung der Jihong-Brücke wieder aufbauen und an beiden Flußufern Amtsgebäude errichten.

Im Jahr Kangxi 37 (1698) wurde die Brücke zerstört. Im Jahr 38 (1699) ließ der Unterpräfekt Tang Hanbi sie in Hupingkou wieder aufbauen. Der VizeRegionalkommandeur Zhang Youfeng spendete sein Beamtengehalt zur Unterstützung der Bauarbeiten. Im ersten Jahr der Ära Yongzheng (1723) ließen Präfekt Lin, Vize-Kommandeur Sun und Unterpräfekt Yang sie reparieren“. ${ }^{907}$

Später wurde die Instandhaltung der Brücke vernachlässigt, was während des chinesischbirmanischen Krieges in den Jahren 1766 bis 1769 den Vormarsch der Truppen nach Südwesten erheblich erschwerte: Da die Brücke über den Longchuanjiang damals nicht mehr benutzbar war, mußten die Soldaten den Fluß in Einbäumen ( $d u$ mu chuan) überqueren. Eine Petition wurde eingereicht, um diesen Mißstand zu beheben, woraufhin die Zentralregierung im Jahr 1768 Finanzmittel aus dem Staatsschatz für eine Reparatur der Brücke

\footnotetext{
${ }^{906}$ YCFZ, S. 70.

${ }^{907}$ YCFZ, S. 70
} 
zur Verfügung stellte. Die Arbeiten wurden von Angehörigen der örtlichen Gentry überwacht. $^{908}$

Die Baugeschichten der Jihong- und der Longchuanjiang-Brücke sind exemplarisch für die der meisten Brücken in der Präfektur Yongchang. Sie machen die Schwierigkeiten, mit denen der Ausbau der Verkehrswege in der Region verbunden war, ebenso deutlich, wie das Geschick der Baumeister bei der Überwindung dieser Hindernisse und zeigen die kontinuierlichen Bemühungen der lokalen Beamten, die Brücken instand zu halten. In der Ming-Zeit waren es die Militärbeamten, die mit Bau und Reparatur von Brücken befaßt waren. Während der Qing-Zeit gehörte die Durchführung dieser Arbeiten zum Aufgabenbereich der örtlichen zivilen Verwaltungsbeamten. Gelder für die Bauarbeiten stammten aus der Staatskasse oder aus Spendensammlungen. ${ }^{909}$ An Bau, Instandhaltung und Reparatur von Brücken waren auch die Angehörigen der örtlichen Gentry beteiligt. ${ }^{910}$ So wurde zum Beispiel die Eisenketten-Brücke Xiangyang im Norden Tengyues im Jahr 1770 mit Pachteinnahmen, die die Bürger gespendet hatten, wieder aufgebaut. ${ }^{911}$ Diese Bauprojekte standen in der Regel unter der Leitung des Präfekten bzw. Unterpräfekten; so initiierte der Präfekt von Yongchang im Jahr 1882 die Renovierung der Shuida-Brücke südlich von Tengyue an der Hauptverkehrsstraße nach Longling, die von Kaufleuten (shangmin) finanziert und ausgeführt wurde. ${ }^{912}$ Für die Instandhaltung von Brücken wurden dann die Bewohner der nahegelegenen Ortschaften herangezogen: Die Jieming-Brücke an der Grenze in Mingguang wurde von den Leuten aus Jiaojie, die Chengde-Brücke in Qushi wurde von den Bewohnern Yezhuqings instand gehalten. ${ }^{913}$

Aus den tusi-Gebieten der Unterpräfektur Tengyue wird lediglich eine Brücke im TYTZ erwähnt: Südwestlich von Nandian verläuft die Straße nach Ganya über die NangzhuanBrücke, eine Eisenketten-Brücke, deren Bau der tusi von Ganya veranlaßt hatte. ${ }^{914}$

Von Tengyue aus folgen die Hauptverkehrswege nach Birma den von Norden nach Südwesten verlaufenden Flußtälern, so daß dort Brücken weniger wichtig für die Aufrechterhaltung der Verkehrsverbindungen waren, als auf der Strecke nach Zentral-Yunnan, die die Flüsse und Gebirgszüge des Stromschluchtenfächers in Ost-West Richtung kreuzt.

\footnotetext{
908 TYZZ, S. 27-28. Wu Kai, der nach dem Krieg als Unterpräfekt in Tengyue tätig war, veranlaßte während seiner Amtszeit (1770-1779) Renovierungsarbeiten an der Brücke (TYTZ, S. 57).

909 Auch die Beamten spendeten für die Brückenbauarbeiten. So stellte z.B. Unterpräfekt Tang Hanbi im Jahr 1700 sein Gehalt für Arbeiten an der Jiewei-Brücke im Norden Tengyues zur Verfügung und im darauffolgenden Jahr spendete Präfekt Luo Lun sein Gehalt für den Bau der Yongji-Brücke nördlich von Yongchang (YCFZ, S. 70).

${ }_{910}$ Die örtlichen Akademiker engagierten sich ebenfalls beim Brückenbau. Im Jahr 1765 initiierte der Student (shengyuan) Dong Yu den Bau der Eisenketten-Brücke Tianji über den Fluß Lujiang. Ende des 19. Jahrhunderts beauftragte Unterpräfekt Chen Zonghai den Studenten der staatlichen Hochschule (jiansheng), Yin Qimao, die Reparaturarbeiten an der Lujiang-Brücke zu beaufsichtigen (TYTZ, S. 57, siehe Tianji qiao bzw. Lujiang qiao).

${ }^{911}$ TYTZ, S. 57; YCFZ, S. 70

912 YCFZ, S. 70

913 TYTZ, S. 57

${ }^{914}$ Die tusi von Ganya sollen insgesamt sechs Brücken in ihrem Herrschaftsgebiet gebaut haben (TYZZ, S. 27).
} 
Grund für die häufigen Reparaturarbeiten an den Brücken war vor allem das jahreszeitlich bedingte Hochwasser der Flüsse. Vielerorts sah es so aus, wie am Oberlauf des Nangsonghe, wo „man das Wasser im Frühling und Winter durchwaten konnte; im Sommer und im Herbst hingegen war die Strömung so heftig, daß sie sogar Steine zerschlug“.915

Ein weiterer Grund lag in der strategischen Bedeutung der Flußübergänge. Im Laufe von militärischen Auseinandersetzungen wurden immer wieder Brücken zerstört. Die Angaben in den fangzhi beschränken sich dabei auf die Erwähnung, daß Brücken von Banditen (zei) oder von Soldaten (bing) zerstört worden sind. ${ }^{916}$

Die Tianji-Brücke, die den Salween am Mamian-Paß im Nordwesten der Stadt Tengyue überspannte, wurde hingegen auf ausdrückliche Anweisung von Regierungsbeamten zerstört: Da birmanische Truppen Mitte des 18. Jahrhunderts immer weiter nach Norden vordrangen, um die Shan-Staaten unter ihre Kontrolle zu bringen, zeigten sich einige der Beamten in der Region Yongchang zunehmend besorgt. Als dann zu Beginn des chinesischbirmanischen Krieges eine chinesische Armee von den Truppen aus Birma bis in das Gebiet der tusi von Ganya und Zhanda zurückgedrängt wurde, beschlossen

„Wuerdeng'e von der Garnison Yong-Shun und Chen Dalü, der Präfekt von Yongchang, aufgrund der zunehmenden Zwischenfälle im Grenzgebiet im Jahr Qianlong 31 (1766), den Fluß [Lujiang] als Grenzlinie zu nehmen (hua jiang) und sich selbst [am östlichen Ufer] zu verteidigen. Deshalb ließen sie [die Tianji-Brücke] zerstören“. ${ }^{917}$

Die Unterbrechung dieser Verkehrsverbindung nach Westen macht deutlich, wie bedrohlich der Vormarsch der Truppen aus Birma den lokalen Beamten in Yongchang erschienen sein muß, die anscheinend wenig Vertrauen in die eigenen weiter im Westen agierenden Truppen hatten. Letztlich war der Abriß der Tianji-Brücke sicher eine zu voreilige Maßnahme.Die Verfasser des TYTZ stellen denn auch fest, daß „die Menschen [die Zerstörung der Brücke] noch heute bedauern“. ${ }^{918}$

Ende des 18. Jahrhunderts konnten die Fährboote das steigende Verkehrsaufkommen zwischen Yongchang und Tengyue nicht mehr bewältigten und so wurde eine neue Eisenkettenbrücke, die ,Brücke der zwei Regenbogen‘(Shuanghong qiao) über den Salween gebaut (siehe oben Abb.1, S. 303).

\footnotetext{
915 TYTZ, S. 58 (siehe Ji’nan qiao). Siehe auch Shuida qiao (YCFZ, S. 70), Xinjie qiao oder Feifeng qiao (TYTZ, S. 58). Der Nangsonghe entspringt im Südwesten von Tengyue, zwischen dem Wanren- und dem Jushi-Paß und mündet in den Dayingjiang (TYTZ, S. 46).

${ }^{916}$ Von Banditen (zei) sind z.B. die Lujiang qiao und die Jieming qiao, von Soldaten (bing) die Xiangyang qiao, die Longdong qiao und die Jiaxiangshi qiao zerstört worden (TYTZ, S. 57-58).

${ }^{917}$ Die Eisenketten-Brücke war erst im Jahr 1765 errichtet worden (TYTZ, S. 57, Tianji qiao). Im Jahr 1789 wurde dann die Shuanghong-Brücke über den Lujiang gebaut.

918 TYTZ, S. 57
} 
Sie überquerte den Fluß an der Lujiang-Furt und hatte eine Länge von über einhundertundsechzig Meter; die beiden Teilstücke der Brücke überspannten den Fluß in einer Höhe von zwölf und vierzehn Meter. ${ }^{919}$ Die ,Brücke der zwei Regenbogen` befand sich

„140 li [ca.70 km] westlich der Stadt [Yongchang]. Das ist die Verkehrsverbindung nach Tengyue am Oberlauf des Lujiang. In der Mitte des Flusses stehen Felsen. Nachdem dort Steine gesetzt worden waren, konnten von beiden Ufern aus Eisenketten an ihnen befestigt werden, die waagerecht über dem Fluß schwebten. Von weitem sahen sie aus wie zwei Regenbogen, daher der Name der Brücke.

Der Bau der Brücke war im Jahr Qianlong 54 (1789) von Präfekt (zhifu) Chen Xiaosheng organisiert worden. Im Jahr Xianfeng 9 (1859) wurde sie von den Moslem-Rebellen zerstört. Gegenwärtig [d.h. im Jahr 1885] ist sie noch nicht wieder repariert worden“. ${ }^{920}$

Seit der Gründung der Unterpräfektur Longling im Jahr 1770 wurden zudem bessere Verkehrsverbindungen benötigt, die von Yongchang aus weiter südlich nach Westen führten, um eine kürzere Verbindung zwischen der neuen Verwaltungseinheit und der Präfekturstadt zu schaffen. Zunächst überquerten südlich der ,Brücke der zwei Regenbogen` lediglich Boote den Salween. Der Bau einer weiteren Brücke über diesen Fluß erfolgte erst Anfang des 19. Jahrhunderts. Mit zunehmendem Verkehrsaufkommen reichte der Fährdienst dort nicht mehr aus, so daß im Jahr 1839 die ,Brücke zum Nutzen der Menschen` (Huiren qiao) gebaut wurde. ${ }^{921}$

Der Neubau und die kontinuierliche Instandhaltung der Brücken in der Region des Stromschluchtenfächers durch die Beamten der Militär- und der Zivilverwaltung der Präfektur Yongchang waren sowohl Voraussetzung als auch Folge der erfolgreichen Anbindung der Region an die Gebiete Zentral-Yunnans. Die strategische Bedeutung der Brücken kam

\footnotetext{
$\overline{{ }^{919} \text { Liu Bingchao/ Ni Kaisheng, S. 46-47 }}$

${ }^{920}$ YCFZ, S. 69. Die ,Brücke der zwei Regenbogen` ist später wieder aufgebaut worden, sie ist die einzige Eisenkettenbrücke in der Region, die heute noch vollständig erhalten ist. Im Jahr 1988 wurde sie von der Provinzregierung zu einem besonders schützenswerten Kulturdenkmal der Stadt Baoshan erklärt (Liu Bingchao/ Ni Kaisheng, S. 46-47).

${ }^{921}$ Siehe YCFZ, S. 69-70. Anderen Quellen zufolge wurde mit dem Bau der Brücke bereits im Jahr 1830 begonnen und die Arbeiten im Jahr 1839 beendet (Liu Bingchao/ Ni Kaisheng, S. 47-48).

Auch die Huiren Brücke wurde, im Jahr 1984, zu einem besonders schützenswerten Kulturdenkmal der Stadt Baoshan erklärt (Liu Bingchao/ Ni Kaisheng, S. 47-48). Etwa zwei Kilometer südlich der Huiren-Brücke wurde im Jahr 1952 eine neue Verkehrsverbindung, die Dongfeng-Brücke [,Ostwind-Brücke'], über den Nujiang gebaut, die nunmehr die HuirenBrücke ersetzt (ebd.).
} 
Ende des 19. Jahrhunderts erneut zum Ausdruck, als während der Moslem-Rebellion die meisten Brücken in der Präfektur zerstört und nach der Niederschlagung der Rebellion umgehend wieder instand gesetzt wurden.

Erst die verbesserten Brückenverbindungen an den Hauptverkehrsrouten ermöglichten der Zentralregierung die dauerhafte politische und militärische Kontrolle über den fernen Westen der Provinz. Sie erleichterten zudem den Transport nicht nur der in den Bergbaubetrieben gewonnenen Metalle, sondern vor allem den der Waren des Fernhandels mit Birma, der die wirtschaftliche Grundlage für die Entwicklung Tengyues zu einem Handelsund Verwaltungszentrum in der Region des Stromschluchtenfächers bildete. 


\section{B. Rebellion und Restauration: Die Verwaltungseinheit Tengyue im 19. Jahrhundert}

\section{Die Moslem-Rebellion in Yunnan}

\section{1. Überblick über die historische Entwicklung der moslemischen Bevölkerungs- gruppe in Yunnan}

Bereits in der Tang- (618-907) und der Song-Zeit (960-1279) waren Moslime aus dem arabisch-persischen Raum nach China gekommen. Dies waren hauptsächlich Kaufleute, die entlang der Seidenstraße und über den Seeweg nach China gelangt waren und die sich im Nordwesten Chinas sowie in Handelszentren im Süden und Osten, wie Guangzhou oder Quanzhou, niedergelassen hatten. ${ }^{922}$ Nach Yunnan kamen größere Gruppen moslemischer Zuwanderer aus Zentral-Asien erst während der Yuan-Zeit (1271-1368), wo sie sich vor allem in der Region Dali ansiedelten. Im chinesischen Reich der Mongolen genossen die Moslime als Gruppe insgesamt eine höhere Stellung als die Han-Chinesen und bekleideten verhältnismäßig viele hohe Staatsämter.

Mit den mongolischen Truppen war im 13. Jahrhundert eine große Anzahl moslemischer Soldaten nach Yunnan gekommen. Ihr prominentester Vertreter war Gouverneur Sayyid Ajall (chin. Saidianchi Shansiding), der Yunnan von 1274 bis 1279 verwaltet und mit seiner ,konfuzianisch` geprägten Politik einen entscheidenden Beitrag zur Integration des Südwestens in das chinesische Reich geleistet hat. Um die Herrschaft über die neu eroberten Gebiete zu sichern, ließ er Soldaten in Garnisonen an strategisch wichtigen Punkten überall in der Provinz stationieren, wo sie Land zugeteilt bekamen, das sie urbar machten und bewirtschafteten.

Nach den Feldzügen gegen Birma sind auch in der Region des Stromschluchtenfächers moslemische Soldaten im Gebiet von Jinchi (in Shidian und Baoshan) stationiert worden. Während der Regierungszeit von Khan Timur (1295-1308) wurden weitere moslemische Soldaten in Jinchi angesiedelt und im Jahr 1310 wurde in Yongping, im Norden der Präfektur Yongchang, eine Garnison mit fünfhundert moslemischen Soldaten gegründet. ${ }^{923}$

In ihrer Position als Eroberer und Angehörige einer zentralen Militär- und Verwaltungshierarchie sowie als Anhänger einer monotheistischen Religion unterschieden sich die

\footnotetext{
${ }^{922}$ Mees, S. 17-19

${ }^{923}$ Wang Jianping, S. 48, 51, 74
} 
Neuankömmlinge erheblich von der einheimischen Bevölkerung der Region des Stromschluchtenfächers. Es kam daher zu keiner Assimilierung an diese Bevölkerungsgruppen, sondern es entstanden Moslem-Enklaven, die sich unter der nachfolgenden Ming-Dynastie zu größeren moslemischen Siedlungen entwickeln sollten. ${ }^{924}$

Die Verfasser des Baoshan xian zhi weisen in diesem Zusammenhang auf die friedliche Koexistenz von Han und Moslimen hin und fassen zusammen:

„In der Yuan-Zeit wurde in Yongchang ein Bataillon (qianhusuo) von moslemischen Soldaten stationiert ..., seitdem existiert der Islam (Hui jiao) in Yongchang. Nach dem Ende der Yuan wurden diese Soldaten als Zivilhaushalte registriert; es gab keine Unterschiede zu den Han, nur daß jene ihre Religion ausübten. $^{925}$

Unter der Ming-Dynastie (1368-1644) verloren die Moslime in China ihre Privilegien und waren einem starken Druck von Seiten der Zentralregierung ausgesetzt, sich der Hanchinesischen Bevölkerung anzupassen. Das Verbot, ausländische Kleidung zu tragen, und die Vorschrift chinesische Familiennamen anzunehmen, förderten den Prozeß der Sinisierung, in dessen Verlauf die Moslime viel von der materiellen chinesischen Kultur (auch die chinesische Sprache) übernahmen und sich zu einer chinesischen Bevölkerungsgruppe moslemischen Glaubens entwickelten, die in China als Huihui oder Hui bezeichnet wurde. ${ }^{926}$ Aufgrund dieser Bereitschaft, sich anzupassen, zeigte sich der Ming-Staat tolerant gegenüber den Moslimen, was sich zum Beispiel in der Erlaubnis zum Bau von Moscheen äußerte. ${ }^{927}$

Moslemische Soldaten und Generäle kämpften in den Armeen der Ming, die unter dem Oberbefehlshaber Mu Ying Yunnan eroberten und bis in die Region des Stromschluchtenfächers vordrangen. Um ihre Herrschaft über Yunnan zu festigen, stützten sich die Ming auch auf die Moslime, die bereits in der Provinz ansässig waren und nutzten deren Kontakte zur und Kenntnisse über die einheimische Bevölkerung. So behielten viele Hui die Positionen, die sie unter der Yuan-Dynastie innegehabt hatten; die Moslem-Enklaven

\footnotetext{
${ }^{924}$ Wang Jianping, S. 65, 69

${ }^{925}$ Baoshan xian zhi, Kapitel 14 (Religionen), S. 70

${ }^{926}$ Seit Mitte der Ming-Zeit war ,Huihui` als Bezeichnung für alle Moslime in China gebräuchlich, die während der Qing-Zeit allgemein zu ,Hui` abgekürzt wurde (zum Begriff ,Huihui` bzw. ,Hui` siehe Wang Jianping, S. 18-20; Mees, S. 32, 29, 4). Die Hui, die zur Zeit der Moslem-Rebellion im 19. Jahrhundert nach Birma gingen, wurden dort auch als ,Panthay' bezeichnet; daher findet sich in der zeitgenössischen englischsprachigen Literatur auch die Bezeichnung ,Panthay-Rebellion` (siehe auch Anderson, S, 224-225).

${ }^{927}$ Mees, S. 32
} 
wurden zudem in das weisuo-System der Militärverwaltung der Ming eingegliedert. ${ }^{928}$ Als im Verlauf der Ming-Zeit immer mehr Zuwanderer aus dem chinesischen Kernland in den Südwesten kamen, wuchs auch die moslemische Bevölkerung und entlang der Hauptverkehsrouten, im Grenzgebiet sowie an Post- und Zollstationen entwickelten sich aus Militärstützpunkten Hui-Siedlungen. ${ }^{929}$

In Yongchang war Ende des 14. Jahrhundert eine Armee stationiert worden, der eintausend moslemische Soldatenhaushalte angehörten; in Tengchong ließen sich zu dieser Zeit ebenfalls Moslime nieder. ${ }^{930}$ Auch Moscheen wurden gebaut:

„Seit der Ming-Zeit gab es Moscheen (qingzhen si) in Yongchang. Im Provinzhandbuch Yunnan zhi aus der Zeit der Ära Zhengde (1506-1521) heißt es: Die Moschee [von Yongchang] befindet sich südlich der Präfekturverwaltung, dort gibt es ein mehrstöckiges Gebäude, in dem Gott angerufen wird (yu tian lou), das ist der Ort, an dem die Huihui ihren Gottesdienst abhalten. Auch Quellen aus der Zeit der Ära Wanli (1573-1620) ... [bestätigen die Existenz dieser Moschee]. Sie war die älteste Moschee in Baoshan“. ${ }^{931}$

Die Moslime, die sich in der Ming-Zeit neu in Yunnan ansiedelten, hatten seit Generationen in China gelebt, waren stärker an die Han-chinesische Kultur angepaßt und hatten eine eigene Identität als chinesische Moslime, als Huihui, entwickelt. In Yunnan setzte sich der Trend zur Akkulturation an das soziale Milieu der Han-chinesischen Bevölkerungsmehrheit auch unter der Qing-Dynastie fort und führte zur Entstehung einer wegen des unterschiedlichen ethnischen und kulturellen Hintergrundes der Moslime in Yunnan zwar fragmentierten, aber dennoch „lose miteinander verbundenen Hui-Gemeinschaft mit gemeinsamer ethnoreligiöser Identität“, die zudem durch gemeinsame wirtschaftliche Interessen gestärkt wurde. ${ }^{932}$

\footnotetext{
${ }^{928}$ Wang Jianping, S. 79-81

${ }^{929}$ Wang Jianping, S. 52, 58

${ }^{930}$ Wang Jianping, S. 81. So sind z. B. die Ahnherren dreier moslemischer Familien, der Ma, Ming und Zhu, während der Ära Hongwu (1368-1399) nach Tengchong gekommen. Die Familie Ming hatte sowohl Hui, als auch Han-chinesische Mitglieder und ist damit auch ein Beispiel für die friedliche Koexistenz beider Bevölkerungsgruppen in Tengchong (ebd. S. 54 und 92).

${ }^{931}$ Baoshan xian zhi, Kapitel 14 (Religionen), S. 72-73

${ }^{932}$ Wang Jianping, S. 59, 87-88. Wie die Han organisierten sich die Hui auch in Familien-Clans. Der früheste Bericht über eine solche Clan-Organisation in Yunnan stammt aus Yongchang, wo die Familie Ma, in Yongchang absässige Nachfahren des Gouverneurs Sayyid Ajall, im Jahr 1678 zu einem Treffen zusammenkam (ebd., S. 114, 140).
} 
Unter der Herrschaft der Qing-Dynastie (1644-1911) verschlechterte sich die Situation der Moslime in China generell. Die enge Verknüpfung von Staat und Konfuzianismus grenzte die Moslime aus, nur noch wenigen gelang der Aufstieg in Staatsämter, vornehmlich in solche der Militärhierarchie. ${ }^{933}$ Die repressive Politik der Zentralregierung zeigte sich unter anderem im Verbot von Mischehen oder in der Beschränkung der Bewegungsfreiheit der Moslime innerhalb des Reiches; während der Ära Qianlong (1736-1796) war es ihnen zudem zeitweise verboten, Moscheen zu errichten oder nach Mekka zu pilgern. ${ }^{934}$

Anders die Situation in Yunnan: Hinweise darauf, daß sich die Lage der Hui dort mit Beginn der Qing-Zeit generell verschlechtert hätte, gibt es in den historischen Quellen nicht. Als das Qing-Reich im 18. Jahrhundert einen Höhepunkt seiner Macht erreichte, prosperierten auch die Hui-Gemeinden im fernen Südwesten des Reiches. ${ }^{935}$

Seit der Yuan-Zeit waren die Moslime in Yunnan nicht nur als Soldaten und Bauern, sondern auch als Schmiede oder Gerber, in der Jade-Bearbeitung und im Bergbau tätig. Während der Qing-Zeit wurden Viehzucht und Lederverarbeitung in der Provinz fast ausschließlich von den Hui und ihren Gilden kontrolliert. Zu Wohlstand gelangten die Hui aber vor allem als Kaufleute durch den Karawanenhandel mit Birma. Um 1800 war das reichste Viertel in Yongchang das der Hui; in Tengyue waren zu dieser Zeit etwa siebzig Prozent der Geschäfte im Besitz von Hui. ${ }^{936}$

Die Hui in Yunnan waren insgesamt gesehen eine Gruppe mit einem hohen wirtschaftlichen und sozialen Status. So war z. B. der Anteil der Gentry-Bevölkerung in den HuiGemeinden allgemein höher als bei den Han. Einige Hui nahmen an den staatlichen Beamtenprüfungen teil, deren Voraussetzung die Kenntnis der konfuzianischen Klassiker war. Erst als die Konflikte zwischen Han und Hui im 19. Jahrhundert zunahmen, ging die Zahl der Hui-Studenten, die an dieser klassischen Han-chinesischen Bildung interessiert waren, zurück. Außerdem war ein Großteil der Hui im Handel tätig, so erschien ihnen die langjährige Ausbildung für den Staatsdienst, die vergleichsweise geringe materielle Einkünfte versprach, wohl auch wenig erstrebenswert. ${ }^{937}$ Eine größere Anzahl der Hui absolvierte die militärischen Prüfungen, was neben besseren Aufstiegsmöglichkeiten sicherlich auch durch den familiären Hintergrund der Kandidaten bestimmt war, deren Vorfahren als

\footnotetext{
${ }^{933}$ Mees, S. 38, 41

${ }^{934}$ Mees, S. 33-34

${ }^{935}$ Wang Jianping, S. 226-227, 244

${ }^{936}$ Ebd., S. 76, 117, 249

${ }^{937}$ Ebd., S. 239-241
} 
Soldaten in den Südwesten gekommen waren. Vor 1850 waren entsprechend etwa zwei Drittel der Offiziere und Soldaten in der Provinz Yunnan Hui. ${ }^{938}$

Seit der Wende zum 19. Jahrhundert wurden in den prosperierenden Hui-Gemeinden in Yunnan zahlreiche neue Moscheen gebaut und viele Hui haben die Pilgerreise nach Mekka unternommen. Diese Kontakte mit der islamischen Welt stärkten das religiöse Leben in den Gemeinden, förderten ein islamisches Bewußtsein der Hui und führten zur Intensivierung der islamischen Erziehung, die sich in den verschiedenen Hui-Gemeinden unterschiedlich entwickelte, jedoch auch ein Potential für Konflikte mit der Han-Bevölkerung entstehen ließ. ${ }^{939}$

Im Allgemeinen war das Zusammenleben von Han und Hui von vielfältigen sozialen und ökonomischen Kontakten geprägt. Ernste Konflikte zwischen den beiden Bevölkerungsgruppen im Westen Yunnans sind aus der Zeit vor 1800 nicht bekannt. ${ }^{940}$ Als das chinesische Reich im 19. Jahrhundert eine Zeit des Niedergangs erlebte, traten die Spannungen zwischen den verschiedenen Bevölkerungsgruppen jedoch deutlicher hervor. In der Krisensituation, die aufgrund des hohen Bevölkerungswachstums, der Verknappung der wirtschaftlichen Ressourcen, der allgemeinen Rezession sowie dem Vordringen der westlichen Kolonialmächte nach China entstanden war, erwies sich die Zentralregierung als unfähig, diese Probleme in den Griff zu bekommen. Der Zerfall des politischen Systems und die allgemeine Verschlechterung der Lebensbedingungen der Bevölkerung führten schließlich in der zweiten Hälfte des 19. Jahrhunderts zum Ausbruch mehrerer großer Rebellionen (Tab.39), die das ganze chinesische Reich erschütterten und auch die südwestliche Provinz Yunnan erfaßten, wo sich die Spannungen im Rahmen von Konflikten zwischen Han-Chinesen und Hui entluden.

\section{Tabelle 39: Die fünf großen Rebellionen im China des 19. Jahrhunderts}

$\begin{array}{ll}\text { Taiping-Rebellion in Zentral-China, } & 1850-1864 \\ \text { Nian-Rebellion in Nord-China, } & 1853-1868 \\ \text { Miao-Rebellion in Guizhou (SW-China), } & 1855-1872 \\ \text { Moslem-Rebellion in Yunnan, (SW-China), } & 1855-1873 \\ \text { Moslem-Rebellion in Nordwest-China, } & 1864-1877\end{array}$

\footnotetext{
938 Wie zum Beispiel General Ha Guoxing, ein Hui aus der Provinz Hebei, der als Truppenführer am chinesischbirmanischen Krieg (1766-1769) teilgenommen hatte. Einer seiner Nachfolger im Amt des Vize-Regionalkommandeurs des Regionalen Militärbezirks Yongshun, war ebenfalls ein Hui: Xu Shiheng aus Chengdu (Sichuan), ein Absolvent der Militärprüfungen auf Provinzebene (wuju), war um 1780 in Tengyue tätig (TYTZ, S.130; zu General Ha Guoxing siehe Kap. IV, A. 3. 2., S. 213ff; Wang Jianping, S. 56).

${ }_{939}$ Wang Jianping, S. 244

${ }^{940}$ Ebd., S. 233-234
} 


\section{2. Die Moslem-Rebellion in Yunnan}

Die Gründe für die Rebellion der Moslime in der Provinz Yunnan lagen ebenso wie bei den anderen großen Rebellionen dieser Zeit in der allgemeinen Krisenssituation, in der sich das chinesische Reich im 19. Jahrhundert befand. Der Verfall der politischen Strukturen zeigte sich auch im fernen Südwesten des Reiches; Korruption, Ämterkauf und die allgemeine Finanzkrise lähmten die Verwaltung. Zudem führten religiöse und kulturelle Unterschiede zwischen den beiden Bevölkerungsgruppen der Han und Hui in Yunnan immer wieder zu lokalen Unruhen, die durch wirtschaftliche Konflikte insbesondere im Bergbau verstärkt wurden; inkompetente Verwaltungsbeamte vor Ort und die Ausbreitung des Banditentums verschärften die Situation, die sich schließlich zu einer Rebellion auswuchs. ${ }^{941}$ Bis zu ihrer Niederschlagung durch Regierungstruppen vergingen achtzehn Jahre, in denen die Aufständischen von ihrem Zentrum in Dali aus den gesamten Westen der Provinz beherrschten und auch mehrfach die Provinzhauptstadt Yunnan fu (Kunming) belagerten.

\section{2. 1. Die Vorboten der Rebellion: Die Unruhen in Yongchang in den Jahren 1843 bis 1848 und die Entwicklung in Zentral-Yunnan}

Erste Vorboten der Rebellion waren Konflikte unter den Arbeitern in den Minenbetrieben Yunnans. In den etwa siebzig Jahren von 1737 bis 1810 hatte die Bergbauindustrie in der Provinz eine Blütezeit erlebt und zahlreiche Zuwanderer aus dem ganzen Reich angezogen; ebenso wie im Fernhandel waren auch im Bergbau viele Hui tätig. Wenige Jahrzehnte später hatte sich die Lage jedoch erheblich verändert (s.o. Kap. IV, A. 7., S. 277ff). In der allgemeinen Finanzkrise des Staates, mit dem Verfall der Kupferwährung während der Ära Daoguang (1821-1851) sowie der Erschöpfung vieler Förderstätten hatten sich die Lebensbedingungen der Minenarbeiter erheblich verschlechtert, viele hatten ihre Arbeit ganz verloren: Das Banditenunwesen nahm zu und Konflikte führten immer häufiger zu gewaltsamen Auseinandersetzungen. Schon im Jahr 1821 war es zu Streitigkeiten in den Minen von Baiyang, in der Unterpräfektur Yunlong (westlich von Dali) gekommen, die noch von den örtlichen Verwaltungsbeamten beigelegt werden konnten. Nach einem Massaker an den Hui in Mianning (Präfektur Shunning) im Jahr 1839 gelang dies jedoch nicht mehr. Die Hui sahen sich bei der anschließenden gerichtlichen Untersuchung benachteiligt, auch eine Throneingabe, mit der sie beim Kaiser um Gerechtigkeit nachsuchten, blieb erfolglos und so kam es erneut zu Unruhen.

\footnotetext{
${ }^{941}$ Wei, S. 30
} 
Während sich diese Konflikte zunächst im Umfeld der Bergbaubetriebe zumeist aus Streitigkeiten der Arbeiter untereinander oder auch aus dem Konkurrenzkampf der Minenbetriebe entwickelt hatten, kam es in Yongchang in einem anderen Umfeld zu gewalttätigen Unruhen, die in einem Massaker an der Hui-Bevölkerung im Jahr 1845 kulminierten. Begonnen hatten die Konflikte schon im Jahr 1843 (Daoguang 23):

\begin{abstract}
„Im siebten Monat sammelten sich die Hui (Hui min) der Stadt Yongchang und lieferten sich vor dem Longquan-Tor einen Kampf mit den Han (Han min). Viele Han wurden verletzt. In der Stadt mußten die Geschäfte geschlossen werden. Präfekt Chen Tongsheng ließ die Rädelsführer ... festnehmen. Das war der Beginn der Kämpfe zwischen den Han und den Hui in [der Präfektur] Yongchang“. ${ }^{942}$
\end{abstract}

Auslöser für diesen und weitere gewaltsame Zusammenstöße der beiden Bevölkerungsgruppen in Yongchang waren religiöse Überzeugungen. Immer wieder störten Gruppen von Hui, zumeist Jugendliche, Feierlichkeiten und Prozessionen der Buddhisten und Daoisten oder belästigten Tempelbesucher. Die religiösen Führer der Hui unternahmen nichts, um ihre Anhänger zur Ordnung zu rufen und den örtlichen Beamten gelang es nicht, die Situation in den Griff zu bekommen, so verschärften sich die Konflikte zwischen den beiden Bevölkerungsgruppen. Ein Zwischenfall auf dem Markt in Banqiao („Bereits im 4. Monat desselben Jahres hatten die Hui in Banqiao Streit angefangen. “943) führte im Mai 1845 schließlich zum Ausbruch gewalttätiger Unruhen, die in der Region über zwei Jahre lang immer wieder aufflammten.

Während bei früheren Auseinandersetzungen häufig die Hui die besser organisierte Gruppe waren, trafen sie auf dem Markt in Banqiao auf die Mitglieder einer der Geheimgesellschaften, die sich in der Region zur Verteidigung gegen Banditen zu Milizen zusammengeschlossen hatten. ${ }^{944}$ Deren gut organisierte Mitglieder brachten den Hui eine schwere Niederlage bei, außerdem zerstörten sie eine Moschee und verschiedene Häuser der Hui. ${ }^{945}$

\footnotetext{
${ }^{942}$ YCFZ, S. 137

${ }^{943}$ YCFZ, S. 137. Banqiao befindet sich im Nordosten von Yongchang (siehe Karte 13, S. 327). Zu dieser Zeit lebten dort etwa sechstausend Menschen, ein Viertel davon Moslime (Wei, S. 35).

${ }^{944}$ Da die örtlichen Beamten angesichts der zunehmenden Bedrohung durch herumziehende Banditen nicht in der Lage waren, für den Schutz der Bevölkerung zu sorgen, hatte diese sich auch in Yongchang in Geheimgesellschaften organisiert, in den Nachbarschaften (xiang) innerhalb und außerhalb der Präfekturstadt ebenso wie in entfernteren Gebieten. Anfänglich waren diese Geheimgesellschaften von Han-Chinesen lediglich als Schutzgemeinschaften gegründet worden, als es aber immer häufiger zu Konflikten zwischen den Bevölkerungsgruppen kam, wandten sie sich auch gegen die Hui (Wei, S. 39-40, 83-84).

${ }^{945}$ Wei, S. 36; Wang Jianping, S. 254-256
} 
Diese suchten Unterstützung bei Glaubensbrüdern in der Umgebung. Bevor jedoch eine Gruppe von Hui unter der Führung von Ma Baixiang, die sich südlich von Yongchang in der Gegend von Yunzhou aufgehalten hatte, Banqiao erreichen konnte, hatte sich die Situation dort beruhigt. Ma Baixiang wandte sich stattdessen nach Jinji:

„Im 6. Monat führten die Moslem-Banditen (Hui fei) Ma Baixiang und Jiu Kanmao aus Yunzhou in [der Präfektur] Shunning eine Gruppe von über vierhundert Leuten an, die das Dorf Jinji im Norden der Präfekturstadt angriffen. Unter der Führung von Shen Jucheng, einem Mann aus dem Dorf, kämpften dessen Einwohner mit aller Kraft, um [die Angreifer] zu vernichten““. ${ }^{946}$

Zwar gelang es den Bewohnern von Jinji, die Banditen zu vertreiben, diese zogen jedoch weiter in der Gegend umher und erhielten immer mehr Zulauf, sowohl von Hui als auch von Angehörigen einheimischer Völker.

„[Über eintausend] Moslem-Banditen (Hui fei) sammelten sich im 7. Monat in Mengtingzhai [südwestlich von Yongchang]. Dann griffen sie Simuche an und brannten auch Kukejie und Taojiazhai nieder. Außerdem griffen sie ... [den Truppenstützpunkt] Bingma an. Dort wurde der Beamte Gao Lang im Kampf getötet. Dann besetzten sie den Lotos-Tempel am Ostberg. Der Brigade-Vizekommandant Yang Chaoxun, der Kommandant Pan Huiyang und über einhundert Soldaten, [die dort stationiert waren], wurden allesamt von ihnen [getötet und der Stützpunkt wurde] geplündert.“9477

Mit den Überfällen auf die Militärstützpunkte hatten die Unruhen in der Präfektur Yongchang ein neues Stadium erreicht. Zum ersten Mal sind Regierungstruppen direkt angegriffen worden, von einer zahlenmäßig überlegenen Gruppe, die sich mit ihrer Aktion zudem weitere Waffen verschaffen konnte. Hier handelte es sich nicht mehr um Streitigkeiten zwischen Bevölkerungsgruppen, sondern um einen Angriff auf staatliche Institutionen. Die Provinzregierung reagierte darauf mit der Entsendung von Truppen in die Region.

„Im 8. Monat führten Luo Tianchi von der Verwaltungsregion Yixi und der Sonderbeauftragte (weiyuan) Hengwen Soldaten nach Yongchang. Als sie

\footnotetext{
${ }^{946}$ YCFZ, S. 137. Alice Wei nennt hier lediglich eine Zahl von etwa achtzig Personen, aus denen diese Gruppe bestanden haben soll (Wei, S. 37). Jinjicun, das ,Dorf der goldenen Hühner‘ befindet sich 15km nordöstlich von Baoshan (siehe Karte 13, S. 327), in diesem Gebiet befand sich der Han-zeitliche Kreis Buwei.

${ }^{947}$ YCFZ, S. 137; siehe auch Wei, S. 37.
} 
sahen, daß die Banditen außerhalb [der Stadt] ihr Unwesen trieben und von einigen hundert Moslem-Familien der Stadt schon von fern anerkannt wurden, zogen sie ihre Truppen zusammen. Am 2. Tag des 9. Monats machten sie den Helfershelfern in der Stadt ein Ende und töteten viele von ihnen. Dann stellten sie den Frieden in der Präfekturstadt wieder her. Auf Druck der beiden Kommandanten, erhängte sich Chang Jingyun, der Assistierende VizeRegionalkommandeur von Yongchang, in seinem Amtssitz.“948

Deutlich wird in dieser Zusammenfassung der Geschehnisse im YCFZ auch die Stärke der Banditen, die die Kämpfe bereits in die Präfekturstadt getragen hatten, ohne daß das im Gebiet von Yongchang stationierte Militär in der Lage gewesen wäre, sich ihnen entgegenzustellen. Es waren Truppen der übergeordneten Verwaltungsregion (Yixi dao) und deren Kommandeure, die gegen die Banditen vorgingen und die den örtlichen Kommandanten für sein Versagen zur Rechenschaft zogen.

Als die gewaltätigen Auseinandersetzungen wenig später auch Tengyue und das Grenzgebiet erreichten (wo der örtliche Kommandant eine bessere Figur machte als in Yongchang), mußten zusätzlich noch Soldaten aus der benachbarten Verwaltungsregion Süd für den Feldzug mobilisiert werden, der von einem der obersten Militärkommandanten der Provinz angeführt wurde:

„Im 10. Monat [des Jahres 1845] führten der Provinz-Militärkommandant (tidu) Zhang Bilu und Zhou Shu aus der Verwaltungsregion Süd (Nan dao) erneut Soldaten nach Yongchang. Zu dieser Zeit brandschatzten und mordeten die Moslem-Banditen ... [im Gebiet] entlang der Grenze. Brigade-Kommandant Zhu Yuegong vom Regionalen Militärbezirk Tengyue, kämpfte gegen sie, bis er in der Schlacht getötet wurde. ... Die Signalfeuer brannten, innerhalb und außerhalb [der Stadt] herrschte Ausnahmezustand (jieyan). Provinz-Militärkommandant Zhang Bilu führte seine Soldaten in den Kampf, mit ganzer Kraft leitete er die Schlacht und beendete sie erst, nachdem er über einhundert [der Aufrührer] enthauptet und ihnen die Ohren abgeschnitten hatte. Die Banditen (zei) stürzten daraufhin in heilloser Flucht davon“ “. ${ }^{949}$

\footnotetext{
948 YCFZ, S. 137

${ }^{949}$ Ebd., S. 138, 156
} 
Zwar heben die Verfasser des YCFZ in ihrer Darstellung die Erfolge des chinesischen Militärs hervor, aber die rasche Folge immer neuer Kampfeinsätze unter Hinzuziehung neuer Truppeneinheiten zeigt doch, daß es der Armee nicht gelang, den Frieden in der Region des Stromschluchtenfächers wiederherzustellen. Selbst ein Feldzug unter Führung des Militärkommandanten der Provinz konnte die Unruhen nicht beenden und auch in den folgenden zwei Jahren flammten die Kämpfen immer wieder auf, unter anderem im Dorf Jinji und in Mengtingzhai, aber auch in Yongping, Yunzhou und Mianning. ${ }^{950}$

Hinter der oben zitierten knappen Darstellung der Geschehnisse in der Stadt Yongchang im Oktober 1845 im Lokalhandbuch YCFZ verbirgt sich ein Massaker, daß einen ganzen Tag über andauerte und den größten Teil der Hui-Bevölkerung der Stadt das Leben kostete. Der offizielle Bericht an den Provinz-Gouverneur He Changling sprach von einer erfolgreichen Verteidigung der Stadt; erst als He wenig später selbst nach Yongchang reiste, erkannte er das tatsächliche Ausmaß dieser Militäraktion und kam zu dem Schluß, daß sie unverhältnismäßig gewesen ist. ${ }^{951}$ Die Aufarbeitung des Massakers von Yongchang und seine Folgen sollten in den nächsten Jahren auch seine Amtsnachfolger noch beschäftigen.

Da es Gouverneur He Changling nicht gelang, den Frieden in der Region wiederherzustellen, wurde er im Jahr 1846 vom Kaiser seines Amtes enthoben. Sein Nachfolger Li Xingyuan sandte erstmals eine sorgfältige Analyse der Konflikte zwischen den Bevölkerungsgruppen im Westen Yunnans an den Hof und forderte die Entlassung der für das Massaker von Yongchang verantwortlichen Militärführer und Zivilbeamten. Als ein Edikt aus Peking in Yunnan eintraf, in dem der Kaiser eine neuerliche Untersuchung der Vorfälle anordnete, war bereits ein neuer Generalgouverneur für Yunnan und Guizhou ernannt worden: Lin Zexu übte dieses Amt zwei Jahre lang aus, von Juli 1847 bis September 1849. ${ }^{952} \mathrm{Zu}$ seinen ersten Amtshandlungen gehörte die Untersuchung des Massakers von Yongchang.

Mit ein Grund für die kaiserliche Aufforderung zur Aufklärung der Umstände des Massakers war die Ankunft von Moslimen aus Yongchang in Peking:

\footnotetext{
${ }^{950}$ Siehe Wei, S. 45-47; YCFZ, S. 138..

${ }^{951}$ Wei, S. $42-43$

${ }^{952}$ Wei, S. 45; 47-50. Lin Zexu (1785-1850) war zuvor als kaiserlicher Sonderkommissar in Kanton tätig gewesen, wo er versucht hatte, den Opiumhandel einzudämmen. Das hatte zur Konfrontation mit den Briten geführt, die Lins Politik zum Anlaß für den 1. Opiumkrieg in den Jahren 1840 bis 1842 nahmen, der ihnen hohe Entschädigungszahlungen und die Öffnung der ersten fünf Vertragshäfen (treaty ports) einbrachte.
} 
„Im 27. Jahr der Ära Daoguang (1847) begaben sich die Hui Ding Canting, Mu Wenke, Du Wenxiu und Liu Yi nacheinander in die Hauptstadt, wo sie eine Klageschrift überreichten, die zweihundertundsieben Bürger (shimin) des Regierungsbezirks Yongchang namentlich unterzeichnet hatten““ ${ }^{953}$

In der Klageschrift wurden Banditen für den Ausbruch der Unruhen, bei denen mehrere tausend Hui getötet worden waren, verantwortlich gemacht. Daraufhin ließ Lin Zexu einige der in der Klageschrift Beschuldigten verhaften und in die Provinzhauptstadt bringen. Dort kamen sie jedoch nie an. Die Militäreskorte wurde unterwegs von einer großen Gruppe von Mitgliedern der Geheimgesellschaften und anderen Han-Chinesen unter Führung von Männern aus Jinji überfallen, die die Gefangenen befreiten. In der Präfekturstadt wurde der Ausnahmezustand erklärt und die Stadttore geschlossen. Dennoch gelang es der Menge, in die Stadt einzudringen, wo es im Januar 1848 zu einem zweiten Massaker an der moslemischen Bevölkerung der Stadt kam. Außerdem wurden der Amtssitz des Präfekten niedergebrannt und die Beamten festgehalten. Die Rebellen unterbrachen auch die Hauptverkehrsverbindung über die Mekong-Brücke im Osten der Stadt. ${ }^{954}$

Die Unruhen in der Präfektur Yongchang hatten wieder ein neues Stadium erreicht. Waren bisher alltägliche Streitigkeiten oder Überfälle von ,Moslem-Banditen` Anlaß für Kämpfe gewesen, so hatten nun Han-chinesische Bürgermilizen und ihre Anhänger eine Stadt besetzt. Gouverneur Lin reagierte prompt mit der Entsendung von Truppen, deren Einsatz er persönlich leitete:

„Regierungstruppen aus den beiden Provinzen Yunnan und Guizhou haben sich verteilt und sind vorgerückt, um [die Rebellen] zu vernichten“.955

Die Rebellion wurde niedergeschlagen, ihre Anführer an Ort und Stelle zum Tode verurteilt; „insgesamt waren es über vierhundertunddreißig Menschen, die streng bestraft wurden“. 956

Eine der Maßnahmen mit denen Gouverneur Lin Zexu den Frieden in Yongchang wiederherstellen wollte, war

\footnotetext{
953 YCFZ, S. 138

${ }^{954}$ Wei, S. 54-55; YCFZ, S. 138

${ }^{955}$ YCFZ, S. 138

${ }^{956}$ YCFZ, S. 138
} 
„die Umsiedlung der Hui [von Yongchang] in die Nähe des [vierzig Kilometer westlich] gelegenen Berges Guannai, jenseits des Flusses [Salween]“; außerdem reorganisierte er die Militärstützpunkte. So wurde unter anderem „ein Assistierender Kommandant (xie shoubei) für Yongchang ernannt, der in Yongping [an der Hauptverkehrsroute nach Dali] stationiert wurde““. ${ }^{957}$

In der Provinz insgesamt ließ Lin zudem die Kontrolle über die Bergbaubetriebe verstärken. Mit seinem Militäreinsatz und den weiteren Maßnahmen gelang es Gouverneur Lin Zexu zwar nicht, die Ursachen für die Konflikte in der Provinz zu beseitigen, zumindest oberflächlich konnte er den Frieden im Westen Yunnans wiederherstellen.

Neue Unruhen flammten jedoch schon bald darauf wieder auf. Im Jahr 1850 kam es zu Kämpfen in Minenbetrieben in der Präfektur Puer im Süden der Provinz Yunnan. Der nächste Schauplatz von gewalttätigen Auseinandersetzungen war der Kreis Nan'an in der Präfektur Chuxiong zwischen Kunming und Dali. Streitigkeiten über die Erzpreise in der Silbermine Shiyang waren Auslöser der Kämpfe im Jahr 1854, die sich im Rahmen der schwelenden Konflikte zwischen Han und Hui im Jahr 1855 rasch auch auf angrenzende Gebiete ausdehnten und in einem Massaker an der Hui-Bevölkerung von Yunnan fu (Kunming) kulminierten. Damit hatten die Unruhen im Mai 1856 die Provinzhauptstadt erreicht. Der Gouverneur von Yunnan, Shuxing’a, sandte jedoch erst einen Monat später einen beschönigenden Bericht an den Kaiserhof, in dem er den Moslimen die Schuld an den Unruhen zuschob. Die Zentralregierung war zu dieser Zeit mit der Bekämpfung der Rebellionen der Taiping und der Nian in Nord- und Zentral-China beschäftigt, die eine ernste Bedrohung für das Qing-Reich darstellten. In dieser Situation fanden Konflikte im fernen Yunnan wenig Aufmerksamkeit; die Beamten der Provinzregierung blieben auf sich allein gestellt.

Der Generalgouverneur von Yunnan und Guizhou, Hengchun, der zur Zeit des Massakers in Guizhou gegen aufständische Miao gekämpft hatte, kehrte zwar nach Yunnan fu zurück, konnte aber die Unruhen in der Region nicht beenden.

Als 1857 eine große Gruppe von Hui unter der Führung von Ma Rulong aus der Präfektur Lin'an und dem Imam Ma Dexin vor die Provinzhauptstadt zog, die Bestrafung der Verantwortlichen für das Massaker von 1856 forderte und mit Angriff drohte, reagierte Hengchun zunächst nicht. Erst als die Hui ihre Drohung wahr machten, ließ er die Stadt-

\footnotetext{
${ }^{957}$ YCFZ, S. 138
} 
tore schließen. Wie in anderen Städten lebte auch in Yunnan fu ein großer Teil der Bevölkerung in den Vorstädten außerhalb der Stadtmauer, die nun von den Angreifern völlig zerstört und ihre Bewohner getötet wurden. ${ }^{958}$

\section{2. 2. Die Gründung des Sultanats von Dali}

Nach dem Massaker von Kunming im Jahr 1856 kam es auch in Dali zu Kämpfen zwischen Han und Hui, die von Hui aus Menghua unterstützt wurden. Die Abwesenheit des Provinz-Militärkommandanten (tidu), die schlechte Ausrüstung und Organisation der Garnisonstruppen sowie die fehlende Kooperation zwischen Militär- und Zivilbeamten ermöglichten es den Hui nach nur zweiwöchigen Kämpfen, die Stadt im September 1856 zu besetzen.

Mit der Eroberung Dalis veränderte sich der Charakter der Unruhen in der Region. Die Hui hatten mit der Stadt eine Basis gewonnen, in der sie sich zu organiseren begannen. Zunächst wählten sie einen Anführer: Du Wenxiu aus Yongchang, der 1847 nach Peking gereist war. Im Oktober des Jahres 1856 wurde Du zum Oberbefehlshaber (zongtong bingma da yuanshuai) ernannt und gründete das Sultanat von Dali. ${ }^{959}$

War es den Hui bisher zumeist darum gegangen, Druck auf die örtlichen Verwaltungsbeamten auszuüben, um Wiedergutmachung für erlittenes Unrecht zu erlangen, so formulierte Du Wenxiu nun ein sehr viel weiterreichendes Ziel, nämlich den Sturz der QingDynastie. Zu diesem Zweck bemühte er sich, alle Bevölkerungsgruppen Yunnans unter seiner Herrschaft zu vereinigen und fand auch Unterstützung bei Han-Chinesen und Angehörigen der einheimischen Völker. ${ }^{960}$

In den folgenden Jahren konsolidierte Du Wenxiu seine Herrschaft; seine Truppen eroberten zunächst das Gebiet der Präfektur Dali, dann drangen sie weiter nach Süden bis

\footnotetext{
${ }^{958}$ Wei, S. 79

${ }^{959}$ YCFZ, S. 139.

Du Wenxiu (1823-1872) stammte aus Xiacun bei Yongchang, wo er als Adoptivkind einer moslemischen Familie aufwuchs. Sein Adoptivvater war im Handel mit Birma tätig. Du war ein begabter Student, er hatte das erste staatliche Examen bestanden und den akademischen Titel eines xiucai erworben. Während des Massakers von Yongchang im Jahr 1845 hatte er seine Eltern und den Familienbesitz verloren. Infolgedessen war er 1847 nach Peking gereist, um eine Klageschrift am Kaiserhof einzureichen. Nach seiner Rückkehr nach Yunnan reiste er zunächst herum, schloß sich für einige Zeit dem Imam Ma Dexin an und ließ sich schließlich in Menghua südlich von Dali nieder. Dort schloß er sich mit anderen Hui zu einer Bruderschaft zusammen; als einer ihrer Anführer zog er 1856 nach Dali (ZGRMDCD, S. 210; Wei, S. 61-63).

${ }_{960}$ Wei, S. 94, 98, 216. Zwar übernahm Du Wenxiu auch Forderungen der christlich orientierten Taiping-Rebellen in Zentral-China und führte deren Kalender in Dali ein, zu direkten Kontakten mit den Taiping kam es jedoch nicht (Wei, S. 101). Zur Organisation und Verwaltung des Sultanats von Dali siehe Wei, Kap. V, S. 168-232.
} 
in die Präfektur Shunning vor. Im Westen rückten sie im Jahr 1860 nach Yongping und über den Mekong bis nach Shidian vor. ${ }^{961}$

Zu Beginn des Jahes 1861 (Xianfeng 11) eroberten die Hui unter ihrem General Cai Qier (auch Cai Dechun) die tusi-Gebiete Zhenkang und Wandian und schließlich nach langer Belagerung die Präfekturstadt Yongchang und anschließend auch die Stadt Tengyue:

„Am 23. Tag des 6. Monats nahmen die Banditen die Stadt Yongchang ein. Um die Stadt zur Kapitulation aufzufordern, schickten sie Leute nach Tengyue: Im 8. Monat befahl der Anführer der Banditen, Cai Qier, seinen Gefolgsleuten Guibu, Wan Quan u. a. sich von Shangjiang nach Tengyue zu begeben“. 962 „Im 9. Monat begab sich Cai Qier selbst nach Tengyue. Außerdem ließ er einige Dutzend der lokalen Anführer (toumu ren) von Baoshan töten und siedelte die Moslime von Longling in die Stadt Yongchang um, mit deren Verteidigung er seinen jüngeren Bruder Cai Fachun beauftragte.“ “963

Mit der Besetzung von Tengyue hatten die Rebellen die Oberhoheit über die Städte in der Region des Stromschluchtenfächers errungen. Zahlreiche Han leisteten jedoch weiterhin Widerstand; so daß die Rebellen das Hinterland an der Grenze zu Birma nie ganz befrieden konnten.

Nach der Eroberung Dalis war die Kommunikation mit der Zentralregierung unterbrochen worden. Erst Anfang 1857 informierte die Throneingabe eines Zensors den Kaiserhof über die Rebellion; der Name ihres Anführers Du Wenxiu wurde in Peking erst 1861 bekannt. ${ }^{964}$ Da die Qing-Regierung nach wie vor mit den Rebellionen in Zentral-China befaßt war, blieb die Provinzverwaltung von Yunnan weiterhin auf sich allein gestellt. Regierungstruppen aus der Provinz unternahmen in den Jahren 1856 bis 1860 von Yunnan fu aus zwar vier Feldzüge zur Rückeroberung von Dali, sie blieben jedoch sämtlich erfolglos.

\footnotetext{
961 YCFZ, S. 139

962 TYTZ, S. 194

${ }^{963}$ YCFZ, S. 141

${ }^{964}$ Wei, S. 96-97
} 
Zwischen den Regierungstruppen und den Rebellen in Dali hatte sich Ma Rulong, der Anführer der Hui, die 1856 Kunming belagert hatten, in der Präfektur Chuxiong festgesetzt und dort im Jahr 1860 mit Du Wenxius Genaral Cai Qier ein Waffenstillstandsabkommen geschlossen, in dem sie ihre jeweiligen Einflußsphären abgrenzten. ${ }^{965}$ Ma Rulong wandte sich nach Osten und belagerte erneut Yunnan fu. Dort führte er 1862 Friedensverhandlungen mit der Provinzregierung, die ihm weitgehende Zugeständnisse machte, woraufhin sich Ma Rulong und der Imam Ma Dexin den Qing anschlossen. ${ }^{966}$ Beide erhielten hohe Titel verliehen und in Abwesenheit des Gouverneurs von Yunnan herrschte Ma Rulong als Provinz-Militärkommandant (tidu) praktisch über die Provinzhauptstadt. ${ }^{967}$

Karte 13: Verwaltungseinheiten der Provinz Yunnan zur Zeit der Moslem-Rebellion (Ausschnitt)

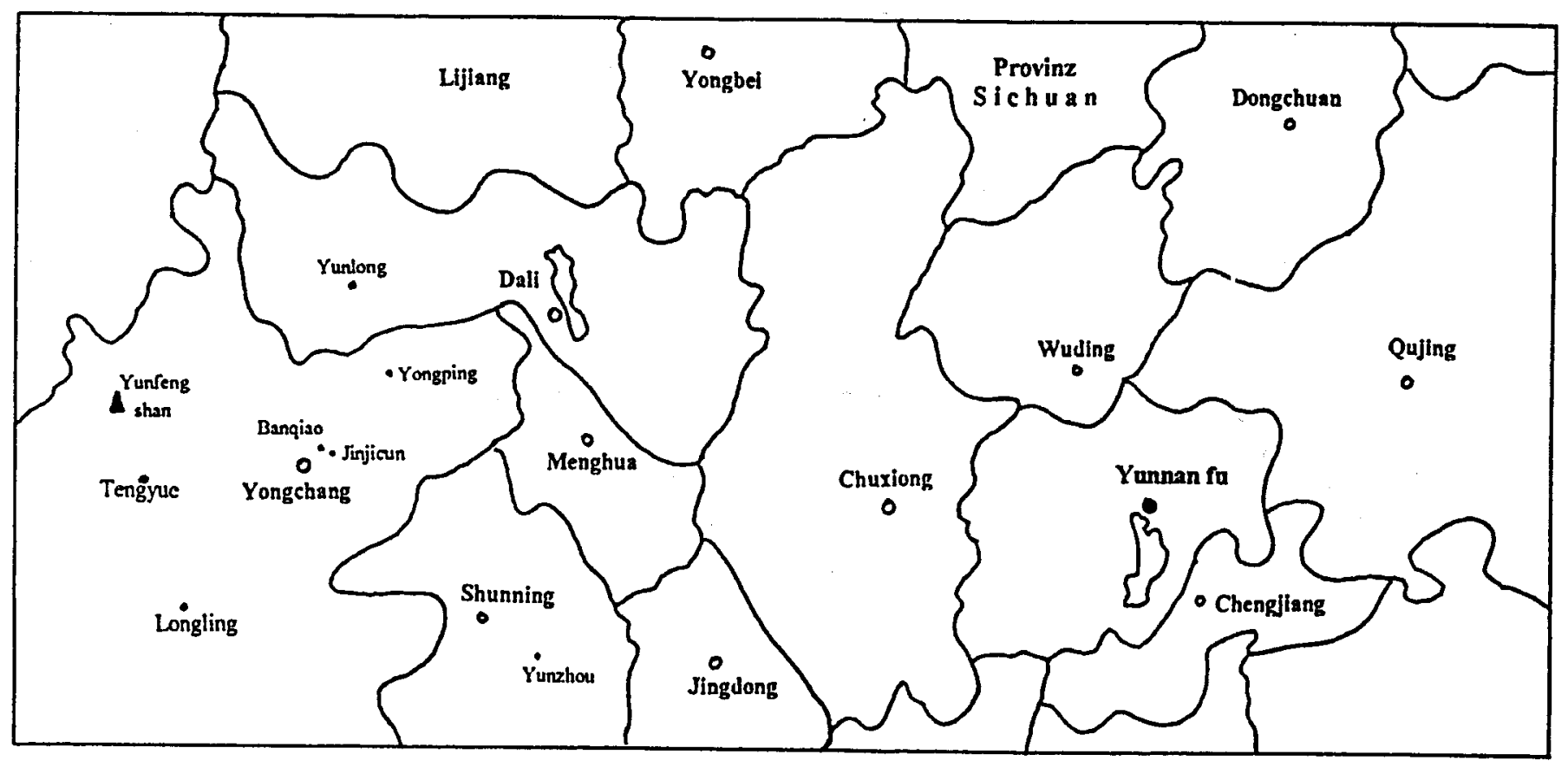

Damit hatten sich die Fronten in Yunnan geklärt: Der Westen der Provinz wurde von Du Wenxiu und seinem Sultanat Dali beherrscht, der Osten von Beamten der Qing, das heißt von Ma Rulong und dem Truppenführer Cen Yuying, der die Präfektur Qujing befriedet

\footnotetext{
${ }^{965}$ Wei, S. 140

${ }^{966}$ Wei, S. 114

${ }^{967}$ Wei, S. 114, 120, 122
} 
und den Waffenstillstand mit Ma Rulong ausgehandelt hatte. ${ }^{968}$ Deutlich wird hier auch, daß die Rebellion in Yunnan nicht nur ein Kampf von Hui gegen Han-Chinesen war, sondern weit vielschichtiger; Hui ebenso wie Han standen sich auf beiden Seiten gegenüber. ${ }^{969}$

Mehrere Versuche von Seiten Ma Rulongs, ein Friedensabkommen mit Du Wenxiu auszuhandeln, blieben ohne Erfolg, ebenso wie ein erster Vorstoß seiner Soldaten nach Westen. Im Gegenzug rückten Truppen aus Dali nach Zentral-Yunnan vor. Cen Yuying war zu dieser Zeit noch in der Provinz Guizhou mit dem Kampf gegen aufständische Miao beschäftigt. Als er im Sommer 1867 nach Qujing zurückkehrte, waren die Rebellen bereits in den Nordosten der Provinz vorgedrungen. Auf dem Höhepunkt ihrer Macht in der Mitte der sechziger Jahre des 19. Jahrhunderts beherrschten die Hui von Dali aus dreiundfünfzig Städte in ganz Yunnan, bis an die Grenzen zu den Nachbarprovinzen Sichuan und Guizhou. ${ }^{970}$ Mitte des Jahres 1868 belagerten sie die Provinzhauptstadt mit einer Armee von etwa zweihunderttausend Mann unter dem Oberbefehl von Du Wenxius Tochter und Schwiegersohn. Ma Rulong verteidigte die Stadt, bis die Armee Cen Yuyings die Belagerung durchbrach und Cen, der inzwischen zum Gouverneur von Yunnan ernannt worden war, im November 1868 in die Stadt einzog. In den folgenden zwei Jahren reorganisierte Cen Yuying die Verwaltung der Provinz sowie das Finanz- und das Schulwesen. Im Herbst

\footnotetext{
${ }^{968}$ Cen Yuying (1829-1889) stammte aus einer einflußreichen Familie aus Xilin in der Provinz Guangxi. Im Alter von sechzehn Jahren erwarb er 1845 den akademischen Titel eines xiucai. In seiner Heimat organisierte er eine Miliz, mit der er 1857 und 1859 Regierungstruppen in Yunnan unterstütze. Für seine Verdienste wurde er zum Verwaltungsbeamten des von ihm eroberten Kreises Yiliang befördert. Dort bildete er Soldaten aus und vergrößerte seine Armee, mit der er 1861/ 1862 erneut nach Yunnan fu zog und Friedensverhandlungen mit Ma Rulong führte. Cen kämpfte in den folgenden Jahren gegen aufständische Miao im Grenzgebiet der drei Provinzen Yunnan, Guizhou und Sichuan.

Als er 1868 die Belagerung von Yunnan fu durchbrach, wurde er zum Gouverneur der Provinz Yunnan befördert, deren Verwaltung er reorganisierte. Nachdem seine Truppen die Moslem-Rebellion niedergeschlagen hatten, wurde er 1874 zum Generalgouverneur von Yunnan und Guizhou ernannt. Während der Margary-Affäre (1875) wurde Cen vom Kaiser kritisiert (s. u. 2. 2., S. 349). Wenig später zog er sich von seinem Posten zurück, um die Trauerzeit für seine Mutter einzuhalten. Im Jahr 1879 reiste er zum ersten Mal nach Peking und wurde zum Gouverneur von Guizhou ernannt. 1881 amtierte er als Gouverneur von Fujian, 1882 wurde er erneut zum Generalgouverneur von Yunnan und Guizhou ernannt. In den Jahren von 1883 bis 1885 war er an den Kämpfen gegen die Franzosen in Annam beteiligt. Er erhielt vom Kaiser verschiedene Ehrentitel verliehen und wurde im Tempel für berühmte Staatsmänner in Peking verehrt; in Kunming, Guiyang und anderen Orten wurden Tempel für ihn errichtet (Hummel, S. 742-746; ZGRMDCD, S. 263; Wei, S. 123130, 144-146).

969 Insbesondere für die Hui, die in der Qing-Armee dienten, ergab sich ein Loyalitätskonflikt, der, wie das Beispiel des Kommandanten Zhao Fayuan aus der Präfektur Yongchang zeigt, nicht unbedingt zugunsten der Religionsgemeinschaft entschieden wurde:

„Im 3. Monat [des Jahres Daoguang 26 (1846)] griff der Anführer der [Moslem-]Banditen, Zhang Fuhuang Baba, mit seiner Bande von über eintausend Leuten die Brücke über den Mekong an. Kommandant (shoubei) Zhao Fayuan, der mit Verteidigung der Brücke beauftragt war, war ursprünglich ein Hui aus Zhaozhou (heute Zhaoxian, Provinz Hebei). Die Banditen waren der Meinung, daß ein Mann ihres Glaubens (tongjiao) sie in jeder Hinsicht willkommenheißen würde. Aber [Zhao] tat das nicht. Daraufhin überquerten sie weiter oberhalb heimlich den Fluß, umzingelten [den Stützpunkt an der Brücke] und griffen an. [Der Truppenführer Yang Tingzuo wurde getötet. Zhao Fayuan hingegen] wurde lebend gefangengenommen. [Die Banditen] schlugen ihm die Gliedmaßen ab und rissen außerdem noch sein Herz heraus. Dann machten sie sich die Gelegenheit zu Nutze, um die Dörfer entlang des Flusses zu brandschatzen und zu plündern“ (YCFZ, S. 138, 156).

${ }^{970}$ Wei, S. 265
} 
1870 wurden zum ersten Mal seit 1856 wieder Provinzprüfungen abgehalten, die von Cen persönlich geleitet wurden. ${ }^{971}$

Währenddessen hatte Ma Rulong mit der Rückeroberung der besetzten Städte im Süden und Osten Yunnans begonnen und Yang Yüke, ein General Cen Yuyings, hatte seine Truppen nach Westen geführt. Dort war die Unterpräfektur Longling bereits 1869 von lokalen Widerstandskämpfern erobert worden, die Präfekturstadt Yongchang folgte im Jahr 1871. Im Jahr darauf eroberte Yang Yuke Yongping und rückte bis in die direkte Umgebung von Dali vor. Ein halbes Jahr lang verteidigten die Rebellen die umzingelte Stadt. Ende Dezember 1872 ergab sich Du Wenxiu (nachdem er zuvor Gift geschluckt hatte) Yang Yuke, der ihn enthaupten ließ. Mehrere Anführer wurden ebenfalls hingerichtet, ein Großteil der Rebellen wurde bei Kämpfen in der Stadt oder auf der Flucht getötet. ${ }^{972}$

Im Frühjahr 1873 eroberten die Regierungstruppen schließlich die noch verbliebenen Stützpunkte der Aufständischen in Shunning, Yunzhou und Tengyue; ihre letzte Bastion in Wusuo, im Norden von Tengyue, konnten sie erst Mitte des Jahres 1874 einnehmen. ${ }^{973}$ Damit war die Rebellion der Hui von Dali beendet.

\footnotetext{
${ }^{971}$ Wei, S. 160. Im folgenden Jahr wurden auch die Provinz-Militärprüfungen wieder aufgenommen (Wei, S. 161). ${ }^{972}$ Wei, S. $162-165$

${ }^{973}$ Wei, S. 167
} 
Tabelle 40: Chronologie der Moslem-Rebellion in Yunnan

1821

1839

1845

1847

1848

1850

$-1855$

1856

1856

$-1860$

1857

1860

1861

1862

1868

1871

$-1872$

1872

1874

Konflikte zwischen Han und Hui in den Minen von Baiyang (Unterpräfektur Yunlong, westlich von Dali).

Massaker an den Hui in Mianning (Präfektur Shunning).

Massaker an der Hui-Bevölkerung in Yongchang

Du Wenxiu und andere Hui aus Yongchang reisen mit einer Bittschrift nach Peking.

Lin Zexu wird General-Gouverneur für Yunnan und Guizhou (bis Sept. 1849).

Zweites Massaker an der moslemischen Bevölkerung von Yongchang.

Gewalttätige Auseinandersetzungen in Minenbetrieben in der Präfektur Puer, im Kreis Nan'an und in der Silbermine Shiyang (Präfektur Chuxiong).

Massaker an der Hui-Bevölkerung von Yunnan fu (Kunming). Kämpfe zwischen Han und Hui in Tengyue, Massaker an der Hui-Bevölkerung. Die Hui ernennen Du Wenxiu zum Oberbefehlshaber, Gründung des Sultanats von Dali.

Regierungstruppen unternehmen von Kunming aus vier Feldzüge zur Rückeroberung von Dali, die jedoch sämtlich erfolglos bleiben.

Unter der Führung von Ma Rulong aus Lin'an und dem Imam Ma Dexin fordern die Hui vor der Provinzhauptstadt die Bestrafung der Verantwortlichen für das Massaker von 1856. Generalgouverneur Hengchun läßt die Stadttore schließen: Die Angreifer zerstören die Vorstädte.

Waffenstillstandsabkommen zwischen Ma Rulong in der Präfektur Chuxiong und Du Wenxius General Cai Qier, dessen Armee rückt nach Yongping und über den Mekong bis nach Shidian vor.

Die Hui erobern die tusi-Gebiete Zhenkang und Wandian und nach langer Belagerung auch die Präfekturstadt Yongchang; die Stadt Tengyue ergibt sich.

Ma Rulong führt Friedensverhandlungen mit der Provinzregierung: Ma Rulong und der Imam Ma Dexin schließen sich den Qing an.

Die Hui von Dali kontrollieren 53 Städte in ganz Yunnan, bis an die Grenzen zu den Nachbarprovinzen Sichuan und Guizhou.

Cen Yuying, Gouverneur von Yunnan, beendet die Belagerung von Yunnan fu durch die Moslem-Rebellen. Ma Rulong und Yang Yüke, ein General Cen Yuyings, beginnen mit der Rückeroberung der von den Rebellen besetzten Gebiete. Die Unterpräfektur Longling wird von lokalen Milizen zurückerobert.

Regierungstruppen erobern Yongping und rücken bis nach Dali vor. Sechs Monate dauern die Kämpfe um die Stadt, dann ergibt sich Du Wenxiu; Yang Yuke läßt ihn enthaupten. Li Fengxiang, der zum Kommandeur des Regionalen Militärbezirks Tengyue ernannt wurde, erobert die Stadt Tengyue.

Die Regierungstruppen erobern die noch verbliebenen Stützpunkte der Rebellen in Shunning, Yunzhou und Tengyue.

Die Regierungstruppen erobern die letzte Bastion der Rebellen in Wusuo, im Norden von Tengyue. 


\section{3. Tengyue in der Zeit der Moslem-Rebellion}

\section{3. 1. Die Hui und die Moslem-Rebellion in den Lokalhandbüchern von Tengyue}

Die Lokalhandbücher von Tengyue sind ein bzw. zwei Jahrzehnte nach der Niederschlagung der Moslem-Rebellion neu zusammengestellt bzw. herausgegeben worden: Das TYTZ im Jahr 1888 und das TYZZ im Jahr 1897. Dennoch oder vielleicht gerade wegen der zeitlichen Nähe zu den Ereignissen enthalten sie nur wenige Informationen über die Hui-Bevölkerung von Tengyue und über die Geschehnisse in der Stadt während der Rebellion. $^{974}$

Anders als die einheimischen Völker, die in der Unterpräfektur ansässig waren, waren die Hui (ebenso wie die Han) Zuwanderer aus dem chinesischen Kernland oder aus dem Nordwesten, die sich, abgesehen von ihrer Religionszugehörigkeit, nicht von den Han-Chinesen unterschieden und daher in den fangzhi weder im Kapitel über die einheimischen Völker (zhongren) noch bei den Bevölkerungszahlen gesondert als Gruppe ausgewiesen werden.

Zudem waren die meisten Hui in Tengyue als Kaufleute und im Karawanenhandel tätig, ein Thema, mit dem sich die Literaten-Beamten, die mit der Zusammenstellung der fangzhi befaßt waren, nur marginal beschäftigt haben.

Lediglich im letzten Kapitel des TYTZ sind zwei kurze Texte enthalten, die sich mit der Religion der Hui und der arabischen Welt beschäftigen. ${ }^{975}$ Nach einem Abschnitt zu Mohammed, dem Stifter des Islam, folgt eine zweiter mit Informationen über das Königreich Medina („Das ist das Land der Vorfahren [zuguo] der Huihui in der Nähe von Mekka.“), in dem auch der Kernpunkt der Religion der Huihui hervorgehoben wird:

„Der Himmel gilt [ihnen] als oberster [Gott] (tian wei zhu); es gibt keine Abbildungen von ihm; jeden Tag knien sich [die Gläubigen] nach Westen gewandt zum Gebet nieder““.976

Das Verhältnis zu China wird mit dem Verweis auf die Tributbeziehungen beschrieben: „Während der Ära Xuande (1426-1436) sandte der Herrscher (qiuzhang) [von Medina] gemeinsam mit [dem Herrscher von] Mekka Tribut“. Außerdem wird auf die zwei

\footnotetext{
${ }^{974}$ Gleiches gilt auch für das 1885 neu herausgegebene YCFZ.

${ }^{975}$ Kap. 20, Miszellen, S. 384 - 385; ebenso im TYZZ, Kap. 11, Miszellen, S. 171-172.

${ }^{976}$ TYTZ, S. 384
} 
auffälligsten Charakteristika hingewiesen, die die Hui von den Han unterscheiden: „Sie essen kein Schweinefleisch und bedecken den Kopf mit einem weißen Tuch“. ${ }^{977}$ Abschließend gibt es noch einen knappen Hinweis darauf, daß die Religion der Hui in den verschiedenen Gemeinden (lian) der Unterpräfektur Tengyue weit verbreitet war und daß

„die Gebildeten unter [den Hui] in ihrem Erscheinen den gelehrten Konfuzianern glichen. ... Es gab jedoch auch viele Banditen unter ihnen, die mit strengen Gesetzten diszipliniert worden sind. Nach der Rebellion gab es nur noch wenige Hui in Tengyue, die ihre Religion jedoch nach wie vor ausübten“. ${ }^{978}$

Berichte über die Geschehnisse in Tengyue während Moslem-Rebellion in den Jahren 1855 bis 1873 finden sich in den fangzhi in der ,Chronologie der militärischen Ereignisse‘ ${ }^{979}$ Die Darstellung konzentriert sich auf die Kämpfe in der Umgebung der Unterpräfekturstadt; geschildert werden die Eroberungen der ,Moslem-Banditen“ (Hui fei) und der Widerstand der Bewohner der angegriffenen Dörfer und Gemeinden. Über die Jahre 1869 bis 1871 (Tongzhi 8 bis 10), in denen der Moslem-General Li Guolun (seit 1866 in Tengyue) die Stadt beherrschte, gibt es keine Informationen. Erst mit der Offensive der Regierungstruppen zur Rückeroberung der Region des Stromschluchtenfächers im Jahr 1872 wird die Chronologie wieder aufgenommen.

Zwar macht schon diese Chronologie deutlich, daß die Bevölkerung der Unterpräfektur Tengyue zwei Jahrzehnte andauernder Kämpfe durchlebt hatte, ein vollständigeres Bild der Auswirkungen der Rebellion auf Tengyue ergibt sich jedoch erst in Zusammenhang mit anderen Kapiteln der fangzhi. In den Abschnitten über die Brücken, die Schulen und die Tempel wird das Ausmaß der Zerstörung von Bauwerken und Infrastruktur in der Region des Stromschluchtenfächers erkennbar. ${ }^{980}$ Vor dem Hintergrund der Beschreibung der materiellen Schäden wird mit der Auflistung der Namen der Frauen und Männer, die (häufig mit ihrer ganzen Familie) während der Rebellion umgekommen sind, das Leid der Bevölkerung anhand dieser persönlichen Schicksale sehr plastisch geschildert.

\footnotetext{
977 TYTZ, S. 385

${ }^{978}$ Ebenda; siehe auch TYZZ, S. 172.

${ }^{979}$ TYTZ, Kap. 11, S. 193-195

${ }^{980}$ Auf diese materiellen Schäden in Tengyue wird unten in Abschnitt 3. 3. (S. 367ff) über die Maßnahmen zum Wiederaufbau unter der Leitung von Unterpräfekt Chen Zonghai eingegangen.
} 
Im anschließenden Abschnitt dieser Studie folgt zunächst eine Darstellung der Ereignisse in der Unterpräfektur Tengyue anhand der Informationen aus den fangzhi. Ergänzend wird aus dem ausführlichen Reisebericht von Dr. John Anderson zitiert, der mit der britischen Expedition von Major E. B. Sladen im Jahr 1868 in die von den Moslem-Rebellen beherrschte Stadt Tengyue gekommen war. Hingewiesen sei zudem auf das Sammelwerk von Bai Shouyi, Huimin qiyi (,Der Moslem-Aufstand',1953), in dem er unter anderem auch zeitgenössische Materialien von der Rebellion in Tengyue zusammengestellt hat. Darunter befindet sich der ,Tatsachenbericht über Tengyue in der Zeit des Aufstandes von Du Wenxiu“ (Tengyue Du luan jishi; 1910) von Cao Kun aus Tengyue, der die Geschehnisse in der Unterpräfektur chronologisch darstellt. Weiterhin enthält der Sammelband ,Die ,Proklamation der Hui von Tengyue‘ (Tengyue Huimin xiwen). ${ }^{981}$

\title{
1. 3. 2. Die Moslem-Rebellion in Tengyue
}

Die Unterpräfektur Tengyue hatte seit den ersten Dekaden des 19. Jahrhunderts unruhige Zeiten erlebt. Immer wieder war es im Grenzgebiet zu Kämpfen zwischen Angehörigen einheimischer Volksgruppen, Banditen und Bürgermilizen gekommen, in die sich auch Regierungstruppen eingeschaltet und unter anderem in den Jahren 1841 bis 1843 den Expansionsbestrebungen des Dao Chengxu von Nandian ein Ende gemacht hatten. ${ }^{982}$

Hinweise auf Konflikte bzw. gewalttätige Auseinandersetzungen zwischen Han und Hui in dieser Zeit gibt es in den fangzhi von Tengyue hingegen nicht. Die Hui von Tengyue beschreiben das Zusammenleben der beiden Bevölkerungsgruppen selbst als eine traditionell friedliche Koexistenz, geprägt von sozialen und ökonomischen Kontakten:

\begin{abstract}
„Die Hui und die Han haben in Teng seit jeher friedlich zusammengelebt. Die Gelehrten haben Tuschstein und Sitzplatz miteinander geteilt; die Land besitzenden Familien [stritten nicht wegen] des Feldrains. Einmütig wurde Handel getrieben, das Gold wurde wie bei Guan und Bao geteilt; es gab enge Beziehungen, die nur hinter denen des Dorfes der Familien Zhu und Chen
\end{abstract}

\footnotetext{
981 ,Die ,Proklamation der Hui von Tengyue‘ ist ein von Li Fangbo verfaßter Text, der ursprünglich den Titel ,Proklamation über die in Tengyue geübte Vergeltung im Jahr bingchen der Ära Xianfeng“ hatte. „Es ist eine Proklamation, in der nach dem Massaker an den Hui von Tengyue am 3. Tag des 10. Monats des 6. Jahres der Ära Xianfeng [1856] die Umstände des Verbrechens der lokalen Staatsorgane der Qing öffentlich verkündet und darüber hinaus zum bewaffneten Kampf aufgerufen wurde“ (Bai Shouyi, Peking 28.10.1951; in: Bai Shouyi, Huimin qiyi, Bd. 2, S. 13-14). Eine vollständige Übersetzung der ,Proklamation‘ findet sich im Anhang.

982 Siehe TYTZ, S. 193
} 
zurückstanden. Noch nie sind Grenzen aufgestellt, noch nie sind die Familien in unterschiedliche Gruppen eingeteilt worden“. ${ }^{983}$

Nach dem Massaker an den Hui in Yunnan fu im Mai und wenige Wochen nach der Gründung des Sultanats von Dali im Herbst 1856 kam es dann aber auch in der Stadt Tengyue zu Kämpfen zwischen Han und Hui. Unter diesem Datum erwähnen auch die Verfasser der fangzhi erstmalig Konflikte zwischen den beiden Bevölkerungsgruppen in der Unterpräfektur. Diese waren so schwerwiegend, daß sie sich sogar in Naturescheinungen widerspiegelten und entsprechend auch im Kapitel über die ,Omina“ im TYTZ vermerkt wurden: Nachdem sich zuvor schon am Mingguang-Paß im Norden der Stadt ein Erdbeben ereignet hatte, war auch am Himmel ein beunruhigendes Spektakel zu beobachten gewesen:

„Im 6. Jahr der Ära Xianfeng (1856), am 3. Tag des 10. Monats fielen zahllose Sterne durcheinander [vom Himmel] herunter (qun xing luan zhui): In dieser Nacht kämpften Han und Hui gegeneinander“. ${ }^{984}$

Die Hui von Tengyue beschreiben die Ereignisse dieser Nacht in ihrer ,Proklamation` sehr viel realistischer:

„Unsere Eltern wurden getötet, unsere Brüder massakriert, unsere Ehefrauen umgebracht,unser Eigentum geplündert, unsere Felder besetzt. Sie gierten nach unseren Häusern; überall wurden die Moscheen vollständig niedergebrannt. ... Alles was passieren konnte, war geschehen. Man bringt es nicht übers Herz, davon zu sprechen, davon zu hören ist unerträglich““. ${ }^{985}$

Deutlich wird, daß die Hui auch den Neid auf die wohlhabenden Hui-Kaufleute als Motiv für die Übergriffe der Han sehen: „Was den Lebensunterhalt betrifft, so glaubten sie, daß die Hui das ganze Geld verdienen würden“. Besonders beklagen die Hui, das sich die Zivil- und Militärbeamten von Tengyue auf die Seite der Han-Chinesen stellten und keine Maßnahmen zum Schutz der Hui-Bevölkerung ergriffen: „Heute sind die Han so grausam zu den Hui, wie oben beschrieben, und die Beamten unterstützen sie noch bei diesen Brutalitäten. Sie sind ungerecht .... 986

\footnotetext{
983 ,Guan Zhung und Bao Shuya': Zwei berühmte Freunde. ,Das Dorf der Familien Zhu und Chen“: Das ganze Dorf ist miteinander verwandt; auch symbolisch für Eheschließungen (CY 815. 3-4).

984 TYTZ, S. 30

${ }^{985}$,Proklamation der Hui ‘, Bai Shouyi, Bd. 2, S. 13-14

${ }^{986}$ Ebenda, S. 14
} 
Zwar wurde die ,Proklamation“ der Hui in der Absicht verfaßt, die eigene Ausübung von Gewalt als Reaktion auf das erlittene Unrecht darzustellen und als notwendige Selbsthilfe zu rechtfertigen, dennoch wird in dem Text deutlich, daß die Konflikte zwischen den beiden Bevölkerungsgruppen ein Stadium erreicht hatten, in dem sie kaum noch friedlich beizulegen waren.

Den Regierungsbeamten in Tengyue gelang dies denn auch nicht. In wie weit sie tatsächlich an einer Aufklärung der Ereignisse interessiert waren, bleibt fraglich. Unterpräfekt Wang Xiuyu (ein jinshi aus der Provinz Anhui), der erst im Jahr 1856 sein Amt in Tengyue angetreten hatte, versuchte wohl, die seit der Gründung des Sultanats von Dali angespannte Lage zu beruhigen:

„Gemeinsam mit dem Regionalkommandeur (zongbing) Mingqing, den Regierungskommissaren (wei shenshi) Liu Jinkang, Ming Qinglong und anderen Angehörigen der Gentry ließ er in den Dörfern Verlautbarungen bekanntgeben, doch damit ließen sich [die Konflikte] nicht beenden““. ${ }^{987}$

Die Beamten von Tengyue waren in dieser Zeit auf sich allein gestellt, denn seit der Eroberung Dalis durch Du Wenxius Truppen waren die Verkehrsverbindungen nach Osten unterbrochen worden, die Kommunikation mit den übergeordneten Instanzen war nicht mehr möglich und Unterstützung aus der Provinzhauptstadt nicht zu erwarten.

In den folgenden Jahren eskalierten die Kämpfe in der Region. Von ihren Stützpunkten Wusuo und Majiacun im Norden von Tengyue eroberten die Hui Dörfer und Militärposten, „die sie plünderten und nahezu vollständig niederbrannten“; zudem „verbündeten sich die Banditen aus Wusuo mit verschiedenen Wilden aus den Bergen (shan ye yi)“.988

In den Gemeinden in der Umgebung von Tengyue formierte sich der Widerstand der Hanchinesischen Bevölkerung: Yin Yi in Hexi, Liu Guanghuan in Guyong, Li Zhenguo in Qiluo und andere organisierten Bürgermilizen. ${ }^{989}$

\footnotetext{
987 TYTZ, S. 193

988 TYTZ, S. 194

${ }^{989}$ Cao Kun, ,Tatsachenbericht',S. 221
}

Yin Yi stammte aus der Gemeinde Hexi, südlich von Tengyue. Er hatte im Jahr 1834 den akademischen Titel eines juren erworben und einen Amtsposten in Guangdong zugewiesen bekommen, den er aber wegen der allgemeinen Unruhen nicht hatte antreten können. Er hinterließ zahlreiche Gedichte, in denen seine differenzierte Haltung zu der Rebellion deutlich wird. Während des Massakers von 1856 hatte er moslemische Freunde in seinem Haus versteckt. Als sich die Unruhen in der Unterpräfektur weiter ausbreiteten, organisierte er in seinem Heimatort Hexi eine Miliz, die dank seiner Planungen den Rebellen erfolgreich Widerstand leisten konnte. Yin Yi starb 1867 etwa sechzigjährig bei der Verteidigung von Hexi gegen einen Angriff der Truppen Li Guoluns (TYTZ, S. 201, 213, 223; Wei, S. 262, 268-270). [Weiter auf S. 336.] 
Heftig umkämpft waren die strategischen Militärstützpunkte in der Region. Besonders die Garnison in Nandian im Süden von Tengyue: 1857 mußte der Vizekommandant der dort stationierten Linken Brigade, Chen Shangjin, seinen Stützpunkt gegen Angreifer aus Majiacun verteidigen; im folgenden Jahr „verbündeten sich Hui aus Shanmulong mit den verschiedenen Wilden aus den Bergen und griffen die Garnison Nandian mit über zweitausend Mann an“, konnten sie jedoch nicht erobern. ${ }^{990}$

„Gewalt und Unterdrückung [von Seiten der Rebellen] riefen allgemein große Empörung hervor“; Unterpräfekt Wang Xiuyu bemühte sich den Aufstand in seinem Amtsbezirk niederzuschlagen:

\begin{abstract}
„Er selbst beaufsichtigte die Rekruten aus den Gemeinden (lian) von Tengyue und kämpfte am Yubishan gegen die Rebellen, ohne Steine oder Pfeile [die gegen ihn gerichtet wurden] zu beachten; weil er sich dabei überanstrengte, wurde er krank“.991 „Im 4. Monat des Jahres Xianfeng 10 (1860) starb Unterpräfekt Wang Xiuyu. Besondere militärische Angelegenheiten wurden nun allein von Regionalkommandeur (zongbing) Mingqing entschieden“.992
\end{abstract}

An der Darstellung der Geschehnisse in Tengyue fällt auf, daß in den fangzhi zwar die Bemühungen des Unterpräfekten Wang gewürdigt werden, der dort stationierte ranghohe Militärkommandant Mingqing wird hingegen nur am Rande erwähnt und scheint wenig zur Verteidigung der Region unternommen zu haben. Möglicherweise verzichten die Verfasser auch aufgrund der eher unrühmlichen Rolle, die er im weiteren Verlauf der Ereignisse gespielt hat, darauf, sein Verhalten im Einzelnen darzustellen.

[Zu Fußnote 989, S. 337:] Liu Guanghuan aus Tengyue wird im TYTZ in der Liste der Militärbeamten als Nachfolger von Mingqing genannt, der den Posten in Abwesenheit des eigentlichen Amtsinhabers übernommen hatte (huli) (TYTZ, S. 131). Cao Kun bezeichnet ihn als Regionalkommandeur (zongbing; Cao Kun, S. 237), an anderer Stelle auch als Generalkommandeur der westlichen Gebiete (xilu zongtong) und Li Zhenguo (s.u.) als Generalkommandeur der östlichen Gebiete (donglu zongtong) (S. 226). Liu Guanghuan kämpfte seit 1861 zusammen mit Jiang Xiangshi zunächst von Guyong aus gegen die Hui-Truppen, später verlegte er seinen Stützpunkt nach Mianqing.

Li Zhenguo stammte aus Tengyue. Sein Vater war durch den Handel mit Birma reich geworden, seine Mutter, eine geborene Meng, war die Schwester einer Konkubine des birmanischen Königs; als vierter Sohn wurde er auch , der vierte Herr Li-der-Birmane‘ (Li si lao mian) genannt. Anderson gibt den Namen als ,Li-sieh-tai‘ wieder. In den Quellen werden unterschiedliche Angaben zu seinem Amtsposten als Militärbeamter gemacht: Er wird als Vize-Regionalkommandeur (fujiang) bezeichnet (TYTZ, S. 235; Cao Kun, S. 237; Wei, S. 242-243). Der Name Li Zhenguo erscheint in der Liste der Militärbeamten des TYTZ in der Rubrik der Kommandeure des Regionalen Militärbezirks (zong zhen; TYTZ, S. 132) sowie in der Rubrik der Brigade-Vizekommandanten (dusi; TYTZ, S. 133). Cao Kun bezeichnet ihn auch als Generalkommandeur der östlichen Gebiete (donglu zongtong) (S. 226). Nach der Niederschlagung der Rebellion war Li Zhenguo als Militärbeamter in Tengyue tätig. Im Jahr 1875 war Li in die Ermordung von Augustus Margary, dem Dolmetscher einer britischen Expedition, die im Grenzgebiet zwischen China und Birma unterwegs war, verwickelt (s. u. 2. 2., S. 349350). Li Zhenguo starb im Jahr 1888 (Hummel, S. 745).

${ }_{990}$ Cao Kun, ,Tatsachenbericht', S. 222

${ }^{991}$ TYTZ, S. 146

992 TYTZ, S. 194 
Im Jahr 1860 griffen die Hui aus Wusuo Beilian und Mianqing an, anschließend erreichten die Kämpfe auch die Unterpräfekturstadt: Die Banditen überquerten nachts den Fluß und „brannten über fünftausend Wohnhäuser in ... [der südwestlichen Vorstadt] nieder, zwei Tage lang mordeten und plünderten sie““ ${ }^{993}$ Li Zhenguo konnte die Angreifer mit seinen Truppen nach Mianqing zurückdrängen; im Süden vertrieb Liu Guanghuan Hui-Truppen, die das Dorf Heshun angegriffen hatten. Die Garnison in Nandian war weiter umkämpft, Minglang wurde von Aufständischen besetzt und in der Gemeinde Qingshui wurde ein Dutzend Dörfer niedergebrannt. ${ }^{994}$

Die jahrelangen Kämpfe hatten die Landwirtschaft in der Region stark beeinträchtigt: Die Gemeinden Minglang, Mianqing, Qingshui und andere in der Umgebung von Tengyue waren inzwischen „vier Mal von den Banditen verwüstet worden“, „die Mehrzahl der jungen Männer hatte zu den Waffen gegriffen, niemand bestellte mehr die Felder“, so war Reis extrem teuer geworden, in manchen Monaten kam überhaupt kein Reis mehr auf den Markt, „in den Dörfern vor der Stadt lagen die vielen Hungertoten zuhauf herum, denn schon in den vergangenen Jahren hatte es Mißernten gegeben“ und es waren sogar Fälle von Kannibalismus vorgekommen. ${ }^{995}$

Im Sommer des Jahres 1861 hatte die Armee aus Dali Yongchang erobert. Anschließend entsandte ihr Befehlshaber, General Cai Qier, seinen Offizier Guibu (auch Kuipu geschrieben), einen Mandschu, nach Tengyue, dieser überzeute den zongbing Mingqing, ebenfalls ein Mandschu, den Rebellen die Stadttore zu öffnen. ${ }^{996}$

Ma Xingtang, ein General Du Wenxius, war mit einer Armee von etwa zehntausend Soldaten bereits in die Nähe von Tengyue vorgerückt; die Gemeinde (lian) Dadong hatte angesichts der Übermacht kapitulieren müssen. ${ }^{997}$ Hinzu kam die Hungersnot, so daß Mingqing, der nach den Quellen zu urteilen bisher ohnehin tatenlos in der Stadt verweilt hatte, sich zur Kapitulation entschloß.

Im TYTZ heißt es dazu lapidar:

\footnotetext{
${ }^{993}$ Cao Kun, ,Tatsachenbericht', S. 223

${ }^{994}$ Ebenda, S. 224

${ }^{995}$ Ebenda, S. 224

${ }^{996}$ Wei, S. 134

${ }^{997}$ Cao Kun, ,Tatsachenbericht', S. 225
} 
„Am 18. Tag des 9. Monats haben Ma Xingtang und Ma Guoxi, diese PseudoGeneräle der Banditen, die Stadt Tengyue in Besitz genommen“. 998

„Im 7. Monat des Jahres 1862 bekämpften die Anführer der Banditen Ma Guoxi und Ma Biansi einander in der Stadt. Alle Bewohner wurden ausgeplündert und aus der Stadt vertrieben. Hou Baihuan nahm anschließend Zhanxi ein, Ma Lianer versetzte Zhanda und Ganya in Unruhe.““999

Die Rebellen rekrutierten in den eroberten Gebieten Männer für ihre Armee: „Eintausend aus den größeren Gemeinden; drei-, fünf- oder achthundert aus den kleineren Gemeinden, insgesamt waren es 24.500 Mann, ... von denen nur etwa zwei- bis dreihundert wieder heimkehrten“. ${ }^{1000}$ Andernorts trieben sie gewaltsam eine Art ,Kapitulationssteuer` ein: In dem durch den Fernhandel reich gewordenen Dorf Heshun „zwanzigtausend liang, in den anderen Gemeinden abnehmend zehntausend, acht-, fünf- oder dreitausend“. ${ }^{1001}$

Die Vertreibung der Bevölkerung aus den eroberten Städten, in denen stattdessen Hui angesiedelt wurden, war charakteristisch für das Kampfgeschehen während der Rebellion, so waren auch Hui aus Longling nach Yongchang umgesiedelt worden. Innerhalb der Mauern von Tengyue wurden nun Hui „aus Xilian, Guyong und den Vororten [von Tengyue]“ angesiedelt. ${ }^{1002}$ John Anderson beschreibt die Trennung der Hanvon der Hui- Bevöl-kerung in Tengyue im Jahr 1868 folgendermaßen: Die „breiten rechtwinkeligen Straßen lagen ziemlich verlassen da, abgesehen von einigen PanthaySoldaten, die mit ihren Familien die einzigen Bewohner innerhalb der Mauern waren“; „die ganze Basar-Vorstadt war von einer niedrigen Ziegelmauer mit mehreren Toren umgeben, jedes in der Nacht mit einem Wächter besetzt, und hier wohnten die Chinesen, die offensichtlich aus der Stadt ausgesperrt waren“. ${ }^{1003}$

\footnotetext{
998 TYTZ, S. 194. Nach der Darstellung Cao Kuns hat Mingqing am 20. Tag kapituliert und den Banditen am 21. Tag die Stadttore geöffnet (Cao Kun, S. 225).

Nicht alle Beamte der Stadt stimmten einer Kapitulation zu. Im TYTZ wird besonders das loyale Verhalten des Gefängnisdirektors Zhang Shaoping hervorgehoben, der Vorschläge zur Verteidigung Tengyues gemacht und die anderen Beamten aufgefordert hatte „mit aller Kraft Widerstand zu leisten und das Leben für ihr Land zu opfern. Aber in der Kommandantur waren alle stumm geblieben“. Unverrichteter Dinge war Zhang heimgegangen, wo er gemeinsam mit seiner Familie aus Loyalität Selbstmord beging, denn die „Familie ist dem Land seit Generationen treu gewesen. Wie könnte es da sein, daß wir uns, nur um lebend zu entkommen, den Banditen ergeben?“ (TYTZ, S. 150; 235).

999 TYTZ, S. 195. Auch die Hui-Armee hatte Verluste zu beklagen: „Am 11. Tag des 12. Monats zerstörten sie Dörfer in der Umgebung von Guyong [im Norden von Tengyue]. Die Gemeindevorsteher (lianmu) Hong und Zhai ließen dort insgeheim ein großes Geschütz (da pao) aufgestellen, mit dem sie am 12. Tag [den General] Cai Qier erschossen. Die Banditen erschraken und wurden vernichtend geschlagen, doch später nahmen sie die Belagerung [von Guyong] wieder auf“ (TYTZ, S. 194). Cai Qier war ein enger Verbündeter Du Wenxius; er hatte den Waffenstillstand mit Ma Rulong im Osten ausgehandelt und das westliche Yunnan besetzt und damit die Grundlage für das Fortbestehen des Sultanats von Dali geschaffen.

${ }^{1000}$ Cao Kun, ,Tatsachenbericht‘, S. 225; Wei, S. 197-198, 228

1001 Ebenda., S, 225

1002 Ebenda.

${ }^{1003}$ Anderson, S. 192, 201
} 
In der Unterpräfektur Tengyue waren die folgenden Jahre von Kämpfen zwischen Truppen der Hui, die im Zeichen der weißen Fahne kämpften, und denen der Han, deren Zeichen die rote Fahne war, um die Vorherrschaft in den verschiedenen Ortschaften geprägt. Die Han-chinesischen Milizen von Liu Guanghuan und Yin Yi unterstützten sich gegenseitig und konnten sich weiterhin gegen die Hui behaupten. Li Zhenguo hatte die Unterstützung des tusi von Ganya gewinnen können. ${ }^{1004}$ Zwei Jahre später begannen die Hui eine neue Offensive nach Südwesten; Daxilian und Heshun wurden besetzt, außerdem eroberten sie Ganya; der tusi von Husa kapitulierte. ${ }^{1005}$

Immer wieder gelang es jedoch den chinesischen Milizen, die Handelswege nach Birma zu blockieren, so daß der Fernhandel ganz zum Erliegen kam und die Regierung in Dali keine Waren (vor allem Baumwolle, aber auch Waffen waren aus Birma geliefert worden) mehr aus dem Westen beziehen konnte. Li Zhenguo hingegen nutzte seine familiären Beziehungen, um weiterhin Handel mit Birma zu treiben.

In Tengyue veschlechterte sich die Lage der verbliebenen Bevölkerung zusehends:

„Im 4. Jahr der Ära Tongzhi (1865) übernahmen die Banditen des PseudoGenerals, der die Ferne befriedet (wei suiyuan jiangjun), Xie Guangmei und des Pseudo-Generals der Kavallerie (wei cheqi jiangjun) Ma Nianyu die Verteidigung von Teng. Rücksichtslos schickten sie ihre Truppen [überall hin]. Das Leben der Menschen wurde unerträglich. Die Räuber schwärmten herbei wie ein Bienenschwarm. Der Preis für Reis stieg enorm an: Jeder sheng kostete 240 Kupfermünzen. Viele Einwohner starben den Hungertod“،. 1006

Im Jahr 1866 entsandte Du Wenxiu neue Truppen in die Region des Stromschluchtenfächers und ernannte den General Li Guolun zum neuen Oberbefehlshaber (dasikong) von

\footnotetext{
${ }^{1004}$ Noch während sich Li Zhenguo in Ganya aufhielt, war es den Rebellen gelungen, seinen Stützpunkt Jiucheng (bei Ganya) anzugreifen und seine Frau, ,eine geborene Yang, mit ihrem Kind und Dienerinnen, insgesamt vier Personen gefangenzunehmen“.Die Rebellen veranlaßten Frau Yang, ein Schreiben an ihren Mann zu senden, mit der Aufforderung, die Waffen niederzulegen und Verhandlungen aufzunehmen. Die Rebellen „hatten ihr erklärt, wenn ihr Mann den Vorschlag akzeptiert, dann würden Mutter und Sohn zu ihm zurückgeschickt werden. Frau Li ging zum Schein darauf ein, aber [am vereinbarten Treffpunkt] am Ufer des Flußes Xuanmao [angelangt] rief sie Zhenguo mit einem Mal mit lauter Stimme [eine Warnung] zu ... Daraufhin wollte sie in den Fluß springen. [Als sie dies gehört hatten, waren] die Banditen voller Haß zum Flußufer geeilt und hatten sie getötet“; später wurde für Frau Yang eine besondere Gedenkstätte errichtet (TYTZ, S. 235). Ihr kleiner Sohn wurde von einem der Hui-Soldaten in seiner Familie aufgezogen, er heiratete später eine Tochter der Familie. Als er die Wahrheit über seine Herkunft erfuhr, war sein Vater bereits gestorben und er schloß sich dann Gouverneur Cen Yuying an (Cao Kun, ,Tatsachenbericht‘, S. 226-227).

${ }^{1005}$ Cao Kun, ,Tatsachenbericht', S. 228

1006 TYTZ, S. 195. Das Hohlmaß sheng entspricht einem Liter.
} 
Tengyue. Um seine Position zu festigen und auch Unterstützung bei der Han-chinesischen Bevölkerung zu gewinnen, ergriff Li Guolun verschiedene Maßnahmen, um die Ordnung in der Stadt wiederherzustellen. Unter seiner Herrschaft wurden Bodensteuern nun nur einmal pro Jahr eingezogen und zusätzliche Abgaben abgeschafft, die Bevölkerung wurde aufgefordert, Brachland wieder urbar zu machen, Befugnisse wurden geregelt und die Armee geordnet, außerdem ließ Li Banditen konsequent festnehmen und auch Hui, die gegen Gesetzte verstießen, entsprechend den Gesetzen bestrafen; „für die Bevölkerung von Tengyue, die solange in Not und Elend gelebt hatte, war das schon fast wie eine Wiedergeburt“. 1007

Im Jahr 1867 hatten die Hui von Dali im westlichen Yunnan cirka sechzigtausend Soldaten in fünfundzwanzig Städten bzw. Militärstützpunkten aufgestellt. In Yongchang und Tengyue waren jeweils etwa zehntausend Mann stationiert, in Yongping zweitausend, weitere Garnisonen standen in Longling und Shunning, mit je zwei- bis dreitausend Mann. ${ }^{1008}$ Trotz der starken Truppenpräsenz gelang es den Hui nicht, die Region des Stromschluchtenfächers gänzlich zu befrieden. Im Jahr 1868 erreichten die Kämpfe wieder einmal die Stadt Tengyue selbst:

„Im 11. Monat des Jahres Tongzhi 7 (1868) versammelten Liu Guanghuan, Li Zhenguo, Jiang Xiangshi und andere ihre Truppen und griffen die Stadt an. Li Guolun schickte seine Banditen-Soldaten, um sie zu verteidigen“. ${ }^{1009}$

Die Verteidigung war erfolgreich, die Belagerer konnten Tengyue nicht erobern. In den folgenden Jahren war die Lage in der Stadt unter der Herrschaft Li Guoluns relativ friedlich.

Im Mai des Jahres 1868 erreichte die britische Expedition aus Niederbirma unter dem Kommando von Major E. B. Sladen Tengyue. Ihr Ziel war es, die Gründe für die Unterbrechung des Handels zwischen Yunnan und Birma festzustellen. Sie wurden von General Li Guolun freundlich empfangen, da er ebenso wie auch Du Wenxiu in Dali daran interessiert war, den profitablen Fernhandel wieder aufzunehmen. Eine Weiterreise nach

\footnotetext{
${ }^{1007}$ Cao Kun, ,Tatsachenbericht', S. 229; siehe auch Wei, S. 226

${ }^{1008}$ Wei, S. 220-222, Tab. 6

1009 TYTZ, S. 195. Jiang Xiangshi aus Daxi führte zusammen mit seinem Bruder eine Bürgermiliz (tuanlian) an, die einige Jahre erfolgreich gegen die Rebellen kämpfte; Jiang und über vierhundert seiner Leute wurden später bei Kämpfen in Wusuo getötet (TYTZ, S. 223).
} 
Dali war für die Expedition aufgrund der unsicheren Lage in der Region nicht möglich, so daß die Briten nach einem zweiwöchigen Aufenthalt in Tengyue wieder nach Birma zurückkehrten. Dr. John Anderson, der Arzt der Gruppe, hat im Anschluß an die Expedition einen ausführlichen Reisebericht verfaßt, aus dem im Folgenden einige Abschnitte zitiert werden, die die Auswirkungen der Rebellion auf Tengyue und seine Bevölkerung deutlich machen.

Auf seinem Weg in die Stadt zum ersten Empfang im Gebäude der Unterpräfekturverwaltung bei General Li Guolun (,einem kräftigen ein Meter neunzig großen Mann ..., in dessen Gesicht etliche Narben auf die Teilnahme an vielen Kämpfen verwiesen“) bemerkte Anderson zunächst „eine große manierliche Menge verarmter Chinesen, deren Erscheinungsbild den zerstörten Häusern in den Vorstädten entsprach“، ${ }^{1010}$

Bei einem Besuch auf dem Markt in der südwestlichen Vorstadt traf er auf eine „dichte Menge von Chinesen, Shan und Panthays [Hui], dazwischen einige Lisu und Kachin“. An den Ständen fand sich ein reiches Angebot an Obst und Gemüse (darunter auch Kartoffeln, die in der Nähe des Dieshuihe-Wasserfalls angebaut wurden), obwohl es zuvor eine lange Zeit der Dürre gegeben hatte. ${ }^{1011}$ Gehandelt wurden zudem chinesische und englische Stoffe, Schmuck aus Bernstein und Jade sowie Geflügel, Büffel, Schweine, Schafe, Pferde und Maultiere. In Seitenstraßen gab es Schneidereien, Kupferschmiede, Werkstätten für Jadebearbeitung und andere Geschäfte, die Medizin oder Bücher anboten sowie etliche Gaststätten. ${ }^{1012}$

Anderson zeichnet das Bild eines lebhaften Marktes, weist aber auch darauf hin, daß viele Ruinen davon zeugen, daß der Markt früher noch sehr viel größer gewesen ist. „Mit Ausnahme dieses von einer Mauer umgebenen Basars, sind die einst dicht bevölkerten Vorstädte von Tengyue nur noch Ruinen“, nur „die Häuser in einem kleinen Gebiet im Norden, die von schönen Gärten umgeben sind und zwischen dem Fluß und der Stadtmauer liegen, sind der Zerstörung entgangen“. ${ }^{1013}$

Nicht nur in der Stadt, auch in den Ortschaften in der Umgebung bestimmten Ruinen und Gräber die Landschaft. In den Ruinen der demolierten Tempel und Klöster lebten nur noch

\footnotetext{
${ }^{1010}$ Anderson, S. 193

${ }^{1011}$ Ebenda, S. 199, 200, 205

1012 Ebenda, S. 205

1013 Ebenda, S. 214
} 
einzelne Mönche, nur in einem Tempel exisitierte noch eine Schule. ${ }^{1014}$ Auch im Südwesten der Stadt bot sich ein Bild der Zerstörung: Heshun (das reichste Dorf der Gegend) war von den Hui erobert und seine Bevölkerung ermordet worden; nun hatten viele Flüchtlinge innerhalb seiner Umfassungsmauern Zuflucht gefunden. ${ }^{1015}$

Abschließend faßt Anderson den Zustand Tengyues und seiner Bevölkerung noch einmal zusammen: „Armut in unterschiedlichem Ausmaß charakterisiert all die unglücklichen Einwohner der zerstörten Vorstädte, die die fast leere Stadt umgeben; ... äußerste Trostlosigkeit und Zerstörung sind das Ergebnis der lange andauernden Kampfhandlungen“. ${ }^{1016}$

Und die Kämpfe gingen auch in den folgenden Jahren weiter. 1871 und 1872 griffen Li Zhenguos Truppen die Stadt wiederholt an. Zu dieser Zeit hatten die Regierungstruppen bereits Dali erobert. Anschließend entsandte Gouverneur Cen Yuying Truppen in die Region des Stromschluchtenfächers, darunter eine Armee von fünftausend Mann, die nach Tengyue zog:

„Gouverneur Cen Yuying beauftragte den Kommandeur des Militärbezirks Tengyue Li Weishu, den Provinz-Militärkommandanten Xu Liankui, den Brigade-Kommandanten Wang Cheng und den Unterpräfekten Lin Guiqing, ihre Truppen [nach Westen] zu führen und [die Moslem-Banditen] zu vernichten. Brigade-Kommandant Wang Cheng hatte schon zuvor mit aller Macht den Schlupfwinkel der Banditen in Majiacun angegriffen“.

„Am 5. Tag des 5. Monats des Jahres Tongzhi 12 (1873) brachten Xu Liankui, Li Weishu, Unterpräfekt Wu Qiliang und die Anderen die Stadtmauer an drei Ecken durch Artilleriebeschuß zum Einsturz. Die Banditen hatten daraufhin nicht mehr die Kraft weiter Widerstand zu leisten“. ${ }^{1017}$

Li Guolun war jedoch die Flucht aus der belagerten Stadt nach Wusuo gelungen. Als die Regierungstruppen 1874 Wusuo eroberten, konnte er erneut fliehen und zog sich auf den Berg Yunfengshan im Norden von Tengyue zurück. Auch dort konnte er der Umzingelung seiner Verfolger wieder entkommen.

\footnotetext{
1014 Anderson, S. 209, 214-215, 217-218

1015 Ebenda, S. 213

1016 Ebenda, S. 22

${ }^{1017}$ TYTZ, S. 195; siehe auch Cao Kun, ,Tatsachenbericht‘, S. 233
} 
Schließlich gelang es dem neuernannten Brigadekommandanten (youji) für Tengyue, Ding Huai,

„den Pseudo-Minister Li Guolun am 4. Tag des 7. Monats am Heishan-Tor bei der Poststation Ganlan gefangenzunehmen. Dann ließ er ihn enthaupten. Damit waren die militärischen Auseinandersetzungen in Tengyue zu Ende“. ${ }^{1018}$

Die Chronologie der Ereignisse in der Unterpräfektur, die Berichte von Kämpfen, Vertreibung und Zerstörung, verweist nur indirekt auf die große Anzahl von Menschen, die während der Moslem-Rebellion umgekommen sind. Bevölkerungszahlen aus jenen Jahren gibt es nicht und da auch alte Register während der Kämpfe zerstört worden sind, fehlen Angaben dazu, wieviele Menschen aus Tengyue im Verlauf der Rebellion umgekommen sind. Die letzte Registrierung der Bevölkerung vor der Rebellion war im Jahr 1823 erfolgt, bei der 48.512 Haushalte und 373.870 Personen in der Unterpräfektur gezählt worden waren. ${ }^{1019}$ Als im Jahr 1879 erstmals wieder die Bevölkerungszahlen in der Unterpräfektur Tengyue zusammengestellt wurden, waren es nurmehr 10.936 Haushalte bzw. 55.407 Personen: Lediglich ein Viertel aller Haushalte bzw. ein Sechstel der Einwohner der Unterpräfektur hätten demnach die Rebellion überlebt. ${ }^{1020}$

Stellvertretend für die vielen Opfer der Rebellion sind im TYTZ insgesamt einhundertzweiundachtzig ,Märtyrer‘(zhonglie) aufgelistet worden: Männer, die wärend der MoslemRebellion in der Stadt Tengyue oder in den Dörfern und Gemeinden der Unterpräfektur umgekommen sind. Manche sind nur mit Namen genannt, einige zudem mit ihren akademischen oder Amtstiteln, bei anderen wird ihr Kampf gegen die Rebellen kurz geschildert. $^{1021}$

Am Ende der Liste werden zudem achtzehn ,anständige Hui‘ (liang Hui) besonders erwähnt, die sich nicht den Rebellen angeschlossen, sondern (zum Teil mit ihrer ganzen Familie) Selbstmord begangen hatten. Sie waren fast alle Männer mit einem gewissen

\footnotetext{
1018 TYTZ, S. 195. Anmerkung im TYTZ: „Schon Ding Huais Vater, Ding Fengzhang, hatte sich bei der Verteidigung der Stadt Yongbei blutige Kämpfe mit Li Guolun geliefert. Als [den Verteidigern] in den folgenden Jahren die Lebensmittel ausgingen und auch keine Unterstützung kam, opferte Ding am 4. Tag des 7. Monats des Jahres Tongzhi 3 (1864) sein Leben. Welch ein unerwartetes Zusammentreffen, daß [sein Sohn] ihn nun am selben Tag des selben Monats im 13. Jahr ergreifen und Rache [für seinen Vater] nehmen konnte“ (TYTZ, S. 195). Ding Huai stammte aus der Unterpräfektur Heqing (Präfektur Lijiang); er hatte verschiedene Ämter innerhalb der Militärhierarchie von Tengyue inne (youji, dusi, shoubei) und wurde schließlich im Jahr 1886 (Guangxu 12) ebenda zum Regionalkommandeur befördert (TYTZ, S. 131). ${ }^{1019}$ TYTZ, S. 50

${ }^{1020}$ Ebenda; siehe auch YCFZ, S. 99.

${ }^{1021}$ TYTZ, S. 218-221
} 
gesellschaftlichen Status, die zu den Beamtenprüfungen (zivilen und militärischen) zugelassen waren (wensheng, wusheng), verschiedene akademische Titel (juren, lingong, jiansheng) erworben oder sich einen Beamtenstatus erkauft hatten (juan zhi), einer von ihnen war als Vorsteher der Kontrollstation (qia liantou) von Guyong tätig gewesen. ${ }^{1022}$ Mangels weiterer Angaben läßt sich über die Gründe für die Selbstmorde nur spekulieren. Der ausdrückliche Hinweis auf diese Männer verbunden mit der Nennung ihrer Titel, deutet darauf hin, daß die Verfasser des Lokalhandbuches dieses Verhalten als Ausdruck der Loyalität gegenüber dem Kaiserreich interpretiert haben. Die Hervorhebung dieser ,anständigen Menschen“ (liang), die den in den fangzhi häufig genannten ,Moslem-Banditen“ (Hui fei, zei) quasi gegenüberstellt werden, zeigt den Ansatz einer differenzierteren Betrachtungsweise der jüngsten Ereignisse, die die Bevölkerungsgruppe der Hui nicht pauschal verurteilt, sondern die Komplexität der Rebellion berücksichtigt.

Daß auch die Frauen in der Unterpräfektur zu den Opfern der Rebellion gehörten, wird in der Auflistung der verstorbenen ,tugendhaften Frauen“ (lienü) hervorgehoben, dem einzigen Kapitel der Lokalhandbücher, in dem überhaupt auf die weibliche Bevölkerung von Tengyue Bezug genommen wird. ${ }^{1023}$

Hier werden insgesamt dreiundsiebzig Frauen genannt, die während der Moslem-Rebellion umgekommen sind. ${ }^{1024}$ Die meisten von ihnen (52 von 73) haben Selbstmord begangen, um nicht in die Hände der Rebellen zu fallen. Bei der Mehrzahl derer, die von den Rebellen getötet wurden (14 von 21), wird ausdrücklich darauf hingewiesen, daß die Frauen jene vor ihrem Tod noch beschimpft hatten. ${ }^{1025}$ Andere Möglichkeiten der Gegenwehr lagen auch kaum in ihrer Macht. Dennoch leisteten einige Frauen, wie aus der Liste der ,tugendhaften Töchter، (lienü) ersichtlich wird, sehr energisch Widerstand. Wie zum Beispiel die zwanzigjährige Wang Zhendi aus Guyong:
„Als die Banditen im Jahr Xianfeng 11 (1861) ihr Dorf zerstörten, ergriff sie eilends ein Gewehr, mit dem sie auf die Banditen schoß und einen verwundete. Danach schnitt sie sich die Kehle durch. Die Banditen zerstückelten ihren Leichnam“. ${ }^{1026}$

\footnotetext{
1022 TYTZ, S. 221

1023 TYTZ, Kapitel 14, S. 229-238; siehe auch TYZZ, S. 131-133 und YCFZ, S. 312-328.

${ }^{1024}$ Darunter 38 ,tugendhafte Ehefrauen“ (zhenlie) und 35 ,tugendhafte Töchter (lienü) (ebenda). Die weit größere Gruppe der in diesem Kapitel aufgelisteten Frauen (172 insgesamt), bilden jedoch die wegen ihres tugendhaften Lebenswandels oder pietätvollen Verhaltens genannten Frauen (TYTZ, Kapitel 14, S. 229-234).

1025 TYTZ, S. 235-238

${ }^{1026}$ TYTZ, S. 237
} 
Auch die neunzehnjährige Hong Chengfeng aus Guyong setzte sich tatkräftig, wenn auch vergeblich, zur Wehr, als sie im Jahr 1858

„von einem Banditen gefangengenommen wurde, der sie fesselte und auf seinem Rücken davontrug. Sie schimpfte laut und schließlich gelang es ihr, dem Banditen mit der Hand ein Auge auszuschlagen. Daraufhin warf der Bandit sie auf den Boden und erschoß sie“. ${ }^{1027}$

Die Schicksale der in den fangzhi namentlich erwähnten Frauen und Männer stehen exemplarisch für die vielen Ungenannten, die der Rebellion zum Opfer gefallen sind. Schon diese kurzen biographischen Notizen lassen die Schrecken der Rebellion und das Leid der Bevölkerung sehr plastisch hervortreten.

Zwei Jahrzehnte lang war das Leben in der Unterpräfektur Tengyue von Kampfhandlungen bestimmt gewesen. Landwirtschaft, Handel, Gewerbe und Industrie waren zum Stillstand gekommen. Viele Dörfer waren geplündert oder zerstört worden, die Stadt Tengyue selbst stand zu großen Teilen leer, öffentliche Gebäude waren verfallen, die Vororte lagen in Ruinen. Überall herrschten, wie John Anderson beobachtet hat, Armut und Trostlosigkeit. Eine Ausnahme bildete lediglich der Markt in der südwestlichen Vorstadt, wo die verschiedenen Bevölkerungsgruppen der Region nach wie vor zusammentrafen und, wenn auch in kleinerem Rahmen als in früheren Zeiten, ein recht vielfältiges Warenangebot präsentierten.

Der Handel war auch der Bereich, in dem sich das Leben am schnellsten wieder normalisierte. Bereits kurz nach der Niederlage des Sultanats von Dali im Jahr 1872 waren erste Karawanen von Yunnan nach Birma unterwegs; in den folgenden Jahren nahm der Fernhandel rasch weiter zu, was erheblich zur Neubelebung der Region des Stromschluchtenfächers beitrug. ${ }^{1028}$

\footnotetext{
${ }^{1027}$ TYTZ, S. 237. Ähnlich erging es Wang Shuquan aus dem Dorf Ganzhe, die 1861 „von den Banditen nach Wusuo verschleppt wurde. Als sie mit einem Messer bedroht wurde, konnte sie dieses an sich reißen und verletzte damit einen der Banditen, ehe sie ihre Hand herumdrehte und sich die Kehle durchschnitt“ (ebd.).

${ }^{1028}$ Anderson, S. 345-346
} 


\section{Tengyue nach der Moslem-Rebellion}

Mit der Rückeroberung der Unterpräfektur Tengyue durch die Regierungstruppen im Jahr 1874 war zwar die Moslem-Rebellion in Yunnan endgültig beendet worden, es sollten jedoch noch einige Jahre vergehen, ehe die Region des Stromschluchtenfächers tatsächlich befriedet werden konnte. Zunächst ereignete sich im Jahr 1875 im Grenzgebiet zu Birma ein internationaler Zwischenfall, der für das chinesische Reich insgesamt weitreichende Folgen hatte. Im Jahr darauf kam es zu einer Revolte unzufriedener Militärs in der Unterpräfektur, die die Stadt Tengyue besetzten, so daß diese erneut von Regierungstruppen zurückerobert werden mußte (siehe 2.3.).

\section{1. Exkurs: Britische Handelsinteressen in Yunnan im 19. Jahrhundert}

Schon die Expedition nach Tengyue im Jahr 1868 hat das Interesse Großbritanniens am Handel mit China über Birma und Yunnan gezeigt. Das Geschehen des Jahres 1875 stand ebenfalls in engem Zusammenhang mit den britischen Handelsinteressen, die die weitere Entwicklung Birmas aber auch des Grenzgebietes und der Provinz Yunnan beeinflußten und auf die deshalb hier zunächst zusammenfassend hingewiesen wird, um den Kontext der Ereignisse zu verdeutlichen.

Im 19. Jahrhundert war das Interesse westlicher Nationen, besonders der Briten an Yunnan, von dem Bestreben geprägt, die alten Handelswege zu nutzen, um Zugang zu den im Innern Chinas erwarteten Märkten zu gewinnen. Bereits in den Jahren 1684 und 1685 hatte die britische East India Company Captain Peter Dod nach Birma entsandt, nicht nur um über einen Handelsvertrag mit dem König von Ava zu verhandeln, sondern auch um festzustellen, ob die Möglichkeit bestünde, Handelsverbindungen mit China über Bhamo zu knüpfen. ${ }^{1029}$ Auch wenn dem Plan zu jener Zeit noch kein Erfolg beschieden war, so macht er doch deutlich, daß das britische Interesse an Birma auch in dieser frühen Zeit durchaus schon im größeren Zusammenhang des Handels mit China gesehen wurde.

Nach der Eroberung Arakans und Tenasserims im Jahr 1826 wurden verschiedene Verbindungen des britischen Empire mit China vorgeschlagen, sei es von Assam oder von Moulmein ausgehend. Die Bemühungen, diese Pläne zu realisieren, verstärkten sich nach dem 2. Anglo-Birmanischen Krieg von 1852. Einzelne Strecken wurden von Expeditionen erkundet und es wurde versucht, die im Grenzgebiet ansässigen Völker ebenso wie

${ }^{1029}$ Woodman, S. 27 
Händler aus China für das Projekt zu gewinnen. Die Priorität, die die Briten in ihrer BirmaPolitik setzten, machte der Secretary of State, Lord Cranbourne, deutlich: „[Birma] selbst ist nicht von großer Bedeutung. Aber eine günstige Verbindung zu den Massen, die das westliche China bewohnen, ist eine Angelegenheit von nationaler Bedeutung“. ${ }^{1030}$

Zwei in den Jahren 1862 und 1867 mit König Mindon abgeschlosse Handelsverträge verschafften den Briten eine Basis in Oberbirma, die die weitere Erkundung der Routen nach China ermöglichte. Im Jahr 1867 machte sich dann eine von Handelskreisen in Rangun finanzierte Expedition unter der Leitung von Colonel Sladen, dem Britischen Agenten in Mandalay, von Bhamo aus auf den Weg nach Yunnan. Wegen des Moslem-Aufstandes in der Provinz konnte sie nicht über Tengchong hinaus gelangen, welches zu dieser Zeit von den Aufständischen besetzt gehalten wurde. Diese waren zwar auch an der Wiederaufnahme des Handels und besonders an der Unterstützung durch den Britischen Agenten sowie am Erwerb von Waffen interessiert, die instabile Lage innerhalb der Provinz und die Kämpfe in der Region verhinderten jedoch regelmäßige Handelsbeziehungen. Erst nach der Niederschlagung des Aufstandes durch die chinesische Regierung im Jahr 1873 kamen wieder chinesische Handelskarawanen nach Bhamo. Obwohl Colonel Sladen nach seiner ersten Expedition deutlich gemacht hatte, daß die tatsächlichen Handelsmöglichkeiten weit hinter den Erwartungen zurückblieben, gab es in britischen Handelskreisen weiterhin eine starke Lobbyisten-Gruppe, die sich für die Entwicklung des Handels über Yunnan und den Ausbau der Überlandverbindungen nach China einsetzte. ${ }^{1031}$

Als 1872 eine birmanische Mission in Europa neben England auch Italien und Frankreich besuchte, wurden auch wieder Stimmen laut, die vor französischem Einfluß in der Region warnten, der tatsächlich zwar kaum bemerkbar war, in der Diskussion über das weitere britische Vorgehen in Birma jedoch ein nützliches Argument für eine offensivere Politik gegenüber dem Königreich in Oberbirma lieferte. ${ }^{1032}$

Um ihren Einfluß auch auf der anderen Seite der Grenze, in der Provinz Yunnan selbst zu festigen, nutzten die Briten einen Zwischenfall, der sich bei der Expedition Colonel Sladens nach Yunnan im Jahr 1875 ereignet hatte (s.u. 2. 2.). Der von den Briten ausgeübte Druck auf die Untersuchung des Vorfalls mündete in das ,Chefoo-Agreement` von 1876, in dem sie der chinesischen Regierung verschiedene Konzessionen abforderten. ${ }^{1033}$

\footnotetext{
${ }^{1030}$ Lord Cranbourne (später Lord Salisbury; 1885: Foreign Secretary), Dezember 1866; zitiert nach Woodman, S. 184.

${ }^{1031}$ Woodman, S. 188, 194

${ }^{1032}$ Ebd., S. 194, 197

1033 Ebd., S. 199
} 
Bei all diesen Aktivitäten wurde immer deutlicher, daß die Annektion Oberbirmas für die Realisierung direkter Handelsverbindungen unabdingbar war. Während die Regierung zu diesem Schritt zunächst noch nicht bereit war, setzten sich die Handelskammern und Verbände sowohl in Rangun als auch in London intensiv für die Annektion ein und sollten mit ihrem Drängen schließlich Erfolg haben. Mit einer Mission nach Frankreich im Jahr 1883 versuchte Birma dem Druck der Briten entgegenzuwirken, letzlich gelang es der birmanischen Regierung jedoch nicht, die Rivalitäten der beiden Kolonialmächte für sich zu nutzen. Eher diente diese Maßnahme den Briten, die ihren wirtschaftlichen Interessen nun auch noch ein politisches Argument hinzufügen konnten, obwohl ihnen spätestens seit September 1885 bekannt war, daß Frankreich zwar am Handel mit Birma interessiert war, jedoch keineswegs eine politische Vorherrschaft über Oberbirma anstrebte. ${ }^{1034}$

Wie der Handel mit dem Südwesten Chinas zu jener Zeit tatsächlich aussah, macht der Vizekönig von Indien, Lord Dufferin, 1886 deutlich: „Aus verschiedenen Gründen ist der Yunnan-Handel zur Zeit unbedeutend, er kann jedoch erheblich ausgeweitet werden ...“. ${ }^{1035}$ Gerade diese Hoffnung auf eine Steigerung des Handelsvolumens war schließlich der Hauptgrund für die weitere Expansion des Britischen Empire. Dem stand weniger die französische Konkurrenz im Wege, als die Tatsache, daß „das schwerwiegendste Hindernis in der Entwicklung des Handels auf dem Irawadi darin besteht, daß sich zwischen BritishBurma und Yunnan ein gänzlich unabhängiges birmanisches Königreich befindet“ “ ${ }^{1036}$

Mit der im November 1885 erfolgten Eroberung Oberbirmas bestand dieses Hindernis nicht länger. Im Dezember 1885 erreichten britische Truppen die Stadt Bhamo, in der sie eine Garnison einrichteten. Das britische Empire war nun direkter Nachbar des chinesischen Reiches geworden und hatte mit Bhamo einen wichtigen Knotenpunkt des chinesisch-birmanischen Handels unter seine Kontrolle gebracht. Dessen Zentrum verlagerte sich nun vom ,alten‘ weiter östlich gelegenen Bhamo (Manmo) hin zum ,neuen‘ Bhamo, direkt am Ufer des Irawadi. Verschiedene Maßnahmen der Briten, wie die Verbesserung der Verkehrswege zu Wasser und zu Land, trugen zum Aufschwung des Handels an der Wende zum 20. Jahrhundert bei. Eine Entwicklung, die schließlich dazu führen sollte, daß Tengyue im Jahr 1902 den Status eines ,Vertragshafens‘ (treaty port) erhielt und ein kaiserliches Seezollamt (Imperial Maritime Customs) gegründet wurde. ${ }^{1037}$

\footnotetext{
${ }^{1034}$ Woodman, S. 229

${ }^{1035}$ Ebd., S. 230

${ }^{1036}$ Lord Dufferin, um 1886, zitiert nachWoodman, S. 230.

1037 Nach Mengzi (1889) und Simao (1897) war Tengyue die dritte Stadt in Yunnan, in der ein Zollamt eröffnet wurde. Dieses unterhielt Zweigstellen in Manwyne (Manyun), Longzhangkai (in Ganya) und ab März 1903 auch in Longling (Tengyue Trade Report, 1903, S. 916).
} 


\section{2. Ein Zwischenfall im Grenzgebiet: Die ,Margary-Affäre`}

Im Jahr 1875 verließ eine britische Expedition unter der Leitung von Colonel Horace Brown Bhamo. Der Gruppe hatte sich auch der Konsularbeamte Augustus Margary angeschlossen, der zunächst ganz China durchquert hatte, um von Peking nach Bhamo zu gelangen. Ziel der Expedition war es, das südwestliche China und die Verkehrsverbindungen nach Zentralchina zu erkunden. Zu diesem Zweck sollten ihre Teilnehmer von Birma nach Yunnan und dann weiter bis nach Shanghai reisen. ${ }^{1038}$

Noch im Grenzgebiet Yunnans, bei Manyun im Tal des Dayingjiang (nahe der modernen Staatsgrenze von China und Birma) wurde die Expedition angegriffen und ihre Vorhut, zu der auch Margary gehörte, von einer bewaffneten Gruppe, vermutlich Kachin und Chinesen, getötet. ${ }^{1039}$ Die anderen Expeditionsteilnehmer kehrten daraufhin nach Birma zurück. Die genauen Umstände des Angriffs konnten in dieser unruhigen Zeit kurz nach der Niederschlagung der Moslem-Rebellion nie geklärt werden. Ob es nun einheimische ,Banditen` waren oder Truppen, die auf Veranlassung Li Zhenguos und anderer Beamter von Tengyue (die in den Handelsbeziehungen, die die Briten mit den Kachin und Shan geknüpft hatten, sowie der Gründung einer britischen Vertretung in Bhamo 1869 auch eine politische Einflußnahme auf das Grenzgebiet befürchteten) gehandelt haben, wie Generalgouverneur Cen Yuying nach Peking berichtete, blieb fraglich. ${ }^{1040}$

Dieser Zwischenfall im Grenzgebiet Yunnans hatte allerdings ein politisches Nachspiel mit weitreichenden Folgen für das Qing-Reich. Der britische Gesandte in Peking, Sir Thomas Wade, spielte die Angelegenheit hoch, drohte mit Abbruch der diplomatischen Beziehungen und militärischer Intervention und konnte so den Abschluß des britisch-chinesischen Vertrages von Zhifu (Chefoo-Agreement;1876) erzwingen, der die Öffnung weiterer Vertragshäfen und Steuervergünstigungen für Importwaren beinhaltete. ${ }^{1041}$

Auch in Bezug auf die Provinz Yunnan mußte sich die chinesische Regierung zu Konzessionen bereit erklären: Die neuen Handelsvorschriften wurden auf den Birma-Handel angewendet; zudem erhielten die Briten die Erlaubnis, Expeditionen nach Yunnan zu entsenden und dort auch britische Beamte zu stationieren. ${ }^{1042}$

\footnotetext{
${ }^{1038}$ Zur Expedition von 1875 und den Geschehnissen, die zum Tod Margarys führten,siehe Anderson, Kapitel XII - XVI.

${ }^{1039}$ Wang Shen-tzu, S. 51

1040 Siehe auch Anderson, S. 337.

${ }^{1041}$ Aufgrund des Vertrages von Zhifu wurden Beihai (Pakhoi), Wuhu und Yichang (Ichang) als Vertragshäfen geöffnet (Elder, S. XXVII-XXVIII).

${ }^{1042}$ Woodman, S. 199
} 
Außerdem mußte China eine ,Sühnemission“ nach Großbritannien entsenden. Der Leiter der Mission, Guo Songdao, blieb anschließend in London und so wurde infolge eines Zwischenfalls im Grenzgebiet im Westen Yunnans im Jahr 1877 zum ersten Mal ein chinesischer Botschafter im Ausland akkreditiert. ${ }^{1043}$

\section{3. Die Militärrevolte und der Kampf um Tengyue im Jahr 1876}

Im Frühling des Jahres 1876 (Guangxu 2) hatten Untergebene des Kommandeurs Li Fengxiang vom Regionalen Militärbezirk Tengyue und des Brigade-Kommandanten Wang Cheng (beide waren maßgeblich an der Niederschlagung der Moslem-Rebellion in der Präfektur Yongchang beteiligt gewesen) einen Aufruhr angezettelt, der sich rasch ausbreitete. ${ }^{1044}$ Einen Monat danach rebellierten Soldaten aus der Garnison in Tengyue. Ihr Anführer Su Kaixian

„hatte zunächst von Unterpräfekt Zhou Weisun (seit 1875 im Amt) den Sold verlangt; als dieser der Forderung nicht nachkam, plünderten [Su und seine Leute] das Amt der Unterpräfektur, wobei ein Stabsoffizier erschossen wurde. Dann bemächtigten sie sich des Waffendepots und des Getreidespeichers. Regionalkommandeur Duan Ruimei ergriff eiligst die Flucht“. ${ }^{1045}$ „Unterpräfekt Zhou Weisun kapitulierte. ... Die Stadt Shunning wurde ebenfalls [von rebellierenden Militärs] besetzt und in der Stadt Yong[chang] herrschte Ausnahmezustand“. ${ }^{1046}$

He Yao, stellvertretender Regionalkommandeur (shu Tengyue zhen) von Tengyue, hatte seine Truppen nach Yongchang geführt und konnte dort einen der Anführer des Aufruhrs festnehmen, die anderen flohen in die Berge, wo sie von Soldaten umzingelt, gefangengenommen und schließlich enthauptet wurden. Da die Truppen aus Tengyue im Norden der Unterpräfektur engagiert waren und die leitenden Beamten keinen Widerstand organisierten, konnte sich die Revolte in Tengyue weiter ausbreiten. Hinzu kam noch, daß

„ein daoistischer Magier namens Wang in Zhanda einige hundert törichte Banditen $(y u$ fei) um sich geschart hatte. Heimlich verschwor er sich nun mit dem Rebellen Su und eroberte [mit seinen Leuten] überraschend Nandian und

\footnotetext{
1043 Osterhammel, S. 156; Hummel, S. 745

1044 YCFZ, S. 144

1045 TYTZ, S. 195-196

${ }^{1046}$ YCFZ, S. 144
} 
rückte dann weiter in Richtung auf die Stadt [Tengyue] vor. ... Zunächst aber griff er das Dorf Heshun an, das er rücksichtslos ausplündern ließ““. ${ }^{1047}$

Da der Aufruhr in Yongchang inzwischen niedergeschlagen worden war, führte der VizeRegionalkommandeur von Tengyue, Ding Huai, seine Truppen zurück nach Südwesten. Nachdem sie unterwegs die Anhänger Su Kaixians, die die Hauptverkehrsroute besetzt gehalten hatten, vertreiben konnten, eroberten Dings Soldaten auch Heshun zurück. Anschließend begann ein einmonatiger Kampf um die Stadt Tengyue, die zunächst von den Regierungstruppen umzingelt wurde. Da ein direkter Angriff auf die massiven Stadtmauern keinen Erfolg versprach,

„wurde Tag und Nacht an einem Tunnel gegraben. Viele Bunker (diao) der Banditen in der Nähe der Mauer konnten dann zerstört werden. Alle Straßen wurden von Soldaten versperrt, so daß niemand heraus konnte. Die Lage in der Stadt war so prekär wie ein Stapel angehäufter Eier““. ${ }^{1048}$

Doch erst als Provinz-Militärkommandant Yang Yuke, der sich zu dieser Zeit in Yongchang aufhielt, Hilfstruppen nach Tengyue entsandte, die mit ihren Kanonen die Stadtmauer an mehreren Stellen zum Einsturz brachten, konnte die Stadt zurückerobert werden.

„Die Aufrührer Su und Wang [hatten sich nach Mianqing geflüchtet], wo sie von Dorfbewohnern gefangengenommen und [den Regierungstruppen] übergeben wurden. Beide wurden hingerichtet. [Regionalkommandeur] Duan Ruimei war tot. Unterpräfekt Zhou Weisun wurde in die Provinzhauptstadt beordert. Damit war die Revolte von Tengyue (Teng luan) niedergeschlagen.“1049

Die Unruhen in der Präfektur Yongchang im Jahr 1876 sind von unzufriedenen Regierungssoldaten ausgelöst worden; von Soldaten, die zur Niederschlagung der Rebellion in den Westen Yunnans gekommen waren und nun in einem Gebiet stationiert waren, dessen zerstörte Infrastruktur kaum Ressourcen bot. Im TYTZ wird der Grund für ihre Revolte ausdrücklich genannt: Die Forderung der Soldaten nach der Auszahlung des Soldes.

\footnotetext{
1047 TYTZ, S. 196

1048 Ebenda.

${ }^{1049}$ Ebenda. Auch die Stadt Shunning wurde von den Regierungstruppen zurückerobert (YCFZ, S. 144).
} 
Die Finanzierung der Rückeroberung Yunnans war bei der schlechten Finanzlage des Kaiserreiches ohnehin schwierig. Erst nachdem die Rebellionen in Zentralchina niedergeschlagen worden waren, hatte die Zentralregierung Yunnan zusätzliche Mittel aus anderen Provinzen zugewiesen. Gouverneur Cen Yuying beklagte jedoch in einem Memorandum an den Kaiserhof, daß er in den Jahren von 1868 bis 1874 nur knapp die Hälfte der ihm zugesagten Summen erhalten hätte. ${ }^{1050}$ In der Präfektur Yongchang und besonders in Tengyue, der westlichsten Grenzregion Yunnans, die erst 1874 von den Regierungstruppen zurückerobert worden war, hatte sich das Fehlen ausreichender Finanzmittel besonders folgenreich bemerkbar gemacht. ${ }^{1051}$

Die Unruhen in Tengyue waren jedoch nicht allein auf die Revolte der Soldaten beschränkt geblieben, auch ,einige hundert Banditen` aus dem tusi-Gebiet Zhanda hatten sich daran beteiligt. Weitere Erläuterungen gibt es in den fangzhi dazu nicht. Diese pauschal als ,Banditen` bezeichnete Gruppe weist auf die vielen entwurzelten Einwohner der Unterpräfektur hin, die während der Moslem-Rebellion aus ihren Heimatorten geflohen bzw. vertrieben worden waren und sich dann im Grenzgebiet durchschlagen mußten. Insgesamt machen die Ereignisse das allgemeine Machtvakuum deutlich, daß in der Zeit direkt nach der Moslem-Rebellion in Tengyue und der Grenzregion herrschte.

Es vergingen jedoch nur wenige Jahre, bis die Maßnahmen der Beamten zur Restauration der Region des Stromschluchtenfächers Erfolge zu zeigen begannen. Als es im Gebiet der Präfektur Yongchang im Jahr 1879 erneut zu Unruhen kam, weil über einhundert ,Banditen` (tufei) von Gengma (Präfektur Shunning) nach Zhenkang im Süden von Yongchang vorgedrungen waren und den Stützpunkt auf dem strategisch wichtigen Gebirgspaß Yaoguan niedergebrannt hatten, waren die im Kreis Baoshan stationierten Regierungstruppen inzwischen wieder soweit reorganisiert, daß sie die ,Banditen“ in einer gemeinsamen Aktion mit einer Bürgermiliz besiegen konnten. ${ }^{1052}$

\footnotetext{
${ }^{1050}$ Wei, S. 275-276. Alice Wei schätzt die Kosten für die Niederschlagung der Moslem-Rebellion in Yunnan insgesamt auf 25 Millionen tael. Vor der Rebellion hätten die Ausgaben für die Provinz Yunnan lediglich etwa eine Millionen tael pro Jahr betragen. Bei Einnahmen von nur ca. 700.000 tael, war die Provinz ohnehin schon auf Unterstützung von der Zentralregierung angewiesen (Wei, S. 277).

${ }^{1051}$ Nach der Niederschlagung der Revolte scheint die Finanzierung der Truppen in der Unterpräfektur besser geregelt worden zu sein, zumindest gibt es in den fangzhi keinen Hinweis auf Schwierigkeiten bei der Finanzierung der Grenzverteidigung bzw. auf weitere Revolten von Soldaten.

${ }^{1052}$ YCFZ, S. 144
} 


\section{4. Die Bevölkerungsentwicklung in Tengyue Ende des 19. Jahrhunderts}

Während der Moslem-Rebellion wurde die Stadt Tengyue zwölf Jahre lang, von 1861 bis 1873, von den Aufständischen besetzt gehalten.

„Während der Ära Xianfeng (1851-1862), der Ära Tongzhi (1862-1875) sowie zu Beginn der Ära Guangxu (1851-1875) hatten die Kämpfe [im Verlauf der Moslem-Rebellion] weit um sich gegriffen. Die Bevölkerung hatte sich zerstreut und so konnte die Anzahl der Haushalte sowie der Personen nicht festgestellt werden.“ ${ }^{1053}$

Erst nachdem Tengyue von den Regierungstruppen zurückerobert worden ist, wurde die Registrierung der Bevölkerung wieder aufgenommen. Dennoch lassen sich die Auswirkungen der Rebellion in der zweiten Hälfte des 19. Jahrhunderts auf die Bevölkerungsentwicklung in der Region des Stromschluchtenfächers durchaus auch aus den in den fangzhi abgedruckten Daten ablesen. Erste Zahlen sind im Jahr 1874 ermittelt und wie zuvor Haushalte und Einzelpersonen gezählt worden. Allerdings liegen Bevölkerungsdaten für das Jahr 1874 nicht aus der Unterpräfektu, sondern lediglich aus dem Handbuch der Präfektur Yongchang vor:

„Im Jahr Tongzhi 13 (1874) [gab es in der Unterpräfektur Tengyue] 10.958 Haushalte (hu) der einheimischen Bevölkerung (tuzhumin).

Männer und Frauen, Erwachsene und Kinder (nan fu da xiao), [alle zusammengerechnet] waren es 56.325 Personen (dingkou)“. ${ }^{1054}$

Im Jahr 1823, dem letztgenannten Jahrgang vor der Rebellion, sind noch 48.512 Haushalte und 373.870 Personen in Tengyue registriert gewesen (siehe oben Tab. 20, S. 241). Nach der Niedeschlagung der Rebellion hatte sich die Anzahl der Haushalte damit um drei Viertel, die der Personen um fünf Sechstel reduziert.

Daß sich die Bevölkerung der Unterpräfektur also nicht nur ,zerstreut' hatte, zeigen zudem die schon erwähnten langen Listen im TYTZ, die die Namen von Männern und Frauen aus Tengyue enthalten, die während der Unruhen umgekommen sind. 
In den folgenden Jahren hat die registrierte Bevölkerung von Tengyue wieder kontinuierlich zugenommen. Im YCFZ ist diese positive Entwicklung dokumentiert und ausdrücklich vermerkt worden, wieviele Einwohner jeweils hinzugekommen sind (siehe unten Tab. 41):

„Im Jahr Guangxu 4 (1878) kamen 212 Haushalte neu hinzu (xin zeng minhu), Männer und Frauen, Erwachsene und Kinder, [zusammen] 2496 Personen. Im 9. Jahr (1883) kamen 312 Haushalte bzw. 3642 Personen neu dazu. Die tatsächliche Anzahl der Einheimischen (tuzhumin) betrug somit 11.482 Haushalte; Männer und Frauen, Erwachsene und Kinder, [zusammen] 62.462 Personen“. 1055

Tabelle 41: Die Bevölkerungsentwicklung in der Unterpräfektur Tengyue Ende des 19. Jahrhunderts nach Angaben des YCFZ

$\begin{array}{lrrrc}\text { Jahr } & \text { Haushalte } & \text { Personen } & \text { Personen pro Haushalt } \\ \mathbf{1 8 7 4} & & 10.958 & 56.325 & 5,1 \\ & \text { plus } & 212 & 2496 & 11,8 \\ & & & & 5,2 \\ \mathbf{1 8 7 8} & & 11.170 & 58.821 & 11,7 \\ & \text { plus } & 312 & 3642 & 5,4\end{array}$

Rechnet man die Anzahl der Einzelpersonen auf die Haushalte um, so erhält man für die drei genannten Jahrgänge einen Durchschnittswert von etwas über fünf Personen pro Haushalt, mit leicht steigender Tendenz. Ein Wert, der etwas unter dem Durchschnitt von 5,9 Personen pro Haushalt liegt, den Ho Ping-ti für das Jahr 1812 in ganz Yunnan ermittelt hat. ${ }^{1056}$ Bildet man jedoch die entsprechenden Werte für die neu registrierten Haushalte, so sind diese im Ergebnis mit durchschnittlich knapp zwölf Personen zu hoch und verweisen darauf, daß auch im 19. Jahrhundert in der Unterpräfektur Tengyue besonders viele Einzelpersonen auch ohne Haushaltszugehörigkeit neu registriert worden sind. ${ }^{1057}$

\footnotetext{
${ }^{1055}$ Die Summe der angegebenen Einzelposten beträgt 62.463 Personen (YCFZ, S. 99). Das YCFZ wurde im Jahr 1885 herausgegeben worden.

${ }^{1056}$ Ho Ping-ti, S. 56

${ }^{1057}$ Die entsprechenden Durchschnittswerte für die Anzahl der Personen pro Haushalt bei den in den zwei Jahren von 1777 bis 1779 neu hinzugekommenen Einwohnern Tengyues (siehe oben Tab. 21, S. 244), ergeben bei den Einheimischen (tuzhumin) einen Wert von 2,6, bei den Militärkolonisten (tunmin) einen Durchschnitt von 9,1 Personen pro Haushalt. Ein Wert, der darauf hinweist, daß die Militärkolonisten zumeist als Einzelpersonen zugewandert sind.
} 
Betrachtet man die Bevölkerungszahlen der Unterpräfektur Tengyue für die letzten genannten Jahrgänge aus der zweiten Hälfte des 19. Jahrhunderts, so fallen die Differenzen zwischen den Zahlenangaben in den verschiedenen fangzhi aus der Präfektur auf:

$\begin{array}{lll}\text { YCFZ: } & \text { Jahr } 1874 & 10.958 \text { Haushalte / } 56.325 \text { Personen } \\ \text { YCFZ: } & \text { Jahr } 1878 & 11.170 \text { Haushalte / } 58.821 \text { Personen } \\ \text { TYTZ: } & \text { Jahr } 1879 & 10.936 \text { Haushalte / 55.407 Personen } \\ \text { YCFZ: } & \text { Jahr } 1883 & 11.482 \text { Haushalte / } 62.463 \text { Personen. }\end{array}$

Die Daten für die Jahre 1874 bis 1883 im YCFZ weisen auf eine Zunahme der chinesischen Bevölkerung in Tengyue hin, während im Handbuch der Unterpräfektur selbst aus dieser Zeit nur Zahlen für das Jahr 1879 genannt werden, welche sogar niedriger sind, als die im YCFZ für das Jahr 1874 verzeichneten. Die Ursache für diese Differenz liegt wahrscheinlich in unterschiedlichen Berechnungskriterien, die jeweils zugrunde gelegt worden sind und die den Vergleich mit den Bevölkerungszahlen früherer Jahre insgesamt erschweren. Mangels weiterer Daten aus den fangzhi von Tengyue selbst kann lediglich anhand der Angaben des YCFZ allgemein eine kontinuierliche Zunahme der chinesischen Bevölkerung der Unterpräfektur Tengyue nach der Niederschlagung der Rebellion festgestellt werden, deren Gesamtzahl zwar immer noch erheblich niedriger war als die der schon im 18. Jahrhundert registrierten bis zu zweihunderttausend Personen, die aber um das Jahr 1883 bereits wieder mehr als sechzigtausend Personen umfaßte, die sich auf die Unterpräfekturstadt sowie die achtzehn Gemeinden und sechs Dorfgemeinschaften verteilten. ${ }^{1059}$

\section{Die Restauration der Verwaltungseinheit Tengyue}

In diesem Abschnitt wird zunächst die Organisation der Zivil- und Militärverwaltung vor der Rebellion kurz zusammengefaßt sowie auf einige Veränderungen, die zu Beginn des 19. Jahrhunderts erfolgt sind, eingegangen, um deutlich zu machen, auf welcher Grundlage der Wiederaufbau der zivilen und militärischen Verwaltungsstrukturen der Unterpräfektur nach der Rebellion erfolgte. Im Anschluß daran wird der Wiederaufbau der Stadt Tengyue unter der Leitung von Unterpräfekt Chen Zonghai beschrieben. Abschließend folgt eine

\footnotetext{
1058 Siehe TYTZ, S. 50; YCFZ, S. 99.

1059 Die ländlichen Gemeinden und die zugehörigen Dörfer werden im TYTZ aufgelistet (S. 51-53). Dazu zählten achtzehn Gemeinden mit überwiegend Han-chinesischen Bewohnern (lian; s.Wiens, S. 242): Dong lian, Dadong lian, Qiluo lian, Heshun lian, Qingshui lian, Mingliang lian, Mianqing lian, Xiaoxi lian, Daxi lian, Bei lian, Longjiang lian, Puwo lian, Guyong lian, Qushi lian, Wadian lian, Jietou lian, Hexi lian und Zhanxi lian. Hinzu kamen sechs weitere Gebiete: Die beiden Dörfer (zhuang) Sanyi zhuang und Siyi zhuang, die strategischen Orte (ai) Mingguang ai und Diantan ai, sowie die Dorfgemeinschaften Mengbang jia und Nangsong zhili jia (siehe Karte 17.1-2, S. 398-399).
} 
Darstellung der Entwicklung in den tusi-Gebieten und der verschiedenen Maßnahmen zur Sicherung der chinesischen Oberhoheit über das Grenzgebiet im Südwesten der Unterpräfektur gegen Ende des 19. Jahrhunderts.

\title{
3. 1. Der Status quo ante: Die Verwaltungseinheit Tengyue vor der Moslem-Rebellion
}

Seit die Verwaltung der Region des Stromschluchtenfächers nach Beendigung des chinesisch-birmanischen Krieges Mitte der Ära Qianlong (1736-1796) reorganisiert wurde (Neugründung der Unterpräfektur Longling sowie der tusi-Gebiete Husa und Lasa), ist der Aufbau der Zivilverwaltung mit ihren verschiedenen Einheiten und Verwaltungsebenen ebenso wie die Zuordnung der tusi-Gebiete nahezu unverändert geblieben. Mitte des 19. Jahrhunderts verwaltete die Präfektur Yongchang die beiden Kreise Baoshan und Yongping, die beiden Unterpräfekturen (ting) Longling und Tengyue sowie die einheimische Präfektur (tufu) Mengding und die einheimischen Unterpräfekturen (tuzhou) Zhenkang und Wandian (siehe Karte 14, S. 357).

Tabelle 42: Die Verwaltungseinheiten der Präfektur Yongchang mit den tusi-Gebieten im 19. Jahrhundert

\author{
Präfektur \\ Yongchang: $\quad$ Mengding tufu, Zhenkang tuzhou, Wandian tuzhou \\ Kreis Baoshan: Luzhang tuqianzhong, Denggeng tuqianzhong, Maozhao tumu \\ Kreis Yongping: \\ Unterpräfektur \\ Longling: $\quad$ Lujiang anfusi, Mangshi anfusi, Zhefang fu xuanfusi \\ Unterpräfektur \\ Tengyue: $\quad$ Nandian xuanfusi, Ganya xuanfusi, Zhanda fu xuanfusi, Longchuan \\ xuanfusi, Mengmao anfusi, Husa zhangguansi, Lasa zhangguansi, \\ Mingguang ai, Datang ai und Guyong ai tubazhong, Diantan guan tumu
}




Die einzige größere Veränderung innerhalb der Verwaltungorganisation der Region des Stromschluchtenfächers in diesem Zeitraum ereignete sich im Jahr 1820 (Jiaqing 25), als Tengyue auf Veranlassung des Unterpräfekten Yilibu (von 1816 bis 1821 im Amt) aufgrund ihrer besonderen geographischen Lage zu einer Unabhängigen Unterpräfektur (zhili ting) aufgewertet wurde. ${ }^{1060}$ Als Unabhängige Unterpräfektur war Tengyue direkt der Provinzverwaltung unterstellt, gleichrangig mit der Präfektur Yongchang und ebenso wie diese Teil der Verwaltungsregion Yixi. Schon im Jahr 1822 (Daoguang 2) ist Tengyue wieder zu einer regulären Unterpräfektur (ting) zurückgestuft und wie zuvor der Präfektur Yongchang zugeordnet worden. Die kurzfristige Umwandlung betraf lediglich den Status Tengyues in der Hierarchie der Verwaltungseinheiten der Provinz, Veränderungen innerhalb der Verwaltungsorganisation der Unterpräfektur waren damit nicht verbunden. ${ }^{1061}$

Ebenso wie die Zivil- ist auch die Militärverwaltung der Unterpräfektur während der Ära Qianlong (1736-1796) reorganisiert worden. In Tengyue ist im Jahr 1776 eine Regionale Militärkommandantur (zhen) gegründet worden. Damit einhergehend ist besonders die Verteilung der Truppen neu geregelt und auf die Verteidigung der Hochebene von Tengyue konzentriert worden. In Nandian, im Südwesten der Hochebene, war die chinesische Garnison bereits entsprechend verstärkt worden. Die Truppenpräsenz im Grenzgebiet hingegen ist dann insgesamt reduziert worden und im Jahr 1779 wurden auch die Militärstützpunkte (xun) abgeschafft.

Nachdem sich zu Beginn des 19. Jahrhunderts immer wieder Zwischenfälle im Grenzgebiet ereignet hatten, wie im Jahr 1811, als „im Frühling wilde Banditen (ye fei) aus Luobusizhuang [in Nandian] entlang der Grenze Unruhe verbreitet und Dörfer gebrandschatzt und geplündert hatten“, veranlaßte Unterpräfekt Hu Qirong im Jahr 1823, daß

„,in der Unterpräfektur Tengyue, die auf allen vier Seiten von den Dörfern der Wilden (ye yi) umgeben ist und von wo aus man direkt in die Gebiete jenseits der Paßstationen (guan wai) gelangt, entsprechend den Regelungen in [den Provinzen] Guizhou und Hubei, entlang der Grenze (yan bian) siebenundsiebzig Befestigungsanlagen (diao bao) errichtet werden, die von der

\footnotetext{
1060 TYTZ, S. 64; CH 148; CY 1193. 3

${ }^{1061}$ Mit der Umwandlung in eine Unabhängige Unterpräfektur wurde der Amtstitel des Unterpräfekten von Tengyue von zhizhou in tongzhi abgeändert; diese Bezeichnung des obersten Verwaltungsbeamten von Tengyue blieb bis zum Ende der Qing-Zeit weiterhin gebräuchlich (TYTZ, S. 110). Im Jahr 1823 (Daoguang 3) erhielten die beiden untergeordneten Beamten der Unterpräfektur neue Amtstitel: Der Assistierende Unterpräfekt (zhoupan) von Tengyue wurde in Amtsleiter (jingli) umbenannt; der auch mit polizeilichen Aufgaben befaßte Gefängnisaufseher (limu) erhielt eine andere Amtsbezeichnung, die seine Aufgabe als Gefängnisdirektor (siyu) hervorhob (TYTZ, S. 112, 117; YCFZ, S. 183, 185).
} 
Zivilbevölkerung ( $\min$ ren) selbst bzw. von den Militärhaushalten in den Gemeinden (tun lian) zu sichern sind“. ${ }^{1062}$

Für diese Bauprojekte stellte die Regierung erhebliche Finanzmittel bereit. ${ }^{1063}$ Bei den Befestigungsanlagen handelte es sich um Wälle, Wachtürme, Verschanzungen oder Bunker, die aus Erde, Holz oder Steinen errichtet wurden. Sie dienten der Selbstverteidigung der Dörfer, da es kaum möglich war, den weiträumigen und schwer zugänglichen Südwesten der Unterpräfektur mit Regierungstruppen direkt zu kontrollieren. Ihren ursprünglichen Zweck haben diese Anlagen kurzfristig scheinbar erfüllt, denn Berichte über Angriffe von einheimischen ,Wilden` auf Dörfer in den Gemeinden der Unterpräfektur gibt es in den fangzhi erst wieder aus der Zeit etwa fünfzehn Jahre nach dem von Hu Qirong 1823 veranlaßten Bau der Befestigungsanlagen. ${ }^{1064}$

Hier zeigt sich, daß die Grenzsicherung Anfang des 19. Jahrhunderts nach wie vor die Hauptaufgabe der Militärhaushalte in den Gemeinden (lian) war, die dafür jeweils eine bestimmte Zahl von Männern zur Verfügung zu stellen hatten. Die Dörfer der Gemeinden sollten ähnlich wie die tusi eine Pufferzone zu den Gebieten der einheimischen Bevölkerung jenseits der chinesischen Verwaltungseinheiten bilden, während die Regierungstruppen in erster Linie für die Sicherung der Unterpräfekturstadt und von strategischen Orten in ihrer Umgebung eingesetzt wurden. Der Bau der Befestigungen steht in der Tradition der Maßnahmen zur Kontrolle der Grenzregion, wie sie während der Ära Qianlong getroffen worden sind und ist so auch ein Zeichen für die Kontinuität der chinesischen Vorstellungen von der Grenzverteidigung. Diese hatten ebenso wie die allgemeine Organisation der Militärkommandantur Tengyue von der Ära Qianlong bis in das 19. Jahrhundert hinein nach wie vor Bestand.

\footnotetext{
1062 TYTZ, S. 181. Hu Qirong war der Amtsnachfolger von Yilibu und von 1821 bis 1827 in Tengyue tätig. Er stammte aus der Provinz Hubei, die er hier als Vorbild empfiehlt. Im Zitat wird die Gesamtzahl der Befestigungen mit 77 angegeben. Die Liste der einzelnen Standorte im TYTZ umfaßt jedoch lediglich 57 Befestigungsanlagen (ebd.). Im YCFZ wird die Gesamtzahl der Befestigungen ebenfalls mit 77 (53 diao und 24 bao) angegeben, die auch einzeln aufgelistet sind (YCFZ, S. 145-146). Im YCFZ wird zudem darauf hingewiesen, daß Hu Qirong dieses Projekt zusammen mit dem Regionalkommandeur von Tengyue, Ajing’a, durchgeführt hat (S. 145).

Aus den Militärhaushalten der Gemeinden von Tengyue sind insgesamt fünfhundertundsechzig Männer (tun lian ding) zur Instandhaltung der verschiedenen Befestigungen eingeteilt worden. Auch Soldaten wurden dazu herangezogen: Bei Zhayoufang wurden sechs Befestigungsanlagen errichtet, die von Soldaten bewacht wurden (ebd.).

1063 Insgesamt waren es über 48.000 liang Silber (YCFZ, S. 145). Außerdem wurden in den Gemeinden Felder ausgewiesen (lian tian), deren jährliche Erträge zur Finanzierung der Befestigungen verwendet wurden; auch Bürger der Unterpräfektur (ting shu shimin) stellten dafür Felder zur Verfügung (YCFZ, S. 146).

1064 TYTZ, S. 193
} 


\section{2. Die Restauration des Verwaltungsapparates der Unterpräfektur Tengyue}

Nach der Niederschlagung der Moslem-Rebellion wurde die chinesische Zivil-und Militärverwaltung der Präfektur Yongchang auf der Grundlage der seit dem 18. Jahrhundert etablierten Strukturen wieder aufgebaut. Die Beamtenposten in den fünf Verwaltungseinheiten der Präfektur Yongchang wurden wieder neu besetzt. Der oberste Zivilbeamte der Region war der Präfekt (zhifu, Rang 4a, zheng si pin) von Yongchang. Ihm unterstanden die Unterpräfekten (tongzhi) von Tengyue und Longling (beide Rang 5a) sowie die beiden Kreismagistraten (zhixian, Rang 7a) von Baoshan und Yongping.

Bereits während des Feldzuges in die Region des Stromschluchtenfächers hatte Gouverneur Cen Yuying Beamte ernannt, die nach der Niederschlagung der Moslem-Rebellion die Amtsposten in Tengyue übernehmen sollten. Der Kommandeur für den Militärbezirk Tengyue (zongbing), Li Weishu (1872-74 im Amt), Provinz-Militärkommandant (tidu) Xu Liankui (1874-75 als zongbing tätig), Unterpräfekt Lin Guiqing (1871 ernannt) und ab 1872 sein Amtsnachfolger Wu Qiliang waren maßgeblich an der Rückeroberung der Unterpräfektur beteiligt und traten anschließend ihre Ämter in Tengyue an.

Kaum einer der obersten Militär- oder Zivilbeamten blieb jedoch über einen längeren Zeitraum im Amt. In den zehn Jahren nach 1875 (Guangxu 1) waren neun Kommandeure des Regionalen Militärbezirks in Tengyue tätig, bis Ding Huai den Posten im Jahr 1886 übernahm. Die Unterpräfekten wechselten fast ebenso häufig. Nach Wu Qiliang, der eine dreijährige Amtsperiode absolviert hatte, waren von 1875 bis 1878 drei Beamte in Tengyue tätig, die nur jeweils ein Jahr im Amt waren. Erst Chen Zonghai, der 1878 zum Unterpräfekten ernannt wurde, übte sein Amt über einen längeren Zeitraum aus und war fünf Jahre in der ,ersten Stadt an der äußersten Grenze‘ tätig. Nachdem seine beiden Nachfolger wiederum nur jeweils ein Jahr auf ihrem Posten geblieben waren, übernahm Chen Zonghai 1885 erneut das Amt des Unterpräfekten, welches er im Jahr 1888 weiterhin innehatte.

In der Beamtenhierarchie des Qing-Reiches bekleidete der Unterpräfekt von Tengyue den Rang 5a (zheng wu pin). Ihm unterstanden vier niederrangige Beamte: Ein Amtsleiter (jingli, Rang 8a), ein Gefängnisdirektor (siyu, Rang 9b, cong jiu pin) sowie der Schuldirektor (ruxue xuezheng, 8a) und ein Vize-Schuldirektor (xundao, 8b). Die Beamten erhielten 
ein jährliches Gehalt in Silber (feng yin) aus der Staatskasse sowie ein deutlich höheres Zusatzgehalt, „das die Unbestechlichkeit des Beamten erhalten sollte“ (yang lian yin). ${ }^{1065}$

Tabelle 43: Die Jahresgehälter der Zivilbeamten der Unterpräfektur Tengyue ${ }^{1066}$

$\begin{array}{llc}\text { Amtsträger } & \text { Gehalt } & \text { Zusatzgehalt } \\ \text { Unterpräfekt } & \text { 80 liang } & \text { 900 liang } \\ \text { Amtsleiter } & \text { 40 liang } & \text { 80 liang } \\ \text { Gefängnisdirektor } & \text { 31,52 liang } & 60 \text { liang } \\ \text { Schuldirektor } & \text { 40 liang } & \text { - - - } \\ \text { Vize-Direktor } & \text { 40 liang } & \text { - - - }\end{array}$

Mit der Zahlung von Zusatzgehältern trug die Qing-Regierung der Tatsache Rechnung, daß die regulären Gehälter viel zu niedrig waren, um die tatsächlichen Ausgaben der Beamten zu decken, die neben dem Unterhalt ihrer Familien und Bediensteten, den Beiträgen für die Instandhaltung von Amtsgebäuden, Schulen, Straßen, Brücken usw. in ihrem Verwaltungsgebiet, auch noch einen erheblichen Betrag zur Finanzierung der Provinzverwaltung beisteuern mußten (tanjuan). ${ }^{1067}$ Die Zusatzgehälter der Unterpräfekten in den Provinzen des chinesischen Reiches bewegten sich generell zwischen 500 bis 1500 liang in Silber pro Jahr, in Yunnan wurden durchschnittlich 900 bis 1100 liang gezahlt. Das Zusatzgehalt des Unterpräfekten von Tengyue war mit 900 liang also vergleichsweise niedrig. ${ }^{1068}$

Jedem der Amtsträger in der Unterpräfektur standen verschiedene ebenfalls vom Staat besoldete Bedienstete zur Verfügung. Im Amt der Unterpräfektur von Tengyue wurden zwei Torwächter (menzi), zwölf Amtsdiener (zaoli), achtzehn Milizbeamte (minzhuang), sieben Sänften- und Schirmträger (jiaosanfu), vier Gefängniswärter (jinzu), zwei Depotverwalter (kuding) sowie zwei Verwalter der Getreidespeicher (douji) beschäftigt. Insgesamt siebenundvierzig Bedienstete. Dem Amtsleiter standen neun, dem Gefängnisdirektor sechs und den beiden Schuldirektoren zusammen ebenfalls sechs besoldete Bedienstete zur Verfügung. ${ }^{1069}$ Zusammengenommen waren in den Ämtern der Unterpräfektur Tengyue neben

\footnotetext{
1065 TYTZ, S. 99

1066 TYTZ, S. 99

${ }^{1067}$ Chü, S. 24, 157

1068 Chü, S. 23, Tab. 6. Das mit Abstand höchste Zusatzgehalt von 2000 liang erhielt der Unterpräfekt von Yunlong, im Westen der Präfektur Dali, an der Grenze zur Präfektur Yongchang gelegen (ebd.). Die Ausgaben der Beamten waren jedoch weit höher als selbst ihr Zusatzgehalt. Ein Unterpräfekt benötigte schätzungsweise mindestens fünftausend liang pro Jahr, um seinen finanziellen Verplichtungen nachzukommen; dies konnte er nur durch das Einziehen von zusätzlichen Gebühren von der örtlichen Bevölkerung erreichen (lougui) (Chü, S. 26).

1069 Dem Amtsleiter unterstanden ein Torwächter, sechs Amtsdiener und zwei Stallknechte bzw. Schirmträger (longma san fu), dem Gefängnisdirektor standen ein Torwächter, vier Amtsdiener und ein Stallknecht (mafu) zur Verfügung, in der Schule waren zwei Schulbedienstete (zhaifu), zwei Köche (shanfu) und zwei Torwächter beschäftigt (TYTZ, S. 99).
} 
den fünf Zivilbeamten weitere achtundsechzig vom Staat bezahlte Personen angestellt. In den fünf Verwaltungseinheiten der Präfektur Yongchang waren insgesamt 348 be-soldete Amtsbedienstete beschäftigt; das Hilfspersonal wurde in allen Verwaltungseinhei-ten der Präfektur einheitlich bezahlt: Jeder Bedienstete erhielt 6 liang Silber pro Jahr. ${ }^{1070}$

Während die Anzahl der Bediensteten, die Hilfsarbeiten ausführten, relativ groß war, wurde die eigentliche Verwaltungsarbeit in der Präfektur, wie das Einziehen der Steuern, die Rechtsprechung, der Schriftverkehr mit den übergeordneten Instanzen usw., lediglich von fünf Männern geleistet, den verantwortlichen Beamten der Verwaltungseinheiten Yongchangs. Der Verzicht auf die Beschäftigung untergeordneter Beamter für die alltägliche Verwaltungsarbeit spiegelt eine allgemeine Entwicklung der Qing-Zeit wieder: Die regionale Verwaltung war gänzlich auf den obersten Zivilbeamten konzentriert, der bei seiner Arbeit folglich umso mehr auf die Unterstützung von Privatsekretären und einheimischem Hilfspersonal angewiesen war. ${ }^{1071}$

Allein in der Unterpräfektur Tengyue war zudem noch ein Amtsleiter (jingli) beschäftigt, der den Unterpräfekten bei der umfangreichen Verwaltungsarbeit unterstützte, während die anderen untergeordneten Beamten, die Schuldirektoren und die Gefängnisaufseher nur für ihren speziellen Aufgabenbereich zuständig waren und dabei wiederum der Kontrolle des Unterpräfekten unterstanden. Ebenso wie die in der Liste der Zivilbeamten der Präfektur Yongchang neben den oben genannten Amtsträgern aufgeführten vier Polizeioffiziere (xunjian), die an strategisch wichtigen Orten (in Shanmuhe und Shidian im Kreis Baoshan, in Longchuanjiang in Tengyue sowie in der Unterpräfektur Longling [siehe Karte 14, S. 357]) stationiert waren.

\footnotetext{
${ }^{1070}$ YCFZ, S. 94-97. Diese verteilten sich nach Angaben des YCFZ folgendermaßen auf die verschiedenen Verwaltungseinheiten. Präfektur Yongchang: 75 Bedienstete, Unterpräfektur Tengyue: 74 Bedienstete, Unterpräfektur Longling: 112, Kreis Baoshan: 36 und Kreis Yongping: 57. Auffällig ist die große Anzahl von Bediensteten im Amt der Unterpräfektur Longling, die die (annähernd gleiche) Anzahl an Bediensteten in der Präfektur Yongchang und der Unterpräfektur Tengyue deutlich übersteigt (ebd., S. 96). Im YCFZ wird abweichend vom TYTZ die Zahl von insgesamt 74 Bediensteten in der Unterpräfektur Tengyue genannt. Legt man diese Zahl von 74 Bediensteten der Unterpräfektur zugrunde, so ergibt sich für das Hilfspersonal der Präfektur Yongchang eine Gesamtzahl von 354 Personen.

${ }^{1071}$ Wurden in einer Verwaltungseinheit assistierende Beamte ernannt, so hatten diese untergeordneten Amtsträger kein klar definiertes Arbeitsgebiet gehabt, sondern bekamen diverse Aufgaben vom Präfekten oder Unterpräfekten zugeteilt und spielten als Ortsfremde mit Ämtern ohne eigene Befugnisse nur eine unbedeutende Rolle innerhalb der Lokalverwaltung. In der Präfektur Yongchang sind die Posten der untergeordneten Beamten, die ursprünglich ebenfalls mit Verwaltungsaufgaben und der Rechtsprechung befaßt waren, bereits zu Beginn des 18. Jahrhunderts abgeschafft worden. Die Amtsposten des Richters (tuiguan) und Amtsleiters (jingli) sind im Jahr 1705 (Kangxi 44) abgeschafft worden, das Amt des Assistierenden Präfekten (tongban) im Jahr 1709 (Kangxi 48) (YCFZ, S. 174). Das Amt des Gefängnisdirektors (siyu) der Präfektur ist bis zum Ende des 19. Jahrhundert ebenfalls aufgelöst worden (YCFZ, S. 94).

Im TYTZ wird darauf hingewiesen, daß es während der Ming-Zeit in Tengyue neben dem Assistierenden Unterpräfekten (zhoupan) und dem Gefängnisaufseher (limu) noch zwei weitere niederrangige Beamte in der Unterpräfektur gegeben hat, die für den Getreidespeicher (cang dashi) bzw. für Handel und Handelssteuern (shui dashi) verantwortlich waren, deren Tätigkeit in den fangzhi jedoch nicht näher erläutert wird; in der Qing-Zeit gab es diese Amtsposten nicht mehr (TYTZ, S. 119).
} 
Um eine umfassende Kontrolle möglichst aller Bevölkerungsschichten und besonders der organisierten Gemeinschaften zu erreichen, wurde in den Verwaltungseinheiten (mit Ausnahme Longlings) zudem je ein Oberhaupt der buddhistischen und der daoistischen Gemeinde (senggangsi, sengzhengsi, daojisi, daozhengsi usw.) ernannt sowie ein Direktor des Amtes für Geomantik (yinyang); auch jeweils ein Direktor der Medizin-Schule (yixue) war dem obersten Verwaltungsbeamten verantwortlich. ${ }^{1072}$

Zur Finanzierung der verschiedenen Verwaltungsaufgaben wurden der Unterpräfektur neben den Gehältern für die Beamten und das Hilfspersonal noch bestimmte Beträge pro Jahr für Zeremonien, wie zum Beispiel Opfer im Tempel des Gottes der Literatur (wenchang gong) und im Tempel des Kriegsgottes (wu miao), für den Fonds für Waisen und Bedürftige sowie die Gelder für die dreißig zu den Provinzprüfungen zugelassenen Regierungsstipendiaten (linsheng) aus der Staatskasse überwiesen. Insgesamt war, nach Angaben des TYTZ, für die Zivilverwaltung der Unterpräfektur Tengyue eine Summe von 2288,84 liang in Silber veranschlagt. ${ }^{1073}$

Die Verfasser des YCFZ haben bei der Zusammenstellung der Kosten für die Zivilverwaltung der Präfektur Yongchang die Zusatzgehälter der Beamten nicht mit berücksichtigt; die dort aufgelisteten Summen sind daher deutlich niedriger, als die im TYTZ allein für die Unterpräfektur Tengyue genannten Zahlen. ${ }^{1074}$

Tabelle 44: Jahresgesamtkosten der zivilen Verwaltungseinheiten der Präfektur Yongchang nach Angaben des YCFZ (in Klammern die Summen der aufgelisteten Einzelposten) ${ }^{1075}$

$\begin{array}{lrl}\text { Präfektur Yongchang } & 746,56 \text { liang } & \text { (877,55 liang) } \\ \text { Kreis Baoshan } & 760,72 \text { liang } & \text { (801,12 liang) } \\ \text { Unterpräfektur Longling } & \text { 855,52 liang } & \text { (943,12 liang) } \\ \text { Unterpräfektur Tengyue } & \text { 880,79 liang } & \text { (910,79 liang) } \\ \text { Kreis Yongping } & 698,52 \text { liang } & (724,52 \text { liang) } \\ \text { Gesamt } & 3942,11 \text { liang } & (4257,10 \text { liang })\end{array}$

\footnotetext{
1072 YCFZ, S. 147. Mit der Verleihung dieser Titel war keine Besoldung verbunden.

1073 TYTZ, S. 100. Für die Opferzeremonien standen der Unterpräfektur insgesamt 70 liang pro Jahr zur Verfügung, für Waisen und Bedürftige 216 liang und für die Stipendiaten 72 liang. Die Summe der im TYTZ aufgelisteten Einzelposten (Beamten- und Zusatzgehälter, Amtsdiener, Zeremonien etc.) beträgt abweichend von der im Text genannten Summe 2407,52 liang (TYTZ, S. 99).

${ }^{1074}$ Die Gehälter der einzelnen Beamten sind im YCFZ nicht eigens aufgeschlüsselt worden.

1075 YCFZ, S. 94-97. Die Gesamtsumme umfaßt die Jahresgehälter der Beamten und des Hilfspersonals, die Gelder für Opferzeremonien, für die 110 Stipendiaten, für Waisen und Bedürftige sowie die Ausgaben für die Poststationen.
} 
Den einzelnen Verwaltungseinheiten der Präfektur Yongchang standen pro Jahr zwischen 700 bis 900 liang aus der Staatskasse zur Verfügung. Die höchsten Beträge erhielten die beiden Unterpräfekturen Tengyue und Longling zugewiesen. Die Gelder wurden jedoch in den beiden Unterpräfekturen unterschiedlich aufgeteilt. In Tengyue verteilten sich die Gelder auf sechs besoldete Beamte und 74 Amtsdiener (TYTZ: 68) sowie verschiedene andere gesondert aufgeführte Ausgabenposten. In Longling waren hingegen lediglich drei besoldete Zivilbeamte (Unterpräfekt, Vize-Schuldirektor und Polizeioffizier) tätig. Dem gegenüber wurden dort die mit Abstand meisten Amtsdiener (menzao, shudou) beschäftigt: 112 Personen, deren Gehälter zusammen 672 liang pro Jahr betrugen. Damit entfielen etwa zwei Drittel der Ausgaben der Unterpräfektur allein auf das Hilfspersonal. Gelder hingegen, die eigens für Opferzeremonien und Stipendien verwendet wurden, standen in Longling, anders als in den anderen Verwaltungseinheiten Yongchangs, nicht zur Verfügung.

Da in der Aufstellung des YCFZ die Zusatzgehälter nicht mit berücksichtigt worden sind, entspricht die genannte Gesamtsumme in Höhe von 3942,11 liang (bzw. 4257,10 liang) lediglich einem Teil der tatsächlichen Ausgaben für die Präfektur. Rechnet man die im TYTZ angegebenen Gesamtausgaben der Unterpräfektur von 2288,84 liang auf die anderen Verwaltungseinheiten hoch, so ergibt sich eine Summe von über 11.000 liang, die pro Jahr für die Finanzierung der Zivilverwaltung der gesamten Präfektur aufzuwenden wäre. Würde man den von Qing-Beamten selbst geschätzten Finanzbedarf für einen Unterpräfekten von mindestens 5000 liang zu Grunde legen, so ergäbe sich sogar eine Gesamtsumme von etwa 25.000 liang pro Jahr. ${ }^{1076}$ In jedem Fall bestand eine erhebliche Diskrepanz zwischen den staatlich zugeteilten Mitteln und dem tatsächlichen Bedarf, die sich nur durch das Einziehen von höheren Steuern und zusätzlichen Abgaben vor Ort überbrücken ließ.

Ebenso wie in der Zivilverwaltung wurden auch die Strukturen der Militärverwaltung der Unterpräfektur Tengyue nach der Moslem-Rebellion so wieder aufgebaut, wie sie seit dem 18. Jahrhundert etabliert waren. Für den Regionalen Militärbezirk (zhen) Tengyue wurde erneut ein Regionalkommandeur ernannt, der direkt dem Provinz-Militärkommandanten und dem Provinzgouverneur unterstellt war. Auch die Anzahl (58) und die Rangstufen der neu ernannten untergeordneten Truppenführer blieben dieselben wie in der Zeit vor der Rebellion (siehe oben Abschnitt A. 4. 2., S. 235-236).

\footnotetext{
1076 Chü, S. 26. Chü verweist in diesem Zusammenhang auf die Untersuchung des Zensors Xie Zhending (1753-1809) aus dem 18. Jahrhundert, der die jährlichen Ausgaben der Unterpräfekten auf fünf- bis zehntausend liang Silber geschätzt hat. Chü geht davon aus, daß diese Ausgaben im 19. Jahrhundert sogar noch gestiegen sind.
} 
Tabelle 45: Die Militärbeamten der Unterpräfektur Tengyue im 19. Jahrhundert ${ }^{1077}$

\begin{tabular}{lccc}
\multicolumn{1}{c}{ Titel } & Rang & Anzahl & $\begin{array}{c}\text { Gehalt + Zusatzgehalt } \\
\text { (pro Person/Jahr in liang) }\end{array}$ \\
Regionalkommandeur (zongbing) & 2a & 1 & $67,575+1800$ \\
$\begin{array}{l}\text { Brigadekommandant (youji) } \\
\text { Brigade-Vizekommandanten (dusi) }\end{array}$ & 3b & 1 & $39,333+450$ \\
Assistierende Brigade-Kommandanten & & 2 & $27,384+300$ \\
$\quad$ (shoubei) & $5 \mathrm{~b}$ & 3 & $18,705+220$ \\
Kompanieführer (qianzong) & -- & 6 & $14,991+140$ \\
$\begin{array}{l}\text { Korporäle (bazong) } \\
\text { Zusätzliche Kompanieführer }\end{array}$ & -- & 12 & $12,471+100$ \\
$\quad$ (waiwei qianbazong) & & & $(24)+22$ \\
Zusätzliche Truppenführer & -- & 18 & (24) \\
$\quad$ (ewai waiwei) & & &
\end{tabular}

Neben ihrem Gehalt und dem Zusatzgehalt erhielten die Militärbeamten gestaffelt nach ihrem Rang noch weitere Gelder für verschiedene Ausgaben zugeteilt. So erhielt der Regionalkommandeur für Lebensmittel, Kerzen, Kohle, Siegelwachs und Papier 448 liang sowie 201 liang für seine 16 Pferde. Dem Brigadekommandanten standen neben dem Gehalt weitere 182 liang und 75 liang für sechs Pferde zu. Insgesamt betrugen die Kosten für die verschiedenen Truppenführer der Militärkommandantur 10.138 liang. ${ }^{1079}$

Hinzu kam noch der Sold für die einfachen Soldaten. Der Regionalkommandeur hatte den Oberbefehl über drei Brigaden (zhong, zuo, you ying), von denen eine in Nandian stationiert war. ${ }^{1080}$ Bei einer Sollstärke von 500 Mann pro Brigade, hätte die Militärkommandantur Tengyue demnach regulär über 1500 Soldaten verfügt. Wieviele Soldaten im Zuge der Niederschlagung der Rebellion und der Militärrevolte tatsächlich nach Tengyue gekommen und in der Unterpräfektur stationiert waren, läßt sich aus den Angaben der fangzhi nicht ersehen. Im TYTZ wird lediglich vermerkt, daß anschließend die Zahl der Soldaten der Militärkommandantur insgesamt reduziert worden ist. Anstelle von früher 2512 Mann waren dort nach der Rebellion nurmehr 1256 reguläre Soldaten stationiert,

\footnotetext{
1077 TYTZ, S. 100-101; siehe auch S, 119, 176.

${ }^{1078}$ Das Jahresgehalt der einzelnen zusätzlich abkommandierten Kompanieführer ergibt sich ebenso wie bei den zusätzlichen Truppenführern aus den im TYTZ genannten Gesamtsummen. 1079 TYTZ, S. 100

1080 TYTZ, S. 131, 133; YCFZ, S. 127
} 
darunter 930 Infanteristen (buzhan bing, Sold: 18 liang pro Jahr) und 326 Grenzschützer (shou bing, Sold: 12 liang). ${ }^{1081}$ Für die Soldaten und die Truppenkommandanten in der Unterpräfektur mußte die Regierung demnach insgesamt 30.790 liang Silber pro Jahr aufwenden. ${ }^{1082}$

Tabelle 46: Militärausgaben für die Unterpräfektur Tengyue

(pro Jahr in liang Silber, nach Angaben des TYTZ )

$\begin{array}{ll}\text { Truppenführer } & 10.138 \text { liang } \\ \text { Soldaten } & 20.652 \text { liang } \\ \text { Gesamt } & \mathbf{3 0 . 7 9 0 ~ l i a n g}\end{array}$

Tabelle 47: Gesamtausgaben des Staates für die Unterpräfektur Tengyue

(pro Jahr in liang Silber, nach Angaben des TYTZ )

$\begin{array}{lr}\text { Militär } & 30.790 \text { liang } \\ \text { Zivilverwaltung } & 2.289 \text { liang } \\ \text { Gesamt } & \mathbf{3 3 . 0 7 9 ~ l i a n g}\end{array}$

Verglichen mit den offiziell genannten Gesamtaufwendungen des Staates für die Zivilverwaltung der Unterpräfektur, für die lediglich eine Summe von knapp 2289 liang in Silber veranschlagt war, verweisen die deutlich höheren Ausgaben für das Militär auf die hohen Kosten, die der Schutz der äußersten Grenze des Reiches verursachte. Die wichtige Rolle, die der Militärkommandantur zukam, zeigt sich dabei nicht nur in der besseren finanziellen und personellen Ausstattung, sondern auch in der Einstufung der Beamtenposten. Die vier obersten Militärführer (zongbing, youji, dusi) waren Amtsträger mit hohen Beamtenrängen (2a bis 4a), während der Unterpräfekt von Tengyue den für sein Amt regulären niedrigeren Rang 5a inne hatte.

\footnotetext{
1081 TYTZ, S. 101. Den Truppenkommandanten standen für die Versorgung ihrer insgesamt 111 Pferde pro Jahr und Pferd je 12,5 liang zu, etwas mehr, als ein Soldat des Grenzschutzes verdiente (TYTZ, S. 100).

${ }^{1082}$ Die Soldaten und die dreiunddreißig zusätzlichen Truppenführer (waiwei, ewai) erhielten neben ihrem Sold pro Mann und Jahr noch 3,6 dan Reis [ca. 360 Liter] zugeteilt (TYTZ, S. 101).
} 


\section{3. Der Wiederaufbau der Stadt Tengyue unter der Leitung von Unterpräfekt Chen}

\section{Zonghai}

Als Mingqing, der Kommandeur des Regionalen Militärbezirks Tengyue, am 18. Tag des 9. Monats des Jahres Xianfeng 11 (1861) den Truppen der Hui aus Dali die Stadttore öffnen ließ, begann eine zwölf Jahre andauernde Herrschaft der Moslem-Rebellen über die Stadt. Diese Zeit bedeutete einen tiefen Einschnitt in die bauliche Entwicklung Tengyues, denn unter der Herrschaft der Rebellen wurden fast alle Tempel, Schulen und Brücken sowie zahlreiche andere Gebäude in der Stadt und in ihrer Umgebung zerstört.

Bei der Rückeroberung der Stadt im Jahr 1873 brachten die Qing-Truppen zudem Teile der Stadtmauer durch Artilleriebeschuß zum Einsturz (yong dipao hong dao cheng san yu). ${ }^{1083}$ Auch die Niederschlagung der Militärrevolte von Tengyue im Jahr 1876 gelang erst, als Regierungstruppen die Stadtmauer im Nordwesten mit Kanonen unter Beschuß nahmen (yi dipao xian qing chengyuan). ${ }^{1084}$

Die folgenden Jahre waren in Tengyue durch den Wiederaufbau der beschädigten Bauwerke geprägt. Sogleich nach der Rückeroberung der Stadt im Jahr 1873 wurde mit den Arbeiten begonnen, zunächst am Amtssitz des Unterpräfekten, an der Stadtmauer, am Tempel des Stadtgottes und am Schultempel. Planung und Finanzierung dieser Bauprojekte war Aufgabe des amtierenden Unterpräfekten. Da die Unterpräfekten in der Zeit nach der Rebellion zunächst jeweils nur etwa ein Jahr lang im Amt waren, wurde zwar mit dem Wiederaufbau einiger Gebäude begonnen, doch erst als nach der Niederschlagung der Militärrevolte in der Stadt wieder Frieden herrschte und mit Chen Zonghai ein Unterpräfekt sein Amt antrat, der mehrere Jahre in Tengyue bleiben sollte, wurden Baumaßnahmen in größerem Umfang durchgeführt.

Chen Zonghai stammte aus dem Kreis Huiji (Präfektur Shaoxing) in der Provinz Zhejiang, wo er den akademischen Titel eines jiansheng erworben hatte. Chen wurde im Jahr 1878 zum Unterpräfekten von Tengyue ernannt und übte dieses Amt zunächst fünf Jahre lang aus. Im Jahr 1885 wurde er erneut in das Amt des Unterpräfekten berufen, das er auch im Jahr 1888 noch inne hatte, als die unter seiner Leitung durchgeführte Kompilation des Lokalhandbuches Tengyue ting zhi abgeschlossen wurde.

\footnotetext{
1083 TYTZ, S. 195

${ }^{1084}$ TYTZ, S. 195, 67
} 
Während seiner beiden Amtsperioden als Unterpräfekt organisierte Chen Zonghai an die einhundert Projekte zur Wiederherstellung zerstörter Bauwerke in der Stadt und im Gebiet der Unterpräfektur. In den zwei Dutzend im TYTZ abgedruckten Gedenkinschriften zu verschiedenen Bauprojekten wird Chens starkes persönliches Engagement für den Wiederaufbau Tengyues deutlich. Neben den Verwaltungsgebäuden und Tempeln waren es die Schulen und darunter vor allem die Freischulen (yixue) in den Gemeinden der Unterpräfektur, deren Aufbau er besondere Aufmerksamkeit schenkte: Insgesamt initiierte er den Neubau bzw. die Renovierung von sechsundvierzig Schulen.

Tabelle 48: Der Wiederaufbau von Tengyue: Bauprojekte unter der Leitung von Unterpräfekt Chen Zonghai (Auswahl)

$\begin{array}{ll}\text { Jahr } & \text { Bauwerk } \\ 1878 & \text { Stadtmauer / Turm über dem Nordtor } \\ & \text { Tempel des Stadtgottes (Chenghuang miao) } \\ & \text { Schultempel (Xuegong) } \\ & \text { Laifeng - Tempel } \\ & \text { Amtssitz des Vize-Schuldirektors (Xundao shu) } \\ & \text { Gedenkhalle für Herrn Zhang (Zhanggong ci) } \\ & \text { Ximeng - Tempel (Wanshou gong) } \\ & \text { Amtsgebäude des Unterpräfekten (Ting shu) } \\ & \text { Amtsgebäude des Gefängnisdirektors (Siyu shu) } \\ & \text { Turm über dem Nordttor } \\ & \text { Tempel des Gottes der Literatur (Wenchang gong) } \\ & \text { Laifengshan - Akademie } \\ & \text { Gedenkhalle der offenkundigen Treue (Zhaozhong ci) } \\ & \text { Prüfungshallen (Kaopeng) } \\ & \text { Altar des Erdgottes und des Gottes des Getreides } \\ & \text { (Sheji tan) } \\ & \text { Altar der Gottheiten der Naturerscheinungen } \\ & \text { (Feng yun lei yu shan chuan tan) } \\ & \text { Tempel des Erdgottes (Zhao Teng tuzhu miao) } \\ & \text { Tempel des Drachengottes (Longshen ci) } \\ & \text { Tempel des Kriegsgottes (Guandi miao) } \\ & \text { Tempel des Feuergottes (Huoshen miao) } \\ & \end{array}$


Die Zerstörung von Bauwerken während der Moslem-Rebellion war nicht auf das Stadtgebiet von Tengyue beschränkt geblieben, auch die Gemeinden und die tusi-Gebiete waren davon betroffen. So zeigt sich gerade am Beispiel der Brücken das Ausmaß der Schäden und entsprechend der enorme Umfang der Arbeiten zu ihrer Wiederherstellung: Von den vierundsechzig Brücken in der Unterpräfektur mußte Chen Zonghai den Wiederaufbau von siebenunddreißig Brücken neu organisieren.

\section{3. 1. Prioritäten: Die Stadtmauer und der Amtssitz des Unterpräfekten}

Seit ihrer Errichtung Mitte des 15. Jahrhunderts hatte sich die ,erste Stadtmauer an der äußersten Grenze` als stabiles Bollwerk erwiesen, daß auch Ende des 19. Jahrhunderts erst mit dem Einsatz von Kanonen überwunden werden konnte. John Anderson hat die Stadtmauer im Jahr 1868 noch vor ihrer teilweisen Zerstörung vermessen und die Beschaffenheit der soliden Befestigung von Tengyue in seinem Reisebericht beschrieben:

„[Die Stadt Tengyue] wird von einer solide gebauten mit Zinnen versehenen Steinmauer von 7,50 m Höhe umgeben. In einem Abstand von 18 m von der Mauer umgab früher ein tiefer Graben die Stadt, der an der Ost- und Südseite noch intakt ist, aber an der Westseite zu einer breiten Pfütze verkommen ist, in der sich die Basarschweine gerne wälzen. Die Steinmetzarbeit ist bewundernswert, die gut behauenen Blöcke aus Lavagestein, $60 \mathrm{~cm}$ bis $120 \mathrm{~cm}$ lang, sind in Mörtel eingebettet, der selbst beinahe so hart wie Stein geworden ist. Der Graben ist hingegen mit Steinen ausgekleidet, die ohne Mörtel zusammengefügt sind und zwar so eng und passgenau, daß ein Taschenmesser kaum dazwischen geschoben werden kann. Innerhalb der Mauer dient ein $9 \mathrm{~m}$ breiter und 5,40 m hoher Erdwall als Geschützstand, Exerzierplatz und auch als Promenade. Es gibt keine Bollwerke, aber in Abständen erheben sich Türmchen auf dem Wall, die aus blauen gebrannten Ziegeln gebaut sind, deren glatte Oberfläche und scharfen Kanten die Jahrhunderte unversehrt überstanden haben. Die vier Tore, vor denen sich jeweils eine feste Brücke über den Graben spannt, sind hoch und solide gebaut; zur Zeit unseres Besuches sind zwei der Tore zugemauert gewesen. Das südwestliche oder Basar-Tor ist mit einer halbkreisförmigen Traverse besonders befestigt, an deren Seite ein Eingang in einen tunnelartigen Gang führt, über dem sich ein hoher Wachturm mit konkavem Dach, von starken Pfeilern gestützt, erhebt. Der innere Torweg wird mit 
schweren Torflügeln aus Holz, die mit Eisen verkleidet sind, bei Anbruch der Nacht sorgfältig verschlossen“. ${ }^{085}$

Um die von den Kanonen der Regierungstruppen verursachten Schäden zu beseitigen, sind von den drei amtierenden Unterpräfekten seit 1873 kontinuierlich Reparaturarbeiten an der Stadtmauer veranlaßt worden. In den fangzhi finden sich jedoch keine weiteren Berichte über diese Reparaturarbeiten, erwähnt werden lediglich Arbeiten, die Unterpräfekt Chen Zonghai im Jahr 1878 in die Wege geleitet hat und die sich hauptsächlich auf den Wiederaufbau der eingestürzten Türme über den Stadttoren konzentrierten, insbesondere auf den Turm am Nordtor. Dieser wurde unter der Leitung von Chen Zonghai in den Jahren 1878 bis 1879 zu einem imposanten Bauwerk von siebzehn Metern Höhe und einundzwanzig Metern Breite aufgebaut und im Jahr 1881 erneut renoviert. Genauere Angaben zur Instandsetzung der Mauer, wie zum Beispiel zum verwendeten Baumaterial, werden dort nicht gemacht. Zusammenfassend heißt es lediglich, daß die Stadtmauer anschließend wieder genauso ausgesehen habe wie früher. ${ }^{1086}$

Die Stadtmauer von Tengyue umschloß seit jeher eine Fläche von einem Quadratkilometer, die von zwei Straßen, die das Nord- mit dem Südtor bzw. das Ost- und das Westtor direkt miteinander verbanden, in vier gleichgroße Viertel unterteilt wurde. Innerhalb der Viertel verteilten sich die verschiedenen Tempel und Verwaltungsgebäude, die nach der Rebellion bis auf wenige Ausnahmen wieder an ihren angestammten Plätzen aufgebaut wurden (siehe auch Karte 15, S. 372).

Der Amtssitz des Unterpräfekten befand sich im Nordwesten der Stadt, in der Nähe des Nordtores. Ebenfalls Mitte des 15. Jahrhunderts errichtet, ist der Gebäudekomplex immer wieder renoviert und ausgebaut worden, so war „der Umfang [der ganzen Anlage] äußerst groß“ (guimo jiqi hong). ${ }^{1087}$

Im Jahr 1878 veranlaßte Unterpräfekt Cai Xinyi (1877-78 in Tengyue tätig) den Wiederaufbau des während der Moslem-Rebellion zerstörten Gebäudekomplexes. Allerdings ließ

\footnotetext{
1085 Anderson, S. 191-192. H. R. Davies fand am Ende des 19. Jahrhunderts [1894, 1898, 1899 in Tengyue] nur noch an einer Seite der Stadt Reste des Grabens vor. (S. 44-45).

${ }^{1086}$ YCFZ, S. 55 (yi qie xiu li wan bei ru jiu); TYTZ, S. 67 (ju ru jiu zhi); siehe auch TYZZ, S. 51.

${ }^{1087}$ TYTZ, S. 69
} 
er den Amtssitz „in eine neue Richtung verlegen“ (gai yi xin xiang). Noch ehe die Arbeiten vollendet waren, schied er aus dem Amt und sein Nachfolger Chen Zonghai ließ das Gebäude „auf Anraten der örtlichen Gentry (cong shenshi yi), wieder genau an seinen alten Platz zurück verlegen“ (qian zheng gui jiu xiang).

Von Unterpräfekt Chen „Tag und Nacht überwacht“ (zhao xi du zuo) sind die Bauarbeiten innerhalb von sechs Monaten beendet worden. Insgesamt sind 162 Gebäude, neben der Haupthalle auch Amtsstuben, Archive, Räume für das Hilfspersonal und andere Nebengebäude sowie Tore, Verbindungskorridore usw. wieder aufgebaut und die ganze Anlage schließlich mit einer Mauer umgeben worden. ${ }^{1088}$

Von den zur Finanzierung des Bauprojektes veranschlagten Kosten für Arbeitskräfte und Material (ji gong liao fei) sind 3000 [liang] in Gold vor Ort aufgebracht worden (di fang chou juan zhe), über 1000 [liang] in Gold (jin) stellte Unterpräfekt Chen Zonghai selbst zur Verfügung. ${ }^{1089}$ Nicht nur für den Wiederaufbau seines Amtssitzes spendete Chen Zonghai Geld von seinem Zusatzgehalt (juan lian), auch für andere Bauprojekte, insbesondere für die Instandsetzung der zahlreichen zerstörten Brücken, leistete er persönlich einen finanziellen Beitrag. ${ }^{1090}$

Priorität hatte zunächst auch der Wiederaufbau des Glockenturmes (zhonglou) im Osten der Stadt gehabt, dessen Glocke die Zerstörung des Turmes unversehrt überstanden hatte. Schon Unterpräfekt Wu Qiliang (1873-1875 in Tengyue tätig) ließ einen neuen Turm errichten, doch noch ehe die Bauarbeiten beendet werden konnten, brach im Jahr 1876 die Militärrevolte in Tengyue aus: Die Arbeiten konnten nicht fortgeführt werden, schließlich stürzte der Turm wieder ein. Erst im Jahr 1887 plante Chen Zonghai einen Neubau des Glockenturmes. ${ }^{1091}$

\footnotetext{
1088 TYTZ, S. 69

1089 Ebenda.

1090 Chens Beitrag zu den Kosten für den Wiederaufbau des Amtes der Unterpräfektur erscheint verglichen mit dem regulären jährlichen Zusatzgehalt von lediglich 900 liang in Silber für den Unterpräfekten von Tengyue sehr hoch. Im Jahr 1881 wurde rechts neben der Unterpräfektur das Amtsgebäude des Gefängnisdirektors (siyu shu) wieder aufgebaut, zu dem Chen Zonghai ebenfalls einen finanziellen Beitrag leistete (TYTZ, S. 70).Waren von der Regierung zusätzliche Finanzmittel für den Wiederaufbau bereitgestellt, war das Zusatzgehalt erhöht oder waren Gebühren, Handels- und andere Steuern erhoben worden, stammte das Geld gar aus dem persönlichen Vermögen des Unterpräfekten? Die Verfasser des TYTZ lassen die Frage, woher diese Summen tatsächlich kamen, unbeantwortet.

1091 TYTZ, S. 71. Der Glockenturm wurde später tatsächlich wieder aufgebaut und befand sich bis zur Zeit des 2. Weltkriegs nahe der Stadtmitte, an der Straße zum Osttor (siehe Karte 15, S. 372).
} 


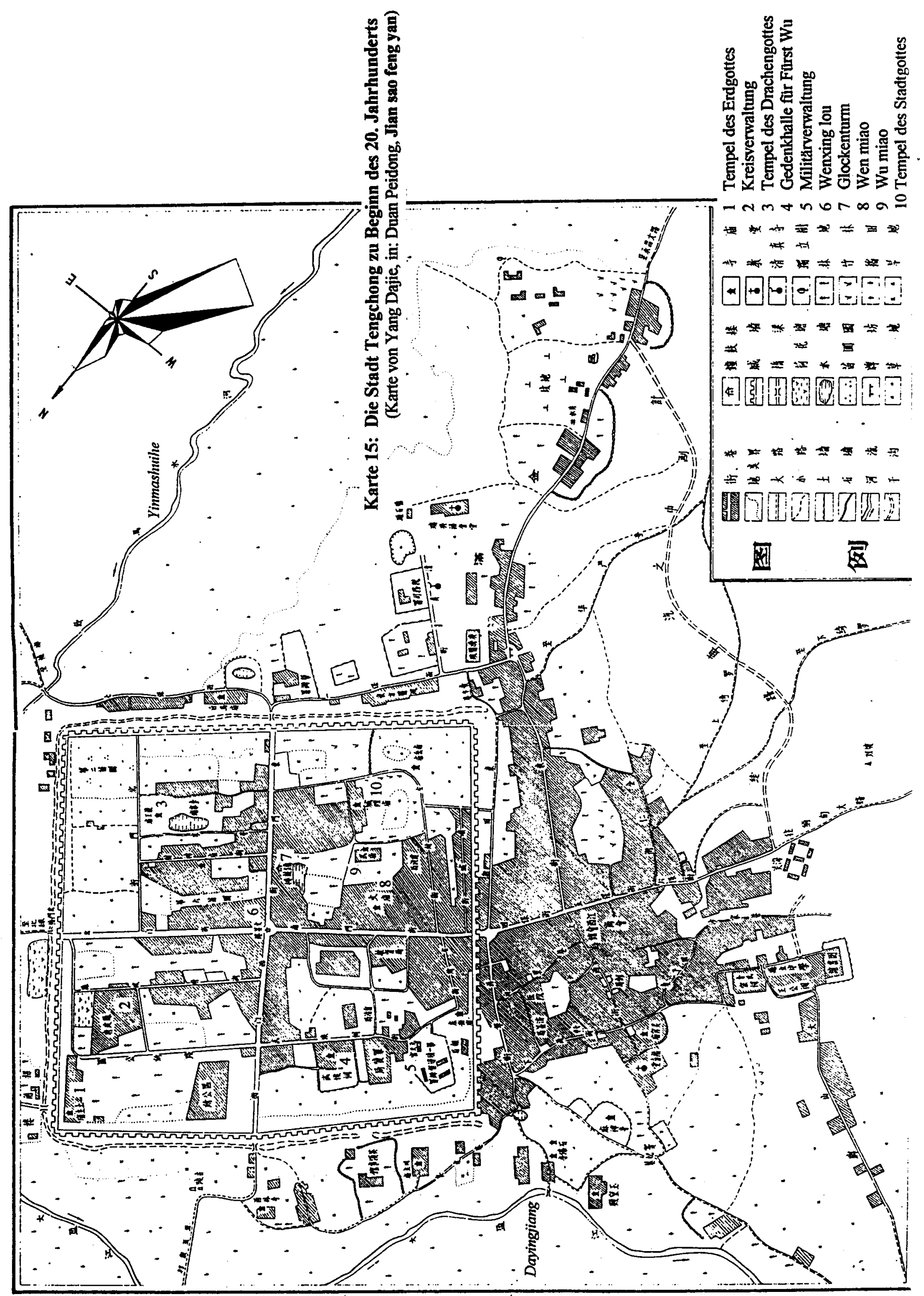




\section{3. 2. Der Tempel des Stadtgottes}

Eines der ersten Gebäude, das nach der Niederschlagung der Moslem-Rebellion unter der Leitung der obersten Verwaltungsbeamten aufgebaut wurde, ist der Tempel des Stadtgottes (Chenghuang miao) im Ostviertel von Tengyue. ${ }^{1092}$

Der Stadtgott war die Schutzgottheit von Tengyue und sein Tempel war eine der wichtigsten religiösen Stätten, wie in jeder chinesischen Stadt. „Obwohl sich Tengyue weit entfernt an der äußersten Grenze befindet, ... haben Zuwanderer aus Wu, Chu, Zhe und Shu schon seit langem die stolzen wilden Sitten (hua qi qiao ye zhi feng) allmählich verändert“ und die Verehrung des Stadtgottes fest in der Gesellschaft verankert. ${ }^{1093}$ Der Stadtgott „kennt die Unter- und die Oberwelt“ (zhi you ming zhi); er stellte die Verbindung zwischen beiden her und verwaltete die jenseitigen Angelegenheiten. Der oberste Verwaltungsbeamte, der sich bei seinem Amtsantritt im Tempel dem Stadtgott vorzustellen hatte, war demgegenüber für alle diesseitigen Angelegenheiten in Tengyue zuständig.

Vor allem aber „beschützt [der Stadtgott] die Bevölkerung“ (wei min), unter anderem auch vor Naturkatastrophen, und sorgte für Gerechtigkeit, indem er die Guten belohnte und diejenigen, die Böses taten, bestrafte. ${ }^{1094}$ Der Gott war ein Symbol für die kulturelle und wirtschaftliche Entwicklung der Stadt, die auch „nicht einen Tag ohne ihn auskommen kann“ (bu ke yi ri wu). ${ }^{1095}$

Folglich hatte die Wiederherstellung des Tempels Priorität. Bereits im Jahr 1875 ließ Unterpräfekt Wu Qiliang (1873-1875 in Tengyue tätig) zunächst die Haupthalle des Tempels des Stadtgottes wieder errichten. Unterpräfekt Chen Zonghai veranlaßte zu Beginn seiner Amtszeit im Jahr 1878, den Wiederaufbau der Tempelanlage fortzusetzen. Doch im Jahr 1884 brannte die Haupthalle ab und alle „früheren Anstrengungen wurden zu Asche“ (qian gong wei jin). Der amtierende Unterpräfekt Wu Qingqi (1884-1885 in Tengyue) „steuerte 300 [liang] in Gold bei und ermunterte den ganzen Ort (he jing), ebenfalls Geld zu spenden (juan qian)“ ${ }^{1096}$ Auch Chen Zonghai ließ anschließend weitere Renovierungsmaßnahmen durchführen, endgültig abgeschlossen wurden die Arbeiten an der Tempelanlage erst zu Beginn des Jahres 1888.

\footnotetext{
1092 TYTZ, S. 157

1093 Chen Zonghai, Gedenkinschrift zur Restaurierung des Tempels des Stadtgottes (TYTZ, S. 309-310). Wu und Zhe bezeichnen die modernen Provinzen Jiangsu und Zhejiang, Chu steht für Hubei und Shu für Sichuan.

${ }^{1094}$ Ebd.; TYTZ, S. 309

1095 Ebenda.

1096 TYTZ, S. 310, 157
} 


\section{3. 3. Weitere Bauprojekte unter der Leitung von Chen Zonghai}

Zur Gruppe der Gebäude, mit deren Wiederaufbau sogleich nach dem Sieg der Regierungstruppen über die Rebellen begonnen wurde, gehörte auch der Schultempel (xuegong). Schon im Jahr 1874 ließ Unterpräfekt Wu Qiliang die Haupthalle des Tempels wiederherstellen; im Jahr 1879 setzte Chen Zonghai die Renovierungsarbeiten an der Tempelanlage fort (siehe A. 6. 1., S. 257).

Zwei Jahre später wurde direkt neben dem Schultempel mit den Arbeiten am Tempel des Gottes der Literatur (Wenchang gong) begonnen. Im Verlauf mehrerer Monate wurde die völlig zerstörte Anlage (pian wa wu cun) wieder hergerichtet, erweitert und mit einer Mauer umgeben. Die Kosten für den Bau betrugen 2000 liang in Silber. ${ }^{1097}$

1882 ließ Chen Zonghai auch die Prüfungshallen (kaopeng) südlich des Amtes der Unterpräfektur wieder herrichten. In der Anlage mußten insgesamt vierzig Bauwerke renoviert werden, unter anderem drei Haupthallen und sechs Seitengebäude, aber auch Küche, Brunnen, Toiletten (chufang, jing, ce) und die Umfassungsmauern. ${ }^{1098}$

Ebenfalls im Jahr 1882 initiierte Chen Zonghai den Wiederaufbau der Anlagen des Altars des Erdgottes und des Gottes des Getreides (Sheji tan) und des Altars der Gottheiten der Naturerscheinungen (Feng yun lei yu shan chuan tan). ${ }^{1099}$ Diese Opferstätte ist eines der wenigen Gebäude, die nach der Rebellion an einen neuen Standort verlegt wurden. Ursprünglich hatte sie sich etwa einen Kilometer westlich der Stadt befunden. Sie war eine ihrer Bedeutung „,angemesene Stätte, nicht übertrieben und nicht anmaßend, so wurde sie in einem alten Handbuch beschrieben; bedauerlicherweise ist [die Anlage] seit langem verödet, zudem sind [die Altäre] während der Rebellion fast vollständig zerstört worden“. ${ }^{1100}$

Chen Zonghai bedauerte, daß er die Altäre erst so spät wieder aufbauen lassen konnte. In seiner Gedenkinschrift zum Neubau schreibt er dazu:

„Ich verwalte Teng[yue] seit nunmehr fünf Jahren und seufzte jedesmal, wenn die Tage des Frühlings- und des Herbstopfers kamen. Weil nun viel gespendet

\footnotetext{
${ }^{1097}$ TYTZ, S. 157, 304 (Gedenkinschrift von Chen Zonghai, TYTZ, S. 303-304).

1098 TYTZ, S. 71. Zum ebenfalls von Chen Zonghai organisierten Wiederaufbau der Akademie Laifengshan siehe oben Abschnitt A. 6. 2., S. 259-261. Auch die Amtsgebäude der beiden Schuldirektoren mußten wieder hergerichtet werden: Der Amtssitz des Schuldirektors (xuezheng shu) war zur Hälfte niedergebrannt, konnte aber renoviert werden; das Amt des Vize-Schuldirektors (xundao shu) hingegen war völlig zerstört worden. Daher veranlaßte Chen Zonghai, es im Jahr 1880 an einem anderen Standort neu zu errichten (TYTZ, S. 70).

1099 TYTZ, S. 157; YCFZ, S. 117. Der Altar der Landwirtschaft (Xiannong tan) war zur Zeit der Herausgabe des TYTZ 1888 noch nicht wieder errichtet worden (ebd.).

${ }^{1100}$ Chen Zonghai, Gedenkinschrift zum Neubau des Altars des Erdgottes und des Gottes des Getreides, TYTZ, S. 306.
} 
worden ist, konnten [die Altäre] schließlich wieder aufgebaut werden und zwar außerhalb des Osttores, ... einige hundert Schritte von der Stadt entfernt“. ${ }^{1101}$

Außerdem organisierte Chen Zonghai auch den Wiederaufbau der Gedenkstätten für berühmte Militärführer der Vergangenheit. 1881 wurde die ,Gedenkhalle der offenkundigen Treue‘ (Zhaozhong ci) renoviert. Dies war eine relativ neue Gedenkstätte, die erst im Jahr 1820 von Unterpräfekt Yilibu zusammen mit dem damaligen Regionalkommandeur errichtet worden war. Sie war Generalgouverneur Mingrui (?-1768) gewidmet, der als Oberkommandierender einen Feldzug im Rahmen des chinesisch-birmanischen Krieges (1766-1769) geführt hatte. Die Gedenkhalle befand sich rechts neben dem Tempel des Stadtgottes. Für ihren Wiederaufbau „sind 750 liang für einen Zeitraum von drei Monaten veranschlagt worden“. 1102

Im Jahr 1888 spendete Chen Zonghai auch persönlich für die Wiederherstellung des ,Tempels für die beiden Generäle Liu und Deng، (Liu Deng er jiangjun miao). Der Tempel war Ende des 16. Jahrhundert errichtet worden, zum Gedenken an die Militärkommandanten Liu Ting und Deng Zilong, die in den Jahren 1582 bis 1583 im Grenzgebiet einen erfolgreichen Feldzug gegen birmanische Truppen geführt hatten. ${ }^{1103}$

Die Gründung der Ming-zeitlichen Stadt Tengchong und der Bau der Stadtmauer Mitte des 15. Jahrhunderts standen unter der Leitung der Vize-Minister des Kriegsministeriums Yang Ning und Hou Jin sowie des Kommandanten Li Sheng. Eine Gedenkstätte für diese Beamten hatte Unterpräfekt Wu Kai im 18. Jahrhundert innerhalb des ,Tempels des Erdgottes‘ (Zhao Teng tuzhu miao) errichten lassen. Chen Zonghai ließ die gesamte Anlage im Jahr 1882 wieder instand setzen. ${ }^{1104}$

Der Wiederaufbau der Gedenkhalle für Zhuge Liang, den Fürsten von Wu, (Wu hou ci) im Westen der Stadt hatte hingegen keine Priorität: Die Halle war zur Zeit der Herausgabe des TYTZ (1888) immer noch zerstört. Ein Nachsatz informiert jedoch darüber, daß „ihre Wiederherstellung gegenwärtig in Planung ist“ (xian ni xiu). ${ }^{1105}$

\footnotetext{
${ }^{1101}$ Ebd., S. 306. Nach fünf Monaten, im Frühling des Jahres 1883 waren die Arbeiten beendet.

${ }^{1102}$ Chen Zonghai, Gedenkinschrift zum Wiederaufbau des Zhaozhong ci, TYTZ, S. 304, siehe auch S. 158.

1103 TYTZ, S. 161

1104 TYTZ, S. 159

1105 TYTZ, S. 158
} 
Zum Gedenken an eine Persönlichkeit aus jüngerer Zeit veranlaßte Unterpräfekt Chen Zonghai selbst den Bau einer neuen Gedenkstätte: Die ,Gedenkhalle für Herrn Zhang‘ (Zhang gong ci). Sie war dem Gefängnisaufseher Zhang Shaoping gewidmet, dem einzigen Beamten von dem die fangzhi berichten, das er sich im Jahr 1861 dagegen ausgesprochen hatte, den Moslem-Rebellen die Stadttore zu öffnen. Chen war beeindruckt von dessen „Treue und Rechtschaffenheit“ (zhong zhen) und ließ deshalb im Jahr 1880 direkt hinter der ,Gedenkhalle der offenkundigen Treue‘ (Zhaozhong ci) drei Gebäude als ,Gedenkhalle für Herrn Zhang‘ errichten. ${ }^{1106}$

Im selben Jahr veranlaßte Chen Zonghai auch die Errichtung von zwei Ehrenpforten mit Gedenkinschriften (jingbiao) zur Erinnerung an die ,tugendhaften Frauen‘, die während der Moslem-Rebellion umgekommen waren. Die eine erinnerte an neun verheiratete Frauen, die während der Moslem-Rebellion Selbstmord begangen hatten (zhenlie), die andere an zwölf ,tugendhafte Töchter` (lienü), die während der Rebellion umgekommen waren, darunter auch die beiden oben genannten jungen Frauen aus Guyong, Wang Zhendi und Hong Chengfeng (s.o. 1. 3. 2., S.344-345). Zum Bau beider Ehrenpforten leistete Chen Zonghai persönlich einen finanziellen Beitrag (juan lian). ${ }^{1107}$

Ein Tempel dessen Restaurierung Unterpräfekt Chen besonders am Herzen lag, war der Tempel des Drachengottes (Longshen ci). Der Tempel hatte sich ursprünglich außerhalb des Westtores befunden, war aber „während der Moslem-Rebellion zu Asche verbrannt“. Gerne hätte Chen den Tempel schon früher restaurieren lassen, denn der Drachengott „, war Bitten um schönes Wetter oder Regen immer nachgekommen und hatte das Getreide auf den Feldern benetzt“; ,jedesmal, wenn der Tag für die Opferzeremonien kam“, so schreibt Chen in seiner Gedenkinschrift, „,bereitete es mir großen Kummer, daß der Gott [hier] keinen Ort mehr zum Verweilen hatte“ (xin shang yu shen wu suo qi). ${ }^{1108}$

Im Jahr 1881 konnte schließlich mit dem Wiederaufbau begonnen werden. Da es jedoch „für die Beamten unbequem war (bu bian), den Tempel außerhalb der Stadt aufzusuchen, um Weihrauch zu verbrennen und ihre Verehrung zu bezeugen“, ließ er ihn in die Stadt

\footnotetext{
1106 TYTZ, S. 306

1107 TYTZ, S. 235, 237. Chen Zonghai spendete zudem Geld für einen weiteren Gedenkbogen zu Ehren von fünf ,pietätvollen Töchtern` (zhennü) (TYTZ, S. 236).

Bereits im Jahr 1876 hatte der Unterpräfekt Wu Zixiu auf kaiserlichen Befehl hin eine besondere Gedenkstätte für die Frau des Militärkommandanten Li Zhenguo aus Tengyue an dem Ort errichten lassen, wo Frau Li von den Rebellen getötet worden war (siehe oben B. 1. 3. 2., S. 339, Fußnote 1004) (TYTZ, S. 235).

${ }^{1108}$ Chen Zonghai, Gedenkinschrift zum Wiederaufbau des Tempels des Drachengottes, TYTZ, S. 308.
} 
verlegen. Chen Zonghai wählte ein „Gelände von über zehn zhang“ am ,Brunnen des weißen Kranichs ‘(Baihe jing) am Nordtor als neuen Standort für die Tempelanlage aus. ${ }^{1109}$ Innerhalb von wenigen Monaten wurde der Tempel neu gebaut. Als sich herausstellte, daß zur Finanzierung des Baus noch über 300 liang Silber fehlten, spendete Chen Zonghai sein Beamtengehalt (juan feng fa gei), um das Defizit zu decken.

Der Wiederaufbau der buddhistischen und daoistischen Tempel Tengyues wurde von den Glaubensgemeinschaften und der Bevölkerung in der Nachbarschaft der Tempel selbst organisiert (li ren xiu zhi). ${ }^{1110}$ Unterpräfekt Chen Zonghai beteiligte sich persönlich lediglich an der Restaurierung der beiden prominentesten buddhistischen Tempel von Tengyue: Im Jahr 1879 initiierte er die Spendensammlung (chang juan) für die Restaurierung des Laifeng-Tempels auf dem Laifengshan im Süden der Stadt. Im Jahr darauf organisierte Chen auch den Wiederaufbau des ,Tempels des westlichen Bündnisses‘ (Ximeng si, auch Wanshou si, Wanshou ting) im Nordwesten der Stadt. Der Tempel war in der Yuan-Zeit errichtet worden und erinnerte an die Anfänge der Stadt Tengyue. ${ }^{1111}$

Der Tempel des Feuergottes (Huoshen miao) ist in keinem der fangzhi in den Listen der Tempel von Tengyue aufgeführt worden. Lediglich eine Gedenkinschrift von Chen Zonghai gibt Auskunft über den Tempel, der sich im südwestlichen Teil der Stadt befand:
„Während des Moslemaufstandes im Jahr bingchen (1856) der Ära Xianfeng gingen die Militärs [im Tempel des Feuergottes] ein und aus. Nachdem die Stadt im Jahr xinyu (1861) eingenommen worden war, sind nicht wenige Tempel zerstört worden. Auch der Tempel des Feuergottes ist so verwüstet worden, daß man es mit Worten nicht beschreiben kann (yi roulin er bu ke yan). Als die Stadt Tengyue dann im 12. Jahr der Ära Tongzhi (1873) zurück erobert wurde, waren Mauern, Gebäude und Tore sämtlich eingestürzt, nur das Äußere des Tempels existierte noch“. ${ }^{1112}$

\footnotetext{
1109 TYTZ, S. 308; YCFZ, S. 117. Das Längenmaß zhang entspricht etwa 3,33 Metern; Chen meint hier wohl ca. 33 Quadratmeter.

${ }^{1110}$ TYTZ, S. 160 (Puji si u.a. ebd.)

1111 TYTZ, S. 160; TYZZ, S. 58; YCFZ, S. 124

1112 TYTZ, S. 312, Chen Zonghai, Gedenkinschrift zum Wiederaufbau des Tempels des Feuergottes. Als Erfinder und Verwalter des Feuers wurden in China mehrere Götter wie Zhurong, Yandi oder Huilu verehrt (Ma Shutian, S. 81). Chen Zonghai nennt in seiner Inschrift Zhurong und auch Tiansi, der zu den Sternengöttern gehört; diese wurden ebenfalls im Tempel des Feuergottes verehrt, als dessen Helfer oder Minister sie nach volkstümlicher Vorstellung galten (Bredon, S. 371-371).
} 
Da der Tempel völlig zerstört war, wurde die Statue des Feuergottes Zhurong von Einwohnern der Stadt vorübergehend in einem benachbarten Tempel untergebracht, der nicht demoliert worden war.

„An jedem Neu- und Vollmond [1. und 15. des Mondmonates] suchten [die Menschen] jenen Tempel auf, um ihre Verehrung $\mathrm{zu}$ bezeugen und waren äußerst bekümmert, denn obwohl die Gegend [nach der Revolte] wieder friedlich war und die verschiedenen Tempel alle schon restauriert worden sind, war dem Platz des Feuergottes ... noch gar keine Beachtung geschenkt worden. Wie kann man [unter solchen Umständen] den Göttern aufrichtige Verehrung und Hochachtung zeigen? Also wurde eilig geplant, Geld gespendet (ji wei chou hua juan lian) und mit den Bauarbeiten begonnen, ... die dann von Brigade Vize-Kommandant Chai Shengzao beaufsichtigt wurden. ... Die Arbeiten waren am ersten Tag des 10. Monats des 13. Jahres der Ära Guangxu (1887) begonnen und sind im 4. Monat des 14. Jahres (1888) vollendet worden.“ 1113

In wie weit Chen Zonghai selbst am Wiederaufbau beteiligt war, geht aus dem Text nicht hervor, lediglich die Formulierung in Bezug auf das gespendete Geld mag darauf hindeuten, daß er auch persönlich einen finanziellen Beitrag geleistet hatte (juan lian). Vor allem aber war es die Bevölkerung, die am Wiederaufbau des populären Tempels interessiert war sowie auch das Militär, schließlich war es einer der Brigadeführer der Militärkommandantur, der den Fortgang der Arbeiten überwacht hatte.

In Zusammenarbeit von Zivil- und Militärbeamten wurde der Tempel des Kriegsgottes (Guandi miao) im Westen der Stadt wieder errichtet: Unterpräfekt Chen Zonghai organisierte gemeinsam mit dem Regionalkommandeur Li Wenyi die Bauarbeiten am Tempel, in dem Guandi, ursprünglich ein General aus dem 3. Jahrhundert n. Chr., nicht nur als Kriegsgott, sondern auch als Gott der Gerechtigkeit und des Reichtums von der Bevölkerung verehrt wurde. $^{1114}$

Dieser Überblick über einen Teil der Bauprojekte unter der Leitung des Unterpräfekten zeigt, daß Chen Zonghai sich dem Wiederaufbau der wichtigsten Verwaltungsgebäude, der

1113 TYTZ, S. 312

1114 TYTZ, S. 157 
regulären und volkstümlichen Opferstätten (diansi, susi) und der beiden prominenten buddhistischen Tempel widmete. Hinzu kam sein Engagement für die Wiederherstellung von Brücken und Schulen.

Die erste Brücke, deren Wiederaufbau Chen noch im Jahr seines Amtsantritts (1878) organisierte, war die Nangzhuang-Brücke im Gebiet der tusi von Ganya. Im Jahr darauf ließ er im Norden von Tengyue drei Brücken über den Longchuanjiang aufbauen, die die Verbindungen zur Präfektursstadt Yongchang wieder herstellten. ${ }^{1115}$ Während seiner ersten Amtszeit in Tengyue (1878-1883) ließ Chen Zonghai fünfzehn Brücken wieder errichten. Auch nach Antritt seiner zweiten Amtszeit im Jahr 1885 engagierte er sich weiter für den Wiederaufbau zahlreicher Brücken. Im Jahr 1887 allein wurden unter seiner Leitung fünfzehn Brücken wieder instand gesetzt. Er organisierte die Finanzierung der Bauprojekte, steuerte auch selbst Mittel dazu bei. Um die Durchführung jährlicher Reparaturarbeiten zu gewährleisten, stellte er für einige Brücken die Erträge von Feldern, die sich im Besitz von Rebellen befunden hatten, zur Verfügung. ${ }^{1116}$ Insgesamt ließ Chen in der Unterpräfektur Tengyue siebenunddreißig Brücken wieder aufbauen. Damit leistete er einen wichtigen Beitrag für die Verbesserung der Verkehrsverbindungen, die die Anbindung an das chinesische Kernland festigten und zukünftig besonders der Entwicklung des Handels mit Birma zugute kamen.

Nicht zu den Aufgaben Chen Zonghais gehörte hingegen der Wiederaufbau der Gebäude der Militärverwaltung von Tengyue. Für die Wiederherstellung der Amtsgebäude der Militärkommandantur war der jeweilige Regionalkommandeur als oberster Militärführer von Tengyue verantwortlich. Dessen Amtssitz war während der Moslem-Rebellion zur Hälfte zerstört worden. Der Wiederaufbau begann im Jahr 1879. Im Jahr 1880 ließ der nächste Regionalkommandeur, Li Wenyi, die Anlage „um Amtsstuben und Küchen (shufang chufang), insgesamt zehn Gebäude erweitern“. ${ }^{1117}$ Auch Ding Huai veranlaßte 1886, dem Jahr seines Amtsantritts, die Errichtung eines Dutzend neuer Gebäude auf dem Gelände. $^{1118}$

\footnotetext{
${ }^{1115}$ Im Jahr 1879 (Guangxu 5) wurden die Longchuanjiang-, die Xiangyang- und die Puji-Brücke sowie die YongjiBrücke in Qushi, am östlichen Ufer des Longchuanjiang, wieder errichtet. Die Bauarbeiten an der Xiangyang-Brücke dauerten drei Jahre, von 1879-1881 (TYTZ, S. 57-58).

${ }^{1116}$ Siehe TYTZ, S. 58 (Wusuo qiao, Jinjie qiao).

${ }^{1117}$ TYTZ, S. 70

${ }^{1118}$ Ebenda.
} 
Das Amtsgebäude des Brigadekommandanten, ebenfalls im Südwesten der Stadt gelegen, war während der Moslem-Rebellion nicht zerstört worden. Vermutlich war es diese Anlage, die General Li Guolun als Amtssitz nutzte, denn John Anderson erwähnt in der Beschreibung des Besuches der britischen Expedition bei General Li, keine zerstörten Gebäude oder Gebäudeteile. ${ }^{1119}$ Erst während der Militärrevolte im Jahr 1876 wurde die Anlage zerstört; „unlängst wurde sie jedoch im großen und ganzen wieder hergestellt“ “ ${ }^{1120}$

Ein Jahrzehnt nach der Rebellion waren die Amtsgebäude der Zivil- und Militärbeamten Tengyues wieder aufgebaut, ebenso wie die meisten der Tempel und anderen Opferstätten. Außerhalb des Südtores erstreckte sich wieder eine prosperierende Vorstadt, in der wie zuvor ein großer Teil der Bevölkerung von Tengyue lebte. Das Gebiet innerhalb der Stadtmauern war hingegen nie sehr dicht besiedelt gewesen und umschloß auch weiterhin Teiche und Grünflächen, wie Wiesen, Bambushaine oder Reisfelder (s. Abb. 2, S. 381). H. R. Davies, der die Stadt Ende des 19. Jahrhunderts mehrfach besuchte, schrieb 1894:

„Tengyue hat eine weitere Eigenart, die charakteristisch für die meisten chinesischen Städte ist, nämlich die, daß sich innerhalb der Stadtmauern große freie Flächen und sogar Felder befinden, während die wichtigsten Läden und Geschäftshäuser in den Vororten liegen“. ${ }^{1121}$

In den Lokalhandbüchern von Tengyue sind es die tabellarischen Auflistungen der Amtsgebäude, Tempel, Schulen oder Brücken, die einen Überblick über die bauliche Entwicklung der Stadt geben. Die einzelnen Einträge enthalten dort fast ausnahmslos einen Vermerk über die Zerstörung des Bauwerkes während der Moslem-Rebellion sowie zum anschließenden Wiederaufbau. Sie zeigen so einerseits den großen Umfang, den die Zerstörung von Bauwerken erreicht hatte, andererseits aber auch die großen Anstrengungen, die von den Beamten und der Bevölkerung unternommen wurden, um die Schäden in einem relativ kurzen Zeitraum wieder zu beseitigen. Der zügige Wiederaufbau war ein deutliches Symbol für die erfolgreiche Restauration der zivilen und militärischen Verwaltungseinheiten in der Unterpräfektur Tengyue, repräsentieren die Amtsgebäude doch die

\footnotetext{
1119 Anderson, S. 193-198

${ }^{1120}$ TYTZ, S. 70. In den Jahren 1881 bzw. 1882 sind auch das Waffen- (Junqi ju) und das Munitionsdepot (Huoyao ju) unter der Leitung des Regionalkommandeurs Zhu Hongzhang wieder renoviert worden (ebd.). Daten zum Wiederaufbau der Amtsgebäude der niederrangigen Militärführer oder der Garnisonsstützpunkte werden im TYTZ nicht genannt.

${ }^{1121}$ Davies, S. 45. Siehe auch Karte 15, S. 372.
} 


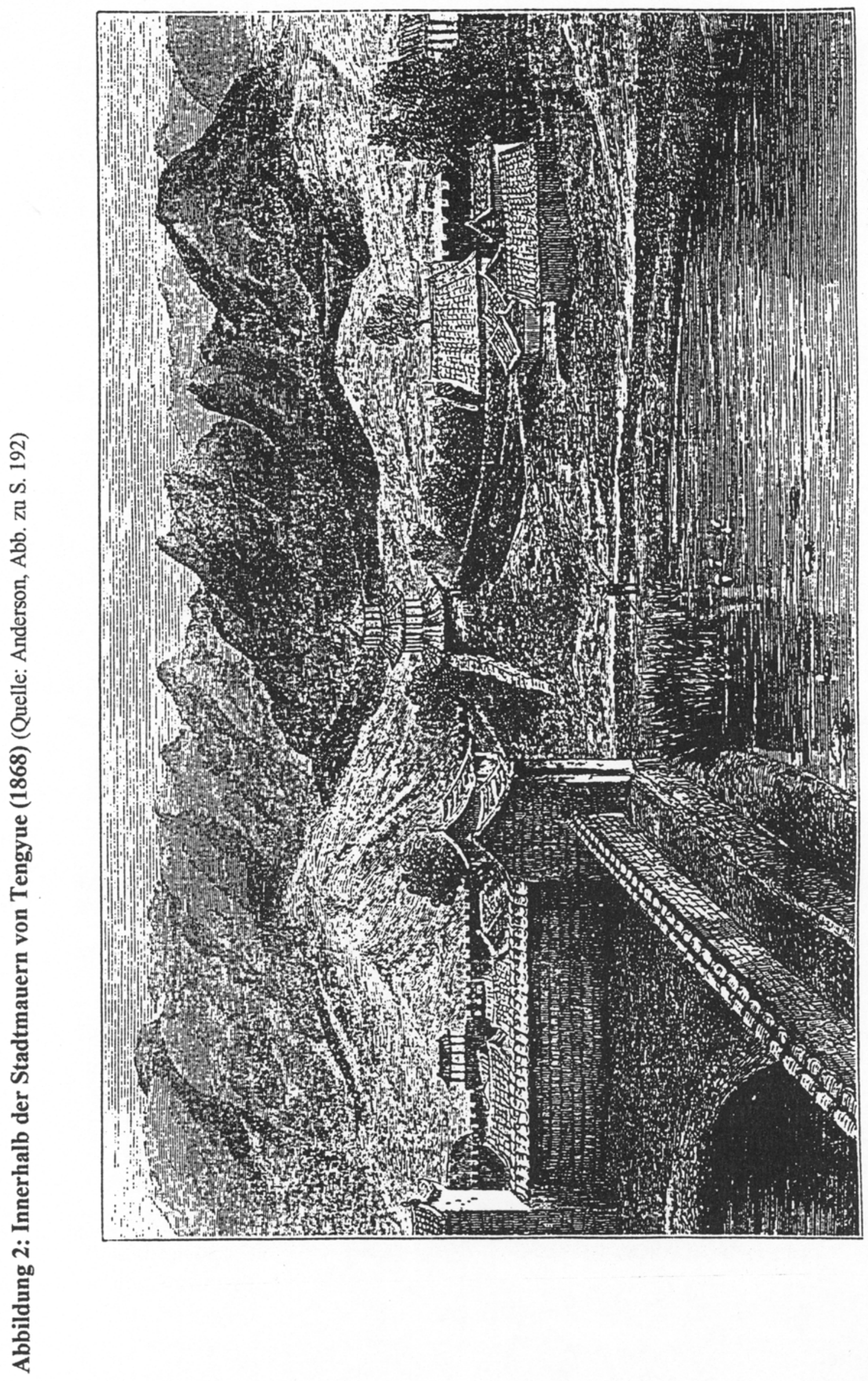


Etablierung der Strukturen Zentralchinas in der Region des Stromschluchtenfächers und betonen, ebenso wie die Wiederherstellung der Brückenverbindungen, die feste Anbindung des Grenzgebietes an die Kernregion. Mit dem Wiederaufbau der Amtsgebäude und besonders der Tempel und Gedenkstätten (an ihren bisherigen Standorten, doch auch erweitert um neue Gebäudeteile) wird bewußt an die Traditionen angeknüpft und ein Bestreben nach Kontinuität zum Ausdruck gebracht, das nicht mehr nur die gewohnheitsmäßige Fortsetzung des Althergebrachten ist, sondern eine aktive Bejahung der Traditionen zum Ausdruck bringt, auf denen die Stadt ihre weitere Entwicklung gründete.

\section{4. Das Schulwesen in Tengyue in der zweiten Hälfte des 19. Jahrhunderts}

Die Zeit der Moslem-Rebellion (1855-1873) bedeutete einen Einschnitt in der Entwicklung des Bildungswesens in der gesamten Provinz, waren doch der Schulbetrieb allerorts eingestellt worden und das staatliche Prüfungswesen in Yunnan ganz zum Erliegen gekommen. Entsprechend haben im Jahr 1855 auch zum letzten Mal Kandidaten aus der Präfektur Yongchang an den Prüfungen teilgenommen: Ein Kandidat aus Tengyue, zwei aus dem Kreis Baoshan und einer aus Longling haben dabei den Titel eines juren erworben.

Tengyue ist zwölf Jahre lang, von 1861 bis 1873, von den aufständischen Moslems besetzt gehalten worden. In diesem Zeitraum sind die Schulgebäude in der Stadt und ihrer Umgebung sämtlich zerstört worden.

Der Engländer John Anderson, der an der Expedition von Colonel E. Sladen nach Yunnan teilgenommen hat, hat während seines Aufenthaltes in Tengyue (Momien) im Jahr 1868 lediglich eine Schule in einem abgelegenen buddhistischen Tempel außerhalb der Stadt vorgefunden, in der noch Unterricht erteilt wurde. In seinem Reisebericht gibt Anderson eine lebendige Beschreibung des Schulalltags:

„In einem der wenigen buddhistischen Tempel, in denen noch Priester lebten und die sich alle an abgelegenen Orten außerhalb der Stadt befanden, entdeckte ich eine Schule für Jungen, die von einem intelligenten Priester geleitet wurde. Ein starker Regenschauer ließ mich dort Schutz suchen und der Lehrer, der an einem niedrigen schwarzen Tisch saß, lud mich höflich ein, Platz zu nehmen. Die Schüler verließen sogleich ihre Tische und drängten um uns herum. Einer Handbewegung, die sie aufforderte zu ihren Tischen und den Aufgaben zurückzukehren, kamen sie nur insoweit nach, als sie alle begannen ihre 
Lektionen, so laut wie sie konnten, aufzusagen. Ein Wort ihres Lehrers sorgte jedoch dafür, das sie auseinanderstoben. Ich holte ein paar Cheroots hervor, der Priester schickte nach Tee und so plauderten wir eine Stunde lang. .... ... Den Jungen im Alter von sechs bis fünfzehn Jahren schien ihr Unterricht Spaß zu machen. Schulstunden waren von neun bis siebzehn Uhr, mit einer Pause von anderthalb Stunden, in der jeder der Jungen sein Mittagessen bei einem Straßenhändler erwarb, der kleine Schüsseln mit chinesischen Leckereien bereithielt. Jeder Junge hatte seine eigenen Bücher, saß an einem Tisch und schrie seine Lektion laut heraus, so lange, bis er sicher war, sie zu beherrschen, um sie anschließend dem Lehrer vorzutragen, dem er während des Vortrags den Rücken zukehrte. Schreiben lernen sie zur selben Zeit wie lesen, denn jeder Junge kopiert zuerst seine Lektion, wobei er die genaue Aussprache jedes Buchstaben und jedes Wortes vom Lehrer erklärt bekommt - so werden ganze Bücher auswendig gelernt. Das babylonische Gewirr der Stimmen ist ohrenbetäubend, daher kann man unseren Schulbehörden [diese Methode] wohl nicht empfehlen“. ${ }^{1122}$

Das Beispiel dieser Tempelschule zeigt, daß man in Tengyue bemüht war, den Schulbetrieb trotz der widrigen Umstände nicht gänzlich zum Erliegen kommen zu lassen. Mit Erfolg, wie sich auch darin gezeigt hat, daß bereits wenige Jahre nach der Niederschlagung der Rebellion wieder Kandidaten aus Tengyue an den Provinzprüfungen teilnahmen.

Im Herbst des Jahres 1870 fanden in Yunnan Prüfungen auf Provinzebene statt. Diese wurden von Gouverneur Cen Yuying geleitet und ebenso wie bei den Militär-Prüfungen, die im darauffolgenden Frühjahr erstmals wieder stattfinden konnten, wurde auch für die Zivil-Prüfungen die Quote für die erfolgreichen Kandidaten erhöht, um die Ausfälle der letzten Jahre auszugleichen. ${ }^{1123}$ An den zivilen Prüfungen dieser Jahre nahmen bereits wieder zwei Kandidaten aus dem Kreis Baoshan (der Präfekturstadt und ihrer Umgebung) teil, ebenso wie an der zusätzlichen Prüfung im Jahr der Thronbesteigung des Guangxu Kaisers (1875), die fünf Kandidaten aus Baoshan erfolgreich absolvierten.

\footnotetext{
${ }^{1122}$ Anderson, S. 217-218. Im Folgenden berichtet Anderson, daß an dieser Tempelschule auch der Sohn eines der moslimischen Offiziere von Tengyue unterrichtet wurde.

${ }^{1123}$ Wei, S. 161. Abweichend von den Angaben bei Alice Wei, nach denen die erste Prüfung nach der Rebellion im Jahr 1870 stattfand, wird im YCFZ bereits für das Jahr Tongzhi 6 (1867) ein erfolgreicher Kandidat der Provinzprüfungen (juren) aus Baoshan aufgelistet (siehe YCFZ, S. 213).
} 
Die Stadt Tengyue gehörte zu den letzten von den Rebellen besetzten Gebieten und wurde erst im Jahr 1873 von den Regierungstruppen zurückerobert. Erstmals nahmen zwei Kandidaten aus Tengyue wieder an den Provinzprüfungen im Jahr 1876 mit Erfolg teil, ebenso wie an den folgenden Prüfungen in den Jahren 1879 und 1882, als drei bzw. zwei Kandidaten aus der Unterpräfektur den Titel eines juren erhielten. ${ }^{1124}$

Insgesamt haben in der Zeit nach der Niederschlagung der Moslem-Rebellion, in den Jahren von 1870 bis 1882 (dem letzten in den fangzhi genannten Jahrgang) vierundzwanzig Kandidaten aus der Präfektur Yongchang den Titel eines juren erworben (darunter sieben aus Tengyue und einer aus der Unterpräfektur Longling, die anderen stammten aus dem Kreis Baoshan). ${ }^{1125}$

Die erfolgreiche Teilnahme der Kandidaten aus Yongchang und Tengyue an den Provinzprüfungen verweist darauf, daß einige Männer auch während der Zeit der Besetzung durch die Rebellen ihre Studien fortgesetzt haben sowie auf eine zügige und erfolgreiche Wiederanknüpfung des staatlichen Bildungs- und Prüfungssystems, nicht nur in der Provinzhauptstadt, sondern auch im fernen Westen Yunnans.

Die Wiederbelebung des Schulwesens in Tengyue nach der Rebellion ist besonders dem Bemühen der Unterpräfekten zu verdanken, die die Renovierung und den Neubau der Schulen initiierten und diese auch selbst mit finanziellen Mitteln unterstützten. Schon im Jahr 1874 (Tongzhi 13) veranlaßte Unterpräfekt Wu Qiliang den Wiederaufbau des 1862 zerstörten Schultempels, der unter seinem Amtsnachfolger Chen Zonghai vollendet wurde.

Der Wiederaufbau der Bildungsstätten und besonders der Freischulen (yixue) war Unterpräfekt Chen ein wichtiges Anliegen. Während seiner Amtszeiten (1878-1883, ab 1885) in Tengyue ließ er insgesamt sechsundvierzig Freischulen renovieren, erweitern oder neu errichten.Verwaltung und Finanzierung der Schulen wurden von ihm neu geregelt, außerdem ließ er ihnen zusätzliche Mittel zur Verfügung stellen. Jeder Schule wurden Ländereien zugewiesen, deren Erträge an die Schule abgeliefert werden mußten. In den fangzhi sind die Angaben zur Lage der Felder und der Mengen, die den einzelnen Schulen zustanden, genau aufgelistet worden.

\footnotetext{
1124 TYTZ, S. 201

${ }^{1125}$ YCFZ, S. 213
} 
Chen Zonghai organisierte nicht nur den Bau der Schulgebäude, sondern spendete (juanlian bangei) jeder yixue ein gutes Dutzend Bücher, deren Titel im TYTZ einzeln aufgeführt worden sind. ${ }^{1126}$ Hierbei handelt es sich um grundlegende Werke des konfuzianischen Bildungskanons, wie die ,vier Klassiker‘ sowie um praktische Lernhilfen, wie das während der Ära Kangxi zusammengestellte Lexikon, das Bedeutung und Verwendung der Schriftzeichen erklärt, sowie um Bücher mit Vorschriften für Schüler bezüglich Unterricht und Prüfungen. Bestandteil der Bücherspende waren zudem die ,Heiligen Edikte‘ des KangxiKaisers, die konfuzianische Tugenden und Werte, wie Kindespietät und normgerechtes Verhalten, propagierten und in allen Verwaltungseinheiten einmal monatlich öffentlich vorgetragen werden sollten.

Diese Bücher vermittelten traditionelles Bildungsgut, zu desssen Verbreitung in den Freischulen der Unterpräfektur, die sich zumeist außerhalb der Stadt Tengyue in den Hanchinesischen Gemeinden wie Guyong, Heshun, Puwo und solchen in Nandian, Shanmulong oder Zhanxi befanden, sie beitragen sollten, um die Verbindung zu den Strukturen des chinesischen Kernlandes, die während der Rebellion unterbrochen worden waren, wieder herzustellen und die Gültigkeit dieser Traditionen auch im äußersten Südwesten des Reiches zu bekräftigen.

Die Wiederaufnahme des Schulbetriebes war somit auch ein Zeichen dafür, daß sich das Leben in der Unterpräfektur wieder normalisiert hatte. Entsprechend wird in dem von Chen Zonghai 1888 herausgegebenen Lokalhandbuch TYTZ der erfolgreiche Neubeginn des Unterrichts in Tengyue besonders betont:

\begin{abstract}
„Nachdem in der Ära Xianfeng (1851-62) die Mauern der Unterpräfektur [von den Aufständischen] erobert worden waren, wurden sämtliche Schulen und Akademien zerstört, so daß kein Unterricht mehr stattfinden konnte. Erst nach fast zwanzig Jahren konnte [die Stadt] zurückerobert werden. Dann wurden allmählich auch die Schulen eine nach der anderen wieder errichtet. Und so
\end{abstract}

\footnotetext{
${ }^{1126}$ TYTZ, S. 174: 1. Shengyu guangxun (,Heilige Edikte‘ des Kangxi-Kaisers von 1662, ergänzt 1670 sowie vom Yongzheng-Kaiser [1723-36]), 2. Qingxiang miyue, 3. Kangxi zidian, (,Das Lexikon der Schriftzeichen aus der Ära Kangxi‘ von 1716) 4. Shihuan jinzhen (mit Anhang), 5. Wendi zhantan (in 6 Artikeln, mit Anhang: Quanshiwen), 6. Yingyan liangfang, 7. Zixue juyu (Mustertexte für die Beamtenprüfungen; hrsg. Von Long Qirui [1814-1858], Bester der Hanlin-Prüfungen während der Ära Daoguang, als Schuldirektor und Direktor des Provinzschatzamtes in Jiangxi tätig [CY 423.4, ZGRMDCD, S. 89.), 8. Fajielu, 9. Kechang tiaoli (,Richtlinien für den Prüfungssaal`), 10. Dizigui (,Vorschriften für Schüler'), 11. Sishu he jiang (,Die vier Klassiker [Lunyu, Mengzi, Daxue und Zhongyong], mit Erläuterungen'), 12. Tongmeng jiyao, 13. Wuzhong yigui, 14. Sishi dushu le (,Lesevergnügen in den vier Jahreszeiten‘, mit Anhang: Jiuchenggong und anderen Musterschriften [CY 60.3]).

Die Druckplatten von neun dieser vierzehn Bücher (1. bis 2. und 4. bis 10.), befanden sich in der Laifengshan Akademie (s.o. A. 6. 2., S. 261).
} 
kann man heute wieder jeden Tag aufs neue die rezitierenden Stimmen hören und die Menschen haben wieder Frieden gefunden. Früher sagte man, daß Riten und Musik das Militärische verändern können, daß Lyrik und Prosa einen guten Charakter (shan qi) heranbilden können. Das ist wirklich richtig“. ${ }^{1127}$

Folglich ziehen die Verfasser des TYTZ am Ende des 19. Jahrhunderts denn auch nicht zu Unrecht eine insgesamt positive Bilanz der Entwicklung des Bildungswesen in der Unterpräfektur:

„Tengyue liegt zwar an der äußersten Grenze des Reiches, steht aber dennoch im Ruf, eine blühende Kultur (wenwu weiran) zu haben““. ${ }^{1128}$

\section{5. Die tusi-Gebiete und die Paßstationen}

Nachdem die Moslem-Rebellen im Jahr 1861 die Stadt Tengyue erobert hatten, dehnten sich die Kampfhandlungen auch auf die tusi-Gebiete im Südwesten der Unterpräfektur aus. Nandian wurde von den Rebellen erobert, die dort einen Militärposten stationierten. Auch nach Ganya, dessen tusi zunächst Li Zhenguo unterstützt hatte, waren die Rebellen vorgedrungen. Der tusi des weiter südlich gelegenen Husa unterhielt Beziehungen zu den Chinesen und den Rebellen und hatte so deren Vordringen in sein Herrschaftsgebiet verhindern können.

John Anderson beschreibt die Lage in den tusi-Gebieten, die die britische Expedition im Jahr 1868 auf ihrem Weg von Bhamo dem Tal des Dayingjiang nach Norden folgend passierte, aus eigener Anschauung:

„Die Stadt Hotha [Husa] besteht aus etwa einhundertundfünfzig Häusern, die von einer niedrigen Mauer umgeben sind.“ Ein lebhafter Markt befindet sich etwa fünfhundert Meter außerhalb der Stadt. ${ }^{1129}$

\footnotetext{
1127 TYTZ, S. 163

${ }^{1128}$ Ebenda.

${ }^{1129}$ Anderson, S. 279, 283. Auch im TYTZ werden die Residenzen der tusi (wie Ganya, Longchuan oder Husa) Ende des 19. Jahrhunderts als ummauerte Städte (cheng) bezeichnet (siehe TYTZ, S. 155).
} 
„Die Stadt Sanda (Zhanda) befindet sich auf einem Bergrücken in einem Seitental etwa drei Kilometer nördlich des Flußes Tapeng [Dayingjiang]. Reste einer dicken Mauer mit Schießscharten umgeben eine Fläche von ungefähr fünfhundertundfünfzig Quadratmetern, über die achthundert bis tausend Häuser verteilt sind, mit einer Bevölkerung von vier- bis fünftausend Menschen.“ Mit Ausnahme des Hauses des Sawbwa [tusi] sind alle größeren Gebäude von den Moslem-Rebellen zerstört worden, als diese 1863 die Stadt eroberten; sie waren im Jahr 1868 noch nicht wieder aufgebaut. Etwa vierhundert Meter nordöstlich der Stadt befindet sich der Markt, „ein Dorf, welches ausschließlich von Chinesen bewohnt wird ... und aus zwei Reihen von Häusern besteht, die Straße dazwischen wird an jedem Ende von einer Mauer begrenzt“. Der chinesische Tempel neben dem Eingang ist ebenfalls von den Rebellen zerstört worden. ${ }^{1130}$

„Muangla oder Mynela [Ganya] befindet sich hoch auf einem Abhang am linken Ufer das Tapeng [Dayingjiang] und ist von einer etwa acht Meter hohen Mauer aus Ziegelsteinen mit zahlreichen Schießscharten und einigen Wachtürmen umgeben. Die Mauer mit ihren sechs Toren ... erscheint in sehr viel besserem Zustand zu sein als die in Sanda [Zhanda]. Abgesehen von der breiten Basar-Straße sind die anderen bloße Gassen, die mit Kopfsteinen gepflastert sind. Innerhalb der Mauern leben nicht mehr als zweitausend Menschen“, noch einmal soviele leben in den Dörfen in der nahen Umgebung der Stadt. Die chinesischen Tempel sind zerstört worden. ${ }^{1131}$

Im Tal von Nandian passierte die Expedition zunächst „die kleine Stadt Muangtee oder Myne-tee [Nandian tusi] der Shan“. Die engen Straßen innerhalb der Mauern sind überfüllt, hauptsächlich von Frauen und Kindern, da die meisten Männer während der Kämpfe umgekommen sind. „Knapp einen Kilometer entfernt befindet sich die kleine ummauerte chinesische Stadt Nantin [Nandian]. ... Nantin war allen Anzeichen nach eine blühende chinesische Stadt. Jetzt liegt ihre eine Hälfte in Ruinen, die andere wird von einer erbärmlich armen spärlichen Bevölkerung bewohnt.“ Auch in Nandian sind die chinesischen Tempel zerstört worden. Aufgrund der strategischen Lage ist hier ein Kontingent von Moslem-Soldaten stationiert, das die Hauptverkehrsroute nach Tengyue kontrolliert. ${ }^{1132}$

\footnotetext{
${ }^{1130}$ Anderson, S. 169

1131 Ebenda, S. 173

1132 Ebenda, S. 179
} 
John Andersons macht in seinem Reisebericht deutlich, daß die Hauptorte der tusi-Gebiete Ansiedlungen von einiger Bedeutung waren: Residenzen der lokalen Machthaber, umgeben von Schutzmauern; mit lebhaften Märkten, die von ihrer Lage an der Hauptverkehrsroute nach Birma ebenso profitierten, wie vom Handel mit den Bergvölkern der Kachin oder Lisu. Auch Chinesen waren in den tusi-Gebieten ansässig, in eigenen Siedlungen mit ihren Tempeln, eng verbunden mit Handel und Märkten.

Während der Moslem-Rebellion, so belegen Andersons Beobachtungen, ist die Entwicklung in den tusi-Gebieten sehr unterschiedlich verlaufen. Zhanda und Nandian sind während der Rebellion größtenteils zerstört worden, in Ganya hatten die Rebellen „im Jahr 1862 Unruhe gestiftet“ und Tempel verwüstet. ${ }^{1133}$ Dem sawbwa von Husa war es mit geschickter Diplomatie gelungen, sein Herrschaftsgebiet aus den Kämpfen herauszuhalten. Die Rebellen waren zwar zeitweise in einige tusi-Gebiete vorgedrungen, die lokalen Machtverhältnisse hatten sich dadurch jedoch nicht verändert: Die tusi hatten sich mit den verschiedenen kämpfenden Parteien arrangiert und behielten so weiterhin die Kontrolle über ihre Herrschaftsgebiete.

Aus chinesischer Sicht haben sich die tusi ,in der Sache der Moslem-Rebellion“ (Hui ni an) loyal verhalten, indem sie, darauf weisen die Verfasser des TYTZ jeweils ausdrücklich hin, die chinesische Seite materiell und finanziell unterstützt hatten (juan liang zhu xiang). ${ }^{1134}$ Für diese Verdienste erhielten sie nach der Niederschlagung der Rebellion höhere Ränge in der Beamtenhierarchie. Mit ihrem Status als Befriedete Gebiete war in der Regel ein fünfter oder sechster Rang in der neunstufigen Beamtenhierarchie verbunden, nun wurden sie entsprechend ihrer Vedienste befördert. Der Herrscher von Husa, der nicht nur Unterstützung geleistet hatte, sondern zudem „geholfen hatte, [die Rebellen] zu vernichten“ (zhu jiao), wurde in den „zweiten Rang mit Pfauenfeder und Hutknopf“ (er pin ling ding) erhoben. Die tusi von Nandian, Longchuan und Zhanda wurden in den „dritten Rang mit Pfauenfeder“ (san pin hualing) befördert. Mengmao und Lasa erhielten den vierten Rang, letzterer mit einer „blauen Pfauenfeder“ (lan ling). ${ }^{1135}$ Die Verleihung unterschiedlicher Ränge zeigt, daß die verantwortlichen Verwaltungsbeamten das Verhalten der tusi während der Rebellion durchaus differenziert beurteilt, Unterschiede festgestellt und

\footnotetext{
1133 TYTZ, S. 154

${ }^{1134}$ TYTZ, S. 151-155

1135 TYTZ, S. 151, 153-155. Auch der tusi von Ganya erhielt eine Beförderung, eine Rangstufe ist jedoch nicht vermerkt (ebd. S. 154).
} 
entsprechend bewertet haben. Im Lokalhandbuch sind diese pauschal mit der Bemerkung von der geleisteten Unterstützung (juan liang zhu xiang) zugunsten der Betonung der Loyalität der tusi überdeckt worden. Lediglich die sorgfältige Dokumentation der Rangstufen und Abzeichen weist darauf hin, daß die Unterstützung tatsächlich doch recht unterschiedlich ausgefallen sein muß und auch entsprechend honoriert wurde.

Die Machtposition der einheimischen Herrscher vor Ort war, ebenso wie ihr Status als Träger chinesischer Amtstitel, über Generationen in ihren Familien weitervererbt worden. Die Kontinuität der Herrschaft dieser tusi-Familien wird auch in den fangzhi besonders hervorgehoben, beinhaltet sie doch auch die Kontinuität des Status der tusi-Gebiete als dem chinesischen Reich unterstellte Verwaltungseinheiten. ${ }^{1136}$

Tabelle 49: Die tusi-Gebiete der Unterpräfektur Tengyue am Ende des 19. Jahrhunderts ${ }^{1137}$

$\begin{array}{llll}\text { Name } & \begin{array}{c}\text { Status } \\ \text { (des Befriedeten Gebietes) }\end{array} & \begin{array}{c}\text { Herrscherfamilie } \\ \text { (seit Generationen) }\end{array} & \begin{array}{l}\text { Steuerleistung } \\ \text { (pro Jahr in Silber, } \\ \text { früher / heute) }\end{array} \\ \text { Nandian } & \text { xuanfu si } & \text { Familie Dao (20) } & \text { 100 liang / } 11 \text { liang } \\ \text { Ganya } & \text { xuanfu si } & \text { Familie Dao (23) } & \text { 50 liang / } 6 \text { liang } 6 \text { qian } \\ \text { Zhanda } & \text { fu xuanfu si } & \begin{array}{l}\text { Familie Dao (auch } \\ \text { Dao Si oder Si) (20) }\end{array} & -- \text { / } 4 \text { liang } 4 \text { qian } \\ \text { Longchuan } & \text { xuanfu si } & \text { Familie Duo (25) } & \text { 107 liang / } 8 \text { liang } \\ \text { Mengmao } & \text { anfu si } & \text { Familie Kan (15) } & -- \text { / -- } \\ \text { Husa } & \text { zhangguan si } & \text { Familie Lai (17) } & -- \text { / } 6 \text { liang } \\ \text { Lasa } & \text { zhangguan si } & \text { Familie Gai (20) } & -- \text { / } 4 \text { liang }\end{array}$

Als Verwaltungseinheiten des chinesischen Reiches waren die tusi-Gebiete zu Steuerleistungen (chai fa yin) verpflichtet. Die Höhe der Abgaben hat sich im Laufe der Zeit erheblich verändert: Die Steuerquoten (jiu e) der drei tusi Nandian, Ganya und Longchuan waren zu einem (nicht genannten) früheren Zeitpunkt um etwa ein zehnfaches höher, als

\footnotetext{
${ }^{1136}$ Auch im Chongxiu yitongzhi (juan 498) einer Chronik aus der Zeit der Ära Jiaqing (1796-1821) wird jeweils ausdrücklich darauf hingewiesen, daß die tusi-Gebiete der Unterpräfektur Tengyue „von der Zeit der Yuan- über die Mingbis zur Qing-Dynastie ohne Veränderungen fortgeführt worden sind“; zitiert nach You Zhong (S. 482).

${ }^{1137}$ TYTZ, S. 151-155; YCFZ, S. 198. Die vier Gebiete Mingguang, Datang, Guyong und Diantan, die im YCFZ als weitere einheimische Verwaltungseinheiten der Unterpräfektur Tengyue genannt werden, werden als niederrangigere Gebiete unter einheimischer Verwaltung erst weiter unten beschrieben (siehe S. 390ff).
} 
am Ende des 19. Jahrhunderts. ${ }^{1138}$ Es oblag dem Unterpräfekten von Tengyue jährlich insgesamt vierzig liang in Silber von den tusi einzuziehen. Die einzelnen Beträge waren nun allerdings eher niedrig. Vergleicht man sie mit den Aufwendungen für die Verwaltung von Tengyue, entsprechen sie durchschnittlich in etwa dem Jahresgehalt eines der Amtsbediensteten.

Die Hoheitsgebiete der sieben tusi von Tengyue unterschieden sich in ihrer Größe erheblich. Zahlen zur Bevölkerung nennt das TYTZ lediglich für die beiden kleineren tusi Husa und Lasa. Ende des 19. Jahrhunderts gab es in Husa „vierundsechzig befestigte Dörfer (zhai), in deren 1110 Haushalten (hu) 13.232 Männer und Frauen“ lebten; zum Hoheitsgebiet von Lasa gehörten hingegen nur „einunddreißig befestigte Dörfer mit 452 Haushalten bzw. 2450 Personen“. 1139

Der tusi von Nandian herrschte über ein größeres Gebiet; einige der einheimischen Anführer, die unter seiner Oberhohheit standen, wurden seit dem 18. Jahrhundert von den chinesischen Beamten ebenfalls als Verwaltungsbeamte (zhishi) bezeichnet, so wie die Herrscherfamilie Xie in Nangsong und die Men in Zhanxi, die ihre chinesischen Amtstitel ebenso wie der tusi innerhalb ihrer Familien weitervererbten. ${ }^{1140}$

Das Hoheitsgebiet von Nandian erstreckte sich auch auf die Paßstationen Shenhu und Tongbi. Zwischen diesen beiden befinden sich die Paßstationen Wanren und Jushi, die zum Gebiet von Zhanda gehörten, während die beiden südlich des Dayingjiang gelegenen Stationen Tiebi und Huju dem tusi von Longchuan unterstanden. Die Gebiete um diese sechs Paßstationen wurden jeweils von Gefolgsleuten der tusi beherrscht, die von der Verwaltung der Unterpräfektur als „einheimische Beamte zur Befriedung der Barbaren“, mit jeweils einem Stellvertreter (zheng fuyi, fu fuyi) in ihrer Position bestätigt wurden. ${ }^{1141}$

Neben den Paßstationen (guan) befanden sich im Grenzgebiet der Unterpräfektur Tengyue noch weitere Gebiete, deren einheimische Herrscher ebenfalls mit chinesischen Amtstiteln bezeichnet wurden (siehe Karte 16.1-2, S. 392-393). Die sogenannten neun strategischen

\footnotetext{
${ }^{1138}$ Vermutlich bezieht sich diese Angabe auf die Zeit der Errichtung der acht Paßstationen Ende des 16. Jahrhunderts, da nur für die tusi Nandian, Ganya und Longchuan, die damals wichtigsten tusi-Gebiete der Unterpräfektur, die in China als die ,drei Befriedeten Gebiete‘ (san xuan) bekannt waren, eine ältere Steuerqoute genannt wird.

1139 TYTZ, S. 155

${ }^{1140}$ TYZZ, S. 139

1141 Die beiden südlichsten Paßstationen Tianma und Hanlong sind bereits „während der Ära Qianlong (1736-1796) an Mubang verloren gegangen“ (TYTZ, S. 156) An anderer Stelle wird darauf hingewiesen, daß sich die Station Tianma im Gebiet von Mengmao befindet (ebd., S. 183); ,einheimische Beamte‘ sind für Tianma jedoch nicht eingesetzt worden.
} 
Pässe (jiu ai): Guyong, Diantan, Mingguang, Zhina, Mengbao, Datang, Bazhu, Shanmulong und Shipopo. Hinzu kam als zehnter ,Paß` noch Cizhuzhai. ${ }^{1142}$ Die strategischen Pässe ziehen sich von Datang im Norden der Unterpräfektur bis nach Shipopo im Südwesten wie eine diagonale Linie zwischen der Stadt Tengyue und den acht Paßstationen entlang.

Die Verwaltungsbeamten haben die Gebiete um die ,strategischen Pässe‘ in zwei Gruppen unterteilt. Die fünf Gebiete im Norden der Unterpräfektur, deren Oberhäupter als „einheimische Beamte“ (tubian) bezeichnet wurden und die fünf weiter südlich gelegenen, die von „einheimischen Beamten zur Befriedung der Barbaren“ (fuyi) regiert wurden. ${ }^{1143}$

Die nördlichen Gebiete Mingguang, Datang, Guyong, Diantan und Cizhuzhai waren schon in der Ming-Zeit als einheimische Verwaltungseinheiten bezeichnet worden. Vorfahren der tubian von Mingguang, Datang und Guyong stammten aus den Provinzen Hunan und Jiangxi. Sie waren in der Yunnan-Armee des Hongwu-Kaisers nach Tengyue gekommen und an diesen strategischen Punkten stationiert worden. Aus dem Kernland, aus Huguang, stammte auch ein Vorfahre von Chai Dezun, der im Jahr 1747, nachdem der Herrscher von Diantan ohne Nachkommen verstorben war, von den Einheimischen zu dessen Nachfolger gewählt wurde. Während der Kämpfe in Jinchuan in der Provinz Sichuan in den Jahren von 1747 bis 1749 hatten die einheimischen Herrscher der Paß-Gebiete den Feldzug der chinesischen Armee gegen Chengjia unterstützt und erhielten anschließend für ihre Verdienste die vererbbaren Amtstitel von einheimischen Korporälen ( $t u$ bazhong), mit Ausnahme von Diantan, dessen Herrscher nun mit dem Titel eines einheimischen Oberhauptes (tumu) bezeichnet wurde. ${ }^{1144}$ Während der Niederschlagung der Moslem-Rebellion hat lediglich der Herrscher von Mingguang aus chinesischer Sicht Verdienste erworben und entsprechend wurde ihm der ,fünfte Rang mit Pfauenfeder` verliehen. ${ }^{1145}$

\footnotetext{
1142 TYTZ, S. 180. Cizhuzhai im äußersten Norden der Unterpräfektur war ursprünglich Teil des Gebietes von Mingguang, das während der Ära Qianlong abgeteilt und ebenfalls als ,strategischer Paß` (ai) bezeichnet wurde. Das Gebiet von Cizhuzhai war, nachdem sein Herrscher im Jahr 1841 (Daoguang 21) einen Aufstand der Lisu von Diantan niedergeschlagen hatte, darüberhinaus zum xuanfusi erklärt und der tusi mit einer Pfauenfeder ausgezeichnet worden (TYTZ, S. 156). An anderer Stelle wird darauf hingewiesen, daß es den sogenannten ,strategischen Paß` „Cizhuzhai ai gegenwärtig [am Ende des 19. Jahrhunderts] nicht mehr gibt“ (TYTZ, S. 180). Im Kapitel über die tusi ist Cizhuzhai weiterhin als Sitz eines einheimischen Beamten (tubian) aufgelistet (TYTZ, S. 155).

${ }^{1143}$ Erstere wurden höher eingestuft, als die unter der Herrschaft der fuyi stehenden Gebiete. Im YCFZ sind entsprechend lediglich die vier Gebiete Mingguang, Datang, Guyong und Diantan als einheimische Verwaltungseinheiten der Unterpräfektur Tengyue genannt.

${ }_{1144}$ TYTZ, S. 155-156, 180; YCFZ, S. 198; You Zhong, S. 485-486

1145 TYTZ, S. 155
} 
Karte 16-1: Die Grenze im Westen der Präfektur Yongchang Ende des 19. Jahrhunderts:

Die Karte der Region des Stromschluchtenfächers im TYTZ (S. 391)

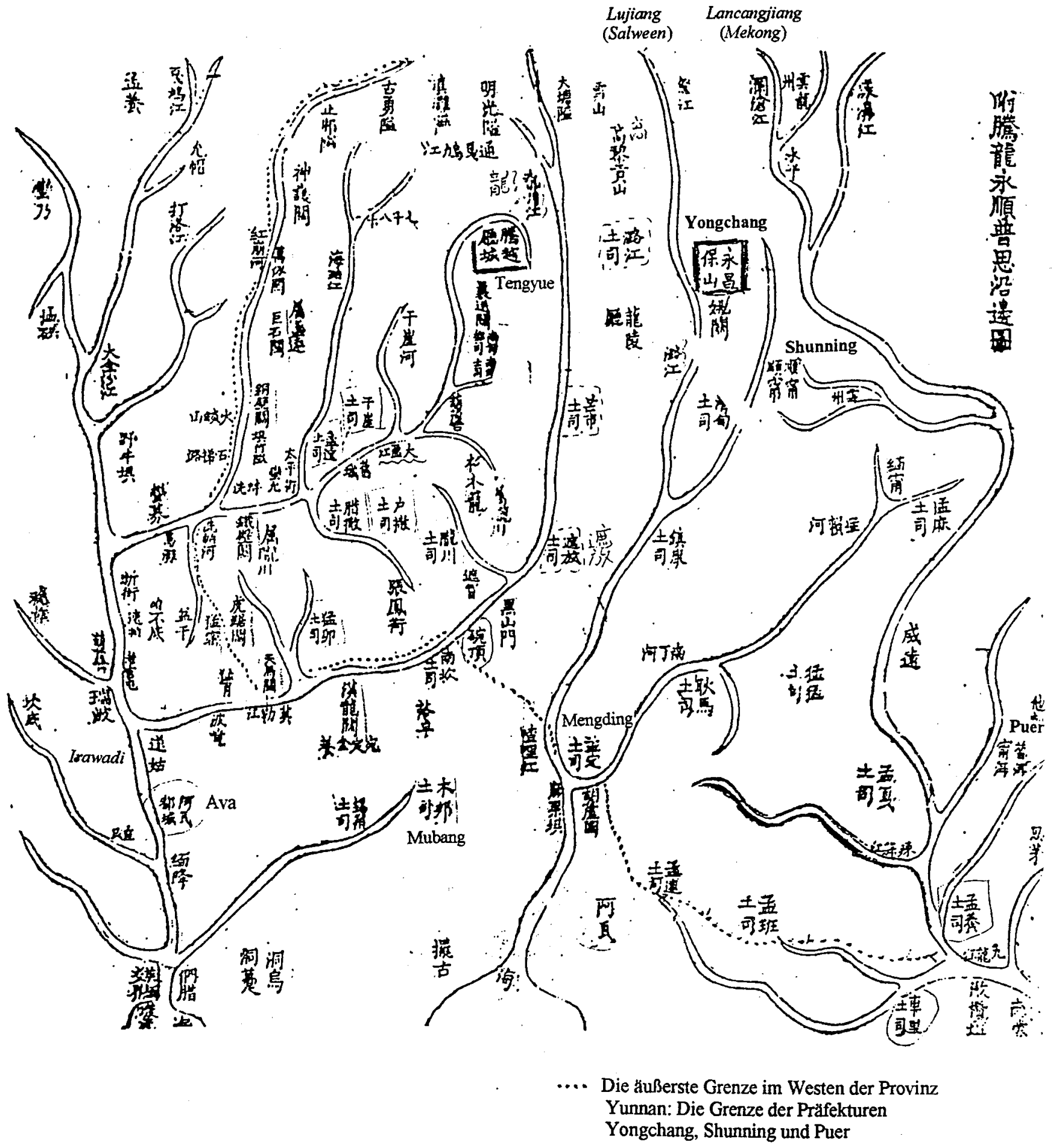


Karte 16-2: Die Grenze im Westen der Präfektur Yongchang: Paßstationen und tusi-Gebiete

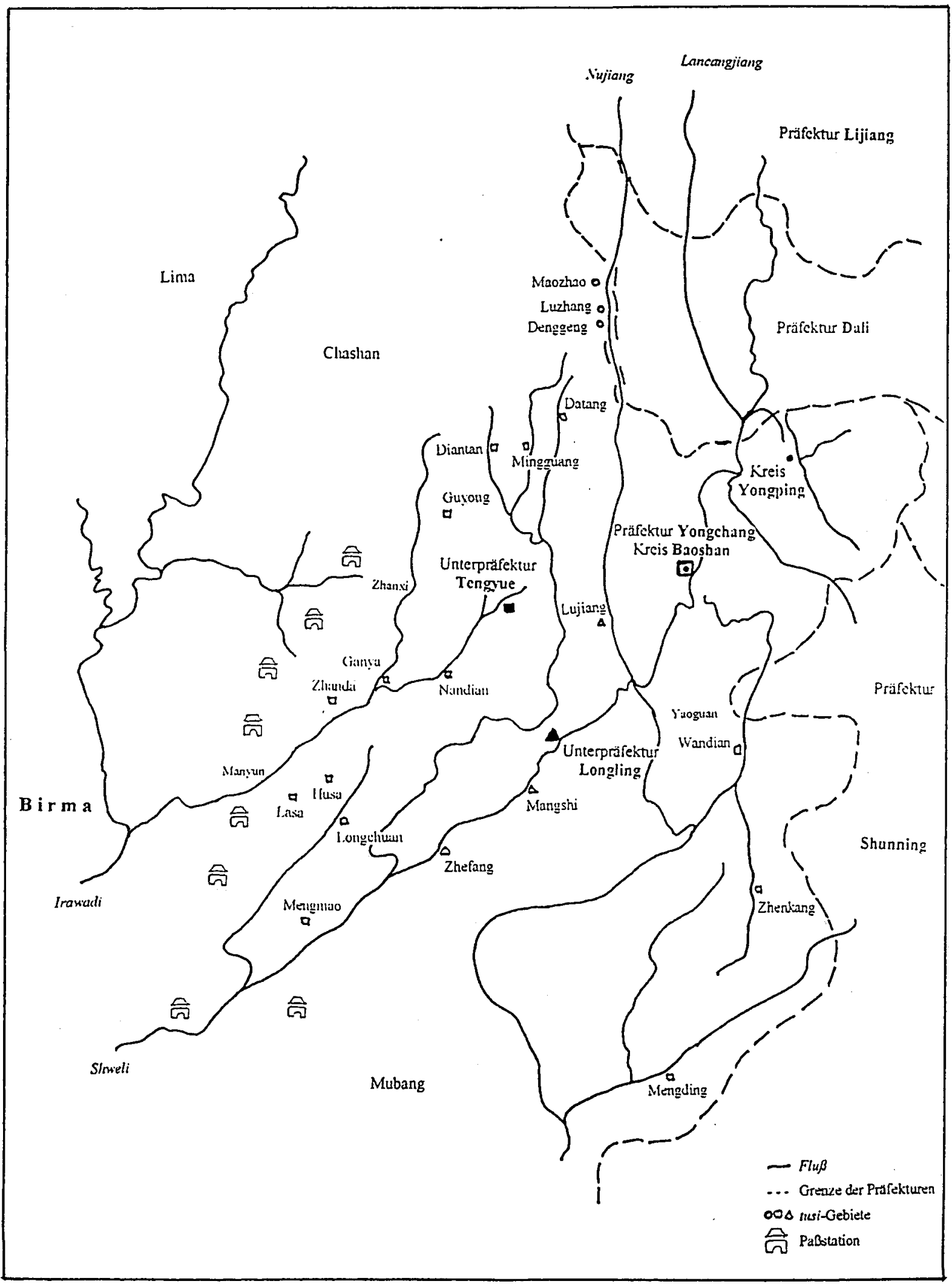


Die weiter südlich gelegenen Gebiete Zhina (im Gebiet von Zhanxi) und Shanmulong (im Südosten von Nandian) sind ebenfalls seit der Ming-Zeit in China als einheimische Verwaltungseinheiten bezeichnet worden. ${ }^{1146}$ Im Laufe der Zeit wechselten die Herrscherfamilien in diesen Gebieten. Zur Kontrolle des Passes von Shanmulong setzte der Generalgouverneur noch im Jahr 1752 (Qianlong 17) Liu Guoren aus der Provinz Jiangxi als neues Oberhaupt des Gebietes ein. ${ }^{1147}$ Die Herrscher von Mengbao im Südwesten von Tengyue und Bazhu am Tongbi-Paß waren beide während der Moslem-Rebellion umgekommen. Daraufhin wählten die einheimischen Würdenträger von Mengbao ein neues Oberhaupt, während in Bazhu ein Gefolgsmann des tusi von Zhanda die Herrschaft übernahm. Besondere Verdienste im Kampf gegen die Moslem-Rebellen hatte lediglich der Herrscher von Zhina erworben und wurde entsprechend mit dem ,dritten Rang mit Pfauenfeder ‘ und dem vererbbaren Amtsposten eines einheimischen Brigade-Vizekommandanten (tu dusi) ausgezeichnet. $^{1148}$

Während die Herrschaft über die tusi-Gebiete seit der Ming-Zeit innerhalb derselben Herrscherfamilien weitervererbt wurde, wechselten diese häufiger in den kleineren einheimischen Verwaltungseinheiten, die zum Teil auch unter der Oberhoheit der tusi standen. In den chinesischen Quellen wird daher vor allem die Kontinuität dieser Gebiete als Verwaltungseinheiten des chinesischen Reiches unabhängig von dem Fortbestand einer Herrscherdynastie betont. ${ }^{1149}$

Die Verleihung unterschiedlicher Amtstitel an die einheimischen Herrscher zeigt das Bemühen der chinesischen Verwaltung, das vielschichtige Grenzgebiet im Südwesten von Tengyue systematisch zu ordnen und es von den Gebieten jenseits des Verwaltungsgebietes der Unterpräfektur abzugrenzen. In wie weit die einheimischen Herrscher die Paßstationen als Grenzen ihrer jeweiligen Hoheitsgebiete betrachtet haben, geht aus den Angaben in den fangzhi nicht hervor. Die Verfasser des TYTZ hingegen heben, nachdem sie die verschiedenen Maßnahmen zur Grenzsicherung - die acht Paßstationen (ba guan), die neun strategischen Pässe (jiu ai), die Befestigungsanlagen (diao bao) und die Kontrollstationen (qia di) - beschrieben haben, zum Abschluß des Kapitels über den Grenzschutz die Bedeutung der Paßstationen als Grenze der Verwaltungseinheit Tengyue ausdrücklich

\footnotetext{
${ }^{1146}$ You Zhong, S. 486-487; TYTZ, S. 156, 180

${ }^{1147}$ You Zhong, S. 487

${ }^{1148}$ You Zhong, S. 487; TYTZ, S. 156, 180

${ }^{1149}$ Siehe auch You Zhong, S. 482-488.
} 
hervor (siehe Karte 17 1-2, S. 398-399). Über die Gebiete außerhalb der Paßstationen der tusi-Gebiete (tusi guan wai) heißt es dort relativ undifferenziert:

„- Jenseits der Paßstationen Shenhu und Tongbi, die zum Nandian si gehören, leben überall wilde Barbaren (yeyi).[Von dort] führen Wege in das Gebiet von Jiajiu.

- In dem zum Ganya si gehörenden Gebiet gibt es weder Paßstationen noch Pässe (guan ai). [Dort leben] wilde Barbaren. Wege führen in das Gebiet von Zhanda.

- Jenseits der Paßstationen Wanren und Jushi, die zum Zhanda si gehören, [leben] überall wilde Barbaren. Wege führen auf das Hochplateau ( $b a$ ) von Yeniu.

- Jenseits der Paßstationen Huju und Tiebi und des Shamulong-Passes, die zum Longchuan si gehören, [leben] überall wilde Barbaren. Wege führen auf das Hochplateau von Meng[mao].

- Jenseits der Paßstation Tianma am Bangzhongshan, die zum Mengmao si gehört, [leben] überall wilde Barbaren. Wege führen in das Gebiet von Mengmi.

- Zu den beiden si Husa und Lasa gehören keine Paßstationen oder Pässe. Wege führen nach Mengyun.

- Jenseits der vier Pässe Datang, Mingguang, Diantan und Guyong [leben] überall wilde Barbaren. Wege führen in das Gebiet von Jiajiu und Jiangtou“. ${ }^{1150}$

Während Tianma hier noch zum Hoheitsgebiet von Mengmao gezählt wird, heißt es an anderer Stelle im TYTZ, daß die beiden südlichsten Paßstationen Hanlong und Tianma bereits während der Ära Qianlong (1736-1796) an Mubang verloren gegangen sind. ${ }^{1151}$ Schon die Unklarheit über die tatsächliche Zugehörigkeit dieser Paßstationen hebt hervor, daß sich dort ein Grenzgebiet befand, in dem die bekannten und geordneten Strukturen endeten, auch wenn diese Grenze in der zweiten Hälfte des 19. Jahrhunderts weniger eindeutig definiert wurde als bei den anderen sechs Paßstationen. ${ }^{1152}$

Von ihrer Gründung Ende des 16. Jahrhunderts an sind die Paßstationen als Eingrenzung des chinesischen Hoheitsgebietes konzipiert gewesen. Im 18. Jahrhundert hat sich diese als Abgrenzung von den Gebieten unter birmanischer Oberhoheit verfestigt. Die Verwaltungshoheit der Unterpräfektur Tengyue erstreckte sich seitdem auf die tusi-Gebiete, auf deren Territorium sich die Paßstationen befanden, jedoch nicht mehr auf die Gebiete jenseits

\footnotetext{
1150 TYTZ, S. 183

1151 TYTZ, S. 156

${ }^{1152}$ Für die Festlegung der Grenze zwischen British-Burma und China Ende des 19. Jahrhunderts mußte die genaue Lage der südlichen Paßstationen erst wieder erkundet werden (siehe H. R. Davies: ,Report on th expedition sent with the chinese official to find the Hu-chi, Tien-ma and Han-lung gates', Rangoon 1984).
} 
davon. Diese werden im TYTZ mit der pauschalen Bemerkung, daß dort überall , wilde Barbaren` (ye yi) ansässig seien, noch einmal deutlich von der ,zivilisierten` Unterpräfektur abgegrenzt, deren Verwaltungseinheiten, tusi-Gebiete usw. in den Lokalhandbüchern differenzierter benannt und beschrieben werden. ${ }^{1153}$

Der Dichter Yin Yi aus Tengyue faßt diese Vorstellung von den Paßstationen als Grenze prägnant zusammen, indem er schildert, wie der Jushi-Paß ,innen von außen trennt und eine Grenze zwischen China und den Fremdvölkern bildet“ (fen nei wai hua yi jie). ${ }^{1154}$ Eine moderne Staatsgrenze, wie sie die Territorien zweier gleichrangiger Staaten trennt, war die ,äußerste Grenze‘ der Unterpräfektur nach chinesischer Auffassung zwar nicht, denn schließlich, so betont auch Yin Yi in seinem Gedicht, „ist alles Land Hoheitsgebiet der kaiserlichen Dynastie“ (pu tian jie shi huang jia tu) und mag wohl eines Tages wieder in „vollkommener Harmonie zusammenfinden“ (he ri che shu hui da tong). ${ }^{1155}$

Tatsächlich war jedoch entlang der Paßstationen und tusi-Gebiete im Westen von Tengyue aus pragmatische Gründen eine sehr reale Grenze entstanden, die sich bis zum Ende des 19. Jahrhunderts de facto als eine administrative, kulturelle und politische Grenze des Qing-Reiches im äußersten Westen der Provinz Yunnan fest etabliert hatte. Geprägt von den geographischen und klimatischen Bedingungen der Region des Stromschluchtenfächers zeigt sie, wie weit das chinesische Reich seine Strukturen aus der Kernregion nach Südwesten ausdehnen, eine Zivilverwaltung aufbauen und militärische Kontrolle ausüben konnte.

\section{6. Maßnahmen zum Grenzschutz und das militärische Engagement Chinas im Grenzgebiet}

Neben dem Wiederaufbau der Militärkommandantur und der Reorganisation der einheimischen Verwaltungseinheiten (Paßstationen, strategische Pässe) wurden in der Zeit direkt nach der Moslem-Rebellion und der Militärrevolte mit dem Ausbau der militärischen

\footnotetext{
${ }^{1153}$ So waren sich die Verfasser des Textes durchaus bewußt, daß Angehörige der gleichen Volksgruppen sowohl innerals auch außerhalb der Unterpräfektur ansässig waren. Als Kriterium für eine Einteilung in unterschiedliche Gruppen dient hier weniger die ethnische Zugehörigkeit, sondern vielmehr der Status als Verwaltungseinheiten des chinesischen Reiches, deren Herrscher außerdem, wie in den fangzhi ausdrücklich betont wird, zumeist einen chinesischen Vorfahren hatten. Das trifft für fünf der sieben tusi-Gebiete und vier der fünf Gebiete unter niederrangigeren einheimischen Beamten (tubian) der Unterpräfektur zu, in denen die Herrscher- und die chinesischen Amtstitel seit der Ming-Zeit kontinuierlich weitervererbt worden sind.

${ }^{1154}$ Yin Yi (?-1867): ,Blick auf Birma von der Höhe des Passes Jushi‘ (Deng Jushi guan wang Miandian) (TYTZ, S. 375-376). Zu Yin Yi siehe oben S. 335, Fußnote 989.

${ }^{1155}$ Yin Yi: ,Blick auf Birma ...““(TYTZ, S. 376).
} 
(Militärposten) sowie der zivilen Verteidigung (Kontrollstationen) verschiedene Maßnahmen zur Sicherung und Stabilisierung des Grenzgebietes der Unterpräfektur getroffen.

Eine dieser Maßnahmen war die noch im Jahr 1876 erfolgte Gründung von zehn neuen Militärposten (xun). Von Gudong im Norden über Zhanxi und Malutang bis nach Puwo im Südosten bilden sie einen weiten Halbkreis um die Unterpräfekturstadt. Die Militärposten befanden sich an strategisch wichtigen Punkten der Verkehrsrouten, am Fluß Daying bis hin zu den tusi-Gebieten Ganya und Longchuan. Jedem Posten wurden dreißig bis fünfzig der Männer zugeteilt, die jeweils einem Korporal unterstellt waren; ein größeres Kontingent mit fünfundsiebzig Soldaten und zwei Truppenführern wurde in Shanmulong im Südwesten der Unterpräfekturstadt stationiert. Insgesamt waren 445 Soldaten zur Verteidigung des Grenzgebietes von Tengyue abkommandiert worden. ${ }^{1156}$

Die siebenundsiebzig Befestigungsanlagen (diao bao), die zu Beginn des 19. Jahrhunderts in den Dörfern im Grenzgebiet errichtet worden waren, sind während der Rebellion fast vollständig zerstört worden. Zum Schutz der chinesischen Siedlungen im Grenzgebiet veranlaßte Unterpräfekt Chen Zonghai im Jahr 1879 zusammen mit dem Regionalkommandeur den Wiederaufbau von Anlagen zum Grenzschutz in Form von achtundsiebzig Kontrollstationen in den Gemeinden der Unterpräfektur (lian qia), denen er anschließend noch zwei weitere Stationen neu hinzufügen ließ.

Für die Bewachung der nunmehr achtzig Kontrollstationen (qia) wurden durchschnittlich fünfzehn Männer aus den jeweiligen Gemeinden eingeteilt: Insgesamt 1191 Mann. ${ }^{1157}$ Der größte Teil der Stationen befand sich in Guyong nördlich von Tengyue, in Zhanxi im Westen und Maofu im Südwesten. Die Kontrollstationen bildeten eine Grenze zwischen den Gemeinden (lian) von Tengyue und den Dörfern mit einheimischer Bevölkerung (ye zhai) jenseits des Verwaltungsgebietes der Unterpräfektur. Indem sie die Abstände zwischen den Militärposten überbrückten, vervollständigten sie das System der Grenzsicherung (siehe Karte 17.1-2, S. 398-399). Ebenso wurden auch in der Unterpräfektur Longling auf Veranlassung der örtlichen Beamten vierzehn Kontrollstationen (qia) „zum Schutz von strategisch wichtigen Orten an der äußersten Grenze“ errichtet. ${ }^{1158}$

\footnotetext{
${ }^{1156}$ TYTZ, S. 177-178, 181, 73-74. Aus dem Text des TYTZ geht nicht hervor, ob es sich hierbei um reguläre Truppen der Militärkommandantur handelte oder ob die 445 Mann zusätzlich aufgestellt worden sind. Im 18. Jahrhundert waren reguläre Soldaten aus den in Tengyue stationierten Brigaden zur Verteidigung der Militärposten eingesetzt worden (TYTZ, S. 73).

1157 TYTZ, S. 181-183

1158 YCFZ, S. 146
} 

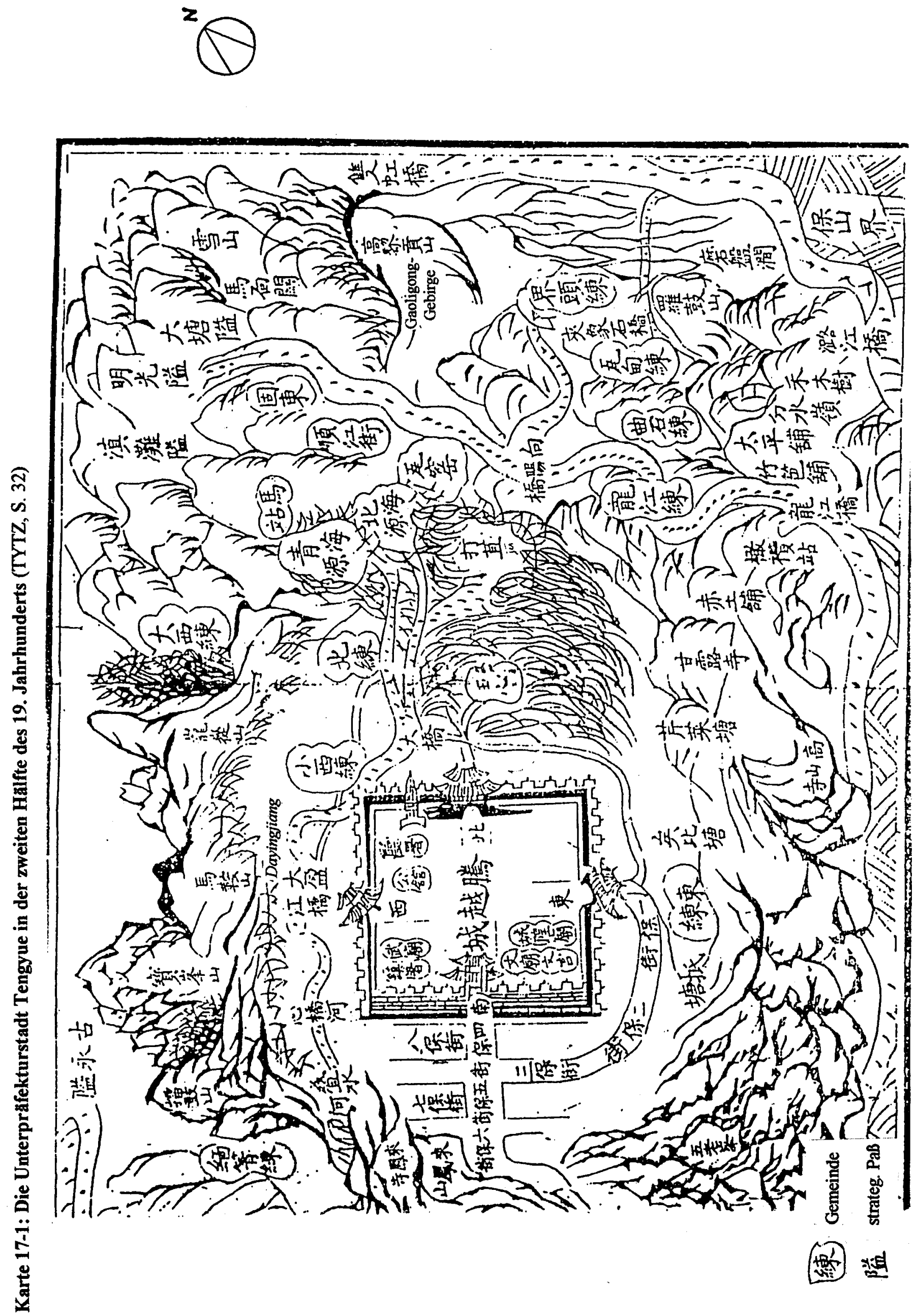
$\div O$

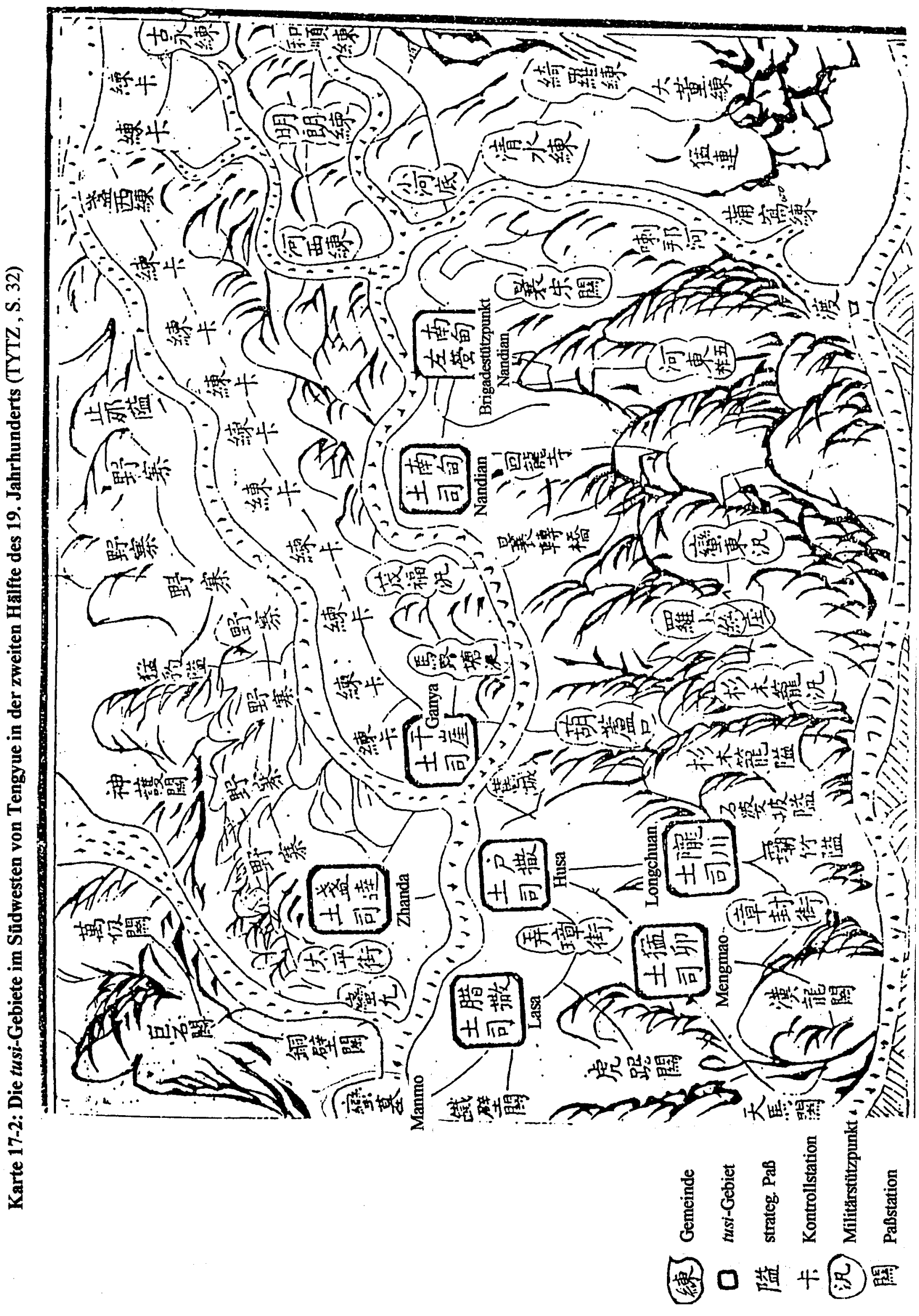


Mit der Wiederherstellung der zivilen und militärischen Verwaltungseinheiten sowie der Bestätigung der einheimischen Amtsträger in den verschiedenen tusi-Gebieten, knüpfte die chinesische Regierung direkt an die Strukturen aus der Zeit vor der Rebellion an. Auch die Paßstationen dienten wie zuvor wieder als Begrenzung des Territoriums der Unterpräfektur. Innerhalb des Grenzgebietes, das zwischen der Stadt Tengyue und den Paßstationen entstanden war, machte das Qing-Reich in den 80er Jahren des 19. Jahrhunderts seine Autorität entschieden geltend, um seine Vormachtstellung in der Region wieder zu behaupten. Der Einsatz von Truppen im Grenzgebiet unterstrich diesen Anspruch, daneben dokomentiert er auch den erfolgreichen Wiederaufbau funktionierender Militärstrukturen in der Region des Stromschluchtenfächers.

Auch wenn es zunächst noch Schwierigkeiten gab. Wie im Jahr 1884 (Guangxu 10), als Gefolgsleute des tusi von Zhanda einen Aufstand angezettelt und „sich mit Banditen, die in dieser Gegend herumzogen, verbündet hatten“. Dem zuständigen chinesischen VizeKommandanten der Linken Brigade war es zwar gelungen, dem Aufruhr im Grenzgebiet Einhalt zu gebieten. Doch erst Brigade-Kommandant Li Zhenguo, der sich auf Befehl des Unterpräfekten und des Regionalkommandeurs nach Zhanda begeben hatte, konnte den Frieden wiederherstellen. ${ }^{1159}$

Im ersten Monat des Jahres 1886 (Guangxu 12) wurde Ding Huai, der als Truppenführer an der Niederschlagung der Rebellion und der Militärrevolte in Tengyue teilgenommen hatte, zum neuen Kommandeur des Regionalen Militärbezirks Tengyue (zhen zong) ernannt, „mit dem Oberbefehl über die Grenztruppen in den Brigadestützpunkten Tengyue, Yongchang, Longling und Shunning. Sein Amtssitz war in Tengyue“. ${ }^{1160}$

Im selben Jahr kam es in Zhanda erneut zu einem Aufstand gegen den tusi, dem seine Untertanen Grausamkeit vorwarfen. Regionalkommandeur Ding Huai befand sich zu diesem Zeitpunkt, zwei Monate nach seinem Amtsantritt, auf einer Inspektionsreise im Grenzgebiet (xun bian). Ding hielt die Vorwürfe der Aufständischen anscheinend für gerechtfertigt und schickte den Amtsleiter (jingli) Chen Wenwei aus seinem Gefolge nach Zhanda, um den tusi Dao Si Hongzuo festzunehmen. Das Amt des tusi wurde dann einem anderen Mitglied der Herrscherfamilie übergeben. Der Wechsel der Person des tusi allein 
führte jedoch nicht zu einem Ende der Kampfhandlungen. Auch „nachdem Hongzuo im Gefängnis gestorben war, trieben seine Leute weiter ihr Unwesen im Grenzgebiet, widersetzten sich den wiederholten Aufforderungen aus der Militärkommandantur in der Unterpräfektur und eroberten sogar noch zehn Dörfer der einheimischen Bevölkerung, die sie gewalttätig unterdrückten“. Im elften Monat führte Ding Huai schließlich persönlich Truppen nach Zhanda und konnte die Dörfer nach dreitägigen Kämpfen zurückerobern. Er ließ „über einhundert der Banditen hinrichten und zerstreute diejenigen, die nur gezwungenermaßen mitgemacht hatten“. Damit war Zhanda befriedet, denn „alle einheimischen Volksgruppen hatten sich furchtsam unterworfen“ (zhu yi you ci wei fu). ${ }^{1161}$

Im Jahr Guangxu 13 (1887) war erneut ein Militäreinsatz in den tusi-Gebieten der Unterpräfektur erforderlich. Ein seit über zehn Jahren schwelender Streit um Landbesitz zwischen Nandian und Zhanxi entlud sich in gewalttätigen Auseinandersetzungen, die sich im Grenzgebiet weiter auszubreiten drohten. Der Kommandeur der Verwaltungsregion (Yixi dao) und Regionalkommandeur Ding Huai beauftragten wiederum den Amtsleiter ( $f u$ jingli) Chen Wenwei, in Zusammenarbeit mit einem Brigade-Vizekommandanten die Kontrahenten zu zerstreuen.

Anschließend begab sich Unterpräfekt Chen Zonghai persönlich nach Zhanxi. Indem er die einheimischen Herrscher, den tusi von Nandian und das Oberhaupt der Familie Meng (an anderer Stelle auch Men genannt) von Zhanxi, zunächst veranlaßte, jeweils erobertes Land zurückzugeben und dann die Hoheitsgebiete beider neu voneinander abgrenzte, gelang es ihm, den jahrelangen Streit zwischen den beiden Parteien zu beenden. Außerdem machte Chen Zonghai die Kontrollstationen (qia) für die Überwachung der einheimischen Bevölkerung mit verantwortlich und ließ zur Sicherung des Gebietes zudem einen Militärposten (xun) in das nahegelegene Tuanpo verlegen. ${ }^{1162}$

Zu Beginn des Jahres Guangxu 14 (1888) „sorgten einheimische ,Wilde aus den Bergen“ (zhu shan yeyi) von Zhanxi unter Führung von Si San erneut für Unruhe im Grenzgebiet“. Weder der verantwortliche einheimische Beamte des strategischen Passes Zhina, noch Milizionäre aus der Gemeinde Zhanxi konnten ihnen Einhalt gebieten oder verhindern, daß sie weitere Dörfer besetzten. Regionalkommandeur Ding Huai und Unterpräfekt Chen Zonghai entsandten zwei Truppenkommandanten und den Amtsleiter Chen Wenwei, um

\footnotetext{
1161 TYTZ, S. 196

1162 Ebenda.
} 
Soldaten nach Zhanxi zu führen. Außerdem beauftragten sie den tusi von Nandian, den fuyi von Zhina und andere, sich den Kommandanten mit ihren einheimischen Hilfstruppen anzuschließen; entsprechend der mit ihrem Amt einhergehenden Verpflichtung, dem chinesischen Militär gegebenenfalls Unterstützung zu leisten.

Auch Unterpräfekt Chen Zonghai beteiligte sich persönlich an der Rückeroberung von Tuanpo, wo er im Jahr zuvor die Gründung eines Militärpostens veranlaßt hatte. Angesichts dieses starken Aufgebotes zog sich Si San nach Bengdong zurück. Die Militärführer brachten ihre Truppen in Position und „eroberten innerhalb von einigen Wochen Bengdong und alle anderen Dörfer zurück; über zweihundert der wilden Banditen (ye fei) wurden dabei gefangen genommen und enthauptet““ ${ }^{1163}$

Ein Jahrzehnt nach der Niederschlagung der Rebellion behauptete das chinesische Militär mit Nachdruck seine Autorität im Grenzgebiet. Mit ein Grund für das energische Eingreifen der chinesischen Truppen zur Sicherung der Kontrolle über das Grenzgebiet war sicherlich auch die Tatsache, daß

„die Engländer (ying yi) im 10. Monat des Jahres Guangxu 11 (1885) das Reich von Birma (Mian guo) besetzt haben“. ${ }^{1164}$

Die Existenz einer expandierenden Militärmacht, deren Truppen im nordöstlichen Birma bereits bis nach Bhamo vorgedrungen waren, weckte in China die Befürchtung, es könnte seine Vormachtstellung im Grenzgebiet verlieren und veranlaßte zu vorbeugendem Handeln. So unternahm Regionalkommandeur Ding Huai im Jahr 1886, bereits kurz nachdem er sein Amt angetreten hatte, eine Inspektionsreise in das Grenzgebiet und schaltete sich prompt in die Konflikte in den tusi-Gebieten ein, um zu verhindern, daß lokale Auseinandersetzungen auf andere Gebiete übergriffen. Denn dabei bestand aus chinesischer Sicht auch die Gefahr, daß eine der Konfliktparteien bei der neuen Militärmacht in Birma um Unterstützung nachsuchen und so deren Vordringen in das Grenzgebiet ermöglichen könnte.

Der Konflikt im tusi-Gebiet von Nandian im Südwesten der Unterpräfekturstadt im Jahr 1887 zeigt eine gut funktionierende Zusammenarbeit von Militär- und Zivilverwaltung. 
Nachdem die Abgesandten des Regionalkommandeurs die Kämpfe beendet hatten, konnte Unterpräfekt Chen Zonghai eine friedliche Lösung mit den beiden Konfliktparteien aushandeln. Auch bei dem Militäreinsatz im folgenden Jahr haben die beiden obersten Amtsträger der Unterpräfektur bei der Entsendung des Truppenkontingents zusammengearbeitet. Unterpräfekt Chen beteiligte sich zudem persönlich an der Rückeroberung der besetzten Dörfer.

Insgesamt betonen die Verfasser des TYTZ, das im selben Jahr unter der Leitung von Chen Zonghai herausgegeben wurde, in ihrer Schilderung der Ereignisse deutlich die Teilhabe des Unterpräfekten auch an militärischen Entscheidungen, vor allem aber seine Erfolge bei der Beilegung von Konflikten und der Befriedung des Grenzgebietes. ${ }^{1165}$

Diese erfolgreiche Befriedung des Grenzgebietes wird im TYTZ zum Abschluß der Darstellung des Militäreinsatzes in Zhanxi im Jahr 1888 erneut hervorgehoben:

\begin{abstract}
„Alle Einheimischen von nah und fern fürchteten nun die Autorität [der QingDynastie] (yuan jin ye yi ju wei wei) und baten um Frieden. Sie verpflichteten sich, sich zu unterwerfen. Außerdem wurde ihnen untersagt, Schußwaffen oder Messer mit sich zu führen, wenn sie auf [die Hochebene Tengyue] heruntersteigen würden. Weiterhin wurde eine mobile Patrouille von einhundert Mann gegründet, die auf Unruhestifter achten soll. Von nun an wird es in Zhanxi keine Bedrohung durch die ,Wilden` mehr geben (yong wu ye huan)“. ${ }^{1166}$
\end{abstract}

Hier wird Chinas Vormachtstellung im Grenzgebiet noch einmal nachdrücklich betont. Mit dieser selbstbewußten Aussage am Schluß der Chronologie der jüngsten Ereignisse in der Unterpräfektur Tengyue schließt auch die Berichterstattung des TYTZ.

\footnotetext{
1165 Ebenfalls einen wichtigen Beitrag zur Befriedung der tusi-Gebiete hatte der Amtsleiter Chen Wenwei geleistet. Im Jahr 1886 war er von Regionalkommandeur Ding Huai nach Zhanda entsandt worden, wo er den tusi festgenommen hatte, 1887 leistete er militärische Vorarbeit für Chen Zonghais Friedensverhandlungen und wurde 1888 wiederum mit der Befriedung von Zhanxi betraut.

Wer aber war dieser Chen Wenwei? Im Text wird er ab 1886 als Amtsleiter (jingli) bzw. als Amtsleiter der Präfektur ( $f u$ jingli) bezeichnet. In den Listen der verschiedenen Amtsträger in den fangzhi wird sein Name jedoch nicht erwähnt. In der Liste der Amtsleiter (jingli) des TYTZ waren, nachdem Hu Shitan dieses Amt im Jahr 1878 (Guangxu 4) angetreten hatte, zwei weitere namentlich genannte Beamte in dieser Position tätig, ehe Zhang Fengzao im Jahr 1887 (Guangxu 13) zum Amtsleiter von Tengyue ernannt wurde. Seine Amtszeit würde sich also mit der von Chen Wenwei überschneiden. In der Präfektur Yongchang ist der Posten des Amtsleiters (jingli) bereits im Jahr 1705 (Kangxi 44) abgeschafft worden. Da das YCFZ nur Daten bis zum Jahr 1885 beinhaltet, wäre es durchaus möglich, daß das Amt später erneut eingeführt wurde, was aber in Anbetracht der allgemeinen Tendenz zur Konzentration in der Verwaltung des Qing-Reiches eher unwahrscheinlich erscheint, andererseits aber mit der Bezeichnung Chens als Amtsleiter der Präfektur (fu jingli) übereinstimmen würde.

1166 TYTZ, S. 196-197
} 


\section{Die obersten Verwaltungsbeamten von Tengyue}

\section{1. Die Unterpräfekten (zhizhou/tongzhi) von Tengyue in der Qing-Zeit}

Der oberste Beamte der Verwaltungseinheit Tengyue war der Unterpräfekt. Ihm oblag die Organisation und Durchführung sämtlicher administrativer Aufgaben, er war zudem verantwortlich für die Rechtsprechung, die Erhebung der Steuern, die Instandhaltung von Amtsgebäuden, Schulen, Brücken und anderen Bauwerken sowie für die Aufrechterhaltung der staatlichen und gesellschaftlichen Ordnung in seinem Amtsbereich.

In der neunstufigen Beamtenhierarchie des Qing-Reiches bekleideten die Unterpräfekten von Tengyue den fünften Rang. Mit dem Amtstitel des zhizhou war zunächst Rang 5b (cong wu pin) verbunden gewesen, als die Unterpräfektur im Jahr 1820 (Jiaqing 25) zu einer unabhängigen Unterpräfektur (zhili ting) aufgewertet wurde, wurde der Amtstitel des Unterpräfekten in tongzhi mit Rang 5a (zheng wu pin) geändert. Diesen behielt der Unterpräfekt auch bei, nachdem Tengyue 1822 wieder in eine reguläre Unterpräfektur umgewandelt wurde.

Der erste Unterpräfekt (zhizhou) in Tengyue in der Zeit der Qing-Dynastie, Duan Rongjian, wurde im Jahr 1660 (Shunzhi 17) ernannt. Insgesamt waren in der Qing-Zeit von 1660 an bis zum Jahr 1888, in dem die Liste der Beamten im TYTZ herausgegeben wurde, dreiundsechzig Männer als Unterpräfekten in Tengyue tätig. Diese Beamten stammten aus verschiedenen Provinzen des Reiches, sie hatten unterschiedliche akademische Titel erworben und auch die Dauer ihrer Amtszeit in Tengyue variierte erheblich.

Tabelle 50: Herkunft der Unterpräfekten / Heimatregionen nach Angaben des TYTZ ${ }^{1167}$

\begin{tabular}{|c|c|c|c|c|}
\hline Anhui & 4 & Jiangnan $^{1168}$ & 1 & Sichuan \\
\hline Fujian & 1 & Jiangsu & 3 & Zhejiang \\
\hline Guangdong & 2 & Jiangxi & 1 & Zhili \\
\hline Guangxi & 1 & Liaodong & 3 & Manzhou \\
\hline Guizhou & 2 & Shaanxi & 1 & Andere Angaben: \\
\hline \multirow[t]{2}{*}{ Hunan } & 2 & Shandong & 2 & Bannerangehörige \\
\hline & & & & Ohne Angabe \\
\hline
\end{tabular}

\footnotetext{
1167 TYTZ, S. 109-111. Die Liste der Unterpräfekten (tongzhi) von Tengyue, die im YCFZ (S. 181-182) aufgeführt ist, enthält abweichend von der des TYTZ folgende Angaben: Anhui (3), Liaodong (7), Jiangsu (4), Zhejiang (10), Unterpräfekten ohne Angabe der Heimatprovinz (11).

${ }^{1168}$ Die in der Zeit der Ära Shunzhi (1644-1662) gegründete Provinz Jiangnan wurde während der Ära Kangxi (16621723) in die beiden Provinzen Jiangsu und Anhui aufgeteilt.
} 
Die Unterpräfekten stammten aus fast allen Provinzen des Qing-Reiches und der Mandschurei (Manzhou). ${ }^{1169}$ Die größte Gruppe darunter bildeten neun Beamte aus Zhejiang, sechs kamen aus der Mandschurei, fünf aus Zhili und jeweils vier aus Anhui und Sichuan. Keiner stammte aus der Provinz Yunnan selbst und nur zwei kamen aus der Nachbarprovinz Guizhou.

Duan Rongjian, der erste Unterpräfekt, stammte aus der Provinz Jiangnan, seine beiden Nachfolger aus den Provinzen Anhui und Liaodong. Noch zwei weitere Beamte aus Liaodong waren im ausgehenden 17. Jahrhundert in Tengyue tätig. Ihre Nachfolger im Amt waren beide Angehörige chinesischer Banner (zhenghuangqi Hanjun bzw. xianghongqi Hanjun), denen ein Beamter aus Zhejiang, ein weiterer Bannerangehöriger sowie ein Beamter aus Shandong nachfolgten. In der Auflistung der Unterpräfekten im YCFZ ist vermerkt, daß die drei Angehörigen der chinesischen Banner ebenfalls aus der Provinz Liaodong stammten. ${ }^{1170}$ Der größere Teil der Unterpräfekten des 17. und 18. Jahrhunderts kam also aus dem Norden Chinas und aus Zhejiang; um 1770 waren auch zwei Männer aus Jiangsu in Tengyue tätig. Lediglich ein Beamter kam aus dem südlichen Guangxi: Tang Shiliang, der von 1743 bis 1753 in Tengyue tätig war.

Nachdem die Bezeichnung des Unterpräfekten von Tengyue 1820 (Jiaqing 25) von zhizhou in tongzhi geändert worden war, waren in den Jahren bis 1840 abwechselnd Beamte mandschurischer Herkunft und Beamte aus Zhili, Zhejiang, Fujian und wiederum Zhejiang ernannt worden. Von 1844 und 1846 an waren nacheinander zwei Männer aus Guangdong als Unterpräfekten tätig. Seit etwa 1870 übten vor allem Beamte aus den Provinzen Guizhou, Hunan und Sichuan dieses Amt aus.

In der Tengyue übergeordneten Verwaltungseinheit, der Präfektur Yongchang, waren zur Zeit der Qing-Dynastie insgesamt vierundsechzig Beamte als Präfekten (zhifu, Rang 4a) tätig. Diese direkten Vorgesetzten der Unterpräfekten von Tengyue stammten aus siebzehn verschiedenen Provinzen des Reiches. ${ }^{1171}$ Betrachtet man die Herkunftsorte der Präfekten, ergibt sich ein ähnliches Bild, wie in der Unterpräfektur Tengyue. Die meisten der obersten Verwaltungsbeamten Yongchangs, neun insgesamt, stammten auch hier aus der Provinz

\footnotetext{
1169 Im Jahr 1723 (Yongzheng 1) wurde das Qing-Reich in achtzehn Provinzen eingeteilt. Bis dahin hatte es zweiundzwanzig dieser Verwaltungseinheiten gegeben (Lui, S. 46).

1170 YCFZ, S. 181. Die Bannerleute waren alle in der zweiten Hälfte der Ära Kangxi in Tengyue tätig, wo sie relativ lange Amtszeiten absolvierten: Tang Hanbi war von 1696 an für elf Jahre in Tengyue, sein Nachfolger Wu Yue neun Jahre lang (von 1707 bis 1716) und Yang Zhisheng sechs Jahre (von 1719 bis 1725) (TYTZ, S. 109).

${ }^{1171}$ Siehe YCFZ, S. 171-173
} 
Zhejiang. Ebenfalls neun Präfekten waren Bannerangehörige. ${ }^{1172}$ Die nächst größere Gruppe bildeten acht Beamte aus Jiangsu (in Tengyue waren lediglich drei aus dieser Provinz tätig). Fünf Präfekten stammten aus Zhili, vier aus Hunan, jeweils drei Anhui und Liaodong sowie der Mandschurei (sechs in Tengyue). Lediglich einer kam aus Guizhou (zwei in Tengyue) und nur zwei aus Sichuan (vier in Tengyue). Auch in Yongchang stammte keiner der obersten Verwaltungsbeamten selbst aus der Provinz Yunnan. Die Besetzung der Amtsposten in der Region des Stromschluchtenfächers erfolgte damit entsprechend der Vorschrift, Beamte nicht an ihrem Heimatort einzusetzen.

In Yongchang waren in den frühen Jahren der Qing-Zeit ebenfalls überwiegend Männer aus dem Norden als oberste Verwaltungsbeamte beschäftigt. Der erste Präfekt, Zhou Yuanfang, stammte aus Liaodong. ${ }^{1173}$ Seine Nachfolger kamen aus Shaanxi, Hebei, Shanxi oder waren Angehörige von Bannern. Während die Bannerleute, die in Tengyue als Unterpräfekten amtierten, sämtlich in der Zeit von 1696 bis 1725 ihr Amt inne hatten, waren Bannerangehörige in Yongchang über eine längeren Zeitraum verteilt, von 1681 (Kangxi 20) bis 1825 (Daoguang 5), im Amt des Präfekten tätig. ${ }^{1174}$ In den fangzhi werden für Yongchang wie auch für Tengyue erst im 19. Jahrhundert Guangdong, Sichuan und Guizhou als Heimatprovinzen der obersten Beamten der Verwaltungseinheit genannt.

Vier der Beamten waren sowohl als Unterpräfekten in Tengyue, als auch als Präfekten in Yongchang tätig: Tu Shulian, Zhou Shu, Li Hengqian und Peng Songyu. Im YCFZ wird jedoch lediglich vermerkt, daß Tu Shulian nach seiner Amtszeit in Tengyue (1788-91) in Yongchang war und im Anschluß daran einen Posten im Provinzkontrollamt (anchasi) von Yunnan angetreten hatte. Zhou, Li und Peng waren während der Ära Daoguang (18211851) Unterpräfekten von Tengyue; Li und Peng haben das Amt des Präfekten in Yongchang ebenso wie zuvor das des Unterpräfekten mit kurzem zeitlichen Abstand nach einander ausgeübt. ${ }^{1175}$

\footnotetext{
1172 Die Heimatprovinz wird lediglich bei zweien der Bannerleute ausdrücklich vermerkt, einer stammte aus Liaodong, einer aus der Mandschurei (YCFZ, S. 172).

${ }^{1173}$ Der Zeitpunkt des Amtsantritts der Präfekten sowie die Dauer der Amtsperioden sind in der Liste der Beamten im YCFZ nicht verzeichnet worden.

${ }^{1174}$ YCFZ, S. 151, 160, 161

${ }^{1175}$ Li Hengqian war von 1844 bis 1846 Unterpräfekt von Tengyue, der Hanlin-Akademiker Peng Songyu von 1847 bis 1848. Weitere Angaben zu ihrer Tätigkeit in Yongchang werden in den fangzhi nicht gemacht (siehe TYTZ, S. 109-110; YCFZ, 172-173; 160, 162).
} 


\section{1. 1. Die Amtszeit der Unterpräfekten}

Aus der Liste der Beamten des TYTZ läßt sich die Dauer der Amtszeit von insgesamt siebenundvierzig der genannten Unterpräfekten ersehen. Im Durchschnitt haben sie ihr Amt etwas mehr als drei Jahre lang ausgeübt, was der vom Staat vorgeschriebenen Amtsperiode entsprach, die nach drei Jahren einen turnusmäßigen Wechsel der Amtsträger vorsah.

Die tatsächliche Amtszeit der einzelnen Beamten wich jedoch stark von diesem Durchschnittswert ab; nur insgesamt vier der genannten Beamten absolvierten tatsächlich eine dreijährige Amtszeit. Einige Unterpräfekten dagegen waren zehn Jahre lang im Amt, andere wiederum nur ein Jahr. Dabei waren kürzere Amtsperioden insgesamt häufiger als längere. So waren sechs Beamte acht bis zehn Jahre lang vor Ort, während neunzehn lediglich ein Jahr und acht Beamte nur zwei Jahre in Tengyue verbrachten.

Zu denen, die nur eine kurze Zeit von ein bis zwei Jahren als Unterpräfekten amtierten, gehörten auch die Beamten mandschurischer Herkunft. Die langen Amtsperioden fielen insbesondere in die erste Hälfte des 18. Jahrhunderts. Der Unterpräfekt mit der längsten Amtszeit war Tang Hanbi, der während der Ära Kangxi elf Jahre lang, von 1696 bis 1707 in Tengyue tätig war. Sein Nachfolger und ebenfalls Angehöriger eines chinesischen Banners, Wu Yue, blieb beinahe ebenso lange im Amt; neun Jahre, von 1707 bis 1716. Ebenfalls deutlich längere Amtszeiten als der Durchschnitt absolvierten Kong Yuzhen, zehn Jahre von 1725 (Yongzheng 3) bis 1735, Wu Zouzhe, neun Jahre von 1735 bis 1743 (Yongzheng 13 bis Qianlong 7) und sein Nachfolger Tang Shiliang, zehn Jahre von 1743 (Qianlong 8) bis 1753. Zu Beginn des 19. Jahrhunderts absolvierte erneut ein Beamter solch eine lange Amtszeit: Unterpräfekt Li Yue, der neun Jahre lang von 1812 (Jiaqing 17) bis 1821 (Daoguang 1) in Tengyue stationiert war.

Die Amtszeiten der Unterpräfekten im weitern Verlauf des 19. Jahrhunderts waren deutlich kürzer. Wang Xiuyu, der im Jahr 1856 (Xianfeng 6) sein Amt antrat, hatte mit fünf Jahren die in dieser Zeit längste Amtsperiode. (Wang Xiuyu war auch der letzte Unterpräfekt, der den höchsten akademischen Titel, den des jinshi, trug).

Drei der Unterpräfekten absolvierten eine zweite Amtszeit, die sich zwar nicht direkt an die erste anschloß, aber in kurzem zeitlichem Abstand auf die erste Amtszeit folgte. So war Unterpräfekt Xu Hengchao von 1805 (Jiaqing 10) an vier Jahre lang im Amt, bis er 1809 von einem Herrn Guo abgelöst wurde, der jedoch nur ein Jahr lang im Amt blieb und 
dessen vollständiger Name den Verfassern der fangzhi nicht mehr bekannt war. Im folgenden Jahr, 1815, war Xu Hengchao noch einmal, ebenfalls für nur ein Jahr, als Unterpräfekten tätig.

Zhuang Yuetai wurde 1840 (Daoguang 20) zum Unterpräfekten ernannt, bereits im Jahr 1841 (Daoguang 21) trat sein Nachfolger Wu Jun sein Amt an, das er zwei Jahre lang innehatte, bis Zhuang Yuetai im Jahr 1843 erneut zum Unterpräfekten ernannt wurde.

Chen Zonghai schließlich führte von 1878 (Guangxu 4) an fünf Jahre lang die Amtsgeschäfte. Seine beiden Nachfolger blieben jeweils nur ein Jahr im Amt, bis Chen Zonghai 1885 wiederum zum Unterpräfekten ernannt wurde.

\section{1. 2. Die akademischen Titel der Verwaltungsbeamten}

Die Mehrzahl der Beamten wird in den Listen der Lokalhandbücher mit ihren akademischen Titeln aufgeführt. ${ }^{1176}$ Ein Vergleich der im Rahmen des staatlichen Prüfungssystems erworbenen Titel der Beamten von Tengyue und Yongchang zeigt, daß für die Tätigkeit als Unterpräfekt bzw. Präfekt Beamte mit denselben akademischen Qualifizierungen ausgewählt worden sind.

Tabelle 51: Akademische Titel der Verwaltungsbeamten von Tengyue und Yongchang

\section{Unterpräfekten \\ von Tengyue}

jinshi

juren

jiansheng

Hanlin [jinshi]

Andere

Ohne Angabe

Gesamt
8

9

13

2

12

19

63

\author{
Präfekten \\ von Yongchang
}

8

7

15

3

19

12

64

Die Anzahl der Beamten, die die Provinzprüfungen und die Prüfungen in der Hauptstadt erfolgreich bestanden hatten (juren und jinshi), war in beiden Verwaltungseinheiten fast gleich. Ebenso wie die Anzahl der Präfekten bzw. Unterpräfekten, die nach dem Erwerb des jinshi-Titels einen Posten an der Hanlin-Akademie in der Hauptstadt innegehabt hatten, ehe sie in den Westen Yunnans gekommen waren.

\footnotetext{
${ }^{1176}$ Im TYTZ werden 44 der 63 Unterpräfekten mit ihren akademischen Titeln genannt, im YCFZ 52 der 64 Präfekten.
} 
Im Jahr 1684 (Kangxi 23) war zum ersten Mal ein jinshi (aus der Provinz Jiangsu) als Unterpräfekt in Tengyue tätig; zum letzten Mal hatte im Jahr 1856 (Xianfeng 6) ein jinshi (aus Anhui) dieses Amt inne. Insgesamt sind Inhaber der verschiedenen akademischen Titel über den ganzen Zeitraum von der Mitte des 17. bis zum Ende des 19. Jahrhunderts verteilt im fernen Südwesten tätig gewesen. In jeder der Gruppen von Beamten mit gleichem akademischen Status gab es sowohl solche mit langen als auch mit kurzen Amtszeiten.

Die größte Gruppe der Beamten führte den Titel eines jiansheng, eines Studenten der staatlichen Universität des guozijian. ${ }^{1177}$ Jiansheng war einer der akademischen Titel, die käuflich erworben werden konnten. Inhaber dieses Titels konnten an den Prüfungen auf Provinzebene teilnehmen oder direkt einen Verwaltungsposten erwerben. ${ }^{1178}$

Drei der Unterpräfekten mit dem Titel eines jiansheng waren am Ende der Ära Kangxi und während der Ära Yongzheng nacheinander in Tengyue tätig und absolvierten relativ lange Amtsperioden von sechs, zehn und acht Jahren.

Von den Beamten, die während der Ära Qianlong als Unterpräfekten amtierten, werden im TYTZ lediglich neun mit ihren akademischen Titeln genannt, darunter drei jiansheng. Die sechs anderen hatten die regulären Staatsprüfungen absolviert und die Titel jinshi (1), juren (4) und bagong (1) erlangt.

Die übrigen Beamten führten verschiedene Titel, die sie als zu den Provinzprüfungen zugelassene Kandidaten und Studenten der staatlichen Universität des guozijian auswiesen, die die regulären Prüfungen absolviert (shengyuan, ensheng) oder Titel gekauft hatten (lingong, fugong, yinsheng u.a.). Drei Beamte in Tengyue und vier in Yongchang führten den Titel eines bagong. ${ }^{1179}$ Ein Präfekt aus Yongchang war zwar bei den Provinzprüfungen durchgefallen, sein Prüfungsergebnis hatte aber noch ausgereicht, um in die ,Liste der würdig Gescheiterten‘ (fubang) aufgenommen zu werden und einen Amtsposten zu erhalten. $^{1180}$

\footnotetext{
${ }^{1177}$ Während der Ming-Zeit bildeten die Absolventen der Provinzprüfungen die größte Gruppe der Unterpräfekten. Neben den sechzehn juren werden in der Auflistung des TYTZ lediglich fünf Beamte mit dem Titel eines jiansheng genannt (siehe oben Kap. III B. 10.2, S. 180-182).

${ }_{1178}$ Watt, S. 24, 40; Chü, S. 18; Hucker 856 (jiansheng: National University Student).

${ }^{1179}$ Den Titel bagong erhielten die Studenten, die über die reguläre Zulassungsquote hinaus einmal alle zwölf Jahre zum Studium an der Staatsuniversität des guozijian empfohlen wurden und an einer speziellen Prüfung am Kaiserhof teilnahmen (Watt, S. 24; Hucker 4372, bagongsheng: Graduate for Preeminence).

${ }^{1180}$ Hucker 2090, fubang: Supplementary List, fuche: Honorable Failures.
} 
Vier der Beamten hatten bereits militärischen Verdienste erworben (jungong), ehe sie den Posten des Unterpräfekten von Tengyue antraten. Sie waren sämtlich in den Jahren nach der Rückeroberung der Stadt von den aufständischen Moslems in Tengyue tätig; sie blieben jeweils nur etwa ein Jahr lang im Amt. Der erste von ihnen, Lin Guiqing von 1871 (Tongzhi 11) bis 1872. Ihm folgte zwischenzeitlich mit Wu Qiliang ein jiansheng, der von 1872 bis 1875 als Unterpräfekt tätig war. Seine Nachfolger mit militärischen Auszeichnungen, Zhou Weisun, Wu Zixiu und Cai Xinyi, blieben wiederum nur ein Jahr im Amt. Im Jahr 1878 übernahm mit Chen Zonghai wieder ein jiansheng für zunächst fünf Jahre die Position des Unterpräfekten.

\section{2. Die Militärkommandeure von Tengyue in der Qing-Zeit}

Zu Beginn der Qing-Zeit ist in Tengyue im Jahr 1660 (Shunzhi 17) zunächst ein VizeRegionalkommandeur (fujiang, Rang 2b) stationiert worden, der als oberster Militärbeamter für den Westen des Regionalen Militärbezirks (zhen) Yong-Shun in der Region des Stromschluchtenfächers verantwortlich war. Im Jahr 1775 (Qianlong 40) wurde Tengyue zum Zentrum des Regionalen Militärbezirks (Tengyue zhen) gemacht und im Jahr 1789 (Qianlong 54) wurde der Posten des obersten Militärbeamten zu einem Regionalkommandeur (zongbing, Rang 2a) aufgewertet.

Den obersten Militärbeamten von Tengyue oblag die Verteidigung des äußersten Westens des chinesischen Reiches; sie waren für den Schutz des gesamten Grenzgebietes der Unterpräfektur verantwortlich, einschließlich der tusi-Gebiete und seit 1775 für die gesamte Region des Stromschluchtenfächers. Diese wichtige Position spiegelt sich auch in dem hohen Rang der Amtsträger wieder; der zweithöchste innerhalb der Beamtenhierarchie und damit deutlich über dem fünften Rang des Unterpräfekten von Tengyue.

Insgesamt waren im Verlauf der Qing-Zeit in den 228 Jahren von 1660 bis 1888 neunundfünfzig Männer im Amt des obersten Militärkommandeurs von Tengyue tätig. Fast ebenso viele wie die dreiundsechzig Unterpräfekten.

Angaben zur Länge der Amtsperioden gibt es in den fangzhi allerdings nur für die sechs fujiang, die zur Zeit der Ära Kangxi (1662-1723) in Tengyue waren. Schon aus diesen wenigen Jahresangaben ist jedoch ersichtlich, daß die Amtsperioden der Militärbeamten 
ebenso wie die der Unterpräfekten sehr unterschiedlich waren, so schwankten die der Kommandeure der Ära Kangxi zwischen einem und vierzehn Jahren. ${ }^{1181}$

Vier der obersten Militärbeamten hatten an den staatlichen Militärprüfungen in der Hauptstadt teilgenommen und den Status eines wu jinshi erlangt. Zwei der fujiang waren Absolventen der Militärprüfungen auf Provinzebene (wuju).

Die wu jinshi wurden von der Zentralregierung als besonders qualifiziert angesehen und entsprechend eingesetzt: Drei der wu jinshi waren in der Zeit des chinesisch-birmanischen Krieges (1766-1969) bzw. direkt danach in Tengyue tätig. Der Vize-Regionalkommandeur wu jinshi Ha Guoxing hatte an den beiden Feldzügen nach Birma in den Jahren 1767 und 1769 teilgenommen und war anschließend an den Friedensverhandlungen beteiligt. Auch die anspruchsvolle Aufgabe der Sicherung des Grenzgebietes nach dem Friedensschluß und der Reorganisation der Militäreinheiten veranlaßte die Zentralregierung erneut Beamte nach Tengyue zu entsenden, die den Titel eines wu jinshi aufzuweisen hatten. ${ }^{1182}$

Der erste Beamte, der ab 1660 als Vize-Regionalkommandeur in Tengyue tätig war, stammte aus der nördlichen Provinz Liaodong (ebenso wie der im selben Jahr ernannte erste Unterpräfekt). Sein Amtsnachfolger kam ebenfalls aus dem Norden, aus Shaanxi; aus dieser Provinz stammten insgesamt fünf fujiang, die zu Beginn der Qing-Zeit im späten 17. Jahrhundert und den ersten Jahrzehnten des 18. Jahrhunderts in den Westen der Region des Stromschluchtenfächers entsandt wurden. In diesem Zeitraum amtierten vierzehn fujiang in Tengyue, elf davon kamen aus Nordchina, drei hingegen aus den südlichen Provinzen Fujian (2) und Jiangxi (1). In der ersten Hälfte des 18. Jahrhunderts, während der Ära Qianlong (1736-1796), waren zum ersten Mal auch zwei Männer aus Yunnan als oberste Militärbeamte in Tengyue tätig.

Die Heimatprovinzen der Militärbeamten werden in den fangzhi ausführlich dokumentiert (siehe Tab. 52, S. 412):

\footnotetext{
${ }^{1181}$ Ein Regionalkommandeur absolvierte zwei Amtsperioden: Zhu Hongzhang aus Guizhou, der im Jahr 1885 das Amt noch einmal für ein Jahr übernahm (TYTZ, S. 131).

${ }^{1182}$ Wang Zhenyuan war um 1770 in Tengyue tätig und Liu Guoliang ab 1773. Dessen Amtsnachfolger Xu Shiheng hatte den Titel eines wuju (TYTZ, S. 130). Der vierte Träger des Titels wu jinshi war Kommandeur Aixing'a, der Mitte des 19. Jahrhunderts in Tengyue war (ebd., S. 131).
} 
Tabelle 52: Herkunft der Regionalkommandeure (fujiang / zongbing)

von Tengyue / Heimatprovinzen nach Angaben des TYTZ ${ }^{1183}$

\begin{tabular}{|c|c|c|c|}
\hline $\begin{array}{l}\text { Heimatprovinz / } \\
\text { andere Angaben }\end{array}$ & Gesamt & $\begin{array}{c}\text { Vize-Regional- } \\
\text { kommandeur } \\
\text { fujiang } \\
(1660-1789)\end{array}$ & $\begin{array}{c}\text { Regional- } \\
\text { kommandeur } \\
\text { zongbing } \\
(1789-1888)\end{array}$ \\
\hline
\end{tabular}

\begin{tabular}{|c|c|c|c|}
\hline Anhui & 1 & 1 & -- \\
\hline Fengtian & 1 & 1 & -- \\
\hline Fujian & 3 & 2 & 1 \\
\hline Gansu & 3 & 1 & 2 \\
\hline Guizhou & 3 & 1 & 2 \\
\hline Henan & 2 & 1 & 1 \\
\hline Hunan & 1 & -- & 1 \\
\hline Jiangxi & 2 & 1 & 1 \\
\hline Liaodong & 1 & 1 & -- \\
\hline Menggu & 1 & -- & 1 \\
\hline Shaanxi & 5 & 5 & -- \\
\hline Shanxi & 3 & 2 & 1 \\
\hline Sichuan & 3 & 1 & 2 \\
\hline Yunnan & 8 & 2 & 6 \\
\hline Zhili & 4 & 3 & 1 \\
\hline Manzhou & 13 & 4 & 9 \\
\hline \multicolumn{4}{|l|}{ Bannerangehörige } \\
\hline (Han) & 1 & 1 & -- \\
\hline (Mandschu) & 3 & 1 & 2 \\
\hline Ohne Angabe & 1 & 1 & -- \\
\hline Gesamt & 59 & 29 & 30 \\
\hline
\end{tabular}

Wie die Militärkommandeure stammte auch der größte Teil der Unterpräfekten des 17. und 18. Jahrhunderts aus den Provinzen Nordchinas. Während allerdings relativ viele der obersten Zivilbeamten aus Zhejiang kamen (neun insgesamt), stammte keiner der Militärbeamten aus dieser Provinz. Die Provinz Yunnan, war Heimat von acht Kommandeuren (der zweitgrößten Gruppe im Vergleich der Heimatprovinzen). Anders als bei den Zivilbeamten spielte die Regelung, Beamte nicht in ihrer Heimat einzusetzen, bei der Ernennung der Militärkommandeure zur Verteidigung des westlichen Grenzgebietes keine Rolle.

Im Jahr 1763 (Qianlong 28) ist erstmals ein mandschurischer Militärbeamter nach Tengyue entsandt worden. Vom Ende des 18. Jahrhunderts, einige Jahre nach der Aufwertung des Amtes zum Regionalkommandeur (zongbing, Rang 2a), bis zur Eroberung Tengyue durch die aufständischen Moslime im Jahr 1861 waren dann besonders viele Mandschu als zongbing im äußersten Westen Yunnans stationiert. Ebenso wie auch in den Jahren 1820 bis 1840 mehrere Mandschu als Unterpräfekten in Tengyue amtierten. 
Nach der Niederschlagung der Moslem-Rebellion (1855-1873) sind vor allem Beamte aus den südlichen Provinzen zu Regionalkommandeuren ernannt worden. Von den zehn bis zum Jahr 1888 amtierenden zongbing kamen fünf aus Yunnan, je einer stammte aus Guizhou, Jiangxi, Sichuan sowie aus Hunan und Henan. Ebenso stammten auch die meisten Unterpräfekten in der zweiten Hälfte des 19. Jahrhunderts aus den Provinzen Südchinas (Guizhou, Hunan, Sichuan). Hier zeigt sich wiederum die in ihren großen Zügen parallele Entwicklung der Besetzung der obersten zivilen und militärischen Amtsposten in der Verwaltungseinheit Tengyue.

\section{3. Die Unterpräfekten als Herausgeber der Lokalhandbücher}

Das erste bekannte Manuskript eines Lokalhandbuches von Tengchong (Tengchong si zhi gao) ist etwa siebzig Jahre nach dem Bau der Stadtmauer im Jahr 1512 von Yi Yizhi, einem Gelehrten aus Tengyue, verfaßt worden. ${ }^{1184}$ Die Zusammenstellung des fangzhi verweist bereits auf zivile Strukturen in Tengchong, die über eine reine Militärpräsenz hinausgehen und die ein Jahrzehnt später, mit der Umwandlung des Militärstützpunktes in die Unterpräfektur Tengyue im Jahr 1522, offiziell bestätigt wurden. Seit 1526 wurde Tengyue von einem Unterpräfekten verwaltet und seitdem ist die Entstehung der fangzhi eng mit den Namen der Unterpräfekten verbunden, die als Herausgeber tätig waren, wobei sie bei der Abfassung der Handbücher von örtlichen Gelehrten tatkräftig unterstützt wurden.

Unterpräfekt Shen Zuxue (1567- 1573 in Tengyue tätig) begann im Jahr 1567 ein fangzhi zusammenzustellen; sein Entwurf wurde später von Wu Zongyao (juren des Jahres 1543) aus Tengyue umfassend ergänzt und als Tengyue zhou zhi in zwei Kapiteln herausgegeben. ${ }^{1185}$ Unter der Leitung von Unterpräfekt Li Zhiren (ab 1614 in Tengyue) wurde im Jahr 1614 von Zhang Bangjiao, einem Angehörigen der örtlichen Gentry (shenshi), erneut ein Lokalhandbuch zusammengestellt. ${ }^{1186}$

In der Qing-Zeit stellte Unterpräfekt Wu Kai (1770-1779 in Tengyue tätig) ein Lokalhandbuch (Tengyue zhou zhi) zusammen, für das er im Jahr 1779 ein Vorwort verfaßte. Wu Kai war nach dem Krieg gegen Birma (1766-1769) in Tengyue tätig. Seine Amtszeit war vor allem vom Wiederaufbau und der Renovierung der in Kriegeszeiten zerstörten

\footnotetext{
1184 TYTZ, S. 213; YCFZ, S. 281

1185 TYTZ S. 108, 141 (Shen Zuxue); TYTZ, S. 209, 199 (Wu Zongyao).

1186 TYZZ, S. 6; TYTZ, S. 142
} 
Gebäude bestimmt. Entsprechend sind zahlreiche seiner Gedenkinschriften zu den diversen Bauprojekten in das Handbuch aufgenommen worden.

Wu Kais Amtsnachfolger Tu Shulian (von 1787 bis 1791 in Tengyue tätig) setzte das Werk seines Vorgängers fort. Tu stellte die Texte der älteren fangzhi neu zusammen und verfaßte zu jedem Kapitel seines Handbuches eine kurze Einleitung. Sein Vorwort zu diesem fangzhi ist auf das Jahr 1790 datiert. Diese von Tu Shulian verfaßten Einleitungen wurden von den Herausgebern des Tengyue zhou zhi aus dem Jahr 1838 übernommen. Dieses Handbuch erschien erneut im Jahr 1897, in einer revidierten Fassung herausgegeben von Cun Kaitai, einem jinshi aus Tengyue, und Huang Bingkun. Tu Shulian wurde jedoch auch weiterhin als eigentlicher Verfasser des Tengyue zhou zhi genannt; seine Einführungen leiten nach wie vor die einzelnen Kapitel ein.

Tabelle 53: Die Herausgeber der Lokalhandbücher von Tengchong / Tengyue

$\begin{array}{lll} & \text { Jahr } & \text { Herausgeber / Verfasser } \\ \text { Ming-Zeit } & 1512 & \text { juren Yi Yizhi } \\ 1567 & \text { Unterpräfekt Shen Zuxue } \\ & ---- & \text { juren Wu Zongyao } \\ & 1614 & \text { Unterpräfekt Li Zhiren, shenshi Zhang Bangjiao } \\ & 1779 & \text { Unterpräfekt Wu Kai } \\ & 1790 & \text { Unterpräfekt Tu Shulian } \\ & 1838 \text { (1897) } & \text { (Unterpräfekt Tu Shulian), } \\ & & \text { jinshi Cun Kaitai, Huang Bingkun } \\ & & \text { Unterpräfekt Chen Zonghai; juren Zhao Duanli }\end{array}$

Im Jahr 1879 (Guangxu 5) wurde ein weiteres Lokalhandbuch fertiggestellt, das Tengyue ting zhi, herausgegeben von Unterpräfekt Chen Zonghai und dem juren Zhao Duanli. Das fangzhi wurde anschließend überarbeitet, so daß als eigentliches Herausgabedatum das Jahr 1888 gilt. $^{1187}$

Chen Zonghai war in den Jahren nach der Niederschlagung der Moslem-Rebellion (18551873) als Unterpräfekt in Tengyue tätig: Zunächst von 1878 bis 1883; im Jahr 1885

\footnotetext{
${ }^{1187}$ In der Liste der Herausgeber des TYTZ wird gleich an zweiter Stelle nach dem Unterpräfekten auch der Name des amtierenden Regionalkommandanten Ding Huai genannt. Anders als der Unterpräfekt tritt Ding Huai als Verfasser eigener Texte jedoch ebenso wenig in Erscheinung wie seine Amtsvorgänger.
} 
übernahm Chen erneut das Amt. Auch seine Amtszeit war geprägt vom Wiederaufbau der während der Kämpfe zerstörten Gebäude sowie der Restauration der Verwaltungseinheit insgesamt. Folglich beinhaltet das Handbuch zahlreiche seiner Gedenkinschriften zur Instandsetzung von Amtsgebäuden, Tempeln, Schulen, Brücken und anderen Bauwerken.

Die Projekte zur Herausgabe von Lokalhandbüchern in der Qing-Zeit standen in engem Zusammenhang mit den beiden Ereignissen, die in dieser Zeit jeweils einen tiefen Einschnitt in der Entwicklung der Verwaltungseinheit bedeutet haben: Den Kriegen mit Birma im 18. Jahrhundert und der Moslem-Rebellion im 19. Jahrhundert. Jeweils nach Beendigung der Kampfhandlungen in der Region begann in Tengyue eine Phase der Restauration und des Wiederaufbaus, in der dann auch ein Lokalhandbuch zusammengestellt wurde. Von den Unterpräfekten initiiert, werden deren Leistungen in den fangzhi entsprechend betont. So sind die fangzhi auch Selbstdarstellung der Beamten, die hier die Erfüllung ihrer Amtspflichten hervorheben. Die Herausgabe der Lokalhandbücher dokumentiert jedoch nicht nur den materiellen Wiederaufbau Tengyues, sondern auch die Wiederanknüpfung an die in Kriegszeiten unterbrochenen Traditionen, deren Gültigkeit in Tengyue nun durch die Unterpräfekten als Repräsentanten des chinesischen Kernlandes ebenso wie in Tengyue selbst durch die örtlichen Gelehrten, die sich jeweils an dem Projekt beteiligt haben, erneut bestätigt wird. 


\section{KAPITEL V}

\section{CHINA UND DIE VÖLKER DER REGION - DAS PROBLEM DER SPRACHLICHEN UND SCHRIFTLICHEN VERSTÄNDIGUNG}

\section{1. ,Die Schriften der Fremden`}

Tengyue ist die ,erste Stadt an der äußersten Grenze‘, das Zentrum einer Verwaltungseinheit an der Peripherie des chinesischen Reiches. Bis hierher erstrecken sich die vielfältigen Strukturen des Kernlandes, die im Laufe der Zeit ein Grenzgebiet entstehen ließen, in dem verschiedene Gruppen miteinander in Kontakt getreten sind, die ihre Hoheitsgebiete immer wieder neu definiert und von einander abgegrenzt haben.

Die chinesischen Verwaltungsbeamten in der Unterpräfektur Tengyue und im Regionalen Militärbezirk Tengyue waren für ein weiträumiges Gebiet verantwortlich, dessen Bevölkerung sich aus Han-Chinesen und nach Angaben der fangzhi siebenundzwanzig verschiedenen Völkern zusammensetzte. Besonders die Shan (chin. Baiyi, heute Dai) übten in der Region des Stromschluchtenfächers regional großen Einfluß aus und konnten ihre Unabhängigkeit über Jahrhunderte erfolgreich behaupten, auch gegenüber ihren großen Nachbarn China und Birma. Zu diesem Zweck unterhielten sie häufig Triutbeziehungen zu beiden Nachbarreichen, die ihrerseits bestrebt waren, die Oberhoheit über diese Gebiete zu gewinnen.

Ein Ausdruck der vielfältigen Beziehungen zwischen Birma, den Kleinstaaten der Shan und dem chinesischen Kaiserreich war der Austausch von Schriftstücken. Vorraussetzung für eine erfolgreiche Kommunikation waren Kenntnisse fremder Sprachen und Schriften, sei es beim Absender oder beim Adressaten eines Schreibens. Aufgrund der geographischen Nähe und der regen Handelskontakte fanden sich in Tengyue immer Menschen, die mit mehreren Sprachen vertraut waren. Auch das Chinesische wurde von den tusi ebenso wie von den anderen Nachbarvölkern durchaus verstanden. So wurde der chinesische Gesandte Su Erxiang im Jahr 1777 von Dolmetschern aus Birma nach Tengyue zurück begleitet. John Anderson berichtete im Jahr 1868, daß der Herrscher des Befriedeten Gebietes von Husa im Südwesten von Tengyue sowohl Shan als auch Chinesisch lesen und schreiben konnte und derzeit gerade das Birmanische erlernte. ${ }^{1188}$ Auch bei den in der Präfektur Yongchang ansässigen anderen Volksgruppen gab es Menschen, die „die chinesische Sprache beherrschten und Handel trieben“ (zhi hanyu tong maoyi). ${ }^{1189}$

\footnotetext{
${ }^{1188}$ Anderson, S. 175, 281

1189 TYTZ, S. 247 (siehe unter ,Puren').
} 
Die Verwaltungsbeamten von Tengyue sahen sich folglich mit einer komplexen Situation konfrontiert: Schriftstücke in verschiedenen Sprachen und Schriften gingen bei ihnen ein, wie zum Beispiel Dokumente, die die Tributgesandtschaften mit sich führten oder ein Ersuchen um militärische Unterstützung von Seiten eines tusi bei Konflikten in der Region; auch als Absender von Schreiben an die einheimischen Herrscher mußten die Beamten eine Sprache wählen, die vom Adressaten verstanden wurde.

Die Zivil- und Militärbeamten waren aus diversen Provinzen des Reiches nach Tengyue gekommen, nachdem sie ihre traditionelle konfuzianische Bildung in den staatlichen Prüfungen bewiesen hatten. Das Erlernen von Fremdsprachen war in ihren Kreisen auch unter der mandschurischen Qing-Dynastie, deren offizielle Dokumente in mehreren Sprachen abgefaßt wurden, nicht üblich und so hatten sie vorab keine Kenntnisse der einheimischen Sprachen der Region des Stromschluchtenfächers erworben. Im Verwaltungsapparat der Unterpräfektur war die Anstellung von besoldeten Dolmetschern oder Übersetzern jedoch nicht vorgesehen. Die Beamten waren also darauf angewiesen, bei Bedarf vor Ort qualifizierte Personen zu finden. Zwar gab es in Tengyue Menschen, die Fremdsprachen beherrschten und mit diesen Kenntnissen eine Anstellung in der Verwaltung erhielten. So wird im TYTZ ausdrücklich vermerkt, daß an der nördlichen Grenze der Unterpräfektur ,der Dolmetscher (tongshi) Duan Sheng als Polizeibeamter (xunjian) am Diantan-Paß stationiert wurde ‘ ${ }^{1190}$ Gerade für die Bearbeitung von offiziellen Dokumenten war es jedoch oft schwierig für die Beamten, geeignete Übersetzer zu finden,die die verschiedenen Sprachen und Schriften gut genug beherrschten.

In den Lokalhandbüchern von Tengyue wird ein Bericht über ,die Schriften der Fremden` aus der zweiten Hälfte des 18. Jahrhunderts überliefert, der sich mit dieser Problematik befaßt (siehe Abb. 3, S. 418). ${ }^{1191}$ Unterpräfekt Wu Kai (von 1770 bis 1779 im Amt) schildert darin eigene Erfahrungen im Umgang mit Schriftstücken aus Birma und den tusiGebieten. Er verweist auf die Schwierigkeiten, Dokumente in fremden Sprachen und Schriften zu bearbeiten und beklagt ausdrücklich den Mangel an qualifiziertem Personal für die Übersetzungen.

\footnotetext{
1190 TYTZ, S. 180

1191 ,Die Schriften der Fremden` (yi zi) (TYTZ, S. 389 und TYZZ, 170). Diese Beschreibung des Umgangs mit fremdsprachlichen Dokumenten in China ist nicht nur in den fangzhi von Tengyue bis ins 19. Jahrhundert überliefert worden, sondern auch in Provinzhandbücher, wie das Diannan zhazhi von 1810 aufgenommen worden (Diannan zazhi, Kapitel 11, Faksimileausgabe S. 420-421).
} 
Der Bericht des Unterpräfekten Wu Kai, der im Lokalhandbuch TYZZ noch unter dem Titel ,Die birmanische Schrift‘ (mian zi) abgedruckt wurde, wurde von den Verfassern des TYTZ erweitert. Unter der neuen Überschrift ,Die Schriften der Fremden` wird der Bericht mit Informationen über die Entstehung der ebenfalls in der Region gebräuchlichen Schrift des Volkes der Yi und deren Verbindung zu den Schriften der Shan zusammengestellt. ${ }^{1192}$

Abbildung 3: ,Die Schriften der Fremden` (yi zi) (TYTZ, S. 389, Zeilen 4-11)
18
$\begin{array}{llllllll}17 & 16 & 15 & 14 & 13 & 12 & 11 & 10\end{array}$
$\begin{array}{lllllllll}9 & 8 & 7 & 6 & 5 & 4 & 3 & 2 & 1\end{array}$

夷

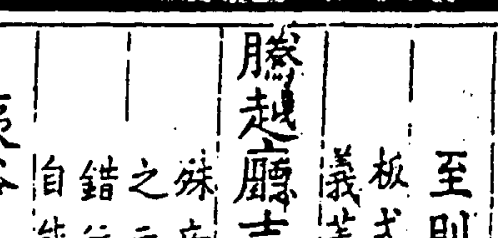

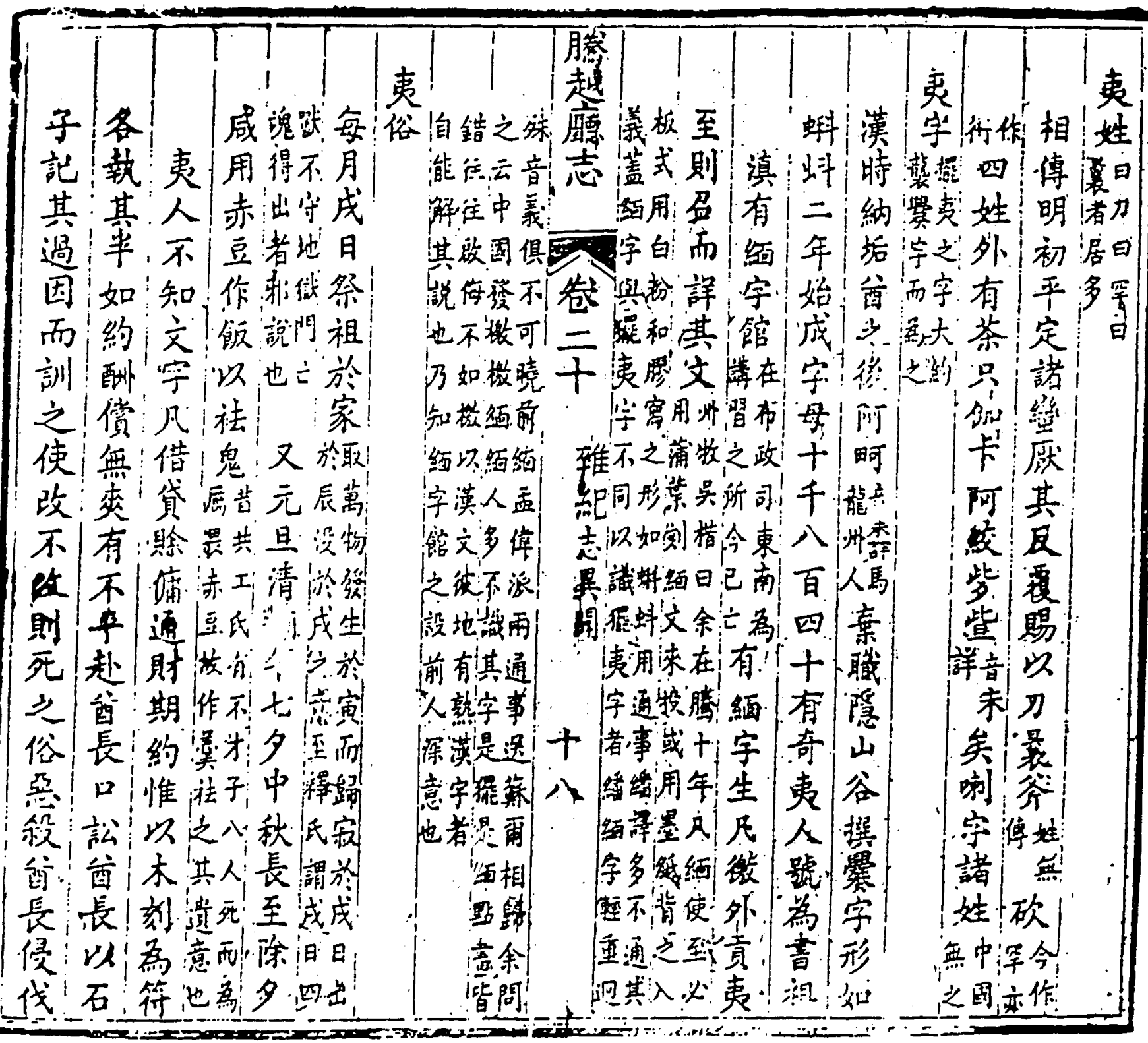

1192 ,Die birmanische Schrift‘ (mian zi), siehe TYZZ, S. 170 (ebenso im Diannan zazhi, S. 420-421). Die Informationen über die Yi-Schrift finden sich im TYZZ an anderer Stelle im selben Wortlaut (siehe TYZZ, S. 168 oben). 


\section{„Die Schriften der Fremden:}

Die Schriftzeichen der Shan (baiyi) sind zum größten Teil aus Entlehnungen von den Schriftzeichen der Cuan gebildet worden. ${ }^{1193}$

A Ji, ein Nachfahre des Stammeshäuptlings von Nagou aus der Han-Zeit, stammte aus dem Bezirk Malong [südwestlich der Stadt Qujing]. Nachdem er sich von seinem Amt in ein Gebirgstal zurückgezogen hatte, schuf er dort die Cuan-Schriftzeichen, deren Form Kaulquappen gleicht. Nach zwei Jahren waren 10.840 Buchstaben entstanden, die [alle ihre] Besonderheiten haben. Die Yi nennen ihn den Ahnen der Schrift.

In [der Provinzhauptstadt von] Yunnan gab es ein Amt für die birmanische Schrift (Mianziguan). Es befand sich im Südosten des Provinzschatzamtes und war ein Ort, an dem gelehrt und studiert wurde. Heute existiert es nicht mehr. [Früher] gab es dort Angestellte, die die birmanische Schrift beherrschten (you mianzi sheng). Jedesmal, wenn Fremde von jenseits der Grenze eintrafen, um Tributgeschenke zu überbringen, dann wurden sie herbeigerufen und übersetzten deren Dokumente.

Wu Kai [von 1770 bis 1779] Unterpräfekt von Tengyue hat [die fremdsprachlichen Schriftstücke und die Schwierigkeiten der chinesischen Verwaltung im Umgang mit ihnen ausführlich beschrieben], er berichtete:

,Ich war zehn Jahre lang in Tengyue. Jedesmal, wenn Gesandte der Birmanen ankamen, übergaben sie birmanische Dokumente, die in Blätter graviert worden waren oder sie benutzten dunkles Papier, dessen Rückseiten geschichtet und in brettartige [Deckel] hineingetan worden waren und verwendeten Kreide und Harz, um darauf zu schreiben. Die Form [ihrer Schriftzeichen] gleicht Kaulquappen.

Bei den Dolmetschern und Übersetzern gab es solche, die die Bedeutung [der Dokumente] nicht verstehen konnten. Denn die birmanische Schrift und die Schriften der Shan sind verschieden. Wenn nun aber diejenigen, die ShanSchrift beherrschten, birmanische Schrift übersetzen sollten, konnte man, da

\footnotetext{
${ }^{1193}$ Cuan ist die chinesische Bezeichnung für eine im Südwesten Chinas ansässige Volksgruppe, die als Vorfahren der Völker der Yi und der Bai gilt. Chinesischen Quellen zufolge soll der Name ihrem Herrscher im 3. Jahrhundert n. Chr. von Zhuge Liang verliehen worden und dann zur Bezeichnung des ganzen Volkes geworden sein (Backus, S. 6-7).
} 
die Phonetik (qingzhong) völlig verschieden war, weder Aussprache noch Bedeutung verstehen. ${ }^{1194}$

Als damals [im Jahr 1777] die Birmanen Meng Wei [und Meng Ling], beide waren Dolmetscher, den Su Erxiang nach Tengyue zurückbegleitet hatten, habe ich sie persönlich befragt. ${ }^{1195}$ [Sie] sagten: ,Wenn China Dokumente auf Birmanisch herausgibt, können die Menschen in Birma deren Schrift vielfach nicht lesen. Ist es Shan oder ist es Birmanisch? Die Strichführung (dianhua) ist ganz falsch. ${ }^{1196}$ Häufig kommt es deswegen zu Mißverständnissen`.

Es wäre daher besser, in solchen Schriftstücken das Chinesische zu verwenden. In anderen Ländern gibt es Menschen, die mit dem Chinesischen vertraut sind und die verstehen können, was in [den Dokumenten] gesagt wird‘.

An [diesem Sachverhalt] erkennt man, daß die Gründung eines Amtes für birmanische Schrift durch unsere Vorfahren von großer Bedeutung war“. ${ }^{1197}$

Wu Kai erweist sich hier als engagierter Verwaltungsbeamter der Unterpräfektur an der Peripherie des Reiches: Er ist mit der besonderen Situation im Grenzgebiet vertraut, sammelt persönlich zusätzliche Informationen, um dann aus eigener Anschauung Lösungsvorschläge, wie zum Beispiel für die Schwierigkeiten mit den fremdsprachlichen Dokumenten, zu machen. Mit einer kritischen Schilderung des Sachverhaltes bildet der Bericht eine Ausnahme von den ansonsten generell in neutralem Ton gehaltenen Darstellungen in den fangzhi. Wu Kais informative Beschreibung des Umgangs mit fremdsprachlichen Schriftstücken gibt einen interessanten und seltenen Einblick in die alltägliche Verwaltungspraxis der Unterpräfektur und macht die Schwierigkeiten deutlich, mit denen die Beamten in ,der ersten Stadt an der äußersten Grenze‘ konfrontiert waren, die sich an einer Schnittstelle in der Kommunikation Chinas mit den Völkern der Region befanden.

\footnotetext{
${ }^{1194}$ Qingzhong (das ,Gewicht‘ der Töne) ist ein Fachausdruck, der für mehrere Unterscheidungen in der Phonologie verwendet wird, z. B. für die Höhe oder die Stärke der Töne, oder auch um zwischen nicht-aspirierten (qing) und aspirierten (zhong) Lauten zu differenzieren (ZGYYXDCD, S.158).

An dieser Stelle ist der Text des TYTZ gekürzt worden. Im TYZZ heißt es ausführlicher: „Wenn nun aber diejenigen, die Shan-Schrift beherrschten, birmanische Schrift übersetzen sollten, dann war die Phonetik völlig verschieden von der, die [Dolmetscher] verwendeten, die in Shan-Schrift schrieben. Wenn die Fremden aber die chinesische Schrift benutzten, so veranlaßte dies die Übersetzer, die birmanische Aussprache hinzuzufügen. Es ist nicht möglich, den Sinn dessen zu verstehen“ (TYZZ, S. 170 oben, Zeile 12-13; ebenso im Diannan zazhi, S. 421, Zeile 6-7).

${ }^{1195}$ Su Erxiang, stammte aus der Provinz Ningxia. Su wurde im Jahr 1770 im Laufe von Verhandlungen zwischen China und Birma über birmanische Gebietsansprüche und Tributleistungen vom Generalgouverneur Yunnans, Zhang Bao, nach Kaungton entsandt und dort vom birmanischen König festgehalten. Erst sieben Jahre später wurde Su freigelassen und von den Gefolgsleuten des birmanischen Generals Deluwen, Meng Wei, Meng Ling, Meng Mei und anderen nach Yunnan zurückbegleitet (TYTZ, S. 21, 137; TYZZ, S. 100; siehe oben Kap. IV A. 3. 2., S. 220).

${ }^{1196}$ Dianhua (,Punkte und Striche`) ist eine Bezeichnung für die einzelnen Striche eines Schriftzeichens sowie auch für die Strichführung insgesamt.

${ }^{1197}$ TYTZ, S. 389; TYZZ, 170
} 


\section{Die Sprachen und Schriften der Birmanen, Shan und Yi}

\section{1. Die Sprachen der Birmanen und der Shan}

Sowohl das Birmanische und das Shan als auch das Chinesische werden zu einer großen Sino-tibetischen Sprachfamilie zusammengefaßt, die sich wiederum in zwei Hauptgruppen, die tibeto-birmanische und die thai-chinesische Sprachgruppe, unterteilen läßt und deren Sprachen durch Monosyllabität und Worttöne zur Differenzierung von Homophonen gekennzeichnet sind.

$\mathrm{Zu}$ der ersten Gruppe gehören neben Tibetisch und Birmanisch auch die Sprachen der in China ansässigen Völker der Yi, Lisu, Naxi und Jingpo (Kachin). Insgesamt umfaßt die tibeto-birmanische Sprachgruppe über zweihundert verschiedene Sprachen. ${ }^{1198}$

Das Birmanische ist, wie fast alle tibeto-birmanischen Sprachen, eine monosyllabische, tonale Sprache, die weder Deklination noch Konjugation kennt, so daß der Wortstellung im Satz und der Verwendung von Partikeln große Bedeutung zukommt. ${ }^{1199}$

$\mathrm{Zu}$ den Thaisprachen gehören neben Thai und Laotisch auch Ahom, Hkamti und Shan sowie die Sprachen der Zhuang-Dong Sprachfamilie in China, zu der dort unter anderem auch die Sprachen der Dai oder die der Li von der Insel Hainan zählen. ${ }^{1200}$

Als Dai bezeichnen die Chinesen heute allgemein die im Westen der Provinz Yunnan ansässigen Thai-stämmigen Völker, deren Sprachen zur Gruppe der Thaisprachen gehören. Früher wurden sie in China zumeist ,Baiyi“ und in europäischen Quellen nach ihrem birmanischen Namen ,Shan` genannt. ${ }^{1201}$

Cushing (1914) unterscheidet in seinem Lexikon des Shan, ebenso wie es in Birma üblich ist, zwei Hauptgruppen des Shan: ,Chinese Shan“ und ,Burman Shan`. ${ }^{1202}$,Chinesisches Shan‘ (birman. rhamh tarup), auch ,Tai mow` oder ,Tai mao‘ genannt, wird hauptsächlich in den östlich und nordöstlich von Bhamo im Grenzgebiet zu China gelegenen Herrschaftsgebieten der Shan gesprochen. ,Birmanisches Shan“ (rhamh bama) hingegen in den ShanStaaten innerhalb der Grenzen des ehemaligen British-Burma. ${ }^{1203}$ Diese Hauptgruppen teilen sich in zahlreiche Dialekte (zum Beispiel der in Kengtung gesprochene Khün), die untereinander oft unverständlich sind. ${ }^{1204}$ Außerdem sind in Siedlungsgebieten der Shan, die unter birmanischer Herrschaft standen, birmanische Lehnworte und in den an China

\footnotetext{
1198 Richter, S. 9; Ramsey, S. 232, 248

1199 Richter, S. 8

1200 Cochrane, S. 208; 232-233

1201 Ramsey, S. 243. Angehörige dieser Volksgruppen sind im Verlauf der Geschichte mit einer Vielzahl von Namen bezeichnet geworden; Scott/Hardiman zählen allein über vierzig verschiedene Namen auf (Scott/Hardiman, S. 187-188).

1202 Cushing, Dictionary, Einleitung, S. 5-6. Shan ist ebenfalls eine monosyllabische tonale Sprache.

1203 Cushing, Dictionary, Einleitung, S. 5-6; Cochrane, S. 15ff; MCK, Bd. yuh-la, S. 404-405

${ }^{1204}$ Cushing, Dictionary, Einleitung, S. 7; Ramsey, S. 243; Scott/Hardiman, S. 188
} 
grenzenden Gebieten, chinesische Lehnworte in die Shan-Sprache aufgenommen worden. ${ }^{1205}$ In China werden die Sprachen der Dai in Yunnan heute in zwei Gruppen eingeteilt, die eine umfaßt die in Xishuangbanna gesprochenen Sprachen und die andere die weiter nördlich im Bezirk Dehong gesprochenen. ${ }^{1206}$

\section{2. Die Schriften der Birmanen und der Shan}

\section{2. 1. Die birmanische Schrift}

Die Entwicklung der birmanischen Schrift begann Mitte des 11. Jahrhunderts, als der birmanische König Anawrahta (ca.1044-1077) das Reich der Mon in Niederbirma eroberte und einen großen Teil der Bevölkerung der Mon-Hauptstadt Thaton sowie Mönche und buddhistische Schriften in seine Hauptstadt Pagan brachte. So kamen die Birmanen in Kontakt mit einer weiter entwickelten Kultur, die ihre eigene entscheidend beeinflussen sollte; der Theravada-Buddhismus wurde zur nationalen Religion der Birmanen und das Pali etablierte sich als seine religiöse Sprache; auf der Grundlage der Mon-Schrift begannen die Birmanen eine eigene Schrift zu entwickeln.

Die Mon hatten ihre Schrift nach dem Vorbild südindischer Schriften, möglicherweise der Pallava- oder der Vengi-Schrift, geschaffen. Die Birmanen übernahmen die Mon-Schrift und Sprache zunächst in ihren Inschriften; im Laufe der Zeit begann dann jedoch der Einfluß der Mon immer mehr nachzulassen, bis er schließlich in der Zeit König Narapatisithus (1173-1210) ganz verschwand und sich das Birmanische als Hauptsprache und Schrift der Inschriften durchsetzte. ${ }^{1207}$ So werden fast alle Mon-Inschriften der Pagan-Zeit vor das Jahr 1174 datiert, während danach die birmanische Schrift dominierte. ${ }^{1208}$

Die birmanische Schrift wird von links nach rechts in horizontalen Zeilen geschrieben; Abstände zwischen den einzelnen Wörtern im Satz werden nicht gemacht, lediglich das Ende eines Satzes oder Textabschnittes wird durch zwei senkrechte Striche deutlich gekennzeichnet. Das Alphabet umfaßt zweiunddreißig Konsonanten und zehn Vokale (siehe Tab. 54, S. 426).

\footnotetext{
${ }^{1205}$ Cushing, Dictionary, Einleitung, S. 14

${ }^{1206}$ Coyaud, S. 137

${ }^{1207}$ Hall, S. 141

${ }^{1208}$ Luce, Old Burma, S. 96
} 


\section{2. 2. Die Schriften der Shan}

Die Thaivölker sind erst relativ spät von Norden in die südostasiatische Halbinsel eingewandert; um 1260 gründeten sie das erste unabhängige Thai-Königreich von Sukhotai, in dem aus der Khmer-Schrift entwickelte Schriftzeichen verwendet wurden. ${ }^{1209}$ Weiter im Osten wanderten die Shan etwa seit dem 13. Jahrhundert nach Birma ein; dort entwickelten sie ihre Schriften nach birmanischem Vorbild. So ähnelt besonders die sogenannte ,alte Shan-Schrift` dem Birmanischen, während andere Shan-Schriften sich an nordthailändischlaotische Schriften anlehnen (s. Abb. 4). ${ }^{1210}$ Es gibt also keine einheitliche Shan-Schrift; im Allgemeinen spricht man von sechs Shan-Schriften. ${ }^{1211}$

Abbildung 4: Beispiele der verschiedenen Shan-Schriften - die Basiskonsonanten (Quelle: Klaus Wenk, Zur gegenwärtigen Situation der Schan-Schriften, S. 118, Tafel 1)

\begin{tabular}{|c|c|c|c|c|c|c|c|c|c|}
\hline ,Alte Schan-Schrift & 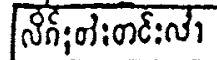 & 0 & J & c & $\infty$ & 02 & 9 & $\infty$ & $\infty$ \\
\hline \multirow{26}{*}{$\begin{array}{l}\text { Schriften der groben Thai- } \\
\text { Hikanti' (nordlichste Gruppe } \\
\text { der Shan) }\end{array}$} & गुम; न:ख्य & $n$ & 2 & c & ro & $\infty$ & $\vartheta$ & $\infty$ & $\infty$ \\
\hline & 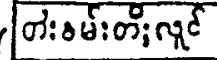 & $m$ & $n$ & c & vo. & en & $n$ & $\infty$ & $\infty$ \\
\hline & की: $2 \sqrt{: 0 \%}$ & $m$ & $\infty$ & c & $n$ & $\bar{\omega}$ & $\cdot p$ & $\infty$ & $\infty$ \\
\hline & 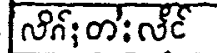 & $m$ & $\infty$ & c & 6 & $\infty$ & $-p$ & $n$ & $\infty$ \\
\hline & ช้ก; ส:รุ. & $m / n$ & $2 \frac{5}{313}$ & 旬 & $01 c^{2}$ & 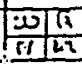 & $(2 / 2)$ & कor & 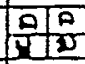 \\
\hline & 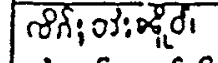 & 1 & 29 & $n$ & $\mathrm{v}$ & $\sqrt{1}$ & $(y)$ & $n$ & 0 \\
\hline & 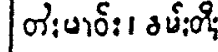 & 7 & a) & $n$ & 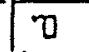 & $v$ & $\mu$ & $m$ & 0 \\
\hline & 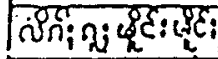 & $\vec{k}$ & $k h \mid x$ & $\eta$ & Is & tsh & n & $t$ & th \\
\hline & 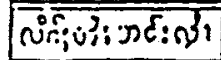 & 26 & $u$ & 16 & $\mathrm{C}_{3}$ & $\theta$ & $\omega$ & $?$ & 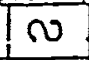 \\
\hline & กर; क':वृह & 26 & $u$ & 6 & - & $\omega$ & w & EI? & $N$ \\
\hline & 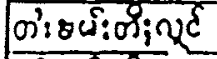 & $r$ & 0 & n & - & $\omega$ & $\omega$ & డ్రి & ט \\
\hline & \%:20:09;: & $\infty$ & $u$ & $\infty$ & $(60)$ & 6 & $\omega$ & $\sqrt{0}$ & $n$ \\
\hline & गम;न: तह & 20 & $u$ & $\infty$ & $(50)$ & 6 & $w$ & 20 & 0 \\
\hline & 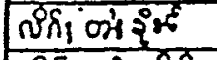 & ving & $5 \%$ & 120 & |हाद & \begin{tabular}{|l|l|l|}
$y$ & 4 \\
\end{tabular} & 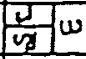 & E & $\times 0$ \\
\hline & 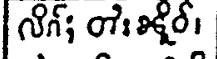 & $n$ & $u^{\circ}$ & $\omega$ & 19 & $\forall$ & $H$ & - & n. \\
\hline & 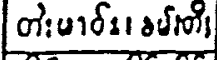 & $n$ & $u$ & $\omega$ & 19 & $\forall$ & $W$ & 5 & 4 \\
\hline & 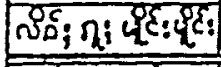 & $n$ & $p$ & $\mathrm{ph}$ & $f$ & $m$ & $j$ & $r$ & $l$ \\
\hline & 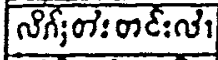 & 0 & 9 & $m$. & $\infty$ & 0. & 8 & 50 & 20 \\
\hline & مैก; त:Rूe & 0 & 9 & $m$ & - & - & - & -1 & $=$ \\
\hline & 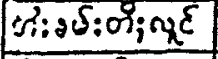 & 0 & es & $m$ & - & - & $=$ & - & - \\
\hline & $01: 25: 091$ & 0 & 2 & $\infty$ & $\div$ & - & - & - & - \\
\hline & กิก; ना:तह & 0 & $p$ & $m$ & - & - & - & - & $=$ \\
\hline & $\Omega^{n} \hat{X}_{1}$ ol: $\{2 \delta$ & \begin{tabular}{l|l}
8 & 0 \\
\end{tabular} & $n / y$ & 27 & 3 & $u$ & $=$ & - & - \\
\hline & กิก; & 0 & n: & $\pi$ & - & - & $\therefore$ & - & - \\
\hline & 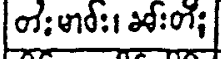 & D & n & $n$ & 0.7 & $\underline{4}$ & 2 & 0 & ơ \\
\hline & 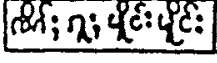 & $w$ & $h$ & (a) & $d$ & $b$ & 9 & 3 & Q \\
\hline
\end{tabular}

\footnotetext{
${ }^{1209}$ Bunnag, S. 191

${ }^{1210}$ Wenk, S. 111

${ }^{1211}$ Scott/Hardiman, S. 188; Wenk, S. 112, 116
} 
In jüngerer Zeit waren sowohl in Birma als auch in China die Regierungen bemüht, diese zahlreichen Schriften zu vereinheitlichen. So wurde in Birma 1973 eine neue Shan-Schrift eingeführt, die für alle Shan-Staaten verbindlich werden sollte. Daneben bestehen jedoch die unterschiedlichen Schriften nach wie vor weiter.

Alle Shan-Schriften werden von links nach rechts in waagerechten Zeilen geschrieben. Die Anzahl der Buchstaben ist bei den einzelnen Schriften unterschiedlich, Wenk nennt einundzwanzig Basiskonsonanten und zehn Basisvokale. ${ }^{1212}$ Ein Charakteristikum der ShanSchriften ist, daß die verschiedenen Töne nicht geschrieben werden, so daß Wörter mit unterschiedlicher Aussprache und Bedeutung gleich geschrieben werden und nur aus dem Textzusammenhang heraus zu verstehen sind. ${ }^{1213}$

In China unterscheidet man heute vier Schriften der Dai-Nationalität: Dai Lewen, Dai Bengwen, Dai Nawen und Jinping Daiwen (Abb. 5, S. 425).

Dai Lewen gilt als die älteste Schrift, sie wird auch Xishuangbanna Daiwen genannt, ihr Alphabet entspricht dem des Pali, sie ist die Schrift der klassischen Werke Laos. ${ }^{1214}$

Dai Bengwen wird auch Shanwen genannt, da diese Schrift hauptsächlich in den nördlichen Shan-Staaten Birmas gebräuchlich ist; ihre runden Buchstaben ähneln dem Birmanischen, sie kennt jedoch lediglich achtzehn Konsonanten und zehn Vokale (sie entspricht der ,alten Schan-Schrift‘ bei Wenk). ${ }^{1215}$

Dai Nawen ist hauptsächlich im autonomen Bezirk Dehong der Dai- und Jingpo-Nationalitäten verbreitet, weshalb heute die Bezeichnung Dehong Daiwen üblich ist. Dai Nawen besitzt neunzehn Konsonanten, ihr Duktus ist eckiger als der der anderen Dai-Schriften und gleicht der im Nordosten Birmas von den Tai Mao-Shan (die am Grenzfluß zwischen den nördlichen Shan-Staaten Birmas und China, dem Shweli [chin. Ruili] leben) verwendeten Schrift. ${ }^{1216}$

\footnotetext{
1212 Wenk, S. 118-119

${ }^{1213}$ Cushing, Handbook, S. 1; Egerod, S. 125

${ }^{1214}$ Zhang, S. 258-259

1215 Zhang, S. 259, 270

${ }^{1216}$ Wenk, S. 111; Zhang, S. 270. Einige Autoren sind der Ansicht, daß die Schrift Dai Nawen unter dem Einfluß der chinesischen Schrift entstanden ist (siehe British Burma Gazetteer, Vol.I, S. 23). Ob diese Vermutung zutreffend ist, bleibt fraglich, jedenfalls gelten die Dai Na als eine von chinesischer Kultur stark beeinflußte Volksgruppe, die deswegen auch ,Chinesische Dai‘ (Han Dai) genannt wird.
} 
Abbildung 5: Tabelle der vier in der VR China gebräuchlichen Alphabete der Dai

(Quelle: Zhang Gongjin, Daizu de wenzi he wenxian, S. 270)

Dai Lewen Jinping Daiwen, Dai Nawen|Dai Bengwen

\begin{tabular}{|c|c|c|c|c|c|}
\hline $\begin{array}{l}\text { 音 } \\
\text { 位 }\end{array}$ & $\begin{array}{l}\overline{3} \\
\text { 京 } \\
\text { 经 }\end{array}$ & $\begin{array}{l}\text { 渎仂文 } \\
(\uparrow 8 ヶ)\end{array}$ & 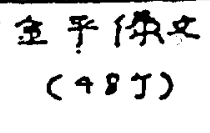 & $\begin{array}{l}\text { 侼积文 } \\
(195)\end{array}$ & $\begin{array}{r}1 \text { 乘318 } \\
(185)\end{array}$ \\
\hline$P$ & 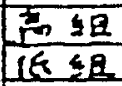 & $\frac{J}{m}$ & $\begin{array}{l}5 \\
5\end{array}$ & $u$ & $\mathcal{U}$ \\
\hline$p^{h}$ & \begin{tabular}{|l|l|}
$\overline{3} 3 R$ \\
$<5 \leqslant 8$ \\
\end{tabular} & $\sigma^{\varepsilon e}$ & $\frac{5}{5}$ & ט & CS \\
\hline$b$ & 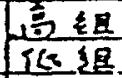 & u & $\frac{r}{m}$ & & \\
\hline$m$ & 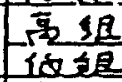 & $\frac{2}{c}$ & $\frac{u r d}{w 5}$ & $y$ & $\theta$ \\
\hline$f$ & \begin{tabular}{|l|l|}
$53 \leq 10$ \\
$15 \leq 1$
\end{tabular} & $\frac{\sigma}{5}$ & $\frac{15}{45}$ & & \\
\hline$V$ & 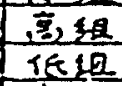 & $\frac{3}{0}$ & $\frac{\ln }{2}$ & 0 & 0 \\
\hline$t$ & \begin{tabular}{|l|l|}
$\frac{1}{n} 38$ \\
1636 \\
\end{tabular} & os 6 & $\frac{w}{w}$ & on & $\infty$ \\
\hline th & 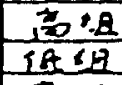 & $\begin{array}{ll}2 & 4 \\
2 & 3\end{array}$ & $\frac{4}{5}$ & $\infty$ & $\infty$ \\
\hline$d$ & \begin{tabular}{|l|}
$\frac{8}{9} 18$ \\
1038 \\
\end{tabular} & 3 & $\frac{26}{2 y}$ & & \\
\hline$n$ & 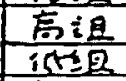 & 53 & $\frac{2 \pi}{25}$ & $\sim$ & 26 \\
\hline 1 & 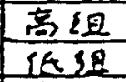 & $\sim \stackrel{a}{a}$ & $\begin{array}{l}x \\
y\end{array}$ & $\sim$ & $\eta \sim$ \\
\hline ts & 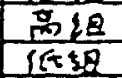 & $\begin{array}{l}0 \\
2\end{array}$ & w & 0 & ro \\
\hline $\operatorname{tsh}$ & $\frac{513}{10928}$ & & $\frac{5}{5}$ & 32 & \\
\hline 5 & 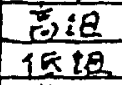 & 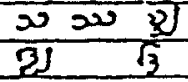 & $\frac{u^{2}}{n^{\prime}}$ & $\sim$ & 2 \\
\hline$r_{0}$ & 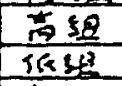 & & $\frac{n}{n x}$ & $\gamma^{\prime}$ & \\
\hline$j$ & 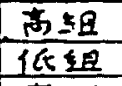 & $\frac{v}{v} v$ & & $M$ & U $\omega$ \\
\hline$K$ & 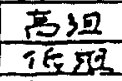 & $m$ & $\frac{n}{n}$ & 7 & $\Omega$ \\
\hline $\mathrm{Xh}$ & 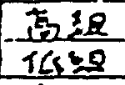 & & $\omega$ & & \\
\hline$x$ & $\frac{\cos 3 Q}{1+5 \pi}$ & ${ }_{21}^{2} \xi$ & $-\frac{9}{4}$ & 3 & $\partial$ \\
\hline$\eta$ & $\frac{3,28}{1+52}$ & $\frac{3}{9}$ & $\frac{v \pi}{6}$ & $n$ & $C$ \\
\hline$h$ & 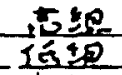 & $y$ is & $-\frac{\omega s}{n}$ & $\phi \lambda$ & $P$ \\
\hline$?$ & 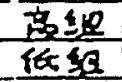 & 3 & $\frac{2}{2}$ & $r$ & 5 \\
\hline
\end{tabular}

Vergleicht man das birmanische Alphabet mit dem der ,alten Schan-Schrift‘ (Wenk; chin. Dai Bengwen), wird deutlich, daß zum einen die Cerebrale (ta, tha, da, dha, na) und la, die im Birmanischen hauptsächlich für aus dem Pali stammende Wörter verwendet werden, zum anderen in den anderen Konsonantenreihen die stimmhaften Laute (wie zum Beispiel ga und gha) fehlen (siehe Tab. 54, S. 426). 
Auch die Schreibweise der Vokale, mit Ausnahme des a, ist in beiden Schriften sehr ähnlich, ebenso können die Halbvokale ya, ra, va im Shan wie im Birmanischen direkt mit den Konsonanten verbunden werden. Beide Schriften verwenden ein Häkchen auf dem Auslaut (birman. a sat, „Töter“), um deutlich zu machen, daß das inhärente a gelöscht ist.

Tabelle 54: Die Alphabete der Birmanen und der Shan (Dai Bengwen)

\begin{tabular}{|c|c|c|c|c|c|c|c|}
\hline $\mathrm{ka}$ & kha & $g a$ & gha & $\dot{n} a$ & $\mathrm{ka}$ & kha & ña \\
\hline$m$ & $\partial$ & $\Omega$ & $v$ & $C$ & $\curvearrowright$ & $\partial$ & $c$ \\
\hline $\mathrm{ca}$ & cha & ja & jha & ñña & sa & sha & ña \\
\hline $\mathfrak{D}$ & $\infty$ & $\alpha$ & ol & ש2 & $\infty$ & כ2 & \\
\hline $\begin{array}{l}t a \\
\text { c }\end{array}$ & $\begin{array}{l}\text { tha } \\
S\end{array}$ & $\begin{array}{l}\text { da } \\
2\end{array}$ & $\begin{array}{l}\text { dha } \\
\text { v }\end{array}$ & ma & - & - & - \\
\hline ta & tha & $\mathrm{da}$ & dha & na & ta & tha & na \\
\hline$\infty$ & $\infty$ & 3 & $\theta$ & $\$$ & $\infty$ & $\infty$ & 26 \\
\hline $\mathrm{pa}$ & pha & ba & bha & ma & $\mathrm{pa}$ & pha & ma \\
\hline$U$ & $\theta$ & $\theta$ & כ & $\theta$ & $U$ & $\infty$ & $\omega$ \\
\hline ya & $r a$ & $1 \mathrm{a}$ & va & sa & ya & $\mathrm{ra}$ & la \\
\hline$\omega$ & $\eta$ & $\infty$ & 0 & 20 & $\omega$ & $\eta$ & $\sim$ \\
\hline ha & $1 a$ & $\mathbf{a}$ & & & ha & $a$ & \\
\hline מ & $\xi$ & 30 & & & 9 & ৯ & \\
\hline
\end{tabular}

Während die Birmanen und die Shan zwei völlig verschiedene, zu unterschiedlichen Sprachfamilien gehörende Sprachen sprechen, sind sich die von ihnen verwendeten Schriften sehr ähnlich. Zudem orientieren sich einige Shan-Schriften direkt am Vorbild der birmanischen Schrift, so daß Texte, allein nach dem Schriftbild beurteilt, kaum der entsprechenden Sprache zugeordnet werden können. Überdies ist zu berücksichtigen, daß es sich bei den Texten, mit denen die Übersetzer in China befaßt waren, um Handschriften handelte, bei denen der individuelle Stil des Schreibers Gemeinsamkeiten oder Unterschiede zwischen den Schriften noch verstärkte. 


\section{3. Sprache und Schrift der Yi-Nationalität}

Die Verfasser des TYTZ verbinden den Bericht von Wu Kai mit einem einleitenden Hinweis auf eine weitere in der Region gebräuchliche Sprache und Schrift (cuan wen), die des Volkes der Yi. Die Yi gehören zu den Völkern der tibeto-birmanischen Sprachgruppe. Ihre Sprache wird in verschiedene Regionalsprachen unterteilt, wobei sich besonders die in der Provinz Yunnan gebräuchlichen von den in Sichuan und Guizhou gesprochenen unterscheiden, so daß deren Sprecher sich zum Teil untereinander nicht verstehen können. ${ }^{1217}$ Die Sprachen der Yi sind monosyllabisch und tonal, mit drei bis fünf Tönen.

Die Schrift der Yi wurde früher auch Cuan-Schrift (cuan wen) oder Standardschrift (wei shu) und in der Ming- und Qing-Zeit, nach der damaligen Bezeichnung für die Yi, auch Schrift der Luoluo (luoluo wen;in westlichen Quellen als Lolo wiedergegeben) genannt. ${ }^{1218}$

Es ist eine Silbenschrift, die besonders durch ihre große Zahl von über eintausend Silben und acht- bis zehntausend Schriftzeichen gekennzeichnet ist. Diese Zeichen werden gebildet, indem eine Grundform (zum Beispiel ein Bogen oder ein ,Z‘) verändert oder ergänzt wird und dann wiederum den Ausgangspunkt für ein neues Zeichen bilden kann; die häufigsten Zeichen bestehen aus einem bis sieben einzelnen Strichen. ${ }^{1219}$

Charakteristisch für die Yi-Schrift ist die je nach Region unterschiedliche Schreibweise in waagerechten oder senkrechten Zeilen, wobei die horizontale Form als die ältere gilt, während die jüngere vertikale auf den Einfluß des Chinesischen zurückgeführt wird. ${ }^{1220}$ In vertikalen Zeilen wird von links nach rechts (hauptsächlich in Yunnan und Guizhou), in horizontalen wird hingegen von rechts nach links geschrieben (zum Beispiel in der Region Liangshan in Sichuan), außerdem werden dabei auch die einzelnen Silbenzeichen um neunzig Grad nach rechts gedreht (siehe Abb. 6, S. 428).

In neuerer Zeit werden Texte auch mit waagerechten von links nach rechts geschriebenen Zeilen verfaßt. ${ }^{1221}$

\footnotetext{
${ }^{1217}$ Ramsey, S. 249

${ }^{1218}$ Maheimuxia, S. 29

${ }^{1219}$ Coyaud, S. 32; Chen Shilin, S. 277

${ }^{1220}$ D‘Ollone, S. 15; Chen Shilin, S. 277; Rheinwald, S. 65

${ }^{1221}$ D`Ollone, S. 13, 212; Chen Shilin, S. 277; Ramsey, S. 260
} 


\section{Abbildung 6: Ein Beispiel für die Yi-Schrift}

(Quelle: D’Ollone, Ecritures des peuples non chinois de la Chine, S. 212, mit

Erläuterungen des Autors zu den verschiedenen Lesarten des Textes.)
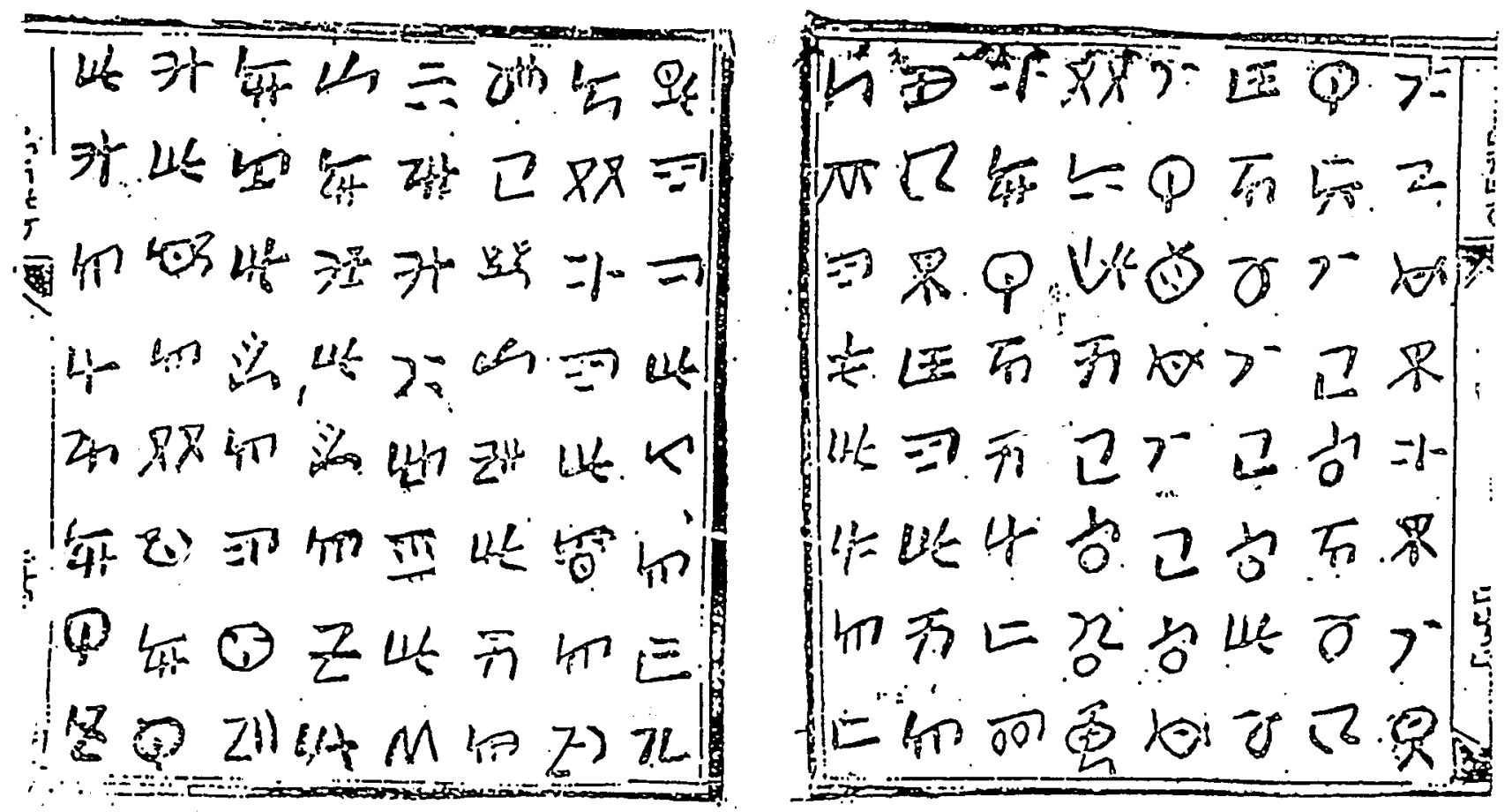

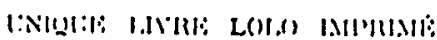

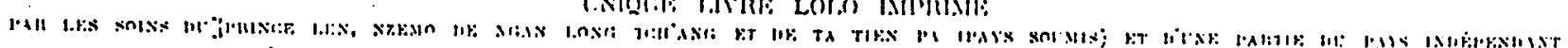

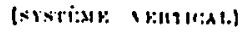

Gleichlautende Worte mit unterschiedlichster Bedeutung können in der Yi-Schrift mit dem gleichen Schriftzeichen geschrieben bzw. verschiedene homophone Zeichen für dasselbe Wort verwendet werden. ${ }^{122}$ Zudem haben die Yi auch chinesische Schriftzeichen direkt entlehnt, die meist nach phonetischen Bedürfnissen ausgewählt worden sind, seltener sind sie in der gleichen Bedeutung übernommen (tong yin jia jie; tong yi jia jie), oft sind diese entlehnten Zeichen dann noch weiter verändert worden. ${ }^{1223}$

Da die Schriftzeichen die Aussprache und nicht die Bedeutung wiedergeben, steht die YiSchrift in sehr enger Beziehung zu den lokalen Sprachen. Die unterschiedliche Entwicklung der Sprache in den verschiedenen Regionen spiegelt sich also auch in der Schrift deutlich wieder und führt dazu, daß Texte in Yi-Schrift oft nur innerhalb ihres räumlichen und zeitlichen Kontextes verstanden werden können.

\footnotetext{
${ }^{1222}$ D`Ollone, S. 16; Chen Shilin, S. 275

${ }^{1223}$ Chen Shilin, S. 276, 293
} 


\section{4. Die Entwicklung der Yi-Schrift (cuan wen) nach chinesischen Quellen}

In den Legenden der Yi wird die Erfindung ihrer Schrift jeweils auf einen ihrer Vorfahren zurückgeführt, der allerdings in den verschiedenen Siedlungsgebieten der Yi unterschiedlich benannt wird. So werden in der Provinz Yunnan Bobogeng, in Guizhou A Ji, Mi Adie, Ji Lu, Yi Awu oder Hengben‘alu als Schöpfer der Schrift bezeichnet; im Gebiet Liangshan in Sichuan gilt Ashilaze, der zu Beginn der Ming-Zeit (1368-1644) gelebt haben soll, als Begründer der Schrifttradition. ${ }^{1224}$

Chinesische Quellen nennen zumeist A Ji, einen Häuptlingssohn aus dem östlichen Yunnan, als Erfinder dieser Schrift. ${ }^{1225}$ Das chinesische Schriftzeichen, das zur Schreibung des Namens Ji verwendet wird, ist ein apokryphes Zeichen, das in den Lexika nur in diesem Zusammenhang, nämlich als Vorname des Schöpfers der Yi-Schrift, erscheint. Sei es, daß mit diesem unüblichen Zeichen der fremde Name der Person wiedergegeben werden sollte oder daß es sich um einen Schreibfehler für ein anderes Zeichen gehandelt haben mag, der sich überliefert hat.

Wie die fangzhi von Tengyue berichten auch verschiedene andere historische Quellen über A Ji, den Schöpfer der Yi-Schrift. Im dreizehnten Kapitel des Dading xianzhi aus Guizhou wird aus dem Yi shu (,Buch der $\mathrm{Yi}^{`}$ ) des An Guotai (Ming-Zeit) Folgendes zitiert:
„A Ji, [der während der ] Tang-Zeit [gelebt hat], war Stammeshäupling von Nagou, er wohnte in einer Felsschlucht und hat dort die Cuan-Schrift geschaf- fen, deren Form Kaulquappen gleicht, nach drei Jahren hatte er 1840 Ideo- gramme vollendet; [die Schrift] wird auch Standardschrift genannt“ ${ }^{1226}$

Ähnliche Berichte gibt es auch im Dian lüe von Xie Zhaozhi (Ming-Zeit), im Xinzuan Yunnan tongzhi aus der Späten Qing-Zeit, im Dianxi zazai des Shi Fan (aus dem Jahr 1817) sowie in zahlreichen Lokalhandbüchern aus dem südwestlichen China. ${ }^{1227}$ Die meisten dieser historischen Quellen stimmen darin überein, daß A Ji zur Zeit der Tang-Dynastie (618-907) gelebt hat. In den fangzhi von Tengyue und ebenso im Dianxi zazai heißt es hingegen, daß A Ji schon in der Han-Zeit (206 v. Chr. - 220 n.Chr.) gelebt hat. ${ }^{1228}$

\footnotetext{
${ }^{1224}$ Chen Shilin, S. 271-271. Ashilaze wird auch als Ashilaji bezeichnet; siehe Li, S. 304.

1225 TYTZ, S. 389 unten, Zeile 5-6; TYZZ, S. 168

${ }^{1226}$ Chen Shilin, S. 271, 273; Li, S. 304 (dort wird der Autor An Guoheng genannt). A Ji gilt auch als der Autor eines klassichen Werkes der Yi-Nationalität, des sogenannten Yi jing (Diannan zazhi, S. 420).

${ }^{1227}$ Siehe Chen Shilin, S. 272; Li, S. 304

${ }^{1228}$ Chen Shilin, S. 272; TYTZ, S. 389; TYZZ, S. 168
} 
In ihren Studien zur Schrift der Yi äußern die Autoren Chen Shilin und Li Min die Vermutung, daß A Ji möglicherweise das Verdienst zukommt, die Schriftzeichen erstmals gesammelt und geordnet zu haben. Später als die Schrift sich weiter entwickelt hatte, könnte sie dann von Ashilaze erneut standardisiert worden sein, wobei sicher auch regional unterschiedliche Entwicklungen eine Rolle gespielt haben mögen. ${ }^{1229}$ Das ist sicherlich eine Möglichkeit, die Legenden mit dem langen Entwicklungsprozeß, den diese Schrift durchlaufen hat, sowie ihren regional unterschiedlichen Formen in Einklang zu bringen. Es scheint jedoch zweifelhaft, ob sich die Anfänge der Schrift wirklich auf diese konkreten Personen zurückführen lassen, deren Existenz bisher noch nicht belegt werden konnte und über deren Lebensdaten sich schon die historischen Aufzeichnungen nicht einig sind.

Die Entstehung der Yi-Schrift in der Tang-Zeit bzw. ihre Existenz im Reich Nanzhao, das von den Vorfahren der modernen Yi beherrscht wurde, konnte bisher nicht durch archäologische Funde belegt werden, während der Gebrauch des Chinesischen in Nanzhao nachgewiesen ist.

Als Blütezeit der Yi-Schrift gilt die Ming-Zeit (1368-1644), aus der zahlreiche Dokumente in Yi-Schrift erhalten geblieben sind. ${ }^{1230}$ Das älteste erhaltene Schriftbeispiel findet sich auf einer Bronzeglocke von 1485, die ältesten erhaltenen Steininschriften stammen aus den Jahren 1533 und 1546. ${ }^{1231}$ Während der Gebrauch der Schrift einerseits mit den Veränderungen des tusi-Systems zu Beginn des 18. Jahrhunderts durch die Ablösung einheimischer Würdenträger durch Beamte der Zentralmacht (gaitu guiliu) unter Generalgouverneur Ortai (1680-1745; von 1726 bis 1731 in Südwest-China im Amt) abgenommen haben soll, weisen andererseits verschiedene Lokalchroniken auf einen weit verbreiteten Gebrauch der Yi-Schrift in der Qianlong- und Jiaqing-Zeit hin. ${ }^{1232}$ Die seltenere Verwendung der YiSchrift, die zeitgenössische chinesische Autoren bemerkt haben, bezieht sich dabei wahrscheinlich nur auf offizielle Schriftstücke, die nach der Ablösung einheimischer tusi durch chinesische Beamte nicht mehr benötigt wurden, während die Yi selbst natürlich weiterhin ihre eigene Schrift verwendeten.

Was nun die Anzahl der standardisierten Yi-Schriftzeichen betrifft, so sprechen die oben genannten Quellen teilweise von 1840 Zeichen, teilweise nennen sie, wie die fangzhi von

\footnotetext{
${ }^{1229}$ Chen Shilin, S. 276; Li, S. 304

${ }^{1230}$ Li Min, S. 305

${ }^{1231}$ Chen Shilin, S. 278

${ }^{1232}$ Ebd., S. 277
} 
Tengyue, sogar 10840 Zeichen. Li Min erklärt den Ausdruck shiqian (zehntausend) schlicht als Schreibfehler für die korrekte Form des Ausdrucks yiqian (eintausend). ${ }^{1233}$

Über die historische Entwicklung der Anzahl der Schriftzeichen ist bisher jedoch kaum etwas bekannt. Es scheint allerdings wenig wahrscheinlich, daß bereits in der Han- oder Tang-Zeit, für die noch nicht einmal die Existenz einer Yi-Schrift nachgewiesen werden konnte, über zehntausend Zeichen existiert haben sollen. Die Gesamtzahl der Schriftzeichen der Yi beläuft sich heute tatsächlich auf etwa acht- bis zehntausend Zeichen, die vermutlich aber erst in der Ming-Zeit entstanden sind, als der Gebrauch der Yi-Schrift stark zugenommen hatte.

Zur Vereinheitlichung der verschiedenen Schriften und zur Reduzierung der Anzahl der Schriftzeichen wurde in der Volksrepublik China im Jahr 1975 eine aus 819 Silbenzeichen bestehende Standardschrift für die Yi-Sprache eingeführt. ${ }^{1234}$

\section{5. Die Beschreibung der ,Schriften der Fremden` im TYTZ}

Während es sich bei dem Birmanischen und dem Shan um Sprachen verschiedener Sprachfamilien mit ähnlichen Schriftsystemen handelt, gehören Birmanisch und Yi zwar beide zu der tibeto-birmanischen Sprachfamilie, wobei Yi dem Birmanischen näher steht als dem Tibetischen, sie verwenden jedoch ganz unterschiedliche Schriftsysteme. ${ }^{1235}$

Beide Schriften, Birmanisch und Yi, werden nun im TYTZ dadurch charakterisiert, daß die Form ihrer Schriftzeichen mit Kaulquappen verglichen wird (xing ru kedou).

Die Kaulquappen-Schrift (kedou shu oder kedou wen) ist eine alte chinesische Schriftform, bei der der ,Kopf‘ eines Schriftzeichens dick und sein ,Schwanz‘ dünn ist, so daß die Form des Zeichens einer Kaulquappe gleicht. In der Wei- und Jin-Zeit war sie besonders verbreitet und wurde, nach einer im Sanzi shujing (3. Jh.) verwendeten Schrift, auch guwen genannt. ${ }^{1236}$ Kedou shu oder Kedou wen bezeichnet darüberhinaus auch alte Schriften, die mit Lack auf Bambus- oder hölzerne Schrifttafeln geschrieben wurden: Beim Aufsetzen des Pinsels kam viel Lack auf die Schreibfläche, dieser lief zum Ende des Schriftzeichens hin dünner aus, so daß die Form des Zeichens einer Kaulquappe ähnelte.

\footnotetext{
${ }^{1233}$ Li Min, S. 304

${ }^{1234}$ Ramsey, S. 261; siehe Coyaud, S. 43 (Tabelle).

1235 Ramsey, S. 249

${ }^{1236}$ Feifel weist darauf hin, das die vor der Qin-Zeit gebräuchliche Schrift (guwen) als Kaulquappenschrift (kedou wenzi) bezeichnet wurde (Feifel, S. 93).
} 
Als Kaulquappenschrift (kedou shu oder kedou wen) wird also allgemein eine Schrift mit ungleichmäßiger Strichführung (,dicker Kopf und dünner Schwanz') bezeichnet. Sowohl die Yi- als auch die birmanische (und die Shan-) Schrift werden mit Stiften, nicht mit dem Pinsel geschrieben bzw. geritzt und weisen daher eine insgesamt eher gleichmäßige Strichführung auf.

Im Birmanischen und im Shan werden die Silben aus den einzelnen Buchstaben zusammengesetzt und die Worte im Satz in horizontalen Zeilen von links nach rechts ohne Zwischenräume nebeneinandergestellt. Jedes Zeichen der Yi-Schrift hingegen repräsentiert eine Silbe; die einzelnen Silben werden mit Abständen in horizontalen oder vertikalen Zeilen angeordnet und weisen ein dem chinesischen sehr ähnliches Schriftbild auf. Vergleicht man nun die Zeichen der Yi-Schrift mit denen der chinesischen guwen-Schrift, so weisen einige Schriftzeichen der Yi eine große Ähnlichkeit mit dieser alten Schrift auf, besonders mit den aus wenigen Strichen bestehenden guwen-Schriftzeichen. Hinzu kommt, daß die Yi auch chinesische Zeichen in ihre Schrift übernommen haben, so daß sich Chinesen beim Betrachten der Yi-Schrift durchaus an archaische Formen der eigenen Schrift erinnerten.

Li Min bezeichnet die Yi-Schrift entsprechend als eine zwischen Siegel- und Kanzleischrift (zhuanshu und lishu) stehende Schriftform, während Chen Shilin vermutet, daß es sich bei der Kaulquappen ähnelnden Schriftform höchstens um eine in Vergessenheit geratene Form der Yi-Schrift handeln könne, da die bisher bekannten Beispiele sämtlich eine gleichmäßige Strichführung aufwiesen; Ähnlichkeiten mit alten chinesischen Schriftformen erwähnt Chen jedoch in diesem Zusammenhang nicht. ${ }^{1237}$

Auch die Verfasser der fangzhi von Tengyue stellen, abgesehen von dem indirekten Hinweis auf archaische Schriftformen, der in der Erwähnung der Kaulquappen-Form mit enthalten ist, keine Verbindung zwischen den Schriftzeichen der Yi und den chinesischen Zeichen her. Aber sie setzen die ,Schriften der Fremden“ in Beziehung zueinander. In dem oben zitierten Bericht heißt es vor der Beschreibung der Yi-Schrift in einem einleitenden Satz, daß die Shan ihre Schriften nach dem Vorbild der Yi-Schrift (cuan wen) geschaffen haben. Diese Bemerkung erweckt den Eindruck, als ob diese beiden Schriften in engem Zusammenhang stehen und somit auch die birmanische Schrift, die sich zwar von den Shan-Schriften unterscheidet (mian zi yu baiyi zi bu tong), jedoch nur in geringem Maße, da man sie ja leicht mit jenen verwechseln kann. Folglich legt der Text die Vermutung

${ }^{1237}$ Li Min S. 304; Chen Shilin S. 273 
nahe, daß sowohl die Shan als auch die Birmanen ihre Schrift von den Yi entlehnt haben. Weitere Erläuterungen dieser Vermutung gibt es jedoch nicht. Es bliebe zu prüfen, in wie weit diese These auch in anderen zeitgenössischen und historischen Werken, die sich mit den Schriften der verschiedenen Völker in der Provinz Yunnan beschäftigen, vertreten worden ist und ob auch andere Klassifizierungen der betreffenden Schriften vorgenommen worden sind.

Da die oben ausgeführten Unterschiede des Schriftsystems der Yi zu denen der Shan und Birmanen deutlich gemacht haben, daß sie von Herkunft und Form her völlig verschieden sind, kann man den Verfassern der fangzhi von Tengyue wohl eine undifferenzierte Betrachtung der fremden Schriften vorhalten bzw. eine reine Zusammenstellung von Zitaten ohne eigene Kenntnis des Sachzusammenhanges. Das mag auch daran gelegen haben, daß in Tengyue die Schrift der weiter im Norden in abgelegeneren Gebieten ansässigen Yi kaum bekannt gewesen sein dürfte, während sich die Verwaltung der Unterpräfektur mit den Sprachen und Schriften der Birmanen und Shan häufig auseinandersetzen mußte, da der Austausch von Dokumenten mit diesen Nachbarn für die chinesische Politik im Grenzgebiet von großer Bedeutung war.

\section{Birmanische-Manuskripte}

In Birma waren traditionell zwei Arten von Manuskripten gebräuchlich: Palmblatt-Manuskripte (birman. pe ca) und Faltbücher aus Papier, die sogenannten Parabaik (birman. pura puik, gesprochen parabaik). ${ }^{1238}$

In ihrer Verwendung unterschieden sich Palmblatt-Manuskripte und Parabaik darin, daß Palmblätter für religiöse, literarische, wissenschaftliche und andere wichtige Texte, sowie Briefe und Horoskope verwendet wurden, während Faltbücher für Notizen, Verwaltungsdokumente aber auch für Briefe benutzt wurden. ${ }^{1239}$

Eine weitere Art von Manuskripten, die in chinesischen Quellen erwähnt werden, sind auf Goldblätter geschriebenen Texte (jinye biaowen; jinye mianwen), die neben den Elefanten und den goldenen Pagoden ein typisches Tributgeschenk der Birmanen waren, wie sie zum Beispiel von den Gesandtschaften an den chinesischen Kaiserhof in den Jahren 1788 und 1790 übergeben worden sind. ${ }^{1240}$

\footnotetext{
${ }^{1238}$ Bechert/Su/Myint S. XVII. Der Buchdruck wurde in Birma erst im 19.Jahrhundert eingeführt und besonders von den Missionaren, wie dem amerikanischen Baptisten-Missionar Adoniram Judson, der 1816 eine Druckerpresse mit birmanischen Drucktypen besaß, gefördert (Clair, S. 81).

${ }^{1239}$ Bechert/Su/Myint S. XVII

${ }^{1240}$ TYTZ, S. 245, S. 277, siehe auch S. 23; TYZZ, S. 161,162
} 
Dabei handelt es sich in der Regel um vergoldete Manuskripte, deren Seiten hergestellt wurden, indem man alte Mönchsroben oder andere aus geeigneten faserigen Materialien bestehende Dinge, die als heilig galten und deswegen nicht weggeworfen werden durften, zerkochte und aus der so entstandenen Paste, ähnlich wie bei der Papierherstellung (s.u. 3.4.), eine Schreibseite, deren Form einer Palmblattseite glich, herstellte. Anschließend wurde jede Seite mit einer Mischung aus Lack und Blattgold überzogen und dann mit schwarzem Lack beschrieben.

\section{1. Palmblatt Manuskripte}

Der Gebrauch von Palmblatt-Manuskripten geht in Birma etwa auf das 8. Jahrhundert zurück, als noch die Pyu das Land beherrschten. ${ }^{1241}$ Für das erste birmanische Reich von Pagan dokumentieren Inschriften aus dem 13. Jahrhundert die Verwendung zweier Arten von Palmblättern für Manuskripte, die bis in die Gegenwart hinein gebräuchlich waren. ${ }^{1242}$

Zum einen wurden die Blätter der Palme Corypha umbraculifera (birman. pe) verwendet, zum anderen die der Borassus flabellifer (birman. thanh; abgeleitet von Sanskrit/Pali tala). Beide Palmen gehören zu der Familie der Coryphoideae; der Typus Corypha umbraculifera Linnaeus (Gattung: Corypha Linnaeus) gehört zu der Klasse der Corypheae, der Typus Borassus flabellifer Linnaeus (Gattung: Borassus Linnaeus) hingegen zur Klasse der Borasseae. ${ }^{1243}$ Die Corypha-Palmen sind unter anderem in Süd- und Südwestchina und Birma beheimatet; die Borassus ist eine der am weitesten verbreiteten Palmengattungen, deren Unterarten auch in Indien und Südostasien zu finden sind. ${ }^{1244}$ Sie können beide bis zu dreißig Meter hoch werden und gehören zu den Fächerpalmen, das heißt, ihre Blattspreite sind fächerförmig gestaltet, die einzelnen Fächerstrahlen sind von einem Zentrum aus gespreizt, wie die Finger einer Hand. ${ }^{1245}$

Die Corypha umbracolifera (auch Talipotpalme genannt) und die Borassus flabellifer (auch Toddy-, Lontar- oder Palmyrapalme genannt) bieten zahlreiche Nutzungsmöglichkeiten. ${ }^{1246}$ Das Holz der Borassus wird zum Bauen verwendet, aus den Früchten und Fruchtständen werden Nahrungsmittel und Palmwein gewonnen. ${ }^{1247}$ Aus den Blattfasern beider

\footnotetext{
1241 Maung Wun S. 224

${ }^{1242}$ Maung Wun S. 224

${ }^{1243}$ Uhl/Dranslield, S. 161, 162, 207, 222

${ }^{1244}$ Uhl/Dransfield, S. 191, 207, 208; Uhl/Dransfield, S. 217, 224

1245 Lötschert, S. 23-24; Uhl/Dransfield, S. 07, 222, 331

${ }^{1246}$ Uhl/Dransfield, S. 208, 224

${ }^{1247}$ Lötschert, S. 74
} 
Palmen werden Körbe oder Matten geflochten, Regenschirme hergestellt oder sie werden eben als Schreibmaterial verwendet. ${ }^{1248}$

Während Palmblatt ein für Birma typisches Schreibmaterial ist, sind Palmblattmanuskripte der Shan eher selten, da in den nördlichen Shan-Staaten aufgrund der klimatischen Bedingungen keine Palmen wachsen. Bekannt sind Palmblatthandschriften nur von den weiter südlich in Xishuangbanna lebenden Dai. ${ }^{1249}$

\section{2. Zur Herstellung von Palmblatthandschriften}

Die Blätter der Palmen werden in Streifen von der Größe einer Seite geschnitten, dann gekocht, getrocknet und geglättet. Danach können die Buchstaben mit einem eisernen Griffel (birman. ka ññac) eingeritzt werden. ${ }^{1250}$ Anschließend wird eine Mischung aus Holzkohle und Baumharz (birman. an tvai; vom Baum Dipterocarpus tuberculatus gewonnenes Harz) aufgetragen und bis auf die Farbe, die sich in den Ritzen festgesetzt hatte, wieder abgewischt, so daß sich die Buchstaben nun dunkel von dem Palmblatt abheben. ${ }^{1251}$ Die übereinandergelegten Manuskriptseiten werden dann zwischen zwei hölzerne Deckel gelegt und mit einer Schnur, die durch zwei Löcher in der Mitte der Einzelblätter gezogen wird, zusammengebunden.

\section{3. Parabaik}

Die zweite traditionelle Form für Manuskripte in Birma sind die Faltbücher (Leporellos; birman. pura puik). Sie sind seit dem Beginn der Pagan-Zeit (11. bis 13.Jahrhunder) bekannt. ${ }^{1252}$ Parabaik werden im allgemeinen aus Papier hergestellt, selten auch aus Leder, Gold- oder Silber(-folie). Parabaik ist auch die typische Manuskriptform der Shan-Staaten, dort verwendete man traditionell hauptsächlich die Rinde des Papiermaulbeerbaumes (Broussonetia papyrifera; birman. cakku hlyo); in Birma wurde das Papier meist aus der Rinde des sa rak khyañ-Baumes hergestellt. ${ }^{1253}$

\footnotetext{
${ }^{1248}$ Lötschert, S. 74; Uhl/Dransfield, S. 208, 224

1249 Zhang, S. 260

${ }^{1250}$ Maung Wun S. 224-225; Quigly S. 30

1251 Judson S. 26; Maung Wun S. 224-225

${ }^{1252}$ MCK, Su S. 284

${ }^{1253}$ Maung Wun S. 226-227; MHCD, S. 959
} 


\section{4. Zur Herstellung von Parabaik}

Das Papier für Faltbücher wurde in Birma und den Shan-Staaten traditionell auf dieselbe Weise wie in China hergestellt. Zuerst wurde die Baumrinde mit Wasser zu einer Paste verkocht,danach wurde die entstandene breiige Masse in einen Bottich mit Wasser geleitet, auf dessen Oberfläche sie schwamm. Eine dünne Schicht konnte dann auf einem hölzernen, mit einem Baumwolltuch bespannten Rahmen geglättet, aus dem Wasser genommen und getrocknet werden. Danach ließ sich der Papierbogen leicht von dem Rahmen lösen. ${ }^{1254}$ Einzelne Bögen wurden zunächst zu Seiten gefaltet, dann wurden mehrere gefaltete Bögen zur gewünschten Länge zusammengeklebt und die oberste und unterste Seite an zwei Buchdeckeln festgeleimt.

Nach der Farbe des Papieres werden zwei Arten von Parabaik unterschieden: Schwarze Parabaik (birman. pura puik nak), die hauptsächlich als Notizbücher verwendet wurden, und weiße Parabaik (birman. pura puik phyu), die eher für Reinschriften gebräuchlich waren. $^{1255}$

Als Schreibmaterial wurde für weiße Parabaik Tinte oder Holzkohle und in neuerer Zeit auch Bleistift verwendet. Auf schwarze Parabaik schrieb man mit Talk oder Speckstein oder man verwendete Kreidestaub, der mit dem Harz des Zedrachbaumes (Melia azedarach, birman. ta ma) vermischt wurde. Geschrieben wurde mit Pinsel oder einem aus Schilf hergestellten Füller (birman. khon tam). ${ }^{1256}$ Die Seiten sind in Birma und den Shan-Staaten mit horizontalen Zeilen beschrieben und werden beim Lesen nach oben umgeblättert.

In China wurden Faltbücher, in der Form der Sutra- (jingzhe zhuang oder fanjia zhuang) oder der Wirbelwind-Bindung (xuanfeng zhuang), seit Mitte des neunten Jahrhunderts zuerst für buddhistische Texte verwendet. ${ }^{1257}$ Als fanjia wurden ursprünglich die indischen Palmblattmanuskripte bezeichnet, deren Einzelblätter übereinandergelegt, zwischen zwei hölzerne Deckblätter geklemmt und mit einer Schnur zusammengebunden wurden. Der Name dieser Art von Manuskriptbindung (fanjia) etablierte sich dann auch für die Papierfaltbücher (fanjia zhuang). ${ }^{1258}$

\footnotetext{
${ }^{1254}$ Milne, Shans, S. $175-176$

1255 MCK, Su S. 285, 289; Maung Wun, S. 228

${ }^{1256}$ Maung Wun S. 228-229; MCK, Su S. 287

${ }^{1257}$ Liu/Zheng, S. 79-80

${ }^{1258}$ Tsien, S. 230
} 


\title{
3. 5. Die Beschreibung birmanischer Manuskripte von Wu Kai
}

Als Wu Kai im Jahr 1770 das Amt des Unterpräfekten von Tengyue antrat, war der Krieg zwischen China und Birma soeben mit der Unterzeichnung eines Friedensvertrages beendet worden. Wu Kai hatte zuvor an einem Feldzug in birmanisches Gebiet teilgenommen und sammelte, wie er in seinem oben zitierten Bericht erläutert hat, auch in seinem neuen Amt persönlich Erfahrungen mit fremdsprachlichen Dokumenten, so daß er die beiden Arten von birmanischen Manuskripten aus eigener Anschauung beschreiben konnte:

\begin{abstract}
„Jedesmal, wenn Gesandte der Birmanen angekommen waren, übergaben sie birmanische Dokumente, die in Blätter graviert waren oder sie benutzten dunkles Papier, dessen Rückseiten geschichtet und in brettartige [Deckel] eingepaßt war. Sie verwenden Kreide und Harz zum Schreiben“. ${ }^{1259}$
\end{abstract}

Wu Kai beschreibt die Materialien, mit und auf denen geschrieben wurde; zum einen wurde mit Kreide und Harz auf dunklem gefalteten Papier geschrieben (weiße Parabaik erwähnt er nicht), zum anderen in Blätter graviert. Zur Benennung dieser Blätter verwendet er den Ausdruck puye (eigentlich ,Binsenblatt`). Puye ist als Bezeichnung für birmanische Dokumente in chinesischen Quellen allgemein gebräuchlich. So wird zum Beispiel in einem Bericht des Generalgouverneurs der Provinzen Yunnan und Guizhou, Jueluo Tuside, ein Schreiben aus Birma (puye mianbing) aus dem Jahr 1777 erwähnt und in der Beschreibung Birmas im fünfzehnten Kapitel des TYTZ ein puyeshu aus Birma aus dem Jahr 1768. ${ }^{1260}$ Ein anderes puyeshu (mit 136 Seiten) wurde von dem tusi Biaogeding überreicht und fortan in Tengyue aufbewahrt. ${ }^{1261}$

$\mathrm{Pu}$ wird allgemeinen mit ,Binse‘ übersetzt, konkreter bezeichnet es auch den breitblättrigen Rohrkolben (huangxiangpu, Typha latifolia). Wie oben ausgeführt, verwenden die Birmanen für ihre Manuskripte jedoch keine Binsen- sondern ausschließlich Palmblätter.

Es ist unwahrscheinlich, daß Wu Kai, der die anderen Schreibmaterialien korrekt beschrieben hat, nicht gewußt haben soll, daß die birmanischen Manuskripte auf Palmblättern geschrieben waren, sondern statt dessen annahm, es wären Binsen verwendet worden.

Die Bezeichnung puye steht in diesem Zusammenhang vermutlich als Abkürzung für pukuiye. Pukui ist der chinesische Name der Livistona chinensis, einer Palmenart, die ebenfalls zur Familie der Coryphoideae und wie die Corypha umbraculifera zur Klasse der

\footnotetext{
1259 TYTZ, S. 389, Zeile 8-9.

${ }^{1260}$ National Palace Museum, Secret Palace Memorials of the Ch`ien-Lung Period (oct.1774-apr.1777), Bd. 37, S. 643; TYTZ, S. 244 unten, Zeile 11

${ }^{1261}$ TYTZ, S. 259, 361. Der Herkunftsort des tusi wird nicht genannt.
} 
Corypheae gehört. ${ }^{1262}$ Die Livistona chinensis ist in Zentral-, Südchina und in Birma beheimatet, sie wird bis zu fünfzehn Meter hoch und gehört zur Gruppe der Fächerpalmen. ${ }^{1263}$ Ihre Früchte sind eßbar; die Blätter werden zum Dachdecken oder für die Herstellung von Regenschirmen verwendet; eine Nutzung als Schreibmaterial ist nicht typisch. ${ }^{1264}$ Wahrscheinlich hat diese Palme, deren Verbreitungsgebiet sich in China und Südostasien mit dem der Corypha umbraculifera überschneidet (während die Gattung der Borassus in China selten ist) und deren Blätter ebenfalls fächerförmig sind, den Manuskripten ihren Namen gegeben, da die chinesischen Autoren die geringen Unterschiede der beiden ähnlichen Palmen nicht so differenziert beurteilt haben. ${ }^{1265}$

Die Verwendung einer weiteren Palmblattart für die Herstellung von Dokumenten wird im Bericht über Birma in der offiziellen ,Geschichte der Yuan-Dynastie‘ (Yuan shi) erwähnt:

„Diejenigen, die ihre Schriften überreichen, verwenden auf Goldblätter Geschriebenes, manchmal verwenden sie Papier, manchmal benutzen sie auch die Blätter der Areca-Palme ( qi wenzi jinshangzhe yong jinye xie zhi ci yong zhi you ci yong binglangye)“. ${ }^{1266}$

Anders als die bisher genannten Palmenarten gehört die Arecapalme (auch Betelnuß- oder Katechupalme genannt;chin. binglang; birman. kvamh sih pan) zur Familie der Arecoideae und ist eine Fiederpalme, das heißt die einzelnen Blättchen stehen von einer Mittelrippe ab, ähnlich wie eine Vogelfeder. ${ }^{1267}$ Sie ist in Birma und Südchina weit verbreitet, ihre Samen werden gekaut und zur Herstellung von Arzneimitteln verwendet; die Nutzung als Schreibmaterial ist nicht bekannt und für Fiederpalmen insgesamt nicht typisch. ${ }^{1268}$ Die Arecapalme wurde hier sicher mit einer der anderen zur Herstellung von Schreibmaterial verwendeten Palmen verwechselt.

Das Schriftzeichen pu, mit dem Wu Kai die birmanischen Manuskripte bezeichnet, wird von den Chinesen auch für die Wiedergabe des Namens der birmanischen Hauptstadt vom

\footnotetext{
1262 Uhl/Dransfield, S. 162, 169

${ }^{1263}$ Lötschert, S. 109, 110; Uhl/Dransfield, S. 192

${ }^{1264}$ Uhl/Dransfield, S. 192

${ }^{1265}$ Uhl/Dransfield, S. 191, 207, 550

${ }^{1266}$ Yuan shi, Kapitel 210, liechuan 97, S.1, Zeile 6-7. Siehe auch TYTZ, S. 244 oben, Zeile 13-14.

${ }^{1267}$ Lötschert, S. 24, 67; Uhl/Dransfield, S. 415

${ }^{1268}$ Lötschert, S. 67
} 
11. bis zum 13. Jahrhundert, Pagan (birman. Pugam; chin. Pugan), verwendet. Zu dieser Zeit sind Palmblattmanuskripte in Birma bereits seit langem gebräuchlich gewesen und waren wahrscheinlich auch in China bekannt; sei es, daß sie von den Gesandtschaften König Kyanzitthas (1084-1112) überreicht wurden oder daß sie später bei der Eroberung Birmas durch die Mongolen im 13. Jahrhundert nach China gelangt waren.

Die Bezeichnung der Palmblatt-Manuskripte aus Birma als puye kann sich somit auch auf den zeitgenössischen Begriff ,Pugan ye‘ (,Blätter aus Pagan`) beziehen und später abgekürzt als Fachausdruck für diese Manuskripte überliefert worden sein.

Der birmanische Fachausdruck für die Palmblatt-Manuskripte (pe ca) wird mit dem chinesischen Ausdruck beiyeshu übersetzt. Beiye oder beiduoluoye sind die phonetischen Transkriptionen von Sanskrit pattra (,Blatt'); duoluoshu ist die chinesische Bezeichnung für Sanskrit tala (Fächerpalme, Borassus flabellifer, auch Corypha umbraculifera; Sanskrit talapattra: ,Palmblatt`).

So schreibt schon der chinesische Indienpilger Xuan Zang (596-664), daß in Südindien die Blätter des duoluoshu als Schreibmaterial verwendet werden. ${ }^{1269}$ Und in der Ming-Zeit erläuterte Wang Shichen (1526-1590), daß im Ausland die Blätter des beiduo-Baumes als Schreibmaterial verwendet werden. ${ }^{1270}$ In der offiziellen Geschichte der Ming-Zeit wird vom Erhalt eines Palmblattmanuskriptes (beiye mianwen) zur Zeit der Ära Wanli (15731620) berichtet; auch in der Darstellung der historischen Entwicklung Birmas im TYTZ wird ein beiye mianwen aus dem Jahr 1573 erwähnt. ${ }^{1271}$ Ebenso wird im Diannan zazhi die Übersendung eines beiyeshu durch den birmanischen König Hsinbyushin (1763-1776) an den Kaiserhof beschrieben. ${ }^{1272}$

In China waren auf Palmblatt geschriebene buddhistischer Texte aus Indien seit alters her bekannt: Die Begriffe beiyeshu oder beiyejing sind seit der Tang-Zeit gebräuchliche Bezeichnungen für den buddhistischen Kanon. Daß auf Palmblatt (beiye) geschriebene buddhistische Texte aus Birma auch in der Qing-Zeit in China bekannt waren, macht ein Gedicht von Wang Yaoqu deutlich. In seiner Serie von zehn Gedichten, in denen er

\footnotetext{
1269 Pan, S. 151; Xuan Zang, S. 889

${ }^{1270}$ Wang Shichen, S. 875 unten, Zeile 3-5

${ }^{1271}$ Ming shi, Kapitel 315, Yunnan tusi san: Miandian, S. 4, Zeile 3-4; Imbault-Huart, S. 142-143; TYTZ S. 243 unten, Zeile 14.

${ }^{1272}$ DNZZ, Kap. 6, S. 243
} 
verschiedene Volksgruppen im Grenzgebiet der Unterpräfektur Tengyue charakterisiert, beginnt das Gedicht über die Birmanen mit den Worten:

„Goldene Schriftzeichen glänzen auf dem Palmblatt-Kanon (Beiye zhuang jing jin zi guang)“. 1273

Die Beispiele zeigen, daß neben den allgemeinen Bezeichnungen für birmanische Schriftstücke (mianbing oder mianzi bingtie) auch noch weitere Begriffe (beiye oder puye) zur Beschreibung der Manuskripte verwendet wurden und daß sich die Verwendung dieser Begriffe teilweise überschnitt.

So war die Bezeichnung bei in chinesischen Quellen generell für buddhistische Texte gebräuchlich, selten wurde sie auch für andere wichtige Dokumente (beiyeshu) verwendet. ${ }^{1274}$ Der Begriff $p u$ wurde hingegen lediglich für Schriftstücke nicht religiösen Inhalts, wie Schreiben, die der direkten Kommunikation zwischen beiden Ländern dienten, verwendet (so z.B. in dem Bericht von Jueluo Tuside aus dem Jahr 1777).

\section{Kanzleipraxis}

Die Beschäftigung mit Fremdsprachen war in China seit dem Altertum hauptsächlich von politischen Interessen bestimmt und somit vor allem eine Sache des Verwaltungsapparates, der im Umgang mit den verschiedenen Völkern innerhalb und außerhalb des chinesischen Reiches Dolmetscher und Übersetzer benötigte, die eine Kommunikation erst ermöglichten. Interesse an den fremden Sprachen an sich gab es kaum, zumal die Kulturen vieler Nachbarvölker Chinas weniger weit entwickelt waren, besonders im Hinblick auf die lange Schrifttradition Chinas. Schon in vorchristlicher Zeit waren bedeutende literarische Werke entstanden, deren Kenntnis zum Kriterium für Kultur schlechthin geworden war. Andere Völker, die noch nicht einmal eine eigene Schrift besaßen, mußten da zwangsläufig als ,Barbaren` erscheinen und boten den Chinesen wenig Anreiz, sich mit ihrer Kultur oder Sprache zu beschäftigen. ${ }^{1275}$

\footnotetext{
1273 TYZZ, S. 213

${ }^{1274}$ Siehe Diannan zazhi, S. 243

${ }^{1275}$ Ein Beispiel für die intensive Auseinandersetzung mit einer Fremdsprache außerhalb von Verwaltungsstrukturen ist die Rezeption des Buddhismus, die seit dem dritten nachchristlichen Jahrhundert mit einer regen Übersetzertätigkeit der buddhistischen Texte hauptsächlich aus dem Sanskrit verbunden war und an der sowohl Chinesen als auch Übersetzer aus Zentralasien beteiligt waren.
} 
Während die Kenntnis fremder Sprachen unter den chinesischen Dynastien hauptsächlich im Umgang mit Tributgesandtschaften und in außenpolitischen Angelegenheiten benötigt wurde, kam unter den beiden Fremddynastien, die ganz China beherrschten, den Yuan und den Qing, noch ein weiterer Aspekt hinzu. Sowohl die Mongolen als auch die Mandschu machten ihre eigene Sprache zur offiziellen Staatssprache, was wiederum hauptsächlich für den Verwaltungsapparat relevant war. In der Yuan-Zeit mußten alle wichtigen Dokumente und Eingaben sowohl der Zentralregierung als auch der Provinzverwaltungen in Mongolisch geschrieben und mit einer chinesischen Übersetzung versehen werden, so daß Übersetzer beschäftigt werden mußten, die die an den Verwaltungsapparat gestellte Forderung nach Dokumenten in verschiedenen Sprachen erfüllen konnten. Als Dolmetscher und Übersetzer waren vor allem Zentalasiaten, Jurchen oder auch Nordchinesen tätig. ${ }^{1276}$ Unter der Herrschaft der mandschurischen Qing-Dynastie erreichte der Vielvölkerstaat China seinen größten Umfang.Die engere Einbindung zentralasiatischer Gebiete (Xinjiang) oder auch Tibets in die Verwaltungsstrukturen spiegelte sich auch in der Verwaltungspraxis wieder, wo Dokumente nicht nur in Mandschurisch und Chinesisch, sondern auch in Uighurisch, Tibetisch und Mongolisch abgefaßt wurden. ${ }^{1277}$

\section{1. Das Siyiguan und das Huitongguan}

Die Übersetzungsbüros in der Hauptstadt des chinesischen Reiches entwickelten sich in engem Zusammenhang mit den Herbergen für Tributgesandtschaften, wie sie schon in der Han-Zeit bestanden hatten. Diese übernahmen zunächst die Organisation von Audienzen für die Gesandten, wie z.B. das in der Sui-Zeit (581-618) gegründete Sifangguan (,Herberge [für Fremde, die aus den] vier Himmelsrichtungen [kommen]`) und wurden allmählich zu Büros, die mit der Übersetzung von Dokumenten beschäftigt waren und die das Personal, das sie für die Kommunikation mit den Fremden benötigten, auch selbst auszubilden begannen. ${ }^{1278}$ Mit der Zunahme der Tätigkeiten entstanden reine Übersetzungsbüros, neben anderen, die für die Unterbringung der Gesandten zuständig waren. So gründeten die Song im Jahr 993 ein Sifangguan in Kaifeng, das Übersetzer beschäftigte, die mit der Bearbeitung von Eingaben und der Organisation von Audienzen befaßt waren, sowie verschiedene andere Institutionen, die für die Unterbringung der Ausländer einzelner Länder zuständig

\footnotetext{
${ }^{1276}$ Endicott-West, S. 84-85

${ }^{1277}$ Im Alltag übernahmen die Mandschus im Laufe der Zeit immer mehr Elemente der chinesischen Kultur, die chinesische Sprache begann die mandschurische zu verdrängen, deren Verfall auch Anordnungen des Kaisers Qianlong (17361796), mit der Aufforderung, das Studium des Mandschurischen zu fördern, nicht mehr aufhalten konnten (Lui, S. 18). ${ }^{1278}$ Pelliot, S. 208, 216-217
} 
waren, wie z.B. das im Jahr 1007 gegründete Huaiyuanyi für Gesandte aus dem Süden und Westen. ${ }^{1279}$

Erst das Siyiguan, das ,Amt [für die Angelegenheiten der] Fremden aus den vier [Himmelsrichtungen]‘, der Ming-Dynastie war vor allem eine Schule für die Sprachen und Schriften der Fremden, sowie ein Übersetzungsbüro, das Personal ausbildete, welches im Umgang mit den zahlreichen Tributgesandtschaften benötigt wurde. ${ }^{1280}$ Denn die Gesandten führten nun immer häufiger auch Schriftstücke mit sich, während in früheren Zeiten viele der Nachbarvölker Chinas noch keine eigenen Schriften hatten. So hatte beispielsweise die Entwicklung der birmanischen Schrift erst gegen Ende des 11. Jahrhunderts, die der Shan-Schriften erst etwa im 13. Jahrhundert begonnen.

Im Jahr 1407 war das Ritenministerium vom Kaiser beauftragt worden, achtunddreißig Studenten des Guozijian auszuwählen, diese der Hanlin-Akademie zu unterstellen, sie schriftliche Übersetzungen üben zu lassen und für ihre Unterbringung in der Hauptstadt eine Schule (guan) einzurichten. ${ }^{1281}$ Später wurden auch Studenten aus Beamten- und Gelehrtenfamilien nach Ablegung einer Prüfung in das Siyiguan aufgenommen. ${ }^{1282}$

Der Lehrplan sah für die Übersetzer-Studenten (yizisheng) hauptsächlich das Auswendiglernen von Vokabeln (zazi) vor, erst in Jahr 1548 wurde auch das Studium von Edikten (chi yu) und Schreiben (laiwen) zur Pflicht. ${ }^{1283}$ Die Studenten, die zwei abschließende Prüfungen bestanden, erhielten den Titel eines Übersetzer-Beamten (yiziguan); Studenten, denen dies nicht sogleich gelang, hatten die Möglichkeit, die Prüfungen, die das Übersetzen einzelner Vokabeln in die Fremdsprache zum Inhalt hatten, noch zweimal zu wiederholen. ${ }^{1284}$

Als Lehrer (jiaoshi) am Siyiguan waren im 15. Jahrhundert neben Chinesen, die Fremdsprachenkenntnisse besaßen, hauptsächlich Ausländer beschäftigt, die dieses Amt jedoch nicht unbedingt freiwillig übernommen hatten; so bat Birma in den Jahren 1451 und 1458 vergeblich um die Rücksendung birmanischer Gesandter, die am Siyiguan zurückgehalten worden waren. ${ }^{1285}$ Später wurden am Siyiguan ausgebildete Studenten als Lehrer angestellt; auch konnte das Amt an qualifizierte Familienangehörige vererbt werden. ${ }^{1286}$

\footnotetext{
1279 Pelliot, S. 218

${ }^{1280}$ Pelliot, S. 227; Hucker 5656

${ }^{1281}$ Pelliot, S. 227

${ }^{1282}$ Wild, S. 618. Die Tätigkeit am Siyiguan konnte auch vererbt werden (shiye zidi, Wild: ,hereditary students‘).

${ }^{1283}$ Wild, S. 628

${ }^{1284}$ Wild, S. 619, 621, 628, 635

${ }^{1285}$ Pelliot, S. 230; Wild, S. 624, 625, 637

${ }^{1286}$ Siehe Wild, S. 626
} 
Das Siyiguan der Ming-Zeit umfaßte zunächst acht Abteilungen (guan):
1. Mongolisch,
5. Sanskrit,
2. Jurchen,
6. Huihui (Sprachen der Moslime),
3. Uighurisch,
7. Birmanisch,
4. Tibetisch,
8. Baiyi (Shan-Sprachen).

Zwei weitere Abteilungen wurden in den Jahren 1511 für Babai (um Chiangmai gesprochene laotische Sprachen) und 1579 für Siamesisch gegründet.

Die Errichtung einer Abteilung für Siamesisch war erfolgt, nachdem eine Gesandtschaft aus Siam im Jahre 1579 ein auf Goldblatt geschriebenes Dokument überreicht hatte, das am Kaiserhof niemand lesen konnte. ${ }^{1287}$ Hier hat die chinesische Seite nicht nur prompt reagiert, sie wußte auch aus der Anwesenheit der Gesandten Nutzen zu ziehen. So berichtet der damalige Direktor des Siyiguan, Wang Zongzai, im Vorwort zu seinem Buch Siyiguan kao (,Bericht über das Siyiguan`), daß er sich bei ihnen über Geographie, Sprache, Sitten und Gebräuche ihres Landes informiert hatte. ${ }^{1288}$ Seinem Ersuchen, auf diese Art auch Informationen von Mongolen und anderen Ausländern, die sich in der Hauptstadt aufhielten, zu gewinnen, wurde jedoch nicht statt gegeben und Wang beklagte, daß die Professoren seiner Zeit keine Kenntnisse über die verschiedenen Länder hätten, sondern lediglich und auch das sei nicht einmal sicher, Sprachen und Schriften kennen würden. ${ }^{1289}$ Aus diesen Bemerkungen geht deutlich hervor, daß die Arbeit des Siyiguan nur darauf ausgerichtet war, den Anforderungen des Verwaltungsapparates zu entsprechen, darüber hinaus jedoch kein Interesse bestand, das Ausland besser kennenzulernen.

Zu den Aufgaben der Übersetzer-Beamten des Siyiguan gehörte es, Gesandtschaften ins Ausland oder auch den Kaiser auf einer Inspektionsreise zu begleiteten, außerdem konnten sie auch an Grenzstationen oder in andere Verwaltungsämter berufen werden. ${ }^{1290}$ Die wichtigste Tätigkeit des Amtes bestand allerdings neben der Ausbildung im Übersetzen fremdsprachlicher Dokumente, die von Tributgesandtschaften in der Hauptstadt überreicht wurden. Doch auch dieser Aufgabe kam das Siyiguan zum Teil nur unzureichend nach, so wurden oft mechanische Übersetzungen ohne Beachtung der grammatischen Regeln der

\footnotetext{
${ }^{1287}$ Goodrich, S. 1441

${ }^{1288}$ Devéria, S. 98

1289 Ebenda.

${ }^{1290}$ Wild, S. 619, 625
} 
anderen Sprache angefertigt oder die Schriftstücke lediglich mit bestimmten zusammenfassenden Formeln wiedergegeben. ${ }^{1291}$

Das Siyiguan genoß innerhalb des chinesischen Verwaltungsapparates kein sehr hohes Ansehen, wie zahlreiche Berichte und Eingaben, die auf die generelle Ineffizienz, die Unterbesetzung einzelner Abteilungen, die Vernachlässigung der Prüfungen und andere Probleme des Amtes hinweisen. ${ }^{1292}$ So fehlte es Mitte des 16. Jahrhunderts und erneut einhundert Jahre später in allen Büros an genügend Studenten; die Abteilung für Shan-Sprachen hatte um das Jahr 1650 gar keine Studenten, für Siamesisch war nicht einmal mehr Lehrpersonal vorhanden. ${ }^{1293}$ Durch Neuregelungen der Aufnahme- und Prüfungsverfahren sowie der Lehrinhalte wurde immmer wieder versucht, das Niveau des Amtes zu heben und die Qualität der Ausbildung dringend benötigter Übersetzer zu verbessern, diese Maßnahmen hatten jedoch nur begrenzten Erfolg.

Eine weitere Institution, die für den Umgang mit ausländischen Gesandten zuständig war, war das Huitongguan, das die Mongolen 1274 gegründet hatten und das in der Yuan-Zeit die wichtigste Institution für die Unterbringung der Gesandten und die Organisation ihrer Angelegeneiten war. Der Aufenthalt der Gesandtschaften war reglementiert, so waren vor dem Huitongguan Wachen stationiert, die die Gesandten am Verlassen der Herberge hindern sollte. Die so beschränkte Bewegungsfreiheit hatte unter anderem zur Folge, daß die Mitglieder der Gesandtschaften bei ihren Verhandlungen mit den Chinesen ganz auf das Personal des Huitongguan angewiesen waren. ${ }^{1294}$

Sowohl das Siyiguan als auch das Huitongguan bestanden unter der Qing-Dynastie weiter, lediglich die Schreibweise des Namens des Siyiguan wurde geändert: Anstelle des Schriftzeichens yi mit der Bedeutung ,Barbaren‘, wurde nun yi (,übersetzen`) verwendet. ${ }^{1295}$ Das Siyiguan wurde der Hanlin-Akademie zugeordnet und umfaßte nunmehr zehn Abteilungen. Das Huitongguan diente weiterhin der Unterbringung der Tributgesandtschaften. Im Jahr 1748 wurden beide Ämter dann zum Huitong-Siyiguan zusammengefaßt und dem Ritenministerium unterstellt. ${ }^{1296}$

\footnotetext{
${ }^{1291}$ Serruys, Tributesystem, S. 452

${ }^{1292}$ Wild, S. 619

${ }^{1293}$ Wild, S. 622, 623, 634

1294 Serruys, Mongols, S. 249

1295 Pelliot, S. 238

1296 Das Huitong-Siyiguan war nicht die einzige Institution, die Fremdsprachenkenntnisse vermittelte, auch das Kaiserliche Hofamt (Neiwufu) hatte für die Ausbildung eigenen Personals im Jahr 1747 eine Schule für Mongolisch
} 
Das Siyiguan und das Huitongguan der Ming- und Qing-Zeit erfüllten unterschiedliche Aufgaben und benötigten auch unterschiedliches Personal. Während das Siyiguan für die schriftliche Übersetzung von Dokumenten zuständig war, die nicht unbedingt wörtlich zu übersetzen waren, benötigte das Huitongguan Dolmetscher, die sich direkt mit den Gesandten verständigen konnten und die Fremdsprache deswegen aktiv beherrschen, sie jedoch nicht unbedingt auch schreiben können mußten. Da ein Teil der Dokumente der Tributgesandten ohnehin auf Chinesisch abgefaßt war und somit keine schriftliche Übersetzung erforderte, wie die Schriftstücke aus Korea, Japan oder Annam, blieb auch die Zahl der Büros des Siyiguan kleiner als die des Huitonggua, das im 16. Jahrhundert achtzehn Abteilungen umfaßte:
1. Korea,
7. Champa,
13. Jurchen,
2. Japan,
8. Java,
14. Uighuren,
3. Ryukyu,
9. Sumatra,
15. Tibet,
4. Annam,
10. Malakka,
16. Indien
5. Kambodscha,
11. Tartar,
17. Birma,
6. Siam,
12. Persien,
18. Baiyi. ${ }^{1297}$

Das Mitte des 18. Jahrhunderts durch Zusammenlegung der beiden Ämter entstandene Huitong-Siyiguan wurde in zwei Hauptbüros unterteilt, das Xiyuguan (zuständig für die Sprachen des Westens: Persisch, Uighurisch, Tibetisch und Sanskrit) und das Baiyiguan (zuständig für Siamesisch, Babai, Baiyi, Birmanisch, Laotisch und andere Sprachen des Südwestens). ${ }^{1298}$

\section{2. Die Wörterbücher der Übersetzungsbüros - Huayi yiyu}

Eine Aufgabe der Übersetzungsbüros des Siyiguan und des Huitongguan war die Erstellung von zweisprachigen Wörterbüchern. Diese Wörterbücher wurden von allen Abteilungen der beiden Ämter etwa seit dem Jahr 1500 herausgegeben. ${ }^{1299}$ In ihrem Aufbau gleichen sie dem im Jahr 1389 erschienenen chinesisch-mongolischen Wörterbuch Huayi yiyu, welches von dem Mongolen Qoninci (chin. Huo Yuanjie) und Masaih Muhammad,

sowie 1756 Schulen für Arabisch und Birmanisch gegründet; seit 1790 übernahm das Hofamt auch selbst den Empfang und die Unterbringung der Gesandten (Torbert, S. 38, 122).

${ }^{1297}$ Maspéro, S. 8

1298 Pelliot, S. 285

${ }^{1299}$ Pelliot, S. 275, 278 
zwei Mitgliedern der Hanlin-Akademie, im Auftrag des Hongwu Kaisers zusammengestellt worden war.

Das chinesisch-mongolische Wörterbuch Huayi yiyu besteht aus drei Teilen:

1. Einer chinesisch-mongolischen Vokabelliste mit 850 Wörtern, in siebzehn Kategorien angeordnet, die beginnend mit Astronomie und Geographie, auch Pflanzen und Tiere, Kleidung, Körpeteile, Nahrungsmittel und anderes umfassen.

2. Fünf Dokumente, die China an die Mongolen gesandt hatte; der mongolische Text wird hier in chinesischen Zeichen transkribiert und mit einer Wort für Wort, sowie einer zusammenfassenden Satz für Satz Übersetzung versehen.

3. Sieben Dokumenten, die von den Mongolen nach China gesandt worden waren und die nur mit einer Wort für Wort Übersetzung versehen sind. ${ }^{1300}$

Das Wörterbuch gibt darüberhinaus keine Informationen zum Satzbau oder zur Grammatik des Mongolischen. Das Vokabelverzeichnis zeigt jeweils den chinesischen Begriff und darunter folgt dann das mongolische Wort, seine Aussprache in chinesische Zeichen transkribiert. Die mongolische Schrift wird nicht verwendet.

Um die unterschiedliche Laut- und Silbenstruktur des Mongolischen in chinesischen Zeichen wiedergeben zu können, benutzten die Autoren verschiedene Hilfsmittel. Zum einen werden im Chinesischen unbekannte Auslaute mit Schriftzeichen dargestellt, die kleiner geschrieben und nach rechts eingerückt sind, so daß deutlich wird, das nur ihr Anlaut für die Aussprache des mongolischen Wortes relevant ist, zum anderen deuten kleine diakritische Zeichen links neben einem chinesischen Zeichen an, daß der Anlaut der Silbe sich von dem der chinesischen unterscheidet. ${ }^{1301}$ Die systematische Verwendung dieser Zusatzzeichen macht deutlich, daß sich die Verfasser des Wörterbuches intensiv mit dem Mongolischen beschäftigt und die Unterschiede zum Lautsystem des Chinesischen sorgfältig herausgearbeitet haben.

Das Huayi yiyu war zwar nicht das erste zweisprachige Wörterbuch, bereits in Zusammenhang mit der Übersetzung buddhistischer Texte waren chinesisch-Sanskrit Wörterbücher entstanden, sein Titel ist jedoch zu einem Synonym für die Wörterbücher der

\footnotetext{
${ }^{1300}$ Goodrich, S. 1125-27; Lewicki, S. 12-14

${ }^{1301}$ Lewicki, S. 17, 49-50, 177
} 
verschiedensten Sprachen geworden, die dem Muster des chinesisch-mongolischen Huayi yiyu folgten und oft sogar dessen Autor Huo Yuanjie als Mitherausgeber nannten.

Auch die zweisprachigen Wörterbücher der verschiedenen Abteilungen der Übersetzungsbüros des Siyiguan und des Huitongguan orientieren sich am System des Huayi yiyu von Huo Yuanjie mit seiner Einteilung der Vokabeln in verschiedene Kategorien, wie sie auch in den chinesischen Enzyklopädien (leishu) zu finden ist. Die Wörterbücher der einzelnen Übersetzungsbüros sind aber nicht identisch, so variieren Anzahl und Reihenfolge der Kategorien ebenso wie die der in ihnen aufgelisteten Vokabeln. Sie stellen also kein geschlossenes Werk des Amtes selbst dar, sondern sind in erster Linie Lehrmittel für die Studenten der einzelnen Abteilungen gewesen, die später zu einem Wörterbuch zusammengestellt worden sind. Die unterschiedlichen Wörterbücher machen deutlich, daß die einzelnen Büros unabhängig voneinander gearbeitet haben und es beispielsweise keine gemeinsamen Lehrpläne gab, sondern lediglich allgemeine Richtlinien, die von den Büros für die verschiedenen Sprachen individuell umgesetzt worden sind.

Besonders unterscheiden sich die Wörterbücher der Übersetzungsbüros in der Hauptstadt darin, daß die des Siyiguan auch die Originalschriften enthalten, während die des Huitongguan nur eine phonetische Transkription in chinesischen Zeichen aufweisen. Sie berücksichtigen also, daß die Dolmetscher des Huitongguan die Fremdsprache ja nur sprechen, sie jedoch nicht auch schreiben mußten. ${ }^{1302}$

Nicht alle Wörterbücher weisen einen Dokumententeil mit direkter Übersetzung auf, wie er in das Huayi yiyu aus dem Jahr 1389 aufgenommen worden ist. Einige Wörterbücher enthalten jedoch neben den Vokabellisten einen Anhang mit Schriftstücken (laiwen), die nicht aus oder in eine Fremdsprache übersetzt sind, sondern lediglich die chinesischen Aussprache in einer anderen Schrift wiedergeben.

Neben der Erstellung von mandschurisch-chinesischen Wörterbüchern oder fünf-sprachigen Wörterbüchern in den Verwaltungssprachen des Kaiserreiches wurde auch die Tradition der Herausgabe zweisprachiger Wörterbücher vom Typ des Huayi yiyu in der QingDynastie fortgeführt. Im 18. Jahrhundert veranlaßte der Qianlong-Kaiser eine Revision der vorhandenen Wörterbücher sowie die Zusammenstellung eines neuen Wörterbuches, das

${ }^{1302}$ Pelliot, S. 277 
die Sprachen aller Völker, mit denen China in Kontakt stand, umfassen sollte. Dieses Sammelwerk bestand aus achtundneunzig Bänden und enthielt sechsunddreißig verschiedene Sprachen, darunter sechs europäische: Deutsch, Englisch, Französisch, Italienisch, Latein und Portugiesisch, sowie die Sprachen und Dialekte der Nachbarvölker Chinas. ${ }^{1303}$

\section{3. Die Wörterbücher des Tengyue ting zhi}

Das Lokalhandbuch TYTZ enthält in Kapitel 15, das sich mit verschiedenen Volksgruppen des Südwestens beschäftigt, zwei Wörterbücher regionaler Sprachen (fangyan) (siehe Abb. 7.1-2. S. 453-458). ${ }^{1304}$ Dabei handelt es sich um ein chinesisch-Shan Wörterbuch und ein chinesisch-birmanisches Wörterbuch, die beide dem Muster der zweisprachigen Wörterbücher, wie sie das Übersetzungsbüro in der Hauptstadt, das Siyiguan, seit Anfang des 16. Jahrhunderts herausgegeben hat, folgen. Das heißt, sie enthalten sowohl eine Wiedergabe der fremden (Shan bzw. birmanischen) Aussprache mittels chinesischer Zeichen als auch die Vokabeln in Originalschrift (Baiyi fangyan bing Yi zi; Mian ren fangyan bing Mian zi). ${ }^{1305}$

Das Wörterbuch der Shan-Sprache umfaßt insgesamt 142 Begriffe, die in fünfzehn Rubriken (lei) eingeordnet sind. In das birmanische Wörterbuch sind nur 133 Begriffe aufgenommen worden, die sich jedoch auf sechzehn Rubriken verteilen, zusätzlich zu denen des Shan-Wörterbuches ist noch die Kategorie der ,Körperteile‘ hinzugekommen. Abgesehen davon ist die Reihenfolge der Rubriken in beiden Wörterbüchern gleich, während die Anzahl und die Reihenfolge der ihnen zugeordneten Begriffe variiert. Unterschiede gibt es auch in der Rubrik ,Zahlen‘: Nur im chinesisch-birmanischen Wörterbuch ist neben dem Zahlwort auch das birmanische Zahlzeichen aufgeführt. ${ }^{1306}$

Die einzelnen Rubriken sind: Astronomie, Geographie, Stadt, Nahrungsmittel, Kleidung, Arbeitsgeräte, Personen, Körperteile, Kostbarkeiten, fünf Farben, fünf Geschmacksrichtungen, Zahlen, Blumen und Bäume, vierfüßige Tiere, Vögel, Schuppen- und Schalentiere.

Die Begriffe innerhalb der Rubriken sind so angeordnet, daß jeweils zwei in einer Zeile stehen, ein Begriff in ihrer oberen und der andere in ihrer unteren Hälfte. Die einzelnen Begriffe sind durchgängig nach dem selben Muster gestaltet: X yue Y zi zuo Z; X (der

\footnotetext{
1303 Pelliot, S. 286

1304 TYTZ, S. 249-254

1305 TYTZ, S. 249 oben, Zeile 12 und S. 252 oben, Zeile 1.

${ }^{1306}$ TYTZ, S. 253 unten, Zeile 2.
} 
chinesische Begriff), gesprochen Y (Wiedergabe der fremden Aussprache mittels chinesischer Zeichen), geschrieben Z (die Vokabel in Originalschrift).

Der erste Eintrag des chinesisch-birmanischen Wörterbuches lautet entsprechend: Tian yue mo (shangsheng) zi zuo muih (,Das birmanische Wort für Himmel ist mo, es wird [mit den birmanischen Buchstaben] muih geschrieben'). So wie in diesem Beispiel wird auch bei einigen anderen Begriffen die fremde Aussprache noch durch die Angabe eines der vier klassischen Toneme (ping sheng, shang sheng, qu sheng, ru sheng) präzisiert.

Die Wörterbücher reihen lediglich die verschiedenen Begriffe und ihre Übersetzung aneinander. Bei den einzelnen Vokabeln handelt es sich fast ausschließlich um Substantive. Ausnahmen sind die Adjektive in den Rubriken Farben bzw. Geschmacksrichtungen, die Zahlen sowie folgende Verben: Essen, trinken, schneiden, kaufen und verkaufen. Die Auswahl gerade der beiden letzteren verweist immerhin auf die große Bedeutung des Fernhandels für Tengyue.

Weder stellen die Wörterbücher die vollständigen Alphabete des Shan und des Birmanischen vor oder erläutern die Art der Vokalbildung (nämlich durch Anfügen der Vokalzeichen an die einzelnen Buchstaben), noch machen sie Angaben zu Grammatik oder Satzbau. Ihre Benutzung setzte somit eine gewisse Kenntnis der Fremdsprachen und ihrer Schriften voraus. Sie sind tatsächlich nur Vokabellisten, mit denen der Leser seien Wortschatz leicht erweitern konnte.

Um hingegen die Vokabeln auch schreiben zu lernen, war eine größere Vertrautheit mit den jeweiligen Schriften notwendig, da hier eine flüssige, individuelle Handschrift als Druckvorlage gedient hat, die es oft schwierig macht, die einzelnen Buchstaben zu erkennen, so zum Beispiel bei dem birmanischen Wort sumh (,drei‘; siehe TYTZ, S. 253 unten, Zeile 2 ). ${ }^{1307}$

\section{3. 1. Das Chinesisch-Shan Wörterbuch}

Im Vergleich des chinesisch-Shan Wörterbuches des TYTZ mit Standardwerken wie dem Lexikon und der Grammatik von Cushing sowie der im Gazetteer von Scott/Hardiman (Vol.I, S.626-727) abgedruckten Wörterliste werden die regionalen Unterschiede zwischen

${ }^{1307}$ Alle Seitenngaben zu Abb. 5. 1-2 beziehen sich auf die Seitenzahlen der Faksimileausgabe des TYTZ, die Zeilenangaben auf die von mir vorgenommene Nummerierung entsprechend der chinesischen Schreibung von rechts nach links. 
den Sprachen und Schriften der Shan deutlich. Das Wörterbuch des TYTZ gibt das in Yunnan gebräuchliche Shan wieder, das teilweise von den bei Cushing und Scott/Hardiman genannten, in Birma verwendeten Begriffen abweicht.

Drei der Vokabeln des Wörterbuches des TYTZ werden von Cushing ausdrücklich als von den Shan in China verwendete Varianten (,Chinese Shan') gekennzeichnet, so zum Beispiel ly (,Fleisch`) an Stelle des in Birma gebräuchlichen ny (S. 249 unten, Zeile 14) und in der Rubrik Tiere, kan (eine Hirschart) für kun (S. 251, Zeile 18). ${ }^{1308}$

Andere Vokabeln im TYTZ unterscheiden sich lediglich im Auslaut von den bei Cushing genannten, z.B. lin (,Erde`) mit einem dentalen n im Auslaut, gegenüber lin mit gutturalem ,n` im Wörterbuch (S. 249 unten, Zeile 2). In einigen Fällen wird auch ein untergeschriebenes , $\mathrm{r}^{`}$ hinzugefügt, wie bei krin (,essen“; S. 249 unten, Zeile 12), bei Cushing lediglich kin. $^{1309}$

Der auffälligste Unterschied zwischen dem Wörterbuch des TYTZ und dem von Cushing liegt jedoch in der Schrift. Cushing verwendet das Alphabet der westlichen Shan, das auch als ,alte Schan-Schrift‘ (Wenk) oder als ,allgemeine Shan-Schrift' und in China heute als Dai Bengwen oder als Shanwen bezeichnet wird. ${ }^{1310}$ Das Wörterbuch des TYTZ verwendet eine andere Schrift, die Wenk als die Schrift der ,großen Thai-Hkamti` bezeichnet und die von den Shan im Norden Birmas an der Grenze zu Yunnan verwendet wird. ${ }^{1311}$

Besonders deutlich ist dies an der Schreibweise des Buchstabens , $\mathrm{k}^{\mathfrak{}} \mathrm{zu}$ erkennen, beispielsweise bei kat (,Markt') oder nuk (,Vogel'), das außerdem ein anders geschriebenes ,n` aufweist (siehe S. 249 unten, Zeile 8 und S. 251 unten, Zeile 3). ${ }^{1312}$ Weitere Beispiele sind das ,kh` in khum (,bitter`) oder die Vokabel sai (,Gürtel`), bei der sich sowohl der Konsonant , $\mathrm{s}^{`}$ als auch das Vokalzeichen deutlich von der , alten Schan-Schrift‘ unterscheiden (siehe S. 250 unten, Zeile 9 und S. 249 unten Zeile 18).

\footnotetext{
${ }^{1308}$ Cushing, Dictionary, S. 602 und S. 5; Übersetzung nach Egerod, S. 259.

${ }^{1309}$ Cushing, Dictionary, S. 31

${ }^{1310}$ Cushing, Handbook, S. 1; Wenl, S. 113-114; Zhang, S. 259

${ }^{1311}$ Wenk, S. 115

${ }^{1312}$ Vergleiche Cushing, Handbook, S. 3 und Wenk, S. 118 (Tafel I).
} 


\section{3. 2. Das Chinesisch-birmanische Wörterbuch}

Der Vergleich der birmanischen Vokabeln des TYTZ mit modernen Lexika (zum Beispiel dem Mian Han cidian oder dem Lexikon von Judson) zeigt, daß die meisten birmanischen Wörter korrekt wiedergegeben worden sind. Bei den häufigsten Abweichungen handelt es sich um typisch birmanische orthographische Varianten:

1. Die abwechselnde Verwendung der Konsonanten ra und ya, die beide wie ya gesprochen werden, wie in ye statt re (,Wasser'; S. 252 oben, Zeile 10) oder mrak cim statt myak ci (,Auge‘; S. 253 oben, Zeile 3).

2. Das (für Handschriften typische) Ausschreiben des Anusvara, wie in khum an Stelle von khum (,Tisch‘; S. 252 unten, Zeile 9).

3. Unterschiedliche Auslaute, die die Aussprache des Wortes jedoch nicht verändern (Gutturale oder Dentale, die den entsprechenden Palatal oder Labial ersetzen), wie in a khyan statt $a$ khyan (,sauer‘; S. 253 oben, Zeile 17), cat für cap (,scharf‘; ebendort).

Dies sind lediglich Schreibvarianten, die eine gleiche Aussprache mit unterschiedlichen Buchstaben darstellen. Dabei handelt es sich um ein typisches Phänomen einer Buchstabenschrift, wie man es auch in historischen Dokumenten in europäischen Sprachen findet und das überdies durch das Vorhandensein unterschiedlicher Dialekte beeinflußt ist, die sich mittels Buchstaben, im Gegensatz zu den chinesischen Schriftzeichen, leicht in Schriftform deutlich machen lassen. ${ }^{1313}$

Bei der Wiedergabe birmanischer Aussprache mittels chinesische Zeichen stimmt diese in allen Fällen mit der birmanische Aussprache überein bzw. nähert sich ihr so weit wie möglich an, wenn es sich um Silben handelt, die die chinesische Sprache nicht kennt. So wird beispielsweise die Aussprache der Vokabel ton (,Berg'), als ,daung‘, mit chinesisch dang wiedergegeben (S. 252 oben Zeile 9).

Das Wörterbuch enthält jedoch auch einige Fehler; so wurde das Wort xue (,Schnee`) mit dem birmanischen muih sih (,Hagel‘, ,Hagelsturm‘) wiedergegeben (TYTZ, S. 252 oben,

\footnotetext{
1313 Ein interessantes Beispiel für die abweichende Orthographie bietet die Vokabel ,Schüssel': Statt der korrekten Schreibweise panh kan steht im Wörterbuch (TYTZ, S. 252 unten, Zeile 8) pu gam die Aussprache beider Varianten ist ,pagan‘. Das hier fälschlicherweise verwendete pu gam ist die korrekte Schreibweise des Namens der Hauptstadt Birmas vom 11. bis 13. Jahrhundert, Pagan (pu gam, gesprochen ,pagan'). Im Chinesischen wird die Aussprache mit bu gan wiedergegeben, wobei das $b u$ als kurzes ,b` gesproch wird. Die Schriftzeichen sind jedoch nicht mit den für die Bezeichnung der Stadt Pagan, chin. pugan, gebräuchlichen identisch.
} 
Zeile 4), shen (,Körper‘) mit kuil, fehlerhaft für kuiy (,Körper‘; von Pali kaya S. 253 oben, Zeile 2). In der Rubrik Kostbarkeiten sind zwei Vokabeln vertauscht worden, Zinn wurde mit khai (,Blei`) und Blei mit sam phru (,Zinn`) übersetzt (S. 253 oben, Zeile 8), die Wiedergabe der Aussprache in chinesischen Zeichen ist ebenfalls vertauscht worden.

Bei den Tieren sind Fuchs und Maus mit rhan und sat an Stelle des gebräuchlichen mre khveh (,Fuchs`) und krvak (,Maus`) übersetzt worden (S. 254, Zeile 2 und 3). 
Abbildung 7: Die Wörterbücher des Tengyue tingzhi

Abbildung 7-1: Das chinesisch-Shan Wörterbuch des TYTZ (S. 249-251)

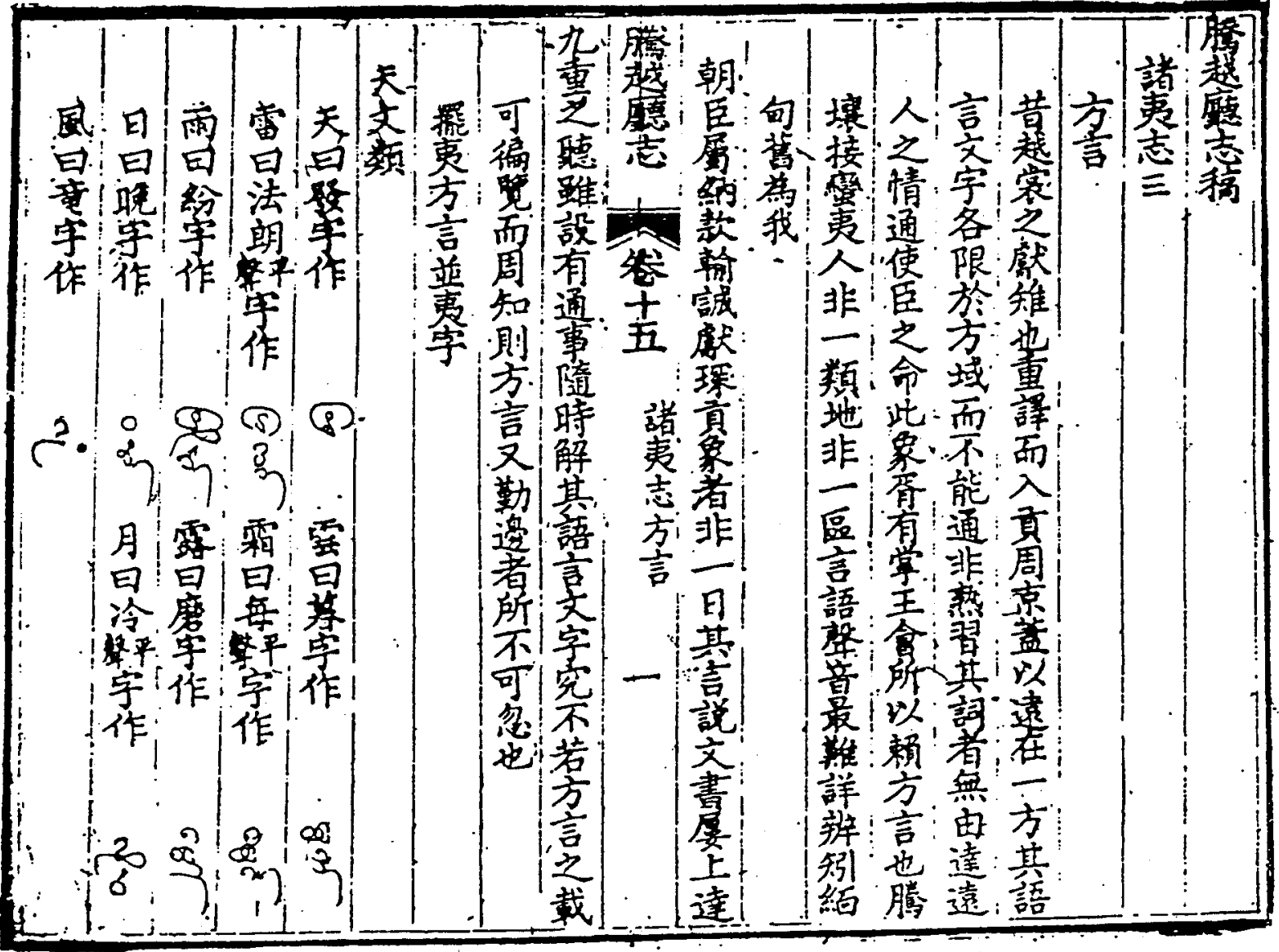

$\begin{array}{llllllllllllllllllll}18 & 17 & 16 & 15 & 14 & 13 & 12 & 11 & 10 & 0 & 9 & 8 & 7 & 6 & 5 & 4 & 3 & 2 & 1\end{array}$

应

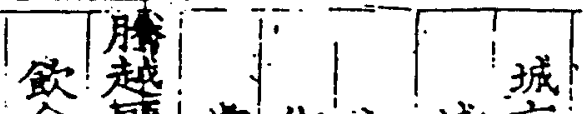

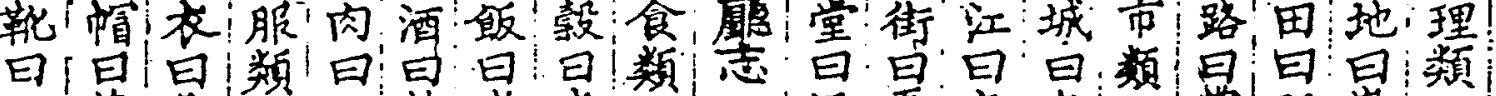

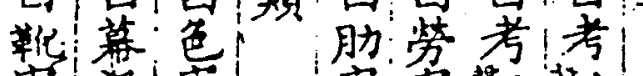

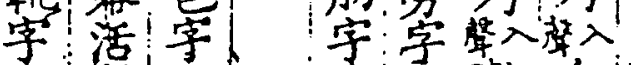

作等! 作

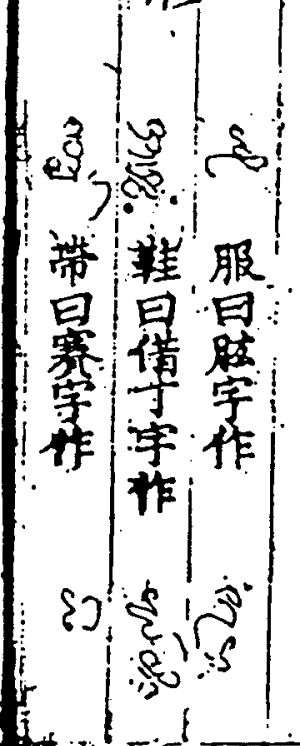
作作教白

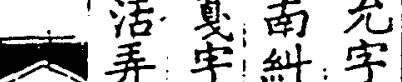

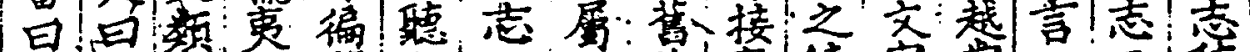

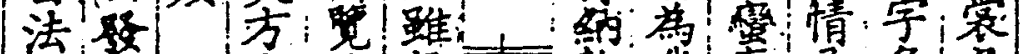




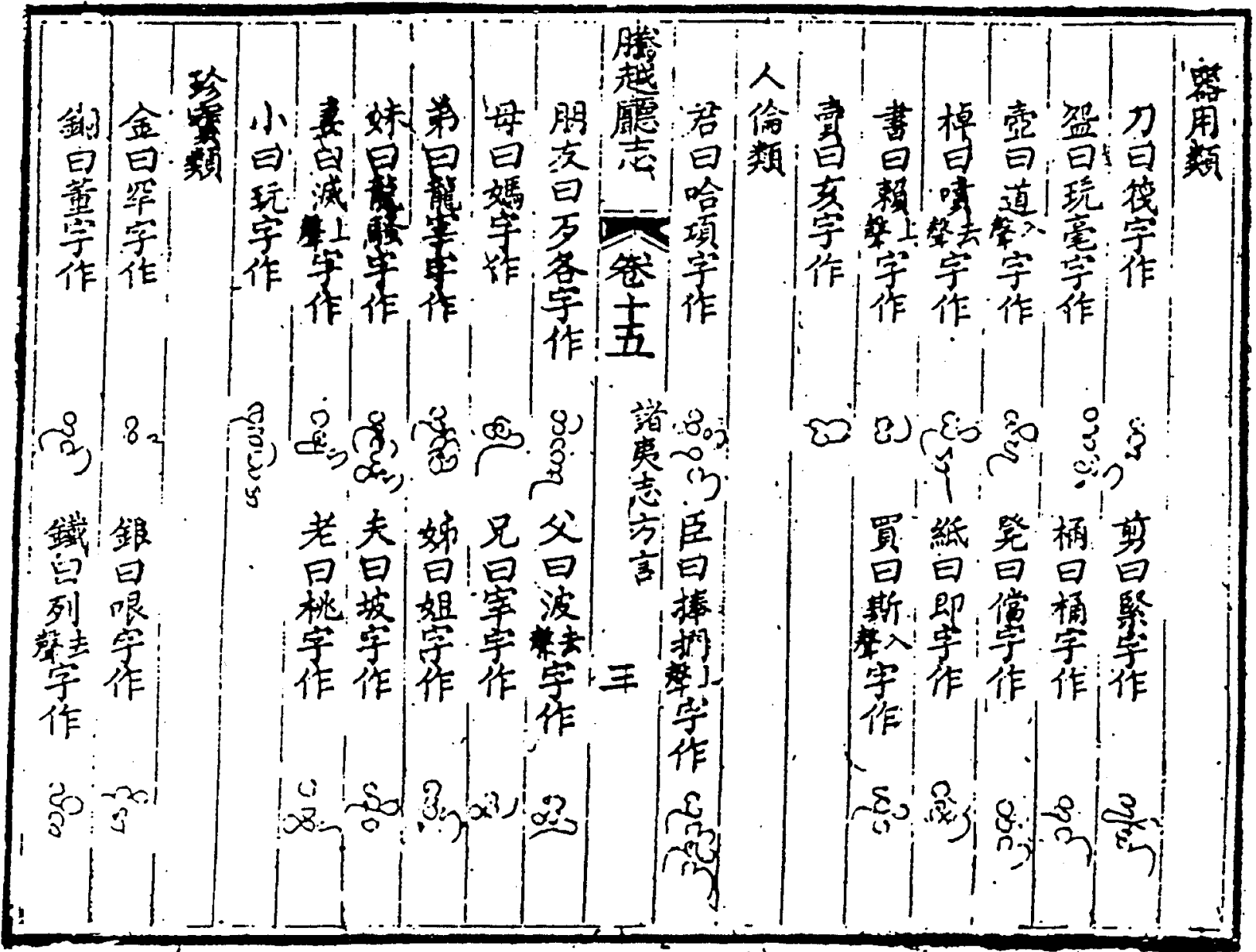

$\begin{array}{lllllllllllllllllll}18 & 17 & 16 & 15 & 14 & 13 & 12 & 11 & 10 & & 9 & 8 & 7 & 6 & 5 & 4 & 3 & 2 & 1\end{array}$

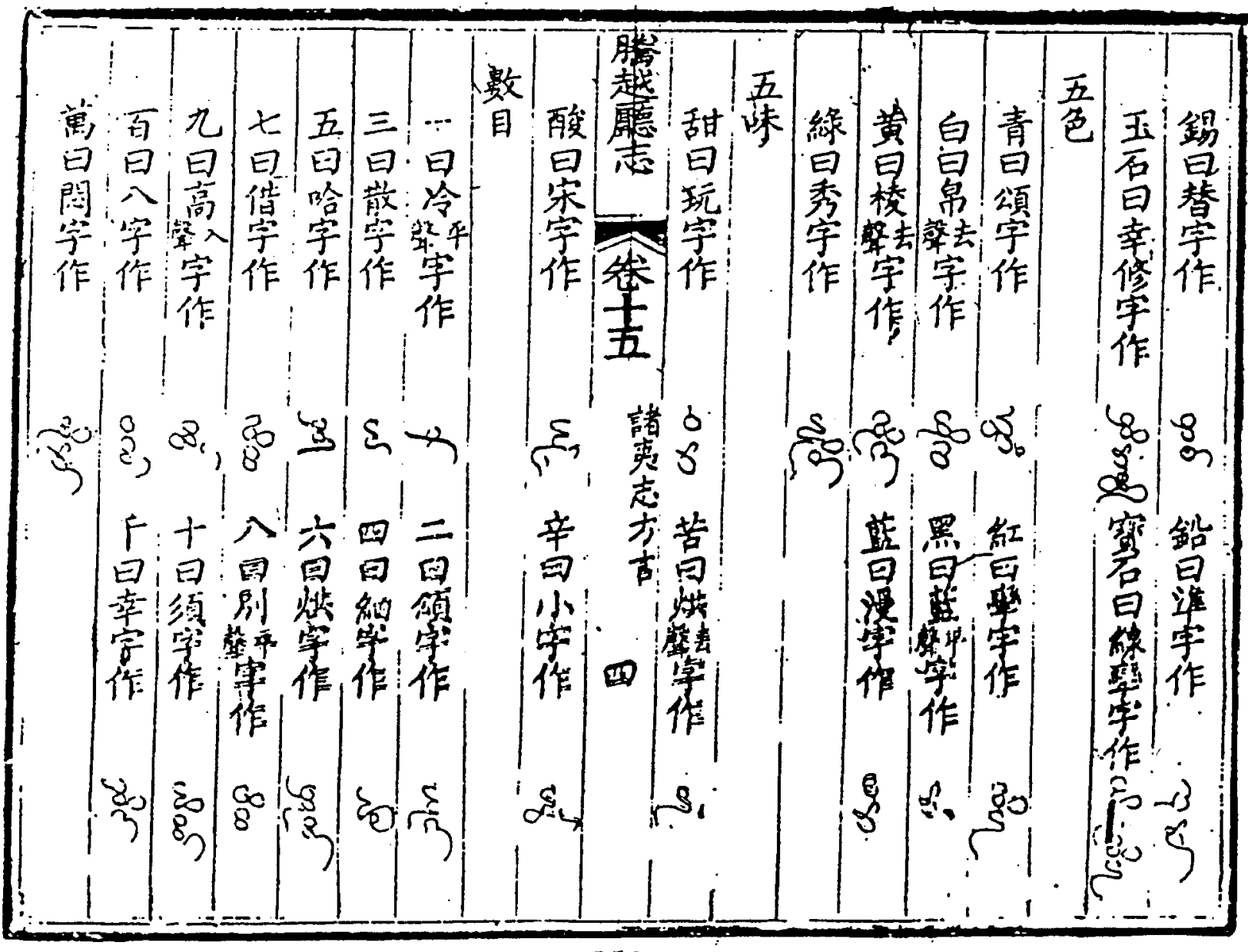




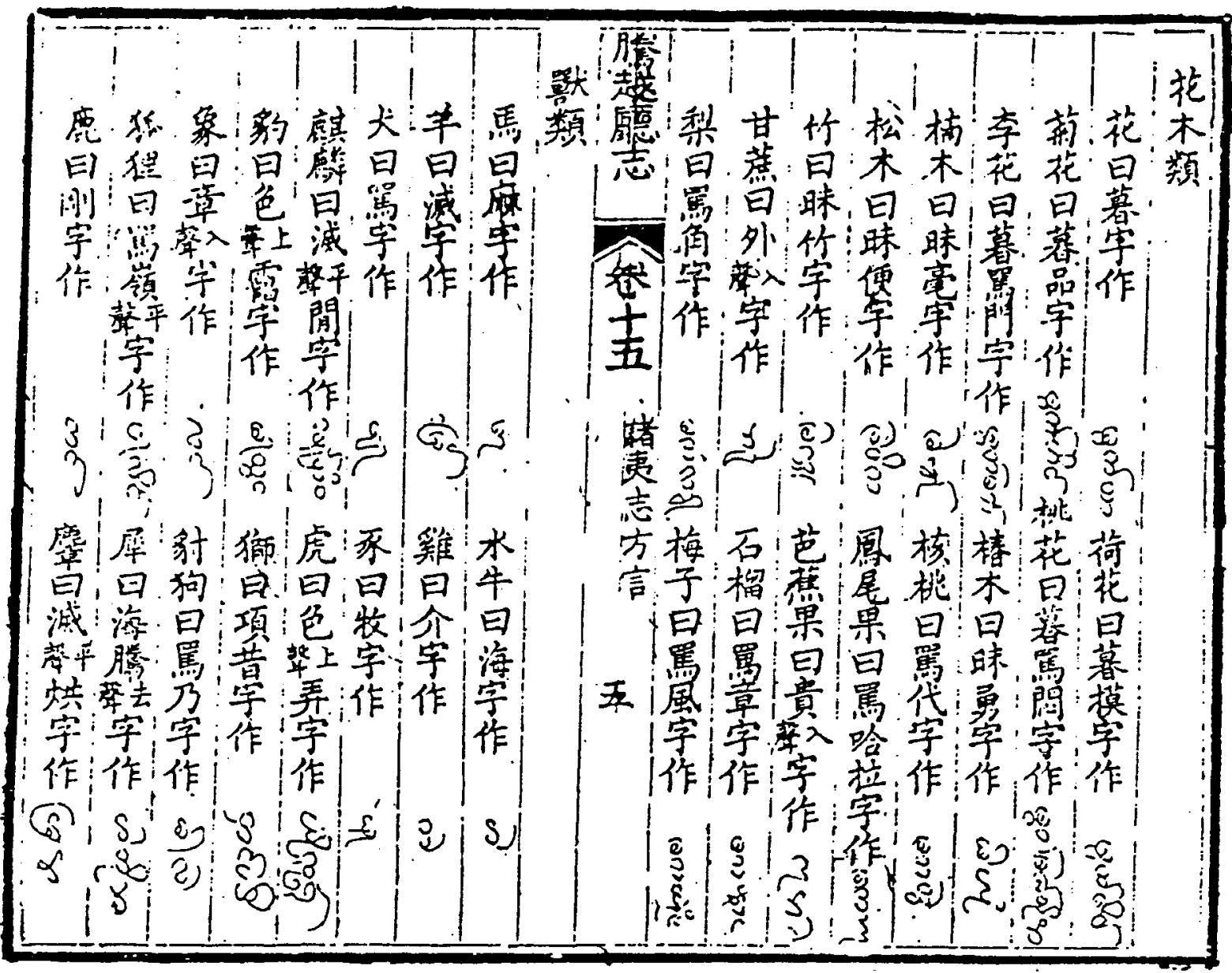

$\begin{array}{lllllllll}18 & 17 & 16 & 15 & 14 & 13 & 12 & 11 & 10\end{array}$

$\begin{array}{lllllllll}9 & 8 & 7 & 6 & 5 & 4 & 3 & 2 & 1\end{array}$

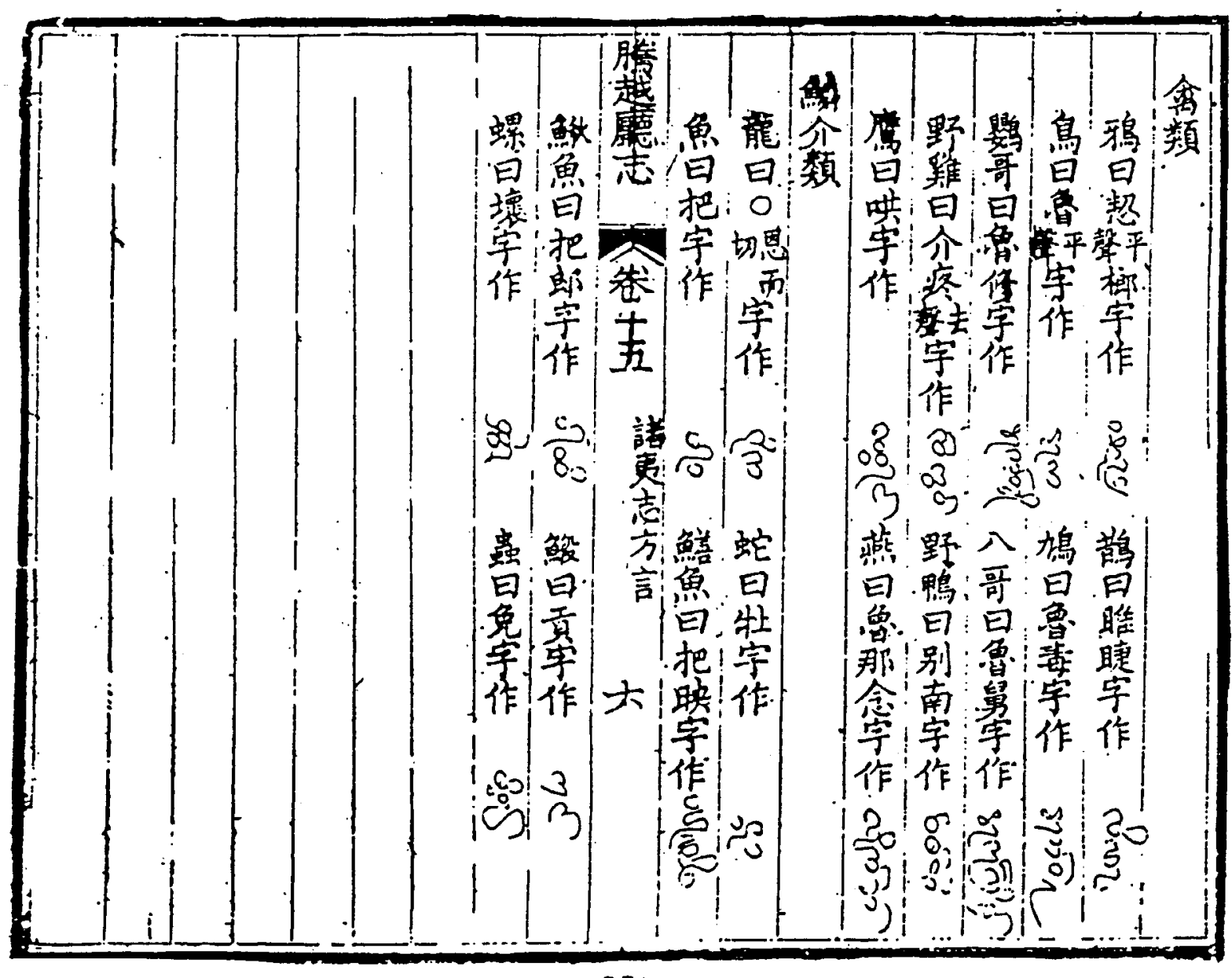


Abbildung 7-2: Das chinesisch-birmanische Wörterbuch des TYTZ (S. 252-254)

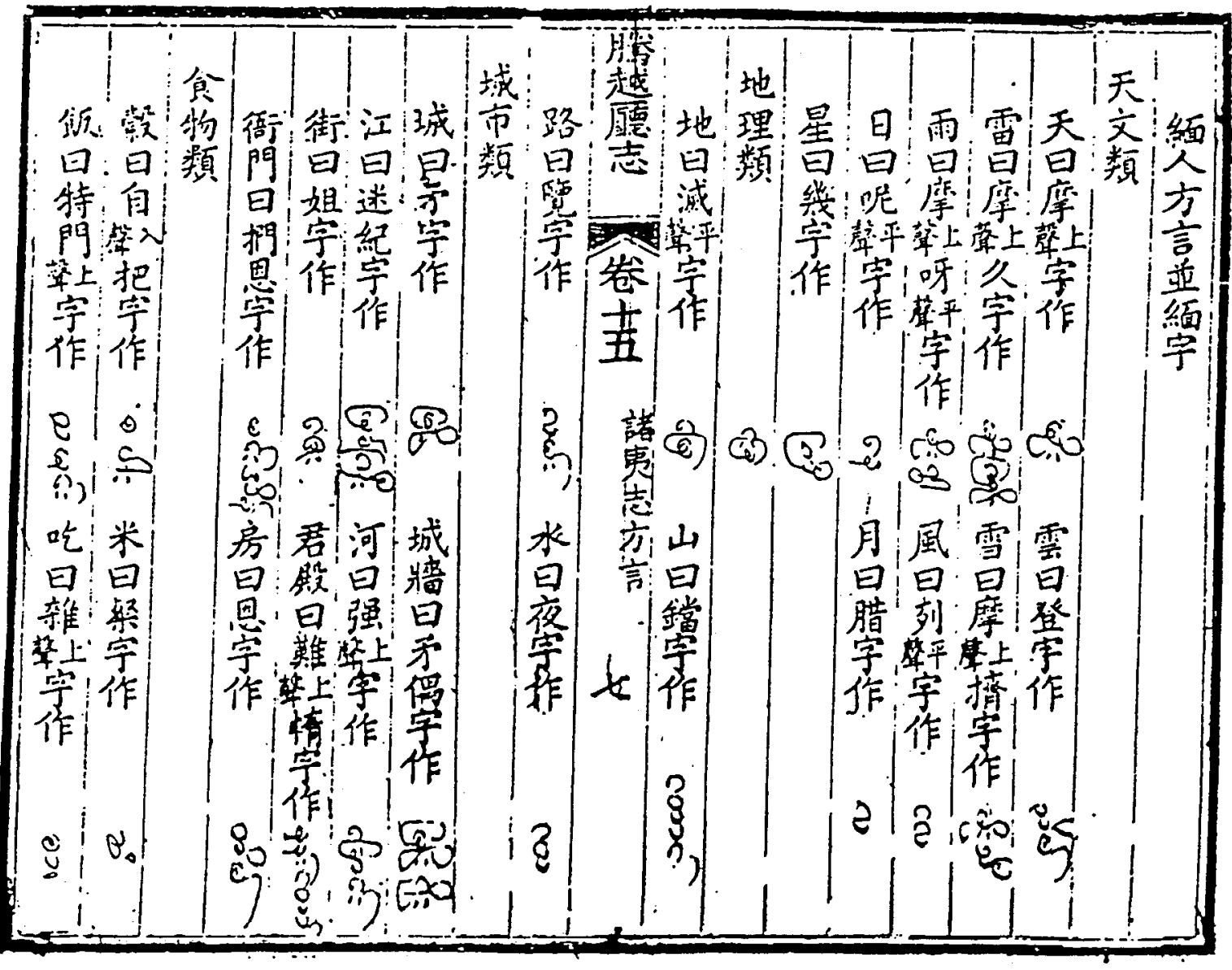

$\begin{array}{llllllllllllllllllll}18 & 17 & 16 & 15 & 14 & 13 & 12 & 11 & 10 & & 9 & 8 & 7 & 6 & 5 & 4 & 3 & 2 & 1\end{array}$

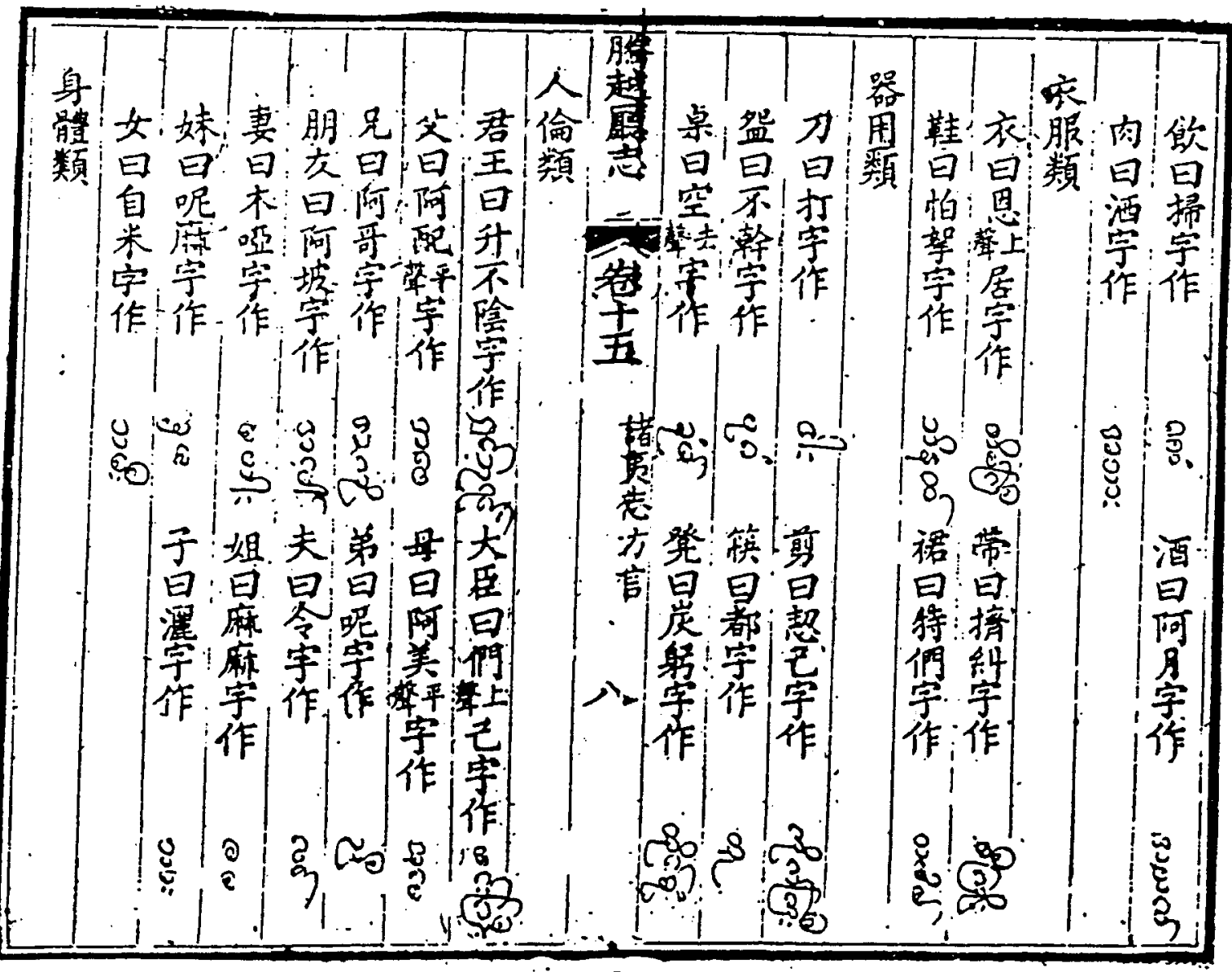




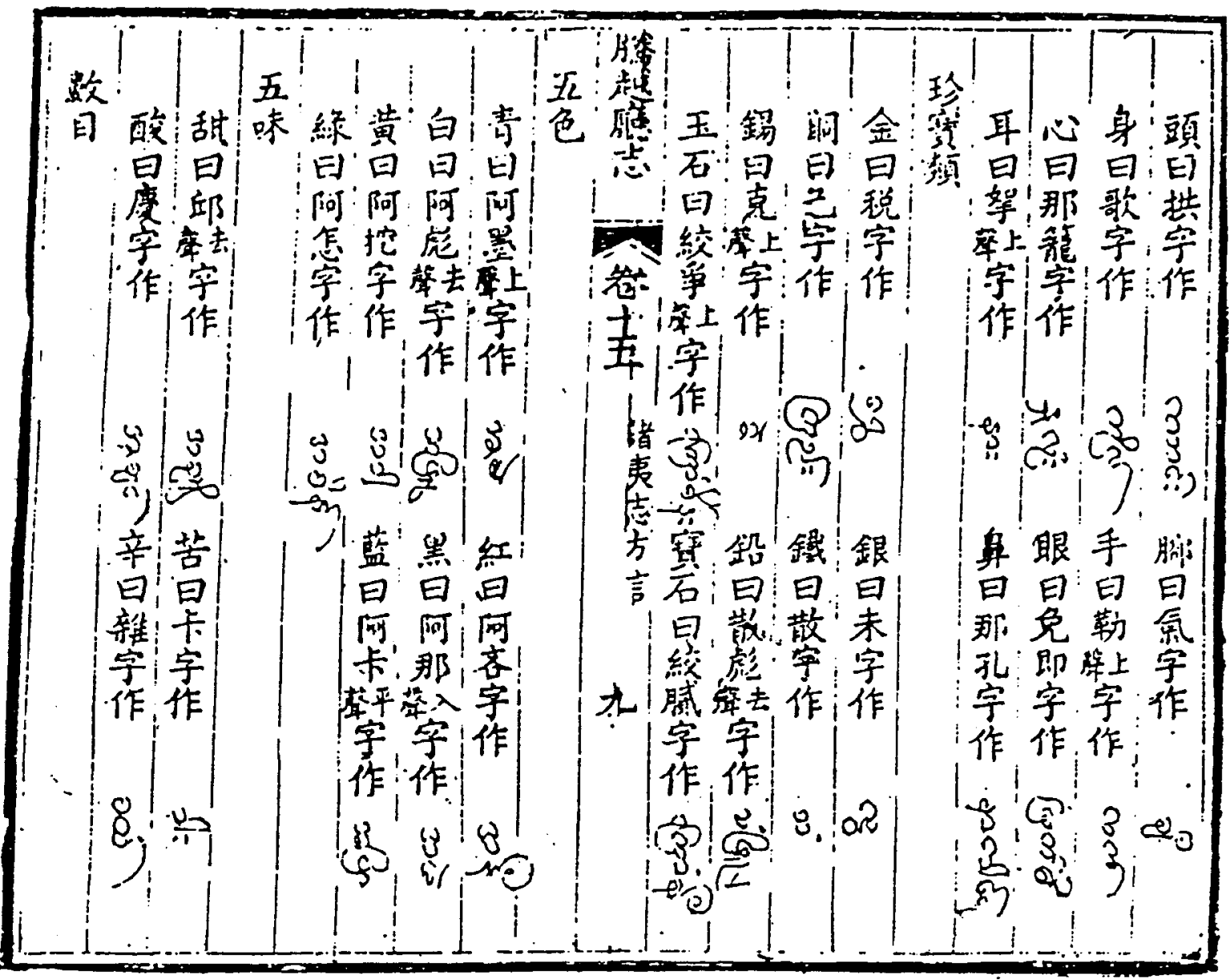

$\begin{array}{lllllllllllllllllll}18 & 17 & 16 & 15 & 14 & 13 & 12 & 11 & 10 & & 9 & 8 & 7 & 6 & 5 & 4 & 3 & 2 & 1\end{array}$

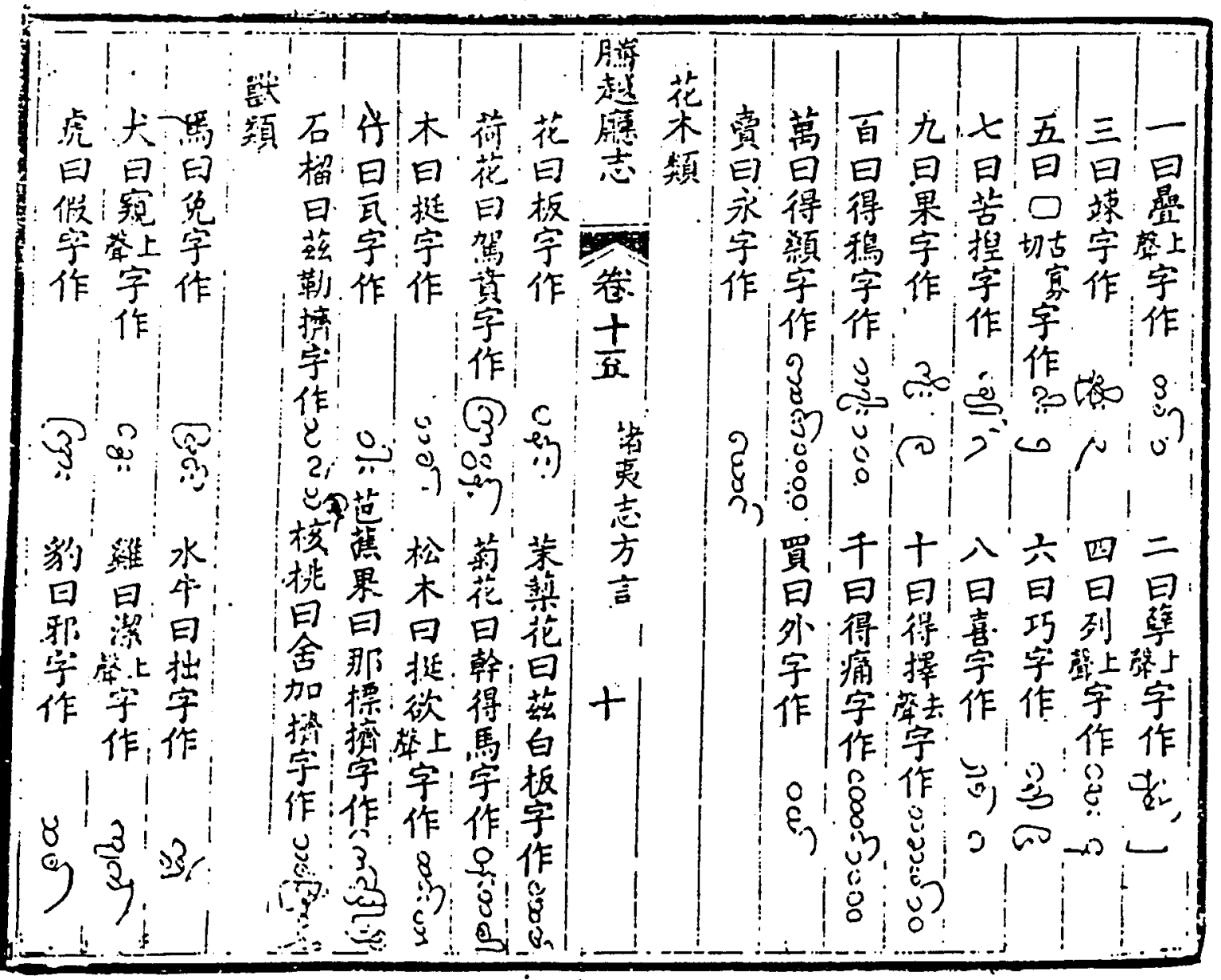









\section{Kanzleipraxis in Yunnan - Probleme in Tengyue}

Die Verfasser des TYTZ haben eine zentrale Instanz der chinesischen Regionalverwaltung für den Umgang mit fremdsprachlichen Schriftstücken in den Mittelpunkt ihrer Beschreibung der ,Schriften der Fremden` gestellt: Das ,Amt für die birmanische Schrift‘ (Mianziguan) in der Hauptstadt der Provinz Yunnan. Dort wurden Übersetzer für das Birmanische ausgebildet und beschäftigt, deren Aufgabe war es, Dokumente, die die Tributgesandtschaften aus Birma mit sich führten, ins Chinesische zu übertragen. Zur Zeit der Herausgabe des TYTZ am Ende des 19. Jahrhunderts existierte das Mianziguan jedoch nicht mehr. Die Verfasser des Lokalhandbuchs bedauern dies und zeigen anhand des Berichtes, den Unterpräfekt Wu Kai etwa einhundert Jahre zuvor verfaßt hatte, welch ,tiefe Bedeutung' (shen yi) für den Umgang mit den Tributstaaten im Südwesten von Tengyue die Gründung dieses Amtes gehabt hatte.

Allerdings gab es bereits in der zweiten Hälfte des 18. Jahrhunderts erhebliche Probleme bei der Übersetzung von Schriftstücken aus Birma. Wu Kai (von 1770 bis 1779 in Tengyue tätig) beklagt das unzulängliche Übersetzungswesen, das vor allem auf das Fehlen von qualifizertem Personal, das das Birmanische beherrschte, zurückzuführen war. Sei es, daß die Ausbildung von Übersetzern am Mianziguan (jiang xi zhi suo) während der Kriege mit Birma (1766-1769) unterbrochen worden war oder daß diese an den Feldzügen nach Birma teilgenommen hatten und umgekommen waren. Auch nach dem Friedensschluß von 1770 blieben die Beziehungen gespannt, das chinesische Handelsembargo wurde erst im Jahr 1790 aufgehoben, nachdem eine birmanische Gesandtschaft an den Kaiserhof gereist war. Jedenfalls mußte man sich in der Nachkriegszeit mit Shan-Übersetzern behelfen. Das sorgte für erhebliche Schwierigkeiten in der schriftlichen Kommunikation. In seinem oben zitierten Bericht weist Wu Kai besonders auf zwei Probleme hin, die sich für die Übersetzer in Tengyue aus dem engen Verhältnis der birmanischen und der Shan-Schriften zueinander ergaben: Zum einen auf die Unterschiede in der Phonetik, dem ,Gewicht‘ (qingzhong), zum anderen auf die Unterschiede in der Schreibweise, den ,Punkten und Linien`(dianhua). Er schreibt dort:

„Bei den Dolmetschern und Übersetzern gab es solche, die die Bedeutung [der Dokumente] nicht verstehen konnten. Denn die birmanische Schrift und die Schriften der Shan sind verschieden. Wenn nun aber diejenigen, die ShanSchrift beherrschten, birmanische Schrift übersetzen sollten, konnte man, da 
die Phonetik (qingzhong) völlig verschieden war, weder Aussprache noch Bedeutung verstehen“. ${ }^{1314}$

Der Fachausdruck qingzhong bezeichnet in der chinesischen Phonologie verschiedene Phänomene. Hier handelt bezieht er sich vermutlich auf die im Shan fehlenden stimmhaften Konsonanten; ebenso kann sich der Begriff auf die unterschiedliche Behandlung der Töne beziehen, die im Birmanischen geschrieben werden, im Shan hingegen in der Regel nicht.

Die große Ähnlichkeit der Schriften der Birmanen und der Shan sowie der Mangel an Übersetzern hatte die chinesischen Verwaltungsbeamten also veranlaßt, auch birmanische Schriftstücke von Shan-Übersetzern bearbeiten zu lassen. Aufgrund der Verschiedenheit der beiden Sprachen konnten die Dolmetscher und Übersetzer diese meist nicht verstehen. Doch nicht nur die Sprachen, auch die Schriften unterscheiden sich voneinander und so kam es, selbst wenn die Shan-Übersetzer Kenntnisse der birmanischen Sprache besaßen zu Mißverständnissen, wenn sie in ihrer Niederschrift an Stelle der birmanischen eine ShanSchrift verwendeten.

Trafen nun in Birma Schriftstücke ein, die von den Shan-Übersetzern verfaßt worden waren, so hatten die Birmanen Schwierigkeiten überhaupt zu erkennen, in welcher Schrift die Dokumente geschrieben waren: „Ist es Shan oder ist es Birmanisch? Die Strichführung (dianhua) ist ganz falsch“. ${ }^{1315}$ Sei es, daß die für die chinesische Verwaltung tätigen ShanÜbersetzer aufgrund geringer Kenntnisse Fehler beim Übertragen in das Birmanische machten oder daß sie eine ihnen geläufige Shan-Schrift verwendeten, die sich in der Schreibweise einzelner Buchstaben (dianhua) deutlich vom Birmanischen unterschied. Hinzu kam, daß es gegen Ende des 18. Jahrhunderts keine einheitliche Rechtschreibung gab, an der sich Übersetzer hätten orientieren können. So verwendeten auch diejenigen, die das Birmanische beherrschten, verschiedene Schreibvarianten, welche wiederum bei den Shan-Übersetzern noch zusätzlich durch die Orthographie des Shan beeinflußt wurde. Den Birmanen bot sich folglich beim Erhalt eines solchen Dokumentes zwar auf den ersten Blick ein insgesamt vertrautes Schriftbild, das sich jedoch bei näherer Betrachtung als unverständlich entpuppte.

\footnotetext{
${ }^{1314}$ Qingzhong (das ,Gewicht‘ der Töne) ist ein Fachausdruck, der für mehrere Unterscheidungen in der Phonologie verwendet wird, z. B. für die Höhe oder die Stärke der Töne, oder auch um zwischen nicht-aspirierten (qing) und aspirierten (zhong) Lauten zu differenzieren (ZGYYXDCD, S.158).

${ }^{1315}$ TYTZ, S. 389, Zeile 10-11
} 
Ähnliche Schwierigkeiten dürften auch bei der Übersetzung birmanischer Dokumente ins Chinesische aufgetreten sein, wenn die Übersetzer nur Shan beherrschten und deren Inhalt nicht verstehen konnten. Wu Kai geht auf diese Problematik nicht ein, so bleibt fraglich, in wie weit Schriftstücke aus Birma, wie sie zum Beispiel der Generalgouverneur Jueluo Tuside im Jahr 1777 (Qianlong 42) mit einer chinesischen Übersetzung (puye mian bing ji yi chu han wen) in die Hauptstadt gesandt hat, wirklich übersetzt worden sind. ${ }^{1316}$ Möglicherweise waren solche Übersetzungen teilweise nur schematische Übertragungen, die ohne Rücksicht auf den tatsächlichen Wortlaut den Inhalt formelhaft nach dem Vorbild chinesischer Throneingaben gestalteten.

Doch Übersetzungen wurden nicht allein in China angefertigt, auch in Birma und den tusiGebieten gab es Dolmetscher und Übersetzer, die das Chinesische beherrschten. So war Unterpräfekt Wu gerade in einem persönlichen Gespräch mit den Birmanen Meng Wei und Meng Ling, zwei Dolmetschern, die den chinesischen Gesandten Su Erxiang 1777 nach Tengyue zurück begleitet hatten, auf die Schwierigkeiten aufmerksam gemacht worden,die man in Birma mit dem Entziffern angeblich birmanischer Schriftstücke aus China hatte.

Im 18. Jahrhundert lebten in Birma zahlreiche chinesische Einwanderer, die in der Hauptstadt Ava ein eigenes Stadtviertel bewohnten und auf deren Sprach- und Schriftkenntnisse die birmanische Verwaltung für die Ausbildung von Dolmetschern und Übersetzern zurückgreifen konnte. ${ }^{1317}$ In den Herrschaftgebieten der Shan hatte mit dem Zustrom Hanchinesischer Zuwanderer nach Yunnan auch die Zahl der Chinesen, die in den Gebieten der Shan-tusi siedelten, zugenommen. An den Höfen der Shan-Fürsten bot sich ihnen die Möglichkeit, gerade aufgrund ihrer Sprach- und Schriftkenntnisse einflußreiche Positionen in der Verwaltung einzunehmen, da sie den Herrschern den Umgang mit ihrem mächtigen Nachbarn China erleichtern konnten.

Folglich gingen bei den Beamten in den chinesischen Verwaltungseinheiten nicht nur fremdsprachliche Dokumente ein, sondern auch Schriftstücke, die bereits auf Chinesisch abgefaßt waren. Dies führte zu einem kuriosen Phänomen, auf das auch Wu Kai hinweist:

„Wenn die Fremden aber die chinesische Schrift benutzen, so veranlaßt dies die Übersetzer, die birmanische Aussprache hinzuzufügen. Es ist nicht möglich, den Sinn dessen zu verstehen“. 1318

\footnotetext{
${ }^{1316}$ National Palace Museum, Secret Palace Memorials, Bd. 37, S. 643; siehe auch TYTZ, S. 273 (Longchuan shanhou shu).

${ }^{1317}$ Harvey, S. 248

1318 TYZZ, S. 170 oben, Zeile 12-13.
} 
Beispiele für die hier erwähnte Transliteration von chinesischen Texten, die aus Birma nach China gesandt worden waren, in birmanische Schrift gibt auch Nishida, dessen Studie über ein birmanisch-chinesisches Wörterbuch auch auf chinesisch abgefaßte Throneingaben (laiwen) enthält, die ins Birmanische übertragen wurden, indem die chinesische Aussprache mit birmanischen Buchstaben wiedergegeben wurde. ${ }^{1319}$ Der so entstandene birmanische Text ist für sich allein genommen unverständlich. Ein ähnliches Beispiel aus einem zweisprachigen Wörterbuch erklärt F.W.K. Müller als einen chinesischen Text, der in einem Shan-Alphabet geschrieben worden ist. ${ }^{1320}$ Warum Dokumente, die ursprünglich auf Chinesisch verfaßt worden sind, in birmanische Schrift transliteriert wurden oder auch die birmanische Aussprache mit chinesischen Zeichen wiedergegeben wurde, bleibt fraglich, vermutlich sollte ihnen durch die Beigabe der fremden Schrift eine zusätzliche ,Authentizität‘ verliehen werden. Unterpräfekt Wu Kai geht auf diese Texte nicht weiter ein, zu Recht erklärt er sie lapidar für sinnlos.

Bei aller Kritik hat Wu Kai jedoch auch einen Lösungsvorschlag anzubieten. Um in Zukunft die Übergabe von fehlerhaften Schriftstücken und die daraus resultierenden Mißverständnisse zu vermeiden, empfiehlt er generell chinesische Dokumente zu überreichen, da es ja auch in anderen Ländern Menschen gebe, die das Chinesische beherrschen würden (bi di you shu han zi zhe zi neng jie qi shuo). ${ }^{1321}$ Wu Kais Vorschlag entspricht oberflächlich betrachtet zunächst überlieferten chinesischen Vorstellungen, wie sie in den ,Zivilisierungsprojekten` zum Ausdruck kommen, die eine Ausbreitung der Han-chinesischen Kultur (wen, das ist auch ,die Schrift‘) auf die Völker an der Peripherie anstrebten. Liest man jedoch seine Gründe für die Verwendung der chinesischen Sprache im amtlichen Schriftverkehr mit Birma, so zeigt sich, daß diese rein pragmatischer Natur sind. Ihm geht es vor allem darum, einem Mangel im eigenen Land abzuhelfen, um den mit der Übersendung unverständlicher Dokumente verbundenen Prestigeverlust zu vermeiden, von dem er im Gespräch mit den Dolmetschern aus Birma erfahren hatte, deren Sprachkenntnisse ihm zugleich die Lösung des Problems nahegelegt haben. Sein Bericht macht zudem deutlich, daß sich auch Nachbarstaaten in ihrer Kommunikation mit dem Kaiserreiches der chinesischen Sprache und Schrift bedienten: In Birma gab es Dolmetscher und in den Herrschaftsgebieten der Shan wurden Schriftstücke auf Chinesisch verfaßt; zweifellos ebenfalls aus

\footnotetext{
${ }^{1319}$ Nishida, Tafel 2 und S. 164ff.

${ }^{1320}$ Müller, S. 329-333; siehe auch Lefèvre-Pontalis, S. 61.

${ }^{1321}$ TYTZ, S. 389, Zeile 11
} 
sehr pragmatischen Gründen, möglicherweise aufgrund von Erfahrungen mit fehlerhaft übersetzten Dokumenten aus China.

Im Gegensatz zu der flexiblen Verwendung von Fremdsprachen im Grenzgebiet, standen einige der chinesischen Verwaltungsbehörden hinter dieser Entwicklung zurück. Sie heben dies nicht etwa als Beispiel für die ,Zivilisierung‘ der Randvölker hervor, sondern transliterierten auf Chinesisch abgefaßte Dokumente wieder in eine fremde Schrift und betonen somit die Abgrenzung der Unterpräfektur Tengyue von den ,exotischen` Gebieten jenseits ihres Einzugsbereiches.

Weder Wu Kai noch sein Amtsnachfolger Tu Shulian, der im Jahr 1790 an der Reise der chinesischen Gesandtschaft nach Birma teilnahm und anschließend birmanische Gesandte in die Provinzhauptstadt Yunnan fu begleitete, erwähnen das Mianziguan. Mit dem Vorschlag Wu Kais, den Schriftverkehr in Zukunft auf Chinesisch zu führen, hat das Amt für ihn keine Bedeutung mehr. Möglicherweise lag in einer veränderten Kanzleipraxis auch der Grund für die an dieser Stelle nicht näher erläuterte Schließung des Amtes für Birmanisch in der Provinz Yunnan.

Die Verfasser des TYTZ heben jedoch gerade in Zusammenhang mit dem Bericht Wu Kais die Bedeutung des Mianziguan erneut hervor. Ebenso wie Wu Kai in der Zeit nach dem chinesisch-birmanischen Krieg, als der chinesische Kaiser ein Handelsembargo verhängt hatte und die Tributbeziehungen zwischen den beiden Ländern zwei Jahrzehnte lang ruhten, haben auch die Verfasser des TYTZ Ende des 19. Jahrhunderts nach den Wirren der Moslem-Rebellion ihr fangzhi in einer Phase der Restauration zusammengestellt, in der die Beziehungen zu den Nachbarvölkern wieder aufgenommen und Loyalitäten neu gefestigt werden mußten. Sowohl der Bericht Wu Kais als auch der Hinweis auf das Mianziguan zeigen, daß für die Unterpräfekten von Tengyue Kenntnisse von den Gebieten jenseits ihrer Verwaltungseinheit von entscheidender Bedeutung für die chinesische Politik im Grenzgebiet waren und zwar nicht nur für die Beamten in der Region, sondern auch für die Zentralverwaltung, die letztlich diese Politik bestimmte. Für deren Erfolg ein fehlerfreier Schriftverkehr und generell bessere Informationen notwendig waren, wie sie die Verfasser in ihren fangzhi mit den Darstellungen historischer Entwicklungen, den Karten und den zweisprachigen Wörterbüchern vermitteln wollten. 


\section{ZUSAMMENFASSUNG}

Nachdem die Region des Stromschluchtenfächers in der Han-Zeit erstmals in das Blickfeld einer chinesischen Zentralregierung gerückt war, begannen sich dort chinesische Zuwanderer anzusiedeln, die die Verbindung mit dem Kernland aufrecht erhalten und so erstmals zeitweise ein Grenzgebiet im Osten des Gaoligong-Gebirges ,eröffnet‘ haben. Doch die eigentliche Grundlage für die Entstehung der modernen Provinz Yunnan ist erst einige Jahrhunderte später von den Herrschern des Königreichs von Nanzhao geschaffen worden. Sie haben ein weites Territorium unter ihre Oberhoheit gebracht und ihre Hauptstädte am Erhai- und Dian-See (heute Dali und Kunming) als Verwaltungszentren der Region fest etabliert. Die zentralen Strukturen ihres Staates, für dessen Organisation sie sich auch am Vorbild des Tang-zeitlichen China orientierten, wurden vom nachfolgenden Königreich von Dali übernommen und auch die Mongolen stützten sich nach ihrer Eroberung der Region auf die bestehenden administrativen Einheiten ihrer Vorgänger.

Schon die Könige von Dali hatten ihr Herrschaftsgebiet, anders als Nanzhao, am Irawadi nach Westen abgegrenzt, auch von dem expandierenden birmanischen Königreich von Pagan, das im 11. Jahrhundert seinen Einfluß bis in das Gebiet des modernen Bhamo geltend machte. Ein Vorstoß der Mongolen nach Birma, erwies sich später als zeitlich begrenzt und die Hochebene von Tengchong wurde Ende des 13. Jahrhunderts zur westlichsten regulären Verwaltungseinheit der neuen chinesischen Provinz Yunnan, an die sich im Südwesten ein Grenzgebiet mit Herrschaftsgebieten unter einheimischer Verwaltung anschloß.

Zwei Faktoren haben diese Entwicklung entscheidend beeinflußt: Die geographischen und die klimatischen Bedingungen der Region des Stromschluchtenfächers. Zur Überquerung der Bergketten und Flüsse hat sich schon in vorchristlicher Zeit eine Hauptverkehrsroute herausgebildet, die bis heute die wichtigste Verkehrsader der Provinz ist und von Kunming über Dali und das Gaoligong-Gebirge nach Birma führt. Armeen und Handelskarawanen zogen auf ihr entlang, Militärstützpunkte und Verwaltungszentren entstanden an der Strecke und ermöglichten die Kontrolle umliegender Gebiete. Jenseits von Tengchong teilte sich diese Hauptroute; verschiedene Strecken führten entlang der Flußtäler des Dayingjiang und Longchuanjiang nach Südwesten. Dort veränderte sich das Klima und Tropenkrankheiten wie die Malaria waren bis in die Neuzeit weit verbreitet, so daß 
Militäraktionen in diese Gebiete für China immer verlustreich und sie auch für Hanchinesische Siedler weniger attraktiv waren. Anders als das höher gelegene Tengchong, auf dessen Plateau die verschiedenen Wege aus Birma zusammenliefen und das sich wegen seines gemäßigteren Klimas hervorragend zur Etablierung der ,charakteristischen zellularen Einheit einer Stadt mit den sie umgebenden landwirtschaftlichen Gemeinden` (Lattimore) sowie als Kontrollpunkt eignete.

Entsprechend wurde dort zu Beginn der Ming-Zeit zunächst wiederum ein Militärstützpunkt gegründet und Mitte des 15. Jahrhunderts mit einer Mauer umgeben. Mit der Zuwanderung von Han-Chinesen und der zügigen Errichtung von Verwaltungsgebäuden, Schulen und Tempeln nach dem Vorbild der Kernregion entstand die ,erste ummauerte Stadt an der äußersten Grenze`, eine Entwicklung die im Jahr 1522 in der Gründung einer Einheit der regulären Zivilverwaltung, der Unterpräfektur Tengyue, kulminierte. Damit war sowohl der administrative als auch der bauliche und soziale Rahmen abgesteckt, in dem Stadt und Verwaltungseinheit weiter konsolidiert wurden.

Südwestlich von Tengyue hatten sich die Herrschaftsgebiete der Shan (Dai) und Kachin (Jingpo) im späten 14. Jahrhundert zu eigenständigen prosperierenden Staaten entwickelt und expandierten in der Region des Stromschluchtenfächers. Die Ming-Herrscher haben diese Gebiete ihrem Reich im Rahmen des tusi-Systems assoziiert und sie nominell ihrer Oberhoheit unterstellt. Die einheimischen Herrscher nutzten ihrerseits die Kontakte zu China und profitierten vom Handel insbesondere mit den am Kaiserhof begehrten Edelsteinen. Auch Tengyue profitierte von den Handelsbeziehungen, die Stadt entwickelte sich zu einem Rast- und Stapelplatz für die Fernhändler sowie zu einem Zentrum der Edelsteinverarbeitung.

Für die Sicherung des Grenzgebietes und ihres Vorpostens Tengyue stand den Ming ein breites Repertoire an Möglichkeiten zur Verfügung, das von diplomatischen Initiativen bis zu Militäraktionen reichte und regional gestaffelt eingesetzt wurde. Chinesische Truppen wurden nur dann mobilisiert, wenn Tengyue selbst bedroht war oder Auseinandersetzungen in den nahe der Unterpräfektur gelegenen tusi-Gebieten dahin überzugreifen drohten. In weiter entfernt gelegene Gebiete wurden allenfalls Beamte entsandt, die als Vermittler agierten. 
Mit ihrem differenzierten Engagement trugen die Ming der unterschiedlichen Entwicklung der verschiedenen Herrschaftsgebiete im Südwesten von Tengyue Rechnung, deren militärische und ökonomische Stärke ebenfalls zur Abgrenzung des Hoheitsgebietes der Unterpräfektur Tengyue beitrugen. Entscheidender Faktor für die Entwicklung des Grenzgebietes war jedoch die Expansion der Birmanen in die Region des Stromschluchtenfächers: Unter der Herrschaft der Könige Bayinnaung und Nandabayin hatten birmanische Truppen in der zweiten Hälfte des 16. Jahrhunderts die Kleinstaaten der Shan westlich des Irawadi und südlich des Shweli erobert und waren bis in das Gebiet der Unterpräfektur Tengyue vorgerückt. Um ein weiteres Vordringen der Birmanen nach Osten zu verhindern, setzten die Ming Truppen ein und errichteten zudem acht strategisch gelegene Paßstationen, von denen aus Soldaten die Verkehrswege kontrollierten. Die Stationen sind nicht als Grenze des chinesischen Reiches konzipiert worden, doch die tatsächlichen Machtverhältnisse ließen sie zu einer Grenze werden: Für die Beamten der chinesischen Militär- und Zivilverwaltung bezeichneten sie die Grenze ihres Amtsgebietes, von Zeitgenossen wurden sie darüber hinaus als ,Grenze der Kulturen‘ (Xu Xiake) bzw. der chinesischen Zivilisation verstanden.

Diese pragmatische Abgrenzung des tatsächlichen chinesischen Einflußbereiches im äußersten Westen Yunnans wurde von geographischen, ökonomischen und politischen Faktoren bestimmt, die auch in der Zeit der Qing-Dynastie ihre Gültigkeit behalten und schließlich zum Entstehen der modernen linearen Staatsgrenze führen sollten.

Zu Beginn der Qing-Dynastie rückte die Region des Stromschluchtenfächers sogleich in das Blickfeld der neuen Herrscher Chinas, deren Truppen den letzten Kaiser der Südlichen Ming über Tengyue bis nach Birma verfolgten. Der zügige Ausbau ihrer Herrschaft über die Provinz hielt die Anbindung des fernen Westens an das chinesische Kernland über den Dynastiewechsel Mitte des 17. Jahrhunderts hinaus kontinuierlich aufrecht. Die zivilen Verwaltungseinheiten der Ming-Zeit blieben weiter bestehen und Tengyues Status als westlichster Militärstützpunkt Yunnans wurde weiter gestärkt. Der verlorene Krieg gegen Birma Mitte des 18. Jahrhunderts zeigte erneut die Kontinuität der Abgrenzung der Einflußsphären der beiden benachbarten Reiche entlang der Paßstationen.

Die eigentliche Grenzverteidigung Chinas wurde allerdings im Verlauf der Qing-Zeit von der Linie der acht Paßstationen weiter nach Osten zurückgezogen. An strategischen Punkten weiter oberhalb am Fluß Daying wurden chinesische Militärposten (im Jahr 1876) gegründet sowie Kontrollstationen (1879) in einem Halbkreis von Nord nach Südwest um 
die Stadt Tengyue herum errichtet, die die Gemeinden mit Han-chinesischer Bevölkerung von den Siedlungsgebieten anderer Volksgruppen abschirmten.

Diese Maßnahmen waren charakteristisch für die Entwicklung des Grenzgebietes des chinesischen Reiches im äußersten Westen Yunnans insgesamt. Trotz des nominellen Anspruchs des Kaiserreiches auf die Oberhoheit über die Nachbarvölker im Südwesten war die chinesische Politik in der Region des Stromschluchtenfächers über die Jahrhunderte auf die Sicherung der Hochebene von Tengchong konzentriert, die durch Anbindung an die Kernregion und Abgrenzung von den Siedlungsgebieten anderer Völker, nicht durch Bemühungen um deren Integration oder durch Expansion erreicht wurde.

Das kommt auch in der Dauerhaftigkeit der beiden Zonen innerhalb der Unterpräfektur zum Ausdruck, die bereits in der Yuan-Zeit entstanden waren und die Gouverneur Chen Yongbin 1603 mit dem Bild des ,Hauses‘ Yunnan, mit den ,Türen` Yongchang und Tengyue und der ,Schutzmauer‘ der tusi-Gebiete östlich der Paßstationen beschrieben hat: Diese tusi-Gebiete wurden zwar von China zum Verwaltungsgebiet der Unterpräfektur gerechnet, waren aber anders als die Stadt Tengyue mit den sie umgebenden Gemeinden dennoch nicht ganz Teil des eigentlichen ,Hauses ‘ Yunnan, sondern hatten ihre Eigenständigkeit in der Peripherie der chinesischen Verwaltungseinheit wahren können.

Diese Strukturierung der Region des Stromschluchtenfächers spiegelt sich noch heute in der Verwaltungsorganisation der VR China wider: Tengchong ist Teil des Bezirkes Baoshan; westlich der Hochebene bis zur birmanischen Grenze schließt sich eine Einheit der regionalen Sonderverwaltung an: Der autonome Bezirk Dehong der Dai- und JingpoNationalitäten. Auch der Verlauf der modernen Staatsgrenze zeigt das Ergebnis dieses Entwicklungsprozesses. Die acht Paßstationen waren Ende des 19. Jahrhunderts Ausgangspunkt für die Festlegung der Grenze zwischen China und British-Burma; seit dem Abschluß des Grenzvertrages zwischen der VR China und der Union von Birma im Jahr 1960 befinden sich die Standorte der vier nördlichen Stationen auf chinesischem, die der vier südlichen auf birmanischem Staatsgebiet.

Die Verfasser der Lokalhandbücher von Tengyue dokumentieren den Entstehungsprozeß des Grenzgebietes mit seinen verschiedenen Zonen ausführlich. In ihrer Gesamtheit vermitteln die Informationen der fangzhi durchaus ein differenziertes und vielschichtiges Gesamtbild der Entwicklung der Stadt und der Verwaltungseinheit. Bei allen geschilderten Veränderungen betonen die Verfasser, ortsansässige Kompilatoren wie ortsfremde Beamte, 
die Kontinuität, nicht nur der Abgrenzung der Unterpräfektur nach Westen, sondern vor allem die der Einbindung in das chinesische Kernland im Osten. Abgrenzung und Einbindung kommen in der Verwaltungsorganisation zum Ausdruck und ebenso auch in der baulichen Entwicklung Tengyues: Die Errichtung der Stadtmauer markierte das chinesische Zentrum der Region und grenzte seine Einwohner von den anderen Völkern in der Region ab. Die Han-chinesischen Zuwanderer siedelten sich allerdings größtenteils außerhalb dieser Begrenzungsmauer an: In der südwestlichen Vorstadt, in Dörfern und Gemeinden in der weiteren Umgebung der Stadt und auch in den tusi-Gebieten; dort jedoch meist in eigenen Siedlungen mit einem Markt- und Handelsplatz in der Nähe der Residenzen der einheimischen Herrscher. Die chinesischen Beamten hingegen konzentrierten sich auf den Ausbau Tengyues und förderten vor Ort fast ausschließlich Bauvorhaben in der Stadt selbst und ihrer direkten Umgebung. Eine Ausnahme bildeten, neben den Militärposten zum Grenzschutz, die Brücken, die im Osten der Unterpräfektur für die Verkehrsanbindung an die Präfekturstadt Yongchang bzw. an Zentralchina sorgten.

Neben dem materiellen Aufbau nach dem Vorbild der Kernregion galt den Regierungsbeamten die Entwicklung des Schulwesens insgesamt als Gradmesser für die gelungene Eingliederung des fernen Westens in das chinesische Reich, deren Erfolg sich in der Zahl der Absolventen der Staatsprüfungen aus Tengyue zeigte. Entsprechend waren die Freischulen, die in den Han-chinesischen Gemeinden seit dem 18. Jahrhundert gegründet wurden, die einzigen rein zivilen Bauprojekte die auf Initiative der Unterpräfekten außerhalb der Stadtmauern durchgeführt wurden.

Mit den kontinuierlichen Bemühungen um den Aufbau und die Instandhaltung der Amtsgebäude und Tempel sowie der Förderung des Schulwesens in Tengyue knüpften die Verwaltungsbeamten an das allgemeine ,Zivilisierungsprojekt‘ an, das sich an die Hanchinesische Bevölkerung richtete und das besonders in der konsequent durchgeführten umfangreichen Restauration aller Institutionen nach dem Krieg gegen Birma in der zweiten Hälfte des 18. Jahrhunderts und erneut einhundert Jahre später nach der Niederschlagung der Moslem-Rebellion zum Ausdruck kommt. Die zügige Rekonstruktion der Stadt und des gesellschaftlichen Lebens sowie deren Dokumentation in den fangzhi bestätigten jeweils auch die Gültigkeit der kulturellen Traditionen und der Wertvorstellungen des Kernlandes, die hier nicht nur gewohnheitsmäßig weitergeführt, sondern als Grundlage für die weitere Entwicklung Tengyues von den Beamten und der Bevölkerung ausdrücklich bejaht wurden. 
Die ,Zivilisierung، oder Assimilierung der Randvölker hingegen war für die Verfasser der Lokalhandbücher kein Thema. Diese waren als tusi-Gebiete in das politische System des Reiches eingegliedert, Kommunikation war mit ihnen auch auf Chinesisch möglich; daß eine weitere Anpassung an die chinesische Lebensweise erwartet wurde, kommt in den fangzhi nicht zum Ausdruck. Ebenso wenig wie in Bezug auf die verschiedenen einheimischen Volksgruppen in der Region, mit denen es Kontakte im Handel und auf Märkten gab, die aber ansonsten als exotisch beschrieben und damit auch im Bewußtsein deutlich von der Han-chinesischen Bevölkerung abgegrenzt wurden.

Die historische Entwicklung Tengyues zeigt, daß die chinesischen Regierungen über die Jahrhunderte kontinuierliche Anstrengungen unternommen haben, um das Grenzgebiet im nach ihren Vorstellungen zu gestalten daß es ihnen mit der pragmatischen Abgrenzung ihres direkten Einflußbereiches in der Region des Stromschluchtenfächers sowie dem konsequenten Aufbau der Stadt nach dem Muster der Kernregion gelungen ist, Tengyue dauerhaft als urbanes Zentrum äußersten Westen Yunnans zu etablieren.

Tengchong hat seine Position als westlichstes Verwaltungs- und Handelszentrum der Provinz Yunnan über die Jahrhunderte behauptet. In der letzten Dekade des 20. Jahrhunderts hat jedoch eine neue Entwicklung begonnen. Während die wichtigsten Handelswege der Provinz in der Ming- und Qing-Zeit noch über die Hochebene von Tengchong führten, hat zu Beginn des 21. Jahrhunderts die südlichere Verkehrsverbindung von Baoshan nach Ruili (die ehemalige ,Burma Road`) deutlich an Bedeutung gewonnen. Diese Strecke ist Teil der geplanten Autobahnverbindung von Shanghai nach Ruili, die auch in Yunnan zügig ausgebaut wird: Ein erstes Teilstück führt von Kunming nach Qujing; der Streckenabschnitt von Dali nach Baoshan ist im Oktober 2002 eröffnet worden.

Ruili liegt direkt an der Staatsgrenze und hat sich seit den 80er Jahren des 20. Jahrhunderts zu einem Handelsplatz und Sitz der Kreisverwaltung entwickelt. Mit der Anlage von breiten Straßen mit einer Fahrradspur, den schlichten in ganz China verbreiteten mehrstöckigen Wohn- und Bürohäusern, mit dem Postamt und der Xinhua-Buchhandlung sowie den zahlreichen neuen Zuwanderern aus anderen Provinzen spiegelt das moderne Ruili die Entwicklung von einem Militärstützpunkt zu einer ,typisch chinesischen Stadt‘ wider, wie sie in Tengchong Mitte des 15. Jahrhunderts mit der Errichtung der Stadtmauer und weiteren Bauwerken nach dem Vorbild der Kernregion eingesetzt hat. 
Zwar profitiert Tengchong heute ebenfalls von der Ausweitung des internationalen Handels, auch die Straßenverbindung von Tengchong nach Myitkyina, Hauptstadt des KachinStaates und nördlicher Endpunkt der Eisenbahnlinie in Oberbirma, ist bereits ausgebaut worden, doch verläuft die Modernisierung hier langsamer als in Ruili. Mit der fortschreitenden Erschließung der Mekong-Region verlagert sich zudem der Schwerpunkt neuer chinesischer Entwicklungsprojekte im Stromschluchtenfächer weiter nach Südosten, wo die Inbetriebnahme der ersten Wasserkraftwerke und die Intensivierung des Schiffsverkehrs bereits Erfolge zeigen und erheblich zum Wirtschaftswachstum Yunnans beitragen.

Welche Auswirkungen dies auf die weitere Entwicklung Tengchongs haben wird, läßt sich heute noch nicht absehen. Sei es, daß Tengchong hinter dem prosperierenden südlicheren Grenzgebiet zurückbleibt oder im Norden dieser neuen Wachstumszone von deren Aufschwung profitieren und sich als ,erste Stadt an der äußersten Grenze` behaupten wird. Für letzteres sprächen die umfangreichen von der Lokalregierung finanzierten Projekte zur Förderung des Tourismus im ,Geologie-Museum der Natur' (,Vulkan-Park', ,Meer der heißen Quellen’), die in Tengchong derzeit umgesetzt werden. In jedem Fall befindet sich Tengchong einmal mehr an einer Grenze, an der Strukturen neu definiert werden und das gesamte westliche Grenzgebiet der Provinz Yunnan in eine ganz neue Entwicklungsphase eintritt. 


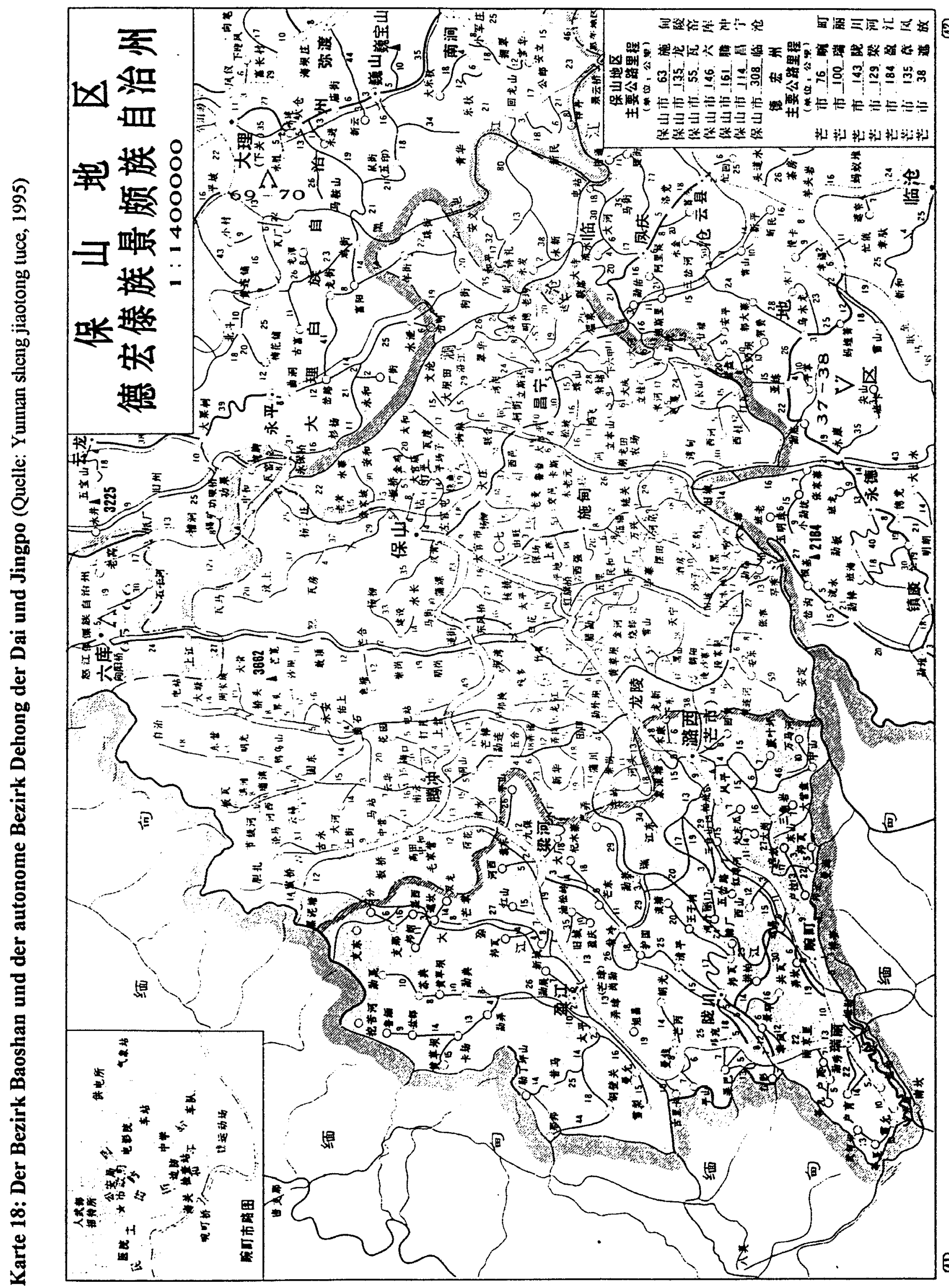




\section{Karte 19: Südostasien (Festland)}

(Quelle: Harley/Woodward, Cartography, vol.2, book2, fig. 18.1)

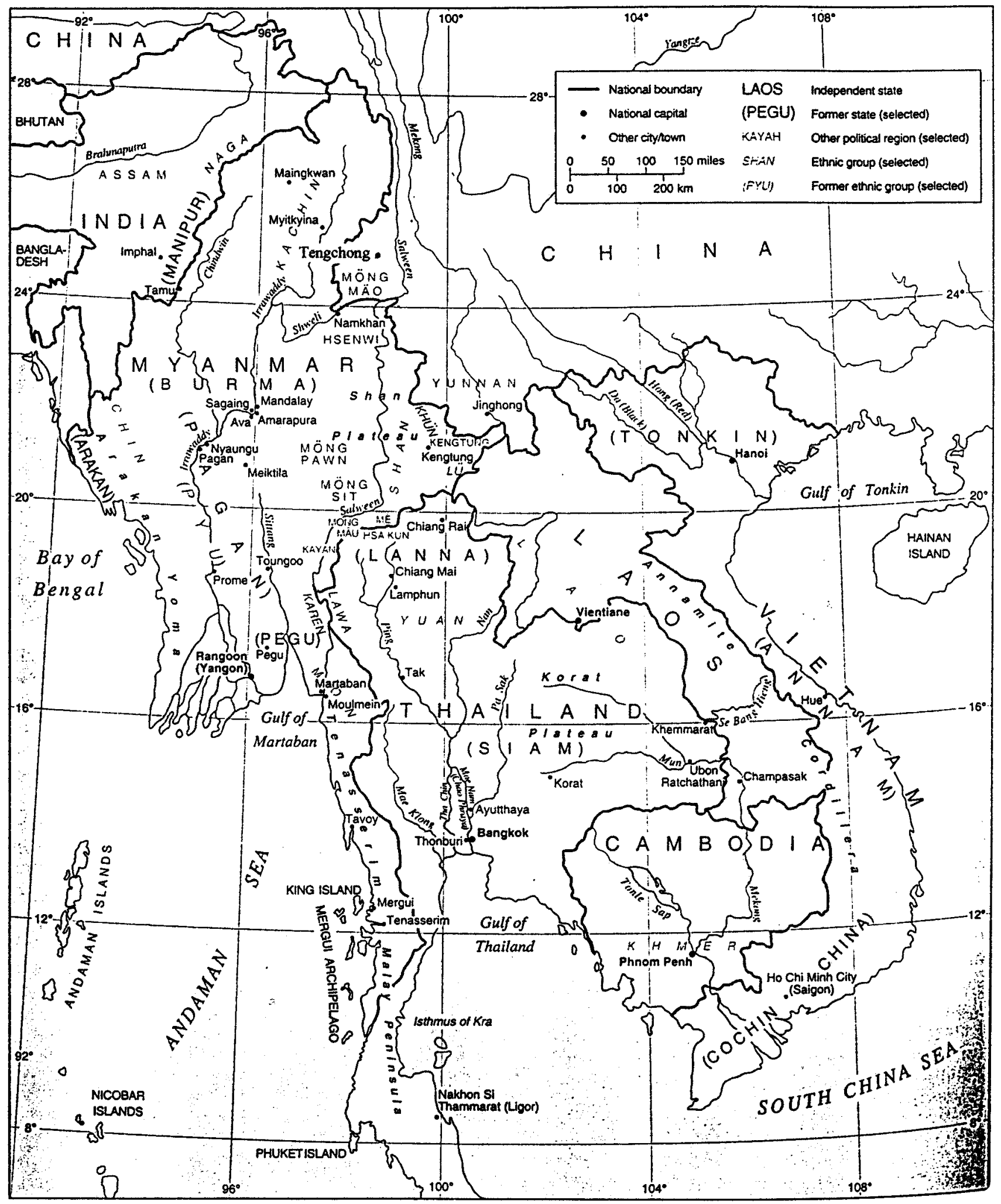




\section{ANHANG}

\section{ÜBERSETZUNGEN}

\section{A. TeXTE ZUR MING-ZEIT}

\section{Die Reise des Gesandten Guo Xu zum Jinshajiang im Jahr 1501}

Die Biographie des ,berühmten Beamten` (ming chen) Guo Xu in den Lokalhandbüchern von Tengyue enthält einen ausführlichen Bericht über seine diplomatische Mission in die tusi-Gebiete am Oberlauf des Irawadi (chin. Jinshajiang) (siehe TYTZ, S. 140; TYZZ, S. 99-100).

„Guo Xu, Beiname Jiye, stammte aus Taikang und hatte zur Zeit der Ära Chenghua (1465-1488) den akademischen Titel eines jinshi erworben. ${ }^{1322}$ Guo war zunächst als Sekretär (zhushi) im Finanz-ministerium (hubu) beschäftigt gewesen, Ehe er nach Yunnan entsandt wurde, wo er als Vize-Direktor (canzheng) der Provinzbehörde tätig war.

Zu der Zeit, als mit der Sicherung des Militärbezirks Jin-Teng begonnen worden war [d.h. im Jahr 1476], war das Befriedete Gebiet (xuanfu si) Mengmi entstanden, indem es sich von dem höherangigen Befriedeten Gebiet (xuanwei si) Mubang abgespalten hatte.

Si Ye, der tusi von Mengmi, hatte Teile von Mubang erobert und diese, obwohl er mehrfach [aus China] den Befehl dazu erhalten hatte, nicht zurückgegeben. Daraufhin wurde angeordnet, daß Si Lu, Oberhaupt (xuanfu) des benachbarten Mengyang, Truppen entsenden solle, um Mengmi einzuschüchtern. Si Ye gab daraufhin die eroberten Gebiete zurück. Da aber im Kampf sehr viele Soldaten aus Mengyang getötet worden waren, schickte Si Lu aus Haß erneut Truppen über den Jinshajiang [den Oberlauf des Irawadi], denen es gelang, Teile der zuvor von Mubang abgetrennten Gebiete nun seinerseits zu erobern. Seitdem waren die beiden Häuptlinge verfeindet.

Im 14. Jahr der Ära Hongzhi (1501) kommandierte der Gouverneur [von Yunnan] Chen Jincheng den Guo Xu und den Amtsleiter Cao Yu dorthin ab. Er ordnete an, daß sie innerhalb von zehn Tagen in Jinchi eintreffen sollten.

Der Regionalkommandant [von Tengchong], Lu He, hatte währenddessen seine Truppen zwei Tagesmärsche entfernt von seinem Stützpunkt zusammengezogen. Dort blieb er zunächst und schickte einen Beamten, der zur Poststation eilen und [Guo Xu] davon unterrichten sollte. Der Beamte richtete die Botschaft jedoch nicht aus. He fürchtete sich [allein weiter vorzurücken] und

$\overline{1322}$ Taikang befindet sich in der modernen Provinz Henan. 
kehrte mit seinen Truppen bis nach Ganya zurück. Dort traf er mit Xu zusammen, schilderte ihm die Lage und warnte ihn davor weiter vorzurücken. Aber darauf ließ sich Xu nicht ein. Cao Yu zog sich aus Krankheitsgründen zurück.

Also ritt Xu allein weiter, nur mit einem Gefolge von einigen Dutzend Leuten. Nach zehn Tagen kamen sie in eine Gegend, wo das Gelände steil und gefährlich war. Sie konnten nicht weiterreiten und mußten sich zu Fuß ihren Weg durch das Gestrüpp bahnen. [Die steilen Berge] konnten sie nur mit Hilfe von Seilen erklimmen. Nach weiteren zehn Tagen erreichten sie einen großen See. Ein einheimischer Beamter (tuguan) kam ihnen mit einer von einem Elefanten getragenen Sänfte entgegen, um sie willkommen zu heißen. Xu [bestieg] die Sänfte und reiste auf schwer begehbaren schlammigen Wegen durch giftige Nebel weiter. Nach mehreren Tagen kam er so in Menglai an, von wo aus es nur noch zwei Tagesmärsche bis zum Jinshajiang waren. [Guo Xu] selbst schrieb eine Proklamation, in der es hieß, daß der chinesische Hof den Wunsch habe, [die Einheimischen] herbeizurufen und schickte einen Boten damit über den Fluß.

Die Barbaren (man) sahen einander an und sagten voller Respekt: ,Der chinesische Bote ist bis in dieses Gebiet gekommen`. Sie schickten daraufhin Soldaten und führten mehrere zehntausend Elefanten und Pferde in der Nacht über den Fluß. In den Händen hielten sie lange Lanzen und starke Bogen. In mehreren Kreisen umringten sie [die Chinesen]. Viele der Gefolgsleute Guo Xus fürchteten sich und baten darum, daß sie nicht weiter vorrücken müßten. Xu zog sein Schwert und rief ärgerlich: ,Morgen müssen wir den Fluß überqueren. Wer es wagt, weiterhin solche Reden zu führen, wird geköpft‘.

Si Lu hatte den Befehl erhalten und verstanden, so daß er nun wußte, welche seiner Taten zu einem guten und welche zu einem schlechten Ergebnis führen würden. Da er gehört hatte, daß die Leute, die da angekommen, waren nur wenige waren, schickte er einen seiner Häuptlinge (qiuzhang) zu ihnen, um die Befehle zu empfangen und ihnen Geschenke zu überreichen. Xu lehnte die Gaben ab, er holte den Befehl hervor und verlas ihn öffentlich. Danach kam Si Lu selbst zu Xu. Xu würdigte zunächst die Verdienste des anderen, dann beseitigte er einige Ungerechtigkeiten, danach aber tadelte er ihn für seine Rebellion. Alle Häuptlinge hörten dies, daraufhin warfen sie sich nieder und riefen ,lang lebe der Kaiser‘ (wansui). Sie baten darum, erobertes Land zurückgeben zu dürfen.

[Später] verhörte Xu den Boten des Lu He, der seine Botschaft nicht übermittelt hatte, und entließ ihn. Als Lu He und Cao Yu davon hörten, eilten sie zu Guo Xu. Da waren die Gebiete schon zurückgegeben worden und [die Einheimischen] zahlten Steuern. Das war im 5. Monat des 14. Jahres der Ära Hongzhi (1501).

Danach zog Xu sich von seinem Amt zurück.“ 


\section{Die Beschreibung des Befriedeten Gebietes Mengmi}

Der Kleinstaat Möng Mit (chin. Mengmi, birmanisch Mo-meit) war einer der Shan-Staaten im Nordosten des modernen Birma, berühmt für seine Rubine, die bis heute in der Umgebung von Mogok in zahlreichen Minen abgebaut werden. Lokalen Chroniken zufolge war Möng Mit ursprünglich Teil des Staates Kengtung (chin. Menggen), dessen Herrscher (Sawbwa) das Gebiet im Jahr 1238 seinem vierten Sohnes Thohanbwa zur Verwaltung übergeben hatte. Dessen Nachfolger Sawkebwa gilt als der eigentliche Gründer der Stadt Möng Mit: Er ließ im Jahr 1279 eine innere und eine äußere Stadtmauer sowie einen Graben anlegen. ${ }^{1323}$

Die historische Entwicklung Möng Mits als lokale Sonderverwaltungseinheit Mengmi des Ming-Reiches wird in den fangzhi von Tengyue ausführlich beschrieben (TYTZ, S. 241 und TYZZ, S. 151-152). ${ }^{1324}$

„Unter den verschiedenen tusi, die während der Ming-Zeit eingerichtet worden sind, war das Befriedete Gebiet (xuanfu si) von Mengmi das letzte. Ursprünglich gehörte es zum Gebiet von Mubang. Es gibt dort eine Stadtmauer aus Ziegeln, aber keine mehrstöckigen Wachtürme. Örtliche Produkte sind Blumen, Obst, Kürbisse und Gemüse, genau wie im Inland. ${ }^{1325}$

Im Norden ragt der Nanyashan steil empor, umflossen von den beiden Strömen Mole und Jinsha [der Oberlauf des Irawadi]. Die Berge sind hoch. Felder gibt es nur wenige, Getreide und Reis sind [deshalb] sehr teuer. Es gibt dort viele Diyanggui, die eine Heimsuchung (sui) für die Reisenden sind. $^{1326}$

Im Norden [von Mengmi], in einer Entfernung von etwa fünfhundert Kilometern, befindet sich die Unterpräfektur Tengyue.Es gibt zahlreiche Wege, die in die Unterpräfektur führen: Einer führt von Mubang und Xipo dorthin, einer von Mengmao über Mengguang, einer führt von Bangkang und Luzu über den Mole-Fluß und den Nanya[shan] und einer führt über Manmo dorthin.

Während der Ära Yongle der Ming-Dynastie (1403-1425) erhielt Han Binfa, Oberhaupt des Befriedeten Gebietes (xuanwei si) von Mubang für seine Verdienste bei einem Feldzug gegen Babai und Birma [die Oberhoheit über] dreizehn Orte in Mengmi [zugesprochen].

\footnotetext{
${ }^{1323}$ Scott/Hardiman, S. 405-406

${ }^{1324}$ Siehe auch YCFZ, S. 330. Eine Englische Übersetzung von E. H. Parker findet sich in: Scott / Hardiman, S. 409-412. ${ }^{1325}$ Im YCFZ (S. 330) heißt es: „... genau wie in China (Zhongguo)“.

${ }^{1326}$ Siehe TYTZ, S. 247. Diyanggui (,Land-Schaf-Teufel`) ist eine Bezeichnung in den chinesischen Quellen für eine im Gebiet von Mengmi ansässige Volksgruppe, deren Angehörige „kurze Haare und gelbe Augäpfel haben ... und Zauberkünste ausüben“ (TYTZ, S. 247; für die vollständige Beschreibung der Diyanggui in den fangzhi siehe unten Anhang B. 4. 9., S. 508-509).
} 
Unter seiner Herrschaft standen auch die Edelsteinminen, die für Mubang äußerst profitabel waren und von dem taomeng Si Waifa verwaltet wurden. Taomeng entspricht dem chinesischen Wort (huayan) für Häuptling (toumu). ${ }^{1327}$ Han Yefa von Mubang verheiratete seine Tochter Nang Han Nong mit Si Waifa. Dessen Name in der ,Geschichte der Ming-Dynastie‘ (Ming shi) mit einem anderen Schriftzeichen für , wa' geschrieben wird.

Nach dem Tode Yefas wurde sein Enkel Kongfa sein Nachfolger. ${ }^{1328}$ In der ,Geschichte der MingDynastie‘ wird er Luofa genannt. Er war trunksüchtig und liebte es zu töten. Für Nang Han Nong war es nicht annehmbar, ihm unterstellt zu sein und so kam es während der Ära Jingtai (1450-57) zur Revolte in Meng Mi. Im 2. Jahr der Ära Tianshun (1458) griff sie zusammen mit Si Keng Luofa (das ist Han Kongfa) an und vertrieb den xuanwei. Sie eroberte dessen Amtssitz und ließ in der Umgebung morden und plündern. Ihre militärische Stärke nahm täglich zu. Sie nannte sich selbst ,Himmlische Herrin“ (tian niangzi) und ihr Sohn Si Bing gab sich selbst den Titel ,Oberhaupt eines Befriedeten Gebietes‘ (xuanwei). Luofa sandte eine Petition an den Kaiser. Ein kaiserliches Dekret erging, die [Parteien] zu besänftigen. Doch Han Nong war stolz und anmaßend, sie gab nicht nach. Überdies schickte sie sich an, auswärtige Beziehungen mit Jiaozhi anzuknüpfen, um Druck auf Mubang auszuüben. ${ }^{1329}$

Zu Beginn der Ära Chenghua (1465-88), als [der Eunuch] Mao Sheng Verteidigungskommandeur in Yunnan war, versprach Mengmi Edelsteine als eigenen Tribut zu senden, ohne sich um Mubang zu kümmern. Der Palasteunuch Qian Neng [1468 bis 1480 in Yunnan] profitierte immer mehr von den Bestechungen mit diesen Kostbarkeiten. Nang Han Nong stützte sich darauf, sie nutzte dies zunehmend aus und ohne Furcht plünderte sie das Land, um ihre [Macht] zu vergrößern. Im 10. Jahr (1474) überfiel sie Longchuan. Mu Zong, [ein Angehöriger des militärischen Oberbefehlshabers von Yunnan], reichte deshalb eine Petition ein.

Als der Palasteunuch Wang Ju im 16. Jahr (1480) aus Mengmi eingeforderte Edelsteine nicht erhielt, richtete er eine Eingabe an den Kaiser, in der er Mengmi der Rebellion gegen Mubang beschuldigte und einen Feldzug vorschlug. Nang Han Nong fürchtete sich deswegen sehr. Zhou Xingwu aus Jiangxi (der nach Mengmi geflohen war) ersann [für sie] den Plan, einen Boten zu schicken, der Gold und Juwelen überreichen sollte, um die Regierung zu bestechen (lu zhengshi), Vergebung zu erbitten und um die Verleihung eines Amtstitels zu ersuchen. Der [Minister am Kaiserhof], Wan An, gestattete dies.

\footnotetext{
${ }^{1327}$ Siehe auch TYZZ, S. 142

${ }^{1328}$ Parker übersetzt: „Sein Sohn Kongfa“.

${ }^{1329}$ Jiaozhi, das ist Annam (siehe CY 82.2 und 81.4.).
} 
Im 18. Jahr (1482) erhielten Vize-Zensor Chen Zong und Su Quan, Beamter (xuban) im Amt für den Empfang ausländischer Gesandtschaften (honglu si), den Auftrag, sich [nach Mengmi] zu begeben. Im folgenden Jahr erreichte Zong Mengmi. Nang Han Nong verließ sich auf die Unterstützung, die sie im Innern [ihres Landes] hatte. Sie blieb hochmütig dort sitzen und kam nicht heraus, um Zong zu empfangen. Überdies verlangte sie, daß Zong den Nanyashan überquere, um sie zu sehen. Bei den Verhandlungen gelang es Zong nicht, sich ihrer Gefolgschaft zu versichern. [Nang Han Nong] selbst sagte: ,Mein Mengmi ist im Verhältnis zu Mubang so wie ein kleiner Elefant zu dem großen Elefanten, der ihn geboren hat. Jetzt ist der Körper des kleinen Elefanten doppelt so groß geworden wie der des großen Elefanten. Wie könnte er da wieder in den Bauch des großen Elefanten zurückkehren?` Zong konnte sie nicht umstimmen. Quan aber nahm heimlich ihr Bestechungsgeld an und täuschte Zong bei der Abfassung der Throneingabe.

Im 20. Jahr (1484) wurde daraufhin das Land, welches Mubang entrissen worden war [Nang Han Nong] übergeben und Si Bing erhielt den vererbbaren Amtstitel eines Oberhauptes des Befriedeten Gebietes (anfu si shi) verliehen. ${ }^{1330}$

Die Leute von Mubang suchten Zong auf, damit er sich für sie einsetze. Zong ließ [die Regierung lediglich] wissen, das es keine Kämpfe mehr gebe. Als diese Verhältnisse bekannt wurden, war die Regierung sehr erfreut und Zong wurde zum Gouverneur von Yunnan ernannt.

Nang Han Nong hatte ihre Position behaupten können und riß nun das ganze Gebiet von Mubang an sich. Han Kongfa war nach Mengzheng geflohen. Obwohl er wiederholt Eingaben an den Thron richtete, hatten seine Klagen keinen Erfolg.

Der Häuptling von Mengyang war sehr beunruhigt und beauftragte den großen taomeng Lun Suo, Truppen in Bewegung zu setzen, um Kongfa [von Mengmi] zu schützen. Sie verkündeten dann, daß Mengmi vernichtet werden müsse.

Mit Beginn der neuen Ära Hongzhi (1488-1506) ließ der Amtsleiter Lin Jun einen kleinen Teil des Territoriums von Mengmi abtrennen und gab es Mubang wieder zurück. Nang Han Nong fürchtete sich und wagte nicht, sich dem Befehl zu widersetzen.

Später gab es die beiden Länder Mubang und Mengmi immer noch und sie befehdeten sich von Generation zu Generation. Im 3. Jahr (1490) führte Han Kongfa Klage darüber, daß Zong und andere Gold angenommen hätten. Zu dieser Zeit hatte Zong bereits einen hohen Posten inne, doch als diese Angelegenheit dem Kaiser berichtet wurde, gab es eine Untersuchung, woraufhin er verurteilt und ins Gefängnis geworfen wurde. [Man sagte ihm], bevor nicht eine Amnestie erlassen würde, würde nicht über seine Begnadigung gesprochen werden.

\footnotetext{
${ }^{1330}$ Im YCFZ werden die Ereignisse folgendermaßen wiedergegeben: Während der Ära Chenghua (1465-88) rebellierte der Häuptling (yi mu) Si Wai gegen Mubang, eroberte und riß dessen Land an sich. Der Zensor (du yushi) Cheng [anderes Schriftzeichen als in den fangzhi aus Tengyue] Zong reichte eine Throneingabe ein, die zur Gründung des Befriedeten Gebietes (xuanfusi) von Mengmi führte, [Si] Wai wurde [der Titel] eines Oberhauptes des Befriedeten Gebietes (anfu) verliehen (siehe YCFZ, S. 330, 51).
} 
Im 6. Jahr (1493) berichtete ein Minister, daß Mengmi Mubang an sich gerissen hätte und anhaltende Kriegswirren das Land verelenden ließen. Dies hätte nun über vierzig Jahre angedauert, mehrmals war [Mengmi] besänftigt worden, mehrmals hatte es rebelliert. Seine Macht war sehr groß geworden und es trieb rücksichtslos sein Unwesen. Deshalb bat er um eine Strafexpedition, die jedoch nicht durchgeführt wurde.

Im 9. Jahr (1496) sandten Han Kongfa und Si Ye jeder Boten mit Tribut[geschenken an den chinesischen Kaiserhof].

Seit Si Bing Oberhaupt des Befriedeten Gebietes (anfu) [von Mengmi] geworden war, waren ihm Si Ye und Si Zhen [in diesem Amt] nachgefolgt. ${ }^{1331}$ Si Zhen war einhundertundzehn Jahre alt geworden. Danach kämpften Si Ben und Si Hun um die Herrschaft. Nachdem die Birmanen Si Ben getötet hatten, wurde Hun [als Häuptling] eingesetzt.

Während der Ära Wanli (1573-1620) änderte Hun seinen Namen in Si Zhong und kehrte gefolgt von Si Fu und Si Hua [von Manmo unter chinesische Oberhoheit] zurück. Daraufhin wurde [Si Zhong] zum Oberhaupt (xuanfu) befördert. Als Zhong sich später wieder Birma unterwarf, ernannte der Hof seine Mutter Han Hong zum Oberhaupt des Befriedeten Gebietes Mengmi. ${ }^{1332}$

Im 16. Jahr (1588) griffen die Birmanen Mengmi an. Han Hong war zu schwach und konnte [dem Angriff] nicht standhalten; sie floh mit ihrem Sohn Si Li und ihrem Neffen Si Ren nach Mengguang. ${ }^{1333}$ So hatten sie Mengmi verloren.

Im 18. Jahr (1590) griffen die Birmanen Mengguang an. Han Hung und Si Li flohen nach Longchuan, Si Ren floh nach Gonghui und so ging auch Mengguang verloren.

Nachdem Si Zhong wieder nach Birma gegangen war, war seine Frau Gan Xiangu eine Verbindung mit Si Ren eingegangen, den sie heiraten wollte. Doch Han Hong gestattete ihnen dies nicht. Dann griff [Si Ren] Longchuan in der Absicht an, Xiangu zu entführen, was ihm aber nicht gelang. ${ }^{1334}$ Deshalb ging er nach Birma. Die Birmanen übergaben ihm Mengmi und hatten sich somit das Gebiet einverleibt.

Das war das Ende von Mengmi (Mengmi wang).“

\footnotetext{
${ }^{1331}$ Im TYZZ wird dazu angemerkt, daß Si Yeh früher Manzhe belagert und die Frau des Oberhauptes (xuanwei) von Mubang deshalb Unterstützung bei Si Lu von Mengyang gesucht hatte. Mengmi hatte die Truppen Si Lus seit jeher gefürchtet. Als sie hörten, daß die Truppen kämen, lösten sie [die Umzingelung]. Mubang und Si Lu planten zusammen Mengmi ganz einzunehmen, so kam das Unheil der Barbaren (man) auch nach Mengyang. Seit den Untersuchungen und unangemessenen Entscheidungen von Wan An und Cheng Zong hatten sich die verschiedenen Häuptlinge immer mal wieder China unterworfen oder sich von [China] getrennt und einige Jahrzehnte lang [ständig ihre] Truppen in Bewegung gehalten (TYZZ, S. 152).

${ }_{1332}$ Im YCFZ wird darauf hingewiesen, daß das Befriedete Gebiet (xuan fu si) Mengmi im Jahr 1588 vom Kaiser ein Siegel erhielt (YCFZ, S. 51).

${ }^{1333}$ An anderer Stelle wird Si Li auch als ihr Enkel bezeichnet (siehe YCFZ, S. 330).

1334 TYZZ, S. 152
} 


\section{Das Befriedete Gebiet Manmo an der Wende zum 17. Jahrhundert}

Das Befriedete Gebiet (xuanfu si) Manmo befand sich im äußersten Westen der Unterpräfektur Tengyue, im Gebiet des Zusammenflusses von Dayingjiang und Irawadi. Sein Hauptort Ort Manmo (das ,alte Bhamo`) lag am Ufer des Dayingjiang. ${ }^{1335}$ Manmo war der zentrale Handels- und Stapelplatz für den Fernhandel zwischen China und Birma. Hier trafen verschiedene Verkehrswege aus Yunnan zusammen, die die Provinz mit dem Irawadi verbanden. Entsprechend der strategischen Bedeutung, die Manmo für China gehabt hat, werden die Kämpfe um das Befriedete Gebiet in der letzten Dekade des 16. und zu Beginn des 17. Jahrhunderts in den fangzhi von Tengyue ausführlich dargestellt (TYTZ, S. 240; siehe auch TYZZ, S. 150-151). ${ }^{1336}$

„Zu Beginn der Ära Wanli gab es einen Häuptling namens Si Hua in Mengmi, der im Anschluß an den Sieg Mubangs über Duo An von Mengmao seinerseits einen Sieg über Birma erringen konnte und bei der Verfolgung der birmanischen Truppen Manmo besetzte. Der chinesische Hof lobte ihn für diese Tat und übergab ihm das Amt des Oberhauptes des Befriedeten Gebietes (xuanfu si) von Manmo. ${ }^{1337}$

Im 19. Jahr (1591) hatten die Birmanen Manmo umzingelt. Si Hua, [der tusi von Manmo] bat [die chinesische Regierung] um Unterstützung. Der Vize-General Wan Guochun eilte [daraufhin] bei Nacht dorthin. Er ließ viele Fackeln anzünden, um so [eine größere als die tatsächliche Anzahl von] Soldaten vorzutäuschen. Die Birmanen fürchteten sich und zogen sich zurück. Sie erlitten eine schwere Niederlage. Dies war der größte Kampferfolg [chinesischer Truppen] im Südwesten seit Beginn der Ära Wanli (1573-1620).

Im 9. Monat des 20. Jahres (1592) griffen die Birmanen Manmo [erneut] an. Si Hua floh zum Berg Denglian. Deng Zilong kam ihm zu Hilfe und griff die birmanischen Truppen in Zheao an. Anschließend kam es in Kongha zu einer weiteren großen Schlacht. Die Birmanen zogen sich zurück und sammelten sich auf einer Sandbank. Dort waren sie [den chinesischen Truppen] gewachsen und hielten über einen Monat lang aus, ehe sie sich zurückzogen. Im 11. Monat des 21. Jahres (1592/93) entsandten die Birmanen den Yunmo, um Truppen nach Manmo zu führen und dieses zu erobern. Si Hua wurde besiegt und mußte fliehen. Yunmo nahm die Verfolgung auf und [seine Truppen] drangen auf verschiedenen Wegen ins Innere [Chinas] vor. Die [auf chinesischer Seite dafür] Verantwortlichen (dang shi) überprüften [die Angelegenheit] nicht. Sie verfaßten sogar eine

\footnotetext{
${ }^{1335}$ Die chinesische Bezeichnung Manmo gibt den Shan Namen Manmaw, auch Wanmaw, wieder, der ,Töpfer-Dorf‘ bedeutet (Scott/Hardiman, S. 56). Die alte Stadt Bhamo der Shan lag ,am Fluß Taping [chin. Taiping, auch Dayingjiang], zwei Tage entfernt vom Irrawaddy, am Fuße der Kachin Hügel“ (Scott/Hardiman, S. 71). Die moderne Stadt Bhamo liegt östlich des alten Bhamo (Manmo), direkt am Ufer des Irawadi.

${ }^{1336}$ Für eine englische Übersetzung des Textes von E. H. Parker siehe Scott/Hardiman, S. 61.

${ }^{1337}$ Siehe TYZZ, S. 144. Im TYTZ heißt es, daß Manmo im Jahr 1587 „wie zuvor“ (reng) zum xuanfu si gemacht wurde“ (TYTZ, S. 240). Im YCFZ heißt es abweichend, daß Manmo bereits im Jahr 1588 (Wanli 16) den Status eines anfu si erhielt (YCFZ, S. 51).
} 
Throneingabe, bezüglich der Unterbringung Si Huas [auf chinesischen Gebiet]. Doch im Gegensatz [dazu] wurde Si Hua die Schuld [an der Invasion] gegeben. Im 10. Monat des 24. Jahres (1596) schickten die Birmanen Si Ren Bingce, um Manmo zu erobern. ${ }^{1338}$ Si Hua bat um Unterstützung; der Regionalkommandant Wu Xuanzhong schlug die Bir-manen und ließ Bingce enthaupten.

Zu dieser Zeit besaß [China] großes Ansehen im Grenzgebiet (bian wei shao zhen), so daß sich sämtliche Barbaren (zhu yi) von Birma lossagten und Tribut [an China] sandten. Im 26. Jahr (1598) kehrte Si Hong, [Oberhaupt von Mengyang], Birma den Rücken und kam wieder zurück [zu China]. Im 27. Jahr (1599) griffen die Birmanen Si Hong an und die verschiedenen tusi wurden [von China] aufgerufen, sie abzuwehren. So wurden die Birmanen vernichtend geschlagen. Si Zheng, der Sohn des Si Hua [von Manmo], und Si Hong [von Mengyang] rückten gemeinsam bis zum Fluß Jinshajiang [dem Oberlauf des Irawadi] vor und kämpften [dort] gegen die Birmanen. Im 29. Jahr (1601) nutzte Si Zheng [die Gelegenheit] und überfiel Longchuan während der Trauerfeier für Duo Sishun, den [verstorbenen] tusi von Longchuan. Dann kehrte er nach Manmo zurück. Im 30. Jahr (1602) überfielen Yong Han von Ava und Han Gai von Mubang Si Zheng, sie enthaupteten ihn und zogen sich wieder zurück. Si Hong hatte seine Elefantenkavallerie in Eilmärschen [nach Manmo] geführt, um ihn zu retten, doch er war nicht mehr rechtzeitig gekommen.

Im 32. Jahr (1604) griffen die Birmanen Mengmi an und wollten dafür auch Truppen von Si Hong rekrutieren. Regionalkommandant Wang Tingguang hielt Hong davon ab, [Truppen zu entsenden]. Dieser ließ den Gesandten der Birmanen enthaupten und [den Kopf] als Geschenk überbringen ${ }^{1339}$. Erzürnt darüber griffen die Birmanen griffen Hong an; Hong kam auf der Flucht [vor ihnen] um. Der Oberkommandierende der Ming-Truppen Wang Wannian war nicht mehr rechtzeitig gekommen, um ihm helfen zu können. Dann ließen die Birmanen Si Hua auch Mengyang angreifen. ${ }^{1340}$

Im Jahr darauf beauftragte Chen Yongbin den General Chen Yin, einen Birmanen (Mian mu) namens Han Fu, [der Manmo kontrollierte], gefangen zu nehmen. Später wurde Manmo jedoch ganz von den Birmanen eingenommen (zhong xian yu Mian).

Am Ende der Ära Chongzhen (1628-1644) verteidigte Si Jin von Manmo den Fluß Nangmuhe für die Birmanen und als der Yongming-Prinz [Yongli, der letzte Kaiser der Südlichen Ming-Dynastie] nach Manmo kam, berichtete Si Jin dies nach Birma.“

\footnotetext{
1338 E. H. Parker vermutet, daß es sich bei Si Ren Bingce (,Mian qian Si Ren Bingce kuan Manmo') um nur einen Namen handelt. ,Bingce‘ wäre demnach ein birmanisches Suffix zu einem Shan-chinesischen Namen und könnte auf ein birmanisches Mitglied des Si-Clans hindeuten (siehe Scott/Hardiman, S. 61). An anderer Stelle im TYTZ heißt es, das die Birmanen im selben Jahr (1594), in dem Duo An getötet wurde, Manmo besigten und dessen Anführer (qu[shi]) Bingce töteten (TYTZ, S. 244). Eine andere Übersetzungsmöglichkeit wäre, „die Birmanen vertrieben Si Ren Bingce und griffen Manmo an“.

${ }^{1339}$ Parker vermutet, daß der Kopf dem chinesischen Kaiser als Geschenk dargebracht worden sei (siehe Scott/Hardiman, S. 61).

${ }^{1340}$ Si Hua: Nicht zu verwechseln mit dem obengenannten Si Hua von Manmo, dessen Name mit einem anderen Schriftzeichen hua geschrieben wird.
} 


\section{Die Balladen von den Edelsteinminen von Yang Shen und Zhang Han}

Die beiden Balladen von den Edelsteinminen von Yang Shen und Zhang Han sind im TYTZ im Kapitel Literatur/ Gedichte (Kapitel 19, siehe S. 360) abgedruckt. Die Verfasser des TYZZ haben die Balladen als Anhang an das Ende des Kapitels über die örtlichen Produkte (Kapitel 3, siehe S. 47-49) angefügt und mit Anmerkungen versehen, die im Folgenden mit übersetzt werden.

[Vor Yang Shens ,Ballade ... ‘ ${ }^{1341}$ ]

„Die Edelsteine waren für viele Generationen in Yunnan wie ein Gift. Hat man Yang Shens Ballade über die Edelsteinminen gelesen, dann muß man Mitleid [mit den Menschen damals] haben. Seine Worte sind folgende:

\section{Ballade von den Edelsteinminen}

\section{von Yang Shen (Mitglied der Hanlin-Akademie)}

Farbige Steine und glänzende Perlen - seit alters her werden sie hoch geschätzt und sind ein Spielzeug der Schönen und Reichen. Wer weiß schon, daß wegen zwei edelen Steinen, die wie Wolken den Haarknoten zieren, die Tributleistungen der Barbaren neu festgelegt worden sind?

Die Edelsteinminen sind bekannt geworden. [Obwohl] die Wege dorthin weit sind und [trotz] der Schlangen und des feuchten Klimas sind [viele Männer] dorthin ans Ende der Welt geeilt. Schnell hat sich die Kunde verbreitet und Tausende sind [ihr] in großer Hast gefolgt. Öffnet man die Landkarte, so sind es zehntausend li [bis zu den Minen] und [doch] eilten sie um die Wette.

Siehst du nicht die Straße, die südlich der Stadt Yongchang zu den Edelsteinen führt? Vor dem Sieben-li-Pavillion befindet sich die Poststation Wanshui? In ihrem Herzen wissen [die Reisenden], daß sie sich hier in den Tod verabschieden und daß nur wenige von ihnen lebend zurückkehren werden. Unter Tränen beklagen ihre [zurückbleibenden] Ehefrauen und Eltern gegenseitig [ihr Schicksal].

Der Weg ist so lang; das laute Schluchzen jener bald weit entfernt und nicht mehr zu hören. Sie sehen nur den goldenen Dunst, der von der gelben Erde aufsteigt; in Lujiang und Bawan herrscht ein feuchtheißes Klima. Ebenen mit gelbem Gras folgen auf Hügel mit wilden Tigern. Das Flechten von Gras ist in der ganzen Gegend verbreitet, die Dörfer sind von Zuckerrohr [umgeben]. Eingestürzte Sandbänke und Treibsand, dort wo der Fluß einst seine Richtung geändert hat. Man sagt, daß es am Nanyashan noch schlimmer wäre.

Die Köpfe umwickelt, die Zähne lackiert, das ist Manmo. Guangyao, Jiadeng und Menglian - für jemanden, der hier an der stummen Malaria erkrankt, gibt es keine rettende Medizin.

${ }^{1341}$ TYZZ, S. 47 
Am Mole-Fluß gibt es viele Diyang. ${ }^{1342}$ In Reihen marschieren sie ins Kontor. Mit rotem Flechtrohr (hong teng) umwickelte Beine das ist der zhaofayou; mit Blattgold belegte Zähne, das ist der König von Birma. ${ }^{1343}$

Wendet man den Kopf, so ist Yunnan zehntausend li entfernt. Hält man vor den Edelsteinminen Ausschau, so meint man das Meer zu sehen.

Purpurne La- und dunkelrote Edelsteine sind tausende von Goldstücken wert. Echte und unechte fallen ins Auge, sie sind nicht zu unterscheiden. Einen Edelstein zu erlangen und heimzukehren, das ist wie eine Wiedergeburt. [Doch aus Angst, das Juwel zu verlieren] fürchtet man jeden Schatten und ängstigt sich noch im Traum.

Ich habe gehört, daß man am Kunlun Gebirges die [Edel]steine den Elstern gibt und am Ort der glückverheißenden Wolken das Gold den Schildkröten hinwirft. Hätte man doch die Fähigkeit der Unsterblichen, Entfernungen zusammenschrumpfen zu lassen, dann könnte man die Edelsteinminen gleich [nach Peking] in die Chang’an Straße verlegen.“

Anmerkung zur ,Ballade von den Edelsteinminen` von Yang Shen im TYZZ:

„[Yang] Shen war nach Jinchi verbannt worden. Er hat die Verhältnisse dort mit eigenen Augen gesehen und selbst unter ihnen gelitten“. ${ }^{1344}$

Direkt im Anschluß an die Ballade des Yang Shen wird in beiden Lokalhandbüchern die gleichnamige Dichtung des Zhang Han abgedruckt.

\footnotetext{
${ }^{1342}$ Diyang oder Diyanggui (,Land-Schaf-Teufel'): Chinesische Bezeichnung für eine einheimische Volksgruppe im Gebiet von Mengmi (siehe auch Eberhard, Randvölker, s 38). Für eine Beschreibung der Diyanggui in den fangzhi siehe unten Anhang II. 4., S. 498-499 (9. Die Diyanggui).

${ }^{1343}$ Zhaofayou: Ein ,Freund (oder Mitarbeiter) der die Gesetze (oder Methoden) [des Minenbetriebs] bekannt gibt'; möglicherweise handelt es sich hier um die lautliche Wiedergabe einer Amtsbezeichnung im Minenbetrieb, vielleicht der des Managers der Minen.

${ }^{1344}$ TYZZ, S. 47
} 


\section{Ballade von den die Edelsteinminen}

von Zhang Han (juren aus Baoshan)

„Schon während der Ära Chenghua (1465-1488) galten Edelsteine als wertvoll. Private Haushalte kauften sie heimlich und auch Beamtenhaushalte kauften sie. In der Hauptstadt gab man Silber aus den Schatzkammern dafür aus und hatte nicht von den südlichen Barbaren verlangt diese Kostbarkeiten als Tribut zu übergeben.

Von der Familie Lin, den Edelstein-[Händlern], hat man in ganz China gehört. Die reichen Kaufleute und Händler sind so dicht versammelt wie die Wolken [am Himmel]. Der Kaiser hat die Familie Lin angewiesen den Zensoren aus dem Weg zu gehen, denn er befürchtete, daß sonst eine Anklageschrift [von den Zensoren] in einer schwarzen Tasche ankommen würde. ${ }^{1345}$

Seit dem Jahr dingke der Ära Jiajing (1527) kommen Beamte als Aufkäufer in die Garnison Yongchang. Die kaiserlichen Beamten zahlen den festgesetzten Regierungspreis. Sie mischen sich in die lokalen Angelegenheiten ein und dem Volk geht es sehr schlecht. Dem Volk geht es sehr schlecht; wozu soll man sich darum kümmern? Auf der Poststraße und in den staatlichen Rasthäusern gibt es viele Tiger und Panther. Sobald die kaiserlichen Aufkäufer ihre Fahnen entrollen, beginnt selbst das Gebirge zu erzittern. [Gezwungen die eigenen] Söhne und Töchter zu verkaufen, weint das Volk bitterlich. Bis heute ist dies vierzehn Mal vorgekommen. Lautlos fließen die Tränen [der Menschen], denen das Herz aus dem Leib gerissen wird.

Während der Ära Chenghua und der Ära Jiajing (1522-66) standen die Kaiser doch Schulter an Schulter mit den drei Kaisern [der Vorzeit]. ${ }^{1346}$ Sie haben besonders mit dem Leid der Bevölkerung in der fernen Grenzregion Erbarmen. Doch wohin das Auge blickt, fliehen die Menschen, ihre Häuser verfallen. Ihre Häuser verfallen - es lohnt sich nicht sich darum zu kümmern. Hunger und Kälte lassen sie zu Räubern werden, die in die Berge und Schluchten gehen; die Städte sind verlassen.In Scharen kundschaften Reiter auf Elefanten und Pferden das Grenzgebiet aus. Das Auskundschaften der Gebiete erschüttert das Grenzland. Über die Jahre haben Sonne und Mond alle Farbe verloren. ${ }^{1347}$

\footnotetext{
1345 In der Han-Zeit (206 v.Chr. bis 220 n.Chr.) übersandten Beamte Throneingaben, die geheime Angelegenheiten betrafen in einer schwarzen Tasche (CY 1180. 2).

${ }^{1346}$ Mit dem Begriff drei Kaiser (san huang) werden verschiedene legendäre Kaiser der Vorzeit bezeichnet, die als Kulturbringer und für ihre weise Regierung berühmt waren, wie z.B. Fuxi, Shennong und Huangdi (siehe CY 18.1).

${ }^{1347}$ Gemeint ist, daß das Leben für die Bevölkerung unerträglich war.
} 
Der Mann aus Qi fürchtet, daß ihm der Himmel auf den Kopf fallen könnte. ${ }^{1348}$ Der Himmel ist noch nicht eingestürzt, da hat er sich mit trübem Wein sehr betrunken und dabei dieses Gedicht verfaßt“".

Anmerkung im Anschluß an die ,Ballade von den Edelsteinminen“ von Zhang Han im TYZZ:

„Diese beiden Gedichte können als Warnung vor den Edelsteinen, diesen Dingen aus der Ferne dienen.

[Der Satz], ,der Kaiser hat die Familie Lin angewiesen den Zensoren aus dem Weg zu gehen`, läßt erkennen, daß die Möglichkeit, Eingaben direkt an den kaiserlichen Hof zu richten, dort durchaus gefürchtet wurde.

Diese Balladen stammen aus der Jiajing-Zeit (1522-66).

Dann hatten sich die Eunuchen verschworen die Grenzangelegenheiten ernst-lich zu stören; sie [und die regulären Beamten] behinderten sich gegenseitig [bei der Verwaltung der Region]. Der Häuptling von Birma nutzte diese Gele-genheit um sich zu erheben. Während der Ära Wanli (1573-1620) griff er mit vielen [Soldaten] Manmo direkt an, wobei er Instruktionen des für den Ankauf von Edelsteinen zuständigen Beamten folgte, der ihm befohlen hatte, Si Zheng von Manmo zu töten, um so den Weg freizumachen.

Entrüstet darüber verfaßte Gouverneur Chen Yongbin eine Throneingabe“، ${ }^{1349}$

\footnotetext{
${ }^{1348}$ Qi ist der Name eines Reiches aus der Zhou-Zeit (11. bis 3. Jahrhundert v. Chr.) im Gebiet der modernen Provinz Henan. ,Der Mann aus Qi fürchtet den Einsturz des Himmels‘ (Qi ren you tian) ist ein Sprichwort (chengyu) das einen Menschen bezeichnet, der sich grundlos Sorgen macht. 


\section{Die Throneingabe des Gouverneurs Chen Yongbin bezüglich der Edelsteinminen von Mengmi}

Die Verfasser des TYZZ haben die Throneingabe von Gouverneur Chen im Anschluß an die Balladen im Anhang des Kapitels über die örtlichen Produkte (Kapitel 3, siehe S. 4749) abgedruckt und mit Anmerkungen versehen, die im Folgenden mit übersetzt werden. $^{1350}$

\section{Eingabe bezüglich der Einstellung der Förderung in den Edelsteinminen}

\section{„[Eingabe des] Ministers:}

Bei Yunnan befindet sich Birma, das seit alters her ein Ärgernis für China war. Dieses ist so habgierig wie Schweine und Schlangen und wagte es sich uns zu widersetzen. Im kleinen fraßen sie wie Seidenraupen Stück um Stück von den Gebieten der verschiedenen Völker in sich hinein, im großen drangen sie bis über die Grenze vor.

In früheren Jahren, zogen eine Millionen [unserer] Soldaten in die Schlacht gegen Luchuan, immer wieder bemühten sie sich, zogen gen Süden und konnten jene doch nicht vernichten. Seit einigen Jahren aber wagt es die birmanische Bande nicht ihre Pferde im Jinsha [dem Oberlauf des Irawadi] zu tränken oder unser Manmo auszuspionieren.

Liegt es etwa an den Fähigkeiten dieses Ministers, daß sie unter Kontrolle gehalten werden? Es ist gut, daß Eure Majestät diesen Minister beauftragt haben, sich um die Grenzangelegenheiten zu kümmern. Dieser Minister hat die Gelegenheit bekomme, seine Glieder zu regen und tätig zu werden. Bezüglich des Inneren hat er das um Fenster und Türen gewundene Band repariert [d.h. Vorbereitungen getroffen] und [alles] geordnet, um nicht [erst wenn es zu spät ist] ordnen zu müssen. Bezüglich des Äußeren hatte er den Plan sich mit den entfernteren [Machthabern] in Verbindung zu setzen, [um so die nahegelegenen einzukreisen] und die Barbaren von Barbaren bekämpfen zu lassen. Den untergeordneten Beamten wurde streng verboten dies außerhalb Chinas bekanntzumachen. Die Birmanen warten auf eine Gelegenheit, die sie sich zu nutze machen könnten, aber es gibt keine und um sich selbst zu behelfen, reichen ihre Fähigkeiten nicht aus.

Früher hatte ich mit Rauchzeichen eine eilige Warnung geschickt, bezüglich des Problems, daß die drei Befriedeten Gebiete (san xuan) ${ }^{1351}$ verlorengehen könnten. Im 2. Monat desselben Jahres nun hatte sich Yonghan, der Häuptling der Birma-Bande (Mian chou) von Ava, mit Mubang und anderen Barbaren (yi) verbündet und war mit über einhunderttausend Mann direkt nach Manmo

1350 Siehe auch YCFZ, S. 363-364 und Yunnan tongzhi (Nachdruck von 1974), juan 29, yiwen 3.

${ }^{1351}$ Die drei Befriedeten Gebiete waren Nandian, Ganya und Longchuan südwestlich von Tengyue. 
vorgedrungen, er hat die drei Befriedeten Gebiete mit Füßen getreten und ist sogar vor Tengyue aufgetaucht. Er teilte mit, daß der Gesandte Chinas, der mit dem Minenbetrieb befaßt war (kai cai Han shi), ihm befohlen hätte Si Zheng zu töten, um den Weg nach Manmo freizumachen. So hätte er ein Übel (hai) für den kaiserlichen Hof beseitigt.

$\mathrm{Zu}$ einer anderen Zeit folgten die Generäle und subalternen Beamten dem Befehl dieses Ministers, der verkündete, daß der Häuptling für das Verbrechen seines Eindringens bestraft werden muß. Wir werden ihn töten, sein Leben wird für alle hingegeben. Ohne ihn hat der Herrscher von Ava keine Gründe mehr [hierzusein]. Gemäß dem schriftlichen Befehl dieses Ministers, sollten sie ihre Rüstungen zusammenrollen und nach Ava zurückkehren. Weshalb blieben also noch Soldaten zurück, um Manmo zu verteidigen. Die verschlagenen Birmanen hatten nur vorgetäuscht, die Edelsteinminen zu übergeben und sich gedacht, sie könnten die Grenze öffnen, indem sie Si Zheng verfolgten, wobei ihnen beim Gedanken an Manmo schon das Wasser im Munde zusammenlief. Ihr heimtückischer Plan ist uns jedoch vollständig zugetragen worden.

Was ist Manmo denn für ein Ort? Es ist der Zaun der drei Befriedeten Gebiete. Die drei Befriedeten Gebiete sind wie eine Mauer für Tengyue und Yongchang. Tengyue und Yongchang sind die Türen zu ganz Yunnan. Wenn Manmo verloren geht, wird es auch die drei Befriedeten Gebiete bald nicht mehr geben. Wenn die drei Befriedeten Gebiete verloren gehen, wird es auch Tengyue und Yongchang bald nicht mehr geben.

Das ganze Unglück Yunnans begann mit der Öffnung der Edelsteinminen. Wenn man die Edelsteinminen betreiben will, dann kann man Manmo nicht zurückgewinnen. Wenn man Manmo zurückgewinnen will, dann kann man die Arbeit in den Minen nicht beginnen. Beides zusammen geht in dieser Situation nicht. Wenn man die Edelsteinminen begehrt, dann muß man den Zaun entfernen. Wenn man den Zaun behalten will, dann muß man den Aufkäufern mitteilen, aufzuhören. Es geht nur eines, nicht alles zusammen. Was die Dinge dieser Welt angeht, wenn man sich einerseits ganz auf etwas konzentriert, so gelingt es, wenn man andererseits viel Falsches tut, wird die Sache mißlingen.

Gegenwärtigt hat Eure Majestät einen Provinzgouverneur eingesetzt, der die militärischen Angelegenheiten zu ordnen hat. Außerdem hat Eure Majestät einen Steuer-Aufseher eingesetzt, der Förderung und Ankauf zu überwachen hat. Derjenige, der die militärischen Angelegenheiten verwaltet soll bezüglich der Grenzangelegenheiten Warnungen mitteilen sowie eindringende Banditen bezwingen. Derjenige, der Förderung und Ankauf zu überwachen hat, soll sich um die Fragen bezüglich der Juwelen kümmern. Warnungen braucht jener nicht zu übermitteln, Banditen braucht jener nicht zu bezwingen. 
Dieser Zustand wird [nun aber] beeinträchtigt. Wenn die Störung nicht aufhört, dann kommt es zu einer Stauung, wenn die Stauung nicht beendet wird, dann werden die Vorbereitungen vernachlässigt. Wenn die Vorbereitungen vernachlässigt werden, dann kann die Kavallerie der Birmanen über Manmo unaufhaltsam bis zu den drei Befriedeten Gebieten vorrücken. Wenn sie in dieses menschenleere Gebiet kommt, muß die Region von Tengyue und Yongchang fürchten, nicht mehr zu Euer Majestät zu gehören. Eure Majestät haben in vielen Jahren Milde gegenüber den Gebieten [im Südwesten] gezeigt. Noch ist das Land der Vorfahren geeint, wenn aber die Minen in Betrieb genommen werden, dann wird das Land in Gefahr sein. Dieser Minister weiß, daß das nicht der Wille eurer Majestät sein kann.

Weshalb sind die Edelsteinminen [eigentlich] Kostbarkeiten? Sind sie nicht nur ein Stückchen Land? Ist ein Edelstein wichtiger oder ist das Land wichtiger? Wegen eines nutzlosen Stückchens Land kann ein zehntausend li großes Grenzgebiet (fengjiang) zerstört werden. Der Handel [mit Edelsteinen] genießt unverdientes Ansehen, doch ist der Preis, den man bekommt in Wirklichkeit Unheil für das Grenzgebiet. Dieser Minister weiß, daß Eure Majestät dies nicht wollen würde.

Dieser Minister hat von Eurer Majestät große Gunst erwiesen bekommen. Im Grenzgebiet sind Sicherheit und Gefahr alles[entscheidend]. Wenn er nur untätig dasitzen und zusehen, aber nicht sprechen würde, würde dieser Minister dem Grenzgebiet Schaden zufügen und sich Eurer Majestät gegenüber undankbar zeigen. Ich hoffe, daß unser Kaiser schnell seine Entscheidung bekanntgibt und die Tätigkeiten des Förderns und Handelns an den Edelsteinminen schnell einzustellen befiehlt. Den bisher [dort tätigen] hohen Generälen und mächtigen Beamten möge er befehlen,schnell an ihren Heimatort zurückzukehren und nicht erneut Streit [über diese Fragen] zu beginnen. Die Generäle und subalternen Beamten im Grenzgebiet sollen sich einig mit der Untersuchung militärischer Operationen beschäftigen. So gibt es die Idee, die Rückeroberung von Manmo zu planen. Wenn die Birmanen abziehen, werden sie nicht verfolgt, wenn sie vordringen müssen sie abgewehrt werden. Dann kann man in allen Grenzangelegenheiten ohne Sorgen sein, denn der Süden wird unterworfen und ungeteilt bleiben. [Verfaßt am] 8. Aug. 1603.“

\section{Anmerkung zur Throneingabe von Gouverneur Chen Yongbin im TYZZ:}

„Diese Throneingabe Yongbins macht die Schwierigkeiten die aus dem Handel [mit den Rubinen] entstanden waren deutlich. Doch dem Kaiser war das nicht bewußt gewesen.

Damals ließ der Steuerbeamte, [der Eunuch] Yang Rong seinen Untergebenen freie Hand, [woraufhin] diese in hemmungsloser Grausamkeit handelten, so daß die Bevölkerung sehr litt. Überdies wollte er [dem tusi von] Lujiang befehlen, Land zurückzugeben, um dies dann selbst ausbeuten zu können. Damit hatte der Häuptling von Birma einen Grund, weit nach [China] hinein vorzudringen. Der Zensor Song Xingzu, sprach deutlich aus, daß [Yang Rong] ein Übel sei und bat darum, daß er und [einige] andere abgelöst würden. Aber der Kaiser folgte diesem Vorschlag nicht. 
Edelsteine ertränken das Herz eines Menschen, so ist das.

Die Edelsteinminen befinden sich jenseits des [Gebietes des] jetzigen Mengmao tusi im Mengmi tusi. Die Edelsteine sind die im Han shu überlieferten ,glänzenden Perlen der Ailao‘ ${ }^{1352}$ In dem älteren Lokalhandbuch von Herrn Wu heißt es, die Förderung von Edelsteinen habe [dort] in der Yuan-Zeit begonnen hat. Tao Zongyi sagt in seinem Chuogeng lu, daß von allen leuchtenden Steinen (huihuishi) die [sogenannten] Hongla die von bester Qualität sind. ${ }^{1353}$

Während der Ära Dade (1297-1308) der Yuan-Dynastie hatte ein Händler ein Stück Hongla-Rubin mit einem Gewicht von 1 liang 2 qian gekauft. Dieses hatte einen geschätzten Wert von 140.000 ding in Zhongtong-Banknoten. Der [Edelstein] wurde [als Schmuck] oben auf eine Kappe gesetzt und viele Generationen lang hochgeschätzt.

Bei den Steinen von hellroter Farbe (danhong se) heißen die schönsten La. Bei den dunkelroten und den hellgrünen (shibo se) heißen die schönsten Bizheda. Die schwarz-roten heißen Kula. Rotbraune [Steine], die nicht von reiner Farbe sind sondern schwarze oder gelbe [Stellen] aufweisen, werden ,alte Magnolien-Stücke‘ (gu mulan kuai) genannt. Obwohl dies große Steine sind, sind sie von niedriger [Qualität]. Aus [ein und] derselben Mine können diese vier und auch andere Sorten [von Edelsteinen] gewonnen werden.

Die Edelsteine aus Yunnan kommen [tatsächlich] von jenseits des Mengmao tusi, aus dem Gebiet von Mengmi, wo es Edelsteinminen gibt. Während der Ming-Zeit hatte sich ein Palast-Eunuch (taijian) als Verteidigungskommandeur (zhenshou) dorthin begeben, um sie zu übernehmen.

Zhang Nanyuan [TYTZ, S. 61: Zhang Nanguo] sagte, daß das Rot dieser Edelsteine das beste auf der ganzen Welt sein muß und daß die durchsichtigen [Steine] besonders wertvoll sind.Er hat sie mit denen verglichen, die der Palasteunuch Wang Ju dort gesehen hatte. Verglichen mit den hellroten (ruanhong) waren sie dunkler (hei), verglichen mit den dunkelroten (yinghong) waren sie klarer (gan).

Meng[mi] ist von Teng über eintausend li entfernt. In dem Gebiet sind Tropenkrankheiten (zhangli) weit verbreitet.

\footnotetext{
${ }^{1352}$ Die Geschichte der Han-Dynastie (Han shu) wurde um das Jahr 82 n.Chr. von Ban Gu und seiner Schwester Ban Zhao verfaßt.

${ }^{1353}$ Tao Zongyi (1316-?) verfaßte das Chuogeng lu (,Die unterbrochenen Landarbeiten`) im Jahr 1366. Das Buch enthält seine gesammelten Notizen (biji) über die Einteilung der Bevölkerung Chinas in ethnische Kategorien durch die Mongolen, die Diskriminierung der Han-Chinesen und die daraus resultierenden Volksaufstände in Südostchina. (ZGRMDCD, S. 531; s.a. Gernet, S. 313).
} 
Der Häuptling Birmas ließ Gebäude um die Edelsteinminen herum bauen und sie sehr streng bewachen. Außer den [sogenannte] La waren in den letzten zehn Jahren in Teng keine anderen schönen Stücke zu sehen. Es ist ja bekannt, daß die Edelsteine schwer zu erlangen sind.

Außer diesen Edelsteinen gibt es welche, die Bijiaxi genannt werden. Sie gibt es in allen Farben. Die tiefroten und die durchsichtigen gelten als die besten, danach kommen die lilafarbenen, gelben, grünen und blaßblauen, als die geringsten gelten die beiden Farben weiß und schwarz. Sie alle gibt es auch in Mengmi. So verhält es sich mit den Edelsteinen [aus den tusi-Gebieten].

Nun habe ich gehört, daß es in jenem Gebiet nur einige Edelsteinminen gibt, die sämtlich von den einheimischen Barbaren mit Gebäuden umgeben worden sind. Im Innern des Gebäudes wird dem Ausgraben begonnen. Wenn nun ein schöner Stein gefunden wird, so erfahren es die Leute draußen nicht. Jedesmal wenn so ein [schöner Stein gefunden wird], wird er dem Häuptling von Birma geschickt. Nur bei den Bijiaxi-[Minen] gibt es welche, die gemeinsam mit Chinesen (zhongtu) eröffnet worden sind.

Findet jemand beim Abbau schöne [Stücke], dann hat er eine prosperierende Mine. Wenn er diese nach außerhalb verkauft, dann kann [der Verkäufer] reich werden. Findet jemand beim Graben nichts oder nur unschöne Steine, dann ist auch der Zustand des Vermögens entsprechend.

Nicht nur während der Ming-Zeit machten die Diyanggui Schwierigkeiten. ${ }^{1354}$ Daß Diyanggui in diesem Gebiet leben, hatte bereits Herr Wu aufgezeichnet“. ${ }^{1355}$

\footnotetext{
1354 Diyang oder Diyanggui (,Land-Schaf-Teufel`): Chinesische Bezeichnung für eine einheimische Volksgruppe im Gebiet von Mengmi (siehe auch Eberhard, Randvölker, s 38). Für eine Beschreibung der Diyanggui in den fangzhi siehe unten Anhang II. 4., S. 498-499 (9. Die Diyanggui).

${ }^{1355}$ Herr Wu (Wu jun), das ist Wu Kai, der von 1770 bis 1779 als Unterpräfekt in Tengyue tätig war und während seiner Amtszeit ein Lokalhandbuch zusammenstellte.
} 


\section{Die Kurzbiographien der Brüderpaare Liu und Wang im YCFZ}

Während der Unruhen am Ende der Ming-Zeit hatte sich Sun Kewang in Zentral-Yunnan etablieren können und bemühte sich, den Herzog Mu Tianbo, der nach Yongchang geflohen war, sowie die örtlichen Verwaltungsbeamten der Präfektur dazu zu bewegen, sich ihm anzuschließen. Dazu waren die Verwaltungsbeamten Liu Tingbiao und Wang Yunkai von Yongchang jedoch nicht bereit. Liu und Wang erwiesen sich nach Ansicht der Verfasser der fangzhi als vorbildliche Beamte, die, nachdem sie ihre Familienangehörigen in Sicherheit gebracht hatten, eher Selbstmord begingen, als sich dem Sun Kewang zu unterwerfen.

In den Kurzbiographien von Liu Tingbiao, Wang Yunkai und ihren jüngeren Brüdern Liu Tingqu und Wang Yunhong im YCFZ wird ihr loyales Verhalten in dieser Zeit des Umbruchs ausführlich geschildert (YCFZ, Kapitel 33, zhonglie, S. 153).

\section{a) Liu Tingbiao}

„Beiname Xiaqi. Liu stammte aus Shanghang, [in der Provinz Fujian (CY 33.1). Er hatte den akademischen Titel eines juren erworben (YCFZ, S. 174).] Er war als Assistierender Präfekt (tongban) in Yongchang tätig.

Während der Revolte von Sha Dingzhou im Jahr dingke (1647) hatte sich der Herzog von Qianguo, Mu Tianbo, nach Yongchang begeben, als sich die Truppen des liukou Sun Kewang näherten. Sie hatten Dian zerstört, Dingzhou umgebracht und waren über Lin'an und Chuxiong nach Dali vorgerückt. In einem schriftlichen Befehl an Yongchang verlangte Sun die Herausgabe der Siegel des Bezirks und der Präfektur (dao fu yin). Zu jener Zeit amtierte Wang Yunkai als Richter (tuiguan) des Bezirks Jin-Teng; Tingbiao amtierte als Assistierender Präfekt der Präfektur. Sie beabsichtigten, den Lancangjiang zu verteidigen, um die Banditen abzuwehren. Tianbo fürchtete sich jedoch [vor den Banditen] und beauftragte Biao und [Wang Yunkai] mit den Siegeln aufzubrechen. Die beiden sprachen mit ernster Miene: ,Wir beide haben ursprünglich nicht zu den Beamten gehört, die ein Amtsiegel besaßen, aber nun befinden sich die Siegel bei uns. Würden wir dem Herzog gehorchen und mit den Siegeln aufbrechen, so würden auch wir kapitulieren. Wir hatten von dem vorigen Kaiser den Befehl (ming) erhalten, dieses Gebiet ( $t u$ ) zu verwalten. Die Veränderungen (bian) des Jahres jiashen (1644) ließen uns erkennen, daß wir wohl sterben würden. Doch wie könnten wir uns Banditen unterwerfen? Überdies sind wir beide höchst rechtschaffene Gelehrte (shusheng), da können wir uns doch nicht einfach unterwerfen. Die Familie Mu hat über dreihundert Jahre lang Verdienste erworben, doch nun sind die Banditen noch nicht einmal da und schon hat [Mu Tianbo] Angst und erwägt zu kapitulieren. Wenn er jetzt sterben würde, wie könnte er da den Vorfahren in der Unterwelt ins Anlitz schauen? [Solange] wir beide noch da sind, kann Sun die Siegel nicht bekommen, wenn wir beide aber gestorben sind, dann kann er sie bekommen`. 
Mu Tianbo konnte sie nicht zwingen, [die Siegel herauszugeben]. Aber die Bevölkerung fürchtete [von den Truppen Sun Kewangs getötet zu werden]. So gingen sie zum Sitz der Präfektursverwaltung und baten [Liu, sich Sun zu ergeben]. Biao wußte, daß er das nicht konnte. Also schickte er nach seinem jüngeren Bruder Tianqu, der seine Familie von Tengyue aus [in Sicherheit] bringen sollte. Die Bevölkerung hörte nicht auf zu lärmen. Biao hörte sie an und sagte zu ihnen, daß ein rechtschaffener Mensch das nicht tun könnte. Die Menschenmenge war sehr aufgebracht und drohte ihn zu töten, wenn er nicht anders handeln würde. Biao lachte darüber und sagte: ,Ihr meint wohl ich habe Angst zu sterben? Ich möchte seit langem schon tot sein`. Er tat Gift in seinen Wein und wollte ihn trinken. Daraufhin zerstreuten sich die Leute.

An diesem Abend trank er zusammen mit Yunkai fröhlich Wein. Mit lauter Stimme sprachen sie beim Abschied: ,Dieser Weg, den wir gehen, ist der richtige‘. Da wußten die Leute, daß Biao [in den Tod] gehen wollte. Als bekannt wurde, daß Yunkai tot war, sagte er: ,Das war wirklich ein Mann. Und ich alter Mann bin noch da‘. Biao nahm ein Bad, zündete Weihrauch an und verfaßte festentschlossen vier Gedichte. Dann erhängte er sich.

Vorher hatten Gäste und Diener versucht, ihn zu überreden, das nicht zu tun. Aber er hatte es dennoch getan. Davor aber hatte Biao auf ein weißes Seidenband [die vier Gedichte] geschrieben und, indem er das Geschriebene hochhielt, zu seinen Leuten gesagt: ,Der Beamte wird im Himmel weiterarbeiten'. Biao wusch sich, spülte seinen Mund aus, rückte Gewand und Kappe zurecht, dann erhängte er sich mit einem Stoffband. So hat Feng Su diese Begebenheit in der ,Geschichte der Ming، (Ming shi) überliefert.“

\section{b) Liu Tingqu}

„Beiname Gongdou. Er stammte aus Shanghang. Er war der jüngere Bruder des Assistierenden Präfekten Liu Tingbiao. Während der Schwierigkeiten mit dem herumziehenden Banditen Sun Kewang war Tingbiao gestorben und die Banditen wollten Qu dazu zwingen, dessen Amt zu übernehmen. Qu widersetzte sich und unterwarf sich nicht. Später im Jahr jihai (Shunzhi 16; 1659), zur Zeit als die Militärrevolte (bingluan) niedergeschlagen worden war, rief er laut aus: ,Wie könnte ich anders handeln als mein älterer Bruder?‘. Gemeinsam mit seiner Frau, einer geborenen Zhang, ging er in den Tod. Damals war [Frau] Zhang 29 Jahre alt. Sie hatte zunächst ihr jüngstes Kind und dann sich selbst zusammen mit Qu erhängt.

Ein Mann aus der Präfektur, Xu Chongyue, lobte dies: Gemeinsam mit dem älteren Bruder zu sterben ist hart, das ist wirklich die Tat eines bemerkenswerten Mannes. Mit dem Ehemann Selbstmord zu begehen, übertrifft dies noch. Darin erweist sich das Pflichtgefühl der tugendhaften Frau. Ihr Enkel Zhetan ging im Jahr 1723 als Siebtbester juren aus den Provinzprüfungen hervor. Zhezhi erreichte den Status eines zusätzlich ernannten Studenten der Staatsuniversität Guozijian (bagong), er übernahm das Amt eines Kreismagistraten (zhixian) des Kreises Pujiang in Sichuan. Die Söhne von Zhetan, Kai und Luan, bestanden die Provinzprüfungen ebenfalls beide als Siebtbeste. Luan 
erreichte zudem den höchsten Titel, den eines jinshi. Er war allseits als loyaler Minister (zhongchen) hoch angesehen.“

\section{c) Wang Yunkai}

„Beiname Zilang. Er stammte aus Jiajiang in der Pprovinz Sichuan.[Er hatte den akademischen Titel eines juren erworben (YCFZ, S. 175).] Er hatte das Amt des Richters (tuiguan) von Yongchang inne und das Siegel des Bezirks (dao) Jin-Teng in seiner Obhut.

Als die herumziehenden Banditen (liukou) Dali erreicht hatten, forderten sie die Herausgabe der Siegel des Bezirks und der Präfektur. Zu dieser Zeit befand sich Mu Tianbo in Yongchang. Er befahl Kai und [Liu Tingbiao] die Siegel zu nehmen und abzureisen. Kai und [Liu] kamen der Forderung nicht nach. Ersterer wandte sich an seinen jüngeren Bruder Yunhong und sagte zu ihm: ,Der jüngere Bruder ist nicht im Staatsdienst tätig, es ist nicht notwendig, daß er aus Pflichterfüllung stirbt. Begleite meine Konkubinen (qie) und geht alle nach Westen. Diesen Leuten soll es nicht gelingen, die Herzen der Menschen zu verführen`.

Die Menschen des Regierungsbezirks (jun) übten ebenfalls Druck auf ihn aus (you qiang zhi bu yi). Doch er trank und lachte in aller Ruhe mit dem Assistierenden Präfekten (tongban) Liu Tingbiao. Dann verabschiedeten sie sich von einander und in der Nacht erhängte er sich.“

\section{d) Wang Yunhong}

„Der jüngere Bruder von Yunkai hatte den akademischen Titel eines juren erworben. Er war dem älteren Bruder nach Yong[chang] gefolgt. Damals war er gerade aus Tengyue weggegangen. Als er die Nachricht vom Tod seines älteren Bruders vernahm, begab er sich zusammen mit Lius jüngerem Bruder Tingqu nach Yong[chang], um sie einzusargen und zu begraben, wie es Sitte war. Andere kondolierten und weinten, sie aber sprachen: ,Für uns beide hier ist das eine alltägliche Sache (bu bo shu su shi). Warum soll man da weinen'. Da die Soldaten [die Stadt] übernommen hatten, wollten Vater und Sohn aus dem Mu-Clan Hong dazu zwingen, den Beamtenposten [seines Bruders] zu übernehmen.

Hong machte sich frohen Mutes auf den Weg und ging zum Mittellauf des Lujiang. Er streckte die Hand aus, übergab dem Diener einen Brief und sagte: ,Älterer und jüngerer Bruder, wie könnten wir beide zwei verschiedene Arten von Menschen sein?‘. Dann sprang er in den Fluß und ging unter. Als er wieder auftauchte, zeigte er einem fröhlichen Gesichtsausdruck. Viele [Leute] eilten hinzu, um zu helfen. Doch Hong winkte mit der Hand, um sie aufzuhalten und versank. Dann wurde sein Brief gelesen. Es hieß darin: ,Nehmt meine Gebeine und bestattet mich gemeinsam mit meinem älteren Bruder. [Die Inschrift soll lauten] Grab der Brüder aus Jiajiang‘. Nach einigen Tagen wurde sein Leichnam aus dem Ufersand geborgen. Seine Gesichtsfarbe war noch wie im Leben.“ 


\section{B. TeXTe ZUR QING-ZeIT}

\section{Die Beschreibung Birmas im Tengyue ting zhi}

Das 15. Kapitel (zhu yi zhi, ,die verschiedenen Völker der Region') des TYTZ enthält unter der Rubrik ,Grenzgebiete` neben den Beschreibungen der verschiedenen tusi-Gebiete jenseits der acht Paßstationen (Mengmi, Mubang usw.) auch einen Abschnitt, in dem die Verfasser die Geschichte Birmas bis zum Ende des 19. Jahrhunderts schildern (Miandian; TYTZ, S. 241-246). Zunächst wird die historische Entwicklung des Landes bis in die Ming-Zeit entsprechend dem Text im Kapitel tusi der ,Geschichte der Ming-Dynastie (Ming shi) ausführlich dargestellt. Im Anschluß daran werden im TYTZ die Ereignisse in der Qing-Zeit und die Beziehungen zwischen den beiden Nachbarn beschrieben.

Die Übersetzung beschränkt sich auf die Textstellen zum Birma der Qing-Zeit und beginnt mit den einleitenden Bemerkungen zur allgemeinen Landeskunde sowie der anschließenden Beschreibung der historischen Ereignisse bis zum Ende des chinesisch-birmanischen Krieges (1766-1769). ${ }^{1356}$

„Im Wenxian tongkao heißt es, daß Birma sich jenseits der Pässe von Tengyue befindet. ${ }^{1357}$ Sein Oberhaupt (qiu) wohnt in der Stadt Ava. Im Süden reicht [das Land] bis ans Meer, im Westen bis nach Mengyang, im Norden bis nach Mengmi. Ihm sind Mubang und andere, insgesamt dreizehn Regierungsbezirke $(l u$ ), unterstellt. Das Gebiet ist weit ausgedehnt. Die Sitten (sushang) sind biegsam und trügerisch (rou zha). In der Gegend von Laoguantun [Kaungton] sind die Berge hoch und es gibt starke Miasmen (zhang da), [das Gebiet] ist kaum zu durchqueren. Kleidung und Schmuck von Beamten und Bevölkerung gleichen denen von Nanzhang. Die Frauen (furen) binden sich die Haare zusammen (shu fa) und durchbohren ihre Ohren. Sie tragen ein kurzes Oberteil (duan yi) und wickeln sich ein farbenprächtiges Tuch (jin fu) zu einem langen Rock um.

Zu den örtlichen Produkten gehören Meersalz (haiyan), Sappanholz, Elfenbein, blaugrüne Eisvogelfedern und der Kapokbaum (Baumwollbaum, mumian).

Im Kapitel über Birma in der ,Geschichte der Yuan-Dynastie“ (Yuan shi) steht geschrieben, daß die Schriftstücke, die von Birma überreicht werden, auf goldenen Blättern geschrieben sind (jin shang wenzi yong jinye xie zhi). Manchmal verwenden sie auch Papier und manchmal die Blätter der Areca-Palme (binglang ye).

\footnotetext{
${ }^{1356}$ Siehe auch TYZZ, Kapitel 10 (Mian kao), S. 162-163.

${ }^{1357}$ Die Enzyklopädie der Institutionen von Ma Duanlin (1254-1323), die 1317 herausgegeben wurde und die das Tongdian von Du You (735-812) fortsetzt (ZGRMDCD, S. 21; Gernet, S. 294); eine gekürzte Fassung wurde im Jahr 1761 neu herausgegeben (siehe CY 739.1).
} 
Es gibt drei Wege, die nach Birma führen; einer über Tianbuma, einer über Piaodian und einer über das Gebiet von Aguo; sie alle treffen in Jiangtoucheng wieder zusammen.

Im Jahr Shunzhi 18 (1661) tötete Mangmeng [Pyemin] seinen älteren Bruder und machte sich selbst zum [König].

Im 7. Jahr der Ära Yongzheng (1729) führte Birma Krieg mit Zhengmai [Chiangmai] und verlangte Tribut, jedoch ohne Erfolg (er bu guo).

Im Jahr Qianlong 15 (1750) schickte Mangdala [Mahadhammaraza Dipati, reg. 1733-1752] als Tribut zwei in Gold und Silber gravierte Schriftstücke (zhuangke biaowen), außerdem eine goldene Pagode, einen gezähmten Elefanten, birmanische Stoffe und andere Dinge.

Ein kaiserliches Edikt lobte die Gesandten und es wurde ein Bankett gegeben, wie es die Regel war, für die Gesandten der Könige der verschiedenen Länder (ge guo wang). Außerdem wurde ihnen in einem kaiserlicher Erlaß verkündet, daß sie eine Gedenktafel mit den vier Schriftzeichen rui ji xi chen (,glückverheißend ist es, die Kostbarkeiten aus dem Westen zu sammeln') von kaiserlicher Hand geschenkt bekommen würden.

Der Häuptling (qiu) von Mushu [Moksobo], Wengjiya [Maung Aung Zeya, König Alaungpaya], riß die Nachfolge an sich. Dann besetzten seine Söhne Xinao [Naungdawgyi, reg. 1760-1763] und Mengbo [Hsinbyushin, reg. 1763-1776] nacheinander [den Thron]. Daraufhin waren die verschiedenen tusi noch mehr in Unruhe versetzt worden.

Im 31. Jahr (1766) hatte sich Generalgouverneur Liu Zao aus Furcht [für seine Fehler bei der Regelung der Konflikte im Grenzgebiet bestraft zu werden] das Leben genommen (huangkong zijin). Yang Yingju hatte irrtümlich auf die Worte von Zhao Hongbang gehört, der anfangs geplant hatte, die Banditen (zei) zu verfolgen, doch er wurde besiegt [und die chinesischen Truppen] mußten sich nach Xinjie [Manmo] zurückziehen.

Im Jahr 32 (1767) erging ein kaiserlicher Befehl an den Oberkommandeur (jiangjun gong) Mingrui, seine Truppen zu einer Strafexpedition nach Birma zu führen (shuai bing tao Mian). Er umging Yongsheng und durchquerte die tusi-Gebiete, wo er Geld und Getreide [als Steurn einziehen ließ]. Im ersten Monat des Jahres 33 begab sich Mingrui nach Manjie und zerstörte nacheinander sechzehn Festungen (lei, ,Schutzwall`) und tötete über zweitausend Banditen (zei). Die Birmanen wichen zurück und besetzten die Tiansheng-Brücke. Unsere Truppen machten einen Umweg und griffen sie von zwei Seiten her an und vernichteten über dreitausend Birmanen. Dabei erlangten sie Proviant und viele Waffen. Dann suchten sie den direkten Weg nach Mengmi und drangen über zweitausend li [ca. 1000km] weit in dieses Gebiet ein. Der andere Truppenführer, Wuerdeng'e, 
sollte ihnen von Hanta aus zu Hilfe kommen, doch er verweilte dort und ließ [seine Truppen] nicht vorrücken.

Daraufhin verlegte Mingrui seinen Stützpunkt nach Mengla, wobei er persönlich die Nachhut bildete. Dabei wurde er von den Banditen verwundet und starb in Wanding.

Der birmanische König ließ ein Schreiben auf Palmblatt (puye shu) überreichen, in dem er darum bat, die Truppen zurückzuziehen.

Im ersten Monat des Jahres 34 (1769) erhielt der kaiserliche Ratgeber Fuheng den Befehl, den Feldzug gegen Birma zu führen. Im 9. Monat erklärten der tusi von Menggong, Hun Jue, und andere ihre Loyalität (lai gui). Am 28. Tag überreichte der nun gefügige Hun Jue von Menggong Elfenbein sowie ein Paar Ochsen. Im 10. Monat übergab er noch vier Paar Elefanten. Daraufhin wurde [für ihn] das Siegel eines Befriedeten Gebietes (xuanfusi) geprägt. Anschließend eroberte [Fuheng] Mengyang und die Birmanen wurden von Furcht ergriffen.

Am 7. Tag des 12. Monats haben [die Truppen] Kaungton umzingelt; Meng Bo [König Hsinbyushin] überreichte ausländische Brokate, ausländische Woll- und Baumwollstoffe (yang jin, yang ni, yang $b u$ ) sowie andere Dinge und ersuchte dringend (kenqiu) darum, die Kämpfe einzustellen; er versprach, alle zehn Jahre Tribut zu übersenden. Der Kaiser gestatte dies. Innerhalb der Grenze (bian nei) wurde ein guter Ort ausgewählt, an dem sich Hun Jue niederließ.

Im 35. Jahr (1770) wurden die chinesischen Truppen abgezogen.

Im Jahr 41 (1770) starb Meng Bo [Hsinbyushin, reg. 1763-1776] und sein Sohn Zhuijiaoya [Singu, reg. 1776-1782] trat die Nachfolge an. Im Jahr 47 (1782) wurde er von Meng Chang [Maungmaung] ermordet. Die Bürger (guoren) setzte Meng Yun [als König ein]. Im Jahr 53 (1788) entsandte Meng Yun einen seiner Anführer (toumu), der ein Schreiben auf Goldblatt, einen gezähmten Elefanten und eine goldene Pagode überreichte. Als sie an der Paßstation anklopften, um Tribut zu überbringen, wurde entschieden, ihnen reiche [Geschenke] zu übergeben und für den begleitenden Minister wurde ein Bankett veranstaltet.

Anschließend wird im Text kurz auf die chinesische Gesandtschaft nach Birma aus dem Jahr 1790 (siehe Kapitel IV. A. 3. 3., S. 220-223) hingewiesen und die Chronologie der Könige Birmas bis zum 19. Jahrhundert fortgeführt, bis schließlich, nachdem die Engländer im Jahr 1826 (Daoguang 6) Arakan und Tenasserim erobert hatten, König Meng Xibo (Thibaw, reg. 1878-1885) die Regierung übernahm, der „ein ausschweifendes Leben“ führte und „der Bevölkerung Geld abpresste“, deren Schicksal „war erbärmlich“. ${ }^{358}$ 
„Am 21. Tag des 9. Monats des 11. Jahres der Ära Guangxu (1885) setzten die Engländer (yingjili ren) heimlich Truppen in Bewegung und überschritten die Grenze. Sie nahmen Xibo, seine Frau und seine Kinder fest und schickten sie weg [ins Exil]; damit war das Land verloren“. ${ }^{1359}$

Zum Abschluß der Darstellung im TYTZ wird das Qing-zeitliche Birma von den Verfassern des fangzhi mit einer kurzen Beschreibung von Land und Leuten vorgestellt und sodann die historische Entwicklung des Landes bis zum Beginn des chinesisch-birmanischen Krieges im 18. Jahrhundert noch einmal in wenigen Sätzen zusammengefaßt.

„Vom Jahr Qianlong 53 (1788) bis zum gegenwärtigen Jahr Guangxu 11 (1885) hat [Birma] Tribut geschickt und wurde als ein sehr gehorsamer Vasallenstaat bezeichnet (cheng fan ji wei gongshun). [Birmas] Regierungssitz befindet sich unterhalb des Xiaomingshan. Der Berg befindet sich außerhalb des Nordtores. Eine Ziegelmauer umgibt eine Fläche von zwölf li [ca.6 km] im Quadrat; sie hat zwölf Tore. Außerhalb ist eine hölzerne Palisade ( $m u$ zha) errichtet worden, innerhalb dieser ist es verboten [auf Pferden] zu galoppieren (jin zhou chi). Außerhalb gibt es zudem einen Graben, der vier bis fünf zhang [ca. 13-17m] breit ist und von kleinen Schiffen befahren werden kann. Innerhalb der hölzernen Mauer ( $m u$ cheng) befindet sich die Residenz des Herrschers (jincheng, ,verbotene Stadt'). Darin gibt es sehr elegante, luxuriöse Hallen und Paläste. Auch zwei Gärten befinden sich dort: Der eine wird Miaowuying genannt, der andere Dongwuying. Zahlreiche Blumen und Sträucher sind dort angepflanzt worden. Im Garten gibt es zudem einen See, auf dem man Boot fahren kann. Straßen (jieshi) führen aus der ummauerten Stadt hinaus. Jenseits der hölzernen Mauer befindet sich im Süden die Straße der Chinesen (hanren jie), wo viele Chinesen Handel treiben. [TYZZ: Sie wählen einen Chinesen als Oberhaupt der Geschäftsstraße aus (jie zhang).] Im Westen befindet sich die Straße der Leute aus dem Westen (yangren jie). Insgesamt gibt es zweiundsiebzig große und kleine Straßen, deren Namen nicht vollständig aufgezeichnet sind.

Die hohen Minister des Königs nennt man wan [birman. wun]; es gibt vier wan. Das ist genauso wie toumu (,Häuptling') auf chinesisch (hua yan). Heute [bezeichnet man sie] fälschlicherweise als yun. Die nächsten [in der Hierarchie] werden wantao genannt, davon gibt es sieben. Da sie alle keine Beamtengehälter beziehen, nehmen sie Prozente (li) von allen Handelsgeschäften als offizielle Gebühren ein.

[Die Birmanen] sind Buddhisten, es gibt hochrangige Mönche (guoshi) und sie schreiben den buddhistischen Kanon in birmanischer Schrift.

Sie verwenden den Kalender der Moslems (huihui) und fügen keinen Schaltmonat ein.

${ }^{1359}$ TYTZ, S. 245 
Ihr Land liegt nahe bei Folangji [Portugal], über Yanggong [Rangun] kann man Fujian und Kanton erreichen. Deshalb verwenden sie viele Waren der Leute aus dem Westen (yangren huowu). [TYZZ: Sie verbreiten Feuerwaffen (huoqi), die sämtlich nach westlicher Methode hergestellt worden sind.]

Früher gab es den Häuptling (qiu) Mang, der herausragende Stärke besaß. Damals war der Militärbefehl äußerst streng. Wenn sie siegten, wurden die [Soldaten] reich belohnt, wenn sie unterlagen, wurden sie getötet. Von denjenigen, die desertierten oder sich versteckten, wurde der gesamte Familienbesitz konfisziert und die ganze Familie versklavt. Heutzutage verstehen Herrscher und Minister, hoch- und niederrangige, nichts vom Krieg. Wenn Gefahr droht, dann entsenden sie eine Bürgermiliz (min bing), die Proviant für drei Tage mitbekommt, wenn dieser aufgebraucht ist, dann zerstreut sie sich ganz von allein wieder. Wenn sie nur einen kleinen Sieg erringen, dann freuen sich alle und tanzen herum, wie Vögel oder wilde Tiere. Erleiden sie eine Niederlage, dann zerbricht (beng) [die Truppe] und löst sich auf, auch der Kommandant kann sie dann nicht mehr kontrollieren.

Von ihrem Wesen her sind [die Birmanen] dumm und mißtrauisch (yu er duo yi). [TYZZ: Sie haben den Charakter von Hunden und Schafen (quan yang xing).]

Jeder neue König muß alle anderen Thronfolger töten, um so Kämpfe [um den Thron] zu verhindern.

Aber wenn er jemanden fürchtete, so war das General Ha Guoxing. Während der Ära Qian-long gab es einen Kampf beim Dorf Lingangzhai. Damals hatten sich die [Birmanen] aus Ehrfurcht vor dem Regionalkommandeur Ha Guoxing unterworfen. Daraufhin baten sie jedesmal, wenn sie wieder um Frieden nachsuchten, um eine Audienz bei General Ha.

So in etwa war das früher in Birma.““1360

${ }^{1360}$ TYTZ, S. 245, TYZZ, S. 163 


\section{Das Kapitel über den ,Grenzschutz‘ im TYTZ}

Im zweiten Abschnitt des Kapitels über das Militärwesen im TYTZ beschäftigten sich die Verfasser des TYTZ mit dem Grenzschutz (bianfang) (TYTZ, Kapitel 11, wubeizhi II, S. 179-180). Nach einer Einleitung zur historischen Entwicklung und der Bedeutung der Sicherung des Grenzgebietes im Südwesten von Tengyue am Ende des 19. Jahrhunderts, folgt eine Beschreibung der Lage acht Paßstationen (ba guan) und der neun strategischen Pässe (jiu ai), die im Folgenden übersetzt wird. Daran schließt sich im TYTZ eine Auflistung der Militärkolonien (tuntian), der Befestigungsanlagen (diaobao) und der Kontrollstationen (qiadi) an. Da diese zumeist nur aus der Nennung der Namen der einzelnen Anlagen besteht, wird hier auf ihre Wiedergabe verzichtet. Die Maßnahmen zur Sicherung des Grenzgebietes sind in Kapitel IV. B. 3. 1., S. 358-359; 3. 5., S. 394-395 und 3. 6., S. 396ff beschrieben.

\section{„Der Grenzschutz}

Der Begriff ,Grenzschutz‘ (bianfang) geht zurück auf das Tongdian von Du You. ${ }^{1361}$ Darin wird überliefert, daß ,die ausländischen Barbaren entweder rebellieren oder sich unterwerfen würden (wai yi panfu); daß Berge und Ströme schwer zu passieren wären und daß, um die Grenze ins Landesinnere zu sichern, an strategischen Punkten Befestigungsanlagen (diaobao, auch ,Bunker`) errichtet worden wären‘; ausführlich erklärt wurde das jedoch nicht.

Teng[yue] liegt nahe bei einer entlegenen Grenze (lin huang jiao). Die in der Umgebung Wohnenden gehören alle zu den Barbaren im Grenzgebiet (yi yi). Deshalb ist früher [in den Jahren 1439 bis 1449] veranlaßt worden, drei weite Feldzüge zu unternehmen, um die Autorität des Himmels in diesen unzivilisierten Gegenden (huawai) zu verbreiten [wörtl.: bo, „,aussäen“].

[Gouverneur Chen] Yongbin reichte dann eine Throneingabe betreffs der Errichtung von Paßstationen in diesem fernen Winkel (xia zou) ein. Dem entsprechend sind Festungen gebaut (jian diao she bao) und Kontrollstationen eingerichtet (an qia) worden. An Orten, die offensichtlich von strategischer Bedeutung waren (eyao), aber auch an versteckteren [Plätzen] wurden zahlreiche Soldaten zur Verteidigung stationiert.

1361 Der Historiker Du You (735-812) arbeitete fünfundreißig Jahre lang, von 766-801 an seinem Werk, einer enzyklopädi-schen Geschichte der politischen Institutionen vom Altertum bis um das Jahr 800 (ZGRMDCD, S. 208; Gernet, S. 233). 
Zwar sind unter dieser großartigen Dynastie (sheng chao) China und das Ausland eine Familie (zhong wai yi jia), auch haben sich Tugend und Autorität bis an die äußersten Grenzen ausgebreitet, so daß alle ausländischen Barbaren (wai yi) miteinander in diesem friedlichen Universum (taiping zhi yu) Umgang pflegen, dennoch dürfen Herrschaft und Kontrolle in Verbindung mit einer Diskussion der Verteidung und des Grenzschutzes in der Verwaltungseinheit (jun) Teng nicht vernachlässigt werden.

Im Norden der Stadt, jenseits des Diantan-Passes, befindet sich Chashan, das [Gebiet] ist das höchste im nördlichen Teil des Gaoligong[-Gebirges] und so kalt, daß die fünf Getreidesorten (wu gu) dort nicht angepflanzt werden können. Die Menschen dort sind herrisch (qianghan) und vortreffliche Kämpfer. (Früher gehörte das Gebiet zu Mengyang.)

Im 3. Jahr der Ära Yongle der Ming-Dynastie (1405) tat sich [der Herrscher von] Mengyang mit Dao Mengyong von oberhalb des Flusses (shang jiang) zusammen, um zu rebellieren. Ein Anführer ( $m u$ ) der Barbaren, Han Zhang, fügte sich [der Forderung, am Kampf teilzunehmen] nicht. Im 5. Jahr (1407) wurde Zhang [zur Belohnung für sein loyales Verhalten vom chinesischen Kaiser] das Amt eines Oberhauptes eines Befriedeten Gebietes (zhangguan si) übergeben.

Anmerkung: Chashan befindet sich im Nordwesten des Kreises Baoshan, bei Shiwuxuan, im Norden von Datang, Mamian und Diantan; Yunlongzhou und Lujiang sind westlich davon.

Man sagt, daß die Grenzangelegenheiten von Yongchang und Tengyue mit [diesen Ereignissen] begonnen haben.

Auf den drei Feldzügen gegen Luchuan [1439 bis 1449] kletterten die Truppen Wang Jis über Mengyang bis nach Mengna (für eine Beschreibung dieses Grenzgebietes siehe das Kapitel bianyi). Alle Stämme (buluo) erzitterten vor Furcht und sagten, seit alters her haben die Chinesen (Han ren) nie den Jinshajiang überquert. Daß die Truppen Wangs bis hierher gekommen sind, zeigt wahrlich die Autorität des Himmels. [Wang] Ji ließ einen Gedenkstein aufstellen, [dessen Inschrift] den Jinjiang als Grenze beschwor, es hieß darin, erst wenn dieser Stein mürbe geworden und der Fluß vertrocknet sein wird, dann wird der Fluß überquert werden können. Si Lu gehorchte dem Befehl. (Ming shi, tusi chuan).

Im 22. Jahr der Ära Wanli (1594) ließ der Gouverneur Chen Yongbin acht Paßstationen errichten und dort Soldaten zu ihrer Bewachung stationieren. Im 23. Jahr (1595) ließ er die beiden Kommandanturen (shoubei) Manha und Longba einrichten und Befestigungsanlagen (bao) bauen. [die neu gegründete Stadt im tusi-Gebiet von] Mengmao wurde Pinglucheng genannt und es wurden dort zweiundzwanzig Militärkolonien eingerichtet. 
In dem ,Überblick über Birma‘ (Mian lüe) von Bao Jianjie heißt es: „Yongbin ließ Paßstationen, Befestigungsanlagen und Militärkolonien errichten, um gegenüber Birma verteidigungsbereit zu sein. Die Birmanen ärgerten sich darüber (ji) und provozierten mehrfach [Zwischenfälle], um Zwietracht zu säen. Deshalb entsandte [Chen Yong]bin den Huang Xi aus Min [Fujian], um mit Siam zu vereinbaren, daß sie [Birma] von beiden Seiten, von diesseits und jenseits der Gebirgsketten, aus angreifen würden. Seitdem hatte die Stärke Birmas abzunehmen begonnen (Mian shi shi ruo).

Die acht Paßstationen (mit einem Anhang über die alten Paßstationen)

Tongbi guan

Wanren guan

Shenhu guan

Jushi guan
320 li südlich der Stadt gelegen, im Gebiet der Verwaltungseinheit (si) Nandian. ${ }^{1362}$ Die Paßstation befindet sich am Bulingshan, diesseits des Man-hashan. Sie kontrolliert die strategisch wichtigen Pässe (ai) nach Manha, Haihei und Manmo.

300 li südlich der Stadt gelegen. Die Paßstation befindet sich hinter der Hängebrücke in Zhanda, auf dem Gipfel des Menglongshan. Sie kontrolliert die Hauptverkehrsstraßen (yaolu) nach Gangde, Gangle und Yixi [d. h. Mengyang].

180 li südwestlich der Stadt gelegen. Die Paßstation befindet sich hinter Zhanxi auf dem Mengjiashan. Sie kontrolliert die Straßen nach Chashan, Guyong, Weimian, Yixi und andere.

330 li südlich der Stadt gelegen, auf dem Ximashan bei Hugang. Sie kontrolliert die Straßen nach Hugang, Yixi u.a.

Diese vier Paßstationen werden von der Kommandantur (shoubei) Manha bewacht.

Tiebi guan

Huju guan

Tianma guan

Hanlong guan
480 li südlich der Stadt gelegen, auf dem Denglianshan. Kontrolliert den Wasserweg (shuilu) nach Manmo.

500 li südlich der Stadt gelegen, auf dem Banghangshan. Kontrolliert die Hauptverkehrsstraßen nach Mangan, Zheao, Xiannao und Mengmi.

Befindet sich auf dem Bangqianshan. Kontrolliert die Hauptverkehrsstraßen nach Mengkuang, Mengqu und Mengmi.

Befindet sich in Gonghui. Kontrolliert die Hauptverkehrsstraßen nach Mengwei, Mengyu, Leinong und Xipo.

Diese vier Paßstationen werden von der Kommandantur (shoubei) Longba bewacht. (Heutzutage, [am Ende des 19. Jahrhunderts] sind die beiden Paßstationen Tianma und Hanlong längst an Mubang verlorengegangen, lun.)

\footnotetext{
${ }^{1362}$ Die Längenmaßeinheit li entspricht etwa 0,5 Kilometer.
} 
Mamian guan

Guyong guan

Meng Lien guan

Heze guan
Früher: Guihui guan. Wird auch Mamian ai genannt. 250 li nordwestlich der Stadt gelegen. Jenseits des Shangjiang, auf dem Gipfel des Xuanshan bei Manyun. Jener Berg ist äußerst hoch und gefährlich. [Die Paßstation] verbindet mit dem fernen Yunlong und Wujing.

160 li westlich der Stadt gelegen.

60 li östlich der Stadt gelegen.

30 li südlich der Stadt gelegen. Die Straße führt nach Yisan.

Die drei letztgenannten Paßstationen gehören alle zum Inland (neidi), zusammen mit dem Mamian guan bilden sie die vier alten Paßstationen (si gu guan).

Quansheng guan

Befindet sich am Wasserscheiden-Paß (Fenshuiling) und liegt heute in Zhanxi.

\section{Die neun strategisch wichtigen Pässe}

(Am Ende wurde noch einer hinzugefügt, so sind es zehn Pässe)

Guyong ai

Mingguang ai

Diantan ai

Zhina ai
165 li westlich der Stadt gelegen, auf dem Tengzhashan. Das Gebiet wird von vier Bergen umschlossen, gegenüber ist der Langyashan, dessen felsiger Gipfel eine ungewöhnlich hohe und gefährliche Steilwand ist.

Tatsächlich wird diese Paßeingang (aikou) genannt. Die Einheimischen (turen) sagen, daß es dort drei Straßen gibt: Die eine führt in einem Tag zum Xiaochashan, wo der Jinshajiang in den Lijiang fließt, eine zweite führt nach Manmo und eine dritte in das Gebiet von Jiajiu.

Von der Stadt [Tengyue] aus sind es 200 li nach Westen bis Mingguang, das auf beiden Seiten von Flüssen begrenzt wird, die sich weiter dahin schlängeln, bis sie sich vereinigen, dann sind es etwa 40 bis 50 li bis zum Eingang des Passes (aikou).

Von der Stadt aus sind es 120 li nach Westen, bis zur Garnison (ying) Gudong, dann 80 li zum Zhongxiao Tempel, 30 li bis zum Hochplateau (ba) von Guantian (,den Feldern am Paß'). Sie [Bevölkerung] kann gut mit der Armbrust umgehen. Auf dem Land in der Umgebung wird Ackerbau betrieben, es ist ein Paradies (yuetu). Im 5. Jahr der Ära Xuande der MingDynastie (1430) wurde dort ein Polizeibezirk (xunjian) eingerichtet sowie das Befriedete Gebiet (zhangguan si) von Chashan. Der Dolmetscher (tongshi) Duan Sheng wurde als Polizeibeamter (xunjian) eingesetzt. Der Vize-Häuptling des Befriedeten Gebietes (fu zhangguan si) von Chashan Han Dachen, dessen Truppen von den Wilden (yeren) getötet worden sind, flüchtete ins Landesinnere. Der Polizeibeamte dieses Passes (guan) dachte auch daran, zur gleichen Zeit zu fliehen. Der gegenwärtige HerrscherPosten (tumu) existiert seit der Ära Yongzheng (1723-1736).

140 li westlich der Stadt gelegen. Im Gebiet von Zhanxi. Sein Fluß fließt von Guyong aus in einem Bogen um Zhanxi herum, bis zur weiten Hochebene (haiba) von Ganya. Er passiert die beiden Grenzstationen Shengu und Wanren und den Benmashan in Guyong. 
Mengbao ai

\section{Datang ai}

Bazhu ai

Shamulong ai

Shipopo ai

Cizhuzhai ai
Über 150 li südwestlich der Stadt gelegen. Jenseits des Flusses Zhanxijiang, im Süden .... Das Gelände ist gebirgig, von Gipfeln umschlossen, nahe an einer Befestigung (zhai) der Yeren. In der Ferne führt es zur Paßstation Wanren. Früher war ein [Unterpräfekt zur] Besänftigung der Barbaren (fuyi) ernannt worden, um ihn zu kontrollieren.

Das ist in Diantang guan. 170 li nördlich der Stadt gelegen, zwischen Mingguang und Mamian. Die Straße verbindet ihn mit den Wilden (ye yi). Auf seinem Gebiet ragt Yuedashan empor, im Südwesten wird es vom Guyongshan umschlossen. Der Gebirgszug im Norden der Stadt [Tengyue] kommt von hier.

Befindet sich am Tongbi-Paß, wenn man von Zhanda 10 li nach Süden geht. Gehört zum Zhanda si.

120 li südöstlich von Nandian gelegen. Gehört zu Nandian si.

Anderer Name: Bangzhang ai. Befindet sich 105 li nördlich des Nandian si, mit Errichtung des Passes wurde der Berg befriedet (ai she ping shan).

Existiert heute nicht mehr.“ 


\section{Die Proklamation der Hui von Tengyue}

Die ,Proklamation der Hui von Tengyue‘ (Tengyue Huimin xiwen) ist ein von Li Fangbo verfaßter Text, der ursprünglich den Titel ,Proklamation über die in Tengyue geübte Vergeltung im Jahr bingchen der Ära Xianfeng` hatte. Nach dem Massaker an den Hui von Tengyue am 3. Tag des 10. Monats des 6. Jahres der Ära Xianfeng (bingchen, 1856) publiziert, werden darin die Schrecken des Massakers dargestellt und das (ebenfalls gewalttätige) Verhalten der Hui noch im Vorfeld der Moslem-Rebellion als Reaktion das von Han-Chinesen erlittene Unrecht gerechtfertigt. ${ }^{1363}$

„Die Hui und die Han haben in Teng seit jeher friedlich zusammengelebt. Die Gelehrten haben Tuschstein und Sitzplatz miteinander geteilt; die Land besitzenden Familien [stritten nicht wegen] des Feldrains. Einmütig wurde Handel getrieben, das Gold wurde wie bei Guan und Bao geteilt; es gab enge Beziehungen, die nur hinter denen des Dorfes der Familien Zhu und Chen zurückstanden. ${ }^{1364}$ Noch nie sind Grenzen aufgestellt, noch nie sind die Familien in unterschiedliche Gruppen eingeteilt worden. Wir Moslems fühlen keine Gewissensbisse, wenn wir unser Verhalten überprüfen. Uns selbst prüfend haben wir oft erklärt, daß wir nicht mit den Menschen gekämpft und hinsichtlich der Welt kein Unglück [bewirkt] haben.

Wer hätte gedacht, daß sich die bereits früher eingesperrt gewesenen örtlichen Rowdies Huang Daiwan, Dong Dayong, Zheng Lan und Cun Rongsheng, die noch nicht festgenommenen Unruhestifter Zhao Liancheng, Li Zhipei, Luo Guoyan, Huang Xing und Wang Yuliang, der böse Wang De, die durchtriebenen Beamten Chen Jian,Gan Shutang und Zhang Yaodian, die schlechten Büttel niederen Ranges Li Jinfang, Li Wenjian und Yang Jinchen im Bunde mit den korrupten Reichen Liu Hanyi, Feng Shaolian und Li Dalu sowie den bösartigen Angehörigen der Gentry Yue Yangcheng, Lin Yunpeng, Shang Wensheng und andere unter Verbrennen von Weihrauch und mit einem Schwur zu einem Bündnis zusammenschließen würden. Der Tempel der Treue und Kindespflicht (Zhongxiao si) war in Wirklichkeit ein Unruheherd, die Mönche waren gewillt Unrecht zu begehen und ließen die Krähen sich versammeln; die beiden Dorfgewaltigen Mao und Ni übten eine böse Macht aus, handelten gewissenlos und gaben doch vor ehrlich zu sein.

Der Speicher der Familie Dong war mit Gold gefüllt und so kam ihre Schlechtigkeit zur Geltung. Früher gehörte die Familie Lin zum [Volk der] Pu, auch sie haben schlechte Wurzeln. Der von den Zivil- und Militärbehörden entsandte Kontrolleur ebenso wie die zu Dorfältesten ernannten

\footnotetext{
1363 ,Die ,Proklamation“ ist in dem Sammelband Huimin qiyi von Bai Shouyi enthalten (Bd. 2, S. 13-14).

1364 Guan Zhung und Bao Shuya. Zwei berühmte Freunde. Das Dorf der Familien Zhu und Chen: Das ganze Dorf ist miteinander verwandt; auch symbolisch für Eheschließungen (CY 815. 3-4).
} 
[Personen], täuschten vor nichts zu wissen und verschwiegen [diese Mißstände]. Sie täuschten ihre vorgesetzten Beamten und verschleierten [die Schwierigkeiten] der Hui-Bevölkerung.

Im 8. und 9. Monat kamen viele Gerüchte auf. Nach der zwieten und dritten Doppelstunde verließen die Han heimlich ihre Häuser. Die Banditen benutzten dann die Taktik des Gegenangriffs; die Hui dachten nach wie vor, daß alles ruhig sei.

Was besonders verabscheuungswürdig war: Das Militär hat gemeinsame Sache mit dem Verräter Shi Huayong gemacht und unterstützte ihn offen mit Waffen; die Zivilbeamten verbündeten sich mit dem großen Gauner Yi Qingyun und unterstützten ihn heimlich mit bösen Plänen. Kein Wunder, daß die Gauner in den Dörfern alle ganz ungehemmt auftraten. [Selbst] kleine Gauner hatten soviel Kraft wie ein Tiger. Die Haupträdelsführer hatten mehrere Dutzend Helfershelfer; die Helfer derjenigen, die diesen schlechten Vorbildern folgten breiteten sich aus wie Vogelfedern. Die [Zivilbeamten] haßten die Aufrechten wie Schlangen und Skorpione gehaßt werden und fürchteten die Cliquen der Banditen wie Tiger und Wölfe. Verdienstvolle Taten wie das Erbauen von Brücken oder das Reparieren der Straßen fürchteten sie so, wie man Dornen in den Augen fürchtet. Unterstützung für die Elenden und Erbarmen mit den Armen, solche unauffälligen guten Taten waren ihnen so lästig, wie eine Nadel, die man hinten in den Kopf gestochen bekommt. Sie beklagten sich darüber, daß es zu viele hochbetagte Alte gäbe, den Jungen waren sie böse, daß diese so jung schon die Staatsprüfungen bestehen würden. Was den Lebensunterhalt anging, so glaubten sie, daß die Hui das ganze Geld verdienen würden, was die Armee anging, so glaubten sie, daß hohe und niedriege Ränge alle von Hui besetzt wären. Das sollte vernünftig sein, hätten sie da noch ein Gewissen gehabt? Sie waren völlig skrupellos und bar jeder Menschlichkeit.

Flugblätter [die verteilt wurden] waren der erste Schritt hin zum Unheil; die Bekanntmachung war keine rettende Medizin. Der dritte Tag des zehnten Monats war festgelegt worden und nach der vierten Doppelstunde wurden Feuer angezündet. Unsere Eltern wurden getötet, unsere Brüder massakriert, unsere Ehefrauen umgebracht, unser Eigentum geplündert, unsere Felder besetzt. Sie gierten nach unseren Häusern; überall wurden die Moscheen vollständig niedergebrannt. Welche Verbrechen hatten diese Babies begangen, daß sie mit Äxten traktiert wurden? Welcher Vergehen hatten sich diese schwangeren Frauen schuldig gemacht, daß man sie aufgeschlitzt hatte? Leichen bedeckten Stadt und Land, die Gräben waren mit Blut gefüllt. Gewaltsam wurden die schönen Mädchen gezwungen, Konkubinen und Sklavinnen zu werden. Geraubt wurden die klugen Jungen und von angeblichen Eltern in vorgespiegelter Hilfsbereitschaft aufgezogen. Alles was passieren konnte war geschehen. Man bringt es nicht übers Herz davon zu sprechen, davon zu hören ist unerträglich! Den Toten wurde es schwer die Augen zu schließen, für die Lebenden verdoppelte sich die Seelenqual. Sie stampften mit den Füßen und schlugen sich an die Brust, als sie keine 
Tränen mehr hatten, weinten sie Blut. Der Himmel kann uns nicht versöhnen! Die Soldaten können nicht mehr zurückgerufen werden, [ein Kampf kann nicht mehr vermieden werden]!

Denkt man zurück, an das was die Beamten und Militärs gemeinsam unterzeichnet hatten; Han und Hui hatten vereinbart: ,Hui, die zuerst Unruhe verursachen, müssen vernichtet werden; Han, die zuerst Unruhe verursachen, müssen vernichtet werden`.

Heute sind die Han so grausam zu den Hui, wie oben beschrieben und die Beamten unterstützen sie noch bei diesen Brutalitäten. Sie sind ungerecht und ihre Machtposition ist somit zerstört. Das ist nichts anderes, als daß die Beamten das Volk seiner Rechte berauben. Ein Berg von Haß und ein Meer voller Bitternis reichen nicht aus, um das eben gehörte zu verdrängen. Es gibt Ratten auf den Altären und Füchse innerhalb der Stadtmauern, diese zügig einzufangen ist schwierig. Was sollten die Hui also machen?

Wir haben nur diese verwundeten Körper, doch mit [unseren] Klingen fällen wir Bäume um Knüppel daraus zu machen, wir rissen Bambusstangen aus, um Fahnen daraus zu machen unter denen wir die Starken versammelten und denen die Mutigen folgten. Solange der Hauptrebell nicht vernichtet ist, solange werden die Signalfeuer nicht ausgehen. Solange wir die alte Heimat nicht zurückerhalten, solange werden die Waffen nicht ruhen. Wenn diese Hundemeute nicht vernichtet wird, wie können wir dann den Getöteten in der Unterwelt gegenübertreten? Wenn diese Fuchsbande nicht zerschlagen wird, wie können unsere Körper wieder zu Menschen werden?

Dies alles hat unsere Rache ausgelöst. Insbesondere haben wir ihre Sammelplätze eingenommen, um die Habichte [von dort] zu verjagen. Wollte wir etwa alle töten und ihre Schätze verbrennen? Die Tugendhaften in der Stadt und die Guten in den Dörfern usw., diese alle wollen wir nicht vernichten. Jene können sorglos in ihren Kissen ruhen, sie brauchen sich keinerlei Sorgen zu machen. Andere aber, die stark sind und die Schwachen vernichten, die viele sind und die Wenigen vernichten; solche, die ein lächelndes Anlitz und das Herz eines wilden Tieres haben, die sollen nicht mehr sagen können, daß man die Menschen schikanieren kann! Die Menschen kann man schikanieren, aber der Himmel wird das nicht länger zulassen. Sagt nicht, daß die Hui vernichtet werden können! Die Hui können vernichtet werden, doch allein werden die Han dann nicht leben können. Glück und Unglück wechseln einander ab. Wenn man die Menschen, die früher Grausamkeiten verübt haben heute bestraft, so macht man keinen Fehler. Der Weg des Himmels ist eine ausgleichende [Gerechtigkeit]. Wenn die Waren der Banditen von außerhalb von den Einheimischen genommen werden, so ist das nicht gewinnsüchtig.

Zusammengefaßt, es gibt stinkende und duftende Pflanzen, Gestank und Wohlgeruch werden unterschieden. So wie beim Jing- und beim Wei-Fluß gilt es das Klare und das Trübe zu unterschieden. Bitte betrachten Sie die beiden Seiten, die sich heute gegenüberstehen; auf welcher Seite wird Tengyue schließlich sein!“ 


\section{Die ,Völker der Region‘ (zhongren)}

Nach der Darstellung der historischen Entwicklung Birmas und der Kleinstaaten der Shan jenseits der acht Paßstationen haben die Verfasser des TYTZ Kurzbeschreibungen der verschiedenen in der Region des Stromschluchtenfächers ansässigen Völker (zhongren) in das 15. Kapitel ihres Lokalhandbuches aufgenommen (TYTZ, S. 247-248). Die folgende Übersetzung wird ergänzt um die Aufzeichnungen aus dem YCFZ (Kapitel 57, S. 332-333), die, soweit sie von denen des TYTZ abweichen, in die Fußnoten aufgenommen worden sind. Die Beschreibungen der lediglich im YCFZ genannten Völker sind am Ende der Übersetzung angefügt worden, so daß insgesamt siebenundzwanzig ,Völker der Region` aus chinesischer Perspektive betrachtet, vorgestellt werden.

\section{1. Die Xiaoboyi}

„Sie sind ,gekochte Barbaren“ (shu yi), die sämtlich im Südwesten in der Umgebung von Tengyue leben. Männer und Frauen tragen nur wenig Kleidung und Schmuck. Sie sind beinahe chinesisch (jin zhonghua) und können auch die chinesische Sprache sprechen (neng hanyu). Sie wohnen in befestigten Dörfern (cun zhai). Ihr Charakter ist folgsam und besonnen (xing shun jin). Sie pflügen, um sich zu ernähren und weben ihre Kleidung (geng shi zhi yi). Sie haben keine Etikette für Erwachsene und Kinder (wu chang you li).“1365

\section{2. Die Daboyi}

„Sie leben im Westen von Longchuan. Die Männer schneiden sich die Haare und tätowieren ihre Körper. Die Frauen (furen) [gehen] barfuß, färben sich die Zähne (ran chi [YCFZ, S. 333: ran chi yi se]) und umwickeln ihren Kopf mit einem Tuch. Sie wohnen gern nahe am Wasser. Männer und Frauen (nü) baden alle nackt im Fluß. Die Frauen (furen) behüten ihre beiden Brüste sorgfältig. Sie sagen, diese seien nicht von Vater und Mutter geboren, sondern von Himmel und Erde geschenkt worden. Man soll sie [anderen] Menschen nicht zeigen. Die Männer ruhen sich aus, die Frauen arbeiten (nan yi nü lao), sie spinnen und weben, ihre Verpflichtungen hören nicht auf (fudan bu chuo).“1366

\section{3. Die Puren}

Früher wurden sie Baipu genannt. Sie leben verstreut in Bergschluchten. Man findet sie südlich von Yongchang. Sie haben häufig ein grobes und dunkeles Aussehen (xingmao cu hei). Männer und Frauen (nü) binden alle ihr Haar zu einem Knoten zusammen. Die Männer wickeln sich ein dunkles

\footnotetext{
1365 TYTZ, S. 247; ebenso im YCFZ, S. 333.

${ }^{1366}$ Ebenda.
} 
Tuch um den Kopf, um die Taille binden sie eine Schnur. Die Frauen (furen) tragen ein gemustertes Tuch (huabu). Sie alle arbeiten fleißig und ertragen viele Mühen (qin li nai lao). Sie pflügen und jäten, was sie angepflanzt haben: Buchweizen, Baumwolle und Sojabohnen. Sie kennen die chinesische Sprache (zhi hanyu) und treiben Handel (tong maoyi)، “1367

\section{4. Die Achang}

„Sie werden auch Echang genannt. Sie können Kälte ertragen, fürchten aber die Hitze; sie freuen sich über Trockenheit und verabscheuen Feuchtigkeit. Sie lieben es auf hohen Bergen zu wohnen. Sie betreiben Brandrodung (daogeng huozhong). Sie sind gierig. Sie bringen Hunde als Opfer dar. Zum Wahrsagen benutzen sie dreiunddreißig Bambusstäbe. Die Methode ist etwa so wie das Wahrsagen (mit Schafgarbe). Sie gieren nach Alkohol. Sie tragen Lasten auf dem Rücken und nicht an einer Stange auf der Schulter. Sie suchen nichts schmutziges aus. Heutzutage gibt es in Husa, Lasa und Longchuan viele von ihnen.““1368

\section{5. Die Piaoren}

„Sie sind die Nachfahren der Nu von Zhupo. Ihre Vorfahren befanden sich in Jinchi und im Reich der Piao. Die Frauen (furen) umwickeln ihre Köpfe mit einem weißen Tuch. Sie tragen kurze Hemden und umwickeln ihre Taille mit rotem Flechtrohr (hong teng), mit dem sie ihre Röcke

${ }^{1367}$ TYTZ, S. 247. YCFZ (S. 332): „Früher wurden sie Baipu genannt. Im Zhou shu (,Geschichte der nördlichen ZhouDynastie‘, im Jahr 636 vollendet) werden die Wei, Lu, und Peng sämtlich ,Menschen des Westens‘ (xiren) genannt. Im Chunqiuzhuan (vermutlich das Cq. Sanzhuan yitong shuo von Ma Rong, 79-166), chudeng, gibt es sie auch als ,Einheimische des Südens‘ (nantu). Ursprünglich lebten sie jenseits der südwestlichen Grenze von Yongchang. Fälschlicherweise wurde ein anderes Schriftzeichen für pu verwendet, weil sie für diejenigen, die das Land benannt haben, von der gleichen Art wie Pupiao und Pugan [Pagan] zu sein schienen.

Die Männer wickeln sich ein dunklrotes Tuch um den Kopf, um die Taille binden sie schmale dunkelgrüne Seidenbänder (taosheng), zumeist sind das die Vornehmen. Die Geringen haben keine Kleidung. Sie ziehen sich Baumwollstoff als Gewand über. Unterhalb der Knie binden sie sich schwarzes Flechtrohr (hei teng) um. Die Frauen (furen) tragen einen Dutt im Nacken und stecken sich dunkelgrüne Perlen an. Sie wickeln sich buntgemusterten Baumwollstoff (huabu) als Rock um die Taille. Daran binden sie einige Dutzend Muscheln (haibei) fest und wickeln sich Suoluo-Stoff um die Schultern [suoluo bu; suobu, einheimische Stoffe; suoluo shu, Reevesia].

In Yongchang, in Fengxi und Shidian, in fünfzehn Befriedeten Gebieten und achtundzwanzig befestigten Dörfern (zhai) gibt es diese Volksgruppe. Sie pflügen und säen fleißig. Sie gehen barfuß und steigen so schnell auf die Berge, daß sie die fliegenden Vögel übertreffen. Heutzutage sind sie allmählich arm und schwach geworden (pin ruo). Sie sind in den Regionalen Militärbezirk Ami, nach Xinxing und Lufeng eingewandert und nach Süden bis Jingdong, Mengzi und Kaihua, in achtzehn befestigte Dörfer. Ihr Charakter, ihre Eigenschaften, ihre Aufmachung (xing zhi zhuangshu ge shu) sind alle verschieden; sie werden im Tongzhi beschrieben.“

Siehe auch Eberhard, Randvölker, s 30.

${ }^{1368}$ TYTZ, S. 247. YCFZ (S. 332): „Die Echang. Sie werden auch Achang genannt. Sie fürchten die Hitze und verabscheuen Feuchtigkeit. Sie lieben es auf hohen Bergen zu wohnen. Sie betreiben Brandrodung (daogeng huozhong). Die Frauen (furen) tragen rotes Flechtrohr (hong teng) als Taillenschmuck. Als Opfer bringen sie Hunde dar. Zum Wahrsagen benutzen sie dreiunddreißig Bambusstäbe. Die Methode ist etwa so wie das Wahrsagen [mit Schafgarbe in China]. Sie sind begierig auf Alkohol. Sie tragen Lasten auf dem Rücken. Sie suchen Vögel, wilde Tiere, Insekten und Würmer, die sie sämtlich roh [essen]. Sie pflücken Gift-Sumach (yege) und machen daraus Kleidung. Sie haben keine Stammesoberhäupter (buchang) und leben verstreut in Gebirgstälern. Entsprechend den tusi sind sie der Fron unterworfen (ting tusi yi shu). Heutzutage leben sie in Yongchang in den drei befestigten Dörfern Luogu, Luoban und Luoming.

Früher war es Sitte, daß [ein Mann], wenn der Vater oder der ältere Bruder gestorben waren, die Mutter oder die Schwägerin zur Frau nahm. Nachdem der Häuptling Baifu Zaozheng gestorben war, wollte seine Ehefrau Fang'ai ihre Tugend bewahren und fügte sich dem nicht, daraufhin hungerte sie und starb. Dann wurde diese Sitte abgeschafft“.

Siehe auch Eberhard, Randvölker, k 101 [O-chang]. 
festbinden, die aus zwei Lagen Cocogras-Gazestoff (suo luobu) bestehen, deren obere kurz und deren untere lang ist.“1369

\section{6. Die Hala}

„Männer und Frauen (nü) haben eine Hautfarbe so dunkel wie Lack. Sie wissen sich nicht zu waschen und zu kämmen. Die Männer kleiden sich in gemustertem Stoff. Die Frauen (furen) wickeln sich rotes oder schwarzes Flechtrohr (hong hei teng) einige Dutzend Mal um die Taille. Wenn sie ein Kind geboren haben, dann fertigen aus Bambus einen Beutel und tragen [das Kind darin] auf dem Rücken. Sie sind dieselben wie die Gula (,alten La‘).“1370

\section{7. Die Jiexie}

„Diese Volksgruppe kommt aus Mengyang. Sie haben runde Augen und haben Münder wie die Vögel (huan yan niaohui). Sie tragen große Ringe aus Elfenbein in den durchbohrten Ohrläppchen, die bis zu den Wangen reichen. Sie nehmen einen ein zhang [ca. 3,33m] langen roten gemusterten Stoff, den sie zu einem Turban wickeln, dabei lassen sie hinten einen Streifen herunterhängen. Ein Umhang bedeckt ihren halben Körper, aber die rechte Schulter bleibt frei.“1371

\section{8. Die Zhexie}

„Sie schlingen ihr Haar zu einem Knoten zusammen. Männer und Frauen (nü) durchbohren ihre Ohren und stecken Ringe hindurch. Sie lieben prächtige bunte Kleidung, die fast den [ganzen] Körper verhüllt. Sie sind starke Kämpfer mit Pfeil und Bogen und verlassen sich auf spezielle Feuerwaffen (te lu chong) ebenso wie die Birmanen. In der Gegend von Mengyang leben viele von ihrer Art. “1372

\section{9. Die Diyanggui}

„Sie haben kurze Haare und gelbe Augäpfel. Sie haben ein entschlossenes und durchtriebenes Wesen (xing jian jiao). Sie sind auf ihren Vorteil bedacht. Sie tauchen urplötzlich auf und verschwinden wieder. In einem alten Lokalhandbuch heißt es, wenn sie mit einem Menschen verfeindet sind, dann verstehen sie es Gerätschaften zu benutzen, um damit Zauberkunst auszuüben (xing

\footnotetext{
1369 TYTZ, S. 247. YCFZ (S. 333): „Das sind die Piaoren (piao mit dem Pferderadikal). Sie leben jenseits der Grenze im Südwesten. Sie sind die Nachfahren der Nu von Zhupo. Ihre Vorfahren befanden sich in Jinchi und im Reich der Piao. Nanzhao hat dieses Gebiet fortwährend kontrolliert (chang zhi). Zu Beginn der Yuan-Zeit haben sie ihre Loyalität erklärt und es wurde ein Oberhaupt eines Befriedeten Gebietes (xuanfushi) ernannt. Während der Ära Hongwu [der Ming] wurde eine Präfektur eingerichtet und außerdem die Garnison Jinchi. Heute gibt es im Westen des Kreises Baoshan das Dorf Pupiaozhai. Dies Gebiet wurde so genannt, weil die Puren und die Piaoren dorthin gezogen waren.“ Siehe auch Eberhard, Randvölker, k 109.

${ }^{1370}$ TYTZ, S. 247. Siehe auch Eberhard, Randvölker, k 37.

${ }^{1371}$ Ebenda.

1372 Ebenda. Siehe auch Eberhard, Randvölker, i 38.
} 
yaoshu) und die Leber, das Herz, die Galle oder die Nieren in Holz oder Stein zu verwandeln. [Der Mensch] ist nicht mehr zu retten und stirbt. Auch [mischen] sie [das Gift] gu in Speisen oder Getränke. Eine Frau (fu) gibt [ihrem Mann, der verreisen will,] ein Gift, das entsprechend der Dauer der Reise dosiert ist. Wenn er innerhalb der Frist zurückkehrt, macht sie das Gift unschädlich, überschreitet er jedoch die Frist, dann muß er sterben. Heute gibt es diese Volksgruppe noch in Mengmi.“1373

\section{10. Die Hashe}

„Sie ähneln ein wenig den Hala und Nuren, sie gleichen den Achang. Sie wohnen auf den Gipfeln der Berge. Ihre Sprache ist unverständlich (yuyan bu tong). Nur wenig gleichen sie menschlichen Gestalten (lüe si renxing er yi).“1374

\section{11. Die Yeren}

„Sie leben jenseits des Chashan. Sie haben rote Haare und gelbe Augäpfel (chi fa huang jing). Ihre Kleidung ist aus Baumrinde. Auf dem Kopf tragen sie einen Kranz aus Knochen (gu quan), an den Fasanenfedern angebunden sind und in den rotes Flechtrohr (hongteng) hineingesteckt wird. [So] durchqueren sie gefährliche Orte, als ob sie fliegen könnten (she xian ru fei). Sie lieben es zu töten. Während der vorangegangenen Ming-Dynastie gab es die beiden Befriedeten Gebiete (zhangguan si) Lima und Chashan, die sie unter Kontrolle hielten. Am Ende der Ming-Zeit waren die [Oberhäupter] der beiden Befriedeten Gebiete von den Yeren vertrieben worden und sind ins Landesinnere (neidi) geflohen. Heute haben die Söhne und Enkel dieser tusi den Familiennamen Zao, sie leben in Guyong und Wusuo.“"1375

\section{12. Die Cuanman}

„In einem alten Lokalhandbuch heißt es, daß die alten Cuan vom Mengshan nicht starben. Am Ende ihres Lebens aßen sie Menschenfleisch. Ihre Söhne und Töchter erkannten sie nicht an. Sie liebten die Berge und fürchteten die Familie (wei jia). Sie liefen unermüdlich, wie die wilden Tiere.

\footnotetext{
1373 TYTZ, S. 247. Siehe auch Eberhard, Randvölker, s 38.

${ }^{1374}$ Ebenda.

1375 TYTZ, S. 247. YCFZ (S. 332): „Sie haben keine Häuser. Meist haben sie Grashütten (caopeng). Sie ziehen gerne um (hao qianyi). Sie haben rote Haare und gelbe Augen. Sie haben Kleidung aus Baumrinde und grobem Baumwollstoff, um sich unterhalb des Nabels zu bedecken. Auf dem Kopf tragen sie einen Ring aus Knochen (gu quan), in den Fasanenfedern hineingesteckt werden und an den rotes Flechtrohr (hongteng) angebunden wird. Sie tragen gekrümmte Messer (gou dao) und große Klingen (da ren). Sie jagen und fangen Vögel und wilde Tiere, sie essen Schlangen und Ratten. Ihr Wesen ist rücksichtslos (han, geschrieben mit dem Hunderadikal) und böse. Sie durchqueren schwer passierbare (she xianjun) [Gebirge]. Sie leben jenseits von Chashan und Lima. Einige sind über tausend li von Teng[yue] entfernt, andere sind dreihundert $l i$ von Teng[yue] entfernt. Der Ort, von dem aus die Grenze vor ihnen geschützt wird (qi fang jiexian zhi chu), heißt Diantanguan. Zum Schutz gibt es einen Militärposten, den Soldaten bewachen (bashi, , alles im Griff haben). Siehe auch Eberhard, Randvölker, k 142.
} 
Die Einheimischen (turen) nannten sie Herbstfüchse ( $q i u$ hu). Aber es gab auch welche, die nicht so ausdauernd waren. “1376

\section{13. Die Miao Luoluo}

„In einem Handbuch der Präfektur steht geschrieben: Es gibt eine Gruppe die keine Familiennamen hat. Die Männer gehen barfuß und ungekämmt. Ihre Kleidung ist aus Hanf. Die Frauen (nüren) tragen kurze Kleidung und binden sich einen tonnenförmigen Rock (tongqun) um die Taille. Sie erschließen die Berge, graben in der Erde und säen. Sie pflanzen Buchweizen an. Sie wissen sich nicht den Mund zu spülen oder sich zu waschen. Sie verstehen wenig von Etikette (xian tong liyi). Männer und Frauen (nü) führen eine wilde Ehe (yehe) und suchen sich ihren Ehepartner selbst (zi pei). Die Körper werden nicht eingeäschert, die Knochen werden begraben und ein Kiefernzweig wird [in das Grab] hineingesteckt, damit die Seele darauf verweilen kann (yi qi shen).

Es gibt eine andere Gruppe, deren Angehörige natürlich und aufrichtig sind (chun pu). Die Männer umwickeln ihren Kopf mit einem Tuch, ihre Kleidung ist aus Hanf und reicht ihnen bis an die Knie. Die Frauen (nüren) binden ihr Haar mit einem dunklen Tuch zusammen. Aus dem Rücken tragen sie eine Schaffell. Die Männer pflügen und säen für die Ernährung, die Frauen (nüren) tragen mit dem Zwirnen von Hanf zum Lebensunterhalt bei (yingsheng). Eheliche Verbindungen werden durch einen Heiratsvermittler angebahnt (hunpei tong mei). Wer keine Nachkommen hat, wird eingesargt und begraben. Die Opferfeiern im Frühling und im Herbst (chun qiu jisi) ähneln den Zeremonien der Han (Han li). Ihre Familiennamen sind Zi, He, Zhe, Jiao, Wu, Gan, Luo und Yang. Weitere Familiennamen gibt es nicht.“1377

\section{14. Die Boyi}

„Im Tongzhi steht: Sie werden auch Baiyi genannt, weil die Betonung ähnlich ist, aber das ist falsch. Ihr Charakter ist geduldig. Viele leben in heißem Klima.. Ihre Behausungen sind bescheiden und unter Jujuben gelegen. Deshalb folgten sie den Jujube-Bäumen und weit entfernt im Südwesten Yunnans, wo das Klima feucht ist, gibt es entsprechend viele Wohnsitze der Boyi. Es gibt mehere dutzend Gruppen. Die Sitten unterscheiden sich ein wenig, auch die Namen sind verschieden.

\footnotetext{
1376 TYTZ, S. 247

1377 TYTZ, S. 247. YCFZ (S. 332): „Sie sind sämtlich Nachkommen von Angehörigen der einheimischen Beamten (tu man guan she zhi yi). Sie werden auch ,Feuerköpfe‘ (huotou) oder ,Bataillonskommandeur' (yingzhang) oder elegante Beamte (guan nuo) genannt. Es gibt verschiedenen Gruppen: Schwarze und weiße, die sich gänzlich voneinander unterscheiden (jiongyi). Sie tragen Ringe in den Ohren. Für ihre Alltagskleidung verwenden sie Suoluo-Stoffe [suoluo bu; suobu, einheimische Stoffe; suoluo shu, Reevesia]. Die Kleidung der Frauen (furen) ist an Brust und Rücken mit Blumen geschmückt (zhuang hua). Vorne bedecken sie ihre Unterschenkel nicht, hinten ziehen sie [den Stoff wie eine] lange [Schleppe] auf dem Boden hinter sich her. Die Ränder der Kleider sind gewellt (wanqu), wie das Ende einer Fahne. Sie haben keine Revers und keine Gürtel. Oben [hat das Kleidungsstück] eine Öffnung wie ein Brunnenschacht und wird über den Kopf nach unten angezogen. Der tonnenförmige Rock ist fein gefältelt. Diejenigen, die im Bezirk Ami leben, werden von den verschiedenen Gruppen hoch geachtet und gefürchtet. Wenn ein Begräbnis auszurichten ist, dann legt das gesamte Dorf Gold für Wein zusammen, um dazu beizutragen. Sie leben in Menghua, Lijiang und anderen Orten. Sie sind im Tongzhi verzeichnet. Diejenigen, die in Tengyue leben, sind besonders fähige Jäger.

Siehe auch Eberhard, Randvölker, i 50.
} 
Im Handbuch der Präfektur steht, daß sie Schriftzeichen (bai yi zi) haben, die wahrscheinlich nach dem Vorbild der Schriftzeichen der Cuan (dayue xi Cuan zi) geschaffen worden sind. Zur Han-Zeit gab es einen Nachkommen des Häuptlings Nagou namens Ake. Für die Leute aus dem Bezirk (zhou) Malong verzichtete er auf seinen Posten, zog sich in eine Bergschlucht zurück und verfaßte die Schriftzeichen. Die Zeichen ähneln Kaulquappen (kedou). Im folgenden Jahr hatte er zunächst 10840 Buchstaben (zimu) vollendet. Die erstaunten Yiren nannten ihn den Schöpfer der Schrift (shuzu). “1378

\section{15. Die Lisu}

„Zur Zeit als Yunnan erschlossen wurde, gab es dieses Volk bereits. Sie haben keine Stämme (buluo), sondern leben verstreut in den vier [sic!] Präfekturen Yaoan, Dali und Yongchang. Diejenigen, die in den Schluchten des Liukushan wohnen, sind unter den verschiedenen Völkern die Kühnsten. Sie leben im Grenzgebiet (biandi) in Chishiya, wo der Jinjiang zusammen mit dem Yongjiang die Grenze bildet. Sie sind gerne nahe bei Bäumen und Höhlen im Fels, ihren Aufenthaltsort wechseln sie ganz unregelmäßig. Die Männer umwickeln ihre Köpfe, ihre Kleidung ist aus Hanf. Sie legen sich Oberbekleidung aus Filz um und tragen eine kurze Klinge. Sie benutzen mit Vorliebe die Armbrust und schießen nie vergebens ihre Pfeile ab. Die Frauen (furen) tragen kurze Hemden und lange Röcke; sie gehen barfuß und tragen Bambuskörbe auf dem Rücken, wo sie kommen und gehen. Sie pflanzen überall Buchweizen und Hirse (bai) und zahlen Bodensteuern (shu fu). “1379

\section{16. Die Lalu}

„Ihr Wesen ist kühn. Sie leben in Felshöhlen. Ihre Kleidung ist aus Hanf. Im Gebirge fangen sie Vögel und wilde Ttiere, die sie essen. Bodensteuern und Frondienste (fu yi) gibt es bei ihnen nicht. Sie werden auch Laniao (,Vogel-La`) genannt. Sie leben im oberen Stockwerk, unten füttern sie Ochsen und Schafe. Fleißig gehen sie ihren Tätigkeiten nach. Wenn sie jemandem begegnen, dann müssen sie selbst zurücktreten (tuirang). Ihre verstreuten Wohnorte sind abgelegen. Sie essen Bienen und Schlangen [feng she; wohl ein Schreibfehler für fengmi, ,Honig ‘].“1380

1378 TYTZ, S. 247. YCFZ (S.332): „Diese Volksgruppe lebt jenseits des Heishui. Sie werden Boyi genannt, weil die Betonung dem beinahe entspricht, aber es ist ein Fehler. Ihre Wohnorte sind oft aufgezeichnet worden, so auch im Tongzhi. Diejenigen, die in Tengyue [leben], essen im Feuer geröstetes Fleisch, dabei trachten sie aber nicht danach, daß es auch gar ist (bu qiu qi shu). oder sie nehmen Bienenwaben (feng cao) und essen sie.Sie sind mit der birmanischen Schrift vertraut (xi Mian zi). Sie verwenden Gefäße aus grobem Porzellan (qi yong cu ci)“.

Siehe auch Eberhard, Randvölker, s 26 (bes. S. 313 unten).

${ }^{1379}$ TYTZ, S. 247-248. YCFZ (S. 333): „Die Lisu wohnen in einem Gebiet mit hohen Bergen, wo es äußerst kalt ist. Sie sind wenig anders als die Bengjing. Sie verstehen sich gut auf den Gebrauch der Armbrust $(n u)$ und schießen nie vergebens ihre Pfeile ab. Ihre Pfeile sind vergiftet. Wer von ihnen getroffen wird, der muß sterben. Sie pflanzen Hanf und machen Kleidung daraus. Sie jagen wilde Tiere und essen sie. Sie haben eine Barbaren-Sprache, aber keine BarbarenSchriftzeichen (you yi hua wu yi zi). Man findet sie im allgemeinen jenseits der Flüsse und tief in den Bergen (jiang wai shen shan zhi jian)“. Siehe auch Eberhard, Randvölker, i 31.

${ }^{1380}$ Siehe auchEberhard, Randvölker, s 16. 


\section{17. Die Jiala}

„Überall innerhalb und außerhalb von Yongchang und Tengyue gibt es sie. Sie betreiben Ackerbau. In ihrer Gestalt gleichen sie den Achang. Sie ähneln den Luoluo und sind ebenso draufgängerisch, sie können gut kämpfen. Die Frauen (funü) wickeln sich Brokatstoff schräg um die Taille. Die Jiala wohnen auf Berggipfeln. Sie gehen nicht gerade aus dem Haus heraus und begrüßen die Berge, wenn sie die Tür öffnen (ying shan kai men). Ihren Aufenthaltsort wechseln sie ganz unregelmäßig (qianxi wu chang). Sie bewahren übriggebliebene Kolbenhirse nicht auf.“1381

\section{18. Die Mianren}

„Miandian ist das ehemalige Land von Zhupo. Es befindet sich jenseits der beiden Paßstationen Tianma und Huju. Ihr Häuptling (qiu) lebt in der birmanischen Stadt Ava (Miandian Awa cheng). Vor der Yuan- bis zum Beginn der Ming-Zeit wurden sie zwar als gebändigt angesehen (shi jimi), haben sich während dieser Zeit aber häufig widersetzt und wurden besiegt. Nach dem Jahr Jiajing 3 (1522) haben Mangruiti und sein Sohn eine starke Armee aufgestellt und sich selbst Könige von Birma (Miandian guo wang) genannt und keinen Tribut mehr übersandt.“1382

\section{19. Die Jiexiezi}

Diese Volksgruppe ist aus Mengyang im Westen nach Tengyue gekommen. Sie haben runde Augen und haben Münder wie die Krähen (huan yan wuhui [YCFZ, S. 332: niaohui). Sie tragen große Ringe aus Elfenbein in den Ohren. Sie haben keine Kleidung. Unter dem Bauch bedecken sie sich mit einem Streifen Stoff. Reis und Fleisch essen sie ungekocht. Sie sind tapfer und gesund (yong jian). Gewehr und Messer in Händen haltend verstehen sie zu kämpfen, dabei stoßen sie ein Geschrei aus, wie das Bellen eines Hundes.“1383

\section{20. Die Qiawa}

„Unter den Fremden sind sie die starrsinnigsten (yi zhong zhi wangeng ye). Sie leben jenseits des Linsuanjiang im Südosten von Yongshun. Ihr Äußeres ist häßlich und ihr Charakter schlecht (mao chou xing e). Sie treiben Ackerbau und haben befestigte Siedlungen. Mit rotem Flechtrohr (hongteng) binden sie sich die Haare zusammen, umwickeln ihre Taille und hüllen sich in Hanf-Stoffe. Sie haben scharfe Messer und Spieße, mit denen sie sich insgeheim an den Hauptverkehrswegen in einen Hinterhalt legen, um die reisenden Händler auszuplündern. Diese müssen sich zu mehreren zusammentun und zudem Beschützer haben (baohuzhe), dann erst können sie es wagen, diese Orte zu passieren. Heutzutage wurde zum Schutz Kriegsrecht verordnet, so hört diese Sitte langsam auf. Generell sind es die Kaufleute, die von Tengyue nach Mubang gehen, um Holz und Brokate zu

\footnotetext{
${ }^{1381}$ TYTZ, S. 248; etwas gekürzt im YCFZ, S. 333. Siehe auch Eberhard, Randvölker, k 9: 1382 Ebenda.

${ }^{1383}$ TYTZ, S. 248; ebenso im YCFZ, S. 332. Siehe auch Eberhard, Randvölker, k 16.
} 
kaufen, die deren Territorium durchqueren müssen. Man sagt von, den Qia profitieren die Wa (wei Qia li Wa). Denn es gibt zwei Arten von ihnen, ,rohe“ und ,gekochte‘ (sheng shu): Die ,Rohen“ plündern und die ,Gekochten` schützen die Straßen.“'1384

\section{21. Die Yeman}

„Sie leben mehr als einhunder li [entfernt] im Norden hinter Jinbao-Stadt, in Datan und Zhouhui. Die Yeman haben alle keine Herrscher (junchang). In ihrem Land gibt es giftige Miasmen (zhang $d u$ ). Wenn Leute aus Hetan dorthin gehen, müssen von zehn unter ihnen, die den Miasmen ausgesetzt waren, acht bis neun sterben.

Keluofeng [712-779, König von Nanzhao] hatte einst einen General nach Datan gesandt, der dort eine Stadt [cheng, mit Mauer] baute, um die Yeman zu kontrollieren. Nach kaum einem Jahr waren schon mehr als die Hälfte [seiner Leute] gestorben. Daraufhin beendeten [sie ihre Mission], verließen [das Gebiet] und kehrten nicht mehr dorthin zurück. Die Erde ihrer Berge ist reich und fruchtbar; sie pflanzen Kürbisse und Flaschenkürbisse an, die über ein zhang [ca. 3,33m] lang werden. So auch die Wachskürbisse (donggua), die alle einen Umfang von 3 chi [ca. $33 \mathrm{~cm}$ ] erreichen. Außerdem wächst dort viel Hiobstränengras (yiyi) [manchmal auch als Bez. für pearl-barley, ,Perlgraupen` gebräuchlich]. Sie betreiben keinen Ackerbau, sie ernten Maulbeerbäume ab und dies dient ihnen als Nahrungsmittel. [Ihre Land] ist an drei Seiten vom Daxueshan umgeben, ihre hochgelegenen Orte sind dem Himmel nahe. Häufig kommen Tibeter (tufan) dorthin, um Waren auszutauschen. Sie sagen, daß es in diesen Bergen Wege gibt, auf denen es nicht weit ist bis nach Tibet. “1385

\section{22. Die Mubang}

„Ein anderer Name ist Mengbang. Man erzählt, daß die Menschen dort viel Magie (huanshu) ausüben. Sie können ein Holz[stück] mit den Händen und Füßen eines Menschen vertauschen (yi mu huan ren shou zu). Der Mensch nimmt das anfangs nicht wahr, wenn er aber weit gegangen ist, dann fühlt er einen Schmerz, den er nicht besiegen kann. Wenn jemand nicht glaubt, was von diesem [Menschen] erzählt wird, so soll er ihm am Tag seines Todes den Leib aufschneiden, dann kann er sehen, daß darin tatsächlich Holz ist. Außerdem können sie die Erde verschmutzen. Menschen, die sich ihnen entgegenstellen, verwandeln sie in Schafe oder Schweine. Wenn [einer so jemanden] mit Geld loskauft, dann verwandeln sie ihn wieder zurück in einen Menschen. Diejenigen, die das Wissen besitzen, können leicht schmutzige Dinge an andere Orte bringen. Umgekehrt können diese Menschen sich auch selbst in etwas anderes verwandeln.

\footnotetext{
${ }^{1384}$ TYTZ, S. 248. YCFZ (S. 333): „Unter den Fremden sind sie die starrsinnigsten (yi zhong zhi wangeng ye). Sie leben jenseits der Gebiete von tusi Teng[yue] und Long[chuan]“. Weiter wie im TYTZ, aber etwas gekürzt.

${ }_{1385}$ TYTZ, S. 248. ,Nach Tibet‘: Wörtlich ,nach Zanpu und Yazhang‘; Zanpu Bez. für den Fluß Tsangpo bzw. die Provinz Tsang; nach CY 1617.2 auch eine Bezeichnung für den Herrscher Tibets. Yazhang, nach CY 1070.4 die Fahne vor dem Zelt des Feldherren bzw. Khan].
} 
Die Kleidung der Männer ist weiß, sie tätowieren ihren Körper, rasieren ihren Kopf und schneiden sich den Bart (jie zi). Die Frauen (nü) schmücken sich mit goldenen Ringen und vielen Armbändern. Sie wohnen sämtlich in mehrstöckigen Bambushäusern. Die Männer sind hochgestellt (gui), die Frauen werden geringeschätzt (jian). Sie sehen ihre Ehefrauen (qi) als Sklaven (nu) an und lassen sie für sich arbeiten, pflügen und weben.““386

\section{23. Die Bai Guoluo}

„Die Kleidung der Männer besteht aus zwei Teilen, sie tragen einen turbanähnlichen Kopfputz und gehen barfuß. Die Frauen (furen) tragen Kupferringe in den Ohren. Sie bedecken sich mit einem Kleidungsstück, das einer Mönchskutte (jiasha) gleicht und umwickeln ihre Taille mit einem Wildledergürtel. Bei einem Begräbnis wird kein Sarg verwendet. Ehen schließen sie nur innerhalb ihrer Volksgruppe. Sie halten Ochsen, Pferde, Schweine oder Hühner, aber keine anderen Nutztiere. Sie leben in den Gebirgstälern von Yongchang. Allmählich machen sich zivilisierende Einflüsse (wanghua) bemerkbar und sie gleichen sich der Bevölkerung an.““387

\section{24. Die Baiyi}

„Es gibt zwei Volksgruppen, die nassen und die trockenen (shui han er zhong). Sie wohnen im Flachland, wo es Dunst und Miasmen (yan zhang) gibt. Die Kleidung der Männer ist kurz. Die Frauen (nü) haben einen hohen Dutt und ein Tuch um den Kopf. Sie nähen Seide in fünf Farben zusammen und wickeln sie sich als Rock um die Taille. Ihr Wesen ist schwächlich und furchtsam .Sie pflügen und weben. Einige Tage vor Frühlingsanfang [Lichun, 3.-5. Feb.] verbrennen sie weißes Holz. Einige Tage vor dem Totenfest [Qingming, 4.-5. April] vergießen sie Wasser. Männer und Frauen (nü) holen Wasser in Bambuseimern und begießen einander zum Spaß damit. Die Verehrung des Buddhismus ist allgemein verbreitet. Sie spenden den Mönchen gedämpften und gekochten Reis. Sie opfern dem birmanischen Buddha (Mian fo) und hören den Mönchen zu, wie sie den buddhistischen Kanon rezitieren (song jing) und verneigen sich ehrfurchtsvoll. Äußerst respektvoll lernen sie die Schrift der Barbaren und die kanonischen Bücher der Barbaren (yi zi yi jing). Es gibt auch einige, die chinesische Bücher (han shu) lesen können. Sie leben in allen tusiGebieten, die zur Präfektur gehören.““1388

\section{25. Die Mangren}

Ihre Vorfahren gehörten zu den Volksstämmen, die Birma unterstellt waren. Die Barbaren (yi) nannten ihr Oberhaupt Mang, daraufhin wurde dies als Familienname verzeichnet. Zu Beginn der Ära Jiajing [der Ming (1522-1567)] führten sie blutige Kriege mit Mengyang und Mubang, von

\footnotetext{
${ }^{1386}$ TYTZ, S. 248. Siehe auch Eberhard, Randvölker, l 14.

${ }^{1387}$ YCFZ, S. 332

${ }^{1388}$ YCFZ, S. 332-333
} 
denen sie zerstört wurden. Deshalb unterwarfen sie sich dann [China] (neifu). Heutzutage haben sie sich allmählich verändert und Han-chinesische Sitten [angenommen].“'1389

\section{26. Die Kelie}

„Sie wohnen häufig an Flußufern. Sie haben diese Familiennamen Lai, Sai, Ke, Nang, Pa und Xing. “ ${ }^{1390}$

\section{27. Die Bengjing}

„Diese Volksgruppe ähnelt den Baiyi. Charakter und Sprache sind jedoch verschieden. Die Männer tragen [Lasten] auf dem Rücken, die Frauen (nü) hüllen ihren Kopf in ein spitzes Tuch und wickeln sich Ringe aus Flechtrohr und Bambusbast (teng mie quan) um ihre Taille. Sie lackieren ihre Zähne und tätowieren ihren Körper. Sie leben meist auf den Gipfeln der Berge. Es gibt sie in allen tusiGebieten.“1391 


\section{LITERATURVERZEICFNIS}

\section{Quellen}

Baoshan xian zhi

[Lokalhandbuch des Kreises Baoshan], 35 juan, korrigierte Ausgabe von 1963, Vorworte von Wang Miansheng, Wang Jiefan.[Das Lokalhandbuch stützt sich auf Vorläufer aus der Mingund Qing-Zeit, u.a. auf das gleichnamige von Liu Yuke im 1885 zusammengestellte Werk und ein Manuskript aus dem Jahr 1945.]

Baoshan xian zhi xubian

[Fortsetzung des Lokalhandbuches des Kreises Baoshan], 5 juan [Eine Kopie des Manuskriptes befindet sich in der Bibliothek des Bezirks Baoshan]

\section{Diannan zazhi}

[Notizen aus Yunnan], hrsg. von Cao Shuqiao (Cao Chunlin), (Faksimile der Ausgabe von 1810), o.O.o.J.

\section{Feng Su:}

Dian kao [Ära Kangxi (1662-1723), Vorwort aus dem Jahr 1665], in: Taizhou congshu, part B ed. Song Shiluo, Linhai 1817-21

Li Genyuan:

Yongchang fu wencheng [Sammlung literarischer Werke der Präfektur Yongchang], 1941

Tengchong xian zhi gao

[Manuskript eines Lokalhandbuches für den Kreis Tengchong], 23 juan, hrsg. von Li Genyuan und Liu Chuxiang, Vorwort von Liu Chuxiang aus dem Jahr 1941]

\section{Xin Tang shu}

[Die neue Geschichte der Tang-Dynastie], im Jahr 1060 zusammengestellt von Ouyang Xiu und Song Qi, Neuausgabe des Zhonghua shuju chubanshe, Beijing 1975

Yunnan sheng Tengyue ting zhi

[Lokalhandbuch der Unterpräfektur Tengyue in der Provinz Yunnan], hrsg. von Chen Zonghai; Zhao Duanli (Faksimile der Originalausgabe von 1887) Taipei 1967 (Zhongguo fangzhi congshu, Nr.42)

Yunnan sheng Tengyue zhou zhi

[Lokalhandbuch des Bezirks Tengyue in der Provinz Yunnan], hrsg. von Tu Shulian (Faksi-mile der revidierten Ausgabe von 1897) Taipei 1967 (Zhongguo fangzhi congshu, Nr.41)

Yunnan sheng Yongchang fu zhi

[Lokalhandbuch der Präfektur Yongchang in der Provinz Yunnan], hrsg. von Liu Yuke (Faksimile der revidierten Ausgabe von 1885) Taipei 1967 (Zhongguo fangzhi congshu, Nr.28)

\section{Ming shi}

[Die Geschichte der Ming-Dynastie], hrsg. 1736 von Zhang Tingyu u.a.; Nachdruck, Beijing 1974 


\section{Literatur in asiatischen Sprachen}

\section{1. Literatur in chinesischer Sprache}

Bai Shouyi:

Huimin qiyi [Der Moslem-Aufstand], 4 Bde., Shanghai 1953 (Zhongguo jindaishi ziliao congkan, di si zhong)

Baoshan diqu wenhua gaikuang

[Überblick über die Kultur des Bezirks Baoshan], Baoshan 1986

Bi Jian:

Tengchong de chuanshuo [Legenden aus Tengchong], Kunming 1986

Chen Shilin:

Yiwen yanjiu de jichu he qianjing [Grundlagen und Perspektiven der Erforschung der YiSchrift], in: Zhongguo minzu guwenzi yanjiuhui (Hrsg.), Zhongguo minzu guwenzi yanjiu, S.271-295

Deng Yanlin:

Zhongguo bianjiang tujilu. A catalogue of works on the Chinese borders, Shanghai 1957

Ding Fubao:

Foxue da cidian [Große Enzyklopädie des Buddhismus], (1. Auflage 1922), Shanghai 1991 (Neudruck in zwei Bänden)

Duan Peidong:

Jian sao fengyan. Tengchong kangzhan jishi, Yunnan renmin chubanshe, 2. Auflage, Kunming 1993

Fang Guoyu:

Yunnan shiliao mulu gaishuo, Zhonghua shuju chubanshe, Beijing 1984

Fu Zhenlun:

Zhongguo fangzhixue tonglun (A comprehensive discussion of Chinese local gazetteer studies), 2. Aufl. Shanghai 1936

Gong Yin:

Xinan zhu sheng tusi shezhi ji yanbian gaishuo [On the establishment of the system of appointing national minority hereditary headmen and the development of the system], MZYJ, Heft 1, Peking 1993, S.49-58

Gu Gongxu; et. al. (Eds.):

Zhongguo dizhen mulu (Catalogue of Chinese earthquakes, 1831 B.C. - 1969 A.D.), Kexue chubanshe, Beijing 1989

Guo Xinquan:

Yunnan mingsheng yinglian daguan, Yunnan daxue chubanshe, Kunming 1994

[Huo Yuanjie]; Di Bofu:

Huayi yiyu, [Aussprachewörterbuch für Koreanisch, Vietnamesisch und andere Sprachen der Nachbarvölker Chinas], (Nachdruck) Taipei 1979 
Ji Xianlin; u.a. (Hrsg.):

Da Tang xi yu ji jiaozhu [Kommentierte Ausgabe der ,Reise nach Westen` des Xuan Zang], (1.Auflage, Peking 1985), Peking 1990 (2.Auflage)

Jiang Yingliang (Hrsg.):

Baiyi zhuan jiaozhu, [Kommentierte Ausgabe des Baiyi zhuan (Ming-Zeit, Li Sizong und Qian Guxun zugeschrieben)], Kunming 1980

Lan Yong:

Lishi shiqi xi'nan jingji kaifa yu shengtai bianqian. Economic development and ecological changes of Southwest China in history, Yunnan jiaoyu chubanshe, Kunming 1992 (Xinan yanjiu shuxi. Southwest China Study Series)

Xinan lishi wenhua dili. Historical cultural geography in Southwest China, Chongqing 1997

Li Kunsheng:

Yunnan yishu shi, The history of arts in Yunnan, Yunnan jiaoyu chubanshe, Kunming 1995

Li Min:

Yiwen [Die Yi-Schrift], Minzu Yuwen, Heft 4, Peking 1979, S.304-306

Li Xiejun, Huang Min (Hrsg.):

Bianchui gudao. The Silkroad in the Southwest of China, Yunnan jiaoyu chubanshe, Kunming 1986

Lin Huixiang:

Zhongguo minzu shi [Geschichte der Nationalitäten Chinas], 2 Bde., Taipei 1974

Jindai zhi Bo Shan zu [Die Bo- und die Shan-Nationalitäten in der Neuzeit], in: Zhongguo Minzu shi, Bd.2, S.280-292

Liu Bingchao; Ni Kaisheng:

Nanfang silu shang de lishi wenhua mingcheng - Baoshan [Historische Kuturstädte entlang der Seidenstraße des Südens - Baoshan], Yunnan minzu chubanshe, Kunming 1993

Liu Chai:

Shou Mian jishi, (Ming-Zeit), Reprint Hangzhou 1986

Liu Chunming (Hrsg.):

Xu Xiake Tengyue youji [Xu Xiakes Reisebericht aus Tengyue], Yunnan daxue chubanshe, Kunming 1993

Luo Xianyou:

Yuandai Yunnan diqu de minzu shilu - ,Yunnan zhilüe‘ [,Yunnan Zhilüe‘: The authentic records of ethnic groups in the Yunnan region during the Yuan dynasty], MZYJ, Heft 1, Peking 1993, S.93-101

Ma Shutian:

Quanxiang zhongguo sanbai shen. 300 Chineses gods with portraits, 4. Aufl., Nanchang 1995

Maheimuxia:

,Yiwen guifan fangan' de dansheng ji qi shijian xiaoguo [Die Entstehung des ,Planes für eine standardisierte Yi-Schrift‘ und seine Wirkung in der Praxis], Minzu Yuwen, Nr.3, 1985, S.29ff

Ming shilu youguan Yunnan lishi ziliao zaichao

[Historische Aufzeichnungen über Yunnan aus dem Ming shilu], 3 bde., Kunming 1959-1963 
National Palace Museum (Hrsg.):

Secret palace memorials of the Ch'ien-Lung Period (oct.1774-apr.1777)[Schriftart: Chinesisch], Taipei 1985

Niu Pinghan (Hautpverf.):

Qingdai zhengqu yange zongbiao [Zusammenstellung der Entwicklungsgeschichte der Verwaltungseinheiten in der Qing-Zeit], Peking 1990

Pan Jixing:

Zhongguo zao zhi jishu shigao [Abriß der Geschichte der Papierherstellung in China], Peking 1979

Ruey Yih-Fu:

Dian Mian bianjing si zu xiaoji (fu Yingwen yiwen) [Brief notes on the four tribes of YunnanBurma borderlands (with English translation by Dr. Chu Lew)], in: Ruey, Zhongguo minzu, vol.1, S.371-410

Xi'nan shaoshu minzu chongshou pianpang mingming kaolüe (fu Yingwen cuoyao) [On the origin of the tribal names with insect-beast-signified radicals of southwest minority groups (with English summary)], in: Ruey, Zhongguo minzu,vol.1, S.73-117

Zhongguo minzu ji qi wenhua lungao [China: The nation and some aspects of its culture. A collection of selected essays with anthropological approaches], 3 vols., Taipei1979

Shen Yunlong (Hrsg.):

Xuesheng nianlu, Li Genyuan zhu [autobiographie des Li Genyuan], Wenhai chubanshe (Jinhua Zhongguo shiliao congkan di er ji), o.O.o.J.

Shi Zhengyi u.a. (Hrsg.):

Minzu cidian [Lexikon der nationalen Minderheiten], Chengdu 1984

Shun Fulai:

Qianlong zhongyao zhanzheng zhi junxu yanjiu [Untersuchung des Bedarfs an militärischen Gütern in den großen Kriegen Kaiser Qianlongs], Taipei 1985

Song Enchang:

Yunnan shaoshu minzu shehui diaocha yanjiu [Untersuchung der Gesellschaften der nationalen Minderheiten Yunnan], 2 Bde., Kunming 1980

Song Enchang; Fang Zhengchun; Jin Yuan; Dao Anlu:

Dehong Daizu tusi zhidu diaocha [Untersuchung des tusi-Systems der Dai-Nationalität im Bezirk Dehong], in: Dehong Daizu shehui lishi diaocha (2), Kunming 1984

Sun Benxiang; Liu Ping:

Zhongguo diming qutan [Erörterungen der Ortsnamen in China], Beijing 1995

Tan Qixiang (Hrsg.):

Zhongguo lishi ditu ji [Eine Kartensammlung zur Geschichte Chinas], 8 Bde., Shanghai 1975

Tengchong xian wenshi zhengxie bian (Hrsg.):

Tengchong xian wenshi ziliao (yi) [Materialien zu Literatur und Geschichte des Kreises Tengchong, Bd. 1] , Dehong minzu chubanshe, 1988 
Tengchong xian zhengxie wenshi ziliao bianji weiyuanhui bian (Hrsg.):

Tengchong xian wenshi ziliao xuanji (di er ji), ) [Materialien zu Literatur und Geschichte des

Kreises Tengchong, Bd. 2], Yunnan renmin chubanshe, Kunming 1990

Ting Wen-chiang:

Xu Xiake youji er ce (The travels of Hsu Hsia-ko with a volume of maps), Shanghai 1928

Wang Shichen:

Wanwei yubian, in: Tao Zongyi, Shuo fu san zhong, (Neudruck) Shanghai 1988, Bd.9, S.873877

Wang Wencheng:

Jindai Yunnan bianjiang minzu diqu gaituguiliu shulun [On the reorganization of the local government of the Yunnan frontier minority areas in modern times], MZYJ, Heft 1, 1993, S.41-48

Xiang Da (Hrsg,):

Manshu jiaozhu [Kommentierte Ausgabe des Manshu], Zhonghua shuju chubanshe, Beijing 1962

Xie Guozhen:

Nan Ming shihlüe, Shanghai 1957

Xie Shouchang; Chen Gaoji u.a. (Hrsg.):

Zhongguo gujin diming cidian [Lexikon alter und neuer chinesischer Ortsnamen], Taipei 1932, Neudruck Taipei 1976

Yang Jianyu:

Zhongguo lidai di wang lu [Verzeichnis der Monarchen der historischen Herrscherdynastien Chinas], Shanghai wenhua chubanshe, Shanghai 1992

Yang Jingwei; Zhao Congwen; u.a.:

Baoshan lüyou shouce. Baoshan tourist guide, Waiwen chubanshe, Beijing 1992

Yang Zhongshi; Zhou Wenlin; u.a.:

Baoxiu qingtai. Scenery of Baoxiu, Yunnan renmin chubanshe, Kunming 1988

You Zhong:

Yunnan minzu shi [Geschichte der Völker Yunnans], Yunnan daxue chubanshe, Kunming 1994

Yunnan keai de difang

[Liebenswertes Yunnan] (Sammelband, u.a. mit einer Darstellung historischer Ereignisse in der Provinz), o.O.o.J.

Yunnan sheng jiaotong tuce

[Verkehrsatlas der Provinz Yunnan], Chengdu ditu chubanshe, Chengdu 1995

Zhang Gongjin:

Daizu de wenzi he wenxian [Schriften und Dokumente der Dai-Nationalität], in: Zhongguo minzu guwenzi yanjiuhui (Hrsg.), Zhongguo minzu guwenzi yanjiu, S.258-270

Zhang Jiade:

Baowei Dian-Mian lu, Safeguarding of Dian-Mian (Yunnan - Burma) Highway; Zhongguo kangri yuanzheng shi, History of China Anti-Japanese Expedition, Vol. 1, Yunnan renmin chubanshe, Kunming 1994 
Zhang Xingyong (Hrsg.):

Baoshan shiqian kaogu [Prähistorische Archäologie von Baoshan], Yunnan kezhi chubanshe, Kunming 1992

Zhang Zengqi:

Zhongguo xi‘nan minzu kaogu [Archäologie der Völker im Südwesten Chinas], Yunnan sheng bowuguan bian, Yunnan renmin chubanshe, Kunming 1990

Zhongguo minzu guwenzi yanjiuhui (Hrsg.):

Zhongguo minzu guwenzi yanjiu [Die Erforschung alter Schriften der nationalen Minderheiten Chinas], Peking 1984

Zhongguo renming da cidian (ZGRMDCD):

[Lexikon chinesischer Personennamen], Lishi renwu juan, [Historische Persönlichkeiten] Shanghai 1990

Zhonguo yuyanxue da cidian:

[Encyclopedic dictionary of Chinese linguistics], Nanchang 1991

Zhu Huirong (Hrsg.):

Xu Xiake youji [Das Reisetagebuch des Xu Xiake], Yunnan renmin chubanshe 1985

Zhu Shijia:

Zhongguo difangzhi zonglu [Katalog der Lokalhandbücher Chinas], überarbeitete Ausgabe, Shanghai 1958

\section{2. Literatur in anderen asiatischen Sprachen}

Aung Sein Han (Uh On Sinh Han):

Mranma nuinnam sa muinh sac [Neuere Geschichte Birmas (1752-1948], Rangun 1960

Mranma cvay cum kyamh:

[Birmanische Enzyklopädie] Rangun 1954-1976

Nishida Tatsuo:

Mentenkan yakugo no kenkyu: Biruma gengogaku josetsu [A study of the Burmese-Chinese vocabulary Mien-Tien-Kuan I-Yu. An introduction to Burmese linguistics], Tokio 1972

Than Tun:

A sac mran bama samuinh [Neue Ansichten zur birmanischen Geschichte], Rangun 1975

Than Tun (Ed.):

The royal orders of Burma, A.D. 1598-1885, 10 vols., Kyoto 1983-1990 [Schriftart Birmanisch]

\section{Literatur in westlichen Sprachen}

\section{1. Vor 1949 publizierte Werke}

Anderson, John:

Mandalay to Momien: A narrative of the two expeditions to Western China of 1868 and 1875, London 1876 
Bradley, Neville:

The Old Burma Road. A journey on foot and muleback, London 1945

Bredon, Juliet; Igor Mitrophanow:

The Moon Year. A record of chinese customs and festivals, Shanghai 1927

The British Burma Gazetteer, 2 vols., Rangoon 1880

Broderick, Alan Houghton:

Beyond the Burma Road, London 1944

Brunnert, H.S.; V.V. Hagelstrom:

Present day political organization of China, Peking 1910, (Nachdruck) Taipei 1971

Chapin, Helen B.:

Yünnanese images of Avalokitesvara, HJAS, vol.8, 1944-45, S.131-186

China Imperial Maritime Customs

Trade reports and returns (Reports and abstracts/Statistical series) for the years 1903, 1904, $1907,1910-1914$

Cochrane, Rev. Wilbur Willis:

Language and literature, in: Milne, Leslie, Shans at home, S.208-220

The Northern Shans. A Brief Historical Outline, in: Milne, Leslie, Shans at home, S.1-30

The Shans, Rangoon 1915

Colquhoun, Archibald R.:

Across Chryse, being the narrative of a journey of exploration through the South China borderlands from Canton to Mandalay, 2 vols., London 1883

Quer durch Chryse, Forschungsreise durch die südchinesischen Grenzländer und Birma von Canton nach Mandalay, Übers. v. H. von Wobeser, Leipzig 1884

Cordier, Georges:

Les Musulmans du Yunnan, Hanoi 1927

Coryton, John:

Letter to the Liverpool Chamber of Commerce on the prospects of a direct trade route to China through Moulmein, Moulmein 1870

Cushing, Rev. J.N.:

Elementary handbook of the Shan language, Rangoon 1888, (Neudruck) Westmead 1971

A Shan and English dictionary, Rangoon 1914, (Neudruck) Westmead 1971

Davies, Major Henry Randolph:

Yün-nan. The link between India and the Yangtzi, Cambridge 1909 und reprint: Taipei 1970

Devéria, Gabriel:

Histoire du Collège des Interprètes de Péking. (Fragment), in: Mélanges Charles de Harlez, S.94-102 
Eberhard, Wolfram:

Kultur und Siedlung der Randvölker Chinas, Leiden 1942

Elias, Ney:

A visit to the valley of Shueli, in: Journal of the Royal Geographic Society, Vol. 46, 1876, pp. 198-227

Enriquez, Major C. M. (Theophilus):

Beautiful Burma, Rangoon 1935

Fletcher, H. G.:

Tengyueh. Route book of travels in the neighbourhood, hints for travellers, market day dates, and notes on Yunnan pronounciation, etc., Department of the Inspectorate General of Customs, China, The Maritime Customs, III. Miscellaneous Series: No. 36, Shanghai 1927

Gutzlaff (Dr.):

Frontiers of China towards Birmah, in: Journal of the Royal Geographic Society, vol. 19, 1849, pp. $42-48$

Hackmann, H.:

Vom Omi bis Bhamo. Wanderungen an den Grenzen von China, Tibet und Birma, Halle a.S. 1905

Harvey, G.E.:

History of Burma, London 1925

Hendershot, Clarence:

The conquest, pacification, and administration of the Shan States by the British 1886-1897 (Part of a diss.), Chicago 1938

Hsieh Pao Chao:

The government of China (1644-1911), Baltimore 1925 (Johns Hopkins University Studies in Historical and Political Science, extra volume, New Series, no.3)

Huber, Eduard:

Une ambassade chinoise en Birmanie en 1406, in: BEFEO, tome 4, nos. 1-2, Hanoi 1904

Etudes Indochinoise. V.La fin de la dynastie de Pagan, BEFEO, Tome 9, Nr.4, Okt.-Dez., Hanoi 1909, S.634-680

Imbault-Huart, Camille:

Histoire de la conquête de la Birmanie par les Chinois, sous le règne de Tç'ienn Long (Khien Long), Journal Asiatique, Septième série, Tome 11, Nr.1, Paris 1878, S.135-178

Jack, Robert Logan:

From Shanghai to Bhamo, in: Geographical Journal, vol. 19, 1902, pp. 249-277

Johnston, R. F.:

From Peking to Mandalay. A journey from North China to Burma through tibetan Ssuch'uan and Yunnan, London 1908

[Judson, Adoniram:]

Judson's Burmese-English dictionary, (2.Auflage der erweiterten Jahrhundertausgabe von 1953)

Rangoon 1966 
Kingdon-Ward, Francis:

In farthest Burma. The record of an ardous journey of exploration and research through the unknown frontier territory of Burma and Tibet, London 1921

Lattimore, Owen:

Inner Asian frontiers of China, London 1940; Neudruck Hongkong 1988

Lefèvre-Pontalis, Pierre:

Etudes sur quelques alphabets et vocabulaires Thaïs, T'oung Pao, vol.3, Leiden 1892, S.39-64

Legge, James:

The chinese classics, vol.III.- part II, The Shoo King, Hongkong 1865

Liu Hsiu-yeh:

A selected bibliography of Yunnan and of the tribes of Southwestern China, in: Quarterly Bulletin of Chinese Bibliography (English Edition), Kunming, New Series, Vol.1 no.1,March 1940, pp. 83-113; Vol.1, no. 3, Sept. 1940, pp. 333-348; Vol.1, no. 4, Dec. 1940, pp. 450-468; Vol. 2, nos. 3-4, Dec 1941, pp. 199-225

Luce, Gordon H.:

Chinese invasions of Burma in the 18th century, JBRS, vol. 15, Part 2, 1925, S.115-128

Margary, Augustus Raymond:

The journey of A. R. Margary: from Shanghai to Bhamo, and back to Manwyne. From his journals and letters, with a brif biographical preface; to which is added a concluding chapter by Sir Rutherford Alcock, London 1876

Mc Carthy, J.:

Across China from Chin-kiang to Bhamo 1877, in: Proceedings of the Royal Geographic Society, vol. 1, no. 8, 1879

Milne, Mrs.Leslie:

Shans at home, London 1910

Mitton, G. E. (Lady Scott) (Hrsg.):

Scott of the Shan Hills. Orders and impressions, London 1936

Morse, Hosea Ballou:

The international relations of the Chinese empire, 3 vols., London 1910

Müller, F.W.K.:

Ein Brief in Pa-yi-Schrift, T'oung Pao, vol.5, Leiden 1894, S.329-333

Vocabularien der Pa-yi- und Pah-Poh-Sprachen aus dem ,Hua-I-Yi-Yü‘ (Erster Teil), T‘oung Pao, vol.3, Leiden 1892, p.1-38

Norins, M. R.:

Tribal boundaries of the Burma-Yünnan frontier, in: Pacific Affairs, 12, 1, March 1939, pp. 6779

Ollone, Vicomte Henri Marie Gustave d‘; Mgr.de Guébriant:

(Mission d'Ollone 1906-1909:) Ecritures des peuples non chinois de la Chine. Quatre dictionnaires Lolo et Miao Tseu, Paris 1912

Parker, E. H.:

Digest of the Yung-ch'ang annals on Burma, Simla 1894 
Pe Maung Tin; G.H.Luce:

The Glass Palace Chronicle of the kings of Burma, Rangun 1923

Pelliot, Paul:

Deux itinéraires de Chine en Inde à la fin du VIIIe siècle, extrait du: BEFEO, Jan.-Juin 1904, Hanoi, pp. 121-403

Le Hoja et le Sayyid Hussain de l'histoire des Ming. Appendice III, Le SSeu-Yi-Kouan et le Houei-T'ong-Kouan, T'oung Pao, vol.38, Leiden 1948, S.207-290

Rheinwald, Otto:

Die nichtchinesischen Stämme Südchinas, Tokyo 1942, Neudruck New York 1965 (Mitteilungen der Deutschen Gesellschaft für Natur- und Völkerkunde Ostasiens, Bd. 33, Teil A)

Rocher, Émile:

La province chinoise du Yunnan, 2 vols., Paris 1879/80

Ross, E.Denison:

New light on the history of the Chinese oriental college, and a 16th century vocabulary of the Luchuan language, T'oung Pao, vol.9, Leiden 1908, S.689-695

Schulze, Dieter:

Das politisch-geographische und geopolitische Kräfteverhältnis zwischen den drei chinesischen Südwest-Provinzen (Jün-nan, Kwang-si, Kwang-tung), British Birma und Französisch-Indochina im Spiegel der Geschichte, Dissertation, Heidelberg 1940

Scott; James George

Burma from the earliest times to the present day, New York 1924

Burma and beyond, London 1932

Burma. A handbook of practical information, London 1921

Scott, James George; J.P.Hardiman:

Gazetteer of Upper Burma and the Shan States, 5 vols., Rangoon 1900

Shakespear, Col. L. W.:

History of Upper Assam, Upper Burmah and the north eastern frontier, London 1914

Sladen, Major E. B.:

Expedition from Burma via the Irrawaddy and Bhamo to South-western China, in: Journal of the Royal Geographic Society, vol. 41, 1871, pp. 251-281

Stevenson, H.N.C.:

The hill peoples of Burma, (Burma Pamphlets No.6), o.O.u.J.

Tan Pei-ying:

The building of the Burma Road, New York 1945

Theophilus:

In remote Yunnan (A letter from Tengyueh), in: Oriental Affairs, vol. 3, no. 15, 1935, pp. 73-74 (s. a. Enriquez, Major C. M.)

Terrien de Lacouperie, Albert:

Beginnings of writing in Central and Eastern Asia, or notes on 450 embryo-writings and scripts, 1894, (Neudruck) Osnabrück 1965 
Vial, Paul:

Les Lolos, Shanghai 1898

Wang Shen-tzu:

The Margary affair and the Chefoo agreement, London 1940, reprint: Westport, Conn. 1980

Weiss, Fritz:

Von Bhamo nach Tengyüe, in: Mitteilungen des Seminars für Orient. Sprachen, Jg. 12, Berlin 1909, S. $110-123$

Von Tengyüe über Talifu und Yünnanfu zum Yangtse, in: Mitteilungen des Seminars für Orient. Sprachen, Jg. 13, Berlin 1910, S. 18-48

Wild, Norman:

Materials for the study of the Ssu I Kuan, Bulletin of The School of Oriental and African Studies, vol.11, Part 3, London 1945, S.617-640

Williams, Clement:

Through Burma to Western China, Edinburgh 1869

Wissmann, Hermann von:

Süd-Yünnan als Teilraum Südostasiens, Heidelberg 1943 (Schriften zur Geopolitik, Heft 22)

Woodhead, H. G. W.:

The Sino-Burmese frontier. An Anglo-Chinese agreement, in: Oriental Affairs vol. 3, no. 18, 1935, p. 207-208

\section{2. Seit 1949 publizierte Werke}

Aubin, Françoise (Hrsg.):

The Mongols and Ming China: customs and history, London 1987

Aung-Thwin, Michael:

The myth of the ,Three Shan Brothers' and the Ava period in burmese history, in: JAS, Vol. 55, no. 4, issue 827, Nov. 1996, pp. 881-901

Backus, Charles:

The Nan-chao kingdom and T'ang China‘s south-western frontier, Cambridge 1981

Bechert, Heinz; Richard Gombrich (Hrsg.):

Der Buddhismus. Geschichte und Gegenwart, München 1989

Bechert, Heinz; Daw Khin Khin Su; Daw Tin Tin Myint:

Burmese manuscripts, part 1, Wiesbaden 1979

Bockmann, Harald:

Yunnan trade in Han times: transit, tribute and trivia, in: K. R. Haellquist (Hrsg.), Asian trade routes, (Studies on Asian topics No. 13), S. 174-180

Boorman, Howard L.; Richard C. Howard (Hrsg.):

Biographical dictionary of Republican China, New York 1968 
Bradley, David:

Onomatic, orthographic, dialectal and dialectical borders: the Lisu and the Lahu, in: asia pacific viewpoint, vol. 38, no. 2, Aug. 1997 (Special issue: Ethnic minorities on the borderlands of Southwest China

Brook, Timothy:

Geographical sources of Ming-Qing history, Ann Arbor 1988 (Michigan Monographs in Chinese Studies, Vol. 58)

Burling, Robbins:

Proto Lolo-Burmese, Bloomington 1967

Byon, Jae-Hyon:

Local gazetteers of Southwest China. A handbook, Seattle 1979 (Parerga, Occasional Papers on China 5)

Cady, John F.:

Southeast Asia: It‘s historical development, New York 1964

Chan, Albert:

Glory and fall of the Ming Dynasty, Norman 1982

Chandran, Jeshurun:

The Burma-Yunnan railway:Anglo-French rivalry in mainland Southeast Asia and South China, 1895-1902, Athens, Ohio 1971 (Papers in International Studies, Southeast Asia Series No. 21)

Chang, C.T.:

Burma Road, Singapore 1964

Chang, Luke T.:

China's boundary treaties and frontier disputes, London, New York 1982

Chao Tzang Yawnghwe:

The Shans of Burma. Memoirs of a Shan exile, Singapore 1987

Chen Yi-sein:

The Chinese inscriptions at Pagan, in: BBHC, I, II, Dec. 1960

Foreign relations of Burma in the Pyu period, in: Bulletin of the Burma Studies Group, no. 60, 1997

Chü T'ung-Tsu:

Local government in China under the Ch'ing, Cambridge, Mass. 1962, (Harvard East Asian Studies 9), reprint: 1988 (Harvard East Asian Monographs, 143)

Clair, Colin (Hrsg.):

The spread of printing, o.O.u.J.

Cleaves, Francis Woodman:

A chancellary practice of the Mongols in the thirteenth and fourteenth centuries, in: HJAS, vol.14 (1951), S.493-526

Coyaud, Maurice:

Les langues dans le monde Chinois, tome 1 -3, Paris 1987, 1992, 1994 
Crispin, Shawn W.; Margot Cohen; Bertil Lintner:

, Choke point. China is building dams on the Mekong leaving neighbours to worry over the downstream impact', in: FEER, October 12, 2000

Dabringhaus, Sabine; Roderich Ptak (Eds.):

China and her neigbours. Borders, visions of the other, foreign policy, 10th to 19th century, Wiesbaden 1997 (South China and Maritime Asia, Vol.6)

Davis, S. L.; Prescott, J. R. V.:

Aboriginal frontiers in Australia, Melbourne 1992

Dessaint, Alain Y.:

Minorities of southwest China. An introduction to the Yi (Lolo) and related peoples and an annotated bibliography, New Haven 1980

Diran, Richard K.:

The vanishing tribes of Birma, London 1997

Drake, F.S.:

Symposium on historical, archaeological and linguistic Studies on South China, South-east Asia and the Hongkong Region, Hongkong 1967

Eberstein, Bernd:

Bergbau und Bergarbeiter zur Ming-Zeit, Hamburg 1974 (Mitteilungen der Gesellschaft für Natur- und Völkerkunde Ostasiens, Band 57)

Edmonds, Richard Louis:

Northern frontiers of Qing China and Tokugawa Japan. A comparative study of frontier policy, Chicago 1985 (The University of Chicago, Department of Geography, Research Paper No. 213)

Egerod, Soeren:

Essentials of Shan phonology and script, Academia Sinica, Nr.29, 1957

Eggebrecht, Arne (Hrsg.):

Die Mongolen und ihr Weltreich, Hildesheim 1989

Elder, Chris:

China's treaty ports, Oxford 1999

Endicott-West, Elizabeth:

Imperial governance in Yüan times, HJAS, vol.46, No.2 (1986), S.523-549

Mongolian rule in China. Local administration in Yuan-Dynasty, Cambridge, Mass. 1989

Eng, Kuah Khun:

Negotiating central, provincial and county policies: border trading in South China, in: Grant Evans, u.a. (Hrsg.), Where China meets Southeast Asia, S. 72-97

Evans, Grant; Christopher Hutton, Kuah Khun Eng (Hrsg.):

Where China meets Southeast Asia. Social and cultural change in the border region, Singapore/Kopenhagen 2000

Fairbank, John King:

A preliminary framework, in: Fairbank, J.K. (Hrsg.), The Chinese world order, S.1-19

Ch'ing administration. Three studies, Cambridge, Mass. 1960 
Fairbank, John King:

On the Ch'ing tributary system, in: Fairbank, J.K. (Hrsg.), The Chinese world order, S.107-218

On the Types and Uses of Ch'ing Documents, in: Fairbank, J.K. (Hrsg.), The Chinese World Order, S.36-106

Fairbank, John King (Hrsg.):

The Chinese world order. Traditional China's foreign relationes, Cambridge, Mass. 1968

Feng Han-yi; J.K. Shryock:

The Historical origins of the Lolo, HJAS, vol.3, 1938, S.103-127

Feuerwerker, Albert:

State and society in eighteenth-century China. The Ch'ing empire in its glory, University of Michigan, 1976; reprint 1992 (Michigan Monographs in Chinese Studies, No. 27)

Fistié, Pierre:

La Birmanie ou la quête de l'unité. Le problème de la cohésion nationale dans la Birmanie contemporaine et sa perspective historique, Paris 1985

Fitzgerald, Charles Patrick:

The southern expansion of the Chinese people, New York 1972

Forbes, Andrew D. W.:

The ,Cin-Ho' (Yunnanese Chinese) caravan trade with north Thailand during the late nineteenth and early twentieth centuries, in: JAS 21 no.1 (1987), S. 1-47

Franke, Wolfgang:

An introduction to the sources of Ming history, Singapur 1968

Frasch, Tilman:

Pagan. Stadt und Staat, Stuttgart 1996 (Südasien Institut der Universität Heidelberg, Beiträge zur Südasienforschung, Band 172)

Gaspardone, Emile:

Le lexique Annamite des Ming, Journal Asiatique, Tome 241, 1953, S.355-397

Gaubatz, Piper Rae:

Beyond the Great Wall. Urban form and transformation on the Chinese frontiers, Stanford, Cal. 1996

Gernet, Jaques:

Die chinesische Welt, (1. Auflage 1979) Frankfurt a.M. 1987 (5. Auflage der dt. Übersetzung)

Giersch, Charles Patterson, Jr.:

Qing China's reluctant subjects: indigenous communities and empire along the Yunnan frontier, dissertation, Yale University 1998

,A motley throng: ' social change on Southwest China's early modern frontier, 1700-1880, in: The Journal of Asian Studies 60, no.1 (February 2001): 67-94

Ginsburg, Henry:

Thai manuscript painting, London 1989

Glassner, Martin Ira; de Blij, Harm J.:

Systematic political geography, $4^{\text {th }}$ edition, New York 1989 
Goodman, David S. G. (Ed.):

China's regional development, London 1989

Goodrich, L.Carrington (Hrsg.):

Dictionary of Ming biography 1368-1644, 2 vols., New York 1976

Haase, Mathias:

Die Mekong-Region - Potenziale und Risiken aus chinesischer Perspektive, in: CHINA aktuell, Oktober 2002, S. 1156-1170

Hall, D.G.E.:

A history of Southeast Asia, New York 1955 (4.Aufl. 1981)

Hall, J. C. S.:

The Yunnan Provincial Faction, 1927-1937, (Australian National Library) 1976 (Monographs on Far Eastern History 6)

Harley, J.B.; David Woodward (Hrsg.):

Cartography in the traditional East and Southeast Asian societies, Chicago 1994 [The history of cartography, volume 2, book 2]

Harrell, Stevan (Hrsg.):

Cultural encounters on China's ethnic frontiers,Seattle 1995(Studies on Ethnic Groups in China)

Haubrichs, Wolfgang; Schneider, Reinhard (Hrsg.):

Grenzen und Grenzregionen. Frontières et régions frontalières. Borders and border regions. Saarbrücken, 1994 (Veröffentlichungen der Kommission für Saarländische Landesgeschichte und Volksforschung, 22)

Hay, John (Hrsg.):

Boundaries in China, London 1994

Heissig, Walther:

Das mongolische Publikations- und Übersetzungswesen der Mandju-Zeit, Sinologica, vol. 3, Basel 1953, S.203-209

Herman, John E.:

Empire in the Southwest: Early Qing reforms to the native chieftain System, in: JAS 56, no. 1 (Feb. 1997), pp. 47-74

Hershatter, Gail; Emily Honig; J. N. Lipman; R. Stross (Hrsg.):

Remapping China. Fissures in historical terrain, Stanford, Cal. 1996

Hill, Ann Maxwell:

Merchants and migrants. Ethnicity and trade among Yunnanese Chinese in Southeast Asia, New Haven 1998 (Monograph 47/Yale Southeast Asia Studies)

Hinton, Harold C.:

China's relations with Burma and Vietnam. A brief survey, New York 1958

Ho, Clara Wing-chung (Hrsg.):

Biographical dictionary of chinese women. The Qing period, 1644-1911, Armonk, NY 1998 (University of Hongkong Libraries Publications, No.10) 
Ho Ping-ti:

Studies on the population of China, 1368-1953, Cambridge, Mass. 1959 (Harvard East Asian Studies 4)

Howland, D. R.:

Borders of chinese civilization. Geography and history at empire's end, Durham \& London 1996 (Asia-Pacific: Culture, Politics, and Society)

Hucker, Charles O.:

A dictionary of official titles in Imperial China, Stanford, Cal. 1985

Hucker, Charles O. (Hrsg.):

Chinese government in Ming times. Seven studies, Columbia 1969

Hummel, Arthur W.:

Eminent Chinese of the Ch'ing Period (1644-1912), reprint Taipei 1975

Institute of Geography, U.S.S.R. Academy of Sciences (Hrsg.):

The physical geography of China, Vol. 2, New York 1969 (Praeger Special Studies in International Economics and Development)

Israeli, Raphael:

Islam in China. A critical bibliography, Westport, Conn. 1994 (Bibliographies and Indexes in Religious Studies, No. 29)

Jung, Richard L. K.:

The Sino-Burmese war, 1766-1770. War and peace under the tributary system, Cambridge, Mass. 1971 (Asian Research Center, Harvard Univ., Papers on China, Vol. 24)

Kessler, Lawrence:

K' ang-hsi and the consolidation of Ch'ing rule, 1661-1684, Chicago 1976

Kirkby, R. J. R.:

Urbanization in China. Town and county in a developing economy, 1949-2000 A.D., New York 1985

Koenig, William J.:

The Burmese polity, 1752-1819. Politics, administration, and social organization in the early Kon-baung Period, Michigan 1990 (Michigan Papers on South and Southeast Asia, No. 34)

Kolb, Albert:

Yünnan. Chinas unbekannter Süden, Berlin 1992 (Berliner geographische Studien, Bd. 34)

Korn-Riedlinger, Karin:

Dian, Nanzhao, Dali - Staatsgründungen auf dem Gebiet der heutigen Provinz Yunnan (VR China), (Diss.), Bonn 1988

Kreuzer, Peter:

Staat und Wirtschaft in China. Die kulturelle Grundlage politischer Steuerung: Verwaltungskultur und Verwaltungsstil der Qing Administration, Frankfurt a.M. 1998

Kunstadter, P. (Hrsg.):

Southeast Asian tribes, minorities and nations, 2 vols., Princeton 1967

Lacoste, Yves (Hrsg.):

Dictionnaire de geopolitique, Paris 1994 
Leach, E. R.:

Political systems of highland Burma, London 1954

LeBar, Frank M.; Gerald C. Hickey; John M. Musgrave:

Ethnic groups of mainland Southeast Asia, New Haven, Conn. 1964

Lee, James:

Food supply and population growth in Southwest China, 1250-1850, in: JAS, vol. 41, no. 4, august 1982, pp. 711-746

Lee, Robert H. G.:

Frontier politics in the southwestern Sino-Tibetan borderlands during the Ch'ing dynasty, in: Fogel/Rowe: Perspectives on a changing China, Boulder, Colorado 1979, pp. 35-68

Leslie, Donald; Jeremy Davidson:

Catalogues of Chinese local gazetteers, Canberra 1967 (Guide to Bibliographies on China and the Far East)

Lewicki, Marian:

La langue Mongole des transcriptions Chinoises du XIVe siècle. Le Houa-yi yi-yu de 1389, Wroclaw 1949

Li Chi:

The travel diaries of Hsü-Hsia-K'o, Hongkong 1974

Lieberman, Victor:

Political consolidation in Burma under the early Konbaung Dynasty, 1752 - c. 1820, in: Journal of Asian History, 30 (1996), 2, pp. 152-168

Liew Foon Ming:

Tuntian farming of the Ming dynasty (1368-1644), Hamburg 1984 (MOAG, Mitteilungen der Gesellschaft für Natur- und Völkerkunde Ostasiens, Bd. 97)

The Luchuan-Pingmian campaigns (1436-1449) in the light of offficial chinese historiography, in: Oriens Extremus, Jg. 39, 1996, Heft 2, S.162-203

The treatises on military affairs of the Ming dynastic history (1368-1644), 2 Bände, Hamburg 1998 (MOAG, Bd. 129)

Lintner, Bertil:

The Shans and the Shan States of Burma, Bangkok 1982

,The third wave. A new generation of Chinese migrants fans across the globe', in: FEER, June 24, 1999

Littrup, Leif:

Subbureaucratic government in China in Ming times. A study of Shandong province in the sixteenth century, Oslo 1981 (Instituttet For Sammenlignende Kulturforsknig, Serie B: Skrifter 64)

Liu Guojun; Zheng Rusi:

Die Geschichte des chinesischen Buches, Peking 1988 
Lombard, Denys; Aubain, F. (eds.):

Marchants et hommes d'affairesasiatiques dans L'Ocean Indienne et la Mer de Chine 13-20 siecles, Paris 1987

Lombard-Salmon, Claudine:

Un exemple d'acculturation Chinoise: La province du Gui Zhou au 18e siècle, Paris 1972 (Publications de l'École Française d'Extrême-Orient, vol. 84)

Lötschert, Wilhelm:

Palmen, Stuttgart 1985

Luce, Gordon H.:

Man shu (Book of the southern barbarians), Ithaca, New York 1961

Old Burma - Early Pagan, 3 vols., New York 1969

Phases of pre-Pagan Burma, 2 vols., Oxford 1985

Lufrano, Richard John:

Honorable merchants. Commerce and self-cultivation in late imperial China, Honolulu 1997

Lui, Adam Yuen-chung:

Ch'ing institutions and society 1644-1795, Hongkong 1990

Lutz, Albert (Hrsg.):

Dian. Ein versunkenes Königreich in China, Zürich 1986

Ma Yin (ed.):

China's minority nationalities, 2nd ed., Beijing 1994

Mancall, Mark:

The Ch'ing tribute system: an interpretative essay, in: Fairbank (ed.), Chinese world order, S.63-89

Mangrai, Sao Saimong:

The Shan States and the British annexation, Ithaca 1965 (data Paper no. 57, SEA Program, Cornell University)

Marchant, Leslie R.:

A guide to th archives and records of Protestant Christian missions from the British isles to China, 1976-1914, Nedlands, western Australia 1966

Matznetter, Josef (Hrsg:):

Politische Geographie, Darmstadt 1977 (Wege der Forschung, Band 431)

Maung Wun:

Notes on burmese manuscript books, JBRS, vol.33, part 2, Rangoon, Aug.1950, S.224-229

Mayers:

The Chinese government, (Nachdruck) Taipei 1966

Mees, Imke.

Die Hui - eine moslemische Minderheit in China. Assimilierungsprozesse und politische Rolle vor 1949, München 1984 (Minerva - Fachserie Geisteswissenschaften) 
Miller, David Harry; Jerome O. Steffen:

The frontier. Comparative studies, Oklahoma 1977

Miller, Lucien (ed.):

South of the clouds. Tales from Yunnan, Washington 1994

Millward, James A.:

Beyond the pass. Economy, ethnicity, and empire in Qing Central Asia, 1795-1864, Stanford, Cal. 1998

New perspectives on the Qing frontier, in: Hershatter/Honig, Remapping China,

S. 113-129

Minghi, Julian V.:

Grenzen in der politischen Geographie [Boundary Studies in political geography (1963)], in: Matznetter, Josef (Hrsg.), Politische Geographie, S. 338-389

Moseley, George V. H.:

The consolidation of the South China frontier, Los Angeles 1973

Muir, Richard:

Political geography. A new introduction, Houndsmill, London 1997

Needham, Joseph:

Science and civilisation in China, vol.5, Chemistry and chemical technology, Cambridge 1985

Nivison, David Shepard:

The life and thought of Chang Hsüeh-ch'eng (1738-1801), Stanford, Cal. 1966

Osterhammel, Jürgen:

China und die Weltgesellschaft, München 1989

Pasquet, Sylvie:

L'évolution du système postal: la province du Yunnan à l'époque Qing (1644-1911), Paris 1986

Peers, William R.:

Behind the Burma Road, London 1964

Pirazzoli-t'Serstevens, Michèle:

La civilisation du royaume de Dian a l'époque Han d'après le matériel exhumé à Shizhai shan (Yunnan), Paris 1974 (Publications de l'École Française d‘Extrême-Orient, XCIV)

Prescott, J. R. V.:

Boundaries and frontiers, Totowa, N.J. 1978. Siehe auch unter Davis, S. L.

Political frontiers and boundaries, London 1987

Purcell, Victor:

The Chinese in Southeast Asia, 2nd edition, London 1965

Quigly, E.P.:

Some observations on libraries, manuscripts and books of Burma from the 3rd century A.D. to 1886, London 1956

Ramsey, S.Robert:

The languages of China, Princeton 1987 
Richter, Eberhardt:

Lehrbuch des modernen Burmesisch (Umgangssprache), Leipzig 1983

Richter, Eberhardt; Maung Than Zaw:

Deutsch-Burmesisches Gesprächsbuch, Leipzig 1969

Riemenschnitter, Andrea:

China zwischen Himmel und Erde. Literarische Kosmographie und nationale Krise im 17. Jahrhundert, Frankfurt a.M. 1998 (Europäische Hochschulschriften, Reihe XXVII, Asiatische und Afrikanische Studien, Band 68)

Rosner, Erhard:

Mongolen auf dem chinesischen Kaiserthron, in: A.Eggebrecht (Hrsg.), Die Mongolen und ihr Weltreich, Mainz 1989, S.117-143

Die Südwestgrenze der Provinz Yünnan am Ende des 18. Jahrhunderts, 10 S.

Rowe, William T.:

Hankow. Commerce and society in a chinese city, 1796-1889, Stanford, Cal. 1984

Rumley, Dennis; Minghi, Julian V. (Hrsg.):

The geography of border landscapes, London 1991

Schinz, Alfred:

Cities in China, Stuttgart 1989 (Urbanization of the Earth/Urbanisierung der Erde 7)

Schmidt-Glintzer, Helwig:

China. Vielvölkerreich und Einheitsstaat, München 1997

Schurmann, H.F.:

Mongolian tributary practices of the thirteenth century, HJAS, vol.19, Cambridge, Mass. 1956, S.304-289

Seidenfaden, Erik:

The Thai peoples. Book I. The origins and habits of the Thai peoples with a sketch of their material and spiritual culture, Bangkok 1958

Serruys, Henry:

Foreigners in the metropolitan police during the 15th century, in: Aubin (Hrsg.), The Mongols and Ming China, Kap.7, S.59-83

The Mongols in China: 1400-1450, in: Aubin (Hrsg.), The Mongols and Ming China, Chap.5, pp.233-305

Shorto, H.L.; Judith M. Jacob; E.H.S. Simmonds:

Bibliographies of Mon-Khmer and Tai linguistics, London 1963

Skinner, G. William:

The city in Late Imperial China, Stanford, Cal. 1977

Smith, Richard J.:

China's cultural heritage. The Qing dynasty, 1644-1912, Boulder 1994 ( $2^{\text {nd }}$ edition $)$

Chinese maps. Images of ,All under Heaven`, Hongkong 1996 (Images of Asia) 
Smith, Kent Clarke:

Ch'ing policy and the development of southwest China: aspects of Ortai's governor-generalship, Dissertation, Yale 1970

Spence, Jonathan D.:

The China helpers. Western advisers in China 1620-1960, London 1969

Spence, Jonathan D.; John E. Wills, Jr. (Hrsg.):

From Ming to Ch'ing. Conquest, region, and continuity in seventeenth-century China, New Haven 1979

Stargardt, Janice:

The ancient Pyu of Burma, vol.1, Cambridge 1990

Strupp, Michael:

Chinas Grenzen mit Birma und der Sowjetunion, Hamburg 1987 (Mitteilungen des Instituts für Asienkunde, 93)

Struve, Lynn (ed. \& trans.):

The southern Ming, 1644-1662, New Haven 1984

Voices from the Ming-Qing cataclysm: China in tiger's jaws, New Haven 1993

Su Yongge:

Ecology without borders, in: Grant Evans, u.a. (Hrsg.), Where China meets Southeast Asia, S. $51-71$

Südhoff, Ralf:

Subregionale Kooperation und Wachstumsdreiecke in Südostasien: Das Beispiel des „Goldenen Vierecks“, in: SÜDOSTASIEN aktuell, Juli 1995, S. 289-308

Sun Laichen:

Chinese historical sources on Burma. A bibliography of primary and secondary works, in: The Journal of Burma Studies, Vol. 2: Special issue, DeKalb 1997

Ming-Southeast Asian overland interactions, 1368-1644, Dissertation, The University of Michigan, 2000

Sun Taichu:

Die Entstehung der vor 2000 Jahren untergegangenen Dian-Kultur, in: A.Lutz (Hrsg.), Dian. Ein versunkenes Königreich in China, Zürich 1986, S.17-30

Sutton, Donald S.:

Provincial militarism and the Chinese Republic: The Yunnan Army, 1905-1925, Ann Arbor 1980

Tarling, Nicholas (Ed.):

The Cambridge history of Southeast Asia, vol. 1: From early times to c. 1800, Cambridge 1992

Tasker, Rodney; Bertil Lintner:

,Danger: road works ahead. China's push to open trade routes for its poor inland provinces is raising fears that it's also seeking military access to the Indian Ocean', in: FEER, December 21, 2000

Tate, D.J.M.:

The making of modern Southeast Asia, vol.1: The european conquest, Oxford 1971 
Têng, Ssu-Yü; Knight Biggerstaff:

An annotated bibliography of selected Chinese reference works, vol.2, Cambridge, Mass. 1950

T'ien Ju-k'ang:

Moslem Rebellion in China: A Yunnan controversy, Canberra, 1981

Torbert, Preston M.:

The Ch'ing imperial household department, Cambridge, Mass. 1977

Trager, Frank N. (Ed.):

Japanese and chinese language sources on Burma: An annotated bibliography, (Pt. 1: Japanese sources by Hyman Kublin; Pt. 2: Chinese sources by Lu-yu Kiang), New Haven 1957

Tsai, Shih-shan Henry:

The eunuchs in the Ming dynasty, New York 1996 (SUNY Series in Chinese Local Studies)

Tsao Kai-fu:

The rebellion of the Three Feudatories against the Manchu throne in China, 1673-1681: Its setting and significance, Dissertation, Columbia University, 1965

Tsien Tsuen-Hsuin:

Paper and printing, in: Needham, Science and civilization, vol.5, part 1

Twitchett, Denis:

Printing and publishing in medieval China, London 1983

Uhl, Natalie W.; John Dransfield:

Genera Palmarum. A classification of palms based on the work of Harold E. Moore, Jr., Lawrence, Kansas 1987

Vogel, Hans-Ulrich:

Chinese central monetary policy and Yunnan copper mining during the early Qing, Dissertation, Zürich 1983

Wade, Geoff:

Some topoi in southern border historiography during the Ming (and their modern relevance), in: Dabringhaus/Ptak, China and her neighbours, S. 135-158

The Southern Chinese borders in history, in: Grant Evans, u.a. (Hrsg.), Where China meets Southeast Asia, S. 28-50

Wakeman, Frederic:

The great enterprise. The Manchu reconstruction of imperial order in seventeenth-century China, 2 vols., Berkeley, Cal. 1985

Strangers at the gate. Social disorder in South China, 1839-1861, Berkeley 1966

Wang Jianping:

Concord and conflict: the Hui communities of Yunnan society in a historical perspective, Lund 1996 [Lund studies in African and Asian religions, 11]

Watt, John R.:

The district magistrate in late imperial China, New York 1972 
Wei, Alice Bihyun Gan:

The Moslem rebellion in Yunnan, 1855-1873, Ph.D. diss. University of Chicago 1974

Wenk, Klaus:

Notizen zur Literatur der Schan, in: Nachrichten der Gesellschaft für Natur- und Völkerkunde Ostasiens, Nr. 115, Hamburg 1974, S. 45-62

Zur gegenwärtigen Situation der Schan-Schriften, in: Oriens Extremus, 21. Jg., Heft 1, Juni 1974, S. 111-121

Wiens, Herold J.:

Han Chinese expansion in South China, 2. Aufl., Yale 1967, New Haven 1967 (Formerly entitled: China's march to the tropics; Hamdon, Conn. 1954)

Wiethoff, Bodo:

Bemerkungen zur Bedeutung der Regionalbeschreibungen (fang-chih), in: Oriens Extremus, Jg. 15, Hamburg 1968, S. 149-168

Wilson, Constance M.; Lucian M. Hanks

The Burma-Thailand frontier over sixteen decades: Three descriptive documents, Athens Ohio 1985 (Ohio University, Center for International Studies, Monographs in International Studies, Southeast Asia Series No. 70)

Woodman, Dorothy:

The making of Burma, London 1962

Wu, K.T.:

Chinese printing under four alien dynasties (926-1368 A.D.), in: HJAS, vol.13, 1950, S.447-523

Zurndorfer, Harriet T.:

Change and continuity in chinese local history. The development of Hui-chou prefecture 800 to 1800, Leiden 1989 (Sinics Leidensia, Vol. XX)

China bibliography. A research guide to reference works about China past and present, Leiden 1995 (Handbuch der Orientalistik, Vierte Abteilung, China, Bd. 10)

\section{Internetadressen / Websites}

Asian Development Bank

China Internet Information Center

Far Eastern Economic Review www.adb.org.

www.china.org.cn

www.feer.com 